NIST NCSTAR 1-9

Federal Building and Fire Safety Investigation of the World Trade Center Disaster

\title{
Structural Fire Response and Probable Collapse Sequence of World Trade Center Building 7
}

\author{
VOLUME 1
}





\title{
Federal Building and Fire Safety Investigation of the World Trade Center Disaster
}

\section{Structural Fire Response and Probable Collapse Sequence of World Trade Center Building 7}

\author{
Therese P. McAllister \\ Richard G. Gann \\ Jason D. Averill \\ John L. Gross \\ William L. Grosshandler \\ J. Randall Lawson \\ Kevin B. McGrattan \\ William M. Pitts \\ Kuldeep R. Prasad \\ Fahim H. Sadek \\ Building and Fire Research Laboratory \\ National institute of Standards and Technology \\ Harold E. Nelson \\ Contractor
}

November 2008

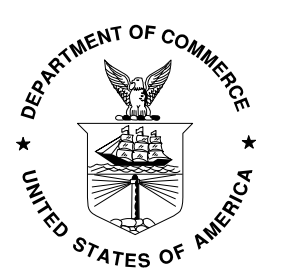

U.S. Department of Commerce

Carlos M. Gutierrez, Secretary

National Institute of Standards and Technology

Patrick D. Gallagher, Deputy Director 
Disclaimer No. 1

Certain commercial entities, equipment, products, or materials are identified in this document in order to describe a procedure or concept adequately or to trace the history of the procedures and practices used. Such identification is not intended to imply recommendation, endorsement, or implication that the entities, products, materials, or equipment are necessarily the best available for the purpose. Nor does such identification imply a finding of fault or negligence by the National Institute of Standards and Technology.

\section{Disclaimer No. 2}

The policy of NIST is to use the International System of Units (metric units) in all publications. In this document, however, units are presented in metric units or the inch-pound system, whichever is prevalent in the discipline.

\section{Disclaimer No. 3}

Pursuant to section 7 of the National Construction Safety Team Act, the NIST Director has determined that certain evidence received by NIST in the course of this Investigation is "voluntarily provided safety-related information" that is "not directly related to the building failure being investigated" and that "disclosure of that information would inhibit the voluntary provision of that type of information" (15 USC 7306c).

In addition, a substantial portion of the evidence collected by NIST in the course of the Investigation has been provided to NIST under nondisclosure agreements.

\section{Disclaimer No. 4}

NIST takes no position as to whether the design or construction of a WTC building was compliant with any code since, due to the destruction of the WTC buildings, NIST could not verify the actual (or as-built) construction, the properties and condition of the materials used, or changes to the original construction made over the life of the buildings. In addition, NIST could not verify the interpretations of codes used by applicable authorities in determining compliance when implementing building codes. Where an Investigation report states whether a system was designed or installed as required by a code provision, NIST has documentary or anecdotal evidence indicating whether the requirement was met, or NIST has independently conducted tests or analyses indicating whether the requirement was met.

\section{$\underline{\text { Use in Legal Proceedings }}$}

No part of any report resulting from a NIST investigation into a structural failure or from an investigation under the National Construction Safety Team Act may be used in any suit or action for damages arising out of any matter mentioned in such report (15 USC 281a; as amended by P.L. 107-231).

National Institute of Standards and Technology National Construction Safety Team Act Report 1A Natl. Inst. Stand. Technol. Natl. Constr. Sfty. Tm. Act Rpt. 1-9, 796 pages (November 2008) CODEN: NSPUE2

\section{U.S. GOVERNMENT PRINTING OFFICE} WASHINGTON: 2005

For sale by the Superintendent of Documents, U.S. Government Printing Office Internet: bookstore.gpo.gov — Phone: (202) 512-1800 — Fax: (202) 512-2250 Mail: Stop SSOP, Washington, DC 20402-0001 


\section{ABSTRACT}

This is the primary technical report on the National Institute of Standards and Technology (NIST) investigation of the collapse of World Trade Center Building 7 (WTC 7), conducted under the National Construction Safety Team Act. The investigation objectives were to determine (1) why and how WTC 7 collapsed, (2) all technical aspects of fire protection, occupant behavior, evacuation, and emergency response, (3) what practices and procedures were used in the design construction, operation and maintenance of WTC 7, and (4) areas in current building and fire codes, standards, and practices that warrant revision. Objectives 1, 2, and 3 are addressed in this report. Objective 4 is addressed in the WTC 7 summary report, NIST NCSTAR 1-1A. This report provides technical details of all aspects of the investigation, including:

- The procedures and practices that were used in the design, construction, operation, and maintenance of the building; structural features, interior layout and contents, and passive and active fire protection measures; and the emergency power systems (Chapters 2, 3, and 4);

- Photographic and videographic records that provided timed data on the debris impact damage caused by the collapse of WTC 1, and the building fires, and structural collapse (Chapter 5);

- The building evacuation and emergency response, including information from emergency communications and interviews of responders and building occupants (Chapters 6 and 7);

- Structural evaluation of the visual evidence of the structural collapse, comparison of uncontrolled fires in other tall office buildings with the fires in WTC 7, the leading hypothesis for the collapse of WTC 7, and evaluation of other hypotheses (Chapter 8);

- Computer simulations of the spread and growth of sustained fires of ordinary combustibles on the tenant floors and possible diesel fuel fires on the lower mechanical floors (Chapter 9);

- Computer simulations of the heating of the insulated steel and concrete structural components to determine temperature time-histories, based on the time-varying gas temperatures from the fire simulations (Chapter 10);

- Computer simulations of the structural response to the fires and debris impact damage, including the degradation of steel and concrete strength and stiffness at elevated temperatures, thermal expansion effects, thermally-induced damage to floor framing members and connections, beam and column buckling, and the propagation of structural damage and failures following an initial failure event of column buckling up to global collapse of WTC 7 (Chapters 11 and 12);

- The probable collapse sequence for WTC 7, based on the available data and evidence, and the computer simulations (Chapter 13); and

- $\quad$ The findings of the NIST Investigation of WTC 7 (Chapter 14)

This report also contains five appendices, which provide supporting background information on the Con Edison substation in WTC 7, analysis of the September 11, 2001 seismogram data recorded near the WTC 
site, video analysis of WTC 7 building vibrations before its collapse, analyses of hypothetical blast scenarios, and plasticity and creep models for WTC 7 steels.

Extensive details of the building collapse analyses are found in the companion report, NIST NCSTAR 19A.

Keywords: building evacuation, emergency response, fire safety, structural collapse, tall buildings, World Trade Center. 


\section{NIST NCSTAR 1-9 CHAPTER AUTHORS}

Chapter 1. Introduction

Chapter 2. Building Construction, Codes, and Standards

Chapter 3. Building Interior and Combustibles

Chapter 4. Fire Protection Measures

Chapter 5. $\quad$ WTC 7 Visual Evidence, Damage Estimates, Fire Timeline, and Collapse Timeline

Chapter 6. Emergency Response

Chapter $7 . \quad$ Evacuation of WTC 7

Chapter 8. Initiating Event Hypotheses

Chapter 9. Fire Simulations

Chapter 10. Structural Heating

Chapter 11. Structural Analysis of Initial Failure Event

Chapter 12. WTC 7 Collapse Analysis: Global Response to Initial Failure Events

Chapter 13. Probable Collapse Sequence

Chapter 14. Principal Findings

Appendix A. The Con Edison Substation in WTC 7

Appendix B. Analysis of September 11, 2001 Seismogram Data

Appendix C. Video Analysis of WTC 7 Building Vibrations Before Collapse

Appendix D. Hypothetical Blast Scenarios

Appendix. E $\quad$ Plasticity and Creep Models for WTC 7 Steels
Fahim H. Sadek, Therese P. McAllister, Richard G. Gann

John L. Gross, Therese P. McAllister, William Thornton (Thornton Engineering Associates)

Richard G. Gann

William L. Grosshandler, Richard G. Gann

William M. Pitts

J. Randall Lawson, Richard G. Gann

Jason D. Averill, Richard G. Gann

John L. Gross, Therese P. McAllister, Joseph Main

Kevin B. McGrattan, William L. Grosshandler, Richard G. Gann

Kuldeep R. Prasad, Richard G. Gann

Therese P. McAllister, John Gross, Mehdi Zarghamee (Simpson Gumpertz \& Heger, SGH), Omer Erbay (SGH), Andrew Sarawit (SGH)

Therese P. McAllister, Fahim Sadek, Robert MacNeill (Applied Research Associates, ARA), Steven Kirkpatrick (ARA), Brian Peterson (ARA), Robert Bocchieri (ARA)

Therese P. McAllister, S. Shyam Sunder, John L. Gross, Fahim H. Sadek

Therese P. McAllister, S. Shyam Sunder, John L. Gross, Richard G. Gann

J. Keith Nelson (Rensselaer Polytechnic Institute), William L. Grosshandler

Won-Young Kim (Lamont-Doherty Earth Observatory, Columbia University), William L. Grosshandler

Kathryn M. Butler

Robert MacNeill (ARA), Charles Needham (ARA), Steven Kirkpatrick (ARA), Michael Anderson (ARA), Lee Ann Young (ARA), and Joseph Crepeau (ARA), Mark Loizeaux (Loizeaux Group International)

William E. Luecke

All authors are with the National Institute of Standards and Technology, except as noted. 
This page intentionally left blank. 


\section{TABLE OF CONTENTS}

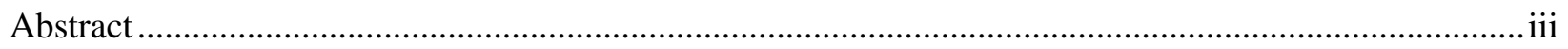

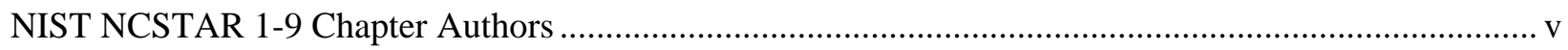

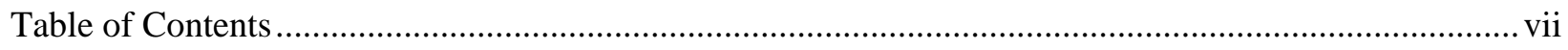

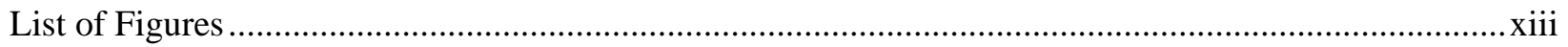

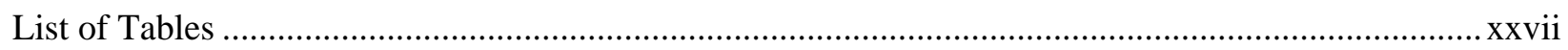

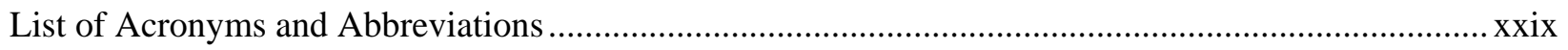

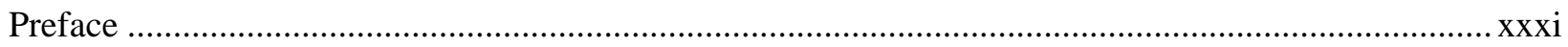

\section{Chapter 1}

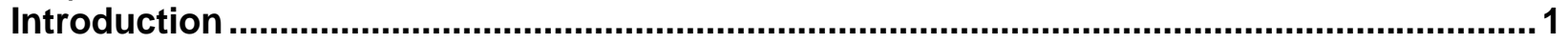

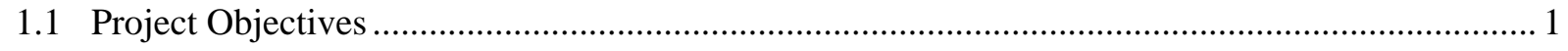

1.2 Technical Approach ......................................................................................................

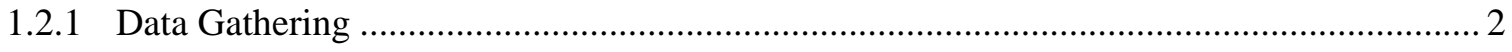

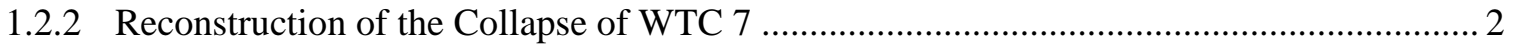

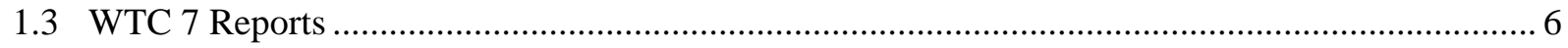

\section{Chapter 2}

Building Construction, Codes, and Standards ….......................................................... 9

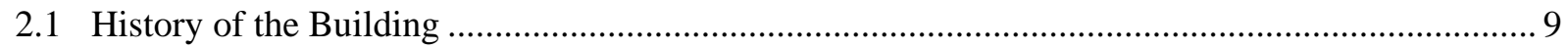

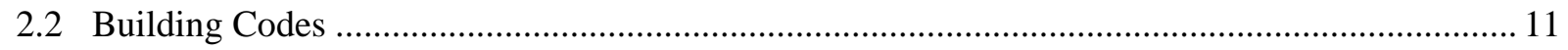

2.3 Con Edison Substation Building Description ........................................................................ 12

2.4 WTC 7 Building Description ................................................................................................... 12

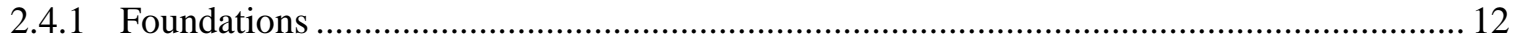

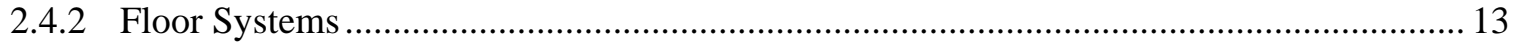

2.4.3 Connections in the Floor System..................................................................................... 22

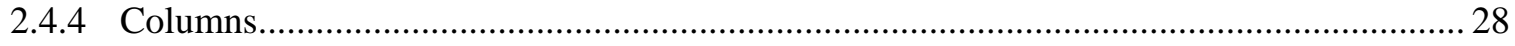

2.4.5 Column Transfer Trusses and Girders............................................................................... 29

2.4.6 Lateral Load Resisting System ..................................................................................... 30

2.5 Passive Fire Protection.......................................................................................................... 32

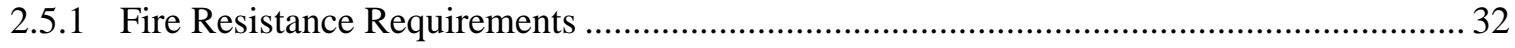

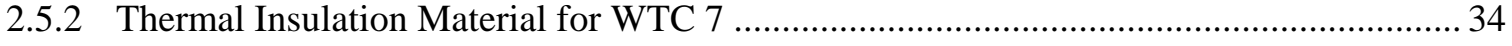

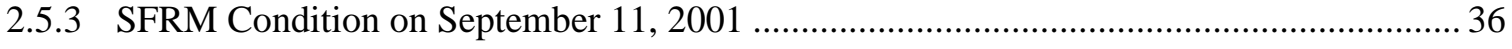




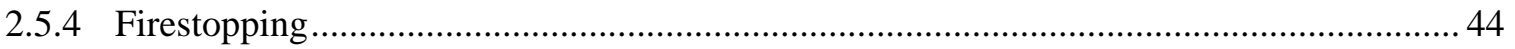

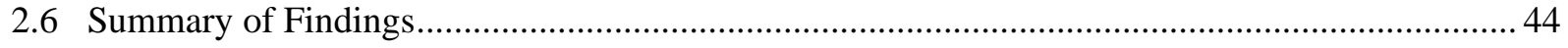

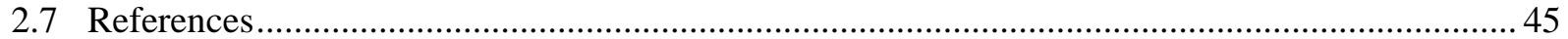

\section{Chapter 3}

Building Interior and Combustibles ........................................................................... 47

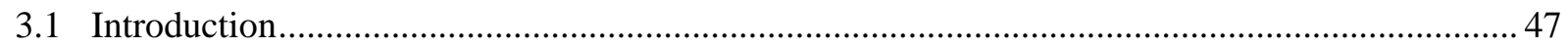

3.2 Focus 47

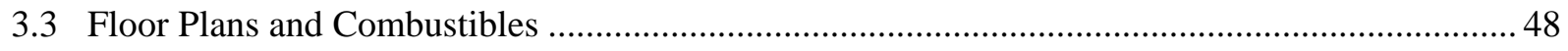

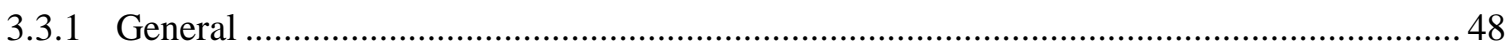

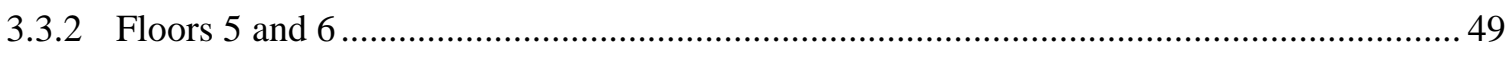

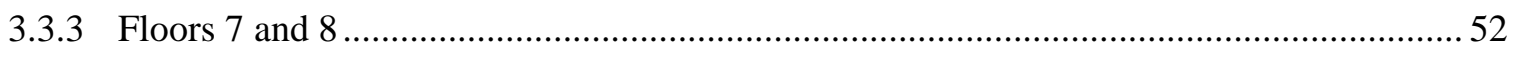

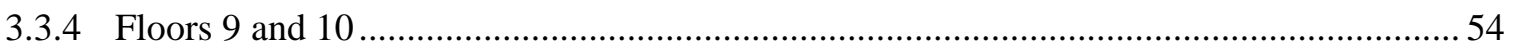

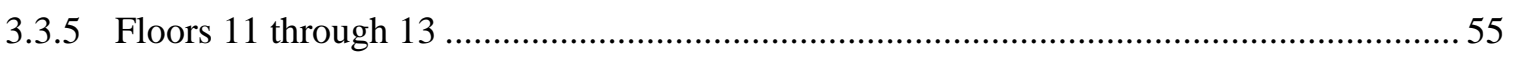

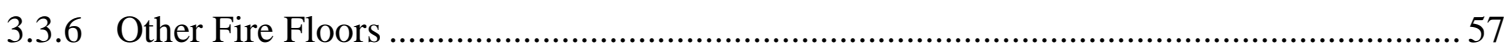

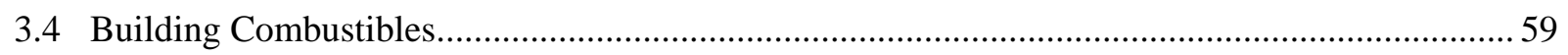

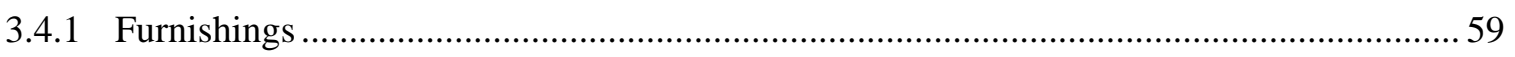

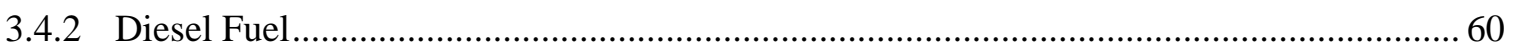

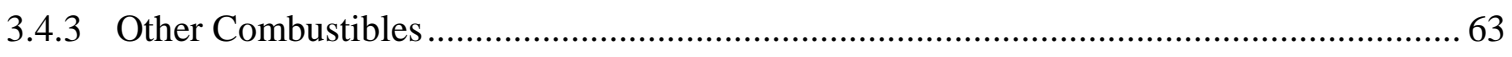

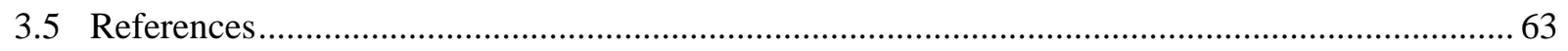

\section{Chapter 4}

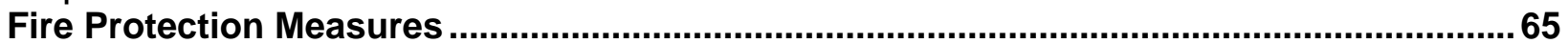

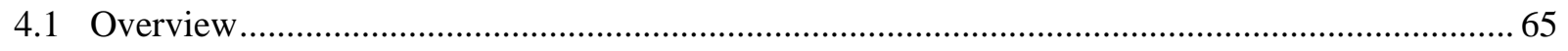

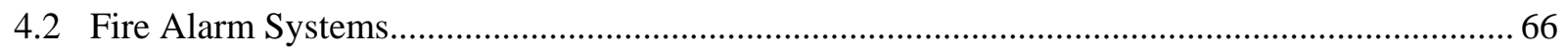

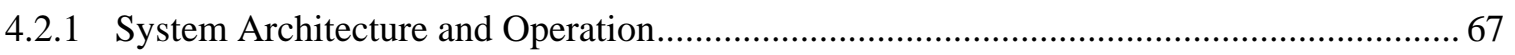

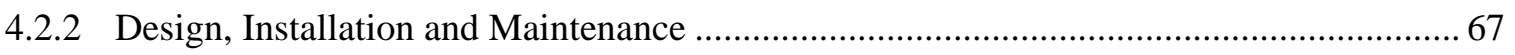

4.2.3 Fire Alarm System Performance on September 11, 2001 ............................................... 68

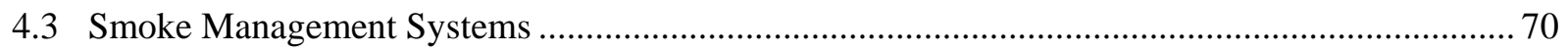

4.4 Sprinklers, Standpipes, and Preconnected Hose Systems .......................................................... 73

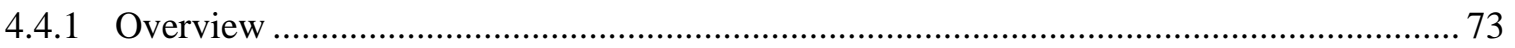

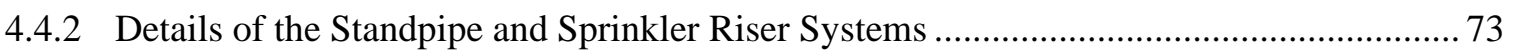

4.4.3 Automatic Sprinkler System Performance under Selected Fire Scenarios......................... 75

4.4.4 Supplemental Manual Operations and Related Procedures............................................... 77

4.4.5 Suppression Systems Performance on September 11, 2001 …........................................ 78

4.5 Active Fire Protection Systems: Summary of Investigation Findings …….................................. 78 


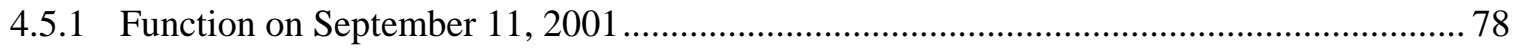

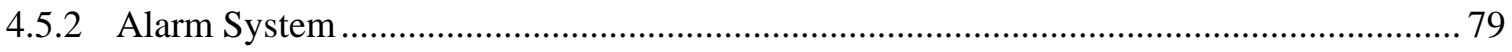

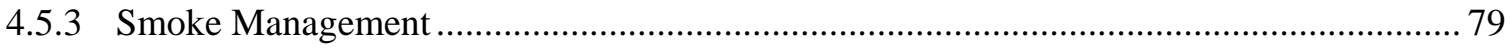

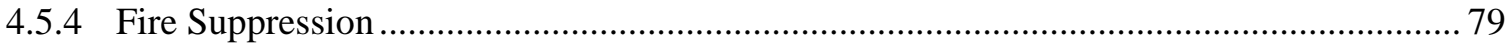

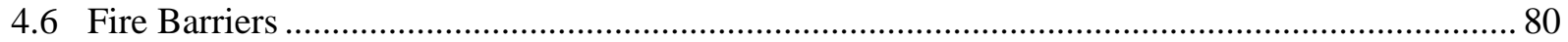

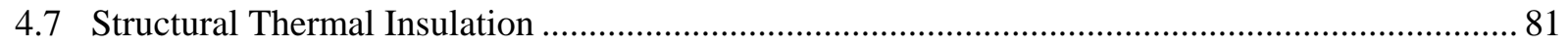

4.7.1 Material Selection, Application, and Condition ................................................................ 81

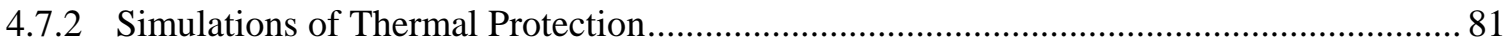

4.7.3 Findings - Structural Thermal Insulation .................................................................. 85

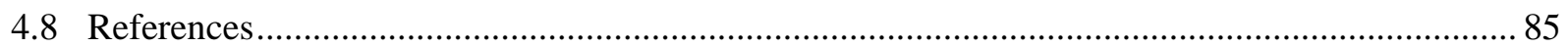

\section{Chapter 5}

WTC 7 Visual Evidence: Damage Estimates, Fire Timeline, and Collapse Timeline .......... 87

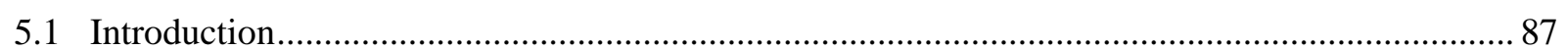

5.2 Collection, Organization, and Timing of Visual Material ......................................................... 88

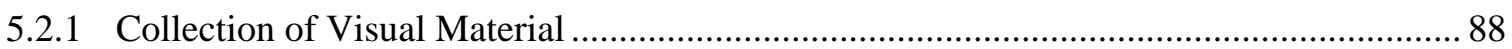

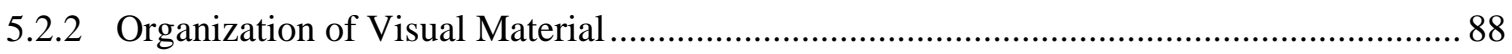

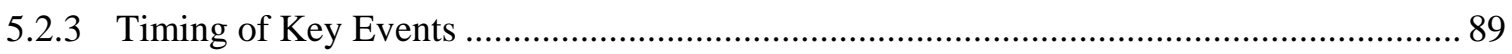

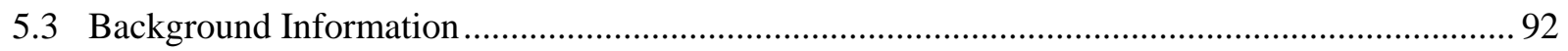

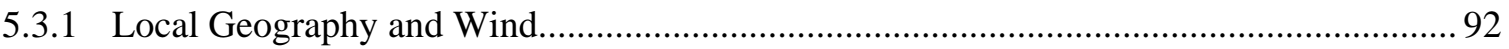

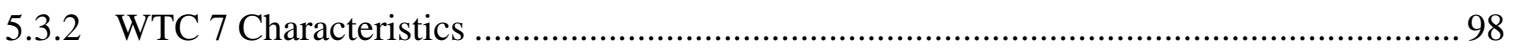

5.4 Visual Imagery Availability for WTC 7 Damage and Fire Characterization ............................. 117

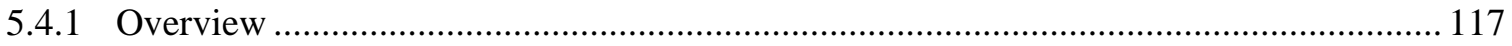

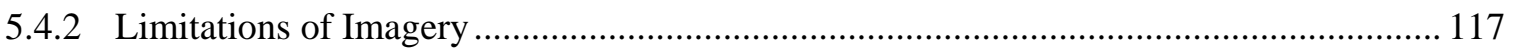

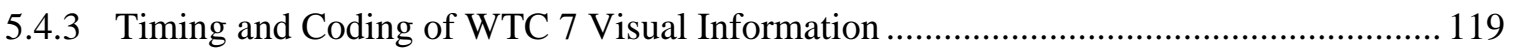

5.5 Damage Estimates for WTC 7 Due to Debris Impact from WTC 2 and WTC 1 Collapses ....... 125

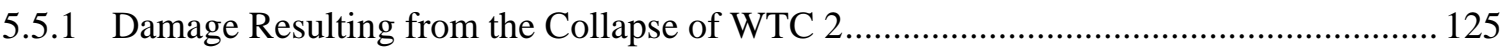

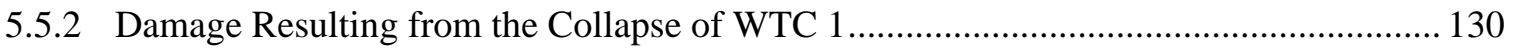

5.5.3 Summary of Debris Damage to WTC 7 Based on Visual Data......................................... 182

5.6 Development and Spread of Fires in WTC 7 ....................................................................... 188

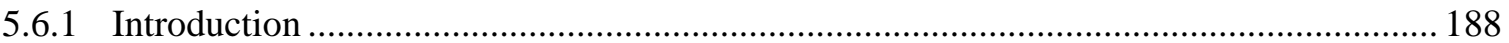

5.6.2 Ignition of Fires Following Collapse of the World Trade Center Towers ....................... 188

5.6.3 Visual Observations of Fire Growth and Spread in WTC 7 ........................................... 194

5.6.4 Summary of Fire Spread Observations in WTC 7 ............................................................ 242

5.6.5 Façade maps of Fire Location and Window Breakage in WTC 7 at Various Times ....... 246 
5.6.6 Summary Graphics of Total Fire Extent in WTC 7 ...................................................... 259

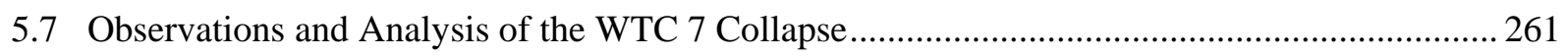

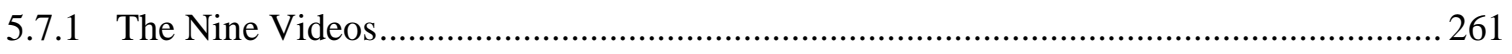

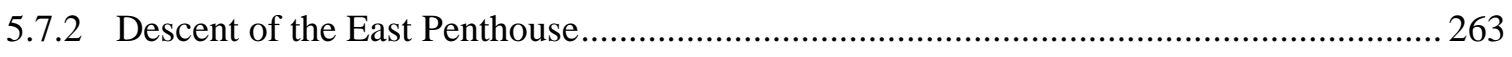

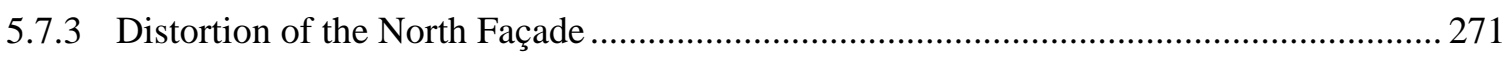

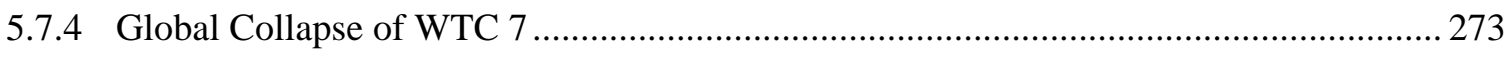

5.7.5 Audio Characteristics Based on Video Soundtracks ..................................................... 289

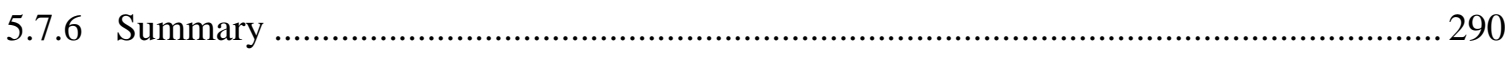

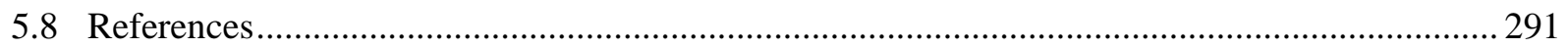

\section{Chapter 6}

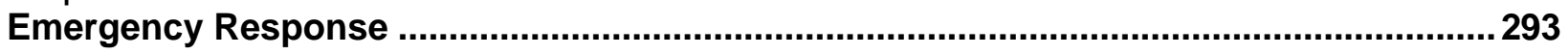

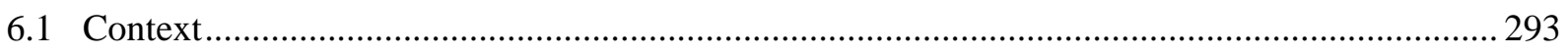

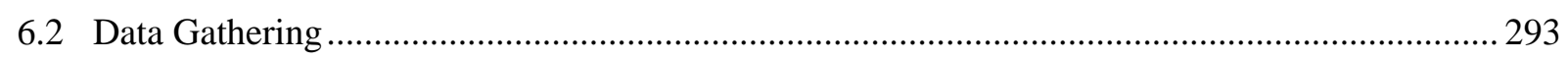

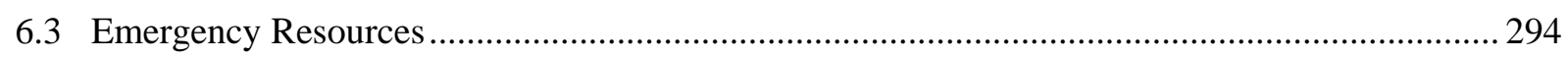

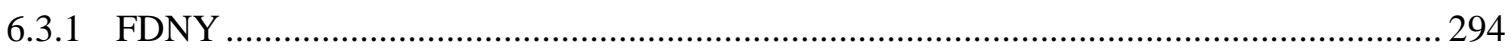

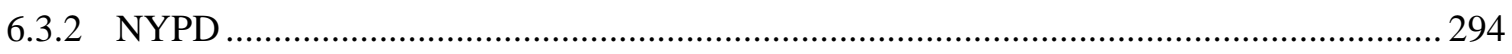

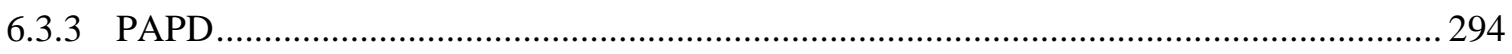

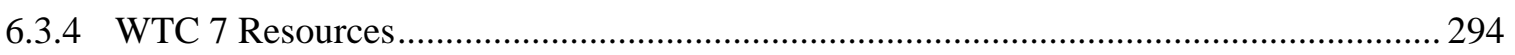

6.4 Activity at WTC 7 from 8:46 a.m. to 10:30 a.m. EDT ........................................................ 295

6.5 Collapse of the Towers and the Emergency Response ....................................................... 297

6.5.1 Restoration of Command Structure and Command Posts ................................................ 297

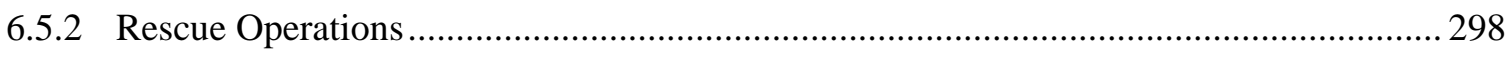

6.6 Activity from 11:02 a.m. to Approximately 2:30 p.m. EDT..................................................... 299

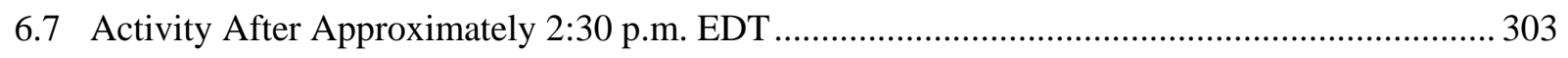

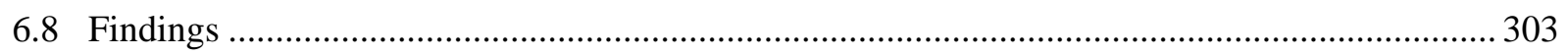

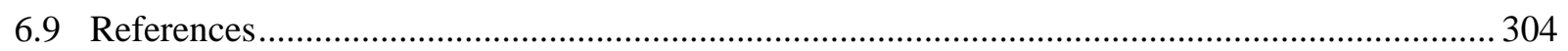

\section{Chapter 7}

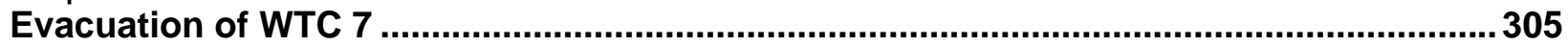

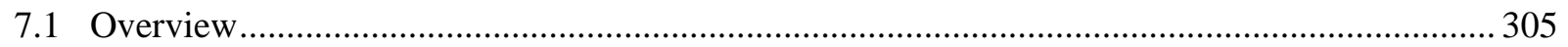

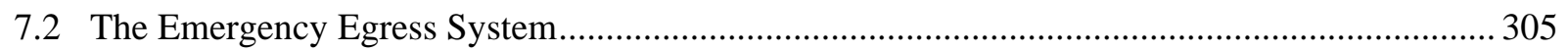

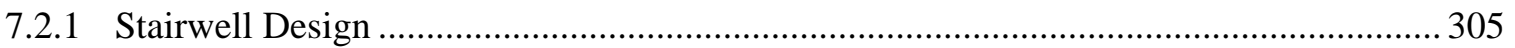

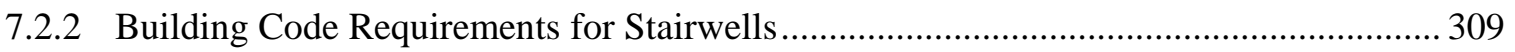

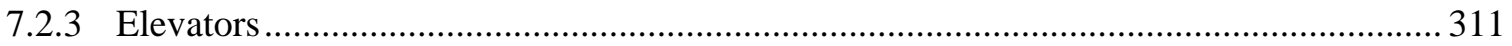

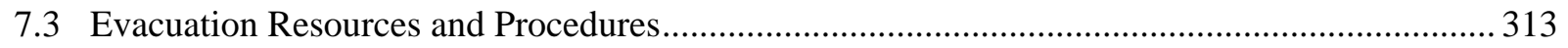




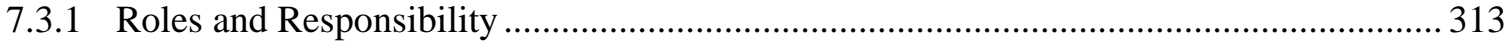

7.3.2 Elevator Usage During Emergencies............................................................................... 313

7.3.3 Occupant and Tenant Training ….................................................................................. 313

7.3.4 Evacuation Procedures for Disabled Persons …................................................................. 313

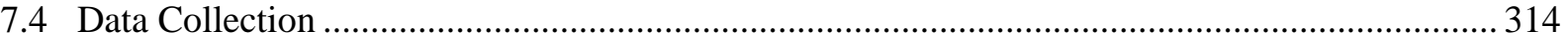

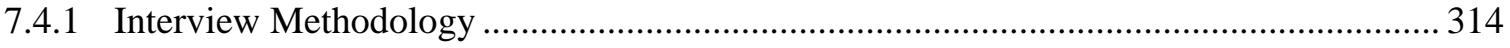

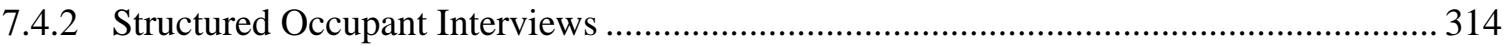

7.4.3 Unstructured Interviews with Selected Personnel ............................................................ 314

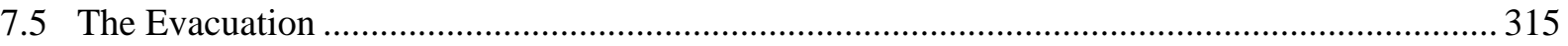

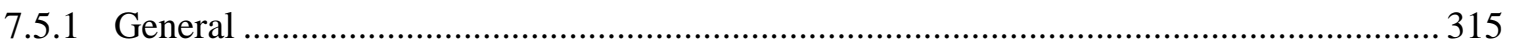

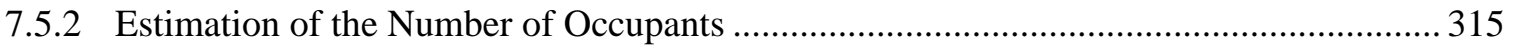

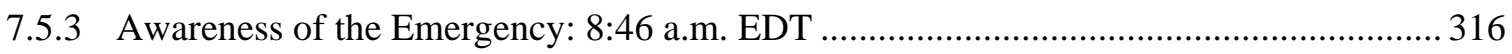

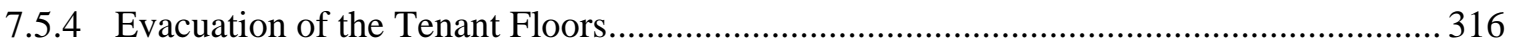

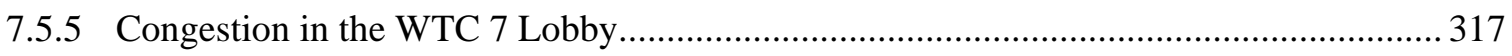

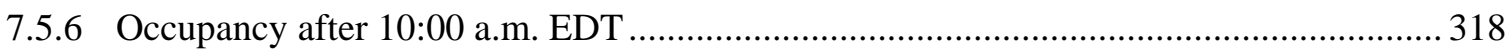

7.5.7 Estimation of the Minimum Required Evacuation Time.................................................. 319

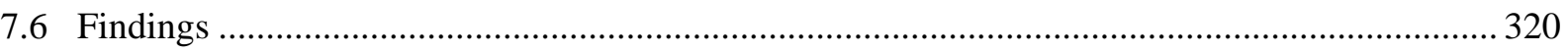

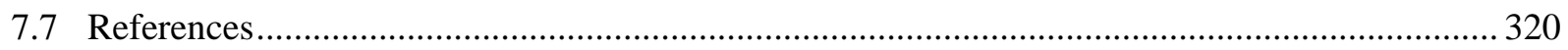

\section{Chapter 8}

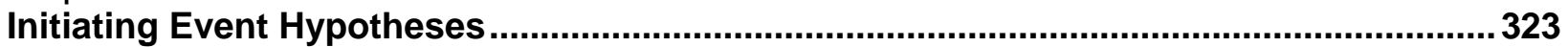

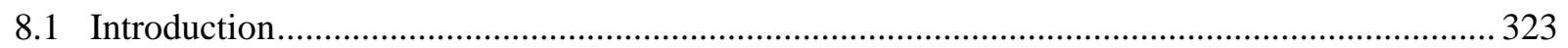

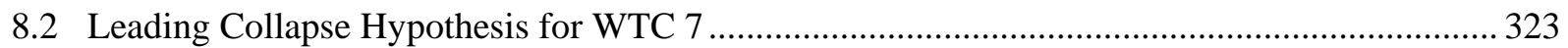

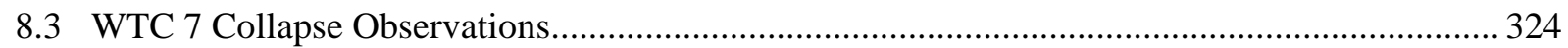

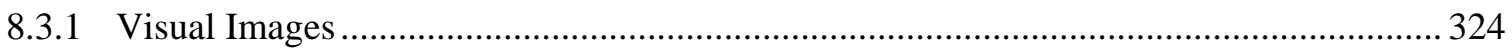

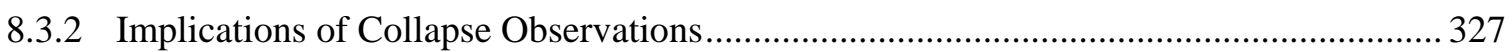

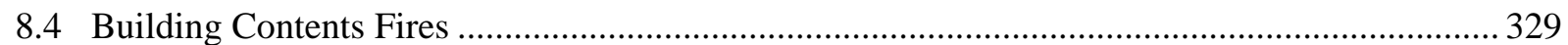

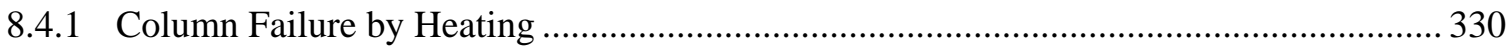

8.4.2 Column Failure by Loss of Lateral Support (increased unbraced length)......................... 330

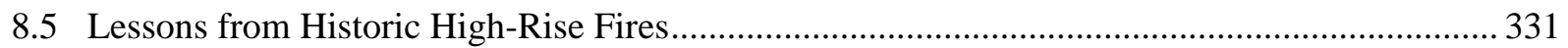

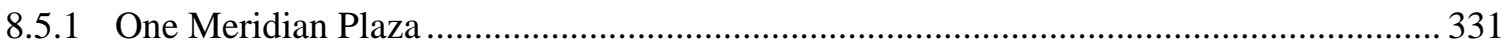

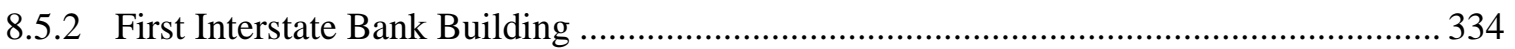

8.5.3 Multi-Story Test Building at Cardington (Test No. 6) ..................................................... 336

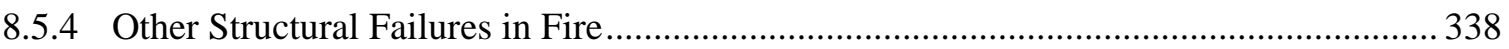

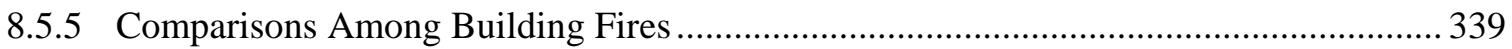




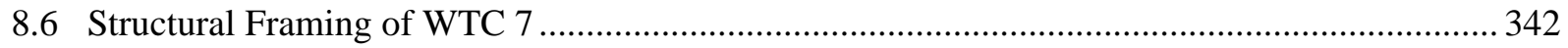

8.7 Implications of Structural Framing Details in WTC 7 ....................................................... 342

8.7.1 Fully Restrained Moment Connections vs. Simple Connections for Girders.................... 342

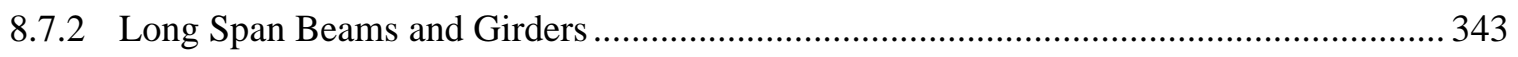

8.7.3 Asymmetrical Framing of Floor Beams into Girders ..................................................... 344

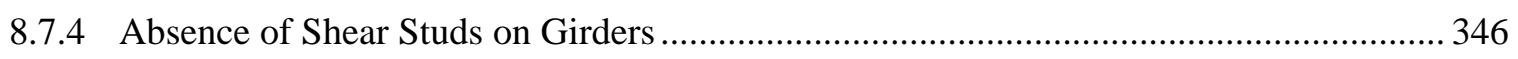

8.7.5 Seats Used for Floor System Connections ................................................................... 348

8.8 Finite Element Analysis of the Northeast Floor Framing System ............................................ 349

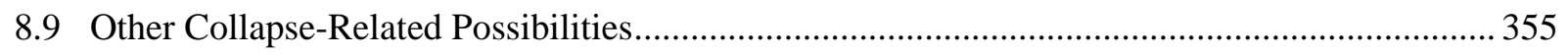

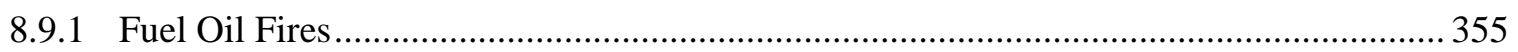

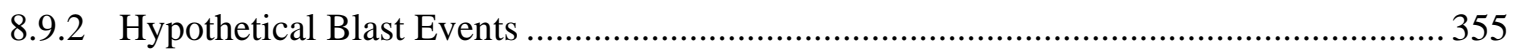

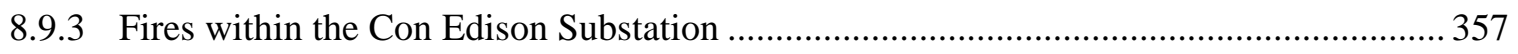

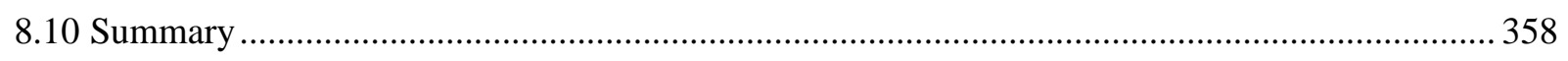

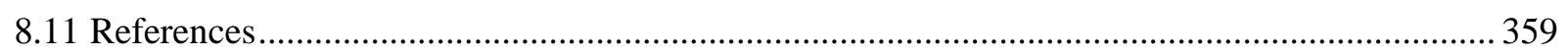




\section{LIST OF FIGURES}

Figure P-1. Technical components of the federal building and fire safety investigation of the WTC disaster.

xxxiii

Figure 1-1. WTC 7 analysis sequence and interdependencies. 3

Figure 1-2. Structural analysis sequence. 5

Figure 2-1. WTC complex. 10

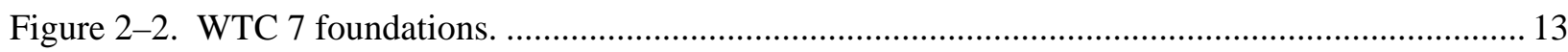

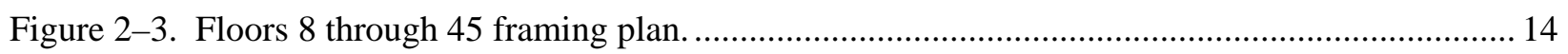

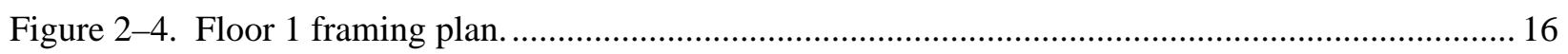

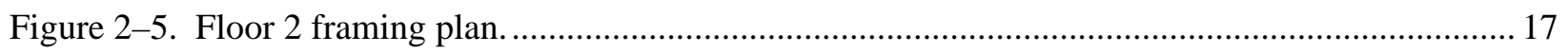

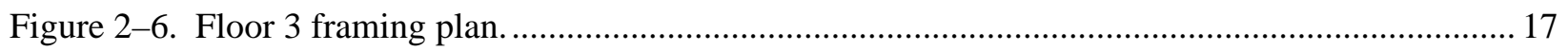

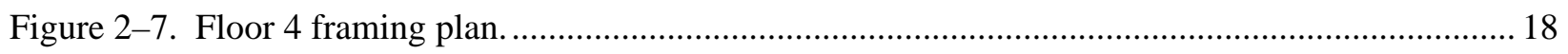

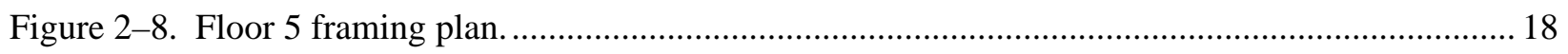

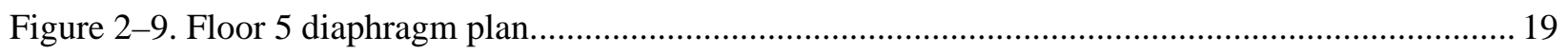

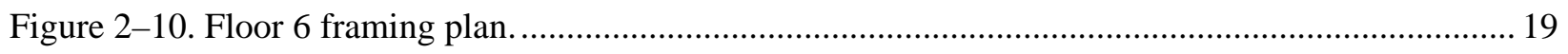

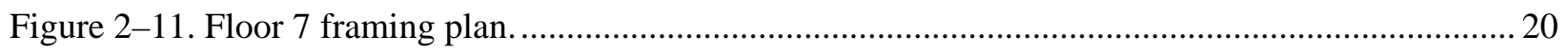

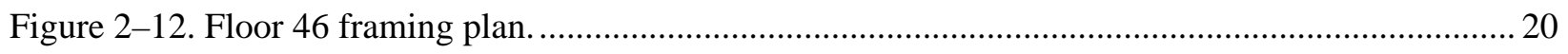

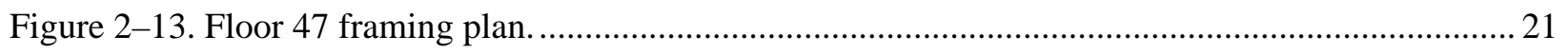

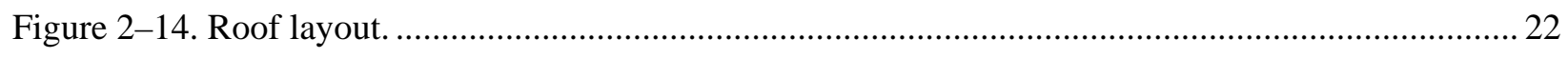

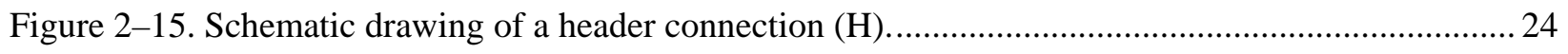

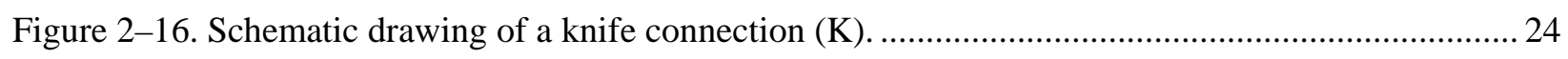

Figure 2-17. Schematic drawing of a fin plate connection (F)........................................................ 25

Figure 2-18. Schematic drawing of a seated connection with web clip (SWC)..................................... 25

Figure 2-19. Schematic drawing of a seated connection with top clip (STC) ......................................... 26

Figure 2-20. Schematic drawing of the seated connection at Column 79............................................. 26

Figure 2-21. Typical tenant floor framing connections.......................................................................... 27

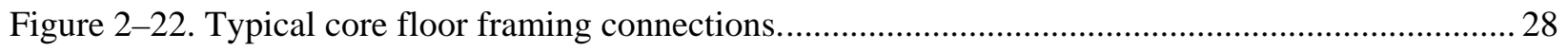

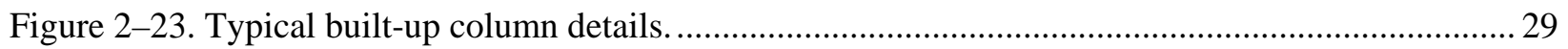

Figure 2-24. 3D schematic view of transfer trusses and girders between Floors 5 and 7....................... 30

Figure 2-25. Exterior lateral load resisting system elevations. .............................................................. 31 


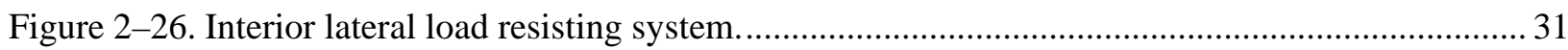

Figure 2-27. Photograph of Floor 5 during renovations showing SFRM on steel beams and metal

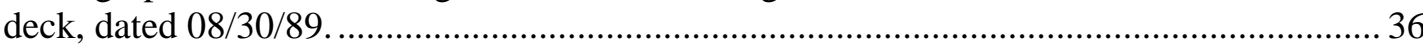

Figure 2-28. Photograph of Floor 33 during renovations showing SFRM on steel beams and metal

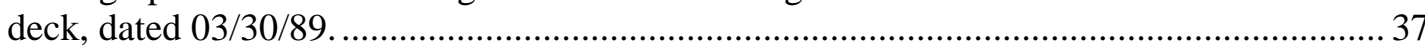

Figure 2-29. Photograph of Floor 36 during renovations, showing SFRM on steel beams and metal

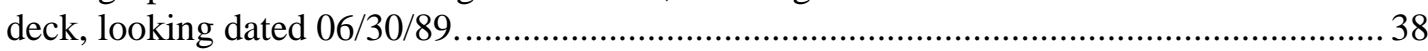

Figure 2-30. Exterior view of damage to the north face of 130 Liberty Street by debris falling from WTC 2.

Figure 2-31. Interior view of damage to the north face of 130 Liberty Street by debris falling from WTC 2.

Figure 2-32. Damaged areas from debris impact on the north face of the building at 130 Liberty Street.

Figure 2-33. Typical floor plan for the building at 130 Liberty Street.................................................. 42

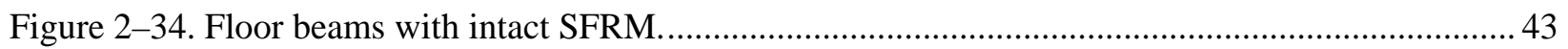

Figure 2-35. Column with removed SFRM and intact primer.

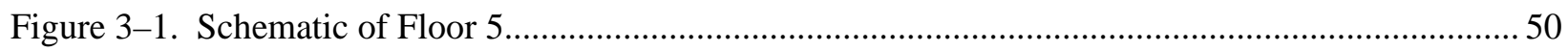

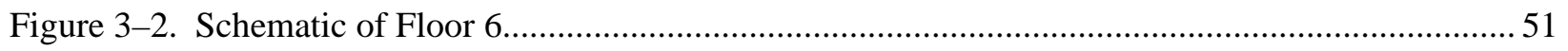

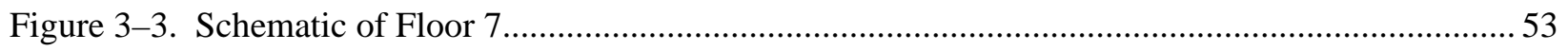

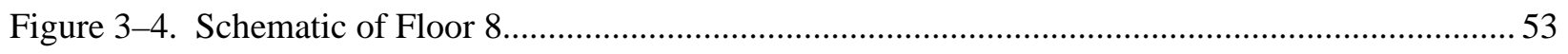

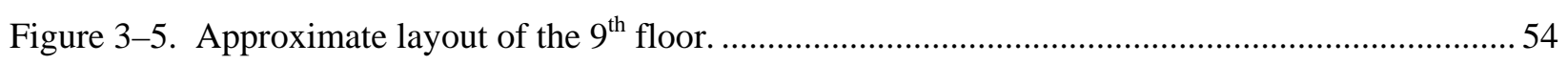

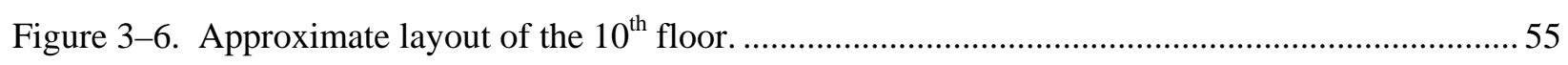

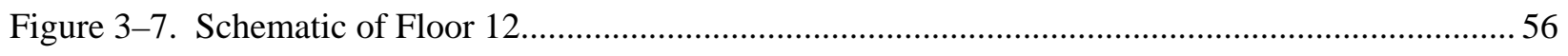

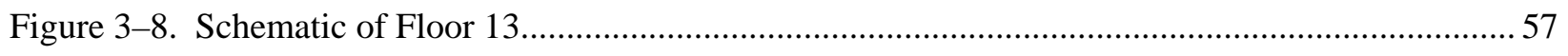

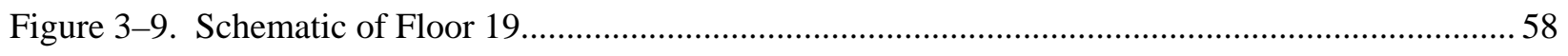

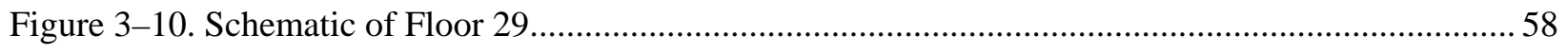

Figure 3-11. Section view of fuel oil distribution components in WTC 7 ............................................61

Figure 3-12. Schematic of the $7^{\text {th }}$ floor of WTC 7 showing the locations of electrical generators and the fuel lines that connected them to below ground fuel tanks............................................ 62

Figure 3-13. Schematic of the $9^{\text {th }}$ floor of WTC 7 showing the locations of the electrical generator and the fuel line that connected it to below-ground fuel tanks.

Figure 4-1. Monitoring station history tape record for the WTC 7 fire alarm system on September 11, 2001. 69

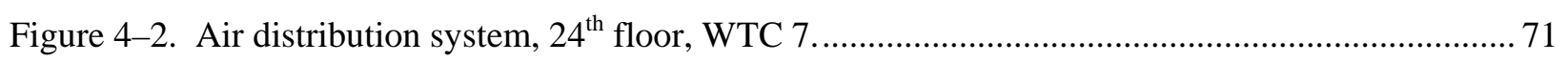

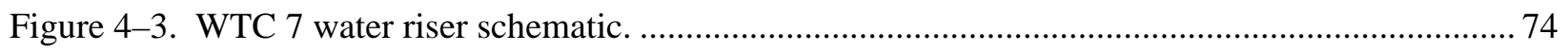


Figure 4-4. Calculated temperature rise in Column 79 at varying insulation thicknesses and thermal exposures.

Figure 4-5. Calculated temperature rise in a typical core or exterior column exposed to $1100{ }^{\circ} \mathrm{C}$ air temperature.

Figure 4-6. Calculated temperature rise in a W14 x 22 floor beam in an insulated composite floor assembly exposed to $1100^{\circ} \mathrm{C}$ air from below.

Figure 4-7. Calculated temperature rise in a 24WF x 55 floor beam in an insulated composite floor assembly exposed to $1100{ }^{\circ} \mathrm{C}$ air from below.

Figure 4-8. Calculated temperature rise in a 36WF135 floor beam in an insulated composite floor assembly exposed to $1100{ }^{\circ} \mathrm{C}$ air from below.

Figure 4-9. Calculated temperature rise in an insulated floor slab heated from below. 85

Figure 5-1. A photograph (top) and a frame from a video clip (bottom) showing the east penthouse of WTC 7 beginning to sink into the building.

Figure 5-2. Map of the area of Lower Manhattan in the immediate vicinity of the WTC site.

Figure 5-3. Map of the lower portion of Manhattan showing the location of the WTC complex relative to the island.

Figure 5-4. Overhead view of the area in the immediate vicinity of the collapsed WTC 7. 95

Figure 5-5. Photograph of WTC 7 and the immediate vicinity taken before noon on September 11, 2001.

Figure 5-6. Photograph of the WTC site taken around 10:21 a.m. from roughly the same direction as the wind was blowing on September 11.

Figure 5-7. Locations of columns and beams for a typical floor of WTC 7.

Figure 5-8. Photograph taken from the southwest at 10:22:50 a.m. on September 11 showing the mechanical systems and penthouses on the roof of WTC 7.

Figure 5-9. Cropped photograph taken from the northwest around 12:00 p.m. on September 11 showing the mechanical systems and penthouses on the roof of WTC 7.

Figure 5-10. Photograph of the north face of WTC 7, looking down Greenwich Street, shot at 8:55:01 a.m. on September 11.

Figure 5-11. Enlargement of a portion of Figure 5-10 showing the lower floors of WTC 7. 102

Figure 5-12. Photograph of the east side of the north face of WTC 7. 103

Figure 5-13. Façade graphic of the north face of WTC 7. 105

Figure 5-14. Photograph showing upper portions of the south and east faces of WTC 7, taken from near the corner of Church Street and Liberty Street on September 11 at 9:51:45 a.m. ....... 106

Figure 5-15. Photograph of a portion of the lower floors of WTC 7 on the south face. 107

Figure 5-17. Frame from a video showing one of the doorways located below the Promenade that led to the WTC 7 loading dock located on the $1^{\text {st }}$ and $2^{\text {nd }}$ floors.

Figure 5-18. An image from a video, shot from Vesey Street and looking toward the east, shows the south face of WTC 7 and the Promenade crossing over to WTC 6. 
Figure 5-19. Image of the Pedestrian Bridge taken from a video shot shortly after the collapse of WTC 1 from near the corner of West Broadway and Vesey Street.

Figure 5-20. Façade graphic of the south face of WTC 7.

Figure 5-21. Cropped photograph shot from near the corner of Broadway and Frankfurt Street showing the upper floors of the east face of WTC 7.

Figure 5-22. Cropped photograph of the lower portion of the east face of WTC 7, taken shortly after 2:00 p.m. on September $11^{\text {th }}$ from near the corner of Barclay Street and West Broadway.

Figure 5-23. Façade graphic of the east face of WTC 7.

Figure 5-24. Cropped photograph of the west face of WTC 7 shot from West Street between 3:30 p.m. and 4:30 p.m. on September 11.

Figure 5-25. Cropped photograph showing the lower floors of the west face and a small section of the north for WTC 7, taken on September 11 sometime after 12 p.m.

Figure 5-26. Façade graphic of the west face of WTC 7.

Figure 5-27. Cropped photograph showing the dust cloud created by the collapse of WTC 2 .....

Figure 5-28. Key used to describe observations with regard to fire, smoke, and window breakage in spreadsheets for individual windows in WTC 7.

Figure 5-29. Portion of the spreadsheet describing fires on the north face of WTC 7 around 3:13 p.m.

Figure 5-30. Photograph showing the north face of WTC 7 around 3:13 p.m. on September 11.

Floor numbers have been added, and the image intensity has been adjusted.

Figure 5-31 Screen capture of a data spread sheet visually representing the fire condition on a portion of the north face of WTC 7 at 3:13 p.m., based on the spreadsheet shown partially in Figure 5-29.

Figure 5-32. An example of a façade map with combined data from fire and window datasheets for the north face of WTC 7 at around 3:13 p.m.

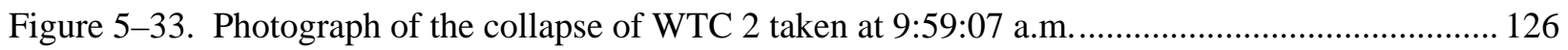

Figure 5-34. Photograph of the collapse of WTC 2 taken at 9:59:15 a.m. 126

Figure 5-35. Cropped photograph showing the dust cloud from the collapse of WTC 2 approaching the south face of WTC 7, taken from just east of the corner of Fulton Street and Broadway at 9:59:24 a.m.

Figure 5-36. Frame from a video filmed just outside of WTC 7 looking east up Vesey Street around 10:15 a.m.

Figure 5-37. Video frame showing the ground floor of the south face of WTC 7, taken around 10:15 a.m.

Figure 5-38. Video frame showing a corner of the main lobby on the $3^{\text {rd }}$ floor of the south side of WTC 7, taken around 10:15 a.m.

Figure 5-39. Video frame looking across the $1^{\text {st }}$ floor lobby on the south side of WTC 7, taken around 10:15 a.m.

Figure 5-40. A series of cropped photographs shot from the north and frames from a video shot from the west show the collapse of WTC 1 . 
Figure 5-41. Three pairs of frames taken from videos shot from the north and west, showing the collapse of WTC 1.

Figure 5-42. Aerial photograph shot $14 \mathrm{~s} \pm 0.5 \mathrm{~s}$ after WTC 1 began to collapse. 136

Figure 5-43. Cropped photograph showing the collapse of WTC 1, taken from just north of west of the WTC site $7.3 \mathrm{~s} \pm 0.2 \mathrm{~s}$ after initiation of the collapse.

Figure 5-44. Cropped photograph showing the collapse of WTC 1, taken from southwest of the WTC site $10.6 \mathrm{~s} \pm 0.2 \mathrm{~s}$ after the collapse initiated.

Figure 5-45. Photograph taken from the north of WTC $711.7 \mathrm{~s} \pm 0.1 \mathrm{~s}$ after WTC 1 began to collapse.

Figure 5-46. Enlarged section of Figure 5-45 focused on the area above WTC 7.

Figure 5-47. Photograph showing a portion of the south face of WTC 7, taken just after 1:30 p.m. ..... 140

Figure 5-48. Frame taken from a video recorded shortly after 1:30 p.m., showing a partial view of the south face of WTC 7.

Figure 5-49. Enlarged sections of the photograph shown in Figure 5-47.

Figure 5-50. An enlarged section of the south face of WTC 7 from the video frame in Figure 548.

Figure 5-51. An enlarged section of the south face of WTC 7 from a second video frame.

Figure 5-52. Photograph showing a portion of the south face of WTC 7 at 12:46:39 p.m.

Figure 5-53. Two enlargements from Figure 5-52, showing the south face of WTC 7 .

Figure 5-54. Frame from a video showing a view of the south face of WTC 7

Figure 5-55. Enlargement of the damaged area visible on the south face of WTC 7 in Figure 5-54..... 151

Figure 5-56. Photograph of damage on the south face of WTC 7, shot looking down Vesey Street between the Verizon Building (left) and WTC 6 (right), shortly after 1:30 p.m.

Figure 5-57. Expanded portion of Figure 5-56 showing damage on the south face of WTC 7.

Figure $5-58$. View of the rubble at the base of the south face of WTC 7.

Figure 5-59. Frame from a video clip shot shortly after 12:30 p.m. showing the south face of WTC 7 framed by the Verizon Building and WTC 6.

Figure 5-60. Photograph of the WTC site shot around 12:35 p.m. from a helicopter. 154

Figure 5-61. Enlarged portion of Figure 5-60 showing the south face of WTC 7. 155

Figure 5-62. Photograph showing the southwest corner of WTC 7 in the early afternoon. 156

Figure 5-63. Enlargement of the lower part of the southwest corner of WTC 7 from Figure 5-62, with certain features identified.

Figure 5-64. Photograph showing the north and west faces of WTC 7, shot from a helicopter between 2:15 p.m. and 2:45 p.m.

Figure 5-65. Enlargement of an area from the photograph in Figure 5-64 showing part of the west face of WTC 7. 158

Figure 5-66. Photographs showing the southwest corner of WTC 7, shot from West Street at 12:47:40 p.m. 159 
Figure 5-67. Photograph showing the north and west faces of WTC 7, shot from a helicopter between 2:30 p.m. and 3:00 p.m.

Figure 5-68. Enlargement of an area from the photograph in Figure 5-67 showing part of the west face of WTC 7.

Figure 5-69. Enlargement of an area from the photograph in Figure 5-64 showing the damaged southwest corner of WTC 7.

Figure 5-70. Black and white photograph shot from the corner of Vesey Street and West Broadway looking west down Vesey Street.

Figure 5-71. Enlargement of the photograph in Figure 5-70 showing the south face of WTC 7.

Figure 5-72. Two versions of a frame from a video taken from the corner of Vesey Street and West Broadway in the early afternoon.

Figure 5-73. Summary of observed damage for the lower 19 floors on the south face of WTC 7 following the collapse of WTC 1.

Figure 5-74. Cropped photograph, taken from a helicopter, showing the roof of WTC 7 from the northwest.

Figure 5-75. Cropped photograph, taken from a helicopter, showing the roof of WTC 7 from just north of due west.

Figure 5-76. Cropped photograph showing the upper portion of WTC 7 as viewed from the southwest.

Figure 5-77. Enlargement of the area of damage on the roof and south sides of the $46^{\text {th }}$ and $47^{\text {th }}$ floors of WTC 7 in Figure 5-76.

Figure 5-78. View of the south face of WTC 7 from a video shot from a helicopter located to the southwest of the WTC site, likely after 12:00 p.m.

Figure 5-79. Cropped photograph showing the west side of the south face of WTC 7, taken between 4:30 p.m. and 5:00 p.m. from near the corner of West Street and Liberty Street. 170

Figure 5-80. Cropped view of the south face of WTC 7 taken from a video shot from a helicopter hovering to the southwest of the WTC site around 1:00 p.m.

Figure 5-81. Cropped photograph showing the south face of WTC 7, shot from West Street in the mid to late afternoon.

Figure 5-82. Cropped view of the south face of WTC 7 taken from a video shot from a helicopter hovering to the southwest of the WTC site around 1:00 p.m.

Figure 5-83. Observed damage on the south face of WTC 7 following the collapse of WTC 1

Figure 5-84. Cropped photograph showing the west face of WTC 7, taken from a helicopter around 3:00 p.m.

Figure 5-85. Cropped photograph showing the west face of WTC 7, taken shortly after 3:00 p.m. from West Street.

Figure 5-86. Image, cropped from Figure 5-67, showing the west face of WTC 7, shot from a helicopter between 2:30 p.m. and 3:00 p.m......

Figure 5-87. Cropped photograph of a partial view of the west face of WTC 7 looking down Washington Street between WTC 7 on the left and the Verizon Building on the right. 
Figure 5-88. Enlarged view of the west side of WTC 7 from Figure 5-87. The intensity levels have been adjusted, and floor numbers have been added.

Figure 5-89. Observed damage on the west face of WTC 7 following the collapse of WTC 1 is shown.

Figure 5-90. Photo showing the east face of WTC 7, taken from the southeast corner of Barclay Street and West Broadway looking down West Broadway, likely around 12:00 p.m.

Figure 5-91. Cropped photograph showing the east side of the lower floors of the north face and an oblique view of the east face.

Figure 5-92 Elevation view of the estimated debris impact damage for the structural analysis of WTC 7, viewed from the south.

Figure 5-93 Elevation view of the estimated depth of interior debris impact damage to the south face of WTC 7, viewed from the west.

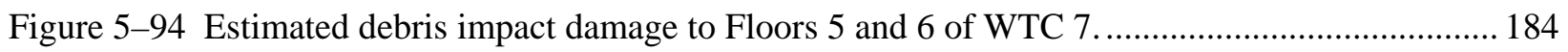

Figure 5-95 Estimated debris impact damage to Floor 7 of WTC 7.................................................... 184

Figure 5-96 Estimated debris impact damage to Floor 8 of WTC 7..................................................... 185

Figure 5-97 Estimated debris impact damage to Floor 9 of WTC 7..................................................... 185

Figure 5-98 Estimated debris impact damage to Floors 10 and 11 of WTC 7 ..................................... 186

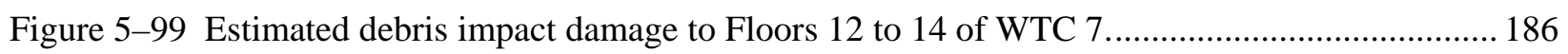

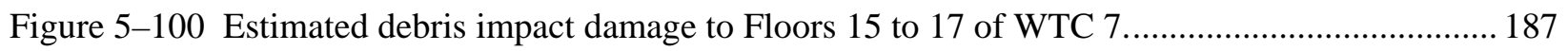

Figure 5-101 Estimated debris impact damage to Floor 44 to the roof of WTC 7............................... 187

Figure 5-102. Cropped photograph showing the north face of WTC 1 at 10:28:23 a.m....................... 189

Figure 5-103. Photograph showing the dust-laden flows spreading away from WTC 1 following its collapse.

Figure 5-104. Cropped photograph showing the north face of WTC 7, shot at 11:28:15 a.m. from the upper story of a nearby building looking down Greenwich.

Figure 5-105. Cropped photograph showing the west face of WTC 7, shot at 11:13:51 a.m. from New Jersey looking across the Hudson River.

Figure 5-106. Photograph taken looking down West Broadway towards WTC 7 from its corner with Park Place.

Figure 5-107. Photograph taken looking down West Broadway towards WTC 7 from near its corner with Park Place.

Figure 5-108. Frame taken from a video clip filmed near the corner of West Broadway and Barclay Street showing flames burning on a number of vehicles.

Figure 5-109. Frame from a video clip showing the southwest corner of WTC 7 around the $22^{\text {nd }}$ floor.

Figure 5-110. Cropped photograph showing a portion of the west face of WTC 7 near the south edge at 12:27:30 p.m. $\pm 1 \mathrm{~s}$ from near the corner of Vesey and West Streets. 195

Figure 5-111. Frame from a video clip showing fires near the southwest corner of WTC 7 on the $29^{\text {th }}$ and $30^{\text {th }}$ floors around $12: 28$ a.m. \pm 3 min. 196 
Figure 5-112. Cropped photograph shot from near the corner of Washington and Barclay Streets shows lower floors on the west side of WTC 7 between 1:30 p.m. and 2:30 p.m. The intensity levels have been adjusted, and floor numbers have been added.

Figure 5-113. Enlargement of a portion of the photograph shown in Figure 5-64 emphasizing areas on the lower floors of WTC 7 near the northwest corner.

Figure 5-114. Oblique view of the east face of WTC 7, taken at 2:08:28 p.m. \pm 1 s from West Broadway near its corner with Park Place.

Figure 5-115. Cropped photograph showing fires on the east face of WTC 7 at 2:11:09 p.m. \pm 1 s...... 201

Figure 5-116. Frame from a video showing a portion of the east face of WTC 7 between 2:15 p.m. and 2:27 p.m.

Figure 5-117. Photograph showing fires on the east face of WTC 7 at 2:28:43 p.m. $\pm 1 \mathrm{~s}$.

Figure 5-118. Photograph of the east face of WTC 7 taken at some time after 2:28:43 p.m. from near the corner of West Broadway and Barclay Street.

Figure 5-119. Photograph showing the north face of WTC 7 taken from a helicopter around 2:57 p.m. \pm 5 min.

Figure 5-120. Frame taken from a video clip shot looking down on WTC 7 from a building to the northwest showing the fires along a length of the north side of the $7^{\text {th }}$ floor of WTC 7 $\ldots . .207$

Figure 5-121. Cropped photograph of the north face of WTC 7, taken from a helicopter around 3:05 p.m. \pm 5 min.

Figure 5-122. Frame taken from a video clip shot looking down on WTC 7 from a building to the northwest shows the fires along a length of the north side of the $12^{\text {th }}$ floor of WTC 7 ...... 208

Figure 5-123. Enlarged section of a long distance aerial shot of the north face of WTC 7 taken around 3:10 p.m. \pm 5 min.

Figure 5-124. Cropped photograph of the north face of WTC 7 taken from a building located to the northwest looking down Greenwich Street at 3:10:46 p.m. \pm 3 s.

Figure 5-125. Cropped close-up photograph of the north face of WTC 7 taken within a few minutes of the image in Figure 5-124.

Figure 5-126. Cropped close-up photograph of the north face of WTC 7 taken between 3:11:15 p.m. and 3:16:51 p.m.

Figure 5-127. Photograph showing the north face of WTC 7, taken around 3:12:50 p.m. with an estimated uncertainty of \pm 5 min from near the corner of Murray and Greenwich Streets.

Figure 5-128. This frame from a video shot from a building to the northwest of WTC 7 was taken around 3:42:30 p.m. with an uncertainty of \pm 2 min.

Figure 5-129. Photograph showing the north face of WTC 7 shot looking down Greenwich Street from near the corner of Greenwich and Warren Streets at around 3:41 p.m.

Figure 5-130. View of the north face of WTC 7 taken around 3:41 p.m. \pm 3 min, enlarged from Figure 5-129.

Figure 5-131. This frame from a video shot from a building to the northwest of WTC 7 was taken around 3:50:13 p.m. with an uncertainty of \pm 3 min. 
Figure 5-132. View of the northwest corner of WTC 7 from a video recorded from inside the lobby of 123 Barclay Street around 3:42 p.m. \pm 5 min.

Figure 5-133. View of the west face of WTC 7 taken from a video recorded from inside the lobby of 123 Barclay Street around 3:41:30 \pm 5 min.

Figure 5-134. View of the north face of WTC 7 taken from a video recorded from inside the lobby of 123 Barclay Street at 3:44 p.m. \pm 4 min.

Figure 5-135. Cropped photograph showing the east edge of the north face and an oblique view of the east face of WTC 7, taken from near the corner of West Broadway and Park Place..... 221

Figure 5-136. Frame taken from a video shot from near the corner of Greenwich Street and Park Place showing the north face of WTC 7 between 3:49 p.m. and 3:54 p.m.

Figure 5-137. Close up of the $6^{\text {th }}$ through $9^{\text {th }}$ floors of the north face of WTC 7 from a video shot between 3:49:30 p.m. and 3:54:30 p.m. near the corner of Greenwich Street and Park Place.

Figure 5-138. Frame taken from a video shot from near the corner of Greenwich Street and Park Place showing windows 8-47B to 8-48A between 3:49 p.m. and 3:54 p.m.

Figure 5-139. This frame from a video shot from a building to the northwest of WTC 7 was taken around 3:54:14 p.m. with an uncertainty of $\pm 3.5 \mathrm{~min}$.

Figure 5-140. Frame taken from a video shot from near the corner of Greenwich and Barclay Streets showing the north face of WTC 7 between 3:51 p.m. and 3:58 p.m.

Figure 5-141. Frame from a video shot from near the corner of West Broadway and Barclay Street showing the eastern side of the north face of WTC 7 between 3:53 p.m. and 4:02 p.m...... 227

Figure 5-142. Frame taken from a video shot near the corner of West Broadway and Barclay Street showing the lower northeast corner of WTC 7 between 3:55 p.m. and 4:04 p.m.....

Figure 5-143. Frame from a video shot near the corner of West Broadway and Barclay Street showing a close up of the northeast corner of WTC 7 at the $8^{\text {th }}$ floor between 3:56 p.m. and 4:05 p.m.

Figure 5-144. Cropped photograph showing the north face of WTC 7, shot from near the corner of Murray and Greenwich Streets near 3:55 p.m.

Figure 5-145. Frame taken from a video clip shot from near the corner of Greenwich and Jay Streets around 4:10 p.m. \pm 5 min......

Figure 5-146. Cropped photograph showing the north face of WTC 7 from near the corner of Greenwich and Harrison Streets at a roughly estimated time of 4:20 p.m.

Figure 5-147. Frame from a video clip shot from the top of a nearby building to the northwest, providing a view of the north face of WTC 7 at 4:37:46 p.m. $\pm 1 \mathrm{~s}$.

Figure 5-148. Frame from a video clip showing a close up view of the north face of WTC 7 at 4:38:11 p.m. \pm 1 s.

Figure 5-149. Frame from a video clip showing a close up view of the north face of WTC 7 at 4:38:14 p.m. \pm 1 s.

Figure 5-150. Cropped photograph showing part of the north face of WTC 7, shot from near the corner of Harrison and Greenwich Streets at 4:39 p.m. \pm 120 s.

Figure 5-151. Frame from a video clip shot from the top of a nearby building, showing the north face of WTC 7 at 4:52:24 p.m. \pm 1 s. 236 
Figure 5-152. Frame taken from a video clip shot over the buildings at 30 West Broadway and 70 Murray Street, showing the western edge of the north face of WTC 7at about 5:00 p.m.

Figure 5-153. This frame from a video shot from a building to the northwest of WTC 7 was taken around 5:03:00 p.m. with an uncertainty of $\pm 120 \mathrm{~s}$.

Figure 5-154. This frame from a video shot from a building to the northwest of WTC 7 was taken around 5:09:03 p.m. with an uncertainty of $\pm 120 \mathrm{~s}$.

Figure 5-155. Cropped photograph of the north face of WTC 7, taken from a building located to the northwest looking down Greenwich Street at 5:13:58 p.m. \pm 3 s.

Figure 5-156. This frame from a video shot from a building to the northwest of WTC 7 was taken around 5:19:45 p.m. with an uncertainty of $\pm 120 \mathrm{~s}$.

Figure 5-157. Frame taken from a video clip shot from the northeast, showing the north face of WTC 7 within a few minutes of the WTC 7 collapse at 5:20:52 p.m.

Figure 5-158. Frame taken from a video clip shot over the buildings at 30 West Broadway and 70 Murray Street, showing the western edge of the north face of WTC 7 within a few minutes of the WTC 7 collapse at 5:20:52 p.m.

Figure 5-159. This frame from a video shot from a building to the northwest of WTC 7 was taken around 5:20:17 p.m. with an uncertainty of $\pm 15 \mathrm{~s}$.

Figure 5-160. Façade map summarizing observations of fires and open windows on the east face of WTC 7 around 2:10 p.m.

Figure 5-161. Façade map summarizing observations of fires and open windows on the east face of WTC 7 around 2:14 p.m.

Figure 5-162. Façade map summarizing observations of fires and open windows on the east face of WTC 7 around 2:30 p.m.

Figure 5-163. Façade map summarizing observations of fires and open windows on the north face of WTC 7 around 2:57 p.m......

Figure 5-164. Façade map summarizing observations of fires and open windows on the north face of WTC 7 around 3:05 p.m.

Figure 5-165. This façade map summarizes observations of fires and open windows on the north face of WTC 7 around 3:10 p.m.

Figure 5-166. Façade map summarizing observations of fires and open windows on the north face of WTC 7 around 3:13 p.m......

Figure 5-167. Façade map summarizing observations of fires and open windows on the north face of WTC 7 around 3:42 p.m...

Figure 5-168. Façade map summarizing observations of fires and open windows on the north face of WTC 7 around 3:44 p.m...

Figure 5-169. Façade map summarizing observations of fires and open windows on the north face of WTC 7 around 3:52 p.m...

Figure 5-170. Façade map summarizing observations of fires and open windows on the north face of WTC 7 around 3:55 p.m..

Figure 5-171. Façade map summarizing observations of fires and open windows on the north face of WTC 7 around 3:55 p.m. 
Figure 5-172. Façade map summarizing observations of fires and open windows on the north face of WTC 7 around 3:57 p.m.

Figure 5-173. Façade map summarizing observations of fires and open windows on the north face of WTC 7 around 4:00 p.m.

Figure 5-174. Façade map summarizing observations of fires and open windows on the north face of WTC 7 around 4:10 p.m.

Figure 5-175. Façade map summarizing observations of fires and open windows on the north face of WTC 7 around 4:20 p.m.

Figure 5-176. Façade map summarizing observations of fires and open windows on the north face of WTC 7 at 4:38:11 p.m.

Figure 5-177. Façade map summarizing observations of fires and open windows on the north face of WTC 7 around 4:39 p.m.

Figure 5-178. Façade map summarizing observations of fires and open windows on the north face of WTC 7 around 5:00 p.m.

Figure 5-179. This façade map summarizes observations of fires and open windows on the west face of WTC 7 around 3:52 p.m.

Figure 5-180. Façade map of the north face of WTC 7 showing where windows were broken and/or fire was observed during the period when fire first appeared on the face shortly before 3:00 p.m. until the building collapsed at 5:20:52 p.m.

Figure 5-181. Façade map of the east face of WTC 7 showing locations where windows were broken and/or fire was observed during the period when fire first appeared on the face around 2:00 p.m. and the building collapsed at 5:20:52 p.m.

Figure 5-182. Façade map of the west face of WTC 7 showing locations where windows were broken and/or fire was observed during the period when fire first appeared on the face before 2:00 p.m. and the building collapsed at 5:20:52 p.m.

Figure 5-183. Locations of the nine video cameras used to analyze the WTC 7 collapse are shown relative to the location of WTC 7.

Figure 5-184. Frame from the Camera 1 video, showing the north face of WTC 7 (on right) seconds before the east penthouse began to fall into the building.

Figure 5-185. Frame from the Camera 2 video, showing the north face of WTC 7 (just right of center) seconds before the east penthouse began to fall into the building.

Figure 5-186. Frame from the Camera 3 video showing the north face of WTC 7 (in center) seconds before the east penthouse began to fall into the building. 264

Figure 5-187. Earliest frame from the Camera 4 video, showing the north face of WTC 7.................. 265

Figure 5-188. Earliest frame from the Camera 5 video, showing the north face of WTC 7................. 265

Figure 5-189. Earliest frame from the Camera 6 video, showing the north face of WTC 7.................. 265

Figure 5-190. Earliest frame from the Camera 7 video, showing the north face of WTC 7.................. 266

Figure 5-191. Earliest frame from the Camera 8 video, showing the north face of WTC 7.................. 266

Figure 5-192. Earliest frame from the Camera 9 video, showing the north face of WTC 7.................. 266 
Figure 5-193. Cropped frames from the Camera 2 video clip and the Camera 3 video clip, showing the north face of WTC $71.0 \mathrm{~s} \pm 0.1 \mathrm{~s}$ after the east penthouse began to move downward.

Figure 5-194. Cropped frames from the Camera 2 video clip and the Camera 3 video clip, showing the north face of WTC $71.3 \mathrm{~s} \pm 0.1 \mathrm{~s}$ after the east penthouse began to move downward.

Figure 5-195. Cropped frames from the Camera 2 video clip and the Camera 3 video clip, showing the north face of WTC $71.7 \mathrm{~s} \pm 0.1 \mathrm{~s}$ after the east penthouse began to move downward.

Figure 5-196. Cropped frames from the Camera 2 video clip and the Camera 3 video clip, showing the north face of WTC $72.0 \mathrm{~s} \pm 0.1 \mathrm{~s}$ after the east penthouse began to move downward.

Figure 5-197. Cropped frames from the Camera 2 video clip and the Camera 3 video clip, showing the north face of WTC $73.5 \mathrm{~s} \pm 0.1 \mathrm{~s}$ after the east penthouse began to move downward.

Figure 5-198. Three cropped difference frames based on the Camera 3 video clip shown in Figure 5-186 created by subtracting a frame from before the east penthouse started downward from each frame in the clip.

Figure 5-199. Cropped frames from the Camera 2 video clip in Figure 5-185 and the Camera 3 video clip in Figure 5-186, showing the north face of WTC $75.0 \mathrm{~s} \pm 0.1 \mathrm{~s}$ after the east penthouse began to move downward.

Figure 5-200. Cropped frames from the Camera 2 video clip in Figure 5-185 and the Camera 3 video clip in Figure 5-186, showing the north face of WTC $77.5 \mathrm{~s} \pm 0.1 \mathrm{~s}$ after the east penthouse began to move downward.

Figure 5-201. Cropped difference frame at $7.5 \mathrm{~s} \pm 0.1 \mathrm{~s}$ after the east penthouse began to move, created by subtracting the frame reproduced in Figure 5-199 from the Camera 3 video clip shown in Figure 5-200.

Figure 5-202. Cropped frames from the Camera 2 video clip in Figure 5-185 and the Camera 3 video clip in Figure 5-186, showing the north face of WTC $78.1 \mathrm{~s} \pm 0.1 \mathrm{~s}$ after the east penthouse began to move downward.

Figure 5-203. Cropped frames from the Camera 2 video clip in Figure 5-185 and the Camera 3 video clip in Figure 5-186, showing the north face of WTC $79.0 \mathrm{~s} \pm 0.1 \mathrm{~s}$ after the east penthouse began to move downward.

Figure 5-204. Images from the Camera 4 video clip showing relative movement of the northeast edge of WTC 7 during its global collapse.

Figure 5-205. Difference images from the Camera 3 video clip showing the rotation of the northeast edge of WTC 7 during the global collapse.

Figure 5-206. Heavily processed difference frame from the camera 3 video, used to estimate the lateral distance the northeast corner of WTC 7 moved from its original footprint during the collapse.

Figure 5-207. Frame from the Camera 6 video clip in Figure 5-189, showing the north face of WTC $79.0 \mathrm{~s} \pm 0.2 \mathrm{~s}$ after the east penthouse began to move downward. 
Figure 5-208. Cropped frames from the Camera 2 video clip in Figure 5-185 and the Camera 3 video clip in Figure 5-186, showing the north face of WTC $710.0 \mathrm{~s} \pm 0.1 \mathrm{~s}$ after the east penthouse began to move downward.

Figure 5-209. Frame from the Camera 6 video clip in Figure 5-189, showing the north face of WTC $710.0 \mathrm{~s} \pm 0.2 \mathrm{~s}$ after the east penthouse began to descend.

Figure 5-210. Frame from the Camera 9 video clip in Figure 5-192, showing the north face of WTC $710.0 \mathrm{~s} \pm 0.2 \mathrm{~s}$ after the east penthouse began to move downward.

Figure 5-211. Cropped frames from the Camera 2 video clip in Figure 5-185 and the Camera 3 video clip in Figure 5-186, showing the north face of WTC $711.0 \mathrm{~s} \pm 0.1 \mathrm{~s}$ after the east penthouse began to move downward.

Figure 5-212. Frame from the Camera 6 video clip in Figure 5-189, showing the north face of WTC $711.0 \mathrm{~s} \pm 0.2 \mathrm{~s}$ after the east penthouse began to move downward.

Figure 5-213. Frame from the Camera 9 video clip in Figure 5-192 shows the north face of WTC 7 $11.0 \mathrm{~s} \pm 0.2 \mathrm{~s}$ after the east penthouse began to move downward.

Figure 5-214. Frame from the Camera 6 video clip in Figure 5-189, showing the north face of WTC $712.0 \mathrm{~s} \pm 0.2 \mathrm{~s}$ after the east penthouse began to move downward.

Figure 5-215. Frame from the Camera 9 video clip in Figure 5-192, showing the north face of WTC $712.0 \mathrm{~s} \pm 0.2 \mathrm{~s}$ after the east penthouse began to move downward.

Figure 5-216. Frame from the Camera 6 video clip in Figure 5-189, showing the north face of WTC $713.0 \mathrm{~s} \pm 0.2 \mathrm{~s}$ after the east penthouse began to move downward.

Figure 5-217. Frame from the Camera 6 video clip in Figure 5-189, showing the dust-laden flow generated by the collapse of WTC 7, $22.0 \mathrm{~s} \pm 0.2 \mathrm{~s}$ after the east penthouse began to move downward.

Figure 5-218. Frame from the Camera 9 video clip in Figure 5-192, showing the dust-laden flow created by the collapse of WTC 7, $22.0 \mathrm{~s} \pm 0.2 \mathrm{~s}$ after the east penthouse began to move downward.

Figure 7-1. Fifth floor plan, indicating stairwell locations and the horizontal transfer corridors. 306

Figure 7-2. First floor plan, indicating the loading dock exit, stairwells, and escalators to and from the $3^{\text {rd }}$ floor.

Figure 7-3. Third floor plan, indicating the elevators, stairs, escalators to and from the $1^{\text {st }}$ floor, and the exits to the Promenade and pedestrian bridge.

Figure 7-4. Photograph of the $3^{\text {rd }}$ floor exits from the south face of WTC 7 ....................................... 308

Figure 7-5. Photograph of the east face of WTC 7 showing the east exit door...................................... 308

Figure 7-6: Schematic of the elevators in WTC 7.

Figure 8-1. East penthouse kinks and begins to collapse. 325

Figure 8-2. East penthouse collapses as roof gives way - windows break between column lines 43 and 45. 325

Figure 8-3. Motion of northwest edge of building detected by video frame subtraction. 326 
Figure 8-4. Daylight visible where roof collapsed on east side of building........................................ 326

Figure 8-5. Global collapse of WTC 7 begins about seven seconds after the onset of collapse of the east penthouse.

Figure 8-6. Entire building continues to collapse............................................................................. 327

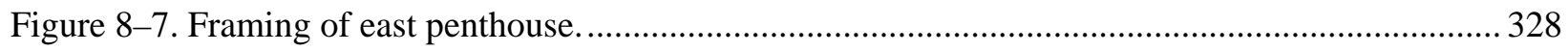

Figure 8-8. Horizontal motion detected on the northwest edge of the building................................... 329

Figure 8-9. One Meridian Plaza fire, Philadelphia, 1991.................................................................. 331

Figure 8-10. Floor framing plan for One Meridian Plaza. ................................................................ 332

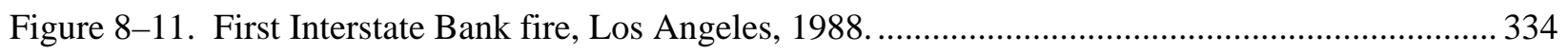

Figure 8-12. Floor framing plan of Cardington test building.............................................................. 336

Figure 8-13. Test areas for Test No. 3 and Test No. 6....................................................................... 337

Figure 8-14. Tear-out of beam web due to uncontrolled fires.............................................................. 339

Figure 8-15. Steel samples recovered from WTC 5, showing tear-out of beam web. ........................... 339

Figure 8-16. Partial floor framing plan showing northeast corner. ...................................................... 343

Figure 8-17. Floor beam buckling at symmetrical framing to girder. .................................................. 345

Figure 8-18. Floor framing where beams frame into only one side of the girder. ................................ 345

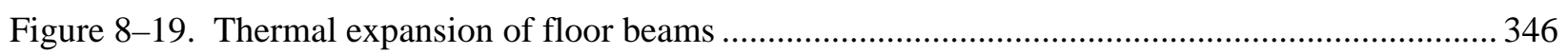

Figure 8-20. Seat connection at exterior column on the north face..................................................... 348

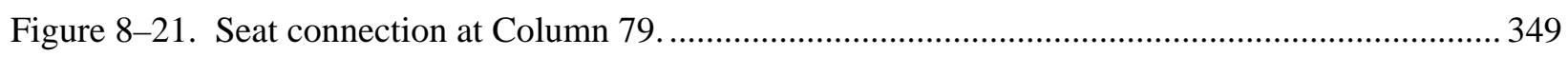

Figure 8-22. Finite element model of northeast corner as viewed from the southeast........................... 350

Figure 8-23. Views from northeast showing seat connection at Column 79 and bolted shear plate

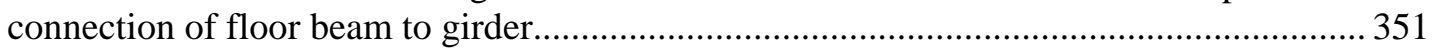

Figure 8-24. Time history of gravity loading, applied as a downward pressure on the concrete slab

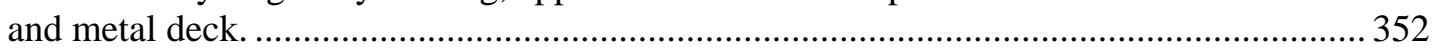

Figure 8-25. Time histories of temperatures prescribed for girders and beams. ................................... 353

Figure 8-26. Lateral displacement of girder due to thermal expansion of floor beam. .......................... 354

Figure 8-27. Buckled floor beams shown from above (a) and along girder (b)................................... 354 


\section{LIST OF TABLES}

Table $\mathrm{P}-1$. Federal building and fire safety investigation of the WTC disaster.

xxxii

Table P-2. Public meetings and briefings of the WTC Investigation.

xxxvi

Table 2-1. UL Fire Resistance Directory ratings for columns and composite floors (UL 1983).

Table 2-2. Statistics of SFRM thickness measurements on steel columns, floor beams, and metal decks in WTC 7.

Table 3-1. Floor layout information obtained.

Table 4-1. Calculated sufficiency of sprinkler water supply.....

Table 5-1. Times for major events on September 11, 2001. 90

Table 5-2. Attributes of videos used for analysis of the collapse of WTC 7.

Table 5-3. Timeline for major WTC 7 collapse observations

Table 8-1. Comparison of building fires. 340

Table 8-2 Progression of observed failures. 353

Table 8-3 Sound Levels Generated by Various Sources of Noise. 356 
This page intentionally left blank. 


\section{LIST OF ACRONYMS AND ABBREVIATIONS}

\section{Acronyms}

ASCE American Society of Civil Engineers

ASTM ASTM International

BPS Building Performance Study

FCD Fire Command Desk

FDNY The Fire Department of the City of New York

FDS Fire Dynamics Simulator

FEMA Federal Emergency Management Agency

FSI Fire Structure Interface

IBC International Building Code

NFPA National Fire Protection Association

NIST National Institute of Standards and Technology

NYC New York City

NYCBC New York City Building Code

NYPD New York City Police Department

NYS New York State

OEM New York Mayor's Office of Emergency Management

PANYNJ The Port Authority of New York and New Jersey

PAPD Port Authority Police Department

SEC Securities and Exchange Commission

SFRM Sprayed fire-resistive material

USC United States Code

WTC World Trade Center

WTC 1 World Trade Center 1 (North Tower)

WTC 2 World Trade Center 2 (South Tower)

WTC $7 \quad$ World Trade Center 7 


\section{Abbreviations and Conversion Factors}

$\begin{array}{lll}{ }^{\circ} \mathrm{C} & \text { degrees Celsius } & \mathrm{T}\left({ }^{\circ} \mathrm{C}\right)=5 / 9\left[\mathrm{~T}\left({ }^{\circ} \mathrm{F}\right)-32\right] \\ { }^{\circ} \mathrm{F} & \text { degrees Fahrenheit } & \\ \mathrm{ft} & \text { feet } & \\ \text { gal } & \text { gallon } & 1 \mathrm{gal}=3.78 \times 10^{-3} \mathrm{~m}^{3} \\ \text { in. } & \text { inch } & \\ \mathrm{kg} & \text { kilogram } & \\ \mathrm{kip} & 1,000 \mathrm{lb} & 1 \mathrm{lb}=0.453 \mathrm{~kg} \\ \mathrm{ksi} & 1,000 \mathrm{lb} / \mathrm{in} .{ }^{2} & 1 \mathrm{~m}=3.28 \mathrm{ft} \\ \mathrm{lb} & \text { pound } \\ \mathrm{m} & \text { meter } \\ \mu \mathrm{m} & \text { micrometer } \\ \text { min } & \text { minute } \\ \mathrm{MJ} & \text { megajoule } \\ \mathrm{MW} & \text { megawatt } \\ \mathrm{psi} & \text { pounds per square inch } \\ \mathrm{S} & \text { second } \\ \mathrm{T} & \text { temperature }\end{array}$




\section{Preface}

\section{Genesis of This Investigation}

Immediately following the terrorist attack on the World Trade Center (WTC) on September 11, 2001, the Federal Emergency Management Agency (FEMA) and the American Society of Civil Engineers began planning a building performance study of the disaster. The week of October 7, as soon as the rescue and search efforts ceased, the Building Performance Study Team went to the site and began its assessment. This was to be a brief effort, as the study team consisted of experts who largely volunteered their time away from their other professional commitments. The Building Performance Study Team issued its report in May 2002, fulfilling its goal "to determine probable failure mechanisms and to identify areas of future investigation that could lead to practical measures for improving the damage resistance of buildings against such unforeseen events.”

On August 21, 2002, with funding from the U.S. Congress through FEMA, the National Institute of Standards and Technology (NIST) announced its building and fire safety investigation of the WTC disaster. On October 1, 2002, the National Construction Safety Team Act (Public Law 107-231), was signed into law. (A copy of the Public Law is included in Appendix A). The NIST WTC Investigation was conducted under the authority of the National Construction Safety Team Act.

The goals of the investigation of the WTC disaster were:

- To investigate the building construction, the materials used, and the technical conditions that contributed to the outcome of the WTC disaster.

- $\quad$ To serve as the basis for:

- Improvements in the way buildings are designed, constructed, maintained, and used;

- Improved tools and guidance for industry and safety officials;

- Recommended revisions to current codes, standards, and practices; and

- Improved public safety.

The specific objectives were:

1. Determine why and how WTC 1 and WTC 2 collapsed following the initial impacts of the aircraft and why and how WTC 7 collapsed;

2. Determine why the injuries and fatalities were so high or low depending on location, including all technical aspects of fire protection, occupant behavior, evacuation, and emergency response;

3. Determine what procedures and practices were used in the design, construction, operation, and maintenance of WTC 1, 2, and 7; and

4. Identify, as specifically as possible, areas in current building and fire codes, standards, and practices that warrant revision. 
NIST is a nonregulatory agency of the U.S. Department of Commerce. The purpose of NIST investigations is to improve the safety and structural integrity of buildings in the United States, and the focus is on fact finding. NIST investigative teams are authorized to assess building performance and emergency response and evacuation procedures in the wake of any building failure that has resulted in substantial loss of life or that posed significant potential of substantial loss of life. NIST does not have the statutory authority to make findings of fault nor negligence by individuals or organizations. Further, no part of any report resulting from a NIST investigation into a building failure or from an investigation under the National Construction Safety Team Act may be used in any suit or action for damages arising out of any matter mentioned in such report (15 USC 281a, as amended by Public Law 107-231).

\section{Organization of the Investigation}

The National Construction Safety Team for this Investigation, appointed by the then NIST Director, Dr. Arden L. Bement, Jr., was led by Dr. S. Shyam Sunder. Dr. William L. Grosshandler served as Associate Lead Investigator, Mr. Stephen A. Cauffman served as Program Manager for Administration, and Mr. Harold E. Nelson served on the team as a private sector expert. The Investigation included eight interdependent projects whose leaders comprised the remainder of the team. A detailed description of each of these eight projects is available at http://wtc.nist.gov. The purpose of each project is summarized in Table $\mathrm{P}-1$, and the key technical components are illustrated in Fig. $\mathrm{P}-1$.

Table P-1. Federal building and fire safety investigation of the WTC disaster.

\begin{tabular}{|c|c|}
\hline Technical Area and Project Leader & Project Purpose \\
\hline $\begin{array}{l}\text { Analysis of Building and Fire Codes and } \\
\text { Practices; Project Leaders: Dr. H. S. Lew } \\
\text { and Mr. Richard W. Bukowski }\end{array}$ & $\begin{array}{l}\text { Document and analyze the code provisions, procedures, and practices } \\
\text { used in the design, construction, operation, and maintenance of the } \\
\text { structural, passive fire protection, and emergency access and } \\
\text { evacuation systems of WTC } 1,2 \text {, and } 7 \text {. }\end{array}$ \\
\hline $\begin{array}{l}\text { Baseline Structural Performance and } \\
\text { Aircraft Impact Damage Analysis; Project } \\
\text { Leader: Dr. Fahim H. Sadek }\end{array}$ & $\begin{array}{l}\text { Analyze the baseline performance of WTC } 1 \text { and WTC } 2 \text { under } \\
\text { design, service, and abnormal loads, and aircraft impact damage on } \\
\text { the structural, fire protection, and egress systems. }\end{array}$ \\
\hline $\begin{array}{l}\text { Mechanical and Metallurgical Analysis of } \\
\text { Structural Steel; Project Leader: Dr. Frank } \\
\text { W. Gayle }\end{array}$ & $\begin{array}{l}\text { Determine and analyze the mechanical and metallurgical properties } \\
\text { and quality of steel, weldments, and connections from steel } \\
\text { recovered from WTC } 1,2 \text {, and } 7 \text {. }\end{array}$ \\
\hline $\begin{array}{l}\text { Investigation of Active Fire Protection } \\
\text { Systems; Project Leader: Dr. David } \\
\text { D. Evans; Dr. William Grosshandler }\end{array}$ & $\begin{array}{l}\text { Investigate the performance of the active fire protection systems in } \\
\text { WTC } 1,2 \text {, and } 7 \text { and their role in fire control, emergency response, } \\
\text { and fate of occupants and responders. }\end{array}$ \\
\hline $\begin{array}{l}\text { Reconstruction of Thermal and Tenability } \\
\text { Environment; Project Leader: Dr. Richard } \\
\text { G. Gann }\end{array}$ & $\begin{array}{l}\text { Reconstruct the time-evolving temperature, thermal environment, } \\
\text { and smoke movement in WTC 1, 2, and } 7 \text { for use in evaluating the } \\
\text { structural performance of the buildings and behavior and fate of } \\
\text { occupants and responders. }\end{array}$ \\
\hline $\begin{array}{l}\text { Structural Fire Response and Collapse } \\
\text { Analysis; Project Leaders: Dr. John } \\
\text { L. Gross and Dr. Therese P. McAllister }\end{array}$ & $\begin{array}{l}\text { Analyze the response of the WTC towers to fires with and without } \\
\text { aircraft damage, the response of WTC } 7 \text { in fires, the performance of } \\
\text { composite steel-trussed floor systems, and determine the most } \\
\text { probable structural collapse sequence for WTC } 1,2 \text {, and } 7 .\end{array}$ \\
\hline $\begin{array}{l}\text { Occupant Behavior, Egress, and } \\
\text { Emergency Communications; Project } \\
\text { Leader: Mr. Jason D. Averill }\end{array}$ & $\begin{array}{l}\text { Analyze the behavior and fate of occupants and responders, both } \\
\text { those who survived and those who did not, and the performance of } \\
\text { the evacuation system. }\end{array}$ \\
\hline $\begin{array}{l}\text { Emergency Response Technologies and } \\
\text { Guidelines; Project Leader: Mr. J. Randall } \\
\text { Lawson }\end{array}$ & $\begin{array}{l}\text { Document the activities of the emergency responders from the time } \\
\text { of the terrorist attacks on WTC } 1 \text { and WTC } 2 \text { until the collapse of } \\
\text { WTC 7, including practices followed and technologies used. }\end{array}$ \\
\hline
\end{tabular}




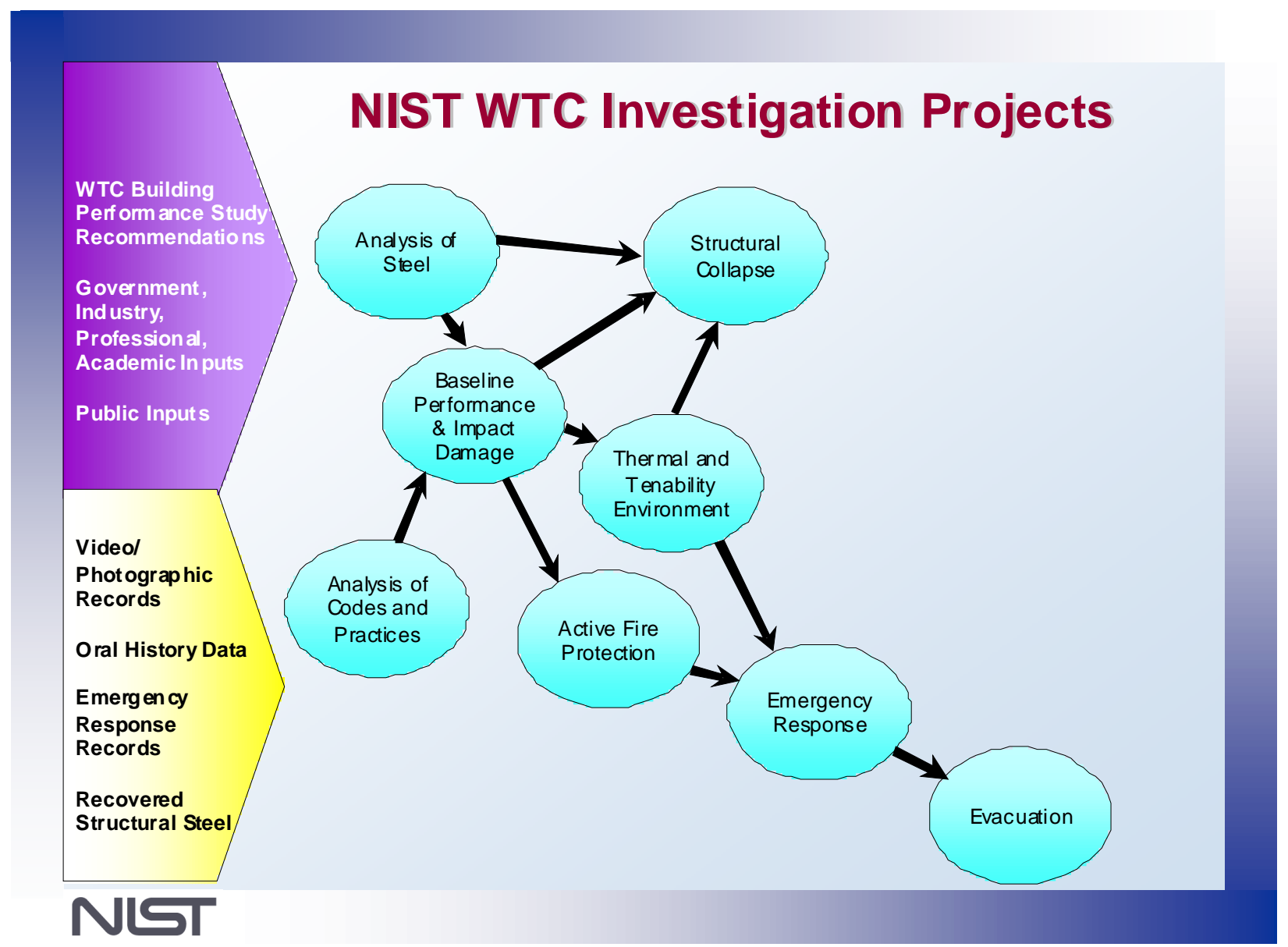

\section{Figure P-1. Technical components of the federal building and fire safety investigation of the WTC disaster.}

\section{National Construction Safety Team Advisory Committee}

The NIST Director also established an advisory committee as mandated under the National Construction Safety Team Act. The initial members of the committee were appointed following a public solicitation. These were, with their terms in parentheses:

- Paul Fitzgerald, Executive Vice President (retired) FM Global, National Construction Safety Team Advisory Committee Chair (2003-2009)

- John Barsom, President, Barsom Consulting, Ltd. (2003-2011).

- John Bryan, Professor Emeritus, University of Maryland (2003-2004)

- David Collins, President, The Preview Group, Inc. (2003-2010)

- Glenn Corbett, Professor, John Jay College of Criminal Justice (2003-2006)

- Philip DiNenno, President, Hughes Associates, Inc.(2003-2006) 
- $\quad$ Robert Hanson, Professor Emeritus, University of Michigan (2003-2009)

- Charles Thornton, Co-Chairman and Managing Principal, The Thornton-Tomasetti Group, Inc. (2003-2011)

- Kathleen Tierney, Director, Natural Hazards Research and Applications Information Center, University of Colorado at Boulder (2003-2007)

- Forman Williams, Director, Center for Energy Research, University of California at San Diego (2003-2011)

This National Construction Safety Team Advisory Committee provided technical advice during the Investigation and commentary on drafts of the Investigation reports prior to their public release. NIST has benefited from the work of many people in the preparation of these reports, including the National Construction Safety Team Advisory Committee. The content of the reports and recommendations, however, are solely the responsibility of NIST.

\section{Public Outreach}

During the course of this Investigation, NIST held public briefings and meetings (listed in Table P-2) to solicit input from the public, present preliminary findings, and obtain comments on the direction and progress of the Investigation from the public and the Advisory Committee.

NIST maintained a publicly accessible Web site during this Investigation at http://wtc.nist.gov. The site contained extensive information on the background and progress of the Investigation.

Prior to publishing the final reports, NIST released a draft of the reports for public comment. NIST received many comments from individuals, designers, professional organizations within the building and fire communities, and building owners. The comments were reviewed by the authors and addressed to the extent appropriate. The reports were modified with clarifications and supplemental text where needed, and the changes resulted in an improved final product. Comments on topics outside the scope of the investigation were not addressed.

\section{Information Quality Standards}

NIST conducted its World Trade Center (WTC) Investigation in accordance with Office of Management and Budget (OMB) directives and the Department of Commerce's and NIST's Information Quality Standards. This ensured that NIST's findings were objective, had utility to the industry, to emergency response professionals and to the general public, and insured the integrity of the information collected and presented in NIST's reports.

As defined in NIST's Information Quality Standards, “Objectivity consists of two distinct elements: presentation and substance. The presentation element includes whether disseminated information is presented in an accurate, clear, complete, and unbiased manner and in a proper context. The substance element involves a focus on ensuring accurate, reliable, and unbiased information." NIST obtained original source materials whenever possible, including design and renovation drawings, reports, correspondence, photographs and videos, and interviews of eye witnesses. Source materials were 
obtained from multiple sources, so as to minimize the influence of individual roles or accounts in understanding the design, construction, and operations of the WTC buildings and the events that occurred that day.

NIST conducted detailed analyses to simulate the impact damage caused by aircraft and/or debris and the fires, the building response to fires, and the subsequent collapse. These were extensive, state-of-the-art reconstructions of the events, and were validated using observations obtained from photographs and videos as well as observations made by emergency responders and building occupants.

All relevant data and analyses were presented in detailed reports (NIST NCSTAR 1-9 and 1-9A for WTC 7). The National Construction Safety Team (NCST) Advisory Committee reviewed NIST's technical approach in open session. The individual Advisory Committee members also conducted detailed reviews of NIST's draft reports, findings, and recommendations in their capacities as individual subject matter experts and provided substantive comments that were addressed in preparing the final reports. In addition, the draft NIST reports on WTC 7 were peer reviewed by five individual subjects matter experts, contracted by NIST, whose comments were also addressed in preparing the final reports. Thus, NIST made every effort to ensure that the investigation was conducted objectively, that the findings were reasonable and consistent with observations, and that the recommendations had a rational, scientific basis.

NIST's Information Quality Standards define Utility as "the usefulness of information to its intended users, including the public.” NIST identified four specific objectives for the WTC Investigation, which are stated at the beginning of the Preface. These goals and objectives were addressed and are reflected in the Principal Findings and Recommendations listed in the NIST NCSTAR 1 report for the WTC towers and the NIST NCSTAR 1A report for WTC 7. Individuals and organizations have responded to NIST's recommendations by developing proposals for changes to codes and standards. At the time of this publication, this effort has resulted in twenty-three changes being adopted into the International Building Code and fifteen introduced into the NFPA 5000 Building Code, NFPA 1 Fire Code, and NFPA 101 Life Safety Code. Some local jurisdictions have incorporated NIST's recommendations in their local codes and some building designers have incorporated the recommendations into their practice. All of these steps will lead to improved safety and security of buildings, building occupants, and emergency responders. The findings and recommendations of the NIST investigation of the World Trade Center disaster have clearly proven to be useful to those charged with ensuring the safety of buildings, building occupants, and emergency responders.

As defined in NIST's Information Quality Standards, “Integrity refers to security - the protection of information from unauthorized access or revision, to ensure that the information is not compromised through corruption or falsification.” NIST has been vigilant in protecting all of the information gathered for use in the investigation from outside sources or produced as a part of the investigation (e.g., computer models) from unauthorized access or revision. Access to information has been limited only to those individuals working directly on the investigation. The WTC reports are available electronically as Adobe .pdf files at http://wtc.nist.gov and have been "locked” to prevent revision or other alterations. These measures have ensured the integrity of materials collected or produced during the course of the WTC Investigation. 


\section{NIST's WTC Public-Private Response Plan}

The collapse of the WTC buildings has led to broad reexamination of how tall buildings are designed, constructed, maintained, and used, especially with regard to major events such as fires, natural disasters, and terrorist attacks. Reflecting the enhanced interest in effecting necessary change, NIST, with support from Congress and the Administration, has put in place a program, the goal of which is to develop and implement the standards, technology, and practices needed for cost-effective improvements to the safety and security of buildings and building occupants, including evacuation, emergency response procedures, and threat mitigation.

Table P-2. Public meetings and briefings of the WTC Investigation.

\begin{tabular}{|c|c|c|}
\hline Date & Location & Principal Agenda \\
\hline June 24, 2002 & New York City, NY & $\begin{array}{l}\text { Public meeting: Public comments on the Draft Plan for the } \\
\text { pending WTC Investigation. }\end{array}$ \\
\hline August 21, 2002 & Gaithersburg, MD & Media briefing announcing the formal start of the Investigation. \\
\hline December 9, 2002 & Washington, DC & $\begin{array}{l}\text { Media briefing on release of the Public Update and NIST request } \\
\text { for photographs and videos. }\end{array}$ \\
\hline April 8, 2003 & New York City, NY & $\begin{array}{l}\text { Joint public forum with Columbia University on first-person } \\
\text { interviews. }\end{array}$ \\
\hline April 29-30, 2003 & Gaithersburg, MD & $\begin{array}{l}\text { NCST Advisory Committee meeting on plan for and progress on } \\
\text { WTC Investigation with a public comment session. }\end{array}$ \\
\hline May 7, 2003 & New York City, NY & Media briefing on release of May 2003 Progress Report. \\
\hline August 26-27, 2003 & Gaithersburg, MD & $\begin{array}{l}\text { NCST Advisory Committee meeting on status of the WTC } \\
\text { investigation with a public comment session. }\end{array}$ \\
\hline September 17, 2003 & New York City, NY & $\begin{array}{l}\text { Media and public briefing on initiation of first-person data } \\
\text { collection projects. }\end{array}$ \\
\hline December 2-3, 2003 & Gaithersburg, MD & $\begin{array}{l}\text { NCST Advisory Committee meeting on status and initial results } \\
\text { and release of the Public Update with a public comment session. }\end{array}$ \\
\hline February 12, 2004 & New York City, NY & $\begin{array}{l}\text { Public meeting on progress and preliminary findings with public } \\
\text { comments on issues to be considered in formulating final } \\
\text { recommendations. }\end{array}$ \\
\hline June 18, 2004 & New York City, NY & Media/public briefing on release of June 2004 Progress Report. \\
\hline June 22-23, 2004 & Gaithersburg, MD & $\begin{array}{l}\text { NCST Advisory Committee meeting on the status of and } \\
\text { preliminary findings from the WTC Investigation with a public } \\
\text { comment session. }\end{array}$ \\
\hline August 24, 2004 & Northbrook, IL & $\begin{array}{l}\text { Public viewing of standard fire resistance test of WTC floor } \\
\text { system at Underwriters Laboratories, Inc. }\end{array}$ \\
\hline October 19-20, 2004 & Gaithersburg, MD & $\begin{array}{l}\text { NCST Advisory Committee meeting on status and near complete } \\
\text { set of preliminary findings with a public comment session. }\end{array}$ \\
\hline November 22, 2004 & Gaithersburg, MD & $\begin{array}{l}\text { NCST Advisory Committee discussion on draft annual report to } \\
\text { Congress, a public comment session, and a closed session to } \\
\text { discuss pre-draft recommendations for WTC Investigation. }\end{array}$ \\
\hline April 5, 2005 & New York City, NY & $\begin{array}{l}\text { Media and public briefing on release of the probable collapse } \\
\text { sequence for the WTC towers and draft reports for the projects on } \\
\text { codes and practices, evacuation, and emergency response. }\end{array}$ \\
\hline June 23, 2005 & New York City, NY & $\begin{array}{l}\text { Media and public briefing on release of all draft reports for the } \\
\text { WTC towers and draft recommendations for public comment. }\end{array}$ \\
\hline $\begin{array}{l}\text { September 12-13, } \\
2005\end{array}$ & Gaithersburg, MD & $\begin{array}{l}\text { NCST Advisory Committee meeting on disposition of public } \\
\text { comments and update to draft reports for the WTC towers. }\end{array}$ \\
\hline
\end{tabular}




\begin{tabular}{|l|l|l|}
\hline \multicolumn{1}{|c|}{ Date } & \multicolumn{1}{|c|}{ Location } & \multicolumn{1}{c|}{ Principal Agenda } \\
\hline $\begin{array}{l}\text { September 13-15, } \\
\text { 2005 }\end{array}$ & Gaithersburg, MD & $\begin{array}{l}\text { WTC Technical Conference for stakeholders and technical } \\
\text { community for dissemination of findings and recommendations } \\
\text { and opportunity for the public to make technical comments. }\end{array}$ \\
\hline December 14, 2006 & Teleconference & $\begin{array}{l}\text { NCST Advisory Committee meeting on status of WTC 7 } \\
\text { investigation and draft annual report to Congress, with a public } \\
\text { comment session. }\end{array}$ \\
\hline December 16, 2007 & Teleconference & $\begin{array}{l}\text { NCST Advisory Committee meeting on status of WTC 7 } \\
\text { investigation and draft annual report to Congress, with a public } \\
\text { comment session. }\end{array}$ \\
\hline August 21, 2008* & $\begin{array}{l}\text { Gaithersburg, MD; } \\
\text { Teleconference }\end{array}$ & $\begin{array}{l}\text { Media and public briefing on release of all draft reports for WTC } \\
\text { 7 and draft recommendations for public comment. }\end{array}$ \\
\hline Teleconference & $\begin{array}{l}\text { Technical briefing on the probable collapse sequence for WTC 7, } \\
\text { draft reports for WTC7, and draft recommendations for public } \\
\text { comment. }\end{array}$ \\
\hline
\end{tabular}

* Appended to table January 2009.

The strategy to meet this goal is a three-part, NIST-led, public-private response program that includes:

- A federal building and fire safety investigation to study the most probable factors that contributed to post-aircraft impact collapse of the WTC towers and the 47 story WTC 7 building, and the associated evacuation and emergency response experience.

- A research and development (R\&D) program to (a) facilitate the implementation of recommendations resulting from the WTC Investigation, and (b) provide the technical basis for cost-effective improvements to national building and fire codes, standards, and practices that enhance the safety of buildings, their occupants, and emergency responders.

- A dissemination and technical assistance program (DTAP) to (a) engage leaders of the construction and building community in ensuring timely adoption and widespread use of proposed changes to practices, standards, and codes resulting from the WTC Investigation and the R\&D program, and (b) provide practical guidance and tools to better prepare facility owners, contractors, architects, engineers, emergency responders, and regulatory authorities to respond to future disasters.

The desired outcomes are to make buildings, occupants, and first responders safer in future disaster events.

\section{National Construction Safety Team Reports on the WTC Investigation}

This report documents the Investigation findings regarding WTC 7 and the techniques and technologies by which these technical results were achieved. A summary report appears as NIST NCSTAR 1A, and a support document, NIST NCSTAR 1-9A, presents the technical details of the WTC 7 collapse analysis. The titles of the full set of Investigation publications are:

NIST (National Institute of Standards and Technology). 2005. Federal Building and Fire Safety Investigation of the World Trade Center Disaster: Final Report on the Collapse of the World Trade Center Towers. NIST NCSTAR 1. Gaithersburg, MD, September. 
NIST (National Institute of Standards and Technology). 2008. Federal Building and Fire Safety Investigation of the World Trade Center Disaster: Final Report on the Collapse of World Trade Center Building 7. NIST NCSTAR 1A. Gaithersburg, MD, November.

Lew, H. S., R. W. Bukowski, and N. J. Carino. 2005. Federal Building and Fire Safety Investigation of the World Trade Center Disaster: Design, Construction, and Maintenance of Structural and Life Safety Systems. NIST NCSTAR 1-1. National Institute of Standards and Technology. Gaithersburg, MD, September.

Fanella, D. A., A. T. Derecho, and S. K. Ghosh. 2005. Federal Building and Fire Safety Investigation of the World Trade Center Disaster: Design and Construction of Structural Systems. NIST NCSTAR 1-1A. National Institute of Standards and Technology. Gaithersburg, MD, September.

Ghosh, S. K., and X. Liang. 2005. Federal Building and Fire Safety Investigation of the World Trade Center Disaster: Comparison of Building Code Structural Requirements. NIST

NCSTAR 1-1B. National Institute of Standards and Technology. Gaithersburg, MD, September.

Fanella, D. A., A. T. Derecho, and S. K. Ghosh. 2005. Federal Building and Fire Safety Investigation of the World Trade Center Disaster: Maintenance and Modifications to Structural Systems. NIST NCSTAR 1-1C. National Institute of Standards and Technology. Gaithersburg, $\mathrm{MD}$, September.

Grill, R. A., and D. A. Johnson. 2005. Federal Building and Fire Safety Investigation of the World Trade Center Disaster: Fire Protection and Life Safety Provisions Applied to the Design and Construction of World Trade Center 1, 2, and 7 and Post-Construction Provisions Applied after Occupancy. NIST NCSTAR 1-1D. National Institute of Standards and Technology. Gaithersburg, MD, September.

Razza, J. C., and R. A. Grill. 2005. Federal Building and Fire Safety Investigation of the World Trade Center Disaster: Comparison of Codes, Standards, and Practices in Use at the Time of the Design and Construction of World Trade Center 1, 2, and 7. NIST NCSTAR 1-1E. National Institute of Standards and Technology. Gaithersburg, MD, September.

Grill, R. A., D. A. Johnson, and D. A. Fanella. 2005. Federal Building and Fire Safety Investigation of the World Trade Center Disaster: Comparison of the 1968 and Current (2003) New York City Building Code Provisions. NIST NCSTAR 1-1F. National Institute of Standards and Technology. Gaithersburg, MD, September.

Grill, R. A., and D. A. Johnson. 2005. Federal Building and Fire Safety Investigation of the World Trade Center Disaster: Amendments to the Fire Protection and Life Safety Provisions of the New York City Building Code by Local Laws Adopted While World Trade Center 1, 2, and 7 Were in Use. NIST NCSTAR 1-1G. National Institute of Standards and Technology. Gaithersburg, MD, September. 
Grill, R. A., and D. A. Johnson. 2005. Federal Building and Fire Safety Investigation of the World Trade Center Disaster: Post-Construction Modifications to Fire Protection and Life Safety Systems of World Trade Center 1 and 2. NIST NCSTAR 1-1H. National Institute of Standards and Technology. Gaithersburg, MD, September.

Grill, R. A., D. A. Johnson, and D. A. Fanella. 2005. Federal Building and Fire Safety Investigation of the World Trade Center Disaster: Post-Construction Modifications to Fire Protection, Life Safety, and Structural Systems of World Trade Center 7. NIST NCSTAR 1-1I. National Institute of Standards and Technology. Gaithersburg, MD, September.

Grill, R. A., and D. A. Johnson. 2005. Federal Building and Fire Safety Investigation of the World Trade Center Disaster: Design, Installation, and Operation of Fuel System for Emergency Power in World Trade Center 7. NIST NCSTAR 1-1J. National Institute of Standards and Technology. Gaithersburg, MD, September.

Sadek, F. 2005. Federal Building and Fire Safety Investigation of the World Trade Center Disaster: Baseline Structural Performance and Aircraft Impact Damage Analysis of the World Trade Center Towers. NIST NCSTAR 1-2. National Institute of Standards and Technology. Gaithersburg, MD, September.

Faschan, W. J., and R. B. Garlock. 2005. Federal Building and Fire Safety Investigation of the World Trade Center Disaster: Reference Structural Models and Baseline Performance Analysis of the World Trade Center Towers. NIST NCSTAR 1-2A. National Institute of Standards and Technology. Gaithersburg, MD, September.

Kirkpatrick, S. W., R. T. Bocchieri, F. Sadek, R. A. MacNeill, S. Holmes, B. D. Peterson, R. W. Cilke, C. Navarro. 2005. Federal Building and Fire Safety Investigation of the World Trade Center Disaster: Analysis of Aircraft Impacts into the World Trade Center Towers, NIST NCSTAR 1-2B. National Institute of Standards and Technology. Gaithersburg, MD, September.

Gayle, F. W., R. J. Fields, W. E. Luecke, S. W. Banovic, T. Foecke, C. N. McCowan, T. A. Siewert, and J. D. McColskey. 2005. Federal Building and Fire Safety Investigation of the World Trade Center Disaster: Mechanical and Metallurgical Analysis of Structural Steel. NIST NCSTAR 1-3. National Institute of Standards and Technology. Gaithersburg, MD, September.

Luecke, W. E., T. A. Siewert, and F. W. Gayle. 2005. Federal Building and Fire Safety Investigation of the World Trade Center Disaster: Contemporaneous Structural Steel Specifications. NIST Special Publication 1-3A. National Institute of Standards and Technology. Gaithersburg, MD, September.

Banovic, S. W. 2005. Federal Building and Fire Safety Investigation of the World Trade Center Disaster: Steel Inventory and Identification. NIST NCSTAR 1-3B. National Institute of Standards and Technology. Gaithersburg, MD, September.

Banovic, S. W., and T. Foecke. 2005. Federal Building and Fire Safety Investigation of the World Trade Center Disaster: Damage and Failure Modes of Structural Steel Components. NIST NCSTAR 1-3C. National Institute of Standards and Technology. Gaithersburg, MD, September. 
Luecke, W. E., J. D. McColskey, C. N. McCowan, S. W. Banovic, R. J. Fields, T. Foecke, T. A. Siewert, and F. W. Gayle. 2005. Federal Building and Fire Safety Investigation of the World Trade Center Disaster: Mechanical Properties of Structural Steels. NIST NCSTAR 1-3D. National Institute of Standards and Technology. Gaithersburg, MD, September.

Banovic, S. W., C. N. McCowan, and W. E. Luecke. 2005. Federal Building and Fire Safety Investigation of the World Trade Center Disaster: Physical Properties of Structural Steels. NIST NCSTAR 1-3E. National Institute of Standards and Technology. Gaithersburg, MD, September.

Evans, D. D., R. D. Peacock, E. D. Kuligowski, W. S. Dols, and W. L. Grosshandler. 2005. Federal Building and Fire Safety Investigation of the World Trade Center Disaster: Active Fire Protection Systems. NIST NCSTAR 1-4. National Institute of Standards and Technology. Gaithersburg, MD, September.

Kuligowski, E. D., D. D. Evans, and R. D. Peacock. 2005. Federal Building and Fire Safety Investigation of the World Trade Center Disaster: Post-Construction Fires Prior to September 11, 2001. NIST NCSTAR 1-4A. National Institute of Standards and Technology. Gaithersburg, MD, September.

Hopkins, M., J. Schoenrock, and E. Budnick. 2005. Federal Building and Fire Safety Investigation of the World Trade Center Disaster: Fire Suppression Systems. NIST NCSTAR 1-4B. National Institute of Standards and Technology. Gaithersburg, MD, September.

Keough, R. J., and R. A. Grill. 2005. Federal Building and Fire Safety Investigation of the World Trade Center Disaster: Fire Alarm Systems. NIST NCSTAR 1-4C. National Institute of Standards and Technology. Gaithersburg, MD, September.

Ferreira, M. J., and S. M. Strege. 2005. Federal Building and Fire Safety Investigation of the World Trade Center Disaster: Smoke Management Systems. NIST NCSTAR 1-4D. National Institute of Standards and Technology. Gaithersburg, MD, September.

Gann, R. G., A. Hamins, K. B. McGrattan, G. W. Mulholland, H. E. Nelson, T. J. Ohlemiller, W. M. Pitts, and K. R. Prasad. 2005. Federal Building and Fire Safety Investigation of the World Trade Center Disaster: Reconstruction of the Fires in the World Trade Center Towers. NIST NCSTAR 1-5. National Institute of Standards and Technology. Gaithersburg, MD, September.

Pitts, W. M., K. M. Butler, and V. Junker. 2005. Federal Building and Fire Safety Investigation of the World Trade Center Disaster: Visual Evidence, Damage Estimates, and Timeline Analysis. NIST NCSTAR 1-5A. National Institute of Standards and Technology. Gaithersburg, MD, September.

Hamins, A., A. Maranghides, K. B. McGrattan, E. Johnsson, T. J. Ohlemiller, M. Donnelly, J. Yang, G. Mulholland, K. R. Prasad, S. Kukuck, R. Anleitner and T. McAllister. 2005. Federal Building and Fire Safety Investigation of the World Trade Center Disaster: Experiments and Modeling of Structural Steel Elements Exposed to Fire. NIST NCSTAR 1-5B. National Institute of Standards and Technology. Gaithersburg, MD, September. 
Ohlemiller, T. J., G. W. Mulholland, A. Maranghides, J. J. Filliben, and R. G. Gann. 2005. Federal Building and Fire Safety Investigation of the World Trade Center Disaster: Fire Tests of Single Office Workstations. NIST NCSTAR 1-5C. National Institute of Standards and Technology. Gaithersburg, MD, September.

Gann, R. G., M. A. Riley, J. M. Repp, A. S. Whittaker, A. M. Reinhorn, and P. A. Hough. 2005. Federal Building and Fire Safety Investigation of the World Trade Center Disaster: Reaction of Ceiling Tile Systems to Shocks. NIST NCSTAR 1-5D. National Institute of Standards and Technology. Gaithersburg, MD, September.

Hamins, A., A. Maranghides, K. B. McGrattan, T. J. Ohlemiller, and R. Anleitner. 2005. Federal Building and Fire Safety Investigation of the World Trade Center Disaster: Experiments and Modeling of Multiple Workstations Burning in a Compartment. NIST NCSTAR 1-5E. National Institute of Standards and Technology. Gaithersburg, MD, September.

McGrattan, K. B., C. Bouldin, and G. Forney. 2005. Federal Building and Fire Safety Investigation of the World Trade Center Disaster: Computer Simulation of the Fires in the World Trade Center Towers. NIST NCSTAR 1-5F. National Institute of Standards and Technology. Gaithersburg, MD, September.

Prasad, K. R., and H. R. Baum. 2005. Federal Building and Fire Safety Investigation of the World Trade Center Disaster: Fire Structure Interface and Thermal Response of the World Trade Center Towers. NIST NCSTAR 1-5G. National Institute of Standards and Technology. Gaithersburg, MD, September.

Gross, J. L., and T. McAllister. 2005. Federal Building and Fire Safety Investigation of the World Trade Center Disaster: Structural Fire Response and Probable Collapse Sequence of the World Trade Center Towers. NIST NCSTAR 1-6. National Institute of Standards and Technology. Gaithersburg, MD, September.

Carino, N. J., M. A. Starnes, J. L. Gross, J. C. Yang, S. Kukuck, K. R. Prasad, and R. W. Bukowski. 2005. Federal Building and Fire Safety Investigation of the World Trade Center Disaster: Passive Fire Protection. NIST NCSTAR 1-6A. National Institute of Standards and Technology. Gaithersburg, MD, September.

Gross, J., F. Hervey, M. Izydorek, J. Mammoser, and J. Treadway. 2005. Federal Building and Fire Safety Investigation of the World Trade Center Disaster: Fire Resistance Tests of Floor Truss Systems. NIST NCSTAR 1-6B. National Institute of Standards and Technology. Gaithersburg, MD, September.

Zarghamee, M. S., S. Bolourchi, D. W. Eggers, Ö. O. Erbay, F. W. Kan, Y. Kitane, A. A. Liepins, M. Mudlock, W. I. Naguib, R. P. Ojdrovic, A. T. Sarawit, P. R Barrett, J. L. Gross, and T. P. McAllister. 2005. Federal Building and Fire Safety Investigation of the World Trade Center Disaster: Component, Connection, and Subsystem Structural Analysis. NIST NCSTAR 1-6C. National Institute of Standards and Technology. Gaithersburg, MD, September. 
Zarghamee, M. S., Y. Kitane, Ö. O. Erbay, T. P. McAllister, and J. L. Gross. 2005. Federal Building and Fire Safety Investigation of the World Trade Center Disaster: Global Structural Analysis of the Response of the World Trade Center Towers to Impact Damage and Fire. NIST NCSTAR 1-6D. National Institute of Standards and Technology. Gaithersburg, MD, September.

Averill, J. D., D. S. Mileti, R. D. Peacock, E. D. Kuligowski, N. Groner, G. Proulx, P. A. Reneke, and H. E. Nelson. 2005. Federal Building and Fire Safety Investigation of the World Trade Center Disaster: Occupant Behavior, Egress, and Emergency Communication. NIST NCSTAR 1-7. National Institute of Standards and Technology. Gaithersburg, MD, September.

Fahy, R., and G. Proulx. 2005. Federal Building and Fire Safety Investigation of the World Trade Center Disaster: Analysis of Published Accounts of the World Trade Center Evacuation. NIST NCSTAR 1-7A. National Institute of Standards and Technology. Gaithersburg, MD, September.

Zmud, J. 2005. Federal Building and Fire Safety Investigation of the World Trade Center Disaster: Technical Documentation for Survey Administration. NIST NCSTAR 1-7B. National Institute of Standards and Technology. Gaithersburg, MD, September.

Lawson, J. R., and R. L. Vettori. 2005. Federal Building and Fire Safety Investigation of the World Trade Center Disaster: The Emergency Response Operations. NIST NCSTAR 1-8. National Institute of Standards and Technology. Gaithersburg, MD, September.

McAllister, T., R. G. Gann, J. D. Averill, J. L. Gross, W. L. Grosshandler, J. R. Lawson, K. B. McGrattan, H. E. Nelson, W. M. Pitts, K. R. Prasad, F. H. Sadek. 2008. Federal Building and Fire Safety Investigation of the World Trade Center Disaster: Structural Fire Response and Probable Collapse Sequence of World Trade Center Building 7. NIST NCSTAR 1-9. National Institute of Standards and Technology. Gaithersburg, MD, November.

MacNeill, R., S. Kirkpatrick, B. Peterson, and R. Bocchieri, 2008. Federal Building and Fire Safety Investigation of the World Trade Center Disaster: Global Structural Analysis of the Response of World Trade Center Building 7 to Fires and Debris Impact Damage. NIST NCSTAR 1-9A. National Institute of Standards and Technology, Gaithersburg, MD, November. 


\section{Chapter 1 \\ INTRODUCTION}

\section{$1.1 \quad$ PROJECT OBJECTIVES}

On September 11, 2001, at 8:46:30 a.m. EDT, five hijackers flew American Airlines Flight 11 (AA 11), a Boeing 767-200ER aircraft, into the north face of World Trade Center (WTC) 1 at a speed of about 440 mph. At 9:02:59 a.m., five other hijackers flew United Airlines Flight 175, also a Boeing 767-200ER, into the south face of WTC 2 at about $540 \mathrm{mph}$. The aircraft impacts did considerable damage to the structure of the towers, but the towers remained standing. The impacts also triggered fires on multiple floors simultaneously. Such fires further weakened the structural systems of WTC 1 and WTC 2 and led to the collapse of both towers. WTC 2 collapsed first at 9:58:59 a.m. EDT, followed by the collapse of WTC 1 at 10:28:22 a.m. EDT.

The collapse of WTC 1 caused structural damage to WTC 7, a 47 story building to the north of the WTC complex. Damage to WTC 7 included severed exterior columns on the lower floors. The collapse of WTC 1 also resulted in initiation of fires on at least 10 floors of WTC 7, extensive window breakage on the south face of WTC 7, and loss of city water that supplied the automatic sprinkler system in the lower zone of WTC 7. After nearly seven hours of burning, WTC 7 collapsed at 5:20:52 p.m. EDT.

A principal part of the National Institute of Standards and Technology (NIST) investigation of the WTC disaster was the examination of the WTC 7 collapse. The specific objectives were to:

1. Determine why and how WTC 7 collapsed;

2. Determine all technical aspects of fire protection, occupant behavior, evacuation, and emergency response;

3. Determine what procedures and practices were used in the design, construction, operation, and maintenance of WTC 7; and

4. Identify, as specifically as possible, areas in current building and fire codes, standards, and practices that warrant revision.

This report describes the technical effort to meet these objectives. Much of the material developed to address Objective 3 and some of Objective 2 is found in the NIST NCSTAR WTC reports published in September 2005. Relevant content is summarized in this report, with references to the prior reports for those seeking more detail. NIST NCSTAR 1A is a summary report of the sequence of events at WTC 7 on September 11, 2001, the findings of the Investigation, and the NIST recommendations. Additional details on the collapse analysis appear in NIST NCSTAR 1-9A. 


\section{$1.2 \quad$ TECHNICAL APPROACH}

\subsubsection{Data Gathering}

Similar to the investigation into the collapse of the WTC towers, data for WTC 7 were collected from a number of sources and reviewed. Such data included information about the structural geometry, details, and connections; the thickness and condition of the passive fire protection in the building; and recorded observations of debris impact damage and fire spread subsequent to collapse of the WTC towers. Information about the building construction was obtained from original drawings and specifications, reports, and available records from The Port Authority of New York and New Jersey (PANYNJ or The Port Authority), Silverstein Properties (SP), and a number of contractors that had worked on the design, construction, or modifications to WTC 7. The documents obtained included erection and fabrication shop drawings of the building, which provided detailed information about the floor and column connections. Additional information and documents regarding the layout of the building interior were obtained from WTC 7 tenants. Interviews with emergency responders and building officials provided accounts of the human activity inside the building and around the WTC site. A large number of photographic and videographic records were acquired, enabling extraction of the details of the damage to and fire in the building. While not as plentiful as the imagery for the WTC towers, the WTC 7 evidence was sufficient to guide the reconstruction of the day's events.

Information about the building design and contents appears in Chapters 2, 3, and 4. The photographic and videographic data are presented in Chapter 5. Chapters 6 and 7 contain the descriptions of the activities of the emergency responders and building occupants, respectively.

\subsubsection{Reconstruction of the Collapse of WTC 7}

The probable WTC 7 collapse sequence developed in this Investigation was based on observations from available evidence (photos, videos, and eyewitness accounts) as well as a series of computer simulations that modeled the complete sequence of events leading to the collapse of WTC 7. The analyses accounted for the debris-impact damage resulting from the collapse of WTC 1, the growth and spread of fires, the heating and thermal damage to structural components, and the progression of local structural failures that led to the collapse of the building. Similar to the analyses conducted for the WTC towers, the analyses of WTC 7 continued to advance the current state of the art and tested the limits of computational capabilities. The collapse analysis of WTC 7 required both the failure initiation and propagation sequences to explain the observed collapse sequence. The unprecedented complexity and sophistication of these analyses required the use of various strategies for managing the computational demands, while adequately capturing the essential physics of the problem.

Figure 1-1 is a flowchart of the analysis sequence and interdependencies for the reconstruction of the WTC 7 collapse, which was similar to the analysis sequence for the WTC towers. However, for the analysis of WTC 7, the structural analysis was divided into two steps - the structural response to fire and the structural response to an initial failure event, as indicated in Figure 1-1. The estimate of debris impact damage, which was based on visual evidence, is provided in Chapter 5. Chapter 8 addresses the possible initiating event and collapse propagating hypotheses for WTC 7. The fire dynamics simulations and the resulting heating of the structure are presented in Chapters 9 and 10, respectively. The analysis of the structural response to the fire, which led to the initial failure event (collapse initiation phase), is presented 
in Chapter 11, and the global response of WTC 7 to the initial failure event (collapse propagation phase) is provided in Chapter 12. Chapter 13 presents the probable collapse sequence for WTC 7.

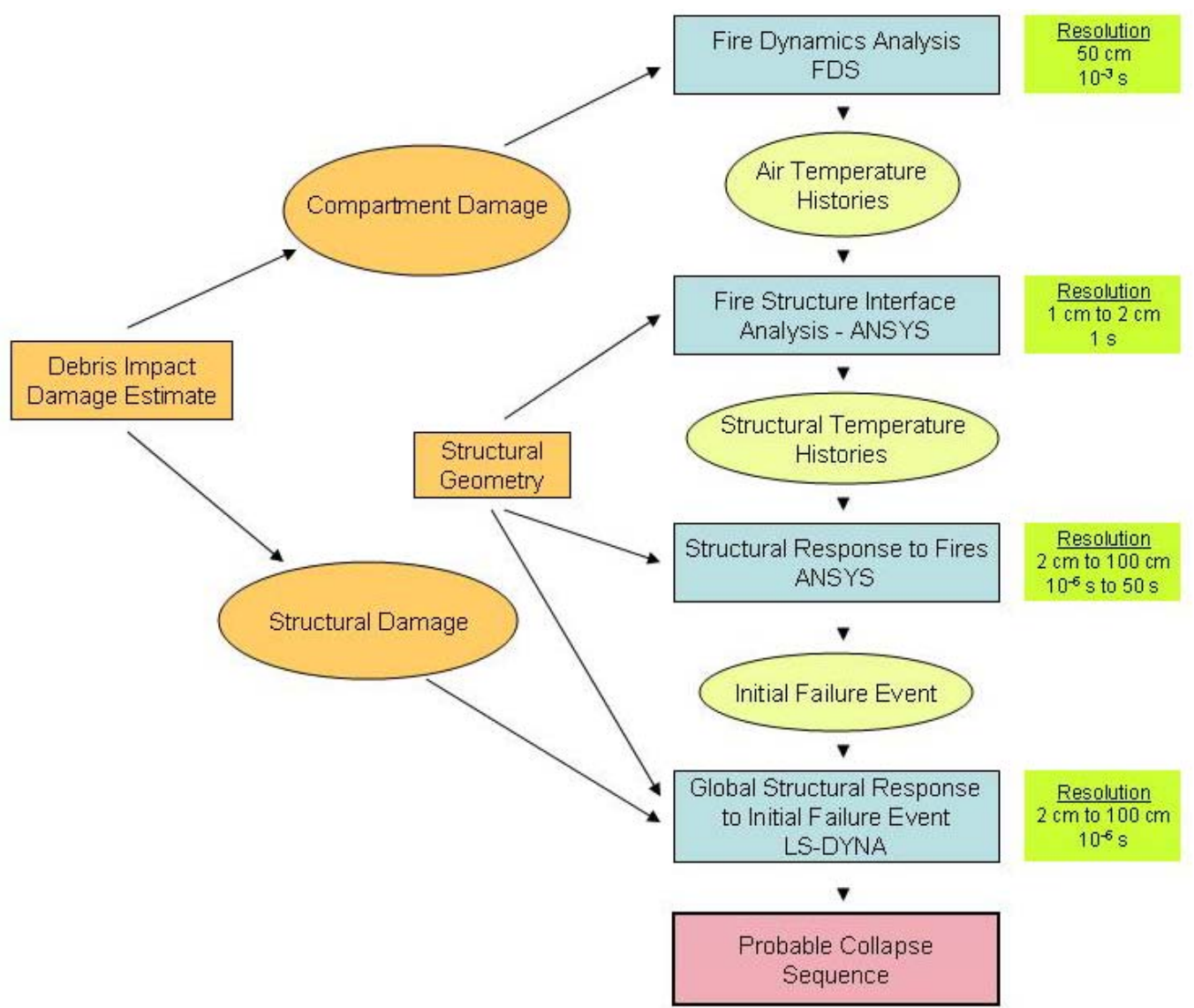

Figure 1-1. WTC 7 analysis sequence and interdependencies.

The analyses performed to determine the probable collapse sequence for WTC 7 considered the response of the structural system to debris impact damage, temperature-dependent properties of steel and concrete, growth and spread of the fires, and heating of structural components. The structural response analyses relied upon the following information:

- Available architectural, structural, fabrication, and erection drawings of the original building and subsequent building alterations.

- Extent of damage to the building by debris impact from the collapse of the WTC towers.

- Photographic and videographic records with time stamps that documented the observed sequence of events, including fire spread and building collapse.

- Temperature-time histories for structural components and connections for fires in WTC 7 based on fire dynamics simulations and thermal finite element analyses. 
- Temperature-dependent mechanical properties of the steels, welds, and bolts used in the construction of WTC 7, including elastic, plastic, and creep properties.

- Column loads due to design loads shown in the design drawings, which were used to verify the structural models.

The fire dynamics and thermal analyses were similar to the analyses described in detail in the WTC towers reports. However, there were some differences in the analyses, which are briefly described here.

The major fires in WTC 7 were simulated using the Fire Dynamics Simulator (FDS). The FDS calculations were similar to those conducted for WTC 1 and WTC 2 (NIST NCSTAR 1-5F). There were fewer photographs and videos of WTC 7 than of the towers. Thus, the details of the WTC 7 fires were not as precise as for the fires in the towers. However, the imagery was sufficient to guide the WTC 7 fire simulations. Unlike the fire simulations for WTC 1 and WTC 2, the fire simulations for WTC 7 were conducted for each floor individually as there were no obvious pathways for the flames and heat to pass from one floor to another, aside from the debris-damaged area in the southwest corner of the building. As described in Section 5.6, sustained and/or late fires were observed on Floors 7 through 9 and 11 through 13. While use was made of the appearance of flames and window breakage in photographs and videos in formulating the simulations, the Investigation Team realized that the timing of the simulations might not align exactly with the timing of the fires on September 11, 2001. In addition, there might have been concealed, yet major fires in the mechanical space on Floors 5 and 6 . Thus, a variety of possible fires on Floors 5 and 6 were studied to determine whether each would have produced a visible telltale and whether they would have been severe enough to weaken key structural elements on those floors.

The Fire Structure Interface (FSI) used the gas temperatures from the FDS simulations (Chapter 10) to heat on the structural components of WTC 7 (Chapter 2) and to predict the evolving thermal state of the building. The FSI created thermal loading data for use by the structural models that simulated the collapse of the building (Chapters 11 and 12). The structural response of WTC 7, simulated to understand the collapse initiation mechanism, was performed using the thermal data. The thermal analysis approach was similar to that used to simulate the fire induced thermal loads on WTC 1 and WTC 2, as described in NCSTAR 1-5G. The temperature data used in the structural analysis of WTC 7 contained thermal data sampled at 30 min intervals for a 6 hour period. For each time step, a set of thermal data was generated that specified the thermal state of the lower 16 stories of the building. Three different thermal response computations were used, which together represented a realistic and reasonable range of fire scenarios for WTC 7 on September 11, 2001. Case A used the temperature data as obtained from the FDS simulation. Case B increased the FDS gas temperatures by 10 percent and Case $\mathrm{C}$ decreased the FDS gas temperatures by 10 percent. Given the limited visual evidence, the Investigation Team estimated, using engineering judgment, that a 10 percent change was within the range of uncertainty in the extent and intensity of the fires.

WTC 7 was a large, complex structural system. To include all of the structural components and connections and their associated behavior and failure mechanisms using refined finite element meshes was not possible. The analysis approach used was a variant of the well-established sub-structuring approach, adapted for the analysis of structures with highly nonlinear behavior that progressed from individual components to major subsystems to global systems, as shown in Figure 1-2. 


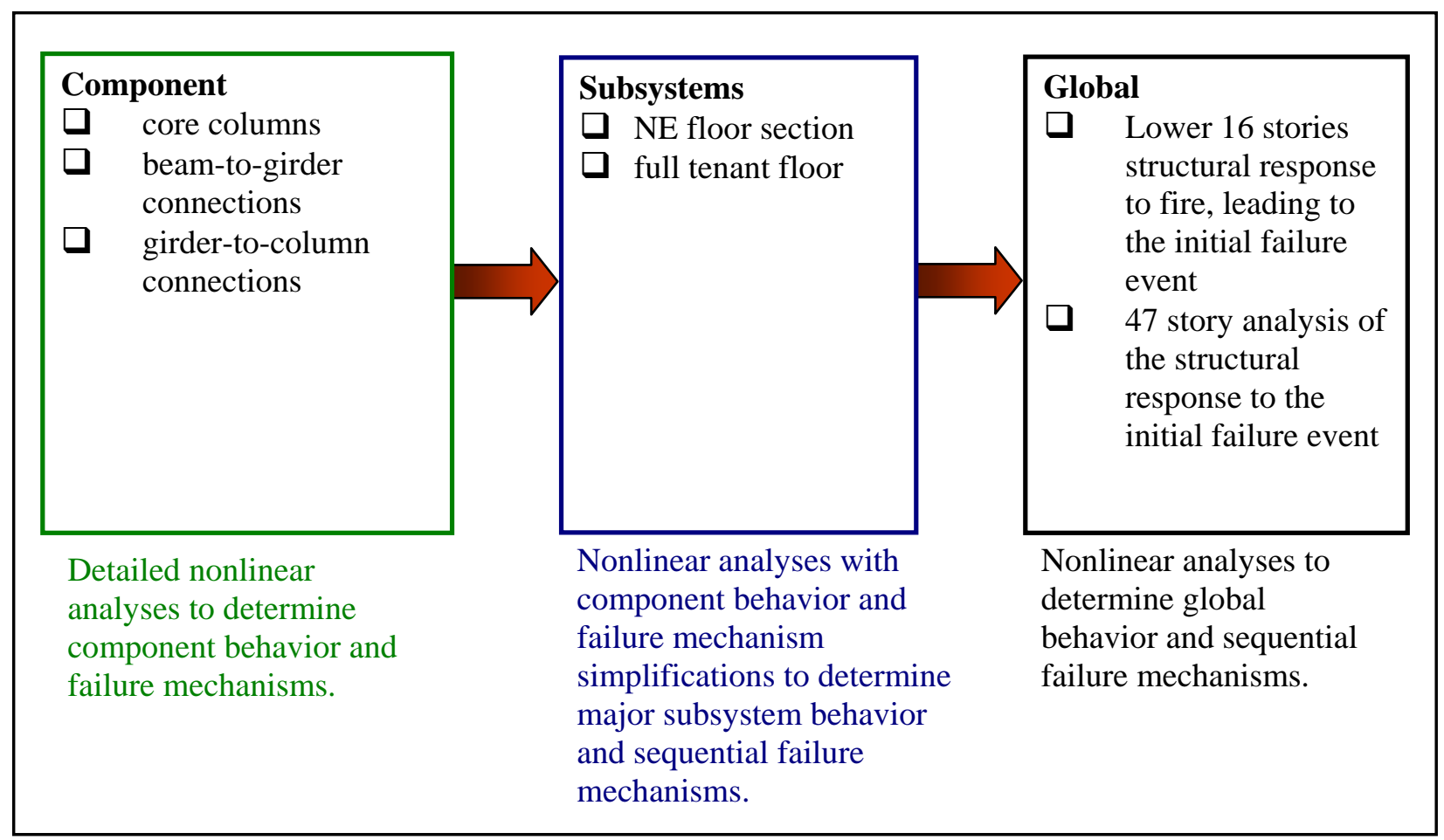

Figure 1-2. Structural analysis sequence.

Component structural analyses were conducted to identify critical behavior and failure mechanisms that contributed to the global structural response of WTC 7. These component analyses included beam-togirder connections and girder-to-column connections under thermal loading. Subsystem analyses were then performed that incorporated the behavior and failure mechanisms identified in the component studies. The subsystem analyses included (1) the northeast corner of a typical floor and (2) a full tenant floor, both under gravity and fire loads. Modifications were made to reduce the model size and complexity and enhance computational performance without adversely affecting the accuracy of the results. Whenever modeling modifications were used, they were validated against the detailed component model results. The two global analyses explained in Figure 1-2 critical behavior and failure mechanisms, determined from component and subsystem analyses, while making necessary modifications in the level of modeling detail.

The two structural models of WTC 7 were developed and executed to understand the response of the building to debris impact damage and subsequent fire effects and to develop the collapse hypothesis.

- The first model, an implicit analysis developed using ANSYS, estimated the structural response to elevated temperatures of the lower 16 stories of the building, where the fires grew and spread, until an initial failure event appeared imminent, due to thermally-induced structural damage (Chapter 11). This model accounted for the temperature-dependent behavior of the structural members and connections in the fire-affected floors, including thermal expansion, stiffness and strength degradation at elevated temperatures, and the failure modes of the various connections under fire. 
- The second model, an explicit analysis developed using LS-DYNA, estimated the structural response of the full 47 story structure to the initial failure event due to fire (from the 16 story ANSYS model), and the vertical and horizontal progression of failures that led to global collapse of WTC 7 (Chapter 12). This model accounted for the potential for progressive collapse in the building, including buckling of columns due to loss of lateral restraint, dynamic effects associated with failure progression, and impact of falling floors. The progressive collapse analysis captured the vertical progression of failure, horizontal progression of failure, and global collapse.

The three thermal response cases (A, B, and C) were used in the ANSYS analysis. Based on ANSYS model results, it became apparent as each of the analyses progressed that the sequential failures that were occurring were at essentially the same locations and with similar failure mechanisms. However, as might be expected, the failures were shifted in time, i.e., Case $C$ failures occurred at a later time than the same failures in Case A, and Case A failures occurred at a later time than Case B failures. As a result, only the fire-induced damage produced by Case B temperatures was carried forward as the initial condition for the LS-DYNA analysis (Chapter 12), since the damage occurred in the least computational time (about 6 months).

\section{$1.3 \quad$ WTC 7 REPORTS}

This report, NIST NCSTAR 1-9, is a detailed technical report of the investigation and analyses. It is written for technical experts in each of the relevant disciplines. The following reports further document the investigation of the collapse of WTC 7.

NIST NCSTAR 1A is a final summary report of the investigation of the collapse of WTC 7, and includes an accounting for readers who are not experts in each of the disciplines relevant to the investigation. It also includes the NIST recommendations to reduce the severity of the outcome of future mishaps in tall buildings.

NIST NCSTAR 1-9A is a detailed technical report of the LS-DYNA model development and analyses. This report is summarized in Chapter 12 of this report.

Previous Investigation reports that documented WTC 7 conditions or events include:

NIST NCSTAR 1-1, summarized the design, construction, and maintenance of structural and life safety systems in WTC 7, as well as the WTC towers. Additional details on these subjects for WTC 7 can be found in the following technical reports:

- $\quad$ NIST NCSTAR 1-1A: Design and Construction of Structural Systems

- $\quad$ NIST NCSTAR 1-1C: Maintenance and Modifications to Structural Systems

- $\quad$ NIST NCSTAR 1-1D: Fire Protection and Life Safety Provisions Applied to the Design and Construction and Post-construction Provisions Applied after Occupancy

- NIST NCSTAR 1-1E: Comparison of Codes, Standards, and Practices in Use at the Time of the Design and Construction 
- $\quad$ NIST NCSTAR 1-1G: Amendments to the Fire Protection and Life Safety Provisions of the New York City Building Code by Local Laws Adopted while WTC Buildings Were in Use

- $\quad$ NIST NCSTAR 1-1I: Post-construction Modifications to Fire Protection, Life Safety, and Structural Systems

- $\quad$ NIST NCSTAR 1-1J: Design, Installation, and Operation of Fuel Systems for Emergency Power

NIST NCSTAR 1-4 summarized the design and installation of the active fire protection systems in WTC 7 and described the normal operation of fully functional systems and their potential effect on controlling the fires on September 11, 2001. Additional details on these subjects for WTC 7 can be found in the following technical reports:

- $\quad$ NIST NCSTAR 1-4B: Fire Suppression Systems

- $\quad$ NIST NCSTAR 1-4C: Fire Alarm Systems

- $\quad$ NIST NCSTAR 1-4D: Smoke Management Systems

Chapter 6 of NIST NCSTAR 1-6A provided the thermophysical properties for Monokote MK-5, the gypsum-based sprayed fire-resistive material (SFRM) used to insulate the WTC 7 steel. 
This page intentionally left blank 


\section{Chapter 2 \\ BUILDING CONSTRUCTION, CODES, AND STANDARDS}

\section{$2.1 \quad$ HISTORY OF THE BUILDING}

WTC 7 was a 47 story commercial office building located immediately to the north of the main WTC complex. It occupied the block bounded by Vesey Street on the south, Barclay Street on the north, Washington Street on the west, and West Broadway on the east. Located approximately $350 \mathrm{ft}$ (105 m) from the north side of WTC 1, it was connected to the WTC complex by a $120 \mathrm{ft}$ wide elevated plaza and a $22 \mathrm{ft}$ wide pedestrian bridge at the $3^{\text {rd }}$ floor level. Its location relative to the WTC Plaza is shown in Figure 2-1. Completed in 1987, WTC 7 contained approximately 2 million $\mathrm{ft}^{2}$ of floor area.

WTC 7 was trapezoidal in plan with dimensions of approximately $329 \mathrm{ft}$ on the longer side, $247 \mathrm{ft}$ on the shorter side, $140 \mathrm{ft}$ wide, and $610 \mathrm{ft}$ high. The building was constructed over a pre-existing electrical substation owned by Consolidated Edison (Con Edison). The original plans for the Con Edison substation included a high-rise building, and the foundation was sized for the planned structure. However, the final design for WTC 7 had a larger footprint than originally envisioned and accommodations were made in the foundation, as described in Section 2.4.1. Over the years, numerous structural modifications were made throughout the building, mainly to suit its largest tenant, Salomon Brothers Inc., later to become Salomon Smith Barney and now Citigroup. One of the more substantial modifications was the addition of a penthouse, referred to as the east penthouse, which was used to house a chiller plant and cooling towers for Salomon Brothers. Also, large portions of Floors 41 and 43 were removed on the east side of the building to accommodate trading floors for Salomon Brothers. The removed floor areas were subsequently restored after the trading activity was moved to another venue.

Above Floor 7, the building had typical steel framing for high-rise construction. The floor systems had composite construction with steel beams supporting normal weight concrete slabs on metal deck, with a floor thickness of 5.5 in. The core and exterior columns supported the floor system and carried their loads to the foundation. The exterior moment frame also resisted wind forces. Many of the columns above Floor 7 did not align with the foundation columns, so braced frames, transfer trusses, and transfer girders were used to transfer loads between these column systems, primarily between Floors 5 and 7 . Floors 5 and 7 had heavily reinforced concrete slabs on metal deck, with thicknesses of 14 in. and 8 in., respectively. A complete description of the structure is given in Section 2.4.

The architectural design was performed by Emory Roth \& Sons, P.C. The structural engineer of record was the Office of Irwin G. Cantor, and the mechanical engineer was Syska \& Hennessy, P.C. Tishman Construction Corporation was the general contractor. 


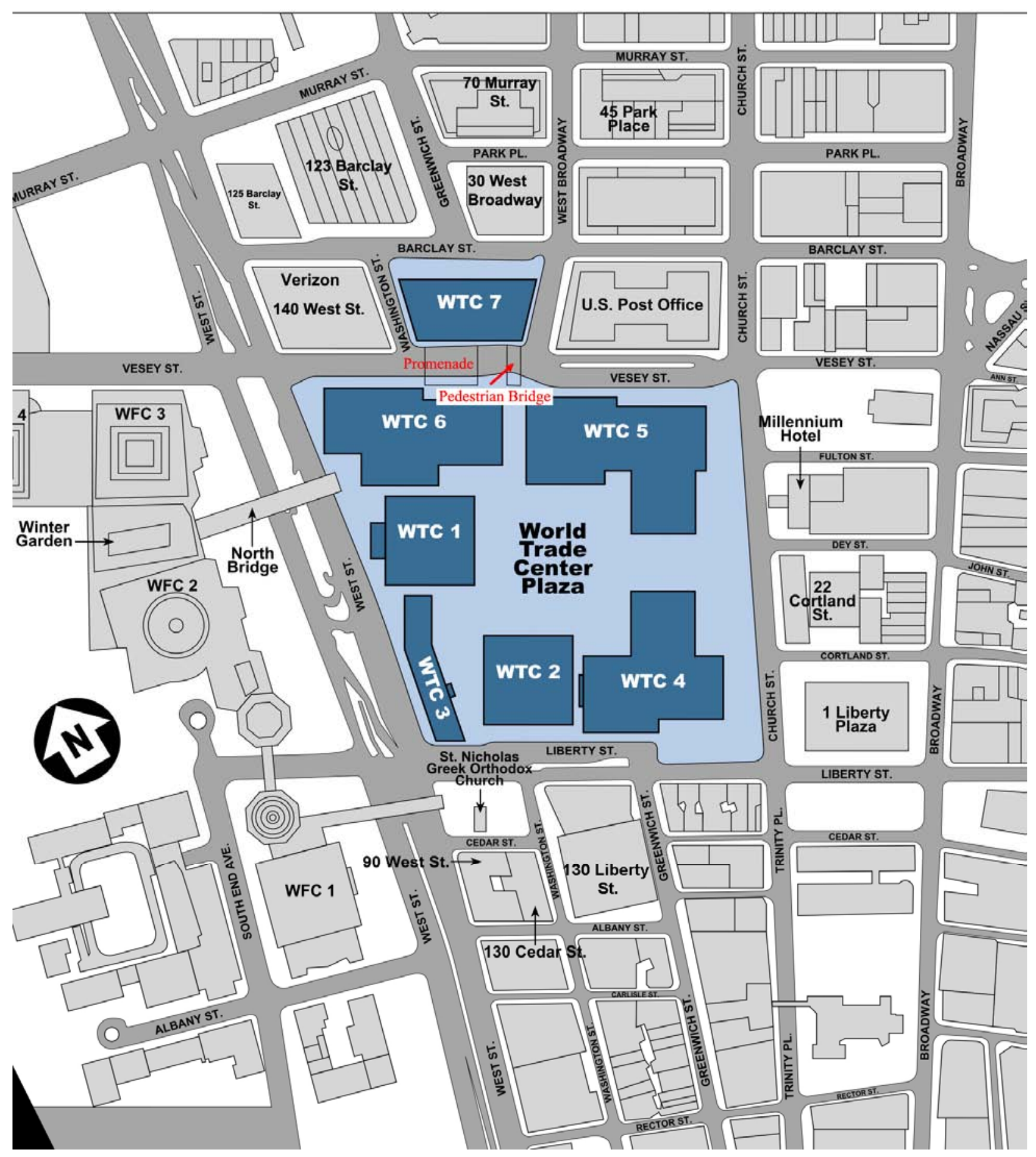

Figure 2-1. WTC complex. 


\section{$2.2 \quad$ BUILDING CODES}

Unlike the World Trade Center Towers (WTC 1 and WTC 2), which were developed and owned by The Port Authority, WTC 7 was developed on land owned by The Port Authority, but the building was owned by Seven World Trade Company and Silverstein Development Corporation, General Partners. It was designed and constructed as a "Tenant Alteration Project” of The Port Authority.

When WTC 7 was designed in the mid-1980s, the 1968 NYC Building Code (NYCBC) with amendments was in effect. A comparison of the 1968 NYCBC with contemporaneous building codes is presented in NIST NCSTAR 1-1E. The Project Specifications for WTC 7, issued in 1984, required that the structural steel be designed in accordance with the then current NYCBC. The November, 1978 edition of the Specifications for the Design, Fabrication and Erection of Structural Steel for Buildings, published by the American Institute of Steel Construction in the Eighth Edition of the AISC Manual of Steel Construction (AISC 1980), was the current steel design specification document.

The Port Authority developed a tenant alteration process for modifications to leased spaces in the WTC complex to maintain structural integrity and fire safety. The Tenant Construction Review Manual contained technical criteria to be used in planned alterations for tenants. The manual included the applicable standards and review criteria to be used by The Port Authority Engineering Department in its review of alteration designs completed by design professionals. At the completion of the work, the asbuilt drawings were to be submitted to The Port Authority. Since WTC 7 was built as a "Tenant Alteration Project," its design and construction followed the requirements of the 1984 edition of the Tenant Construction Review Manual. Details of the Tenant Construction Review Manual are found in NIST NCSTAR 1-1C.

Although the PANYNJ was not subject to the NYCBC, WTC 7 was intended to be designed in accordance with the NYCBC and all applicable reference standards. Based on citations in the construction documents, the 1968 NYCBC, including amendments through January 1, 1985, appears to have been used for the design and construction provisions of WTC 7.

Based on the height, area, primary occupancy classification, and installation of a fire sprinkler and standpipe system, the minimum construction type (permitted by the NYCBC) was type 1-C (2 h protected) classification. However, some documentation, including some building drawings and specifications for bidders on the contract for fireproofing ${ }^{1}$ the structural steel, indicate a Type 1-B (3 $\mathrm{h}$ protected) classification. Chapter 12 in NIST NCSTAR 1-1D gives a summary of fire protection measures used in WTC 7, which were consistent with a Type 1-C classification.

After the publication of the WTC towers investigation reports in September 2005, documents which contained a set of measured thicknesses of the sprayed fire-resistive material (SFRM) used in WTC 7 were obtained. The SFRM thickness measurements were consistent with a Type 1-B classification. A Type 1-B classification required a $3 \mathrm{~h}$ fire resistance rating on the columns and a $2 \mathrm{~h}$ fire resistance rating

\footnotetext{
1 The application of sprayed fire-resistive materials (SFRM) is often referred to as "fireproofing." The sprayed fire-resistive materials themselves are also sometimes called "fireproofing." In this report, SFRM is used to describe the thermal insulation spray-applied to protect the steel, and the term fireproofing is used to describe the act of applying the SFRM. In quotations from contract documents or correspondence, the term "sprayed-on fireproofing" is used for SRFM; in such cases, the original wording is preserved. In no case did the Investigation Team presume that the protected steel was actually "fireproof."
} 
on the floors. For a sprinklered building, a Type 1-C classification required a $2 \mathrm{~h}$ fire resistance rating on the columns and a $1.5 \mathrm{~h}$ fire resistance rating on the floors.

Based on the SFRM measurements and project correspondence, the columns had SFRM thicknesses consistent with a $3 \mathrm{~h}$ fire resistance rating, the metal deck had SFRM thicknesses consistent with a $2 \mathrm{~h}$ fire resistance rating, and the floor framing (beams and girders) had SFRM thicknesses consistent with a $2 \mathrm{~h}$ fire resistance rating. The SFRM for the structural system is presented in Section 2.5. In this report, Type 1-C classification was assumed, but the actual classification may have been type 1-B.

\section{$2.3 \quad$ CON EDISON SUBSTATION BUILDING DESCRIPTION}

The Con Edison substation was constructed in 1967 and consisted of a three-story steel framed structure with cast-in-place concrete floors and walls. It was located on the north side of the site and extended approximately $40 \mathrm{ft}$ beyond the north face of WTC 7, as shown in Figure 2-2. Its southern boundary was irregular.

Some of the WTC 7 columns framed into the substation columns. During the construction of WTC 7, heavy plates were welded to the tops of the existing substation columns, which then supported the new building columns. The exterior columns above the Con Edison structure that did not align with the columns of the Con Edison structure were supported by a series of transfer trusses, girders, and cantilever girders located between Floors 5 and 7 . The arrangements of the transfer trusses and girders are described in Section 2.4.5.

\section{$2.4 \quad$ WTC 7 BUILDING DESCRIPTION}

\subsubsection{Foundations}

WTC 7 and the electrical substation were supported on caisson foundations. When the substation was constructed in 1967, provision was made for a future office tower by including capacity to carry both the substation and the future building. Caissons were also installed in the property adjacent to the substation for the proposed future building. When WTC 7 was constructed approximately 20 years later, it was significantly larger than the originally proposed building, and required additional caissons to be installed, as shown in Figure 2-2.

The typical caisson consisted of several components: a 30 in., 36 in., or 42 in. diameter steel casing, a heavy rolled or built-up steel core shape, vertical reinforcing bars, spiral reinforcing, and concrete fill. At the base of the caisson core, a pattern of shear studs was placed to transfer the load from the steel caisson core into the encompassing concrete, from which it passed into the rock. The caissons were socketed (seated) in the bedrock, approximately $60 \mathrm{ft}$ below the surface. There were vertical caissons as well as battered (or sloped) caissons to carry the lateral load. Above the caissons were heavy grillages composed of built up steel girders. Grillages transferred loads between the building columns and the caissons.

The distance between the caisson grillages and the first floor varied between $8 \mathrm{ft}$ and $30 \mathrm{ft}$. This region was braced by reinforced concrete walls with thicknesses varying from $1 \mathrm{ft}$ to $2.5 \mathrm{ft}$. Many of the WTC 7 steel columns were embedded in these walls, and supporting steel braces were made composite by the addition of shear studs along the height of the embedment. 
Areas between the concrete walls were backfilled with compacted gravel fill and then covered with a concrete slab on grade or framed slab to form closed cells and bring the structure up to the required elevation. In some cases, the area was left unfilled and used to house fuel tanks.

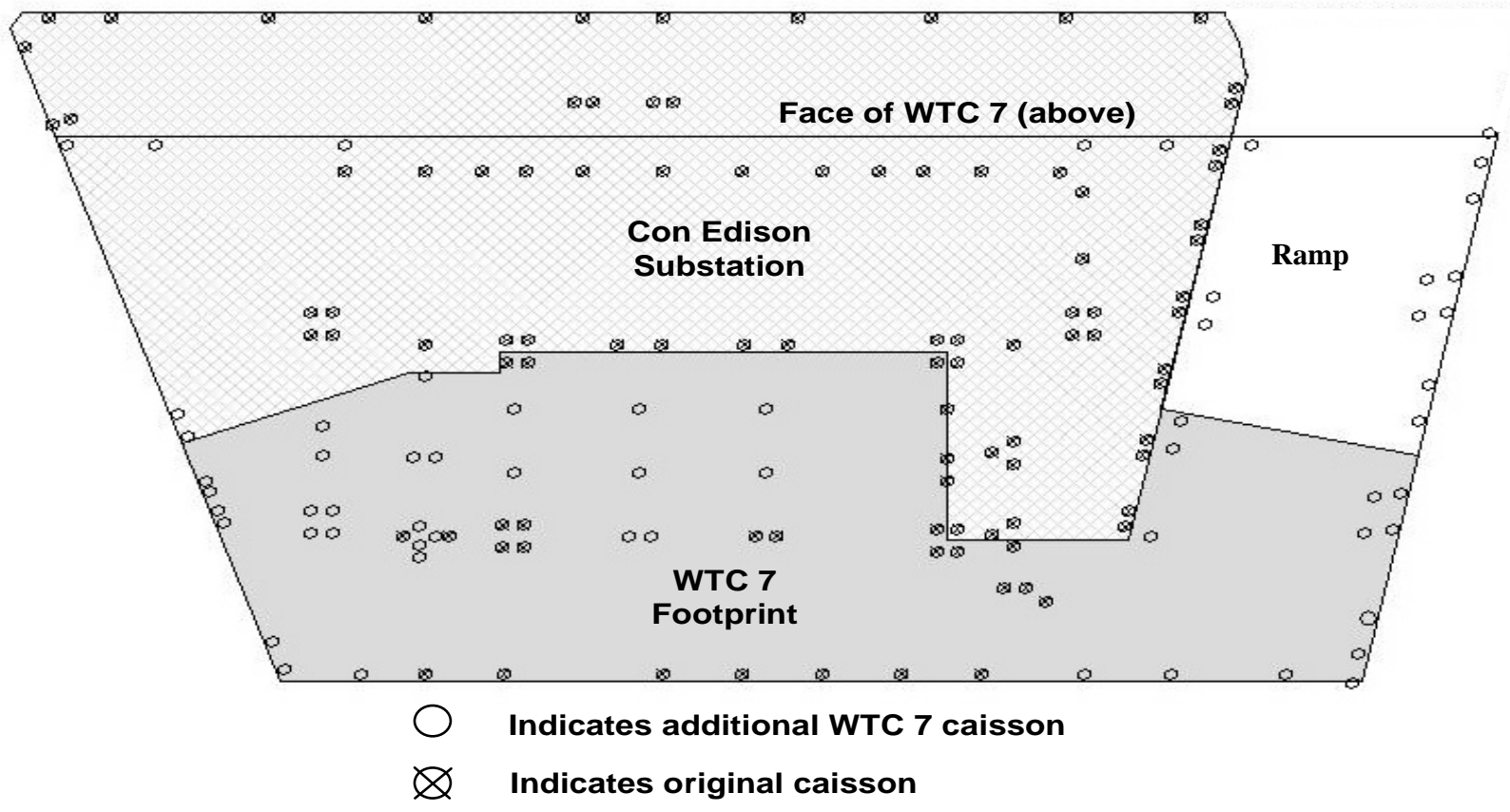

Source: McAllister 2002.

Figure 2-2. WTC 7 foundations.

\subsubsection{Floor Systems}

\section{Typical Floor Systems Floors 8 to 45}

The typical floor framing system, shown in Figure 2-3, was composed of rolled steel wide-flange beams with composite metal decking and concrete slabs. Floors 8 through 45 had essentially the same framing plan, but the core layout varied over the height of the building. Figure 2-3 also shows the column numbering.

Floors 8 through 45 had floor slabs that were composed of a 3 in. deep, 20 gage metal deck with 2.5 in. of 3,500 psi normal weight concrete above the top of the metal deck, for a total floor thickness of 5.5 in. There was one layer of 6 x 6 W1.4xW1.4 welded wire fabric (WWF) within the concrete. The drawings showed a second layer of WWF placed over girders at the slab edges. The fastening requirements for the metal deck were not shown on the drawings, but standard practice provided puddle welds 12 in. on-center at the beams and side lap welds, screws, or button-punching at 36 in. on-center between adjacent panels of deck. The drawings contained a note calling for $1.5 \mathrm{in}$. deep, 20 gage metal deck with 4 in. of concrete topping (5.5 in. total) in the elevator lobbies, where there was a 3 in. floor finish specified by the architect. 
Typical floor framing for Floors 8 through 20 and Floors 24 through 45 consisted of 50 ksi wide-flange beams and girders. Between the core columns was a grid of beams and girders. Core girders ranged in size from W16x31 to W36x135, depending on the span and load. Beams spanned between the core and the exterior of the building, at approximately $9 \mathrm{ft}$ on-center spacing. On the north and east sides, the typical floor beam was a W24x55 with 28 shear studs, spanning approximately $53 \mathrm{ft}$. On the south side, the typical floor beam was a W16x26 with 24 shear studs spanning $36 \mathrm{ft}$. Between the exterior columns, moment connections were used to connect the spandrel beams to the columns as part of the lateral load resisting system of the building.
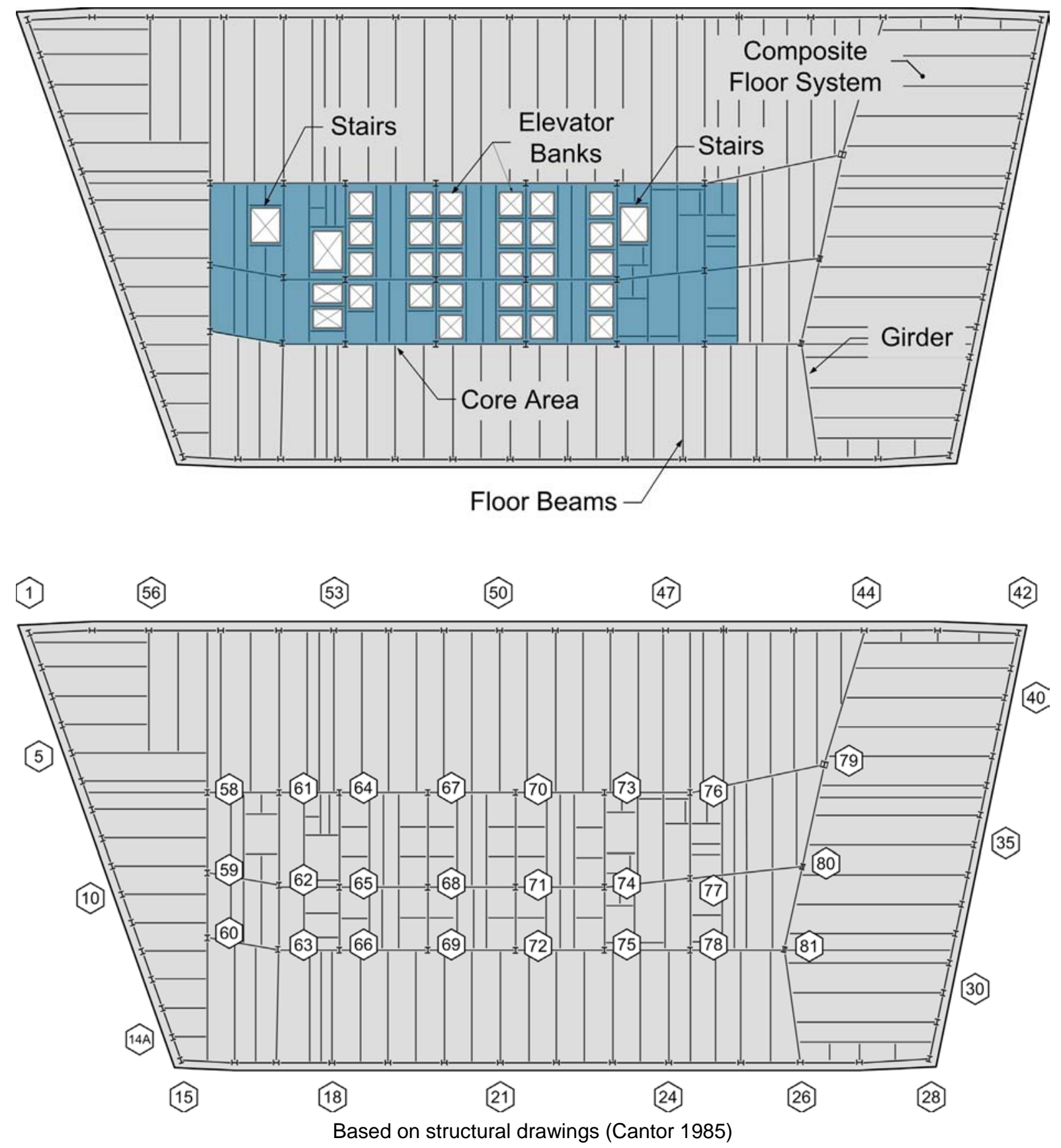

Figure 2-3. Floors 8 through 45 framing plan. 
Floors 21 to 23 had slightly heavier steel framing than the typical floors, as they were designed to support heavy computer equipment. Core girders were generally one size class larger than the typical floor; the beams between the core and the south facade were W16x31 instead of W16x26. There were additional studs on the W24x55 beams on the north and west sides.

Most of the beams acted compositely with the slabs through the use of shear studs. Typically, the shear studs were $0.75 \mathrm{in}$. in diameter by $5 \mathrm{in}$. long, spaced roughly $1 \mathrm{ft}$ to $2 \mathrm{ft}$ on center. The number of studs on a floor beam was indicated on the design drawings. Photographic records showing the demolition of a floor slab (tenant renovation) on the south side of a typical tenant floor confirms the number of studs shown on the drawings. Studs were not indicated on the design drawings for the girders, i.e., composite action did not develop between the girders and the slab.

The structural design drawings (Cantor 1985) specified design forces for connections and suggested a typical detail, but did not show specific connection designs; this was standard practice on the U.S. east coast. The erection drawings (Frankel 1985) indicated that design shear forces for the typical beam and girder connections were to be taken from the American Institute of Steel Construction (AISC) beam design tables for beams without shear studs, using 1.5 times those forces for beams with shear studs. The fabrication shop drawings (Frankel 1985a) were used to confirm information about floor connections, which NIST obtained from the structural and erection drawings and from photographs taken during renovations conducted during 1989 to 1990 on a number of floors. The shop drawings were not sealed by a Professional Engineer, but they included revisions dated 1985 and 1986, and were consistent with the renovation photographs of the floor connections. The shop drawings were used for additional details related to the connections.

Floor beam-to-girder and girder-to-interior column connections were generally a single shear plate or double angle connection, although in several instances, seated connections were used. The typical beamto-exterior column connections were seated connections. The typical bolt used in the simple shear connections was a 7/8 in. diameter ASTM A325, where ASTM A325 is a standard specification for a structural bolt. The bolt used for heavier brace and moment connections was a 1 in. diameter ASTM A490. Details of the connections used in the floor framing are covered in Section 2.4.3.

\section{Other Floors}

The remaining floors, Floors 1 through 7 and Floors 46 and 47, were atypical and are described below and in Figure 2-4 through Figure 2-13.

Floor 1 was built adjacent to the substation and included the truck ramp for the WTC complex. The first floor is shown in Figure 2-4. The floor was framed with steel beams that were encased in a formed concrete slab. The floor slab was 14 in. thick, with typical No. 5 reinforcement bars (5/8 in. rebar) at a 10 in. to 12 in. spacing and No. 6 rebar at 9 in. spacing for the bottom reinforcement; No. 5 rebar at 12 in. spacing was used for temperature reinforcement. The southeast portion of the floor above the WTC truck ramp had a 6 in. formed concrete slab with No. 4 rebar at 12 in. spacing for top and bottom reinforcement; No. 4 rebar at 18 in. spacing was used for temperature reinforcement.

The floor slabs for Floors 2, 3, 4, and 6 had a 3 in. deep, 20 gage metal deck with 3 in. of 3,500 psi normal weight concrete, for a total floor thickness of 6 in. Floors 2 and 3 were also partial floors adjacent to the substation. In addition, they had a floor opening on the south side to form the atrium above the ground 
level lobby (see Figure 2-5 and Figure 2-6). Floor 4 was above the substation and had a large opening over most of the south side of the building, to form a double-height space above the $3^{\text {rd }}$ floor lobby (see Figure 2-7). Floor 6 had two openings on the floor to form a double-height mechanical space, one on the east side and the other in the southwest corner (Figure 2-10). Trusss 1, Truss 2 and Column 80 were located in the east double-height mechanical space.

The Floor 5 slab was 11 in. of 3,500 psi normal weight concrete on top of a 3 in. deep, 18 gage metal deck for a total slab thickness of 14 in. The slab was heavily reinforced, with No. 7 rebar at 12 in. spacing for top reinforcement in both directions and No. 9 rebar at 12 in. spacing for bottom reinforcement that acted as additional diaphragm chord reinforcement in many areas. This floor also had 36 ksi steel WT sections (W, or wide-flange, sections cut in half to look like a ' $\mathrm{T}$ ' section) embedded in the 11 in. concrete slab above the deck. The WT sections were designed to act as a horizontal diaphragm within the plane of the floor to transfer lateral loads from the exterior to the core columns (Figure 2-8 and Figure 2-9).

The $7^{\text {th }}$ floor slab (Figure 2-11) consisted of 5 in. of 3,500 psi normal weight concrete on top of a 3 in. deep, 18 gage metal deck, for a total floor thickness of 8 in. The slab was reinforced with No. 5 rebar at $6 \mathrm{in}$. on center in both directions. Regions of the slab on the south side of the building had 8 in. of formed concrete without any metal deck. In these regions, two layers of steel reinforcement were provided.

Originally, Floors 41 and 43 had the east half removed to provide two-story trading floors. Columns in these areas and areas of Floors 40 and 42 were reinforced to provide adequate capacity for the additional height and change in use by tenants. By 2001, Floors 41 and 43 had been restored to provide full floor space.

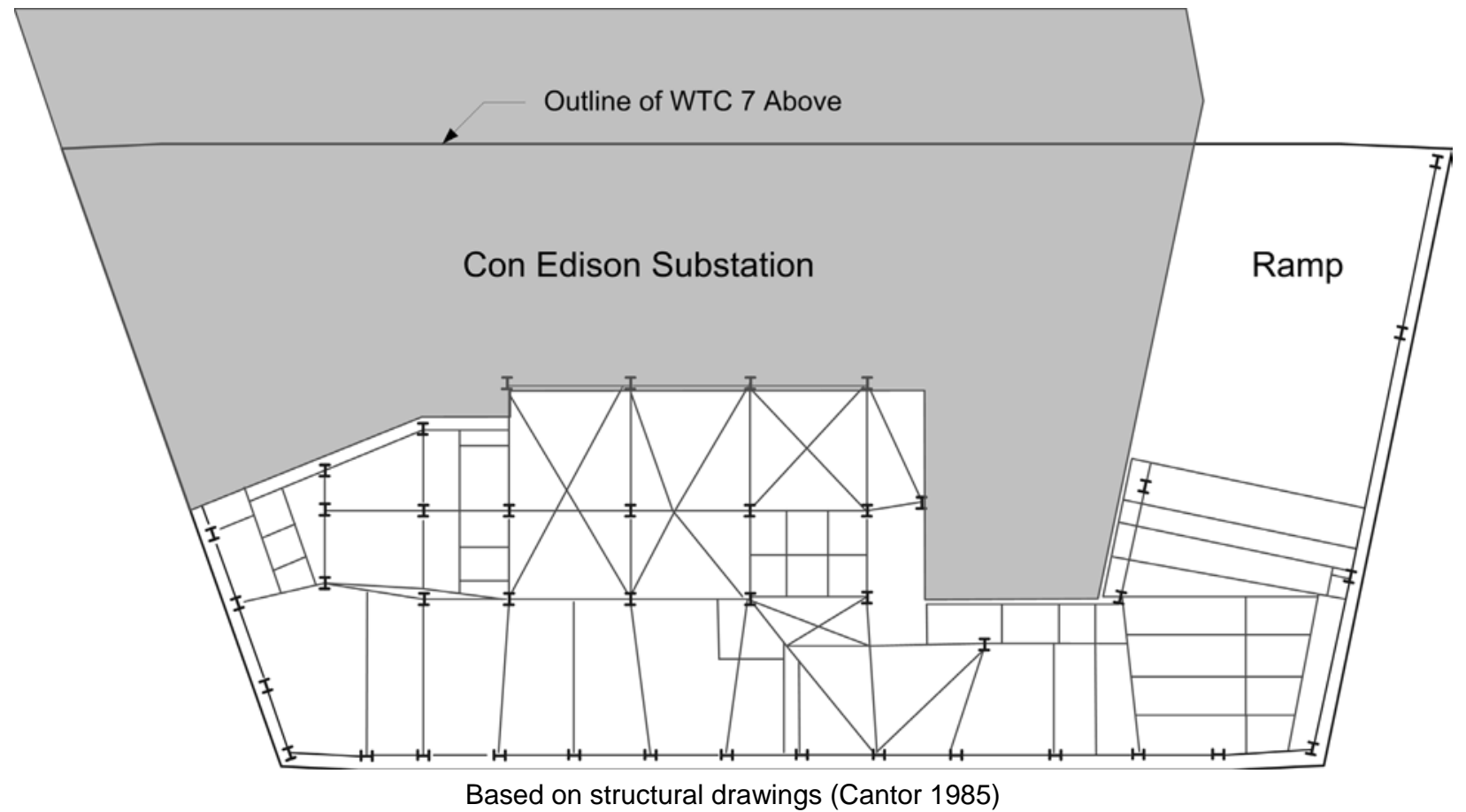

Figure 2-4. Floor 1 framing plan. 


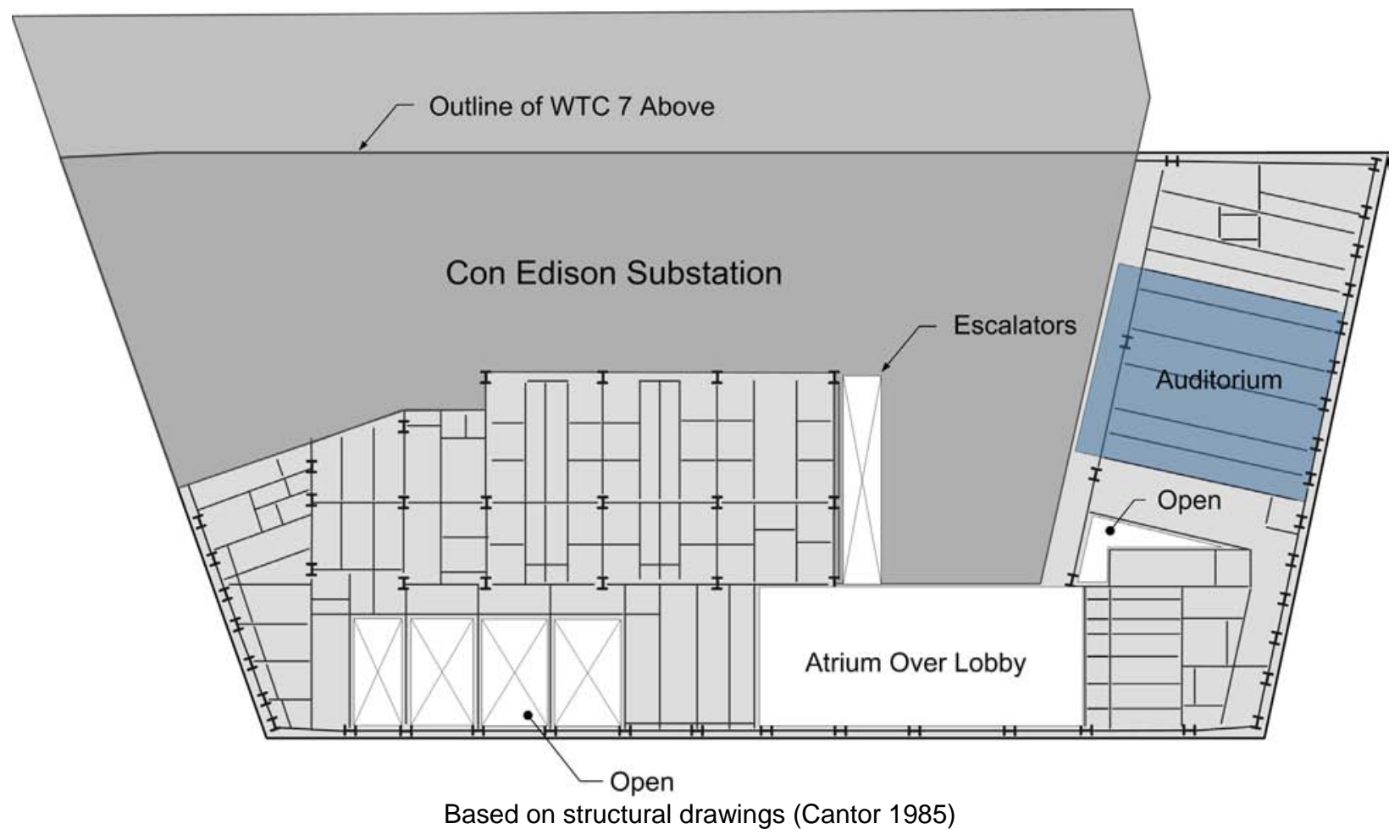

Figure 2-5. Floor 2 framing plan.

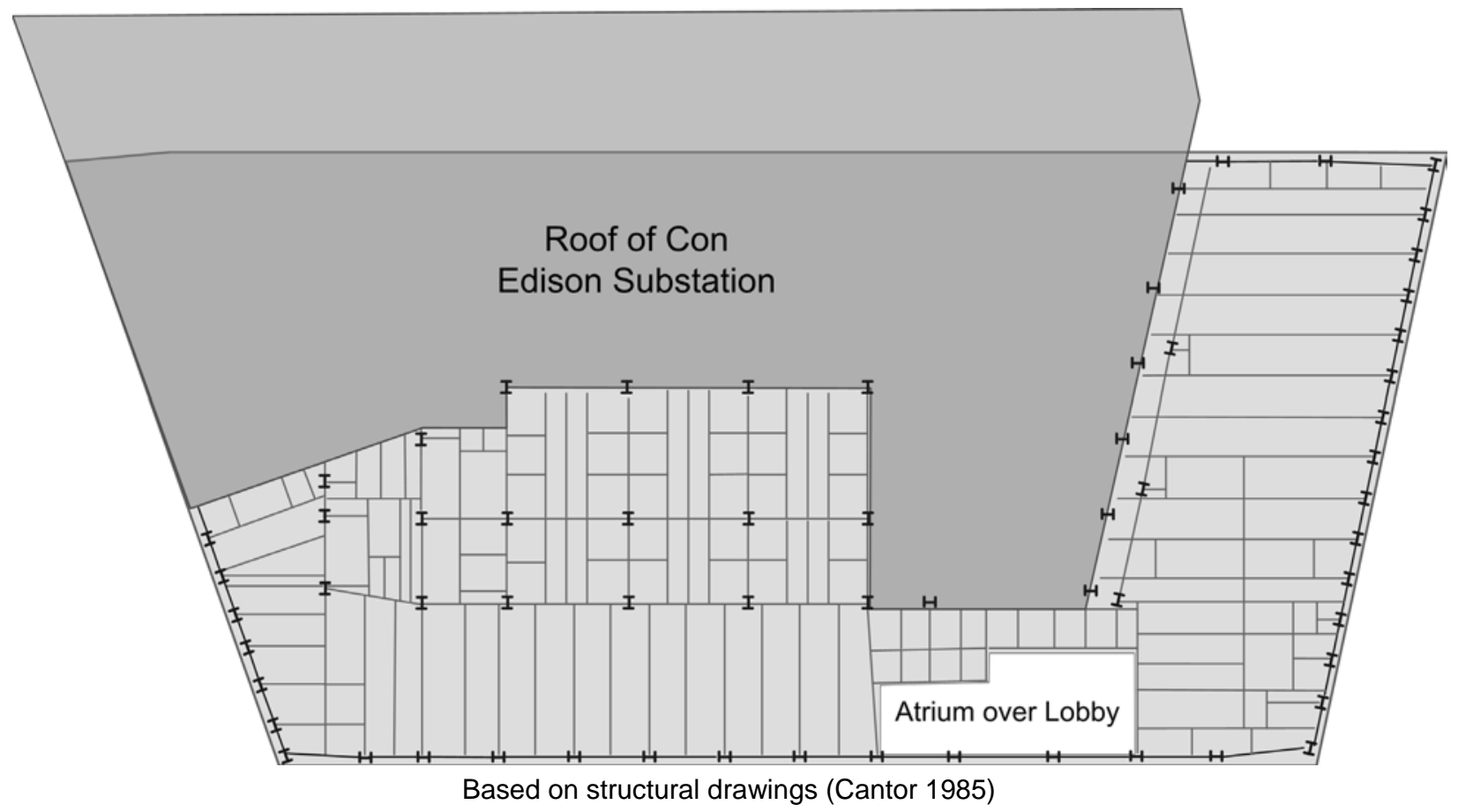

Figure 2-6. Floor 3 framing plan. 
The $46^{\text {th }}$ floor had heavier framing to support the cooling towers on the north side, (with W36x150 between posts and W36x260 under the posts) and the setback roof on the south side (with W21x44 between posts and W36x150 under the posts). There was a 6 in. reinforced concrete slab in a portion of the core and under the cooling towers (see Figure 2-12).

Floor 47 had a double height space extending from the $46^{\text {th }}$ floor to the underside of the roof for the cooling towers on the north side. There was also a setback roof on the south side at Floor 46 (Figure 2-13).

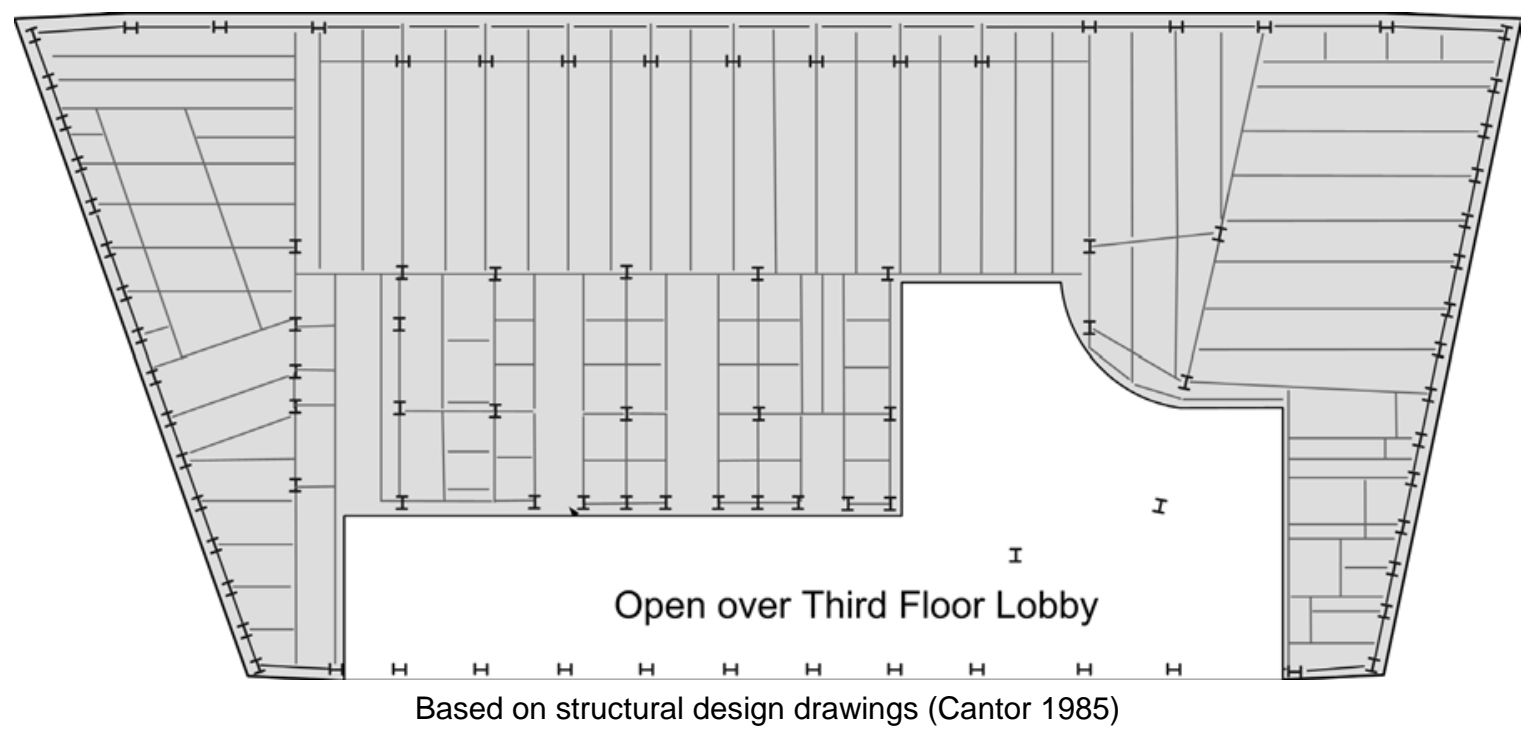

Figure 2-7. Floor 4 framing plan.

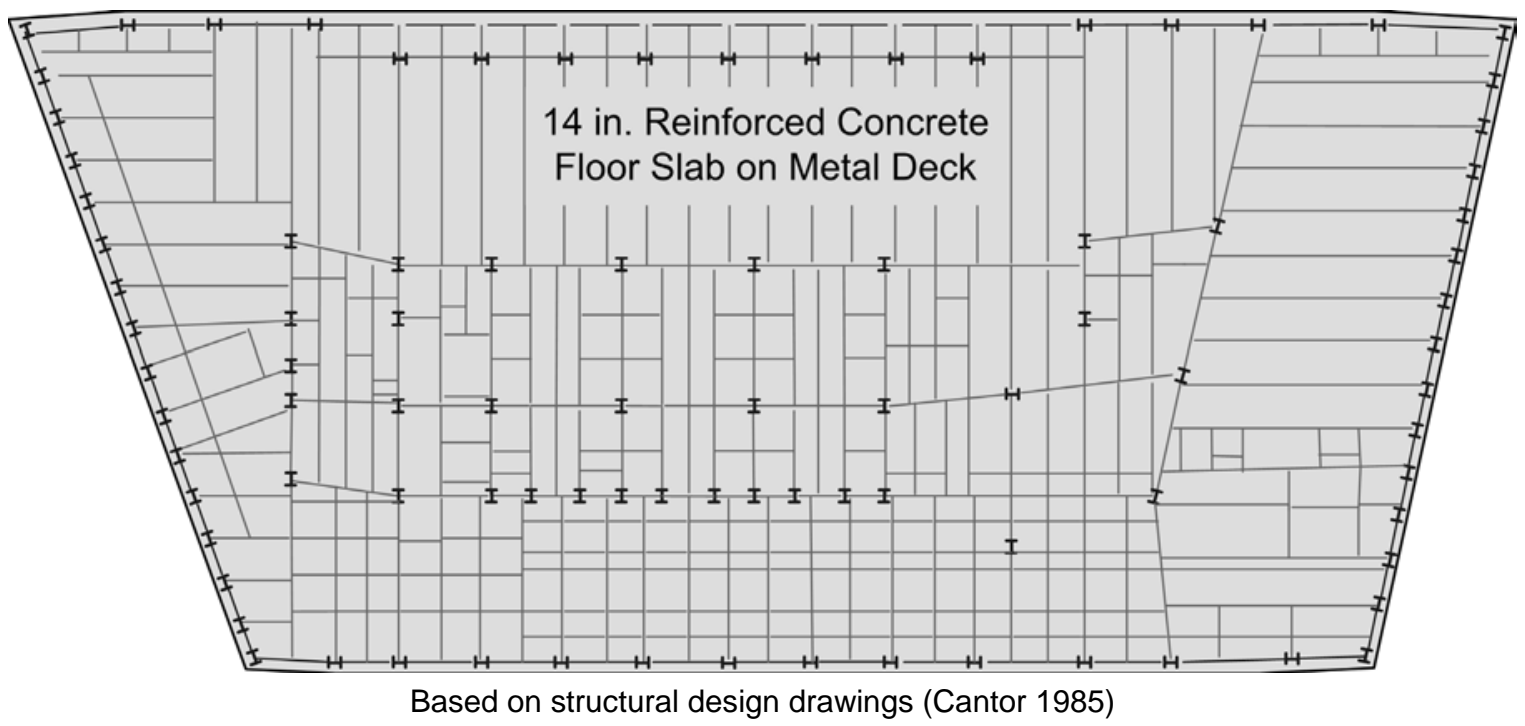

Figure 2-8. Floor 5 framing plan. 


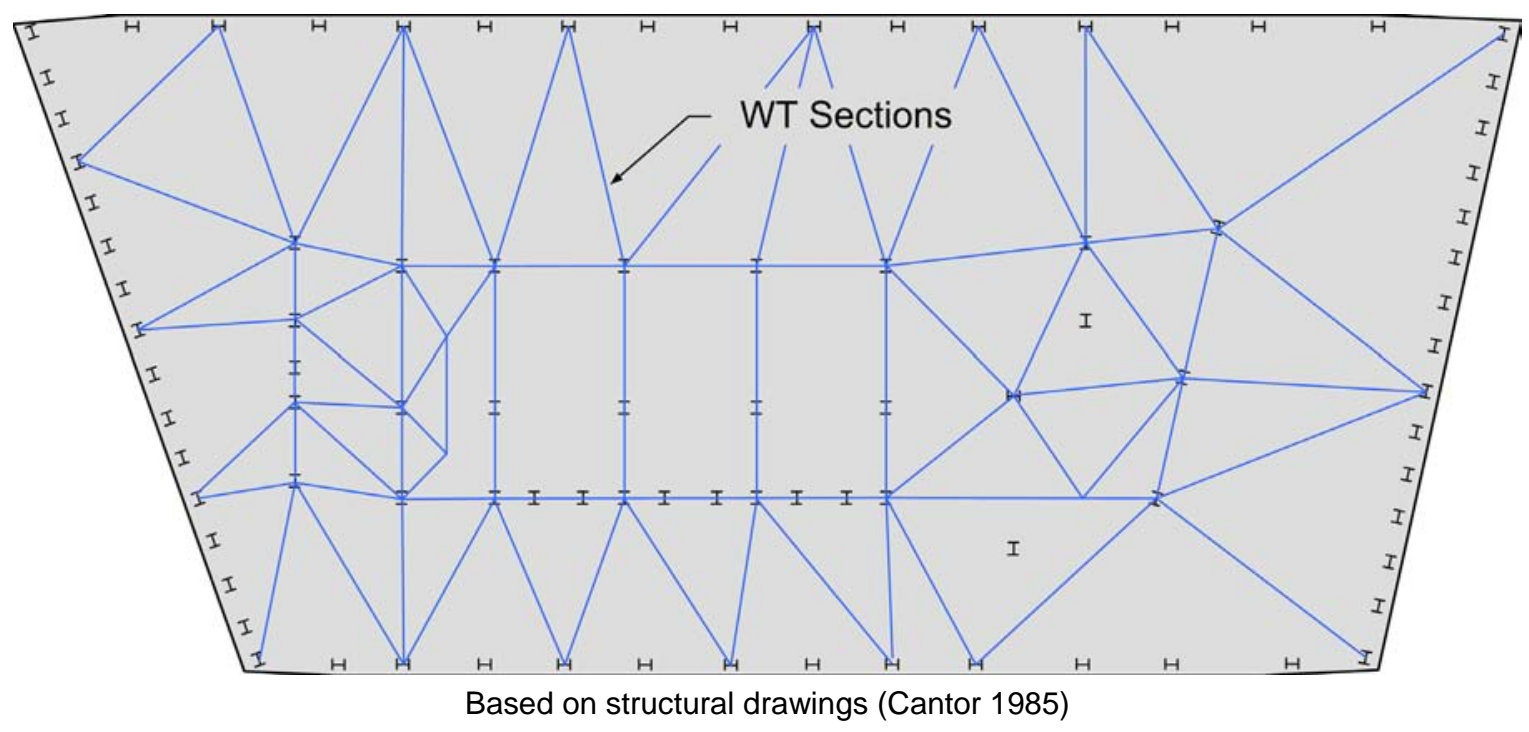

Figure 2-9. Floor 5 diaphragm plan.

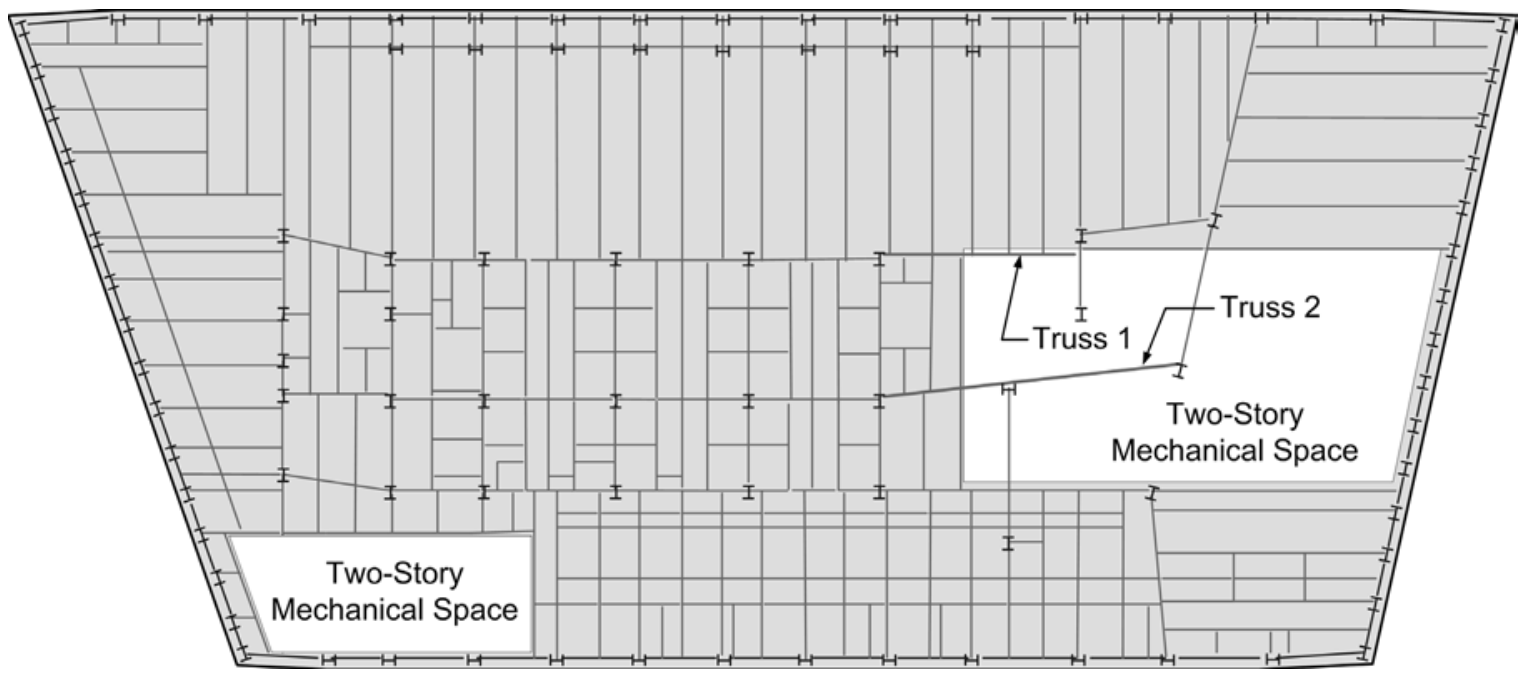

Based on structural drawings (Cantor 1985)

Figure 2-10. Floor 6 framing plan. 


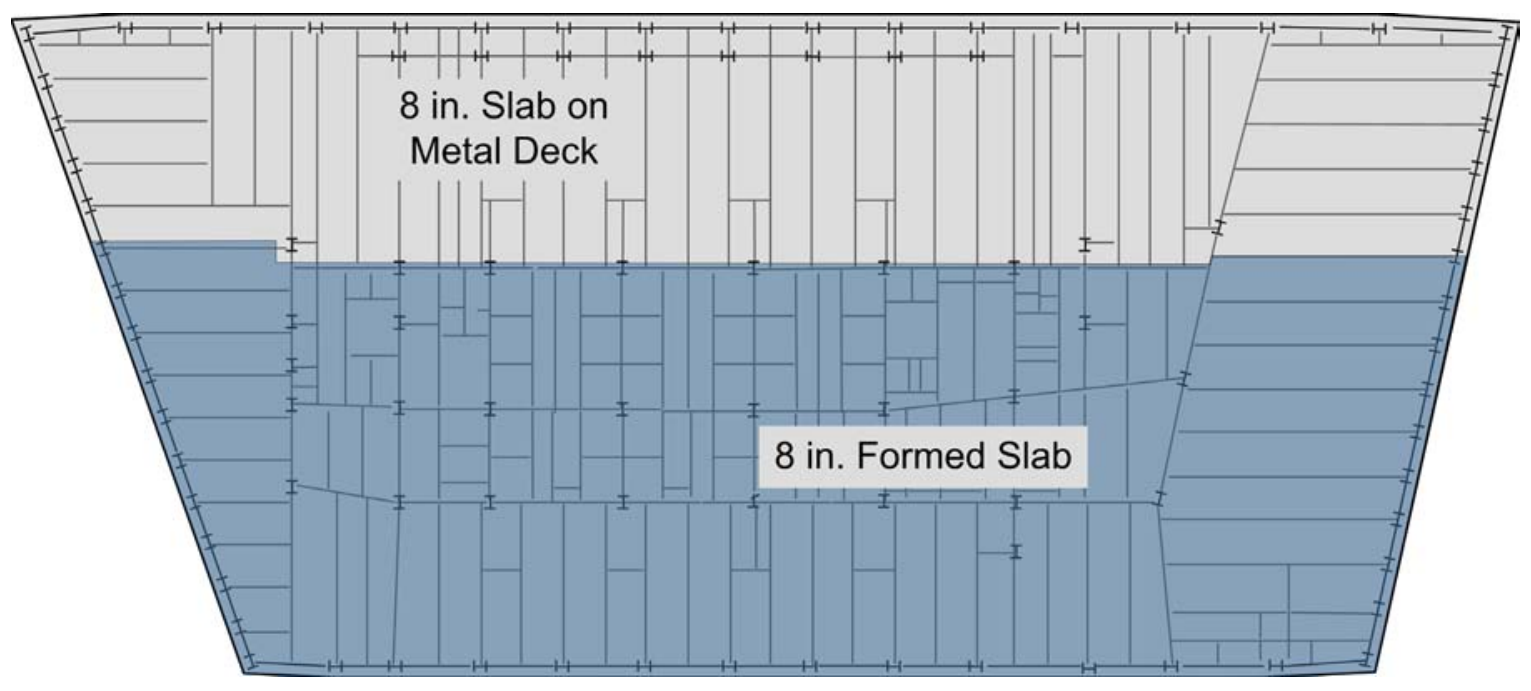

Based on structural drawings (Cantor 1985)

Figure 2-11. Floor 7 framing plan.

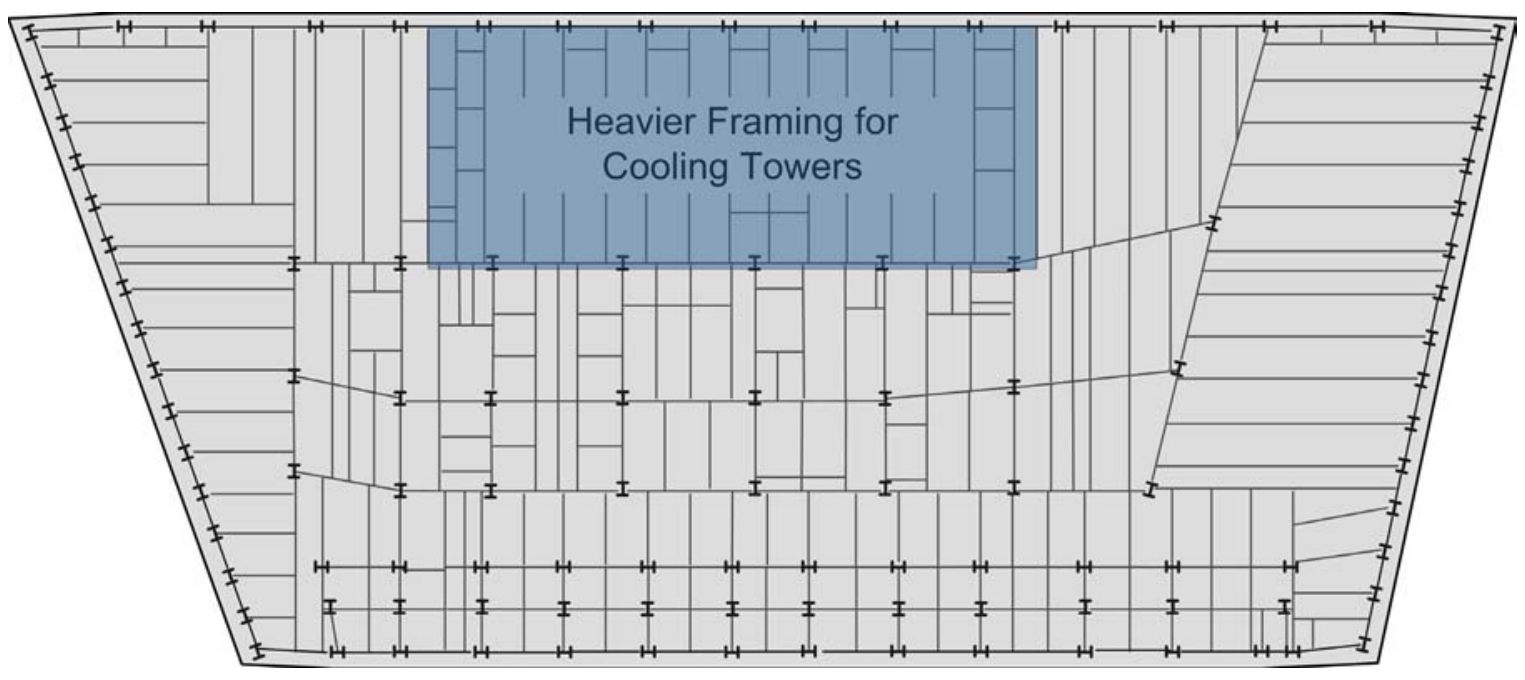

Based on structural drawings (Cantor 1985)

Figure 2-12. Floor 46 framing plan. 


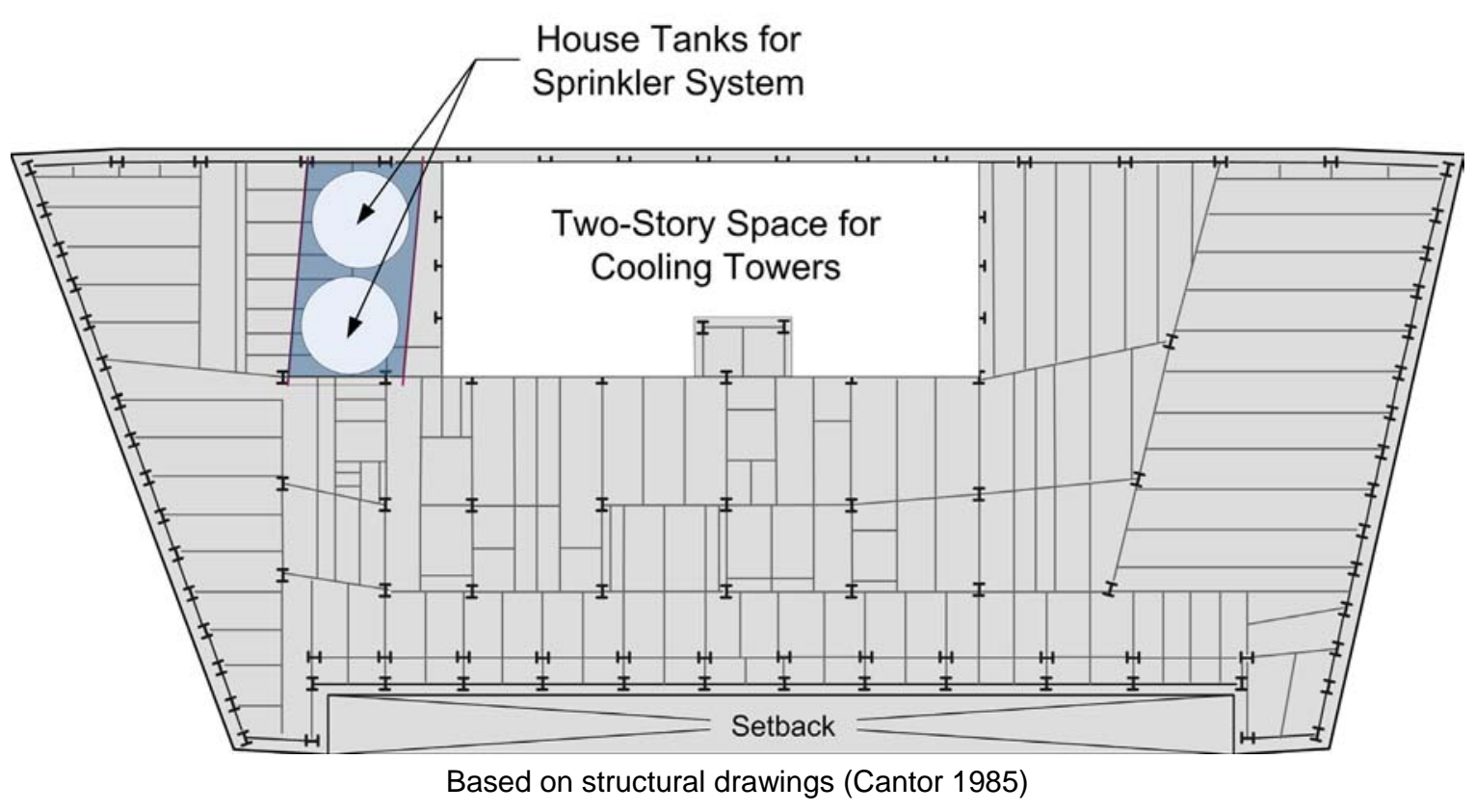

Figure 2-13. Floor 47 framing plan.

\section{Roof and Penthouses}

The roof had a concrete slab on metal deck. The top of the slab was sloped, from an $8.5 \mathrm{in}$. thickness to a 5.5 in. thickness, to provide drainage. The WWF in this slab was $6 \times 6 \mathrm{~W} 2.4 \times W 2.4$, which was 70 percent heavier than at a typical tenant floor. There were slab openings for the cooling towers on the north and the roof setback on the south. The area above the cooling towers was framed in steel, with grating spanning between the beams. A series of diagonal WT6x9 members under the grating provided diaphragm action in this area.

The east penthouse was added to the WTC 7 building in 1989. To accommodate the added load of equipment within the east penthouse, the roof beams and girders were reinforced using cover plates welded to their lower flanges, and a thick concrete pad was cast to support the air-conditioning equipment housed within the penthouse. Steel columns (or "posts" as they were termed on drawings) supported the new penthouse structure. A plan of the roof and penthouse framing is shown in Figure 2-14. The east penthouse posts framed into existing interior columns that fell within the east penthouse footprint (Columns 76, 77, 79, and 80). The other posts were supported by beams at the roof level. 


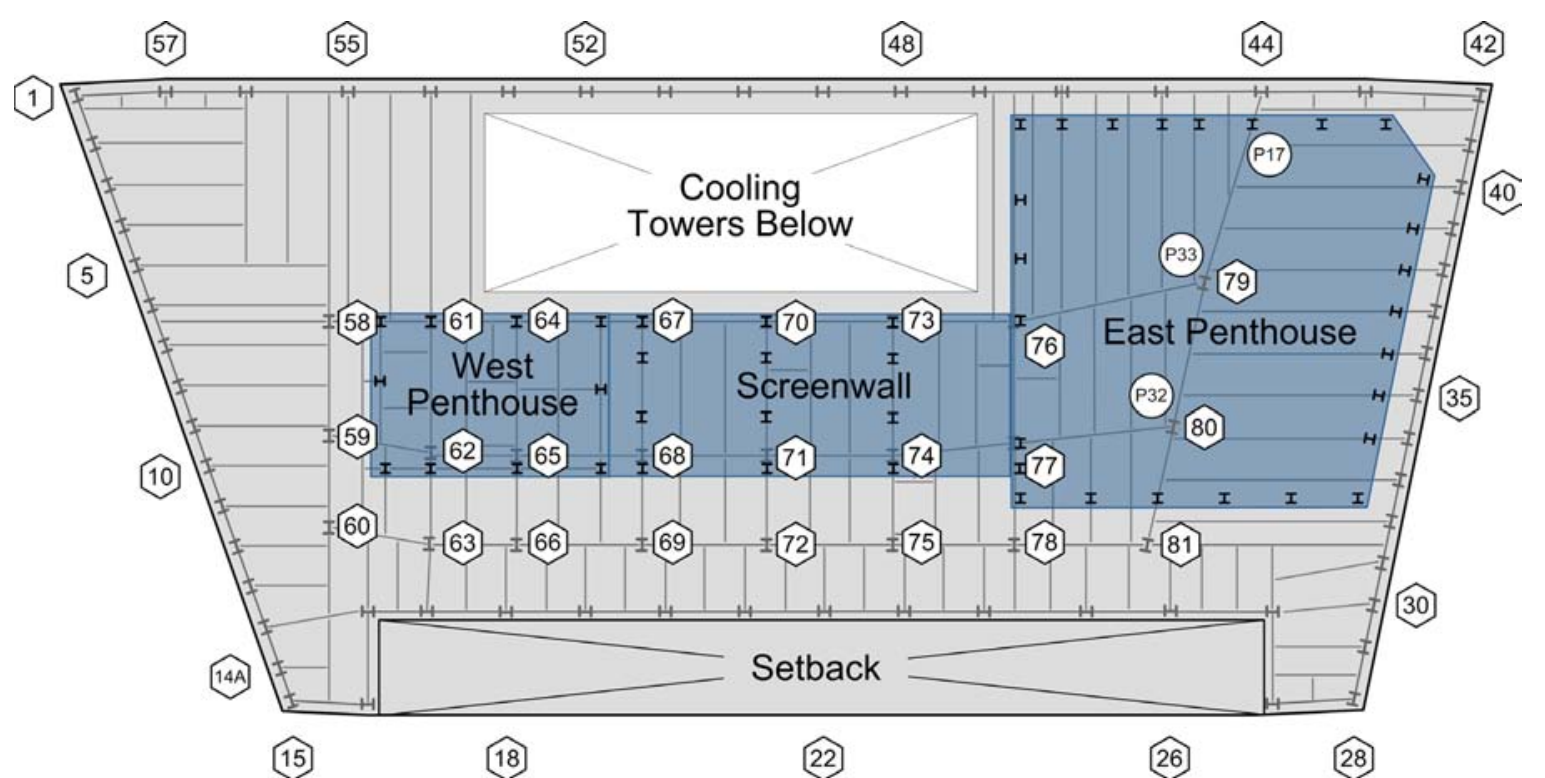

Based on structural drawings (Cantor 1985 and Cantor 1988)

Figure 2-14. Roof layout.

\subsubsection{Connections in the Floor System}

The structural design drawings indicated that the exterior framing (and portions of the core framing at Floors 5 and 7) had moment connections as part of the lateral load resisting system (Section 2.4.6), and that the floor framing had simple shear connections. The structural design and fabrication shop drawings provided details of the connections used in the building. Details of all connections, including steel section sizes, plate thickness and dimensions, weld sizes, bolts sizes, bolt hole locations, and clearances were taken from approximately 2,500 fabrication shop drawings and used in developing the structural models described in Chapters 11 and 12. The fabrication shop drawings, as well as the structural design drawings and erection drawings, served as the source material for Figure 2-15 through Figure 2-23, as well as for the floor plans and details in all chapters of this report.

The typical shear connections used in the floor framing are presented here, as these connections were modeled in detail in the ANSYS and LS-DYNA analyses (Chapters 11 and 12).

All floor beams had simple shear framing connections with high strength bolts. Connections made with double angles were referred to as either header or knife connections.

A header connection consisted of two angles shop fillet-welded to a beam web, and field bolted to either a girder or column, as illustrated in Figure 2-15.

A knife connection was one in which the angles were shop fillet-welded to a girder web or column, and field bolted to a beam or girder web, as illustrated in Figure 2-16. 
A fin connection consisted of a flat plate that was shop welded to the web and underside of a girder flange using double fillet welds, and field bolted to a beam framing into the girder, as illustrated in Figure 2-17.

Seated connections with web clips (SWC) were used for core floor beams framing into girders. A schematic of a SWC connection is shown in Figure 2-18.

Floor beams or girders that framed into exterior columns had a seated connection with a top plate (STP) or a top clip (STC). A schematic of an STC connection, typical of a beam or girder framing into an exterior column on the north or south sides of the building, is shown in Figure 2-19.

Girders that framed into interior Columns 79 and 81 also had seated connections with a top clip (STC). The seat was either a rolled angle or a seat plate welded to the column. The seat plate at Column 81 was stiffened while the seat plate at Column 79 was supported by a plate welded to the side cover plates on the lower stories. Figure 2-20 is a schematic of the seat arrangement for Column 79 where side plates were used. The beam or girder top flange was attached to the column with either a clip angle or plate to provide lateral restraint during construction.

Figure 2-21 and Figure 2-22 are diagrams of typical tenant floors that show the locations of the framing connections, based on the shop drawings and review of photographs.

The typical floor framing connection designs are described here with the following designations used in the investigation:

- $\quad \mathrm{H}$ - Header connection with a single line of $\mathrm{n}$ bolts in each angle, for a total of $2 \mathrm{n}$ bolts;

- $\quad \mathrm{K}$ - Knife connection with a single line of $\mathrm{n}$ bolts;

- $\quad$ F - Fin connection with a single line of $n$ bolts;

- SWC - Seat (either rolled angle or plate) with a single web clip for lateral stability. Typically 2 erection bolts in the seat, and 2 in the web clip angle were installed.

- STC - Seat (either rolled angle or plate) with a clip angle on the top flange for lateral stability. Typically 2 erection bolts in the seat, and 2 in the top flange clip angle were installed.

- $\quad$ STP - Seat (typically a plate) with a plate on the top flange for lateral stability. Typically 2 erection bolts in the seat, and 2 in the top plate were installed. 


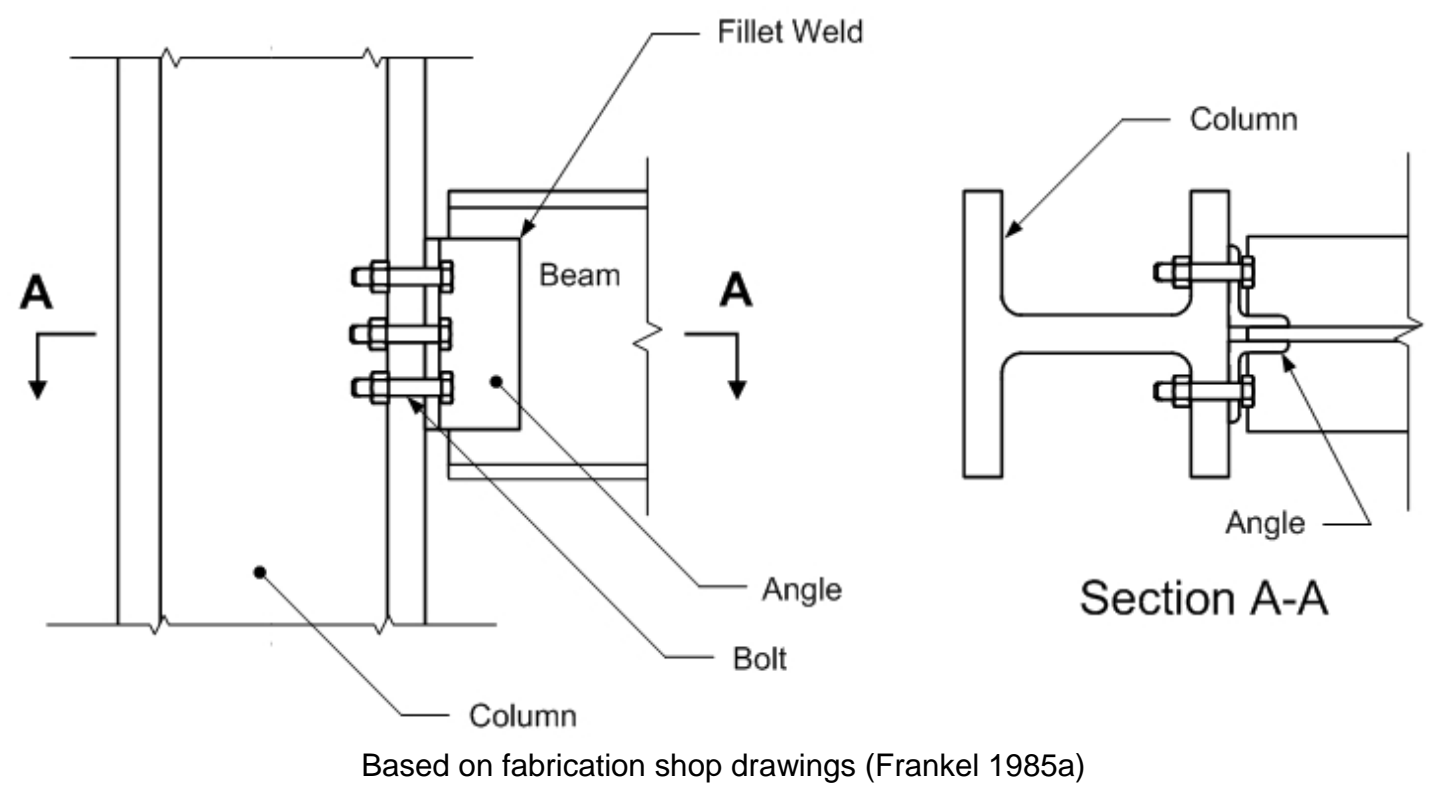

Figure 2-15. Schematic drawing of a header connection $(H)$.

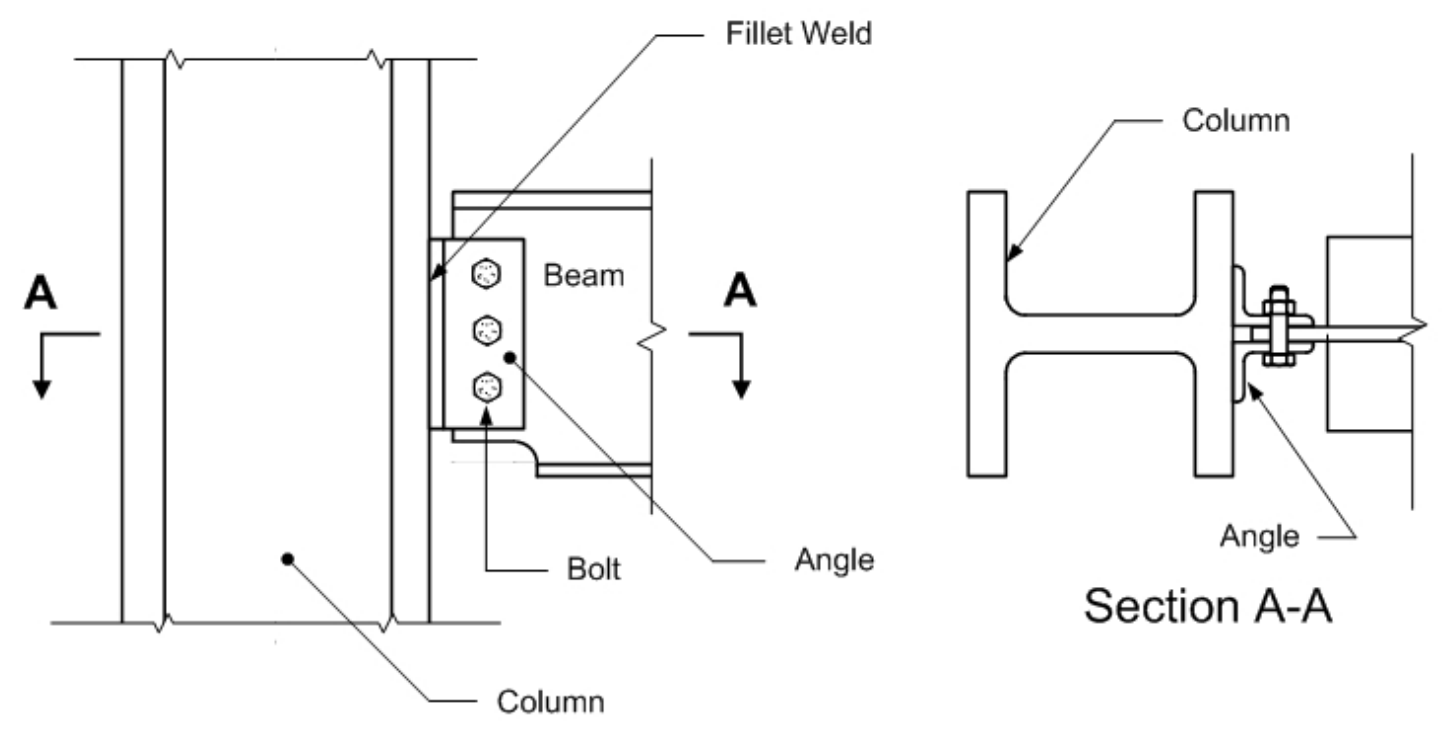

Based on fabrication shop drawings (Frankel 1985a)

Figure 2-16. Schematic drawing of a knife connection (K). 

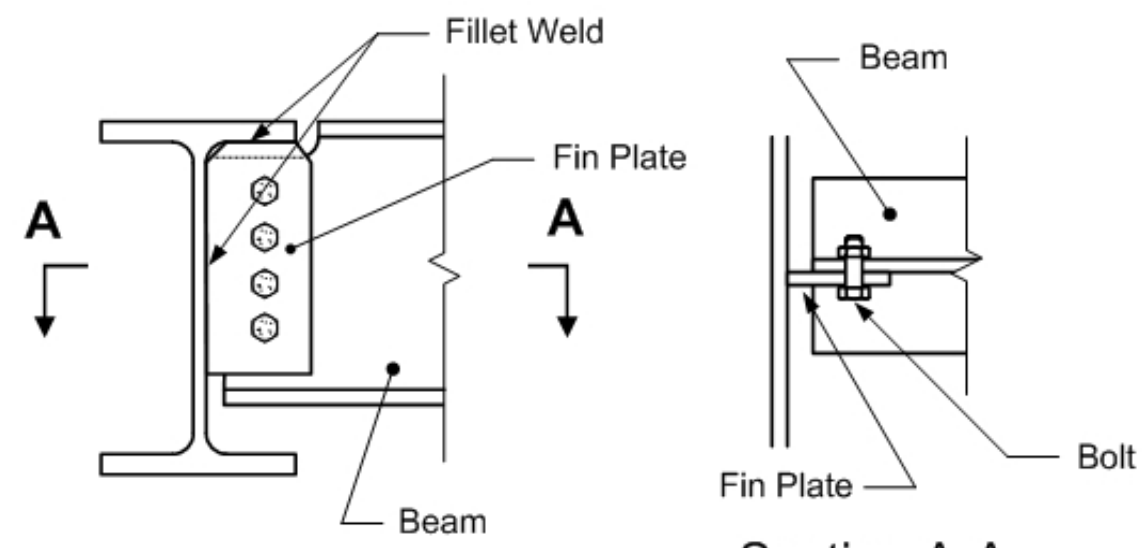

\section{Section A-A}

Based on fabrication shop drawings (Frankel 1985a)

Figure 2-17. Schematic drawing of a fin plate connection (F).

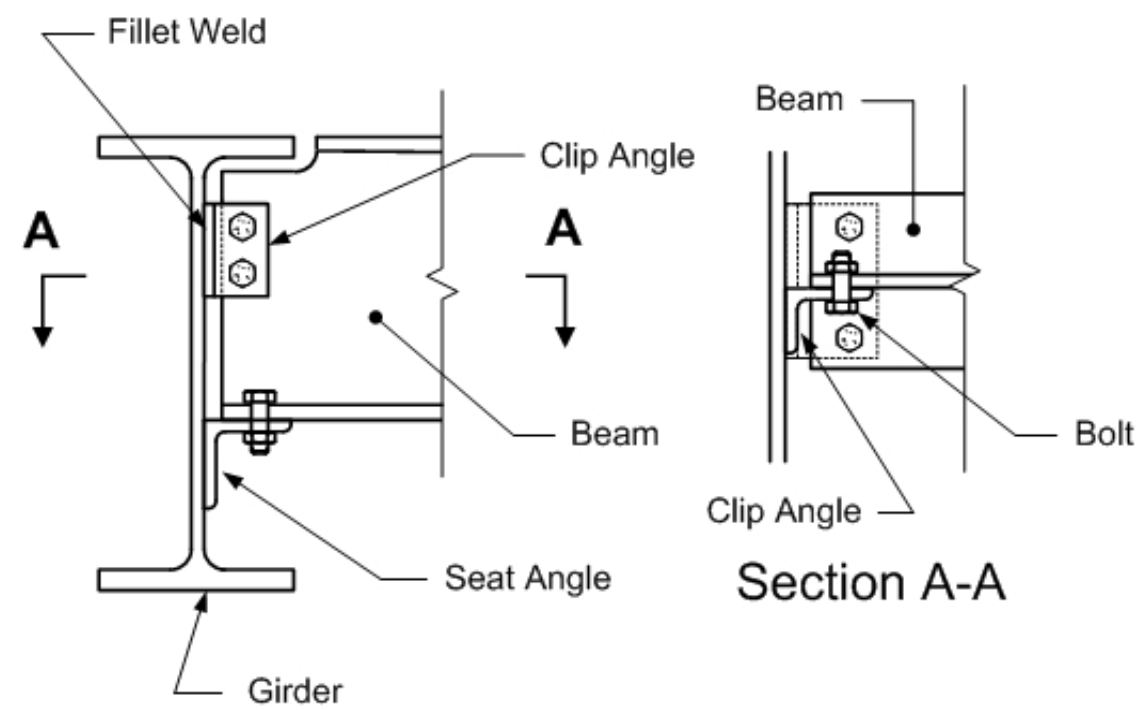

Based on fabrication shop drawings (Frankel 1985a)

Figure 2-18. Schematic drawing of a seated connection with web clip (SWC). 


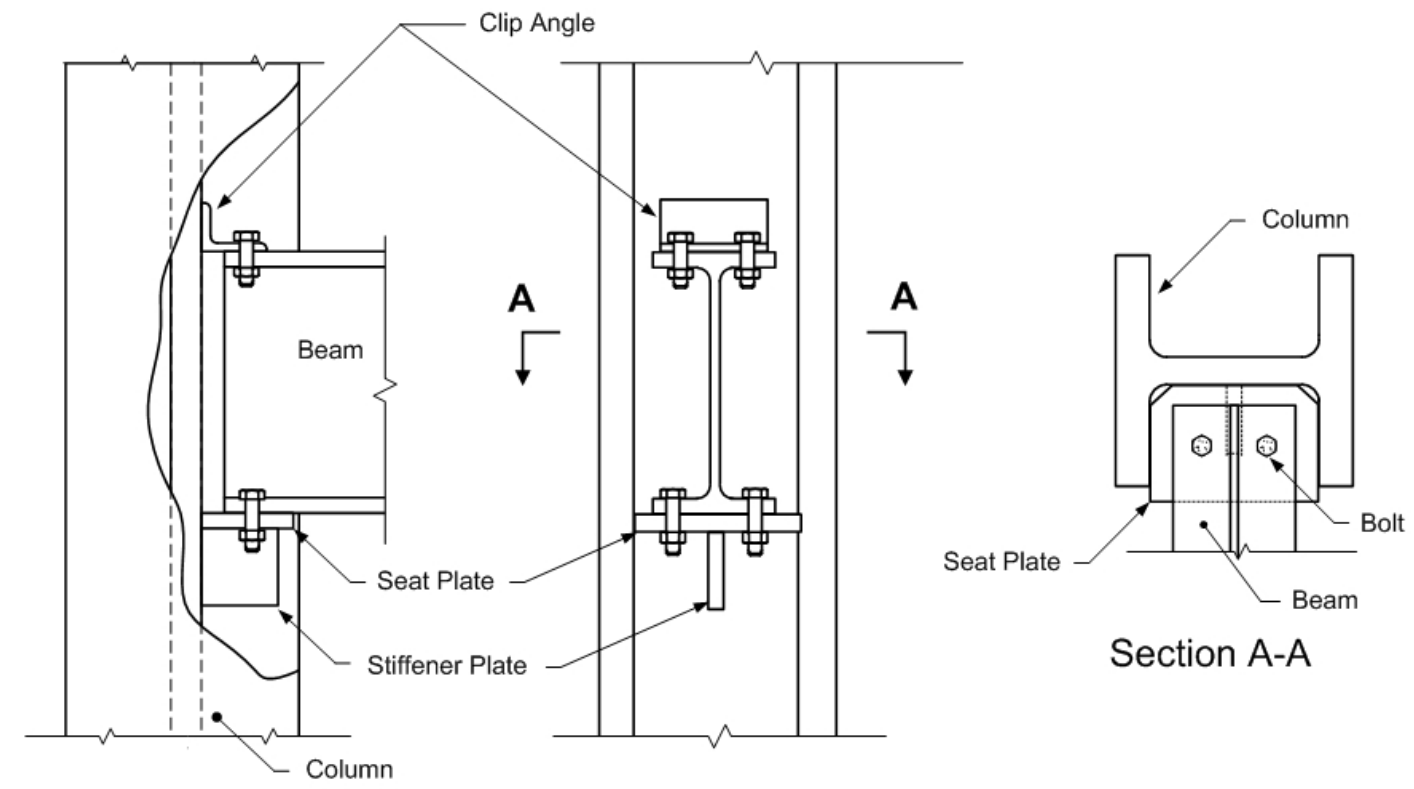

Based on fabrication shop drawings (Frankel 1985a)

Figure 2-19. Schematic drawing of a seated connection with top clip (STC).

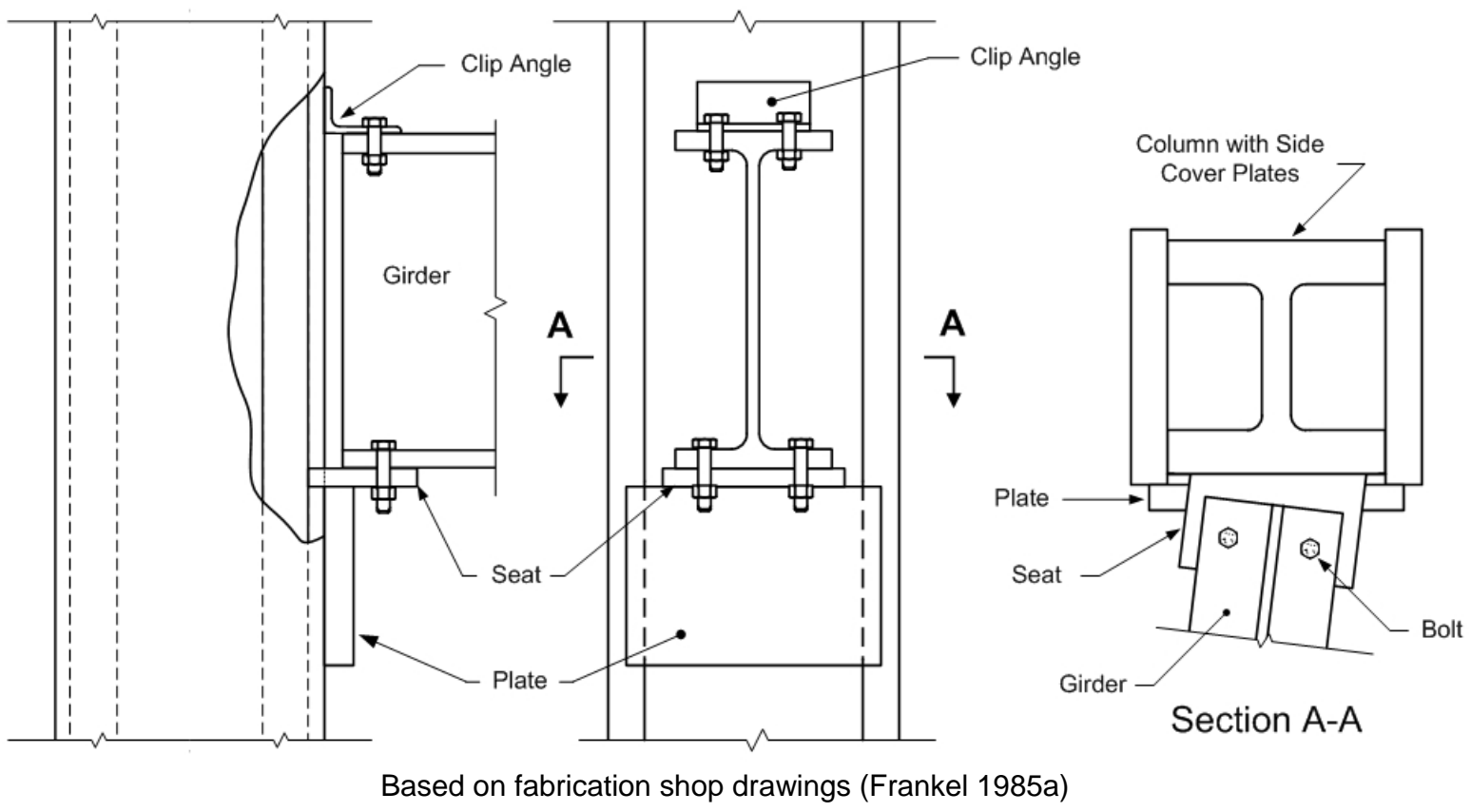

Figure 2-20. Schematic drawing of the seated connection at Column 79. 


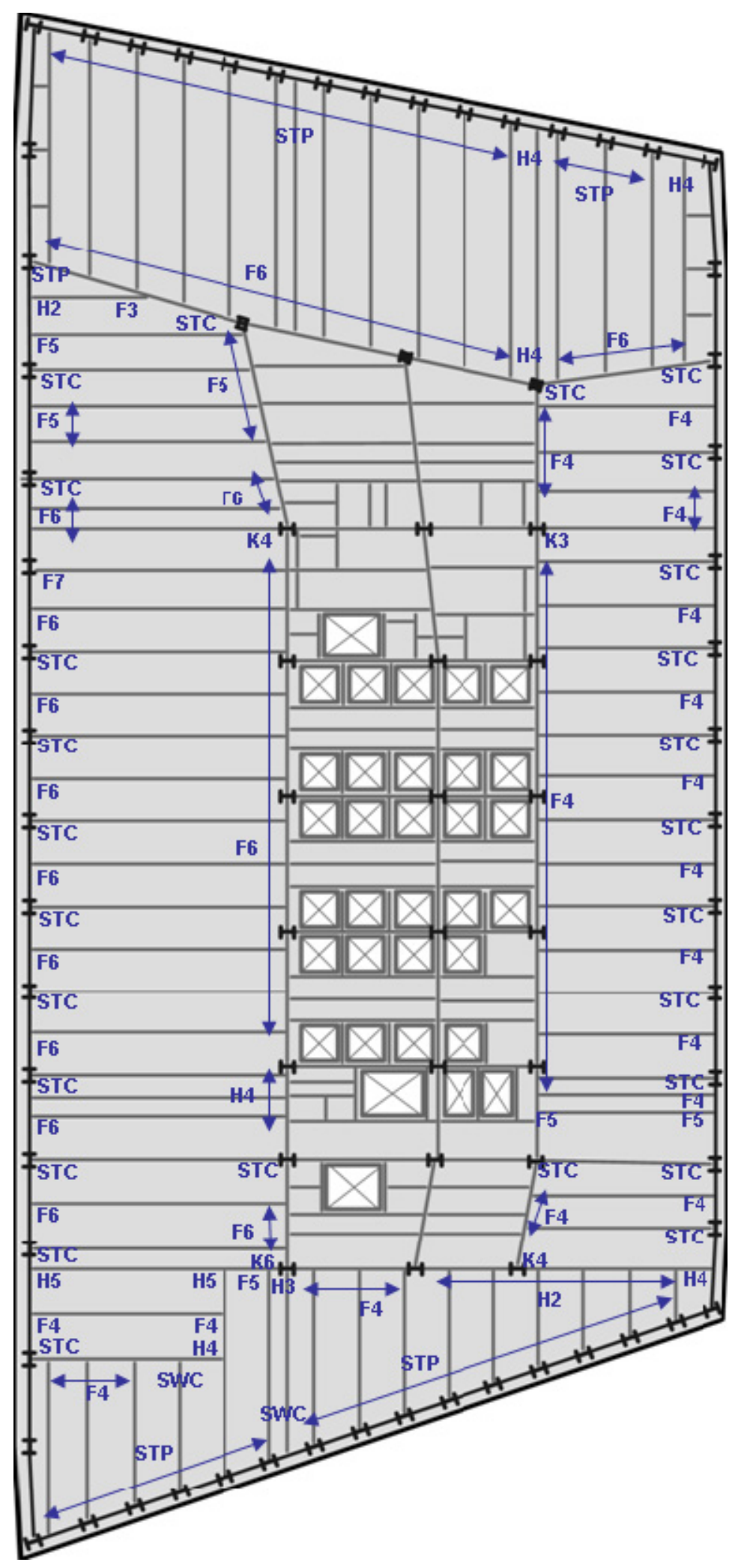

Based on fabrication shop drawings (Frankel 1985a)

Figure 2-21. Typical tenant floor framing connections. 


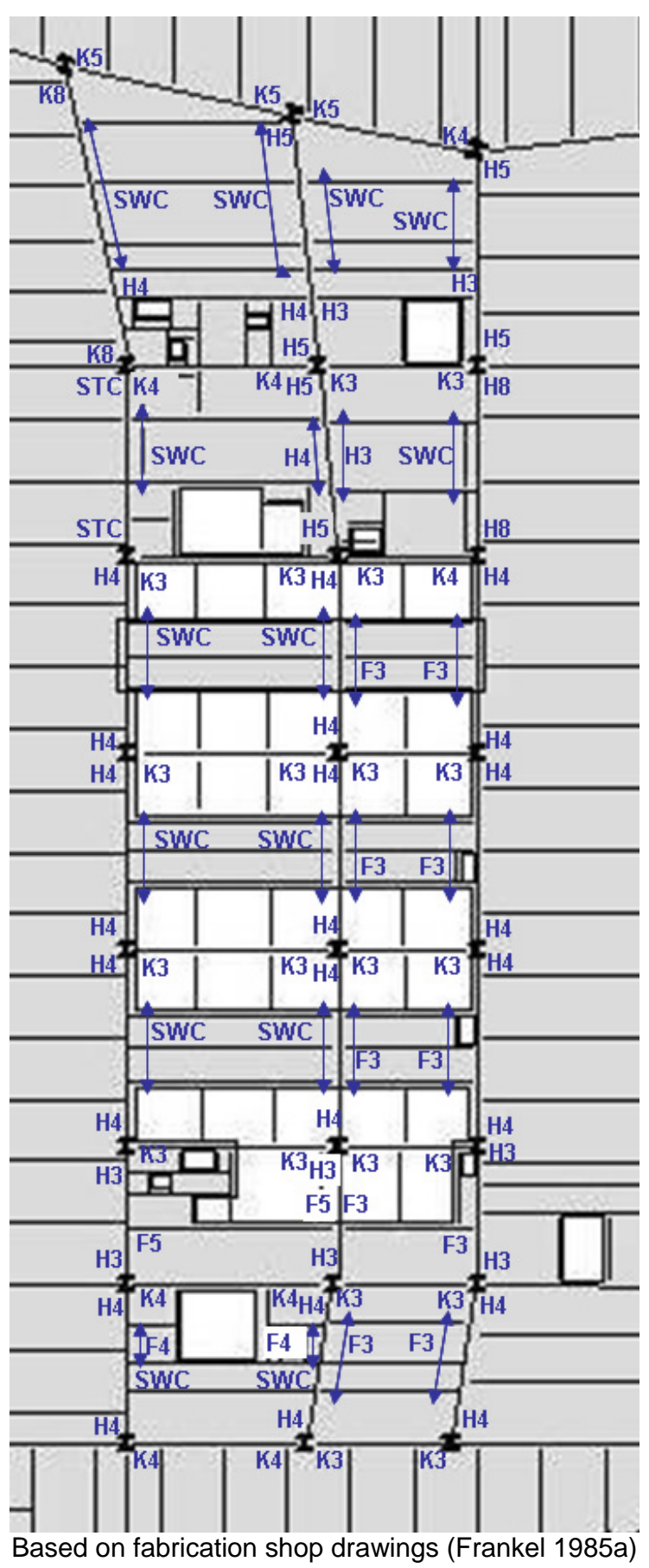

Figure 2-22. Typical core floor framing connections.

\subsubsection{Columns}

The interior columns were primarily rolled wide-flange shapes of Grade 36 or 50 steel. As the loads increased toward the base of the building, many of the column sizes were increased through the use of 
built-up shapes. Built-up columns had a W14x730 section ${ }^{2}$ with side cover plates welded to the flanges (to form a box), or web plates welded between the flanges, as shown in Figure 2-23. The plate welds were specified to be continuous fillet welds at the side cover plates and the web plates. Plate thickness ranged from 1.5 in to 8 in. Plate thickness t (in.) and steel grade were specified as follows:

$\begin{array}{ll}2<\mathrm{t}<4 & \text { ASTM A588 Grade 50 } \\ 4<\mathrm{t}<6 & \text { ASTM A572 Grade 42 } \\ \mathrm{t}>6 & \text { ASTM A588 Grade 42 }\end{array}$

Side cover plate

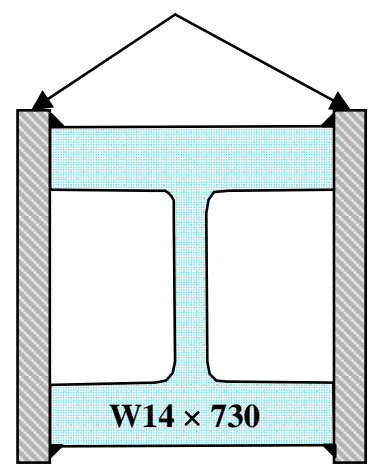

Based on structural drawings (Cantor 1985)
Web plate

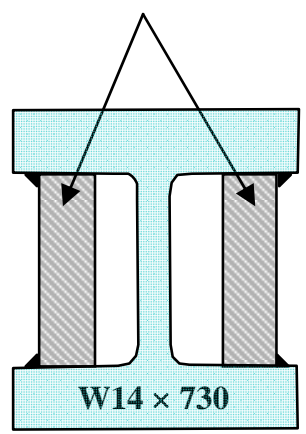

Figure 2-23. Typical built-up column details.

Each interior column was spliced every two stories. Typical interior column splices had milled ends and splice plates were welded or bolted to the outside of the column web and flanges. Built-up columns were also milled at their bearing ends but the splice plates were fillet welded to the cover plate or web plate.

Exterior columns were nominally 14 in. W shapes (W14) of ASTM A36 steel. Exterior column splices were similar to the interior column splices.

\subsubsection{Column Transfer Trusses and Girders}

The layout of the foundation substructure and Con Edison columns did not align with the column layout in the upper portion of WTC 7. Therefore, a series of column transfers were constructed. These transfers occurred primarily between Floors 5 and 7. See Figure 2-24 for a schematic rendering of the transfers.

Columns 47 through 54, at the north facade, were transferred at Floor 7 by cantilever girders to bring them in line with the substation columns, which were offset $6 \mathrm{ft} 9 \mathrm{in}$. to the south. The cantilever girders spanned an additional $46 \mathrm{ft}$, where they were supported by the north side core columns. The easternmost cantilever girder was connected to Truss 1 , and the westernmost cantilever girder was connected to Truss 3 (Figure 2-24).

\footnotetext{
${ }^{2} \mathrm{~W} 14 \times 730$ refers to wide flange section that is nominally $14 \mathrm{in}$. deep end weighs $730 \mathrm{lb} / \mathrm{ft}$.
} 


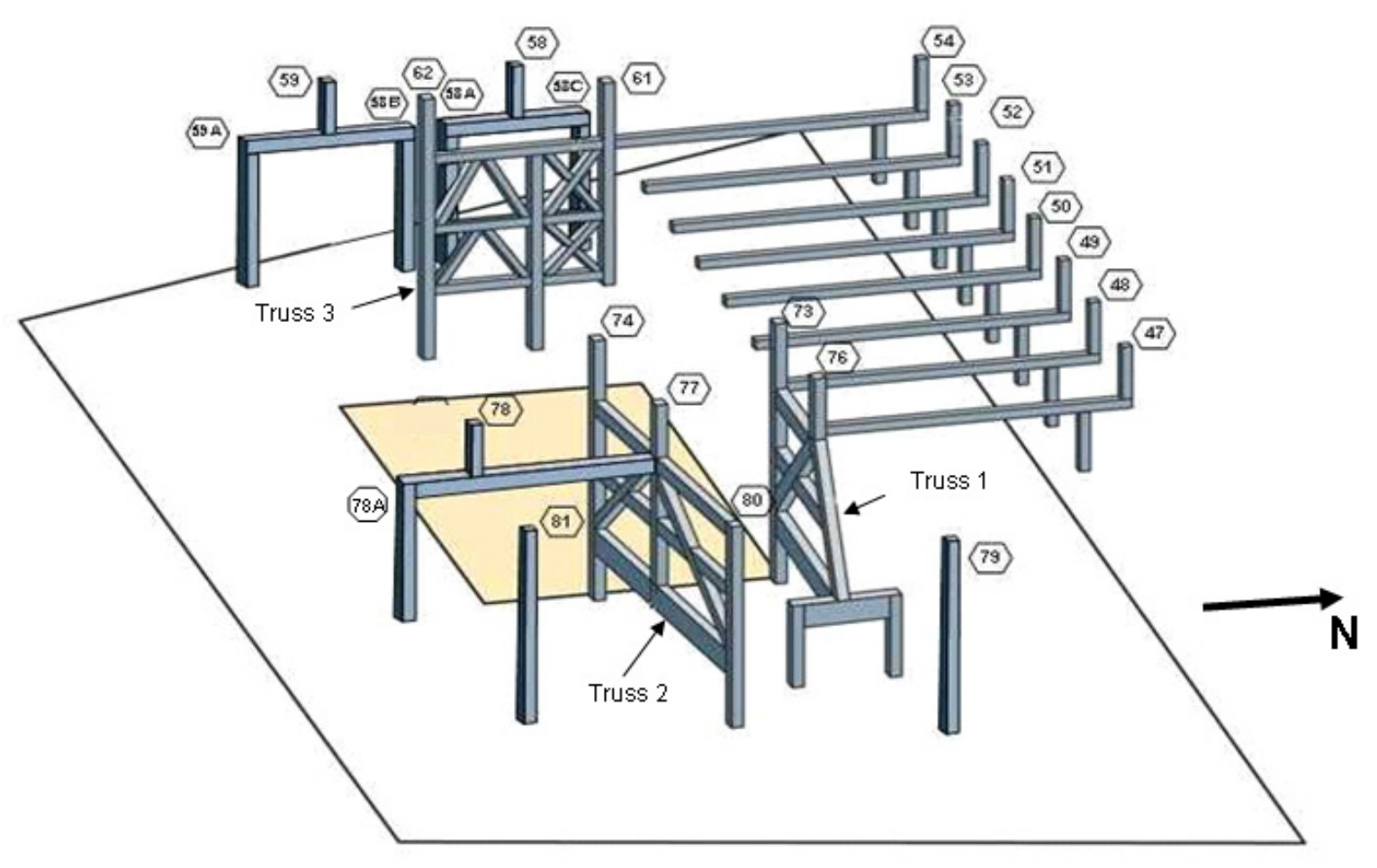

Source: McAllister 2002

Figure 2-24. 3D schematic view of transfer trusses and girders between Floors 5 and 7.

Column 76 was supported at Floor 7 by Truss 1 . The west side of Truss 1 was supported by Column 73, while the east side was supported by a transfer girder oriented in the north-south direction which was, in turn, supported by Columns E3 and E4 at Floor 5.

Columns 58, 59, and 78 were transferred by girders at Floor 7 . Column 77 and the transfer girder supporting Column 78 were supported by Truss 2. Truss 2 was supported by Column 74 at its west end and by Column 80 at its east end.

Column 61 was supported by Truss 3. Truss 3 ran north-south and was supported by Columns 62 and 61A. Truss 3 had a $10 \mathrm{ft}$ cantilever span between Column 61 and Column 61A and an $18 \mathrm{ft}$ back span to Column 62.

\subsubsection{Lateral Load Resisting System}

Above Floor 7, WTC 7 had an exterior moment frame. Column trees were fabricated for the east and west facades with bolted field splices at the spandrel beam midspans. On the north and south facades, the spandrel beams had moment resisting bolted flange and web connections.

At Floors 5 to 7 and Floors 22 to 24, there was a perimeter belt truss, shown in Figure 2-25. Below Floor 7 there was a combination of moment and braced frames around the exterior, and a series of braced frames in the core, as shown in Figure 2-26. The reinforced diaphragms of Floors 5 and 7 transferred in- 
plane loads from the exterior to the core. Above the loading dock at the south facade, two of the columns hung from the belt truss at Floors 5 through 7 . Above the Con Edison vault at the north facade, eight columns also hung from the belt truss between Floors 5 and 7.

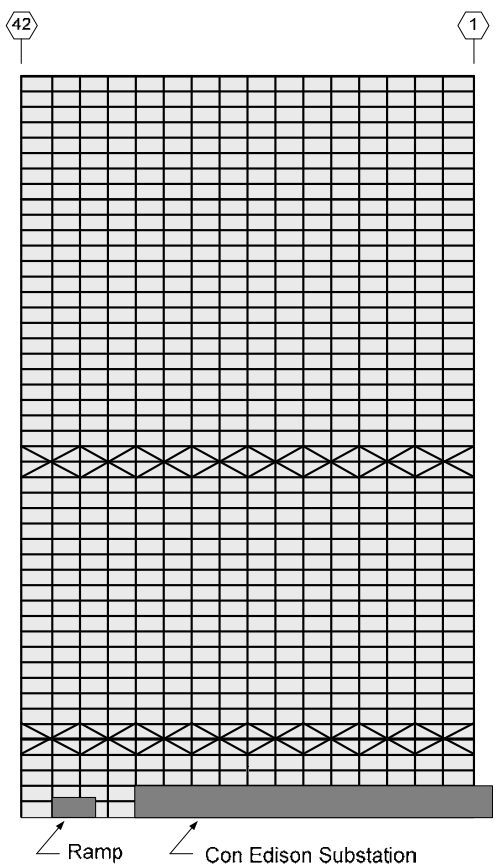

North Elevation

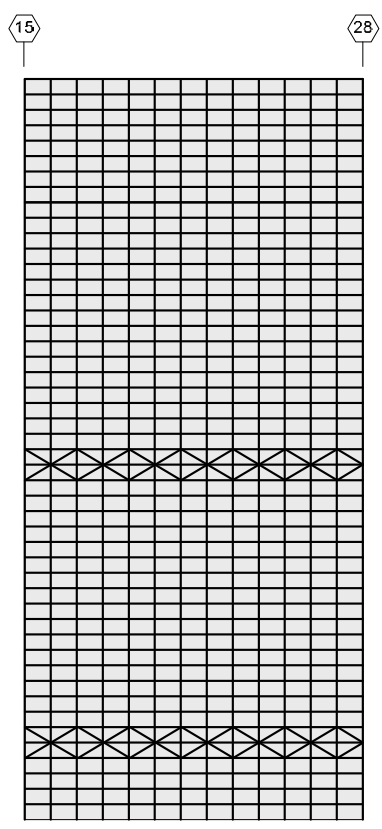

South Elevation
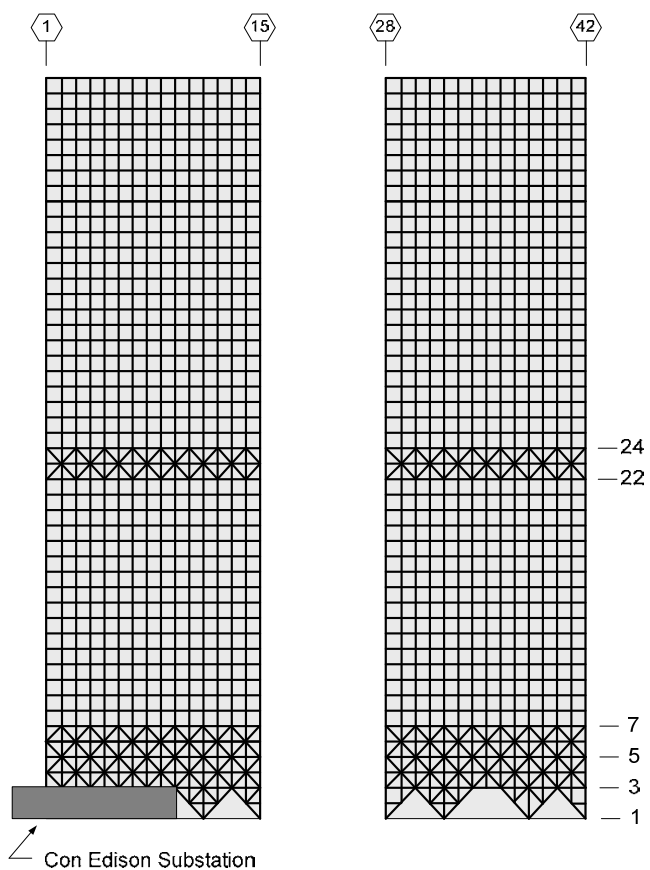

West Elevation

East Elevation

Based on erection drawings (Frankel 1985)

Figure 2-25. Exterior lateral load resisting system elevations.
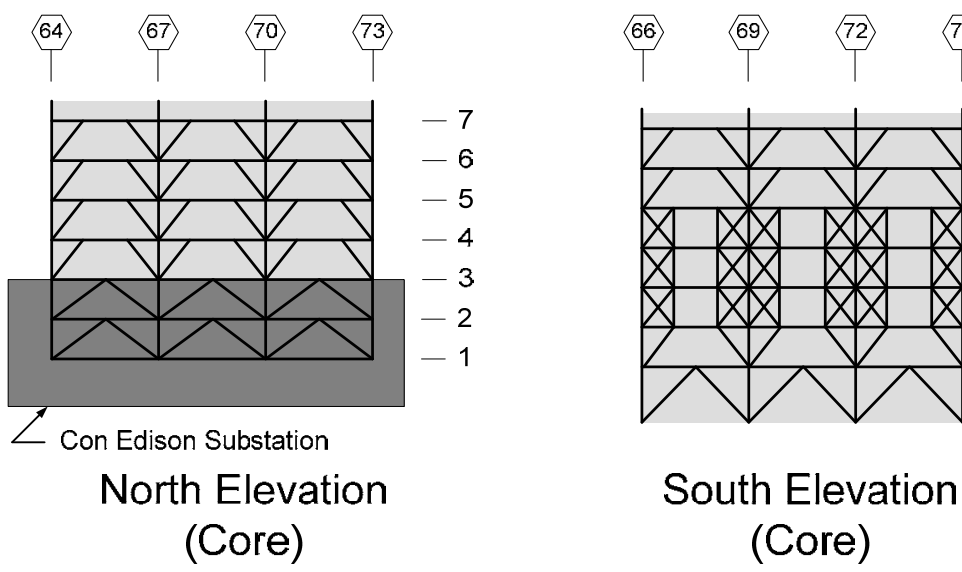

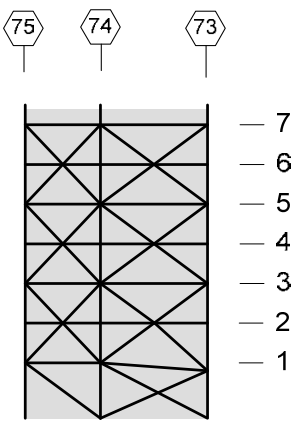

East Elevation

(Core)

Based on erection drawings (Frankel 1985)

Figure 2-26. Interior lateral load resisting system. 


\subsection{PASSIVE FIRE PROTECTION}

A detailed discussion of fire protection provisions for WTC 7, including applicable codes and standards, was provided in NIST NCSTAR 1-1. This section describes the sprayed fire-resistive materials (SFRM) and fireblocking applied to the structural system.

\subsubsection{Fire Resistance Requirements ${ }^{3}$}

Fire resistance requirements in the building codes are greatest for structural members that are essential to the stability of the building as a whole. These include columns and other major gravity load carrying members that connect directly to columns such as girders and trusses. For various construction classes, the building codes specify different fire resistance ratings. The building codes reviewed all specify fire resistance ratings for high-rise office occupancies as follows:

- $\quad$ Type $1 \mathrm{~A}$

- Columns: $4 \mathrm{~h}$ (supporting more than one floor)

- Beams: 3 h (floor construction)

- $\quad$ Type 1B

- Columns: $3 \mathrm{~h}$ (supporting more than one floor)

- Beams: 2 h (floor construction)

- $\quad$ Type 1C (for sprinklered buildings only)

- Columns: $2 \mathrm{~h}$ (supporting more than one floor)

- Beams: 11/2 h (floor construction)

The choice among permitted construction classes for a particular building is made by the architect and/or the owner. Thus, an unsprinklered high-rise office building that was designed according to the 1968 version of the NYC Building Code could follow either Type 1A or 1B. If designed subsequent to the passage of Local Law 16 (effective in 1984), a high-rise office building would have to be sprinklered and could follow Type 1C as a minimum classification. Similar reductions in the minimum required fire resistance ratings for sprinklered buildings were found in all model building codes over this period, as requirements for fire sprinklers, especially in high-rise buildings, had become common.

The 1968 NYCBC, Section C26-501.1 required that,

"Samples of all materials or assemblies required by this code to have a fire-resistance rating, ... shall be tested under the applicable test procedures specified herein ... . The fire-resistance rating of materials and assemblies listed in reference standard RS 5-1 [which references ASTM E 119] may be used to determine conformance with the fire resistance requirements of this code.”

\footnotetext{
${ }^{3}$ The material in this section is from NIST NCSTAR 1-1, Section 9.1.3. It is repeated here for the reader's convenience.
} 
In traditional practice, the architect (sometimes different from the design architect, called the code architect or architect of record) specifies the fire resistance ratings needed to comply with the building code. The required ratings are normally not shown on the architectural drawings (although the construction type may be); rather, they are shown in the supporting material submitted to the building department for plans review.

Building codes require that the fire resistance rating of building elements be determined in accordance with test procedures set forth in ASTM E 119 (ASTM 2007) or by alternate approved procedures. In some cases the architect may choose to use an assembly that has already been tested and rated. Such assemblies are listed by testing laboratories in directories, databases accessed on test laboratory web sites, or in test reports available from manufacturers of materials used in the assemblies such as the producers of SFRM products. These sources are very detailed and indicate the thickness of the specific product tested that is required to achieve a specific hourly rating.

An additional variable that affects the needed thickness of SFRM is whether the assembly is thermally restrained (see ASTM 2007, Appendix X.3 Guide for Determining Conditions of Restraint for Floor and Roof Assemblies and for Individual Beams). It is traditionally assumed that an assembly that is thermally restrained requires less SFRM. Note that the NIST tests of the floor truss assemblies used in the WTC towers showed the opposite (NIST NCSTAR 1-6B). However, the determination of whether a floor system should be considered thermally restrained needs to be specified by the structural engineer.

In some cases, it is not clear who actually determines the required thickness of SFRM material. If the bid specifications for the fireproofing contract simply require the assemblies to be sprayed to achieve a specific hourly rating (which may be the case where a specific product is not identified to be used), then the thickness determination may be left to the fireproofing contractor.

The UL guide information includes a number of limitations on the application of listed assemblies, including:

- Limits on the size (flange width and web depth, pipe outer diameter) without the use of a mechanical break such as metal lath or fasteners,

- Use of bonding agents or conduct of a bond strength test in accordance with ASTM E 736 whenever the steel is painted (other than a paint specified in the listing),

- $\quad$ Conduct of thickness testing in accordance with ASTM E 605 (ASTM 2006).

Local Law 55 (1976) amended the 1968 NYC Building Code to require that all required, sprayed fireresistive material on structural members, except those encased in concrete, be subjected to a controlled inspection, meaning that the inspection must be conducted under the supervision of a building inspector or a licensed design professional who assumes responsibility for compliance. This provision applied to all installations after the date of enactment (November 1, 1976) and was not retroactive. The inspection included verification of the thickness of the material, its density, and its adhesion, as described in the applicable ASTM Standard E 605. Most building codes contain a requirement that sprayed fire-resistive material that is installed in areas where it is subject to mechanical damage shall be protected and maintained in a serviceable condition. 


\subsubsection{Thermal Insulation Material for WTC 7}

Monokote MK-5 was the SFRM product applied to the structural steel framing and metal deck (see NIST NCSTAR 1-6A, Chapter 6). Monokote MK-5 was a gypsum-based SFRM containing vermiculite aggregate that was manufactured by W.R. Grace and Co. (Cambridge, Massachusetts).

Instructions to bidders ${ }^{4}$ for applying the sprayed fire-resistive materials for WTC 7 listed the required fire resistance ratings, as well as the following criteria:

- $3 \mathrm{~h}$ rating for columns, girders, trusses, and all other steel framing supporting two or more floors.

- $\quad 2 \mathrm{~h}$ rating for fluted steel decking and all floor support structural steel.

- $\quad$ Sprayed-on fireproofing shall be of cementitious type or other asbestos free material of approved type. Monokote as produced by the Zonolite Construction Products Division of W.R. Grace is approved for use.

- $\quad$ Steel to which sprayed-on fireproofing will be applied will be unpainted.

- The size of the structural steel and the rating shall determine the thickness of the SFRM.

- The "Design Information Section” of the Underwriter’s Laboratories "Fire Resistance Index" dated January 1975, and any later revisions and the "Guide for Determining Conditions of Restraint ...” including Appendix C from standard UL 263, shall form the basis of all the required work.

- After application, spray-on fireproofing material will be tested by an independent testing agency, retained and paid for by the Owner.

The contract for applying SFRM to WTC 7 was awarded to E. Patti \& Sons in February 1985. The SFRM product selected by E. Patti \& Sons was MK-5. ${ }^{5}$ Internal correspondence from W.R. Grace, dated April 29, $1986^{6}$, which documented a site visit and discussion with E. Patti \& Sons, stated that 7/16 in. of MK-5 was being applied to the floor beams, and 3/8 in. was being applied to the metal decks.

The UL fire resistance ratings used to determine the appropriate SFRM thickness to apply to the columns, floor beams, and metal deck was BXUV.D739. Table 2-1 lists SFRM thicknesses for the structural components in WTC 7.

\footnotetext{
${ }^{4}$ Instructions to Bidders for Sprayed-on SFRM for WTC 7, Emery Roth \& Sons, November 9, 1984.

${ }^{5}$ Letter from Grace Construction Products Division to Tishman Construction Corporation, January 14, 1986.

${ }^{6}$ Grace Construction Products Division Internal Memorandum, from a Technical Service Specialist to internal staff, April 29, 1986.
} 
Table 2-1. UL Fire Resistance Directory ratings for columns and composite floors (UL 1983).

\begin{tabular}{|l|c|c|c|l|}
\hline & Reference & Rating & $\begin{array}{c}\text { Thickness } \\
\text { (in.) }\end{array}$ & \multicolumn{1}{c|}{ Notes } \\
\hline Composite Floor & BXUV.D739 & $2 \mathrm{~h}$ & & For W8x28 steel beams or larger, a normal weight \\
Beams & & $1 / 2$ & concrete slab, and MK-5 SFRM. \\
Deck & & & $3 / 8$ & \\
\hline Column & BXUV.X704 & $3 \mathrm{~h}$ & $7 / 8$ & For W14x228 steel columns or larger. \\
\hline
\end{tabular}

The SFRM application was inspected by Testwell Craig Laboratories, Inc. NIST obtained a set of Inspection Reports ${ }^{7}$ with SFRM thickness measurements for the columns, floor beams, and metal deck showing measurement data taken at Floors 3 through 12, 32 through 40, and 42 through 47. The inspection reports include plan views of the WTC 7 floors indicating where measurements were taken. SFRM thicknesses were listed in the Inspection Reports and were presumably intended for the inspectors who were determining minimum allowable SFRM thicknesses.

The measurements gave the statistics shown in Table 2-2. The column measurements were based on data listed for Floors 3 to 12 and 32 to 40 because the columns at Floors 42 to 47 were smaller than the W14x228 minimum column size. The metal deck measurements used only the data associated with the 3/8 in. SFRM thickness.

Table 2-2. Statistics of SFRM thickness measurements on steel columns, floor beams, and metal decks in WTC 7.

\begin{tabular}{|l|c|c|c|c|c|c|c|}
\hline & $\begin{array}{c}\text { Specified } \\
\text { Thickness (in.) }\end{array}$ & Data Points & $\begin{array}{c}\text { Average } \\
\text { (in.) }\end{array}$ & $\begin{array}{c}\text { Standard } \\
\text { Deviation (in.) }\end{array}$ & COV & $\begin{array}{c}\text { Minimum } \\
\text { (in.) }\end{array}$ & $\begin{array}{c}\text { Maximum } \\
\text { (in.) }\end{array}$ \\
\hline Column & 0.875 & 51 & 0.955 & 0.155 & 0.162 & 0.85 & 2.0 \\
\hline $\begin{array}{l}\text { Floor } \\
\text { Beams }\end{array}$ & 0.5 & 82 & 0.534 & 0.054 & 0.101 & 0.4 & 0.775 \\
\hline Metal Deck & 0.375 & 63 & 0.416 & 0.033 & 0.079 & 0.375 & 0.5 \\
\hline
\end{tabular}

SFRM thicknesses were needed for the thermal finite element analyses of Floors 7 to 14, where uncontrolled fires burned until the building collapsed. The thermal analyses used the gas temperatures from the FDS analyses, which modeled the growth and spread of the fires on Floors 7, 8, and 9, and 11, 12, and 13. The gas temperatures were applied to the surface of the SFRM coating in the finite element analyses (Chapter 10) to determine temperature histories for the steel framing and concrete slab.

NIST used the following uniform thicknesses in the thermal analyses, based on the available information SFRM thicknesses, the lack of gaps in the applied SFRM, and the relatively smooth surface of applied MK-5 to the steel beams and columns (Section 2.5.3):

- $\quad$ 7/8 in. on columns

- $7 / 16$ in. on floor beams

- $\quad 3 / 8$ in. on metal deck

\footnotetext{
7 Inspection Reports prepared by Testwell Craig Laboratories Inc. for Silverstein Development Corporation, 7 World Trade Center, dated from January 1986 to November 1986.
} 
A 7/16 in. thickness was used in the thermal analyses for the floor beams, based on correspondence from W.R. Grace that indicated this thickness was being applied by the contractor. It was later determined that the thickness that was applied was $1 / 2$ in., rather than 7/16 in. This difference has little, if any, effect on the heating of the floor beams, as shown in Section 11.4.1.

\subsubsection{SFRM Condition on September 11, 2001}

\section{As Applied}

The review of available documents and witness accounts indicated that the condition of the SFRM in WTC 7 prior to the events of September 11, 2001, was adequate and well-maintained. The photographs in Figure 2-27 through Figure 2-29 show the condition of the SFRM on Floors 5, 33, and 36 during renovations in 1989. Review of similar photos showed SFRM removal in selected areas for construction purposes, but the general condition of the SFRM in the photos reviewed was adequate, with an even application and no visible gaps.

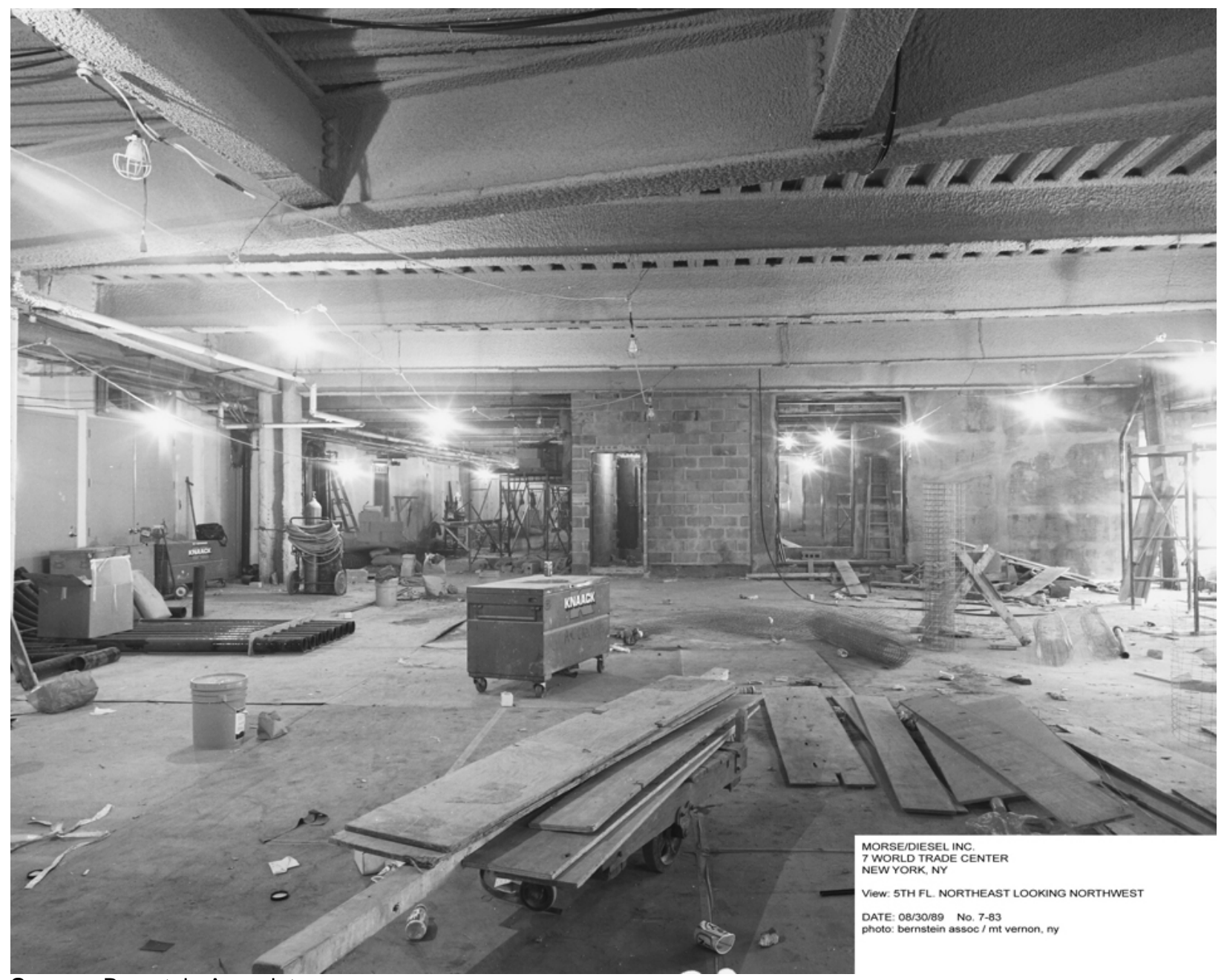

Source: Bernstein Associates

Figure 2-27. Photograph of Floor 5 during renovations showing SFRM on steel beams and metal deck, dated 08/30/89. 


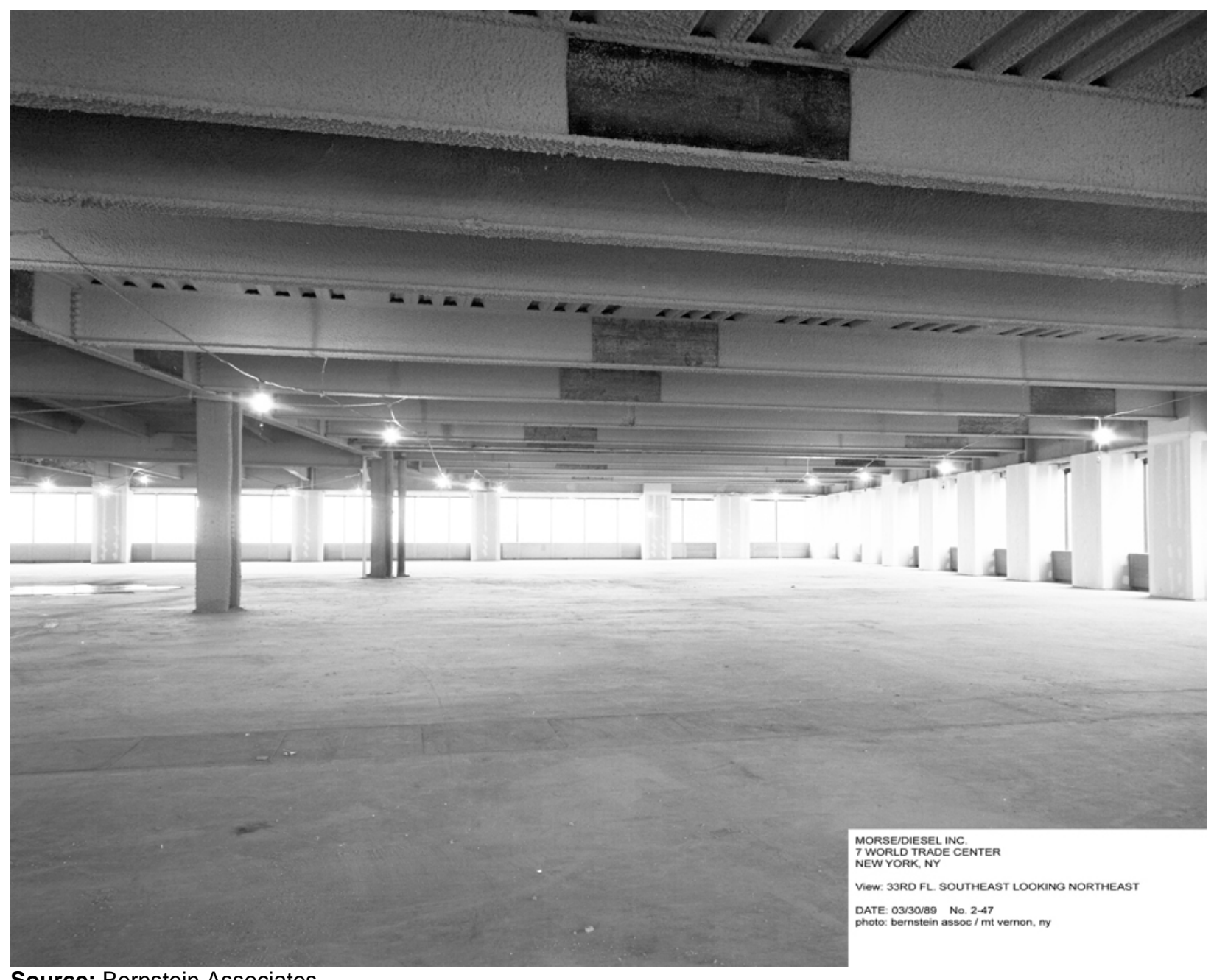

Source: Bernstein Associates

Figure 2-28. Photograph of Floor 33 during renovations showing SFRM on steel beams and metal deck, dated 03/30/89. 


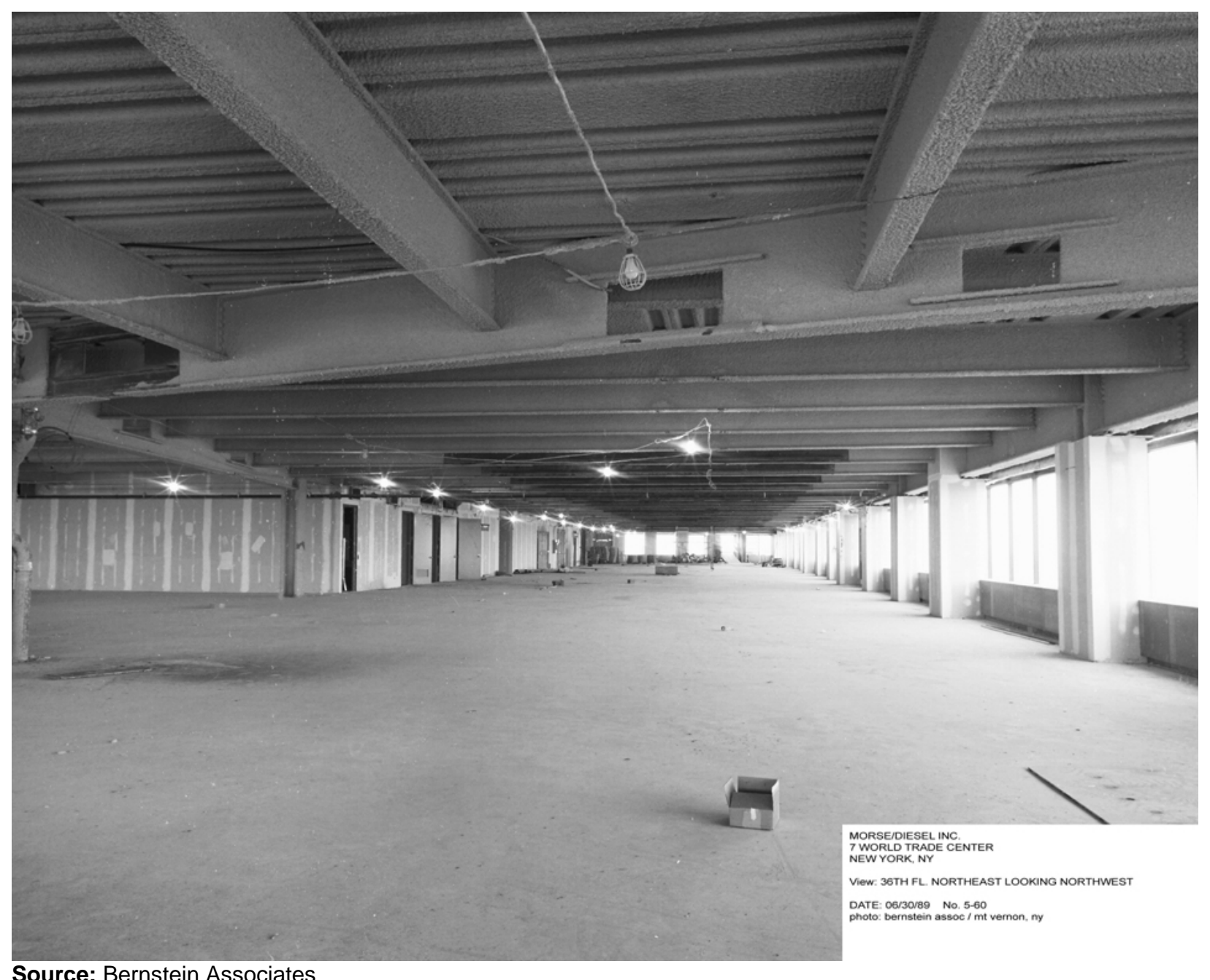

Figure 2-29. Photograph of Floor 36 during renovations, showing SFRM on steel beams and metal deck, looking dated 06/30/89.

\section{After Debris Impact}

After the dust and smoke cleared following the collapse of WTC 1, damage to WTC 7 was observed primarily on the south face near the southwest corner, between Floors 5 and 17 (Section 5.5). Seven exterior columns were severed (six columns on the south face and one column on the west face). The interior damage was not visible but, based on engineering judgment and interview accounts by individuals that were in or around WTC 7, estimates of interior structural damage between the exterior walls and the core were made. Chapter 5 describes the damage observed from photos and videos, and the structural damage in the southwest region is summarized in Section 5.5.3.

The WTC 7 structural damage resulted from debris falling from WTC 1. In a similar fashion, the building located at 130 Liberty Street (referred to as Deutsche Bank or the Bankers Trust building), was damaged by falling exterior panels from WTC 2 as it collapsed. NIST was granted access to inspect floors where damage occurred in the building on 130 Liberty Street on August 21 and 22, 2006. The debris from WTC 2 had penetrated the north face of the 130 Liberty Street building and caused damage to Floors 9 
through 22, as shown in Figure 2-30 and Figure 2-31. The north face had severed spandrel beams between exterior columns, with the damage extending into the interior that grew in magnitude as the debris fell. Figure 2-31 shows that the floor beams framing into intact exterior columns remained in place, but the SFRM in the immediate vicinity of the damage was dislodged.

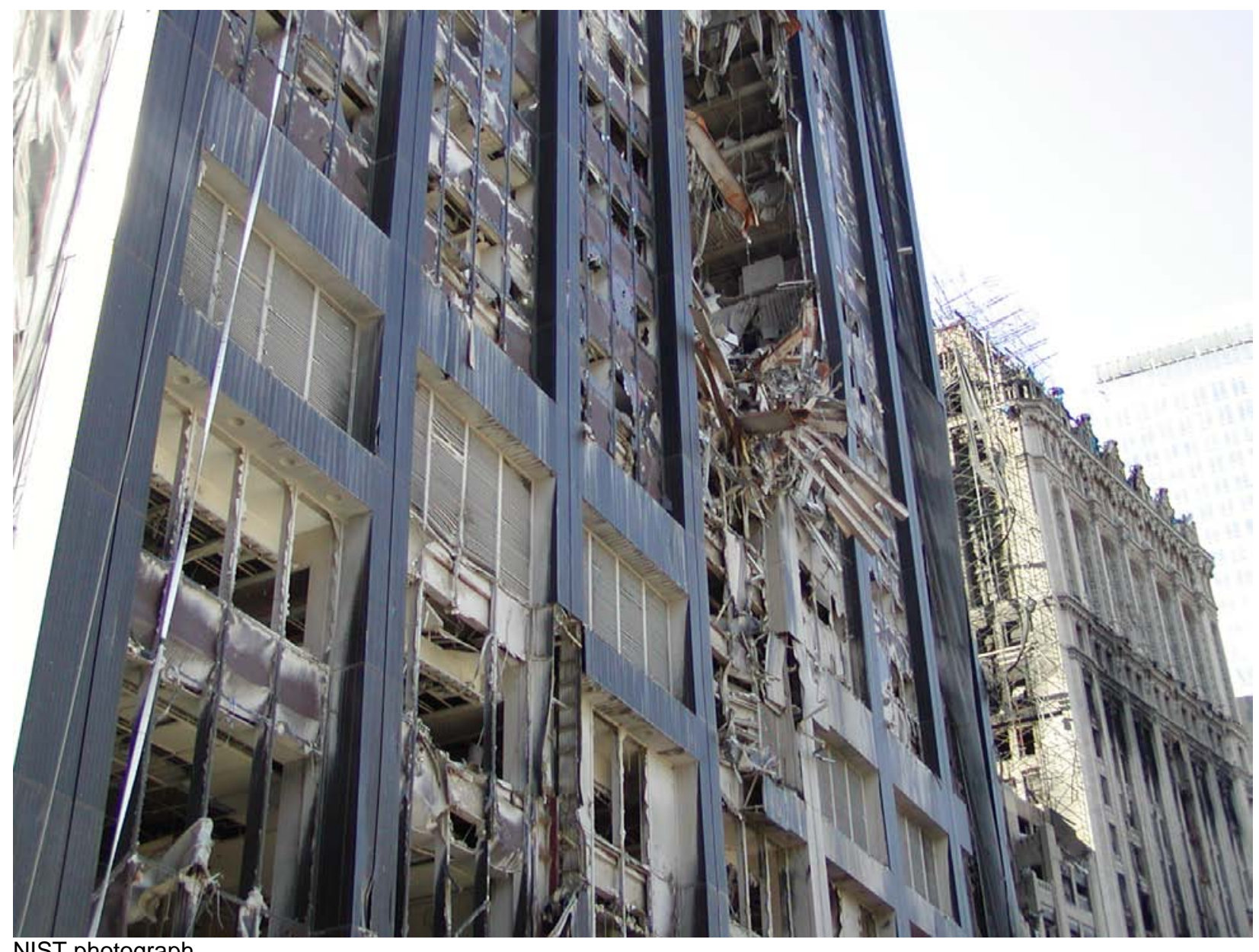

NIST photograph

Figure 2-30. Exterior view of damage to the north face of 130 Liberty Street by debris falling from WTC 2.

Figure 2-32 shows the extent of the damage that was documented by the FEMA WTC Building Performance Study (McAllister 2002). Immediately after the damage was incurred, the ceilings and column enclosures were still in place, so possible SFRM damage in other parts of the building could not be observed. 


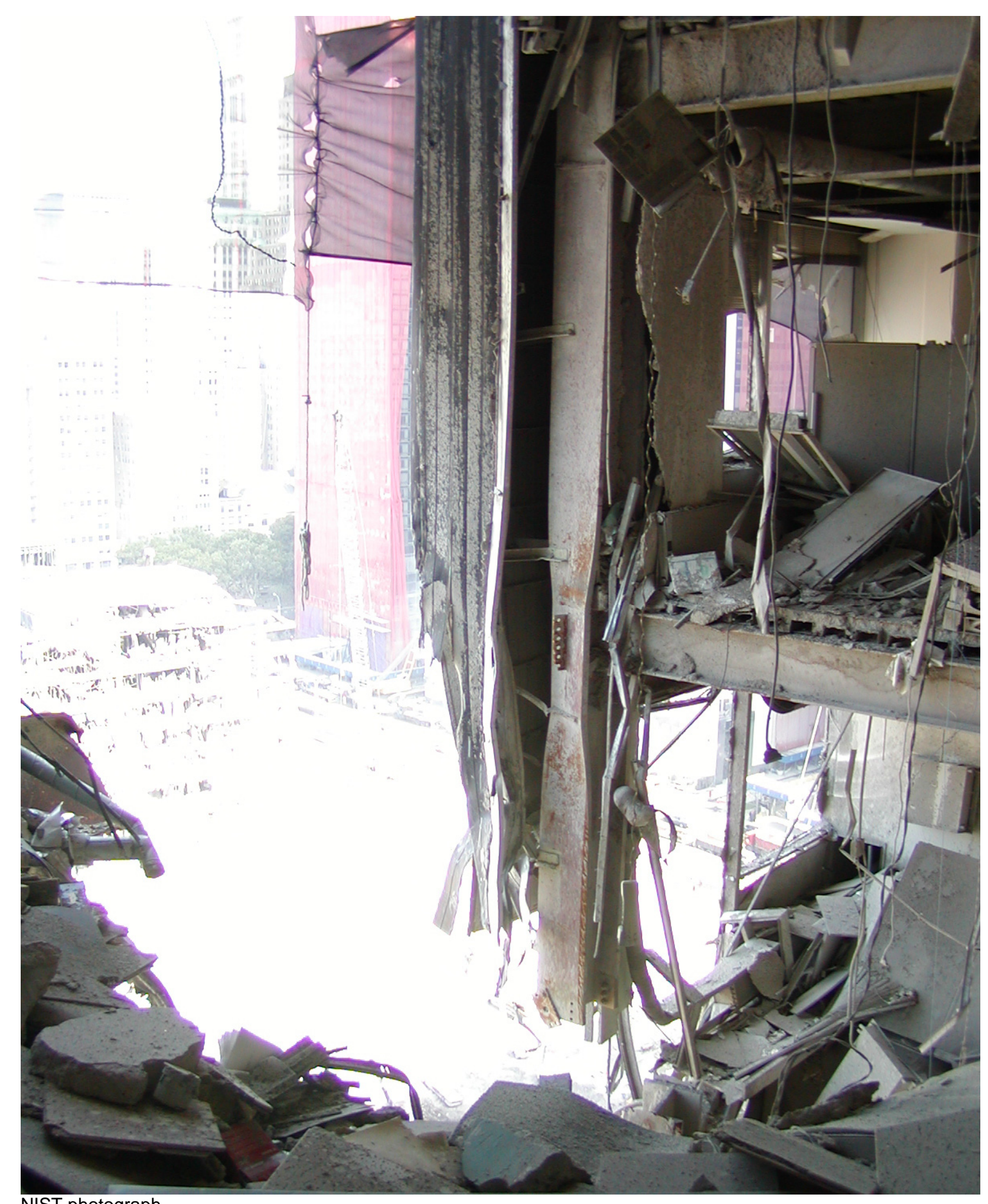

NIST photograph

Figure 2-31. Interior view of damage to the north face of 130 Liberty Street by debris falling from WTC 2. 

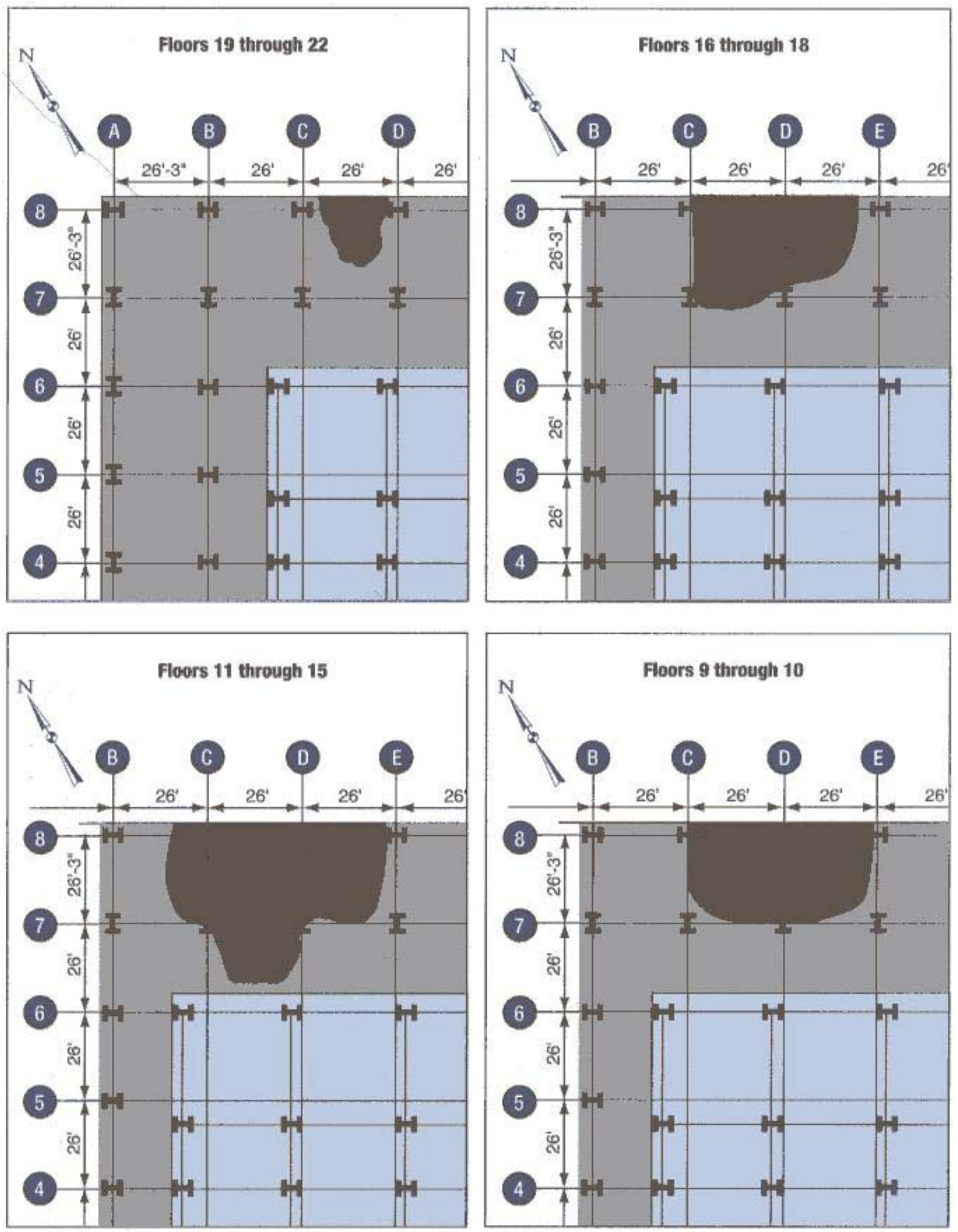

Figure 6-5 Approximate zones of damage - 19th through 22nd floors, 16th through 18th floars, 11th through 15th floors, and 9th through 10th floors.

Source: McAllister 2002

Figure 2-32. Damaged areas from debris impact on the north face of the building at 130 Liberty Street. 
Figure 2-33 shows a typical floor plan with the column line numbering that was used to indicate the locations that were examined. SFRM had been applied to all columns, floor beams, and steel deck observed. The floor beams and metal deck appeared to have had a uniform coating of approximately $3 / 8$ inch to $1 / 2$ inch (visual estimate), as shown in Figure 2-34. The location of the photograph was near F2 on Floor 16. The columns appeared to have had heavier coatings that ranged from approximately 1 in. to several inches (visual estimate). Figure 2-35 was taken at location B6 on Floor 16. In the photograph, the column coatings tended to be thicker at the flange tips. Primer was observed on floor beams and columns in some areas with missing SFRM.

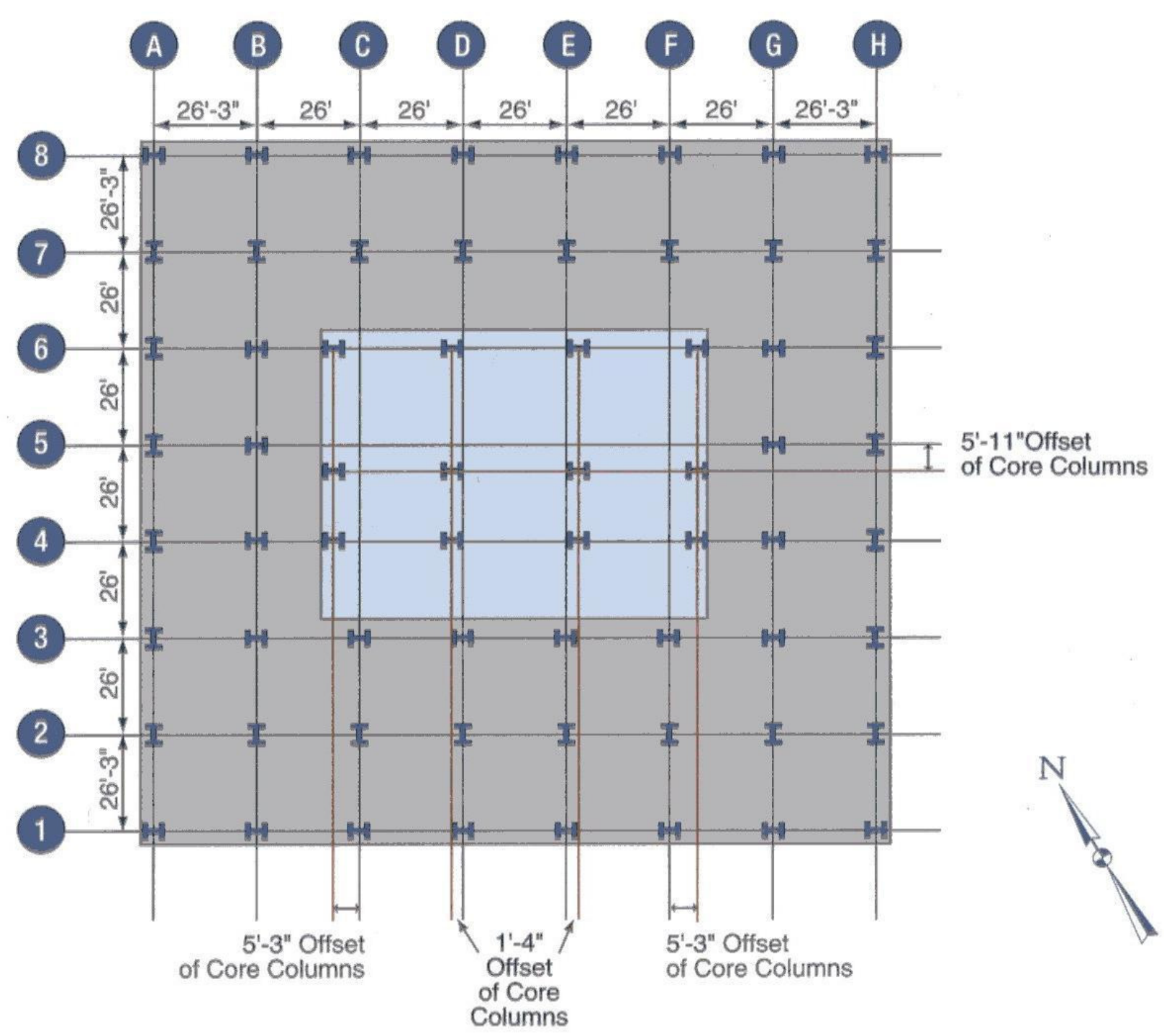

Source: McAllister 2002

\section{Figure 2-33. Typical floor plan for the building at 130 Liberty Street.}

The appearance of the SFRM was consistent with that of a cementitious product, such as a Monokote product. Grace Monokote products MK-4 and MK-5 were introduced to the marketplace in 1973. The building construction was completed in 1974 (http://www.wirednewyork.com/wtc/130liberty). 


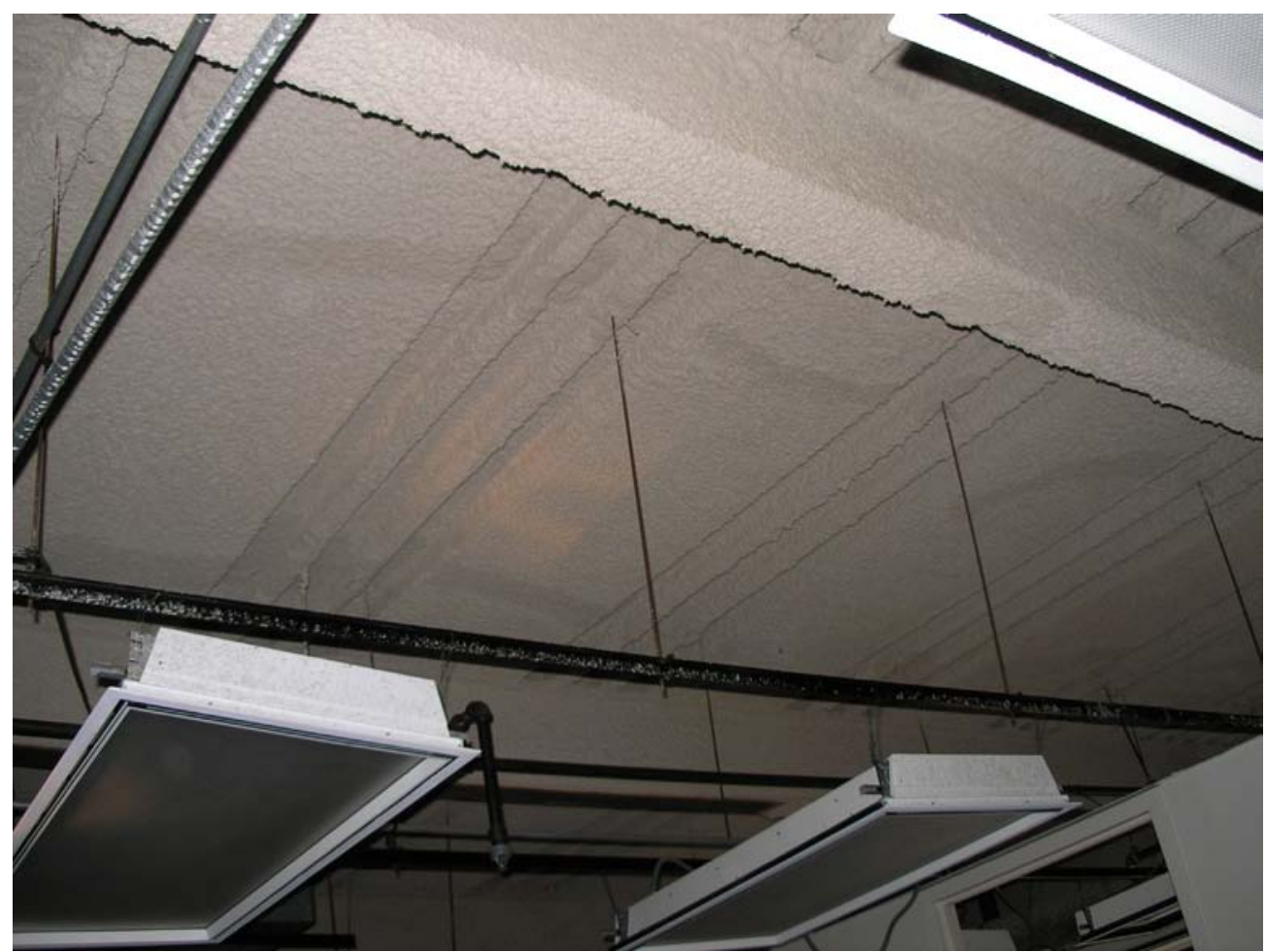

Figure 2-34. Floor beams with intact SFRM.

NIST photograph

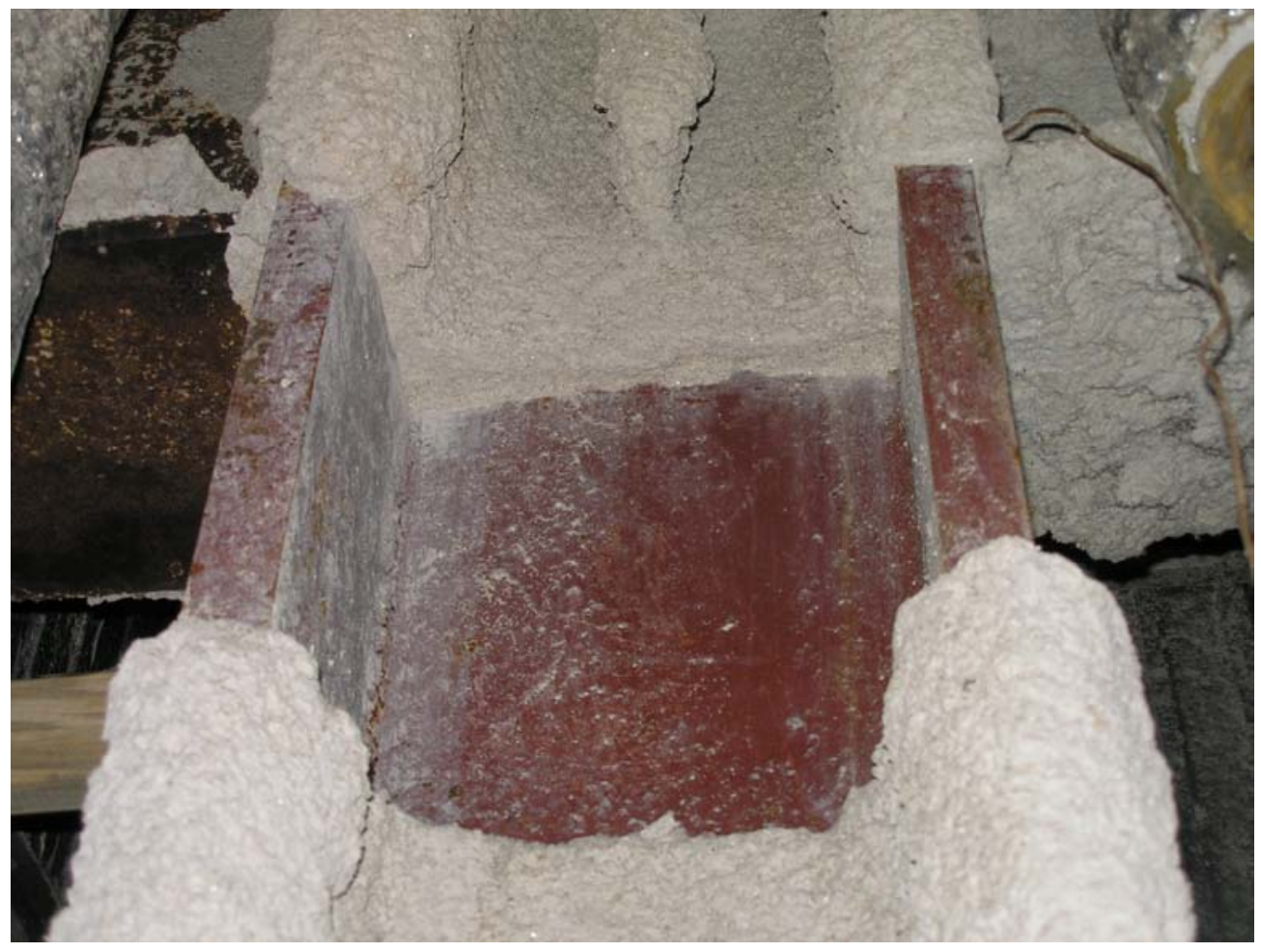

Figure 2-35. Column with removed SFRM and intact primer.

NIST photograph 
In general, the SFRM was observed to be intact a few feet away from the area of structural damage. In some locations, SFRM had been removed and sampled for tests of contaminants in the building (e.g., square shape of removed area). There were also some areas where SFRM was missing from the bottom surface of the lower flanges of floor beams. It was not always clear whether the SFRM had fallen off due to an event unrelated to the sampling or if it had been dislodged while samples were being taken.

Based on these observations, NIST determined that there was no basis for assuming SFRM damage in WTC 7 caused by the debris impact, except in the immediate vicinity of the damage.

\subsubsection{Firestopping}

Firestopping is used to prevent the vertical spread of heat, flames, and smoke through openings and gaps to the floor above. Any penetration through the floor slab, such as those for plumbing and electrical conduits, or gaps between the floor slab and framing, such as that between a curtain wall and the floor slab, should be sealed with firestopping materials to provide the fire rating required by codes and standards. Firestopping materials are varied and may include mineral fibers, sealants, mortar, putties, or other materials or devices to achieve the desired fire rating.

The architectural drawings (Drawing A38) indicated a compressible thermafibre firestop on impaling pins was to be used between the floor slabs and the curtain walls (Roth 1985). The firestopping installation was inspected by Testwell Craig Laboratories, Inc. NIST obtained Firestopping Inspection reports ${ }^{8}$ for Floors 9, 10, and 11 that showed firestopping locations around the core area. The inspections checked firestopping installations at pipe penetrations, wall penetrations, fluted decks over rated walls, and curtain wall penetrations.

NIST located documents that indicated that firestopping material was specified. ${ }^{9}$ NIST obtained interim inspection reports ${ }^{10}$ of the firestopping dated 1986 (i.e., during the construction of WTC 7), but was unable to locate a final inspection report. NIST also obtained documents that indicated an inspection of the firestopping on Floor 23 in 1993 that found gaps ${ }^{11}$, and a subsequent document that said that the application of firestopping material was satisfactory. ${ }^{12}$ NIST was unable to locate documents that appraised the state of the firestopping on other floors.

For the purpose of the fire simulations, NIST assumed that the quality of the firestopping was such that no significant floor-to-floor spread occurred through any gaps that might have existed. The consequences of this assumption are discussed in Section 9.1.2.

\subsection{SUMMARY OF FINDINGS}

Review of the building codes, standards and information on the SFRM resulted in the following findings:

\footnotetext{
${ }^{8}$ Firestopping Inspection reports prepared by Testwell Craig Laboratories Inc. for Silverstein Development Corporation, 7 World Trade Center, November 1986.

${ }^{9}$ Facsimile from Skidmore, Owings, \& Merrill to Solomon Brothers, 5 February 1993.

${ }^{10}$ Firestopping Inspection Engineers Reports, prepared by Testwell Craig Laboratories Inc. for Silverstein Development Corporation, 7 World Trade Center, November 1986.

${ }^{11}$ Letter from SBLM Architects to Silverstein Properties, September 24, 1998.

${ }^{12}$ Letter from IDC Corporation to Silverstein Properties, August 12, 1997.
} 
- The average thickness of the MK-5 SFRM on the columns, based on data available from Testwell Craig Inspection Laboratories Inc., was greater than 7/8 in.

- An MK-5 SFRM thickness of 7/8 in. is consistent with a $3 \mathrm{~h}$ rating for the columns, according to UL BXUV.X704, and a Type 1-B classification (unsprinklered) for the building.

- Correspondence showed that the SFRM contractor, E. Patti \& Sons, planned to apply 7/16 in. of MK-5 SFRM to the floor beams and 3/8 in. of MK-5 SFRM to the metal deck.

- The average MK-5 SFRM thickness measurement on the floor beams and metal deck, based on data available from Testwell Craig Inspection Laboratories Inc., was greater than $1 / 2 \mathrm{in}$. for the beams and $3 / 8$ in. for the metal deck.

- An MK-5 SFRM thickness of 1/2 in. on the floor beams and of 3/8 in. on the metal deck is consistent with a $2 \mathrm{~h}$ rating, according to UL BXUV.D739.

- The NIST survey of the 130 Liberty Street building, damaged by debris impact from the collapse of WTC 2, indicated that the cementitious SFRM was not knocked off by the falling debris, except in the immediate area of damage. For analysis purposes, NIST therefore assumed that the similar SFRM was in place in WTC 7 after the impact of debris from WTC 1.

\section{$2.7 \quad$ REFERENCES}

AISC 1980. Manual of Steel Construction, Eighth Edition, American Institute of Steel Construction Inc. Chicago.

ASTM 2006. Standard Test Methods for Thickness and Density of Sprayed Fire-Resistive Material (SFRM) Applied to Structural Members, ASTM E 605-93 (Reapproved 2006), ASTM International, Conshohocken, PA.

ASTM 2007. Standard Test Methods for Fire Tests of Building Construction and Materials, ASTM E 119-07, ASTM International, Conshohocken, PA.

Cantor 1985. Irwin G. Cantor P.C., Structural Engineers, Structural Drawings, 7 World Trade Center.

Cantor 1988. Irwin G. Cantor P.C., Structural Engineers, Structural Drawings for Salomon Brothers 7 World Trade Center Headquarters.

Frankel 1985. Frankel Steel Limited, Erection Drawings, 7 World Trade Center.

Frankel 1985a. Frankel Steel Limited, Fabrication Shop Drawings, 7 World Trade Center (drawing set was not sealed).

McAllister, T., ed. 2002. World Trade Center Building Performance Study: Data Collection, Preliminary Observations, and Recommendations. FEMA 403. Federal Emergency Management Agency. Washington, DC, May. 
NYCBC (New York City Building Code). 1968. Building Code of the City of New York, 1968 Edition, Gould Publications, Binghamton, NY.

Roth 1985. Emery Roth \& Sons P.C. Architects, Architectural Drawings, 7 World Trade Center.

UL 1983. Underwriters Laboratories, Fire Resistance Directory, January 1983, Underwriters Laboratories Inc. Northbrook, IL 60062. 


\section{Chapter 3 \\ BUILDING INTERIOR AND COMBUSTIBLES}

\section{$3.1 \quad$ INTRODUCTION}

The fires in WTC 7 were initiated following debris damage from the collapse of WTC 1 (Section 5.5). The specific ignition processes are not known, e.g., whether from flaming brands, electrical shorts, etc. The fires were fed by the furnishings, interior finish, and other combustibles within the building. Descriptions of the simulation of the fires and the resulting heating of the structure are presented in Chapters 9 and 10, respectively. As input to those simulations, this chapter documents the layout of the floors of interest and the combustibles that might have contributed to the fires.

\section{$3.2 \quad$ FOCUS}

In gathering information regarding the layout and furnishing of WTC 7, the Investigation Team focused its attention on the $5^{\text {th }}$ through $13^{\text {th }}$ floors:

- As will be seen in Section 5.6, there were sustained, though not always concurrent, visible fires only on Floors 7 through 9 and 11 through 13. There might have been fires on Floors 5 or 6 that were not visible (Section 3.3.2). An analysis of possible fires on these floors appears in Chapter 9.

- Above Floor 13, fires were observed on Floors 19, 22, 29 and 30, and these occurred early (i.e., were not observed for 3 hours prior to collapse) and were smaller and of shorter duration than those on the lower floors. Late in the afternoon, a small fire was observed briefly on Floor 14, which was vacant. Floors 15 and above were furnished office spaces.

The information NIST needed regarding the interiors of each of these nine floors was similar to the information needed for the reconstruction of the fires in the WTC towers:

- The nature and location of the interior walls. The interior walls could have acted as fire barriers, delaying the fire progression and subsequent exposure of structural components to the intense heat from the fires. The interior walls of perimeter offices or conference rooms could also have prevented photographs from recording fires in the building interior and kept flames and smoke from billowing out the windows.

- The nature of the suspended ceiling tile systems. The suspended ceiling tile system could have provided a (modest) time delay for access of the hot fire plume to the bottom of the floor structure above (Chapter 9). Smoke could also spread throughout the entire ceiling space, possibly emerging in remote locations and thus giving false impressions of the fire location.

- The nature and locations of any stairwells, elevators, shafts, or other passages between floors. Such passages could have provided a means for floor-to-floor fire spread. 
- The general nature and mass of the office furnishings and any unusual combustibles (e.g., high density file storage areas or significant quantities of highly flammable items). This is discussed further in Section 3.4.

\subsection{FLOOR PLANS AND COMBUSTIBLES}

\subsubsection{General}

Silverstein Properties managed WTC 7 from the date of first occupancy through the collapse on September 11, 2001. Their copies of the floor plans were lost in the collapse. NIST staff requested that the tenant companies and government agencies provide their most recent architectural drawings of their space, relative to the time of the collapse, as well as information regarding the furnishings. Staff of the occupying organizations and Silverstein Properties staff were also interviewed to gain additional insights into the layout, furnishing, and overall fuel load of Floors 5 through 13.

As shown in Table 3-1, NIST obtained floor plans for the nine focus floors. However, despite the quality of the drawings and verbal descriptions obtained by NIST, there was some uncertainty regarding the nature of some spaces. Notably, the U.S. Securities and Exchange Commission (SEC) and American Express occupied all but the east side of the $13^{\text {th }}$ floor, and NIST was unable to find people who recalled the nature of the unoccupied space.

Table 3-1. Floor layout information obtained.

\begin{tabular}{|c|l|c|l|}
\hline Floor & \multicolumn{1}{|c|}{ Tenant } & $\begin{array}{c}\text { Material } \\
\text { Received }\end{array}$ & \multicolumn{1}{|c|}{ General Description of Tenant Layout } \\
\hline 13 & $\begin{array}{l}\text { U.S. Securities and Exchange } \\
\text { Commission/American Express }\end{array}$ & FP, V & $\begin{array}{l}\text { Cubicles on southwest corner; meeting rooms on } \\
\text { north face; storage room on northwest corner; east } \\
\text { side unknown. }\end{array}$ \\
\hline 11,12 & $\begin{array}{l}\text { U.S. Securities and Exchange } \\
\text { Commission }\end{array}$ & FP, V & $\begin{array}{l}\text { Almost entirely walled offices. Library, file and } \\
\text { supply rooms on west side of core on } 12^{\text {th }} \text { floor. }\end{array}$ \\
\hline 10 & U.S. Secret Service & FP, V & Mostly walled offices around perimeter. \\
\hline 9 & U.S. Secret Service & FP, V & Mixture of walled offices and open landscaping. \\
\hline 5,6 & American Express & FP, V & Mostly cubicles. Generator vaults on south side. \\
\hline
\end{tabular}

a. Types of descriptive material received: FP: floor plan; V: verbal description of interior.

On Floors 5 through 13, the building core was approximately the same size and was bounded by demising walls. The demising walls were fire-rated walls constructed of gypsum board over steel studs and reached from the floor slab below to the floor slab above. Similar walls provided tenant separation on floors where there were or had been multiple tenants. The doors through these demising walls were firerated and had self or automatic closers.

Interior walls in the tenant spaces were also of gypsum board and steel stud construction, but generally extended from the floor slab to just above the suspended ceiling. These walls, though unrated, also could have confined the fire for a short period of time. The space bounded by the upper concrete floor slab and the suspended ceiling formed a plenum; for a tenant floor with a single tenant and no interior demising walls, the plenum would have extended across the full area of that floor. The hot upper layer generated 
by the fire effluent could then have spread floor-wide, unlike the (multiple tenant per floor) case with interior demising walls. There were some slab-to-slab walls surrounding sound-sensitive offices and conference rooms that could also have interrupted fire spread. Such walls were usually not fire-rated.

Doors within tenant spaces typically are not fire-rated and do not have self or automatic closers. For modeling purposes, NIST generally presumed these doors were open. However, in some cases, the observed interrupted progress of fire across a series of windows could have indicated a partitioned area with a closed door.

Within the tenant spaces on Floors 7 through 13, the floor slab was generally carpeted; there were some areas with slightly raised floors for power and data cabling and of wood- or stone-covered floor areas. There was little information regarding the suspended ceiling systems. NIST assumed that the ceiling systems were similar to those in the WTC towers and that they were intact outside the zone affected by debris impact from the collapse of WTC 1. There was no available information on the thermal properties of the ceiling tile systems on these floors. The ceiling systems were not part of the passive fire protection design and, as such, were not fire rated. NIST assumed that the thermal response of the ceiling systems was similar to those in the towers.

The Investigation Team digitized drawings of the focus floors (see below and Chapter 9), including the layout of the partitions, stairwells and other features that might affect fire spread. These were used as input to the fire simulations described in Chapter 9.

\subsubsection{Floors 5 and 6}

\section{Layout}

The $5^{\text {th }}$ floor was a mechanical floor, $4.0 \mathrm{~m}(13.0 \mathrm{ft})$ in height from slab to slab. ${ }^{1}$ As shown in Figure 3-1, along the west-to-east midsection of the floor were, in turn, a segment of the west stairwell, banks of elevators, the second building stairwell, and a two story mechanical space housing the ventilation and air conditioning equipment. Along the north and south faces were vaults housing power transformers for the building.

The emergency power for the building initially came from the two $900 \mathrm{~kW}$ diesel generators (indicated in green in Figure 3-1) located near the southwest corner of the floor. The vault surrounding the generators in this area was two stories tall. Added in 1994 were nine additional generators that provided emergency power to the Salomon Smith Barney spaces above Floor 14; these are shown in orange. A unified description of the fuel supply for the emergency generator system is presented in Section 3.4.

Two-story aluminum plenums that provided air for the diesel engines were located along portions of the west and east walls. A building exhaust plenum was located on the west side of the southwest generator room and the south central portion of the east wall. The diesel engines were exhausted through plenums on the west side of the south wall and along the north wall where the diesel generators were

\footnotetext{
${ }^{1}$ The descriptions of the $5^{\text {th }}$ and $6^{\text {th }}$ floors were derived from architectural and mechanical design drawings provided by Emery Roth \& Sons (Roth 1985), Irwin Cantor (Cantor 1985), Syska \& Hennesy (Syska \& Hennessy 1985), and Flack \& Kurtz (Flack \& Kurtz 1988). Some of the details may differ from the actual layout on September 11, 2001.
} 
located. Thirty-six $18 \mathrm{~m}^{3} / \mathrm{s}\left(38,000 \mathrm{ft}^{3} / \mathrm{min}\right)$ fans provided intake air to the east and west plenums for emergency diesel engine combustion and generator cooling. The maximum air flow was $645 \mathrm{~m}^{3} / \mathrm{s}$ $\left(1,400,000 \mathrm{ft}^{3} / \mathrm{min}\right)$.

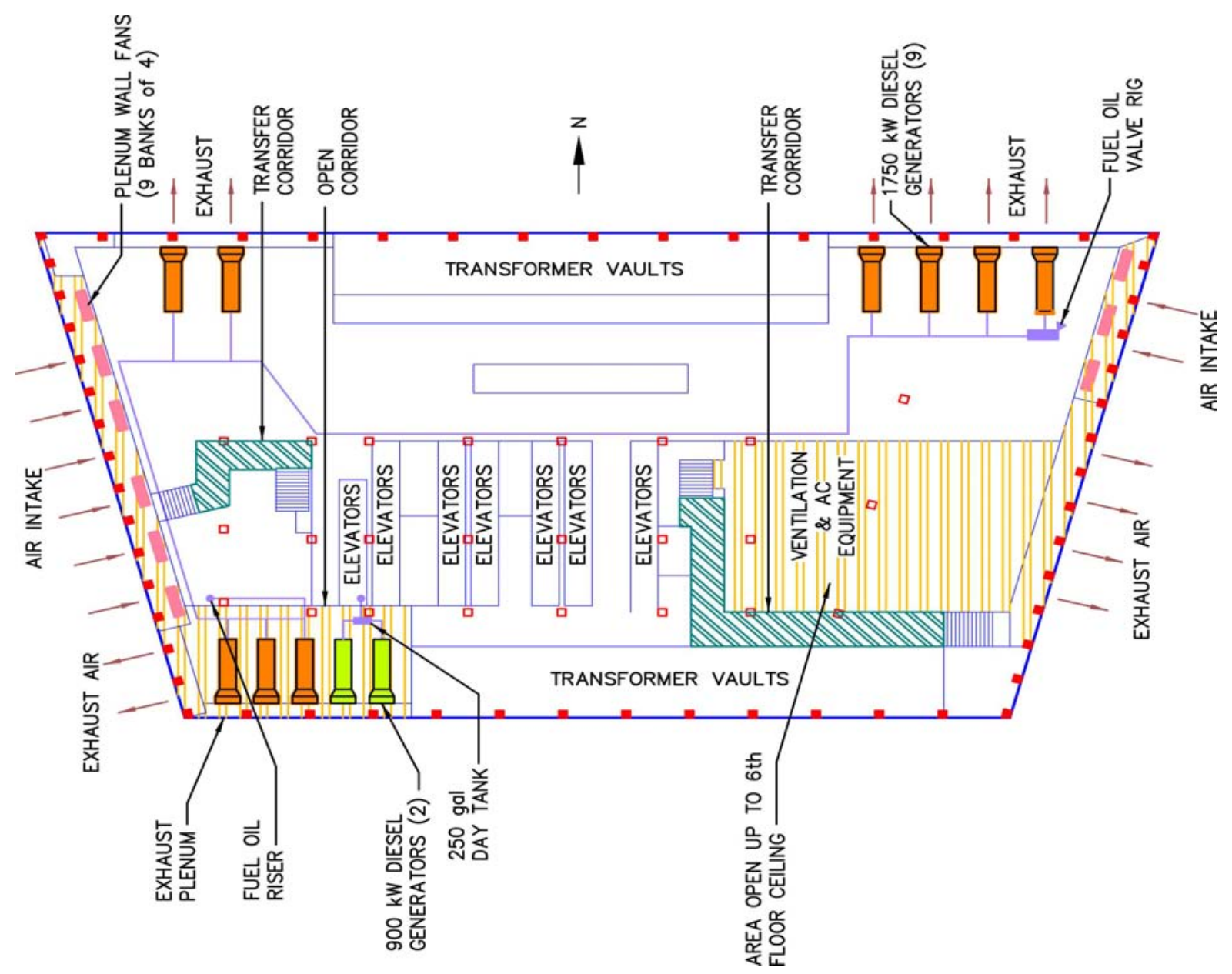

Figure 3-1. Schematic of Floor $5 .^{1}$

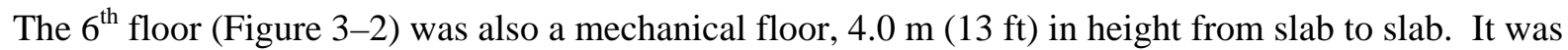
isolated from the $5^{\text {th }}$ floor by a floor slab, the walls of the two story mechanical space containing the air conditioning equipment, and the upward extension of the vault containing the southwest generators.

Along the east and west walls were the upper parts of two story plenums. The space along the north side of the floor was crossed by the deep cantilever girders on the $7^{\text {th }}$ floor. Both the north and south sides of the floor contained ventilation ducts, plumbing, and miscellaneous electrical and mechanical equipment.

Aside from the fuel for the generators, NIST was unable to identify significant combustible material on the $5^{\text {th }}$ floor. There were no documented combustibles to sustain a fire on the $6^{\text {th }}$ floor, although staff reported that their janitorial supplies were stored there. For flames to burn on the $6^{\text {th }}$ floor and heat structural members, the flames from a fire on the $5^{\text {th }}$ floor would have had to penetrate one of the aluminum plenum walls, rise through a gap created by debris damage on the south side of the building, or collapse a portion of the $6^{\text {th }}$ floor slab. 


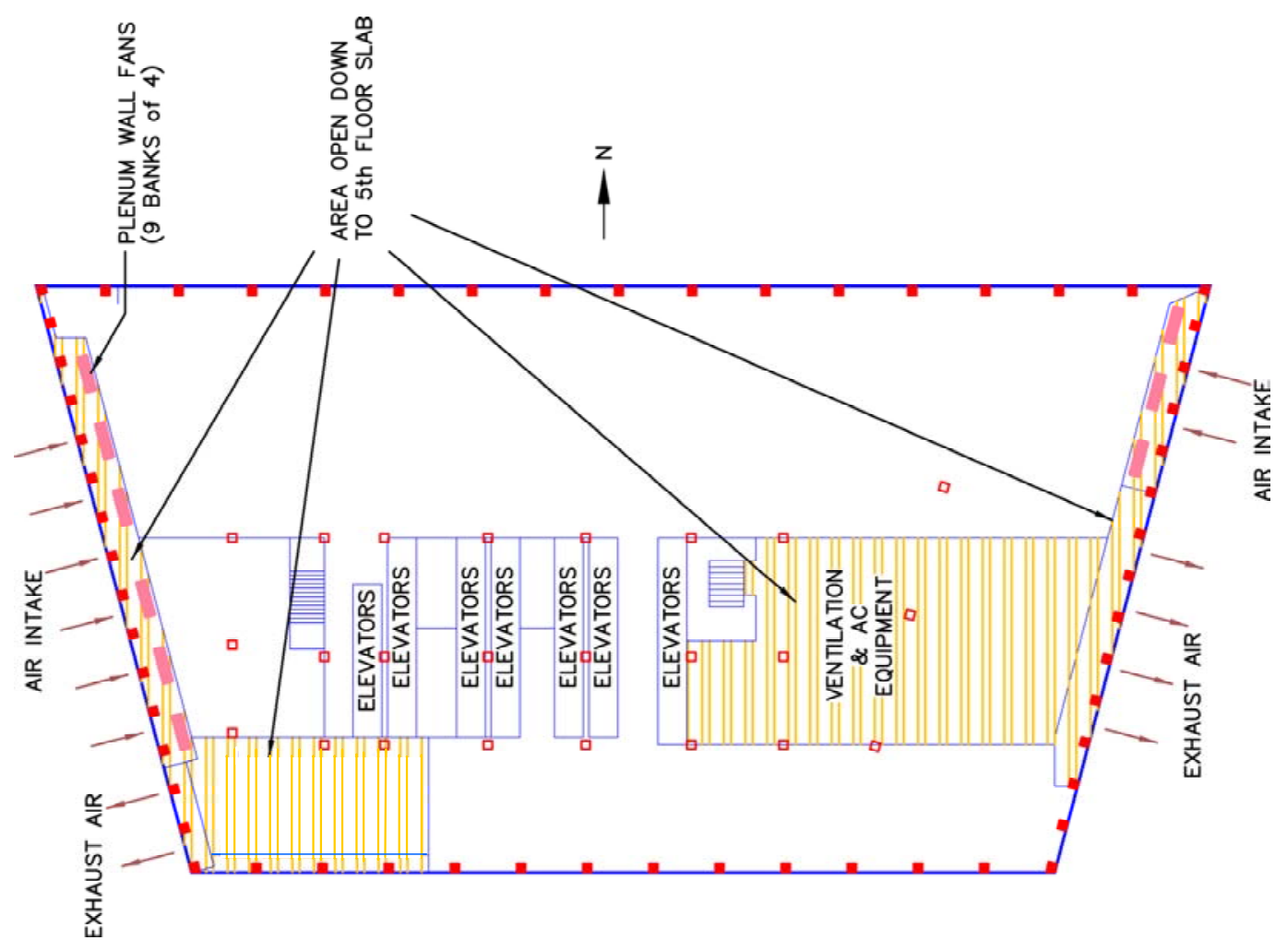

Figure 3-2. Schematic of Floor $6 .^{1}$

\section{The Facade}

Aluminum louvers were installed along the exterior walls of the $5^{\text {th }}$ and $6^{\text {th }}$ floors to protect the mechanical floors from the weather. The louvers opened automatically when the fans were operating. From a distance, it was difficult to see if the louvers were opened or closed because there was an exterior mesh, where the windows were located, to keep debris out.

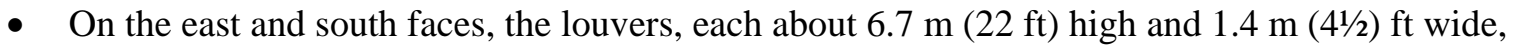
extended almost the combined height of the $5^{\text {th }}$ and $6^{\text {th }}$ floors.

- $\quad$ On the west face, louvers approximately $2.3 \mathrm{~m}(71 / 2 \mathrm{ft})$ high by $2.0 \mathrm{~m}(61 / 2 \mathrm{ft})$ wide were installed in 14 of the window frames on each of the $5^{\text {th }}$ and $6^{\text {th }}$ floors. These louvers were the same shape and size as the windows on the $7^{\text {th }}$ floor and above. The end windows on the $5^{\text {th }}$ and $6^{\text {th }}$ floors were wider, contained double panes, and were filled with a solid panel rather than louvers.

The louvers, the transformer vault walls, and the interior plenum walls would have blocked any view into the building interior from the east, south or west. However, if a large fire penetrated a plenum wall and if the louvers were open, flames might have been visible, and smoke might have emanated from the exhaust openings. NIST found no photographic records or eyewitness accounts of smoke or fires that could be attributed to fires on these two floors. 
On the north face, louvers were located in the window frames on the $5^{\text {th }}$ floor, and tinted glass windows were used on the $6^{\text {th }}$ floor to match the appearance of the upper stories. The view of any interior fires on the $5^{\text {th }}$ floor was blocked by the exhaust plenum walls at the east and west ends and by the bank of transformer vaults along the center of the north face. To become visible from the north, a $5^{\text {th }}$ floor fire would have had to be of sufficient intensity to breach the transformer vault or the exhaust plenum. By contrast, a fire on the north side of the $6^{\text {th }}$ floor would have been almost as visible (due to the tinted glass) as on one of the tenant floors. Since there was essentially no combustible material to support a significant fire on the $6^{\text {th }}$ floor, the flames from a significant fire on the $5^{\text {th }}$ floor would have had to penetrate one of the aluminum plenum walls or collapse a portion of the $6^{\text {th }}$ floor slab. In addition, if there were an underventilated fire on the $5^{\text {th }}$ floor, unburned pyrolysis products could have spread through such a gap and, if ignited, burned on the $6^{\text {th }}$ floor. NIST found no photographic records or eyewitness accounts of smoke or fires that could be attributed to fires on these floors.

\subsubsection{Floors 7 and 8}

American Express moved into Floors 7 and 8 in 1994 and was the first tenant in that space. Their layouts, as of October 2000, are depicted in Figure 3-3 and Figure 3-4. ${ }^{2}$ The flooring material was $46 \mathrm{~cm}$ (18 in.) square carpet tiles of unknown composition. The walls were painted, with some poster art. There was a limited amount of fluoropolymer-insulated fire alarm and security cabling above the suspended ceiling tiles. Communications cabling ran through raceways in the floor slabs. There were some firestopped holes in the $8^{\text {th }}$ floor slab for communication cables between the two floors.

The north side of the $7^{\text {th }}$ floor was filled with clusters of cubicles and a few walled offices. On the east side of the $7^{\text {th }}$ floor was a large data center, whose walls ran from slab to slab. A vault in the middle of the south side contained, among other equipment, three generators to provide emergency power for the Mayor's Office of Emergency Management (OEM), located on the $23^{\text {rd }}$ floor. The vault also contained a $1.25 \mathrm{~m}^{3}$ (275 gal) fuel tank for the generators. Approximately $650 \mathrm{~m}^{2}\left(7,000 \mathrm{ft}^{2}\right)$ of space on the west side of the floor had been vacated (in exchange for space on the $13^{\text {th }}$ floor) in 1997. Employees of the Mayor's Office of Emergency Management said that they were using the vacated space for storage. The people who had occupied the area between the west face and the building core had been moved to the $13^{\text {th }}$ floor, and the $7^{\text {th }}$ floor space had been turned over to Silverstein Properties, which intended to use it for storage. There might have been little combustible material in this space.

Virtually all the $8^{\text {th }}$ floor was densely filled with clusters of cubicles. Along the west wall was a small vault that had contained a single emergency power generator and a $1.25 \mathrm{~m}^{3}$ (275 gal) fuel tank until 2000 (Section 3.4.2). The vault walls ran slab to slab and were fire-rated. The generator and fuel tank had been removed prior to September 11, 2001. ${ }^{3}$

American Express did not require employees to clear their desktops at the end of a workday. However, the offices were generally neat, as they did nightly sweeps to avoid clutter and for fire safety. Some of their material was stored in lateral file cabinets, and a lot of material was stored in a nearby building to maximize the availability of space for staff.

\footnotetext{
${ }^{2}$ Floor plans provided by American Express and supplemented by NIST interviews with American Express staff, April and May 2006.

${ }^{3}$ Letter from Trammel Crow Company (as manager for American Express) to Silverstein Properties, dated April 12, 2002.
} 


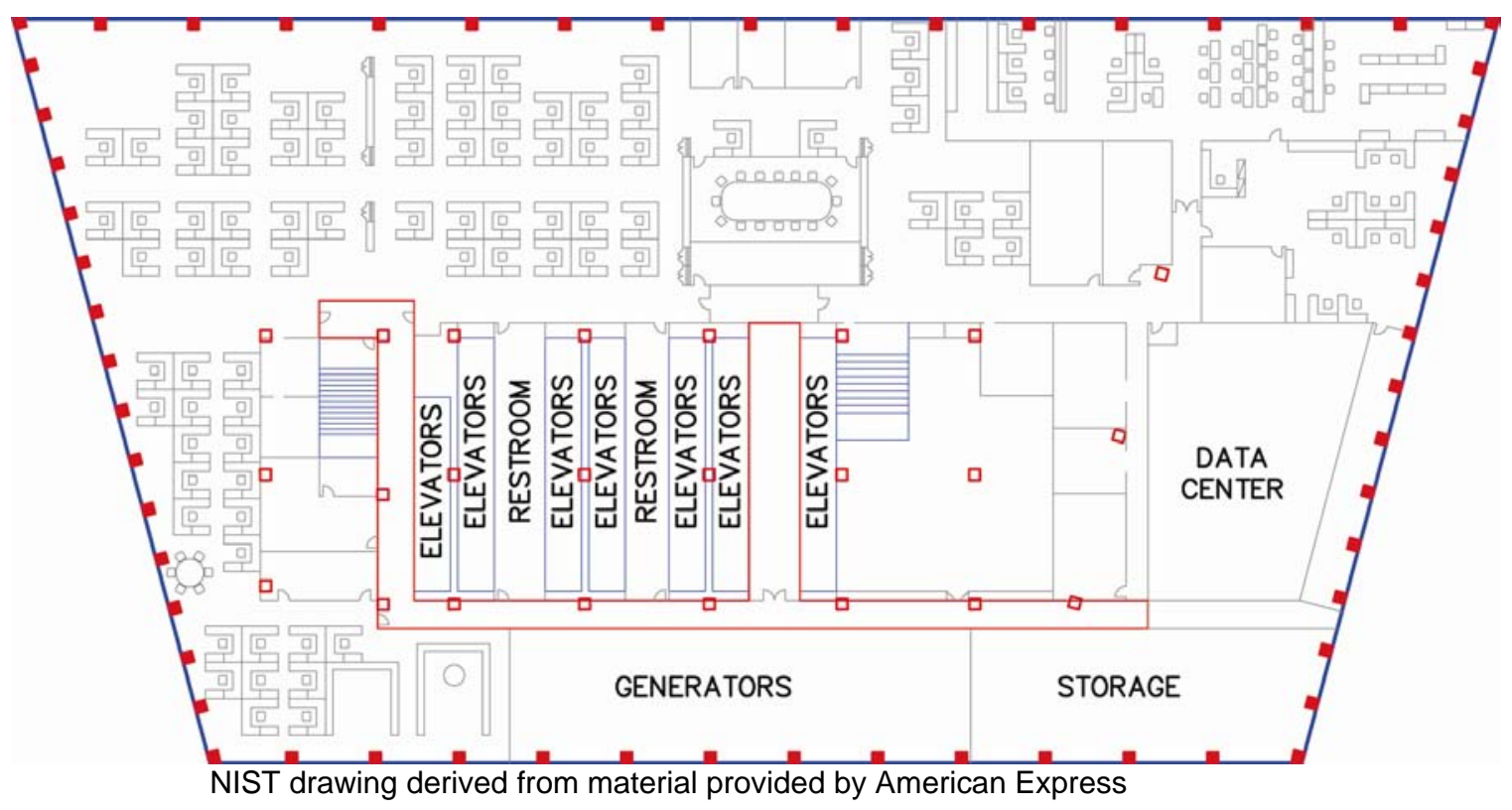

Figure 3-3. Schematic of Floor 7.

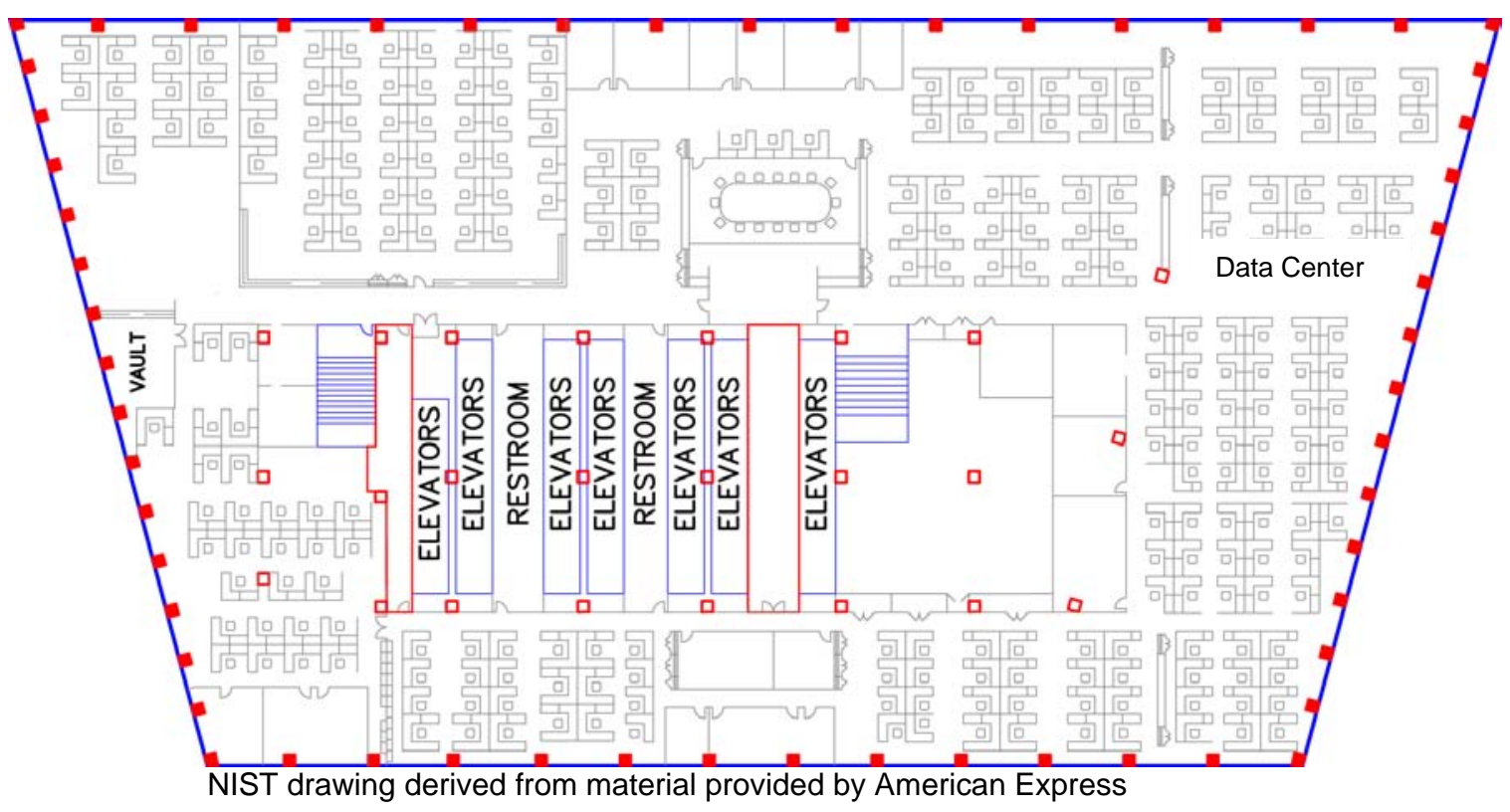

Figure 3-4. Schematic of Floor 8. 


\subsubsection{Floors 9 and 10}

The U.S. Secret Service moved into WTC 7 in 1995 and, as of September 11, 2001, occupied all of the $9^{\text {th }}$ floor and all but the east side of the $10^{\text {th }}$ floor. Secret Service staff recollected that there had been no prior tenants, although an undated Citigroup floor $\operatorname{plan}^{4}$ showed some landscaping.

The $9^{\text {th }}$ floor had a few walled offices on the building perimeter, but was mostly landscaped with cubicles. The number and layout of the cubicles is unknown. There was a room housing a generator and day tank at the north end of the west wall. East of the building core was an evidence storage area contained by fire-rated walls. It normally held paper materials (e.g., envelopes, folders, counterfeit currency, etc.) related to case work. The evidence area doors were closed and locked at all times unless authorized access had been granted. There was a corridor between this room and the east face. A deduced approximate floor plan is shown in Figure 3-5. ${ }^{5}$

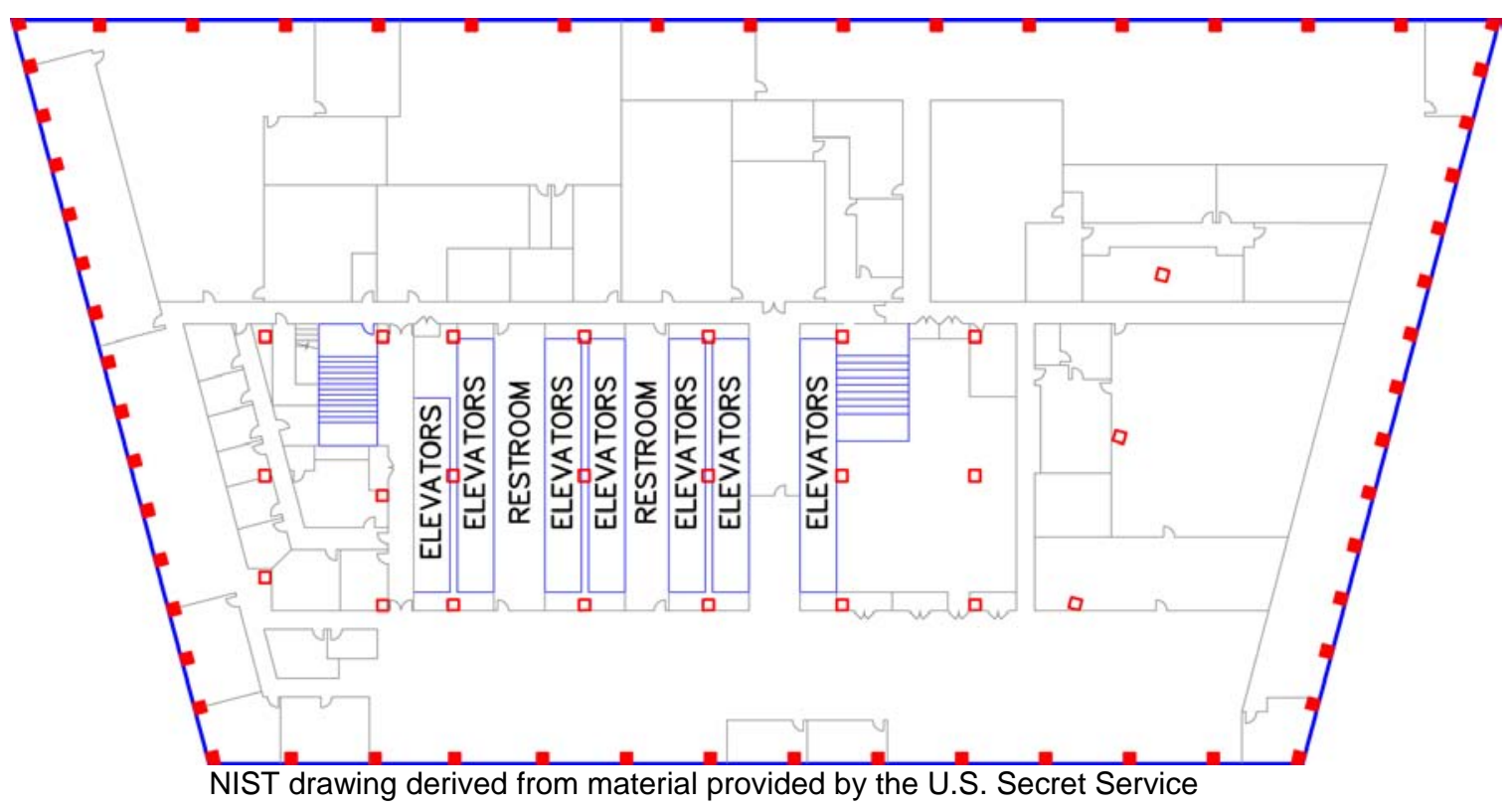

Figure 3-5. Approximate layout of the $9^{\text {th }}$ floor.

On the $10^{\text {th }}$ floor, there was a heating, ventilation and air conditioning (HVAC) room at the northwest corner and walled offices along most of the perimeter. The remainder of the occupied floor space was open landscaping. As with the $9^{\text {th }}$ floor, the number and layout of the cubicles is unknown. The east side of the $10^{\text {th }}$ floor was described by the Secret Service as empty and was being held for future overflow. A deduced approximate floor plan is shown in Figure 3-6.

Secret Service staff described the ceiling tiles as "normal.” Cables above the ceilings were for information transfer, video and alarm systems. The flooring was generally carpet tiles, although there were some areas with vinyl tiles.

\footnotetext{
${ }^{4}$ Floor plan provided by Citigroup, December 2003.

${ }^{5}$ Floor plans provided by U.S. Secret Service and supplemented by NIST interviews with Secret Service staff, May and June 2006.
} 


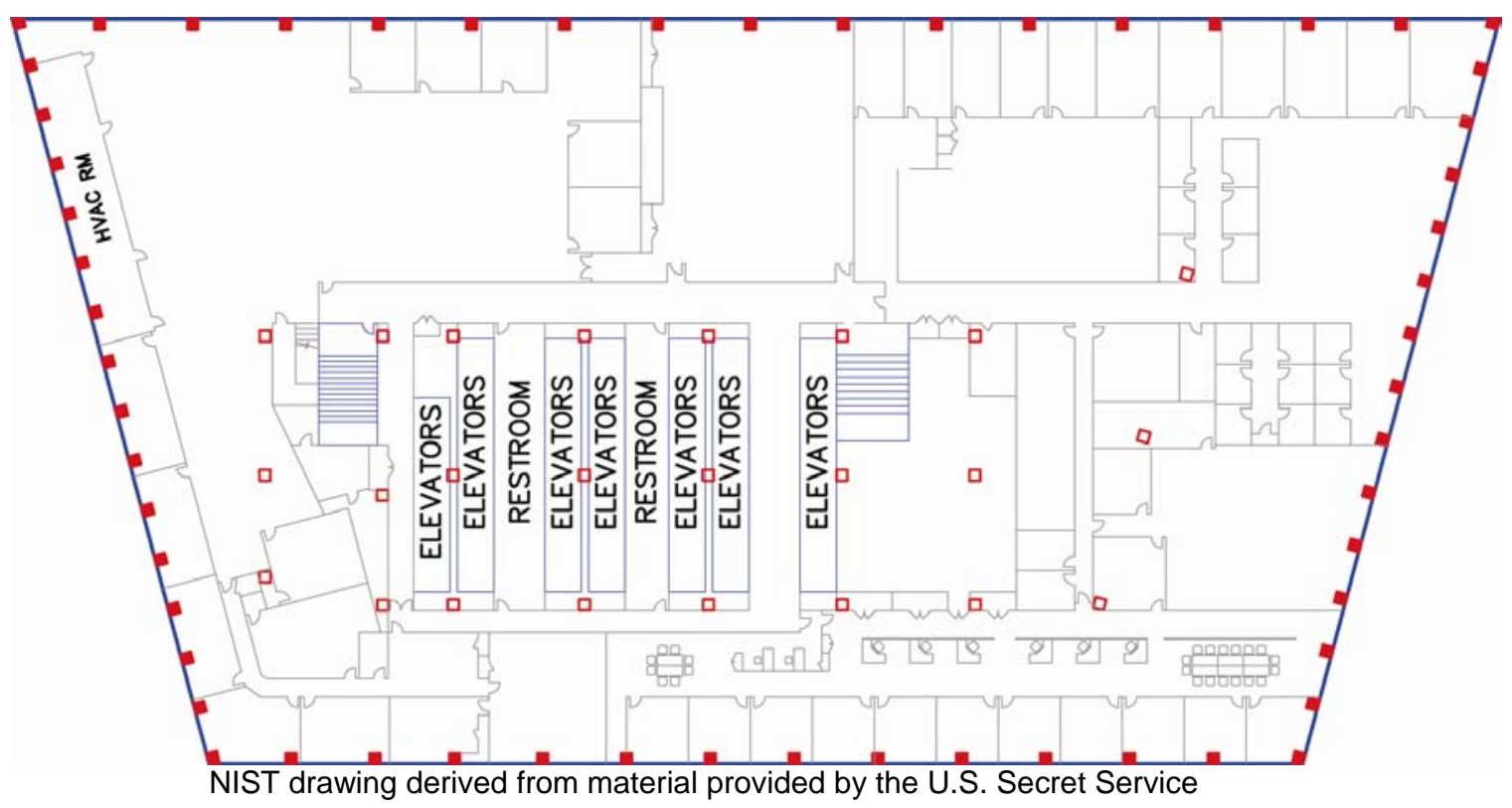

Figure 3-6. Approximate layout of the $10^{\text {th }}$ floor.

In building photographs, the windows on these two floors appear to be darker than those on the other floors. However, the Secret Service staff stated that they had done nothing to the windows during or after the build out. The fact that photos showed late fires and broken windows on the north face of the $9^{\text {th }}$ floor indicated that a fire could be seen and could break these windows.

The cubicle areas were kept relatively clear of papers, since most of the papers in the Secret Service space were evidence and could not be left out overnight. On the desks, there may have been some files containing notes on active cases. The bulk of the paper was stored in file rooms and evidence vaults.

There were several pistols and shotguns stored on the $9^{\text {th }}$ floor. Secret Service staff stated that there were no other types of weaponry in WTC 7 and estimated that there were fewer than 500 rounds of ammunition for the small arms.

No fire was observed on the $10^{\text {th }}$ floor, and only a very late fire was observed on the $9^{\text {th }}$ floor (Section 5.6). NIST did not model the $9^{\text {th }}$ floor in detail. How NIST treated the fire on this floor is presented in Chapter 9.

\subsubsection{Floors 11 through 13}

The U.S. Securities and Exchange Commission (SEC) had occupied the $11^{\text {th }}$ and $12^{\text {th }}$ floors and the north side of the $13^{\text {th }}$ floor since about 1991. They outfitted the space to their needs, including removal of old cables, plumbing fixtures, etc. Interviewed SEC staff had no recollection or records of any renovations after the SEC moved in. ${ }^{6}$

\footnotetext{
${ }^{6}$ NIST Interviews with U.S. Securities and Exchange Commission staff, December 2005 through March 2006.
} 
American Express occupied the southwest sector of the $13^{\text {th }}$ floor. ${ }^{2}$ The space was mainly filled with cubicles. There was also a small bank somewhere on the east part of the south face. ${ }^{6}$ NIST was unable to obtain any other information regarding the occupancy of the east side of Floor 13.

The layouts of the $11^{\text {th }}$ and $12^{\text {th }}$ floors were similar to each other ${ }^{7}$, and a single floor plan was used for the fire simulations (Figure 3-7). The layouts of both floors were quite different from those of the other focus floors. The space was principally subdivided into walled offices, with a few cubicles. There were single-person offices all around the perimeter. Interior to these was a full corridor, with a second rectangle of solo offices opening outward onto the corridor. There was a second corridor inside these offices and outside the building core. Generally, one could not see outside the building from either corridor. The principal exception was near the $12^{\text {th }}$ floor library on the west side of the building. There was frosted glass on some of the office walls.

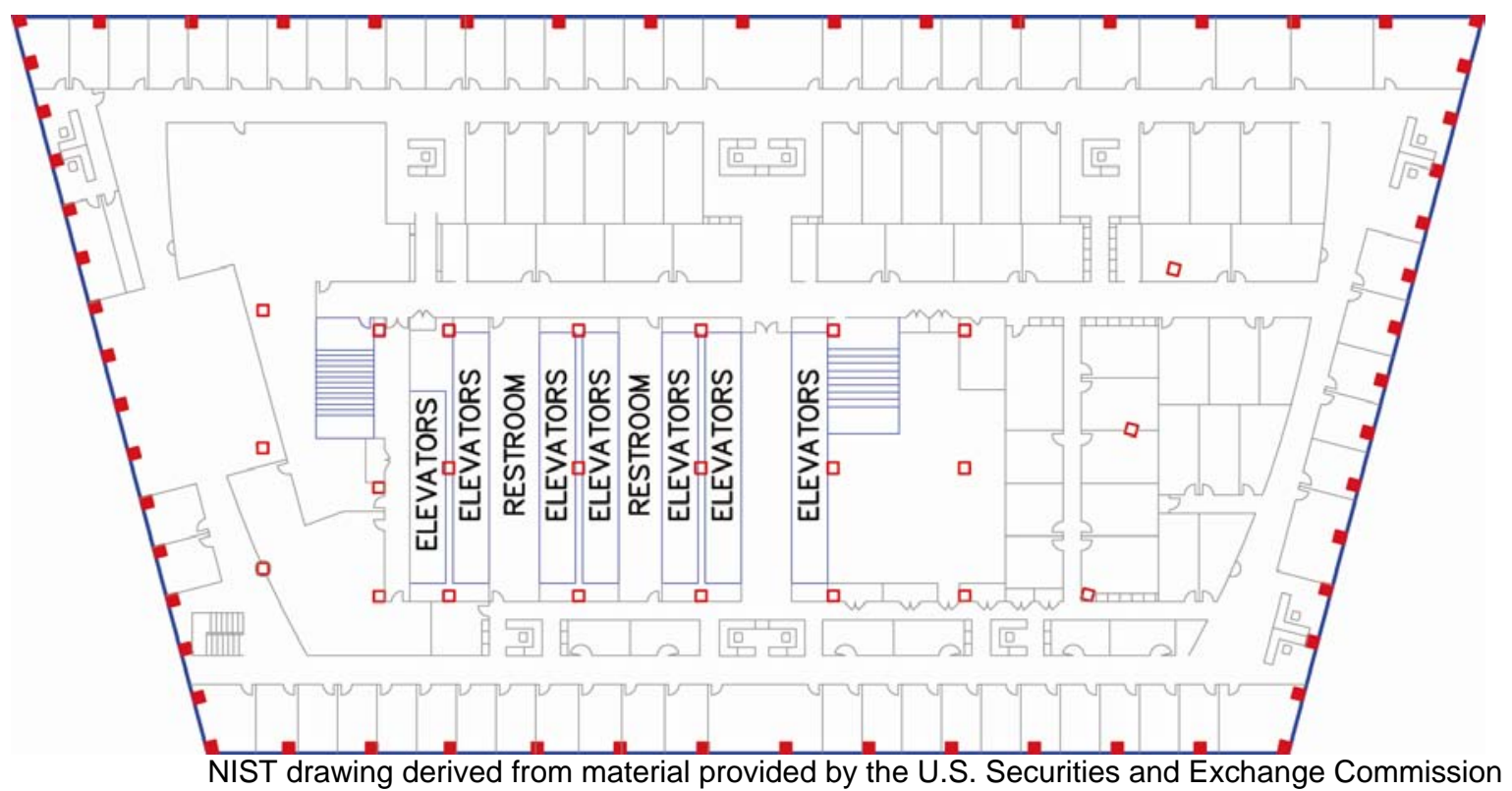

Figure 3-7. Schematic of Floor 12.

There was a convenience stairway between the $11^{\text {th }}$ and $12^{\text {th }}$ floors, located near the southwest corner. The stairway was open, with no walls or doors.

The furniture was mostly modular, generally consisting of decorative laminate over particle board. There were some older solid wood pieces scattered among the managers' offices. The combustible load in the offices was described as high by interviewed SEC managers. There was no clean desk policy. Open case files were left on surfaces. There were many bookcases, file cabinets, and cartons of files in the offices.

Occupants of the south side offices reported that a large number of windows were broken by the percussion and debris from the aircraft impact into WTC $1{ }^{6}$

The $13^{\text {th }}$ floor was less heavily subdivided (Figure 3-8). Along the central section of the north perimeter was a corridor, with a hearing room and multiple testimony rooms facing it. There were additional

\footnotetext{
${ }^{7}$ Floor plans provided by the U.S. Securities and Exchange Commission.
} 
testimony rooms on the northern portion of the east side of the floor and a storage room at the northwest corner. The testimony rooms were sparsely furnished, with just a table and a few chairs.

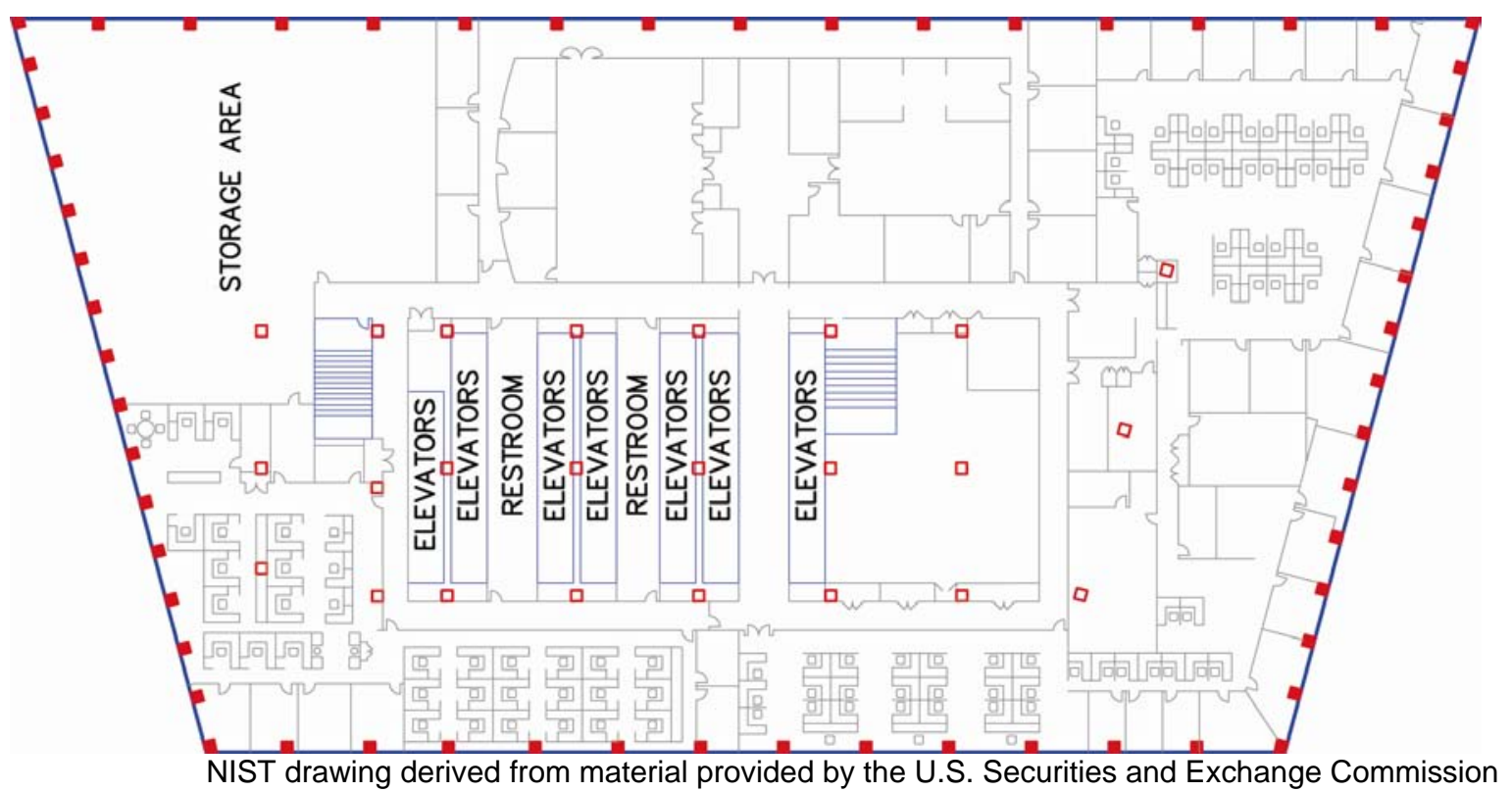

Figure 3-8. Schematic of Floor 13.

\subsubsection{Other Fire Floors}

As will be seen in Section 5.6, early fires were noted on Floors 19 (occupied by the Hartford Insurance Company), 22 (Federal Home Loan Bank), 29 (Citigroup), and 30 (Citigroup). These fires were recorded in photos and videos from shortly after noon until about 1:30 p.m.

NIST was able to obtain floor plans for the east side of the $19^{\text {th }}$ floor ${ }^{8}$ (Figure 3-9) and the $29^{\text {th }}$ and $30^{\text {th }}$ floors. ${ }^{9}$ The latter two floors were nominally identical (Figure 3-10). While it is not clear why the early fires did not continue to propagate, there were no features of these floors that offered a mechanism for a long-lasting fire to burn without reaching an exterior wall by 5:00 p.m. (Chapter 9). No plan for the $22^{\text {nd }}$ floor was available, but it is quite unlikely that continuation of the early burning would not have become visible.

On the $14^{\text {th }}$ floor, a small fire was observed at the far east of the north face at about 5:03 p.m. It was not observed at 4:52 p.m. and 5:09 p.m. On September 11, 2001, the $14^{\text {th }}$ floor was unoccupied and should have had a very small combustible fuel load. From this evidence, the Investigation Team deduced that it was unlikely that there had been a sustained fire of appreciable heat output (Section 9.1.2.).

NIST also obtained layout plans for nearly all the remaining floors ${ }^{9}$, on which no signs of fires were observed. Nothing in these floor plans indicated construction that would conceal a sustained fire (such as that on the $12^{\text {th }}$ floor) from being viewed from outside the building.

\footnotetext{
${ }^{8}$ Floor plan provided by the Hartford Insurance Company.

${ }^{9}$ Floor plans provided by Citigroup.
} 


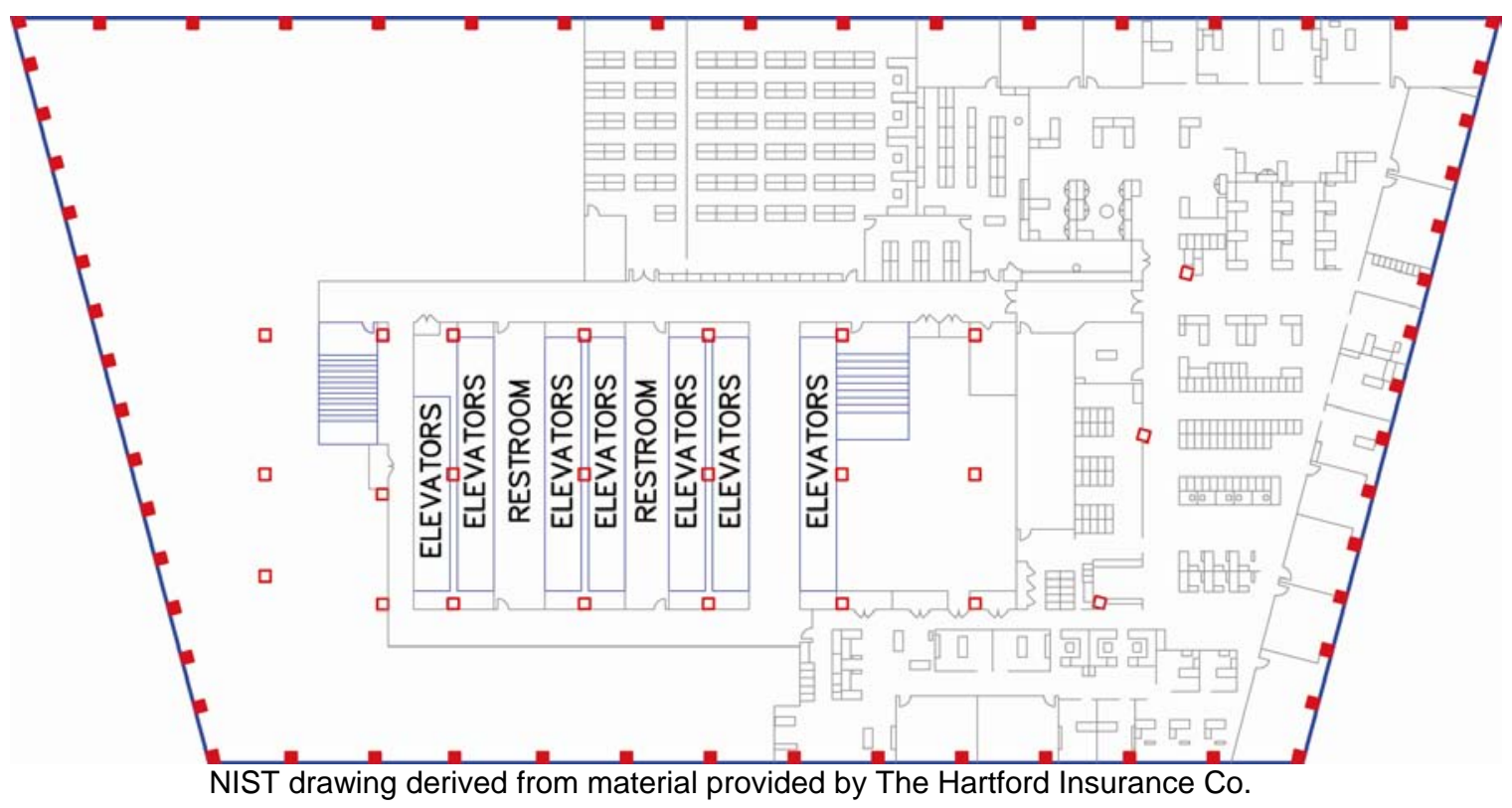

Figure 3-9. Schematic of Floor 19.

No information was available on the layout of the west half of the floor.

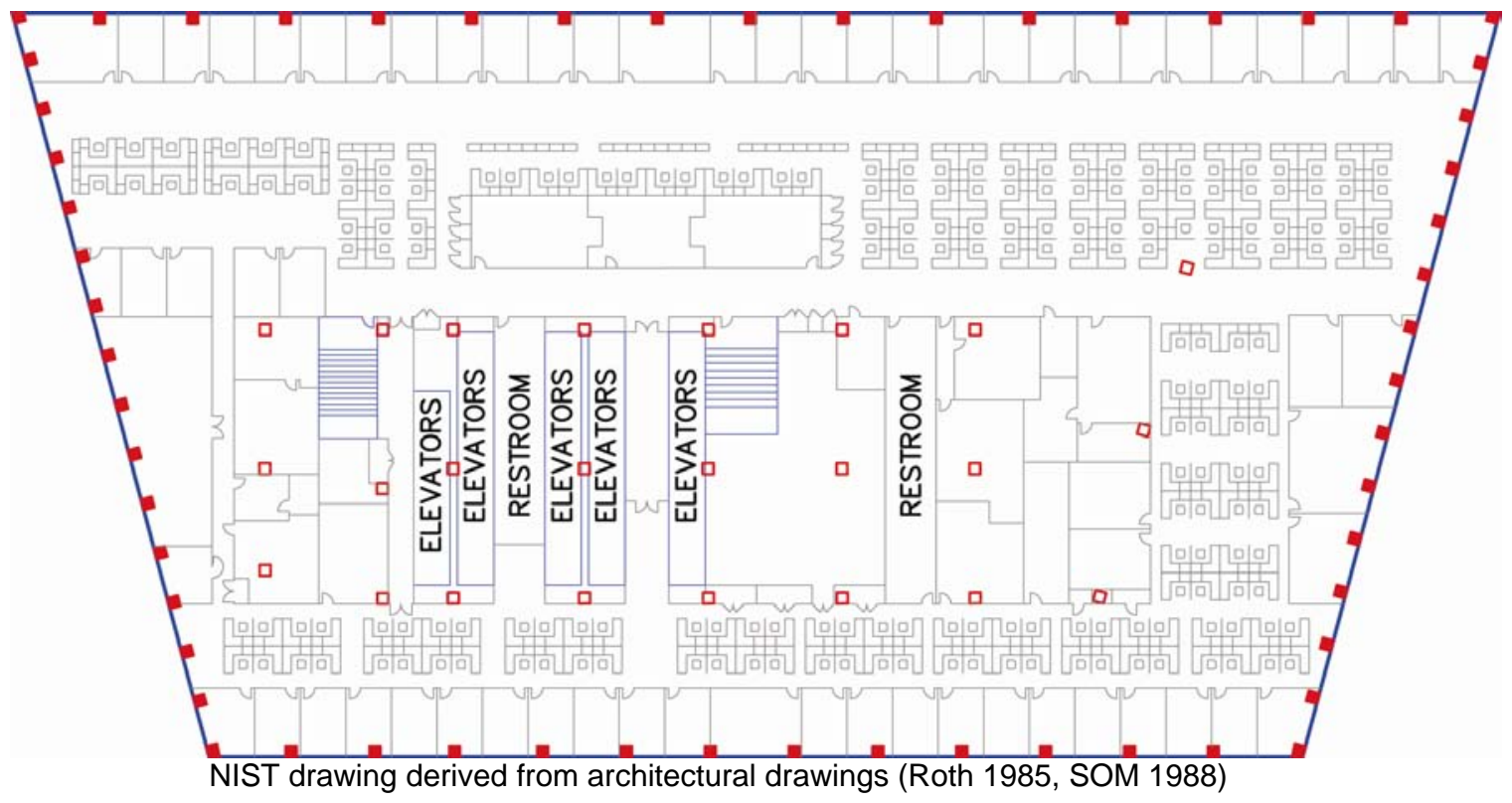

Figure 3-10. Schematic of Floor 29.

Small fires on these floors might not have been visible through the windows due to the extensive office partitions. However, it is likely that a fire of sufficient duration and intensity to threaten the floor systems or the columns would have burned toward and broken windows on the north, east, or west sides, where photographs would have recorded their presence. 


\subsection{BUILDING COMBUSTIBLES}

\subsubsection{Furnishings}

The most prevalent combustibles on Floors 7 through 13 were the large array of workstations (also referred to as office modules or cubicles). There were almost certainly different types of workstations in the building. However, discussions with office furniture distributors and visits to showrooms indicated that, while there was a broad range of prices and appearances, the cubicles were fundamentally similar. A typical cubicle was bounded on four sides by privacy panels, with a single entrance opening. Within the area defined by the panels was a self-contained workspace: desktop (almost always a wood product, generally with a laminated finish), file storage, bookshelves, carpeting, chair, etc. Presumably there were a variety of amounts and locations of paper, both exposed on the work surfaces and contained within the file cabinets and bookshelves. These cubicles, as many as 200 or more per floor, were grouped in clusters or rows.

Unlike the case for the two WTC towers, there was no widespread spraying of jet fuel to ignite numerous workstations simultaneously. Rather, in the earlier hours of the WTC 7 fires, the fire would have spread from one individual workstation to another. Thus, the fire spread would have been dependent on the specific spacing of the cubicles and their ease of ignition. Replicating such fire growth was not feasible since (1) the information available on the office layouts was not sufficiently detailed, and (2) there was insufficient visual evidence to support such a detailed approach.

The combustible fuel load ${ }^{10}$ for the floors was estimated as follows.

- Floors 7 and 8. The architectural drawings showed densities of workstations similar to those on most of the fire floors in the WTC towers. (Recall that the south and east sides of the $7^{\text {th }}$ floor were given to other uses.) The exact nature of the workstations was not known, nor was the mass of paper in each cubicle. Thus, the Investigation Team assumed the combustible masses $(200 \mathrm{~kg}$ per workstation plus $50 \mathrm{~kg}$ of paper) were similar to those in the towers (NIST NCSTAR 1-5). For example, the architectural drawings of the $7^{\text {th }}$ floor showed about 100 workstations on the north side of the $7^{\text {th }}$ floor and about 130 workstations on the north side of the $8^{\text {th }}$ floor, although the exact number of workstations on September 11, 2001 is not known. The floor area north of the building core was about $1500 \mathrm{~m}^{2}$. Thus, the estimated combustible fuel load was about $20 \mathrm{~kg} / \mathrm{m}^{3}\left(4 \mathrm{lb} / \mathrm{ft}^{2}\right)$. Simulations of the fires with a higher combusted fuel load (Chapter 9) showed little effect on the rate of fire propagation.

- Floors 9 and 10. The floor plans did not indicate the number of workstations on these floors. As noted in Section 3.3.4, there would not have been excess paper on the desks or floors. Thus, the estimated combustible fuel load was the same as for the $7^{\text {th }}$ and $8^{\text {th }}$ floors (and the towers), about $20 \mathrm{~kg} / \mathrm{m}^{3}\left(4 \mathrm{lb} / \mathrm{ft}^{2}\right)$. No fire was observed on the $10^{\text {th }}$ floor, and a sizable fire on the $9^{\text {th }}$ floor was observed for only about an hour (Section 5.6). Thus, there was no means to estimate the effect of different combustible mass loadings on agreement with the observed fire growth patterns.

\footnotetext{
${ }^{10}$ In the fire simulations, the entire combustible fuel load can be burned. In actuality, not all of, e.g., a wood desk is consumed. Thus, the combusted fuel loads estimated for these simulations are somewhat lower than the actual fuel loads in prior surveys (NIST NCSTAR 1-5).
} 
- Floors 11 and 12. As described in Section 3.3.5 and shown in Figure 3-7, these floors were divided into individual offices, rather than open landscaped. There were approximately 130 offices per floor, distinctly fewer than the number of cubicles on a fully landscaped floor. The mass of the furnishings per office was not known; the mass of additional paper materials was described as very high. As indicated in Section 9.3.1, the Investigation Team began with an initial estimation of the combusted fuel load of approximately $32 \mathrm{~kg} / \mathrm{m}^{3}\left(6.4 \mathrm{lb} / \mathrm{ft}^{2}\right)$. Simulations of the fires with a lower combusted fuel load (Chapter 9) resulted in poor agreement with the observed fire spread rates.

- Floor 13. There was little information regarding the combustibles on this floor, and there was little visual evidence for estimating the effect of different combustible mass loadings on agreement with the observed fire growth patterns. NIST assumed a combusted mass similar to that on the $11^{\text {th }}$ and $12^{\text {th }}$ floors.

\subsubsection{Diesel Fuel}

There was considerable capacity for diesel fuel storage within and under WTC 7. The Investigation Team compiled information in order to estimate how much diesel fuel might have been available to feed fires in various locations in the building on September 11, 2001. The information collected (NIST NCSTAR 1-1J) is summarized as follows.

\section{Fuel Tanks}

Figure 3-11 through Figure 3-13, reproduced from NIST NCSTAR 1-1J, depict the floor-by-floor locations of the electrical generators, the day tanks, and the fuel lines that connected them to the below ground fuel tanks. The text in this section is abridged from that report, as well.

There were two $55 \mathrm{~m}^{3}$ (12,000 gal) tanks located below the loading dock. These provided the primary supply for what was known as the base building system. This system, installed in 1987, consisted of two generators installed on the $5^{\text {th }}$ floor of WTC 7, along with a $1.25 \mathrm{~m}^{3}$ (275 gal) day tank, which was set within a $2.5 \mathrm{~m}^{3}$ (550 gal) capacity collecting tank. The day tank was replenished with a $0.33 \mathrm{~L} / \mathrm{s}$ (4.4 gal/min) pump. Additions to the system in 1994 were:

- A single generator located on the $8^{\text {th }}$ floor, along with a separate $1.25 \mathrm{~m}^{3}$ (275 gal) day tank (American Express modification). The $8^{\text {th }}$ floor generator and the day tank were removed in $2000 .^{3}$

- A single generator on the $9^{\text {th }}$ floor with a $0.23 \mathrm{~m}^{3}$ (50 gal) day tank located on the generator (Ambassador modification for the U.S. Secret Service).

The pumps that filled the three day tanks from the large storage tanks were located on the $1^{\text {st }}$ floor. 
The Salomon Brothers ${ }^{11}$ system was installed in 1990. This consisted of two $27 \mathrm{~m}^{3}$ (6,000 gal) tanks located under the loading dock and pumps located on the $1^{\text {st }}$ floor in a separate space from the base building pump sets. The Salomon Brothers system's nine generators were all located on the $5^{\text {th }}$ floor. Since the New York City regulations had a limit of one day tank up to $1.25 \mathrm{~m}^{3}$ (275 gal) per floor, and since the base generators located on the $5^{\text {th }}$ floor already made use of a $1.25 \mathrm{~m}^{3}$ (275 gal) day tank, the Salomon Brothers system used a pressurized fuel distribution system, in which the pumps continuously circulated fuel whenever the generators were running. There was enough fuel (160 L, 35 gal) stored at pressure in the valve rig and piping located on the ceiling near the northeast corner of the $5^{\text {th }}$ floor (Figure 3-1) to start the diesel engines, which, in turn, would supply power to operate the circulating pump. The maximum fuel flow was $5.3 \mathrm{~L} / \mathrm{s}$ (70 gal/min) at $340 \mathrm{kPa}(50 \mathrm{psi})$.

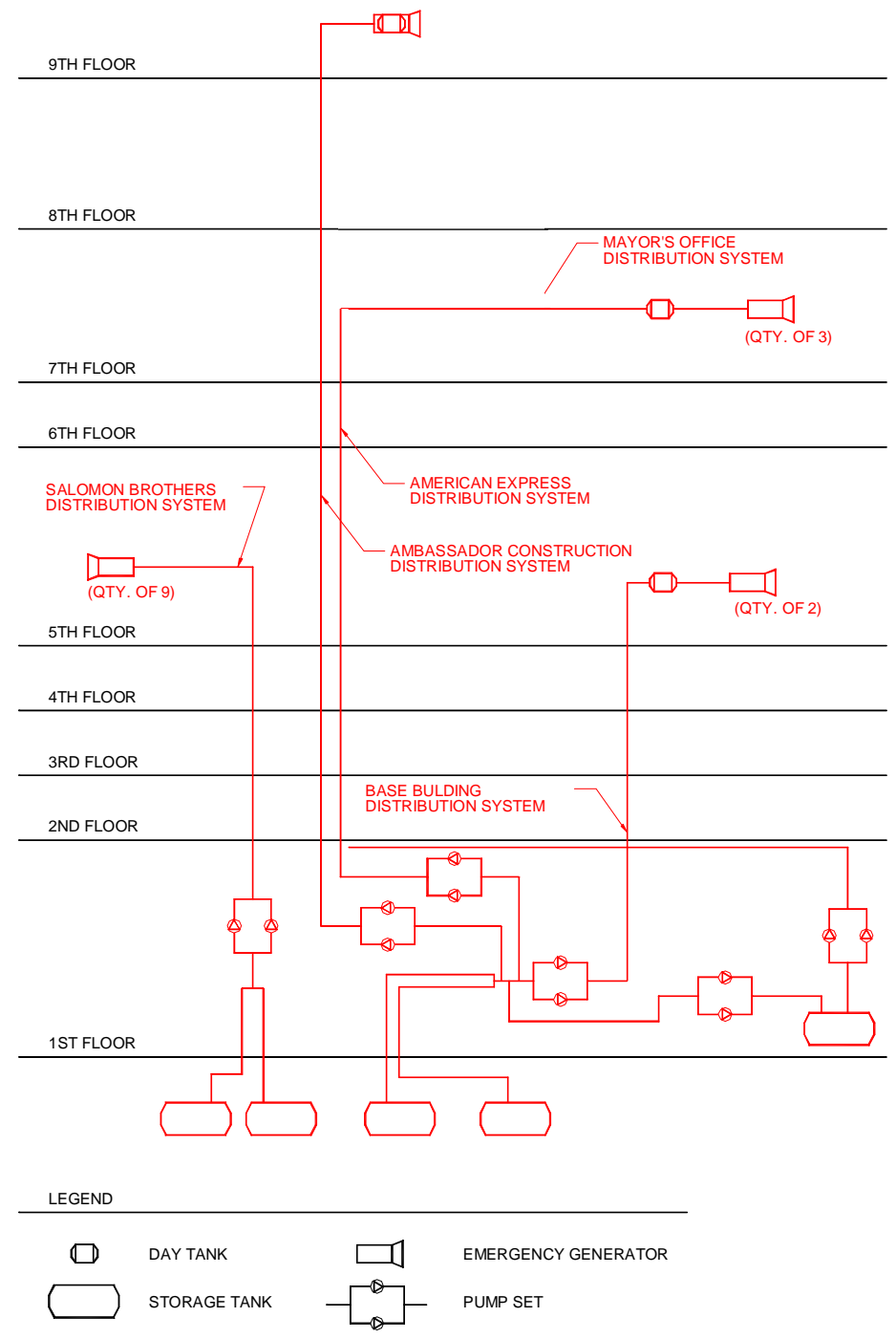

NCSTAR 1-1J, based on Figure 8-1

Figure 3-11. Section view of fuel oil distribution components in WTC 7.

\footnotetext{
${ }^{11}$ Renovations were made in 1988 and 1989 to the space leased by Salomon Brothers Inc. in WTC 7. In 1998, Smith Barney Inc. merged with Salomon Brothers Inc. to form Salomon Smith Barney. In 1999, Salomon Smith Barney Inc. merged with Citicorp Inc. to form Citigroup Inc.
} 


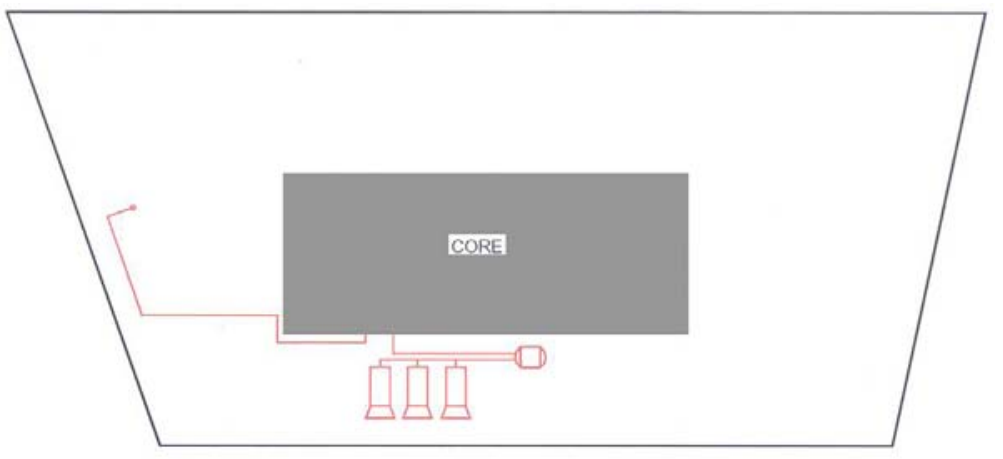

NCSTAR 1-1J, Figure 6-2

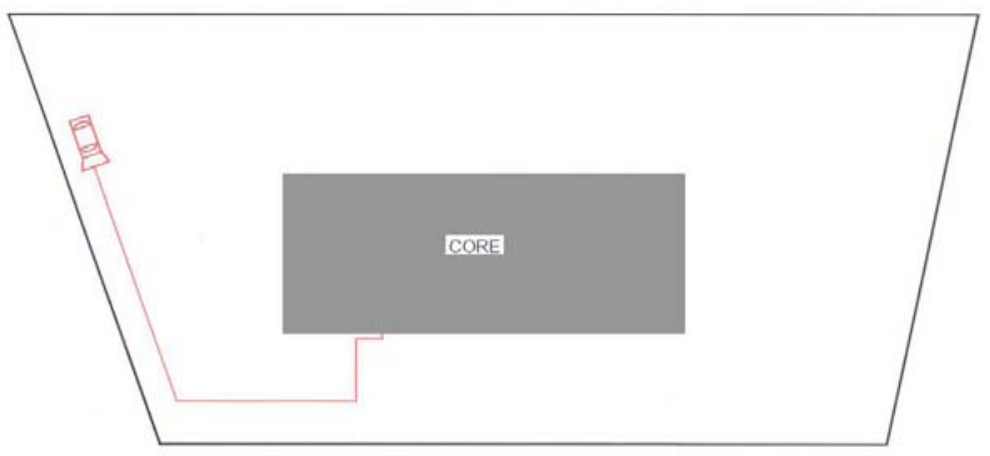

Figure 3-13. Schematic of the $9^{\text {th }}$ floor of WTC 7 showing the locations of the electrical generator and the fuel line that connected it to below-ground fuel tanks.

NCSTAR 1-1J, Figure 4-2

The Mayor's OEM system, installed in 1999, consisted of a separate $27 \mathrm{~m}^{3}$ (6,000 gal) storage tank located on the $1^{\text {st }}$ floor of the building, along with its pumps, in a separate space from the other pumps. Three generators and a $1.25 \mathrm{~m}^{3}$ (275 gal) day tank were located on the $7^{\text {th }}$ floor.

\section{Fuel Accounting}

The Silverstein Properties building management had a contract with a fuel oil supplier to check and fill the base building system supply tanks (which had a total capacity of $110 \mathrm{~m}^{3}$ (24,000 gal)) regularly. Thus, NIST assumed that the base building tanks were full on September 11, 2001. In the days following the attacks on the WTC, a contractor (GZA 2002) recovered an estimated $100 \mathrm{~m}^{3}$ (23,000 gal) of fuel from these tanks. The uncertainty in these volumes is unknown, and NIST assumed that approximately $10 \mathrm{~m}^{3} \pm 10 \mathrm{~m}^{3}$ was unaccounted.

The distribution system was designed to keep the three day tanks full by transferring fuel from the base building supply tanks, so NIST also assumed that these day tanks (total capacity of $2.7 \mathrm{~m}^{3}$ (600 gal)) were full on September 11, 2001. The fate of this fuel is unknown. The volume of the riser pipes was modest compared to the volume of the tanks, and it was not known how full of fuel they might have been. Thus, NIST assumed that the most fuel that could have been supplied to fires from the base building system was about $2.7 \mathrm{~m}^{3}$ (600 gal).

The two $27 \mathrm{~m}^{3}$ (6,000 gal) tanks for the Salomon Brothers system were found to be damaged by WTC 7 collapse debris and were empty; there was no significant quantity of fuel identified in the soil and gravel below the tanks. Thus, all $55 \mathrm{~m}^{3}$ (12,000 gal) of fuel from this system would have been available to feed 
fires either at ground level or on the $5^{\text {th }}$ floor. The latter scenario would have required power to the pumps to remain, and a breach in the $5^{\text {th }}$ floor fuel system that was not sensed by the leak detection system in the outer pipe. (Refer to Chapter 9 for further details on this scenario.)

No trace of the Mayor's OEM system tank nor the $27 \mathrm{~m}^{3}$ (6,000 gal) of fuel it contained was ever found, so NIST assumed that the full volume might have been available to the building fires. This tank was located in a $1^{\text {st }}$ floor room adjacent to the elevator bank, enclosed in $4 \mathrm{~h}$ fire rated construction, and provided with a total flooding fire suppression system. Since the pumps used to fill the day tank on the $7^{\text {th }}$ floor would only run when the low fuel switch came on, and since the distribution piping would drain by gravity when the pumps were off, most of this fuel likely would only have been available on the $1^{\text {st }}$ floor. It is, however, possible that a break in the day tank supply line on the $7^{\text {th }}$ floor could have led to a diesel fuel pool on this floor. (See Section 9.2.2.)

\subsubsection{Other Combustibles}

In interviews with staff of WTC tenants, The Port Authority, and Silverstein Properties, NIST was told that there were no exceptional combustibles in the building other than the aforementioned small arms and limited ammunition on the $9^{\text {th }}$ floor.

\subsection{REFERENCES}

Cantor 1985. Irwin G. Cantor P.C., Structural Engineers, Structural Drawings, 7 World Trade Center.

Flack and Kurtz 1988. Flack and Kurtz Mechanical Engineers, Mechanical and Electrical Drawings for Salomon Brothers 7 World Trade Center Headquarters.

GZA GeoEnvironmental, Inc. 2002. Underground Storage Tank Closure Report, September 9.

Roth 1985. Emery Roth \& Sons P.C., Architects, Architectural Drawings, 7 World Trade Center.

SOM 1988. Skidmore, Owings \& Merrill, Architects / Engineers, Architectural Drawings for Salomon Brothers 7 World Trade Center Headquarters.

Syska \& Hennessy 1985. Syska \& Hennessy Engineers, Mechanical, Electrical, and Plumbing Drawings, 7 World Trade Center. 
This page intentionally left blank. 


\section{Chapter 4 \\ FiRE PROTECTION MEASURES}

\subsection{OVERVIEW}

Active and passive elements were used in the fire protection systems of WTC 7. The active fire protection systems in WTC 7 consisted of fire sensors and alarms, notification systems, automatic fire sprinklers, water supplies, and smoke management. The sprinkler systems were the first line of defense. Water stored in the building from public sources or pumped from fire apparatus was supplied through dedicated piping to the area of the fire. Also present in the buildings were hoses, pre-connected to a water supply through standpipes located in the stairwells and other utility shafts. The standpipes provided hose connections at each floor for the Fire Department of the City of New York (FDNY). In addition, preconnected standpipe hoses were installed for trained occupants to suppress fires.

Occupants in the building depended on the fire alarm and emergency notification system to detect fires and provide information for emergency evacuation. Capabilities were also designed for the ventilation system to operate in a way to purge smoke produced by fires from the building. Smoke purging was intended to be used for post-fire clean-up, but could be used during a fire event at the discretion of the FDNY.

Passive fire protection provided a second line of defense against structural damage by uncontrolled fires. The passive components included both horizontal and vertical fire barriers and spray-applied fire resistive material (SFRM). The concrete floor slabs were fire rated, as were the walls surrounding the power transformers and the building core. Because the building was fully sprinklered, no partitioning of the open floors (within a single tenant space) with demising walls was required by the New York City Building Code. Nonetheless, some of the interior walls in the tenant spaces provided temporary obstructions to flame spread. The structural steel columns, beams, and girders, as well as the underside of the concrete floor slabs, were coated with Monokote MK-5, a spray-applied fire resistive material, as documented in Chapter 2.

NCSTAR 1-4 includes a thorough examination of the design and installation of the active fire protection systems in WTC 7 (as well as in WTC 1 and WTC 2) and a description of the normal operation of fully functional systems and their potential effectiveness for controlling the fires on September 11, 2001. The applicable building and fire codes and standards, as well as the history of fires in these buildings, were also documented in NCSTAR 1-4. The following section provides a summary of the key information from NCSTAR 1-4 as it pertains to WTC 7.

There was no evidence to suggest that the fires that eventually brought WTC 7 down originated or propagated within the Con Edison substation located on the lower floors of WTC 7 (Appendix A). Thus, the Con Edison fire protection systems are not presented here. (Information on the design and operation of the substation can be found in Appendix A of this report.) 


\subsection{FIRE ALARM SYSTEMS}

The fire alarm system for WTC 7 was the original system installed during the initial construction of the building (NIST NCSTAR 1-4C). Modifications were performed as needed to accommodate renovations and tenant fit-outs. Project development documentation found and analyzed was limited in this investigation to design criteria, specifications, riser diagrams, and a limited number of tenant fit-out drawings that included fire alarm work.

The Basic Design Criteria document, labeled as "Revised November 5, 1984," was prepared by Syska \& Hennessy, and it referenced the applicable local building codes at the time of construction. The basic system was required to contain the following components to monitor and annunciate the status of its devices and initiate an appropriate response (Syska \& Hennessy 1984):

- $\quad$ A Fire Command Station (FCS) located in the lobby of the building on the entrance $\left(3^{\text {rd }}\right)$ floor;

- Remote alarm display panels in the Mechanical Control Center and Fire Safety Director’s location;

- Manual fire alarm stations provided in each story along the path of escape with additional stations installed so that the maximum travel distance between stations would not exceed $200 \mathrm{ft}(60 \mathrm{~m})$;

- Speakers located on all floors and stairways that could be operated in the FCS- the elevator intercommunication system was provided separately;

- Visual alarm devices (strobes) in public common use areas;

- Floor warden stations on each floor that provided two-way communication with the FCS;

- Standpipe firefighter telephone system with communication stations provided at the FCS, each floor near the standpipe riser, gravity tank rooms, and fire pump rooms;

- Fire sprinkler water flow alarm and malfunction monitoring;

- Tenant fire alarm panels monitoring for alarm and system fault conditions;

- Fan shutdown and restart system for smoke control;

- Elevator recall upon its smoke detector activation;

- $\quad$ Fire stair door releases; and

- Smoke and heat detection.

The only performance criterion in the design that exceeded the minimum requirements of the applicable codes was the statement requiring that "All monitoring, communication and control for the fire alarm system shall be on a separate multiplex channel with its own processor.” (Syska \& Hennessy 1984) 


\subsubsection{System Architecture and Operation}

The fire alarm system chosen for WTC 7 was the Firecom 8500 (Syska \& Hennessy 1984). The main user interface was at the Fire Command Station, where the head-end fire alarm panel provided central monitoring and control through a monitor with keyboard, illuminated displays, microphone, and control switches. The Class B Signaling Line Circuit riser from the head-end panel went to a Terminal Transmission Box (TTB) on each floor, which was the data gathering panel for the detection, notification and control devices for each floor. The TTB provided Class B conventional Initiating Device Circuits and Notification Appliance Circuits for the manual pull stations, smoke detectors, and speakers. The TTB also provided the circuit interfaces to control the door releases and air handling units. Bulk amplification for all loudspeakers associated with the emergency voice alarm communication system was generated from the $5^{\text {th }}$ floor.

The specifications provided a sequence of operation during alarm conditions for the different types of devices found on the fire alarm system (NIST NCSTAR 1-4):

1. Activation of a manual pull station, smoke detector, heat detector, duct detector, or sprinkler water flow switch would:

a. Automatically sound all loudspeakers on the floor of alarm and the floor above;

b. Automatically transmit the fire alarm signal to the fire department via a central monitoring office;

c. Unlock the doors in the fire stairs; and

d. Sound a fire alarm signal and provide location identification at the FCS, Mechanical Control Center, and Fire Safety Director's location.

2. In addition to \#1 above, the duct detectors would:

a. Stop air supply and air return from the floor of alarm activation by automatically shutting down air supply and return fans serving these floors; and

b. Open smoke exhaust dampers of smoke shafts on the floor of alarm activation, and start associated smoke exhaust fans.

3. In addition to \#1 above, the elevator lobby detectors and sprinkler water flow switches would cause elevators serving the floor of alarm activation to return non-stop to street floor or to the lowest landing above street floor when the lowest landing of the elevator bank was above street floor. If the lowest landing were the floor of alarm activation, the elevator would return to a landing two floors above.

\subsubsection{Design, Installation and Maintenance}

NIST reviewed documentation consisting of modified riser as-built diagrams and floor plans with fire alarm device locations (Syska \& Hennessy 1984). Comprehensive as-built drawings for the system were not located. 
The modified riser diagrams were conceptual in nature and provided the installation contractor with the number of devices to be installed on each floor, type of fire alarm equipment on each floor, and the number and type of wire interconnecting the devices and equipment. The modified riser diagram had areas crossed-off, which indicated that the area had undergone renovation. Additional renovation drawings provided a section of the riser with its modifications. The final drawings consisted of the partially modified riser diagrams with areas crossed-out, separate drawings containing a revised section of the riser, and floor plans with the locations of the devices on each designated floor.

From the available drawings, it appears that the contractor was responsible for determining the final circuit configurations for the devices and equipment. Limited information was found on the specific location of the fire alarm control equipment, initiating devices, and communication equipment.

The $3^{\text {rd }}$ floor lobby was designated as the FCS. On a typical floor, manual pull stations were located at each stair entrance, and smoke detectors were provided in electrical/telephone closets and in elevator lobbies. Sprinkler water flow switches and valve supervisory switches in each stairwell were monitored by fire alarm interface devices. Duct smoke detector locations were not identified, but the criteria required detectors to be installed in heating, ventilation and air-conditioning (HVAC) systems over $3,400 \mathrm{~m}^{3} / \mathrm{h}\left(2,000 \mathrm{ft}^{3} / \mathrm{min}\right)$. Fire warden stations were typically installed on the north wall outside the elevator lobby.

The Investigation Team did not locate drawings that provided guidance on the installation of the fire alarm devices to meet tolerances required by code and the manufacturer. The riser diagrams indicated that the smoke detector, manual pull station, speaker and strobe circuits were configured to be a Class B type. The use of a Class B circuit was consistent with the minimum requirements for performance, but a Class B circuit does not have the higher level of survivability associated with a Class A circuit.

The Investigation Team also did not locate drawings showing the number of wires required to run between each device, and between the device and equipment, nor were fire alarm power calculations located to document the capability of the fire alarm equipment to power the number and type of devices connected to the equipment. No quality control documentation was found for the installation, and no testing and commissioning procedures were located.

Inspection, testing, and maintenance were mandated by the applicable building codes after a fire alarm system was installed and in operation. The building owner was responsible for inspection, testing, and maintenance of the systems. The inspection, testing and inspection were permitted to be done by qualified and experienced personnel employed by the owner, or the work could be performed under contract. These duties were conducted by a contractor; and, based upon the information reviewed for 2000 and 2001, were adequately documented.

\subsubsection{Fire Alarm System Performance on September 11, 2001}

Information on the performance of the WTC 7 fire alarm system on September 11, 2001 was limited to the record of the offsite system monitoring company. The printout shown in Figure 4-1 indicates the system registered an alarm at 10:00:52 a.m., just after the collapse of WTC 2. Even though a fire alarm is indicated, alternatively the record might have been the result of dust entering smoke detectors. Although the entire alarm history record was obtained from AFA Protective Services (AFA), the system monitoring company, the amount of information it shows is typical of system monitoring operations and is meager. 
Records show that the system was placed on test condition every morning at about the same time, and specifically had been tested for the seven days preceding September 11, 2001. The readout for this date is shown in Figure 4-1.

\begin{tabular}{|c|c|c|c|c|}
\hline 09/11/01 & $14: 48: 22$ & 4612 & 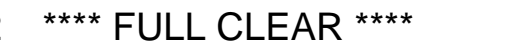 & \\
\hline 09/11/01 & $14: 47: 22$ & LATE 3923 & SYSTEM TEST OVER & \\
\hline 09/11/01 & $14: 47: 22$ & COMMENT: & TEST: ALL & \\
\hline 09/11/01 & $14: 47: 21$ & COMMENT: & LAST SET: 09110164742 & \\
\hline 09/11/01 & 10:00:52 & $1510 \mathrm{CO}$ & TO CLASS E & *T \\
\hline 09/11/01 & $06 ; 47: 43$ & COMMENT: & RIC: WILLIAMS & \\
\hline 09/11/01 & $06: 47: 03$ & 4210 & PLACE ON TEST & CAT:11 \\
\hline 09/11/01 & $06: 47: 03$ & COMMENT: & $\begin{array}{llll}091101 & 647 & 091101 & 1447\end{array}$ & \\
\hline 09/11/01 & 06:47:02 & COMMENT: & TEST: ALL & \\
\hline 09/11/01 & 06:05:01 & $\mathrm{RP}$ & 20 TIMER TEST & \\
\hline
\end{tabular}

Figure 4-1. Monitoring station history tape record for the WTC 7 fire alarm system on September 11, 2001.

The fire alarm history tape record is read from the bottom to the top. Some entries occur as the result of normal operations, and others are the result of actions taken by operators. The bottom line of the record shows that at 6:05:01 a.m. on September 11, 2001, the fire alarm system completed a normal communications check with the central monitoring station. This check was made every day.

At 6:47:02 a.m., AFA placed WTC 7 in a "TEST: ALL" condition. This was normally done in response to a request from the building manager. Ordinarily, it was requested when maintenance or other testing was being performed on the system, so that any alarms received from the system were considered the result of the maintenance or testing and were ignored. NIST was told by AFA that for systems placed in the TEST condition, alarm signals were not shown on the operator's display, but records of the alarm were recorded into the history file. ${ }^{1}$

At 6:47:03 a.m., the record includes an explanation of the request to put the system in the TEST condition. Continuing to read from bottom to top, the date and time the system was placed in TEST was recorded. In this case it was 091101647 (6:47 a.m., September 11, 2001), and the system would have automatically gone back to normal monitoring after eight hours, a system default value, at 0911011447 (September 11, 2001, 2:47 p.m.). On the next line above, "RIC" identifies the AFA operator; 4210 is a code number for the "PLACE ON TEST" message. CAT:11 indicates the authority of the person requesting the action, identified in the next line as Williams. Records indicated that the building alarm system was often placed on test.

At 10:00:52 a.m., a fire condition [1510 CO TO CLASS E] was indicated in WTC 7. The *T at the right end of that record indicates that the system was in TEST at the time. The alarm record also shows that the fire condition was in AREA 1. NIST has been told by AFA that AREA 1 was not a specific area within

1 Letter from President, AFA Protective Systems to NIST, July 16, 2003. 
the building, but referred to the entire building. In other words, a fire detected in any fire alarm zone in the building would have resulted in the same AREA 1 identification at the monitoring station. The time, 10:00:52 a.m., is shortly after the collapse of WTC 2. NIST could not determine whether this fire alarm was triggered by smoke from a fire or by dust entering smoke detectors. None of the interviews conducted by the Investigation Team contained any mention of an alarm received at the Fire Command Station.

At 2:47:21 p.m. and 2:47:22 p.m. (14:47:21 hr and 14:47:22 hr), at the time the eight hour "TEST: ALL" condition was set to expire, additional actions were recorded that ended in an operator (DYJ) entry to "FULL CLEAR.” Since there were several large fires in the building at this time (Section 5.6), it appears that either the building alarm system was not functioning after about 2:47 p.m. (and probably after 10:01 a.m.), or that the offsite monitoring system or its link to WTC 7 was incapacitated in some way.

A much greater amount of information would have been collected and recorded by the fire alarm equipment within WTC 7. None of that information was recovered from the building systems, which were destroyed in the collapse. Typically, and in the case of WTC 7, specific fire information beyond the fact that a fire condition has been detected is rarely sent to the monitoring site.

\subsection{SMOKE MANAGEMENT SYSTEMS}

In the event of fire in WTC 7, there were two primary means to control smoke movement throughout the building:

- Smoke barriers, which were typically integrated into the architecture of the building, as well as into the ductwork through which heating, ventilation, and air-conditioning (HVAC) air flowed. The use of smoke barriers is referred to as compartmentation, and walls and smoke dampers are used to form these compartments.

- Air movement equipment, either dedicated for smoke management or used to provide HVAC air to the building.

The design of the smoke management systems was guided by local building code requirements, widely used and accepted installation standards, and fire protection engineering practice. The design and installation of the smoke management systems in WTC 1, WTC 2 and WTC 7 have been documented in NCSTAR 1-4D; this section provides an overview of the systems in WTC 7.

The original building layout consisted of a mechanical equipment room located on each floor. Building ventilation was provided on the tenant floors (Floors 7 through 47) for the base building configuration in WTC 7 by supply air fans located on each floor. As shown in Figure 4-2, conditioned air was distributed to the floor in two zones, corresponding to the north/east, and south/west portions of the building. The fan room served as a return plenum. Return air was drawn into the fan room via ducts that connected the fan room to the return air plenums above the occupied space of each floor. Make-up (outdoor) air was drawn into the fan room via make-up air shafts that connected to the exterior of the building either at the roof or at the $6^{\text {th }}$ floor via louvers through the side of the building. 


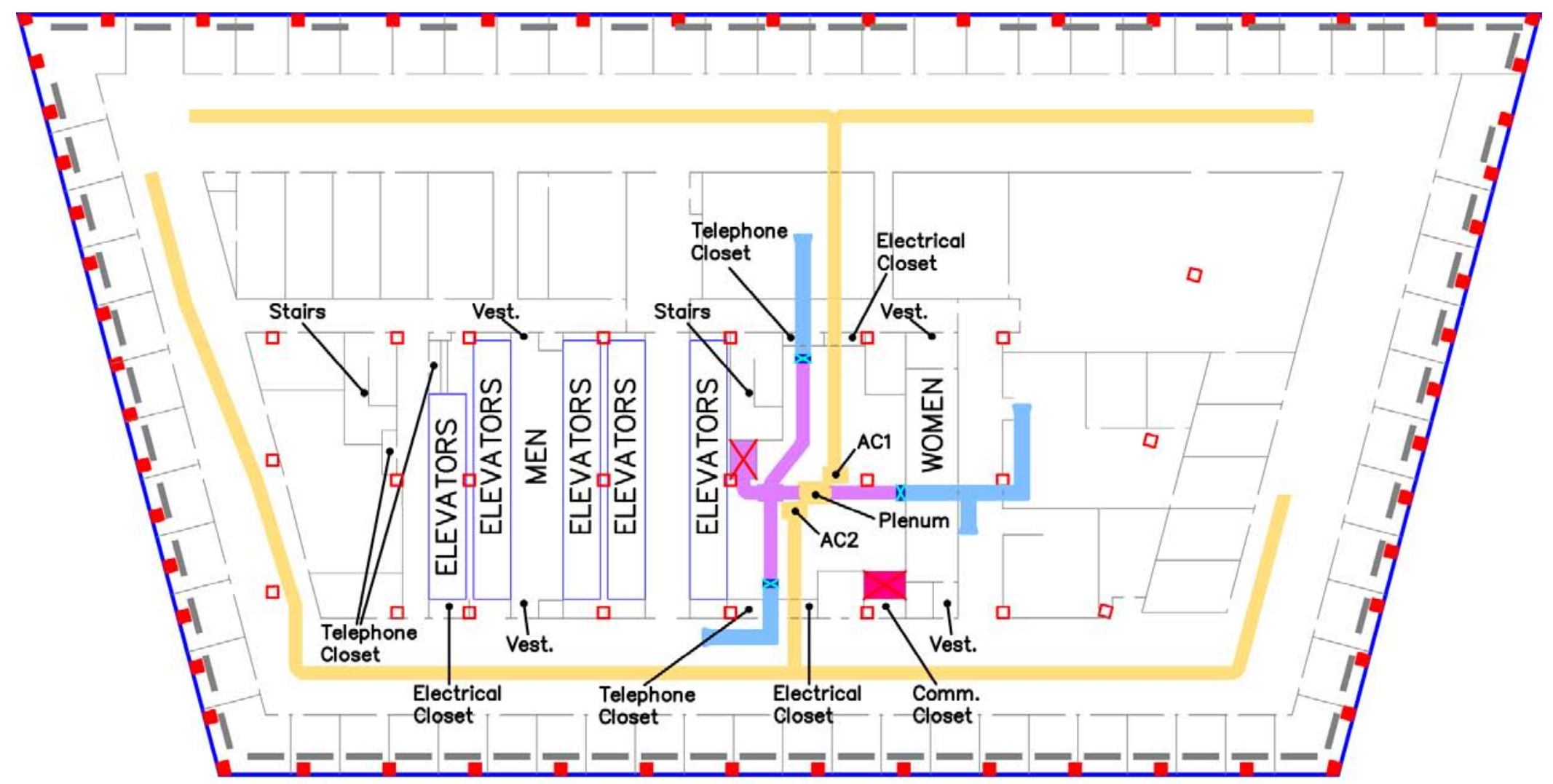

$\square$ Supply Fans/Ductwork

Return Ductwork

$\approx$ Return Dampers

Smoke Exhaust/Purge Ductwork

$\triangle$ Smoke Exhaust/Purge Shaft

Drawing based on architectural and mechanical design drawings provided by Emery Roth \& Sons (1985),

Cantor (1985), Syska \& Hennesy (1985), and Flack \& Kurtz (1988). Some of the details may differ from the actual layout on September 11, 2001.
Make-up Air Shaft

Perimeter Hot Water Radiant Heater

Figure 4-2. Air distribution system, $24^{\text {th }}$ floor, WTC 7. 
Consistent with the NYCBC, the WTC 7 HVAC systems were designed to incorporate a smoke purge mode, by which each floor of the building could be exhausted/purged of smoke manually on a floor-by-floor basis from the Fire Command Center, which was located on the $3^{\text {rd }}$ floor of the building at the main lobby security desk. Two smoke exhaust fans were originally located within the building on the $6^{\text {th }}$ floor and $47^{\text {th }}$ floor. The return air ductwork was connected to the exhaust duct. Return air either dumped into the fan room via the return dampers in each branch duct or was exhausted via the smoke exhaust riser. A smoke exhaust damper would have opened at the shaft within each mechanical room, and the return dampers would have closed to exhaust smoke in the smoke purge mode. Curtain fire dampers were located throughout the building where ductwork crossed fire rated shaft walls, consistent with the NYCBC. Separate pneumatic smoke dampers were used in the fan room to direct airflow within HVAC ductwork.

During the early 1990s, Salomon Smith Barney (SSB) performed a major tenant retrofit to Floors 28 through 45. The retrofit included the combining of adjacent floors into single floors, the relocation of HVAC shafts, and the provision of new HVAC equipment to supplement base building equipment. This renovation included changes to the smoke management system, detailed in NIST NCSTAR 1-4D.

The building operations manual for WTC 7 specified three alarm modes pertaining to operation of the building HVAC systems. ALARM-1 initiated shutdown of HVAC equipment based on duct smoke detection. ALARM-2 initiated smoke purge on the affected floor. ALARM-3 specified the smoke purge sequence for non-affected floors. The smoke management sequence pertaining to the smoke purge function involved exhausting the fire floor and pressurizing the remaining floors with supply air.

Local Law \#16 required that all buildings in occupancy group E (business), which included WTC 7, be provided a manual override capability for exhausting one floor at a time at a rate of six air changes per hour, or $1 \mathrm{cfm} / \mathrm{ft}^{2}$ of floor area, whichever is greater. For WTC 7, with a footprint area of approximately $48000 \mathrm{ft}^{2}$, this would require an exhaust capacity of at least $48,000 \mathrm{ft}^{3} / \mathrm{min}\left(82,000 \mathrm{~m}^{3} / \mathrm{h}\right)$. The base building system serving the lower floors of the building provided a smoke exhaust capacity of $36,000 \mathrm{ft}^{3} / \mathrm{min}\left(61,000 \mathrm{~m}^{3} / \mathrm{h}\right)$, which was not consistent with the minimum value specified by code. An $84,000 \mathrm{ft}^{3} / \mathrm{min}\left(143,000 \mathrm{~m}^{3} / \mathrm{h}\right)$ exhaust fan was provided for the SSB floors during the tenant retrofit, which exceeded the capacity required by code.

WTC 7 was sprinklered throughout and was, therefore, exempted from the requirement for stair pressurization systems. The building was provided with a Class E fire alarm system consistent with the NYCBC, was provided with emergency power serving all emergency systems, and was equipped throughout with fire dampers at duct penetrations into vertical shafts, consistent with the NYCBC.

NIST found no documentation to indicate whether the smoke management system operated or did not operate on September 11, 2001. The following inferences indicate that it was unlikely that the system was in operation that day. First, as noted in Section 6.5.2, around 11:00 a.m., the stairways were filling with smoke, indicating that the smoke management system was not in use up till that time. Few people entered the building after that time. Second, at about 2:30 p.m., the decision was made to abandon the building (Section 6.6), so the system was not turned on after that. Third, in the NIST interviews with FDNY personnel, there was no mention of action to activate the smoke purge system. Fourth, none of the visual images showed smoke flowing from the exhaust louvers on Floors 6 and 47. 
Fire Protection Measures

\subsection{SPRINKLERS, STANDPIPES, AND PRECONNECTED HOSE SYSTEMS}

\subsubsection{Overview}

Available documents and drawings indicated that automatic fire sprinkler systems were installed in nearly all areas of WTC 7. The exceptions were the electrical equipment spaces (including switchgear, networking, and switchboard rooms), generator rooms, and bathrooms. In addition, the $5^{\text {th }}$ floor was not protected by sprinkler systems, with the exception of the mechanical space on the east side of the core (Syska \& Hennessy 1984). The loading berth and fuel oil pump rooms in WTC 7 were protected by drypipe sprinkler systems. The first floor room containing the 6,000 gal fuel oil tank was protected by an Inergen clean agent fire suppression system. ${ }^{2}$ The elevator storage area beneath the tank was protected by a wet pipe sprinkler system.

A standpipe system was installed in each of the two stairwells. Pre-connected hoses were located in the stairwells at each floor and were connected to the standpipe. In addition, a supplemental pre-connected hose cabinet was located on the east side of each floor. Additional hose cabinets were installed in different locations on different floors in order to achieve the required reach for the hose lines.

\subsubsection{Details of the Standpipe and Sprinkler Riser Systems}

The primary water supply for WTC 7 was provided by the 12 in. water main beneath Washington Street. Fire department connections (FDCs) were located on the south, east, and west sides of the building. A $3 \mathrm{~m}^{3} / \mathrm{min}$ (750 gal/min) manual fire pump that served the entire building was located on the ground floor.

Three vertical zones within WTC 7 were identified based on the water source and flow path (Figure 4-3).

- Low zone. A $2 \mathrm{~m}^{3} / \mathrm{min}$ (500 gal/min) automatic fire pump, located on the ground floor, supplied the sprinkler and dual standpipe systems from the ground floor through the $20^{\text {th }}$ floor. A cross connection main, located on the $20^{\text {th }}$ floor, connected the risers to each other; an isolation valve could be closed to isolate the risers from each other. The pump was provided with an emergency power source via an automatic transfer switch (Syska \& Hennessy 1984).

- Mid-level zone. The $21^{\text {st }}$ floor through $39^{\text {th }}$ floor sprinkler systems and dual standpipe systems running from the $21^{\text {st }}$ floor through the $44^{\text {th }}$ floor were supplied from two connected, gravity-fed water storage tanks on the north side of the $47^{\text {th }}$ floor. Each tank had a holding capacity of $70 \mathrm{~m}^{3}$ $(17,500$ gal). The water could be used for both domestic plumbing and fire suppression, although the last 7,500 gal in each tank was reserved for fire use. The make-up water to fill each tank was supplied by three $1.7 \mathrm{~m}^{3} / \mathrm{min}$ (435 gal/min) capacity booster pumps via an 8 in. domestic express supply riser from the second floor. Each pump was provided with two float switches in each tank. A single pump operated when the water level dropped to a set point established by the electrode control unit. The pumps operated individually, but would operate simultaneously if the demand exceeded the capacity of one pump (Syska \& Hennessy 1984), whether due to domestic usage or fire water usage. A control valve in the discharge piping below each tank enabled isolating the tank from the standpipe and sprinkler systems.

\footnotetext{
${ }^{2}$ Inergen is a proprietary fire suppressant, consisting of $52 \%$ (by volume) nitrogen, $40 \%$ argon, and $8 \%$ carbon dioxide.
} 
- High zone. The $40^{\text {th }}$ floor through $47^{\text {th }}$ floor sprinkler systems and dual $45^{\text {th }}$ floor through $47^{\text {th }}$ floor standpipe systems were supplied from the storage tanks on the $47^{\text {th }}$ floor via a $2 \mathrm{~m}^{3} / \mathrm{min}$ ( $500 \mathrm{gal} / \mathrm{min}$ ) booster pump on the $46^{\text {th }}$ floor. The pump was a single stage pump rated for $380 \mathrm{kPa}$ (55 psi) at $2 \mathrm{m3} / \mathrm{min}$ (500 gal/min) (Syska \& Hennessy 1984). The water discharged from the tank on the $47^{\text {th }}$ floor, flowing down to a cross connection on the $44^{\text {th }}$ floor where it fed each riser.

The water supply met the requirements of the NYCBC 9 (NIST NCSTAR 1-1E).

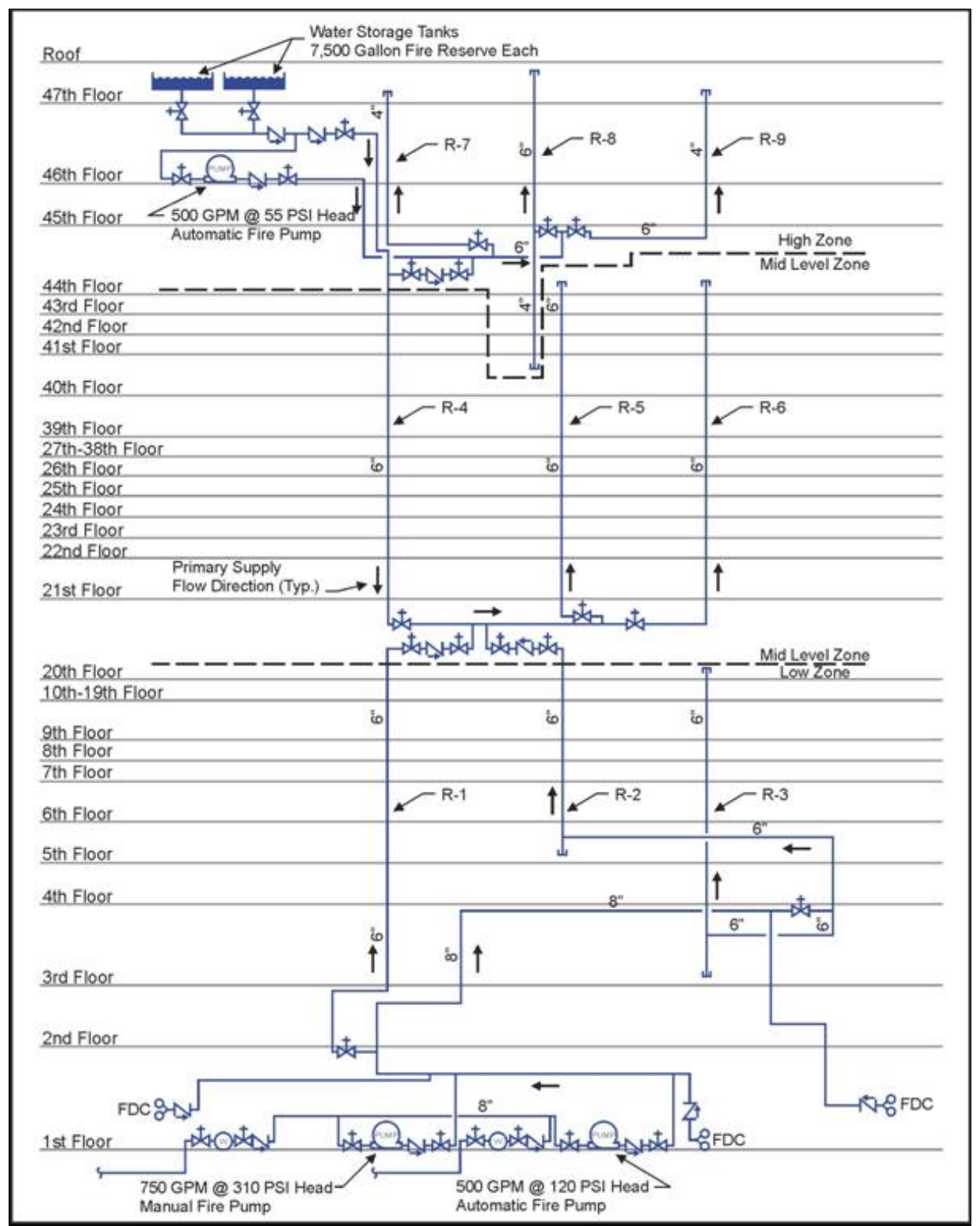

Source: NIST NCSTAR 1-4B

Figure 4-3. WTC 7 water riser schematic. 
Check valves were located at the top of the mid-level zone risers at the connection with the high zone cross connection main. The check valve was oriented so that water could not flow from the high zone down to lower zones. However, the high zone could be served from lower zones through the check valve by the manual fire pump, which served as a secondary supply. Check valves also prevented water from flowing from the mid-level zone down to the low zone. However, the mid-level zone could be served from the low zone through the check valves by the manual fire pump (which served as a secondary supply) or from excess pressure served by the city supply and automatic fire pump serving the low zone.

The emergency power generators described in Chapter 3 provided back-up power to emergency systems in the building, including the fire pumps.

\subsubsection{Automatic Sprinkler System Performance under Selected Fire Scenarios}

Hydraulic calculations were performed to evaluate the expected sprinkler system performance based on the configuration of the water supply (NIST NCSTAR 1-4B). The objective of the analysis was to characterize the capabilities of the water supply within each water supply zone. A commercial computer program, Hydraulic Analyzer of Sprinkler Systems, Version 7.5, was used to perform the calculations (HRS Systems 2004).

Calculations were performed with variations in the number of sprinklers flowing water for the high and mid-level zones to observe the effects on how long the flow could be maintained. For the low zone sprinkler systems, water was supplied from an automatic fire pump drawing suction directly from the NYC distribution. Therefore, the supply would be continuously provided as long as the water distribution and electrical systems were intact and operational.

The hydraulic analyses relied on the minimum delivered density and pressure requirements in NFPA 13 as the criteria for evaluating the fire control capacity of the sprinkler systems. These required densities and pressures are based on the assumption that an installed fire sprinkler system is designed to control a single fire. In addition, in the analyses performed here, small fires were assumed to be approximately the size of the area covered by a four-sprinkler array (i.e., approximately $65 \mathrm{~m}^{2}, 700 \mathrm{ft}^{2}$ ). In fact, available performance history indicates that typical fires in high-rise office buildings are controlled or suppressed by fewer than four sprinklers, lending additional conservatism to the estimates of system capacity presented here. Finally, the calculations were based on availability of the primary water supplies only, without any consideration for fire department actions to provide a secondary water supply. In NYC such action is routine, and the secondary water supply is considered infinite in duration, with equivalent or higher capacity to the primary water supply.

Representative system configurations were selected within each water supply zone to provide bounding results (in terms of available pressure, flow and duration) for each vertical hydraulic zone in the buildings. The calculations were based on the following bounding conditions for each vertical zone:

- Number of Operating (Opened) Sprinklers: Four sprinklers (smaller than the required design area); 8 to 15 sprinklers (design area for Light or Ordinary Hazard Occupancy); 18 to 25 sprinklers (larger than the required design area).

- $\quad$ Floor Level within the Vertical Zone: $47^{\text {th }}$ floor (highest floor system in high water supply zone); $40^{\text {th }}$ floor (lowest floor system in high water supply zone); $39^{\text {th }}$ floor (highest floor system in mid- 
level water supply zone); $21^{\text {st }}$ floor (lowest floor system in mid-level water supply zone); $20^{\text {th }}$ floor (highest floor system in low water supply zone); $1^{\text {st }}$ floor (lowest floor system in low water supply zone)

Supply calculations for each combination of these conditions provided estimates of the water flow and pressure that would be expected based on typical sprinkler system arrangements. The duration was determined by dividing the storage capacity by the calculated flow. The calculations did not account for the supplemental make-up supplies from the automatic refill lines supplied by the domestic water supply systems. The results of these calculations were intended to approximate the actual delivered discharge densities based on representative sprinkler system layouts provided from the available documentation of the systems. The results represent the actual performance more accurately than would a calculation using the minimum required flows determined by multiplying the density times the design area specified by NFPA 13 for the applicable hazard.

The calculations for Light Hazard areas in WTC 7 used a coverage area of $16 \mathrm{~m}^{2}\left(168 \mathrm{ft}^{2}\right)$, a value for the discharge coefficient, $\mathrm{k}$, of $5.6 \mathrm{gal} / \mathrm{min} / \mathrm{psi}^{1 / 2}$, and $1 / 2 \mathrm{in}$. orifice sprinklers. The first floor loading dock area was provided with a dry pipe sprinkler system and had a layout consistent with Ordinary Hazard spacing (coverage area of approximately $12 \mathrm{~m}^{2}\left(126 \mathrm{ft}^{2}\right)$ per sprinkler). Table $4-1$ is representative of the results for the different zones in WTC 7 for fire areas of $140 \mathrm{~m}^{2}\left(1,512 \mathrm{ft}^{2}\right)$ and either 9 or 12 sprinklers operating, depending upon whether it was designated as Light Hazard or Ordinary Hazard, respectively. Additional results of sprinkler configurations are presented in NCSTAR 1-4B.

The most demanding floor with regard to water supply duration is the lowest floor in the zone, due to the larger head pressure and flow. Reference Standard RS-17-2, Section 2-1 of the NYCBC, requires a minimum water supply duration of $30 \mathrm{~min}$, which was exceeded in all the calculations shown in Table 4-1.

Table 4-1. Calculated sufficiency of sprinkler water supply.

\begin{tabular}{|c|c|c|c|c|c|c|}
\hline Zone & Floor & $\begin{array}{c}\text { Sprinkler } \\
\text { Heads/Area } \\
\left(\mathbf{f t}^{2}\right)\end{array}$ & $\begin{array}{c}\text { Supply } \\
\text { (gal/min) }\end{array}$ & $\begin{array}{c}\text { Calculated } \\
\text { Delivered } \\
\text { Density } \\
\left(\mathbf{g a l} / \mathbf{m i n} / \mathbf{f t}^{2}\right)\end{array}$ & $\begin{array}{c}\text { Required } \\
\text { Density } \\
\left(\mathrm{gal} / \mathbf{m i n} / \mathbf{f t}^{2}\right)\end{array}$ & $\begin{array}{c}\text { Supply } \\
\text { Duration } \\
\text { (min) }\end{array}$ \\
\hline high & 47 & 9/1512 & 265 & 0.18 & 0.10 & 57 \\
\hline high & 40 & 9/1512 & 336 & 0.22 & 0.10 & 45 \\
\hline mid & 39 & 9/1512 & 245 & 0.16 & 0.10 & 61 \\
\hline mid & 21 & 9/1512 & 290 & 0.19 & 0.10 & 52 \\
\hline low & 20 & 9/1512 & 285 & 0.19 & 0.10 & unlimited \\
\hline low & 1 & 12/1512 & 311 & 0.21 & 0.15 & unlimited \\
\hline
\end{tabular}

A cluster of six cubicles occupied a floor area of about $380 \mathrm{ft}^{2}$. Thus, it appears that, if the primary water supply were intact, there would have been a sufficient delivered density and duration in all zones to control fires of four such clusters, either all on one floor or single clusters on four floors.

These calculations do not take into account any make-up (secondary) water supply. As noted in Section 4.4.2, the secondary water to the high and mid zones was supplied from the city water mains, so that under normal conditions, there would be a continuous water supply for an indefinite period of time. The 
only supply for the low zone was from the city water mains. Thus, should the city water mains be unavailable (as was the situation following the collapse of WTC 1 on September 11, 2001), there would still have been sufficient water to control four six-cubicle fires in the mid or high zones, but there would have been no water to control a fire in the lowest 20 floors.

\subsubsection{Supplemental Manual Operations and Related Procedures}

The City of New York has a challenge, in common with other large cities, involving firefighting operations among the ever-growing number of high-rise office buildings. The Fire Department of the City of New York (FDNY) addressed this challenge by developing a standard set of procedures for dealing with high-rise office building fires. In 1986, the FDNY developed Fire Fighting Procedures and Fire Operations for High-Rise Office Buildings to meet the challenge (FDNY 1990). Among the procedures and operations outlined in the manual were the methods used by the FDNY to supplement automatic sprinkler systems and standpipe systems within high-rise office buildings.

The NYC Building Code required all new high-rise buildings to have a primary water supply and a secondary water supply to supplement the fire protection water demands (NYCBC 1968). In buildings over $90 \mathrm{~m}$ (300 ft) in height, a manual fire pump, or combination of manual fire pumps must be installed as a secondary water supply. However, fire department connections (FDC) were also required as an auxiliary water supply. Therefore, in buildings over $90 \mathrm{~m}$ (300 ft) in height, the FDNY procedures included connecting to the FDC to provide a tertiary supply to the automatic sprinkler systems and standpipe systems in high-rise office buildings (NIST NCSTAR 1-1D and 1-1G). A system of colorcoded caps identified whether the FDC supplied a standpipe system, automatic fire sprinkler system, combined sprinkler and standpipe system, or a high pressure supply for upper floor level systems. Specific procedures and recommended pressures were outlined in the Fire Fighting Procedures and Fire Operations for High-Rise Office Buildings manual developed by the FDNY (FDNY 1990).

The FDNY had two types of pumper engines, conventional and high-pressure. The conventional pumpers contained two-stage pumps with either $4 \mathrm{~m}^{3} / \mathrm{min}$ (1 $\left.000 \mathrm{gal} / \mathrm{min}\right)$ or $8 \mathrm{~m} / \mathrm{min}$ (2 $000 \mathrm{gal} / \mathrm{min}$ capacity. The high-pressure pumpers contained a third stage capability that can supply $2 \mathrm{~m}^{3} / \mathrm{min}(500 \mathrm{gal} / \mathrm{min})$ at 4.8 MPa (700 psi). Whether used singly or supplementarily, these pumpers have the capability of supplying floors in high-rise buildings up to 110 stories. The Fire Fighting Procedures and Fire Operations for High-Rise Office Buildings manual suggested supplying the standpipe systems with at least two pumpers at two different siamese connections to ensure that an adequate water supply was added to the system.

The Fire Fighting Procedures and Fire Operations for High-Rise Office Buildings manual outlined the recommended pump pressures to be used based on floor level and nozzle type attached to the hose lines. The pressures were based on calculations that took into account nozzle pressure, friction loss of three lengths of $2 \frac{1}{2} \mathrm{in}$. hose, head loss, system friction losses, and the friction loss of two lengths of $3 \frac{1}{2} \mathrm{in}$. hose supplying the siamese FDC.

The WTC 7 building maintenance and engineering staff was familiar with the locations of emergency equipment and the required actions to support the systems in an emergency situation. Such actions during a fire event included starting the manual fire pump on the first floor. Other emergency actions included closing isolation valves to support systems in the case of a ruptured pipe. The WTC 7 operations and 
maintenance manual included a riser diagram that indicated the arrangement of valves on the systems (PANYNJ 1987). The use of system isolation valves was referenced as follows: "Emergency conditions unrelated to a system response to a fire, which may require actions based on this manual include: Isolation of a riser or sprinkler zone because of a rupture, also a mechanical failure which will activate the flow switch resulting in an alarm. Both conditions require isolation of the ruptured pipe or sprinkler head.”

\subsubsection{Suppression Systems Performance on September 11, 2001}

NIST learned from Investigation interviews that around 11:30 a.m., there was no water emerging from the hydrant system and no water in the standpipe system (Section 6.5 of this report). It was reported that hose lines connected to the standpipe system in WTC 7 were used to fight fires in other buildings of the WTC complex prior to the collapse of any of the buildings. Thus, it is likely that the primary water supply to the mid and upper levels of WTC 7 was diminished by the time the towers collapsed, and that the city water supply, which was the primary source of water for the lower level of the building, was severely compromised even before the fires began in WTC 7.

As will be seen in Section 5.6, fires were seen on the $22^{\text {nd }}, 29^{\text {th }}$, and $30^{\text {th }}$ floors as early as $12: 10$ p.m. The flames were no longer seen on the $22^{\text {nd }}$ floor after $12: 27$ p.m. and the fires on the $29^{\text {th }}$ and $30^{\text {th }}$ floors were no longer evident after 12:47 p.m. These three floors were in the mid-level zone, where the primary water supply to the automatic sprinkler system was from the tanks on the $47^{\text {th }}$ floor. As seen in Section 4.4.3, the sprinkler system had the capacity to control fires on multiple floors, each involving a few cubicles. Note, however, that since there were no people on those floors around this time, none of the Investigation interviews contained observations of functioning automatic sprinklers.

The water supply to the automatic sprinklers from the ground floor to the $20^{\text {th }}$ floor was directly from the city water supply, which had been interrupted following the collapses of the WTC towers. Thus, the fires on the $7^{\text {th }}$ through $13^{\text {th }}$ floors went unchecked by the automatic sprinklers. The only evidence of fire on the $19^{\text {th }}$ floor is a single photograph showing smoke marks above two windows on the far south of the west face (Chapter 5). NIST was unable to obtain evidence to indicate why this fire did not spread.

\subsection{ACTIVE FIRE PROTECTION SYSTEMS: SUMMARY OF INVESTIGATION FINDINGS}

\subsubsection{Function on September 11, 2001}

The active fire protection systems installed in WTC 7 were designed to alert building occupants to the smoke and heat produced early in a fire, to activate sprinklers in the fire zone when a threshold temperature was reached, and to manage the smoke in a way that aided evacuation and fire fighting operations. None of these systems played a role in preventing the loss of life (no lives were lost in WTC 7), increasing the effectiveness of fire fighting operations (the FDNY did not attempt to extinguish fires in WTC 7), or in keeping the building standing (WTC 7 collapsed about seven hours after WTC 1) on September 11, 2001. Nonetheless, a number of significant findings resulted from NIST's investigation of the active fire protection systems. These are listed below. 


\subsubsection{Alarm System}

- The alarm system in WTC 7 was only capable of determining and displaying (a) areas that had at some time reached alarm point conditions and (b) areas that had not. The WTC 7 alarm system recorded information at one location in the building: the FCS in the $3^{\text {rd }}$ floor lobby.

- On September 11, 2001, the fire alarm system installed in WTC 7 sent to the monitoring company only one signal indicating the time and date of a fire condition in the building. This signal, sent shortly after the collapse of WTC 2, did not contain any specific information about the location of the fire within the building. No subsequent signals were recorded or sent, despite the prevalence of fires in the building until the building collapsed.

- No fire alarm system equipment or documentation from WTC 7 was located during the site cleanup on site, nor were there indications that anyone looked for it during the clean-up.

- Transmission of critical data outside the building to a monitoring station would have provided one means to preserve event data. Although modern systems are capable of this communication, it is not done in practice.

- Survivability of alarm systems data on computer hard drives, memory modules, or printouts in building fires and collapse environments is not addressed in present installation standards.

\subsubsection{Smoke Management}

- WTC 7 was sprinklered throughout and was, therefore, exempted from the requirement for stair pressurization systems. The building was equipped throughout with fire dampers at duct penetrations into vertical shafts, consistent with the NYCBC.

- $\quad$ The base building system serving the lower floors of WTC 7 provided a smoke exhaust capacity of $36,000 \mathrm{ft}^{3} / \mathrm{min}\left(61,000 \mathrm{~m}^{3} / \mathrm{h}\right)$, which was less than the minimum value required by Local Law \#16 (48,000 $\left.\mathrm{ft}^{3} / \mathrm{min}\right)$, as of 1984 .

- Consistent with the NYCBC, the WTC 7 HVAC systems were designed to incorporate a smoke purge mode, by which each floor of the building could be exhausted/purged of smoke manually on a floor-by-floor basis from the Fire Command Center, which was located on the $3^{\text {rd }}$ floor of the building at the main lobby security desk.

\subsubsection{Fire Suppression}

- In general, the water supplies, automatic sprinklers, and standpipe/pre-connected hose systems in WTC 7 exceeded the minimum applicable code requirements, as well as associated engineering best practices.

- Sprinkler protection was installed throughout WTC 7 on September 11, 2001, with the exception of specific rooms and spaces where sprinkler protection was permitted to be omitted by the NYCBC. 
- The water supplies for Floors 21 through 47 included large capacity storage tanks and direct connections to the NYC water distribution system. These supplies provided redundant sources of water for the standpipe and sprinkler system infrastructures. The storage tanks provided adequate duration of supply for normally expected fire exposures to allow the fire department to respond and supplement the demand.

- Water for Floors 1 through 20 was supplied directly from the NYC water distribution system through two service lines from the street main on Washington Street. An automatic fire pump was used to supply the water to the combined sprinkler and standpipe risers. The water supply tanks located in the upper part of the building did not service the lower floors. Therefore, there was no source of water for controlling fires on the lowest 20 floors when the NYC system became inoperable following the collapse of WTC 1.

- The suppression systems in WTC 7 required manual operation of the electric fire pumps in order to provide secondary water. An automatic supplemental water supply is required by NFPA 14 and represents current best practice. Whether or not the building maintenance staff performed this task on September 11, 2001 could not be confirmed.

- $\quad$ Based upon the documents examined, the sprinkler systems installed in WTC 7 were appropriately designed, with calculated water spray densities considerably greater than typically provided for high-rise office buildings. The sprinkler systems met or exceeded the applicable installation requirements in the NYCBC and NFPA 13.

- Calculations showed that the capacity of the automatic sprinkler system was sufficient to control fires involving about four clusters of cubicles. This might explain why some fires on and above Floor 20 did not spread into the afternoon.

- Documentation indicated that the standpipe pre-connected hose system installations were consistent with the applicable requirements in the NYCBC. They were not consistent with the flows and durations required in the 2003 version of NFPA 14. Since the water supply was interrupted, and since there were no people in the building to use the hoses, these inconsistencies would not have affected the outcome of the fires.

- No information was found that indicated that the generator/fuel day-tank enclosures in WTC 7 on Floors 5 and 7 were protected by automatic sprinklers or other special hazard suppression systems; the NYCBC does not require a suppression system for this application. However, the generator rooms on the $8^{\text {th }}$ and $9^{\text {th }}$ floors were protected with sprinklers.

- A $24 \mathrm{~m}^{3}$ (6,000 gal) fuel oil storage tank on the first floor was protected with an Inergen clean agent system. Its role on September 11, 2001, could not be determined due to the absence of any information regarding the system's performance.

\subsection{FIRE BARRIERS}

The characteristics of office walls, masonry walls for mechanical spaces, and reinforced concrete for transformer vaults and floors were described in Chapter 2. Depending on the information available, this included the specified or selected fire ratings. 


\subsection{STRUCTURAL THERMAL INSULATION}

\subsubsection{Material Selection, Application, and Condition}

As presented in Chapter 2, Monokote MK-5 was the sprayed fire resistive material (SFRM) used to insulate the structural elements in WTC 7. Chapter 2 also presents the available documentation of the thermal properties and installed condition of the insulation.

\subsubsection{Simulations of Thermal Protection}

To understand the susceptibility of various structural components to fires of varying duration, NIST performed a number of computations in which a single beam, column, or floor assembly was subjected to elevated temperature. Typically, these simulations involved a furnace-like exposure, i.e., immersing the structural element in a steady state temperature bath. This was conservative, since in an actual fire, the gas temperature field to which the element was exposed would rise less quickly and would wane as the combustibles were consumed. The temperatures at various locations in the structural element were monitored as time progressed.

The computations were performed for five entities:

- Columns. For the following sizes, the WTC 7 specifications had a 3 h fire resistance rating. This was achieved with 7/8 in. of Monokote MK-5.

- $\quad$ One of the heaviest columns, typified by Column 79, which had a W14x730 steel section and additional steel plates welded across the open face of the flanges. Interior columns 58, 61, and 73 to 81 also had this massive section (Column schedule, Cantor 1985).

- A lighter column, with a W14x500 steel section. This is typical of a number of columns in the building core and the exterior (Column schedule, Cantor 1985).

- Composite Floor Assemblies. Typical of tenant floor sections, these assemblies consisted of one of three sizes of steel beams supporting a corrugated steel deck ( 3 in. corrugations) and a 5.5 in. thick concrete slab, $2.5 \mathrm{in}$. of which was above the steel deck. The steel deck was insulated with $3 / 8$ in. of Monokote MK-5 to achieve a $2 \mathrm{~h}$ fire resistance rating. The floor beams were modeled with 7/16 in. of Monokote MK-5 (Section 2.5). The floor beams were later found to have been protected with $1 / 2 \mathrm{in}$. of MK-5, for the specified $2 \mathrm{~h}$ fire rating of the floor assembly. The beam sizes analyzed were:

- A light floor beam - W14x22 steel section.

- A medium mass floor beam - W24x55 steel section.

- A heavy floor beam - W36x135 steel section.

Figure 4-4 shows the temperature rise in the heavy column. 
- In the upper left graph, the column is insulated with 7/8 in. of Monokote MK-5 (based on the specified fire rating) and exposed to an air temperature of $1100{ }^{\circ} \mathrm{C}$.

- The upper right graph shows the rise in steel and insulation temperatures for a thinner, 9/16 in., layer of insulation.

- The lower left graph shows the rise in steel and insulation temperatures with no applied insulation.

- The lower right graph is a repeat of the upper left graph, but with a higher exposure air temperature of $1400^{\circ} \mathrm{C}$.

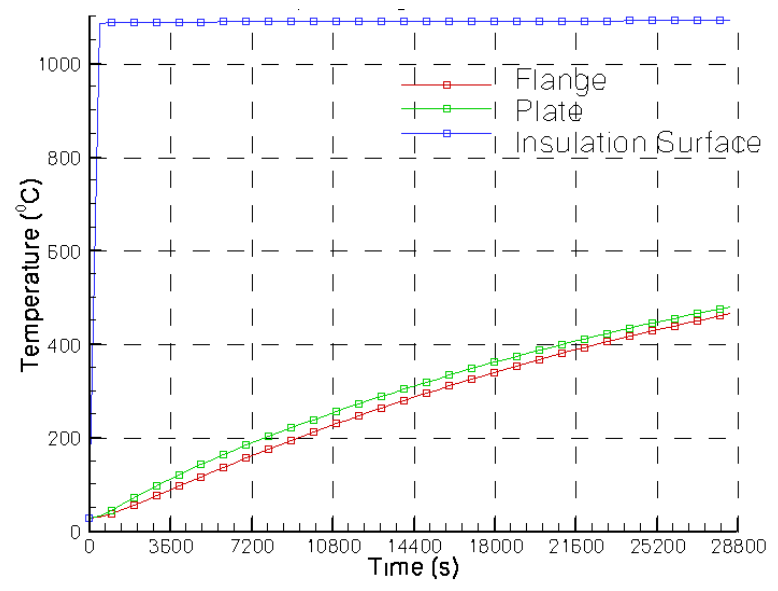

$7 / 8$ in. MK-5 and $1100{ }^{\circ} \mathrm{C}$

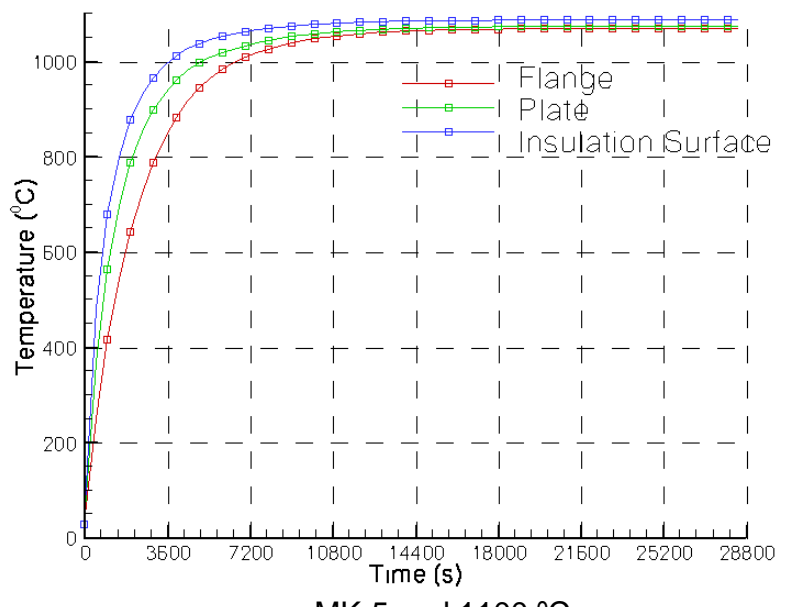

no MK-5 and $1100^{\circ} \mathrm{C}$

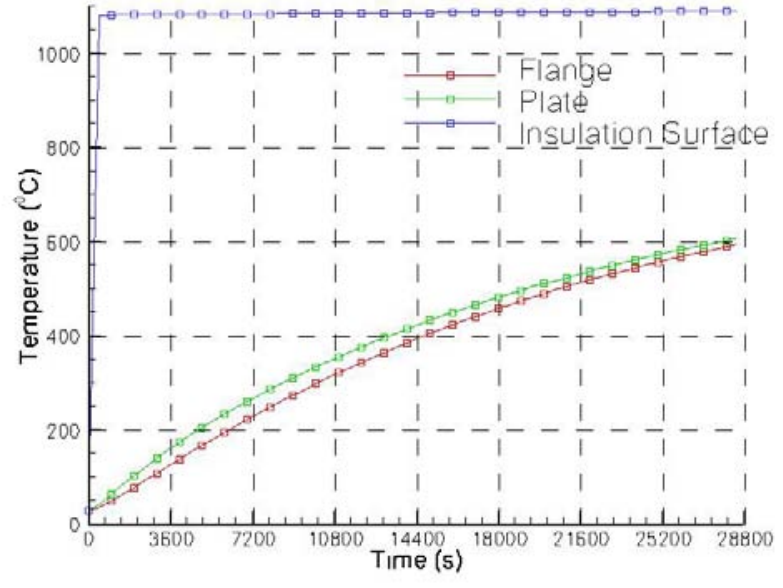

9/16 in. MK-5 and $1100^{\circ} \mathrm{C}$

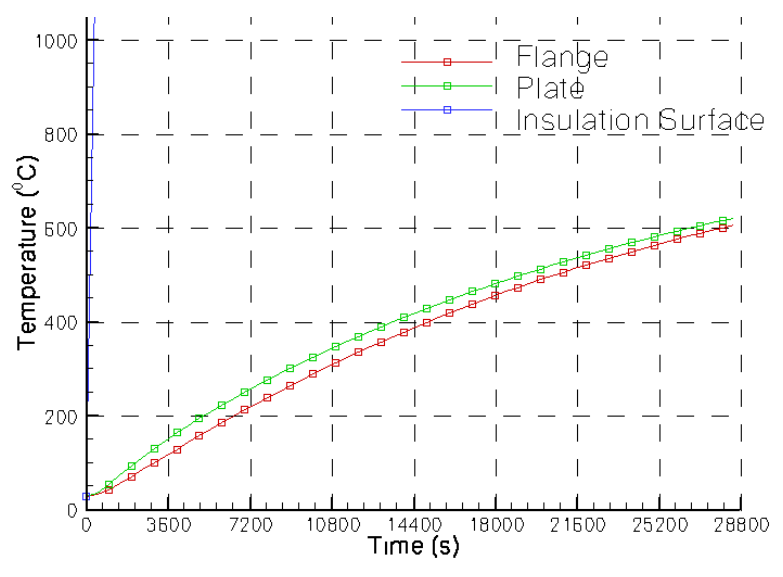

$7 / 8$ in. MK-5 and $1400^{\circ} \mathrm{C}$

Figure 4-4. Calculated temperature rise in Column 79 at varying insulation thicknesses and thermal exposures. 
With either thickness of insulation applied, it would take at least $7 \mathrm{~h}(3,600 \mathrm{~s}=1 \mathrm{~h})$ for the steel to reach $600{ }^{\circ} \mathrm{C}$, the temperature at which the steel would have lost approximately 50 percent of its strength. (See NIST NCSTAR 1-3D for a thorough description of the loss of strength as a function of temperature.) For the fires in the WTC towers and in WTC 7 (see Chapter 9 of this report), the compartment air temperatures typically were near $1100{ }^{\circ} \mathrm{C}$ for less than $2 \mathrm{~h}$. Even if the room temperature from the fires reached $1400{ }^{\circ} \mathrm{C}$, a temperature that might be realized in a wind-aided fire and an extreme upper limit to the air temperatures probable in the types of fires experienced in WTC 7, the steel temperature would remain low enough after 4 to $5 \mathrm{~h}$ of such intense fire exposures for the steel to preserve its strength. By contrast, with no thermal insulation, the column would lose much of its strength within the first half hour of exposure to $1100{ }^{\circ} \mathrm{C}$.

Figure 4-5 shows the results of similar calculations for the lighter, W14 x 500, column. The green data represent temperatures at the outer surface of the thermal insulation; the red data represent temperatures at the interior of the center of the web plate. For the insulated column, shown in the left plot, the web temperature reaches $600{ }^{\circ} \mathrm{C}$ in about $4 \mathrm{~h}$. With no insulation (right plot), this temperature is reached in a matter of minutes. As expected, the lighter columns heat somewhat more rapidly, but, if properly insulated, the steel temperature would remain low enough after $3 \mathrm{~h}$ of such intense fire exposures for the steel to preserve its strength.
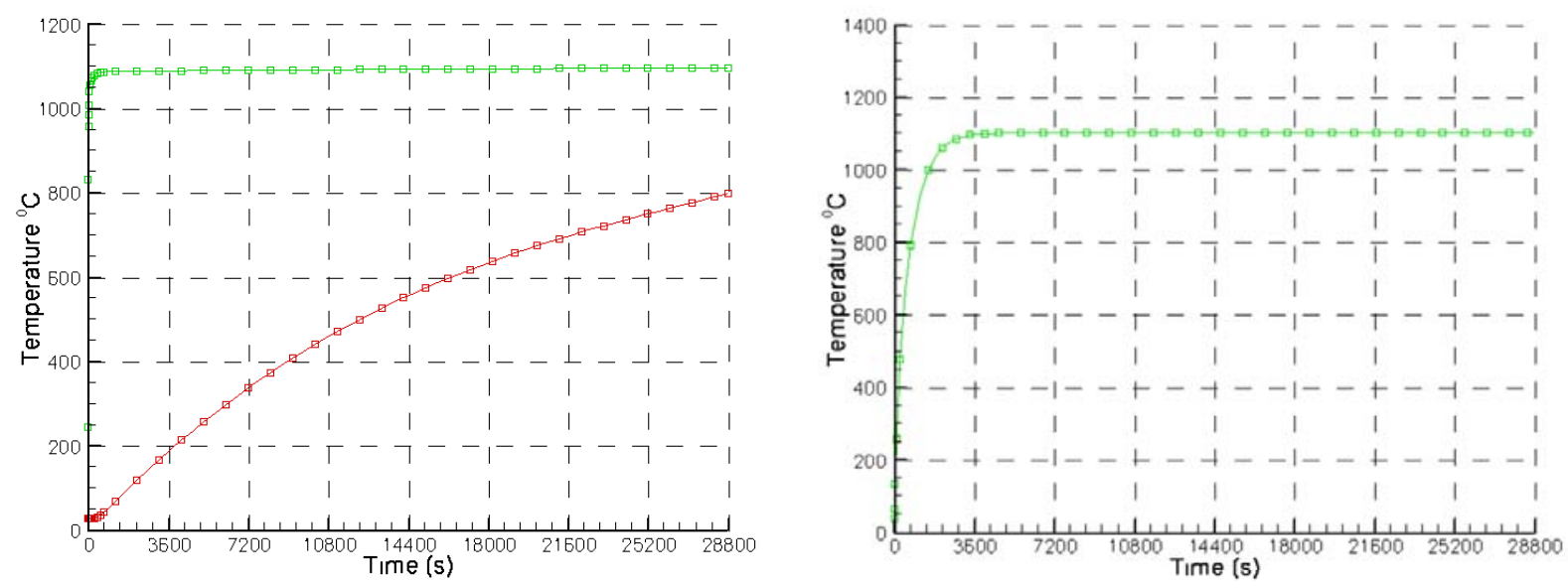

Figure 4-5. Calculated temperature rise in a typical core or exterior column exposed to $1100^{\circ} \mathrm{C}$ air temperature.

Left: insulated with 7/8 in. Monokote MK-5; right: uninsulated.

Each composite floor, with one of three representative beam sections, was exposed to an $1100{ }^{\circ} \mathrm{C}$ air temperature from below. Figure 4-6 shows the result of heating the floor with the insulated lightest steel section. The lower flange of the steel reached compromising temperatures in about $15 \mathrm{~min}$, the upper flange in about $1 \mathrm{~h}$. Figure 4-7 and Figure 4-8 show the slower temperature rises in the insulated midweight and heaviest beams, respectively. The lower flange temperatures are virtually identical to the web plate temperatures. Figure 4-9 shows the temperatures reached at the top and bottom of a typical floor slab at the thinnest sections located at the top of the steel deck corrugation. 

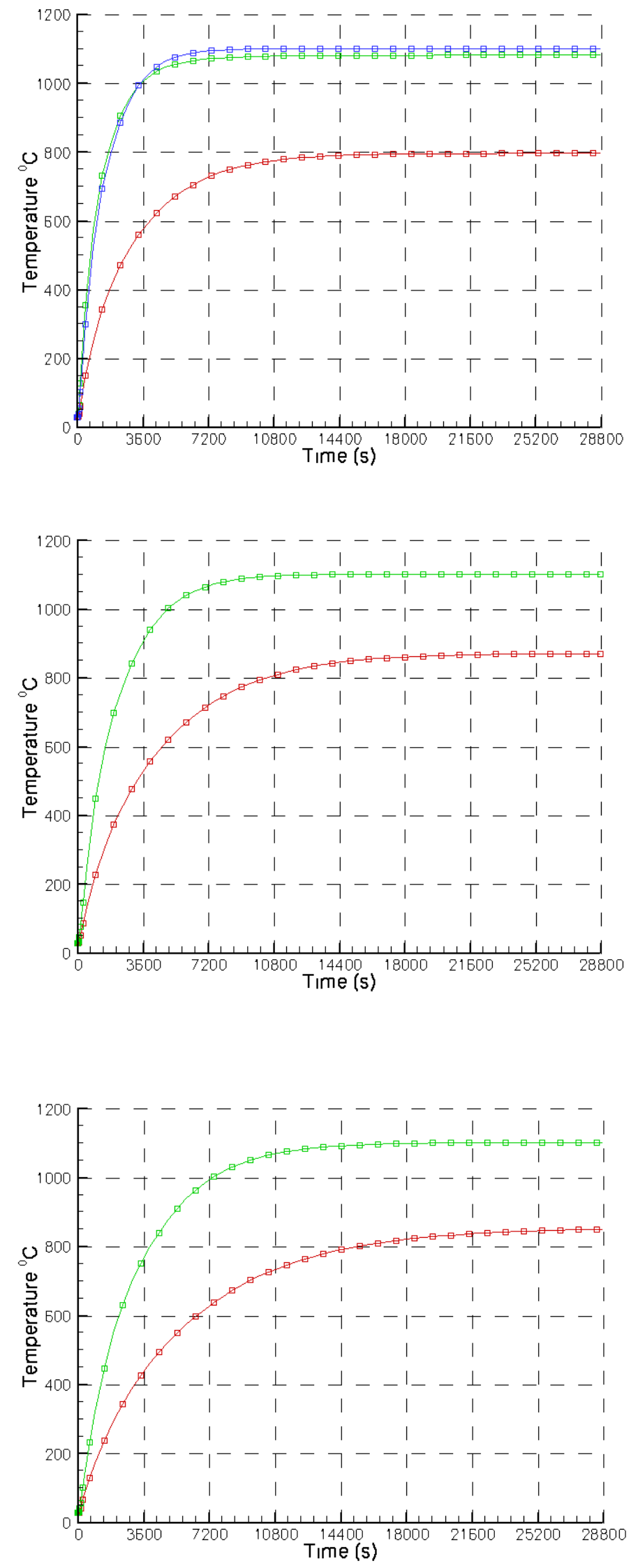

Figure 4-6. Calculated temperature rise in a W14 x 22 floor beam in an insulated composite floor assembly exposed to $1100{ }^{\circ} \mathrm{C}$ air from below. Blue: lower flange; green, web plate, red: upper flange.

Figure 4-7. Calculated temperature rise in a 24WF x 55 floor beam in an insulated composite floor assembly exposed to $1100^{\circ} \mathrm{C}$ air from below. Green, lower flange and web plate, red: upper flange.

Figure 4-8. Calculated temperature rise in a 36WF135 floor beam in an insulated composite floor assembly exposed to $1100^{\circ} \mathrm{C}$ air from below. Green, lower flange and web plate, red: upper flange. 


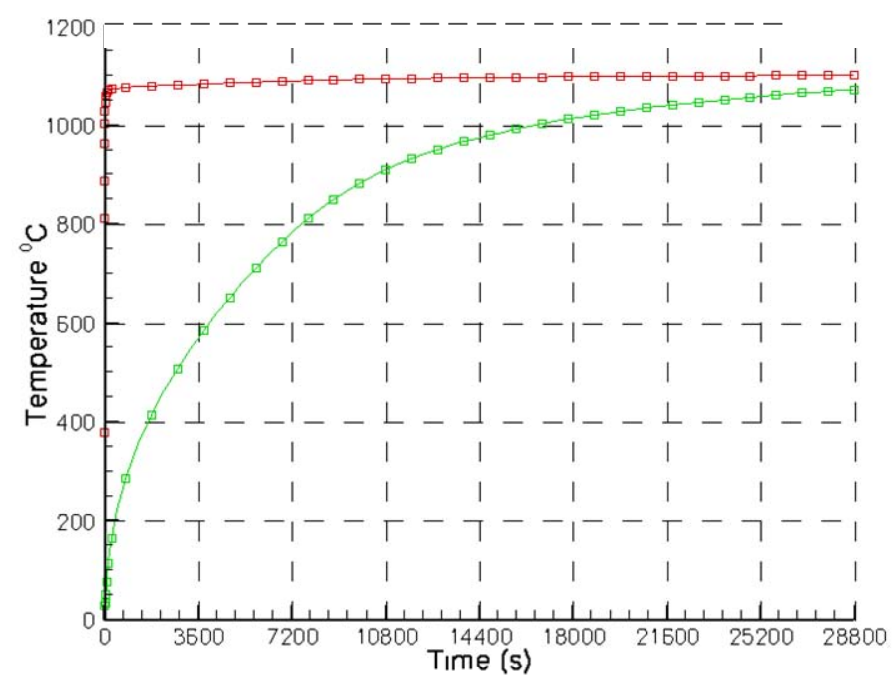

Figure 4-9. Calculated temperature rise in an insulated floor slab heated from below. Green: top of slab; red: bottom of slab at top of corrugation.

\subsubsection{Findings - Structural Thermal Insulation}

- For the heaviest columns in WTC 7, when insulated for a $3 \mathrm{~h}$ fire rating, simulations show that it would take an exposure of about $7 \mathrm{~h}$ at post-flashover upper layer gas temperatures to raise the steel temperature to $600{ }^{\circ} \mathrm{C}$, the point at which the steel strength has been reduced by half. As will be seen in Chapter 9, this is far longer than the time over which post-flashover gas temperatures were sustained in the computed WTC 7 fires. For comparison, this steel temperature would be reached in under $1 / 2 \mathrm{~h}$ if the insulation were not applied.

- Simulations for the insulated lighter columns in WTC 7 show that this steel temperature is reached in about $4 \mathrm{~h}$. This is also longer than the time over which post-flashover gas temperatures were sustained in the computed WTC 7 fires. With no applied insulation, the steel temperature reaches $600{ }^{\circ} \mathrm{C}$ in under $1 / 2 \mathrm{~h}$.

- Simulations of different size beams in a floor assembly showed that the two lighter steel beams (insulated for a $2 \mathrm{~h}$ rating) and the bottom of an insulated floor slab (insulated for a $2 \mathrm{~h}$ rating), exposed to $1100{ }^{\circ} \mathrm{C}$ air temperatures, reached $600^{\circ} \mathrm{C}$ in approximately $1 \mathrm{~h}$. The heaviest floor beam reached $600{ }^{\circ} \mathrm{C}$ in almost $2 \mathrm{~h}$. These times are modestly longer than the time over which post-flashover temperatures were sustained in the computed WTC 7 fires.

\subsection{REFERENCES}

Cantor 1985. Irwin G. Cantor P.C., Structural Engineers, Structural Drawings, 7 World Trade Center.

FDNY (New York City Fire Department). 1990. Fire Fighting Procedures and Fire Operations for HighRise Office Buildings, New York, NY.

Flack and Kurtz 1988. Flack and Kurtz Mechanical Engineers, Mechanical and Electrical Drawings for Salomon Brothers 7 World Trade Center Headquarters.

HRS Systems, Inc. 2004. Hass (Hydraulic Analyzer of Sprinkler Systems) Version 7.5. Software. 2004. 
NFPA 13. 2002. Standard for the Installation of Sprinkler Systems, National Fire Protection Association, Quincy, MA.

NFPA 14. 2003. Standard for the Installation of Standpipe and Hose Systems, National Fire Protection Association, Quincy, MA.

NYCBC (Building Code of the City of New York). 1968. Building Code-Local Law No. 76 of the City of New York. New York, NY.

PANYNJ (Port Authority of New York and New Jersey). 1987. World Trade Center Instruction Manual No. 18: Operation and Maintenance of Sprinkler Systems. New York, NY, April.

Roth 1985. Emery Roth \& Sons P.C., Architects, Architectural Drawings, 7 World Trade Center.

SOM 1988. Skidmore, Owings \& Merrill, Architects / Engineers, Architectural Drawings for Salomon Brothers 7 World Trade Center Headquarters.

Syska \& Hennessy Group Inc. 1984. 7 World Trade Center: Summary of Mechanical and Electrical Systems. New York, NY, May.

Syska \& Hennessy 1985. Syska \& Hennessy Engineers, Mechanical, Electrical, and Plumbing Drawings, 7 World Trade Center. 


\section{Chapter 5 \\ WTC 7 Visual EVIDENCE: DAMAge Estimates, FiRE TIMELINE, AND COLLAPSE TIMELINE}

\section{$5.1 \quad$ INTRODUCTION}

This chapter documents the visual evidence used to guide the reconstruction of the fires and the global collapse analysis of WTC 7, as NIST NCSTAR 1-5A did for the World Trade Center towers. Many of the details concerning the general approaches to acquiring and cataloging the visual material, the timing of the photographs and videos, the development of fire time lines, and additional analyses of the visual material, were documented in that report. This Chapter is organized as follows:

- Section 5.2 provides specific details relevant to WTC 7 with regard to the visual material that was recorded on September 11, 2001 and approaches that were used to identify, collect, log, time, and catalog the material.

- Section 5.3 provides background information about the local geography and wind direction, relevant WTC 7 structural and architectural details, a numbering system for describing window locations on WTC 7, and some interior details needed to understand the observations of fires and damage.

- Section 5.4 presents how NIST identified the initial damage to WTC 7 and documented the time development of fires within the building. This section also provides details of the analysis and procedures employed to develop the time lines. The primary output is a series of numerical data sheets as a function of time that provide window-by-window assessments of whether or not a fire was present, and, if present, a measure of the local intensity, and whether or not glass was in place for a given window. The use of the data has been assisted by visualizing the contents using color façade maps.

- Section 5.5 reproduces multiple images showing the damage to WTC 7 by debris generated by the collapses of the two 110 story WTC towers, WTC 2 (South Tower) and WTC 1 (North Tower), at 9:58:59 a.m. and 10:28:22 a.m., respectively. The collapse of WTC 1, in particular, caused structural and façade damage to the WTC 7 south and west faces. Both the extent of the damage and the limitations of the imagery for assessing this damage are emphasized. The results of the visual analysis were used to develop color-coded damage maps for the south and west faces and for each floor of WTC 7.

- Shortly after the towers collapsed, fires began to appear at multiple locations in WTC 7. Section 5.6 first discusses possible ignition sources for these fires. Next, the visual evidence for the growth and spread of these fires until the building collapsed at 5:20:52 p.m. is presented and discussed. The descriptions of the fires at various times are then visualized using color-coded façade maps. 
- Section 5.7 presents imagery of the collapse of WTC 7. From these images, the Investigation Team derived important clues concerning the time sequence of the collapse and possible initiating events.

Since there is a large amount of detail in this chapter, a summary of the debris damage to WTC 7 is given in Section 5.5.3. A summary of the progress of the fires is given in Section 5.6.4. Finally, a summary of the observations of the building collapse is given in Section 5.7.5.

\subsection{COLLECTION, ORGANIZATION, AND TIMING OF VISUAL MATERIAL}

\subsubsection{Collection of Visual Material}

Section 2.1 in NIST NCSTAR 1-5A provides a description of the camera-rich environment that existed in New York City on September 11. When the two towers were struck by aircraft, the damage was well above nearby buildings and was, thus, easily visible from surrounding areas. As a result of this environment and the locations of the towers, an immense number of cameras in Manhattan, Brooklyn, Queens, and New Jersey captured the aircraft impacts and resulting fireballs, initial damage, fire growth and spread, and the collapses of WTC 1 and WTC 2. This wealth of visual information proved to be invaluable for determining the collapse mechanisms of both towers.

As discussed below, there was considerably less information available concerning WTC 7. However, the images that were available provided sufficient information to guide the reconstruction of the WTC 7 collapse.

The identification and collection of visual material related to WTC 7 were fully integrated into the overall effort. Relevant material was identified and collected in the same manner as described in Section 2.2 and Section 2.3 of NIST NCSTAR 1-5A. An overview of sources for photographs and videos is included in Section 2.3.

The overall amount of visual material from September 11 was immense. Well in excess of 7,000 photographs, representing more than 200 photographers, and over 300 hours of video, from professional organizations and over 40 individuals, on nearly 150 separate tapes were assembled and logged.

It is difficult to estimate the actual amount of relevant visual material recorded on September 11, 2001, and, thus, to estimate how complete the Investigation collection efforts were. There is certainly material that has not been identified and collected. However, NIST believes that the large collection of visual material that it assembled is sufficient for purposes of the Investigation.

\subsubsection{Organization of Visual Material}

It would have been impossible to use the vast amount of visual material collected for the Investigation effectively without some means of organizing and cataloging the material. An approach was adopted in which all collected visual materials judged to be relevant to the Investigation were converted to digital format (if necessary) and saved in a large digital database. Section 2.5 in NIST NCSTAR 1-5A includes details about the digital database and preparation of materials for inclusion in the database. 
To organize the images in this database, NIST used Cumulus, a commercial database program written specially for organizing visual material. This software was designed to collect individual "assets" (i.e., photographs and video clips) in specified catalogs and to allow the assets to be characterized with a variety of attributes assigned using specially designed forms for data entry. Once a catalog had been assembled, it was possible to search for assets having a specific attribute or combinations of attributes.

Two separate catalogs, one for photographs and one for video clips, were created for visual materials collected as part of the Investigation. Each catalog had a similar set of attributes that was used to characterize the assets that were included. These attributes were chosen in consultation with Investigation staff, based on the expected needs of the reconstruction of the day's events. Additional details concerning the catalogs and search approaches are included in Section 2.5.3 of NIST NCSTAR 1-5A.

\subsubsection{Timing of Key Events}

It was important to assign times of known accuracy to assets included in the two image catalogs. This task was greatly complicated by the absence of accurate times for the majority of visual material collected. Chapter 3 in NIST NCSTAR 1-5A describes the difficulty of this task and the different ways in which times were assigned. Ultimately, a "boot strap” approach was adopted in which the impact of the aircraft on the south face of WTC 2 was assigned a time of 9:02:54 a.m., based on times for major events included in the earlier Federal Emergency Management Agency (FEMA) report (McAllister 2002). Starting with imagery that included the aircraft impact, relative times could be assigned to photographs and images at other times by comparison to materials having known relative times. In this way, it was possible to work backward and forward from the second aircraft impact and assign times for visual material covering the period from the first aircraft impact on WTC 1 until the collapse of WTC 7. Assigned times, along with estimates of uncertainty, were included in the database.

To assist in the timing process, relative times for the five major events of September 11, 2001 - first aircraft impact, second aircraft impact, collapse of WTC 2, collapse of WTC 1, and collapse of WTC 7 were determined with $\pm 1 \mathrm{~s}$ accuracies. These relative times appear in Column 2 of Table $5-1$. Note that the building collapse times are defined to be when the entire building was first observed to start to collapse. Specifically, in the case of WTC 7, the sinking of the east penthouse into the building before the main collapse started did not define the building collapse time.

The value used for the second aircraft impact time in the database was taken from the FEMA report (McAllister 2002). NIST independently determined this time using four independent television broadcasts and found a $5 \pm 1 \mathrm{~s}$ difference. As a result, $5 \mathrm{~s}$ were added to times in the databases in order to report actual times.

The times listed for the major events in the FEMA report (McAllister 2002) were based on seismic signals (and analysis) recorded by the Lamont-Doherty Earth Observatory (LDEO) of Columbia University at a location 21 miles from the WTC site in Palisades, New York. These signals have subsequently been reanalyzed by LDEO, under a contract from NIST (Appendix B). This analysis of the seismic signals received resulted in slightly revised times for the major events. The results of this recent analysis are also included in the last column of Table 5-1. The uncertainty for the first aircraft impact on WTC 1 , the collapse of WTC 2, and the collapse of WTC 1 were reported by LDEO to be $\pm 1 \mathrm{~s}$, while that for the aircraft impact on WTC 2 is $\pm 2 \mathrm{~s}$. Recalling that uncertainties for times of the major events 
based on the television broadcasts are estimated to be $\pm 1 \mathrm{~s}$, it can be seen from Table $5-1$ that the two aircraft impact times derived by NIST and LDEO now agree within the combined uncertainties.

Table 5-1. Times for major events on September 11, 2001.

\begin{tabular}{|l|l|l|l|l|}
\hline \multicolumn{1}{|c|}{ Event } & \multicolumn{1}{|c|}{$\begin{array}{c}\text { Relative Time } \\
\text { from Visual } \\
\text { Analysis }\end{array}$} & $\begin{array}{c}\text { NIST Time } \\
\text { (Adjusted from } \\
\text { Television } \\
\text { Broadcasts) }\end{array}$ & $\begin{array}{c}\text { Time Reported in } \\
\text { the FEMA Study }\end{array}$ & $\begin{array}{c}\text { Time Reported in } \\
\text { LDEO Analysis } \\
\text { (Appendix B) }\end{array}$ \\
\hline First aircraft impact & 8:46:25 a.m. & $8: 46: 30$ a.m. & $8: 46: 26$ a.m. & $8: 46: 29$ a.m. \\
\hline Second aircraft impact & $9: 02: 54$ a.m. & $9: 02: 59$ a.m. & $9: 02: 54$ a.m. & $9: 02: 57$ a.m. \\
\hline Collapse of WTC 2 & $9: 58: 54$ a.m. & $9: 58: 59$ a.m. & $9: 59: 04$ a.m. & $9: 59: 07$ a.m. \\
\hline Collapse of WTC 1 & $10: 28: 17$ a.m. & $10: 28: 22$ a.m. & $10: 28: 31$ a.m. & $10: 28: 34$ a.m. \\
\hline Collapse of WTC 7 & 5:20:47 p.m. & 5:20:52 p.m. & 5:20:33 p.m. & 5:20:42 a.m. \\
\hline
\end{tabular}

The times listed in Table 5-1 for the collapses of the two towers and WTC 7 that are based on the television records and the revised LDEO analysis differ by up to $13 \mathrm{~s}$. The differences for the towers are due to different definitions used for the collapse times. The times based on visual analysis refer to the time when the collapse of a tower first became visually evident, while the times based on seismic records indicate the time when sufficient falling debris struck the ground to cause a seismic signal. The differences between the two times were estimated to be approximately $8 \mathrm{~s}$ for WTC 2 and approximately $12 \mathrm{~s}$ for WTC 1, based on videos of the collapses. When the times required for falling debris to reach the ground were subtracted from the LDEO times, the collapse times agreed within the reported uncertainties.

The relative time for the collapse of WTC 7 was estimated by NIST as follows. Figure 5-1 shows a longdistance photograph taken shortly after the east penthouse on the roof of WTC 7 began to sink into the building. As discussed in Section 5.7, this penthouse began to disappear into the building $6.9 \mathrm{~s}$ before the entire building began to fall. The camera used for this photograph recorded digital timestamps with the photographs. The photographer who shot the image took numerous photographs on September 11, including shots of the towers earlier in the morning. By using the tower shots, it was possible to accurately determine the difference between the timestamps and the relative time. When this difference was accounted for, the relative time for the photograph was calculated to be 5:20:41 p.m. The photograph was then compared with an untimed video clip showing the collapse of WTC 7. A frame taken from the clip is shown on the bottom of Figure 5-1. The close agreement between the two images indicates the video frame was taken very close to the same time. In the video, the full collapse of WTC 7 started $6.2 \mathrm{~s}$ after the video frame shown in Figure 5-1, yielding the relative collapse time of 5:20:47 p.m.

The probable reason for the time difference between the NIST time and the LDEO result with regard to the collapse of WTC 7 is discussed in Appendix B. The seismic signal that was $10 \mathrm{~s}$ prior to the time derived from the television broadcasts was likely due to the falling of debris from the structural damage that preceded the descent of the east penthouse.

For this Investigation, the times used were those adjusted from the television broadcasts (Column 3). 


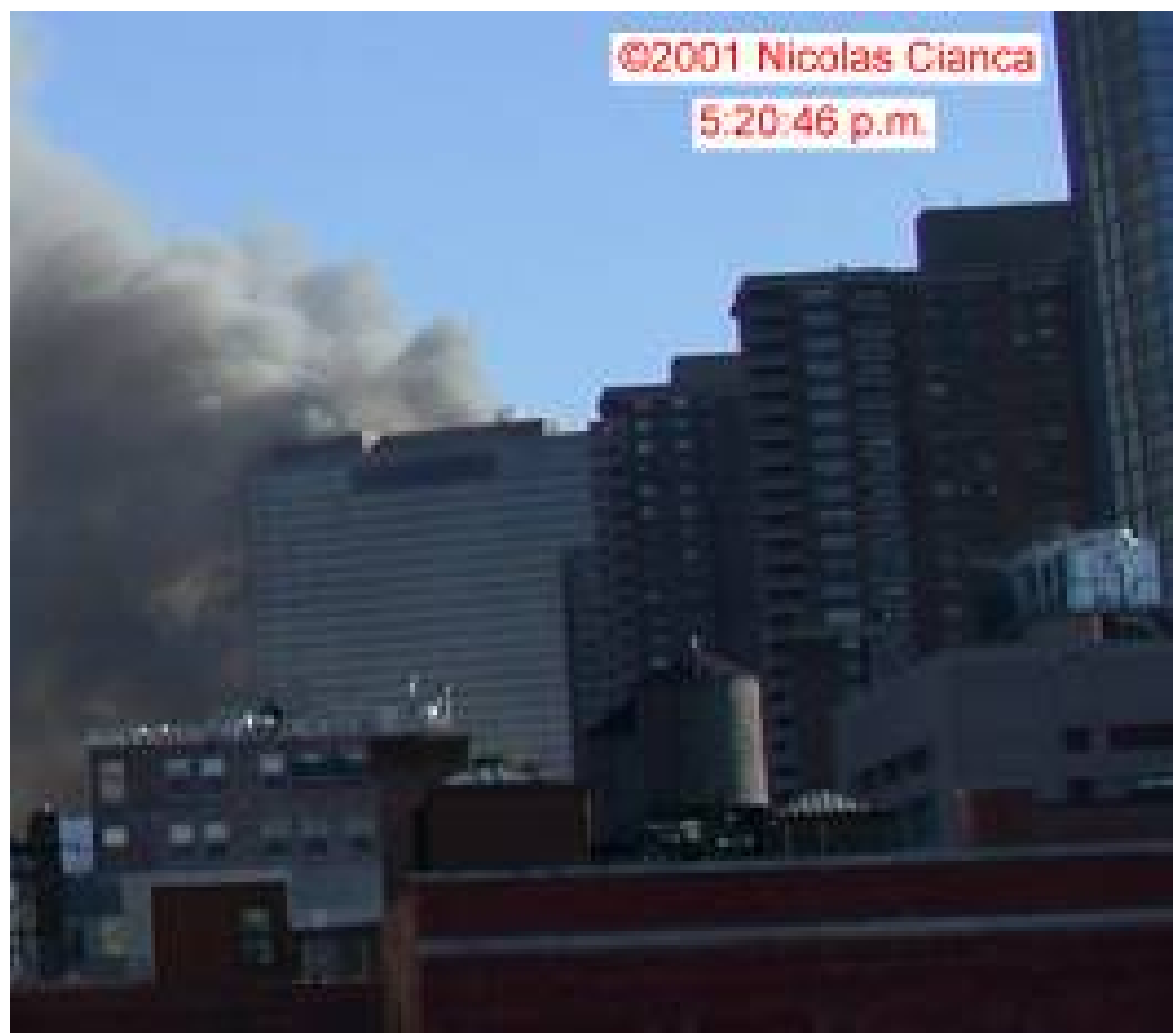

Figure 5-1. A

photograph (top) and a frame from a video clip (bottom) showing the east penthouse of WTC 7 beginning to sink into the building.

Q 2001 CBS News Archwes
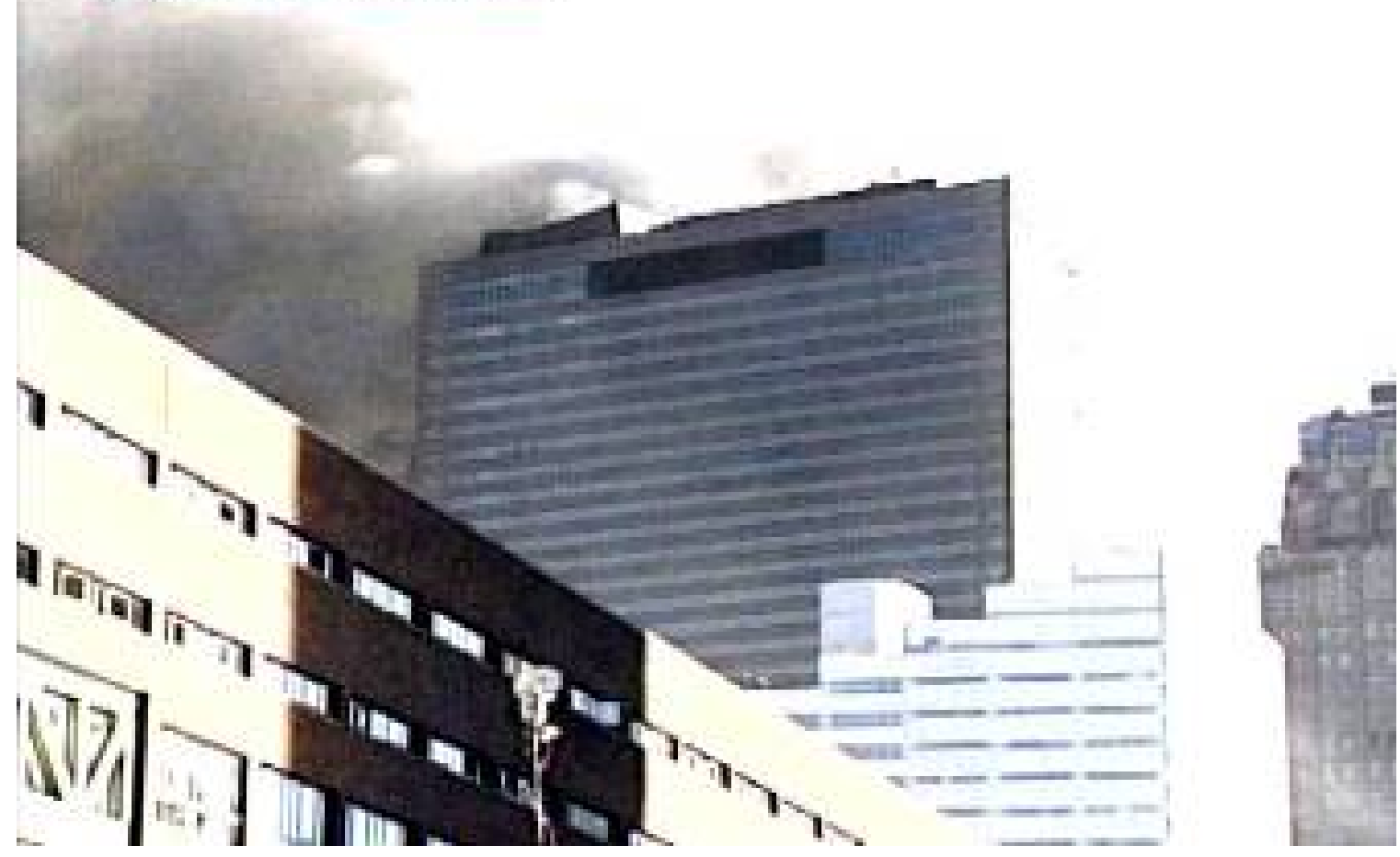


\subsection{BACKGROUND INFORMATION}

This section provides nomenclature and information on local geography, wind direction, and WTC 7 design that will be useful for the detailed characteristics, analyses, and discussion that are presented in the following sections. The interdependence of these characteristics and the visual record is emphasized. Nomenclature that will be used in the remainder of the report is introduced. Most of the information related to WTC 7 is taken from design drawings.

\subsubsection{Local Geography and Wind}

Figure 5-2 is a map of the WTC complex and the immediate surrounding streets as they existed on the morning of September 11, 2001. Figure 5-3 indicates the location of the WTC complex on Manhattan, an island that forms one of the five boroughs of New York City.

As is evident in Figure 5-3, Manhattan is elongated with the upper end of the long direction aligned roughly to the northeast. Even though not strictly true, New Yorkers view Manhattan as running northsouth, and areas uptown are considered to be located to the north. This nomenclature has been adopted for this report, so references are to the north and south towers, as well as the north, east, south, and west faces of WTC 7. For each of these cases, north refers to the building or the side that faces uptown. It should be kept in mind that the north face of WTC 7 was actually oriented roughly $29^{\circ}$ clockwise from true north (NIST NCSTAR 1-2).

Figure 5-2 shows that WTC 7 was located just to the north of the main WTC site, separated from the main site by Vesey Street. The locations of two bridges, referred to as the Promenade and the Pedestrian Bridge, that crossed from WTC 7 to the main WTC complex are indicated. The four streets that surrounded the building were Vesey Street to the south, West Broadway to the east, Barclay Street to the north and the short section of Washington Street to the west. 


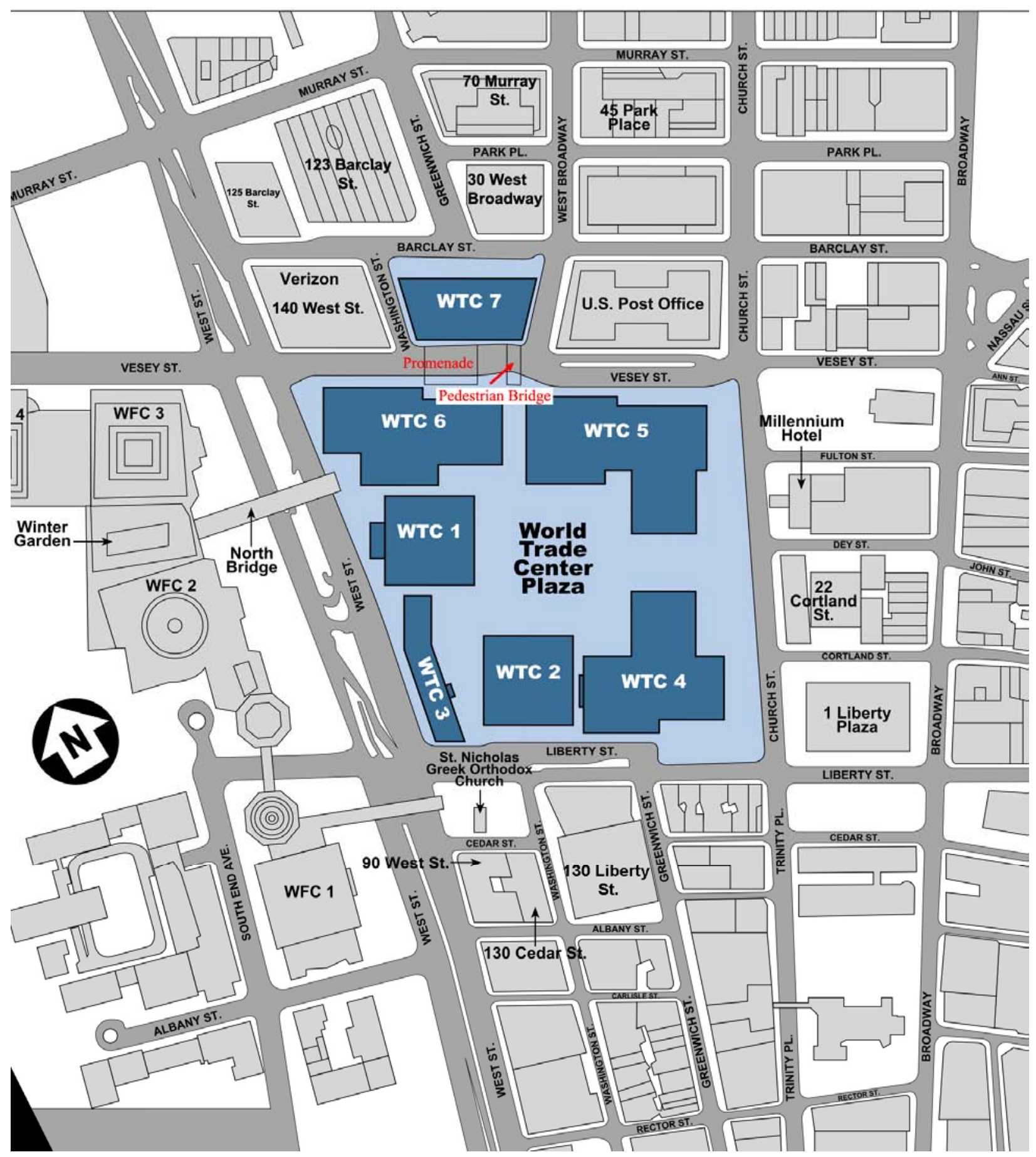

Figure 5-2. Map of the area of Lower Manhattan in the immediate vicinity of the WTC site. 


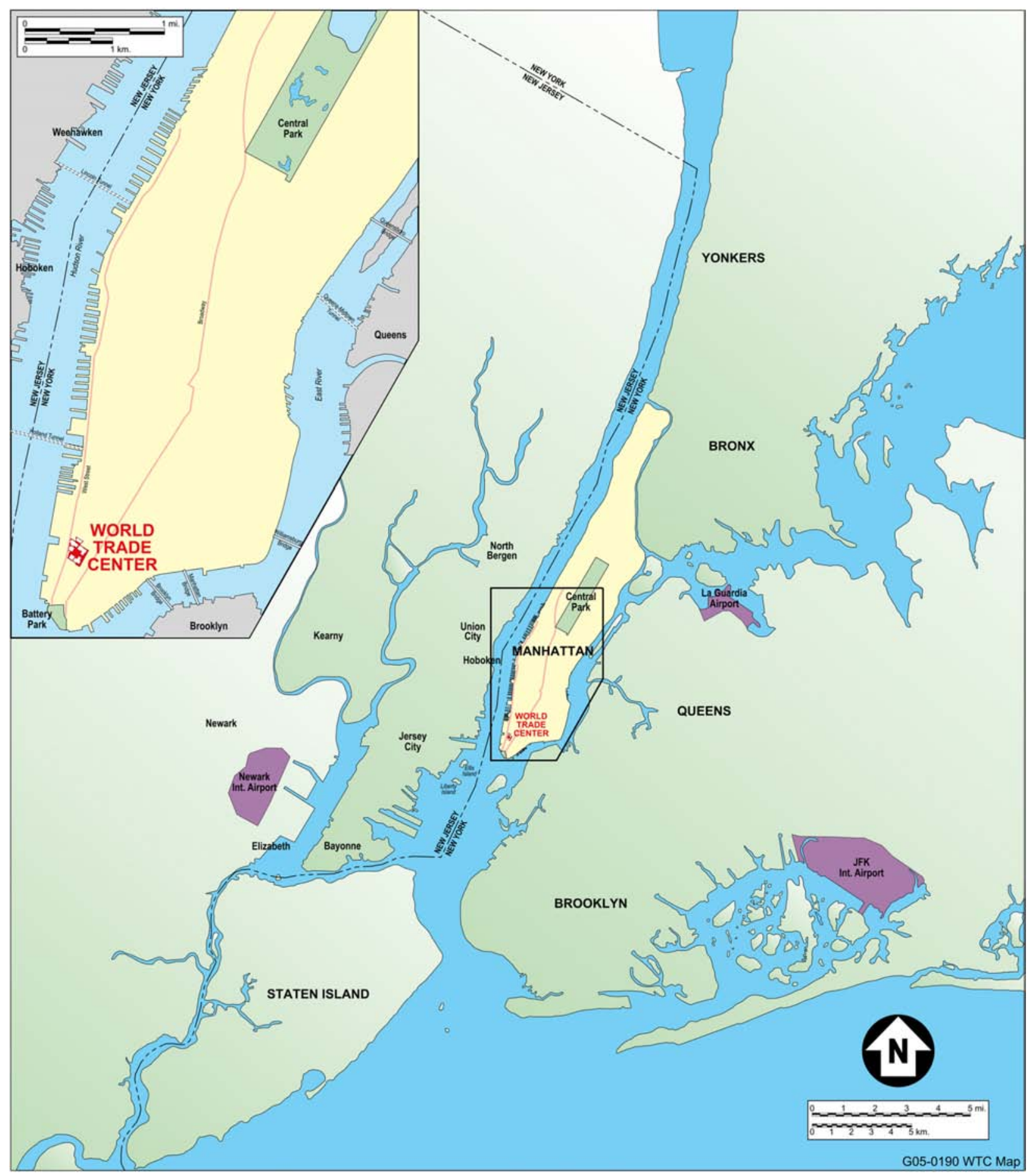

Figure 5-3. Map of the lower portion of Manhattan showing the location of the WTC complex relative to the island.

WTC 7 was surrounded on four sides by other buildings. The locations of these buildings will be shown to play a critical role with regard to the details that can be gleaned from visual imagery concerning WTC 7 on September 11. The locations of these buildings are indicated on the map in Figure 5-2, and 
they are identified also in Figure 5-4, which is taken from an aerial photograph shot on September 23, 2001, and Figure 5-5, which is another aerial view taken on September 11.

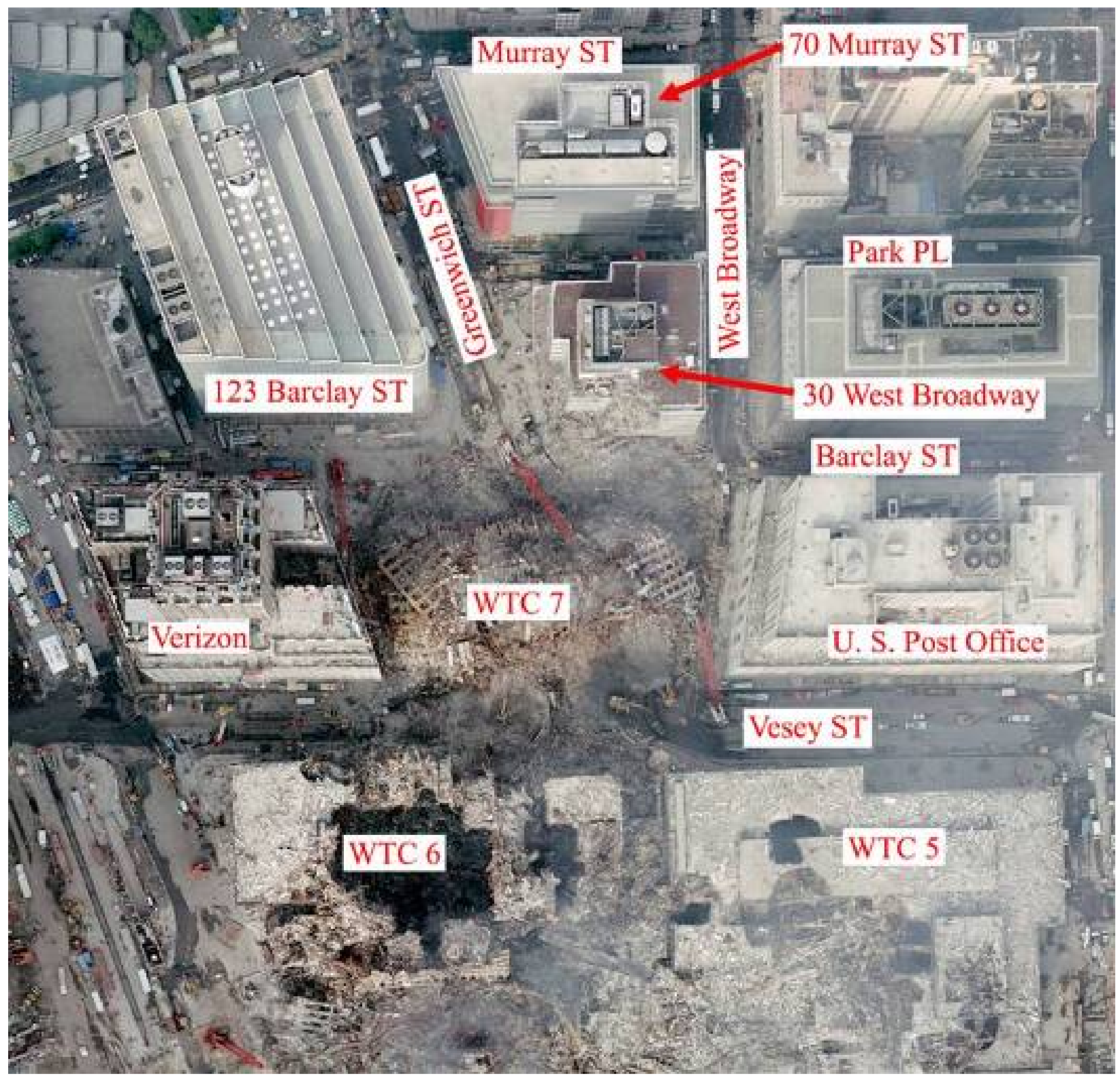

Figure 5-4. Overhead view of the area in the immediate vicinity of the collapsed WTC 7. This photograph was taken by a NOAA aircraft on September 23, 2001. It has been enhanced and labels have been added.

Two of the nearby buildings, WTC 5 and WTC 6, were located to the south across Vesey Street on the main WTC site. These buildings were nine and eight stories tall, respectively. The 15 story U. S. Post Office was located immediately to the east across West Broadway at 90 Church Street. There were two buildings to the immediate north of WTC 7. The one on the east side will be referred to as 30 West Broadway. It is also known as Fiterman Hall and is part of Manhattan Community College. It has 15 floors. The address of the building to the immediate north of 30 West Broadway is 70 Murray Street, and it has 13 stories. The building to the northwest of WTC 7 is located at 123 Barclay Street and has 26 
stories. This building is easily identified by its stepped roofline. The 29 story Verizon Building was located across Washington Street to the west. Its address is 140 West Street.

From the overhead view of the area in Figure 5-4 and the angled view in Figure 5-5, it is clear how close the nearby buildings were to WTC 7. These buildings tended to block views of the lower floors of WTC 7 from all sides. In Figure 5-2 and Figure 5-4, it can be seen that Greenwich Street ran from the northwest and terminated near the center of the north side of WTC 7. This street ran straight for many blocks, and thus an observer along this street had a partial view of the lower sections of the north face.

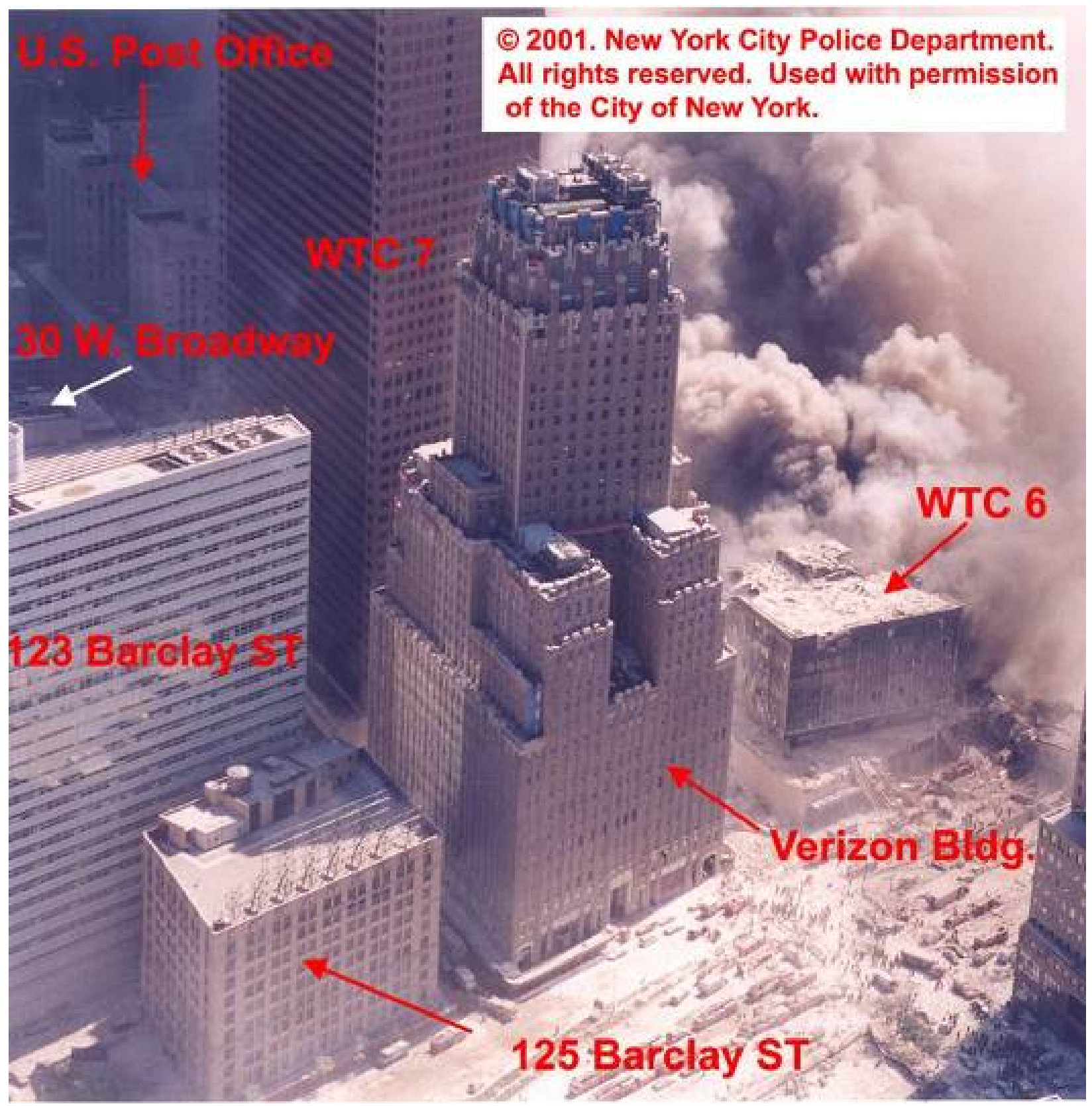

Figure 5-5. Photograph of WTC 7 and the immediate vicinity taken before noon on September 11, 2001.

The original image has been cropped and labels identifying buildings have been added. 
On September 11, 2001 the wind in New York City was primarily from true north. Rehm et al. (2001) used wind records recorded by aircraft in the New York City area on the morning of September 11, 2001 to estimate that the wind direction was from the north (within a few degrees) and had a speed between $11 \mathrm{mph}$ and $22 \mathrm{mph}$ at the heights (roughly 1,000 ft) where the aircraft impacted the towers. Similar information is not available for times following the collapses of the towers. However, the direction of the smoke plumes from fires burning on and near the WTC site indicates that the wind blew from roughly the same direction throughout the afternoon.

Wind behavior is strongly influenced by the presence of upstream structures. On September 11, the wind was coming from across the Hudson River. (See Figure 5-3.) Figure 5-6 shows a view of the WTC site shot from a helicopter around 10:21 a.m. from roughly the same direction that the wind was blowing. At this time WTC 2 had already collapsed and WTC 1 continued to burn. WTC 7 is indicated by an arrow. The lower portions of WTC 7 are at least partially shielded from the wind by buildings located between WTC 7 and the Hudson shoreline, while upper portions were directly exposed.

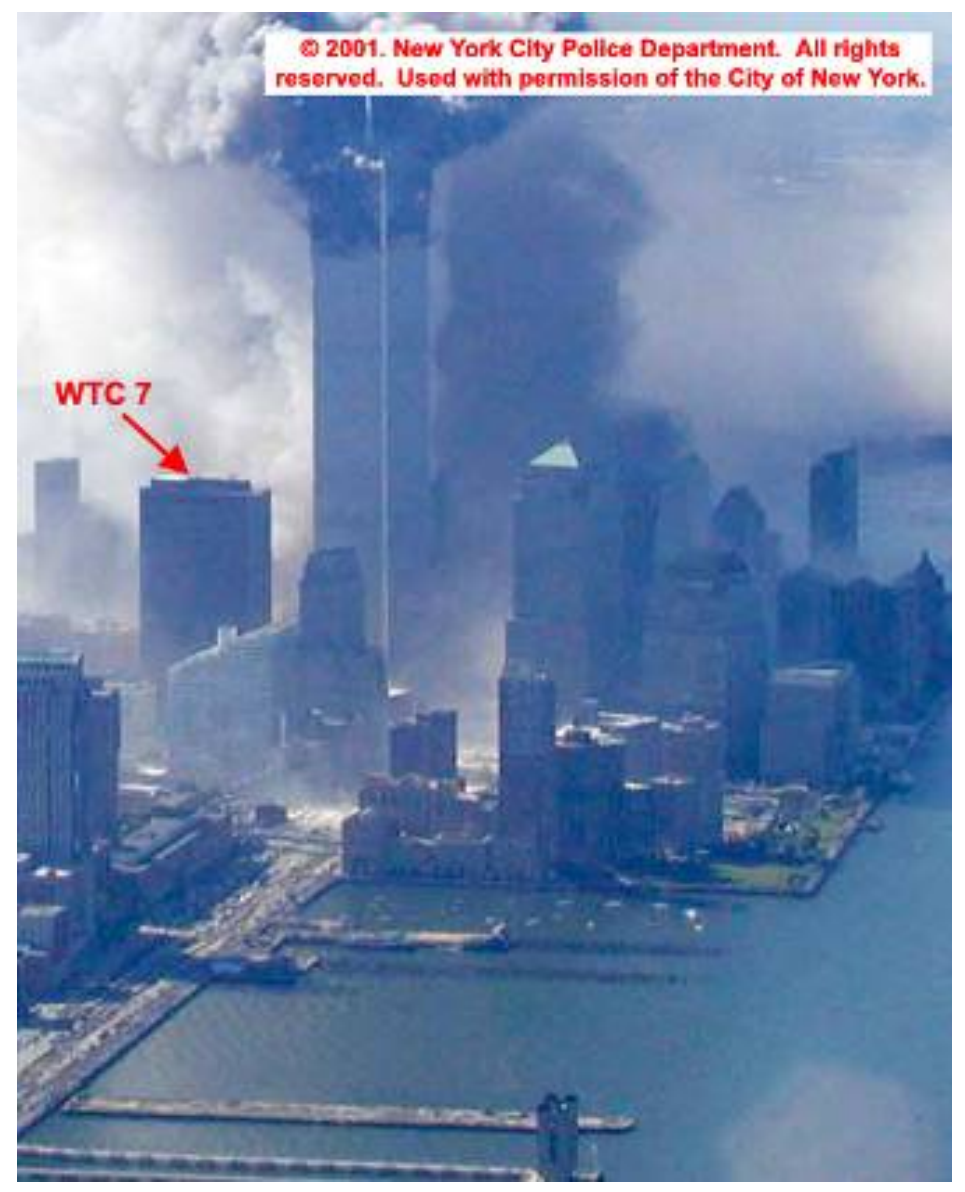

Figure 5-6. Photograph of the WTC site taken around 10:21 a.m. from roughly the same direction as the wind was blowing on September 11. The image has been cropped and enhanced.

As described in NIST NCSTAR 1-5A, the wind had a strong influence on smoke and dust flows around the towers. The wind also affected the behavior of flames and smoke flow from the towers. Similar effects will be described below for WTC 7 . 


\subsubsection{WTC 7 Characteristics}

This section repeats some features of WTC 7 (more fully described in Chapter 2) that are needed to understand the visual observations. This section also introduces some of the nomenclature that will be used in later sections.

\section{General Structure}

WTC 7 was a 47 story office building whose height from the ground floor to its roofline was approximately $186 \mathrm{~m} \mathrm{(610} \mathrm{ft).} \mathrm{The} \mathrm{structure} \mathrm{was} \mathrm{built} \mathrm{over} \mathrm{an} \mathrm{existing} \mathrm{Consolidated} \mathrm{Edison} \mathrm{electrical}$ substation. A series of transfer trusses and girders on the $5^{\text {th }}$ and $6^{\text {th }}$ floors transferred loads from higher stories to columns that extended to the ground. The upper part of the building had a trapezoidal shape. The south side was $75.2 \mathrm{~m}$ ( $247 \mathrm{ft}$ ), the east side was $45.0 \mathrm{~m}$ (149 ft), the north side was $100.3 \mathrm{~m}$ (329 ft), and the west side was $46.7 \mathrm{~m}$ (153 ft). On the north face, an approximately $278 \mathrm{ft}$ wide, two story section of the substation extended outward an additional $42 \mathrm{ft}$ along the base of the west wall.

Figure 5-7 shows the locations and numbers of the structural columns for Floor 8 and above. See Chapter 2 for similar drawings for the lower floors. Column numbers 58 to 78 formed a $15.7 \mathrm{~m} \times 48.2 \mathrm{~m}$ $(51.5 \mathrm{ft} \times 158 \mathrm{ft})$ rectangular core, consisting of a standard steel skeleton constructed from columns and beams. The long side of the core was oriented along the east-west direction. Note that the core was offset toward the west side of the building. Various building services, including mechanical and electrical systems, stairways, elevators, and restrooms, were located in the core. Columns 79, 80, and 81 provided additional support for the long floor spans between the east side of the core and the east face of the building.

The remaining 58 columns were located around the periphery of the building. These columns were numbered starting at the northwest corner and progressing counterclockwise around the building. There was a Column 14A between Column 14 and 15 on the west face. All of these columns were connected by steel wide-flange beams having nominal heights (which varied slightly with location) of $0.9 \mathrm{~m}$ (36 in.).

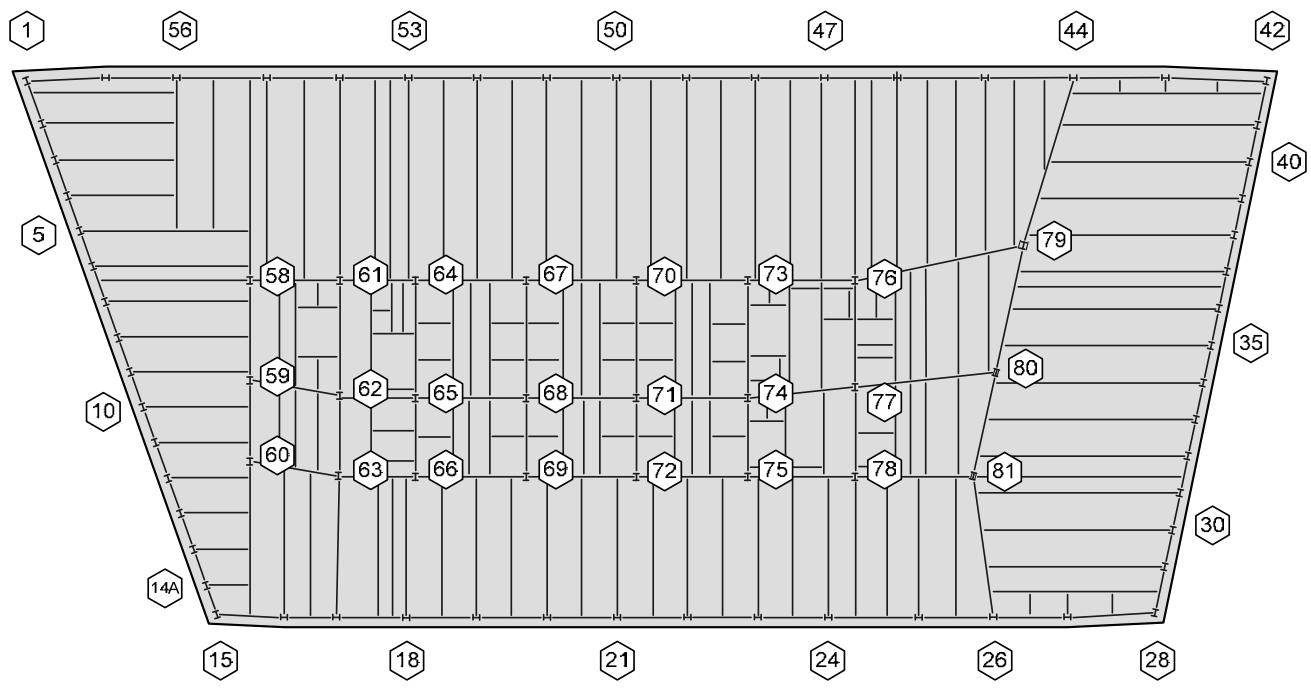

Source: McAllister 2002

Figure 5-7. Locations of columns and beams for a typical floor of WTC 7. 
Portions of Floors 5, 6, 22, 23, 46, and 47 were dedicated to mechanical systems for the building. The tenant floors typically had a slab-to-slab spacing of $3.89 \mathrm{~m}$ (12 ft $9 \mathrm{in}$.). The spacings for mechanical floors varied between about $4 \mathrm{~m}$ to $4.5 \mathrm{~m}$ (about $13 \mathrm{ft}$ to $15 \mathrm{ft}$ ).

On the $5^{\text {th }}$ and $6^{\text {th }}$ floors, there were air intake and exhaust vents. The locations and functions of these vents are discussed in Chapter 3.

There were also mechanical systems on the roof of WTC 7. Figure 5-8 and Figure 5-9 show two views of the roof taken on September 11. There were two fully enclosed structures on the roof which are referred to as the "east penthouse" and the "west penthouse." Two parallel screenwalls ran between the two penthouses and formed an open area that held additional mechanical equipment. To the north of the enclosure, five cooling towers, which extended down to the $46^{\text {th }}$ floor, are visible projecting through the roof. Note that a $1.3 \mathrm{~m}(4 \mathrm{ft})$ high parapet wall extended around the building above the roof.

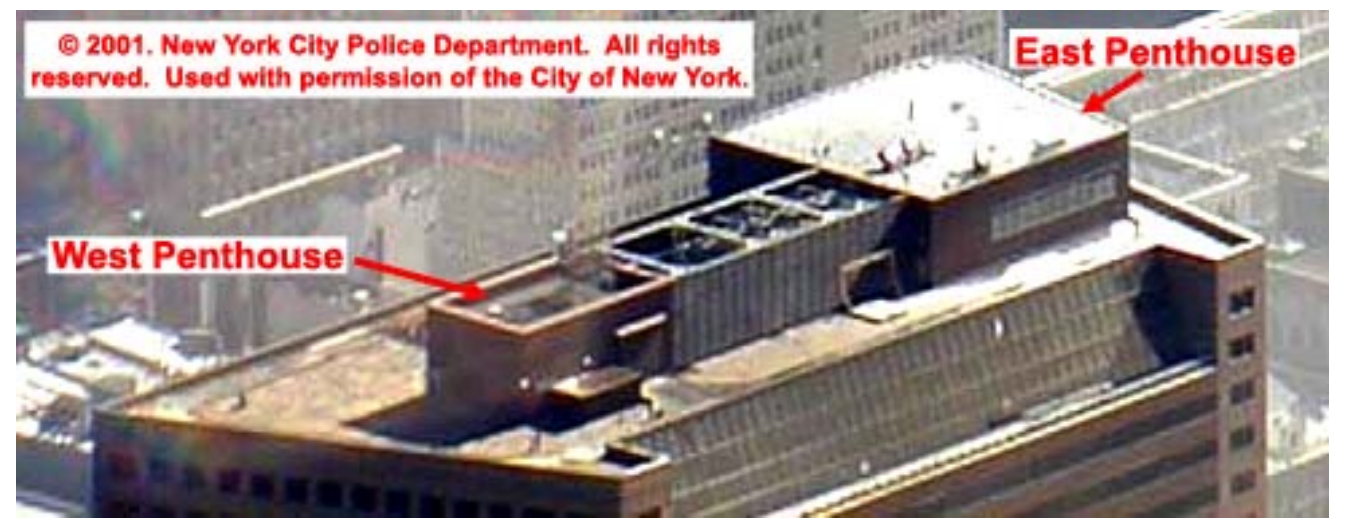

Figure 5-8. Photograph taken from the southwest at 10:22:50 a.m. on September 11 showing the mechanical systems and penthouses on the roof of WTC 7.

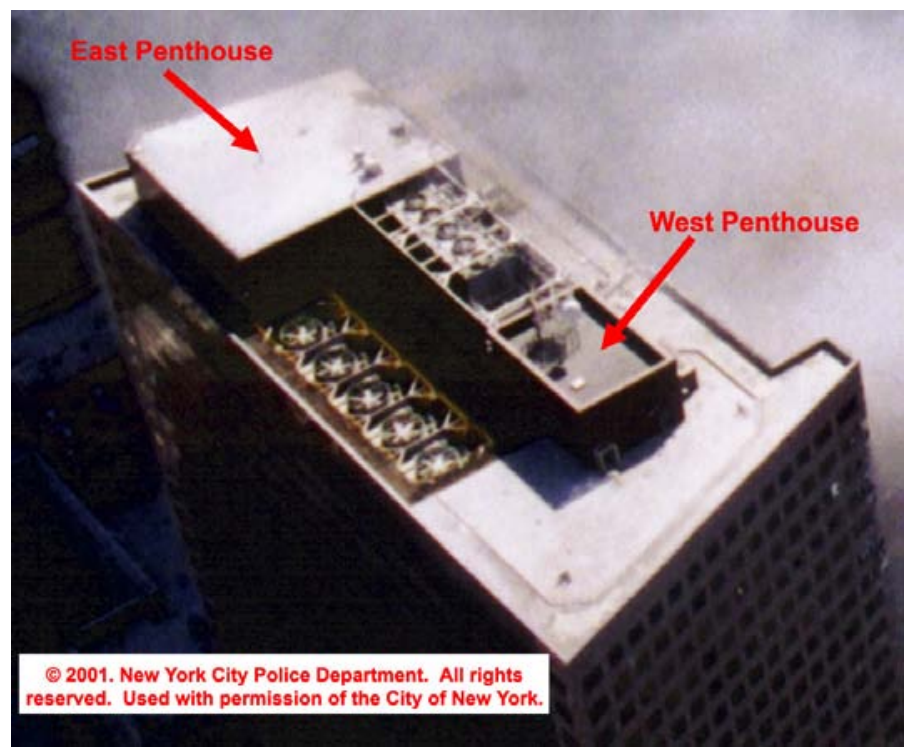

Figure 5-9. Cropped photograph taken from the northwest around 12:00 p.m. on September 11 showing the mechanical systems and penthouses on the roof of WTC 7 . 


\section{Building Exterior}

\section{General}

The outward appearance of the building was determined by the covering, often referred to as a curtain wall, which was attached to the exterior steel frame. The curtain walls included glass that covered the windows. The curtain walls were held in place by supports attached to the steel. The primary materials used to form the outer curtain walls were polished finish granite sections, aluminum window frames, and glass.

The placement of the windows in conjunction with three colors of granite gave the WTC 7 its characteristic appearance. The window arrangements on the north and south faces were similar, but differed from those on the east and west faces. For a given face, the spatial arrangement of windows and granite was repeated on most of the floors. Variations were present on the lower floors, at the $22^{\text {nd }}$ and $23^{\text {rd }}$ mechanical floors, and near the top on the $46^{\text {th }}$ and $47^{\text {th }}$ floors.

The $32 \mathrm{~mm}\left(1 \frac{1}{4} \mathrm{in}\right.$.) thick granite sections were attached to rectangular box structures, referred to as trusses on the building drawings, which were fabricated from $1.2 \mathrm{~mm}$ (0.048 in.) thick galvanized steel. These boxes had the same dimensions as the exterior granite plates and were $127 \mathrm{~mm}$ (5 in.) deep. The box structures were, in turn, attached by brackets to the steel framework. The centerlines for the exterior steel columns and beams were located $0.61 \mathrm{~m}$ (24 in.) inward from the outer part of the curtain wall. Window frames were also attached to the trusses.

\section{North Face}

Figure 5-10 shows a partial view of the north face of WTC 7 taken on the morning of September 11 shortly after WTC 1 (the tower on the right) was struck by a jet airliner. The appearance of the north face is dominated by alternating reddish and darker-colored bands due to the granite facing and window glass, respectively. The light-colored areas at both ends were where tan granite was used.

An enlargement from Figure 5-10 of the lower portion of WTC 7 is shown in Figure 5-11. Floor numbers have been added. Floors 6 to 21 and Floors 24 to 44 had the same appearance.

Close inspection shows vertical lines running across the bands of window glass and granite. The bands are due to $76 \mathrm{~mm}$ (3 in.) wide window frames, which were aligned with the juncture of adjacent granite sections. In the contiguous center section, there are a total of 63 windows on a floor.

There are two additional, adjacent windows near the east and west edges of the building that are separated from the continuous section and encircled by tan colored granite plates.

Most of the windows on the north face had widths of $1.40 \mathrm{~m}$ (4 ft $7 \mathrm{in}$.), but some had slightly different values. The heights of the windows were $1.98 \mathrm{~m}$ (6 ft $6 \mathrm{in}$.), including the $76 \mathrm{~mm}$ (3 in.) wide frames at the top and bottom. The granite plates had heights of $1.87 \mathrm{~m}$ (6 ft 13/4 in.). When the $16 \mathrm{~mm}$ (5/8 in.)

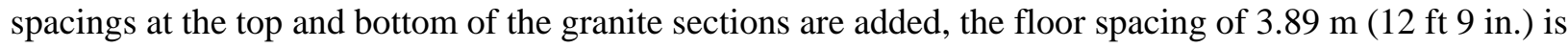
obtained. (The concrete floors were located behind the granite sections.) The distance between the top of a floor slab and the bottom of a window opening was $0.76 \mathrm{~m}$ (30 in.), and the distance between the top of a window opening and the base of the floor above was $1.15 \mathrm{~m}$ ( $3 \mathrm{ft} 91 / 2 \mathrm{in}$.). The nominally $0.9 \mathrm{~m}$ (36 in.) 
high steel spandrel beams were located immediately below the floors. On the interior, there were typically false ceilings that ran to the top of the window glass. The glazing for the windows on these typical floors was $25 \mathrm{~mm}$ (1 in.) thick darkened, insulated glass panels.

The top of the north face in Figure 5-10 has a difference appearance. This is the area of the mechanical spaces on the $46^{\text {th }}$ and $47^{\text {th }}$ floors. The darker area near the center is due to a series of adjacent vertical louvers through which air was fed to the cooling towers visible on the north side of the roof in Figure 5-9. The area to the immediate left of the louvers consisted of 17 glass sections. In the 10 sections to the immediate right of the louvers, the glass was backed by a closed wall. The remaining eight sections to the right were the same as the 17 sections on the left. On either end of the floors there were two adjacent windows separated from the contiguous central region by tan granite sections.

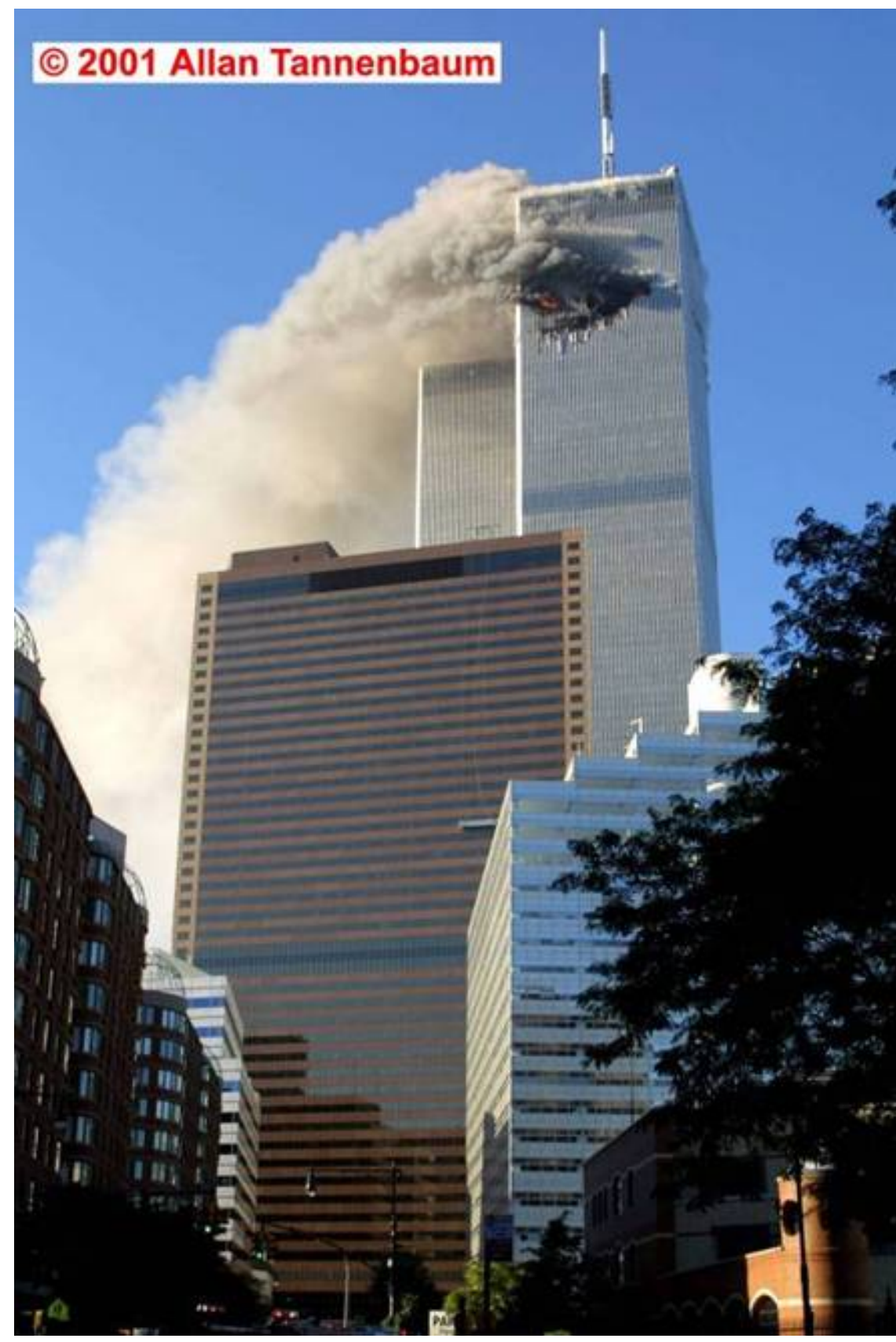

Figure 5-10. Photograph of the north face of WTC 7, looking down Greenwich Street, shot at 8:55:01 a.m. on September 11. The WTC towers (WTC 1 on the right and WTC 2 on the left) are visible above WTC 7. 


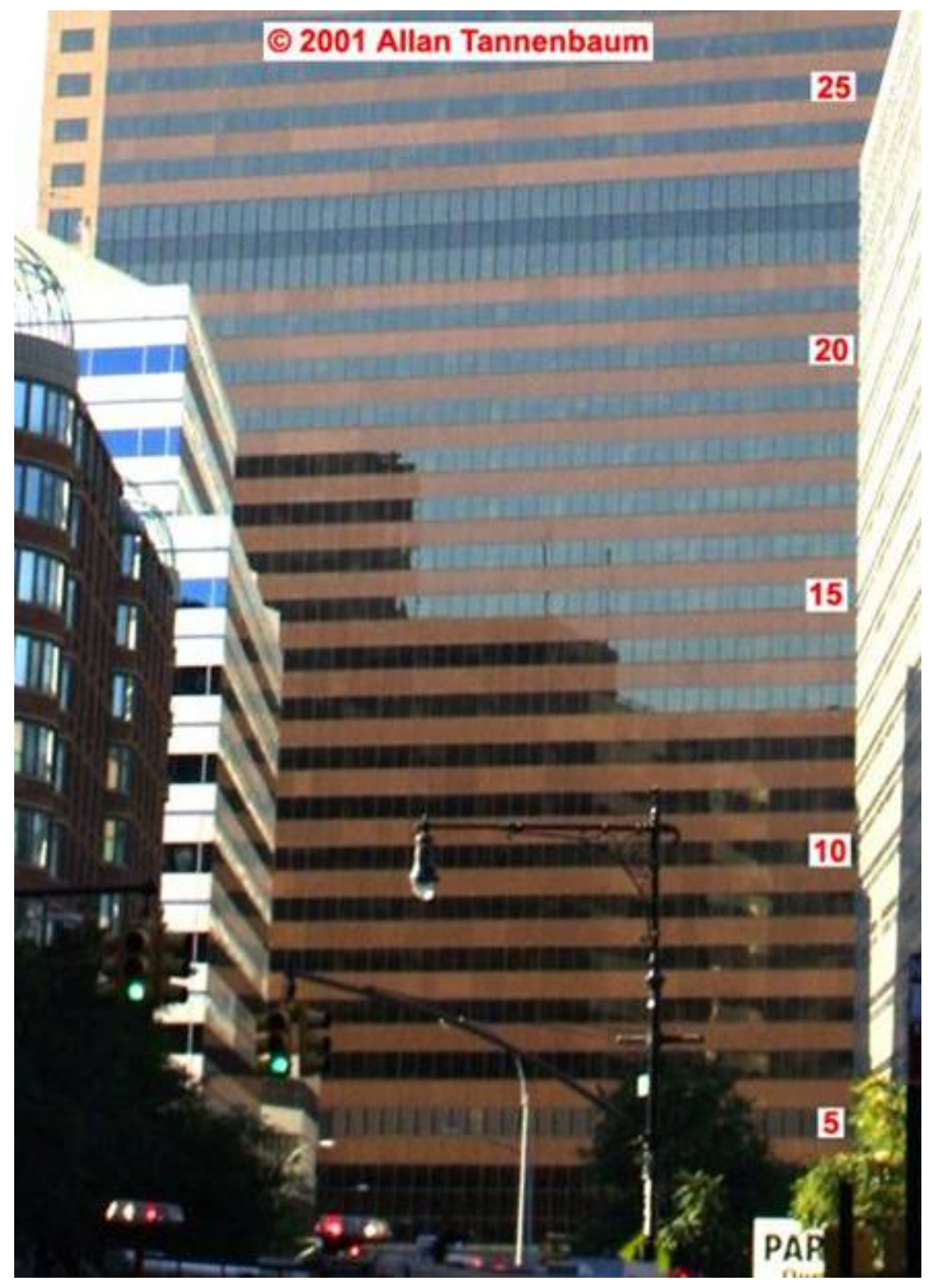

Figure 5-11.

Enlargement of a portion of Figure 5-10 showing the lower floors of WTC 7.

Floor numbers have been added, and the image has been enhanced.

The central part of the curtain wall at the $22^{\text {nd }}$ and $23^{\text {rd }}$ floor had a similar appearance to that of the areas on either side of the louvers on the $46^{\text {th }}$ and $47^{\text {th }}$ floor. This consisted of $2.64 \mathrm{~m}$ (8 $\mathrm{ft} 8 \mathrm{in}$.) windows above and below $1.91 \mathrm{~m} \mathrm{(6} \mathrm{ft} 3$ in.) glass panels.

In Figure 5-11, it is evident that the windows on the $5^{\text {th }}$ floor had a different appearance than those on higher floors. This is because the windows contained louvers instead of glass (Chapter 4). These louvers are visible in Figure 5-12, which shows a view of the lower floors of the eastern edge of the north face. There is a large area of connected windows visible below the $5^{\text {th }}$ floor louvers. These windows were on the $3^{\text {rd }}$ and $4^{\text {th }}$ floors. Each of these windows consisted of three glass sections divided by frames in the vertical direction. The upper and lower sections consisted of $25 \mathrm{~mm}$ thick $1.83 \mathrm{~m}(6 \mathrm{ft})$ high insulating glass, while the center section was a $6 \mathrm{~mm}\left(\frac{1}{4} \mathrm{in}\right.$.) thick, $1.98 \mathrm{~m}(6 \mathrm{ft} 6 \mathrm{in}$.) high glass plate. 
The white section of WTC 7, visible immediately below the $3^{\text {rd }}$ floor, is the eastern end of the substation that housed the Con Edison transformers. To the immediate left of the substation is an opening for the underground ramp that led to a truck loading dock under the main WTC complex. There is an entrance doorway to the immediate left of the ramp entrance that is not visible in Figure 5-12. There was a second entrance doorway near the center of the north face.

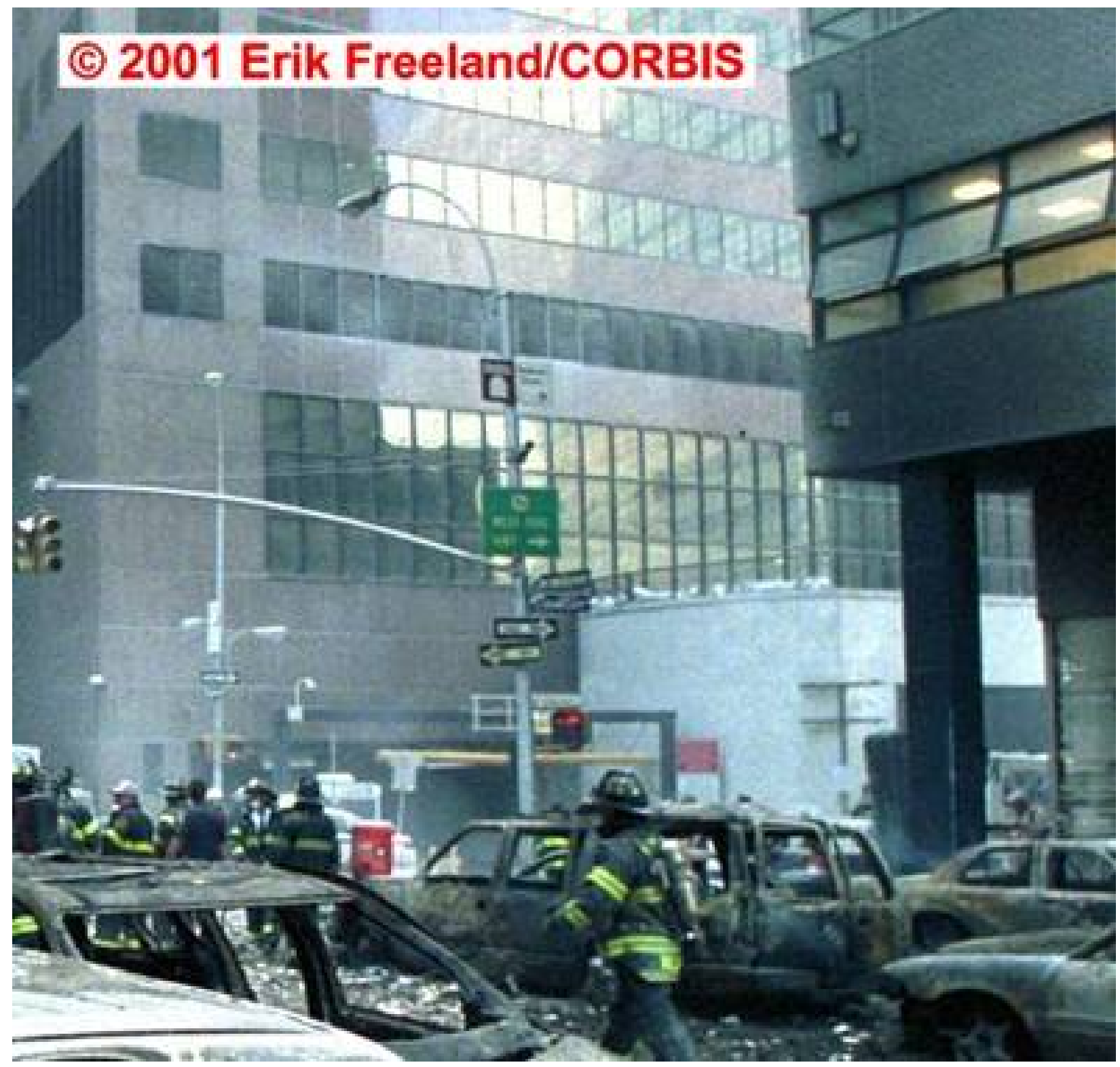

Figure 5-12. Photograph of the east side of the north face of WTC 7.

The original photograph was cropped, and the intensities were adjusted.

For later image analyses, it will be necessary to be able to identify individual windows on various floors of the building. A nomenclature has been adopted in which windows are designated based on their location relative to the exterior steel columns of WTC 7. On the north face, these columns are numbered from 42 to 1 (Figure 5-7) going from left to right as viewed from outside. On this face, three to five windows are located to the right of a given column. Using design drawings and images, a properly scaled 
façade drawing for the north face has been created and is shown in Figure 5-13. The numbers on the left side of the drawing indicate floors. Each number is associated with a short line that shows the location of the floor slab for that particular floor. The locations of columns across the face are indicated by numbers placed above the windows on the $21^{\text {st }}$ floor. The windows associated with a given column are those to the immediate right. By using the general notation $x-y z$, where $x$ represents a floor, $y$ a column number, and $z$ the letter for a particular window, it is possible to identify any window on the face. As examples, the leftmost window on the $7^{\text {th }}$ floor is identified as $7-42 \mathrm{~A}$, the $14^{\text {th }}$ window from the left on the $15^{\text {th }}$ floor is denoted $15-44 \mathrm{E}$, and the rightmost window on the $30^{\text {th }}$ floor is $30-57 \mathrm{C}$.

\section{South Face}

Figure 5-14 is a cropped photograph, taken from near the corner of Liberty Street and Church Street on the morning of September 11, that shows the upper portion of the south face of WTC 7. Floor numbers have been added for reference. The two buildings in the foreground are WTC 4 and WTC 5. These buildings block views of WTC 7 below the $20^{\text {th }}$ floor from this direction and demonstrate how difficult it was to record images of the lower parts of this face of WTC 7.

The general appearance of the south face of WTC 7 for Floors 7 to 45 was the same as the north face. (Compare Figure 5-14 with Figure 5-10 and Figure 5-11.) There are continuous sections of windows in the center with reddish polished granite spandrel covers above and below. On either edge of the center section windows, there are two windows framed by an area of tan colored granite.

Even though the appearances of the two faces were similar, details concerning column and window placement differed. There were 45 contiguous windows in the center area of the south face, as contrasted with the 63 contiguous windows per floor on the north face. The dimensions of the windows were the same as on the north face, although, again, there was some modest variation in the width of some of the windows.

The south side of the top two floors $\left(46^{\text {th }}\right.$ and $\left.47^{\text {th }}\right)$ can be seen in Figure 5-8. The center area corresponding to the contiguous window locations on other floors is recessed inward. There is a narrow roofline at the base of the $46^{\text {th }}$ floor that is connected to the top edge of the roof parapet by a sloping curtain wall. The recessed area is also visible at the top of WTC 7 in Figure 5-14. In Figure 5-8, it can be seen that the sloping curtain wall was broken into vertical four glass sections separated by frames.

The eastern edges of the $22^{\text {nd }}$ and $23^{\text {rd }}$ floors are just visible in Figure 5-14. The central window region has the same appearance and composition as the corresponding floors on the north face, with a dark horizontal band and two somewhat lighter bands immediately above and below. 


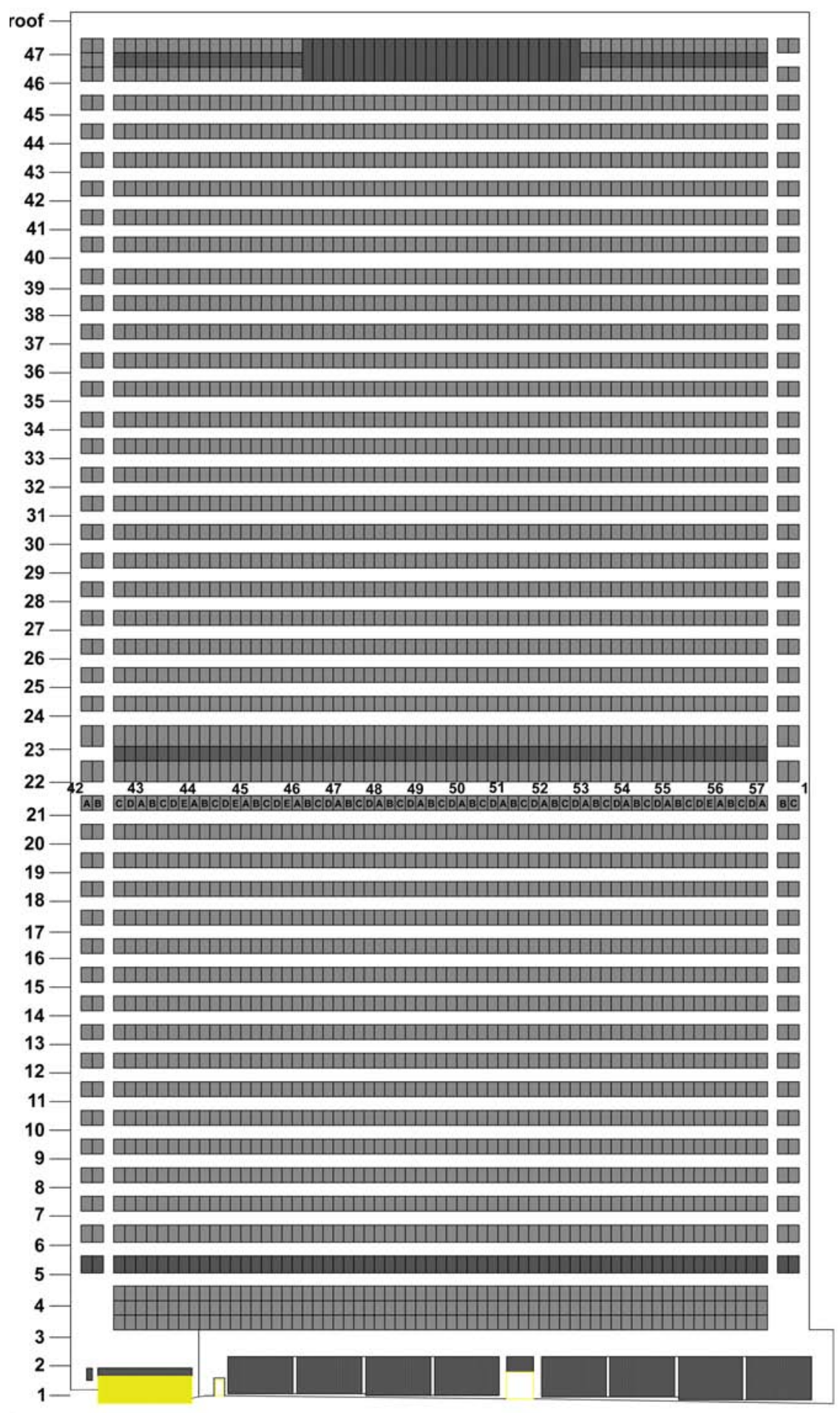

Figure 5-13. Façade graphic of the north face of WTC 7.

Floor numbers are indicated with the lines representing the slab locations. Column locations are indicated by the numbers at the $21^{\text {st }}$ floor. Individual windows are identified by the nearest column to the immediate left and the corresponding letters. 


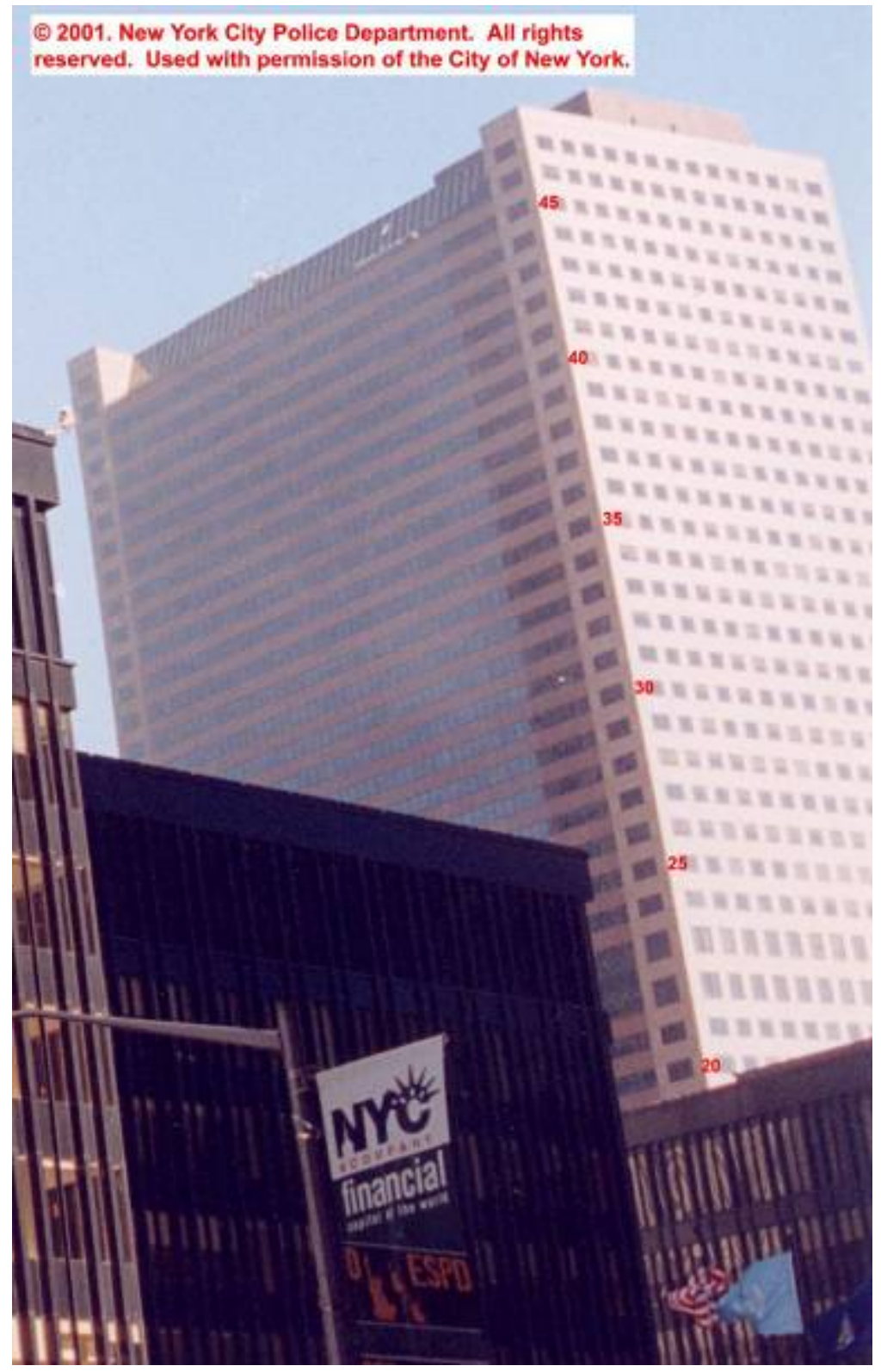

Figure 5-14. Photograph showing upper portions of the south and east faces of WTC 7, taken from near the corner of Church Street and Liberty Street on September 11 at 9:51:45 a.m.

The two buildings in the foreground are WTC 4 (left) and WTC 5 (right). Floor numbers have been added, and the image was cropped and enhanced.

Figure 5-15 and Figure 5-16 show views of the lower floors of WTC 7 on the south face. The two story black area is a series of louvers located on the $5^{\text {th }}$ and $6^{\text {th }}$ floors. These louvers line up with the continuous sets of windows in the center parts of the higher floors. The louver heights were $6.07 \mathrm{~m}(19 \mathrm{ft}$ 11 in.). Recall that on the north face, louvers were only present on the $5^{\text {th }}$ floor and had a different appearance. (See Figure 5-12.) Unlike the higher floors, there were no openings on these floors at the east and west edges of the south face. There was a two story generator vault located behind these louvers on the west end of the south side of the $5^{\text {th }}$ and $6^{\text {th }}$ floors. To the east, a series of transformer vaults ran along the south wall of the $5^{\text {th }}$ floor. Associated electrical equipment was located above each of these vaults on the $6^{\text {th }}$ floor.

In the area visible between the Promenade and Pedestrian Bridge there was a four story high atrium that can be seen clearly in Figure 5-15. The area was enclosed in clear glass, and it is possible to see the columns and spandrels through the windows in Figure 5-15. The four columns visible between the two 

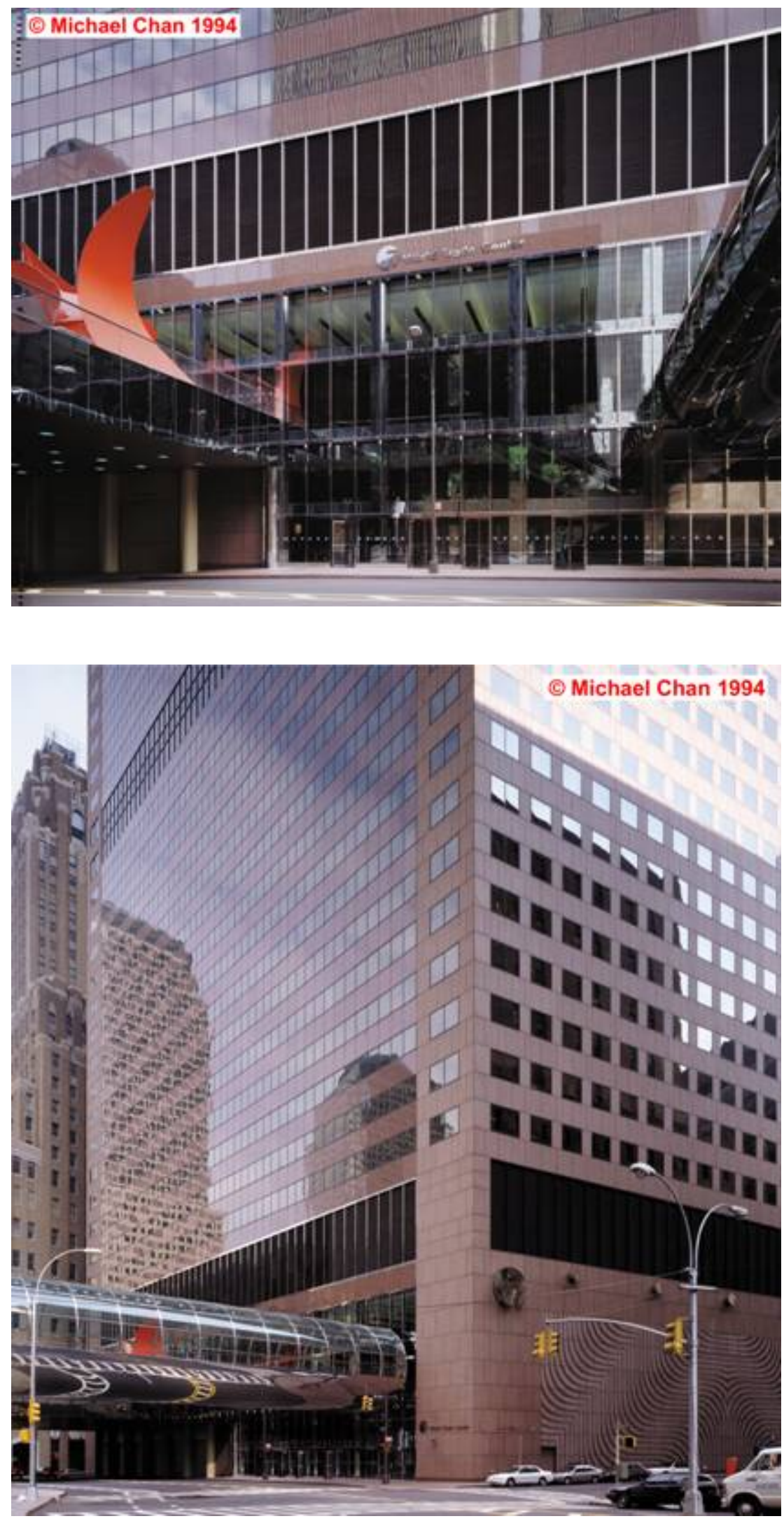

Figure 5-15. Photograph of a portion of the lower floors of WTC 7 on the south face.

It was shot from across

Vesey Street between the Promenade on the left and the Pedestrian Bridge on the right.
Figure 5-16. Photograph showing the lower southeast corner of WTC 7. 
bridges are numbered 23 to 26 . A number of revolving and swinging doors entering the lobby are visible on the first floor. Figure 5-16 also provides good views of the pedestrian bridge and south face entrances.

Entrances onto the Promenade and the Pedestrian Bridge were located on the $3^{\text {rd }}$ floor. Areas above the Promenade were also enclosed in clear glass on the $3^{\text {rd }}$ and $4^{\text {th }}$ floors. Column 22 is visible through the window above the Promenade in Figure 5-15. The clear glass on these floors extended as far west as Column 16. The area above (to the $4^{\text {th }}$ floor) and below the Pedestrian Bridge was also enclosed by clear glass. A small section of Column 27 is visible above and to the right of the Pedestrian Bridge in Figure 5-15. The glass on the east side extended just beyond Column 27.

Access from Vesey Street to a two story high loading dock for WTC 7 was located under the Promenade between Columns 16 and 22. Six large doorways with rollup doors provided this access. One of these doorways is visible in Figure 5-17. Additional doorways were located between the columns visible to the left of the image. The round columns were outside of WTC 7 and provided support for the Promenade.

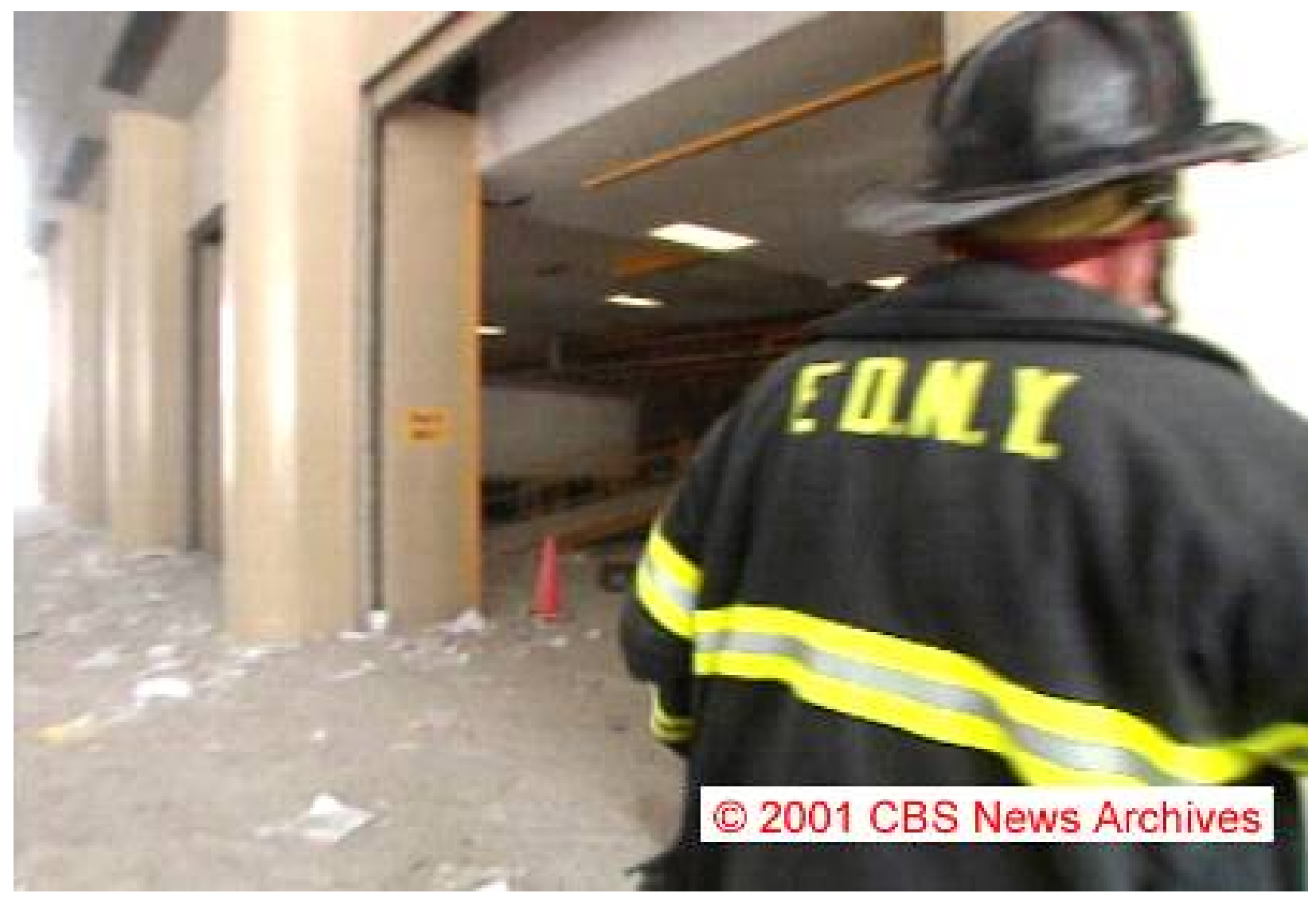

Figure 5-17. Frame from a video showing one of the doorways located below the Promenade that led to the WTC 7 loading dock located on the $1^{\text {st }}$ and $2^{\text {nd }}$ floors. The image has been enhanced. 
Figure 5-18 shows a side view of the Promenade looking east along Vesey Street. This image was taken around 10:15 a.m., between the times when WTC 2 and WTC 1 collapsed. The Promenade extended a distance of $37.8 \mathrm{~m}(124 \mathrm{ft})$ between Columns 16 and 23 on the south face of WTC 7. It was enclosed on either side by transparent walls that ran from WTC 7 across to WTC 6 . The walls on the east side are visible in Figure 5-15, and those on the west side can be seen in Figure 5-18. The large red object visible on the Promenade in Figure 5-15 is a sculpture that was located near the northeast corner.

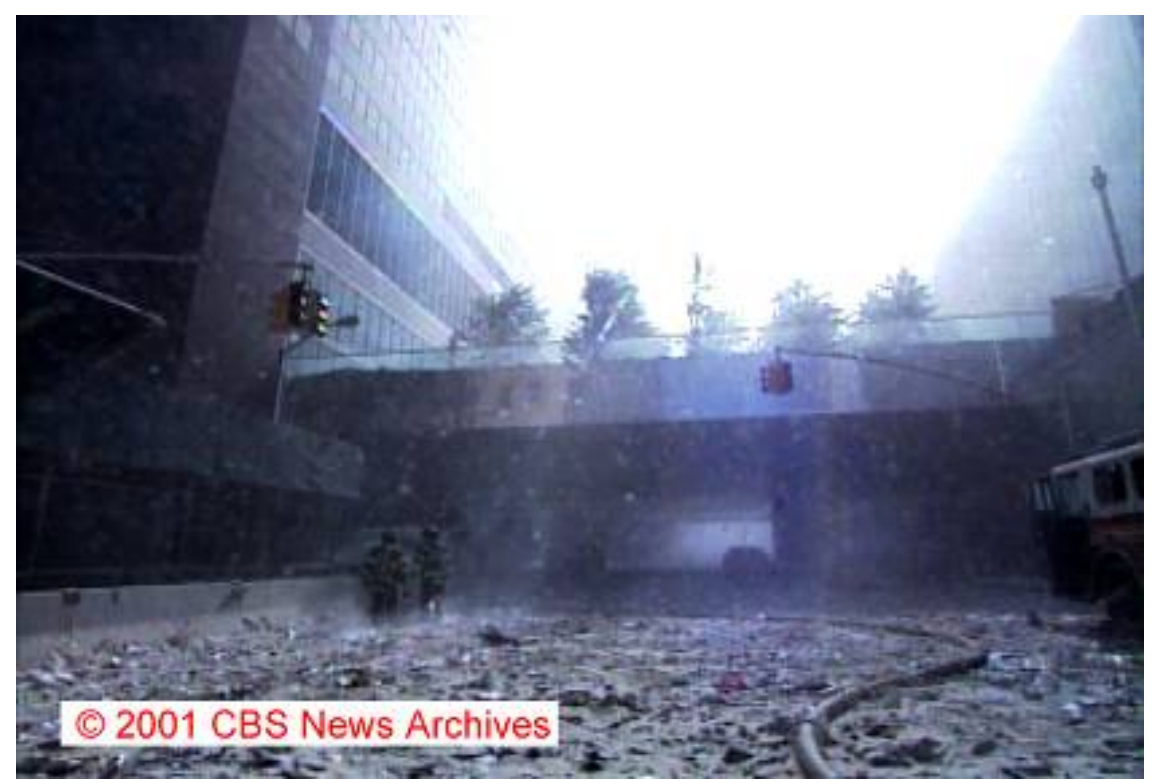

Figure 5-18. An image from a video, shot from Vesey Street and looking toward the east, shows the south face of WTC 7 and the Promenade crossing over to WTC 6 . The video was recorded around 10:15 a.m. on September 11. The intensity levels of the image have been adjusted.

The Pedestrian Bridge was located near the east edge of the south face. Figure 5-16 shows this bridge prior to September 11. Figure 5-19 shows a view of the bridge taken from a video shot on September 11 shortly after the collapse of WTC 1 from another angle. The bridge was tubular in shape with a diameter

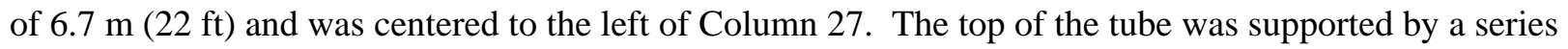
of ribs and was transparent. The sides were open.

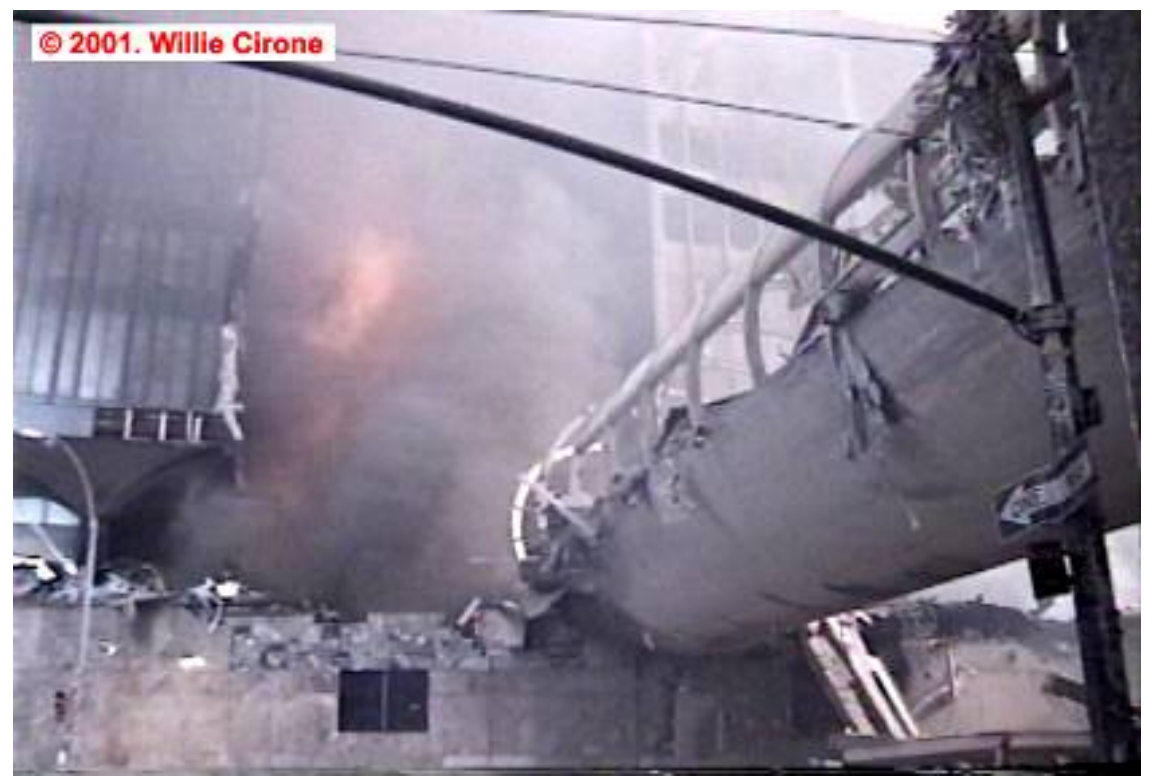

Figure 5-19. Image of the Pedestrian Bridge taken from a video shot shortly after the collapse of WTC 1 from near the corner of West Broadway and Vesey Street.

The buildings across Vesey Street are WTC 5 (left) and WTC 6 (right). The image intensity has been adjusted. 
A properly scaled drawing of the south façade of WTC 7 is shown in Figure 5-20.

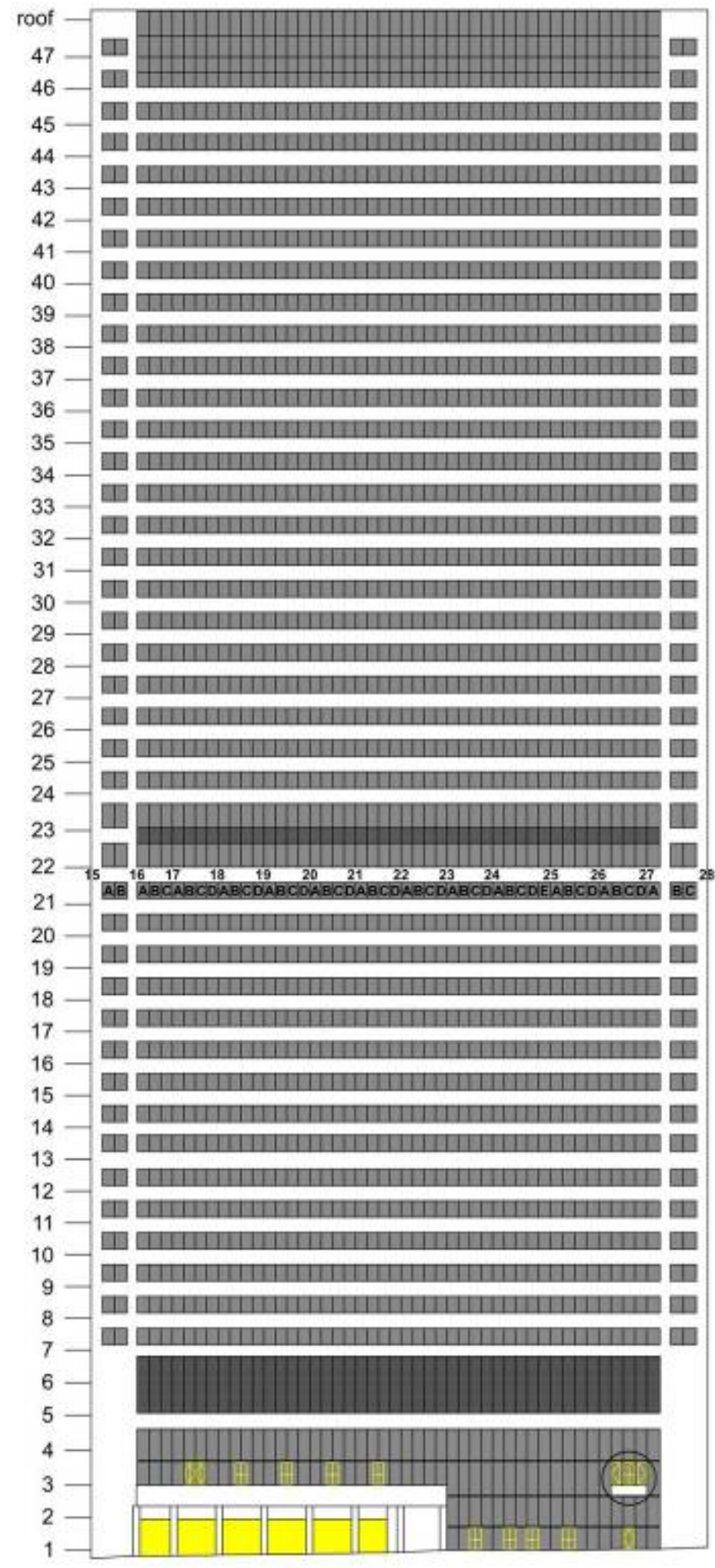

Figure 5-20. Façade graphic of the south face of WTC 7.

Floor numbers are indicated with the lines representing the slab locations. Column locations are indicated by the numbers at the $21^{\text {st }}$ floor. Individual windows are identified by the nearest column to the immediate left and the corresponding letters. 
While not shown explicitly, the locations of the Promenade and Pedestrian Bridge are apparent at the base of the $3^{\text {rd }}$ floor. Using the same notation as for the north face, floor numbers and slab locations are indicated. As above, windows are identified by the nearest column to the immediate left and a letter representing the location of the window relative to the column position.

\section{East Face}

As noted earlier, the east and west faces of WTC 7 had appearances different from the north and south faces. Figure 5-21 shows an image of the east face of WTC 7, in which the upper floors are visible. Instead of the distinct alternating color pattern apparent on the north and south faces, the east face had a waffle appearance. This pattern was created by using $1.83 \mathrm{~m}$ (6 ft 0 in.) square sections of $25 \mathrm{~mm}$ ( 1 in.) thick insulated window glass with $76 \mathrm{~mm}$ (3 in.) wide frames (total width $1.98 \mathrm{~m}, 6 \mathrm{ft} 6 \mathrm{in}$ ) surrounded by sections of tan granite panels. On each floor, the openings at the north and south edges, each containing two windows, were somewhat wider $(2.6 \mathrm{~m}, 8 \mathrm{ft} 6 \mathrm{in}$.) than the central 12 windows. This configuration was repeated on Floors 7 to 49 with the exception of Floors 22 and 23, where the window heights were increased by 50 percent to $2.90 \mathrm{~m}$ (9 ft 6 in.), including the 3 in. wide frame.

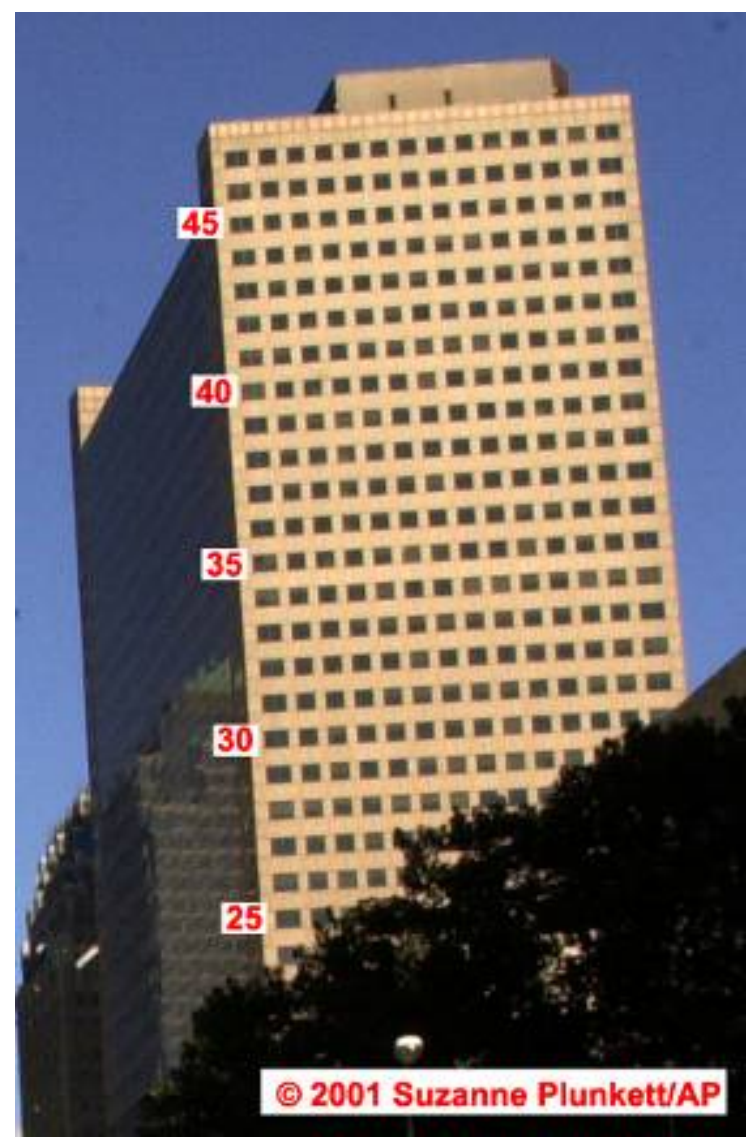

Figure 5-21. Cropped photograph shot from near the corner of Broadway and Frankfurt Street showing the upper floors of the east face of WTC 7.

Floor numbers have been added. The building on the far side of WTC 7 is the Verizon Building. The intensity levels have been adjusted.

A photograph of the lower floors of the east face of WTC 7 is shown in Figure 5-22. A partial view from the other end of the face is shown in Figure 5-16. The lowest row of windows with glass is on the $7^{\text {th }}$ floor. Immediately below these windows there is a span of black louvers that were located on the $5^{\text {th }}$ and $6^{\text {th }}$ floors. As described in Chapter 3, these louvers were connected to a pair of two story plenums that provided air intake and exhaust for diesel-powered generators for electrical power backup. Below the $5^{\text {th }}$ 
floor, there were no other openings on the east face, with the exception of two doors located at the ends of the three story mural that ran for a length of $33 \mathrm{~m}$ (108 ft 2 in.) and was centered on the face (Figure 5-16 and Figure 5-22). The northern door, hidden behind the mail truck in Figure 5-22, provided access to an exterior store room behind the wall, while the southern door accessed a stairwell that connected to the first four floors.

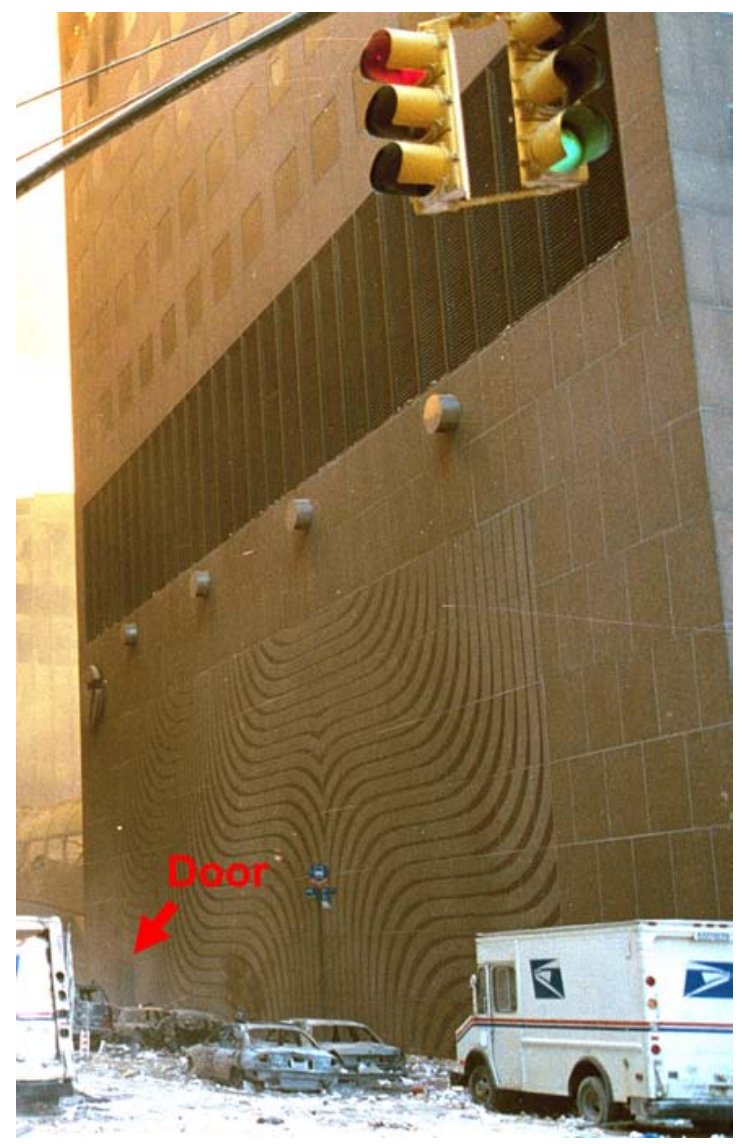

Figure 5-22. Cropped photograph of the lower portion of the east face of WTC 7, taken shortly after 2:00 p.m. on September $11^{\text {th }}$ from near the corner of Barclay Street and West Broadway. The intensity levels have been adjusted.

Source: George Miller, New York City Transit Authority (NYCTA)

Figure 5-23 shows a façade drawing of the east face of WTC 7. The numbers indicate floor slab and column locations. Since only single windows are present to the left of Columns 29 to 40, it is not necessary to use letters to identify these windows. The pairs of windows on either end of a floor are identified using "A" and "B."

\section{West Face}

A view of the upper floors of the west face of WTC 7 is shown in Figure 5-24. The face has a waffle-like appearance that is similar to the east face, and the 12 windows between the window pairs on either end were configured identically to those on the east face. However, on the north edge of the west face, there was one pair of windows with the same dimensions as the pairs on the north and south edges of the east face, and on the south edge of the west face, there were two adjacent two-window groupings. The left hand pair of these windows had a width of $2.74 \mathrm{~m}$ (9 $\mathrm{ft} 0 \mathrm{in}$.), and the right hand pair width was $3.35 \mathrm{~m}$ (11 ft 0 in.). The arrangement of windows visible in Figure 5-24 was repeated as far down as the $7^{\text {th }}$ floor, except for the windows on the $22^{\text {nd }}$ and $23^{\text {rd }}$ floors. These were the same as on the east face. 


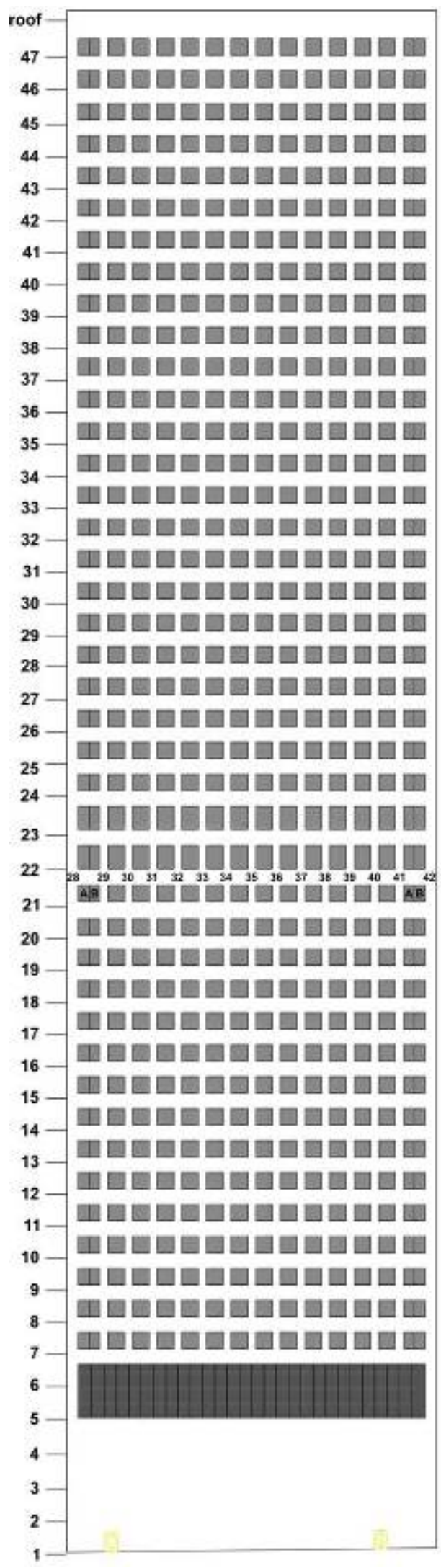

Figure 5-23. Façade graphic of the east face of WTC 7.

Floor numbers are indicated with the lines representing the slab height. Column locations are indicated by the numbers at the $21^{\text {st }}$ floor. Individual windows are identified by the nearest column to the immediate left and the corresponding letters. 
Figure 5-25 shows a view of the lower part of the west face of WTC 7. This photograph was taken on September 11. There is considerable collapse debris in the street (Washington Street) next to the building, and some damage is evident on the face. The appearance of the lower six floors differs considerably from that for the east face. (See Figure 5-16 and Figure 5-22.)

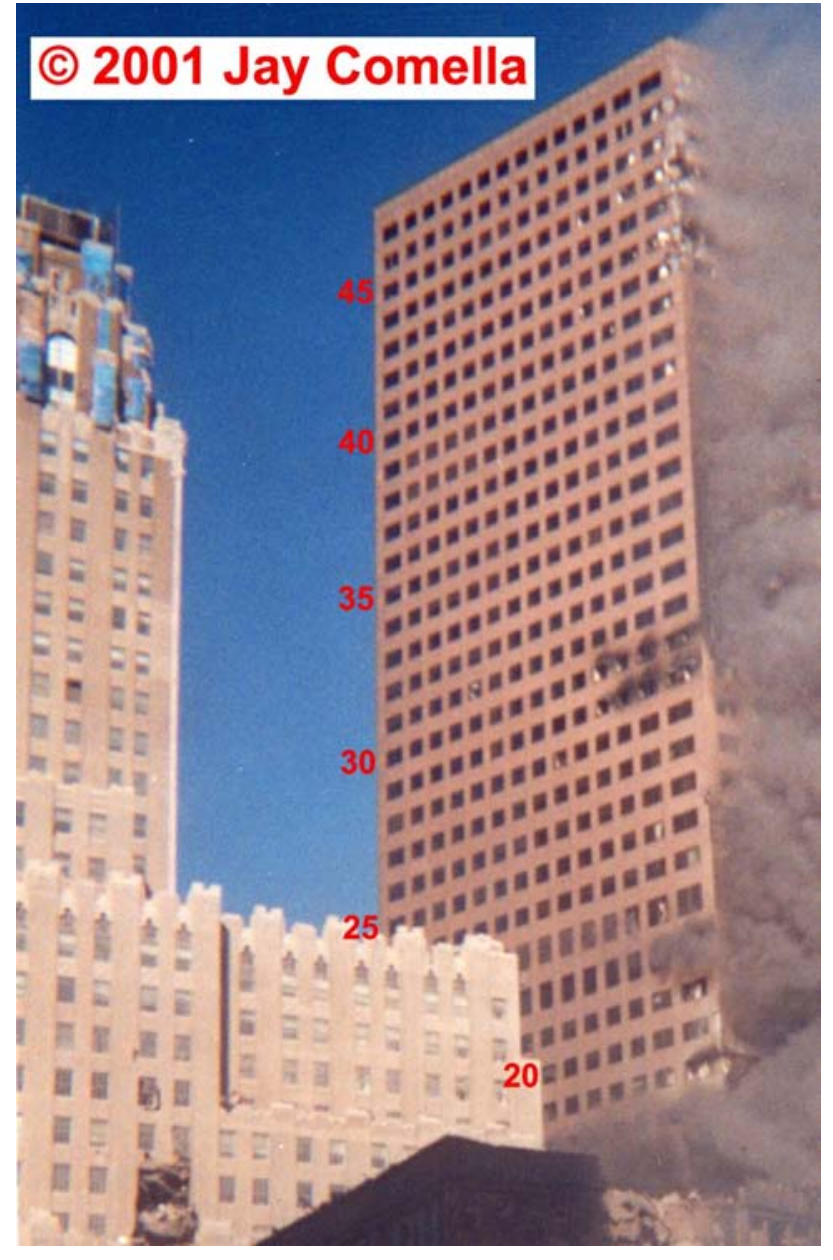

Figure 5-25. Cropped photograph showing the lower floors of the west face and a small section of the north for WTC 7, taken on September 11 sometime after 12 p.m.

The light area in the upper left-hand corner was in shadow, and the intensity has been adjusted to make it more visible.
Figure 5-24. Cropped photograph of the west face of WTC 7 shot from West Street between 3:30 p.m. and 4:30 p.m. on September 11.

The structure on the left is the Verizon Building, and the building just visible at the bottom is WTC 6 . The intensity levels have been adjusted.

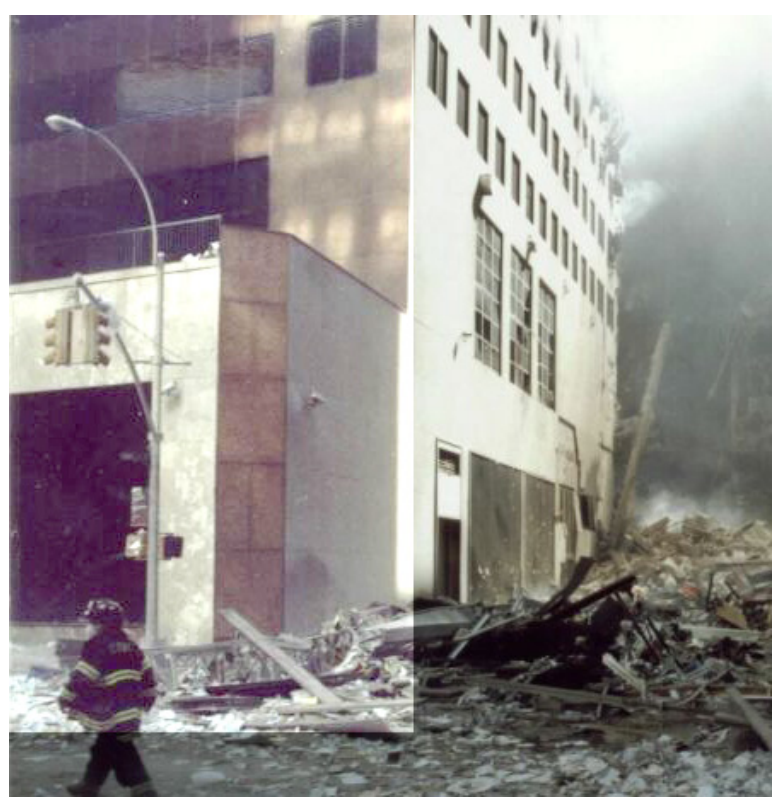

Source: George Miller, New York City Transit Authority (NYCTA) 
The two story high extension that covered the substation (discussed earlier) stands out at the base of the northwest corner. A portion of the louvers for the westernmost transformer vault on the north side is visible on the north face. On the main portion of the west face, the two lower rows of windows that span the full face are on the $5^{\text {th }}$ and $6^{\text {th }}$ floors. While not evident from the angle of Figure 5-25, these openings contained louvers that connected to a pair of two story high plenums that served as air intakes and exhausts. On higher floors, there were isolated windows that also contained louvers instead of glass.

In Figure 5-25, three large windows divided into $3 \times 6$ sections are visible. These windows were located on the $3^{\text {rd }}$ and $4^{\text {th }}$ floors. Each measured $4.50 \mathrm{~m}$ wide $\times 6.07 \mathrm{~m}$ high $(14 \mathrm{ft} 9 \mathrm{in} . \times 19 \mathrm{ft} 11 \mathrm{in}$.). These windows were open to the outside and covered with bird screen. Just below these windows, two louvered sections were located on the $1^{\text {st }}$ floor and part of the $2^{\text {nd }}$ floor. These louvers were raised slightly off of

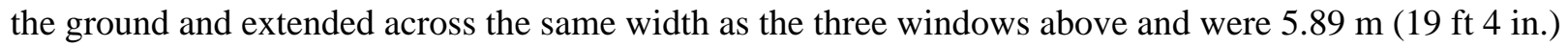
tall. These louvers provided access to and ventilation for the two transformers that were located behind. The area visible to the left of the louvers on the first floor was a rollup door that provided access to the Con Edison space. There was a small louvered area at the base of the second floor above this door.

To the immediate right of the large ground floor louvers, an area is visible on the $2^{\text {nd }}$ floor where the granite cladding has been knocked off. Immediately below the damaged area there is a set of inactive vertical louvers. Immediately below these louvers, there was a $2.49 \mathrm{~m} \mathrm{(8 \textrm {ft }} 2 \mathrm{in}$.) high vestibule with two entry doors. The doors led to a stairway that provided employee access to the $2^{\text {nd }}$ through $4^{\text {th }}$ floors.

There is an additional opening visible in Figure 5-25 further to the right of the ground floor vestibule and louvered area. This was an area of active louvers located at the base of the $2^{\text {nd }}$ floor. These louvers opened to a plenum that extended upward to the $3^{\text {rd }}$ floor slab. The plenum served a small mechanical equipment room in the southwest corner of this floor.

Figure 5-26 is a façade drawing for the west face of WTC 7. Similar to the drawings of the other faces, the locations of floors are indicated by the lines on the left side and the locations of perimeter columns by the number above the windows on the $21^{\text {st }}$ floor. Windows are identified by the column numbers to the immediate left. For most locations there were only single windows to the right, and no additional window identifiers are required. There were two windows to the immediate right of Column 1 and Column 13, and these are denoted by "A" and "B" as shown.

Note that Column 1 to Column 13 and Column 15 were located behind polished granite column covers, but that Column 14 was located behind the right hand edge of window 13B, and Column 14A was behind both window 14 and window 14A. This arrangement differs from the east face, where all columns were placed behind granite covers.

Another feature of the west face that differed from the other faces was the presence of louvers on nonmechanical floors. In façade drawings, the louvered windows are indicated by a darker shade of gray than was used to indicate window glass. For nonmechanical floors, where present, the louvers were located in window 6. 


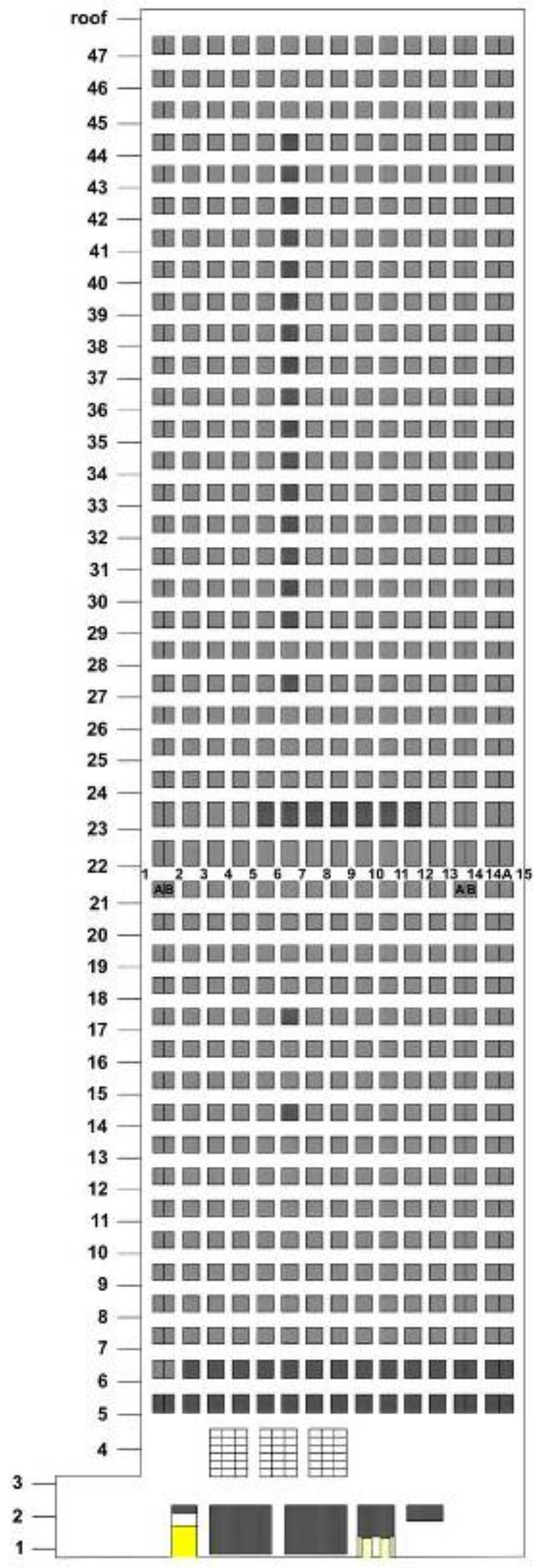

Figure 5-26. Façade graphic of the west face of WTC 7.

Floor numbers are indicated with the lines representing the slab locations. Column locations are indicated by the numbers at the $21^{\text {st }}$ floor. Individual windows are identified by the nearest column to the immediate left and the corresponding letters. 


\subsection{VISUAL IMAGERY AVAILABILITY FOR WTC 7 DAMAGE AND FIRE CHARACTERIZATION}

\subsubsection{Overview}

There was a period of nearly seven hours between the WTC 1 and WTC 7 collapses. The availability of imagery of the lower 13 floors of WTC 7, where most of the structural damage and fire activity occurred, was sporadic and variable over this period. The images that were available provided sufficient information to guide the reconstruction of the WTC 7 collapse. However, the degree of detail was less than that for the WTC towers.

\subsubsection{Limitations of Imagery}

\section{Obstructed View}

As shown earlier in this chapter, views of the lowest 13 floors from any distance beyond the immediate vicinity were generally blocked by nearby buildings. The principal exception was the lower portion of the north face, which was observable looking down Greenwich Street. Views of the lower floors elsewhere were only available from locations very close to WTC 7 or from overhead.

\section{Dust from the Collapse of the WTC Towers}

When WTC 2 collapsed at 9:58:59 a.m., the situation around the WTC complex completely changed. The collapse generated a huge dust cloud that, due to its high density, spread much like a liquid around the buildings of Lower Manhattan. An image of this cloud taken nearly four minutes after the collapse is shown in Figure 5-27. In the immediate aftermath it was not possible to see WTC 7. Thousands of people rapidly fled the area. As a result, the amount of collected imagery shot from the vicinity of the WTC site abruptly dropped when WTC 2 collapsed. Due to the prevailing wind, the dust cloud around WTC 7 began to clear by around 10:15 a.m. and some nearby imagery of WTC 7 was recorded during the period between the collapse of WTC 2 and the collapse of WTC 1 at 10:28:22 a.m.

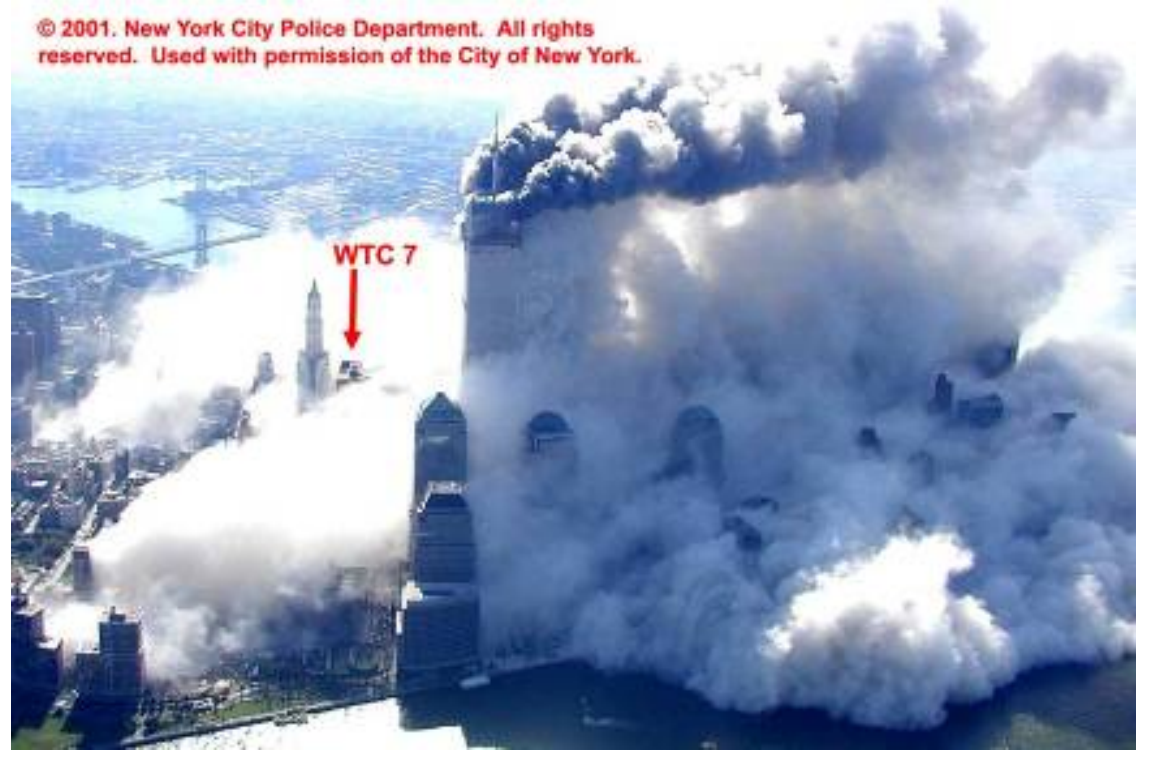

Figure 5-27. Cropped photograph showing the dust cloud created by the collapse of WTC 2.

The image was shot from the west at 10:03:56 a.m. WTC 7 can barely be seen above the cloud. The intensity levels of the photograph have been adjusted. 
The dust cloud generated by the collapse of WTC 1 further blocked views of the WTC site, and the second collapse created additional confusion and panic as people continued to stream away from the site. The collapses of the towers created extremely difficult conditions around the WTC site. Large amounts of tower steel and façade debris were on the ground; several buildings were heavily damaged; numerous fires were ignited in debris piles, vehicles, and nearby buildings; and a large number of people, including emergency responders, had been killed. As a result of these conditions, very little imagery taken from near WTC 7 has been identified for roughly an hour following the collapse of WTC 1, even though some long range imagery showing the upper floors of WTC 7 is available.

\section{Smoke Obscuration}

The earliest views of the south face available following the collapse of WTC 1 show large amounts of smoke obscuring the face. This smoke was present at later times as well. It was not clear whether the smoke was coming from lower locations within WTC 7 or was from fires near WTC 7 whose smoke was being drawn into a low pressure area formed on the face due to the flow of the prevailing wind from the north around the building. (Similar effects of the wind caused partial obscuration of the east and south faces of WTC 1 prior to its collapse, as discussed in NIST NCSTAR 1-5A.) The presence of this smoke further limited clear views of the south face.

\section{Limited Site Access}

During this first hour following the collapse of WTC 1, emergency responders, some ordinary citizens, and professional photographers and film crews began to work their way slowly back to the WTC site. As a result, starting around 11:00 a.m., limited imagery of the lower floors of WTC 7 was taken. Also starting around this time, police helicopters with photographers aboard approached the site, and some photographs were taken showing the lower floors of WTC 7 from above. Television news helicopters were an extremely valuable source of footage of the towers, but they provided only limited helpful imagery of the lower floors of WTC 7 after the towers collapsed. Even before WTC 1 collapsed, news helicopters had been ordered to hover several miles from the WTC site. From this distance, they could not observe the lower floors of WTC 7. A no-fly policy was being implemented across the nation, and early in the afternoon, most news helicopters were required to land. The last helicopter news footage of the site was recorded from across the Hudson River at around 3:23 p.m.

During the early period following the tower collapses, the area in the immediate vicinity of the WTC site was not secured, and photographers were apparently able to approach relatively freely. However, as time passed and emergency responders became better organized, a perimeter was established several blocks from the site, and access was controlled. Many people within the perimeter without a clear reason for being there were asked to leave.

FDNY communications from the early afternoon of September 11 show that commanders were concerned about a possible collapse of WTC 7 due to damage that it suffered from falling debris and the fires that were beginning to grow within the building. (See Chapter 6.) Orders were given for FDNY personnel to pull back from the immediate vicinity around mid-afternoon. 
As a result of these conditions, only a limited number of photographers and videographers were able to approach WTC 7 closely enough to obtain imagery of the lower floors after 11:00 a.m. Very little imagery was collected showing the lower 13 floors during the last hour or so before WTC 7 collapsed.

\section{Rubble from the WTC 1 Collapse}

The southern face of WTC 7 was located approximately $107 \mathrm{~m}$ (350 ft) from the base of WTC 1. (See Figure 5-2 for orientation.) When this tower collapsed, it deposited a large pile of debris on Vesey Street in front of WTC 7 and along the east side of the south face of the Verizon Building. These piles of debris hindered approach to WTC 7 along these streets. As a result, it was very difficult to even reach a position with a clear view of the lower floors of the WTC 7 south face.

The collapse of WTC 1 also deposited a significant amount of debris on Washington Street between WTC 7 and the Verizon Building. Scaffolding that had been on the Verizon Building was dislodged and was also piled in the street. The debris limited access to the west side of WTC 7, and most available views of the lower floors of this face were taken from near the corner of Washington Street and Barclay Street.

\section{Vehicle Fires}

Shortly after the collapse of WTC 1, a large number of vehicle fires grew on West Broadway between Park Place and Vesey Street. While these fires temporarily limited access to WTC 7, they were extinguished fairly early, and it later became possible to enter this area, since there was very little heavy debris between WTC 7 and the U.S. Post Office. Several photographers and videographers managed to work their way up West Broadway as far as Vesey Street.

\section{Fires in WTC 7}

Around 2:00 p.m., fires broke out on the east side of WTC 7, and it became dangerous to be on the street below due to falling glass and the intensity of the fires. People were moved up West Broadway to at least its intersection with Barclay Street. Some views of the lower floors burning on this face were taken from here. In general, it was possible to move along Barclay Street behind WTC 7, and limited imagery is available showing close-ups of the lower floors of the north face of WTC 7. It certainly became less safe to move along this street when fires appeared on the north face around 3:00 p.m.

\subsubsection{Timing and Coding of WTC 7 Visual Information}

Once the photographs and videos had been acquired and cataloged (NIST NCSTAR 1-5A and Section 5.2 of this report), it was necessary to assign times to them. The process used was similar to that for the more numerous images available for the WTC towers, although the limited available imagery made it more challenging to time the images and to develop a full time line for the fire behavior in WTC 7.

A portion of the imagery of WTC 7 was shot in digital formats that provided timestamps. For some of these, cameras times could be accurately determined, since their clocks could be tied to events that occurred before WTC 1 collapsed. These images provided a limited number of views of WTC 7 at well defined times. There were also larger numbers of photographs and videos taken at times that could not be 
precisely determined, either because there were no timestamps or, if timestamps were available, the actual clock time was unknown. Timing of these images was difficult due to the limited amount of material with known times available for comparison. In many cases, it was necessary to estimate times for such imagery based on such general characteristics as the locations of fires in windows or the locations of shadows on buildings. Such estimates were often subject to substantial uncertainties. In the following discussion, estimated uncertainties are included when times are indicated.

The approach for characterizing the fire development and spread in WTC 7 was also similar to that used for the towers. The presence or absence of fire, whether or not smoke was coming from windows, and whether ventilation pathways were open or closed were the three properties used to characterize fire behavior. As discussed below, observations related to smoke flow and the presence of fire were broken into broad classes of smoke flow rate and fire intensity. Windows were characterized as open or closed. Note that these three properties are not independent. For example, smoke flow generally occurs from open windows, and it is possible for smoke to hide an underlying fire from view.

The key in Figure 5-28 was used as the basis for the window-by-window assessment of fire behavior. The results were coded in three separate data sheets using Microsoft Excel. Floor and window locations were identified using the numbering system described in Section 5.3.2 and shown in Figure 5-13, Figure 5-20, Figure 5-23, and Figure 5-26. Separate files containing the three data sheets were generated for each face of WTC 7 and time analyzed.

The first sheet characterized the observed fire condition:

- If a particular window could be observed, and no flame was visible, it was assigned a "0.”

- If a small, isolated fire was present, it was identified as a "spot fire” and assigned a value of " 1 ." A spot fire was gently burning, indicative of relatively low heat release.

- If a larger fire covering two or more contiguous windows was visible through the window, and flames were not coming out of the window, the fire was identified as "fire visible inside" and assigned a value of " 2. ”

- If flames were coming out of the window, the fire was identified as "external flaming" and assigned a value of " 3. ”

- There were many instances where the fire condition could not be determined for a given window for a variety of reasons, including smoke obscuration, insufficient image resolution, or lack of a suitable image for analysis. These windows were assigned values of "9."

Figure 5-29 shows a portion of such a data sheet, describing fires on the north face of WTC 7 around 3:13 p.m. Floors are indicated by the column of vertical numbers along the left-hand edge of the worksheet in blue, and window locations are indicated by the upper two horizontal rows of numbers and letters at the top. The assignments are based primarily on the photograph of the north face shown in Figure 5-30.

The second worksheet was used to identify whether smoke was flowing from a window.

- If no smoke was observed, the window was assigned a " 0. ” 
- If a light smoke flow was observed, it was assigned a “1.” Light smoke generally flowed from the very top of a window and was often light in color.

- If heavy smoke was observed, it was assigned a "2.” A heavy smoke flow filled a larger fraction of a window and was often dark in color.

- If a particular window could not be observed, the worksheet cell was assigned a value of "9."

While these designations are qualitative in nature, in practice, consistent ratings were provided by a number of individuals who participated in the generation of the data sheets.

The third worksheet described the condition of windows and required fairly close-up imagery.

- If the window glass was broken out, it was assigned a value of " 0. ”

- If the glass was intact, it was assigned a value of " 1. "

- If a given window could not be observed, it was assigned a value of “9."

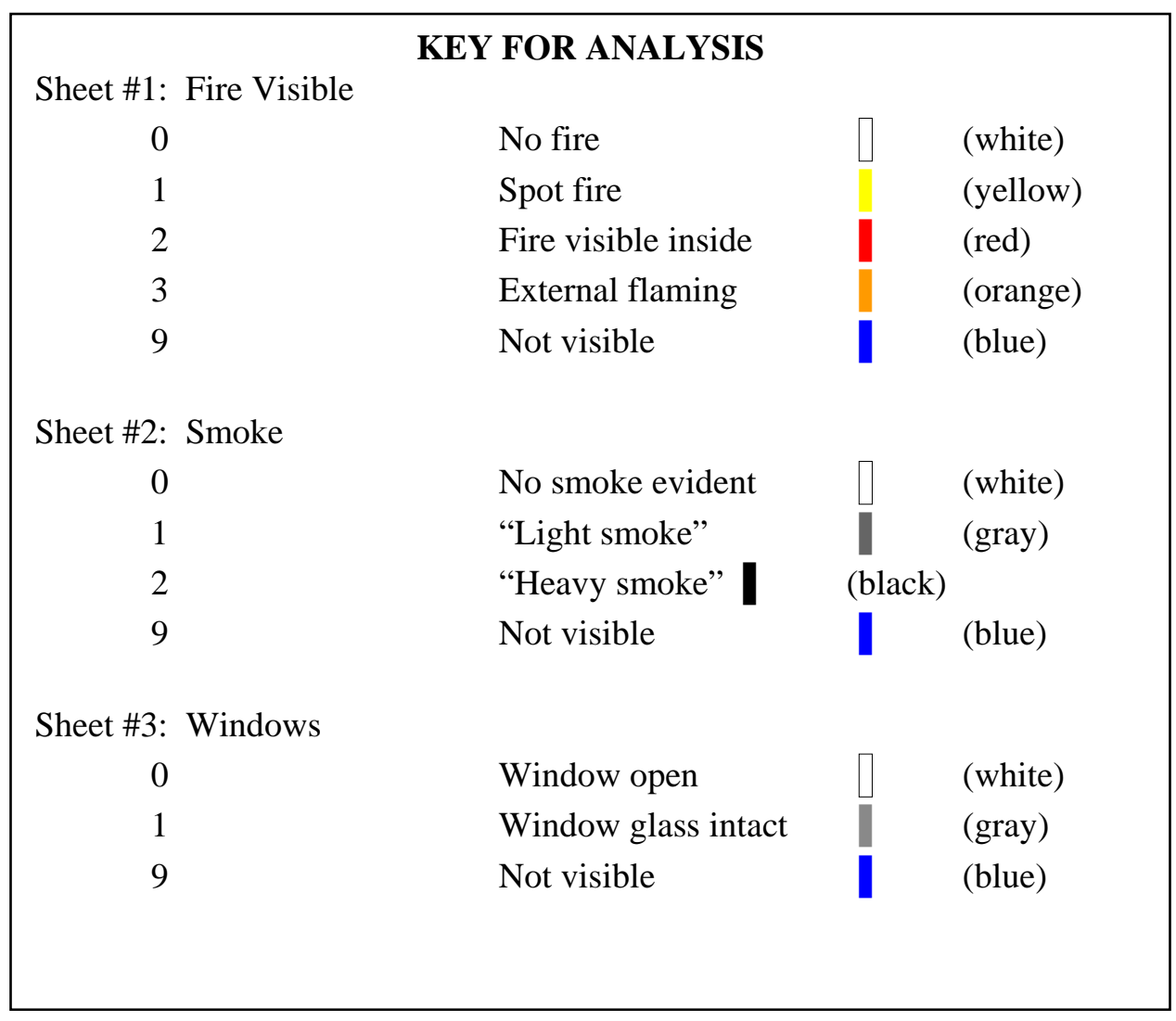

Figure 5-28. Key used to describe observations with regard to fire, smoke, and window breakage in spreadsheets for individual windows in WTC 7.

The color codes used to represent the data in façade maps are shown to the right. 
While the data sheets captured the behavior of the fires, it proved difficult to use them to track changes without visualizing the results. An approach based on the Excel worksheets was used for rapid visualization. Cell backgrounds and contents were color coded in such a way that they provided an indication of the spatial distribution of the parameter of interest. Figure 5-31 shows an example based on the fire spreadsheet shown in Figure 5-29.

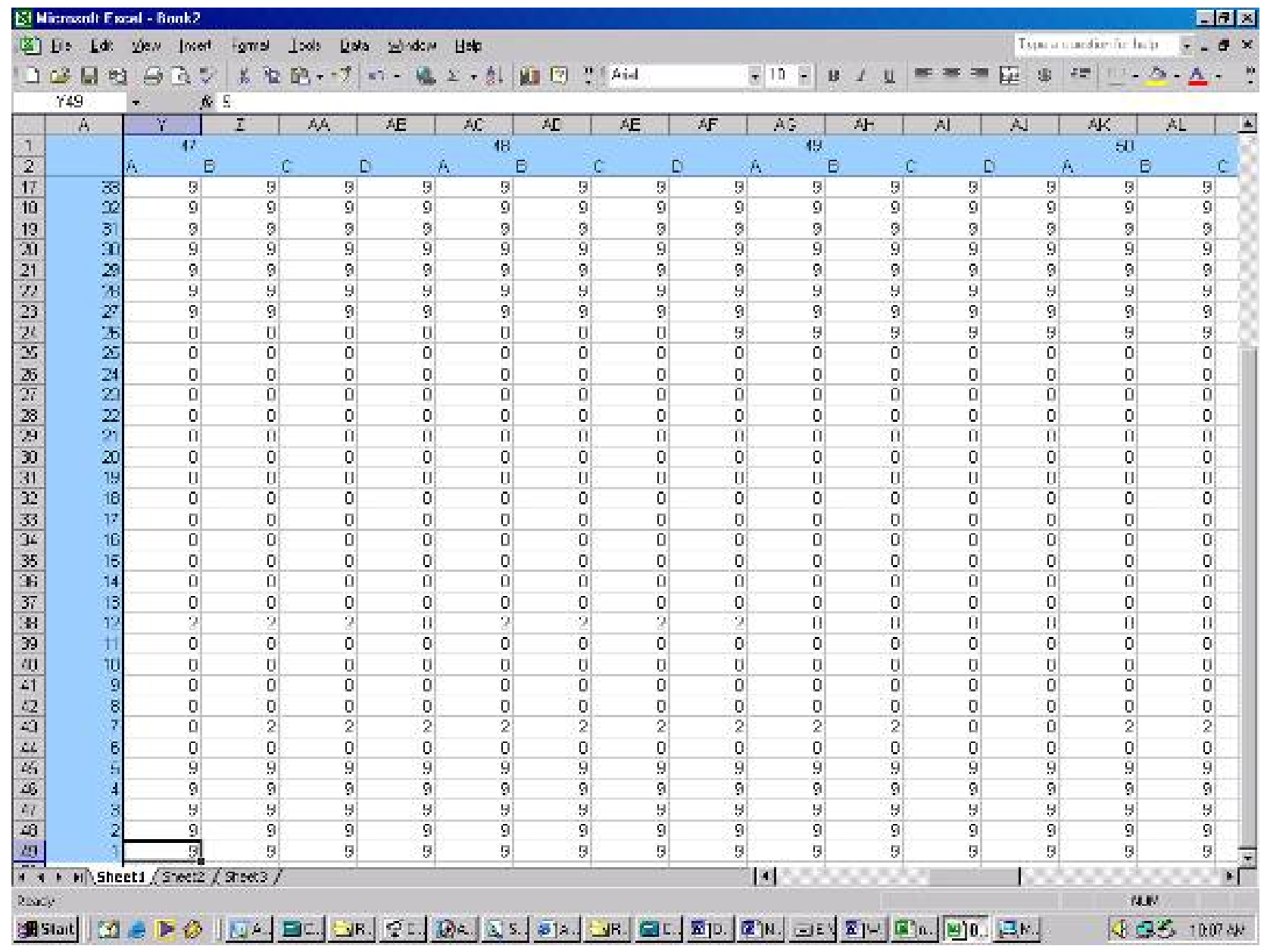

Figure 5-29. Portion of the spreadsheet describing fires on the north face of WTC 7 around 3:13 p.m.

The numbers at the left refer to floors, and numbers and letters at the top are column numbers and associated windows, respectively. 


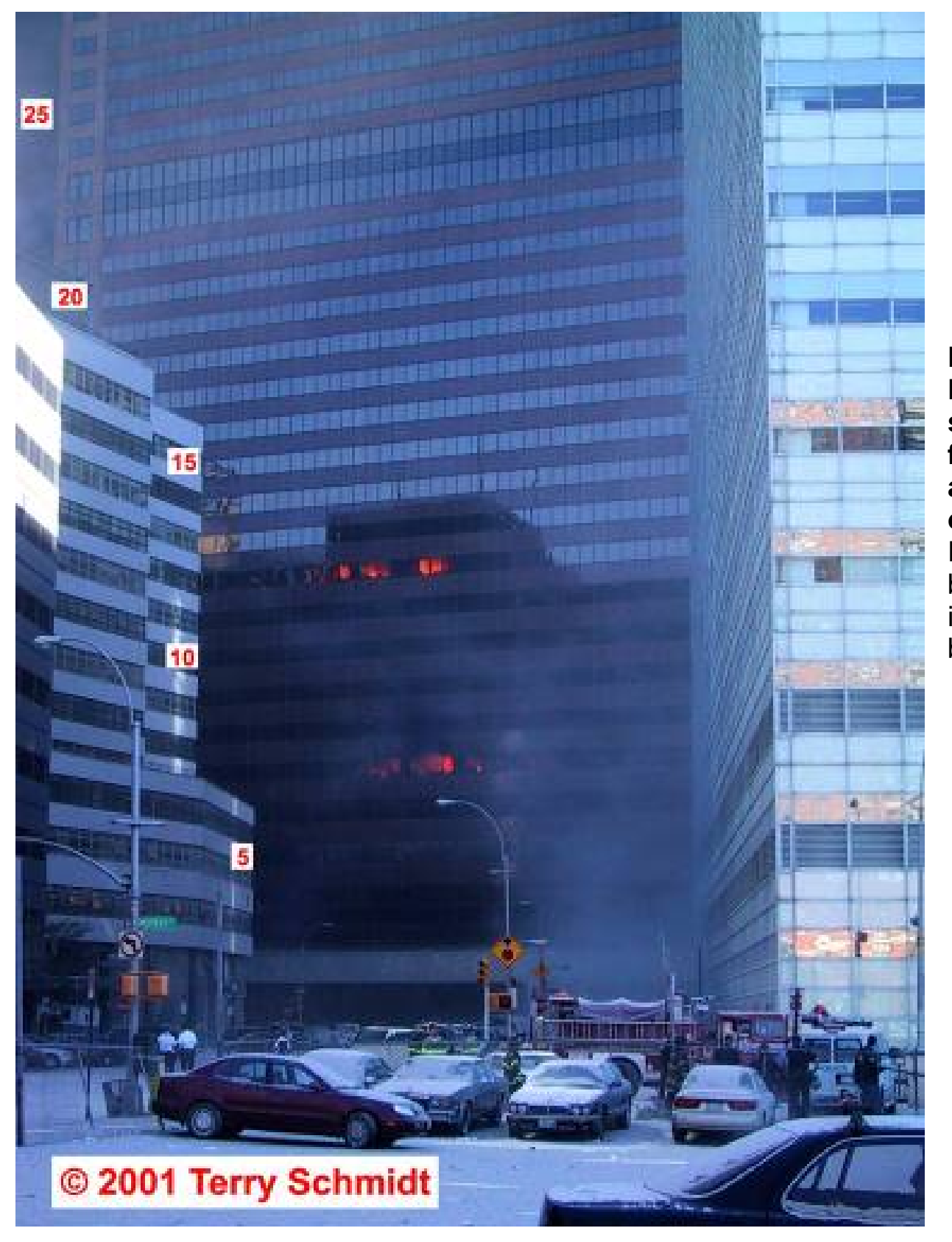

Figure 5-30.

Photograph showing the north face of WTC 7 around 3:13 p.m. on September 11. Floor numbers have been added, and the image intensity has been adjusted.

For this report, clearer visualizations were prepared using the scaled drawings of the WTC 7 faces shown in Figure 5-13, Figure 5-20, Figure 5-23, and Figure 5-26. Since the severe fire activity was observed on the lower floors, the drawings were usually cropped to display the lower 14 floors, and the column numbers and window indicators were included on the $15^{\text {th }}$ floor. The information was color coded using the key included in Figure 5-28. Figure 5-32 shows an example of a map that combines datasheet results for windows and fires based primarily on the image in Figure 5-30. Individual windows were treated such that if a fire was present or if a value could not be assigned, the color code corresponding to the assignment in the fire spreadsheet was displayed. Otherwise, the color corresponding to the code for the window spreadsheet was used. 


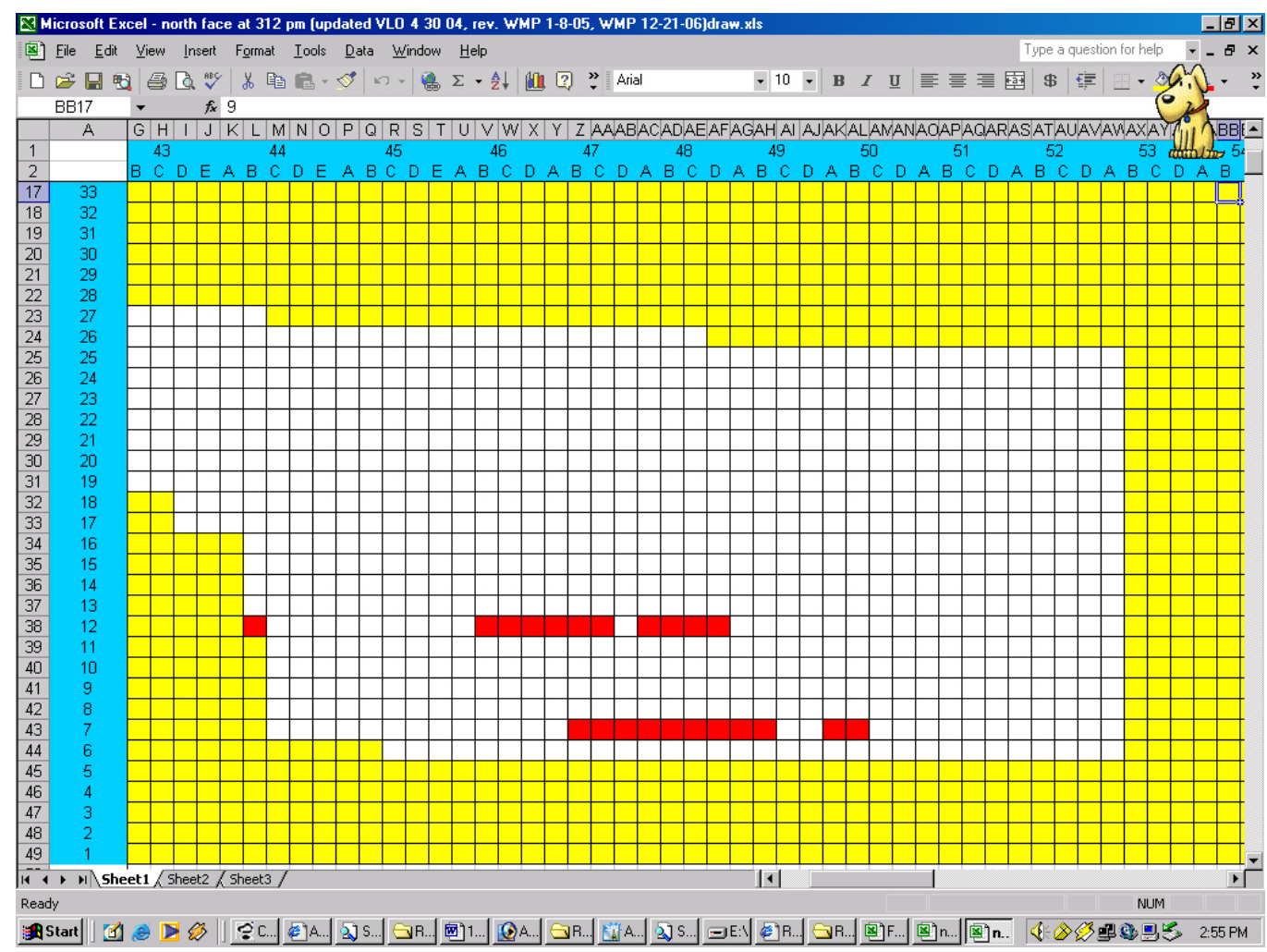

Figure 5-31 Screen capture of a data spread sheet visually representing the fire condition on a portion of the north face of WTC 7 at 3:13 p.m., based on the spreadsheet shown partially in Figure 5-29.

Cell backgrounds and numbers are color coded as follow: "0"-white, "1" to "3"-red, and "9"-yellow.

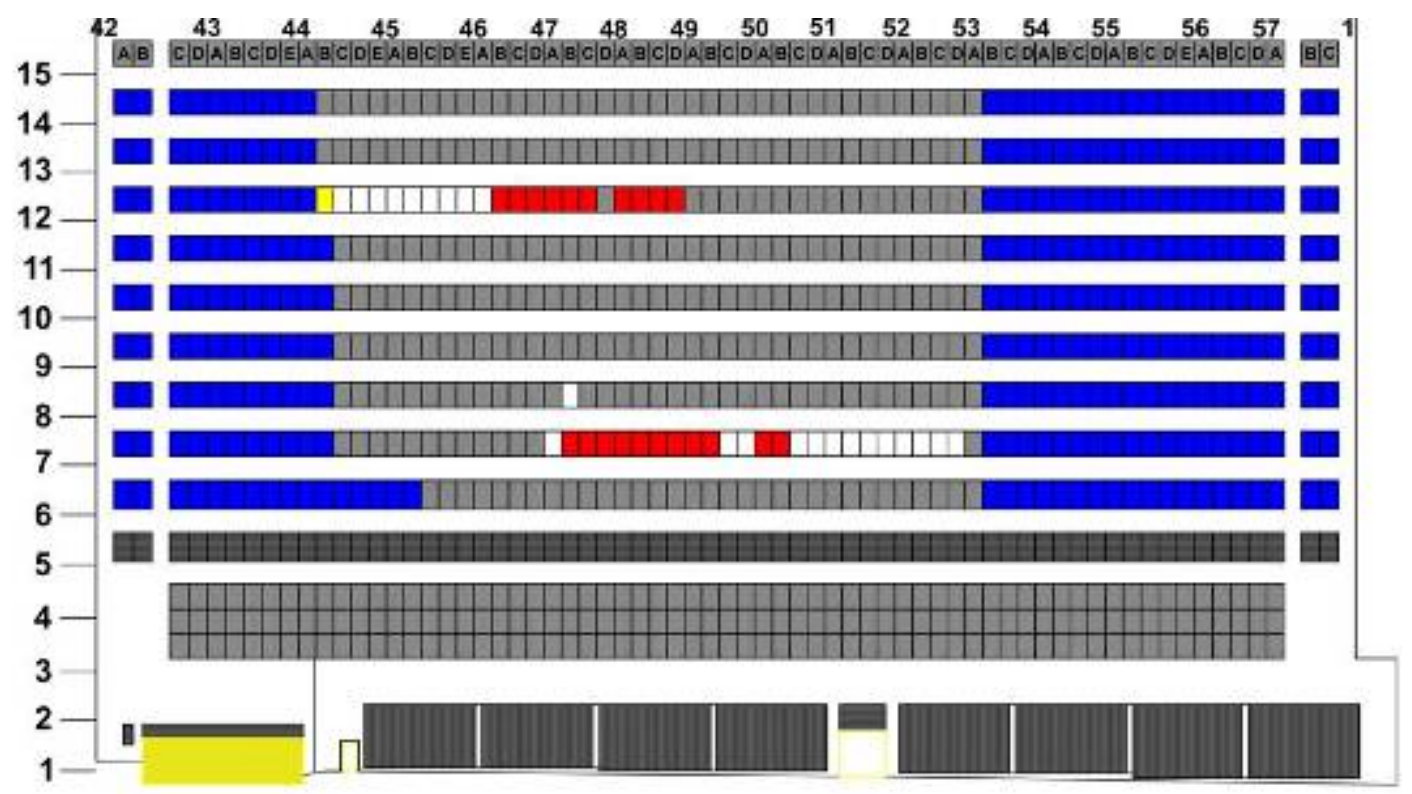

Figure 5-32. An example of a façade map with combined data from fire and window datasheets for the north face of WTC 7 at around 3:13 p.m. 


\subsection{DAMAGE ESTIMATES FOR WTC 7 DUE TO DEBRIS IMPACT FROM WTC 2 AND WTC 1 COLLAPSES}

\subsubsection{Damage Resulting from the Collapse of WTC 2}

WTC 2 began to collapse at 9:58:59 a.m. It took roughly $11.5 \mathrm{~s}$ for the first large debris to reach the ground. Videos and photographs taken from a variety of directions show that most of the heavy debris came down around WTC 2 and did not reach out as far as WTC 7, which was located $210 \mathrm{~m}$ (675 ft) from the north face of the tower. An indication of the relative distance between WTC 2 and WTC 7 can be seen in Figure 5-33, which shows the collapsing WTC 2, WTC 1 to its left, and WTC 7 near the left edge. Heavy debris can be seen falling around the base of WTC 2 that is far removed from WTC 7. Additional supporting evidence that large and heavy debris did not reach WTC 7 from the collapse of WTC 2 is that the roofs of WTC 5 and WTC 6, which were in between WTC 2 and WTC 7 did not sustain substantial damage based on review of photographs and videos taken from above these buildings after the collapse of WTC 2, but prior to the collapse of WTC 1 . Note that a large section of WTC 4, which was located to the south of WTC 5 and was immediately to the east of WTC 2, was collapsed by debris falling from WTC 2.

The large dust cloud generated by the collapse of WTC 2 was described earlier and can be seen in Figure 5-27. This dust cloud was pushed out rapidly from the base of WTC 2. A long distance video shot from the west indicates that the first part of the cloud reached the south face of WTC 7 about $12.5 \mathrm{~s}$ after the collapse of WTC 2 started. The dust cloud can be seen pushing up against WTC 7 in Figure 5-34, which was taken about $16 \mathrm{~s}$ after WTC 2 started to collapse. The dust cloud visible between WTC 7 and the building to the west of WTC 1 (World Financial Center 2) obscures the lower 15 floors of WTC 7. The dust cloud, visible as a reflection from the south face of the building, is roughly 40 stories high.

Another view of the dust cloud is shown in Figure 5-35, which was taken looking up Fulton Street from just east of Broadway. The building visible below the dust cloud is WTC 5. The Verizon Building is just visible beyond WTC 7.

For several minutes following the collapse of WTC 7, NIST found no images showing the south face of WTC 7. However, after the dust had cleared and several minutes prior to the collapse of WTC 1, a camera crew turned the corner at West and Vesey Street, proceeded east on Vesey Street to one of the ground floor entrances, entered the ground floor lobby, and proceeded up an escalator to the $3^{\text {rd }}$ floor main lobby, before retracing their steps and leaving the area. Much of their progress was taped.

A frame taken from this video is reproduced in Figure 5-18. Even though the street is passable, a large amount of dust and small debris, such as paper, has been deposited on the street. The trees on the Promenade are upright and appear unharmed. Windows on several floors above the Promenade appear to be intact.

Another frame from this video taken closer to WTC 7 is shown in Figure 5-36. The amount of dust and debris is greater than seen further west on Vesey Street. It appears to be several inches deep. Most of the debris appears to be paper. A portion of the south face of WTC 7 is visible to the left. Numerous plate glass windows at the ground floor are broken out between Column 24 and Column 26. There appears to be some light façade damage higher up near the Pedestrian Bridge. There is no indication of any structural damage on WTC 7. The covering on the Pedestrian Bridge appears to be intact following the collapse of WTC 2. There are no indications of fire in the image. 


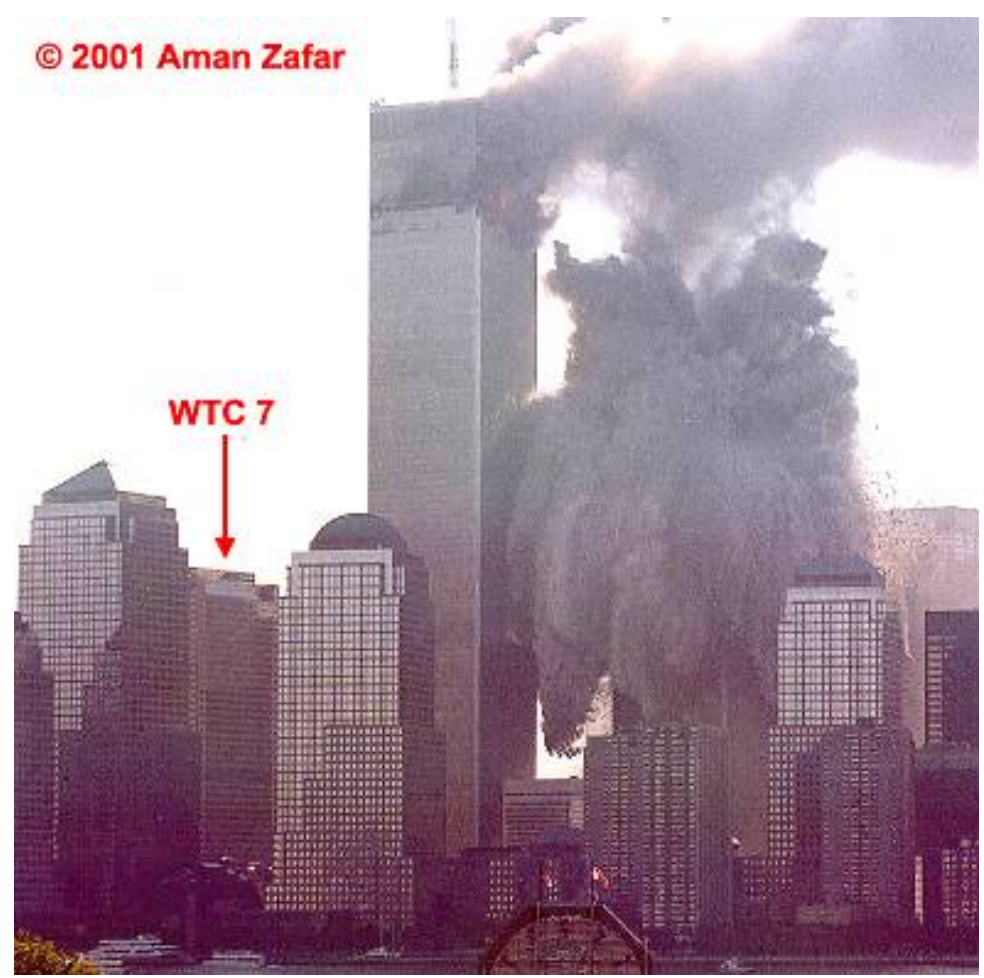

Figure 5-33. Photograph of the collapse of WTC 2 taken at 9:59:07 a.m. (with an uncertainty of $2 \mathrm{~s}$ ). An arrow has been added to identify WTC 7 . The original image has been cropped and the intensities have been adjusted.

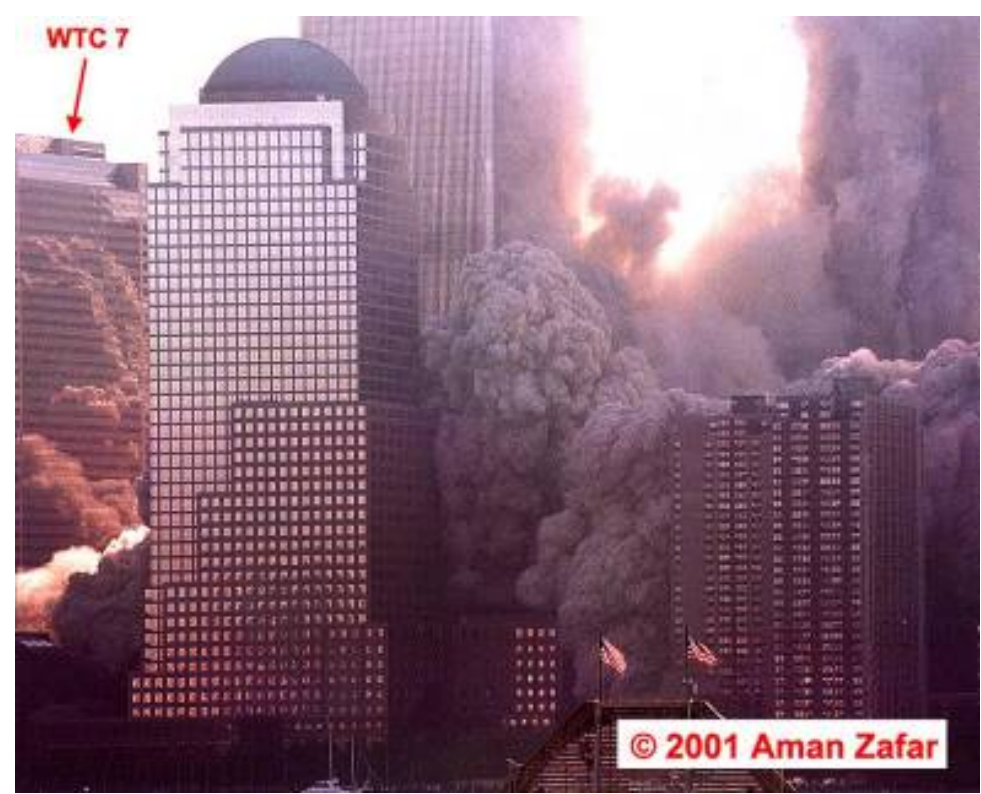

Figure 5-34. Photograph of the collapse of WTC 2 taken at 9:59:15 a.m. (with an uncertainty of $5 \mathrm{~s}$ ). An arrow has been added to identify WTC 7 . The original image has been cropped and the intensities have been adjusted. 


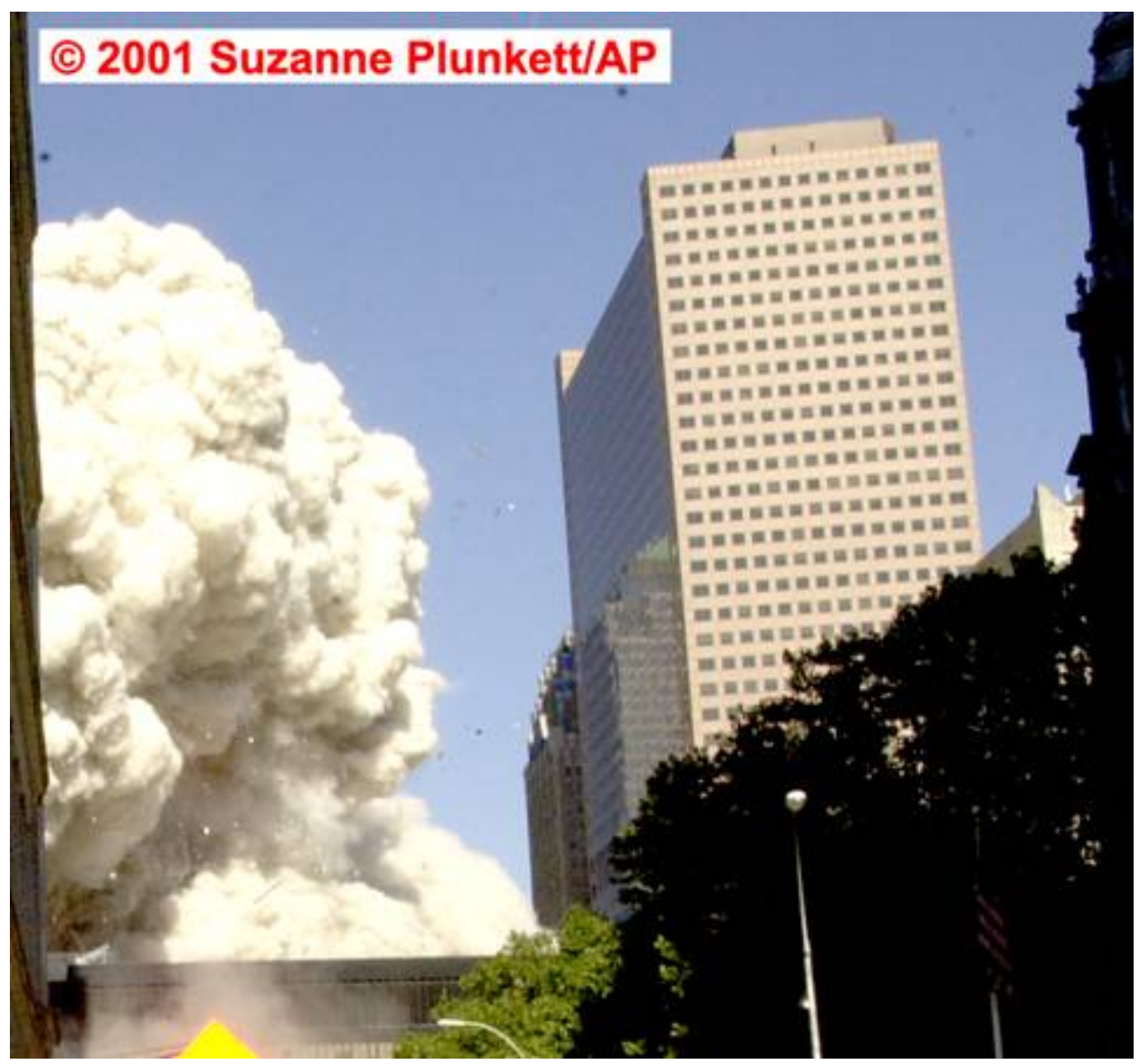

Figure 5-35. Cropped photograph showing the dust cloud from the collapse of WTC 2 approaching the south face of WTC 7, taken from just east of the corner of Fulton Street and Broadway at 9:59:24 a.m. (estimated uncertainty of $5 \mathrm{~s}$ ). The intensity levels have been adjusted.

A closer view of the broken windows on the ground floor of WTC 7 is shown in Figure 5-37. A broken window is apparent above the door on the right side. An enclosed Column, 25, is visible near the center of the image. It is clear that this column was undamaged at this time. The deep piles of dust and light debris have been pushed though the broken windows at the base. As the videographer entered the $1^{\text {st }}$ floor lobby, the video shows that the entire floor was also covered by a thick layer of dust and light debris.

The main entry lobby for WTC 7 was located on the south side of the $3^{\text {rd }}$ floor. The videographer went up a nonoperating escalator from the ground floor lobby to this area. Emergency alarms were sounding and emergency lighting seemed to be operational. On the east side of lobby, there was heavy dust and light debris, as can be seen in Figure 5-38, which shows the rear corner of the lobby that was roughly $20 \mathrm{~m}$ (60 ft) across from the revolving door that opened onto the Pedestrian Bridge. (See Figure 5-20.) The large amount of debris suggests that windows were also broken out at this level, even though there are no images that confirm this. 


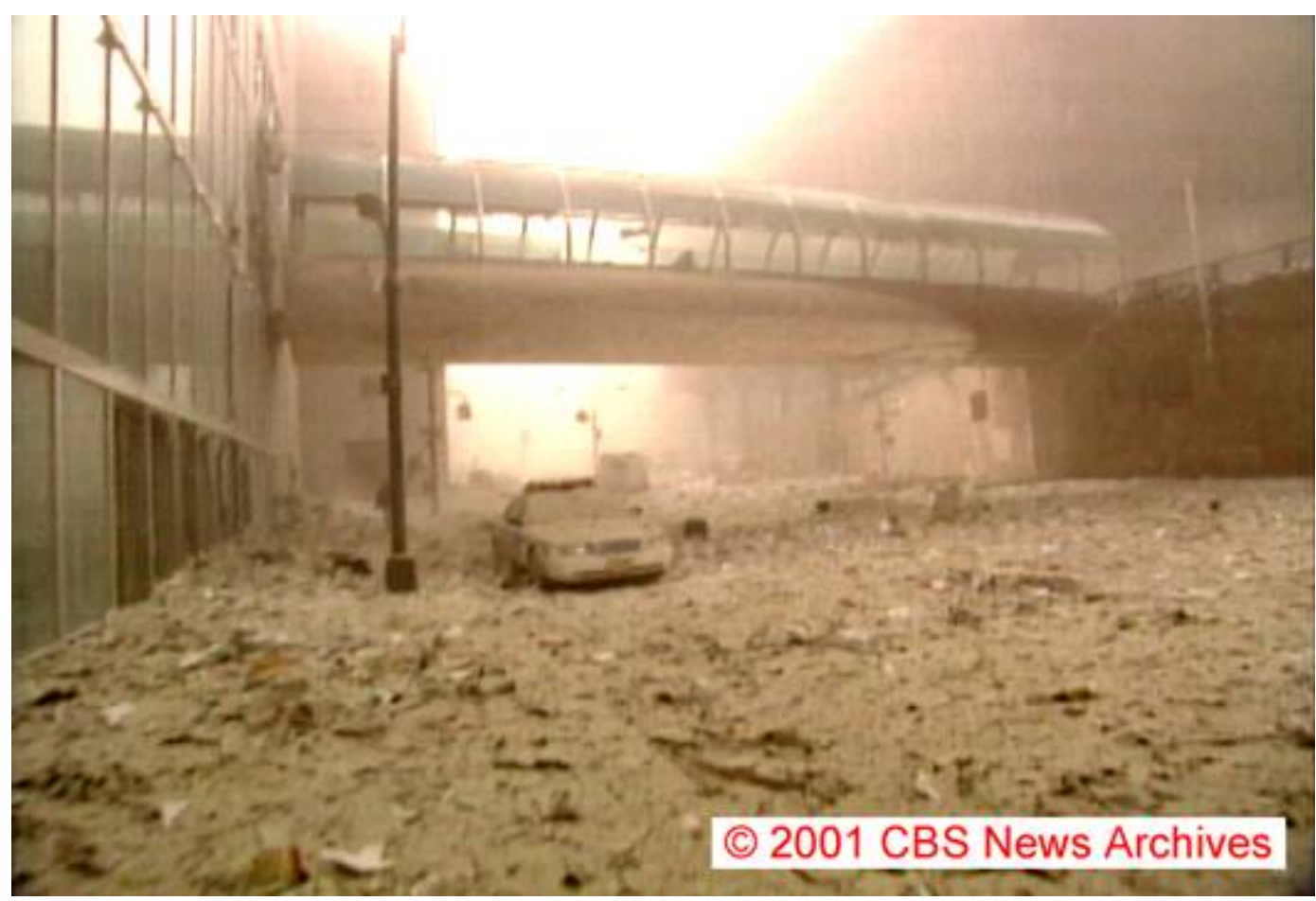

Figure 5-36. Frame from a video filmed just outside of WTC 7 looking east up Vesey Street around 10:15 a.m.

WTC 7 is on the left, the U.S Post Office is straight ahead across West Broadway, and WTC 5 is visible behind the Pedestrian Bridge on the right. The intensity levels have been enhanced.

On exiting the building, the videographer again shot the interior of the $1^{\text {st }}$ floor lobby. Figure 5-39 shows a view looking across the four story high atrium from the northwest towards the southeast. Some of the broken windows on the south face are visible. Columns 24 to 27 are visible, and it is clear that they have not sustained significant damage.

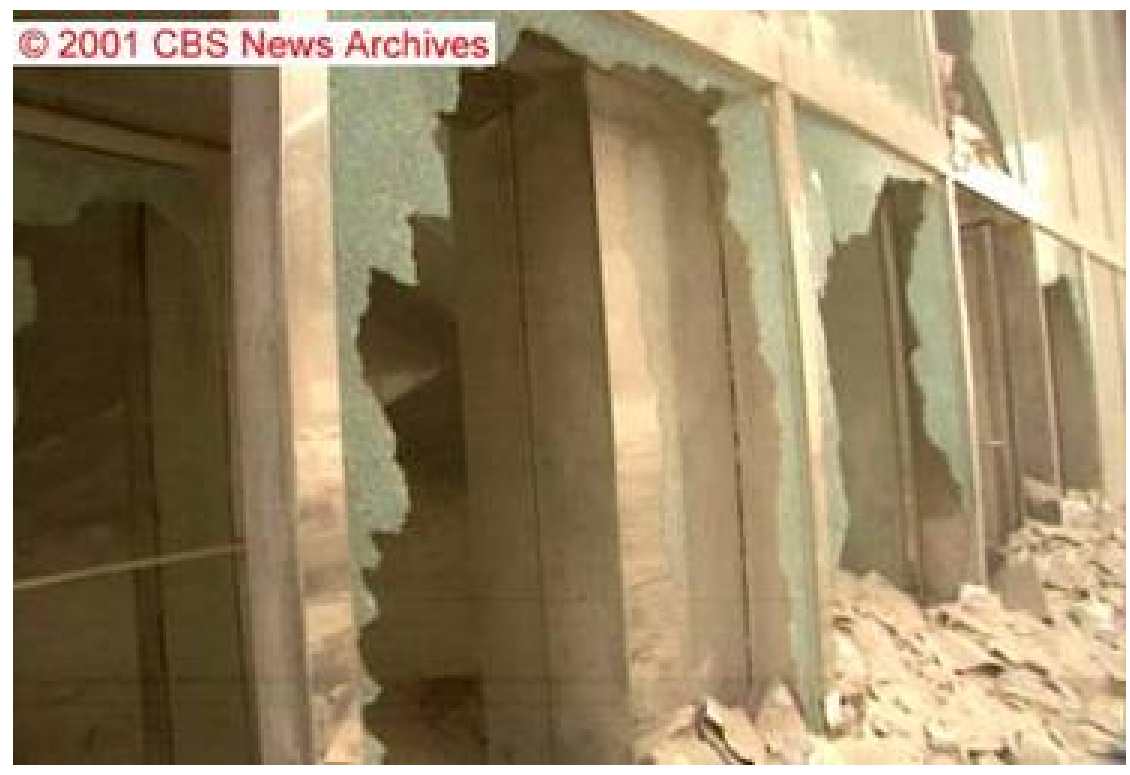

Figure 5-37. Video frame showing the ground floor of the south face of WTC 7, taken around 10:15 a.m. The column visible near the center is the base of Column 25. The intensity levels have been enhanced. 


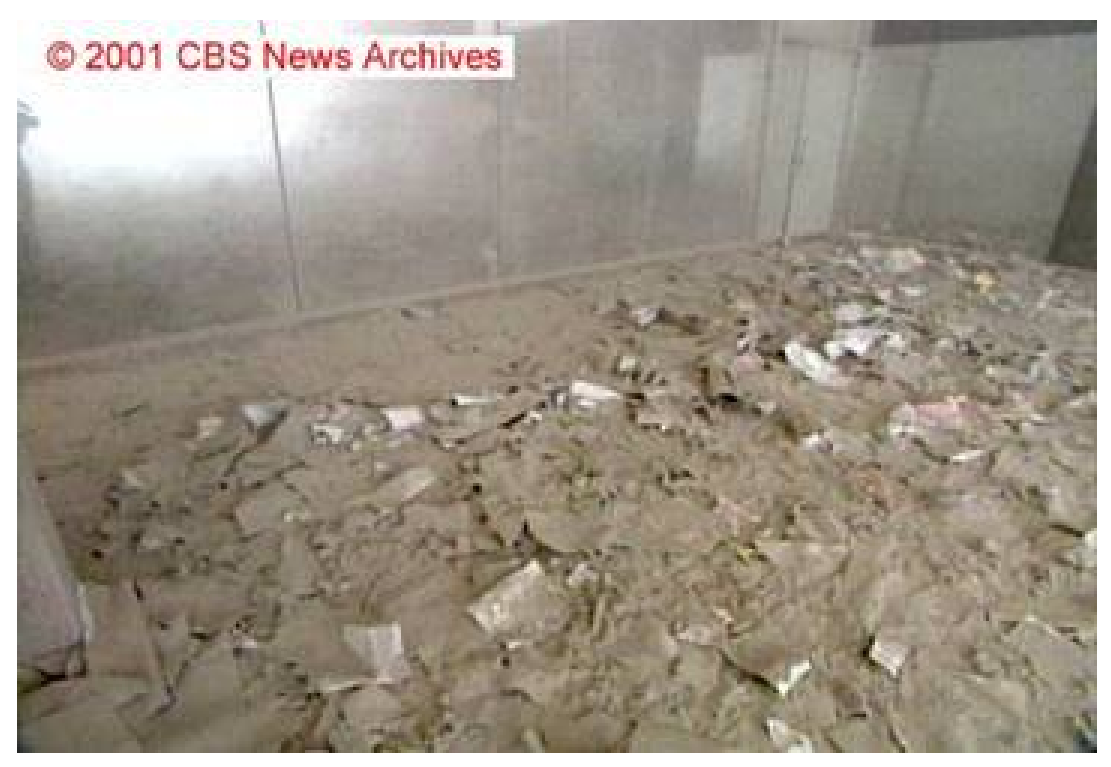

Figure 5-38. Video frame showing a corner of the main lobby on the $3^{\text {rd }}$ floor of the south side of WTC 7, taken around 10:15 a.m. The intensity levels have been enhanced.

Figure 5-39. Video frame looking across the $1^{\text {st }}$ floor lobby on the south side of WTC 7, taken around 10:15 a.m.

The intensity levels have been enhanced.

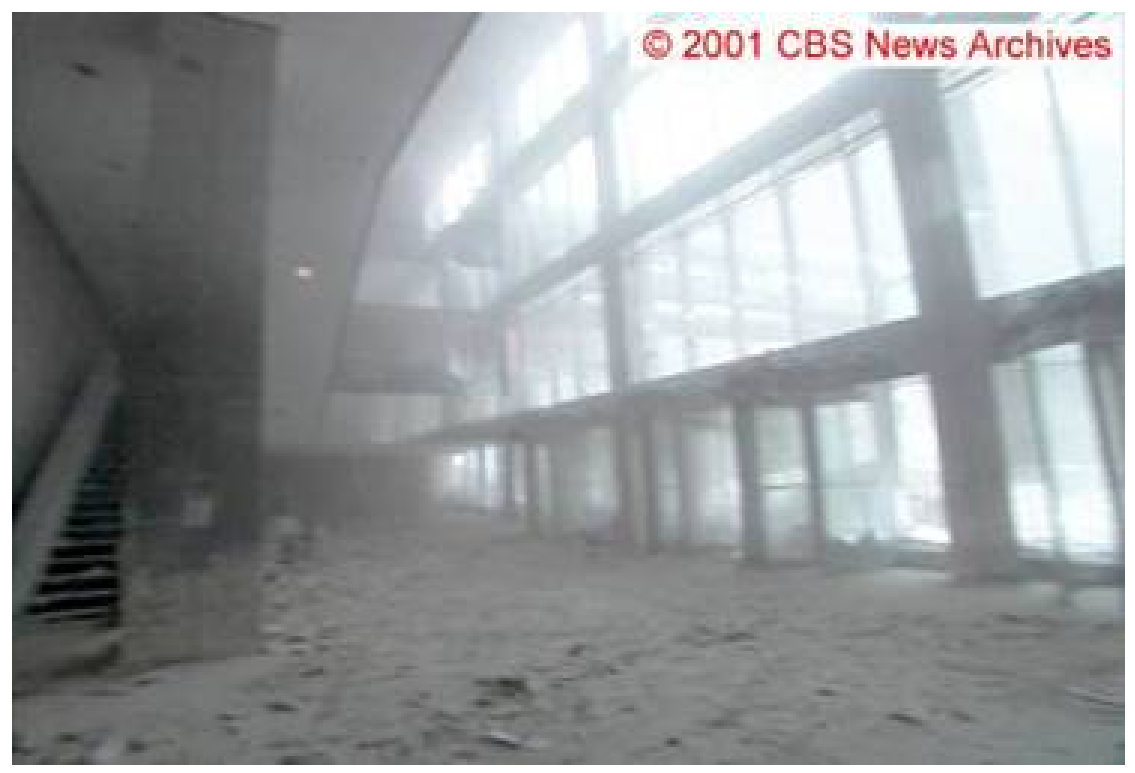

The database contains an image showing the lower part of the east face and a small section of the north face. There is a large amount of dust on West Broadway, but there is no indication of damage on the east side or northeast corner of WTC 7. NIST did not obtain other images showing the remainder of the north face at times between the collapses of the two WTC towers.

As shown below, images shot after the collapse of WTC 1 indicate that there was no significant damage on the east and north faces of WTC 7, and, therefore, none had been caused by the WTC 2 collapse. Following the collapse of WTC 1, damage was observed on the west face of WTC 7. However, since this face was shielded from the debris-laden flow generated by the first collapse, it is almost certain that this damage resulted from the collapse of WTC 1. 
The available imagery suggests that, while the dust cloud and light debris that reached WTC 7 from the collapse of WTC 2 was sufficient to break out windows that were directly impacted, and to enter into WTC 7, the material lacked sufficient momentum to cause any significant structural damage. The absence of visible smoke and fire makes it likely that no fires were ignited in the building as a result of the collapse of WTC 2 .

\subsubsection{Damage Resulting from the Collapse of WTC 1}

\section{The Collapse of WTC 1}

WTC 1 began to collapse at 10:28:22 a.m. The collapse was captured in numerous videos and photographs. Videos indicate that it took roughly $10 \mathrm{~s}$ for the first debris to reach the ground. Figure 5-40 shows a series of six pairs of images taken during the collapse of WTC 1 from just west of north (cropped photographs) and from just north of west (frames from a video shot from a helicopter). The paired images are coincident in time to within $0.06 \mathrm{~s}$. In the photographs from the north, WTC 7 is immediately in front of WTC 1 and is partially obscured by a water tank on top of a closer building. WTC 7 is indicated by an arrow in the video frames.

The video frame taken $6.50 \mathrm{~s}$ after the collapse started shows that the initial large debris created by the collapse fell close to the outer wall of WTC 1 . As the collapse continued, the debris extended further outward from WTC 1, but the west view shows that the majority of the debris was still falling well away from WTC $710.63 \mathrm{~s}$ after the collapse began and $0.5 \mathrm{~s}$ after the first debris reached the ground. However, starting around this time, several substantial pieces of debris were expelled outward toward WTC 7 from the main cloud of the falling material. The first of these is visible in the images taken at $10.63 \mathrm{~s}$ (marked with arrows). Several of these pieces appeared to arc downward toward the south face of WTC 7.

In the images taken at $11.67 \mathrm{~s}$, the arc (marked with arrows) formed by the initial ejected building section is distinct in both views. In the north photograph, this falling debris is visible above WTC 7 just to the right of the west penthouse. An additional piece of debris (also marked with arrows) is just beginning to emerge from the cloud. The western view at $12.33 \mathrm{~s}$ shows that the arc from the initial ejected debris is approaching WTC 7. The additional debris to the left and above has fully emerged and is moving outward from the main debris cloud. By $12.97 \mathrm{~s}$, the later ejected material (marked with arrows) has formed a distinct arc as seen from the west, and appears just above the west penthouse in the corresponding photograph from the north. 

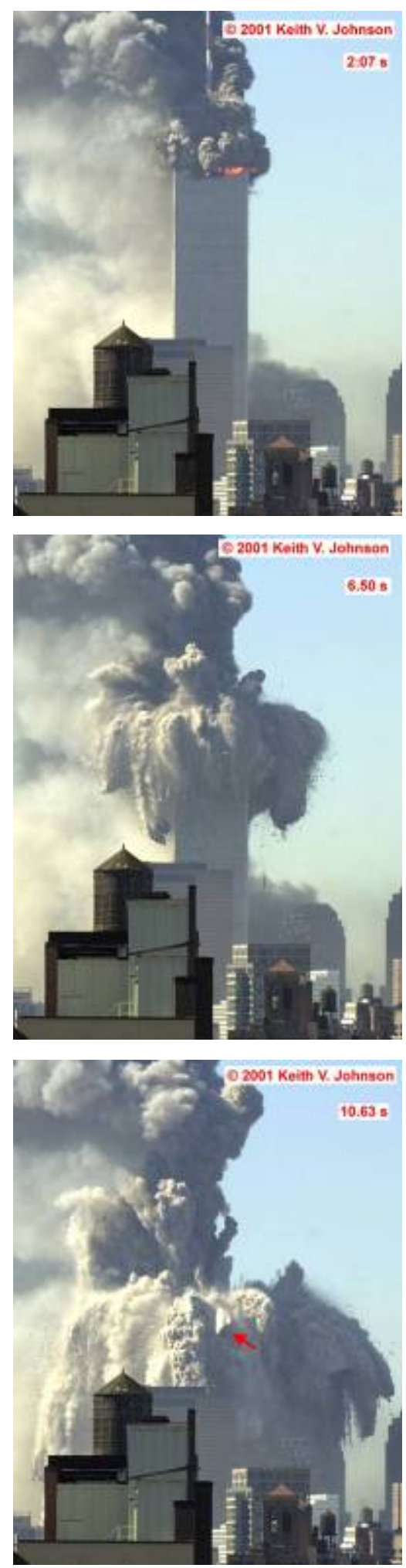
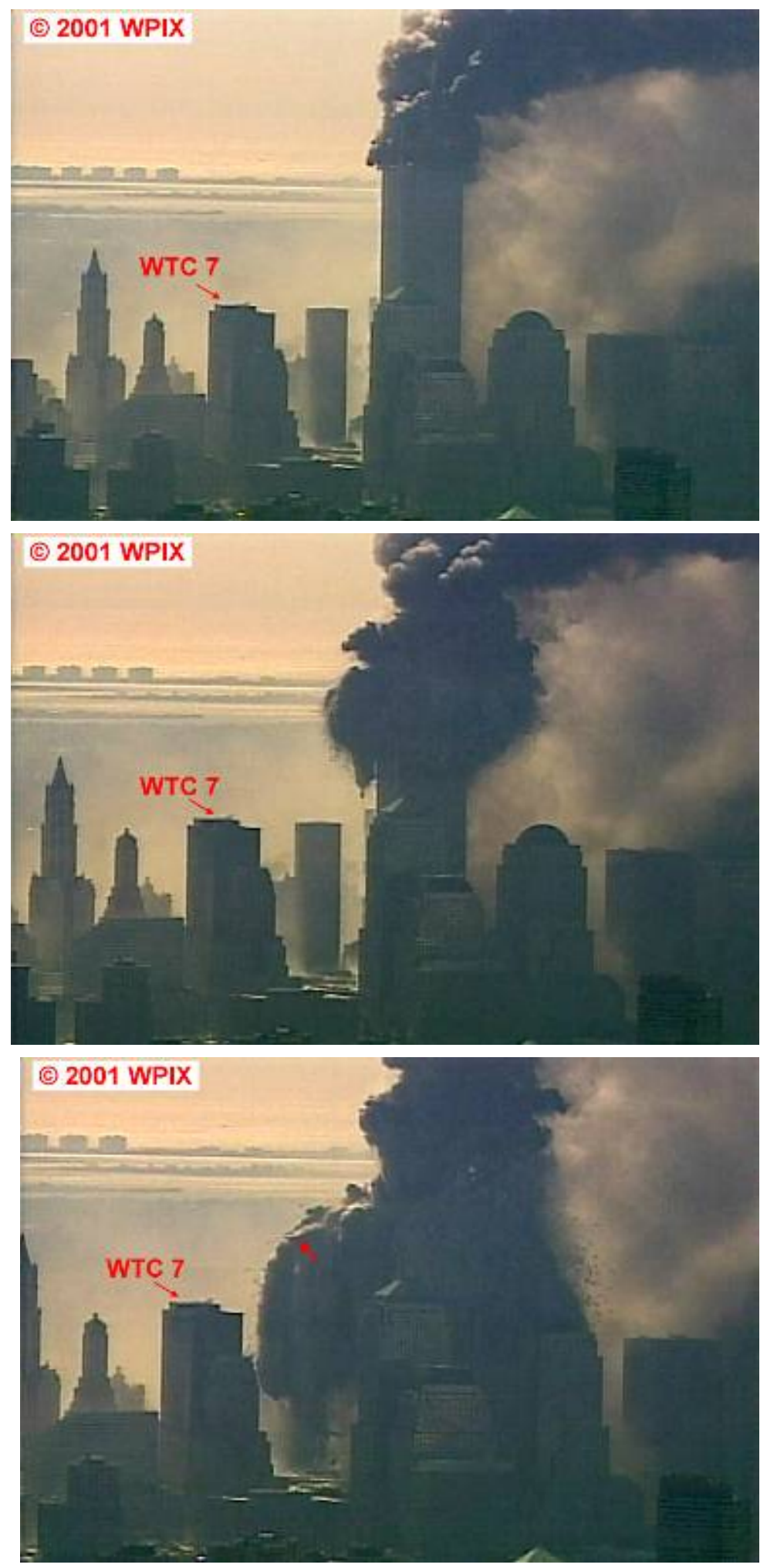

Figure 5-40. A series of cropped photographs shot from the north and frames from a video shot from the west show the collapse of WTC 1.

Times are relative to the start of collapse. The intensities of the video frames have been adjusted. 

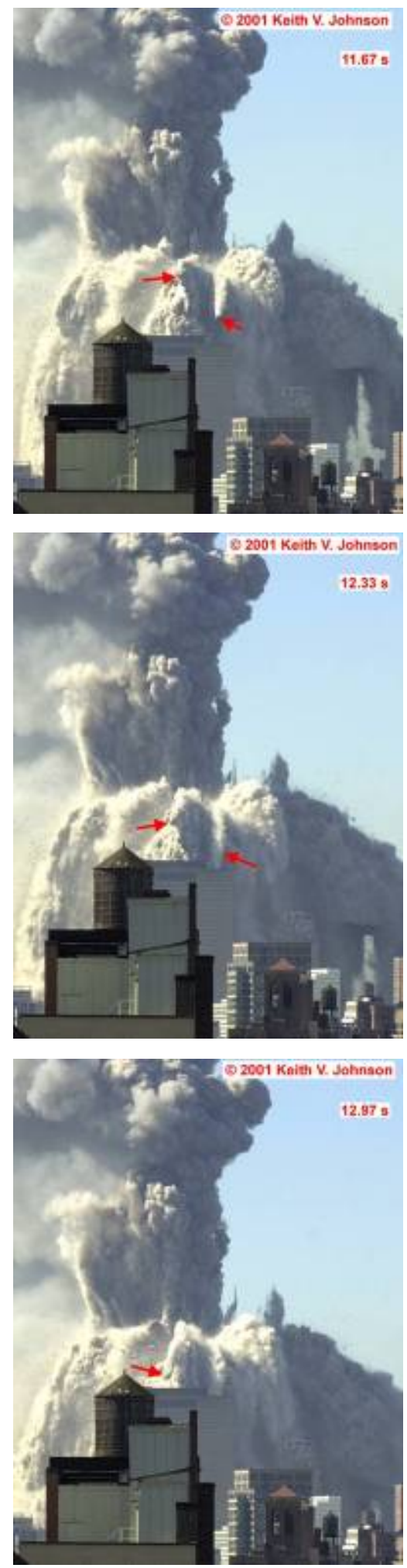
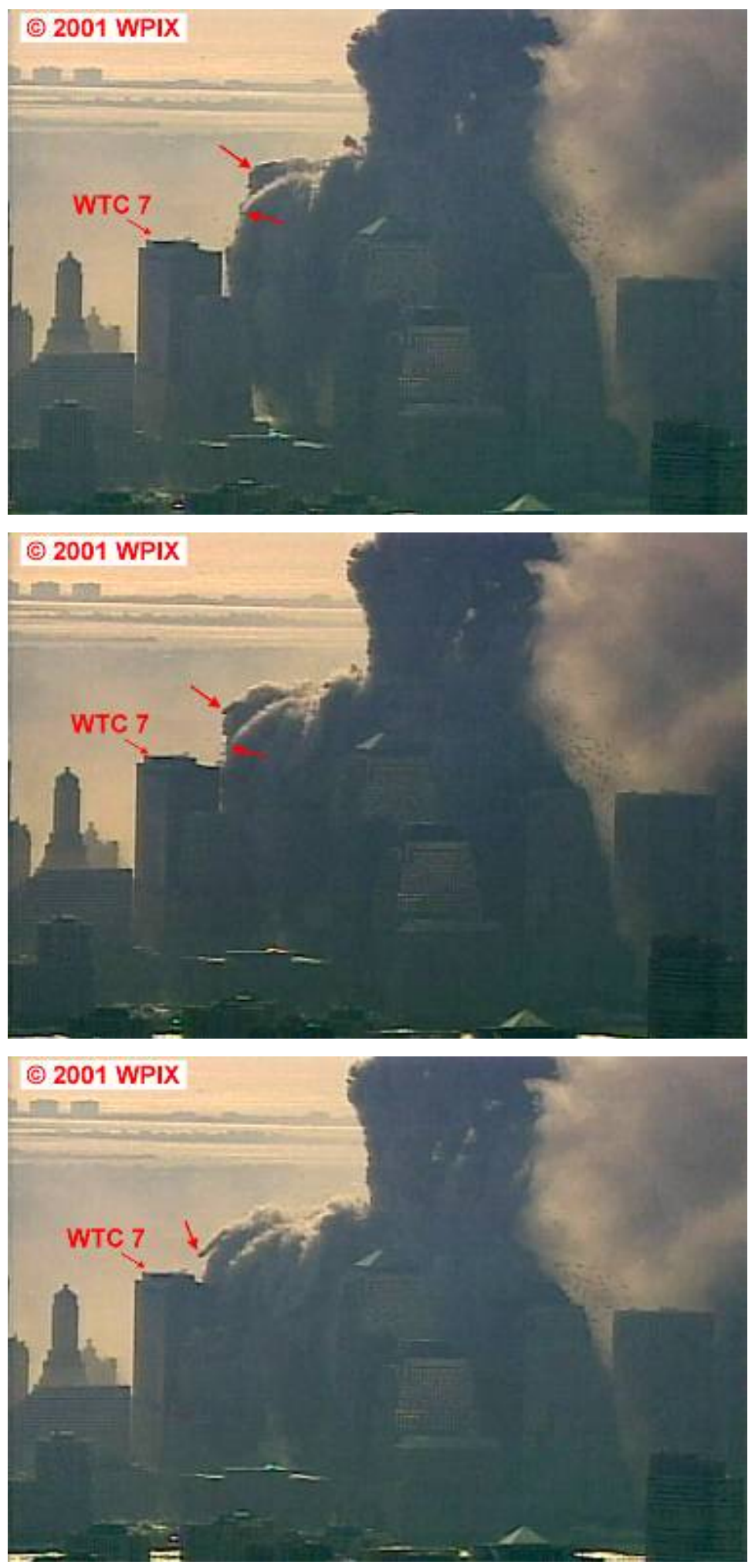

Figure 5-40. (continued). A series of cropped photographs shot from the north and frames from a video shot from the west show the collapse of WTC 1. Times are relative to the start of collapse. The intensities of the video frames have been adjusted. 
Figure 5-41 provides additional comparisons of north and west views of the collapse of WTC 7. The north views are taken from a video that was shot from much closer to WTC 7 than that shown in Figure 5-40. The west views are taken from the same video as in Figure 5-40. The first pair shows frames taken $10.43 \mathrm{~s}$ after the start of the collapse of WTC 1 . This is just prior to the time for the third image pair shown in Figure 5-40. Arrows mark the same locations in the north and west views. Close inspection shows that the ejected debris appears as a dark planar object that is long in one direction and narrow in the other. As discussed in NCSTAR 1-5A, the exterior walls of the towers were constructed from preassembled steel panels consisting of three story columns joined by spandrels to form a $3.0 \mathrm{~m}$ wide $\times 11.0 \mathrm{~m}$ high $(10 \mathrm{ft} \times 36 \mathrm{ft})$ wall section. These exterior panels were bolted together to form the exterior walls. When the towers collapsed, the walls tended to break along the bolt lines, thus creating large pieces of debris consisting of one or more panel sections. The appearance of the falling object in Figure 5-41 suggests that it was formed from at least one panel section.

The next pair of images was recorded $12.17 \mathrm{~s}$ after the collapse started. The arcing path formed by the object observed at $10.43 \mathrm{~s}$ is visible from both directions (marked with arrows), even though the object itself has moved behind WTC 7 by this time in the north view. Note that this object appears to have passed behind WTC 7 at a location roughly halfway between the end of the west penthouse and the edge of the building. The two arrows to the left in the north view indicate additional objects that are just beginning to emerge from the dust cloud. These objects are also visible in the west view. The upper object is the same as observed for the three latest times in Figure 5-40. It ultimately formed the distinct arc seen in the images taken at $12.77 \mathrm{~s}$ that seemed to travel further outward. The videos show that the debris marked by the lower arrows in the images taken at 12:17 also arced downwards and had apparently disappeared behind WTC 7, just to the west of the building center, by $12.77 \mathrm{~s}$.

An aerial view from the northeast, showing the falling debris from WTC 1 with WTC 7 in the foreground, is shown in Figure 5-42. This photograph was taken about $14 \mathrm{~s}$ after the start of the collapse, or just over one second after the last pairs of images in Figure 5-40 and Figure 5-41. Arrows have been added indicating the three arcs generated by debris ejected from the primary debris cloud. Comparison with videos shows that these arcs resulted from the same material as those marked with arrows in Figure 5-40 and Figure 5-41. In this photograph, the easternmost arc, which was generated by the highest debris in the earlier photographs, appears to be approaching WTC 7 just west of the building center, while the westernmost arc seems to have passed just to the west of the building. In Figure 5-40 and Figure 5-41, the arcs appeared to be located slightly further east. This difference is mostly likely associated with parallax effects due to the relative locations of the cameras and the debris at the times the images were recorded. 

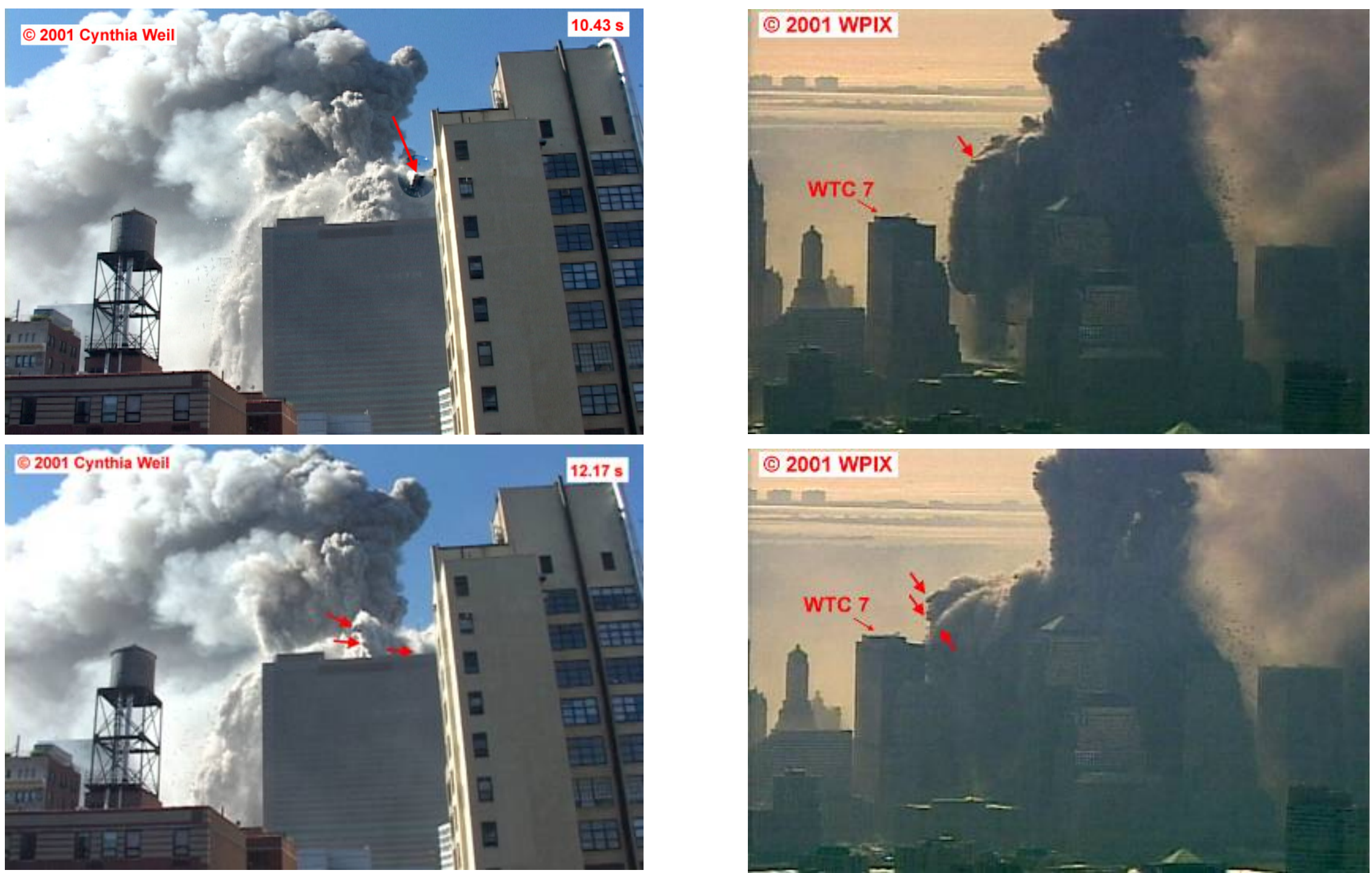

Figure 5-41. Three pairs of frames taken from videos shot from the north and west, showing the collapse of WTC 1. Times are relative to the start of the collapse. Arrows indicate large objects that were projected toward WTC 7 . The intensities of the video frames have been adjusted. 

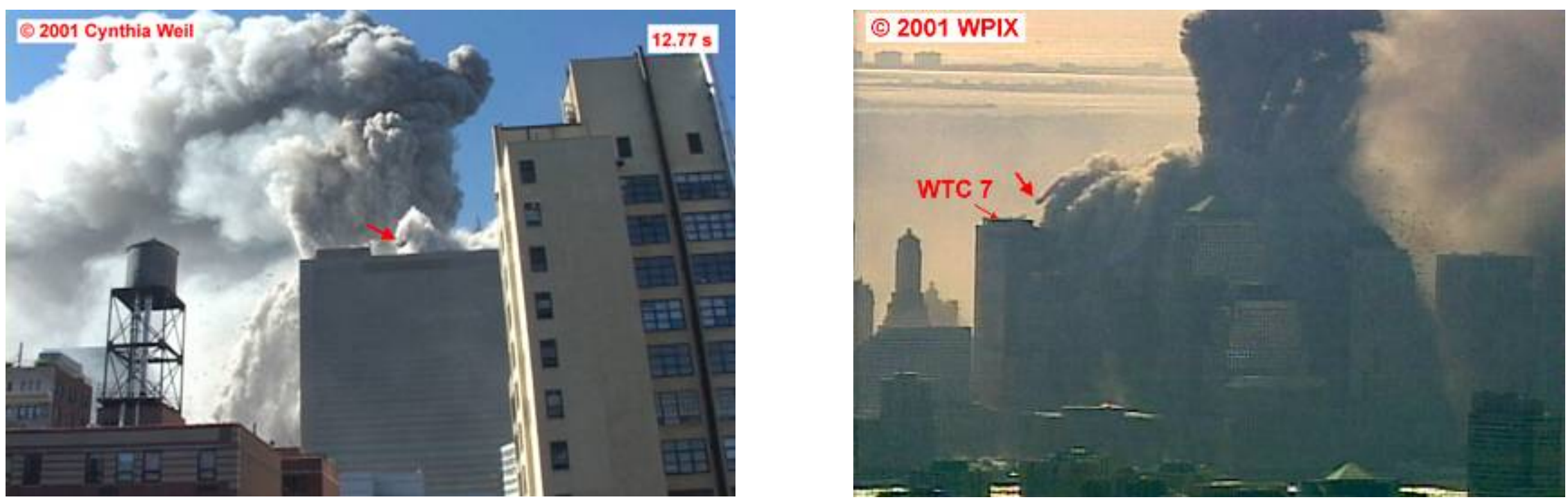

Figure 5-41. (continued). Three pairs of frames taken from videos shot from the north and west showing the collapse of WTC 1.

Times are relative to the start of the collapse. Arrows indicate large objects that were projected toward WTC 7 . The intensities of the video frames have been adjusted. 
The positions of the debris relative to WTC 7 are more accurately indicated by Figure 5-42, since it was shot looking down on the scene at a time when the debris was closer to WTC 7.

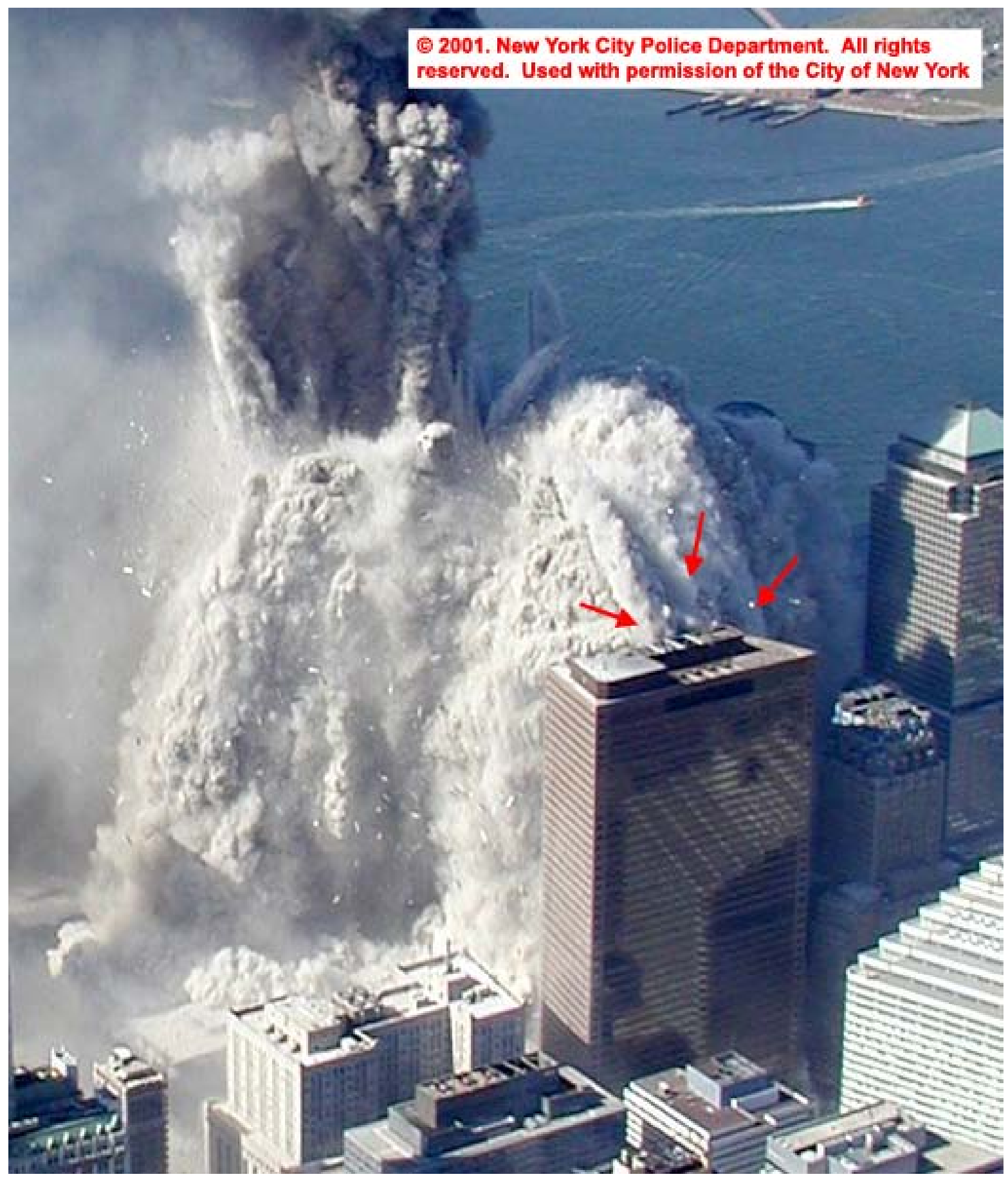

Figure 5-42. Aerial photograph shot $14 \mathrm{~s} \pm 0.5 \mathrm{~s}$ after WTC 1 began to collapse. Arrows mark arcs formed by debris that seemed to be ejected outwards from the debris cloud.

It is difficult to get an idea of the sizes of some of the falling debris from WTC 1 based on the images shown thus far. The following photographs provide a better indication. Figure 5-43 shows a photograph 
that was taken from just north of due west about $7.3 \mathrm{~s}$ after the collapse started. This is shortly after the second pair of images shown in Figure 5-40. WTC 7 is indicated. The building visible between WTC 1 and WTC 7 is the Millennium Hotel, and the taller building in the foreground on the right is World Financial Center 3. (See Figure 5-2 for locations.) A large piece of falling debris is visible. The image has sufficient resolution to identify the individual columns and spandrels that formed the external wall of WTC 1 . This particular piece appears to be at least two panel sections high and six panel sections wide, corresponding to about $18 \mathrm{~m} \times 18 \mathrm{~m}(60 \mathrm{ft} \times 60 \mathrm{ft})$.

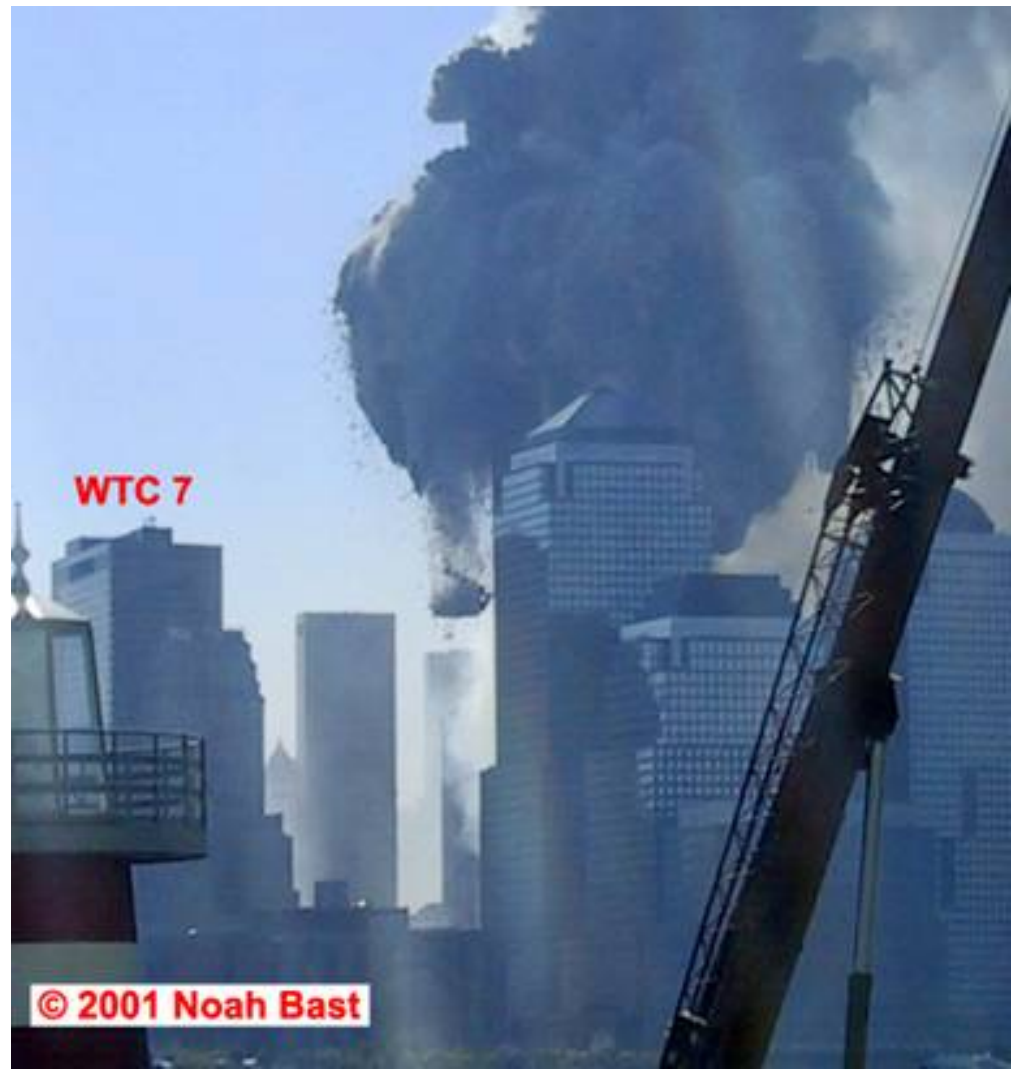

Figure 5-43. Cropped photograph showing the collapse of WTC 1, taken from just north of west of the WTC site $7.3 \mathrm{~s} \pm 0.2 \mathrm{~s}$ after initiation of the collapse.

The intensity levels have been adjusted.

A view of the collapse from a different perspective is shown in Figure 5-44 which was shot from the southwest and provides a view of the south face of WTC 7. This image was taken $10.6 \mathrm{~s}$ following the start of the collapse. This is very close to the time of the third pair of images in Figure 5-40, which were taken at $10.63 \mathrm{~s}$. Note that the falling debris visible in Figure 5-44 is still relatively far removed from the south face of WTC 7. Large sections of steel are visible in the falling debris on both sides of WTC 1.

Figure 5-45 is a high resolution photograph of the collapse of WTC 1 taken $11.7 \mathrm{~s}$ after initiation. This is very close to the time when the fourth pair of images in Figure 5-40 were taken and between the times for the first and second pairs of images in Figure 5-41. This is around the time when the large pieces of debris were expelled toward WTC 7. The section of this photograph above WTC 7 is enlarged in Figure 5-46. Several large sections of steel are visible. On the right side of the photograph, a falling piece of WTC 1 wall is visible that is at least three panel sections wide and two high. There is another large portion of exterior steel frame visible immediately above WTC 7 just to the right of the west penthouse. It is difficult to make out the individual columns and spandrels, but this piece appears to be roughly the same size as the one further to the right. Comparison with videos shows that this large steel section was 
the first large debris that was ejected from the dust cloud toward WTC 7. Its trajectory, visible in Figure 5-40 and Figure 5-41, suggests that it may have reached the south face of WTC 7.

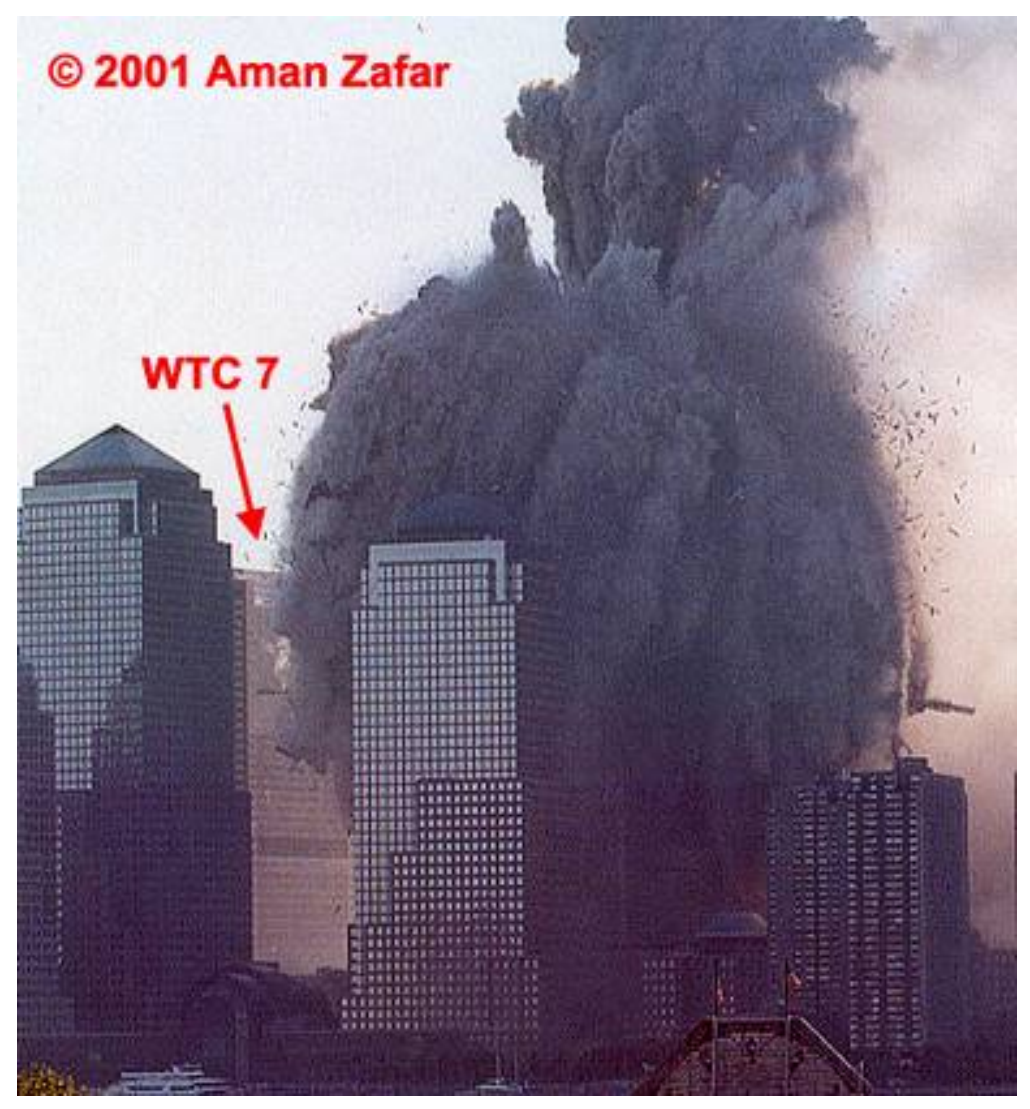

Figure 5-44. Cropped photograph showing the collapse of WTC 1, taken from southwest of the WTC site $10.6 \mathrm{~s} \pm 0.2 \mathrm{~s}$ after the collapse initiated.

The intensity levels have been adjusted.

When the photograph in Figure 5-45 was taken, pieces of debris were also appearing from the dust cloud higher up and to the east of the large steel section. (See the fourth pair of images in Figure 5-40 and the second pair in Figure 5-41.) In Figure 5-46, it is apparent that several other large pieces of debris were present in this area. The highest piece visible was ejected the furthest and formed the distinct arc visible in the last image pairs of Figure 5-40 and Figure 5-41. As noted above, the large debris below the highest peice was also thrown toward the south face of WTC 7 on a somewhat lower trajectory.

A large amount of smaller debris is visible outside of the primary debris field in Figure 5-46. Their size and shape suggest that many of these smaller pieces are individual $3.6 \mathrm{~m} \mathrm{(12} \mathrm{ft)} \mathrm{long} \mathrm{aluminum} \mathrm{cladding}$ that covered the outer steel skeleton of the towers. These are described in NIST NCSTAR 1-5A. The opacity of the dust cloud created by the collapse of WTC 1 is also evident in the photograph.

The imagery of the collapse of WTC 1 indicates that the vast majority of debris fell relatively close to the tower and did not impact WTC 7 directly. However, there were at least a few substantial pieces of the exterior steel frame that were expelled far enough to impact the south side of WTC 7. A substantial amount of dust and small debris is likely to have struck the south face. 


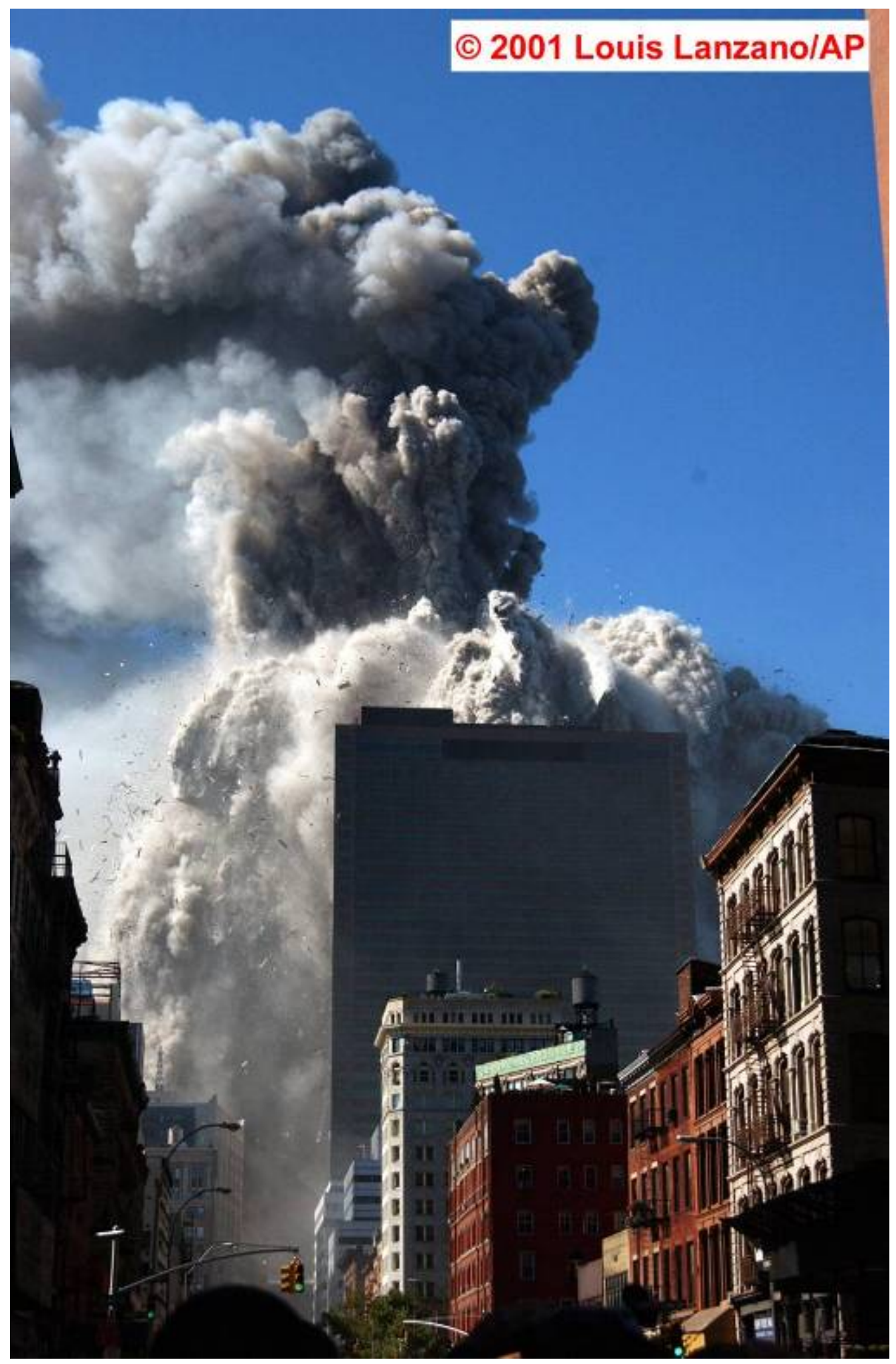

Figure 5-45. Photograph taken from the north of WTC $711.7 \mathrm{~s} \pm 0.1 \mathrm{~s}$ after WTC 1 began to collapse. 


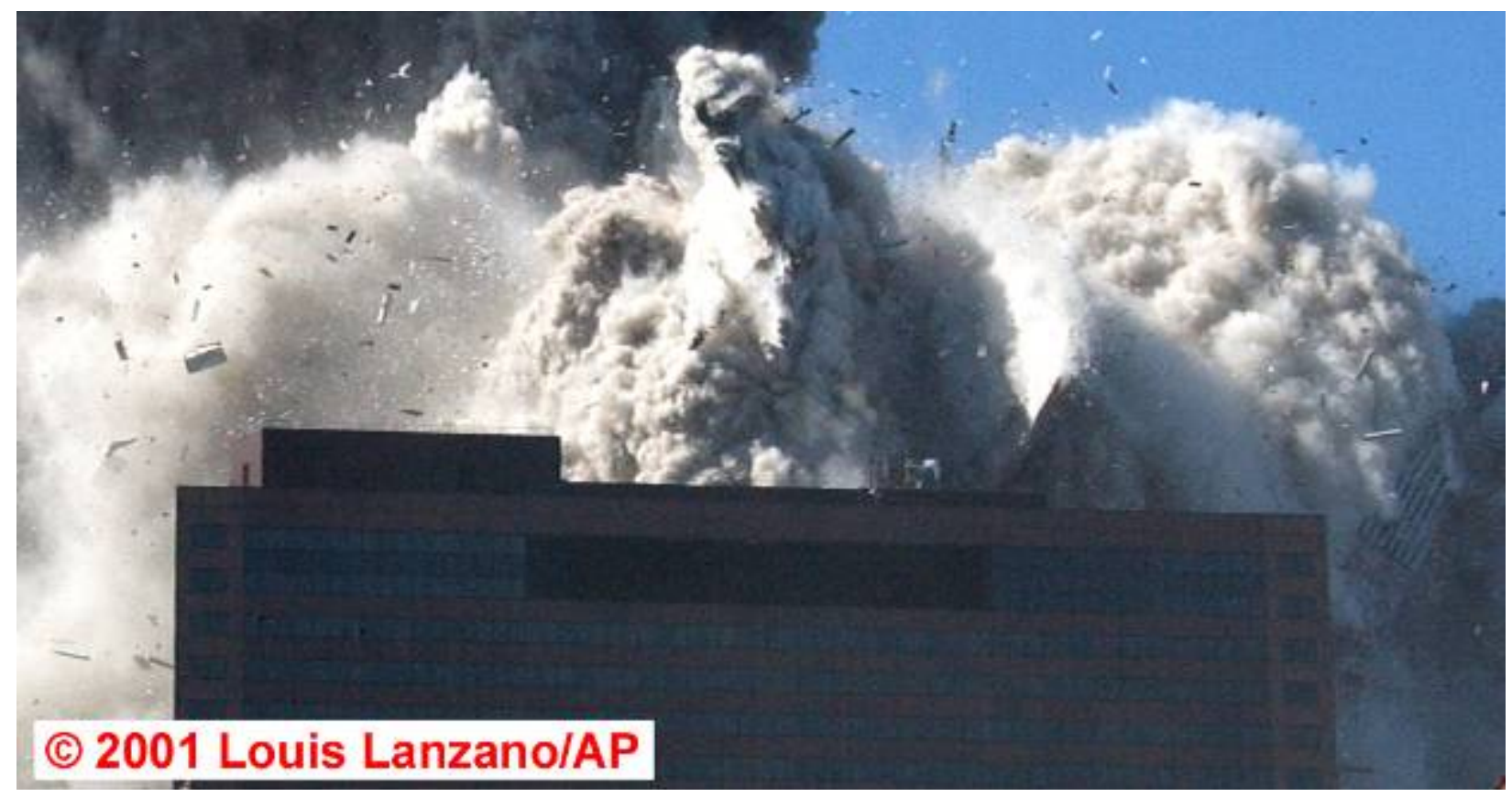

Figure 5-46. Enlarged section of Figure 5-45 focused on the area above WTC 7.

\section{Damage to Floors 5 through 19 on the South Face of WTC 7}

The clearest shot showing WTC 7 south face damage available to the Investigation is shown in Figure 5-47. It was taken shortly after 1:30 p.m.

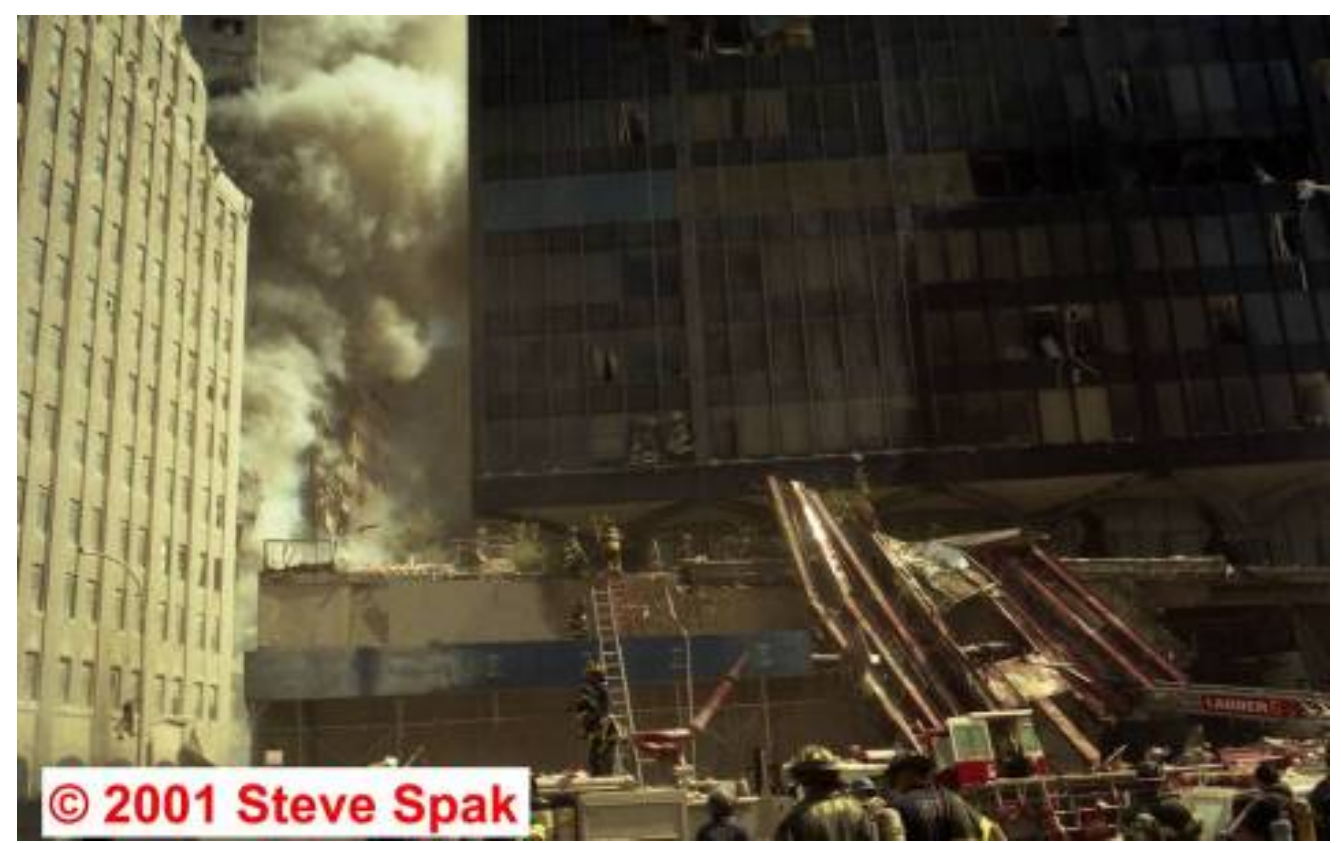

Figure 5-47. Photograph showing a portion of the south face of WTC 7, taken just after 1:30 p.m.

The intensity levels have been adjusted, and auto contrast was applied. 
This photograph was shot from West Street just to the south of its intersection with Vesey Street, looking toward the southwest corner of WTC 7. The building on the left is the Verizon Building, and WTC 6 is on the right. The southwest corner of WTC 7 is visible immediately above the Verizon Building. The three windows visible above the smoke on the west face are on the $19^{\text {th }}$ floor through the $21^{\text {st }}$ floor. A smoke trail partially obscures the windows immediately below. Note that WTC 6 is built on a raised foundation that blocks most of the width of the lower floors on the south face of WTC 7 from view.

A damaged area is visible on the south face of WTC 7, and an opening has been created on the left side of the visible part of the face. Heavy smoke appears to be coming from this opening. A closer inspection shows there is an area to the right where the alternating spandrels and windows, characteristic of the south face (see the earlier discussion), are visible. A series of white vertical lines are also present. These lines reveal the locations of the steel columns that were located along the south periphery of the building, immediately behind the windows. These columns appear white because of their enclosures.

This photographer also recorded a short video segment of the south face from near the same location at roughly the same time as the photograph in Figure 5-47. As the smoke rolled across the south face in the video, additional areas on the south face (primarily on the east side) were momentarily revealed. Figure 5-48 shows a frame taken from this video. By appropriate scaling (the video has much lower resolution) and rotation of such frames, it was possible to obtain good overlap of the captured video frames and the image shown in Figure 5-47.

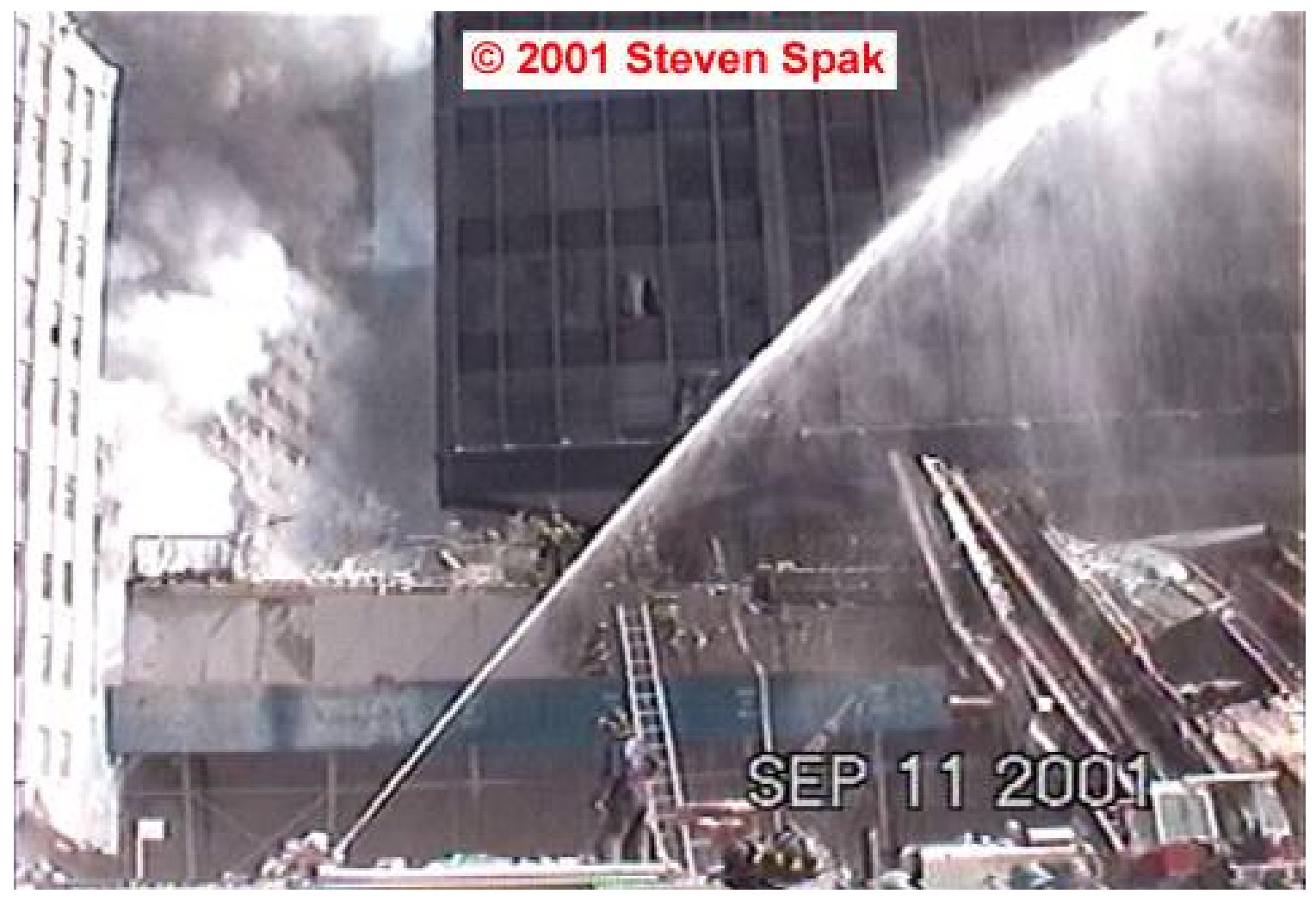

Figure 5-48. Frame taken from a video recorded shortly after 1:30 p.m., showing a partial view of the south face of WTC 7. 
There was sufficient information in the photograph and video frames to determine locations visible on the face and to prepare an overlay showing floor and column locations. This task was complicated by the strong perspective distortion due to the sharp angle from which the images were taken. The first step was to obtain an estimate of locations on the face using information available in the images. As noted above, the west edges of the $19^{\text {th }}$ through $21^{\text {st }}$ floors are visible in Figure 5-47. Several floors can be seen in the photograph and video that are located well below these floors. By recognizing that all of these floors have the same height and correcting for image parallax effects, the row of windows visible above the raised foundation of WTC 6 was tentatively identified as being located on the $9^{\text {th }}$ floor.

In Figure 5-47, the four sets of columns to the immediate right of the damaged area have roughly the same spacings, but the distance to the next set of columns appears to be somewhat larger. In fact, the

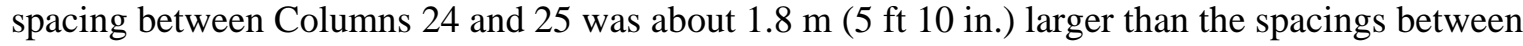
Columns 21, 22, 23, and 24. On this basis, the five sets of columns visible to the right of the damaged area were tentatively assigned as Column 21 to Column 25.

A more careful analysis confirmed these assignments. The starting point was an assumption that all distortions in the images were linear, i.e., straight lines on the building appear as straight lines in the images. This assumption allowed three sides of a quadrilateral to be identified. These sides are shown as blue lines on an enlargement of the damaged area in Figure 5-49 and are extensions of the southeast and southwest corners of WTC 7 and the base of the windows on the tentatively assigned $11^{\text {th }}$ floor. It was desirable to close the quadrilateral near the top of the image, but there were no visible features to use for this purpose. An approximate solution was obtained by drawing a line from the southwest corner, starting at the height of top of the windows on the $20^{\text {th }}$ floor (extrapolated from windows visible on the west face), across to the east side, at an angle consistent with those visible on the lower floors. The angle for this line was then refined as described below.

With these four closed lines, it was possible to perform an approximate perspective correction using a transform available in Photoshop. The result was a distorted version of the original image in which the four lines formed a rectangle. If simple perspective distortion had been the only type in the image, the transform would have provided a properly scaled two dimensional view of the face. Not surprisingly, additional distortion was present, and further corrections were required. The next step was to draw lines that passed along the tops of the windows visible in the photograph for the floor below, on the same floor, and the floor immediately above the baseline defined in Figure 5-49. These lines were adjusted until they were parallel to the baseline in the perspective transform.

The crossing points for these new lines at the southwest corner allowed the number of pixels between the tentatively assigned $10^{\text {th }}$ and $11^{\text {th }}$ floors and the $11^{\text {th }}$ and $12^{\text {th }}$ floors to be determined. The corresponding number of pixels on the corner were also determined directly from the image for the $19^{\text {th }}$ and $20^{\text {th }}$ floors and the $20^{\text {th }}$ and $21^{\text {st }}$ floors. As expected, the number of pixels per floor was found to decrease with increasing height. By using the tentative lower floor assignments and assuming that the decreasing number of pixels per floor varied linearly with height, it was possible to derive an expression for the positions where the projected lines along the tops of the windows intersected the west edge for the floors between the $10^{\text {th }}$ and $21^{\text {st }}$ floors. The result fit the projected lower floor spacings and the observed upper floor spacings very well. The locations of the intersection points for lines running along the tops of windows on the $6^{\text {th }}$ through $9^{\text {th }}$ floors were estimated by extrapolation using the same approach. The locations of these intersections are indicated by small red tic marks along the southwest corner on the overlaid grid included in Figure 5-49. 

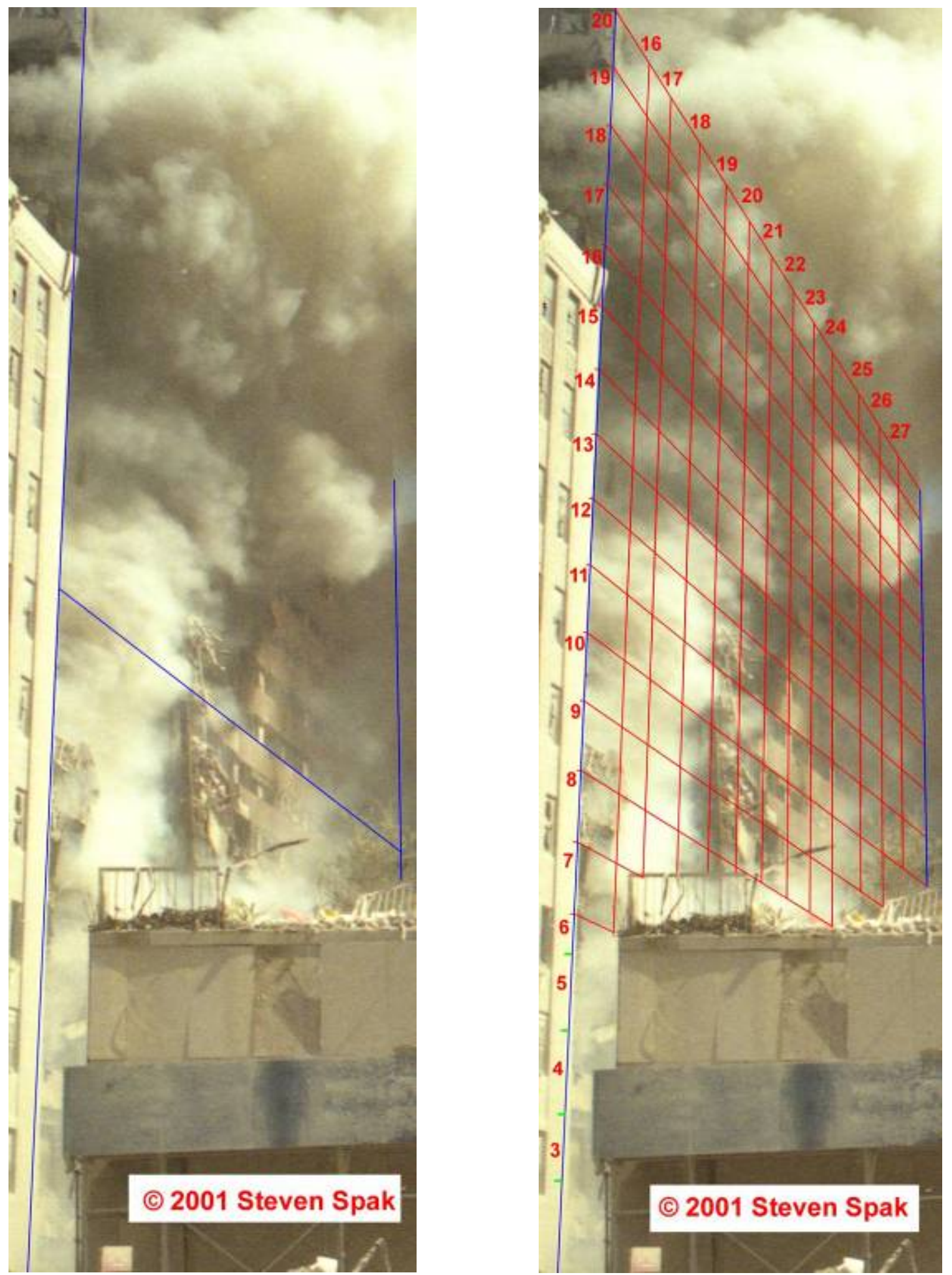

Figure 5-49. Enlarged sections of the photograph shown in Figure 5-47. In the view on the left, blue lines have been added that indicate projected locations for the southwest and southeast corners and for a baseline aligned along the bottom of windows located on the $11^{\text {th }}$ floor. A superimposed grid indicating column positions and lines for the top edges of windows on given floors is shown on the right. 
Using the calculated locations at the western edge as the starting locations for lines passing across the south face and by requiring these lines to be parallel to the baseline in the perspective transform, it was possible to draw lines that should have passed along the tops of windows on higher floors. Using the initial guess for the line along the tops of the windows on the $20^{\text {th }}$ floor, it was clear that the lines determined in this manner passed well above the tops of windows visible on higher floors in the photograph and video clips. However, by trial and error, it was possible to adjust the angle for the $20^{\text {th }}$ floor line and, after redrawing the lines for the intervening floors and using the requirement for parallel lines in the perspective drawing, find a condition where the calculated lines passed along the tops of all of the windows visible on these floors in the images. This good agreement confirmed the tentative assignments for the visible floors.

Using the same approach as above, the predicted locations for the tops of windows on the $6^{\text {th }}$ floor to the $9^{\text {th }}$ floor were determined. The approach was extended further down along the western edge of the face. Since the appearance of the face changed on lower floors (Figure 5-20), the locations of floor slabs were calculated for the $3^{\text {rd }}$ floor through the $6^{\text {th }}$ floor. These are indicated with green tics in Figure 5-49.

The perspective transform was also used to estimate column locations. If the perspective correction had been perfect, the separations between Columns 21 through 24 would have appeared equally spaced along the baseline in the perspective view. They were not. However, a plot of the five visible columns' locations, normalized by the building edges separation from the perspective view, yielded a straight line when plotted against the known relative positions based on the dimensions of the building. The slope was slightly greater than one. Since the fit included Column 25, which had a much greater actual separation from Column 24 than the equal column separations between Columns 21 and 24, this provided strong evidence that the tentative column assignments were accurate.

Even though the line fit for the column locations was very good, it did not accurately predict the building edge locations in the perspective view. Additional distortion was present. In order to calculate the positions of the remaining columns along the baseline, the amount of additional distortion at each edge was estimated from the difference between the predicted and actual locations of the edges in the images. It was then assumed that the distortion was linearly distributed over the separations between the edge and the nearest of the five identified columns. This allowed the locations of Column 15 to Column 20 and Column 26 to Column 28 in the perspective view to be predicted using their known positions on the face. These locations on the actual image were then adjusted until they agreed with the estimated locations in the perspective view.

Once the column locations along the baseline were determined, one additional step was required to draw the lines corresponding to the columns on the face. The lines along the edges of the building were nearly vertical in the image, but they differed by a few degrees. It was assumed that the angle of the lines for the columns would vary linearly across the face, and the angles were calculated for each column location along the baseline. The combination of location along the baseline and angle allowed the column lines to be drawn.

Figure 5-49 shows the grid generated by the procedure described above overlaid on an enlarged section of Figure 5-47. The red lines running from west to east indicate the calculated positions for the tops of the windows on the $6^{\text {th }}$ to $20^{\text {th }}$ floors. These lines agree well with the window openings visible on the $8^{\text {th }}$ to $15^{\text {th }}$ floors. Note that the tops of the windows are actually located $1.06 \mathrm{~m} \mathrm{(3 \textrm {ft }} 6 \mathrm{in}$.) below the base of the slab for the floor immediately above. The vertical red lines correspond to the calculated locations of 
Column 16 to Column 27 centerlines. Locations for Column 15 and Column 28 are not indicated. These

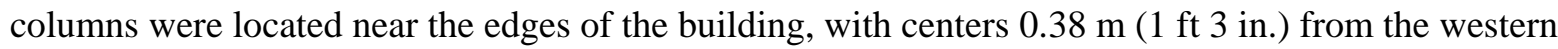

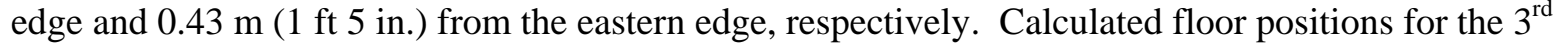
through $6^{\text {th }}$ floor are indicated by the short green lines along the blue line identifying the southwest corner.

Figure 5-50 shows an enlargement of the damaged south face from the video frame shown in Figure 5-48 overlaid on the photograph shown in Figure 5-49. On the right, the grid taken from Figure 5-49 has been superimposed on the same image. While the image has a relatively low resolution, it is clear that the columns and spandrels to the right of the damaged area were essentially intact, but that most of the window glass had been broken out.

An enlarged section of another frame taken from this video is overlaid on the photograph in Figure 5-51. The grid from Figure 5-51 has been superimposed on the right side. Note that windows are visible on higher floors, including one on the $20^{\text {th }}$ floor for which the grid line passes close to the top by the upper edge. This provides additional evidence that the grid closely represents actual locations on the face. The debris visible between Columns 18 and 19 on the $13^{\text {th }}$ floor was seen sporadically through the smoke in the video.

Figure 5-52 is another photograph showing damage to the south face of WTC 7. It was shot from West Street looking down Vesey Street. The Verizon Building is on the left, WTC 7 is behind it, and WTC 6 is on the right. Even though this image provides a more oblique view than the photograph in Figure 5-48, it is possible to see locations closer to the street.

The area of the image showing WTC 7 is enlarged in Figure 5-53. In the enlargement on the left, a line has been added showing the location of the southwest corner extrapolated from above, where is it visible. The approximate locations of the floors are indicated. These were estimated using the pixel separations between the floors visible above the Verizon Building, along with the known floor separations as the basis for a correction assuming only linear distortion is present in the image. 

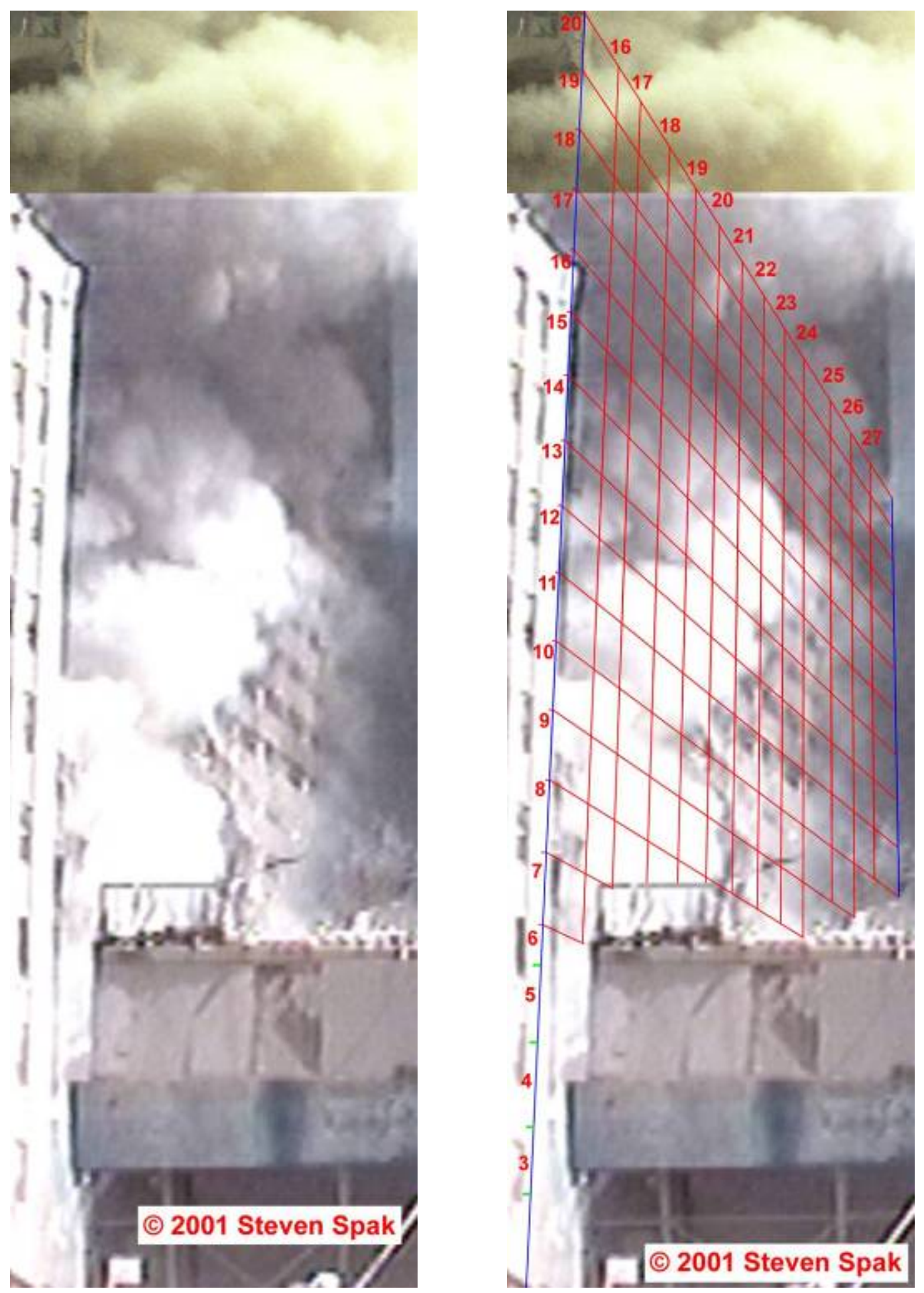

Figure 5-50. An enlarged section of the south face of WTC 7 from the video frame in Figure 5-48.

The pixel size and rotation of the video frame have been adjusted to overlay the photograph (portion visible at top) shown in Figure 5-47. On the right is the same section, with the grid shown in Figure 5-49 superimposed, indicating column locations and lines running along the tops of windows. 

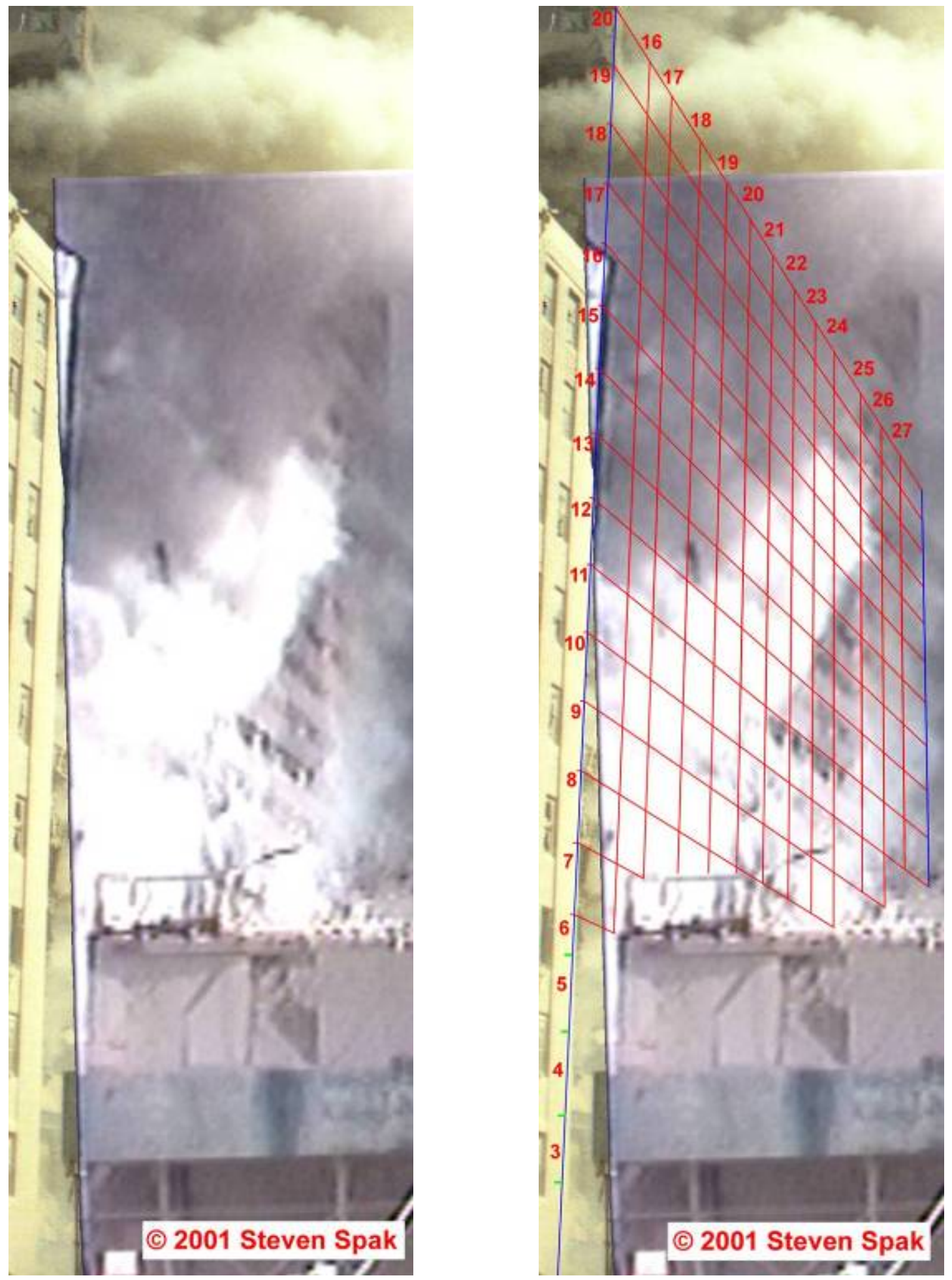

Figure 5-51. An enlarged section of the south face of WTC 7 from a second video frame. The pixel size and rotation of the video frame have been adjusted to overlay the photograph (portion visible at top) shown in Figure 5-47. On the right is the same section, with the grid shown in Figure 5-49 superimposed, indicating column locations and lines running along the tops of windows. 


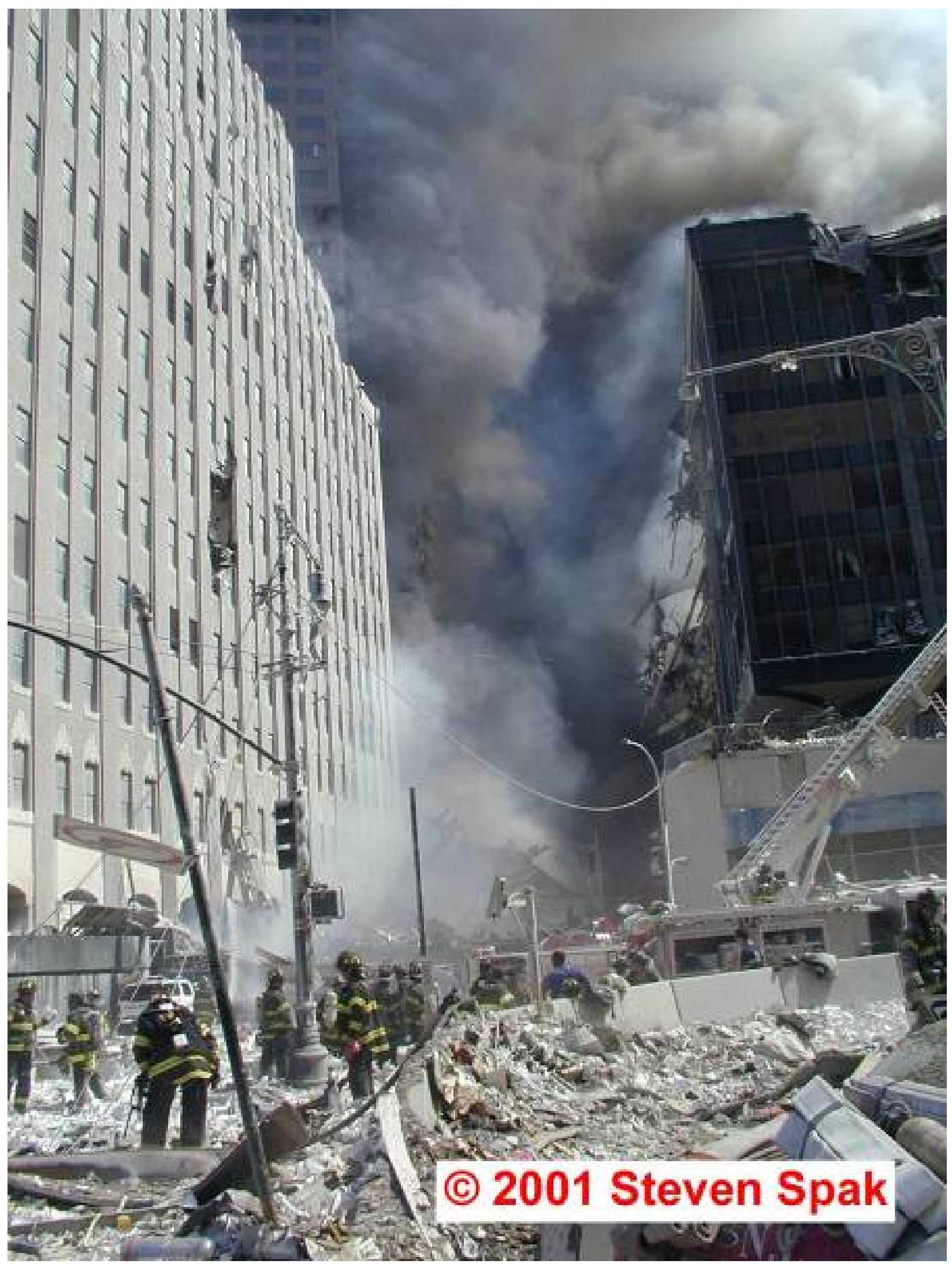

Figure 5-52. Photograph showing a portion of the south face of WTC 7 at 12:46:39 p.m. 


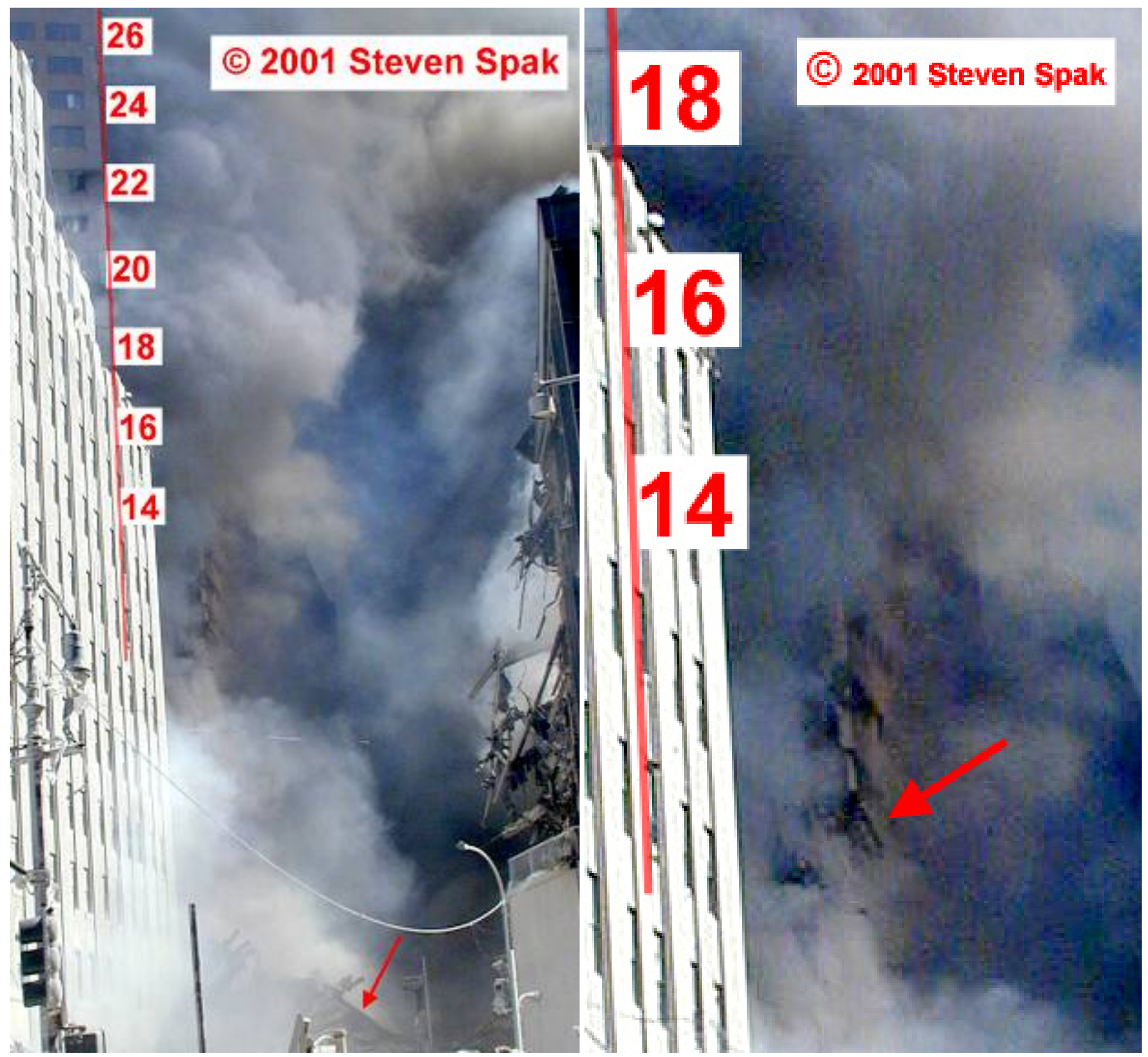

Figure 5-53. Two enlargements from Figure 5-52, showing the south face of WTC 7. The vertical red line indicates the location of the southwest corner of the building. Floor number locations were determined as described in the text. The red arrow in the left enlargement identifies debris that may be from the Promenade, and the arrow on the right indicates a characteristic damage pattern.

A large amount of collapse debris is visible near the base of WTC 7 in the left portion of Figure 5-53. The distinctive three-column arrangement characteristic of panel sections from the towers identifies at least some of this debris as steel from WTC 1. The arrow on the left indicates a straight edge that may be a collapsed section of the Promenade.

The damaged area visible on the south face is enlarged further on the right side of Figure 5-53. The arrow indicates a distinct damage feature in the granite. Sighting along the tops of the windows immediately above the arrow indicates that these windows are on the $14^{\text {th }}$ floor. An analysis similar to that employed to create the grid shown in Figure 5-49 was used to estimate the locations of columns 
visible in Figure 5-53. These assignments indicated that the damage was located near Column 22 or Column 23. Figure 5-53 shows that the façade damage extended up to at least the $15^{\text {th }}$ floor. In the images of the area shown earlier, the $14^{\text {th }}$ and $15^{\text {th }}$ floors had been hidden by smoke.

Another partial view of the damage on the south face is shown in Figure 5-54. This image is a frame from a video shot a few minutes earlier than the photograph shown in Figure 5-52. Based on relative locations to the front of the Verizon Building for the light pole and street sign visible in Figure 5-52 and Figure 5-54, the video was taken from a location slightly closer to WTC 7 than the photograph. Since the video and photographs were taken from nearly the same locations, differences due to parallax effects are small at the south face of WTC 7. The video frame was scaled and rotated so that it could be accurately overlaid on the photograph shown in Figure 5-52.

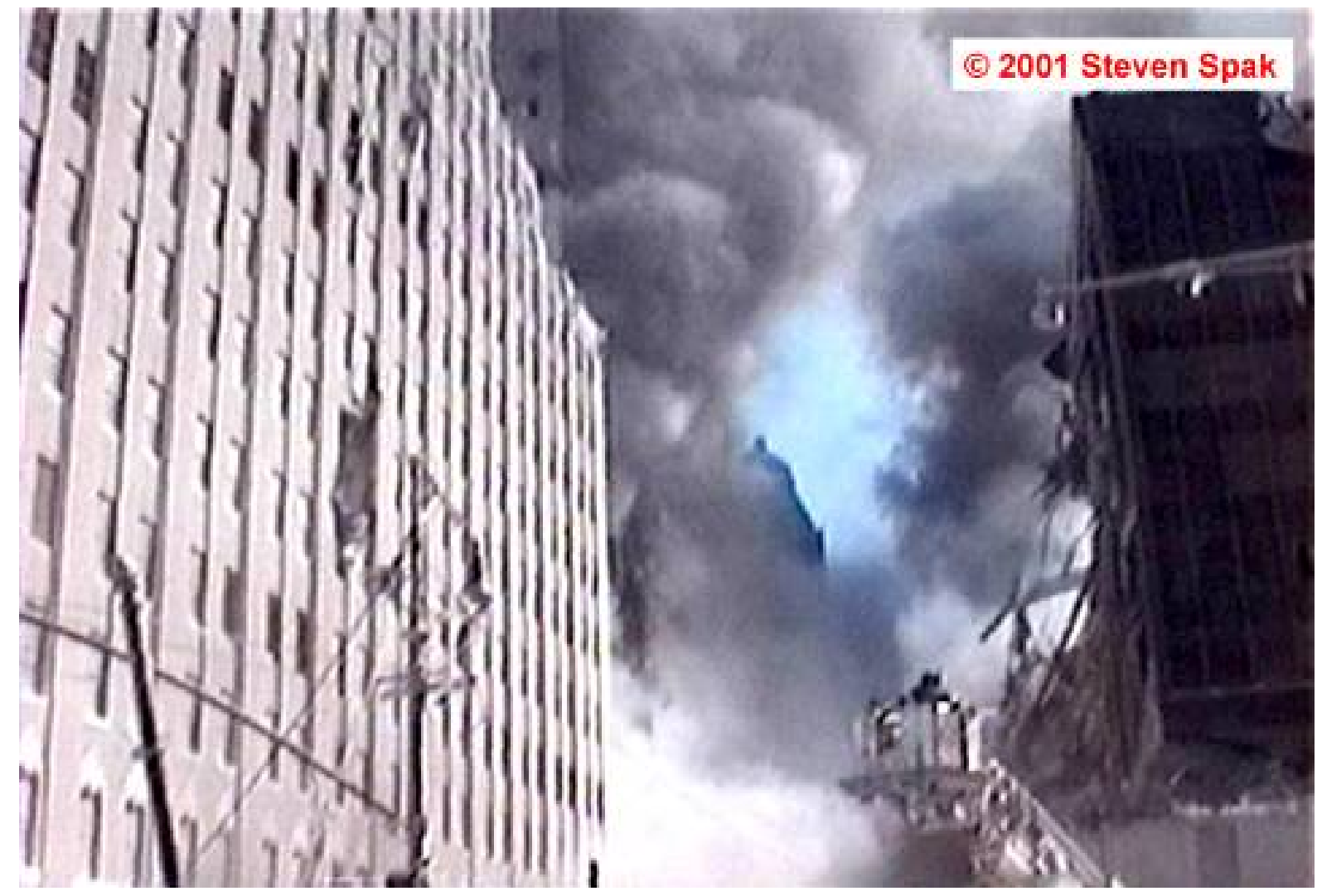

Figure 5-54. Frame from a video showing a view of the south face of WTC 7 shot from roughly the same location as Figure 5-53, earlier than and within a few minutes of 12:46:39 p.m. The intensity levels have been adjusted.

The smoke that obscured much of damaged area had cleared somewhat, and a larger area of the damage on the south face is visible than in the images described above. The damaged area is enlarged in Figure 5-55. Based on the overlay of the image on the photograph, an arrow indicates the location marked in the image on the right-hand side of Figure 5-53. Comparison with Figure 5-53 indicates that the damage visible in Figure 5-55 spans multiple floors downward from the $15^{\text {th }}$ floor and is at least two columns wide. Areas higher up on the south face remain hidden by smoke. 


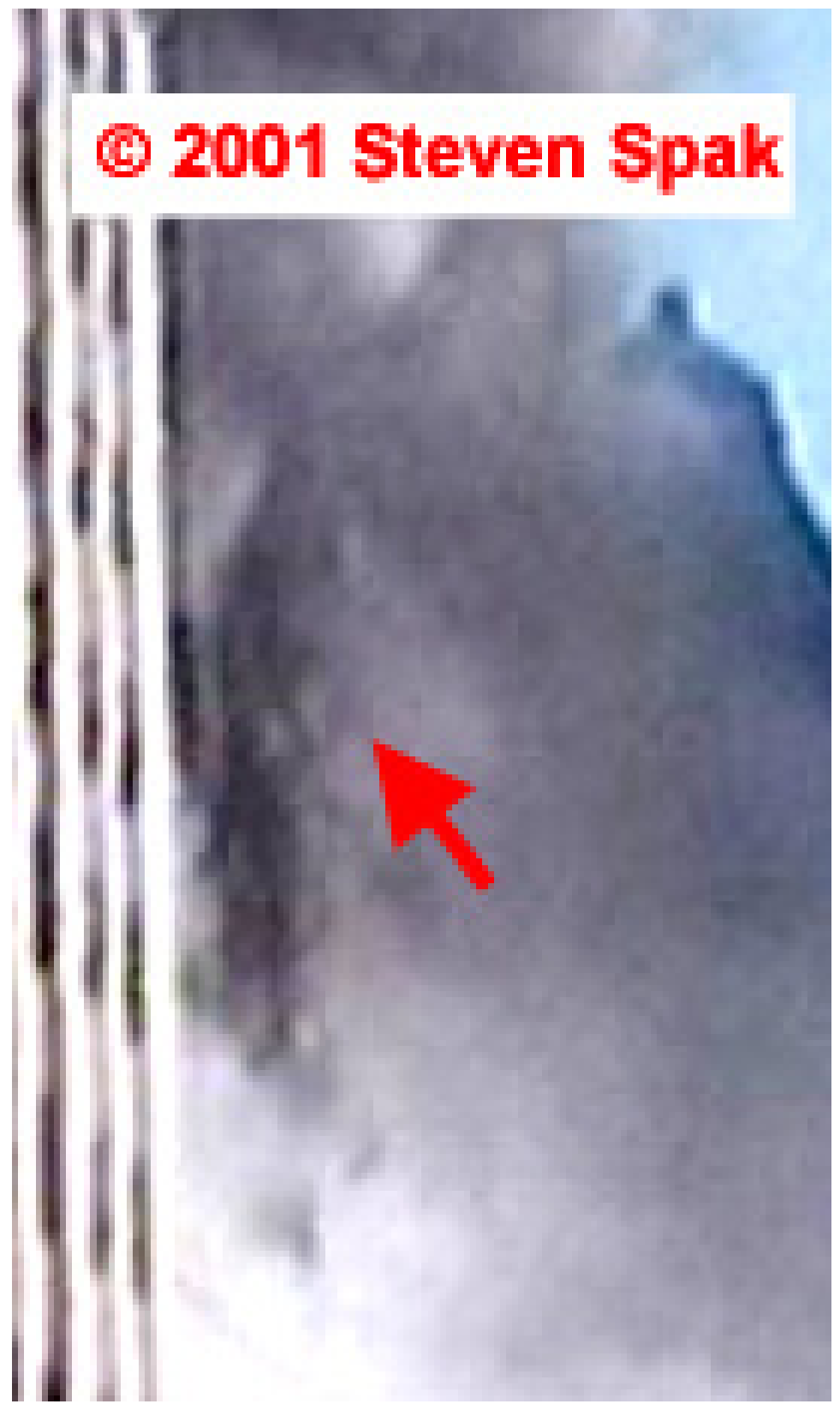

Figure 5-55. Enlargement of the damaged area visible on the south face of WTC 7 in Figure 5-54.

The arrow is positioned at roughly the same location as that shown in the right-hand image in Figure 5-53.

Figure 5-56 shows another view of the south face of WTC 7 shot looking down Vesey Street from a location somewhat closer to WTC 7. A large number of steel panel sections from WTC 1 are visible lying in the street. At least one of these panel sections struck the south face of the Verizon Building and created an opening on the $6^{\text {th }}$ and $7^{\text {th }}$ floors. One panel section is leaning against this building at ground level. Further down the street, a number of panel sections are visible lying at the base of the south face of WTC 7. Some of these panel sections can be identified in Figure 5-52 and Figure 5-53, but they are much clearer in Figure 5-56. The debris that may be a portion of the collapsed Promenade, indicated by an arrow in the right-hand image in Figure 5-53, is difficult to identify because it is in a shadow. 


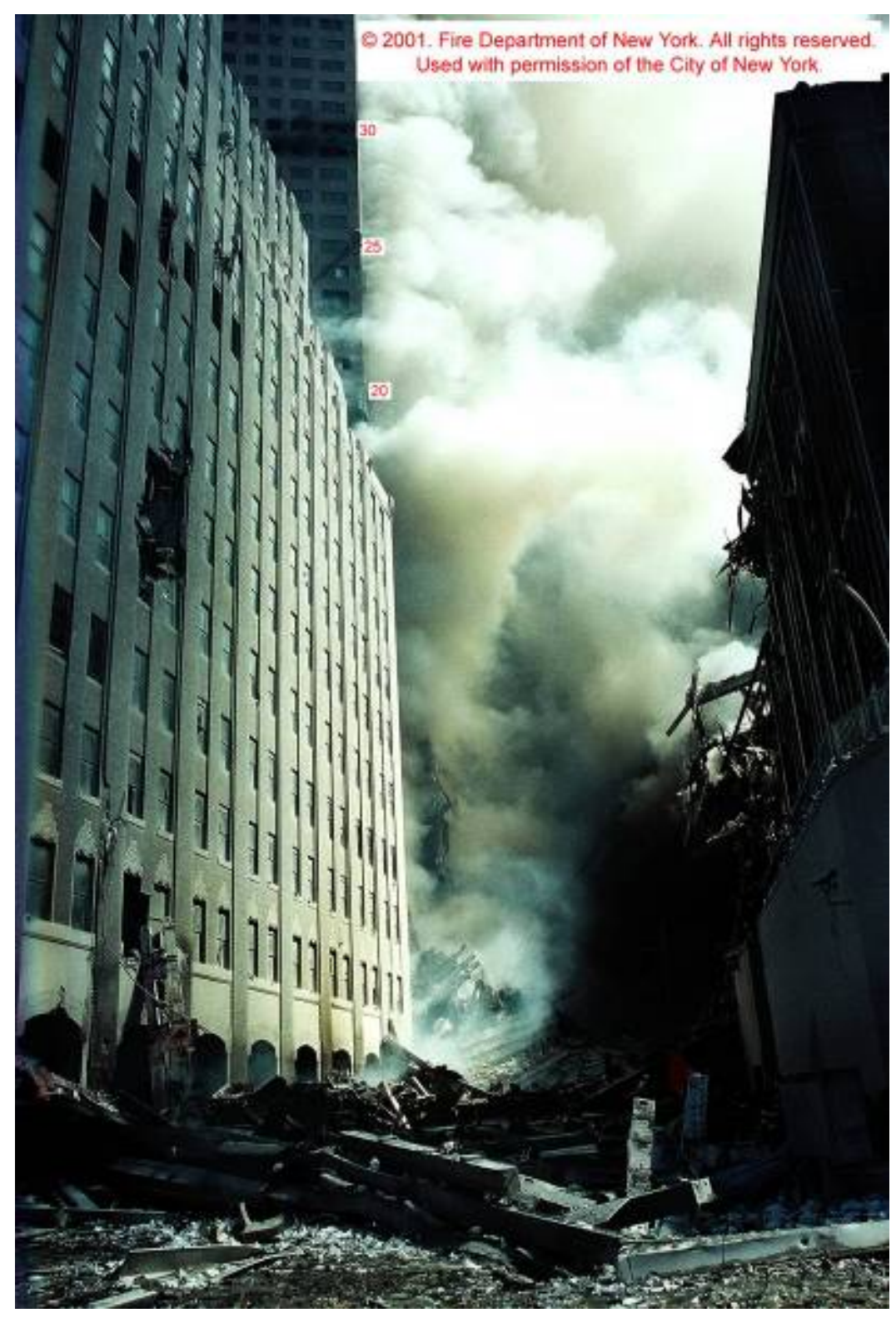

Figure 5-56. Photograph of damage on the south face of WTC 7, shot looking down Vesey Street between the Verizon Building (left) and WTC 6 (right), shortly after 1:30 p.m.

The intensity levels have been adjusted.

The smoke near the base of WTC 7 had momentarily cleared at this time, and it is possible to observe a damaged area on the lower part of the south face. An opening in the building spanning several floors is apparent. This part of the image has been enlarged in Figure 5-57. A row of several windows with some columns visible can be seen near the top of the visible damage. Closer inspection reveals that there is another row of windows immediately below. A single window is visible just to the right of the curved damage section. Lower down a single rectangular opening is present to the left of the opening in the face. This opening is much taller than the windows visible above. Its shape indicates that it is one of the vents that spanned the $5^{\text {th }}$ and $6^{\text {th }}$ floors. Thus, the damage visible in the image spans the $5^{\text {th }}$ to $8^{\text {th }}$ floors.

There is insufficient information in the image to identify the exact horizontal location of the damage on the face. However, it is likely that the damage area is a downward extension of the opening visible in Figure 5-47 and Figure 5-49 to the immediate left of Column 20. If this is correct, the opening in this area extends from at least the $5^{\text {th }}$ floor to the $15^{\text {th }}$ floor. 
Another view of the debris piled up at the base of WTC 7 is shown in Figure 5-58. The large number of steel panel sections from WTC 1 is evident. A small fire is burning in the pile. The large amount of debris in Vesey Street is consistent with the large areas of WTC 1 panel sections that were described earlier as falling toward WTC 7.

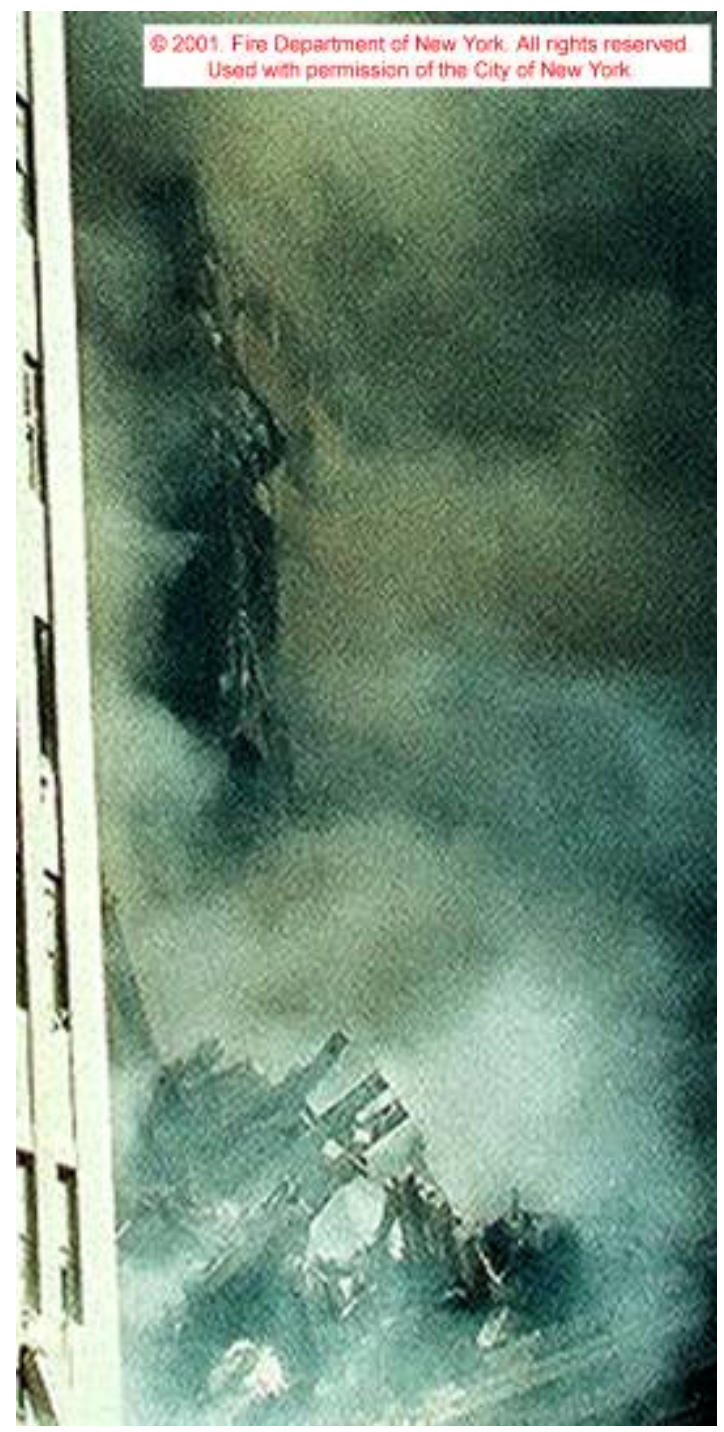

Figure 5-57. Expanded portion of Figure 5-56 showing damage on the south face of WTC 7. The contrast of the image has been enhanced.

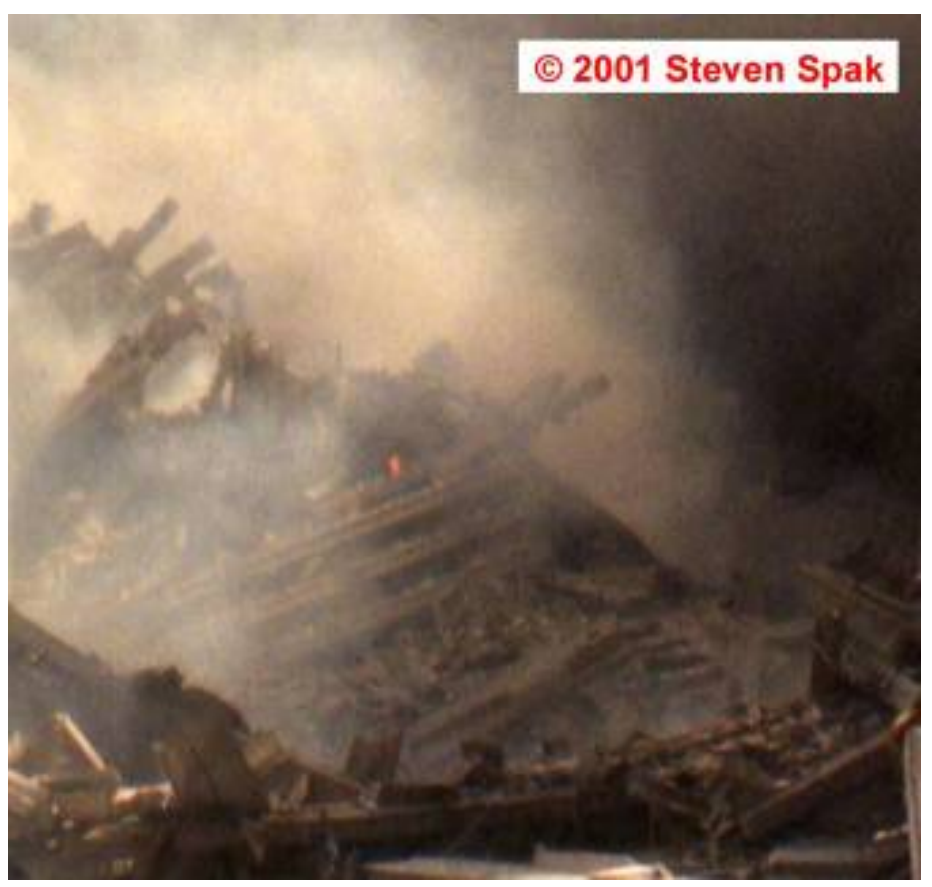

Figure 5-58. View of the rubble at the base of the south face of WTC 7.

The original image was cropped, and the intensity levels and contrast were adjusted.

Another frame from a video clip showing the south face of WTC 7 taken looking up Vesey Street is shown in Figure 5-59. Visible floors along the south edge of the west face are indicated. The hole near the center of the south face is only partly visible, but this image is noteworthy because the smoke is clear enough to confirm that the spandrels and columns are intact over a large area to the east of the hole. By using lines running along the tops of the windows to extrapolate to the west edge, it was possible to identify this area as extending from the $11^{\text {th }}$ floor to the $15^{\text {th }}$ floor. 


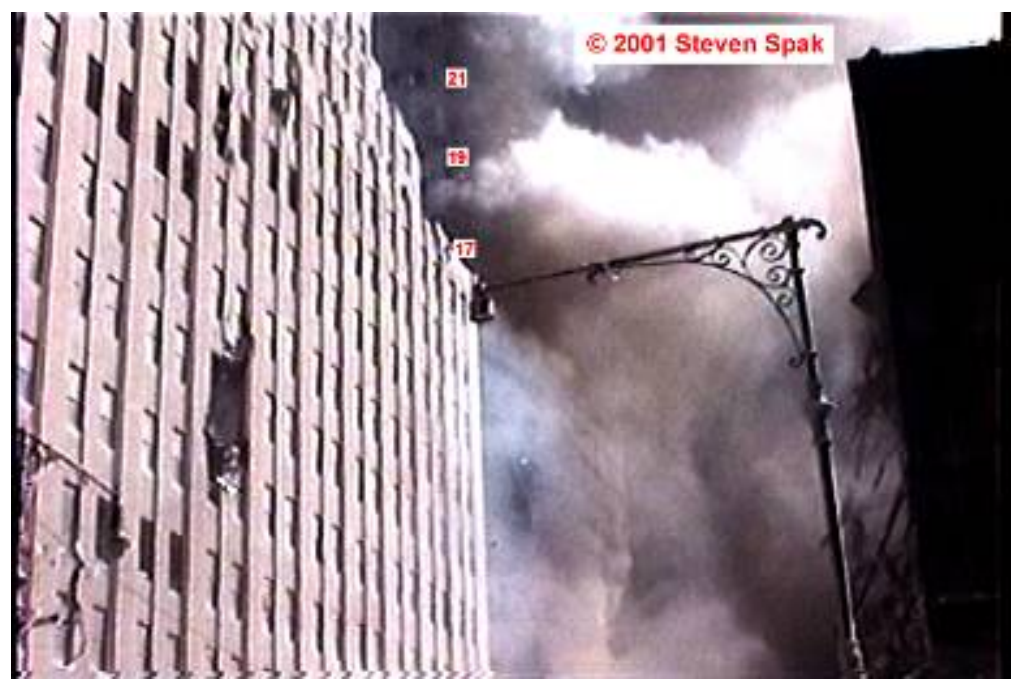

Figure 5-59. Frame from a video clip shot shortly after 12:30 p.m. showing the south face of WTC 7 framed by the Verizon Building and WTC 6. The intensity levels have been adjusted and floor numbers have been added.

Figure 5-60 shows a long-distance photograph shot from a helicopter just after 12:30 p.m., in which the south face of WTC 7 is partially visible. Red lines have been added indicating the west and east edges of the face. The west edge was easily identified, but, due to the presence of smoke, the east edge line had to be drawn by starting at the upper corner, which is just visible, and assuming the east edge was parallel to the west edge.

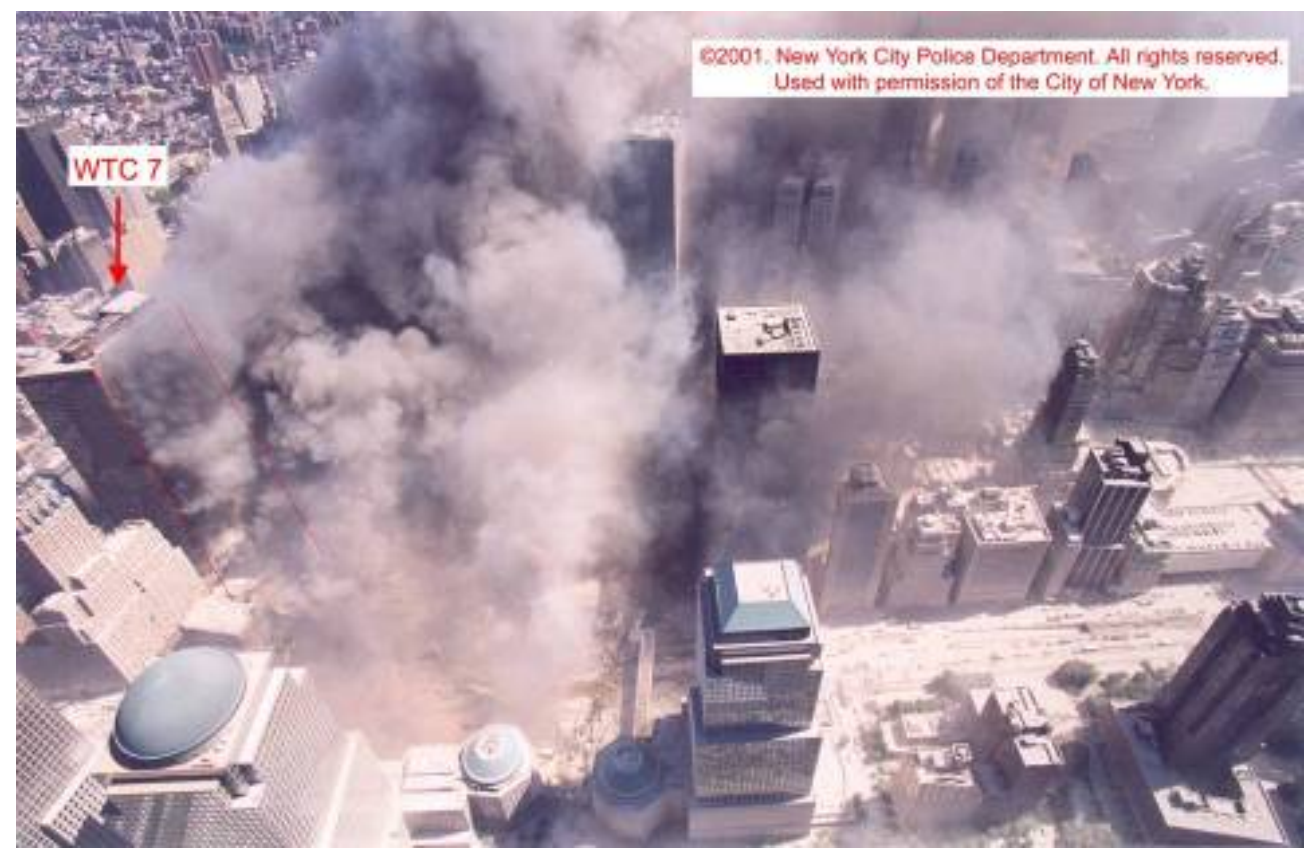

Figure 5-60. Photograph of the WTC site shot around 12:35 p.m. from a helicopter. The red lines identify the west and east edges of the south face of WTC 7.

Figure 5-61 is an enlargement of the lower portion of WTC 7 from Figure 5-60. Floor numbers have been added along the southern edge of the west face. Details are difficult to discern due to the distance of the photograph, but it is possible to see parts of the south face that were damaged during the collapse of WTC 1. A dark area extending up to the $14^{\text {th }}$ or $15^{\text {th }}$ floor can be seen near the center of the face. This location suggests that this is the damage identified earlier near Column 22, based on Figure 5-52 to Figure 5-55. This damage appears to extend downward to about the $9^{\text {th }}$ floor. As observed earlier, intact spandrels are visible to the right of this opening. 


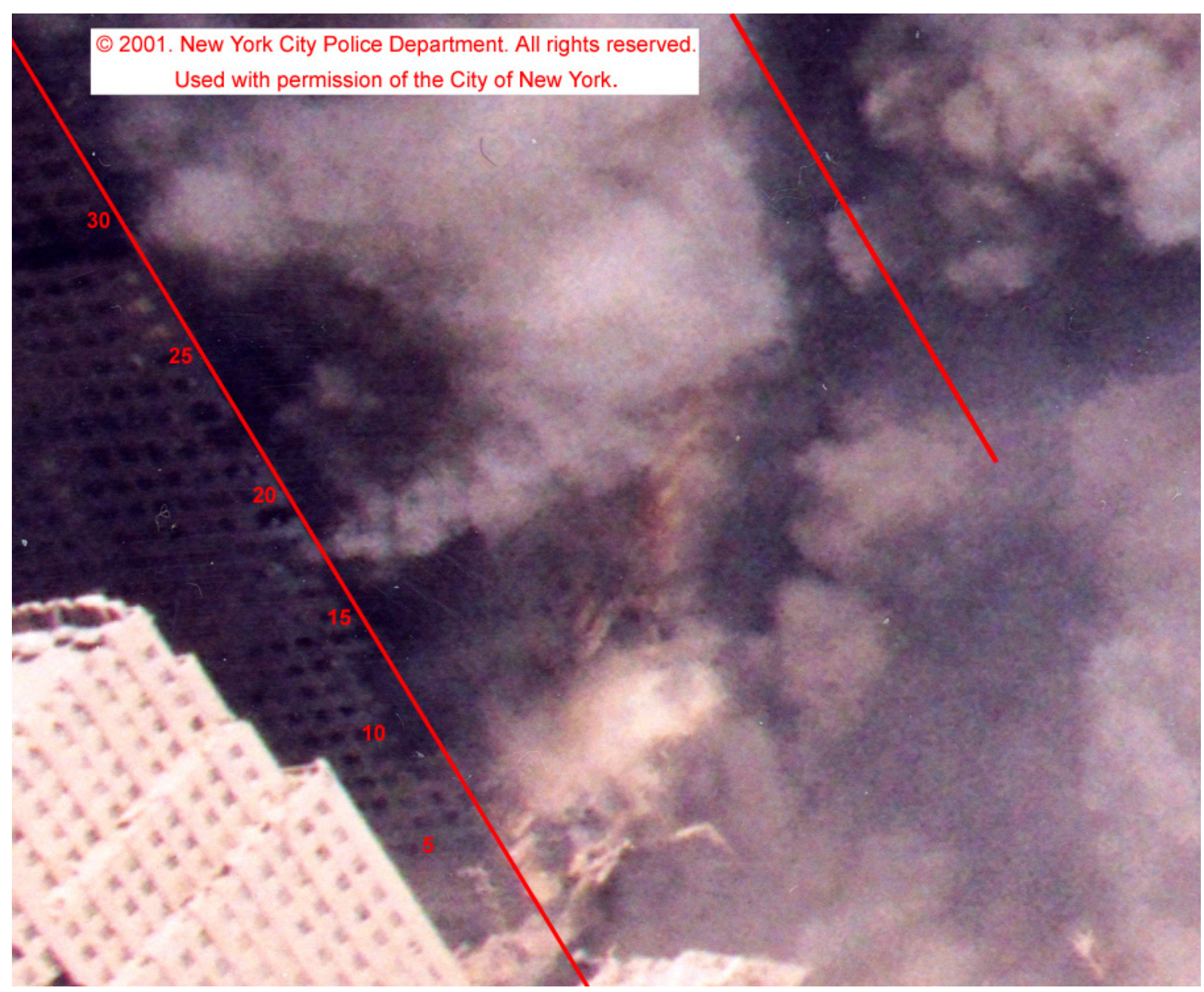

Figure 5-61. Enlarged portion of Figure 5-60 showing the south face of WTC 7. The section has been enhanced by adjusting the intensity levels. The red lines indicate the west and east edges. Floor numbers have been added.

A second damaged area is apparent just to the left and below that described above. This opening seems to extend down to about the $5^{\text {th }}$ floor where it becomes hidden by smoke. The location of this damage is consistent with that identified earlier in Figure 5-47, Figure 5-49, Figure 5-56, and Figure 5-57. There appear to be two spandrels located just above this opening near the $8^{\text {th }}$ and $9^{\text {th }}$ floors. Closer inspection suggests that these spandrels have been partially dislodged since they do not line up well with the spandrels visible to the right.

There appear to be one or more panel sections lying up against the south face of WTC 7. These seem to be raised off the ground somewhat, but appear to be too low to be on top of the Promenade. It is possible that the Promenade has partially collapsed in this area. There appear to be two openings in the south face of the building immediately above the panel sections. It is not possible to confirm whether the smaller opening on the right resulted from structural damage, since this area was primarily glass enclosed (see Figure 5-20), and the glass may simply have been broken out. On the other hand, the opening on the left seems to extend well above the $4^{\text {th }}$ floor, suggesting that some structural damage is present in this area. The granite at this height on the southwest corner appears to have been disrupted, which agrees with damage visible on this corner in Figure 5-47 and Figure 5-49. 
There is a dark area in Figure 5-61 extending from the $8^{\text {th }}$ floor to the $13^{\text {th }}$ floor, where it is difficult to make out the southwest corner of WTC 7. As shown in Figure 5-62 and Figure 5-63 below, the southwest corner was damaged at this location by falling debris from WTC 1.

Figure 5-62 was shot from Jersey City on the opposite side of the Hudson River. It shows portions of the southwest corner and adjacent faces of WTC 7, flanked by World Financial Center 3 on the left and by World Financial Center 2 on the right. The Winter Garden lies at the base of WTC 7. The roofline of WTC 6 is visible just above the Winter Garden, and a small corner of the Verizon Building is also visible just to the right of World Financial Center 3. WTC 7 floor numbers have been added to the photograph.

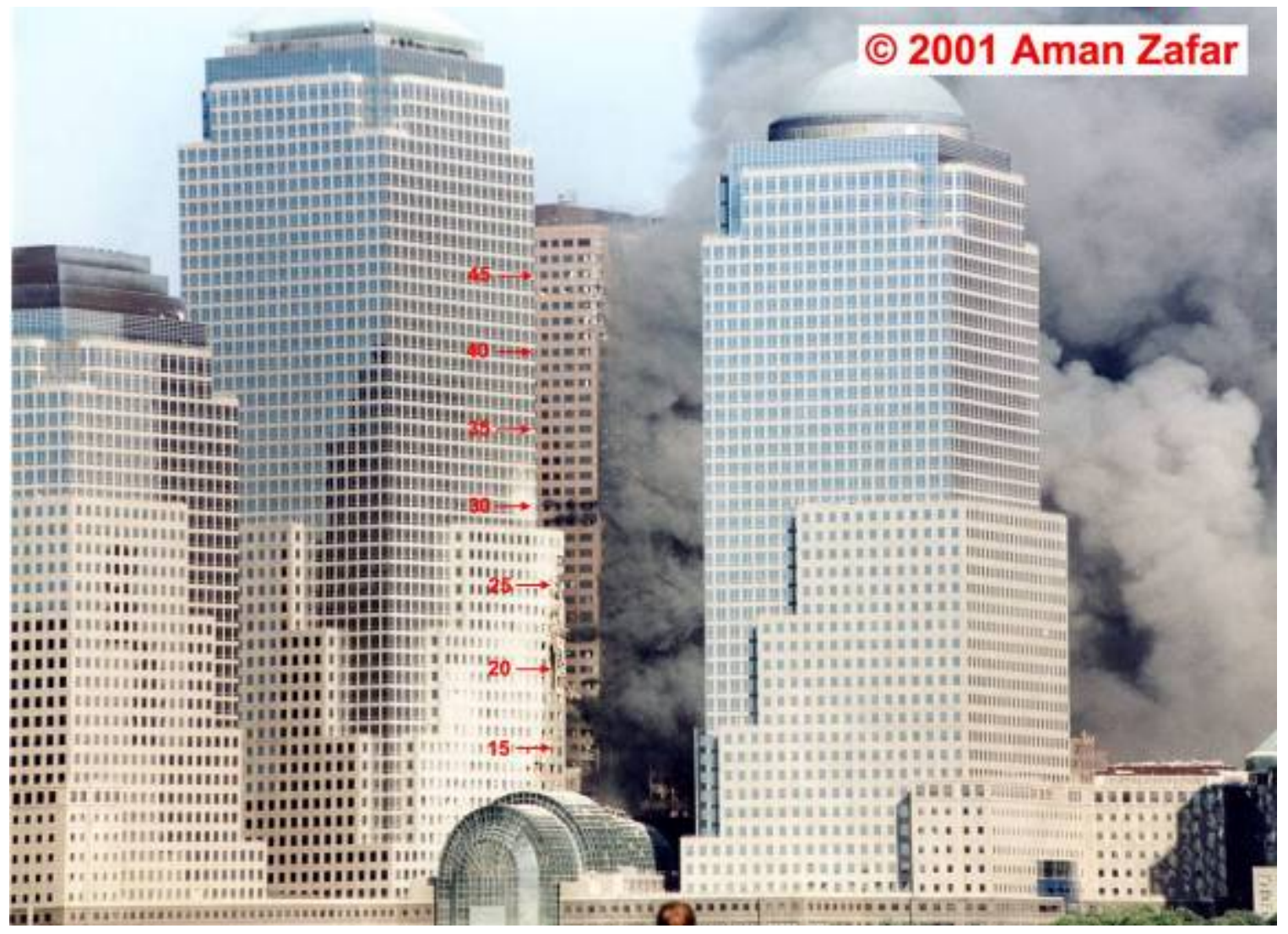

Figure 5-62. Photograph showing the southwest corner of WTC 7 in the early afternoon.

The buildings visible on the right and left are World Financial Center 2 and World Financial Center 3, respectively. The structure in the foreground is the Winter Garden. The base of WTC 7 is also hidden by WTC 6 . Numbers and arrows indicate WTC 7 floors.

Figure 5-63 shows an enlargement of the region of the lower floors of WTC 7 from Figure 5-62. Floor locations and certain features have been noted. This image of the building reveals considerable detail about the condition of the building at the southwest corner. Consider the feature marked "Debris." It appears to be an object on the $12^{\text {th }}$ floor spandrel. A similar feature is visible on the $12^{\text {th }}$ floor spandrel, just to the left of Column 20 in Figure 5-49. Four equally spaced sets of columns are easily identified to the immediate right of the debris in Figure 5-63. If the rightmost of these is identified as Column 20, there should be space for Column 16 to Column 19 between this column and the west edge of the face. By simply drawing lines along the corner of the building and along the visible columns in Figure 5-62, it 
was possible to confirm that the spacing visible between the building edge and the first column to the right of the debris was consistent with its assignment as Column 20.

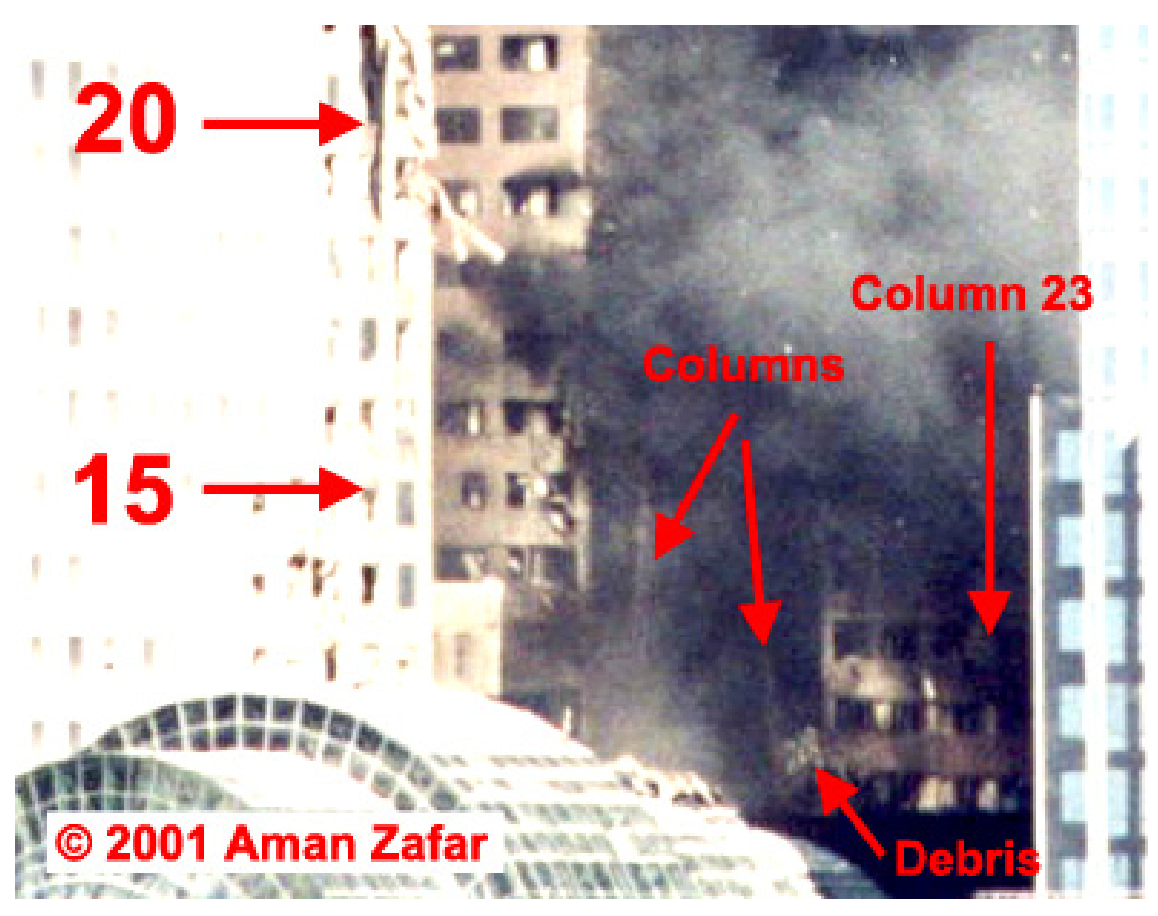

Figure 5-63.

Enlargement of the lower part of the southwest corner of WTC 7 from Figure 5-62, with certain features identified.

The intensity levels have been adjusted.

In Figure 5-49, the area to the immediate right of Column 20 on the $11^{\text {th }}$ and $12^{\text {th }}$ floors appeared dark, as if it was an opening, while the higher floors were hidden by smoke. However, it is clear from Figure 563 that the columns between Column 20 and Column 23 were intact on the $11^{\text {th }}$ through $14^{\text {th }}$ floors, along with the spandrel beams and at least part of the granite cladding on the $12^{\text {th }}$ through $14^{\text {th }}$ floors. In Figure 5-49, the granite cladding appears to be damaged below the $13^{\text {th }}$ floor near Column 23.

In Figure 5-63, the area between corner Column 15 and Column 20 appears to be open over the $11^{\text {th }}$ floor to the $15^{\text {th }}$ floor. Closer inspection reveals what appear to be two columns (marked with arrows) in the opening. They are located near the positions expected for Columns 16 and 19. These columns are not parallel to the building edge or Columns 20 to 23. The top of the visible section of Column 19 is bent inward toward the west, and the bottom of Column 16 is bent in the same direction. In Figure 5-49, there is a straight edge visible near the expected location for Column 19 on Floors 9 and 10 that appears to have been pushed towards Column 20. There are no signs of Columns 17 or 18 in Figure 5-63.

\section{Damage to the Southwest Corner}

Evidence shows that there was extensive structural damage to the southwest corner of the building, and in particular the corner Column 15, from the $17^{\text {th }}$ floor down to the $7^{\text {th }}$ floor. The indications of damage on the southwest corner of WTC 7 in Figure 5-63 are more clearly seen in the following figures.

Figure 5-64 shows a photograph of WTC 7 shot from a helicopter between 2:15 p.m. and 2:45 p.m.

Damage is visible low on the southwest corner of the building. This area has been enlarged in Figure 5-65, and arrows and numbers have been added that identify the floors corresponding to given rows of windows. 

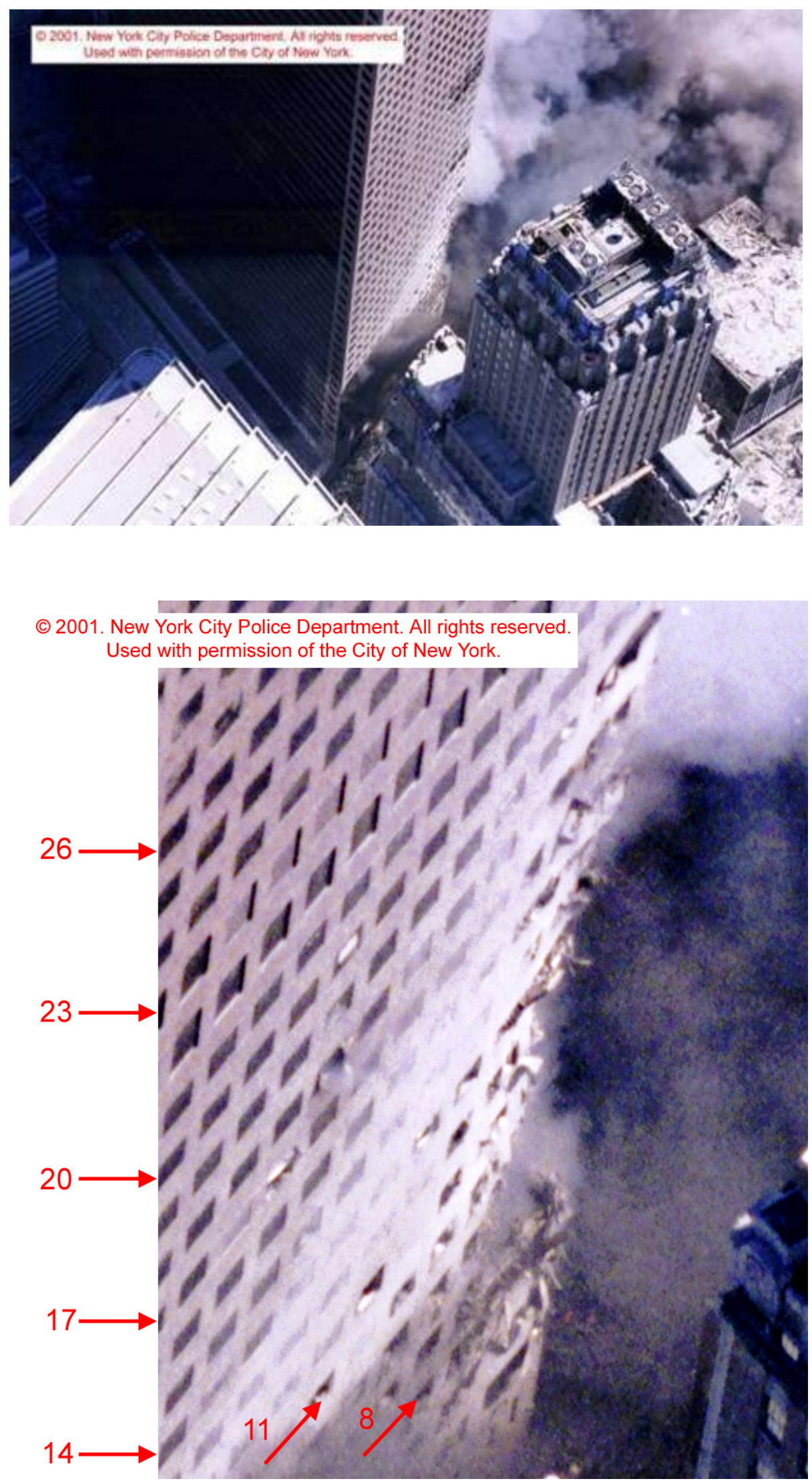

Figure 5-64.

Photograph showing the north and west faces of WTC 7, shot from a helicopter between 2:15 p.m. and 2:45 p.m.

Figure 5-65.

Enlargement of an area from the photograph in Figure 5-64 showing part of the west face of WTC 7.

The image intensity has been adjusted, and arrows and floor numbers have been added for the corresponding rows of windows. 
The image shows considerable damage to the southwest corner, starting at the $17^{\text {th }}$ floor and extending downward to at least the $8^{\text {th }}$ floor. Below the $17^{\text {th }}$ floor, the corner of the building appears to be missing. At a minimum, the granite cladding and its supports have been removed. Figure 5-66 shows a photograph taken at 12:48 p.m. from West Street showing the same area of WTC 7 and an enlargement of the southwest corner. In this image, it is clear that the corner granite has been removed, and it appears that the corner Column 15 (Figure 5-20 and Figure 5-26) has been exposed, but is still in place down to the $12^{\text {th }}$ floor. This column was located just behind the southwest corner. The dull color of the steel indicates that its insulation had been stripped away.
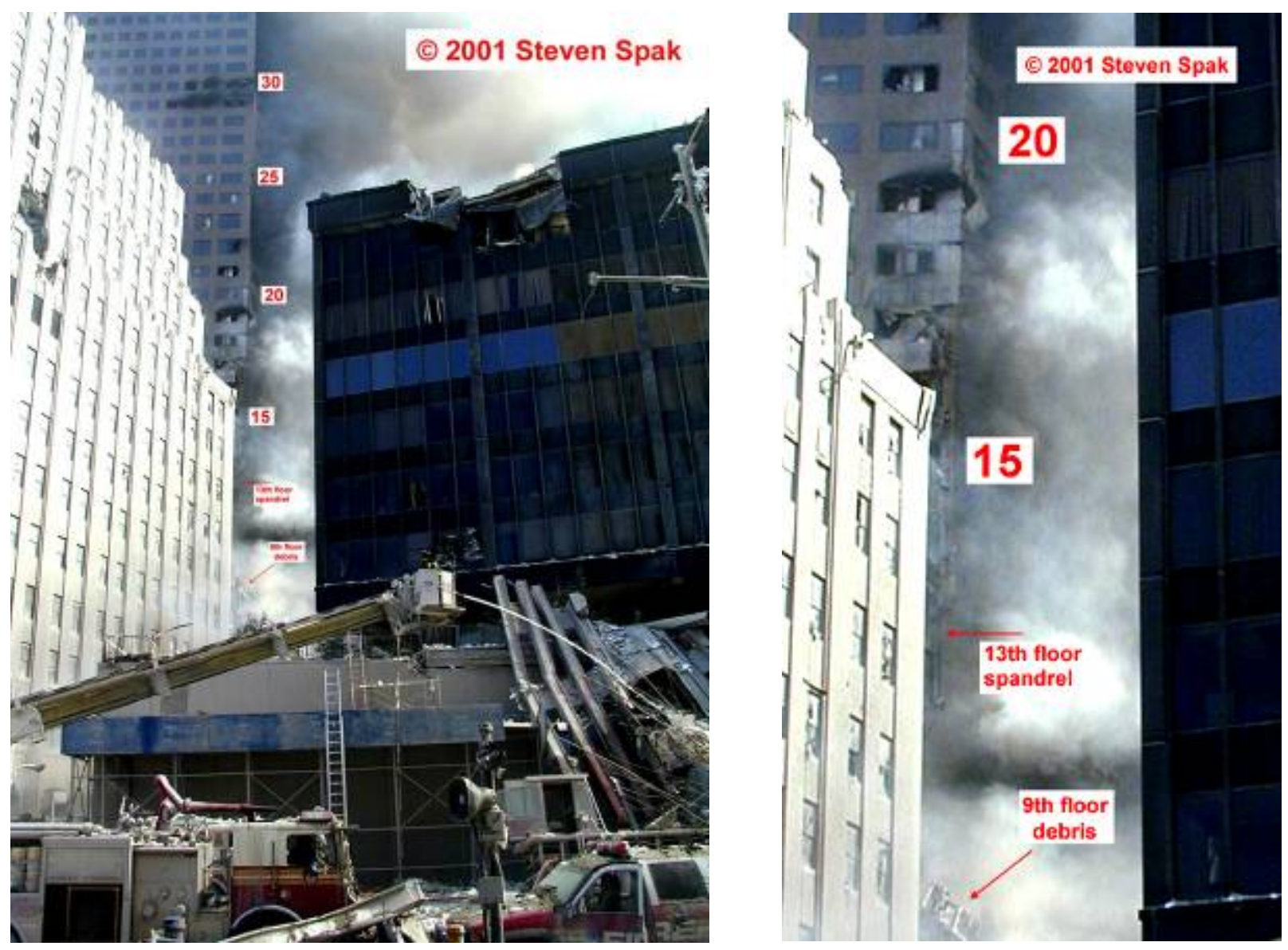

Figure 5-66. Photographs showing the southwest corner of WTC 7, shot from West Street at 12:47:40 p.m.

The intensity levels have been adjusted, and floor labels have been added. The area of the corner is enlarged on the right.

A second aerial photograph (Figure 5-67) provides a partial view of the damaged area from a closer location and a less oblique angle than those in Figure 5-64 and Figure 5-65. The damaged area from this photograph is enlarged in Figure 5-68 with floor numbers indicated. In this image, the end of the horizontal member at the base of the $17^{\text {th }}$ floor windows can be seen clearly, and there is no indication that Column 15 is attached to it.

In Figure 5-65, it can be seen that damage to the corner of the $14^{\text {th }}$ floor extends further along the west wall than on higher floors. It is clear in Figure 5-68 that the corner at this floor had been pushed inward, 
and that there was considerable façade damage. The aerial views in Figure 5-65 and Figure 5-68 suggest that there was substantial damage between Column 14 and the south edge on the $13^{\text {th }}$ floor. There is no sign of corner Column 15 in these images. Although this column appears to be present in ground shots shown in Figure 5-63 and Figure 5-66, it was likely displaced.

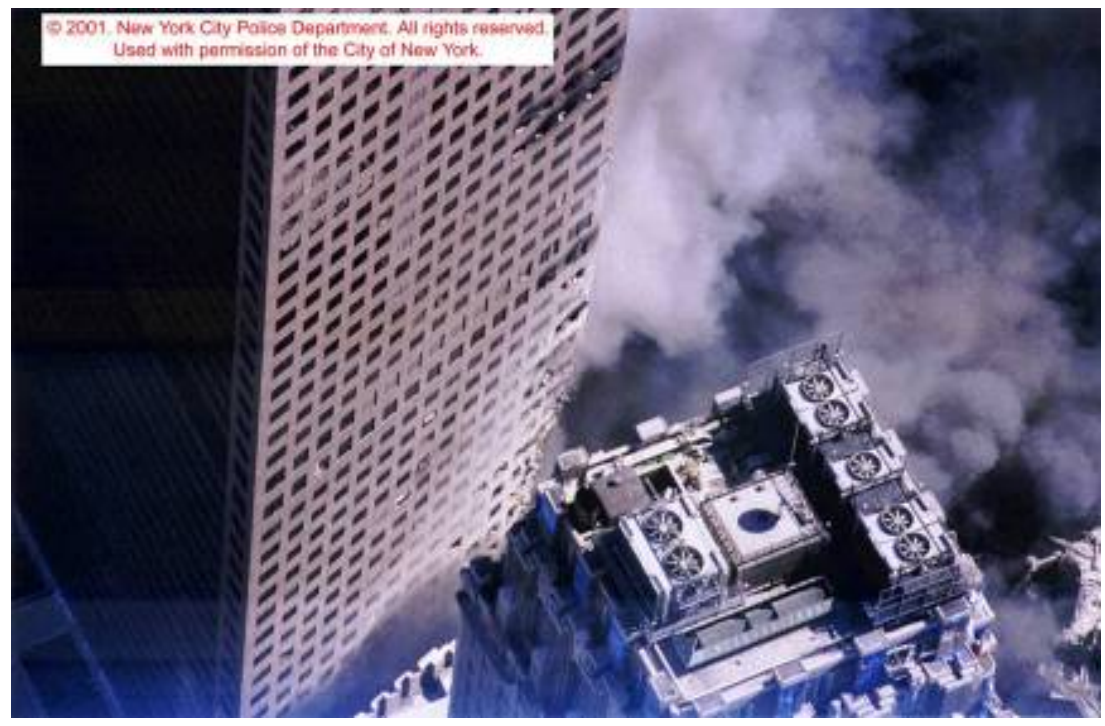

Figure 5-67. Photograph showing the north and west faces of WTC 7, shot from a helicopter between 2:30 p.m. and 3:00 p.m.

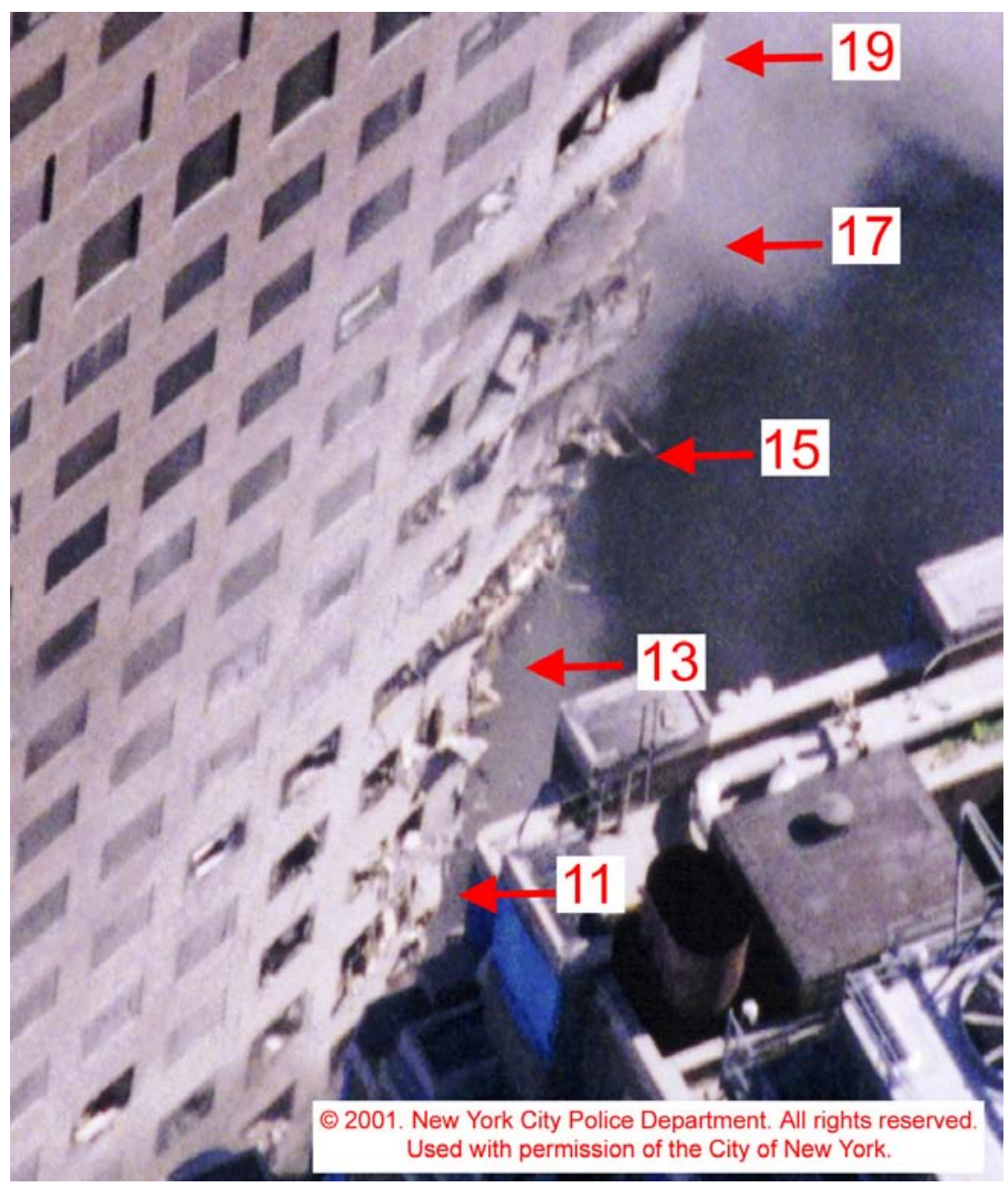

Figure 5-68. Enlargement of an area from the photograph in Figure 5-67 showing part of the west face of WTC 7.

Arrows and floor numbers have been added for the corresponding rows of windows. 
In Figure 5-66, the southwest corner is not visible below the $13^{\text {th }}$ floor. In Figure 5-65, the corner column certainly appears to be absent from the $12^{\text {th }}$ floor down to the $9^{\text {th }}$ floor. Closer inspection of this image provides strong evidence that this is the case. The southwest corner area of WTC 7 from Figure 564 is enlarged further in Figure 5-69, and circles and arrows have been added indicating features discussed in the following paragraphs.

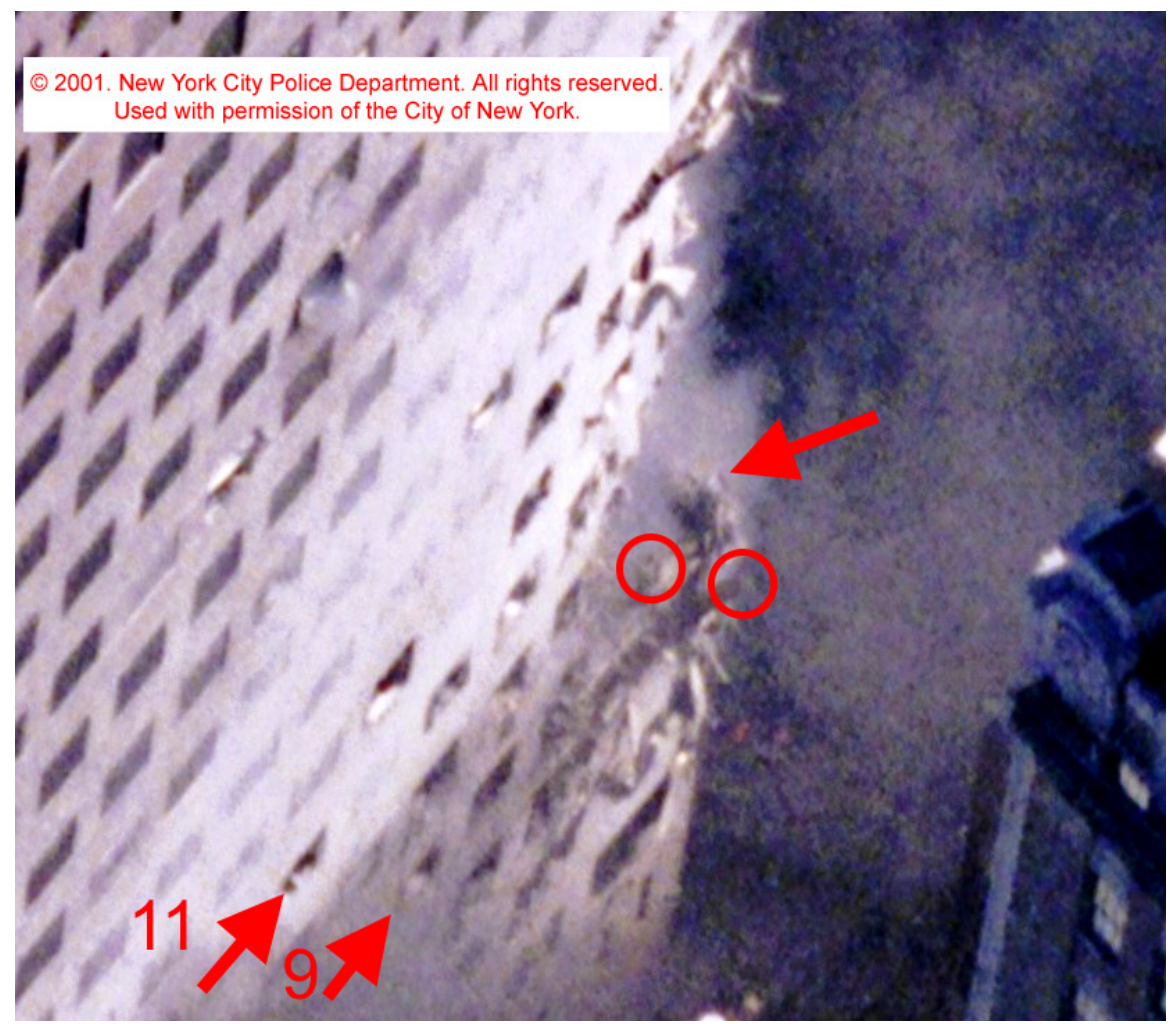

\section{Figure 5-69. Enlargement of an area from the photograph in Figure 5-64 showing the damaged southwest corner of WTC 7.}

The image intensity has been adjusted and arrows and floor numbers have been added for the corresponding rows of windows. The circles and arrow indicate features discussed in the text.

The circles and arrow in Figure 5-69 indicate features that appear to be the tops of columns, where the upper column sections have been dislodged or severed. Though barely resolved, it is possible to make out the flanges on the top and bottom of the wide flange spandrel steel beams that joined the columns on the $9^{\text {th }}$ floor. By comparing the depth of the horizontal structure on the $9^{\text {th }}$ floor with that on the floor immediately below, it is clear that its width was much narrower. This is because the depth of the exposed

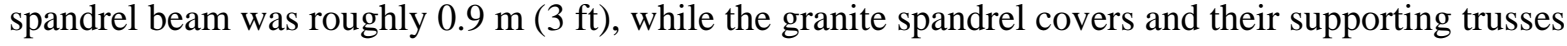
spanned $1.9 \mathrm{~m}$ (6 ft 2 in.).

The right circle in Figure 5-69 encloses the end of a column near the corner that appears to have been dislodged from the steel spandrel and pushed outward. The arrow in the image points to a third object near the corner that also appears to be a column that has been cut off. In this case, the column is located close to the corner, suggesting that it is corner Column 15. If correct, the spacings indicate that the two circled locations are Columns 14 and 14A. It was important to determine whether it was reasonable to have observed three severed columns at this location. The design drawings indicate that two story steel 
column sections were connected with bolted splices at the odd floors. The connections were $1.07 \mathrm{~m}$ ( $3 \mathrm{ft}$ 6 in.) above the floor. Failures could occur at splice connections, so the locations of the ends on Floor 9 for the three severed columns visible in the image are consistent with their expected locations.

The spandrel at the base of the $9^{\text {th }}$ floor, visible in Figure 5-69, appears to turn $90^{\circ}$ near the corner (right arrow) and to continue to the east for a short distance before abruptly terminating. This suggests that the spandrel beam on the $9^{\text {th }}$ floor on the south face was cut by the falling WTC 1 steel near the southwest corner. Strong visual evidence supporting this conclusion is available in Figure 5-47 (enlarged in Figure 5-49), Figure 5-50, and Figure 5-66. In each of these images, a short section of spandrel is visible at the southwest corner of the $9^{\text {th }}$ floor that appears to extend as far as the expected location for Column 16, before abruptly disappearing. The combined observations on the south and west faces confirm that structural damage was present in a band from Column 14 on the west face to Column 19 on the south face.

There is considerable damage to the façade on the $8^{\text {th }}$ floor. The misalignment of Column 14A certainly extends to this level. There seems to have been some damage to the corner of the building as low down as the $6^{\text {th }}$ and $7^{\text {th }}$ floors. For some reason, the window at the far end of the $6^{\text {th }}$ floor, which contained vents, stands out in Figure 5-69. It is likely that the vents were broken out.

\section{Damage to the East Side of the Promenade, Pedestrian Bridge, and East Sides of Floors 1 through 4 on the South Face}

Images of the lower floors on the south face of WTC 7 shot from the east side of the building are very limited. However, some photographers and videographers did manage to reach as far as the corner of Vesey and West Broadway. Figure 5-70 reproduces a black and white photograph that was shot from the intersection of Vesey Street and West Broadway looking west down Vesey Street. The entire length of the Pedestrian Bridge is visible, and it is clear that it was not collapsed by debris from the towers. Another view of the bridge following the collapse of WTC 1 was shown in Figure 5-19. While the bridge was covered with debris, the only substantial damage to its cover was on the southern side near the WTC passageway between WTC 5 and WTC 6.

The Promenade is visible behind the Pedestrian Bridge. There is a large pile of steel formed by several panel sections from WTC 1 located between the Pedestrian Bridge and the Promenade near the base of WTC 6 on the south side of the street. There appears to be either a part of or a single panel section located near the center of the street. There is also a single piece of large debris visible near the base of the Pedestrian Bridge that seems to be leaning against the south face. It is not clear if this is structural steel from the towers. These are the only indications of large steel pieces between the Promenade and the corner of West Broadway and Vesey Street. The large pieces of steel observed on Vesey Street from the west are beyond the view of this photograph.

An enlarged and enhanced section of Figure 5-70 showing the south face of WTC 7 is included in Figure 5-71. The debris deposited near the south face of WTC 7 is nearly one story high. Many columns can be discerned on the south face looking under the Pedestrian Bridge. The spacing and size of these columns indicate that these were part of the nonstructural system used to support glass and doors in the four story atrium area. (See Figure 5-15, Figure 5-16, Figure 5-36, and Figure 5-37.) The glass was apparently broken out between the columns based on the depth visible. It is also possible to discern some of the horizontal supports for the glass façade. Even though it is not possible to identify individual columns 


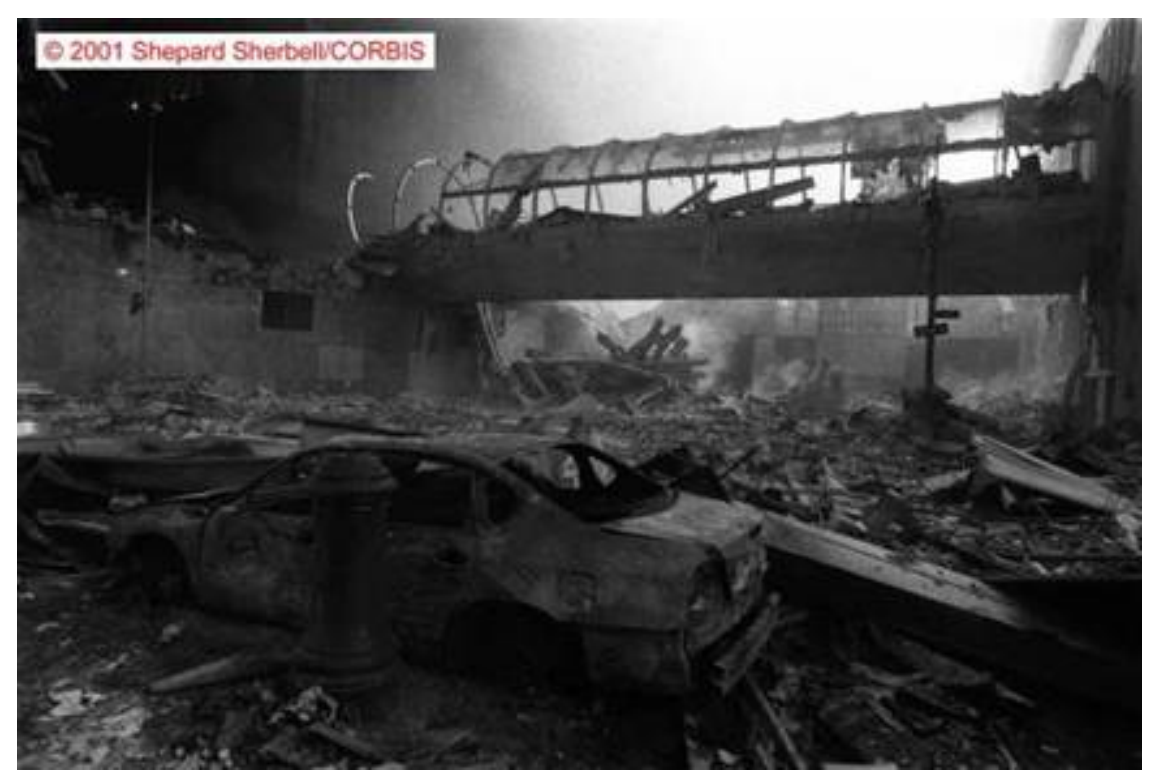

Figure 5-70. Black and white photograph shot from the corner of Vesey Street and West Broadway looking west down Vesey Street. The time of the photograph is unknown, but it was taken prior to the time when flames appeared on the east face of WTC 7 around 2:00 p.m.

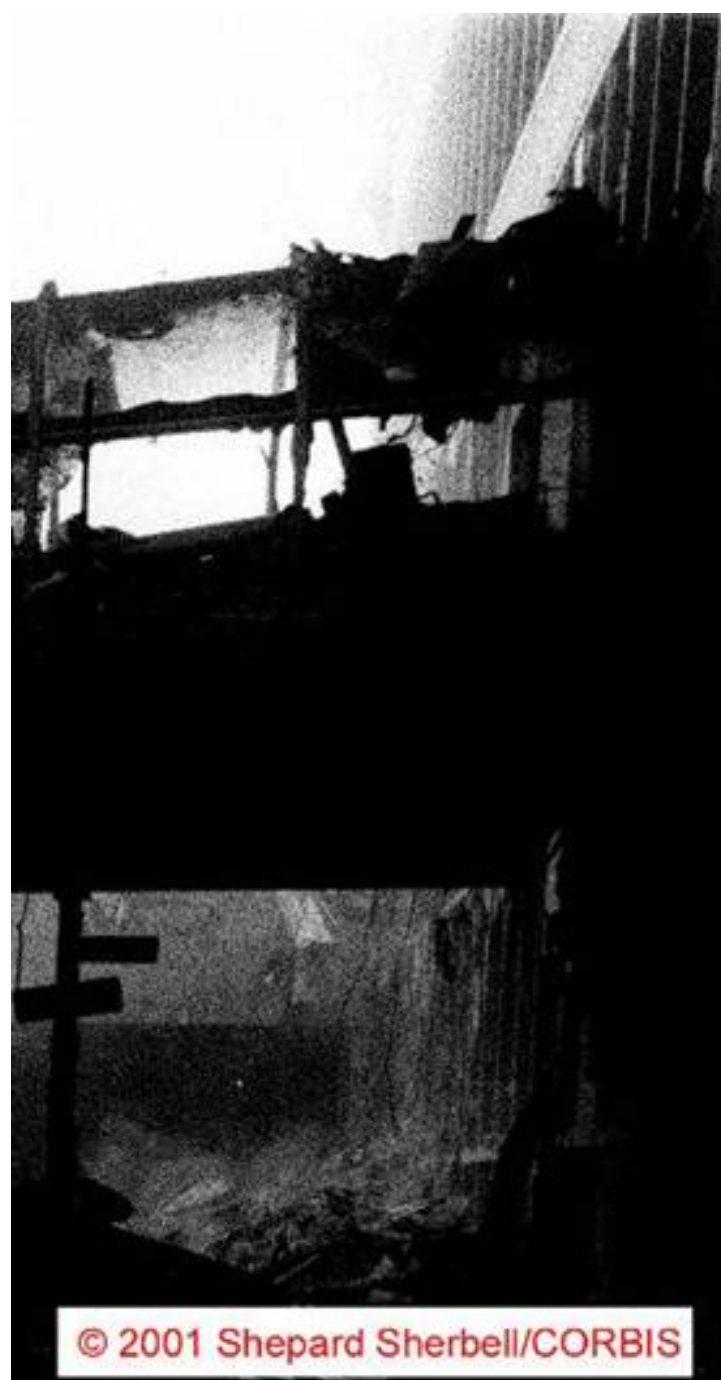

Figure 5-71. Enlargement of the photograph in Figure 5-70 showing the south face of WTC 7. The segment has been enhanced by adjusting the intensity levels. 
over the entire distance between the Pedestrian Bridge and the Promenade, there are no indications of large openings on the $1^{\text {st }}$ and $2^{\text {nd }}$ floors in this area.

On the right in Figure 5-71, at least 15 similar columns are visible at the level of and above the Pedestrian Bridge. A wide band is visible running horizontally across the face above the bridge. Based on the façade drawing for the south face in Figure 5-20 and photographs in Figure 5-15 and Figure 5-16, this band is the granite spandrel covers that separated the glass enclosed atrium from the louvers located on the $5^{\text {th }}$ and $6^{\text {th }}$ floors. As evident from the drawing and photograph, these louvers were supported by non structural columns that lined up with those in the lobby area. Columns are visible on either side of the Pedestrian Bridge below the granite spandrel cover indicating that the atrium glass support system was intact on the $3^{\text {rd }}$ and $4^{\text {th }}$ floors at these locations.

The area visible above the granite in Figure 5-71 starts just to the left of the Pedestrian Bridge and extends towards the west at least as far as the fifteenth support column from the east edge. As can be seen in Figure 5-20, these columns nearly span the distance from the east edge of the face to the Promenade. Structural steel Columns 23 to 28 were located on this section of the face (see Figure 5-20). Since these columns were located behind the glass and louver support systems, these observations indicate that there was likely no structural damage to these columns on the $1^{\text {st }}$ through $6^{\text {th }}$ floors.

A second view of Vesey Street and the Promenade taken from a short video clip is shown in Figure 5-72. The dark area at the top of the image is the bottom of the Pedestrian Bridge. In the unaltered left view, large amounts of smoke are visible on the far side of the Promenade. In the right view, the intensity levels have been adjusted to emphasize the darker areas in the image. A number of steel panel sections are visible on the left side of the street between the Pedestrian Bridge and the Promenade. It is also possible to see that several panel sections landed on or near the south end of the Promenade, and this end may be partially collapsed. The portion of a panel section near the center of the street is visible, but is not as easily identified as in Figure 5-70. A part of the large piece of debris observed earlier leaning up against the south face of WTC 7 is visible at the far right of the image. The size and shape of the object suggest that it was a steel column or beam. In all, the main portion of the east side of the Promenade, with the possible exception of the far south end, was not collapsed by the steel from WTC 1, although the raised side structures had suffered considerable damage.
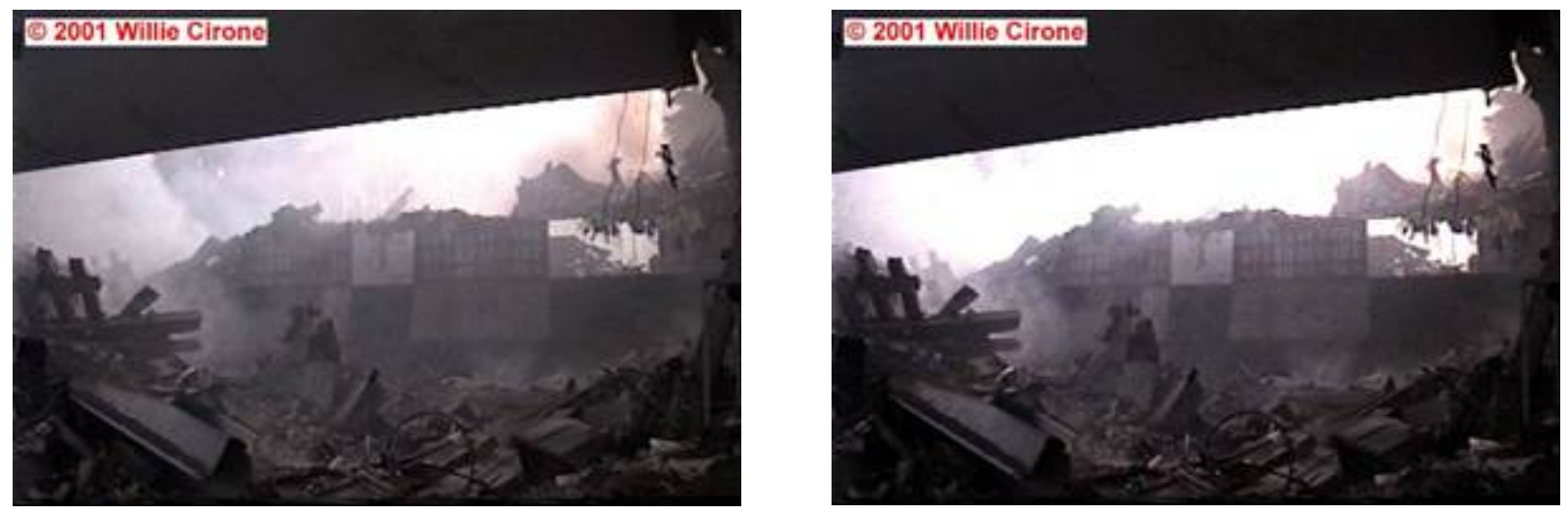

Figure 5-72. Two versions of a frame from a video taken from the corner of Vesey Street and West Broadway in the early afternoon.

Left: the frame as captured; Right: the image with intensities adjusted to emphasize the darker areas. 
The south face of WTC 7 was just beyond the right side of this image. Nonetheless, a pile of debris several stories high is visible rising above the Promenade at the right hand edge of Figure 5-72. Recall that there was evidence of debris in the same area from ground and aerial views taken from the west. The presence of this debris is consistent with the south face damage observed at higher floors at roughly the same location.

\section{Summary: Damage to the Lower 19 Floors}

The available visual evidence concerning damage inflicted on the lower floors of the south face of WTC 7 due to the collapses of WTC 2 and WTC 1 has been reviewed. While the evidence is fragmentary, it seems clear that portions of the western side of the south face were struck by substantial sections of steel from WTC 1 and that the structural framework of the building was damaged. The observations have been summarized in the color-coded damage map for the south face shown in Figure 5-73. This map is based on Figure 5-20 and shows the lower 19 floors.

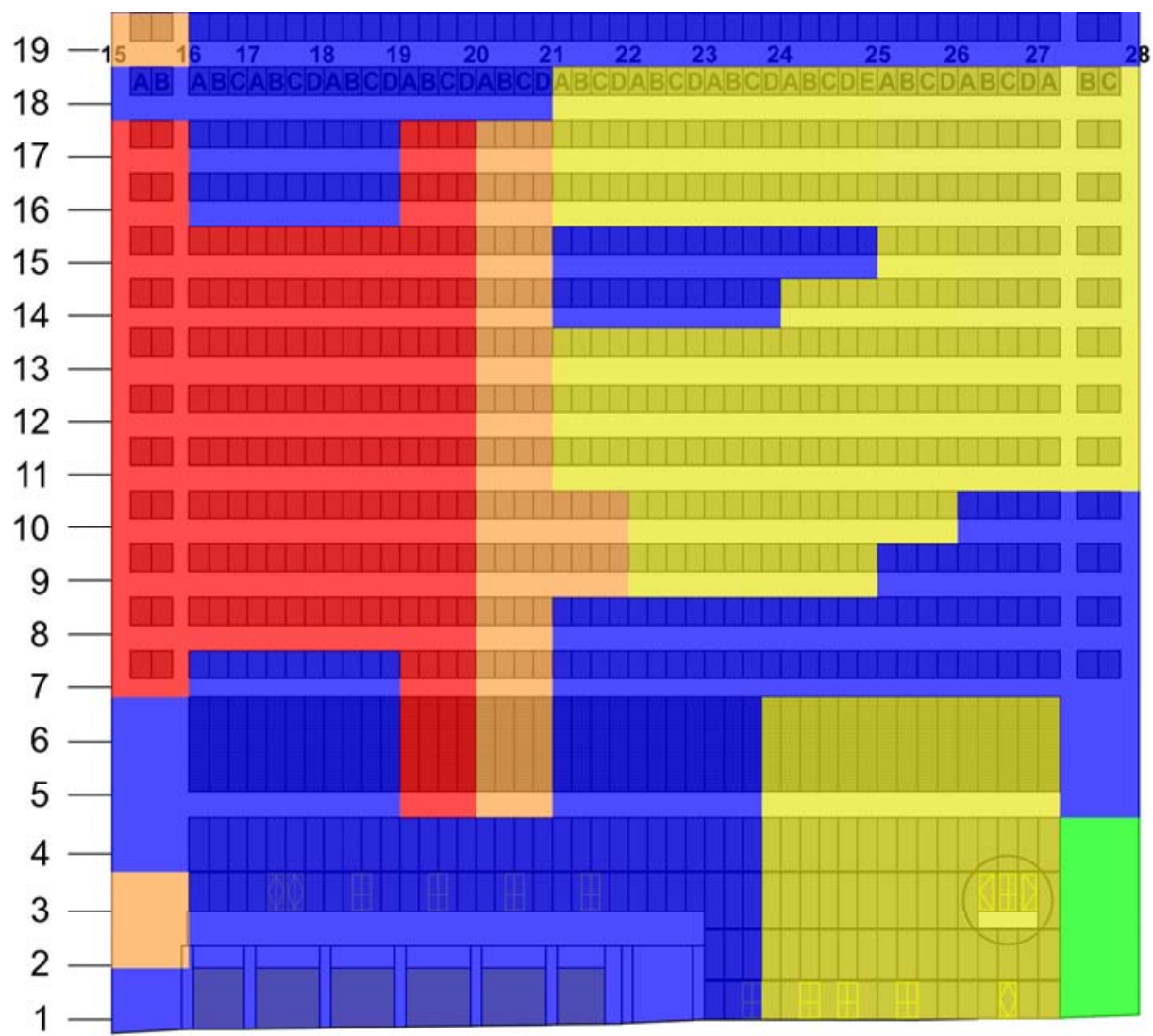

Figure 5-73. Summary of observed damage for the lower 19 floors on the south face of WTC 7 following the collapse of WTC 1.

Damage is color coded as follows: green ( $\square$ )-- no visible damage, yellow $(\square)$ - window glass broken out, orange $(\square)$ - granite and underlying truss damage, red $(\square)$ - damage to outer perimeter structural steel, and blue - ( $\mathbf{n})$ - not visible. 


\section{Damage above the $19^{\text {th }}$ Floor on the South Face}

Imagery reveals that portions of the south face above the $19^{\text {th }}$ floor were also struck by debris and damaged. These floors were generally hidden by smoke, but some areas were occasionally visible. The observations will be discussed starting at the roof and working downward. Figure 5-8 shows the roof and upper floors of WTC 7 prior to the collapse of WTC 1. Figure 5-9 is a view from a different angle, taken well after the collapse of WTC 1 . Close inspection reveals some damage to the parapet on the south side of the roofline.

A portion of Figure 5-9 is enlarged in Figure 5-74. Arrows indicate two damaged areas. The lower arrow points to damage on the parapet. Some debris is evident between the parapet and the south penthouse. The second arrow points to an area where the south screenwall connecting the east and west penthouses was damaged.

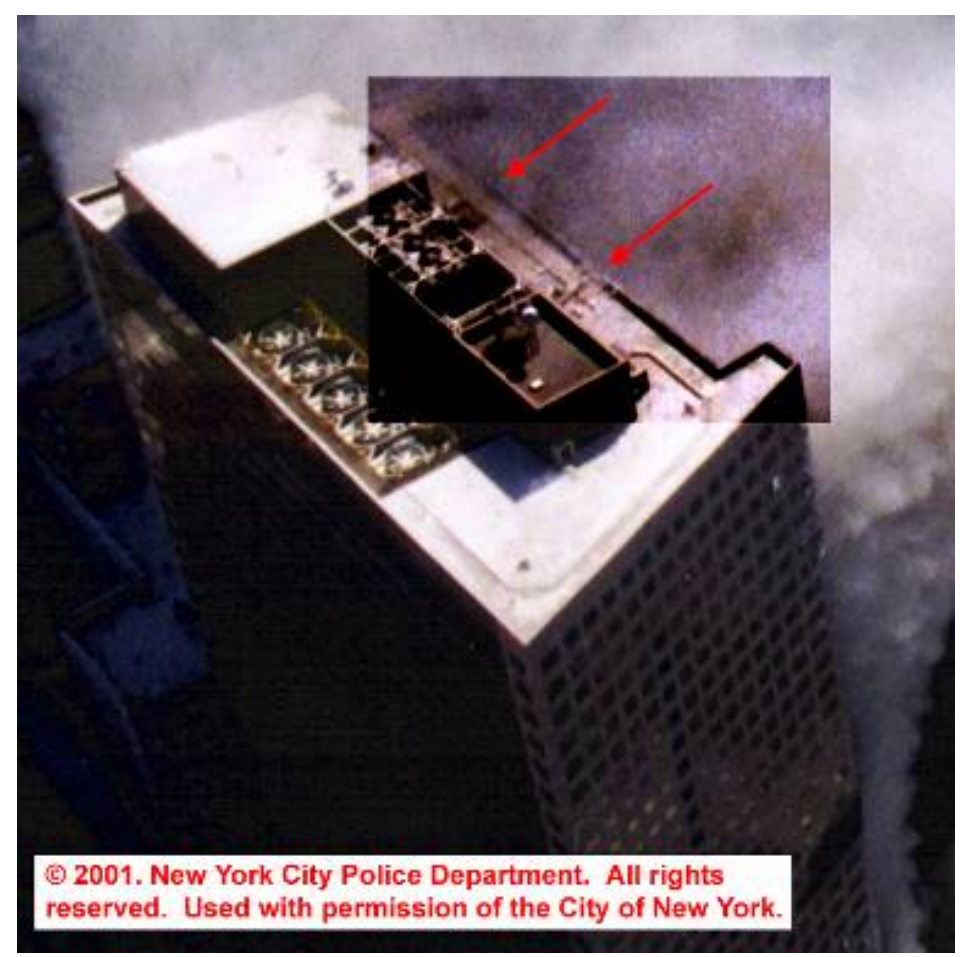

Figure 5-74. Cropped photograph, taken from a helicopter, showing the roof of WTC 7 from the northwest.

A damaged area on the south side has been enhanced by adjusting the intensity levels. Arrows indicate two areas of damage discussed in the text.

Another view of these two damaged areas, taken from a helicopter, is shown in Figure 5-75. The debris at the location between the south face parapet and the east edge of the west penthouse is better resolved. A large object is visible protruding from the roof. The damage to the south screenwall between the two penthouses seems to consist of displaced wall sections. There appears to be at least one column in the immediate vicinity. The damage indicates that substantial pieces of debris (mostly likely steel) struck the roof of WTC 7 on the south side.

Another view of the upper portion of WTC 7 is shown in Figure 5-76. This is roughly the same view as shown in Figure 5-8, which was taken just prior to the collapse of WTC 1. The two damaged areas on the roof are visible in the later photograph. The debris projecting from the roof appears to consist of at least two separate columns. This suggests that it was a part of a panel section from WTC 1. Comparison of the two photographs indicates that a substantial fraction of the screenwall near the east penthouse was dislodged. 

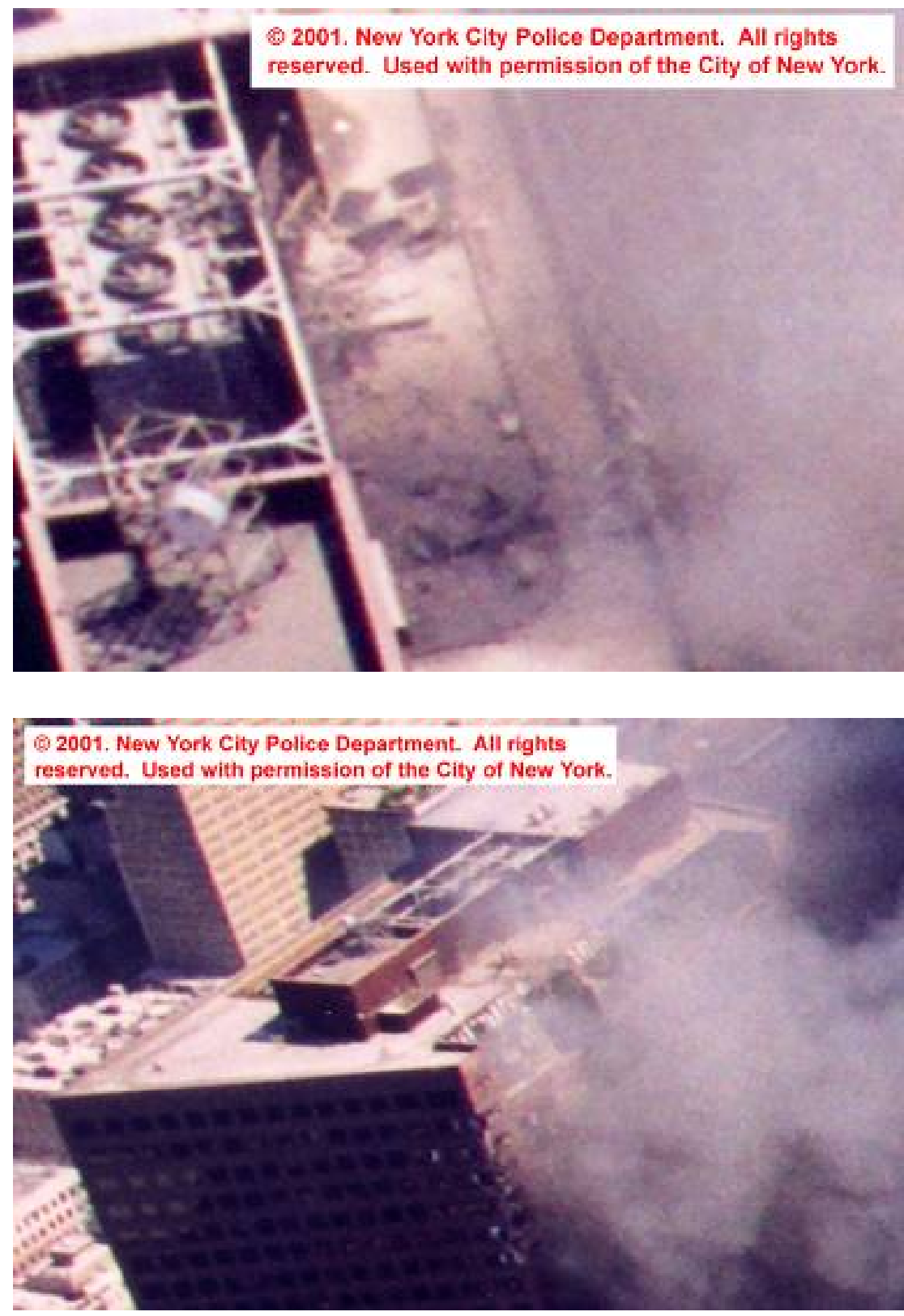

A large opening in the sloped curtain wall running between the $46^{\text {th }}$ and $47^{\text {th }}$ floors is apparent in Figure 5-76 immediately below the damaged area on the roof. Less damaged areas are also visible on either side of this opening. The damaged area has been enlarged in Figure 5-77.

A number of white rectangles are visible running along the upper edge of the face. This is in the area of the $4 \mathrm{ft}$ high parapet where sloped glass had been placed to create the effect of a top row of windows in front of the parapet, as can be seen in Figure 5-8. The different appearances of the area between Figure 5-8 and Figure 5-77 suggests that the glass was broken out during the collapse of WTC 1.

The recessed windows on the south face at Floors 46 and 47 allowed the exact locations and sizes of the damaged areas to be determined. The damage began at the $12^{\text {th }}$ window opening from the west and extended to the east for roughly eight windows. Based on Figure 5-20, the principal damage falls 


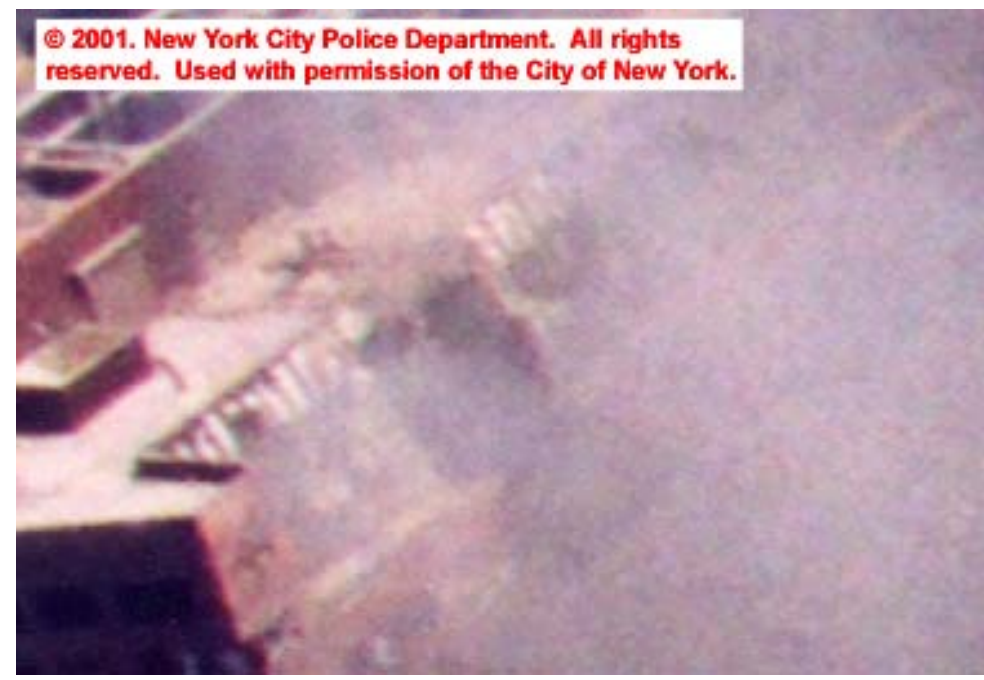

Figure 5-77. Enlargement of the area of damage on the roof and south sides of the $46^{\text {th }}$ and $47^{\text {th }}$ floors of WTC 7 in Figure 5-76.

between Column 19 and Column 21. Smaller openings in the curtain wall are evident at the $5^{\text {th }}$ and $6^{\text {th }}$ windows from the west and over a width of six windows just to the east of the largest opening. While it is clear that the curtain wall has been removed, it is not possible to discern whether or not structural damage occurred. It appears that the recessed concrete roofline at the base of the $46^{\text {th }}$ floor between Column 20 and Column 21 was cut through.

Another view of the damage near the top of the south face of WTC 7 is shown in Figure 5-78. The debris projecting from the roof and the damage to the south screen wall can be discerned. The large opening identified earlier on the $46^{\text {th }}$ and $47^{\text {th }}$ floors can be seen clearly along with columns and beams inside the hole. In this image, the opening extends at least as far down as the top of the $44^{\text {th }}$ floor. The south face

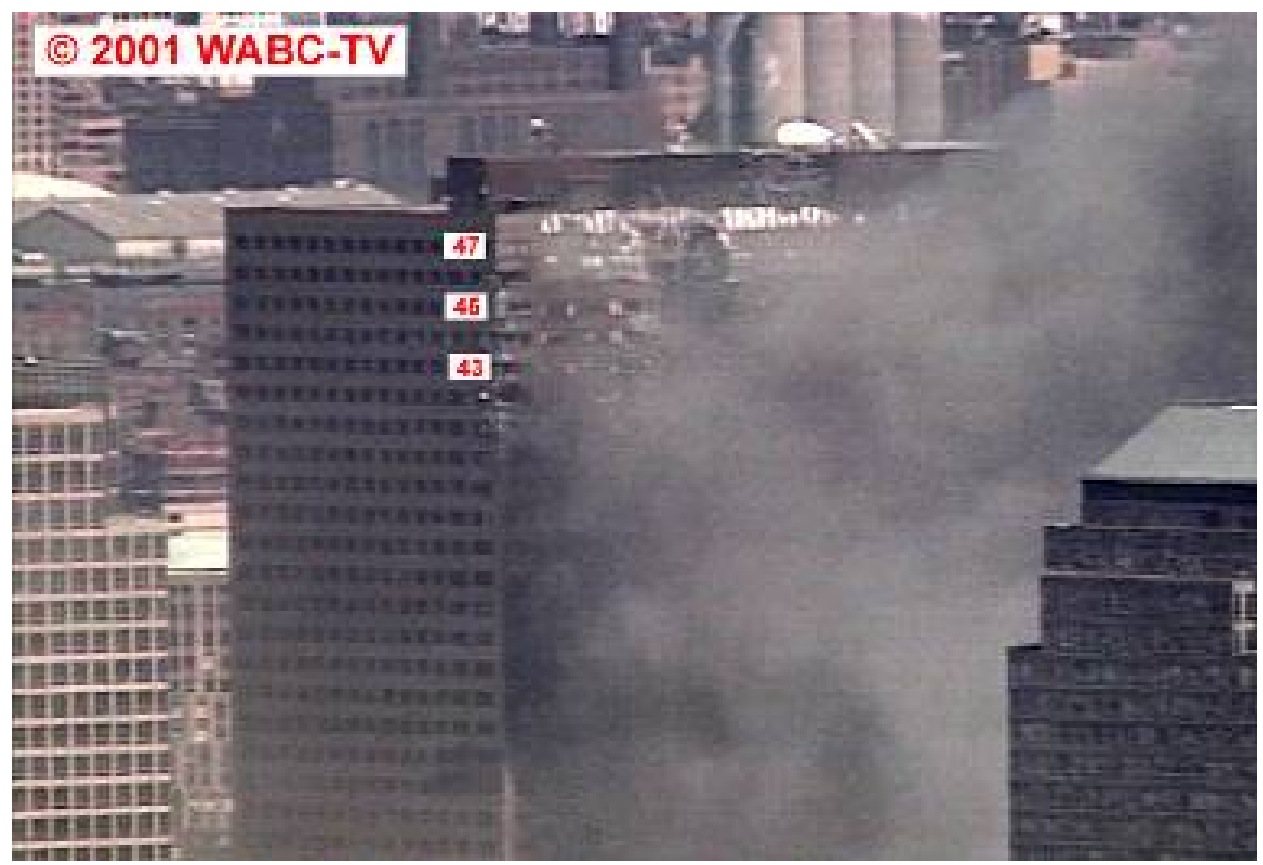

Figure 5-78. View of the south face of WTC 7 from a video shot from a helicopter located to the southwest of the WTC site, likely after 12:00 p.m. The intensity levels have been adjusted. 
below this point is obscured by smoke. Exterior Column 20 and the spandrel beams between this column and Columns 19 and 21 are not visible on the $45^{\text {th }}$ floor. On this basis, it was concluded that structural damage was present between Columns 19 and 21 on the $44^{\text {th }}$ through $47^{\text {th }}$ floors.

The space between the western edge of the face and Column 19 is visible for the $43^{\text {rd }}$ to $47^{\text {th }}$ floors. Some façade damage is visible on the corner (see discussion below) while elsewhere the façade seems to be intact, with the exception of the window glass that appears to have been broken over this area. A portion of the upper part of the south face is visible to the immediate right of the large damaged area. The glass appears to have been broken at numerous locations along the top row of windows, including the 11 openings to the immediate east of Column 21.

Figure 5-79 shows the upper west side of the south face of WTC 7 around 4:45 p.m. The façade damage on the southwest corner can be clearly seen on the $41^{\text {st }}$ to $47^{\text {th }}$ floors. The façade damage is particularly heavy on the $42^{\text {nd }}$ to $44^{\text {th }}$ floors. It appears that an object may have entered window $15 \mathrm{~A}$ on the $42^{\text {nd }}$ floor. The end of the box structure that supported the corner granite spandrel cover on the western edge of the face is visible on this floor. It is possible to discern the area between Columns 15 and 18 from the $34^{\text {th }}$ floor up to the top of the building. While the façade appears to be intact at locations away from the southwest corner, the four columns are visible on most floors, indicating the window glass was broken at most of these locations.

In a frame from a distant view of WTC 7 captured from a helicopter video (not shown) much of the south face was smoke free, and some details could be seen. In particular, it was possible to see the upper east side of the south face down to the $43^{\text {rd }}$ floor. While the alternating granite panel covers and windows could be identified, the columns were not visible. This suggests that this portion of the face was undamaged.

A large area on the west side of the south face was visible down to the $26^{\text {th }}$ floor. Columns were visible at many locations, indicating that most of the window glass in this area was broken. In the same frame it was possible to see a section of the south face from the $35^{\text {th }}$ floor to the $40^{\text {th }}$ floor, east of Column 19 , where it appeared that the spandrel covers on these floors abruptly stopped, and Column 19 was not visible on these floors. There was a dark band between the locations where the granite spandrel covers appeared to end and an area to the east that was hidden by a foreground building. It was not clear whether this vertical dark band was due to the presence of smoke or was a feature on the face of the building. As discussed further below, additional images suggest that the band was likely damage to the building.

Figure 5-80 shows a similar view of the south face taken from another video shot from a helicopter. Heavy smoke covers part of the face, but portions are visible elsewhere. The vertical dark band between Columns 19 and 20 is visible between the $34^{\text {th }}$ floor and $37^{\text {th }}$ floor. While Column 21 is visible on each of these floors to the immediate right of the dark band, it is not clear whether Columns 19 and 20 remain in place. The alternating granite panels and windows are visible further to the east. Columns are visible through a limited number of windows in this area.

The cropped photograph shown in Figure 5-81 provides a better view of the dark vertical band on the south face of WTC 7. It was taken from West Street at a location north of Liberty Street. The distinct vertical dark band can be seen from the $32^{\text {nd }}$ floor to the $40^{\text {th }}$ floor. Most of the columns between the band and southwest corner are easily distinguished and confirm that the band lies between Columns 19 and 20. It appears that both of these columns are in place on some of these floors, particularly Column 19 on the 


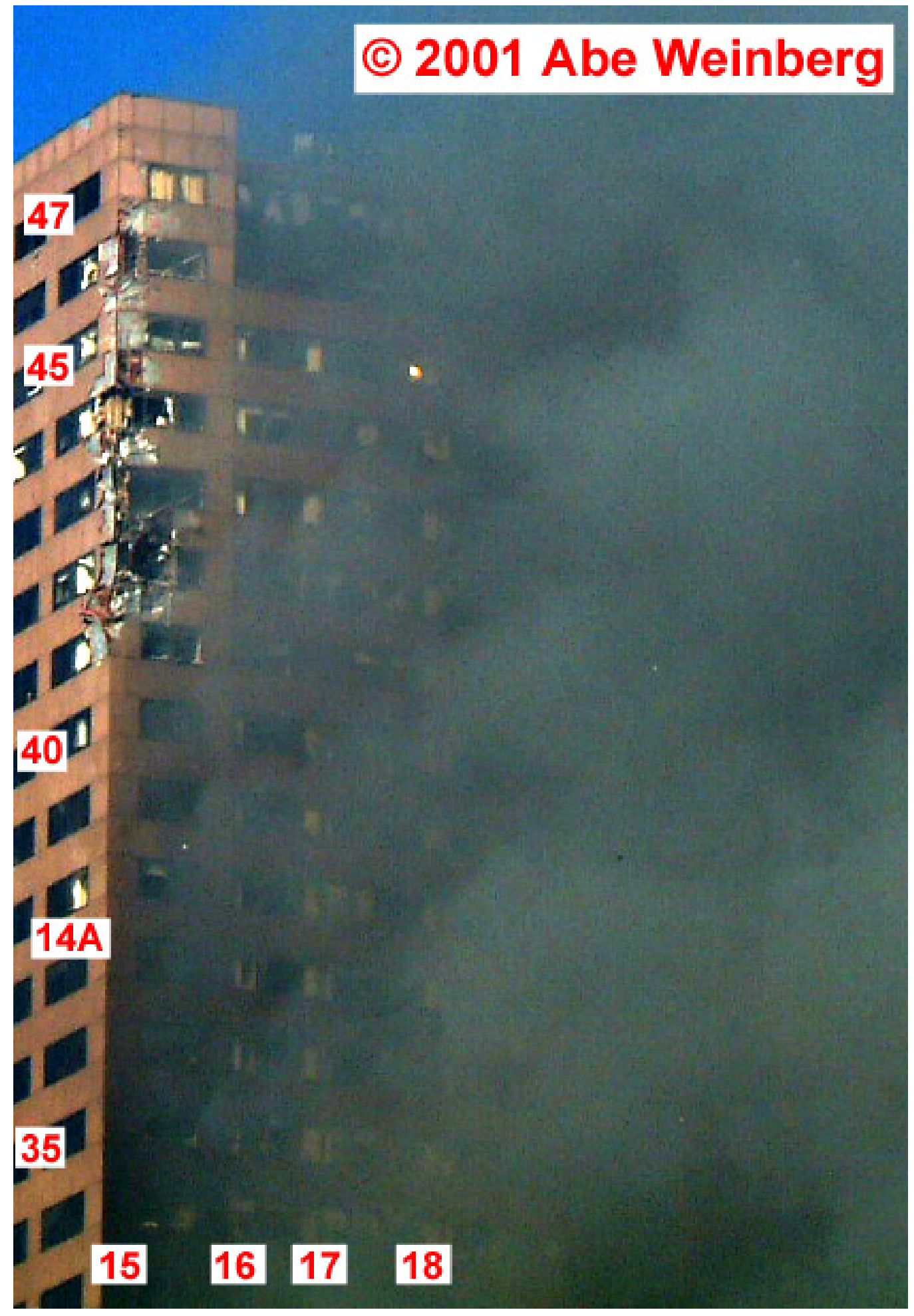

Figure 5-79. Cropped photograph showing the west side of the south face of WTC 7, taken between 4:30 p.m. and 5:00 p.m. from near the corner of West Street and Liberty Street.

The intensities have been adjusted and labels indicating floors have been added. 


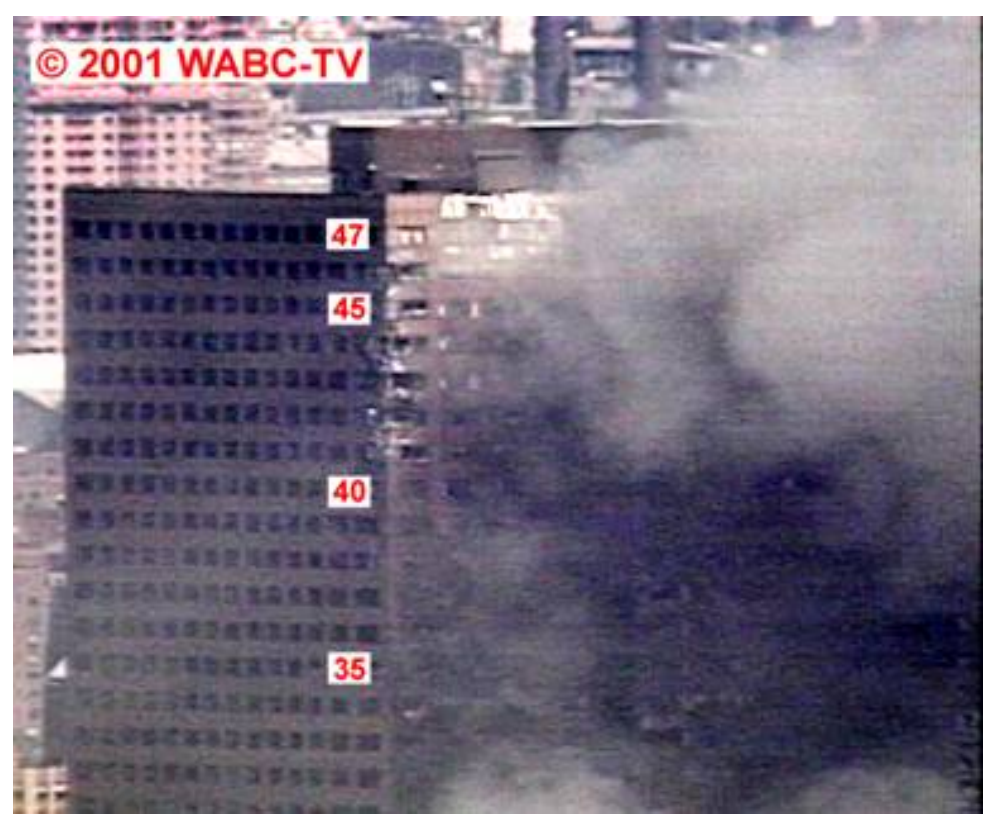

Figure 5-80. Cropped view of the south face of WTC 7 taken from a video shot from a helicopter hovering to the southwest of the WTC site around 1:00 p.m.

The intensity levels have been adjusted, and floor numbers have been added.

Figure 5-81. Cropped photograph showing the south face of WTC 7, shot from West Street in the mid to late afternoon.

The intensity levels and contrast have been adjusted, and floor numbers have been added.

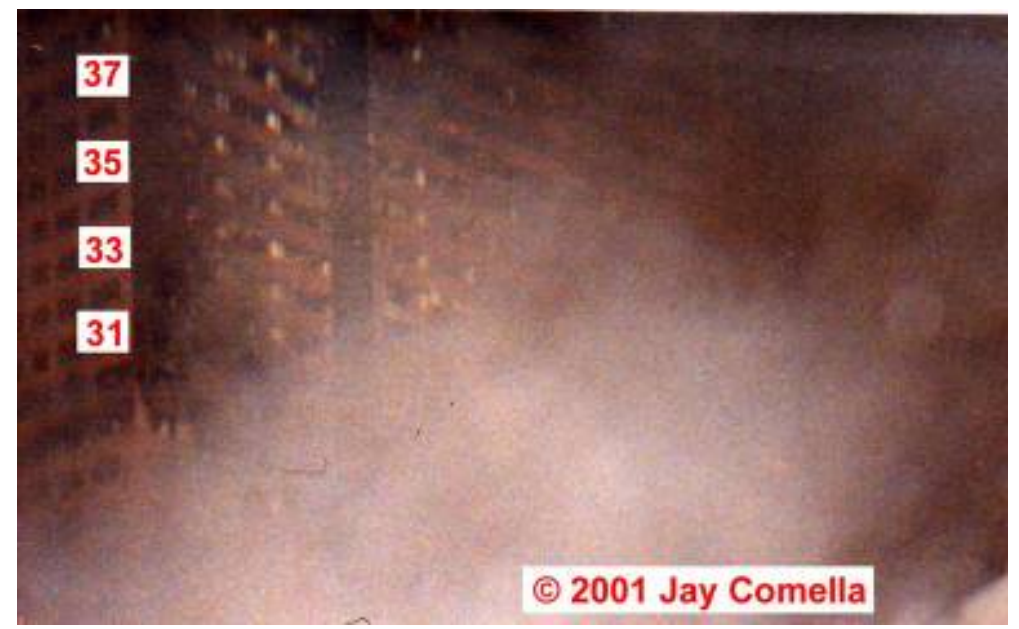

(ㄷ) 2001 Jay Comella

$33^{\text {rd }}$ and $34^{\text {th }}$ floors. At other locations, it is difficult to identify the columns on either side of the dark band. There is no visible indication that the granite spandrel covers are in place between Columns 19 and 20, even though the covers on either side are very distinct. Even though the granite spandrel cover between Columns 20 and 21 on the $34^{\text {th }}$ floor appears to be damaged, in general the granite panel covers seem to be in place to the east of the dark band.

Another aerial view of the south face is shown in Figure 5-82. The vertical dark band is visible extending down to at least the $24^{\text {th }}$ floor. A framework is visible to the immediate left on the $23^{\text {rd }}$ to $26^{\text {th }}$ floors between Columns 18 and 19. The spacings between columns are much wider than window openings seen on floors with intact façade, and the columns widths and spandrel heights are smaller. This indicates that the steel in this area has been exposed by removing the granite spandrel covers and their backing trusses.

The images discussed above, and additional images not reproduced here, were used to prepare the damage map shown in Figure 5-83 for the entire south face of WTC 7. The lower portion of this map was shown in Figure 5-73. The same color key has been used here, with the addition of gray to indicate the vertical 


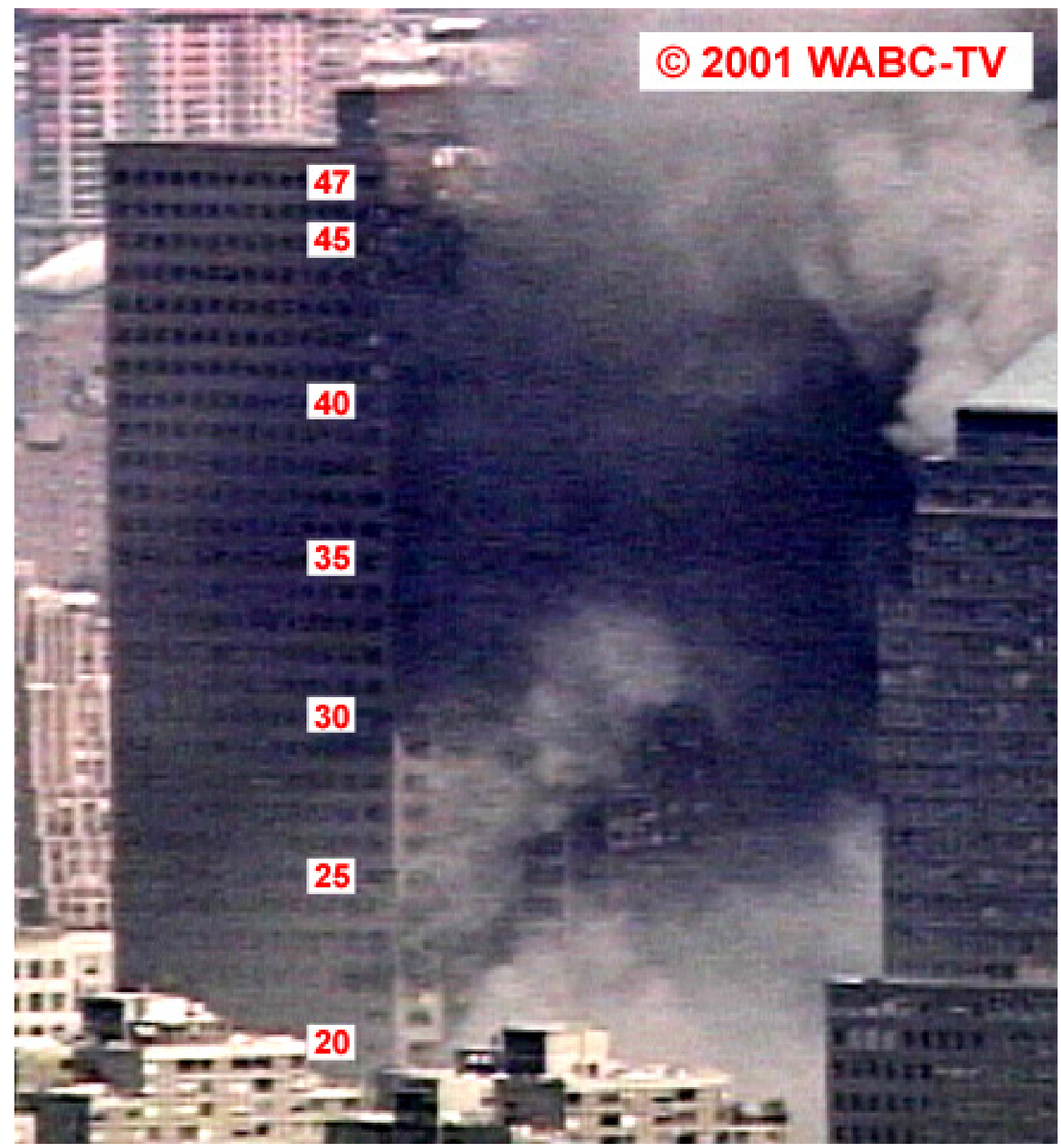

Figure 5-82. Cropped view of the south face of WTC 7 taken from a video shot from a helicopter hovering to the southwest of the WTC site around 1:00 p.m.

The intensity levels have been adjusted.

dark band on the upper floors. While it appears as if the vertical dark band between Columns 19 and 20 is damage to the building, and the location falls immediately below the opening at the top of the building (see Figure 5-76 to Figure 5-78), images with sufficient detail to confirm this have not been identified. It is also unclear if Columns 19 and 20 have been damaged or removed.

While the condition of a large fraction of the south face is characterized in Figure 5-83, large areas of blue are still present. Generally, these areas were hidden by smoke. A large fraction of this area is on the east side of the face. There is no visual evidence suggesting that significant structural or façade damage 
occurred at these locations. It was not possible to observe the area between Columns 19 and 20 on the $42^{\text {nd }}$ and $43^{\text {rd }}$ floors. This might have provided a better understanding of the link between the vertical dark band and the damage seen on higher floors. Significant damage was identified on the west side of the south face, particularly to the west of Column 21. It is possible that additional damage was hidden in the unobserved areas on this side of the face.

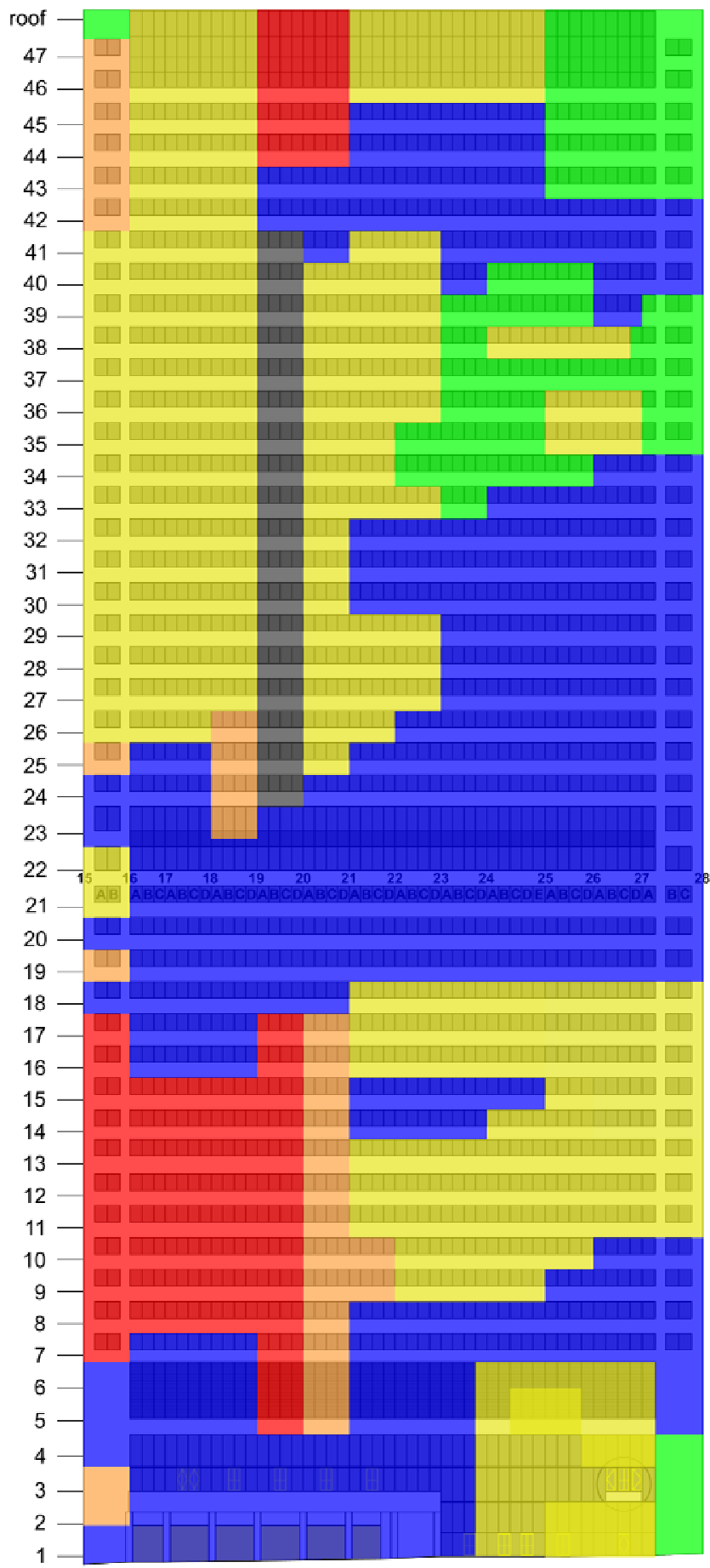

Figure 5-83. Observed damage on the south face of WTC 7 following the collapse of WTC 1.

Damage is color coded as follows: green ( $\square$ )-- no visible damage, yellow ( $)$ - window glass broken out, orange ( $\square$ ) - granite and underlying truss damage, red ( $\square$ ) - damage to outerperimeter structural steel, gray $(\square)-$ possible structural damage, and blue ( $\square$ ) - not visible. 


\section{Observed Damage to the West Face of WTC 7}

Not surprisingly, the major debris damage to WTC 7 was to the south face, which faced WTC 1. However, as can be seen in Figure 5-63 to Figure 5-69, Figure 5-79, and Figure 5-80, some façade damage and window breakage also occurred on the west face. Figure 5-84 shows the upper portion of the west face in a photograph taken from a helicopter. Floor and column locations are indicated. (See Figure 5-26 for column and window nomenclature.) Façade damage is visible on the southwest corner on Floors 40 through 46, and the glass for window 14A was broken on the many floors where Column 14A can be seen. With the exception of a few broken windows on the $44^{\text {th }}$ and $45^{\text {th }}$ floors, the remainder of the façade appears to have been intact on the $34^{\text {th }}$ through $47^{\text {th }}$ floors.

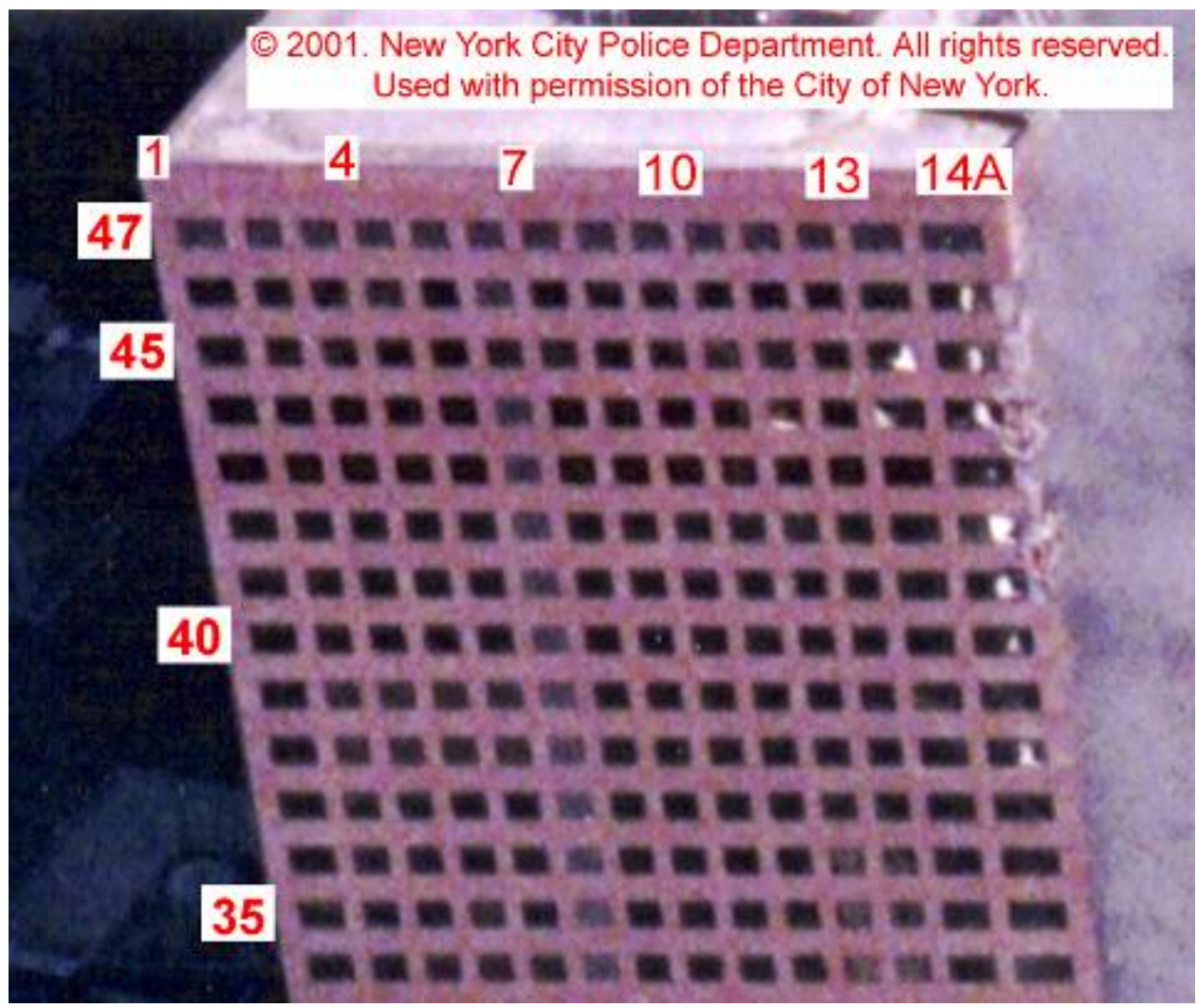

Figure 5-84. Cropped photograph showing the west face of WTC 7, taken from a helicopter around 3:00 p.m.

The intensity levels have been adjusted.

Another photograph showing the upper part of the west face of WTC 7 is reproduced in Figure 5-85. Generally, the damage visible on the $34^{\text {th }}$ to $47^{\text {th }}$ floors is consistent with that seen in Figure 5-84. One exception is window 11 on the $41^{\text {st }}$ floor. A small portion of the glass appears to be broken out in Figure 5-85, which is not evident in Figure 5-84. Most of the granite appears to be intact between the $23^{\text {rd }}$ and $33^{\text {rd }}$ floors, with only minor damage evident at the southwest corner at the base of the $26^{\text {th }}$ floor and on the $25^{\text {th }}$ floor. Glass is missing from windows $13 \mathrm{~A}, 13 \mathrm{~B}, 14 \mathrm{~A}$, and 15 on the $29^{\text {th }}$ and $30^{\text {th }}$ floors. As discussed below, fires were observed in these areas, which may have opened up these windows prior to the time when Figure 5-85 was taken. Elsewhere on these floors, glass is missing from isolated windows 31-5, 28-9, 27-14, 25-13B, 24-14A, 23-12, and 23-13B. 


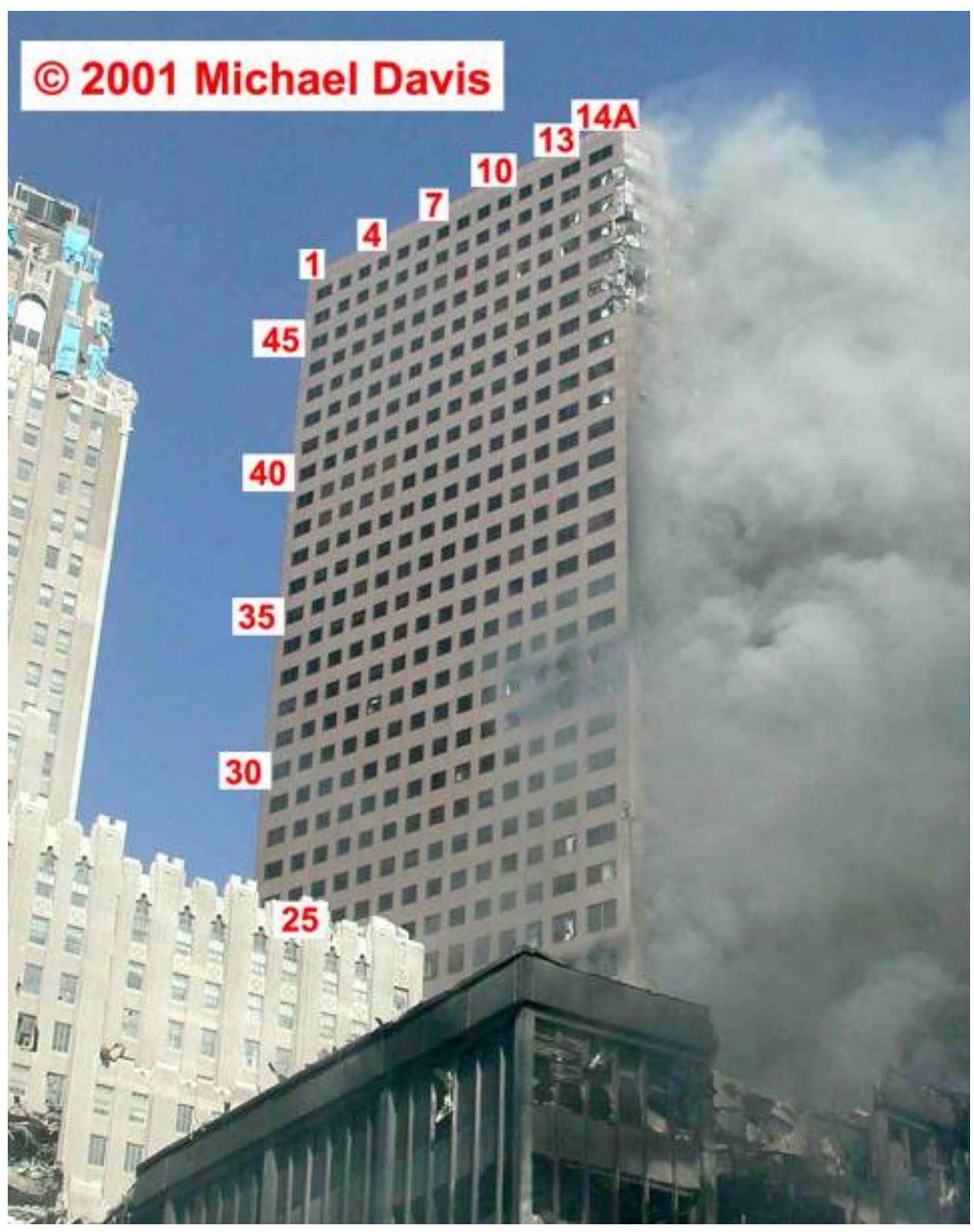

Figure 5-85. Cropped photograph showing the west face of WTC 7, taken shortly after 3:00 p.m. from West Street.

The intensity levels have been adjusted.

In a video taken shortly after 12:00 p.m. from West Street, the glass in windows 13A, 13B, 14, and 14A on the $30^{\text {th }}$ floor was intact. This means that the windows were opened later by the fire that grew on this floor. No complete early views of these windows on the $29^{\text {th }}$ floor were identified, but an aerial photograph taken at 10:41:52 a.m. showed that the glass in window 12 was intact at that time. The initial condition of the windows to the south on this floor could not be determined.

The area on the west face between the $23^{\text {rd }}$ floor and $11^{\text {th }}$ floor can be seen Figure 5-86, which was cropped from the aerial photograph shown in Figure 5-67. The damaged southwest corner starting at the $17^{\text {th }}$ floor will be discussed further below. 


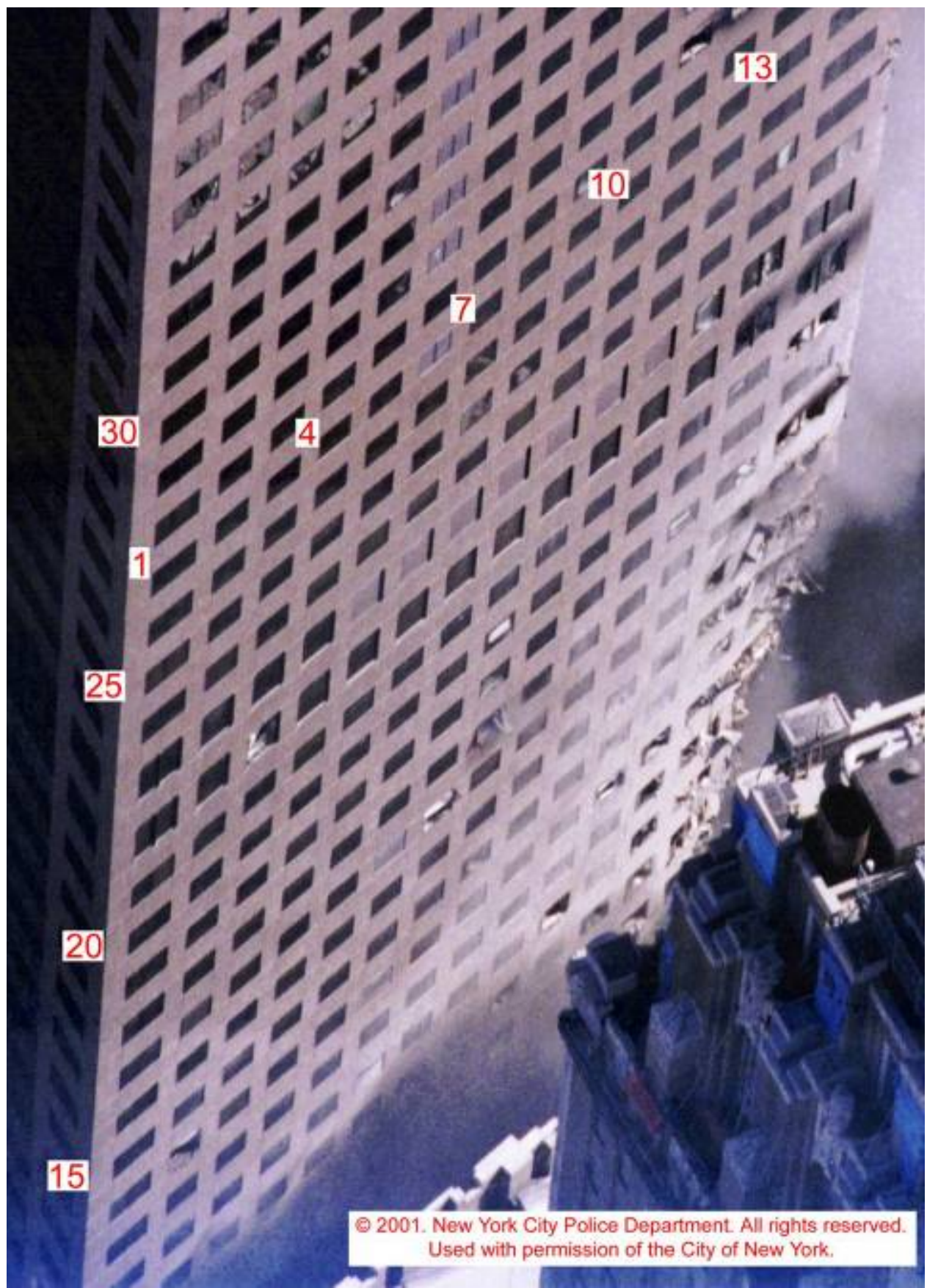

Figure 5-86. Image, cropped from Figure 5-67, showing the west face of WTC 7, shot from a helicopter between 2:30 p.m. and 3:00 p.m.

Column and floor numbers have been added.

There is no façade damage apparent on the $19^{\text {th }}$ to $22^{\text {nd }}$ floors, but glass or louvers are broken or missing in multiple windows. On the $22^{\text {nd }}$ floor, glass is missing from window 3 and from the four windows near the south edge, where a fire had evidently been present earlier. The earliest photograph of this region in the NIST database was taken just before 12:30 p.m. It shows a fire in window 22-14A, but the window glass further to the north was intact on this floor. The initial condition for window 22-14A is assigned as unknown. The following windows were open or damaged: 21-13A, 21-14, 21-14A, 20-8, 20-14A, 19-8, 
19-12, and 19-13B to 19-14A. There are indications that a fire burned in windows 19-14 and 19-14A. Since the window glass immediately below and to the left was broken, it is considered likely that the glass in the two windows closest to the south edge was also broken during the collapse of WTC 1 . There appears to be minor façade damage immediately below windows 14 and $14 \mathrm{~A}$ on the $18^{\text {th }}$ floor, which are open. This damage is also visible in Figure 5-66. Windows 18-8 and 18-13B were also broken.

As discussed with regard to the south face, significant damage to the southwest corner of WTC 7 appeared on the $17^{\text {th }}$ floor and extended downward. Figure 5-68 shows an enlargement of this area. There appears to be some damage to the façade extending north at least as far as window 13B. The glass in windows $17-7$ and $17-13 \mathrm{~A}$ is missing. On the $16^{\text {th }}$ floor, the structural and façade damage appear to extend to Column 14, and windows 12 to $13 \mathrm{~B}$ are either broken or missing. The structural damage on the $15^{\text {th }}$ floor also reaches as far as Column 14, and windows 15-8, 15-11, 15-12, and 15-13B are broken.

On the $14^{\text {th }}$ floor, the structural damage extended further toward the north, reaching at least Column 14, and there appears to be façade damage to Column 13. Glass in windows 14-2, 14-11, and 14-12 was broken. The damage at the southwest corner of the $13^{\text {th }}$ floor was similar to that on the $14^{\text {th }}$ floor. The glass in window 13-11 was cracked, and the glass was broken in window $13-12$. On the $12^{\text {th }}$ floor, the structural damage also appears to reach as far as Column 14, with façade damage as far as Column 13. Windows $12-10$ and 12-12 were broken. On the $11^{\text {th }}$ floor, the structural damage at the southwest corner extended beyond Column 14, and the façade damage seemed to extend to Column 13. All of the windows on the $11^{\text {th }}$ floor cannot be seen clearly in Figure 5-86, but it is clear that the glass in windows 11-9, 1111, and 11-12 was broken.

Figure 5-69 provides a close-up view of the damage to the southwest corner below the $11^{\text {th }}$ floor. On Floors 8 through 10, this damage extended beyond Column 14, with Columns 14, 14A, and 15 clearly severed above the $9^{\text {th }}$ floor. Façade damage reached at least as far as Column 13 . The extent of damage on the $7^{\text {th }}$ floor is unclear, but it does appear that at a minimum façade damage reached as far as Column 13. In Figure 5-69, broken glass is visible in windows $10-10$ to $10-13,9-10$ to $9-13,8-12$ to $8-13$, and 7-12 to $7-13$.

Figure 5-87 shows the lower portion of the WTC 7 west face from the corner of Barclay Street and Washington Street, looking south down Washington Street sometime around or prior to 12 p.m. Figure 5-25 was taken from roughly the same location. A great deal of debris is evident on Washington Street. In particular, a steel panel section can be seen embedded in the ground near the southwest corner of WTC 7. This panel section was also visible in the aerial photograph reproduced in Figure 5-61. There is another panel section lying on its side in the street near the Verizon Building. Additional steel can be seen piled up on Vesey Street beyond the buildings. On September 11, the Verizon Building was undergoing renovation and scaffolding was present on the east side. Some of the supports are still standing, but most of the scaffolding has collapsed, contributing to the debris lying in the street.

The portion of Figure 5-87 showing the west face of WTC 7 is enlarged in Figure 5-88. The façade damage on the $8^{\text {th }}$ floor extends at least as far as window 13A. Façade damage is also evident on the $6^{\text {th }}$ and $7^{\text {th }}$ floors extending to at least Column 14 . Window glass or louvers are broken or missing for windows 9-6, 9-7, 9-10 to the south edge on the $9^{\text {th }}$ floor, for windows $8-6$, 8-8, and 8-10 to the south edge on the $8^{\text {th }}$ floor, and for windows $7-5$ and 7-9 to the south edge on the $7^{\text {th }}$ floor. On the $6^{\text {th }}$ floor, most of the windows contained louvers. All seem to be in place except for windows 14 and 14A near the southwest corner. On the $5^{\text {th }}$ floor, there is no indication that any louvers were broken. 


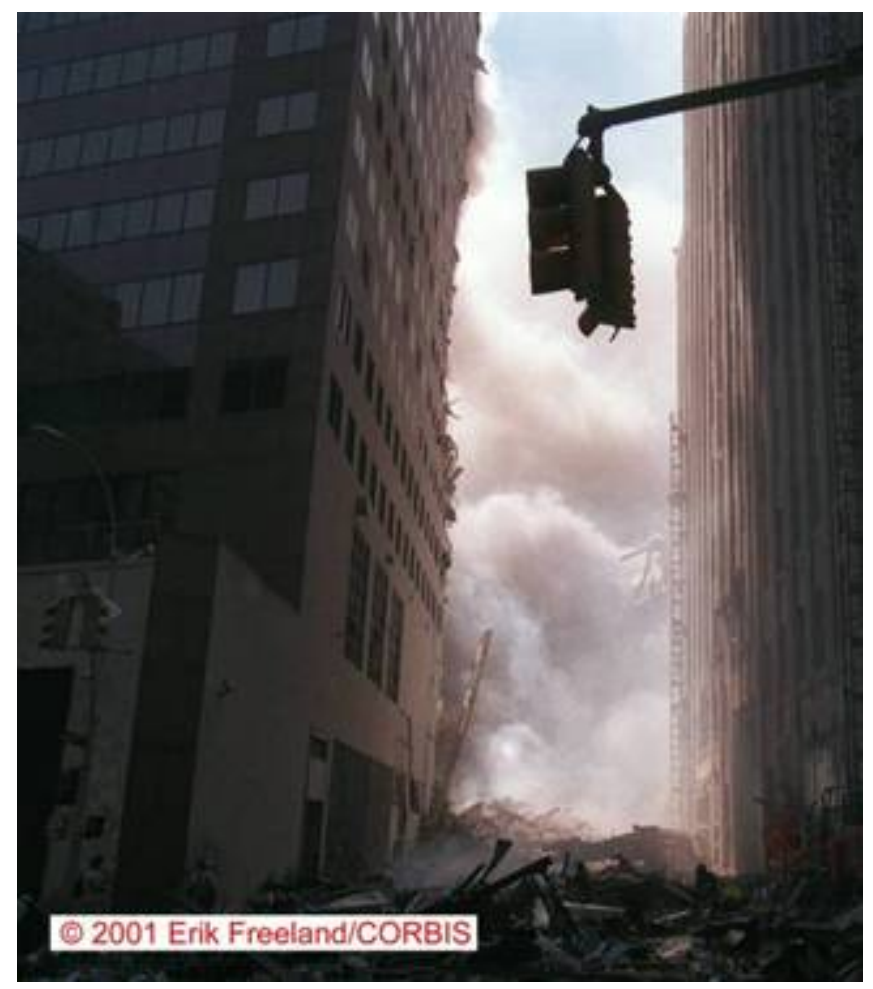

Figure 5-87. Cropped photograph of a partial view of the west face of WTC 7 looking down Washington Street between WTC 7 on the left and the Verizon Building on the right. The time is unknown, but the shadows suggest that it was before noon.

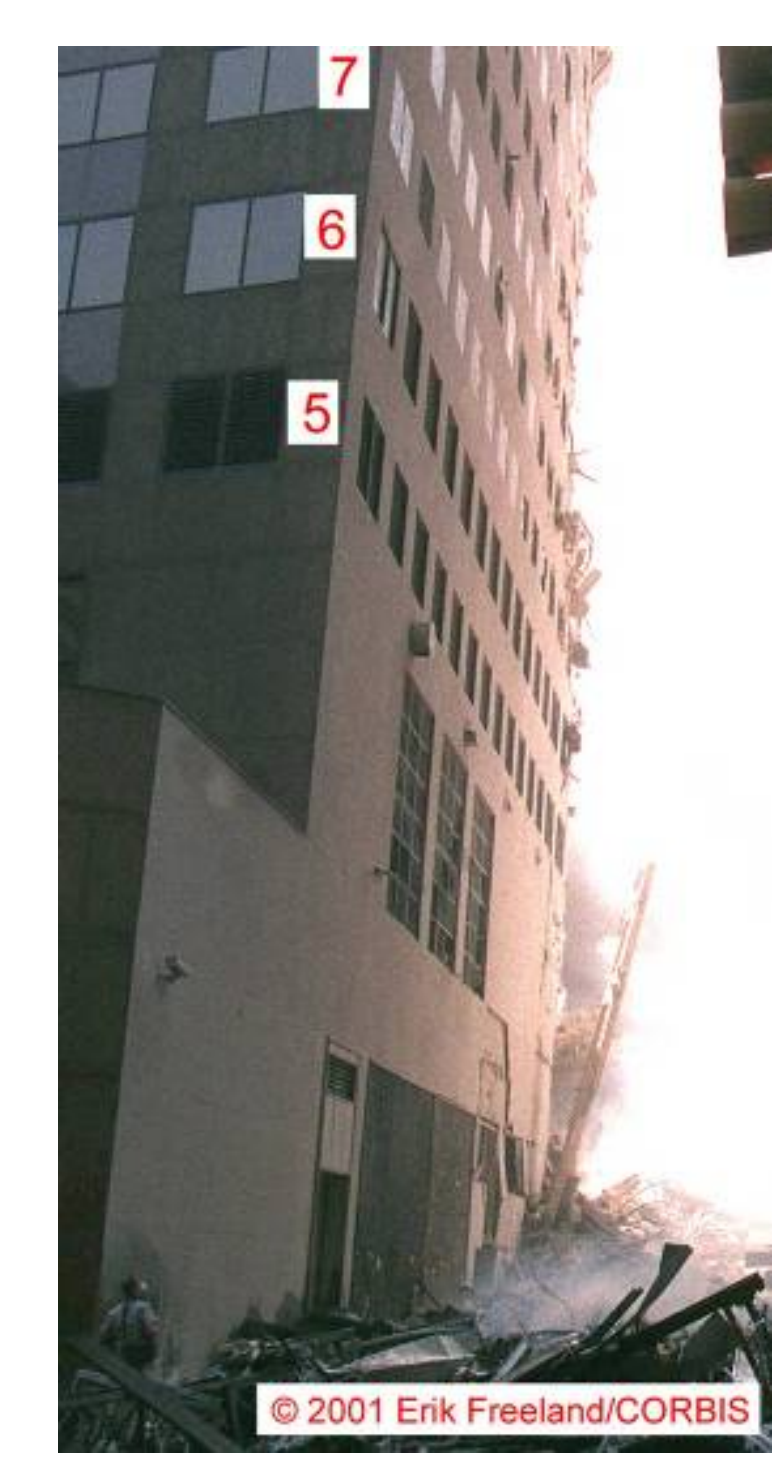

Figure 5-88. Enlarged view of the west side of WTC 7 from Figure 5-87. The intensity levels have been adjusted, and floor numbers have been added.

Some minor façade damage is visible on the southwest corner extending from the $5^{\text {th }}$ floor down to the ground. A section of granite was dislodged above the doorway, just to the south of the center of the face. See Figure 5-26 for the configuration in this area. To the left of this doorway, it appears that the underlying truss that held the granite was partially dislodged. Some of the screens in the large windows near the center of the face on the $3^{\text {rd }}$ and $4^{\text {th }}$ floors were removed, but this is the only evidence of damage to this part of the face. 
A diagram summarizing the observed damage to the west face of WTC 7 is shown in Figure 5-89. This diagram reflects the damage observations from the south face for the southwest corner near the top floors and from the $17^{\text {th }}$ floor down to the $9^{\text {th }}$ floor. The extent of broken windows on the lower floors suggests that the force associated with the event that removed this wedge was large.

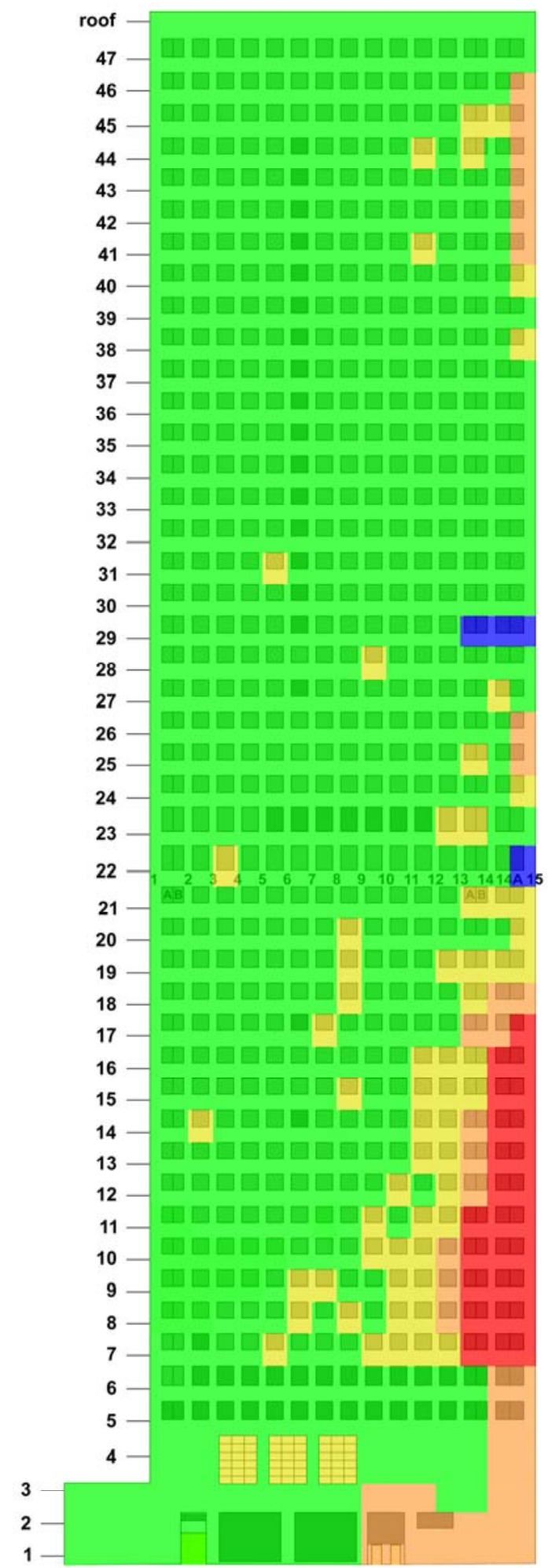

Figure 5-89. Observed damage on the west face of WTC 7 following the collapse of WTC 1 is shown.

Damage is color coded as follows: green ( $\square)--$ no visible damage, yellow ( ) - window glass broken out, orange $(\square)$ - granite and underlying truss damage, and red ( $\square)$ - damage to outer-perimeter structural steel, and blue ( $\mathbf{a})$ - not visible. 


\section{Absence of Damage to the East and North Faces of WTC 7}

Not surprisingly, given the visual evidence concerning the distribution of the large sections of falling debris from WTC 1, no window breakage, façade damage, or structural damage were observed on the east and north faces of WTC 7 following the collapse of WTC 1. Figure 5-90 shows a view of the lower portion of the east face of WTC 7 shot from the corner of West Broadway and Barclay Street, looking down West Broadway. Another, closer view of the face was shown in Figure 5-22. Both figures show that there was a large amount of small debris deposited on West Broadway between the Post Office Building and WTC 7. In Figure 5-90 several larger pieces of debris can be seen. Most of these seem to be the aluminum that covered the exterior steel columns of the towers (NIST NCSTAR 1-5A).

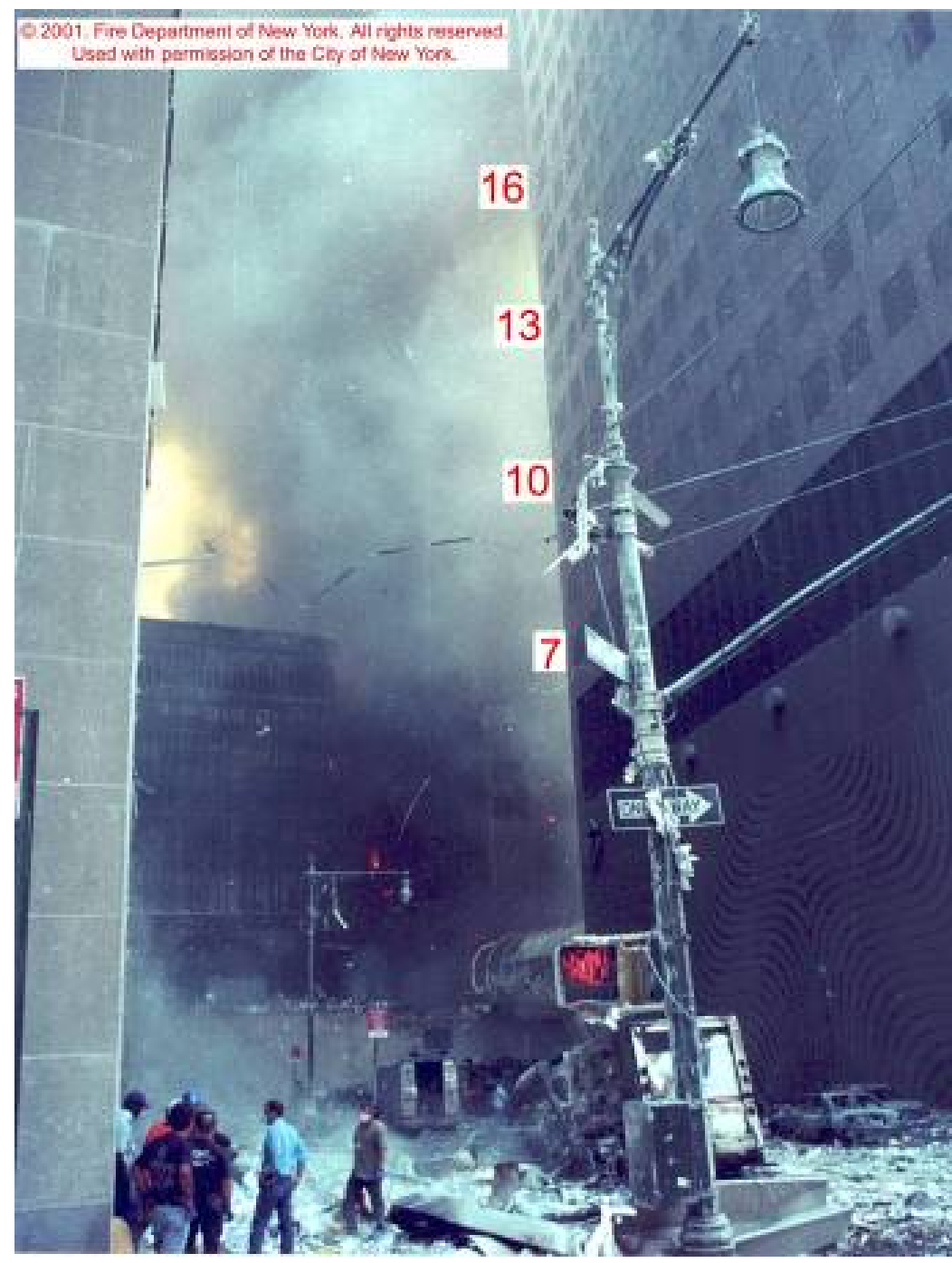

Figure 5-90. Photo showing the east face of WTC 7, taken from the southeast corner of Barclay Street and West Broadway looking down West Broadway, likely around 12:00 p.m.

In Figure 5-90, windows are visible on a portion of the east face up to the $20^{\text {th }}$ floor. There is no indication of façade damage or, with one exception, broken window glass in the image. The only broken glass is the center window on the $8^{\text {th }}$ floor, to the right of Column 36. This open window is also visible in Figure 5-22. Investigation interviews indicated that this window was broken out by people who were trapped on this floor when WTC 1 collapsed (Chapter 6). Video clips in the database show one of these people inside an open window (8-42A) on the eastern edge of the north face. 
At the times when Figure 5-22 and Figure 5-90 were taken, there were no indications of fire or smoke on the east face of WTC 7. Numerous people can be seen on West Broadway immediately below the face.

Review of various images of the north face of WTC 7 revealed that the face appeared undamaged, with the exception of two locations on the $8^{\text {th }}$ floor, where window glass was broken out prior to the time when fires began breaking windows on the face. A view of the undamaged lower nine floors at the northwest corner was shown in Figure 5-87. As noted above, window 8-42A was open on the northeast corner of the $8^{\text {th }}$ floor. This window is visible in Figure 5-91. This cropped image is taken from the same photograph as Figure 5-12. The other open window observed on this side of the building was 8-47B. This open window is visible in Figure 5-30 above the left hand edge of the fire burning on the $7^{\text {th }}$ floor. This window was also broken out by people trapped in the building after WTC 1 collapsed.

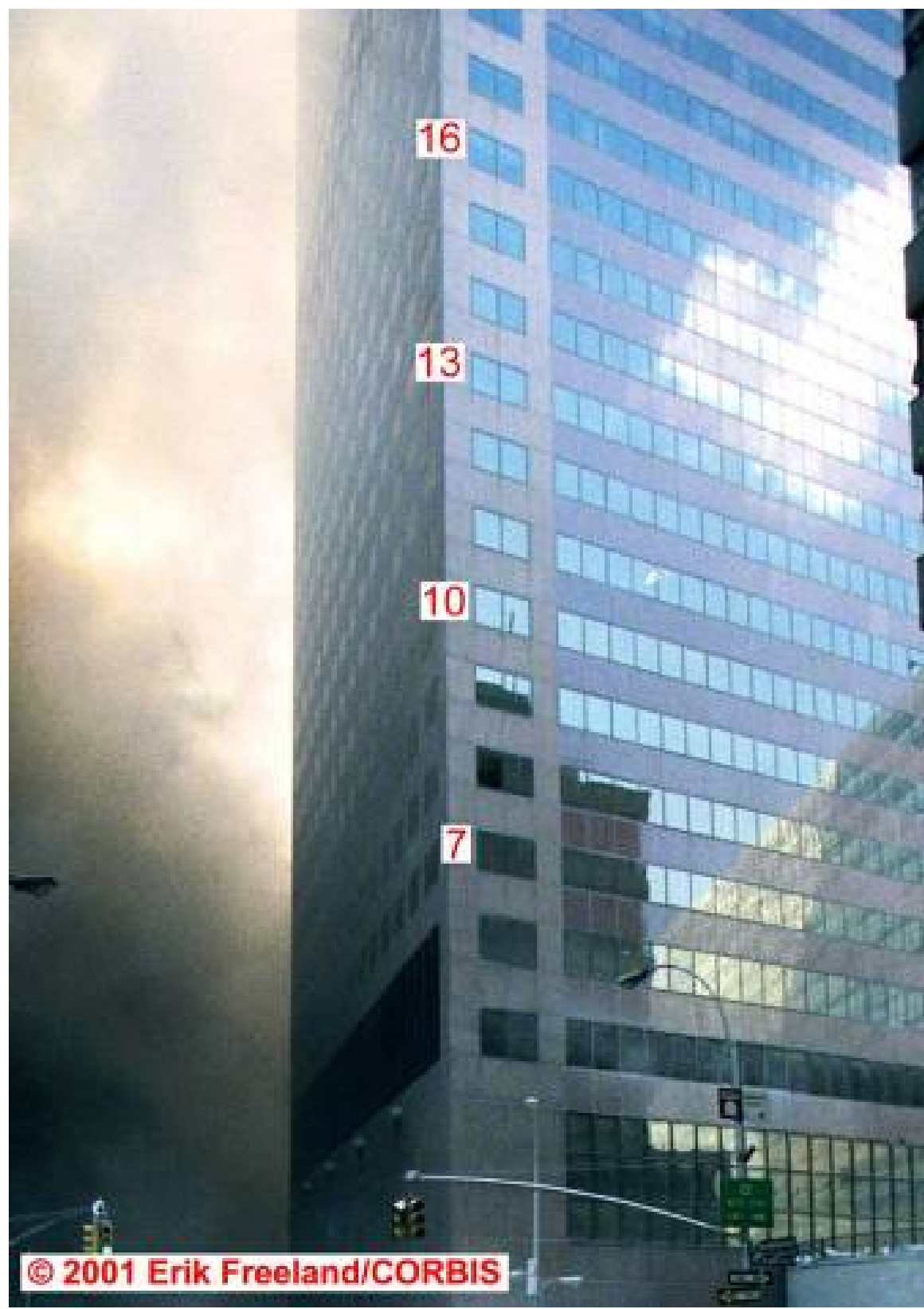

Figure 5-91. Cropped photograph showing the east side of the lower floors of the north face and an oblique view of the east face. Image intensities were adjusted and floor numbers were added. 


\subsubsection{Summary of Debris Damage to WTC 7 Based on Visual Data}

WTC 7 suffered structural damage to its southwest quadrant due to heavy debris falling from WTC 1 during its collapse. Most of the damage was on the south face. It is possible that some additional interior damage occurred, since portions of the face were hidden by smoke or nearby buildings. Damage to the west face primarily occurred along the southern edge. The north and east faces apparently did not sustain damage that could be detected visually.

The damage estimates were based on the observed exterior damage to the south and west faces of the building from the visual evidence discussed above (Figures 5-83 and 5-89). ${ }^{1}$ In addition, interview accounts by individuals who were in or around WTC 7, documented damage to the building at 130 Liberty Street (Figure 2-32), and engineering judgment were used to develop estimates of interior structural damage between the exterior walls and the core.

Figure 5-92 and Figure 5-93 show elevation views of the estimated interior damage below Floor 18 in the southwest region, looking from the south and the west directions, respectively. Figure 5-94 through Figure 5-101 show schematics of the damage estimates for each floor, from Floors 5 to 17, and Floor 44 to the roof.

Along the south face, the interior damage was estimated to extend from the south exterior wall toward the core, with increasing interior damage of the south tenant floor between the south face and the core, from Floor 17 down to Floor 7 . The core columns and girders were assumed to be structurally undamaged. The following floor damage was estimated at the locations where the exterior columns were damaged:

- For Floors 15 through 17, a small portion of the floor span between the south face and the core.

- For Floors 12 through 14, half of the floor span between the south face and the core.

- For Floors 7 through 11, the full floor span between the south face and the core.

- For Floors 5 and 6, the full floor span between the south face and the core between exterior Columns 19 and 20.

For Columns 14A, 15, and 16 at the southwest corner, the following floor damage was estimated:

- For Floor 6 and Floors 10 through 17, a small portion of the floor span between the exterior and the core.

- For Floors 8 and 9, the full floor span between the south and west faces and the core.

Global structural response analyses are presented in Chapter 12 to simulate the collapse of WTC 7 following the damage due to debris impact and fires. These analyses included the damage estimates to the southwest quadrant of the building due to debris impact presented in Figures 5-92 through 5-101.

\footnotetext{
${ }^{1}$ Note that Figures 5-92 through 5-99 were developed based on a preliminary estimate of Figures 5-83 and 5-89. As such, there are minor discrepancies between the two sets of figures. Such discrepancies did not have any significant effect on the results of the structural collapse analyses in Chapter 12.
} 


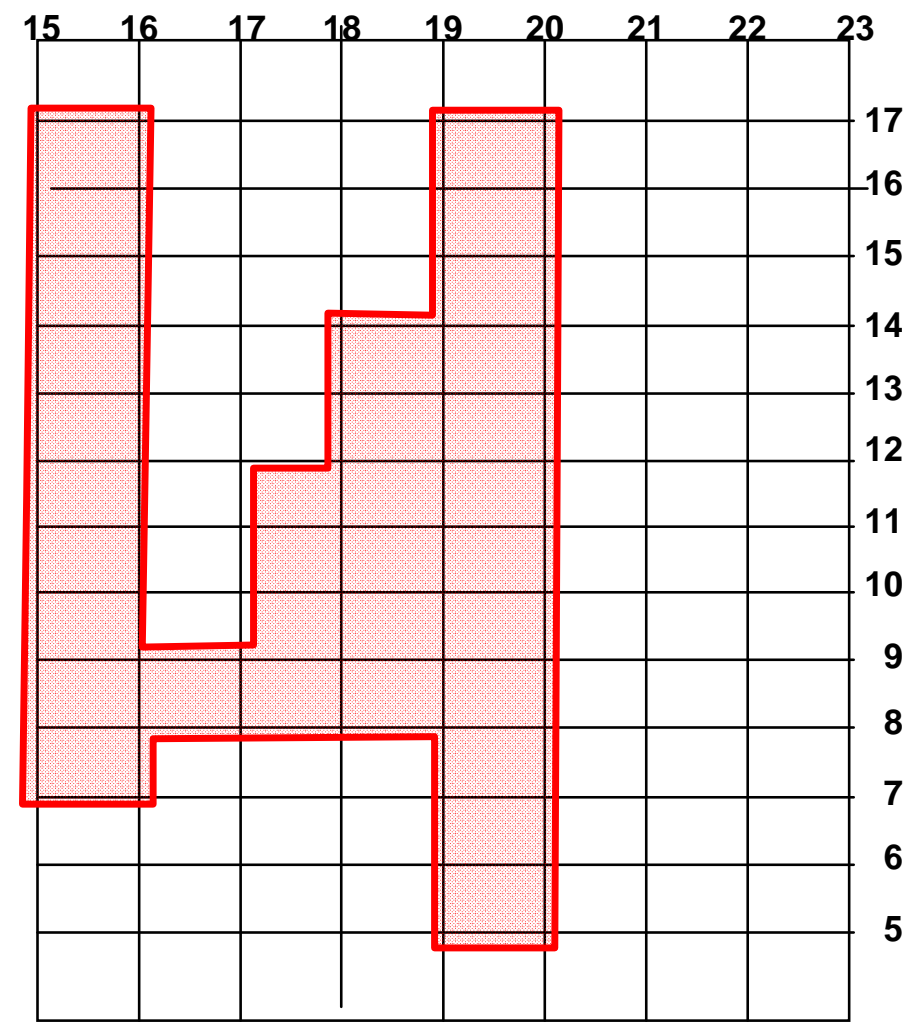

Figure 5-92 Elevation view of the estimated debris impact damage for the structural analysis of WTC 7, viewed from the south.

The numbers across the top denote the column locations; the numbers on the right identify the locations of the floor slabs.

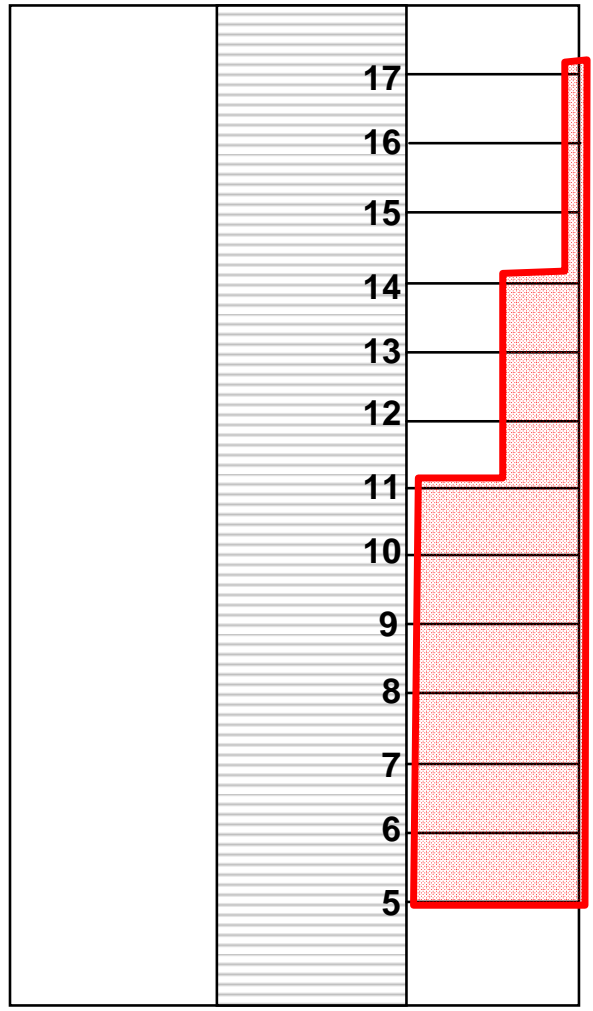

Figure 5-93 Elevation view of the estimated depth of interior debris impact damage to the south face of WTC 7, viewed from the west.

The right side represents the south façade of WTC 7 and the shaded area represents the building core. 


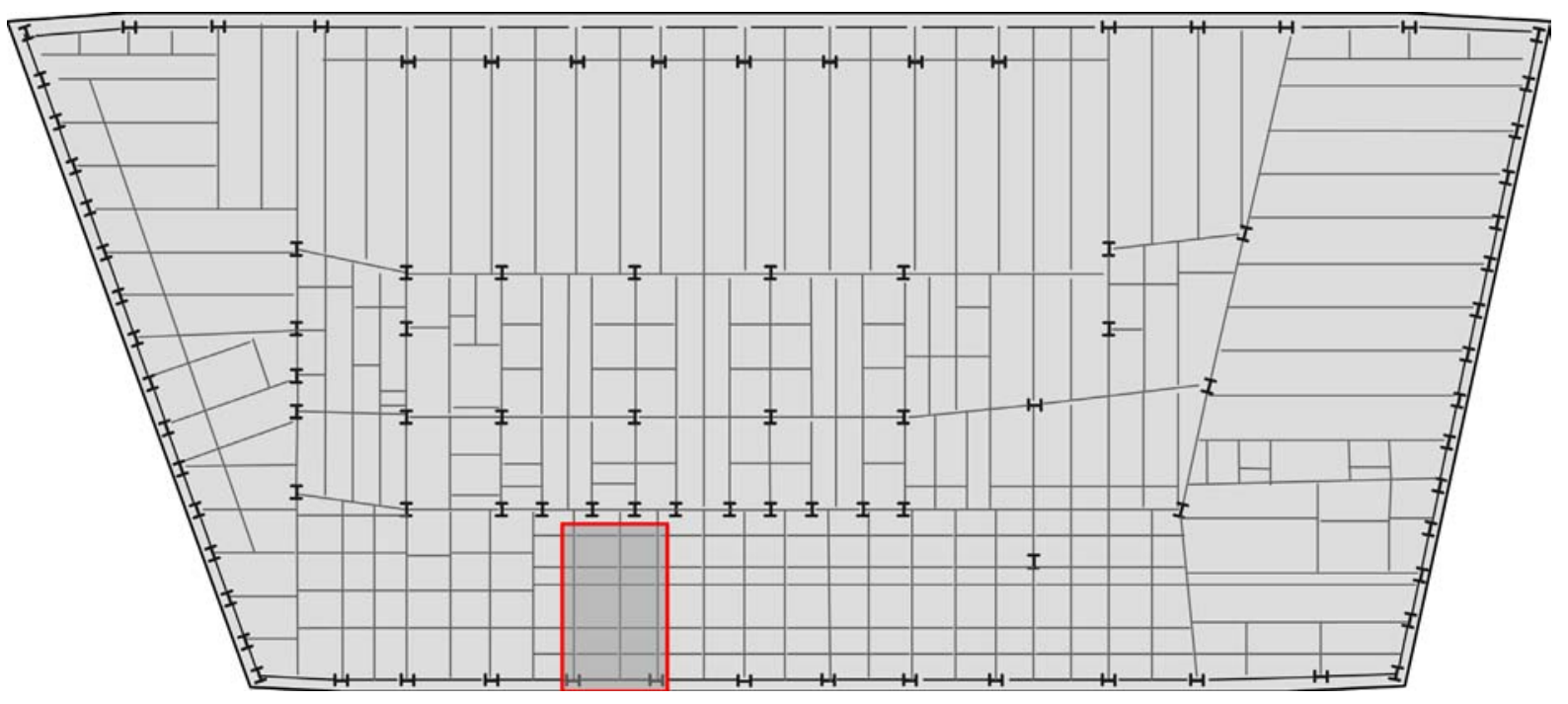

Floor plan based on structural drawings (Cantor 1985) and damage was estimated by NIST

Figure 5-94 Estimated debris impact damage to Floors 5 and 6 of WTC 7. Marked area indicates removed columns and floor segments.

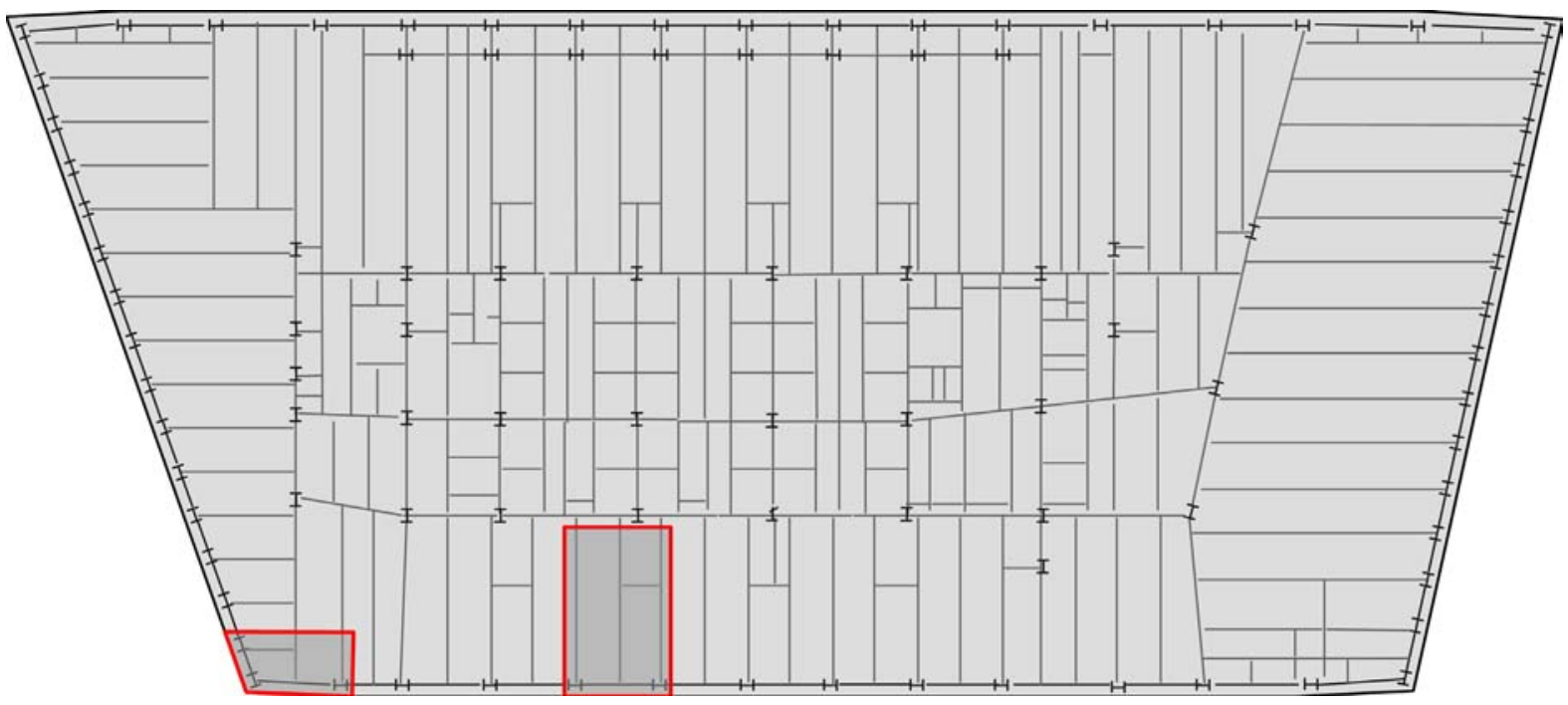

Floor plan based on structural drawings (Cantor 1985) and damage was estimated by NIST

Figure 5-95 Estimated debris impact damage to Floor 7 of WTC 7. Marked areas indicate removed columns and floor segments. 


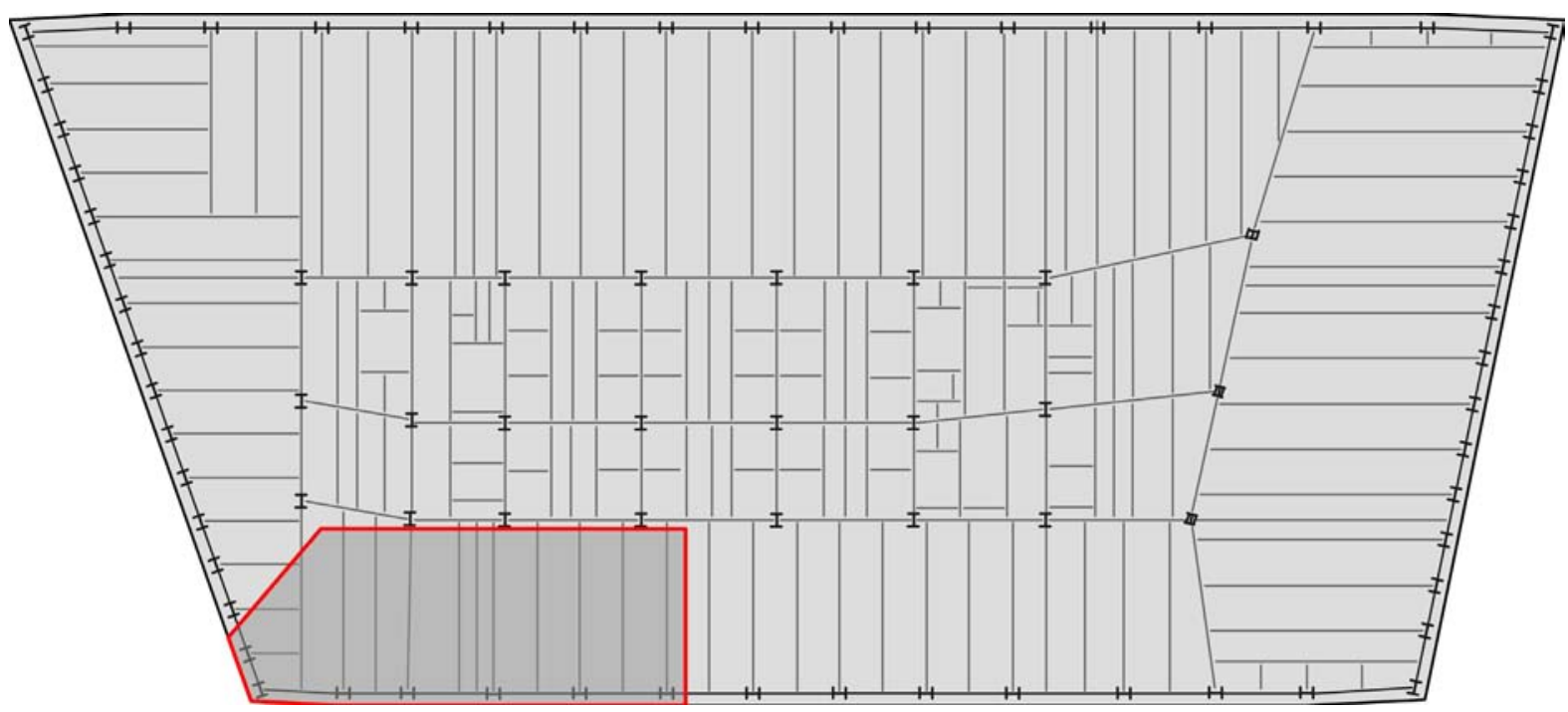

Floor plan based on structural drawings (Cantor 1985) and damage was estimated by NIST

Figure 5-96 Estimated debris impact damage to Floor 8 of WTC 7. Marked area indicates removed columns and floor segments.

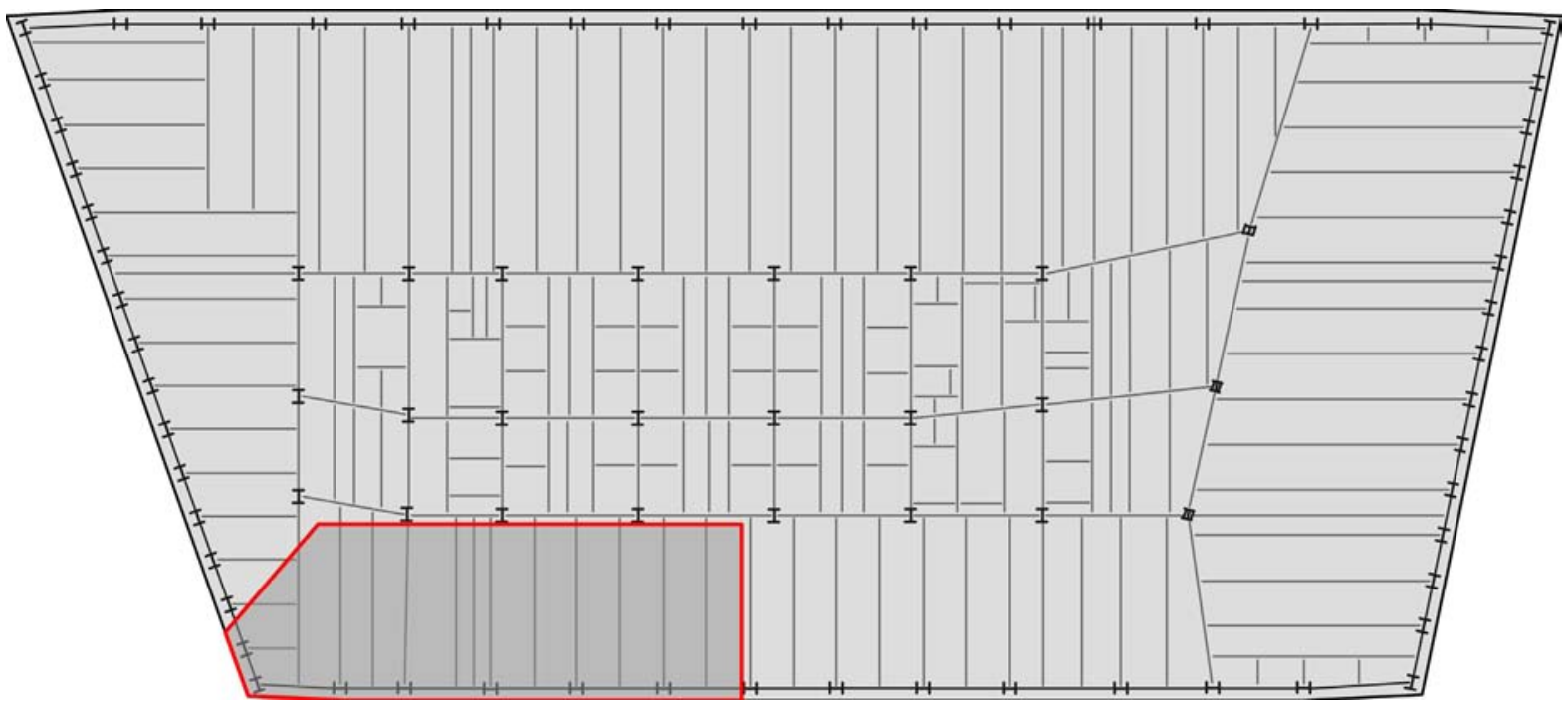

Floor plan based on structural drawings (Cantor 1985) and damage was estimated by NIST

Figure 5-97 Estimated debris impact damage to Floor 9 of WTC 7. Marked area indicates removed columns and floor segments. 


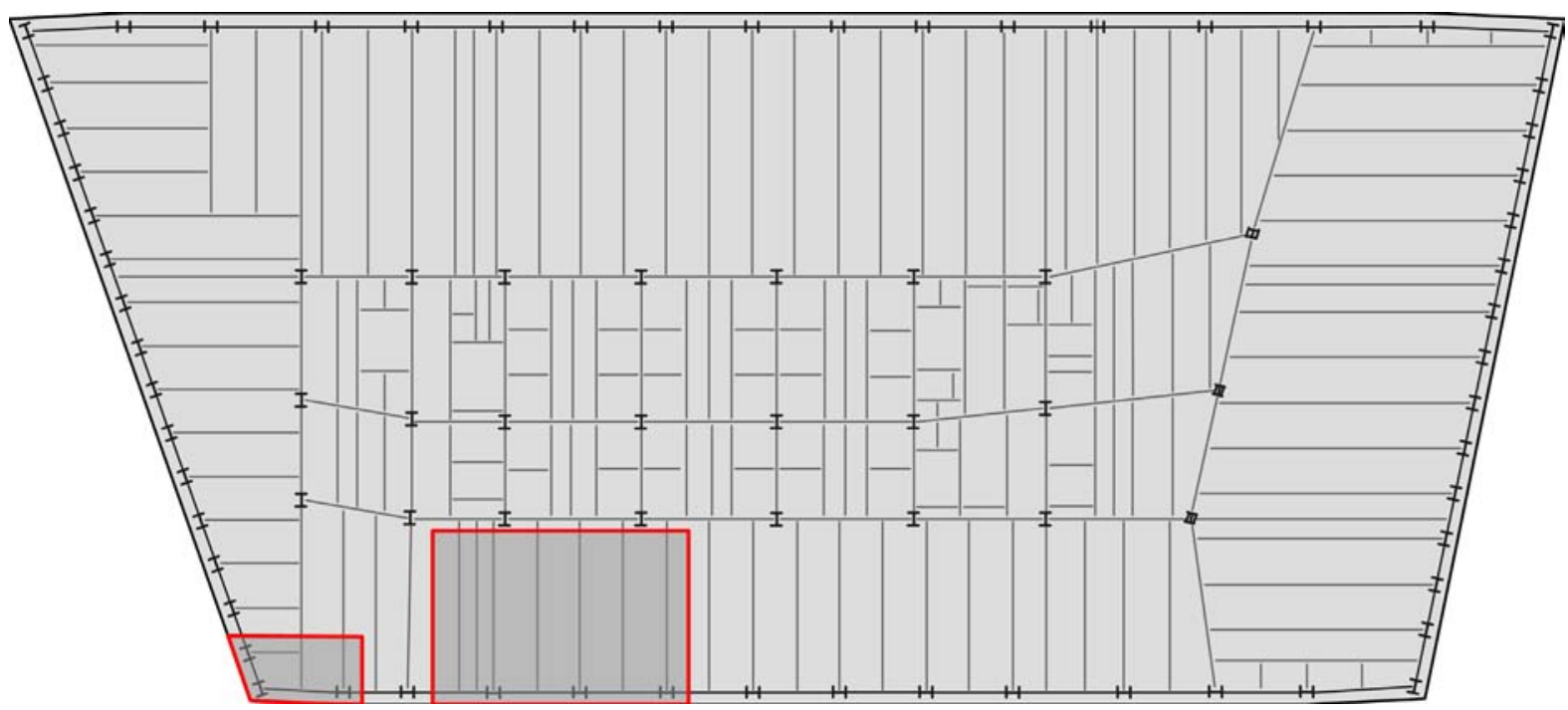

Floor plan based on structural drawings (Cantor 1985) and damage was estimated by NIST

Figure 5-98 Estimated debris impact damage to Floors 10 and 11 of WTC 7. Marked areas indicate removed columns and floor segments.

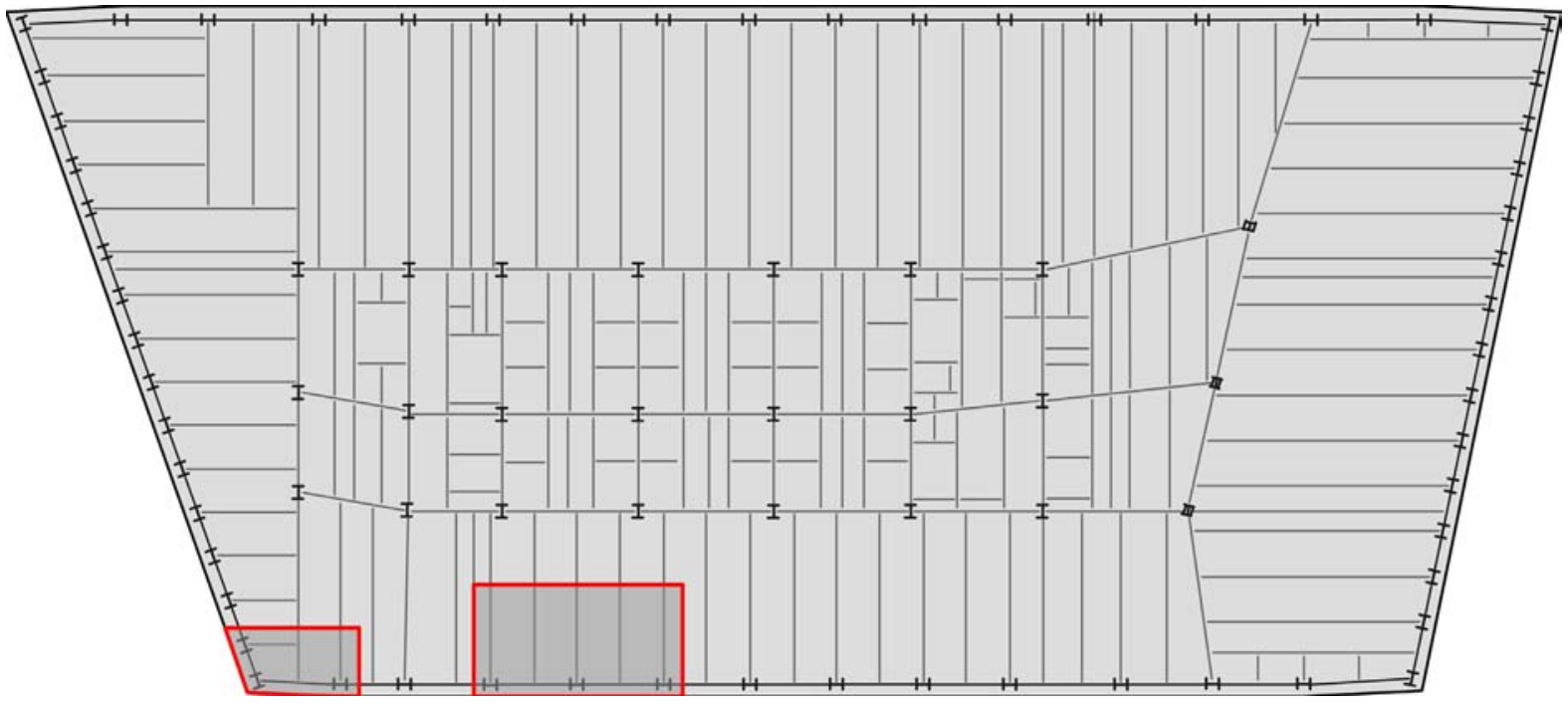

Floor plan based on structural drawings (Cantor 1985) and damage was estimated by NIST

Figure 5-99 Estimated debris impact damage to Floors 12 to 14 of WTC 7. Marked areas indicate removed columns and floor segments. 


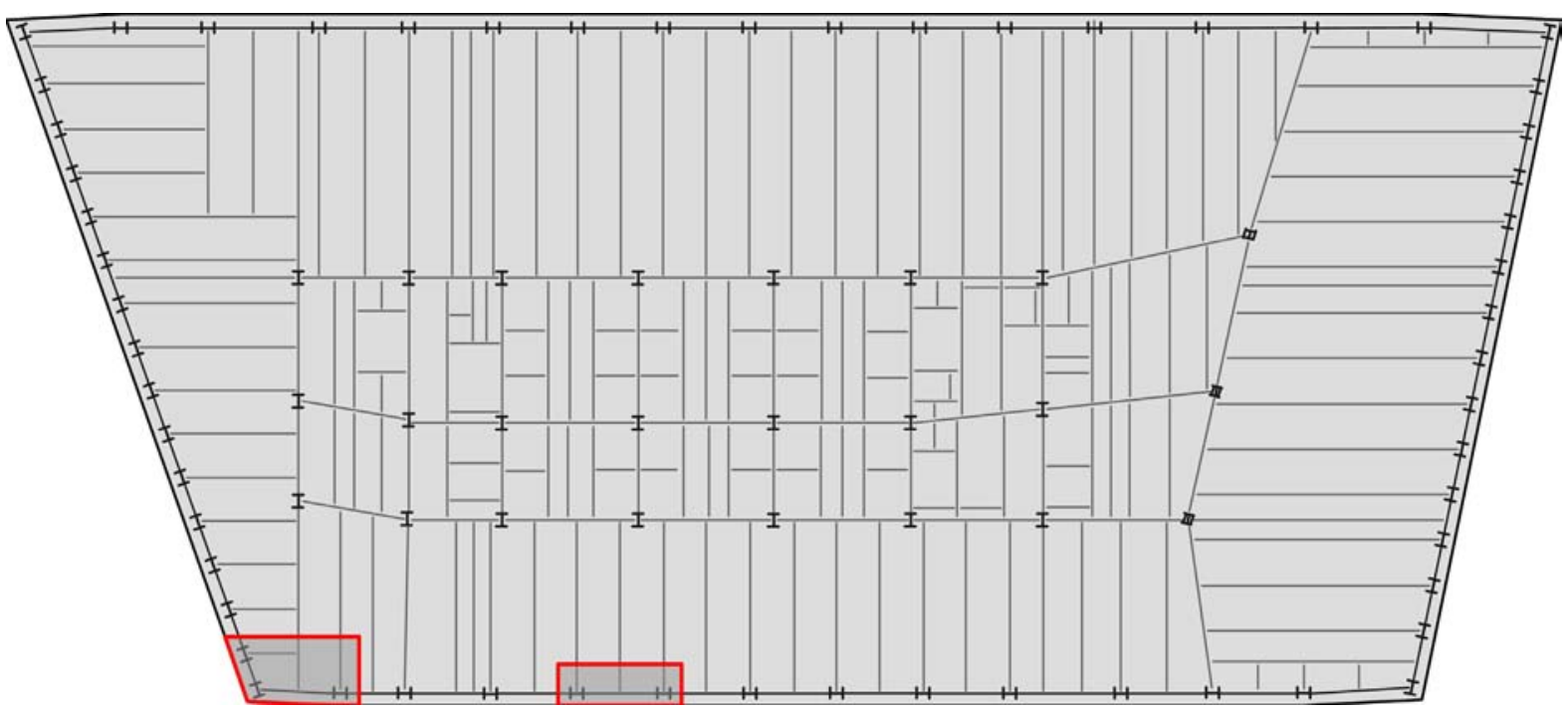

Floor plan based on structural drawings (Cantor 1985) and damage was estimated by NIST

Figure 5-100 Estimated debris impact damage to Floors 15 to 17 of WTC 7. Marked areas indicate removed columns and floor segments.

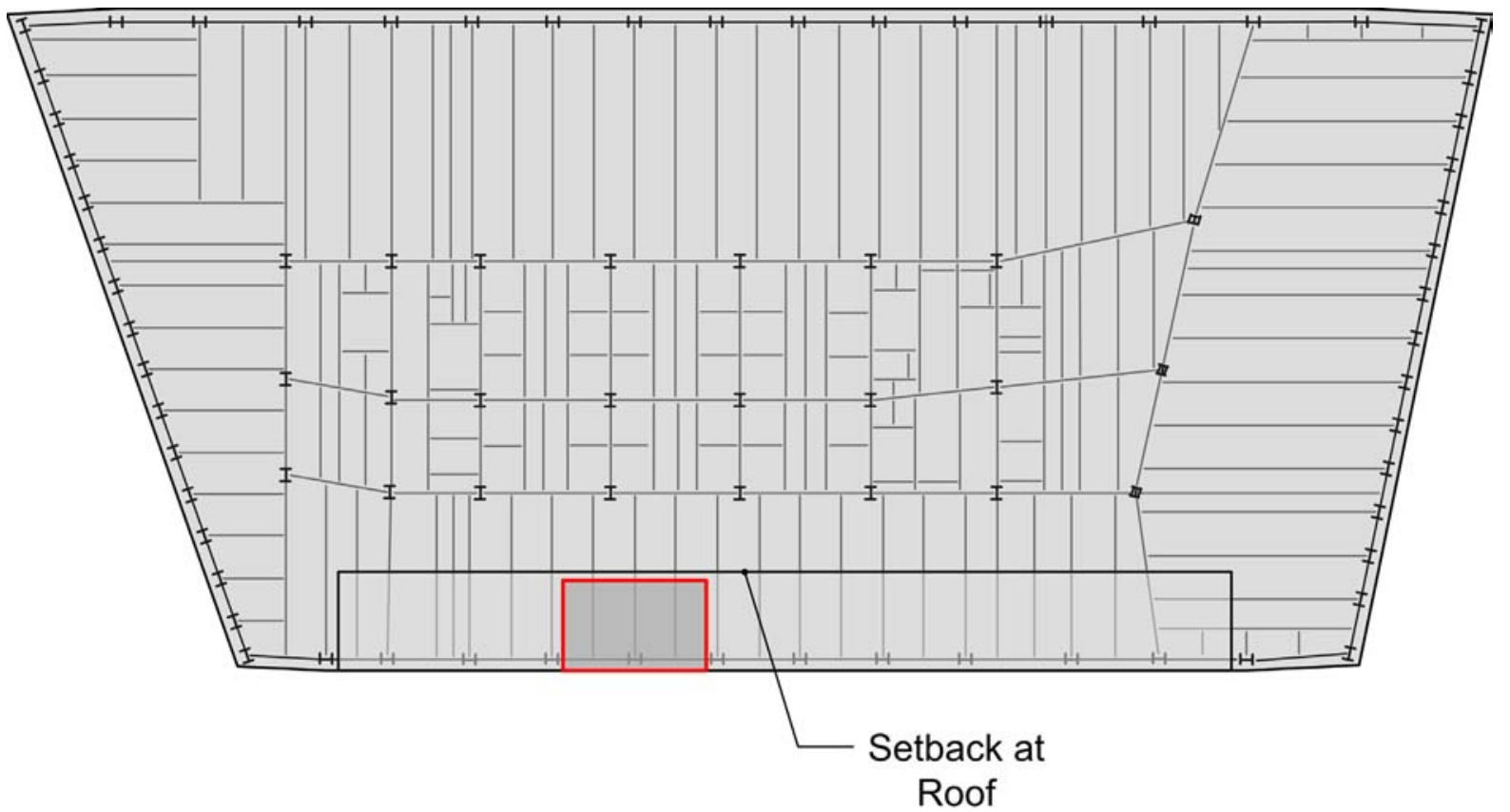

Floor plan based on structural drawings (Cantor 1985) and damage was estimated by NIST

Figure 5-101 Estimated debris impact damage to Floor 44 to the roof of WTC 7. Marked areas indicate removed columns and floor segments. Damage is shown on the Floor 44 floor plan. 


\subsection{DEVELOPMENT AND SPREAD OF FIRES IN WTC 7}

\subsubsection{Introduction}

Fires were observed on multiple floors of WTC 7 between the times when WTC 1 collapsed at 10:28:22 a.m. and WTC 7 collapsed at 5:20:52 p.m. It is important to consider whether the ignition of such a number of separate fires was to be expected, based on observations of fires in the towers and ignition behavior at other locations around the WTC site. This point will be discussed in Section, 5.6.2. In Section 5.6.3 observations concerning fire development and spread within WTC 7 will be discussed with an emphasis on the time behavior. In the final subsection, the fires in WTC 7 are characterized in terms of a number of fire maps designed to provide concise snapshots of the fires at particular times.

\subsubsection{Ignition of Fires Following Collapse of the World Trade Center Towers}

The time-dependent behavior of the fires that developed in the WTC towers was discussed extensively in NIST NCSTAR 1-5A. Particularly relevant to this discussion is the observed fire distributions at the times when the towers collapsed. At the time WTC 2 collapsed at 9:58:59 a.m., a large fire had developed along the west side of its south face on the $80^{\text {th }}$ floor. Flames were pushed out of open windows in this area as the collapse began. Smaller fires were burning at multiple locations in WTC 2 on floors ranging from the $79^{\text {th }}$ to the $83^{\text {rd }}$ floors on the north face. At the time of collapse, fires on the east of WTC 2 face seemed to have died down with the exception of a long-burning fire in the northeast corner on the $81^{\text {st }}$ floor. Fires had not appeared on the west face by the time of collapse.

Subsequent to the collapse of WTC 2, numerous fires were reported to the south and southwest of the WTC site. There is some ambiguity as to ignition sources, since some of these fires could have been ignited by burning materials released when WTC 1 collapsed 29 min later. Large fires grew in the ruins of WTC 3 (Marriott Hotel), which was adjacent to both WTC 1 and WTC 2. (See Figure 5-2.) WTC 4 was heavily damaged by debris from WTC 2, and the remaining structure subsequently burned. Fires also grew on multiple floors in buildings located one block south of WTC 2 at 90 West Street and 130 Cedar Lane. Fires apparently did not develop in the Bankers Trust Building located just to the east at 130 Liberty Street. Fires were reported at an apartment house located to the southwest of the WTC site on the corner of Liberty Street and South End Avenue. Numerous vehicles parked along West Street to the south of the WTC site were consumed by fire. The locations of all of these fires seem to be related to the locations of active fires in WTC 2 at the time of its collapse.

In Section 5.5.1, several images showing superficial damage to the south face of WTC 7 due to the collapse of WTC 2 were reproduced. It was also noted that a videographer entered the lobby of WTC 7 from the south and filmed inside. Even though glass panes were broken at several locations on the south face, there was no indication that fires had been ignited in the building immediately following the collapse of WTC 2.

The fires in WTC 1 were more widespread and intense at the time of its collapse than those in WTC 2. When WTC 1 collapsed, there were several large fires burning in the tower. The most extensive fire on the north face was located on the west side of the $92^{\text {nd }}$ floor. Somewhat smaller fires were present immediately above on the $95^{\text {th }}$ floor and on the east side of the $92^{\text {nd }}$ floor. As the collapse of WTC 1 proceeded, it generated a pressure pulse that pushed flames from internally burning areas out of adjacent 
windows, thus revealing the extent of the fires. This is evident in Figure 5-102 which shows the upper floors of WTC 1 roughly one second after the collapse started. The significant fire on the west side of the $92^{\text {nd }}$ floor is evident. The expelled flames formed a large fireball before extinguishing.

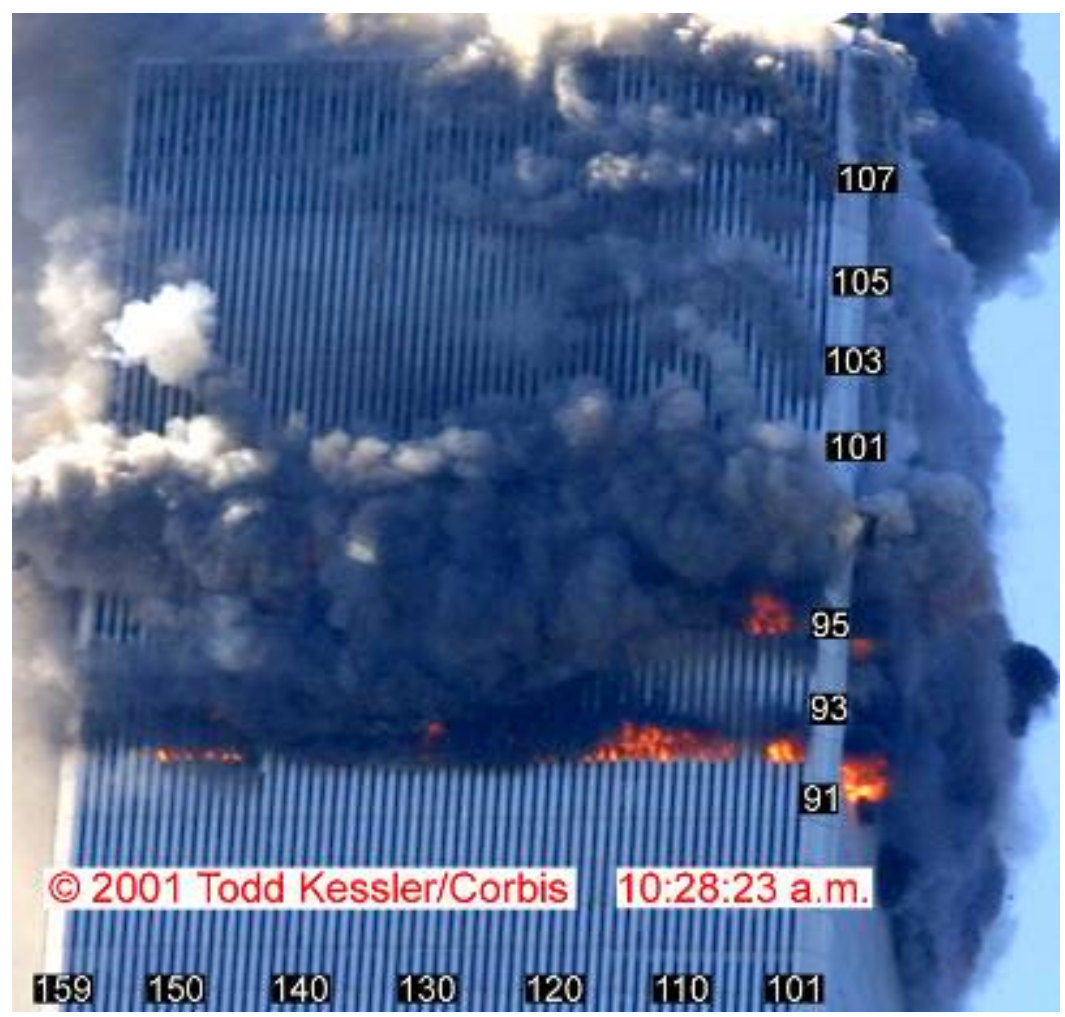

Figure 5-102. Cropped photograph showing the north face of WTC 1 at 10:28:23 a.m.

The image has been enhanced by adjusting the intensity levels. Column and floor numbers have been added.

The major area of intense burning at the time of collapse of WTC 1 was in the southeast quadrant, where large fires were present on a number of floors. Flames were also expelled from nearby windows in this area as the collapse started. In addition to the significant fires in the northwest and southwest quadrants, there was a fire burning on the west face at the $104^{\text {th }}$ floor toward the south end. Numerous smaller burning areas were present at other locations, ranging from the $92^{\text {nd }}$ floor to the $99^{\text {th }}$ floor.

The fires in WTC 1 were likely burning on a wide variety of materials typical of those found in office buildings. These fuels include office paper, furnishings, carpeting, and drapes. Some extinguishing of these burning materials would have occurred during the collapse of the tower, but it is possible that a large number of potential ignition sources (i.e., fire brands) might have survived and been widely distributed with the dust- and debris-laden air around the buildings at the WTC site. In Figure 5-103, it is evident that these dust- and debris-laden flows were many stories tall and that they flowed around WTC 7 and reached well beyond this building. 


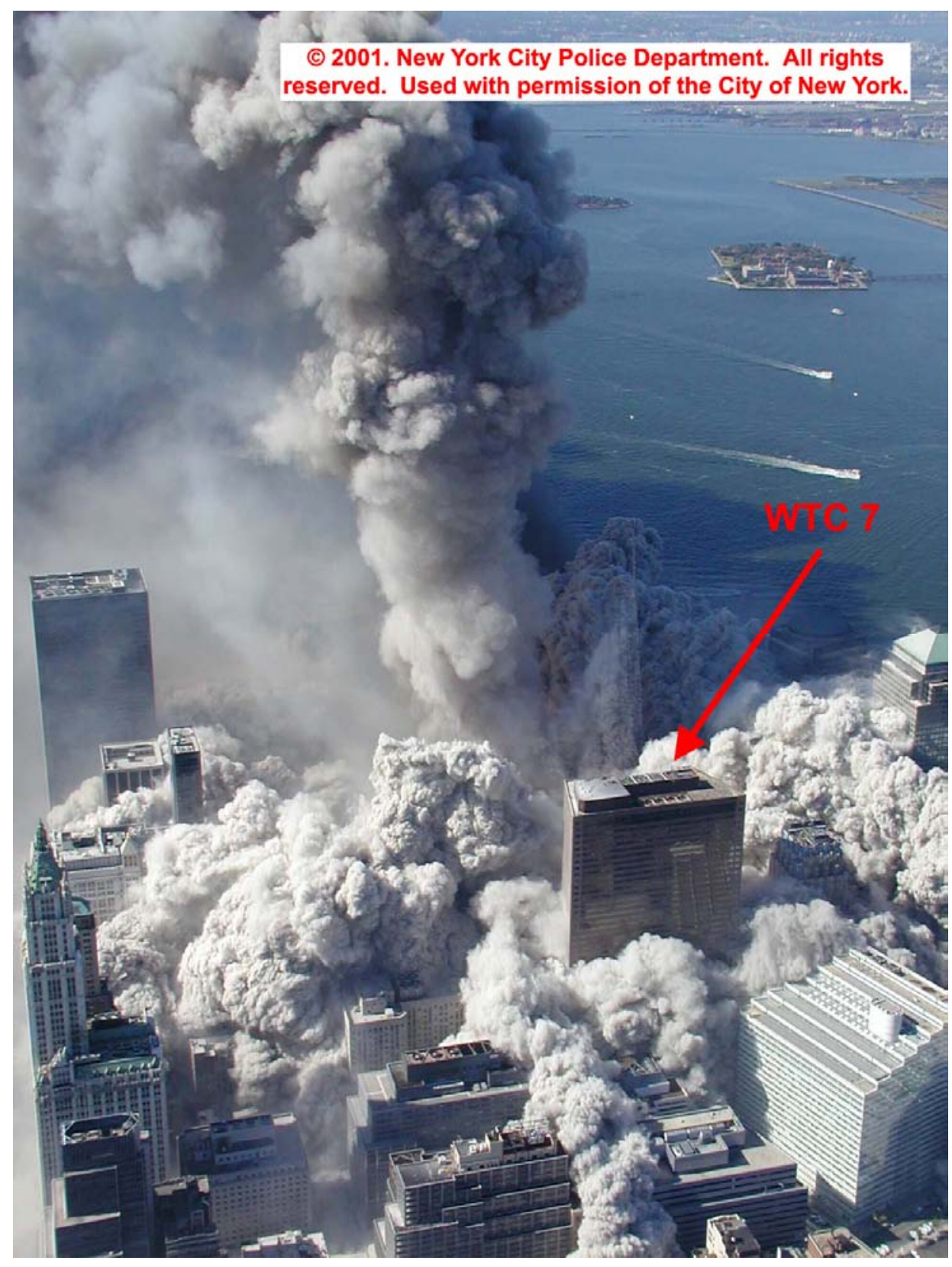

Figure 5-103.

Photograph

showing the dust-

laden flows

spreading away

from WTC 1

following its collapse.

It was taken $32 \mathrm{~s}$

after the start of the

collapse.

The large dust clouds generated by the collapse of WTC 1 hid the lower portions of WTC 7 from view for over 20 min following the collapse. However, as time passed, the dust began to settle, and the faces became less obscured. Figure 5-104 shows a view of the north face of WTC 7 taken at 11:28:15 a.m., i.e., close to one hour after the collapse of WTC 1. Even though some light dust is evident in front of the face, it is possible to discern the base of the building. There is no sign of fire or heavy smoke on the portion of the north face that is visible.

In Figure 5-104, there appears to be a heavy smoke column rising from an area just to the north and east of WTC 7. The location of the smoke relative to the buildings in the area suggests the smoke was coming from or near West Broadway. 


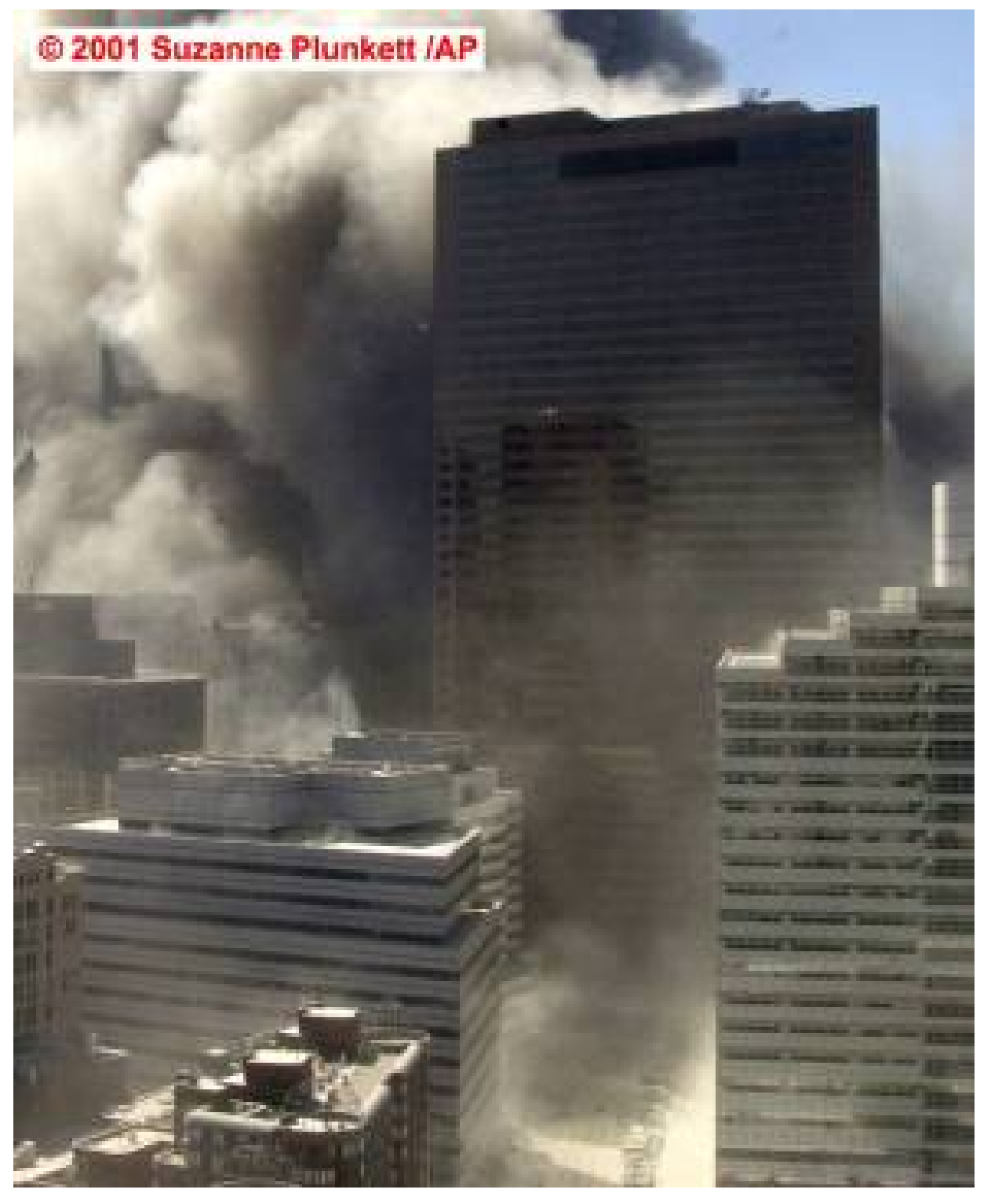

Figure 5-104.

Cropped photograph showing the north face of WTC 7, shot at 11:28:15 a.m. from the upper story of a nearby building looking down Greenwich. The intensity levels have been adjusted.

A view of WTC 7 from the west, taken roughly 15 minutes earlier, is shown in Figure 5-105. The upper portion of WTC 7 is visible at the top of the photograph. A heavy smoke plume was passing in front of the Verizon Building at this time. A second smoke plume can be seen beyond the Verizon Building to the north of WTC 7. It is likely that this smoke is coming from the same general area as the plume in Figure 5-104. Photographs taken from the same location show that the heavy smoke to the west of the Verizon Building was present as early as 10:54 a.m. and was observed as late as 11:19 a.m. By 12:10 a.m., the two smoke plumes visible in Figure 5-105 had dissipated, and the areas to the north of the Verizon Building and WTC 7 could be easily seen through a light veil of smoke and/or dust. 


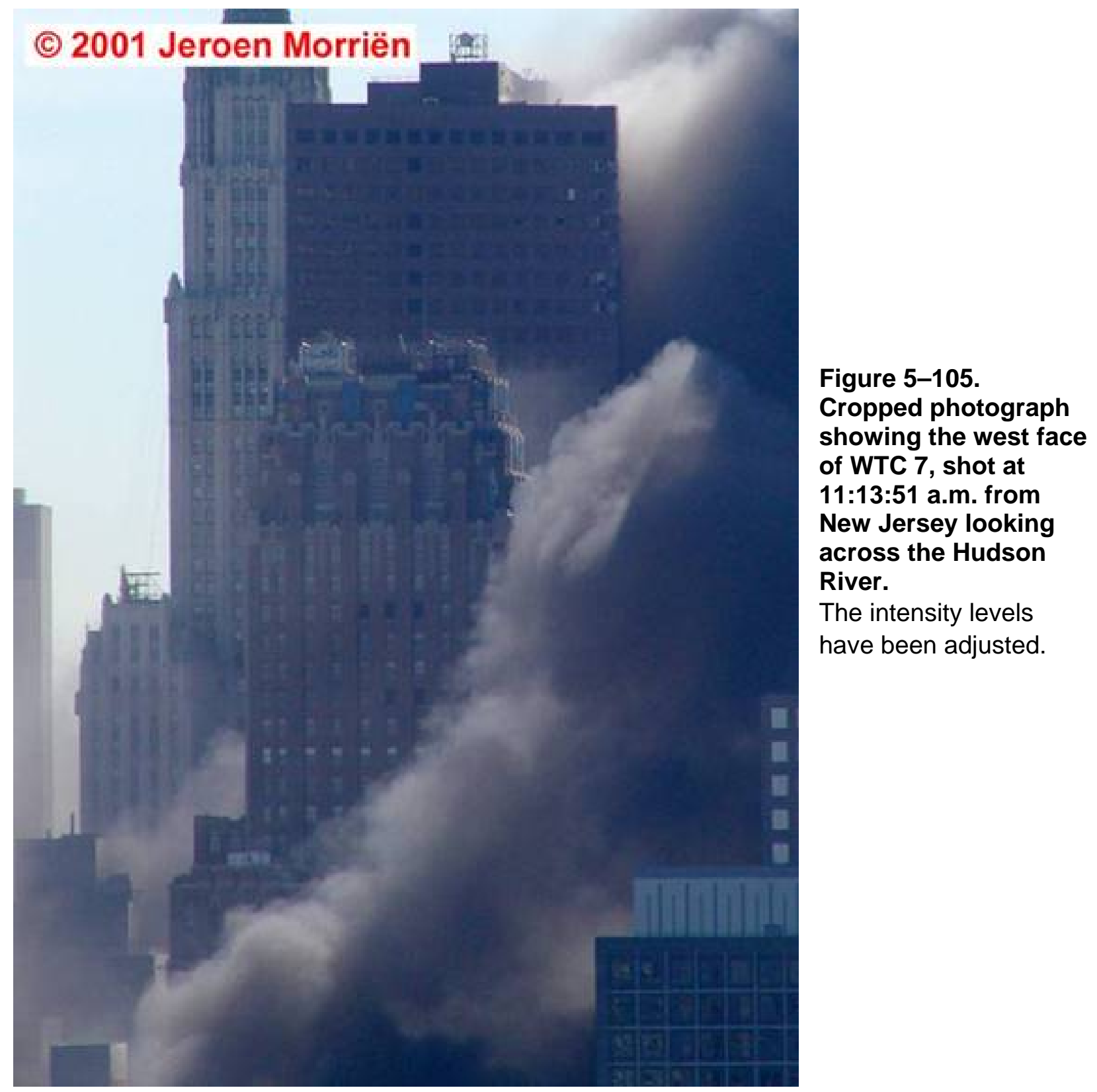

Visual evidence indicates that the smoke plumes seen in Figure 5-104 and Figure 5-105 originated from vehicles that were ignited at numerous locations following the collapse of WTC 1. Several burned out vehicles can be seen on West Broadway between the east side of WTC 7 and the Post Office Building in Figure 5-90. Review of several photographs showed that there were at least six burned automobiles, two postal trucks, and a fire truck on this single block. Another view of West Broadway taken from one block further north near its corner with Park Place is shown in Figure 5-106. Multiple burned vehicles, including a bus, several cars, and trucks, are visible on the street between Park Place and Barclay Street. A second photograph taken much earlier from a location slightly closer to Barclay Street is shown Figure 5-107. In addition to the vehicles visible in these two images, other photographs of the area show that there were several additional burned out automobiles closer to Barclay Street. Nearly every vehicle on this block was ignited. 


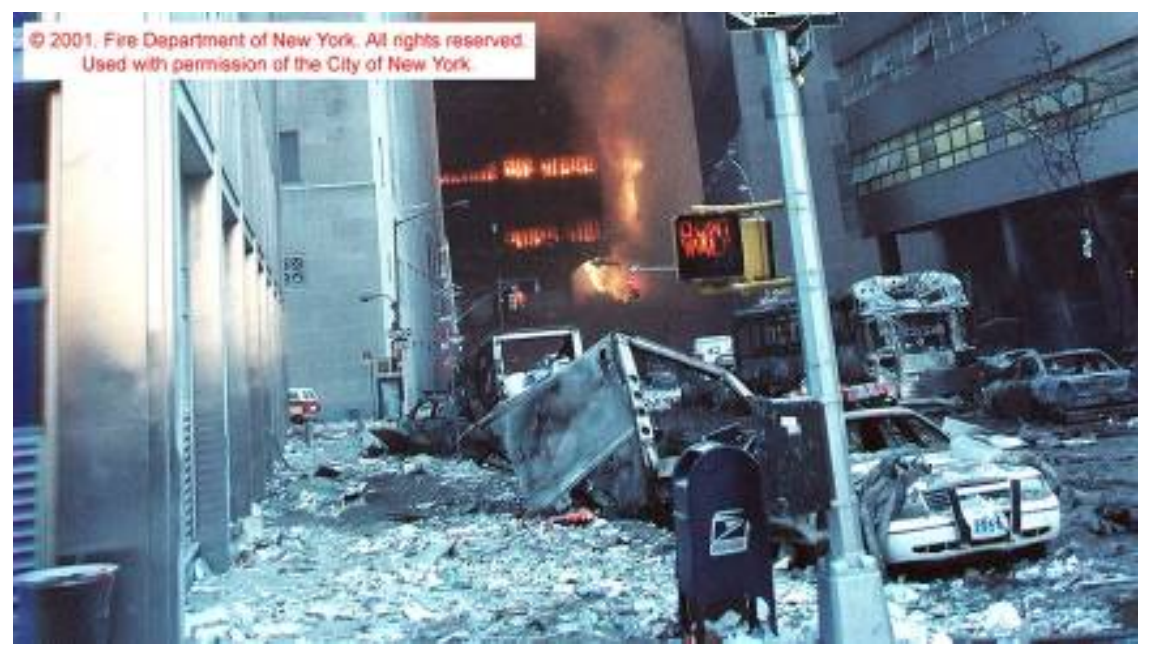

Figure 5-106.

Photograph taken looking down West Broadway towards WTC 7 from its corner with Park Place.

The burning buildings in the background are WTC 5 and WTC 6. The intensity levels have been adjusted.

Figure 5-107. Photograph taken looking down West Broadway towards WTC 7 from near its corner with Park Place.

The intensity levels have been adjusted.

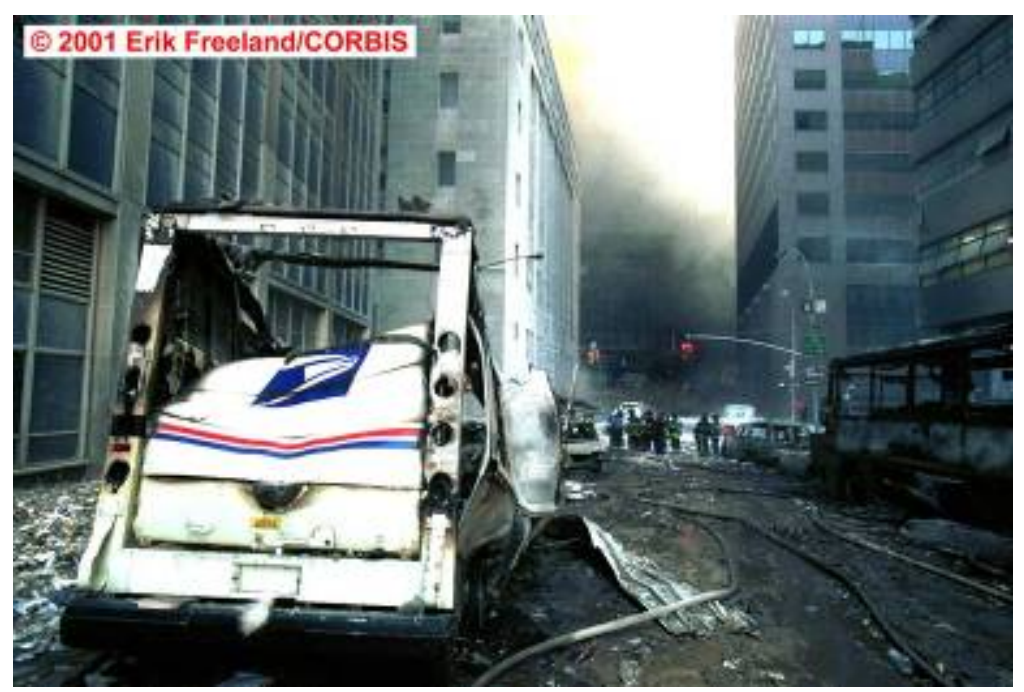

Several fire hoses are visible on the street in Figure 5-107. One of the photographers who provided images for the Investigation reported that he was a fireman visiting from out of town and had joined with a FDNY engine company to extinguish the burning vehicles along West Broadway. They started at the corner of Park Place and West Broadway and moved south until they reached Vesey Street. Based on the smoke plume observations, this must have taken place between roughly 11:00 a.m. and 12:00 p.m.

A video crew managed to reach the area of West Broadway and Barclay Street while the vehicles were still burning. Figure 5-108 shows a frame taken from a video recorded looking from the west of the West Broadway/Barclay Street intersection. The exact time is unknown, but it was likely between 11:00 a.m. and 12:00 p.m. Multiple vehicles were burning at this time. This image provides an indication of the burning intensities and smoke generation by these vehicle fires.

Other images show that fires burned a few vehicles located to the north of WTC 7 on Barclay Street and a large number of vehicles located in a large parking lot located to the west of West Street between Vesey Street and Murray Street. (See Figure 5-2.) The latter vehicle fires were likely at least partly responsible for the smoke observed rising from the north of and to the west of the Verizon Building in Figure 5-105. 


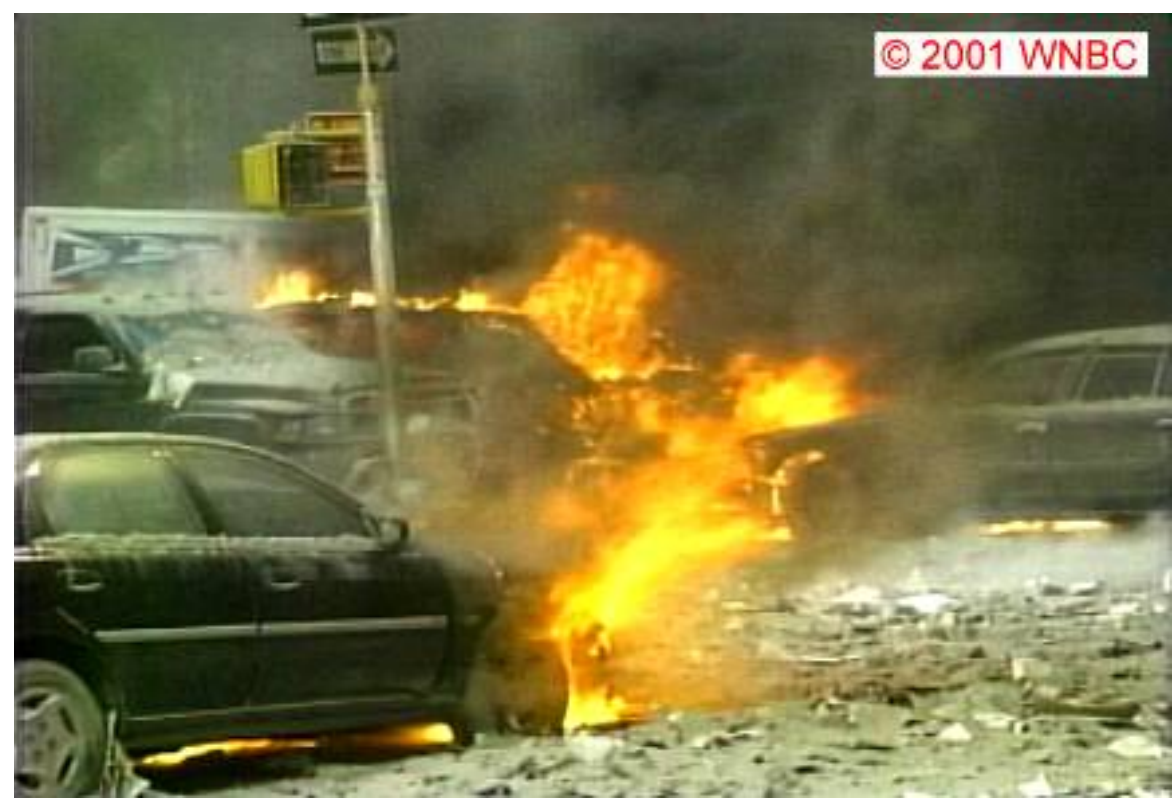

Figure 5-108. Frame taken from a video clip filmed near the corner of West Broadway and Barclay Street showing flames burning on a number of vehicles. The time could not be accurately determined. The intensity levels have been adjusted.

The number and wide distribution of vehicle and building fires ignited following the collapses of WTC 1 and WTC 2 confirm that substantial numbers of burning sources capable of igniting fires reached the ground and were widely distributed by the dust- and debris-laden air flows. Since fires were observed on the ground surrounding WTC 7, it is possible that potential ignition sources entered WTC 7 through openings created in the south and west faces of the building during the collapses of the towers. NIST found no evidence to confirm this possibility, but the available data suggest that this was highly likely.

\subsubsection{Visual Observations of Fire Growth and Spread in WTC 7}

\section{General Comments}

General characteristics of the imagery available for characterizing the fires that developed in WTC 7 following the collapse of WTC 1 were discussed in Section 5.4, along with the procedures for recording observations. It was noted that the available imagery was limited to such an extent that it was difficult to develop detailed timelines for burning on the four faces of the building.

In the following sections, the available imagery is reviewed and used to deduce as much as possible about the ignition, growth, and spread of the fires in WTC 7 prior to its collapse at 5:20:52 p.m. Detailed maps of the fires derived from these images are collected in Section 5.6.4.

\section{Fires above the $14^{\text {th }}$ Floor}

Prior to 12:10 p.m., there was no evidence of fire on the upper floors of WTC 7. Between 12:10 p.m. and 2:10 p.m., the only fires directly or indirectly observed were on Floors 19, 22, 29, and 30.

The earliest visual evidence showing flames in WTC 7 is a video clip of the southwest corner that was recorded between 12:10 a.m. and 12:25 p.m. Figure 5-109 is a frame from this video. Flames are visible in open windows 22-14A and 22-15A. Some smoke is visible flowing from both of these windows, with the heaviest flow on the south face. Windows to the north of window 22-14A were intact at that time. In 
this close up it is easy to identify Column 14 through window $23-13 \mathrm{~B}$ on the $23^{\text {rd }}$ floor and Column $14 \mathrm{~A}$ through windows $21-14$ and $21-14 \mathrm{~A}$ on the $21^{\text {st }}$ floor.

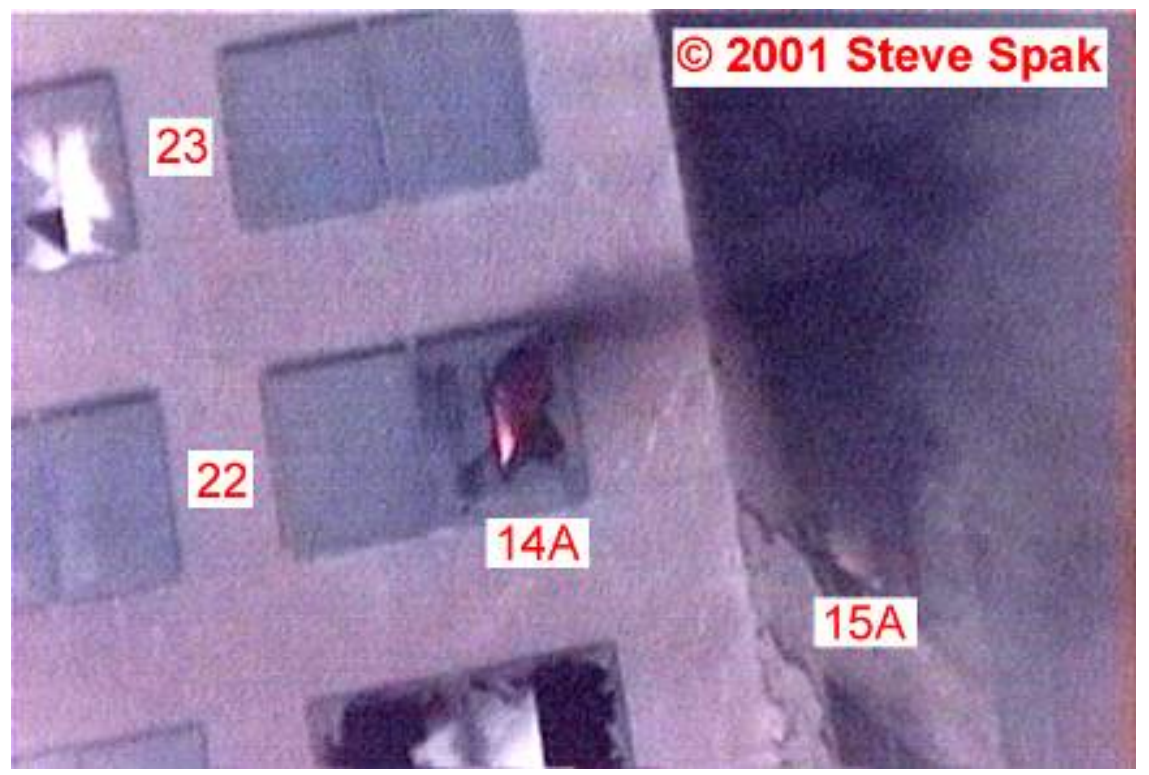

Figure 5-109. Frame from a video clip showing the southwest corner of WTC 7 around the $22^{\text {nd }}$ floor.

The clip was recorded from West Street near its corner with Vesey Street between 12:10 p.m. and 12:25 p.m. Intensity levels have been adjusted, and floor and window numbers have been added.

Figure 5-110. Cropped photograph showing a portion of the west face of WTC 7 near the south edge at 12:27:30 p.m. $\pm 1 \mathrm{~s}$ from near the corner of Vesey and West Streets.

The Verizon Building is in the foreground. The intensity levels were adjusted, and floor numbers have been added.

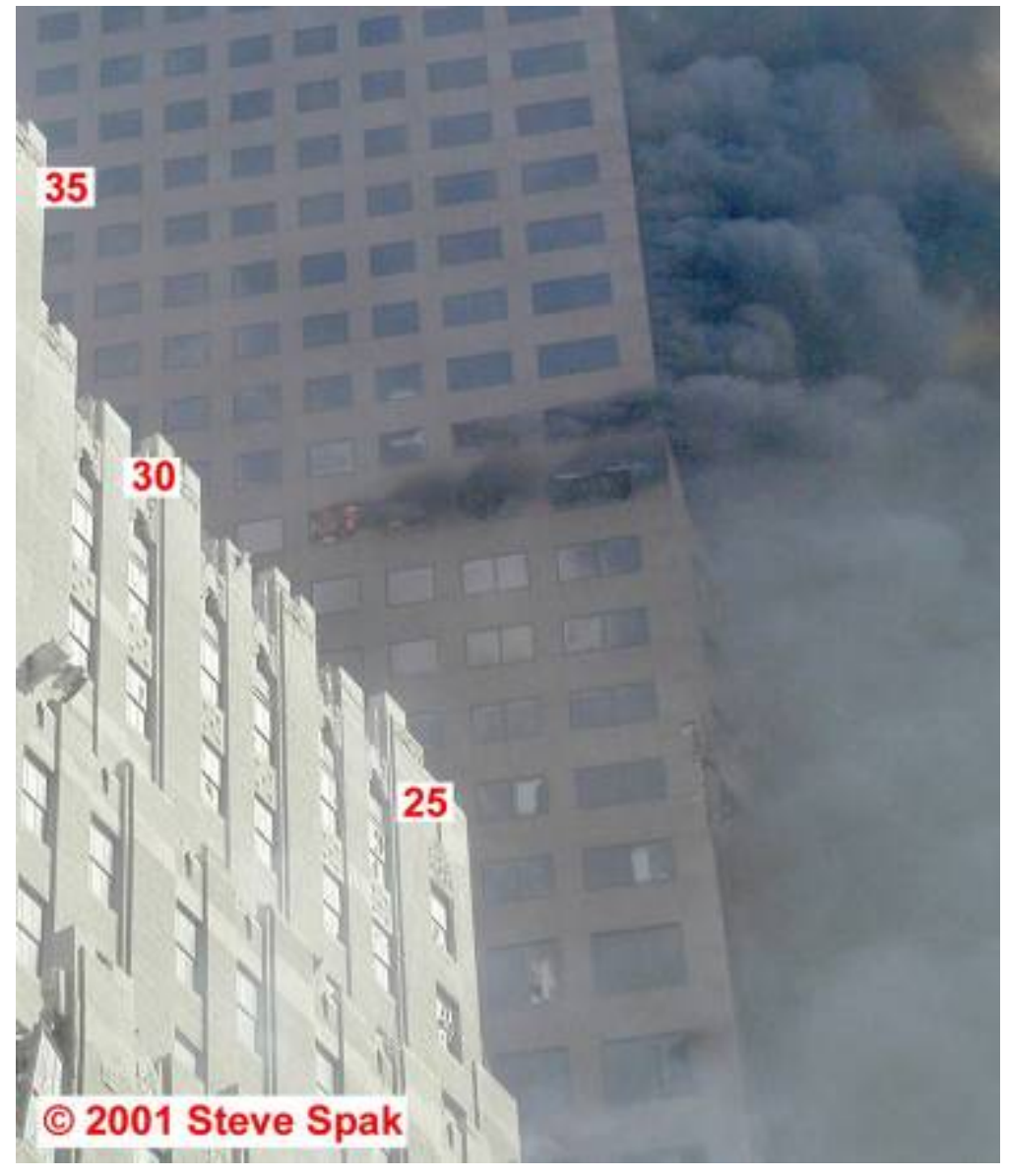


A larger area of the west face near the south edge is visible in the photograph shown in Figure 5-110, which was taken shortly after Figure 5-109 at 12:27:30 p.m. At this time flames were not evident in window 22-14A, but light smoke continued to flow from the window. Higher up on the face, smoke was coming from the six adjacent open windows 29-11 to 29-14A on the $29^{\text {th }}$ floor, with heavy flames filling windows 29-11 and 29-12. As discussed in Section 5.5.2, the condition of windows 29-13A to 29-14A immediately following the collapse of WTC 1 could not be determined, while the glass was intact in windows 29-11 and 29-12. This suggests that the fire burning on this floor had opened windows 29-11 and 29-12 by 12:27:30 p.m.

Heavy smoke was also coming from open windows $30-13 \mathrm{~A}$ to $30-14 \mathrm{~A}$ on the $30^{\text {th }}$ floor at this time. This suggests that a fire was also burning on this floor, but flames are not apparent in Figure 5-110. In a long distance view from the same short video clip from which Figure 5-109 was taken, these windows appeared to be intact. This indicates that the fire burning on this floor broke the glass from these windows during the short time period between the times when Figure 5-109 and Figure 5-110 were taken.

The appearance of the smoke on the south side of WTC 7 in Figure 5-110 demonstrates a difficulty that plagued attempts to use smoke to provide qualitative information about fire behavior. There appears to be relatively light-colored smoke on the south face at all of the floors visible in the image, while much denser and darker, rapidly rising smoke appeared to be flowing from windows near the west edge of the $30^{\text {th }}$ floor. Due to the wind direction, it was common for smoke to "bank up" against the south face. For this reason, it was usually not possible to differentiate different types of smoke or to identify smoke source locations on the south face. Viewing difficulties resulting from the large amount of smoke on the south face were discussed earlier.

Figure 5-111 shows another view of the fires at the southwest corner on the $29^{\text {th }}$ and $30^{\text {th }}$ floors taken within a few minutes of Figure 5-110. At this time flames were visible on both floors. The appearance of the fires on the $29^{\text {th }}$ floor is similar in both images. However, unlike in Figure 5-110, intense flames are visible on the $30^{\text {th }}$ floor. Flames are apparent in windows 30-14, 30-14A, 30-15, and 30-16A to 30-16C. In the video it is clear that flames were coming from multiple windows on the south face. This is an indication that a fully developed flashed over fire was present in the corner of this floor at this time.

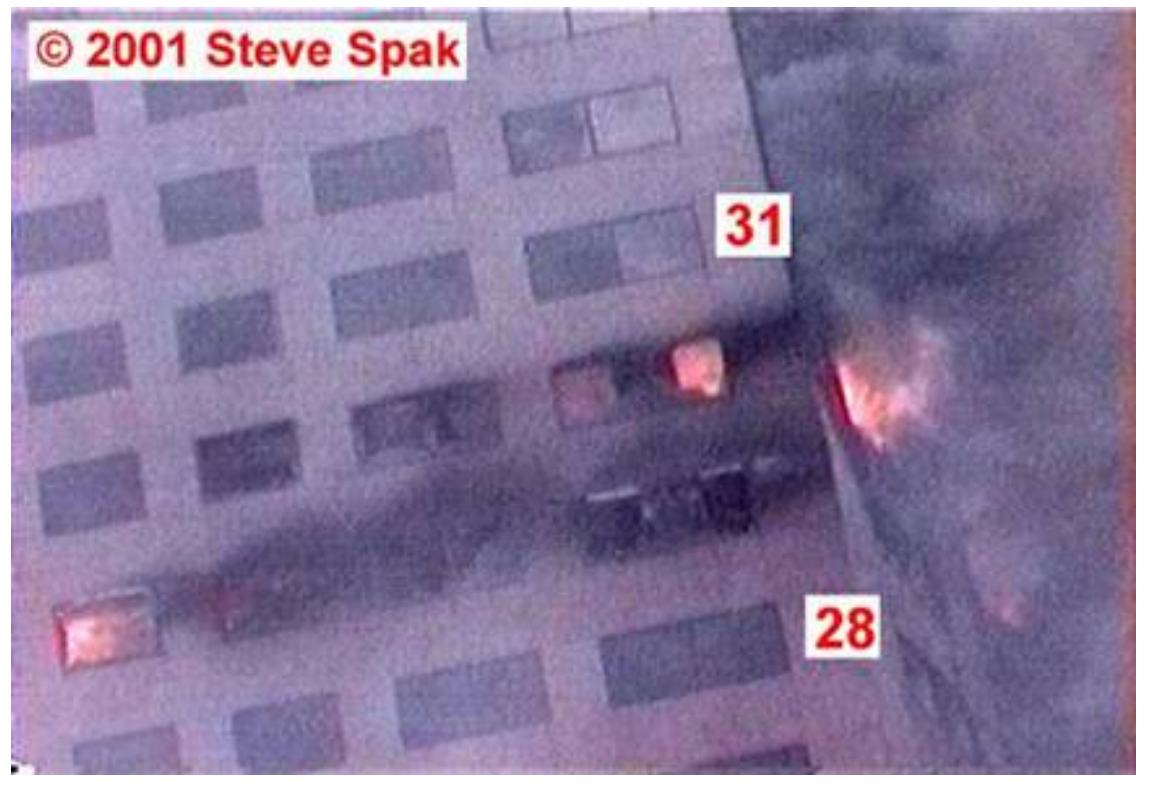

Figure 5-111. Frame from a video clip showing fires near the southwest corner of WTC 7 on the $29^{\text {th }}$ and $30^{\text {th }}$ floors around 12:28 a.m. \pm 3 min. The clip was recorded from West Street near its corner with Vesey Street. Intensity levels have been adjusted, and floor numbers have been added. 
Photographs show that by 12:47 p.m., flames were no longer evident inside any of the open windows on the $29^{\text {th }}$ or $30^{\text {th }}$ floors, and the fires had apparently not progressed further north on the west face, since no additional windows had been broken out. Taken together, these observations suggest that intense fires which grew in the southwest corners of these floors starting around noon had died down by 12:45 a.m. after burning intensely for a short period of time.

Photographs taken around 12:47 showed that the smaller fire seen earlier in window 22-14A had also died down, as can be seen in Figure 5-66. This fire had not grown sufficiently large to break additional windows along the west face. Interestingly, in a video clip shot just before 1:30 p.m. smoke is visible flowing from window 22-14. Apparently, a dormant fire had eventually grown large enough to break the glass in this window. Figure 5-67 shows a view of the west face taken from above much later, between 2:30 p.m. and 3:00 p.m. It appears that the four windows, 22-13A to 22-14A, near the south edge were open at that time. Apparently, the fire on this floor spread very slowly to the north before dying out. Distinct smoke marks are visible above windows 19-14 and 19-14A in Figure 5-66, which was taken at 12:47:40, indicating that a fire had been present in the southwest corner of this floor prior to this time.

There are no images showing flames or other evidence of active fires above the $14^{\text {th }}$ floor after about 1:00 p.m. No images showing flames on the south face or near the south edge of the west face of any floor of WTC 7 are available at times after 1:30 p.m.

\section{Fires on or below the $13^{\text {th }}$ Floor prior to 1:30 p.m.}

There are no photographs or videos of any fires on the lower floors of WTC 7 before 1:30 p.m., although a witness saw a fire on the southwest corner of the $7^{\text {th }}$ floor at about 12:15 p.m., before being rescued (Chapter 6). In the videos and photographs of WTC 7 taken from West Street between 12:00 p.m. and 1:30 p.m., smoke can often be seen flowing along the outer walls of lower floors of the west face at the south edge. Since the wind was blowing from the north and the visual evidence indicates no substantial fires were burning on or near Washington Street, this suggests that fires were burning on lower floors of the west face during this time, but it was not possible to identify windows where the smoke originated.

\section{Fires on or below the $13^{\text {th }}$ Floor on the West Face, 1:30 p.m. to 2:30 p.m.}

Images showing the initial spread of fire across floors on the west side of WTC 7 are very limited. Figure 5-112 shows a view of the west face taken in the early afternoon. Based on shadows apparent on the face the time is estimated to be between 1:30 p.m. and 2:30 p.m. This photograph should be compared with Figure 5-88, which shows the same area of the face at an earlier time.

In Figure 5-112 smoke is visible coming from open windows 7-5 and 7-7 on the $7^{\text {th }}$ floor, and windows 76 and 7-8 appear to be open as well. In the earlier photograph, no smoke was evident coming from windows on this floor, and glass was in place in each of the open windows mentioned above. Light smoke is also visible coming from the louvers in window 7-2 in Figure 5-112. The glass in windows 7-1A, 7-1B, 7-3 and 7-4 was still intact when the photograph was taken. The presence of smoke and additional broken windows indicates that a fire had progressed toward the north edge of the west face on the $7^{\text {th }}$ floor by the time the photograph in Figure 5-112 was taken. Even though a fire was present that was capable of breaking out window glass, no flames are visible. It is possible that flames were present 
earlier and had died away or that the prevailing wind on the face pushed the flames into the building and that the smoke and possibly flames exited primarily through openings on the south face.

Smoke is also visible coming from open windows at a few other locations on the west face in Figure 5-112. Relatively heavy smoke appears to be coming from an open window on the $8^{\text {th }}$ floor near the southwest

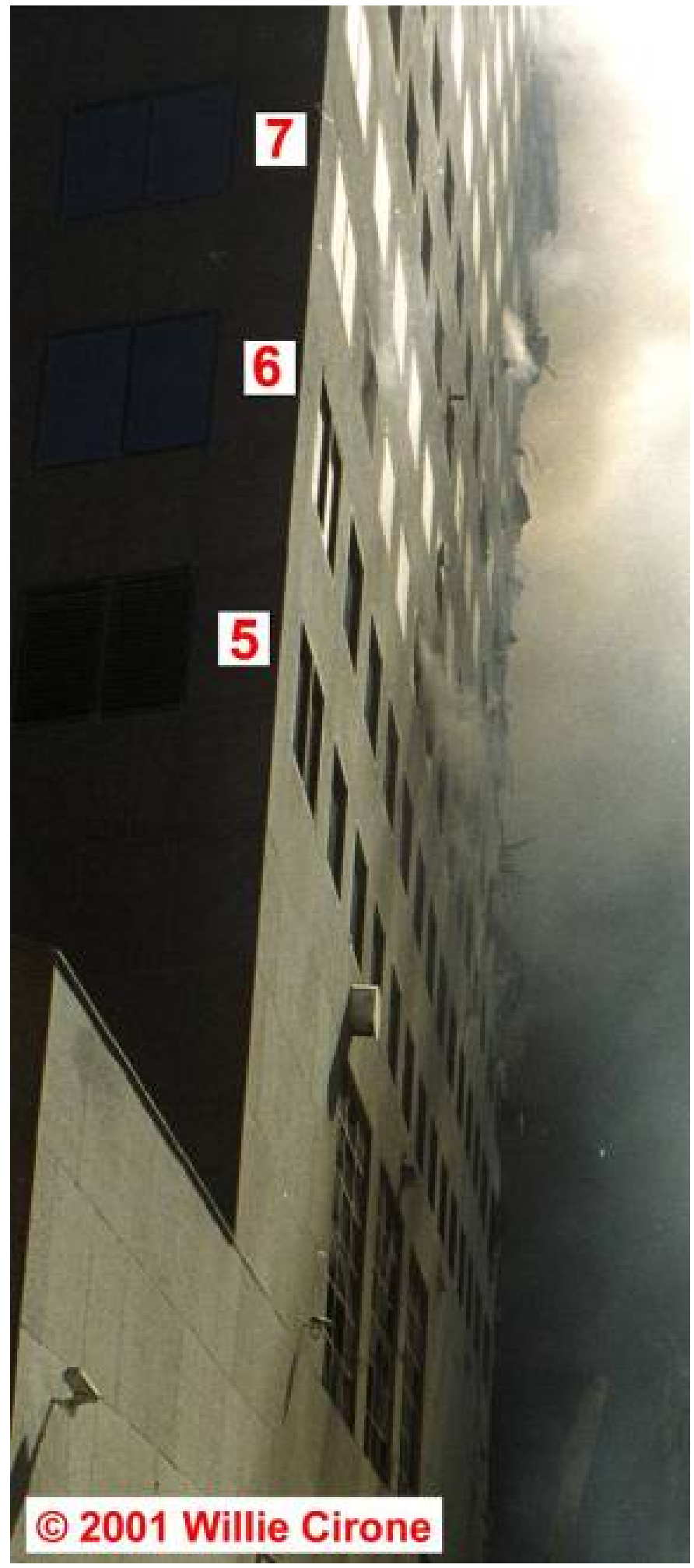

Figure 5-112. Cropped photograph shot from near the corner of Washington and Barclay Streets shows lower floors on the west side of WTC 7 between 1:30 p.m. and 2:30 p.m. The intensity levels have been adjusted, and floor numbers have been added. 
corner. This window was likely 8-10 or 8-11. Smoke is also coming from a window on the $12^{\text {th }}$ floor near the same corner. There does not appear to be significant smoke flow from other open windows at this time.

Figure 5-113 shows a portion of the aerial photograph in Figure 5-64, enlarged to emphasize the areas on lower floors near the northwest corner of WTC 7. This image was estimated to have been taken between 2:15 p.m. and 2:45 p.m. by relating it to other photographs taken earlier that show fires on the east side of WTC 7 and the south side of WTC 5 and by using shadows at various locations around the site.

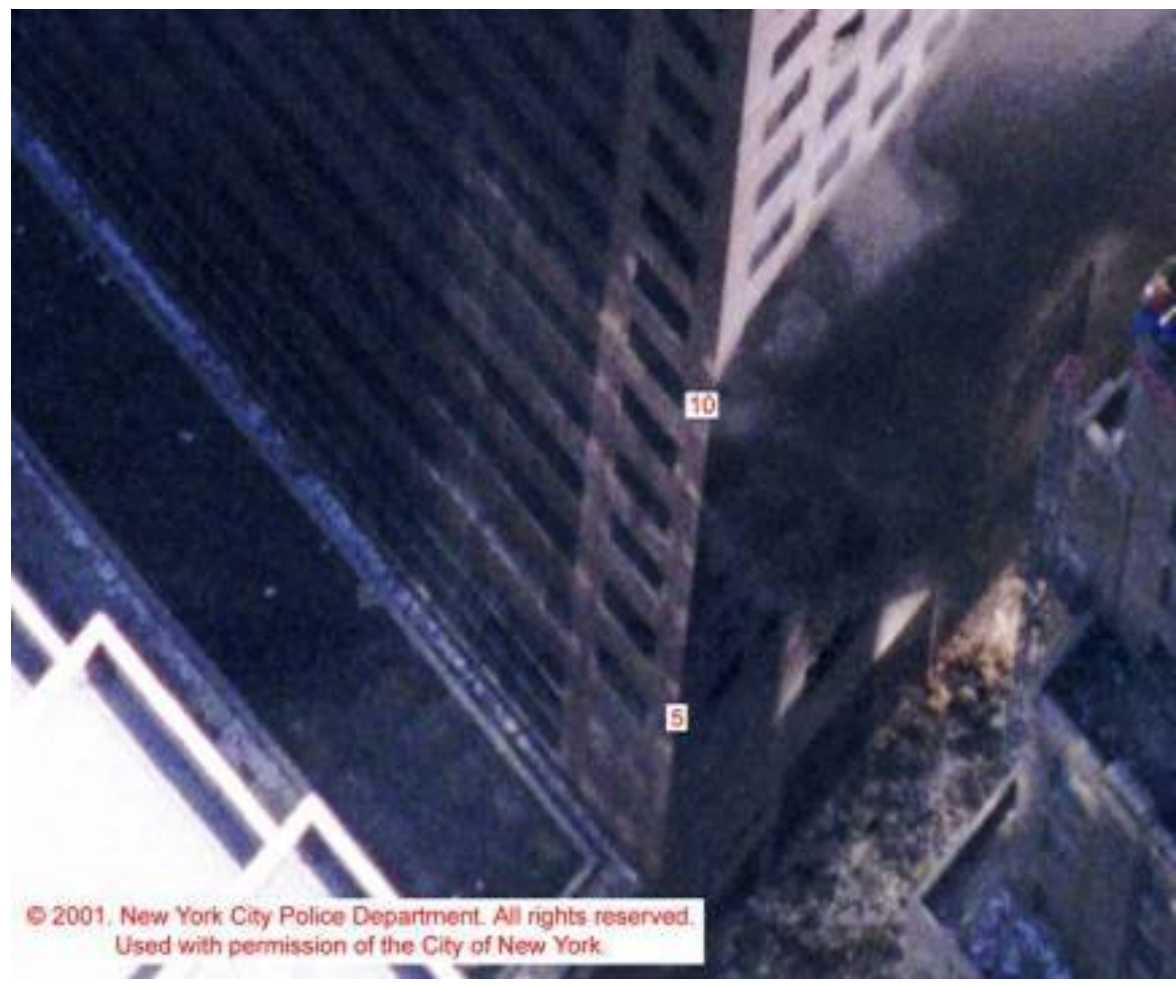

Figure 5-113.

Enlargement of a portion of the photograph shown in Figure 5-64 emphasizing areas on the lower floors of WTC 7 near the northwest corner.

The time is estimated as being between 2:15 p.m. and 2:45 p.m. The roof line of the building in the lower left hand corner is 123 Barclay Street.

Heavy smoke is visible passing over the west face, starting at a point close to the north edge of the building. This smoke appears to be coming from windows on the $7^{\text {th }}$ or $8^{\text {th }}$ floor. It likely was coming from windows on the $7^{\text {th }}$ floor, since fire appeared on the north side of this floor shortly after Figure 5-113 was taken, and there were indications of earlier burning to the south of this location on this floor. Note that there were no visual signs of fire or broken windows on the north face at that time.

Chapter 3 reports that the area between the west face and the core on the $7^{\text {th }}$ floor was not partitioned and had been filled with workstations. However, several years earlier, the people who occupied this space had been moved to the $13^{\text {th }}$ floor, and the $7^{\text {th }}$ floor space had been turned over to Silverstein Properties, which intended to use it for storage (Chapter 3). The relatively slow fire spread and apparently low intensity fires observed may indicate that there was limited combustible material in this space.

\section{Fires on or below the $13^{\text {th }}$ Floor on the East Face, 1:30 p.m. to 2:30 p.m.}

As discussed earlier, only one open window was apparent on the east face of WTC 7 during the period shortly following the collapse of WTC 1 . However, at some point during the early afternoon, fires appeared on the south side of the east face and began to spread to the north. Figure 5-114 shows the 
earliest photograph in the database with fire on the east face. It was taken at 2:08:28 p.m. Flames are present on the $12^{\text {th }}$ floor, and windows appear to be open on the $11^{\text {th }}$ floor. Due to the steep angle, it is difficult to identify exactly in which windows the fires were located.

Figure 5-115 shows a less oblique view of the fires on the east face taken at 2:11:09 p.m. An intense fire with external flaming covers windows $12-29$ to $12-34$ on the $12^{\text {th }}$ floor. Videos taken from the same location indicated that these fires grew substantially in the roughly $2 \frac{1}{2} 2 \mathrm{~min}$ period between Figure 5-114 and Figure 5-115. Windows 12-35 and 12-36 are open, but no flames are apparent. The remaining windows, including 12-27A and 12-27B at the south end of the floor, still have glass in place.

The heavy smoke coming from the windows on the $12^{\text {th }}$ floor rose rapidly and was pulled toward the north. This movement was due to the wind flow over the north face of the building, which created a low pressure region near the northeast corner.

The floor plan for the $12^{\text {th }}$ floor (Chapter 3) indicates that this area was divided into a number of walled offices, including one in the southeast corner with partitioned walls between Columns 27 and 28 and near Column 29. It is likely that these office walls slowed fire spread into the southeast corner. The floor plan suggests that fire may have spread onto the east face from the south by moving along a corridor.

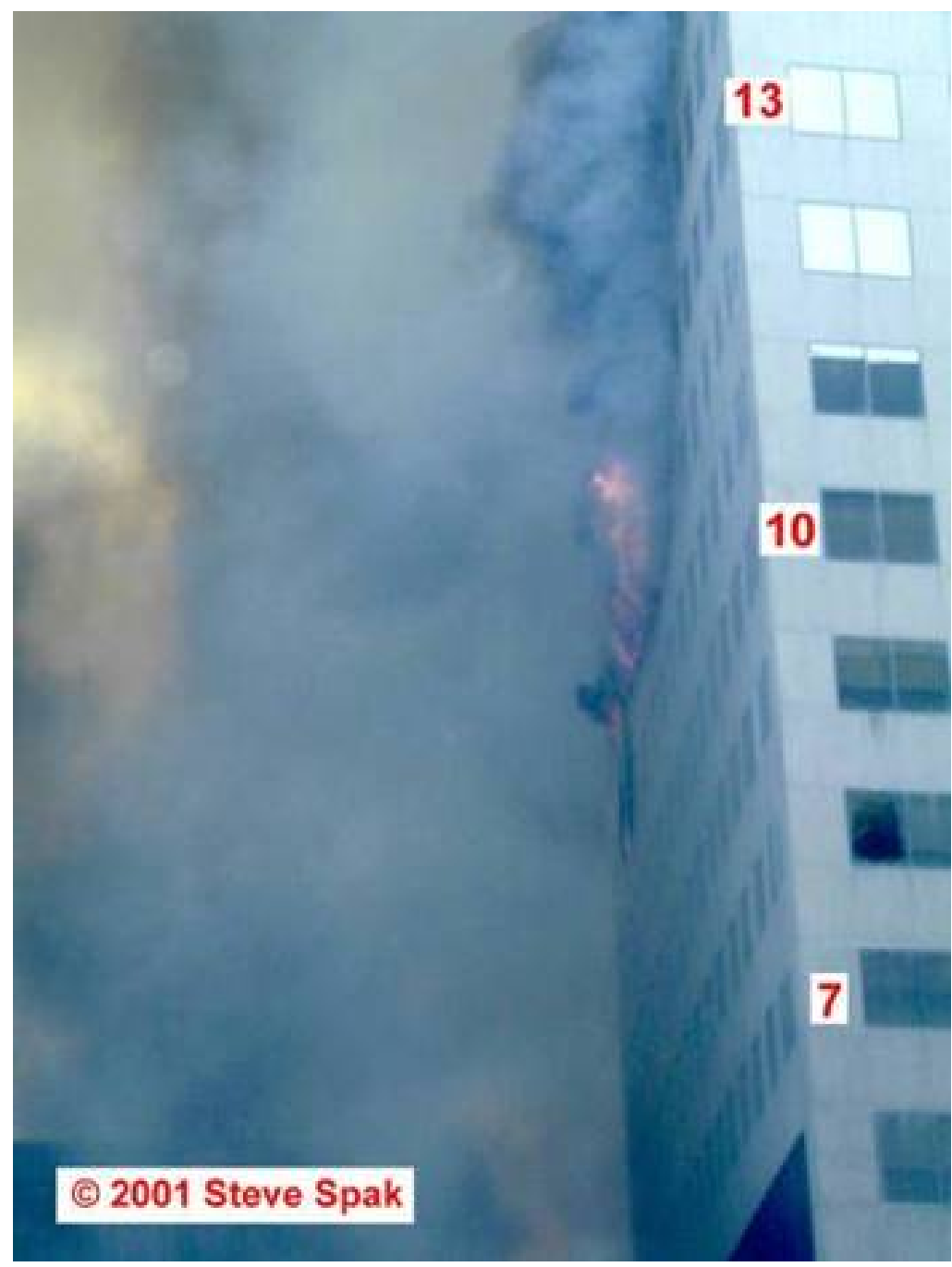

Figure 5-114. Oblique view of the east face of WTC 7, taken at 2:08:28 p.m. \pm 1 s from West Broadway near its corner with Park Place.

Floor numbers have been added. 
Two windows, 11-29 and 11-30, were also open on the $11^{\text {th }}$ floor at 2:11:09 p.m. Upon closer inspection, it is possible to identify a dull red glow through these open windows. The smoke patterns visible above these windows indicate that a more intense fire had burned there earlier and had subsequently died down. The floor plan for the $11^{\text {th }}$ floor (Chapter 3) was similar to that for the $12^{\text {th }}$ floor, and interior walls were present on either side of these two windows. Apparently, these walls slowed the fire spread into enclosed spaces on either side.

Over the next several minutes, the fire on the $12^{\text {th }}$ floor broke additional window glass. Between 2:13:04 p.m. and 2:14:09 p.m., windows 12-28A and 12-28B opened at the south edge of the face, and flames were observed through these windows shortly afterward. Figure 5-116 is a frame taken from a video showing the fires on the east face of WTC 7. The exact time when it was shot is unknown, but it was during a 12 min period starting at 2:15 p.m., based on the appearance of the face compared to photographs for which times were accurately determined. Intense flames were coming from multiple windows on the $12^{\text {th }}$ floor. The arrow indicates a large section of window pane that suddenly fell out of the frame for window 12-37. Heavy smoke poured from the window after it opened, but flames were not immediately evident.

Several video clips showing the east face of WTC 7 are available between 2:15 p.m. and 2:29 p.m. The exact times for these clips are not known. In the clip shot immediately after the one shown in Figure 5-116, window 11-32 on the $11^{\text {th }}$ floor had already broken, and the glass in window 11-33 suddenly fell outward. Low intensity flames appeared in window 11-32 shortly afterwards. By the time the next clip started, windows 11-31 and 11-34 were open, and growing flames were visible through windows 11-31 to 11-34. In this clip, heavy smoke appeared, and flames erupted from window 11-34, likely an indication that flashover occurred at that time. Heavy smoke and flames continued to come from these four windows over the next several minutes.

Figure 5-115. Cropped photograph showing fires on the east face of WTC 7 at 2:11:09 p.m. \pm 1 s.

The intensity levels have been adjusted, and column and floor numbers have been added.

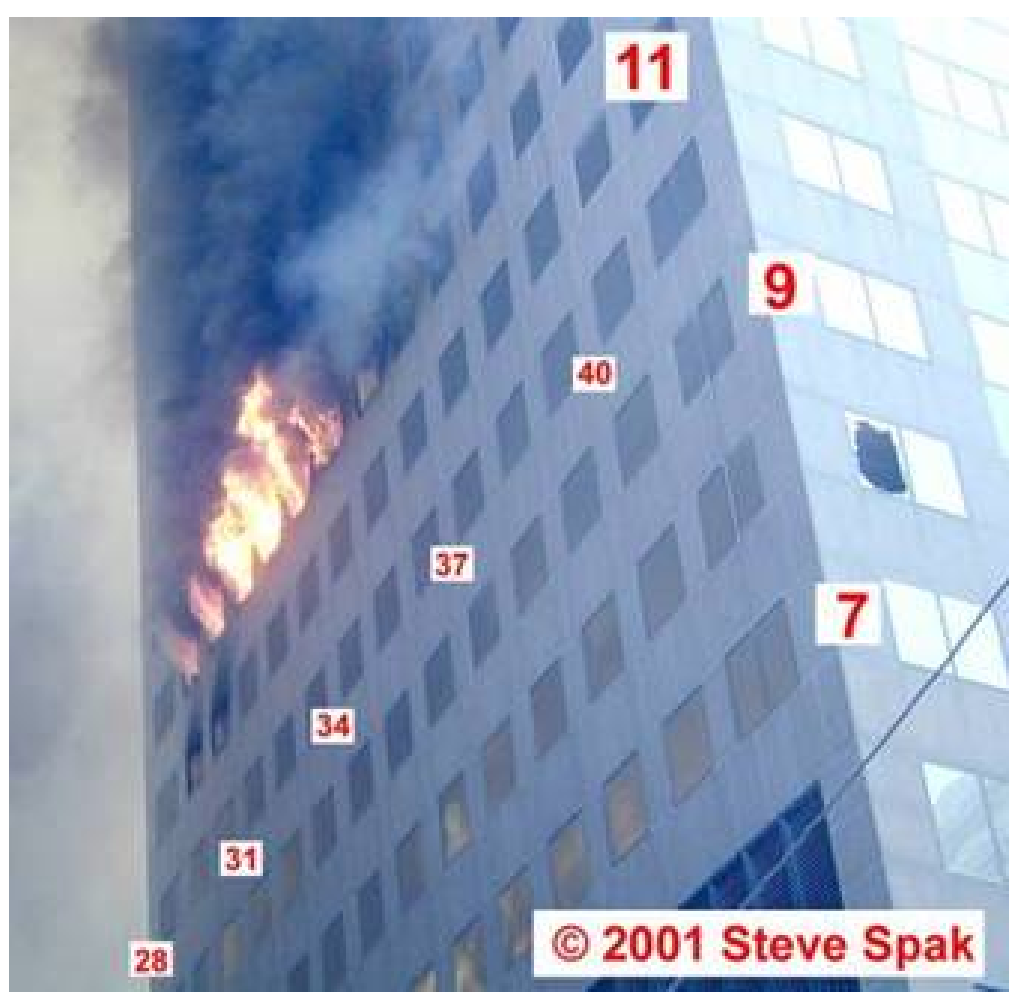




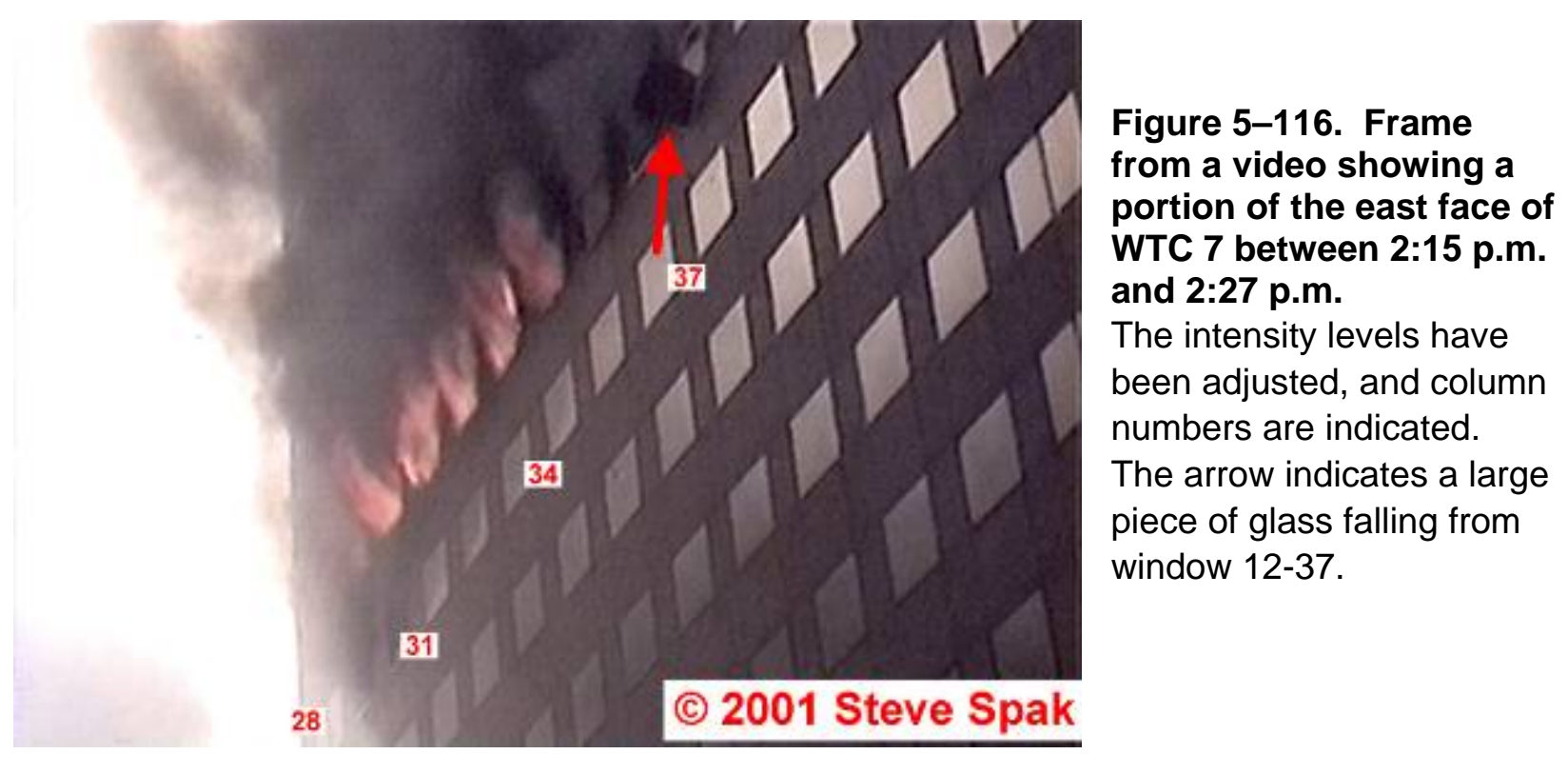

Figure 5-117 is another photograph of the east face, taken at 2:28:43 p.m. On the $12^{\text {th }}$ floor, flames are visible in windows 12-28 to 12-36, with flame extension present from several windows. Heavy smoke was coming from window 12-37 at this time, but flames were not evident. In general, the fire intensity appeared to have declined since the image in Figure 5-116 was recorded. Note that no additional windows had opened on this floor since the time of Figure 5-116. The glass in window 12-38 has a different appearance than other intact windows to the north and appears to be darkened by smoke.

At 2:28:43 p.m., the number of open windows on the $11^{\text {th }}$ floor had increased by one, since window 11-35 was now open. A check showed that the glass was still in place in this window when the last video clip of this face was recorded by the photographer. Interior flames were still visible in windows 11-31 to 11-34, but neither smoke nor flames were evident in open window 11-35. Windows 11-28A and 11-28B at the south edge still had glass in place.

The latest full view of the lower floors on the east face in the Investigation database is shown in Figure 5-118. The time for this image is not known, but it was likely several minutes later than the photograph reproduced in Figure 5-117. On the $12^{\text {th }}$ floor, window 12-37, which was open with a heavy smoke flow at 2:28:43 p.m., now has long extended flames, while window 12-38, which had darkened glass in place at 2:28:43 p.m., is now open with a heavy smoke flow. The glass in the four windows between window 12-38 and the north edge of the face appears to have been intact at this time. On the $11^{\text {th }}$ floor, intense flames are jetting out of window 11-35. In Figure 5-117, this window was open, and interior fire was visible as an orange glow. At the later time, the glass in window 11-36, which was in place at 2:28:43 p.m., has been broken, and an interior fire can be seen through the open window.

The fires observed on the east sides of the $11^{\text {th }}$ and $12^{\text {th }}$ floors slowly spread to the north. The floor diagrams in Chapter 3 indicate that these fires were spreading through a series of enclosed offices located along the face.

Closer inspection of Figure 5-118 reveals that three windows appear to be open on the $13^{\text {th }}$ floor. The glass in window 13-31 is missing, while there appears to be fire visible in windows 13-33 and 13-34. These are the first indications that a fire may be growing on the east side of the $13^{\text {th }}$ floor, in addition to 
those evident on the $11^{\text {th }}$ and $12^{\text {th }}$ floors. Since windows $13-28$ A to $13-30$ seem to be intact, it is possible that these fires spread in the interior from fires on the south side of the building or that the window breakage and fire ignitions on the $13^{\text {th }}$ floor were due to heat transfer from flames extending upward from open windows on the $12^{\text {th }}$ floor.

In Figure 5-118, no smoke or fire is evident on floors below the $11^{\text {th }}$ floor. This includes the $5^{\text {th }}$ and $6^{\text {th }}$ floors, where intake and exhaust louvers were located. (See floor diagrams in Chapter 3.) It is possible to see windows along the south edge of the building up to the $22^{\text {nd }}$ floor. There are no indications of open windows between the $14^{\text {th }}$ and $22^{\text {nd }}$ floors.

\section{(C) 2001 Steve Spak}

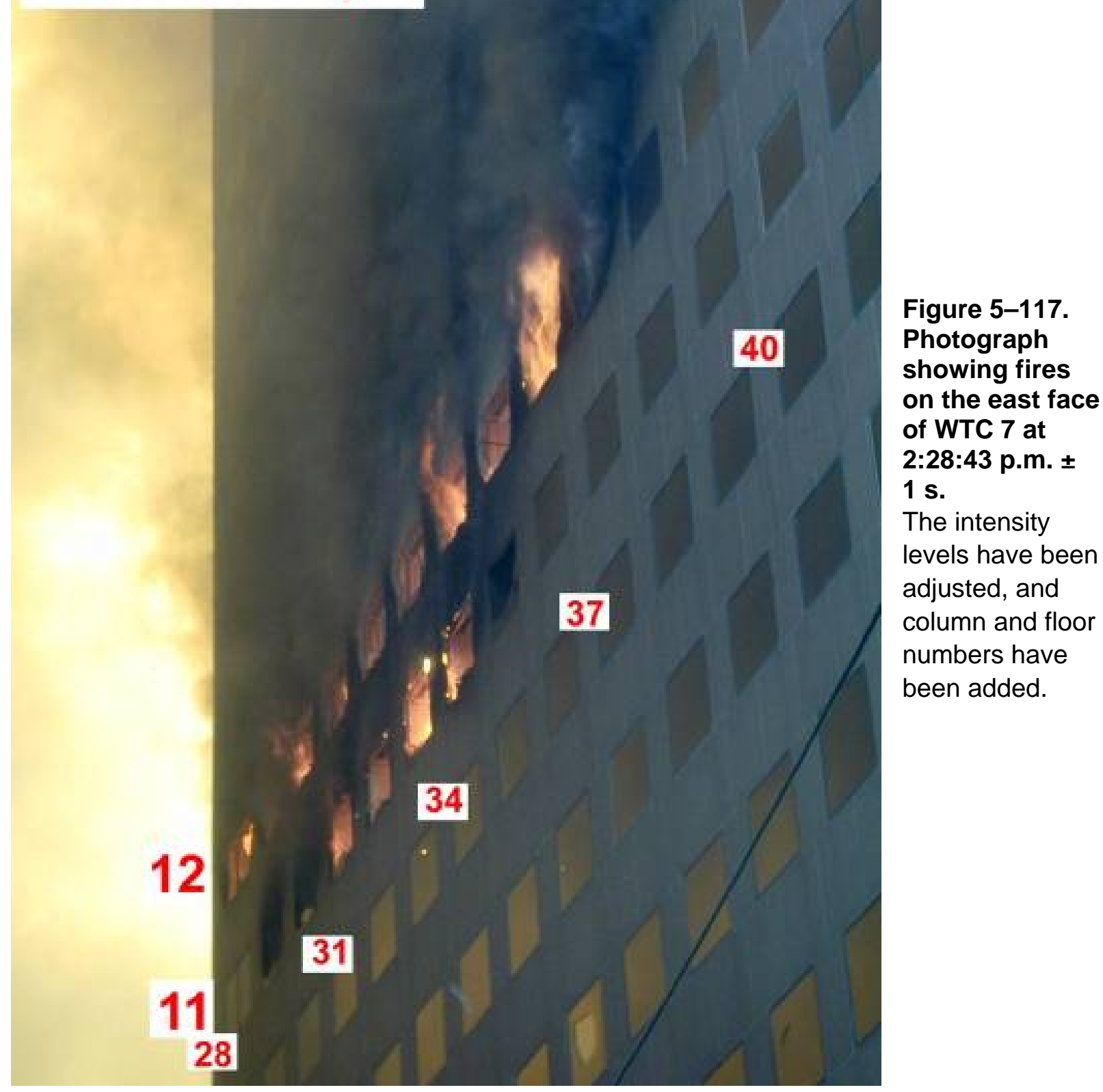


Only partial and long distance views of the east face were available after the time when the photograph in Figure 5-118 was taken. While not known definitely, it seems likely that the immediate area around WTC 7 was more securely cordoned off by security personnel starting around 2:30 p.m. due to the growth of large fires on the east face and later on the north face. If so, potential photographers and videographers would have had a more difficult time reaching locations where this face could be observed.

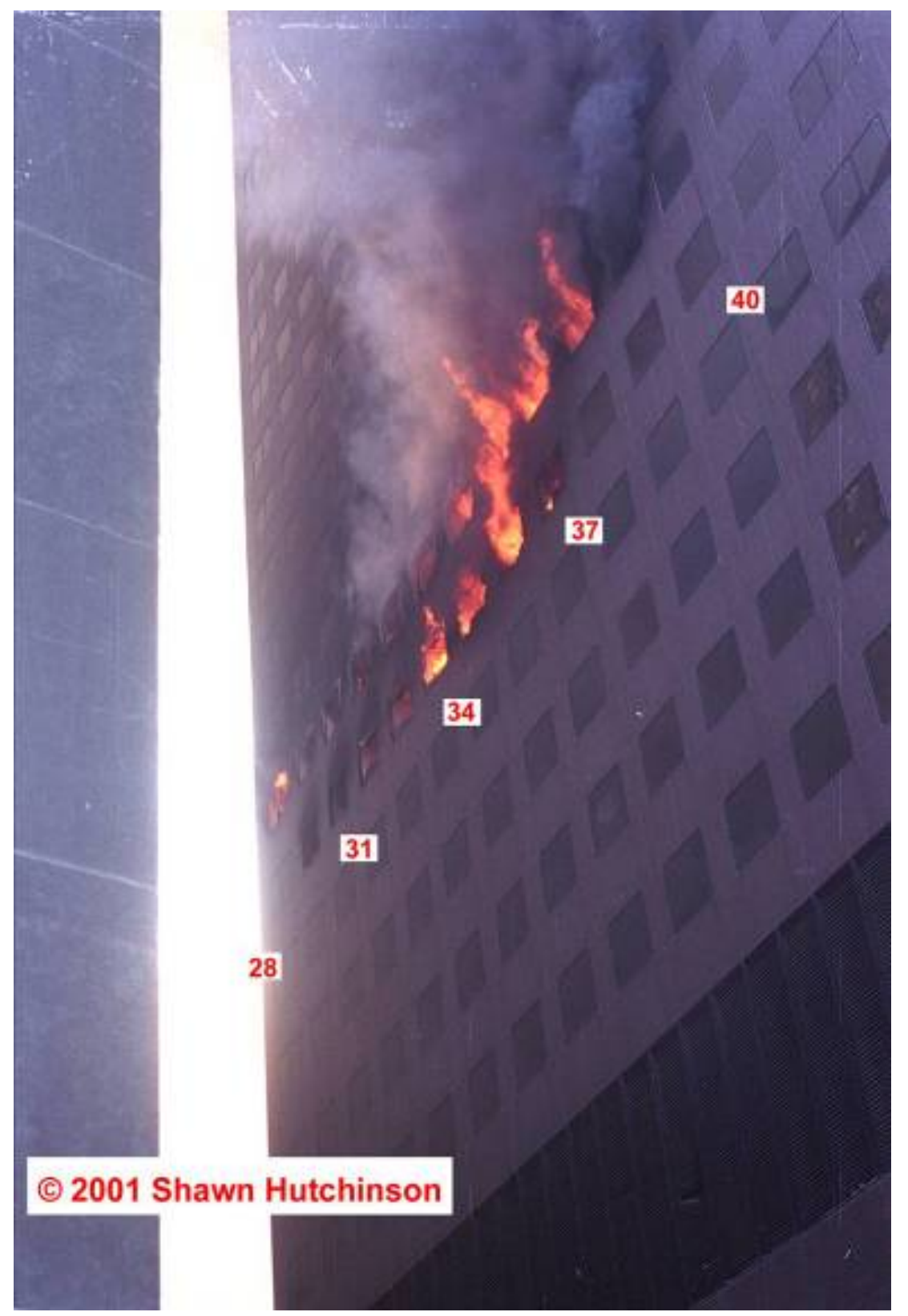

Figure 5-118. Photograph of the east face of WTC 7 taken at some time after 2:28:43 p.m. from near the corner of West Broadway and Barclay Street.

The building to the left is the U.S. Post Office. The intensity levels have been adjusted, and column numbers have been added.

\section{Summary: Fires on or below the $13^{\text {th }}$ Floor, 1:30 p.m. to 2:30 p.m.}

The discussion thus far has shown that around 2:30 p.m. in the afternoon, fires were burning toward the north on the east and west faces of WTC 7 and were approaching the north face. On the west side, fire had been observed on the $7^{\text {th }}$ floor, while on the east side, actively spreading fires were present on the $11^{\text {th }}$ and $12^{\text {th }}$ floors, and there were indications that fire had appeared on the $13^{\text {th }}$ floor toward the south side of 
the east face. Imagery recorded near the end of this period provided no indication of fire or additional broken windows on the north face.

\section{Fires below the $14^{\text {th }}$ Floor on the North Face, 2:57 p.m. to 3:42 p.m.}

There is a substantial time gap in available imagery between the times when Figure 5-113 and Figure 5-118 were taken and the next available image (Figure 5-119) that provides useful information about the fire distribution. The photograph in Figure 5-119 was shot on film, and it was difficult to determine exactly when it was taken. Fortunately, a series of time-stamped digital photographs shot from high on a building to the north on Greenwich Street around the same time provided a view of sunlight and shadows on the roof of the building at 70 Murray Street. (See Figure 5-2.) This roof was also visible in photographs from the same film roll shot prior to and after the image reproduced in Figure 5-119. Using changes in these light and shadow patterns, it was possible to determine that the photograph was taken around 2:57 p.m. The uncertainty in this time is estimated as $\pm 5 \mathrm{~min}$.

The photograph in Figure 5-119 provides a great deal of detail. For instance, it is possible to discern the open windows 8-42A and 8-47B. During the time from roughly 2:30 p.m. to 3:00 p.m. fires had moved to the north face of WTC 7 on both the $7^{\text {th }}$ and $12^{\text {th }}$ floors. The fires on the $12^{\text {th }}$ floor seemed to be just beginning to grow. There is one area of relatively intense orange flame visible through open window 12-45C, and smaller, more reddish flames are visible in windows 12-44C, 12-44D, and 12-45A.

Fire on the north side of the $12^{\text {th }}$ floor first appeared at locations well removed from the eastern edge. Fires had been observed earlier spreading along the east side of the building. The floor diagram in Chapter 3 indicates that there were a series of small offices on the north face that opened onto a corridor that ran from the east side to the west side. The fact that the fires appeared in offices located about 1/3 of the way across from the east edge suggests that the fire took an internal pathway, perhaps along this corridor, to reach these offices.

The fires spreading on the $7^{\text {th }}$ floor displayed a different behavior than those on the $12^{\text {th }}$ floor. By the time Figure 5-119 was taken, this fire had spread over at least 18 windows running from windows 7-50B to 7-54C. All of these windows appeared to be open, with the possible exception of window 7-51A, which was adjacent to Column 51. Note that windows to the west of 7-54C are hidden from view by the building at 123 Barclay Street, and it is not possible to determine where these fires first reached the north side. Several small spot fires are visible through the open windows. The most intense burning area was at windows 7-50C and 7-50D.

A much closer view of the windows near Column 51 on the $7^{\text {th }}$ floor is shown in Figure 5-120. This image is taken from a video clip that was recorded shortly after the photograph in Figure 5-119. The fire visible through window 7-50B had grown somewhat. The flames in this area appear to fill the volume. For some of the windows, only a portion of the glass was broken. It is possible to make out some interior details. For instance, a burning desk is visible through windows 7-50C and 7-50D. In the video, a large object was observed falling from the ceiling through windows 7-51B to 7-51D. Even though the flames are locally heavy, little smoke or flame exited through nearby open windows.

The observations indicate that a relatively low intensity fire with sufficient heat release to break nearby windows spread rapidly across the north edge of the building on the $7^{\text {th }}$ floor. As noted earlier in this chapter, the tenants had been relocated from the western half of the floor, probably reducing the fuel load. 
Consistent with this, the apparent low fire intensities suggest that the fuel load or burning rate was insufficient to induce flashover in this large space.

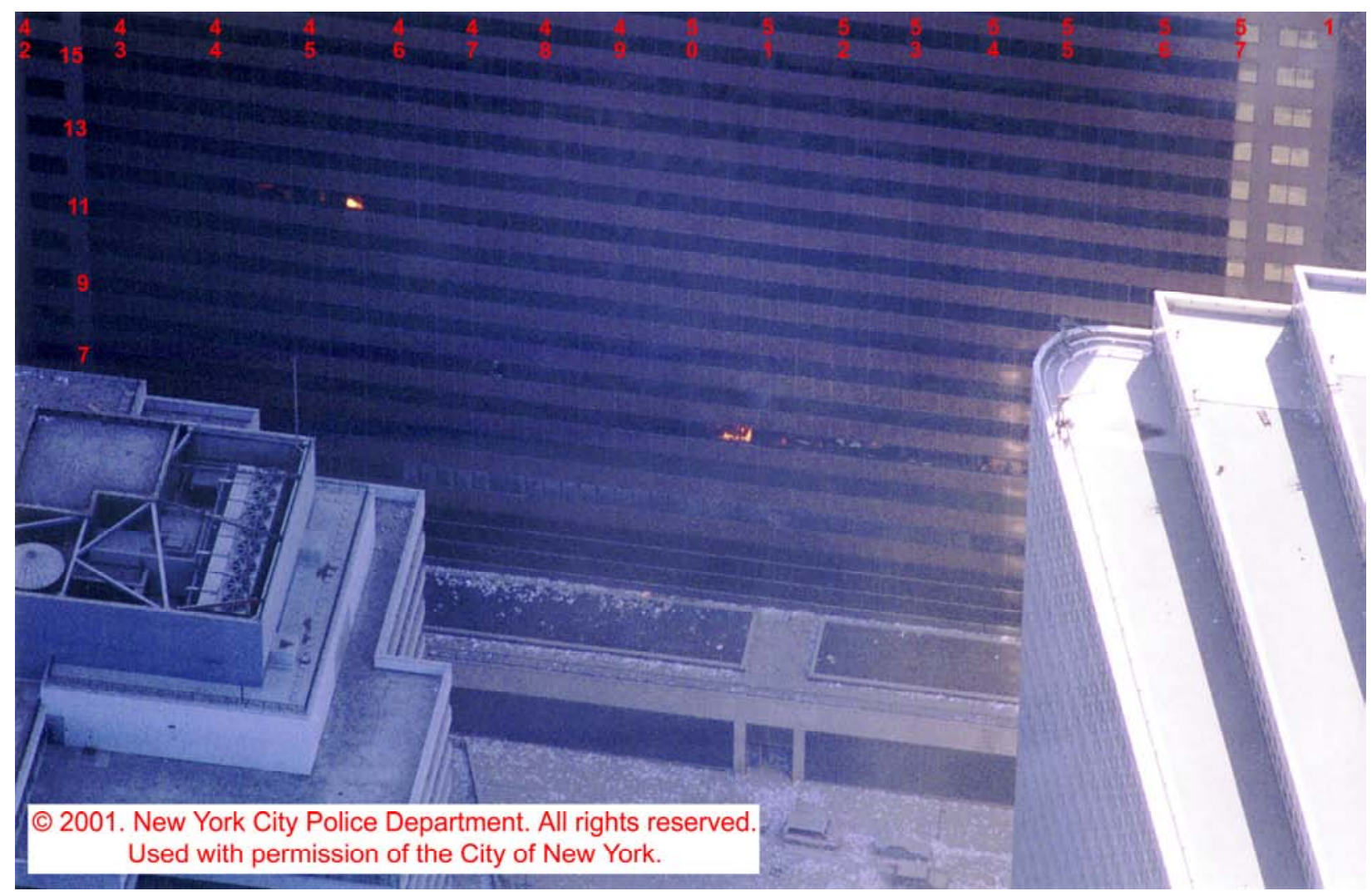

Figure 5-119. Photograph showing the north face of WTC 7 taken from a helicopter around 2:57 p.m. \pm 5 min.

The intensities have been adjusted, and column and floor numbers have been added.

Only very light smoke can be seen coming from the open windows on the $7^{\text {th }}$ and $12^{\text {th }}$ floors. Even though the fires were relatively small, they would be expected to release much more smoke than was observed. It is likely that this smoke was being vented elsewhere from the building, perhaps at locations on the east or south faces. This would be the expected behavior if internal flow pathways were available to these faces due to the positive pressure created at the open windows on the north side by the ambient wind flowing over this face and the corresponding low pressure areas created on the leeward faces.

Figure 5-121 shows another aerial view of the north face taken several minutes after Figure 5-119. The time for this photograph was estimated to be 3:05 p.m. $\pm 5 \mathrm{~min}$ in the same way as for Figure 5-119. During the approximately 8 min between the two images, the fire distributions on the $7^{\text {th }}$ and $12^{\text {th }}$ floors changed noticeably. On the $12^{\text {th }}$ floor, the nascent fires visible in Figure 5-119 have spread to cover windows 12-43C to 12-45E and have grown dramatically in intensity. The drywall-enclosed columns are easily identified through the open windows because they show up as dark areas where they block the flames from view. 


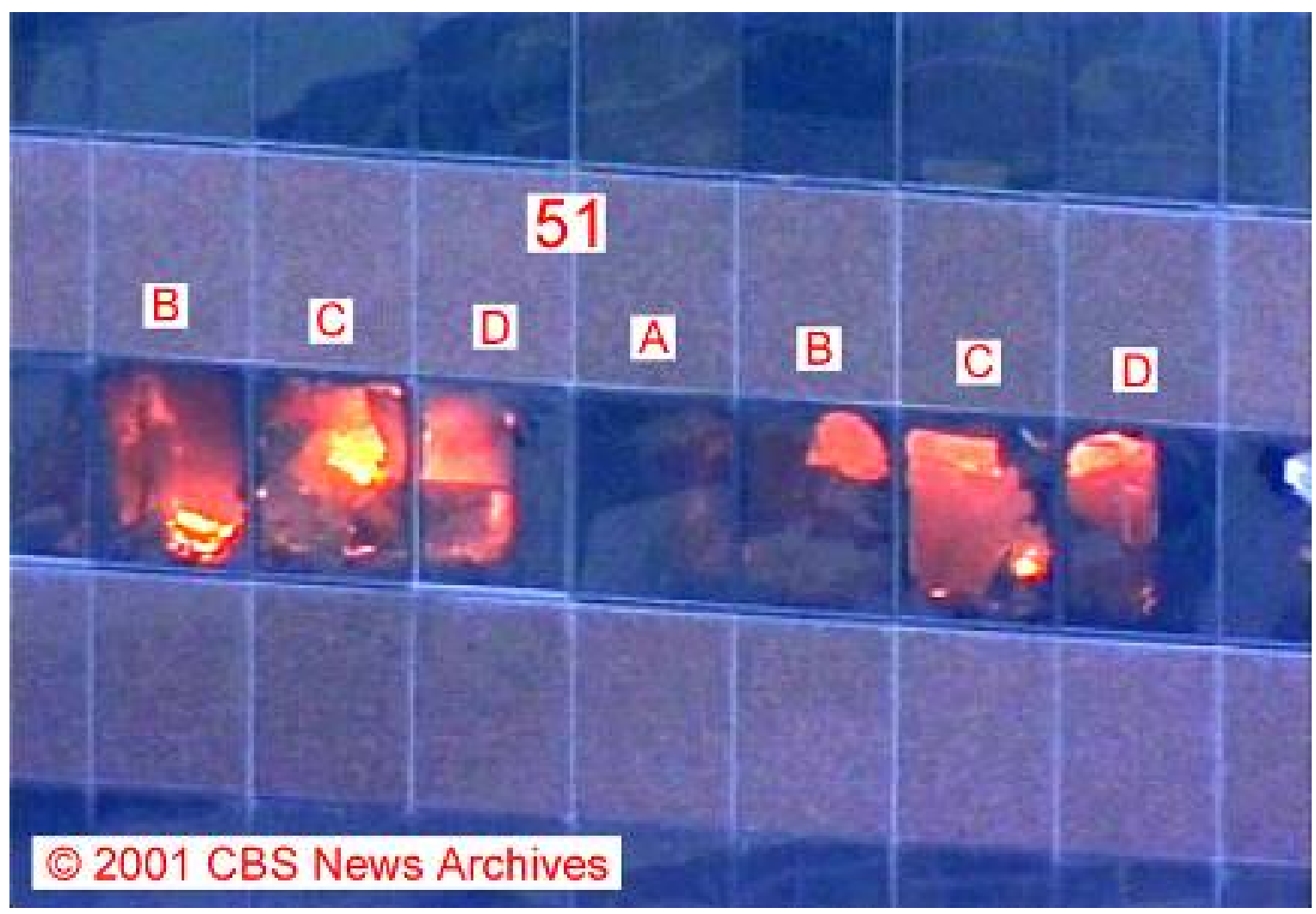

Figure 5-120. Frame taken from a video clip shot looking down on WTC 7 from a building to the northwest showing the fires along a length of the north side of the $7^{\text {th }}$ floor of WTC 7.

The video clip was recorded shortly after the photograph in Figure 5-119 was taken. The intensities have been adjusted and window numbers added.

A closer view of the fires burning on the $12^{\text {th }}$ floor around this time is shown in Figure 5-122. The flames appear to fill the space over the several windows that are visible. Some details are evident inside the building. There appears to be a large file cabinet visible against a wall through window 12-45B. Flames are visible behind window 12-45E, but only a small section of glass seems to have broken out.

Reference to the floor plan in Chapter 3 indicates that the fires on the $12^{\text {th }}$ floor extended over at least four different offices at this time. The fires appeared to be fully developed, completely filling the open windows, suggesting that they were flashed over. Even so, relatively little smoke and flames were coming from the open windows. This behavior can be contrasted with the large flame extensions observed earlier from open windows on the east face of this floor. As discussed above, these differences are likely due to the ambient wind field.

An aerial view of the north face of WTC 7 taken from a much longer distance than Figure 5-119 and Figure 5-121 is shown in Figure 5-123. The time of this photograph was estimated in the same way as the earlier aerial shots as 3:10 p.m. with a \pm 5 min uncertainty. Flames were only visible on the $12^{\text {th }}$ floor from this distance and angle. The fire had spread to the east and west in the roughly 5 min period following the photograph in Figure 5-121. The flames had spread all the way to the east face. 


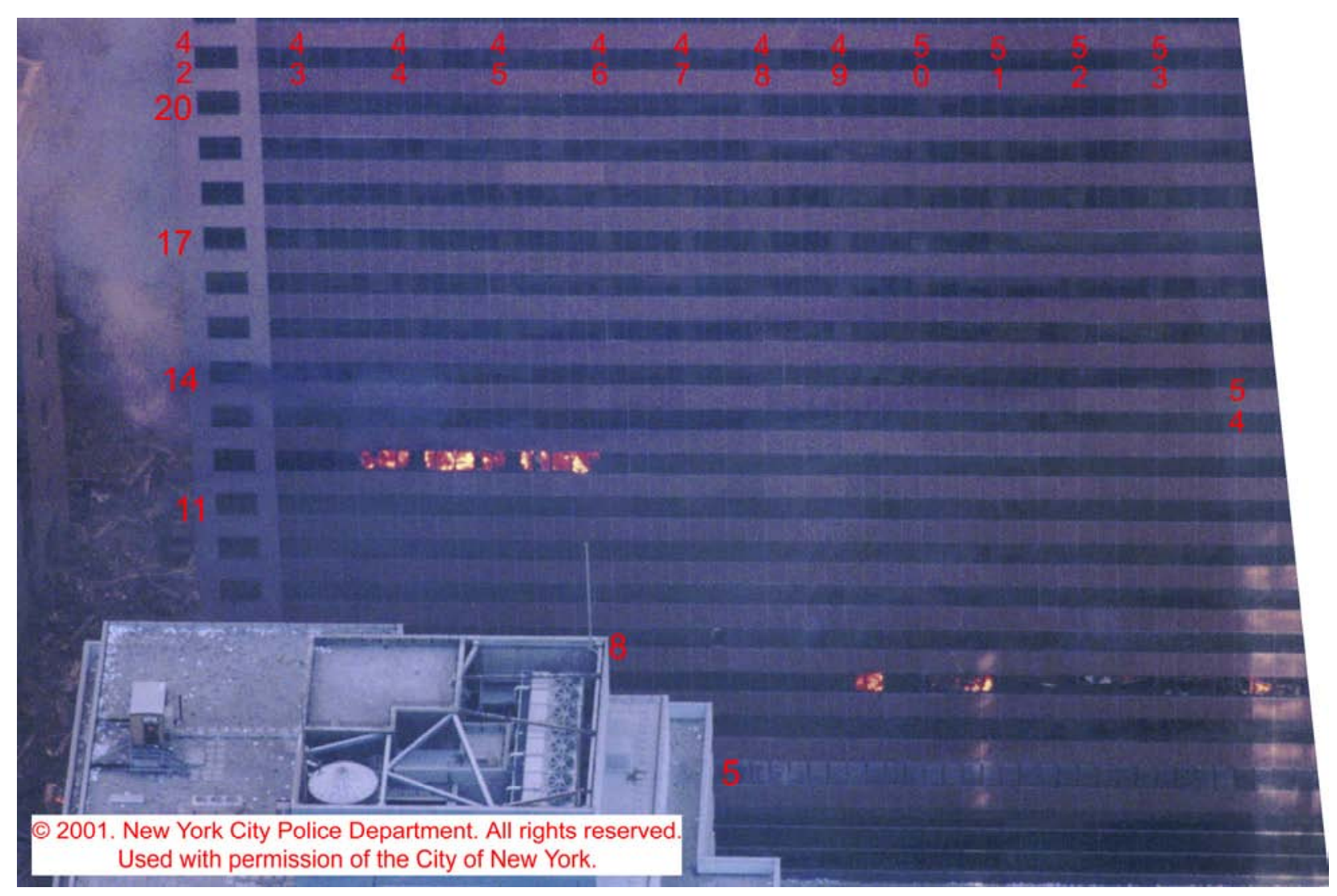

Figure 5-121. Cropped photograph of the north face of WTC 7, taken from a helicopter around 3:05 p.m. \pm 5 min.

The image was rotated $6^{\circ}$ counterclockwise and the intensities were adjusted. Column and floor numbers have been added.

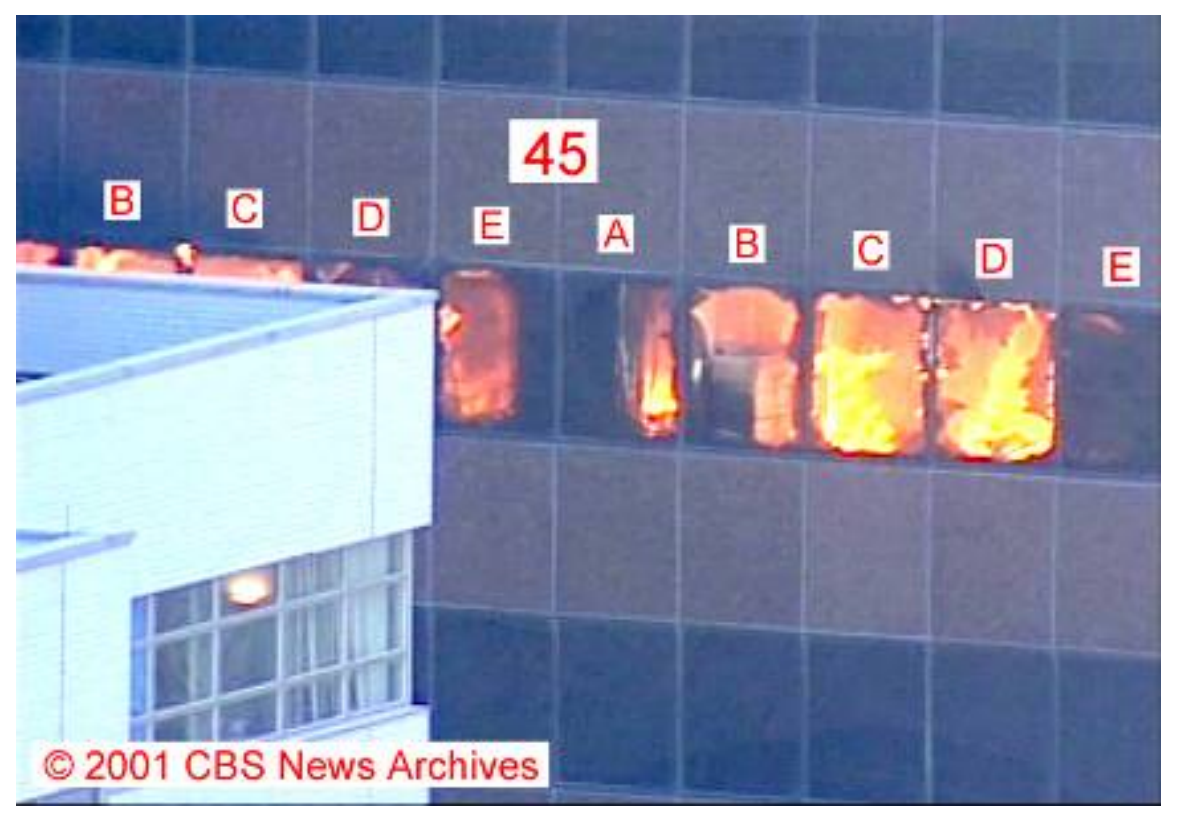

Figure 5-122. Frame taken from a video clip shot looking down on WTC 7 from a building to the northwest shows the fires along a length of the north side of the $12^{\text {th }}$ floor of WTC 7.

The video clip was recorded around the same time as the photograph in Figure 5-121 was taken. The intensities have been modified and window identification added. 


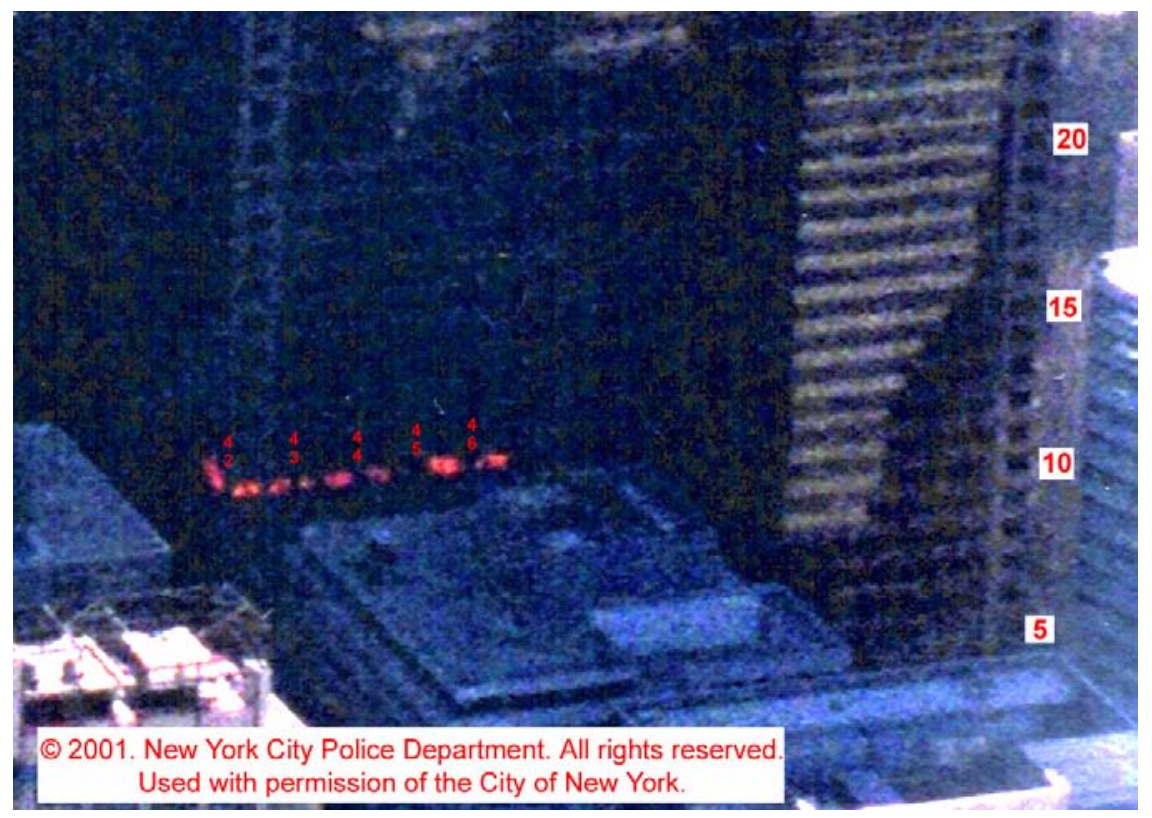

Figure 5-123. Enlarged

section of a long distance aerial shot of the north face of WTC 7 taken around 3:10 p.m. \pm $5 \mathrm{~min}$.

The contrast has been enhanced and the intensity levels adjusted. Floor numbers have been added.

Flames were also visible from at least the two windows on the east face adjacent to the northeast corner, indicating that the flames had engulfed the small unburned island in this corner of the floor. On the west side the flames had moved beyond Column 46. This was the first substantial apparent fire spread in this direction since fire first appeared on the face shortly before 3:00 p.m. (See Figure 5-119.)

The fires on the north side of the $12^{\text {th }}$ floor were extensive, covering a length running approximately from window 12-41A to 12-46C, and intense. Close inspection of Figure 5-123 shows that the fire in the vicinity of windows $12-44 \mathrm{C}$ to $12-44 \mathrm{E}$ had begun to die down. This area is close to where the fires first appeared just before 3:00 p.m., indicating that, for this location, the period of intense burning lasted for roughly $15 \mathrm{~min}$.

Figure 5-124 provides a view of the north face of WTC 7 taken from the northwest at 3:10:46 p.m. It shows an example of the shadow and sunlight distributions on the roof of the building at 70 Murray Street (the stepped white building at the lower left of the photograph) used for timing the aerial photographs described earlier. Flames are visible on the $7^{\text {th }}$ and $12^{\text {th }}$ floors of the north face of WTC 7. Light smoke or dust is visible on the north side of the building. Heavy smoke is also visible rising from the east face, indicating that fires were burning near by or that the effluent from more distant fires was being vented through the face.

A much closer view of the fires visible on the north face in Figure 5-124 is provided by the photograph reproduced in Figure 5-125, which was taken within a few minutes of Figure 5-124. The north face is partially obscured by smoke or dust, but it is possible to make out fires in individual windows on the $7^{\text {th }}$ and $12^{\text {th }}$ floors. Columns are visible inside the windows, and these have been identified on the image. On the $7^{\text {th }}$ floor, windows are open, and flames are visible from windows 7-47B to 7-49C. In Figure 5-121, which was taken at roughly 3:05 p.m., fires on this floor had reached only as far east as window 7-49A. Longer distance photographs indicate that the extended area of intense fire to the east of Column 49 became visible between 3:09:42 p.m. and 3:10:46 p.m. Clearly, fire was continuing to spread toward the east on the $7^{\text {th }}$ floor at this time. 


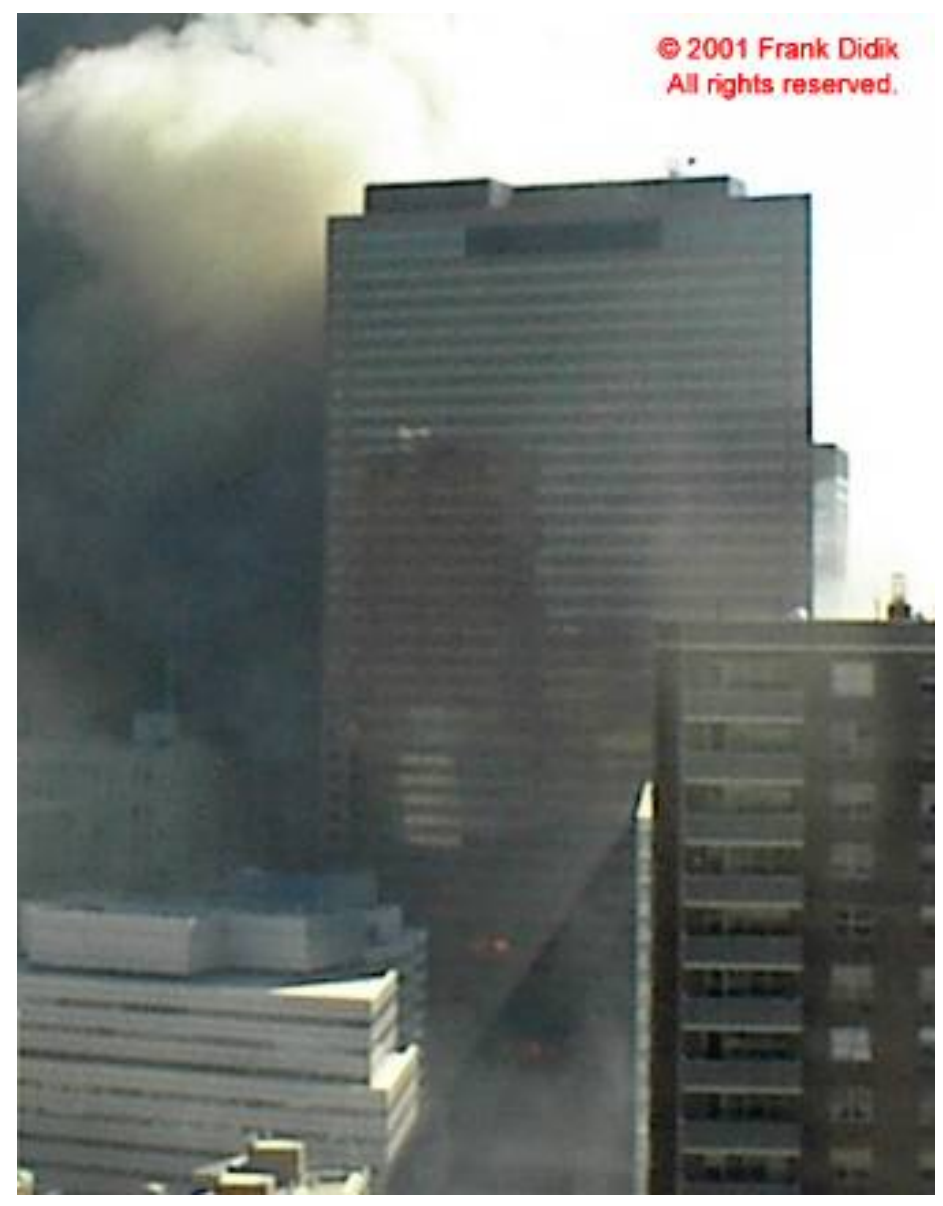

Figure 5-124. Cropped photograph of the north face of WTC 7 taken from a building located to the northwest looking down Greenwich Street at 3:10:46 p.m. \pm 3 s.

The intensities were adjusted.

On the $12^{\text {th }}$ floor, intense flames are visible in Figure 5-125 as far west as window 12-47C, indicating that this image was taken shortly after the photograph shown in Figure 5-123, in which flames were not yet evident to the west of Column 47. The flames completely fill the open windows, suggesting that flashover had taken place within the offices at these locations. As noted earlier, very little smoke or flames are coming from the open windows on this floor, again suggesting that the smoke was venting elsewhere from the building due to the ambient wind direction.

Another close up view of the north face taken from a building to the northwest between 3:11:15 p.m. and 3:16:51 p.m. is shown in Figure 5-126. The fires on the $12^{\text {th }}$ floor are visible, but the image did not extend low enough to show the $7^{\text {th }}$ floor. During the short period between when the images in Figure 5-125 and Figure 5-126 were taken, the fires on the $12^{\text {th }}$ floor broke windows $12-48 \mathrm{~A}$ to $12-48 \mathrm{D}$, and heavy flames appeared. This indicates that the fires on this floor were continuing to spread toward the west.

A close-up ground shot of the north face of WTC 7 taken from near the corner of Greenwich and Murray Streets is shown in Figure 5-127. Even though the photograph was digital, its timestamp information had been lost by the time the image was provided to the Investigation. The assigned time of 3:12:50 p.m. \pm 5 min is based on known times for other photographs from the same camera taken shortly before and afterward. Comparison of Figure 5-127 with Figure 5-126 indicates that Figure 5-127 was taken shortly before Figure 5-126, since windows 12-47D and 12-48A were open in Figure 5-126 and glass was still in place in Figure 5-127. In both figures, windows 12-48B to 12-48D are open, but a larger section of glass was missing from window $12-48 \mathrm{D}$ in the later photograph. 


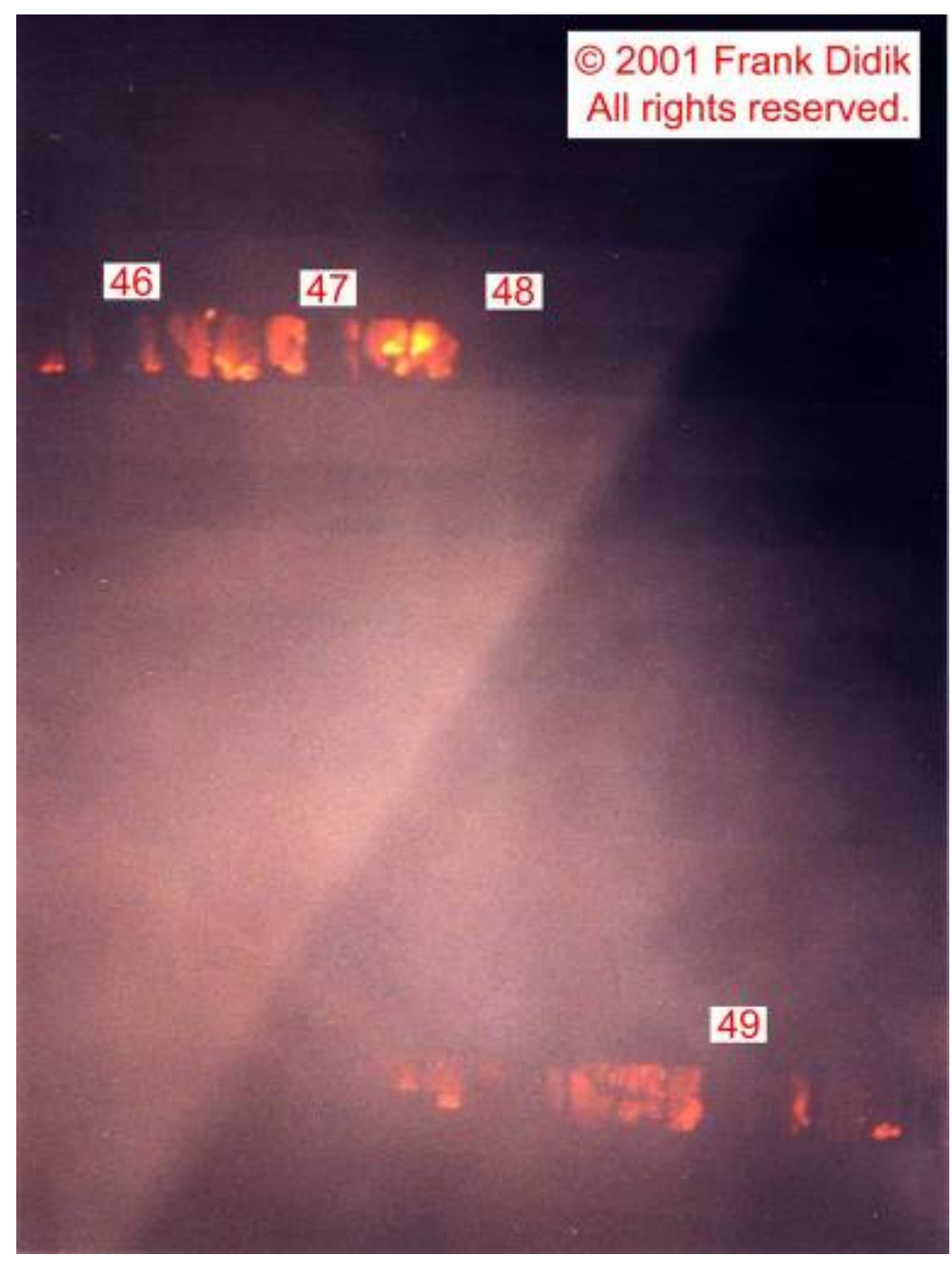

Figure 5-125. Cropped closeup photograph of the north face of WTC 7 taken within a few minutes of the image in Figure 5-124.

Fires are visible on the $7^{\text {th }}$ and $12^{\text {th }}$ floors. Column numbers are indicated, and the intensity levels were adjusted.

Figure 5-126. Cropped close-up photograph of the north face of WTC 7 taken between 3:11:15 p.m. and 3:16:51 p.m.

Fires are visible on the $12^{\text {th }}$ floor. Column and floor numbers are indicated, and the intensity levels were adjusted.

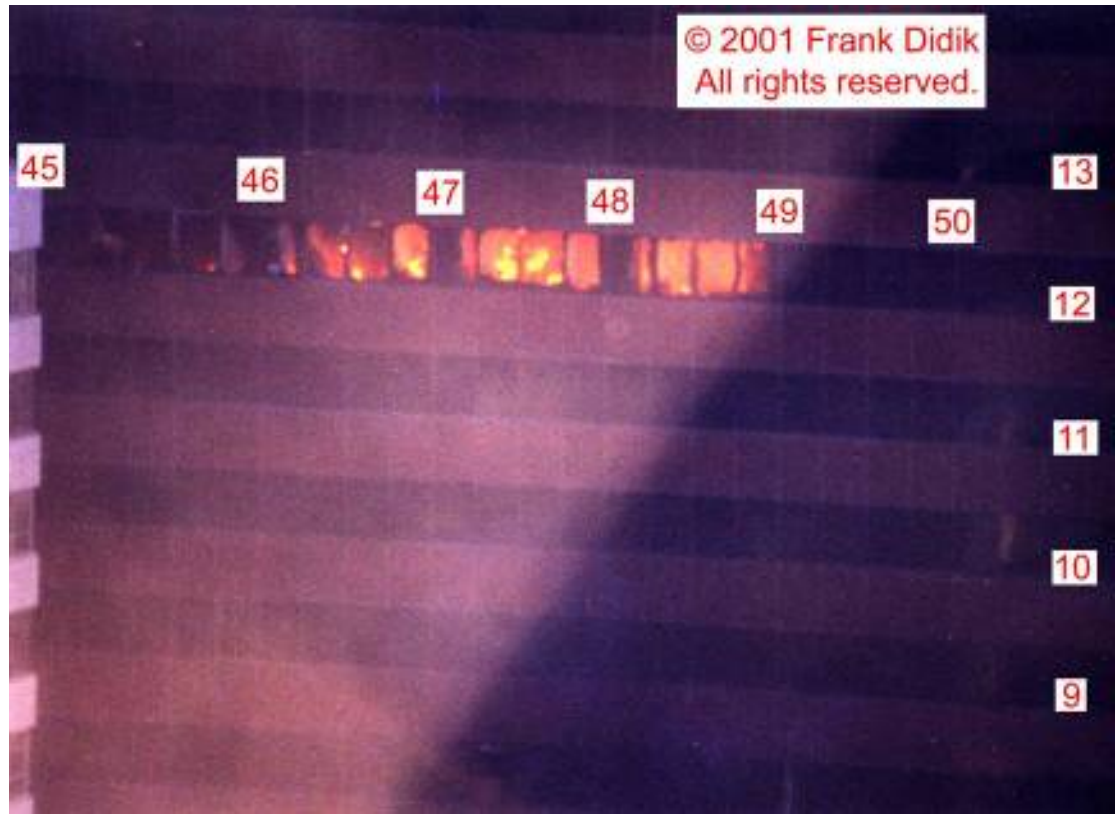


In Figure 5-127, the fires observed earlier on the $12^{\text {th }}$ floor between Columns 44 and 46 have died down substantially. Only small flames are visible near windows 12-44B and 12-45E. On the other hand, the flames further to the west are more intense at this time and appear to fill the open windows, indicating that flashover had occurred. As observed earlier, very little smoke and flame are coming from the open windows, likely indicating that the effluent is being vented elsewhere.

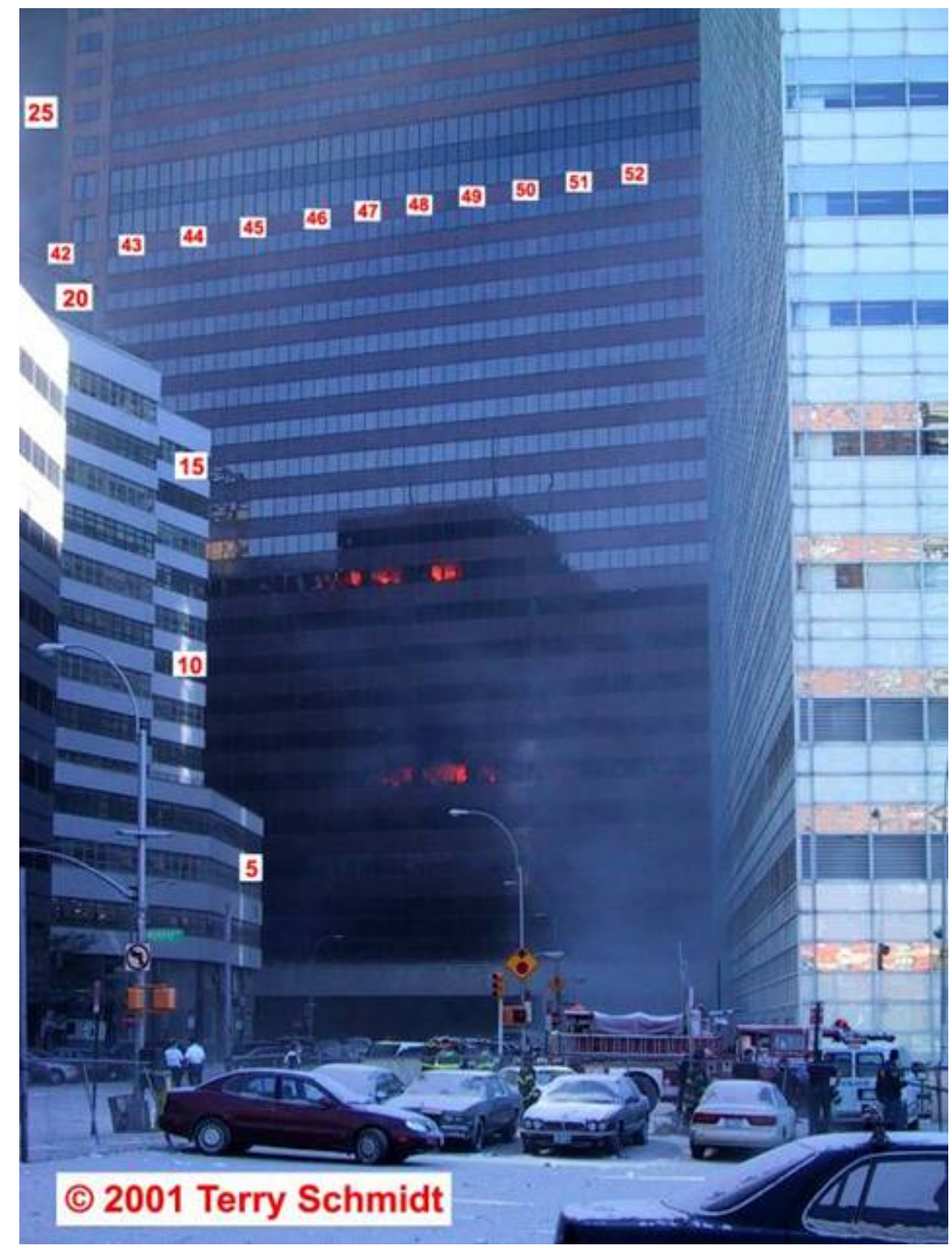

Figure 5-127. Photograph showing the north face of WTC 7, taken around 3:12:50 p.m. with an estimated uncertainty of \pm 5 min from near the corner of Murray and Greenwich Streets.

The intensities have been adjusted, and column and floor numbers have been added. 
Figure 5-127 provides a good view of the fires on the $7^{\text {th }}$ floor around 3:13 p.m. As noted previously, these fires appear to be less intense than those observed on the $12^{\text {th }}$ floor. There are indications of low intensity flames through windows between Columns 50 and 51. Further west, the fire appears to have gone out. The most visible flames extend from windows 7-47B to 7-49B. Window 7-47A appears to be broken, while the glass in windows 7-49C and 7-49D appears to be intact. Comparison with Figure 5125 indicates that, during the few minutes between the two photographs, the fires on the $7^{\text {th }}$ floor had died down somewhat, while not spreading further to the east.

No flames or newly opened windows were present on other floors at this time on the visible portion of the north face. In Figure 5-127 there appears to be light smoke or dust rising from near the ground. There is no evidence to indicate whether this was coming from WTC 7 or from locations outside the building. Several FDNY and NYPD uniformed personnel are visible in Figure 5-127 near Murray Street. Their presence is consistent with the suggestion that the area around WTC 7 had been cordoned off somewhat earlier.

A long distance view of the north face of WTC 7, similar to Figure 5-124, that was shot at 3:22:00 p.m. shows that the fires visible on the $7^{\text {th }}$ and $12^{\text {th }}$ floors about 10 min earlier had died down somewhat and had not spread noticeably. No fires were visible elsewhere on the face.

An overhead view of the north face looking down Greenwich Street from a building to the northwest is shown in Figure 5-128. It was taken around 3:42:30 p.m. \pm 2 min. Fires are visible on the $8^{\text {th }}$ floor between Columns 47 and 52, with the most intense burning toward the east, on the $12^{\text {th }}$ floor between Columns 50 and 52, and on the $13^{\text {th }}$ floor between Columns 44 and 46, with intense burning visible between Columns 44 and 45 . The greatest length of fire is on the $8^{\text {th }}$ floor. An earlier frame from the same video shows fire present on this floor at least one minute earlier. This was the earliest observation of a fire present on the $8^{\text {th }}$ floor.

A view of the north face of WTC 7 shot from Greenwich Street is shown in Figure 5-129 Fires are visible on the lower part of WTC 7. This area is enlarged in Figure 5-130. Even though the image is grainy, it provides useful information about the fire distribution at this time. Comparison of the fire distribution with that visible in Figure 5-128 suggests that this photograph was taken just prior to the time when the video frame was recorded. The time of this photograph is estimated to be 3:41:00 p.m., with an uncertainty of 3 min. Flames cover at least a length from windows 8-47C to 8-53D, even though it appears that the glass in these windows had not yet broken. There could be fires further to the west, but these windows are hidden by the building in the foreground. The large extent of the fire suggests that flames must have appeared in this area earlier since some time would be required for the fire to spread, but no indication of fire on this floor was apparent in a photograph taken from the northwest at 3:22:00 p.m., suggesting that fire spread rapidly on this floor. Where visible, the flames on the $8^{\text {th }}$ floor appear to fill the windows, providing an indication that the fires in the area were flashed over. As observed previously on the north face, relatively little smoke and flames were coming from open windows, suggesting that the fires were likely vented on the south and/or east faces.

Flames are also visible through open windows on the $12^{\text {th }}$ floor. At around 3:14 p.m., fires on this floor were observed as far west as window 12-48D, and the distribution was little changed roughly 5 min later. In Figure 5-130, fire had spread at least as far west as window 12-53C during the roughly $20 \mathrm{~min}$ between close up images. At the later time, flames are only visible as far east as window 12-48D, indicating that the fires visible earlier had mostly died down. The flames visible on the $12^{\text {th }}$ floor around 
3:41 p.m. seem to fill the open windows, suggesting flashover conditions, but several windows still appear to have glass in place. This may be an indication that the fire on the north face was not spreading systematically to the west, but at times jumped over adjacent offices which then ignited somewhat later.

Close inspection shows that a dull red glow is visible in windows $13-45 \mathrm{C}$ to $13-45 \mathrm{E}$ on the $13^{\text {th }}$ floor. These windows can just be seen at the side of the building at 30 West Broadway, which hides windows further to the east. This image provides the earliest visual evidence that fires on the $13^{\text {th }}$ floor, which were identified much earlier on the east face, had spread to the north side of WTC 7. Based on Figure 5128, it is likely that fire was present to the east between Columns 44 and 45 at this time.

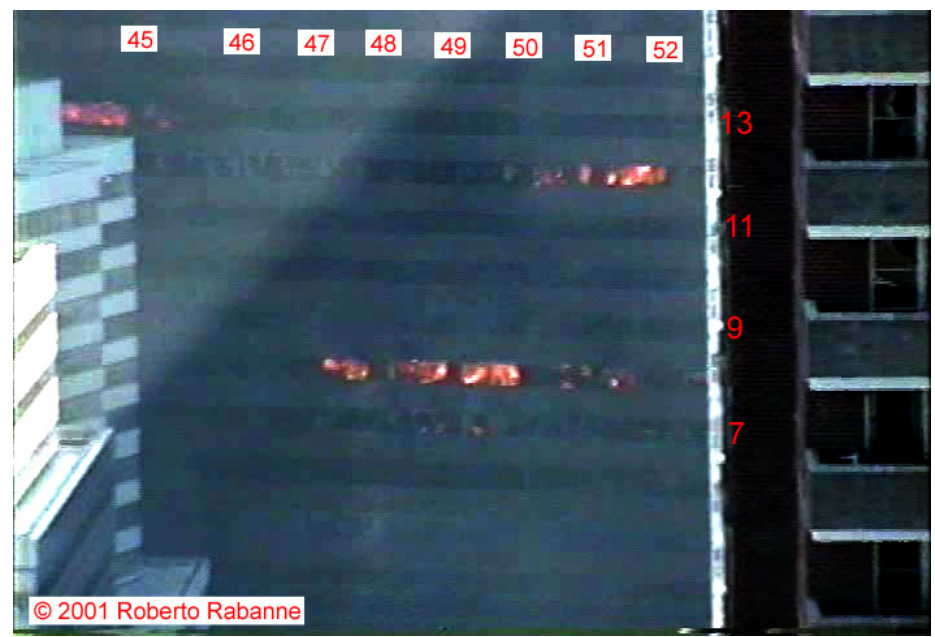

Figure 5-128. This frame from a video shot from a building to the northwest of WTC 7 was taken around 3:42:30 p.m. with an uncertainty of \pm 2 min.

The intensities have been adjusted and column and floor numbers added.

Figure 5-129. Photograph showing the north face of WTC 7 shot looking down Greenwich Street from near the corner of Greenwich and Warren Streets at around 3:41 p.m.

The estimated time uncertainty is $\pm 3 \mathrm{~min}$.

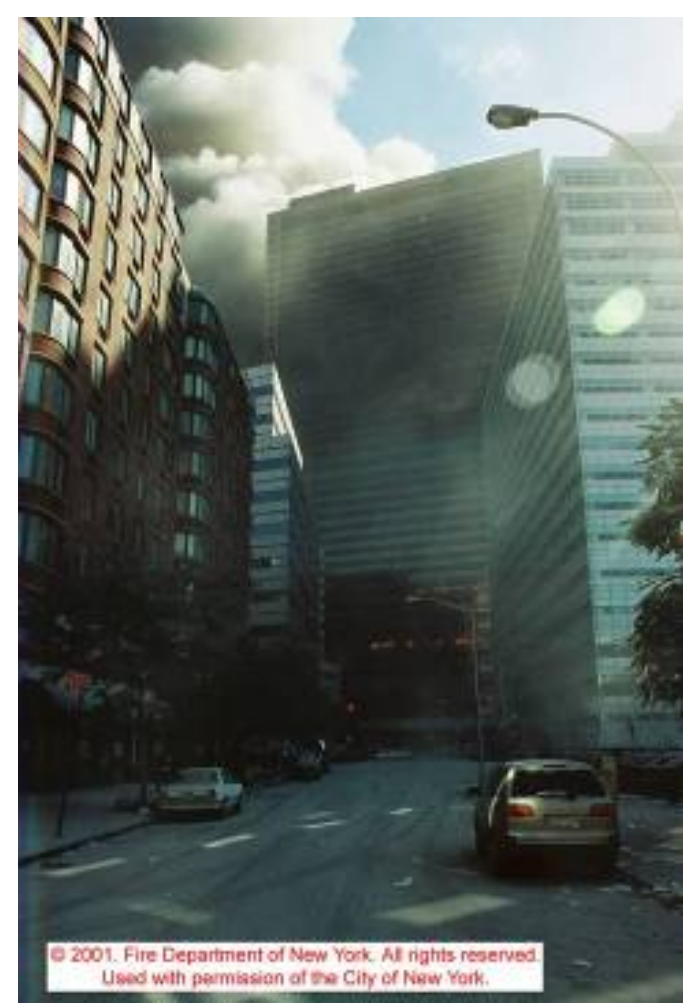




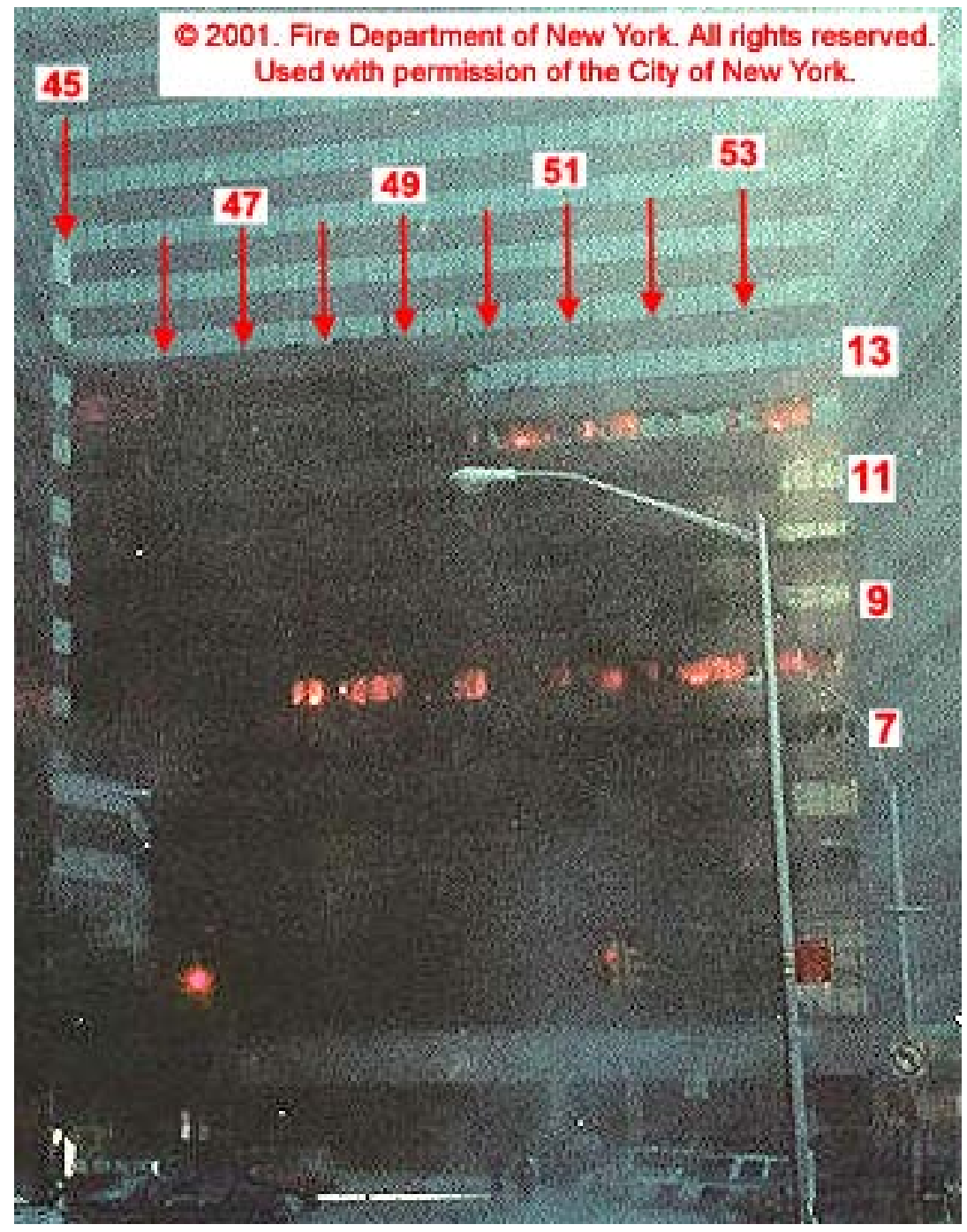

Figure 5-130. View of the north face of WTC 7 taken around 3:41 p.m. $\pm 3 \mathrm{~min}$, enlarged from Figure 5-129. The intensities have been adjusted, and column and floor numbers have been added.

While difficult to discern in Figure 5-130, a number of windows are open on the $7^{\text {th }}$ floor. Most, if not all, of the windows between window 7-47A and 7-53D are open. There is no indication of fire on the floor in this photograph. Apparently, fire present in this area around 3:13 p.m. had stopped spreading and had died down by 3:41 p.m.

There are no indications of fires on other floors in this time interval, between 2:57 p.m. and 3:42 p.m. With the exception of Figure 5-123, which indicates that fire was present on the north edge of the east face around 3:10 p.m., there are no images available during this time period that show the fire distributions on the east, west, or south face of WTC 7.

\section{Fires below the $14^{\text {th }}$ Floor, 3:47 p.m. to 4:40 p.m.}

Figure 5-131 shows a view of the central region of the north face taken from the video shot from a building to the northwest of the site looking down Greenwich Street at a time estimated as 3:50:13 p.m. with an uncertainty of \pm 3 min. During the approximate 7 min 45 s period between the time when Figure 5-128 and Figure 5-131 were taken, the fire on the $8^{\text {th }}$ floor had spread towards the east and was burning vigorously between Columns 46 and 47 at the later time. Windows on this floor around Column 
50 also appear to have opened. On the $12^{\text {th }}$ floor additional windows around Column 51 have opened, and fire has appeared in window 12-52A. On the $13^{\text {th }}$ floor the fire between Columns 44 and 45 has become less intense at the same time that the fire to the west of Column 45 appears more intense.

Around the time when the photograph in Figure 5-130 was taken, a news crew managed to reach Barclay Street by way of the building at 123 Barclay Street and filmed the fires in WTC 7 from several vantage points. This video was not time stamped, so it proved difficult to obtain accurate times for all of the clips. However, as discussed below, by comparison with other images taken at relatively well known times, it was possible to estimate times for this video.

Even though 123 Barclay Street was a full block north of the south face of WTC 7 and was nearly completely shielded from the WTC site by WTC 7 and the Verizon Building (see Figure 5-2), all of the windows in the main lobby facing Barclay Street were broken, and the lobby was covered by a thick layer of dust. This observation provides another example of the potential of the dust clouds created by the collapses of the towers to break windows and distribute material. There was no indication that fires ignited in the lobby. Initial views of WTC 7 shot by this news crew were taken through the broken windows in the lobby. Figure 5-132 shows a view of the northwest corner of WTC 7 taken from a video clip shot through the open windows. The time assigned for this video clip is estimated relative to that for Figure 5-134 provided below. Figure 5-132 reveals a great deal about the recent fire behavior. Consider the west face. Flames are visible coming from window 8-6 on the $8^{\text {th }}$ floor, and heavy smoke is flowing from multiple windows starting at the northwest corner and extending at least as far south as window 8-8. Several video clips were shot from near the same location as Figure 5-132. A frame from one of the clips recorded slightly earlier showing a much closer view of the west face is reproduced in Figure 5-133. In this image, flames are visible in windows 8-3 to 8-5, with heavy flames coming from window 8-3. In a longer distance view from the same clip, flames can also be seen coming from windows 8-1A, 8-1B, and 8-2.

Taken together, these video clips indicate that an intense fire spanning at least half the west side of the $8^{\text {th }}$ floor was burning at this time. Conversely, even though there was heavy blackening of the façade above open windows 7-1A, 7-1B, 7-3, and 7-4 visible in the clips, indicating the earlier presence of a fire, no

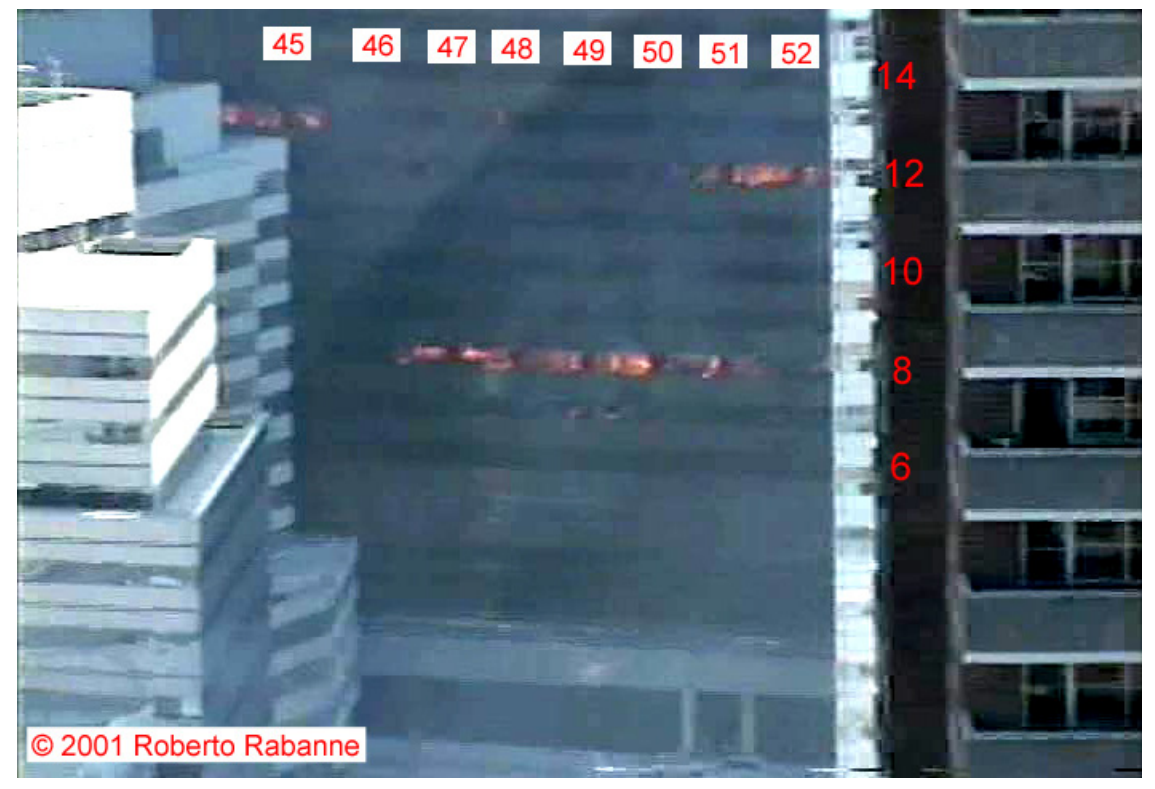

Figure 5-131. This frame from a video shot from a building to the northwest of WTC 7 was taken around 3:50:13 p.m. with an uncertainty of $\pm \mathbf{3}$ min. The intensities have been adjusted and column and floor numbers added. 


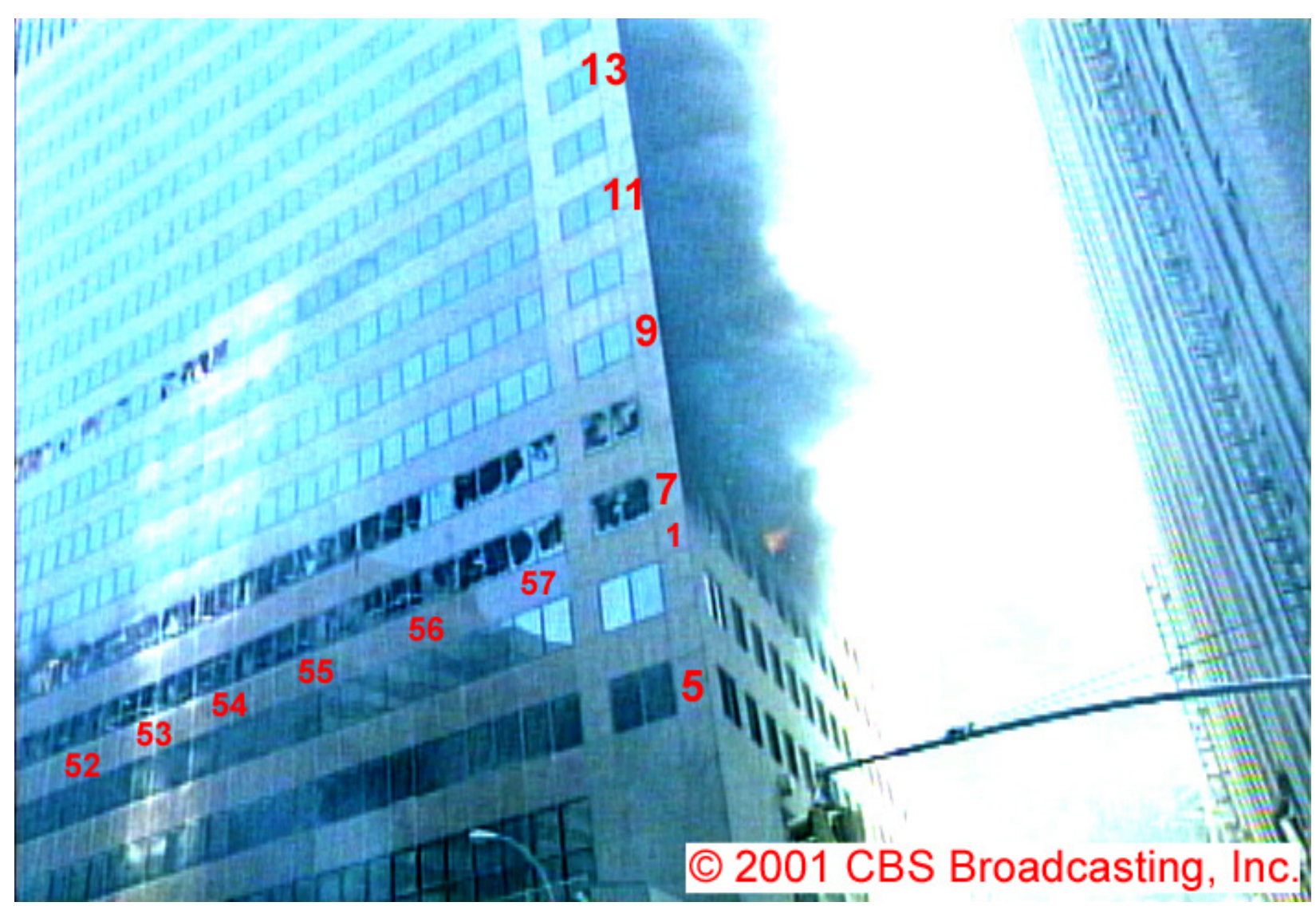

Figure 5-132. View of the northwest corner of WTC 7 from a video recorded from inside the lobby of 123 Barclay Street around 3:42 p.m. \pm 5 min.

The intensities have been adjusted, and column and floor numbers have been added.

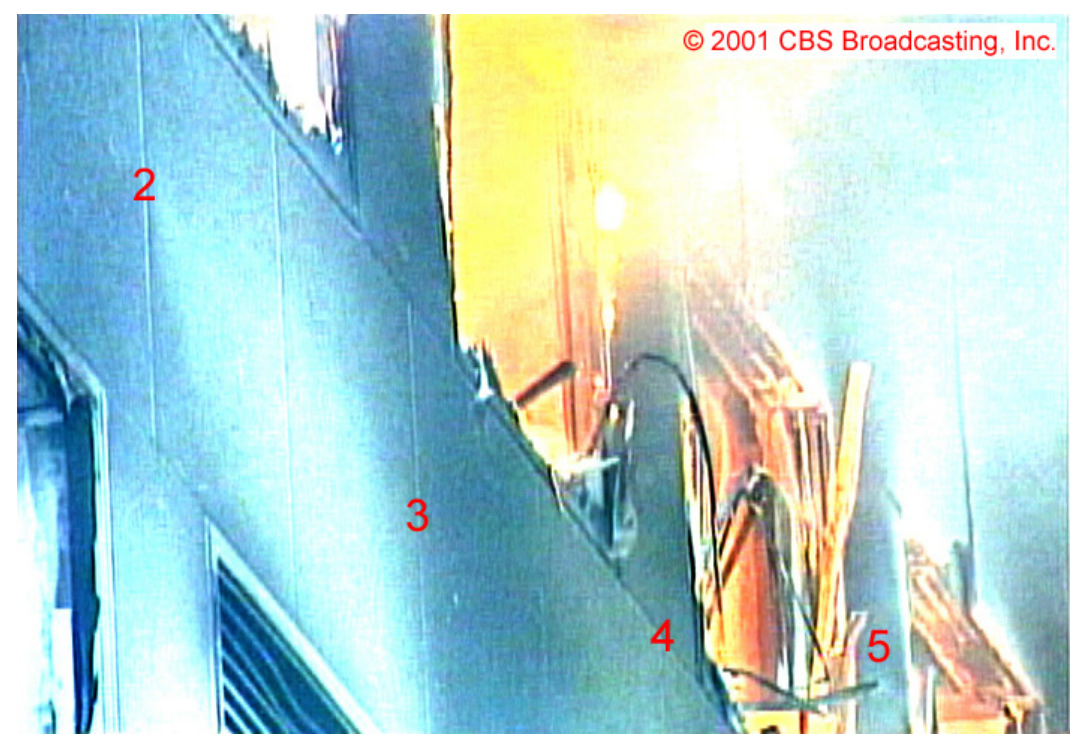

Figure 5-133. View of the west face of WTC 7 taken from a video recorded from inside the lobby of 123

Barclay Street around 3:41:30 \pm 5 min.

The intensities have been adjusted, and column locations are indicated. 
fire was visible, and no smoke was coming from these windows at this time. Recall that window 7-5 was already open by the time Figure 5-112 was taken between 2:15 p.m. and 2:30 p.m. A part of the blackened façade above these windows can be seen in Figure 5-133, where it is also apparent that the louver in window 7-2 is still in place. Apparently, the smoke flow from the louvered window was less than from the nearby open windows, since the façade is less darkened immediately above.

The presence of an earlier fire on the $7^{\text {th }}$ floor that released substantial smoke near the northwest corner is consistent with the smoke seen in the area in Figure 5-113 (see associated discussion), which was estimated to have been taken between 2:15 p.m. and 2:45 p.m. The observation of heavy burning on the $8^{\text {th }}$ floor much later supports the conclusion that the earlier smoke was coming from the $7^{\text {th }}$ floor. The fact that heavy smoke flowed from windows 7-1A to 7-4 suggests that when this area burned, there was no direct pathway to openings on the south or west walls, since the fire would have vented there, as observed elsewhere. This hypothesis is not supported by the floor diagram shown in Chapter 3, which indicates that windows 7-1A to 7-4 were open to the same common area as windows further south. The same conclusion concerning pathways to the south or east face applies for the $8^{\text {th }}$ floor, since heavy smoke and flames were coming from the open windows on the west face.

On the north face, every window on the $7^{\text {th }}$ and $8^{\text {th }}$ floors to the west of Column 51 , with the exception of window 8-56A, was open at the time Figure 5-132 was taken. This is the first visual evidence that fires had burned on these floors between Column 54 and the west edge of the face. The only locations where flames can be seen are near Column 51 on the $8^{\text {th }}$ floor. Other clips shot around the same time show fire in windows 8-57B and 8-57C. In Figure 5-130, intense burning was present between Columns 51 and 54. The fact that these fires had died down by the time of the later video clip indicates that many minutes separate the images in Figure 5-130 and Figure 5-132. This is consistent with the assigned times.

The open windows and fire distributions on the $7^{\text {th }}$ and $8^{\text {th }}$ floors provide clues concerning fire movement.

- On the $7^{\text {th }}$ floor, the evidence indicates that an earlier fire spread up the western edge of the building. Later fires were observed near the center of the north face moving toward the east. The fact that fires had burned earlier on the west side suggests that the fire moving along the west side of the building turned at the northwest corner and began to spread toward the east.

- A different movement is implied by the observations on the $8^{\text {th }}$ floor. A rapidly developing intense fire was first observed near the center of the north face. By the time the western side of the north face was observed, fires in this area had already died down, but intense burning was present on the west face near the northwest corner, with flames also observed just to the east on the north face, suggesting that the initial fires that grew on the north side of the floor had originally bypassed the northwest corner of the floor, only spreading into this area many minutes later. Either the area between windows 8-1A and 8-6 was protected by interior walls, or the fire initially reached the north face by an interior pathway that did not pass along the western edge of the floor. The observation of heavy smoke and fire coming from these windows implies there was no interior flow path to the south and east faces, and could be an indication that interior walls were indeed present.

Even though the open windows on the north sides of the $7^{\text {th }}$ and $8^{\text {th }}$ floors visible in Figure 5-132 were clearly subjected to high temperatures, little blackening of the building façade above the windows is evident. The only substantial blackening was near Column 51 on the $8^{\text {th }}$ floor. As observed at other 
locations on the north face, the fires burning in this area apparently vented on other faces as a result of the pressure distribution created by the ambient wind, in these cases most likely from the south face. Recall that large areas of the south face on these floors were opened during the collapse of WTC 1. Interior pathways from the north side of WTC 7 to the south must have been available on these floors.

Multiple open windows can be seen on the $12^{\text {th }}$ floor in Figure 5-132, reaching as far west as window 12-53C. The window glass between Columns 52 and 53 is mostly intact. The only area where substantial flames are visible is near Column 50. Comparison with Figure 5-130 shows that the fires on the $12^{\text {th }}$ floor had not spread further west during the short period between the images, but that the fires between Columns 51 and 54 had died down considerably. There is no indication of blackening on the façade above the open windows, indicating that the nearby fires had vented elsewhere.

Closer inspection of Figure 5-132 reveals that while the glass in window 12-55C was still in place, it had apparently cracked. This is an early indication that fire was nearby. Another video clip taken from the same location a short while later shows that windows 12-55B and 12-55C had opened and flames filled both windows. After a brief lull, the fires burning on the north side of the $12^{\text {th }}$ floor continued their spread to the west. As noted earlier, the fires on this floor seemed to occasionally skip some closed windows and appear further west. This suggests that instead of spreading continuously along the north edge, the fires were penetrating a series of offices and then growing to the point where windows were broken. Each of these office fires was apparently somewhat independent, which is consistent with the floor plan shown in Figure 3-4.

There are no indications of fire activity below the $7^{\text {th }}$ floor at the time of Figure 5-132. On the west side of the north face open windows are only present on the $7^{\text {th }}, 8^{\text {th }}$, and $12^{\text {th }}$ floors. It is not possible to see windows above the $8^{\text {th }}$ floor on the west face due to the heavy smoke.

An oblique view looking along the north face of WTC 7 is shown in Figure 5-134. It is a frame taken from another video clip shot from inside the lobby of 123 Barclay Street. The image is estimated to have been recorded roughly two minutes later than the frame shown in Figure 5-132, based on clip lengths, open windows, and fire distributions. Using the appearance of the face, the identifiable windows, and the locations of columns visible behind open windows it was possible to assign the indicated column locations. Careful comparison of fire locations and open window locations seen in this image with those in Figure 5-128, Figure 5-130, and Figure 5-131 shows that this video frame was taken very shortly after the frame shown in Figure 5-128. A time of 3:44 p.m. with an uncertainty of 4 min has been assigned.

Figure 5-132 and Figure 5-134 together show that every window on the $7^{\text {th }}$ floor between Column 47 and the western edge of the north face was broken out at this time. No flames are visible on this floor in either image. As shown by Figure 5-127, fire had spread as far east as window 7-47A as early as 3:13 p.m. No further eastward fire spread was observed over the following $45 \mathrm{~min}$, and the fires appeared to have died down.

On the $8^{\text {th }}$ floor, heavy flames are visible between Columns 47 and 51 in Figure 5-134. Comparison with Figure 5-130, which was taken somewhere between 2 min to 10 min earlier, indicates that the flaming area had not moved further east during the intervening time, but that substantial fires, present earlier between Columns 51 and 54, had died down. Several windows that earlier had glass in place between Columns 49 and 51 were open at the later time. Even though no fire is evident to the east of Column 47 in Figure 5-134, there are indications that window glass in several windows to the east of this point had 
begun to break. Despite the heavy fire on this floor, only light white smoke was coming from the open windows.

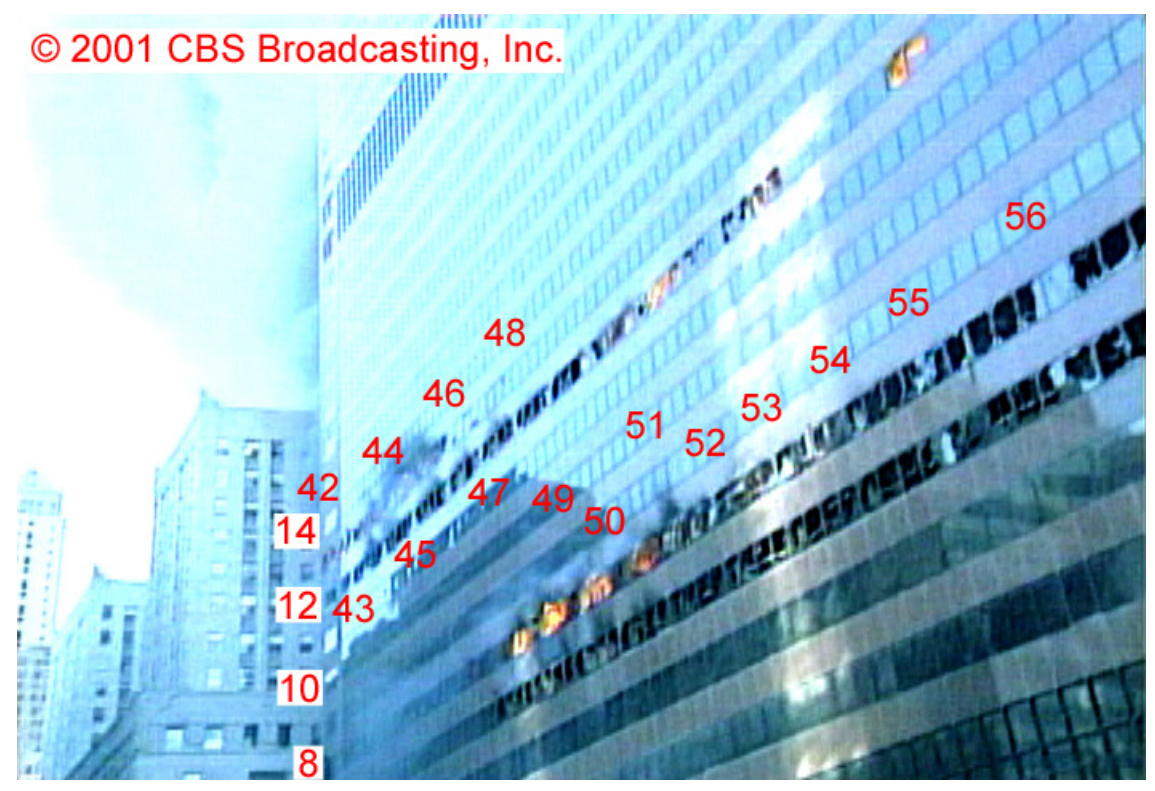

Figure 5-134. View of the north face of WTC 7 taken from a video recorded from inside the lobby of 123 Barclay Street at 3:44 p.m. \pm $4 \mathrm{~min}$. The intensities have been adjusted, and floor and column numbers have been added.

On the $12^{\text {th }}$ floor, the flames that had recently appeared in windows $12-55 \mathrm{~B}$ and $12-55 \mathrm{C}$ stand out. Further east, heavy flames are visible near Column 51. Flames were also visible at the same location in Figure 5-132. All of the windows to the east of Column 51 appear to be open, but there are no indications of active fire. Despite the heavy fire, essentially no smoke or flames were coming from open windows on this floor.

In Figure 5-130, low level flames were visible on the $13^{\text {th }}$ floor immediately to the west of Column 45 . In Figure 5-134, it is clear that windows between the east edge and Column 46 were open at the later time, and there are indications that glass was beginning to break in windows further to the west. It is not possible to observe flaming in these windows at this severe angle.

It is difficult to identify how fire moved onto the north side of the $13^{\text {th }}$ floor from Figure $5-130$ and Figure 5-134. A photograph (Figure 5-135) taken at an unknown earlier time, estimated as between 3:20 p.m. and 3:40 p.m., provides an important clue. This image, shot from near the corner of West Broadway and Park Place, shows an oblique view of the east face. Intense flames appear to be coming from windows $13-39$ to $13-41$ on the $13^{\text {th }}$ floor. A much smaller flame can be seen in window 13-41A. Despite the steep viewing angle, there seems to be a line of flames extending across most of the east face on the $13^{\text {th }}$ floor. Heavy smoke is rising from these fires. There also appears to be lighter smoke lower down on the east face, but it is not possible to identify its source.

Windows at the east edge of the north face are also visible in Figure 5-135. Windows 13-42A to 13-42C still have glass in place on the $13^{\text {th }}$ floor, which means that this image was taken prior to Figure 5-134. The heavy smoke pouring from open window $8-42 \mathrm{~A}$ on the $8^{\text {th }}$ floor indicates that a significant fire was burning on this floor at this time, even though it is clear from Figure 5-134 that nearby windows still have intact glass. Windows $12-42 \mathrm{~A}$ to $12-42 \mathrm{C}$ are open on the $12^{\text {th }}$ floor with no sign of flames nearby, indicating that this photograph was taken well after the aerial view in Figure 5-123, which was taken around 3:10 p.m. and shows heavy flames in these corner windows. 


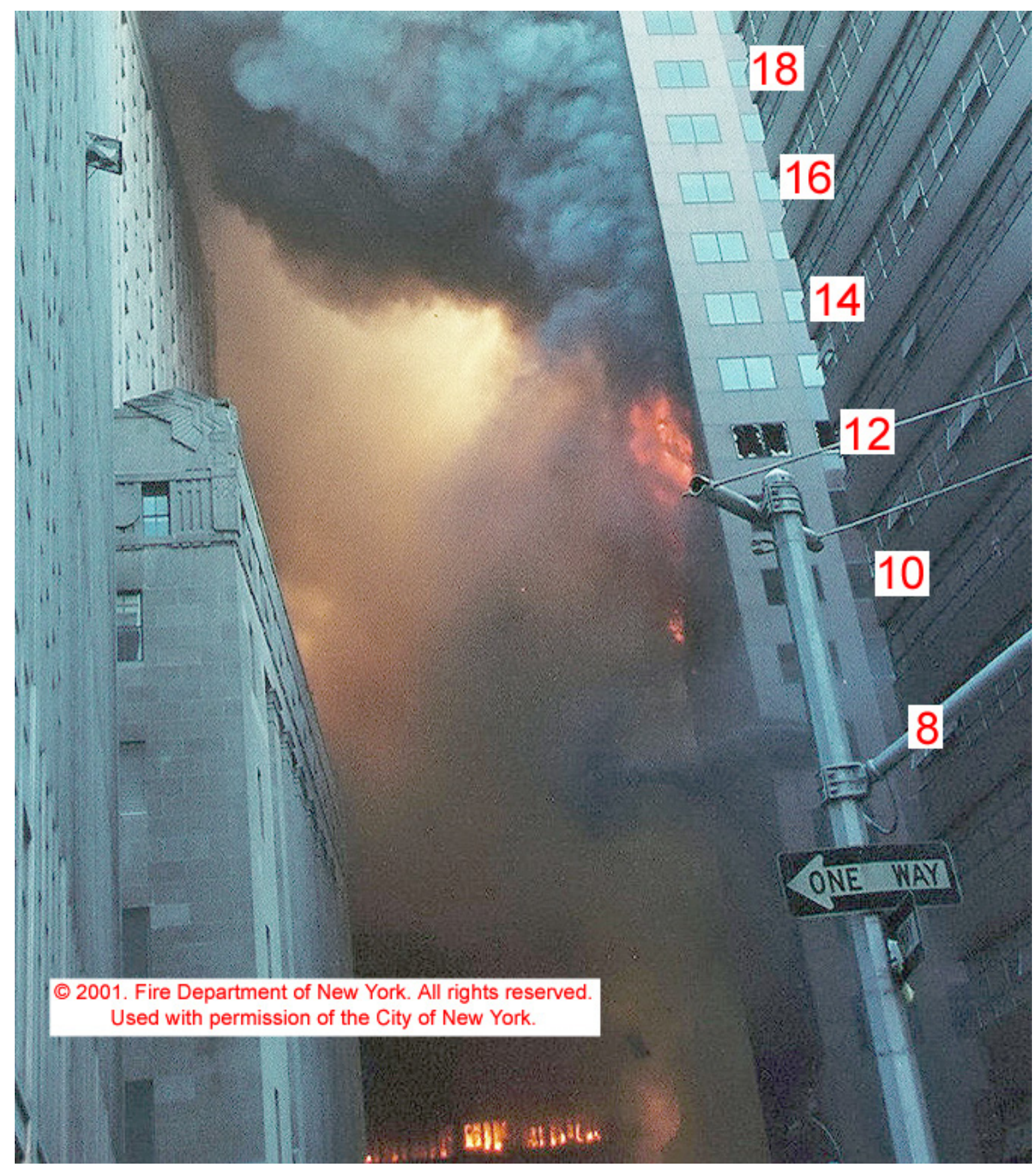

Figure 5-135. Cropped photograph showing the east edge of the north face and an oblique view of the east face of WTC 7, taken from near the corner of West Broadway and Park Place.

It was likely taken between 3:20 p.m. and 3:40 p.m. The buildings burning in the background are WTC 5 (left) and WTC 6 (right), and the U.S. Post Office is on the left. Floor numbers have been added and intensity levels have been adjusted. 


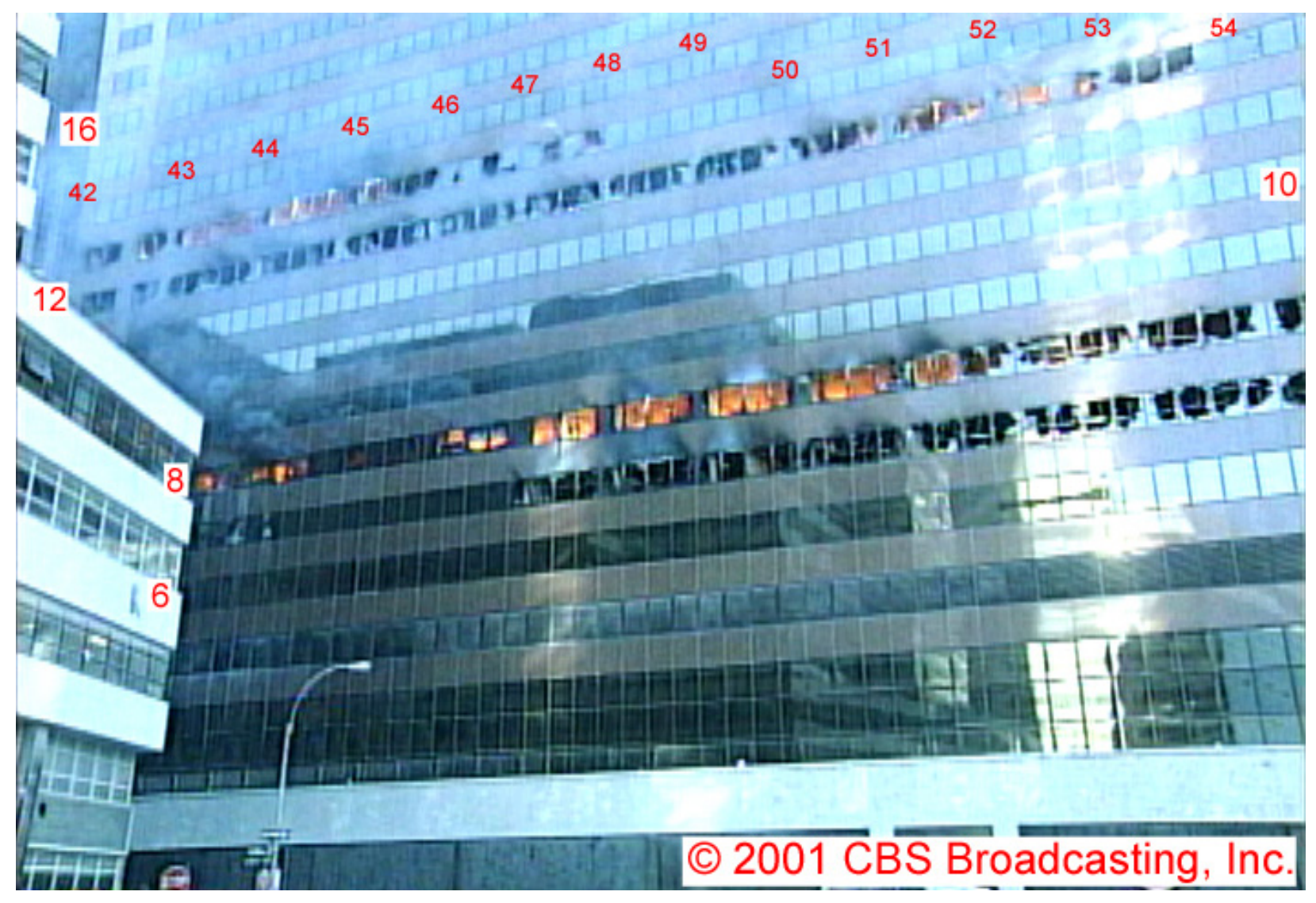

Figure 5-136. Frame taken from a video shot from near the corner of Greenwich Street and Park Place showing the north face of WTC 7 between 3:49 p.m. and 3:54 p.m.

The building on the left is 30 West Broadway. The intensities have been adjusted, and column and floor numbers have been added.

The fire behaviors discussed above suggest that, unlike the fires on the $12^{\text {th }}$ floor, the fires on the $13^{\text {th }}$ floor spread northward up the east side of WTC 7 before turning the northeast corner and moving west across the north face.

After leaving the lobby of 123 Barclay Street, the news crew moved out onto Greenwich Street, where they filmed the north face of WTC 7 from near the corner of Greenwich Street and Park Place. As before, the exact arrival time is unknown, but an assumed 5 min travel time yields an estimate somewhere between 3:49 p.m. and 3:54 p.m. Figure 5-136 shows a frame extracted from this video clip that provides a good head-on view of much of the $7^{\text {th }}, 8^{\text {th }}, 12^{\text {th }}$, and $13^{\text {th }}$ floors. All of the open windows visible on the $7^{\text {th }}$ floor are dark, providing additional confirmation that the fire that had spread as far as window 7-47A died down before covering the entire north face. A couple of the windows near Column 44 appear to have broken glass, but there are no indications of fire in this area.

The appearance of the windows on the $8^{\text {th }}$ floor changed substantially between the times when the video frames shown in Figure 5-134 and Figure 5-136 were taken. At the earlier time, fire was visible as far east as window 8-47A, while in Figure 5-136, fire is not only apparent at the adjacent windows between Columns 46 and 47, but intense flames have appeared much further to the east in windows 43E to 44E. It is possible that the fire is even further to east, but these windows are hidden by the building in the 
foreground. Closer inspection shows that the glass in window 8-45B has also broken, and a telltale orange glow reveals that flames are also growing nearby. The west edge of the fire area is in roughly the same location as earlier.

A closer view of the $7^{\text {th }}$ and $8^{\text {th }}$ floors, taken from a video clip recorded shortly after the one from which Figure 5-136 was taken, is shown in Figure 5-137. The frame includes the location on the $7^{\text {th }}$ floor where fire spread had stopped. There appears to be a wall visible through windows 7-47A and 7-47B that terminates at Column 47. If this wall extended far enough inward, it might have stopped the fire as it spread eastward across the north face. The glow through the open windows on the $8^{\text {th }}$ floor reveals the presence of a substantial fire within this area. However, the only actual flames that could be seen were in window 8-48D. Either the flames responsible for the glow were hidden below the window sill or were located further inside the building. It does not appear that the upper portion of the interior space near the windows was filled with flame. It is thus not possible to identify whether this fire was flashed over.

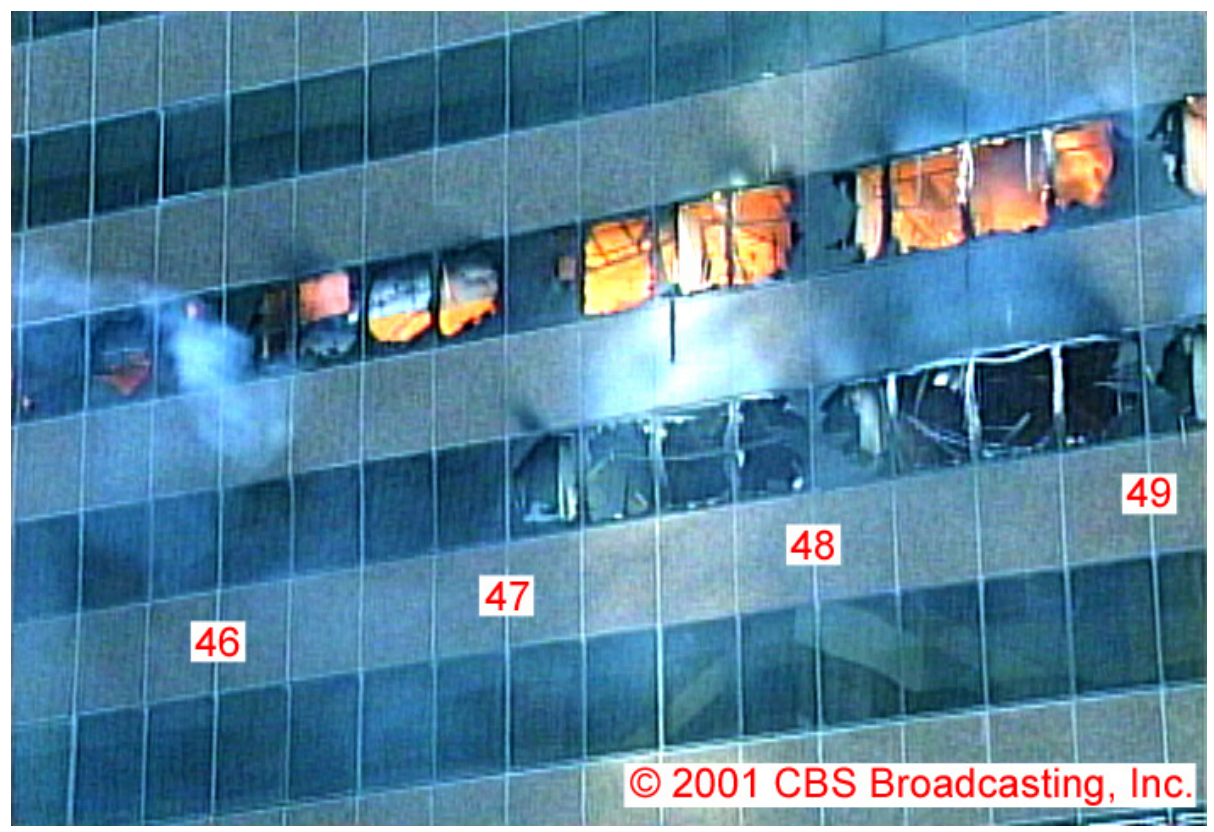

Figure 5-137. Close up of the $6^{\text {th }}$ through $9^{\text {th }}$ floors of the north face of WTC 7 from a video shot between 3:49:30 p.m. and 3:54:30 p.m. near the corner of Greenwich Street and Park Place. The image intensities have been adjusted, and column locations are indicated.

Figure 5-137 provides a good indication of how window glass breakage occurred in this area of the north face. It seems that the glass would first break near the center, leaving a band of glass in the window frame. Later, the remainder of the glass would fall out, leaving a fully open window frame. The column enclosures were located about 6 in. behind the window glass. Even so, they provided some protection for the glass since jagged-edged pieces with widths roughly the same as the enclosed columns often remained in the window frames. A much closer view of this type of breakage is shown in Figure 5-138 for the glass around Column 48 on the $8^{\text {th }}$ floor. This type of glass breakage near columns was widespread, as is evident in Figure 5-136.

Some light smoke is visible coming from open windows on the $8^{\text {th }}$ floor in Figure 5-137, but it is not as dense as would be expected for the amount of fire present. Light blackening of the façade above windows on the $7^{\text {th }}$ and $8^{\text {th }}$ floors suggests that only light smoke had come from the area earlier. Support for the hypothesis that smoke was being vented elsewhere comes from Figure 5-138. Smoke is visible rising upward in windows 8-47B and 8-47D, while flames are visible in 8-47B. Even though this internal smoke is easily seen, the only smoke flowing from the nearby open windows is coming from small flames 
burning on the window frames. In the video clip, it is clear that the internal smoke is flowing away from the open windows. This is the strongest evidence identified that the effluent created by fires burning near the north face of WTC 7 often vented elsewhere from the building, most likely due to pressure differences created by the ambient wind.

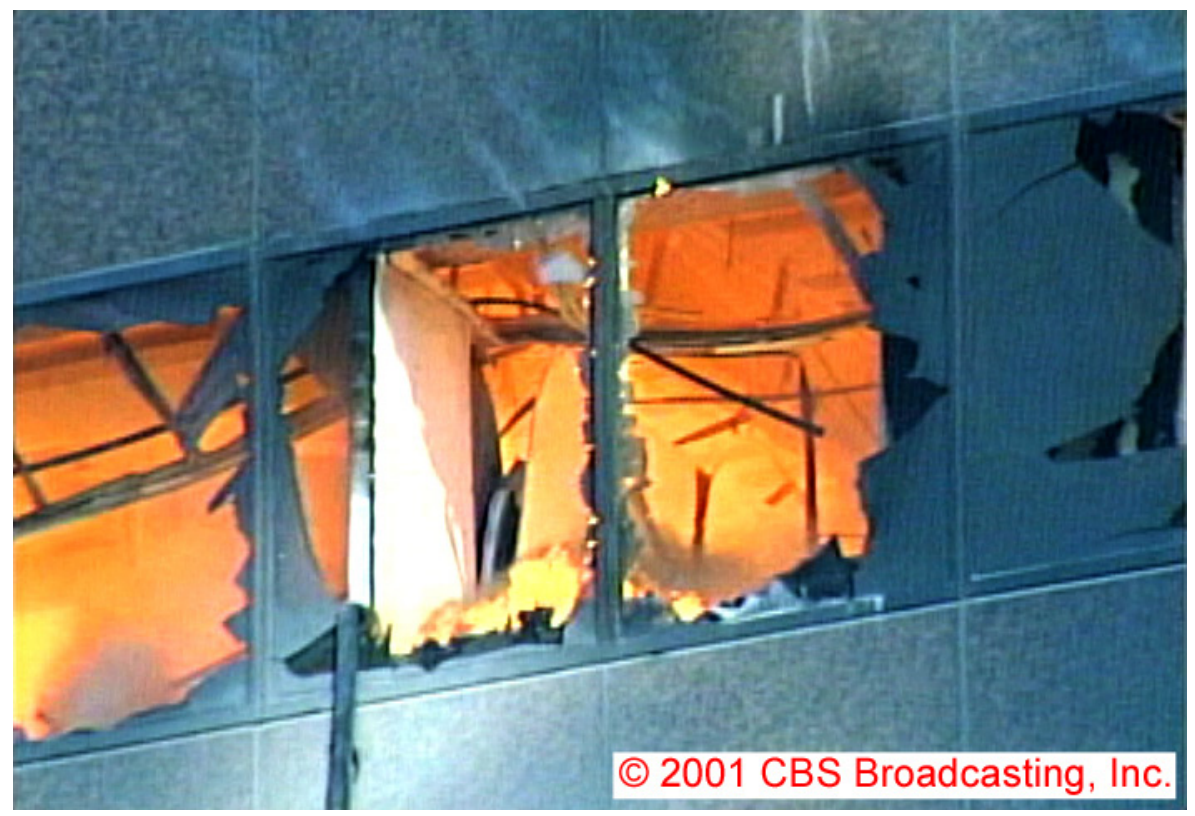

Figure 5-138. Frame taken from a video shot from near the corner of Greenwich Street and Park Place showing windows 847B to 8-48A between 3:49 p.m. and 3:54 p.m.

The intensities have been adjusted.

Additional details concerning the local effects of the fires can be seen in Figure 5-138. For instance, the distorted frame that had held the drop ceiling for the area is still in place above the windows. The ceiling tiles have been dislodged. Further inside, it is possible to see the floor slab for the $9^{\text {th }}$ floor. There appears to be a wall partition visible through window 8-47C. It seems to terminate at the drop ceiling. For this reason, it would have been unlikely to have been an effective fire barrier.

Figure 5-136 also provides good views of the $12^{\text {th }}$ and $13^{\text {th }}$ floors. On the $12^{\text {th }}$ floor, every window pane between the east edge and window $12-52 \mathrm{C}$ is broken. It is easy to identify the column locations due to the intact glass in place in front of the columns. Flames are visible through the open windows from window 12-49D to window 12-52 D. Comparison with Figure 5-134 shows that the fire between Columns 52 and 53 had grown substantially. Additional glass has broken in windows 12-51D to 12-52B, and the flames are much brighter. Window 12-52C still has glass in place. Even though fire had spread earlier to a location between Columns 55 and 56, there is no indication of a fire in windows 12-53D to 12-54C.

Figure 5-136 provides a better view of conditions on the east side of the $13^{\text {th }}$ floor than is available in Figure 5-134. All of the window panes between the east edge and Column 46 have been broken. Several windows between Columns 46 and 48 are also open. Comparison with Figure 5-134 shows that much of the breakage between Columns 46 and 48 occurred during the approximately 5 min period between the two frames. An active area of fire is visible extending from window 13-43A to 13-45B. The fires to the immediate west seem to have already died down, as have those between Columns 42 and 43 at the east edge. The observations suggest that the fires on the north face of the $13^{\text {th }}$ floor are burning similarly to 
those on the $12^{\text {th }}$ floor, i.e., by spreading somewhat erratically through the rooms located along the face. (See Figure 3-7.)

Figure 5-139 shows another view of the WTC 7 north face looking down Greenwich Street from a building to the northwest of WTC 7. The time for this video frame is estimated as 3:54:14 p.m. with an uncertainty of $3.5 \mathrm{~min}$. Comparison with Figure 5-131 indicates that the fire on the $8^{\text {th }}$ floor has moved to the east in the roughly 4 minutes between the two video frames, with an intense fire now visible in windows 8-45a to 8-45e. Note that the time assignment for Figure 5-139 is consistent with the times assigned for Figure 5-136 to Figure 5-138 since window glass was still in place in these windows when those video clips were recorded.

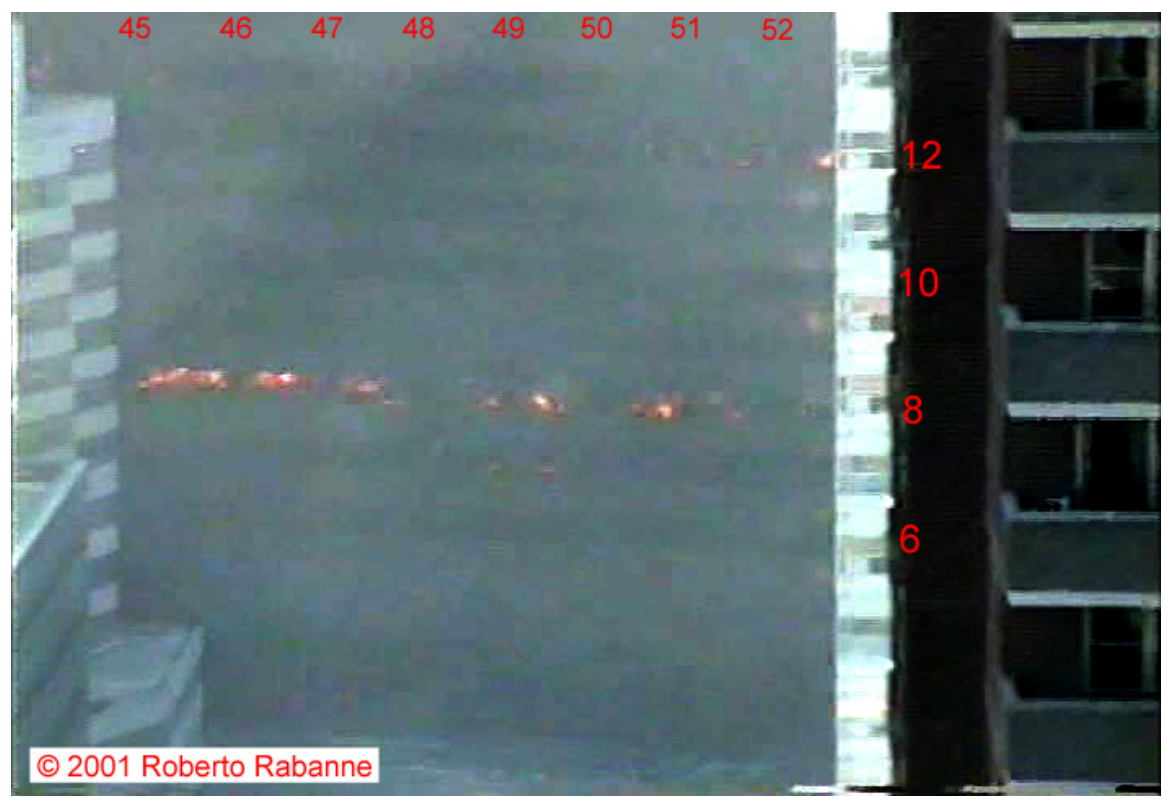

Figure 5-139. This frame from a video shot from a building to the northwest of WTC 7 was taken around 3:54:14 p.m. with an uncertainty of $\pm 3.5 \mathrm{~min}$.

The intensities have been adjusted and column and floor numbers added.

The intensity of the fires on the $8^{\text {th }}$ floor between Columns 48 and 50 decreased markedly during the same period. Similar decreases in fire intensity are evident on the $12^{\text {th }}$ floor between Columns 51 and 52 and on the $13^{\text {th }}$ floor between Columns 44 and 46 .

After filming from near the corner of Greenwich Street and Park Place, the news crew moved down Greenwich Street to its corner with Barclay Street, immediately across the street from WTC 7. Figure 5140 shows a frame from a video clip looking up at the north face shot from this location. The estimated time of between 3:51 p.m. and 3:58 p.m. was obtained by adding three minutes to the estimated time for the clip shown in Figure 5-136. This allows for some time spent near Park Place as well as the time required to move a block south to Barclay Street.

The appearances of the open windows and fires on the face are similar in Figure 5-136 and Figure 5-140, with one major exception. In the later frame, extremely heavy flames and dense smoke are coming from windows 8-44B to 8-44E. This is the first observation of large amounts of effluent flowing from fires on the north side of the $8^{\text {th }}$ floor and suggests that an internal flow pathway to the east or south faces from these windows was not available. This intense fire had grown rapidly, since in the earlier clip only relatively small fires were evident through windows 8-44B and 8-44D, and the glass for window 8-44E, along with window 8-45A, was still in place. Unfortunately, the view of windows 8-45A to 8-45E is 
blocked by a street sign. Determining whether or not these windows were open at this time would have allowed the time uncertainty for this clip to be reduced somewhat.

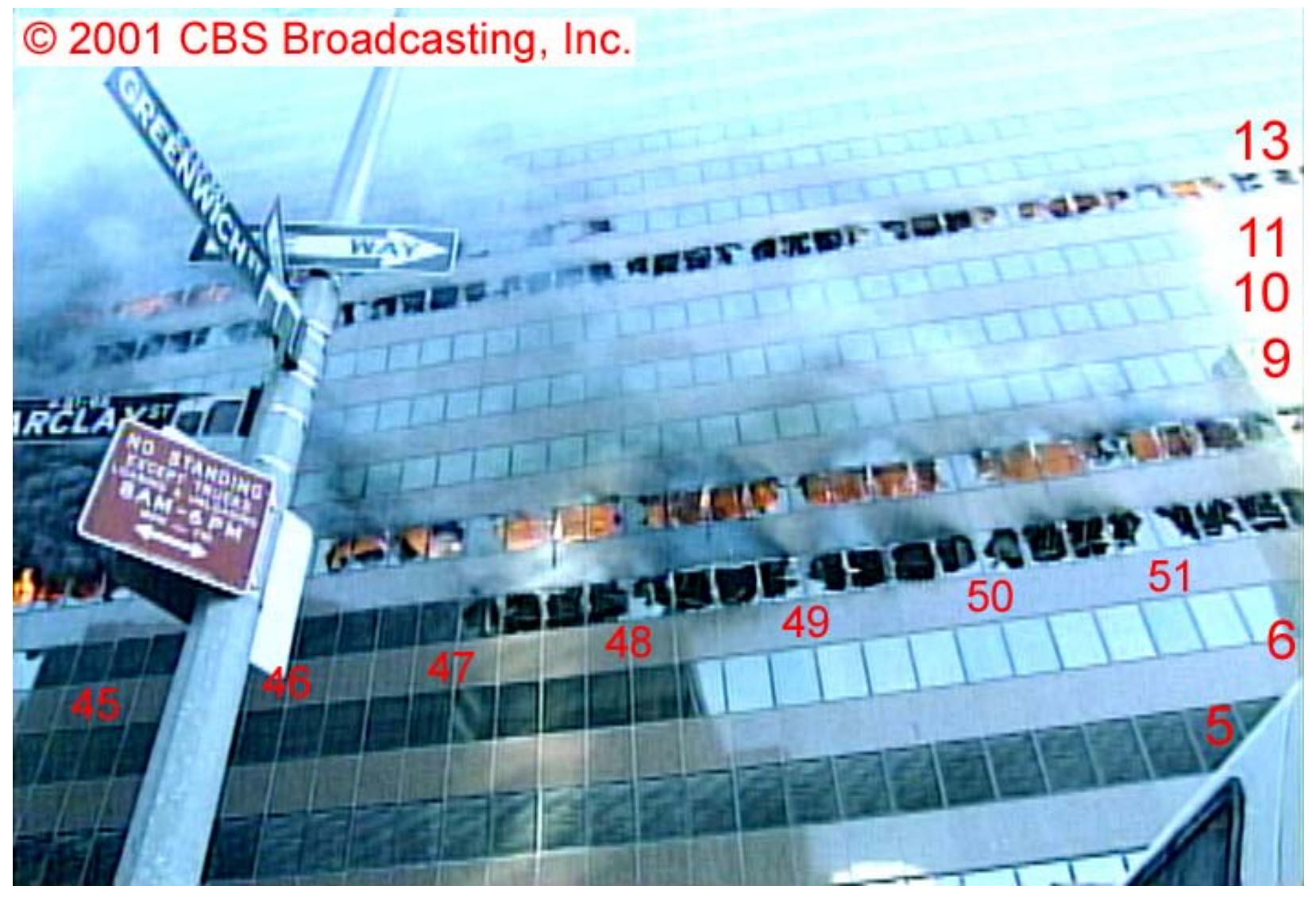

Figure 5-140. Frame taken from a video shot from near the corner of Greenwich and Barclay Streets showing the north face of WTC 7 between 3:51 p.m. and 3:58 p.m. The intensities have been adjusted, and column and floor numbers have been added.

After leaving the corner of Greenwich and Barclay Street, the film crew next moved to the corner of West Broadway and Barclay Street. It is estimated that it would have taken a minimum of 3 min to reach this location after filming on the corner of Greenwich and Barclay Streets. This assumption leads to an estimated time between 3:53 p.m. and 4:02 p.m. Figure 5-141 shows a frame from a video clip recorded shortly after reaching the location.

During the estimated 5 min between the times when the clips shown in Figure 5-140 and Figure 5-141 were taken, the heavy smoke and fire observed coming out of windows between Columns 44 and 45 on the $8^{\text {th }}$ floor in Figure 5-140 had retreated back into the building. The dark bands deposited on the façade above these windows are telltales for the earlier heavy effluent flowing from the nearby fires. Similar darkening is present above windows 8-43C and 8-45B, indicating that earlier heavy smoke flows also took place from these windows. Interestingly, the glass in windows 8-45E and 8-46A appears to be at least partially intact. The fire distribution apparent in Figure 5-139 suggests that these windows are fully open, which may be an indication that the video frame in Figure 5-141 was recorded slightly earlier than the frame show in Figure 5-139. This conclusion is consistent with time uncertainties assigned for these two frames. 


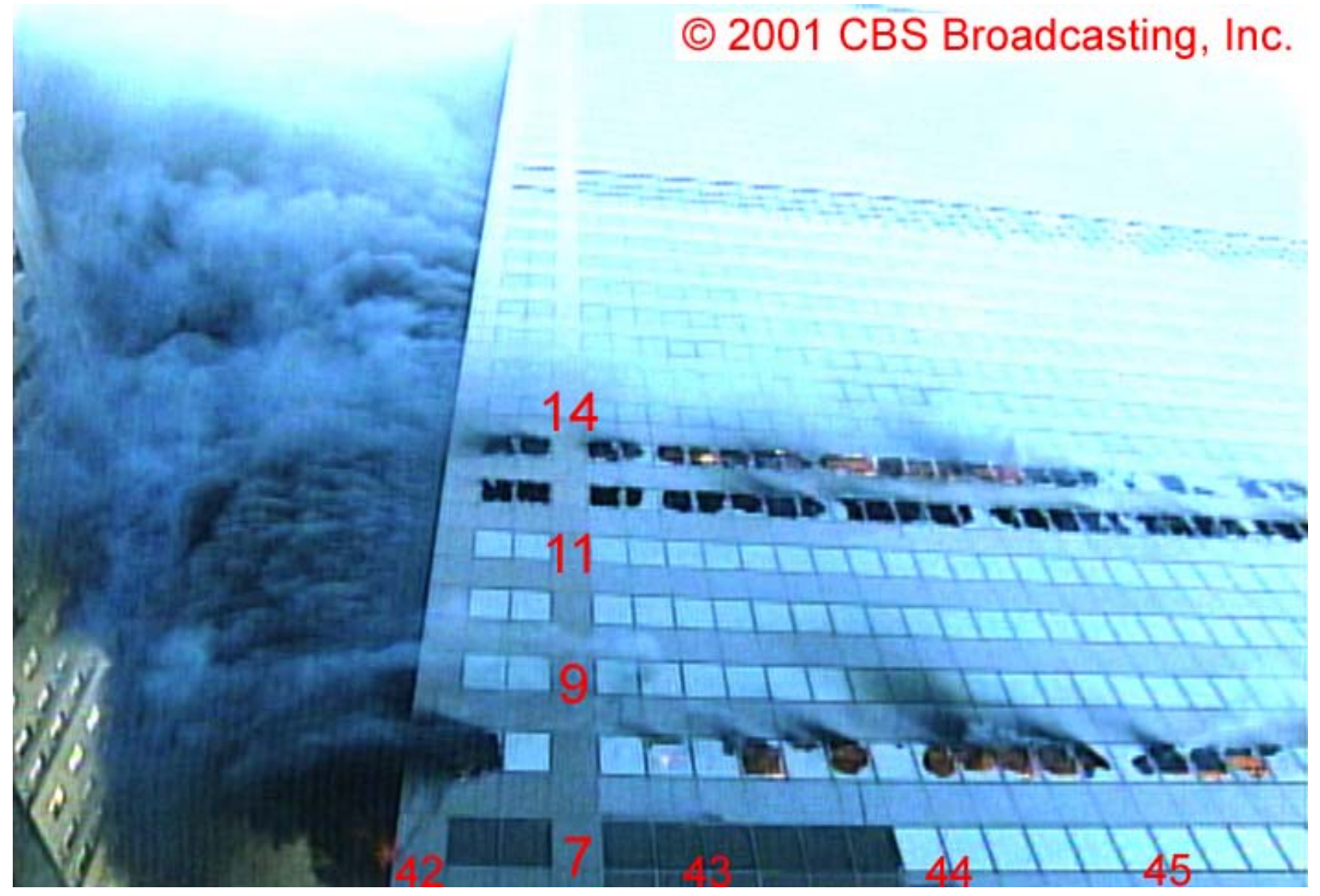

Figure 5-141. Frame from a video shot from near the corner of West Broadway and Barclay Street showing the eastern side of the north face of WTC 7 between 3:53 p.m. and 4:02 p.m.

The intensities have been adjusted, and column and floor numbers have been added.

The fire spreading to the east on the $8^{\text {th }}$ floor had apparently reached the east face by the time Figure 5-141 was recorded. Multiple window panes are broken, heavy fire is visible between Columns 43 and 44, and window 8-42D is open at the top with flames visible through the remaining glass. A small flame has also appeared on the east face, indicating windows were beginning to break on this side of the $8^{\text {th }}$ floor. Within a few seconds this small flame grew much more intense.

Flames are also visible on the $13^{\text {th }}$ floor in Figure 5-141. Review of the video clips indicated that flames were periodically observed from window $13-42 \mathrm{C}$ to window $13-45 \mathrm{C}$. Only light smoke is coming from the open windows on the north side of this floor. As observed earlier, there is no indication of fires burning on the east side of the $12^{\text {th }}$ floor at this time. Elsewhere, window glass on the east side of the north face on the $7^{\text {th }}$ floor, $9^{\text {th }}$ through $11^{\text {th }}$ floors, and above the $13^{\text {th }}$ floor is intact.

Another frame from a video clip recorded roughly 2 min later showing the lower northeast corner of WTC 7 is reproduced in Figure 5-142. The changes on the north side of the $8^{\text {th }}$ floor were substantial over this short period. Additional windows have opened near the eastern edge, and the fires have grown substantially in intensity. While not readily apparent in Figure 5-142, flames were visible in window 8-42A during the short video clip. 


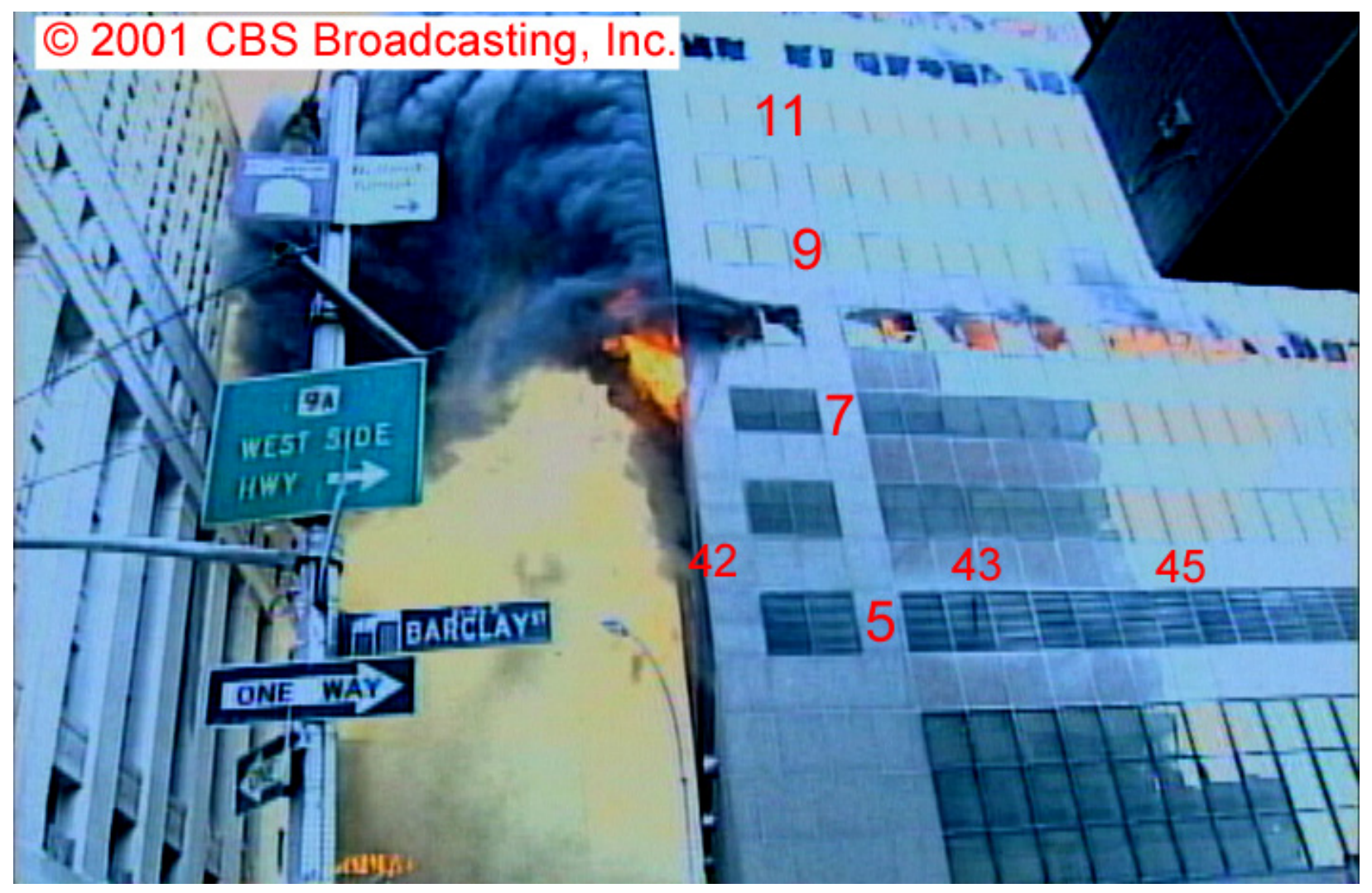

Figure 5-142. Frame taken from a video shot near the corner of West Broadway and Barclay Street showing the lower northeast corner of WTC 7 between 3:55 p.m. and 4:04 p.m.

The intensities have been adjusted, and column and floor numbers have been added.

Some of the more interesting observations from Figure 5-142 are on the east face. Very intense flames were coming from multiple windows on the $8^{\text {th }}$ floor at this time. A close-up of these flames, taken from a video clip recorded about a minute later is shown in Figure 5-143. Note that additional glass has broken out of window 8-42C during the short period between the two frames. Comparison of the flames near the northeast corner on the north and east faces provides a vivid demonstration of the different burning behaviors on these two faces. On the north face, the flames are mostly inside the windows, which was generally true for fires observed on this face, while very intense external burning, similar to that observed on the east side of the $12^{\text {th }}$ floor much earlier, is taking place on the east face. These observations provide additional evidence that pressure differences generated by the ambient wind affected the local fire behaviors observed on different faces.

Closer inspection of Figure 5-142 reveals what appears to be a relatively light plume of white smoke rising from near the top of the louvers that spanned the $5^{\text {th }}$ and $6^{\text {th }}$ floors on the east face. It was not possible to identify the exact location of the plume relative to the edge of the building. At a minimum, the presence of this plume suggests that smoke had been transported to the $5^{\text {th }}$ or $6^{\text {th }}$ floors before being vented. It is also possible that the source of the smoke was a fire burning somewhere on these two floors. The available imagery does not provide evidence indicating which of these two alternatives is correct. 


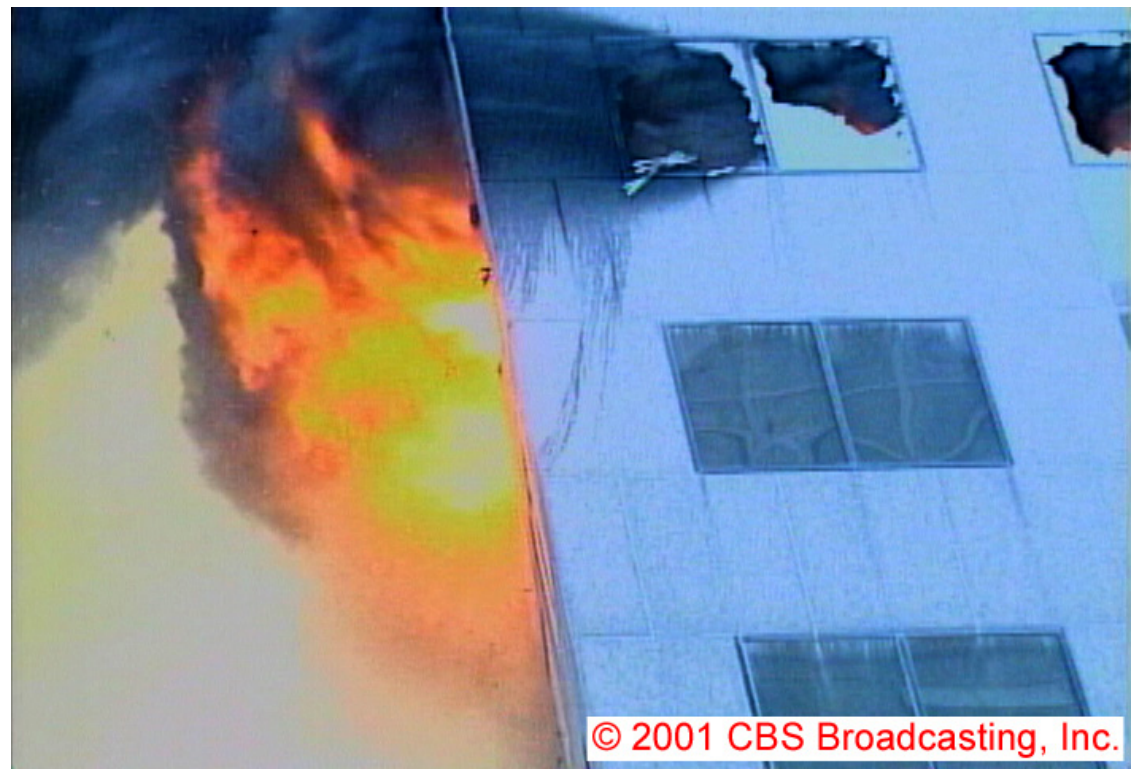

Figure 5-143. Frame from a video shot near the corner of West Broadway and Barclay Street showing a close up of the northeast corner of WTC 7 at the $8^{\text {th }}$ floor between 3:56 p.m. and 4:05 p.m.

The intensities have been adjusted.

Figure 5-144 shows another view of the north face of WTC 7 taken looking down Greenwich Street from a location near its corner with Murray Street. The time of this photograph could not be determined, but comparison of the fire distributions with Figure 5-139 indicates that it was likely taken around 3:55 pm.

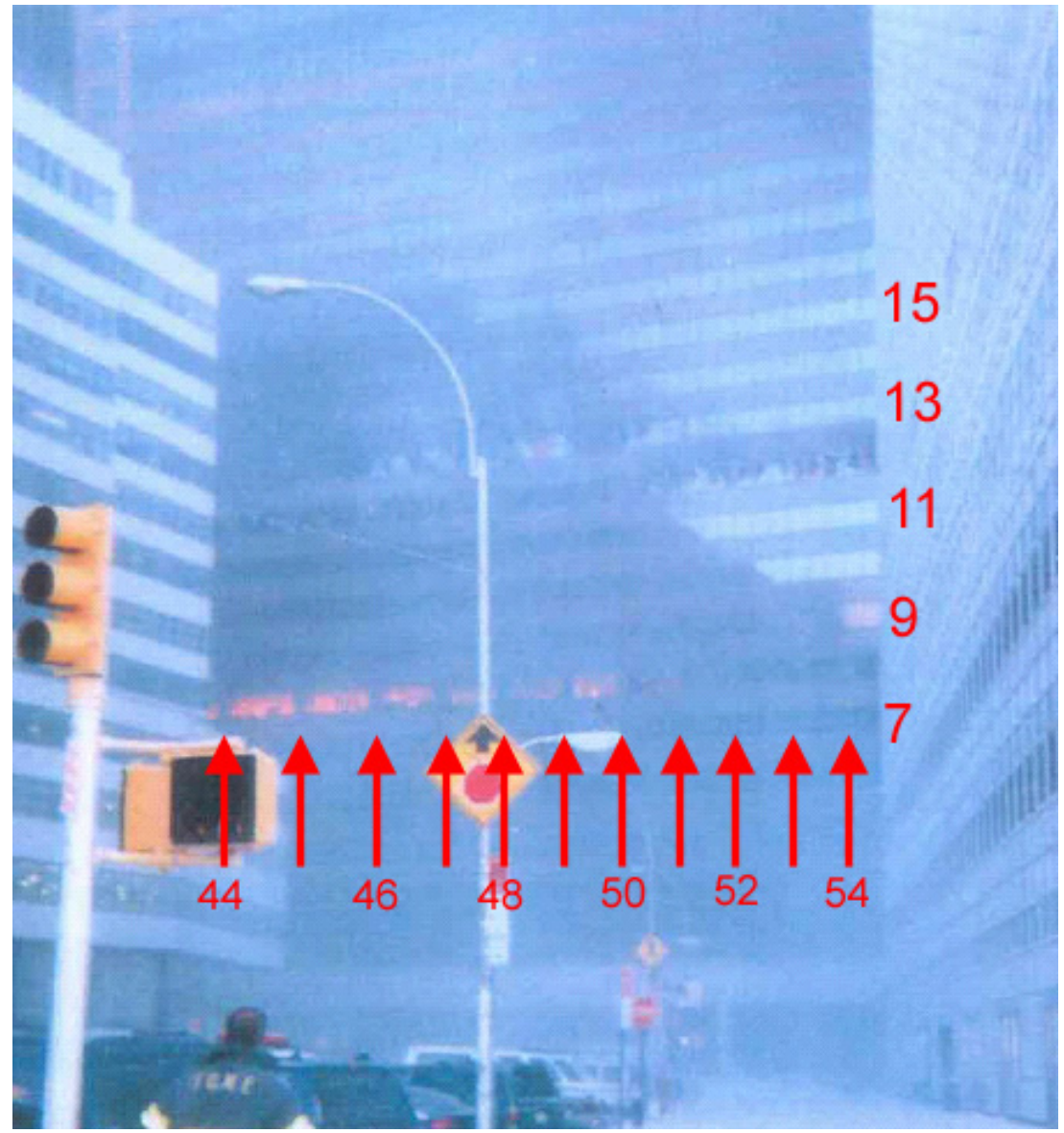

Figure 5-144. Cropped photograph showing the north face of WTC 7, shot from near the corner of Murray and Greenwich Streets near 3:55 p.m. Column and floor numbers have been added.

Source: Unknown 
In the ground shot, flames are visible on the $8^{\text {th }}$ floor from window 8-43D to Column 51 . The fire between Columns 50 and 51 is clearly dying down, while flames are no longer evident to the west of Column 51.

There appear to be flames present in windows 9-54A and 9-54B. There is some ambiguity because the glass in these windows still appears to be intact. It is possible that a reflection is responsible for the reddish color. If there is indeed fire at this location, it represents the earliest indication of fire on this floor.

On the $12^{\text {th }}$ floor, windows $12-53 \mathrm{D}, 12-54 \mathrm{~A}$, and 12-54B were opened between the times when Figure 5-136 and Figure 5-144 were taken. Recall that at the earlier time, flames had been observed further to the west. Apparently, the burning was filling in offices that the fire had previously bypassed. Only light burning is apparent in the immediate vicinity. On the $13^{\text {th }}$ floor, windows appear to be open as far west as Column 50 in Figure 5-144, with flames visible to the west of Column 48. In Figure 5-136, the open windows only extended as far west as Column 48. Clearly, the fire on this floor was continuing to spread to the west.

A frame from a video clip taken from a location much further north on Greenwich Street than the view in Figure 5-144 is reproduced in Figure 5-145. The fire distribution indicates the clip was taken later than the photograph in Figure 5-144. Relatively low intensity flames are visible on the $8^{\text {th }}$ floor from window 8-45E to window 8-49B. In Figure 5-144, the flames were in general more intense and extended to window 8-50D. Since fully developed fires typically burn intensely for about $20 \mathrm{~min}$, it is likely that the time between the two images was less than 20 min. Assuming a 15 min difference yields an estimated time of 4:10 p.m. with at least a 5 min uncertainty.

The most dramatic change in the fire distributions between the two images is on the $9^{\text {th }}$ floor. In the earlier image, there was evidence of a fire growing in windows 9-54A and 9-54B. In the later image, flames and heavy smoke are visible between windows 9-51A and 9-53B. In the video clip and others recorded around the same time, it can be seen that significant external burning was taking place. Such burning was not typical of most locations on the north face. This observation not only suggests that the fire had flashed over at this location, but also that there was no internal path available within WTC 7 for the fire effluent to vent on the east or south faces. In Figure 5-145, isolated flames have reached as far east as windows 9-49B and 9-49C, indicating that the fire was spreading from west to east.

Small isolated flames are evident at several locations on the $7^{\text {th }}$ floor in Figure $5-145$. This is somewhat surprising since the fires on this floor had stopped spreading and died down much earlier. There is still no indications that fire has spread to the east beyond Column 47. No fires or broken windows are apparent on the $6^{\text {th }}, 10^{\text {th }}$, and $11^{\text {th }}$ floors.

The north face of WTC 7 can be seen in the photograph reproduced in Figure 5-146. The time for this image could not be accurately determined, but it was clearly taken after the video frame shown in Figure 5-145. Even though the video was taken from a long distance, it provides useful information about the fire distributions. The most intense fires are on the $9^{\text {th }}$ floor. Flames can be seen on this floor at both ends of the visible length running from window 9-45C to 9-52D. Continuous flames are present between Columns 45 and 50. Apparently, the fire observed between Columns 49 and 50 in Figure 5-145 grew and spread rapidly to the east. Interestingly, there is still no sign of fire between Columns 50 and 51. This may be an indication that there was a room in that location that had not yet been breeched by the fire. As seen earlier, heavy smoke is rising from the fire on this floor. 


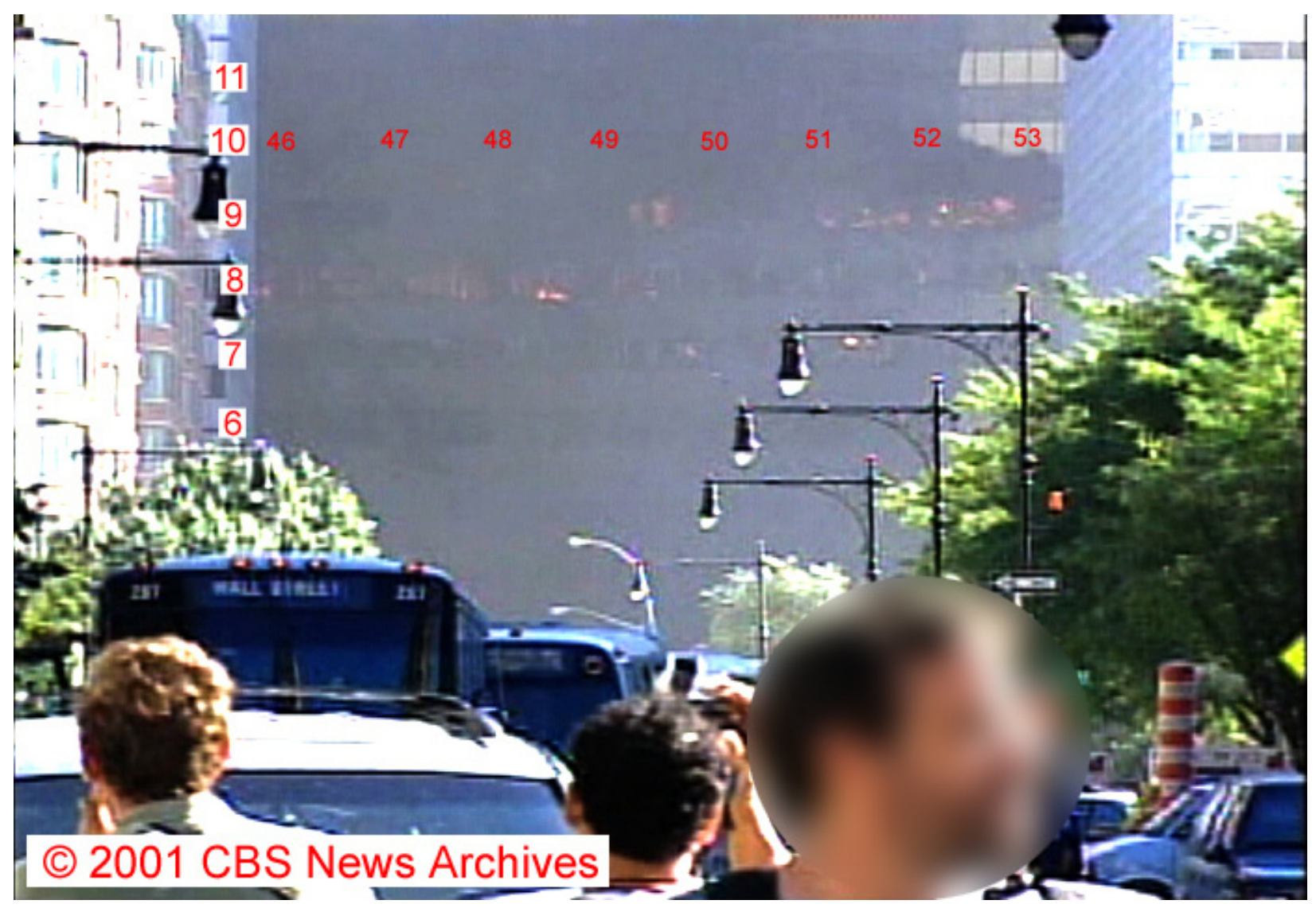

Figure 5-145. Frame taken from a video clip shot from near the corner of Greenwich and Jay Streets around 4:10 p.m. \pm 5 min.

The intensities have been adjusted, a face was blurred, and column and floor numbers have been added.

Low intensity flames continue to burn on the $8^{\text {th }}$ floor between Columns 47 and 49 . Similar flames are also visible on the $12^{\text {th }}$ floor between Columns 51 and 52. In Figure 5-145 it appeared that some of the glass was still in place for some of these windows. This seems to be no longer the case in Figure 5-146.

The amount of fire spread and growth between the times when the images in Figure 5-145 and Figure 5-146 were taken would be expected to require many minutes. Assuming a period of 10 min yields a crude estimate of 4:20 p.m. for the timing of Figure 5-146.

Close inspection of Figure 5-146 reveals that there is an area of flame on the $7^{\text {th }}$ floor between Columns 46 and 47. After a long period of inactivity, fire has clearly made its way to the other side of the obstacle that had earlier halted its spread across the face. Note that there is no indication of how fire arrived at this location. It could have spread from the west, south, or east. 


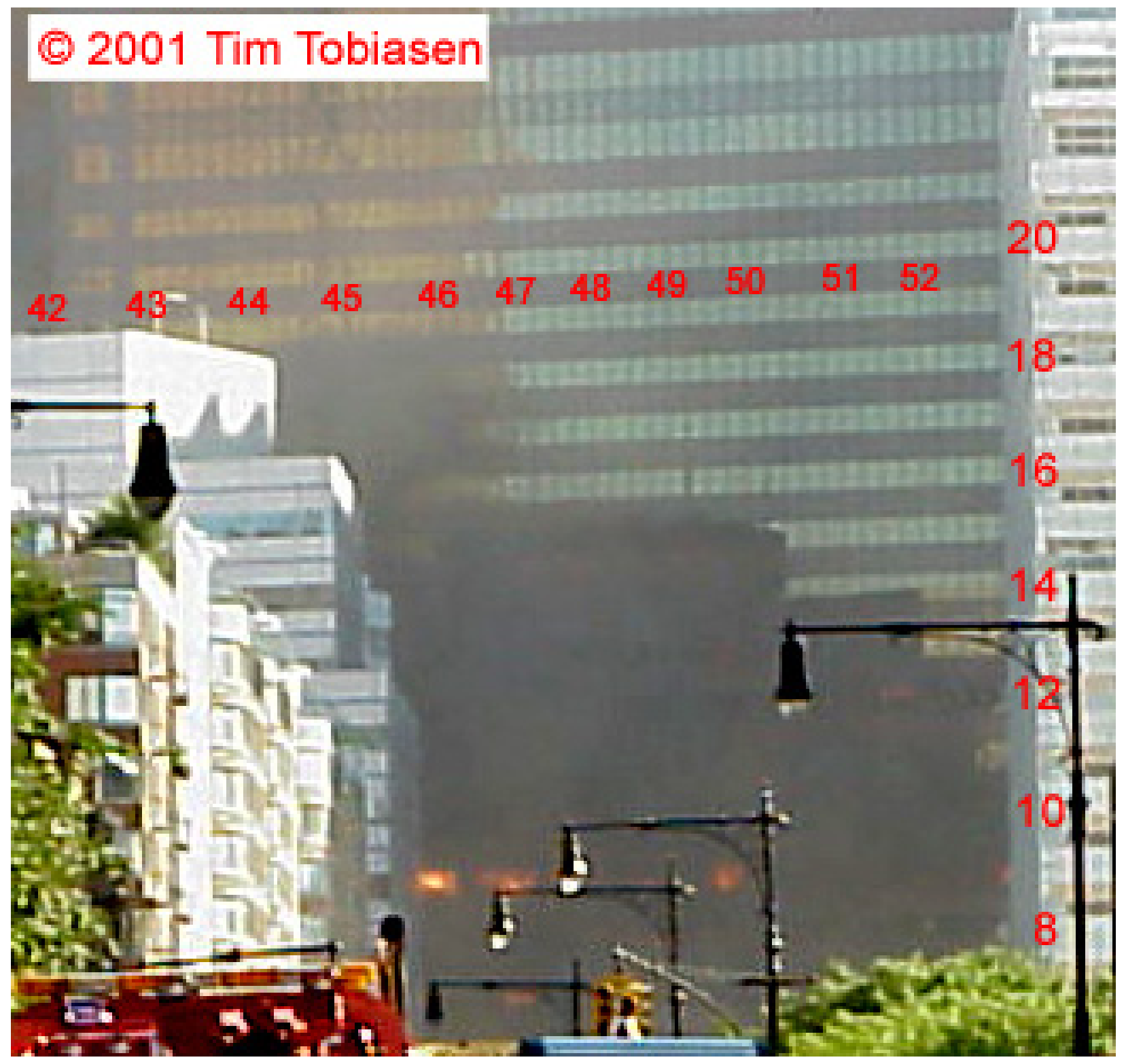

Figure 5-146. Cropped photograph showing the north face of WTC 7 from near the corner of Greenwich and Harrison Streets at a roughly estimated time of 4:20 p.m.

The intensities have been adjusted, and column and floor numbers have been added.

Figure 5-147 provides a view of the north face of WTC 7. The image is a frame taken from a digital video that was accurately timed. This frame was recorded just before 4:38 p.m. Even from the long distance from which the video was filmed, it is possible to see a heavy fire burning on one of the floors. Little or no smoke is evident on the north face, but dense black smoke is rising from the east face. This appears to be another example of fires burning on the north face exhausting through openings on a different face of the building. 


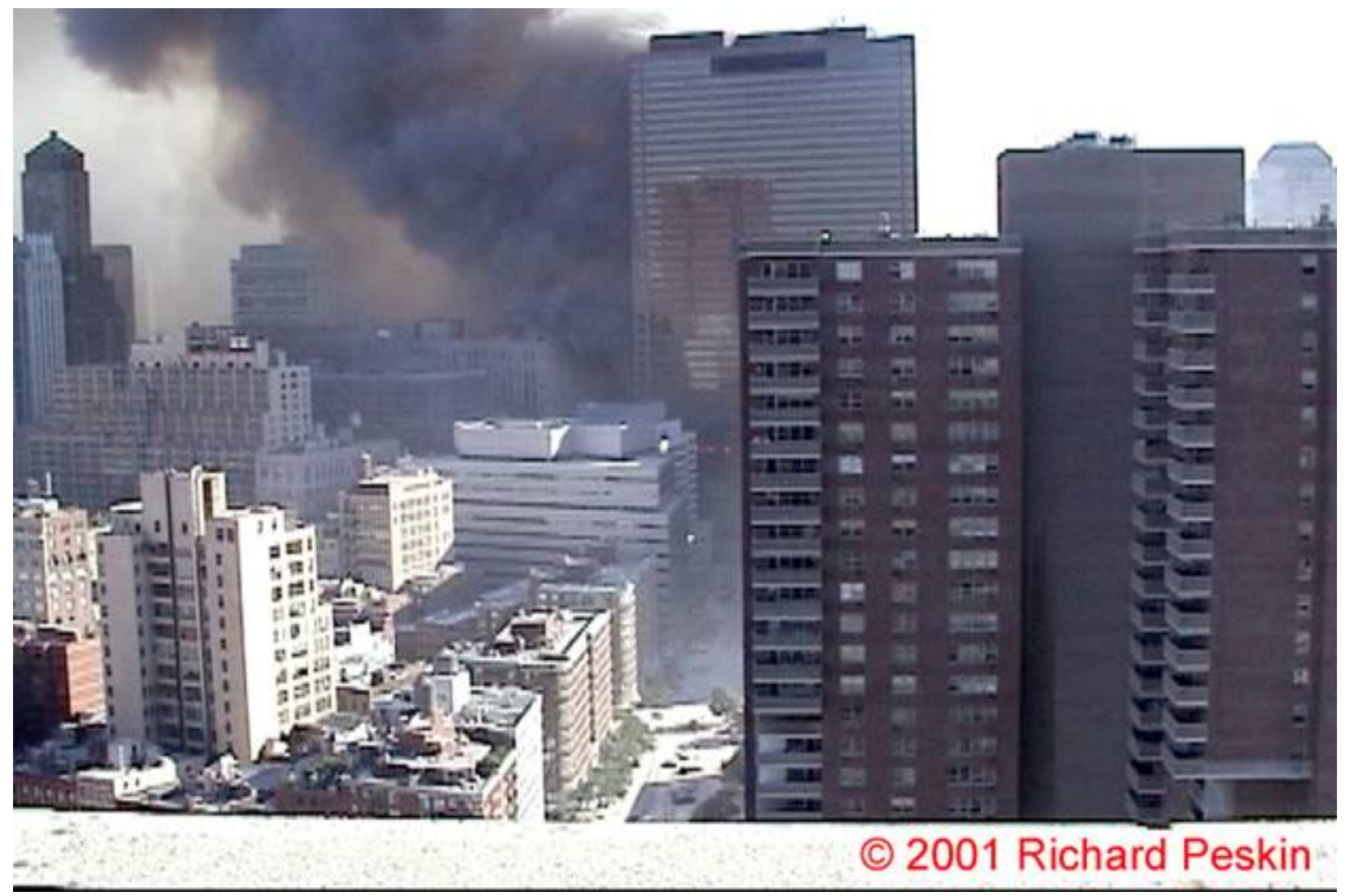

Figure 5-147. Frame from a video clip shot from the top of a nearby building to the northwest, providing a view of the north face of WTC 7 at 4:37:46 p.m. \pm 1 s. The intensity levels have been adjusted.

The videographer zoomed in on the north face of WTC 7 during the same clip from which the frame in Figure 5-147 was taken. Figure 5-148 and Figure 5-149 are two spatially overlapping close-up frames that, taken together, show portions of the $6^{\text {th }}$ through $14^{\text {th }}$ floors just after $4: 38$ p.m. In Figure $5-149$, the visible lengths of the floor extend from just east of Column 45 to just west of Column 47 . All of the visible windows on the $7^{\text {th }}, 8^{\text {th }}$, and $9^{\text {th }}$ floors were open at this time, while all of the windows on the $6^{\text {th }}$ and $10^{\text {th }}$ floors still had glass in place. Small spot fires are visible at numerous locations on the three floors with open windows.

In Figure 5-146, intense fires were visible on the $7^{\text {th }}$ and $9^{\text {th }}$ floors in the same windows visible in the video around 4:38 p.m. A less intense fire was also present on the $8^{\text {th }}$ floor. All of these fires had died down significantly by the time Figure 5-148 was recorded roughly 25 min later. Since the typical intense flaming peak for most of the fires observed in WTC 7 lasted about $20 \mathrm{~min}$, it seems safe to conclude that the photograph shown in Figure 5-146 could not have been taken later than 4:28 p.m., consistent with the estimate of 4:20 p.m for the earlier image. 


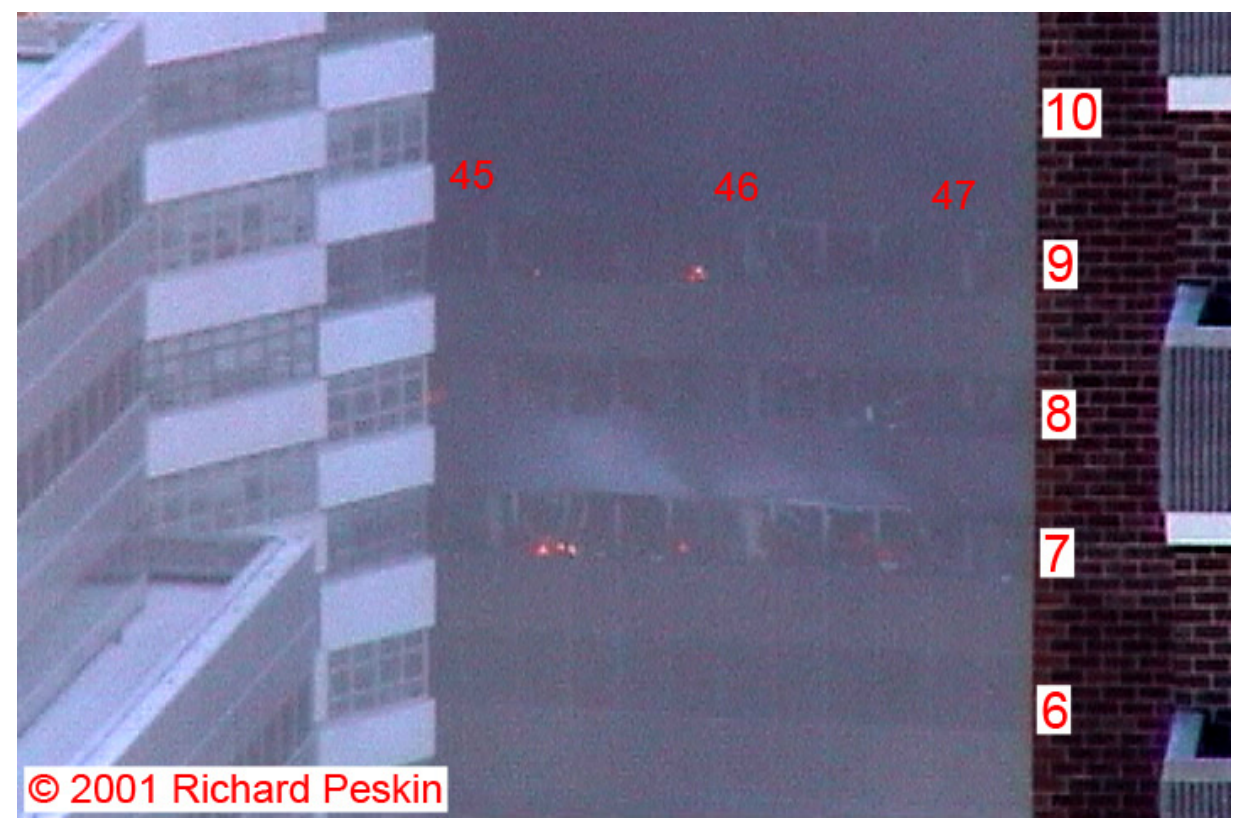

Figure 5-148. Frame from a video clip showing a close up view of the north face of WTC 7 at 4:38:11 p.m. \pm 1 s. The video was shot from the same location as the frame in Figure 5-147. The image intensities were adjusted, and column and floor number have been added.

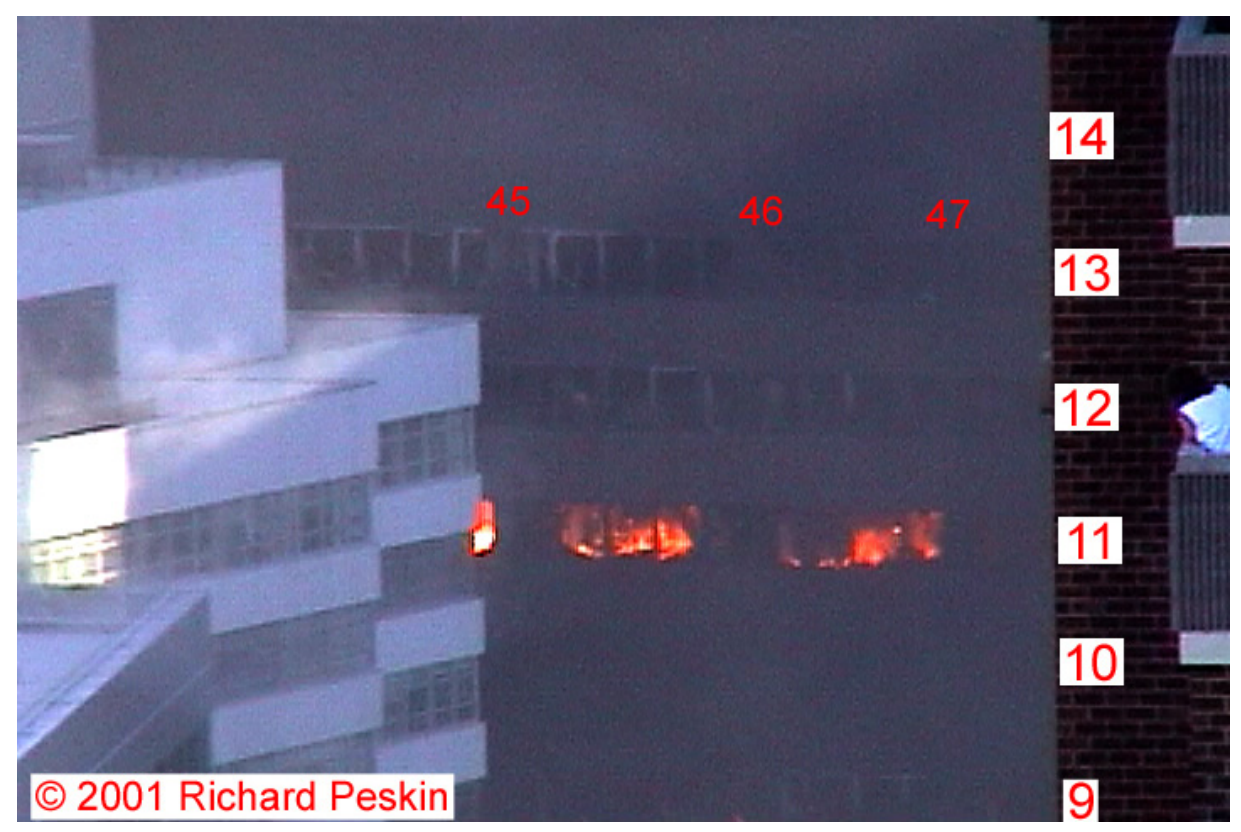

Figure 5-149. Frame from a video clip showing a close up view of the north face of WTC 7 at 4:38:14 p.m. \pm 1 s. The video was shot from the same location as the frame in Figure 5-147. The image intensities were adjusted, and column and floor number have been added.

Figure 5-149 shows the visible portions of the $9^{\text {th }}$ to $14^{\text {th }}$ floors. The most prominent feature is the extensive fire present on the $11^{\text {th }}$ floor between windows $11-44 \mathrm{E}$ and 11-46D. A dull red glow is visible through window 11-47A. This image provides the earliest evidence that the fire on this floor had reached the north face. There was no sign of a fire on this face in earlier images. Recall that a growing fire was observed on the east side of this floor as early as 2:08 p.m. It is remarkable that nearly two and a half hours were required for fire to finally appear on the north side. Even though there is substantial fire present on the floor, no smoke is visible coming from the open windows. This is another example where the fires were venting elsewhere. 
All of the visible windows on the $12^{\text {th }}$ and $13^{\text {th }}$ floors are open in Figure 5-149. There is no indication of fire at these locations on either floor. All of the glass is in place for windows on the $14^{\text {th }}$ floor, and there is no indication that fire is present on this floor at this time.

Another partial view of the north face taken from street level at nearly the same time as Figure 5-148 and Figure 5-149 is shown in Figure 5-150. The photograph was shot on film, so a precise time could not be assigned. However, the same photographer shot an accurately timed digital photograph from nearly the same location at 4:39:19 p.m. The time for the film picture was therefore assigned as 4:39 p.m. with an uncertainty of $\pm 2 \mathrm{~min}$. In Figure 5-149, the intense fire on the $11^{\text {th }}$ floor did not extend beyond Column 47, while in Figure 5-150 it appears to have moved beyond Column 48, suggesting that the photograph may actually have been shot after the video frames.

More flames are evident on the $7^{\text {th }}, 8^{\text {th }}$, and $9^{\text {th }}$ floors in the ground-level photograph than in the video frames shot looking down on the face. In Figure 5-150, the flames on these floors appear to be reddish and to be well removed from the windows. It is possible that these fires were actually so deep inside the building that they were hidden from the view looking down through the windows. As before, there are no indications of burning on the $10^{\text {th }}$ floor in Figure 5-150.

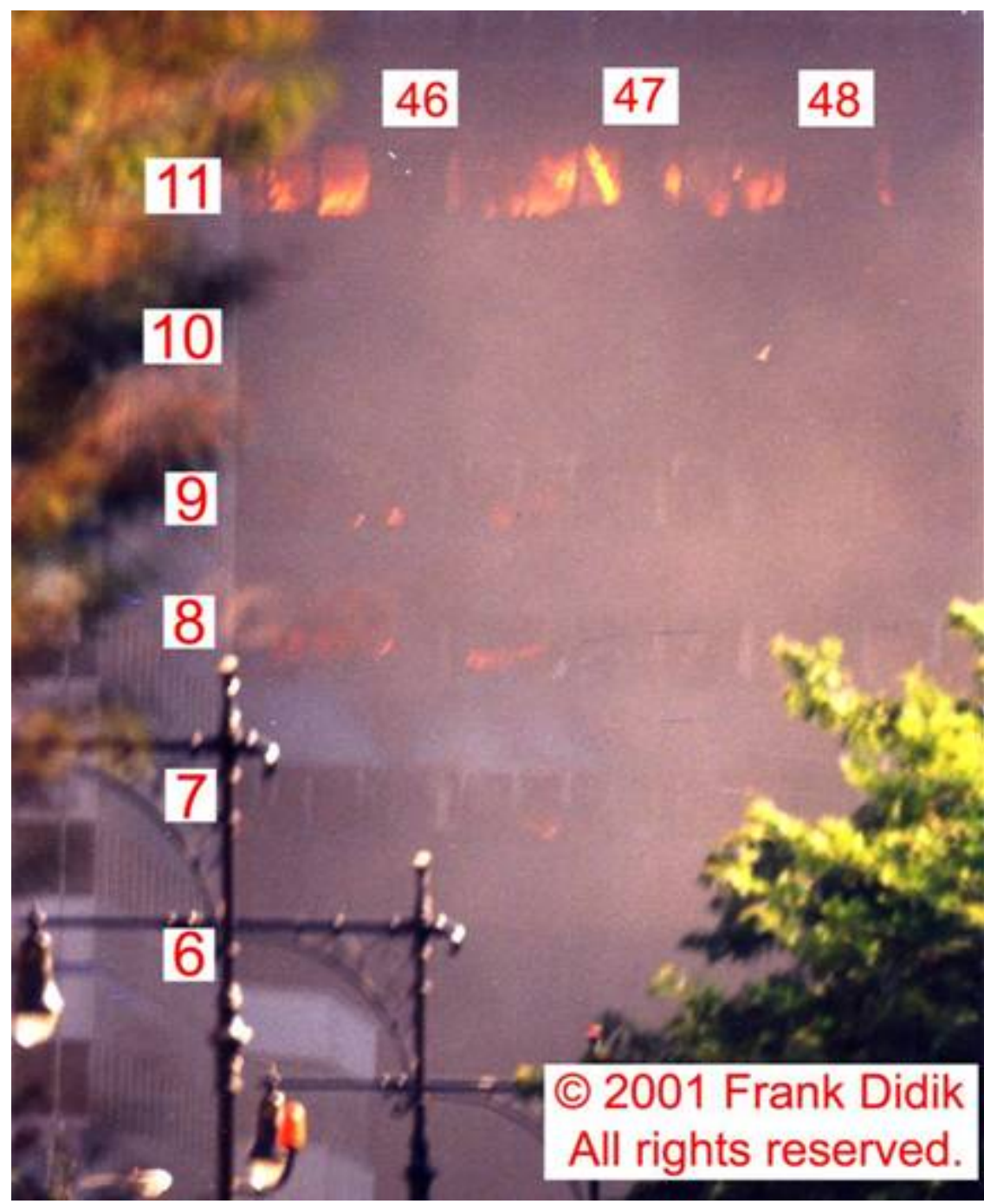

Figure 5-150. Cropped photograph showing part of the north face of WTC 7, shot from near the corner of Harrison and Greenwich Streets at 4:39 p.m. \pm 120 s.

The intensities have been adjusted, and column and floor numbers have been added. 


\section{Fires on or below the $14^{\text {th }}$ Floor, 4:40 p.m. to 5:21 p.m.}

After roughly 4:40 p.m., imagery in the Investigation database showing the north face of WTC 7 is more limited. Figure 5-151 shows a long distance shot of the north face of WTC 7 taken at 4:52:24 p.m. from the same vantage point as Figure 5-147. In the video clip it can be seen that smoke is passing across the lower part of the north face. Unlike Figure 5-147, there is no fire visible on the north face from this distance. It seems the fires on the $11^{\text {th }}$ floor have died down, but it is possible that fire was present, but hidden by the smoke. Heavy, dark smoke is still visible rising from the east face of the building.

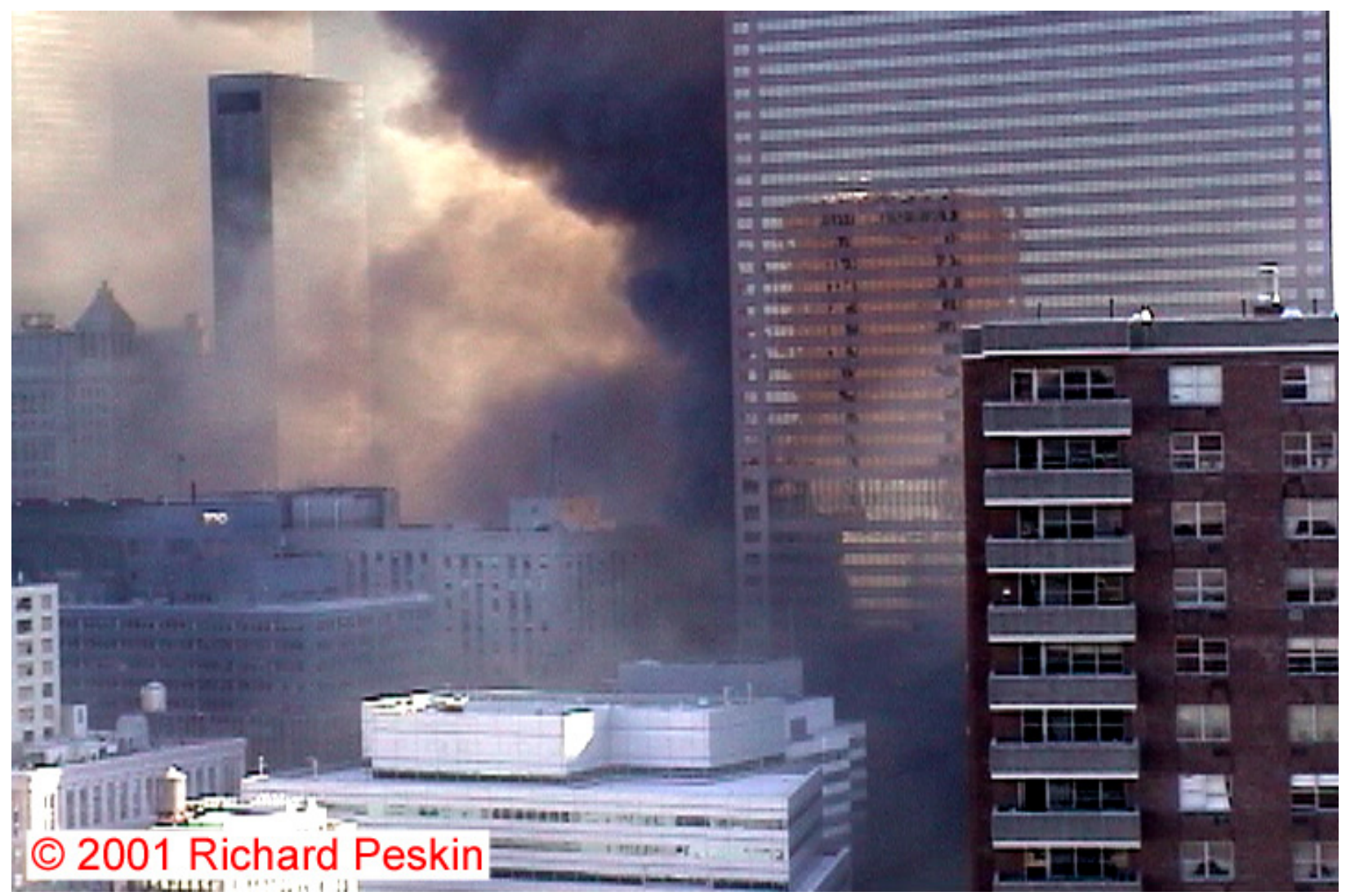

Figure 5-151. Frame from a video clip shot from the top of a nearby building, showing the north face of WTC 7 at 4:52:24 p.m. \pm 1 s.

The intensity levels have been adjusted.

Figure 5-152 shows a limited view of the north face shot from the northeast over the tops of the two buildings to the north of WTC 7. The time was crudely estimated as being around 5:00 p.m. based on the pattern of sunlight and shadow on the building to the immediate north of WTC 7. Only the $12^{\text {th }}$ to $17^{\text {th }}$ floors are visible. Fires are burning on the $12^{\text {th }}$ and $13^{\text {th }}$ floors. On the $12^{\text {th }}$ floor, the fires that were slowly spreading across the north face to the west have reached the northwest corner, with flames barely visible in windows 12-57A and 12-57B. Recall that fire was observed between Columns 55 and 56 around 4:00 p.m. At 2:00 p.m., the $12^{\text {th }}$ floor was burning near the southeast corner. Apparently it took roughly three hours for fire to spread all of the way from the southeast corner to the northwest corner. 


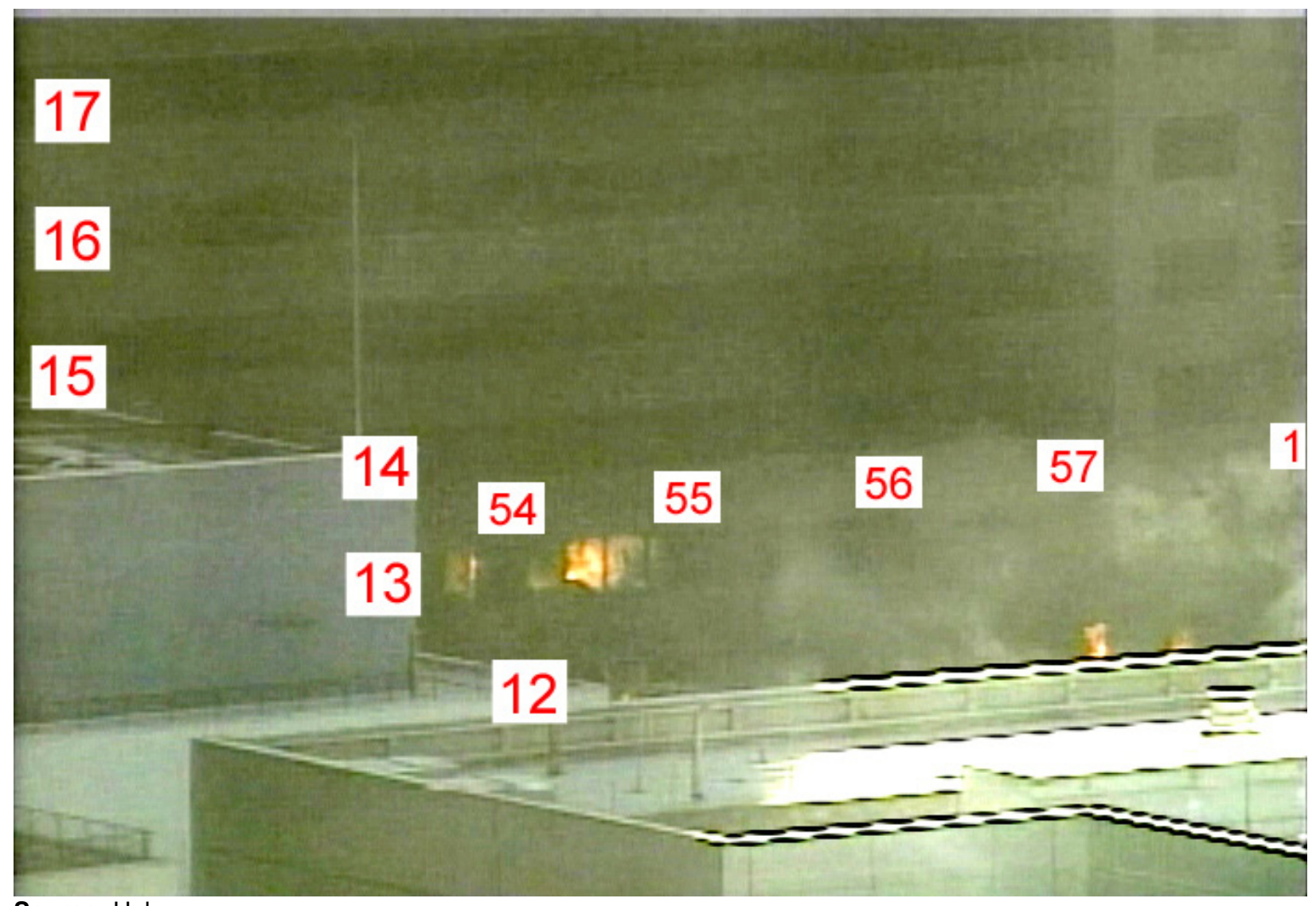

Source: Unknown

\section{Figure 5-152. Frame taken from a video clip shot over the buildings at $\mathbf{3 0}$ West Broadway and 70 Murray Street, showing the western edge of the north face of WTC 7at about 5:00 p.m.}

The time uncertainty is at least ten minutes. The intensities have been adjusted, and column and floor numbers were added.

The fire on the $13^{\text {th }}$ floor has burned westward as far as Column 55. In Figure 5-144, which was estimated to have been taken around 3:55 p.m., flames were observed as far west as Column 50. This fire was continuing to work its way to the west. There are no indications of fire burning in this area on floors higher than the $13^{\text {th }}$ floor. In the video clip, some light smoke was visible blowing across the north face, but there was apparently little smoke coming from the open windows on the $12^{\text {th }}$ and $13^{\text {th }}$ floors, consistent with earlier observations that the effluent for fires on these floor vented at remote locations on other faces.

Figure 5-153 shows a view of the north face of WTC 7 looking down Greenwich Street at 5:03:00 pm. $\pm 2 \mathrm{~min}$. The image is from a digitized video converted from film and is noisy. For this reason, column and floor numbers have not been added. Nonetheless, by comparison with Figure 5-139, which was shot from roughly the same location, some details concerning the fires can be discerned. Flames are only visible at one location on the face, namely near the top of the frame on the left side near the building at 30 West Broadway. Reference to Figure 5-139 suggests that this location is on the $14^{\text {th }}$ floor between Columns 45 and 46. If correct, this represents the first and only visual indication of a fire on this floor. 


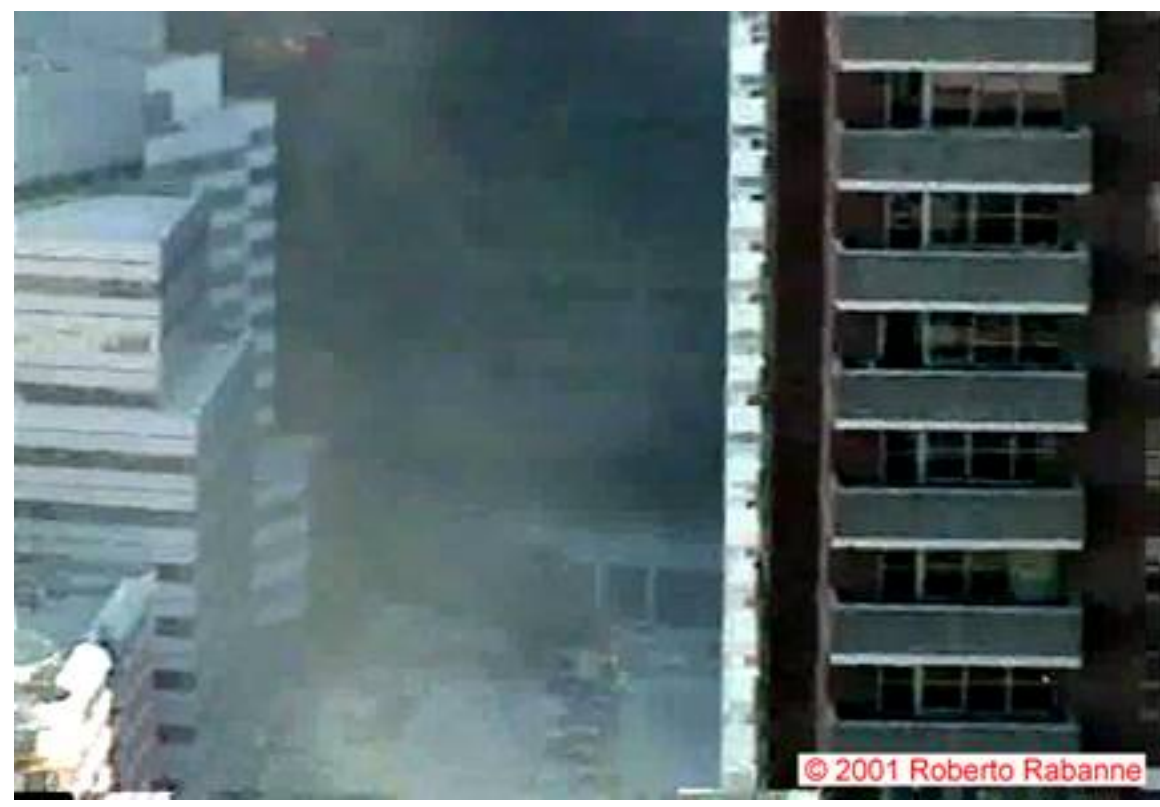

Figure 5-153. This frame from a video shot from a building to the northwest of WTC 7 was taken around 5:03:00 p.m. with an uncertainty of $\pm 120 \mathrm{~s}$.

The intensities have been adjusted.

Light smoke is apparent, moving across the face from west to east in Figure 5-153. From the video, it is clear that this smoke is rising from the street just in front of WTC 7. In the figure flames are barely visible on a vehicle parked near the center of the building on Barclay Street. There is no indication of when or how this vehicle was ignited.

Another frame from the same video as Figure 5-153 is shown in Figure 5-154. This view is somewhat clearer. It was shot from roughly the same location at 5:09:03 \pm 120 s., or roughly 6 min later. In this image the fire present at the upper left-hand corner is no longer apparent, but a fairly intense fire has appeared further down on the face near the center of the visible area. Comparison with Figure 5-139 suggests this fire was located on the $11^{\text {th }}$ floor near Column 49. This location is just to the west of windows where fire was observed on the same floor in Figure 5-150 at 4:39 p.m. Apparently the fire on this floor paused briefly before continuing its movement to the west. Smoke can still be seen rising from the vehicle fire on the street below the face.

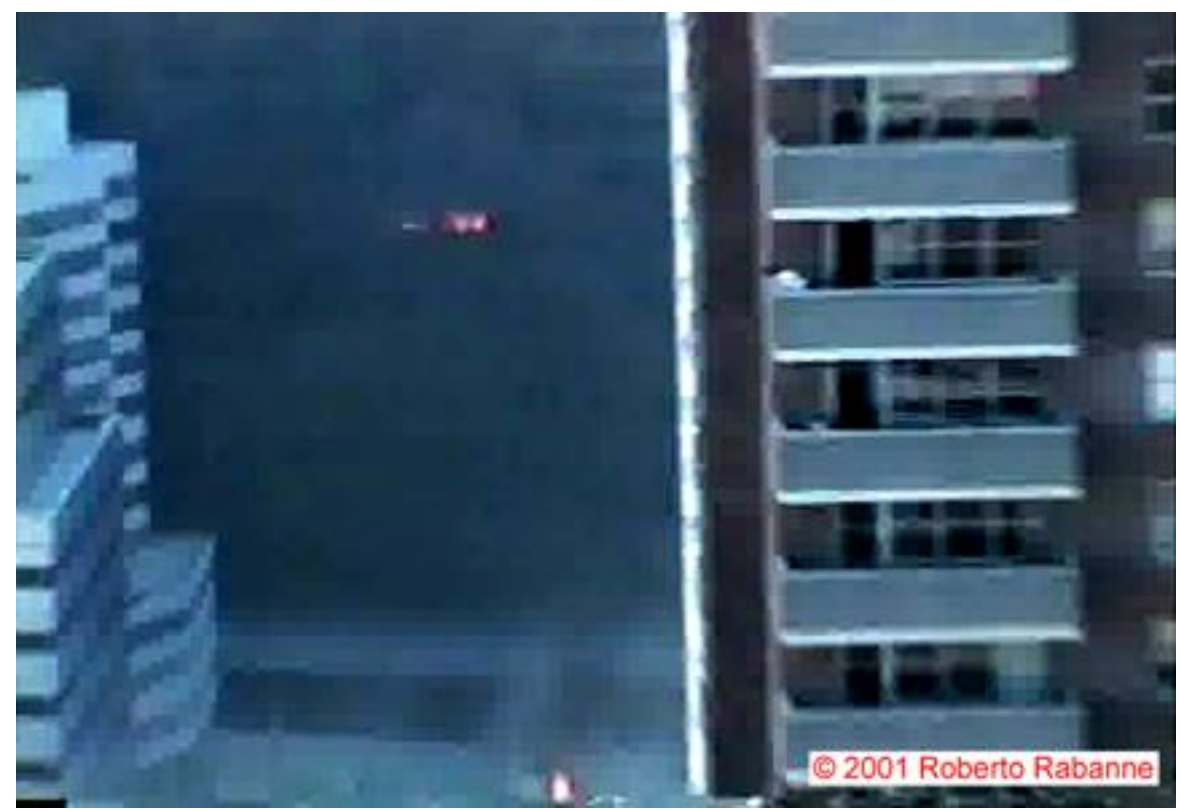

Figure 5-154. This frame from a video shot from a building to the northwest of WTC 7 was taken around 5:09:03 p.m. with an uncertainty of \pm 120 s. The intensities have been adjusted. 


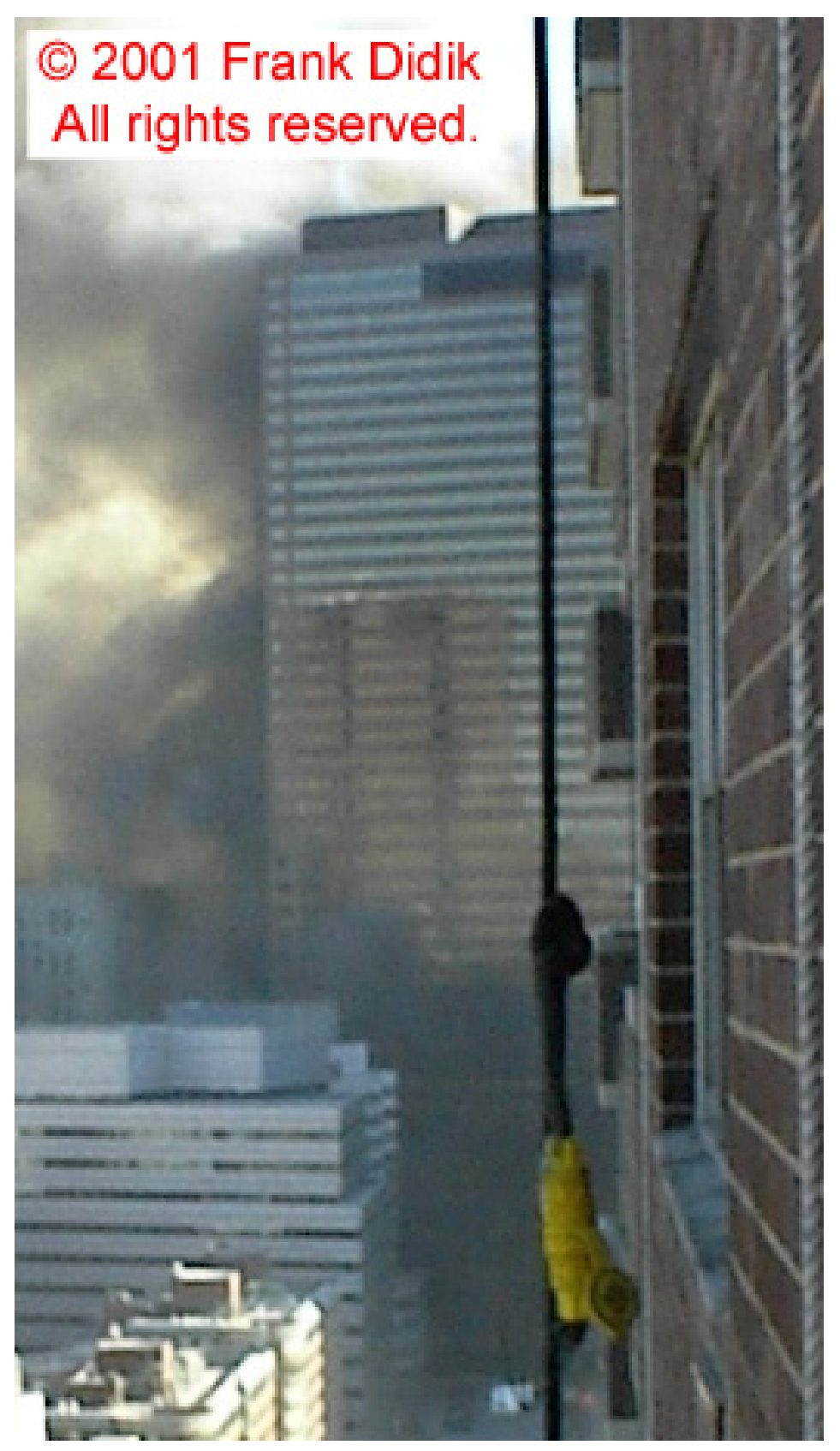

Figure 5-155. Cropped photograph of the north face of WTC 7, taken from a building located to the northwest looking down Greenwich Street at 5:13:58 p.m. \pm 3 s.

A long distance partial view of the north face of WTC 7 shot at 5:13:58 p.m. is shown in Figure 5-155. No flames are visible except on the street at the base of the north face. While some smoke is visible passing over the north face, it is possible to discern the alternating granite spandrel covers and windows on the lower floors. This suggests that no major fires were present over the visible width of the floors. Smoke is still visible rising from the east face, but comparison with earlier similar views indicates that the smoke flow had decreased markedly.

Figure 5-156 shows a frame taken from a video shot at 5:19:45 \pm 2 min from roughly the same location as Figure 5-154. Even though the north face appears to be partially obscured by smoke or dust, fires are evident in multiple windows on the right side of the visible part of the north face. Comparison with 


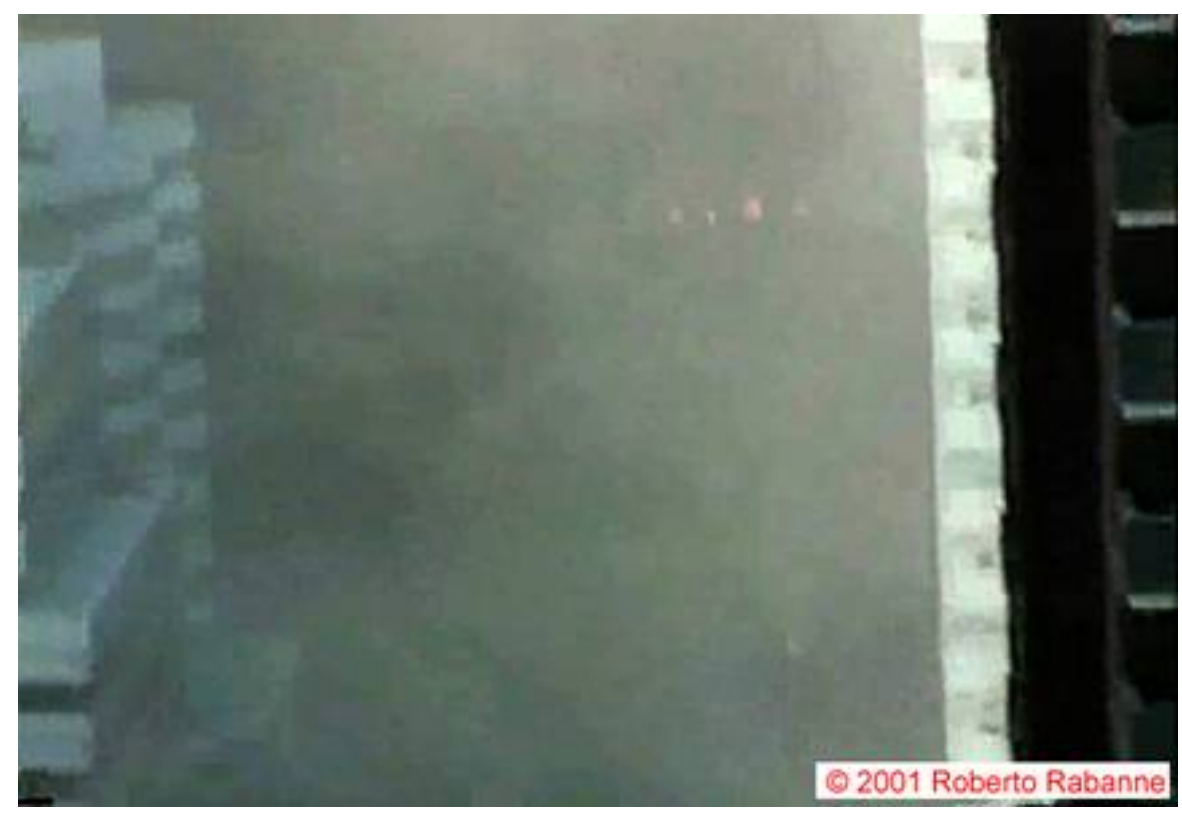

Figure 5-156. This frame from a video shot from a building to the northwest of WTC 7 was taken around 5:19:45 p.m. with an uncertainty of \pm 120 s. The intensities have been adjusted.

Figure 5-139 indicates these windows lie around Columns 50 and 51 on the $11^{\text {th }}$ floor. In the roughly 11 min between Figure 5-154 and Figure 5-156, the fires on this floor have continued to spread toward the west.

Figure 5-157 shows a closer view of the western edge of the north face of WTC 7 taken from a video clip recorded from the same location as that shown in Figure 5-152. This clip was recorded several minutes later than Figure 5-152, as is evident by the change in the shadow on the white building in the foreground. The clip was shot within a couple of minutes of the WTC 7 collapse at 5:20:52 p.m., consistent with the recollection of the videographer. At this time, flames are barely visible on the $13^{\text {th }}$ floor at roughly the same location as in Figure 5-152. Heavy, dark smoke is visible rising along the east side of the building. There is also considerable smoke passing across the north face. The source of this smoke is not immediately obvious.

During the clip from which Figure 5-157 was taken, the camera zoomed in on the same area shown in Figure 5-152. Heavy smoke was visible rising from near the northwest corner. Suddenly, several pulses of jet flames several stories high were pushed out of a window near $13-54 \mathrm{~B}$ on the $13^{\text {th }}$ floor. These pulses continued for about $6 \mathrm{~s}$. Figure 5-158 shows a frame captured during one of these pulses.

The amount of smoke on the north face increased dramatically at the same time as the pulses. This is the only time that this unusual behavior was observed for WTC 7. Similar behaviors observed during the fires in the WTC towers (NCSTAR-1-5A) were attributed to internal pressure pulses generated by events such as local collapses within the buildings. Since the exact time for this particular event is unknown, it is not possible to associate it with a known event within WTC 7.

Figure 5-159 shows a view of the north face of WTC 7 just seconds before it began to collapse. It is a frame from a video clip shot from the northwest at 5:20:17 p.m. \pm 15 s. Comparison with Figure 5-139 indicates that the fires visible in the image were located on the $11^{\text {th }}$ floor between Columns 50 and 52 , showing that the fire on this floor was continuing to spread to the west just prior to the collapse of the building. 


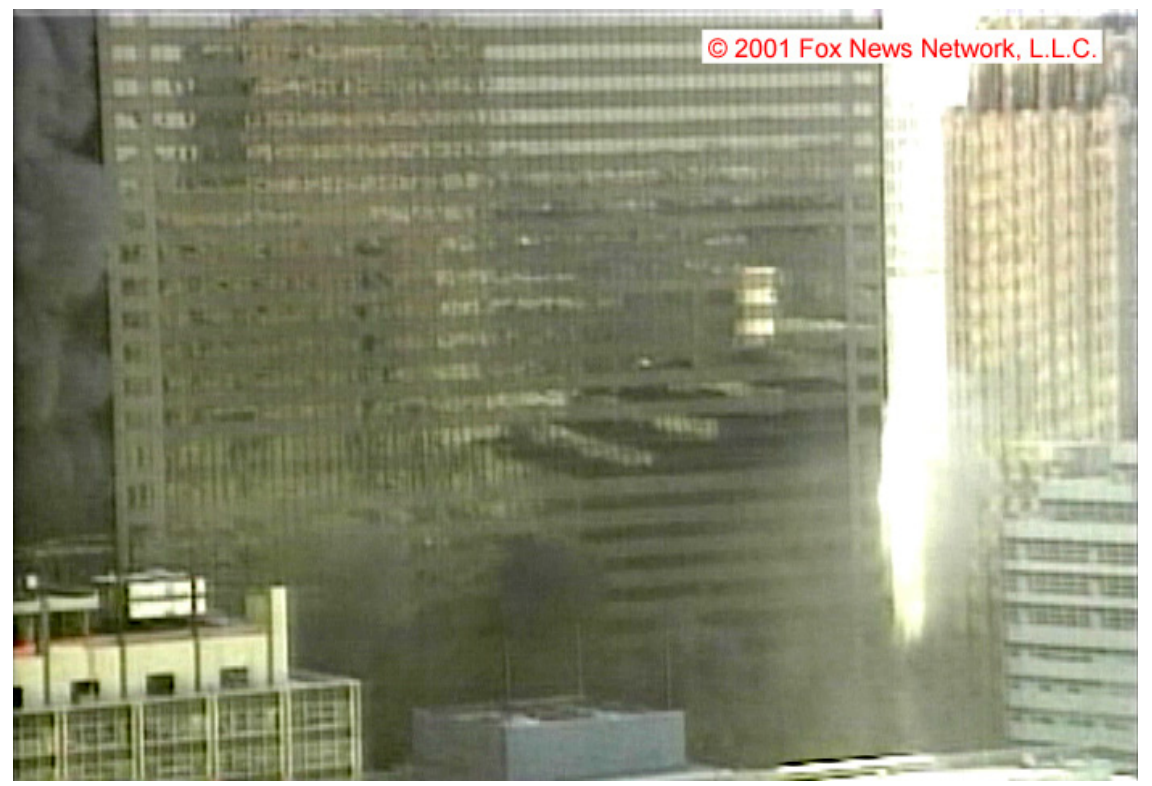

Figure 5-157. Frame taken from a video clip shot from the northeast, showing the north face of WTC 7 within a few minutes of the WTC 7 collapse at 5:20:52 p.m. The intensity levels have been adjusted.

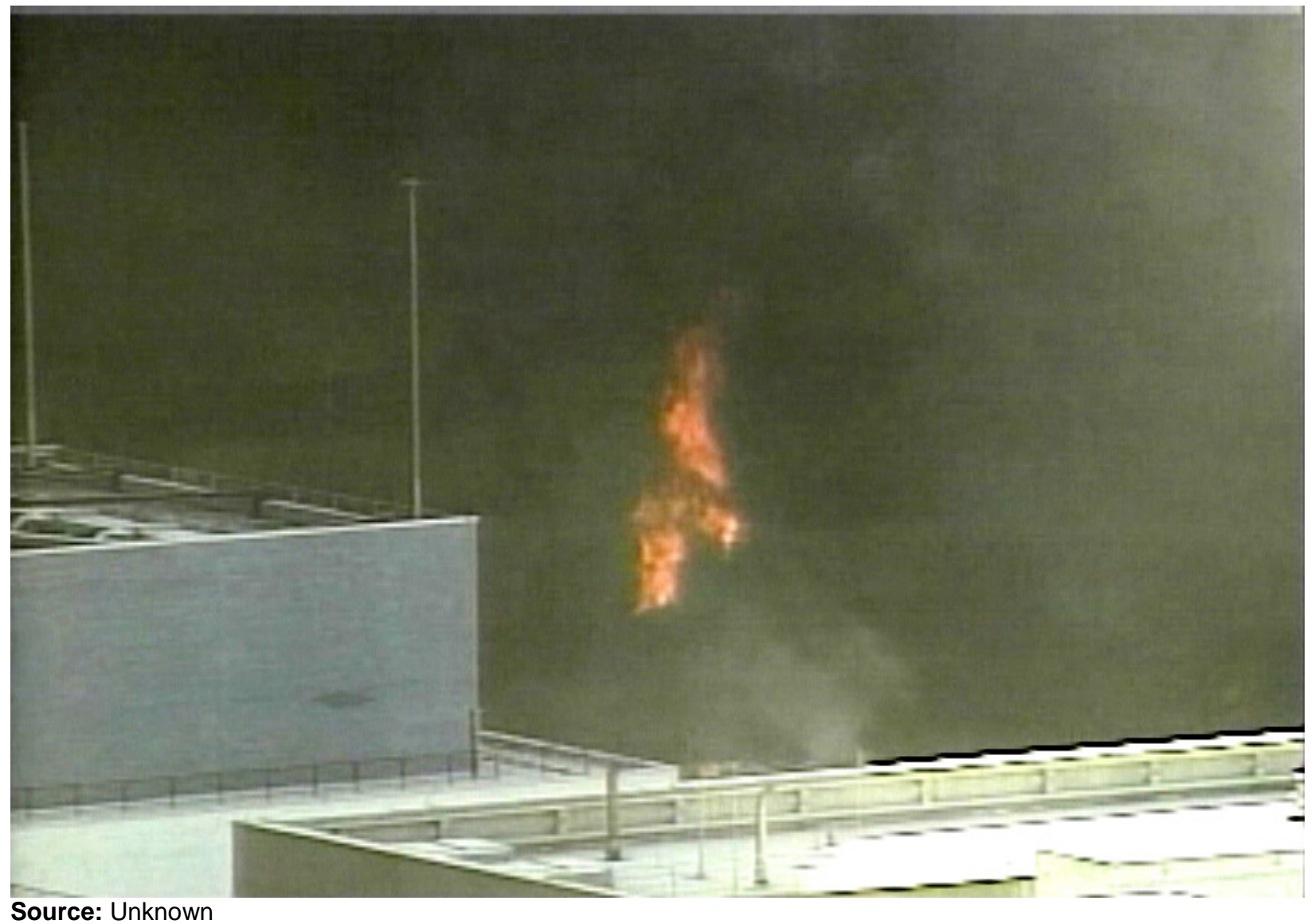

Figure 5-158. Frame taken from a video clip shot over the buildings at 30 West Broadway and 70 Murray Street, showing the western edge of the north face of WTC 7 within a few minutes of the WTC 7 collapse at 5:20:52 p.m.

The intensity levels have been adjusted. 


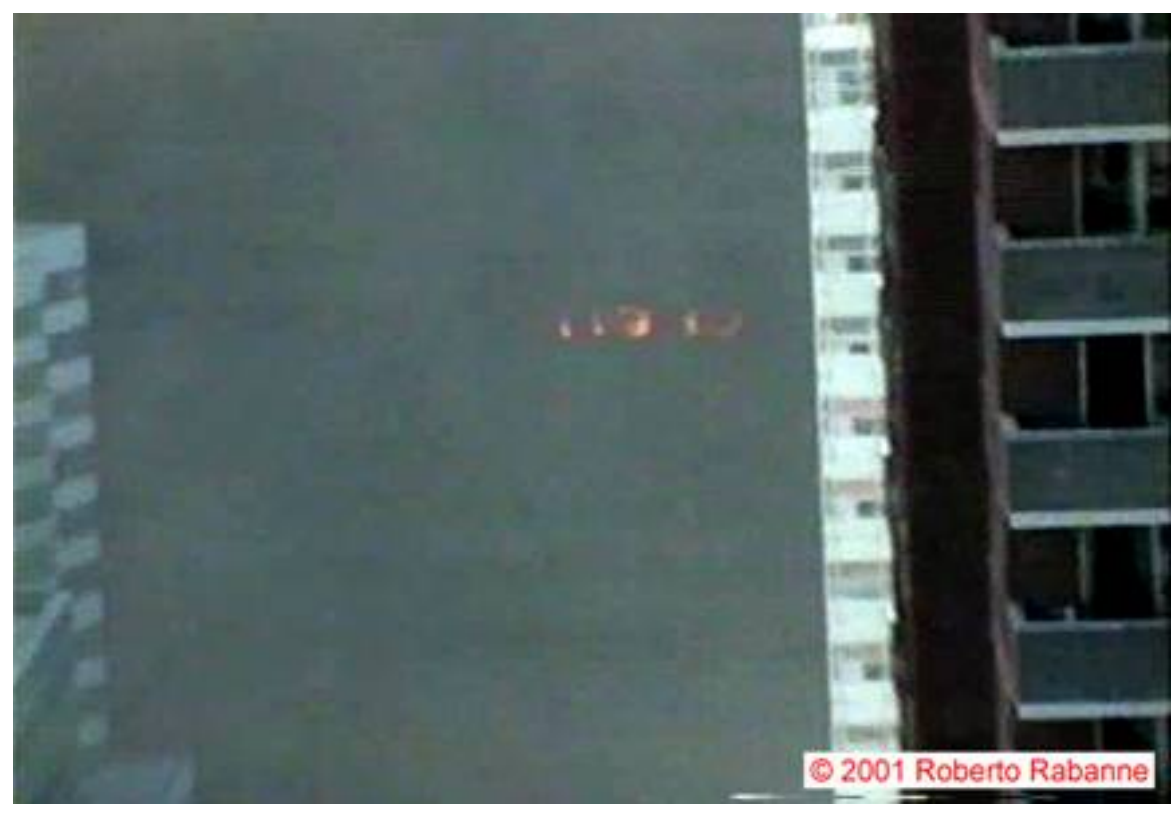

Figure 5-159. This frame from a video shot from a building to the northwest of WTC 7 was taken around 5:20:17 p.m. with an uncertainty of $\pm 15 \mathrm{~s}$. The intensities have been adjusted.

\subsubsection{Summary of Fire Spread Observations in WTC 7}

\section{General}

Even though available images showing the fires in WTC 7 do not allow the detailed description of fire spread that was possible for the WTC towers (NCSTAR 1-5A), there is sufficient information to derive general descriptions of fire ignition and spread on various floors of the building. Here, the observations of the previous two subsections are summarized. At the end of the subsection, a number of fire maps derived from specific images are provided. These maps are then utilized to derive summary maps for the east and north faces showing where fires were observed. It must be kept in mind that the fire observations are based on images of the exterior faces. These images provide little indication about the behavior of fires well removed from the exterior walls.

By the time that imagery of the WTC 7 faces started to become available around 11:00 a.m., following the collapse of WTC 1, numerous vehicles around WTC 7 were on fire and burning intensely. It is likely that nascent fires were also growing within WTC 7 around the same time, but direct visual evidence for fires in the building is not available until around noon. Early fires were primarily observed on higher floors, even though the heavy smoke pouring from the large opening on the south face created by falling debris suggested fires were also present on lower floors.

The evidence shows that early fires were ignited on the $19^{\text {th }}, 22^{\text {nd }}, 29^{\text {th }}$, and $30^{\text {th }}$ floors. These fires were observed at the southwest corners. The images indicate that, while these fires grew large enough to break nearby glass from windows and to spread to the north along the west face, they generally did not spread far before dying out. Possibly, these fires covered larger areas along the south sides of the floors, but this could not be confirmed due to limited imagery and smoke obscuration. There was no indication of fires on these floors later in the afternoon on the east, north, or west walls. 
Between roughly 2:00 p.m. and the collapse of WTC 7 at 5:20:52 p.m., fires were observed spreading on the $7^{\text {th }}$ floor through the $13^{\text {th }}$ floor, with the exception of the $10^{\text {th }}$ floor. One short video clip indicated that a small fire was present on the north side of the $14^{\text {th }}$ floor shortly prior to the collapse. In the following descriptions of these fires, approximate times are used. Details concerning actual times and uncertainties are included in the previous subsection.

\section{$7^{\text {th }}$ Floor}

Early indications of a developing fire were observed on the west side of the $7^{\text {th }}$ floor shortly after 2:00 p.m. This fire spread north along the west face. Initially, very little smoke was released from nearby windows. Heavy smoke eventually appeared from the windows on the west side nearest the north face. The evidence suggests that the fire spreading along the west side turned the northwest corner and began to spread east across the north side sometime prior to 3:00 p.m.

The fire on the north side spread eastward relatively quickly, reaching Column 47 by 3:12 p.m. The fire appeared to stop spreading after reaching this point, and the flames died away. Only indications of small localized spot fires to the west of Column 47 were then observed until around 4:15 p.m. Roughly 10 min after this time, a large fire had developed to the east of Column 47. By 4:38:11 p.m., the last image available, windows were open at least as far east as 7-44D, and the new flames had already died down. No additional images are available to indicate the fire behavior further to the east on this floor. It is likely that the fire continued spreading toward the east face.

In general, with the exception of the north side of the west face, little smoke was released from the west and north face windows by the fires on the $7^{\text {th }}$ floor. It is likely that the fires on these sides of the floor vented through the south face during the period that burning was observed.

\section{$8^{\text {th }}$ Floor}

The earliest fires observed on the $8^{\text {th }}$ floor were on the north face in windows near the center of the face. As late as 3:22 p.m., there was no indication of fire in this area, but about $17 \mathrm{~min}$ later a substantial fire spreading to the east was visible between windows 8-47C and 8-53C. The extent of the fire further west at this time is not clear. NIST found no evidence showing where this fast developing fire first appeared on the north face. Later observations, around 3:42 p.m., of intense burning on the north side of the west face at the same time that fires were dying at nearby locations on the north face suggest that the fire initially bypassed the northwest corner, only burning out this area after the fire became established on the north face.

The rapid development and flame spread on the north side of the floor continued after the fires were first observed, and flames reached the east face around 3:55 p.m. Even though little smoke and flame were visible coming from north face windows located close to the flames, extremely intense external flaming developed on the east face when the fire reached that location. This is strong evidence that the ambient wind and associated external pressure variations around WTC 7 had a large effect on the appearance of flames in windows on the different faces.

By shortly after 4:00 p.m., much of the burning near the center of the north face had died down. The small fires that were observed appeared to be located well away from the exterior wall. 


\section{$9^{\text {th }}$ Floor}

There was no indication of fire in the available imagery on this floor until late in the day. Shortly before 4:00 p.m., a small area of fire was observed in windows 9-54A and 9-54B on the west side of the north face. There are no images suggesting how fire reached this location. Views of the floor as little as 10 min earlier provided no indication that a fire was present.

Once the fire appeared, it grew rapidly and spread to the east. By around 4:10 p.m., flames had reached at least as far east as window 9-49B; roughly ten minutes later, flames were visible between windows 9-45B and 9-52D. There were indications that the flames on the west side of this group of windows were already beginning to die down. At 4:38:11 p.m., only small spot fires were visible between windows 944D and 9-47B.

Limited smoke and flames exited through open windows on the north face, suggesting the fires vented elsewhere from the building.

NIST found no evidence regarding fire behavior after 4:40 p.m. It is possible that the fires continued to spread eastward and moved onto the east face.

\section{$10^{\text {th }}$ Floor}

No fires were observed burning on this floor.

\section{$11^{\text {th }}$ Floor}

A fire was first observed on this floor at 2:08 p.m. on the east face. Windows 11-29 and 11-30 near the southeast corner were open. The appearance of the smoke patterns above these windows suggested that these flames had burned intensely prior to this time. Over the next $20 \mathrm{~min}$, the fire spread slowly northward along the east face, breaking out window glass and burning intensely at windows 11-31 to 11-35.

It was longer than two hours before burning was observed at another location on this floor. Images taken around 4:38 p.m. revealed intense burning in windows 11-44E to 11-46D, just east of the center of the north face. There had been no indication of burning along the entire north side of this floor in imagery taken around 4:00 p.m., or even in the same area where the fire first reappeared as late as 15 min earlier. Shortly after the flames first appeared on the north face, a photograph showed intense burning in windows 11-45C to 11-48A. By around 4:52 p.m., the flames in the area had apparently died down, and flames on this floor were not observed again until around 5:10 p.m.

Burning was observed localized around Column 11-49 at 5:09 p.m. Ten minutes later the fire had spread to the west and was visible between Columns 49 and 51. When the building fell, around 5:21 p.m., fire was visible as far west as Column 52.

NIST found no evidence regarding the pathway that the fire took to reach the north face, nor when the flames first arrived on this face. 
Despite the presence of intense burning on the north face, only light smoke and flame were visible coming from the open windows. This indicates the fire effluent was venting elsewhere on this floor.

\section{$12^{\text {th }}$ Floor}

The first observation of a fire on the $12^{\text {th }}$ floor was on the east face around 2:08 p.m. A clear view of this face at 2:11 p.m. showed flames coming from windows 12-29 to 12-34 on the south side of the face, with window $12-35$ open. Glass was still in place in windows $12-28 \mathrm{~A}$ and $12-28 \mathrm{~B}$ at the south edge, indicating that the fire likely had bypassed the southeast corner as it moved from the south face onto the east. By around 2:30 p.m., the intense flames originally seen on the east face were dying down, while the fire had spread south into the southeast corner and as far north as window 12-38, two-thirds of the way to the northeast corner.

The next time an image showed fire on the $12^{\text {th }}$ floor was just before 3:00 p.m., when flames were observed between windows 12-44C and 12-45C, east of center on the north face. The fire had apparently bypassed the northeast corner of the floor and spread internally to the north face. In less than 15 min, the fire on the north face spread rapidly to the east to fully engulf the northeast corner of the floor and more slowly to the west, reaching as far as Column 47 . Over the following $40 \mathrm{~min}$, the fire spread to the west in starts and stops, sometimes bypassing groups of windows before later opening them. By around 3:45 p.m., flames had appeared between Column 55 and 56, toward the west end of the north face. After this time, views of windows further to the west were limited. An image taken around 5:00 p.m. showed that the fire had continued spreading west, and intense flames were coming from windows on the north face at the northwest corner.

In general, heavy smoke and flames were observed coming from windows on the east side of the building, while only limited amounts were released from north face windows. This is strong evidence that the pressure differences on the faces due to the ambient wind generated internal flows within the building that transported fire effluent away from the west and north faces and toward the south and east faces.

\section{$13^{\text {th }}$ Floor}

The first visual evidence for burning on the $13^{\text {th }}$ floor was seen on the east face around 2:30 p.m. An untimed photograph showed intense smoke and flame coming from windows across much of the east face somewhat later. The evidence suggests that a fire burned along the east side of the face, turned at the northeast corner, and began spreading across the north face. NIST found no evidence concerning this fire spread, but flames had reached Column 46, east of the center of the north face, at about 3:41 p.m. Imagery from around this time showed that many windows between the east face and Column 46 were already open. By shortly after 4:00 p.m. flames had spread at least as far west as Column 50. At 4:38 p.m., the windows between 13-44A and 13-47C (just east of the center of the north face) were open, and the fires responsible for opening the windows had died down to the point where they could no longer be observed.

The next time that flames were observed on the $13^{\text {th }}$ floor was around 5:00 p.m., when intense burning was observed between windows 13-53D and 13-54D, to the west of the center of the north face. A couple of minutes prior to the collapse of the building at 5:20:52 p.m. a jet of flames was pushed from windows in the same area. NIST found no evidence regarding the cause of this unusual behavior, but the behavior 
is similar to smoke and flame expulsions observed in the WTC towers prior to their collapses that were attributed to pressure pulses associated with structural changes (e.g., a partial floor collapse) occurring within the tower.

The limited smoke and external burning observed on the north face indicated that the effluent from fires along the north edge of the $13^{\text {th }}$ floor vented elsewhere from the building.

\section{$14^{\text {th }}$ Floor}

A low resolution image recorded around 5:03 p.m. indicated the presence of a fire between Columns 45 and 46 on the north face. Fire at this location or elsewhere on the floor was not evident in similar images recorded roughly ten minutes earlier and six minutes later. This was the only observation of a fire on this floor.

\section{Fires on Other Floors}

With the exception of the fires on the $19^{\text {th }}, 22^{\text {nd }}, 29^{\text {th }}$, and $30^{\text {th }}$ floors discussed at the start of this section, there is no direct visual evidence of fires on other floors of WTC 7. Heavy smoke was observed coming from the opening created on the south face of WTC 7 by debris falling from WTC 1 . This smoke suggests that internal burning was taking place, but provides little indication of specific locations. Light smoke was observed at the height of the louvers on the east side of the $5^{\text {th }}$ and $6^{\text {th }}$ floors around 4:10 p.m. It was not possible to identify the source of this smoke.

\subsubsection{Façade maps of Fire Location and Window Breakage in WTC 7 at Various Times}

In the following subsection, façade maps indicating the locations of open windows and fires are provided as a function of time. These maps are based on the imagery discussed above. The color codes used for window condition and fire intensity are shown in Figure 5-28, reproduced below.

\begin{tabular}{|llll|}
\hline Fire Visible & $\begin{array}{l}\text { No fire } \\
\text { Spot fire }\end{array}$ & $\begin{array}{l}\text { (white) } \\
\text { (yellow) } \\
\text { Fire visible inside } \\
\text { External flaming } \\
\text { Not visible }\end{array}$ & $\begin{array}{l}\text { (orange) } \\
\text { (blue) }\end{array}$ \\
& Window open & (white) \\
Windows & (gray) \\
& Not visible & (blue) \\
& & & \\
& &
\end{tabular}




\section{East Face}

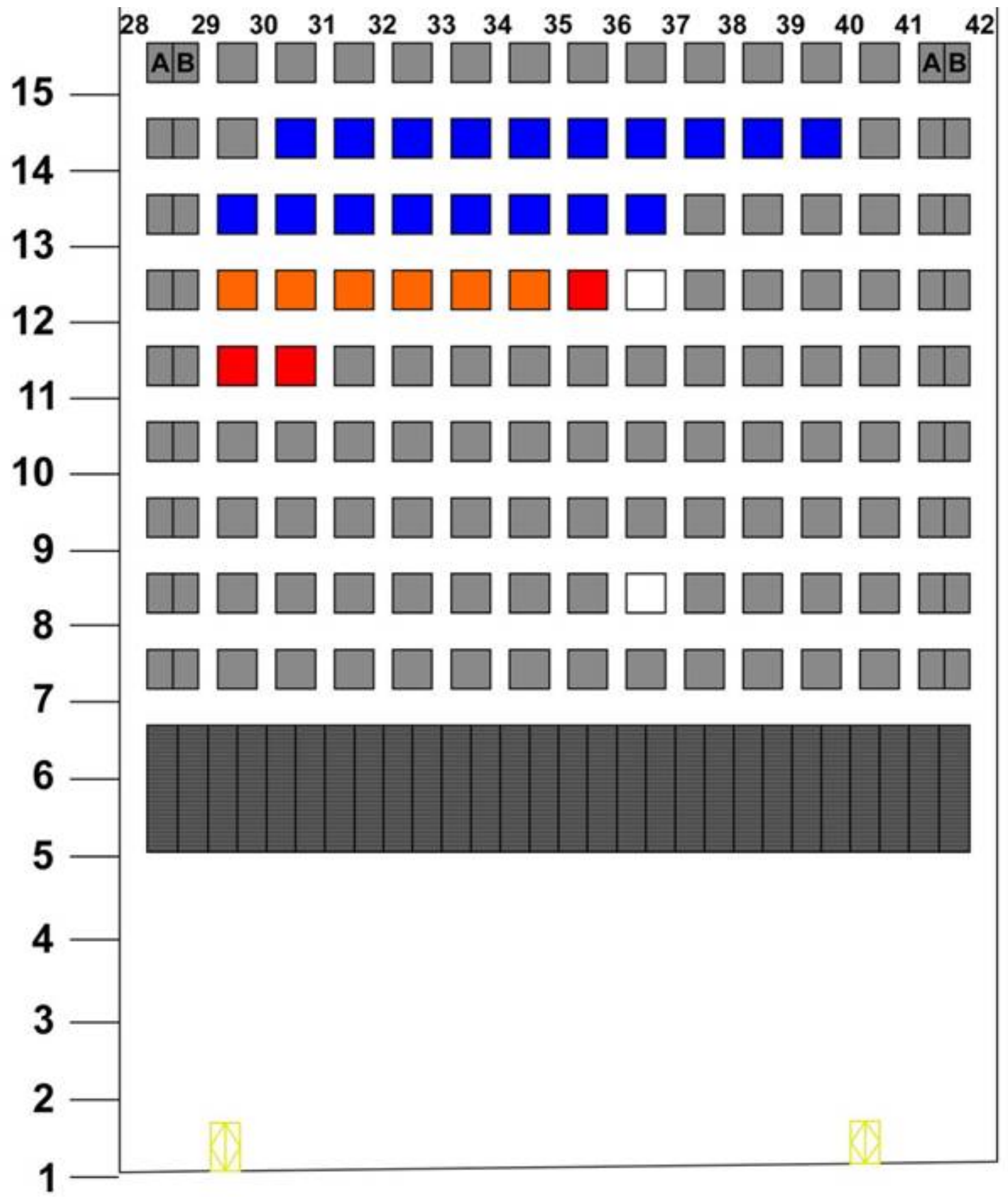

Figure 5-160. Façade map summarizing observations of fires and open windows on the east face of WTC 7 around 2:10 p.m.

Based on Figure 5-115 and a second photograph taken $15 \mathrm{~s}$ earlier. 


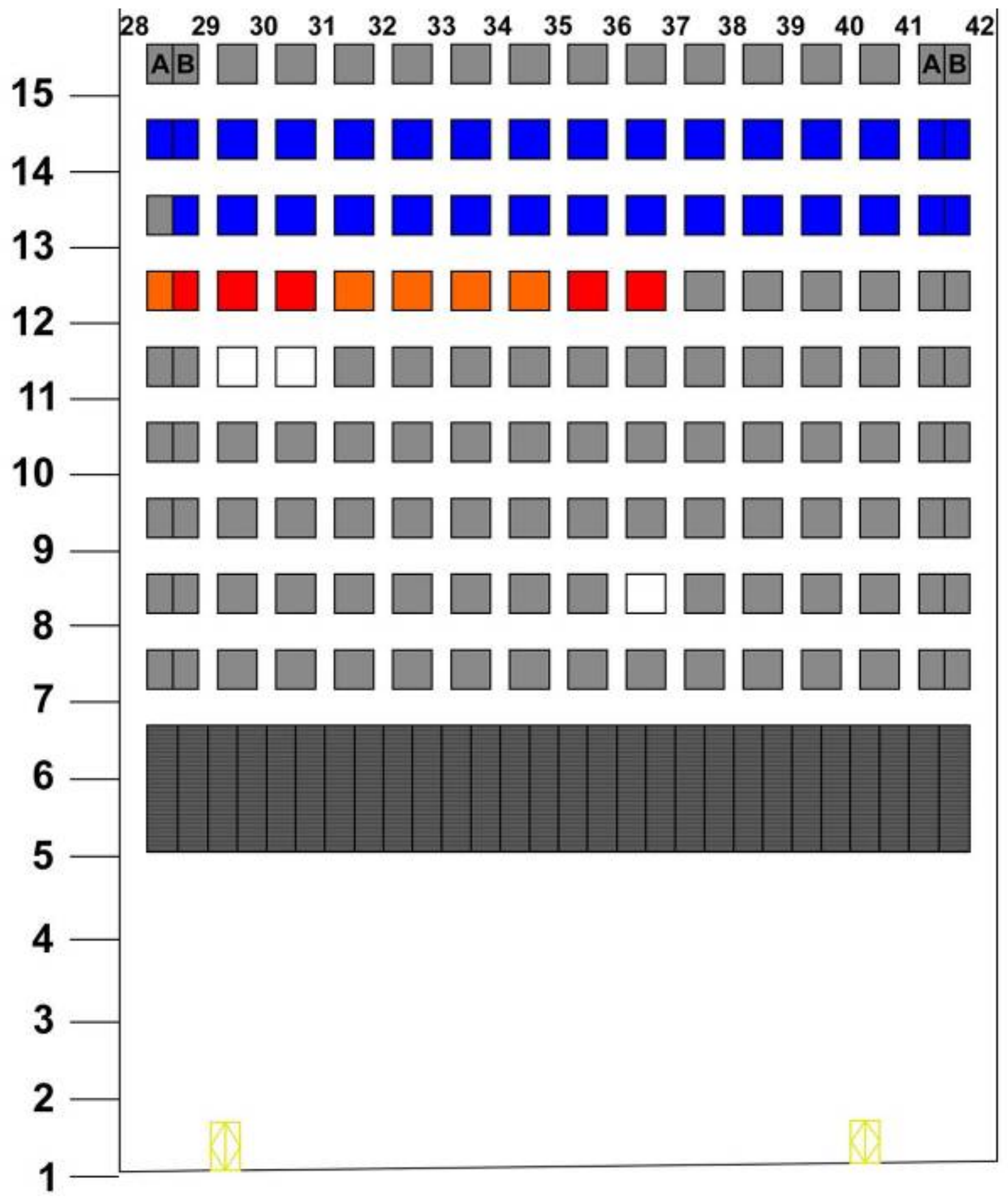

Figure 5-161. Façade map summarizing observations of fires and open windows on the east face of WTC 7 around 2:14 p.m.

Based on two photographs taken within a few seconds of each other. 


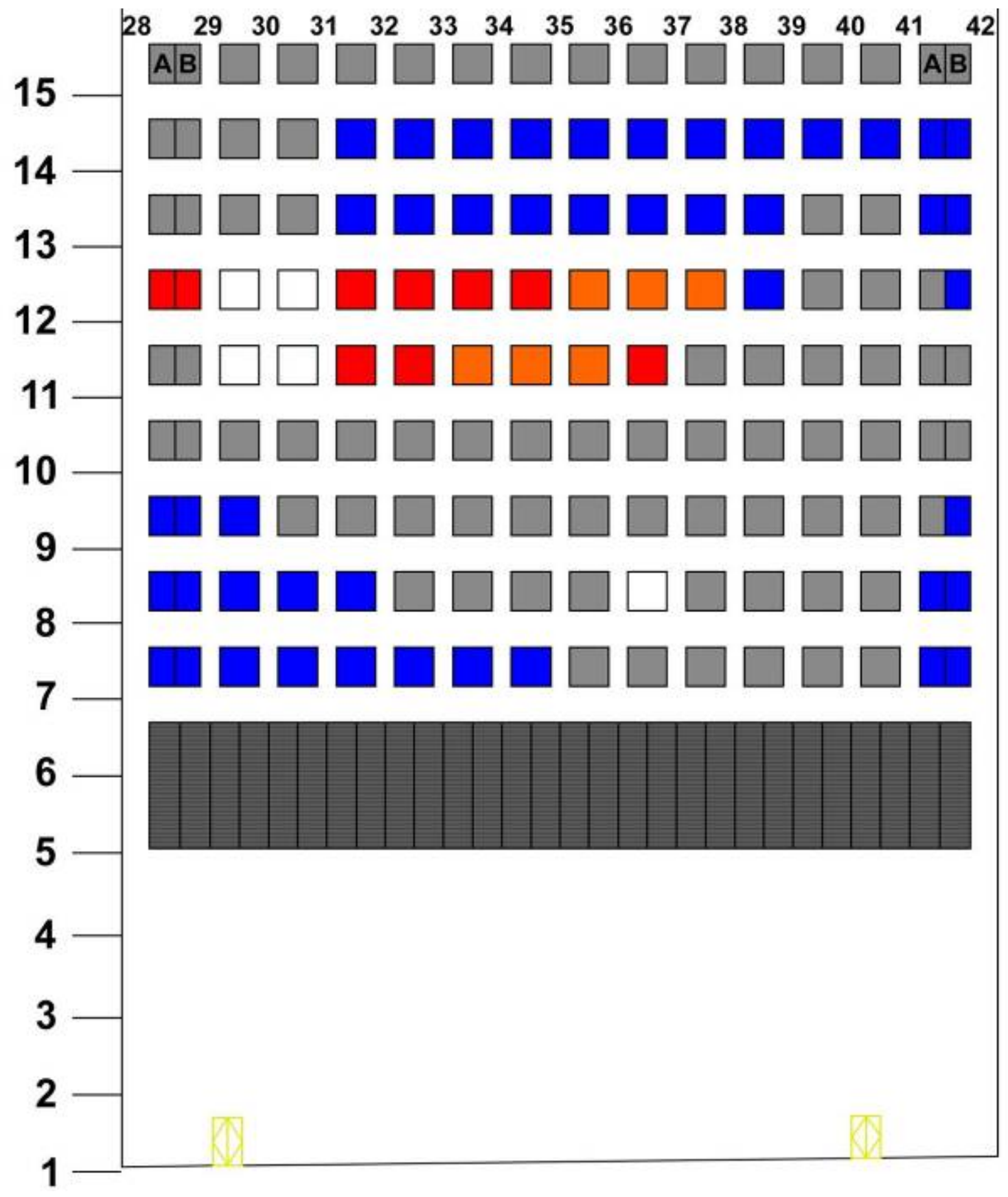

Figure 5-162. Façade map summarizing observations of fires and open windows on the east face of WTC 7 around 2:30 p.m.

Based on Figure 5-117. 


\section{North Face}

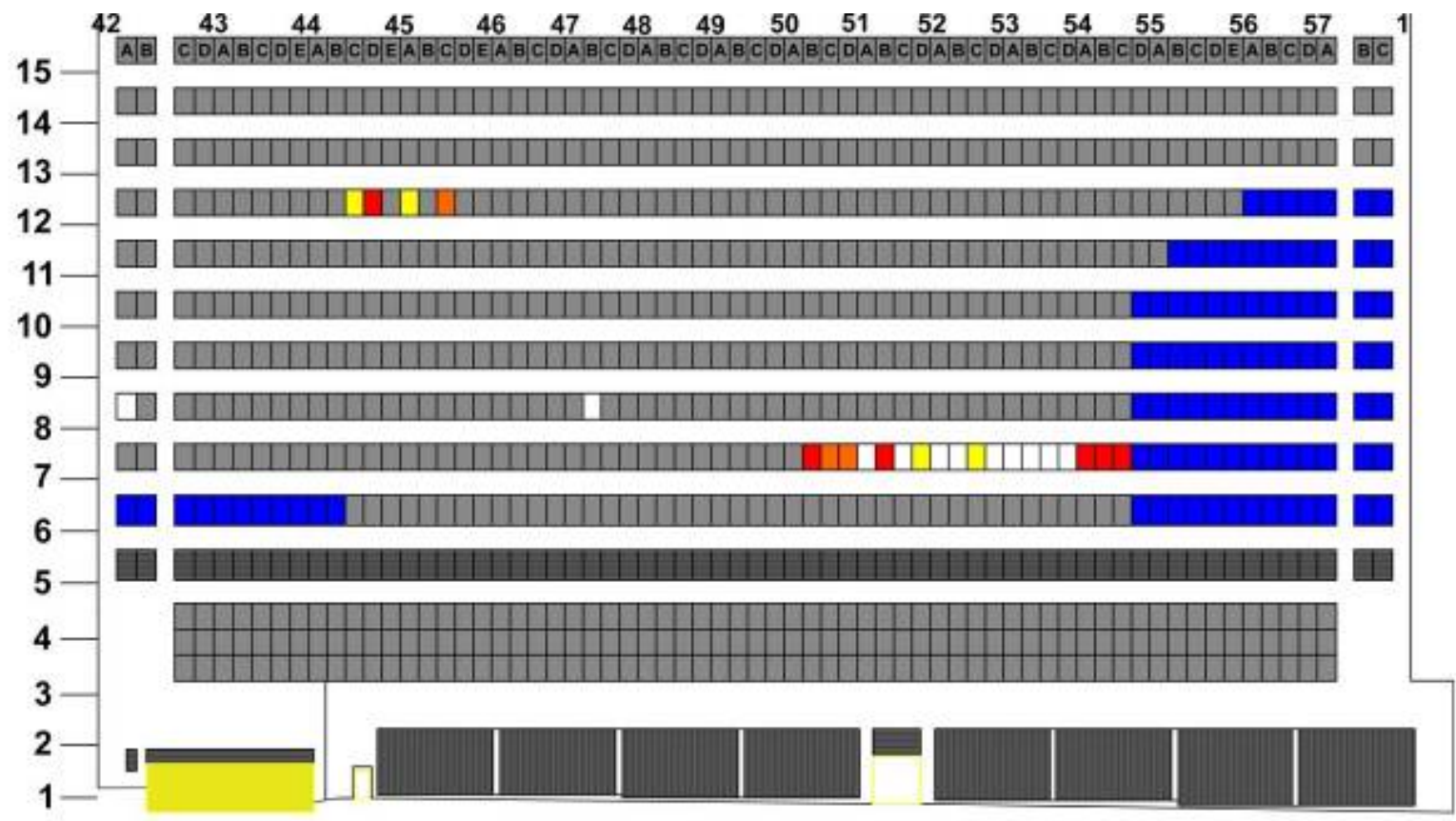

Figure 5-163. Façade map summarizing observations of fires and open windows on the north face of WTC 7 around 2:57 p.m.

Based on Figure 5-119.

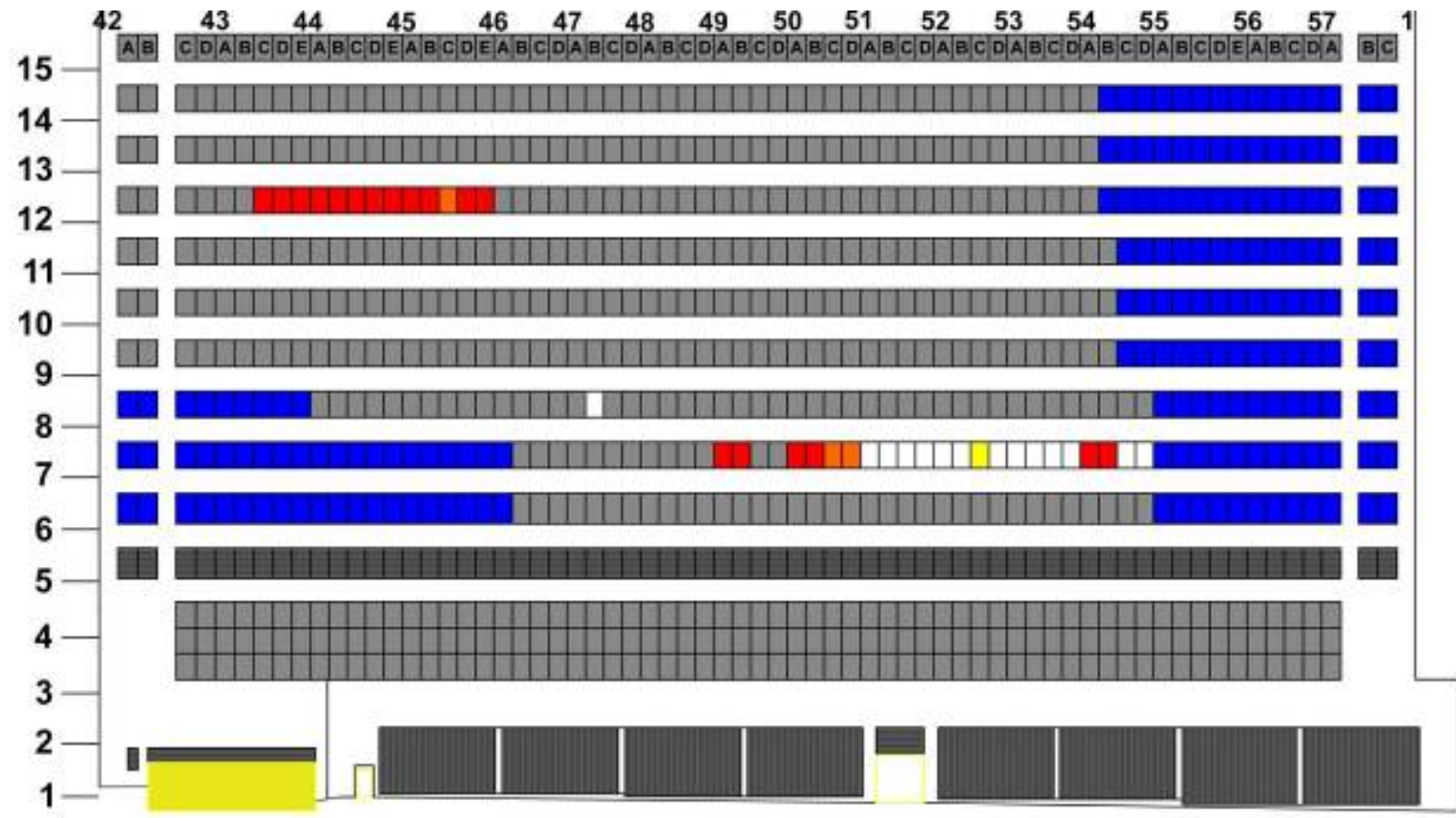

Figure 5-164. Façade map summarizing observations of fires and open windows on the north face of WTC 7 around 3:05 p.m.

Based on Figure 5-121. 


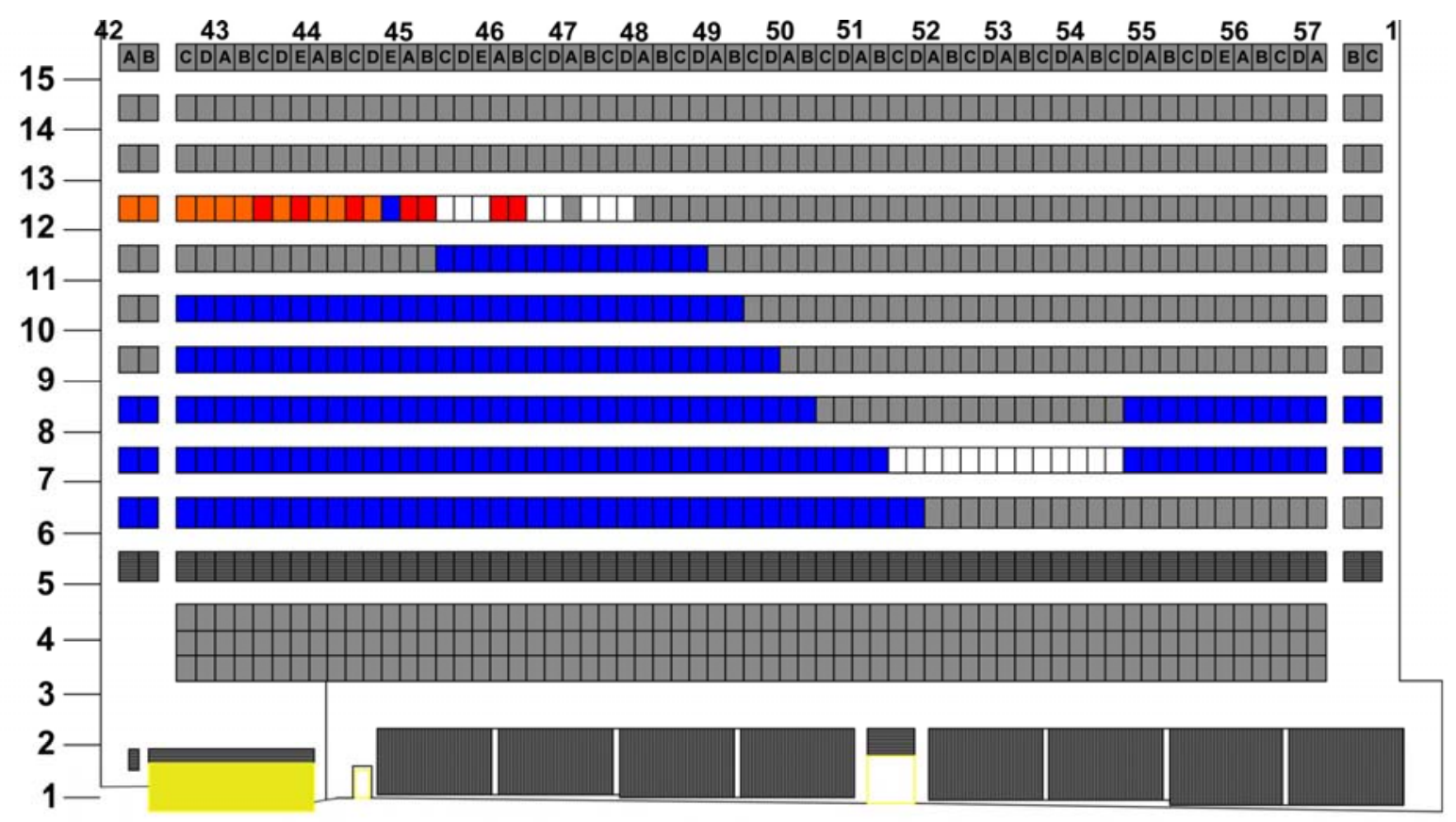

Figure 5-165. This façade map summarizes observations of fires and open windows on the north face of WTC 7 around 3:10 p.m.

Based on Figure 5-123.

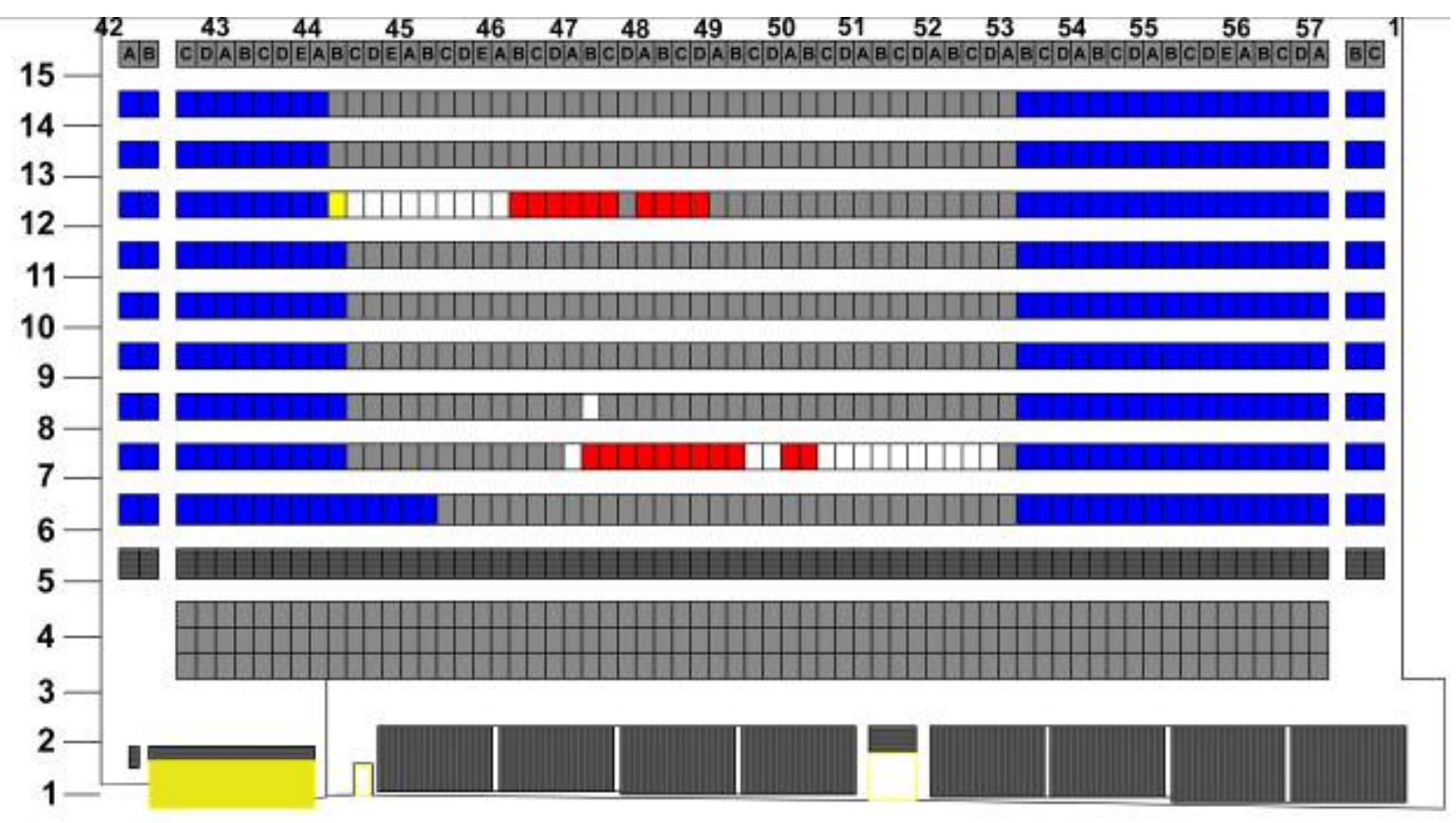

Figure 5-166. Façade map summarizing observations of fires and open windows on the north face of WTC 7 around 3:13 p.m.

Based on Figure 5-127. 


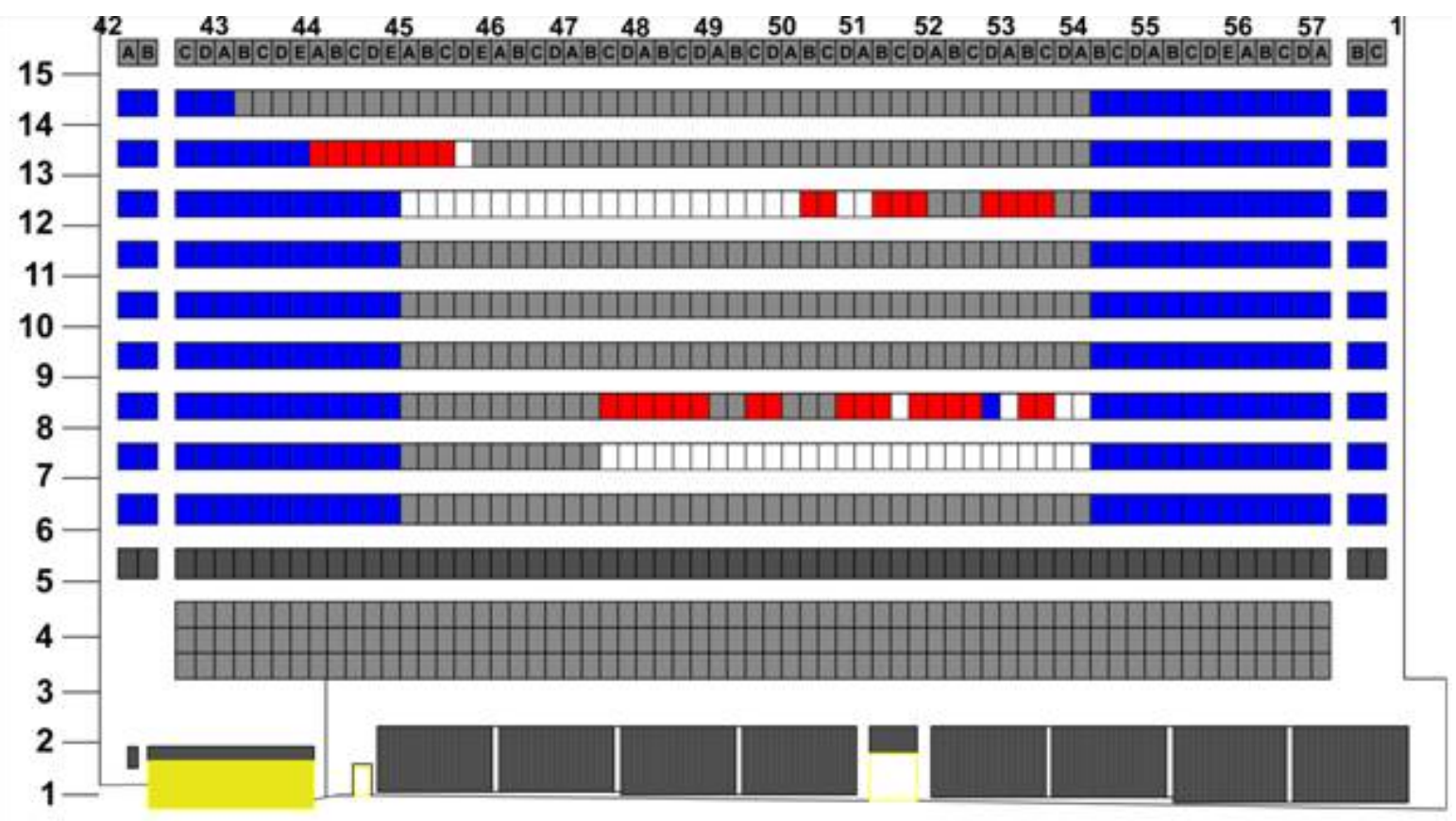

Figure 5-167. Façade map summarizing observations of fires and open windows on the north face of WTC 7 around 3:42 p.m.

Based on Figure 5-128 and Figure 5-130.

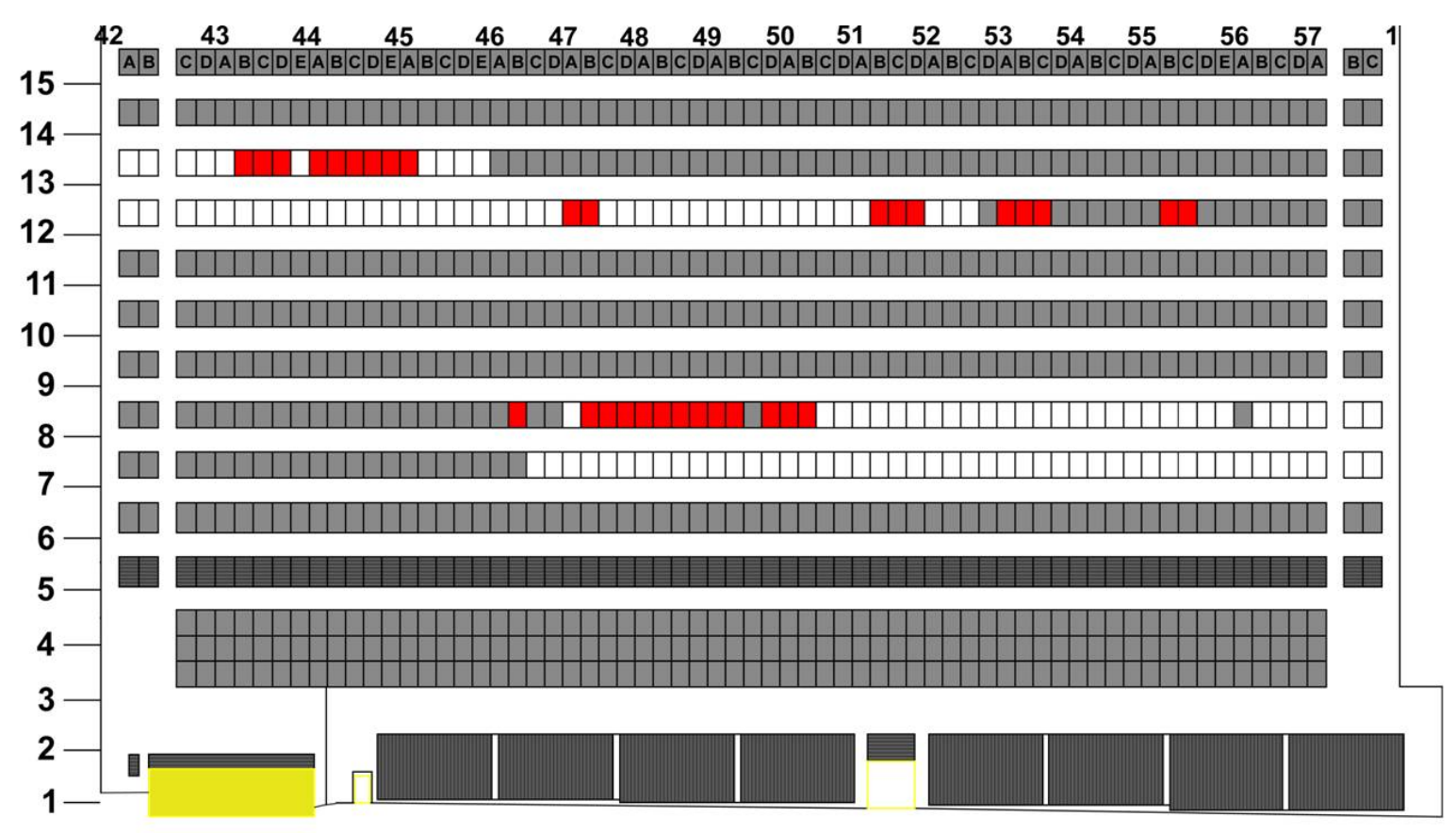

Figure 5-168. Façade map summarizing observations of fires and open windows on the north face of WTC 7 around 3:44 p.m.

Based on Figure 5-134 and the video clip from which it was taken. 


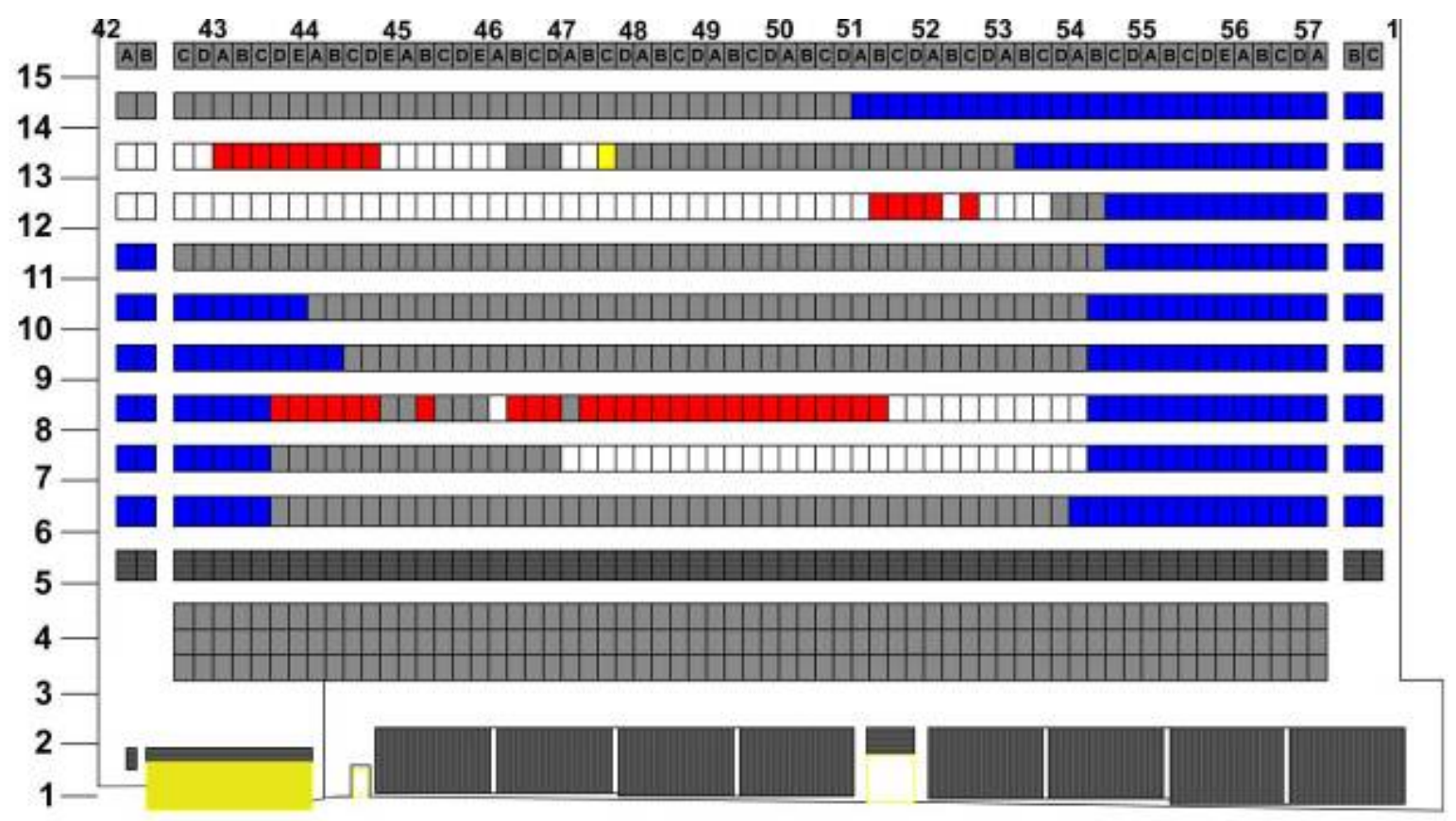

Figure 5-169. Façade map summarizing observations of fires and open windows on the north face of WTC 7 around 3:52 p.m.

Based on Figure 5-136 and the video clip from which it was taken.

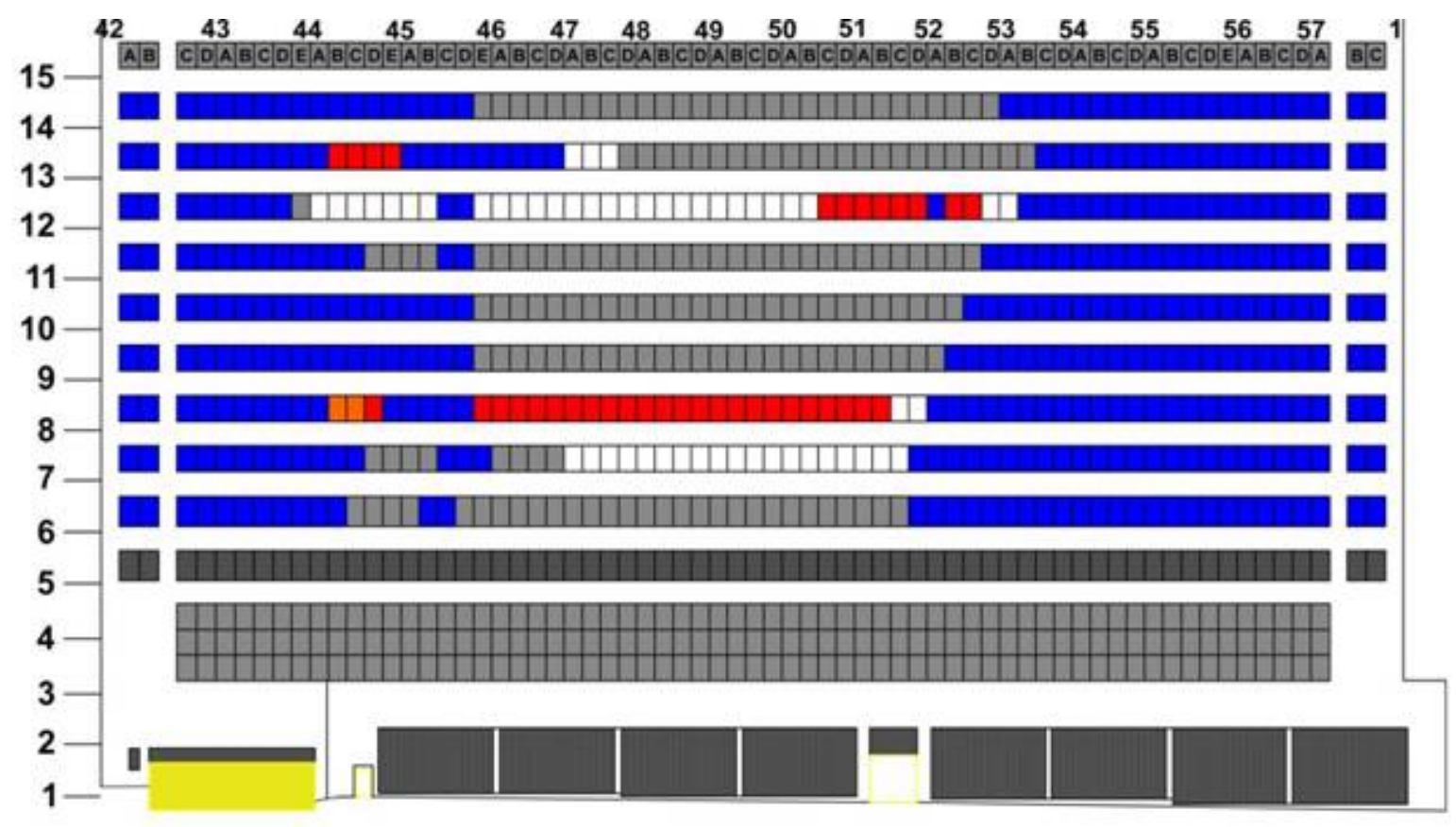

Figure 5-170. Façade map summarizing observations of fires and open windows on the north face of WTC 7 around 3:55 p.m.

Based on Figure 5-140 and the video clip from which it was taken. 


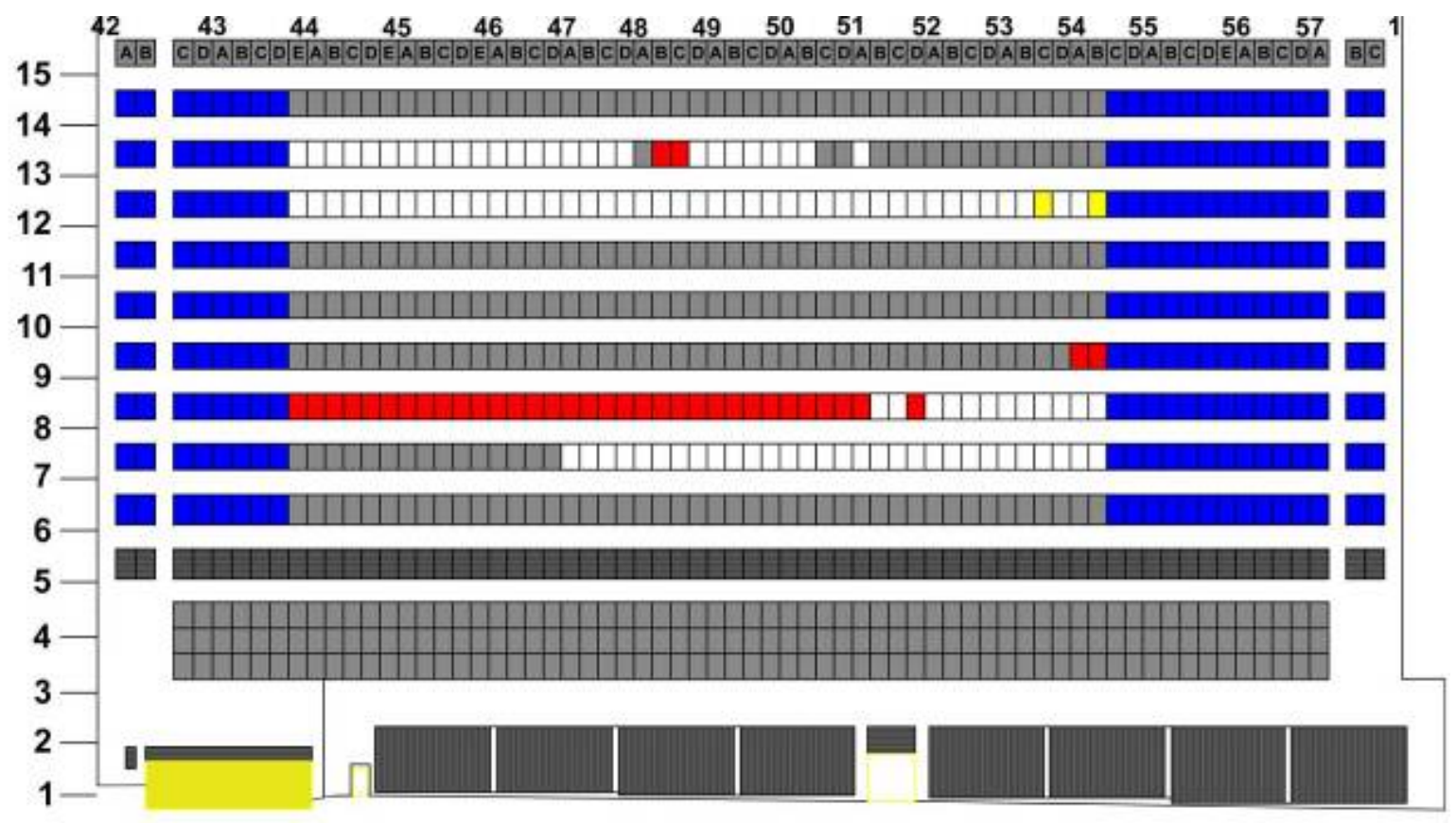

Figure 5-171. Façade map summarizing observations of fires and open windows on the north face of WTC 7 around 3:55 p.m.

Based on Figure 5-144.

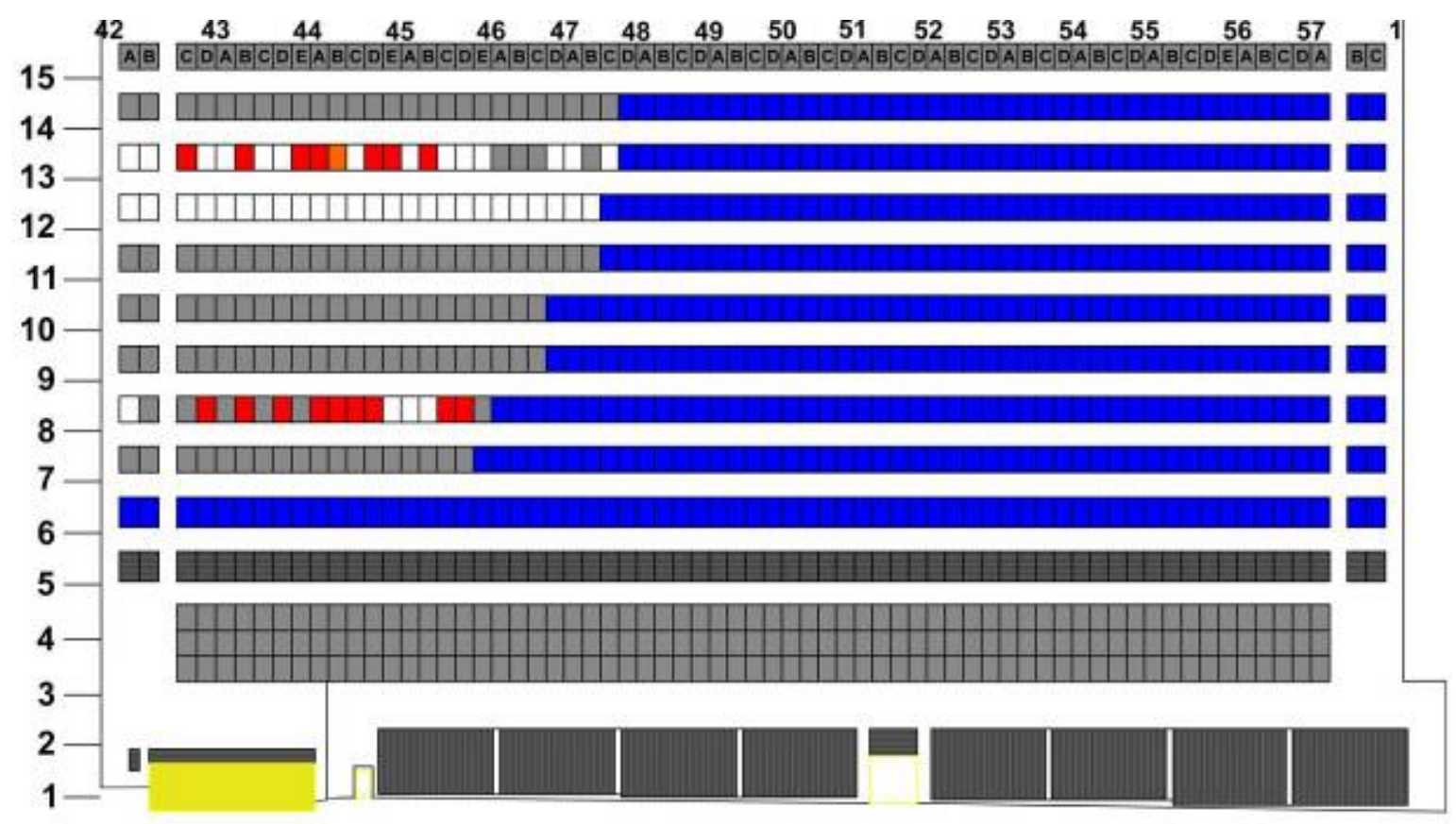

Figure 5-172. Façade map summarizing observations of fires and open windows on the north face of WTC 7 around 3:57 p.m.

Based on Figure 5-141 and the video clip from which it was taken. 


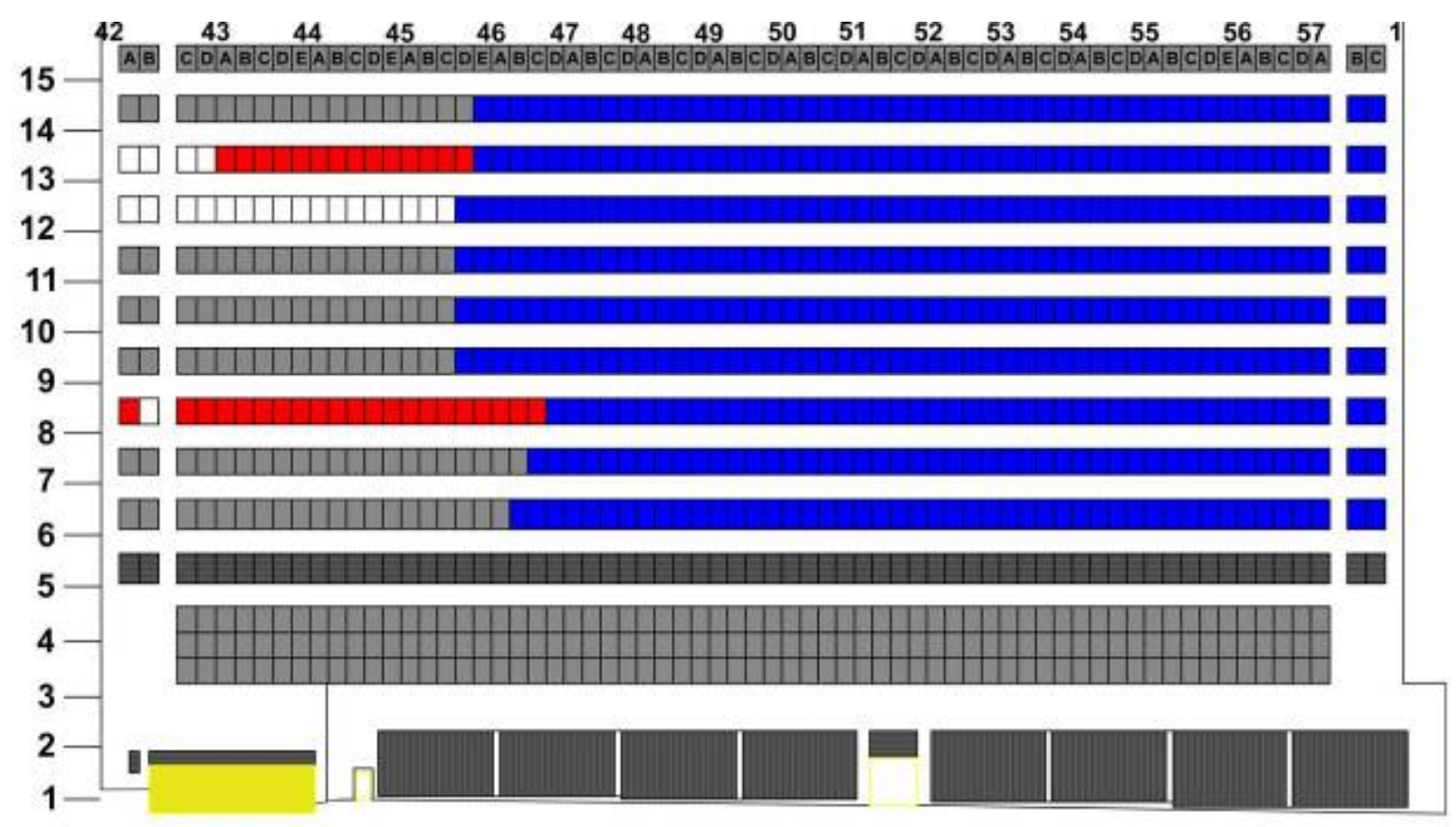

Figure 5-173. Façade map summarizing observations of fires and open windows on the north face of WTC 7 around 4:00 p.m.

Based on Figure 5-142 and the video clip from which it was taken.

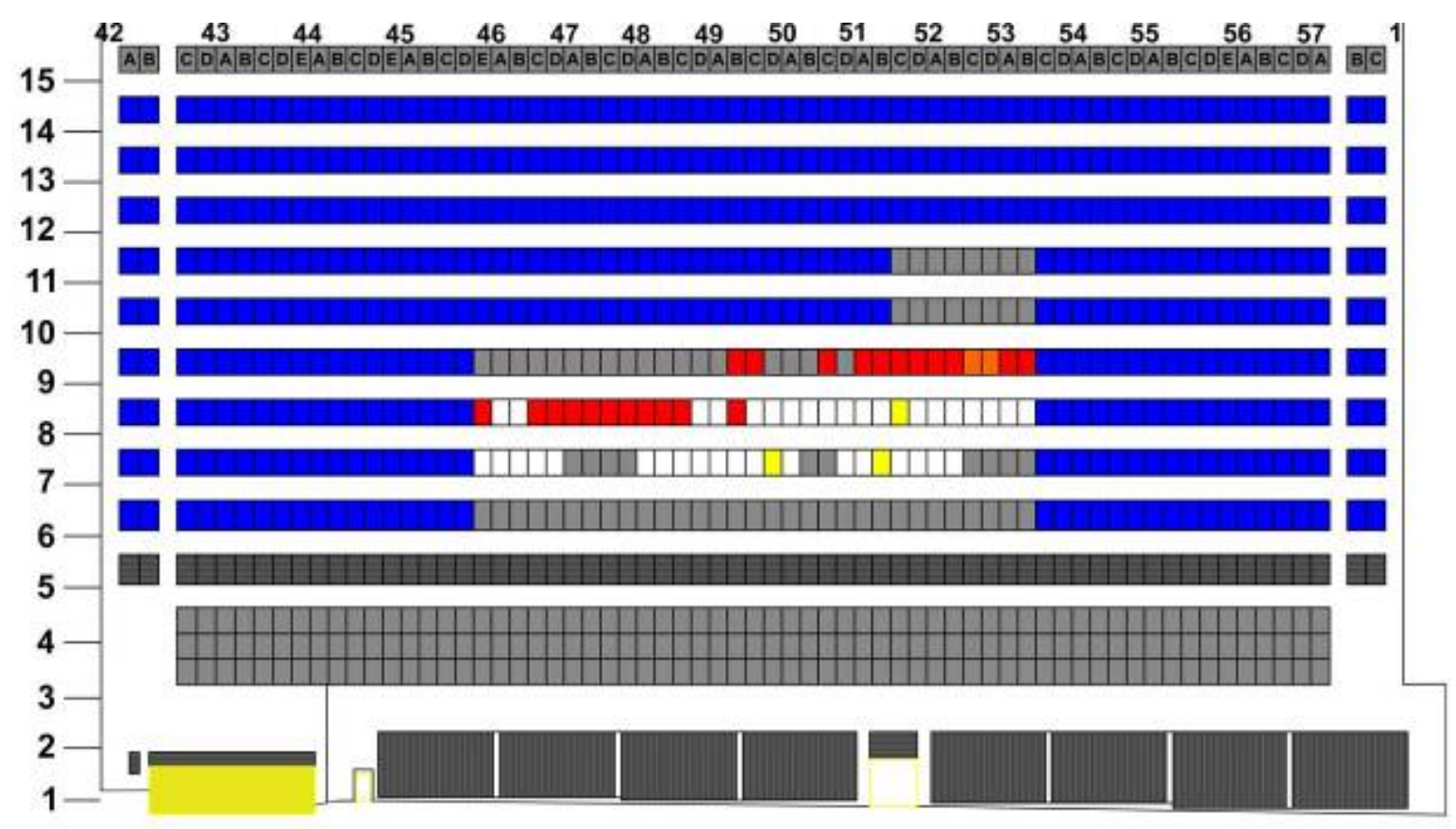

Figure 5-174. Façade map summarizing observations of fires and open windows on the north face of WTC 7 around 4:10 p.m.

Based on Figure 5-145 and the video clip from which it was taken. 


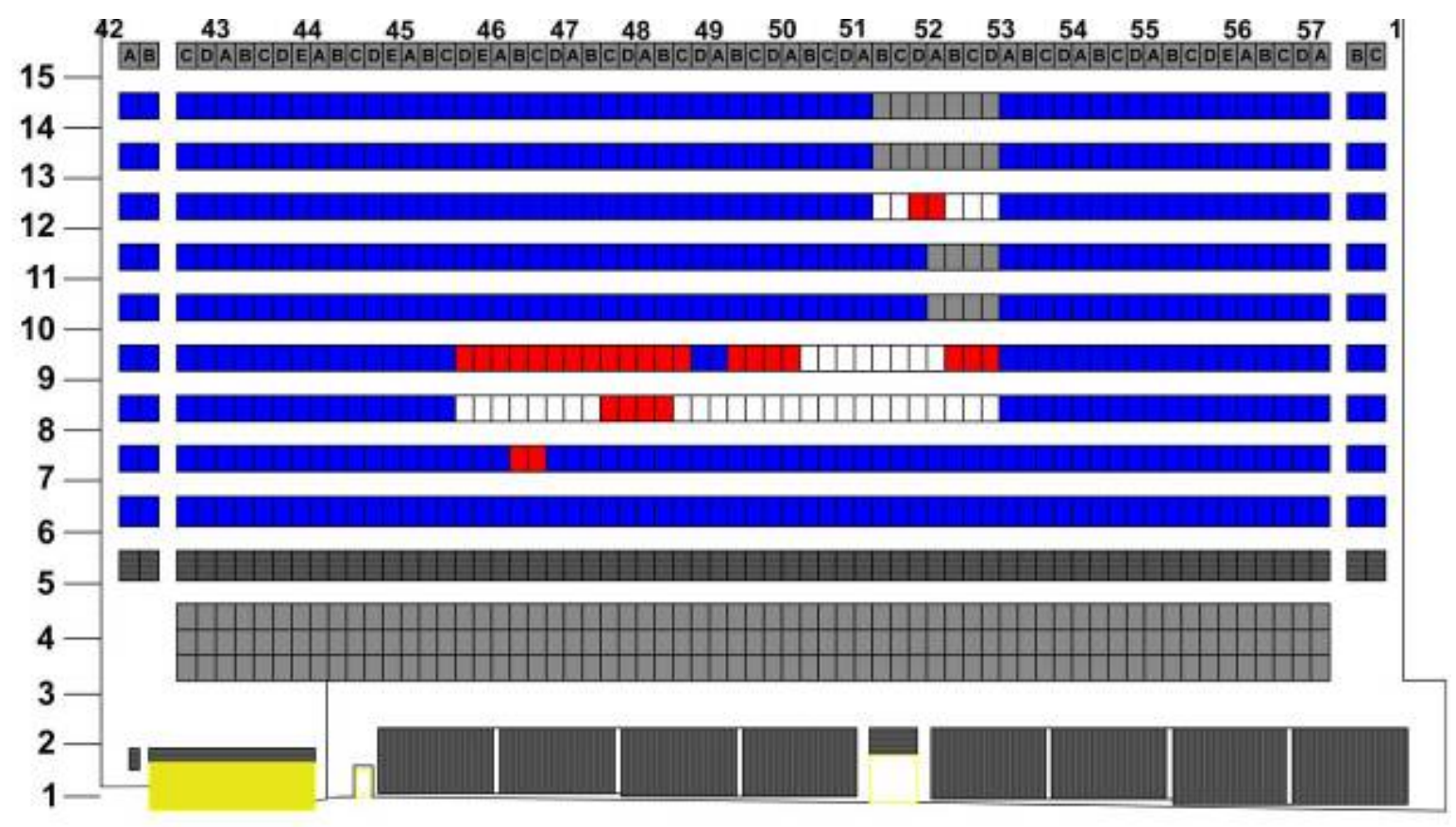

Figure 5-175. Façade map summarizing observations of fires and open windows on the north face of WTC 7 around 4:20 p.m.

Based on Figure 5-146 and a second photograph taken at roughly the same time.

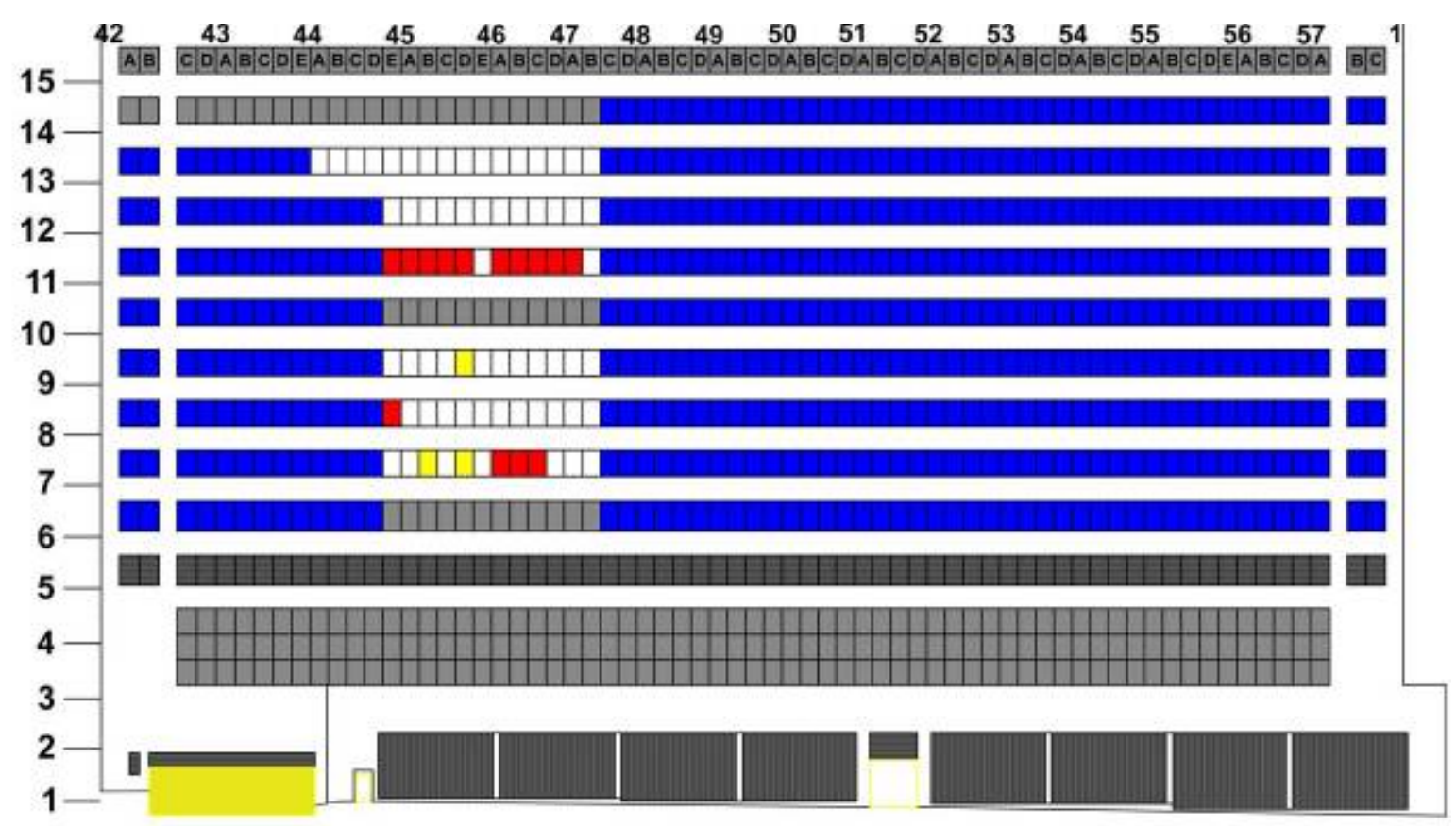

Figure 5-176. Façade map summarizing observations of fires and open windows on the north face of WTC 7 at 4:38:11 p.m.

Based on Figure 5-148 and Figure 5-149 and the video clip from which these frames were taken. 


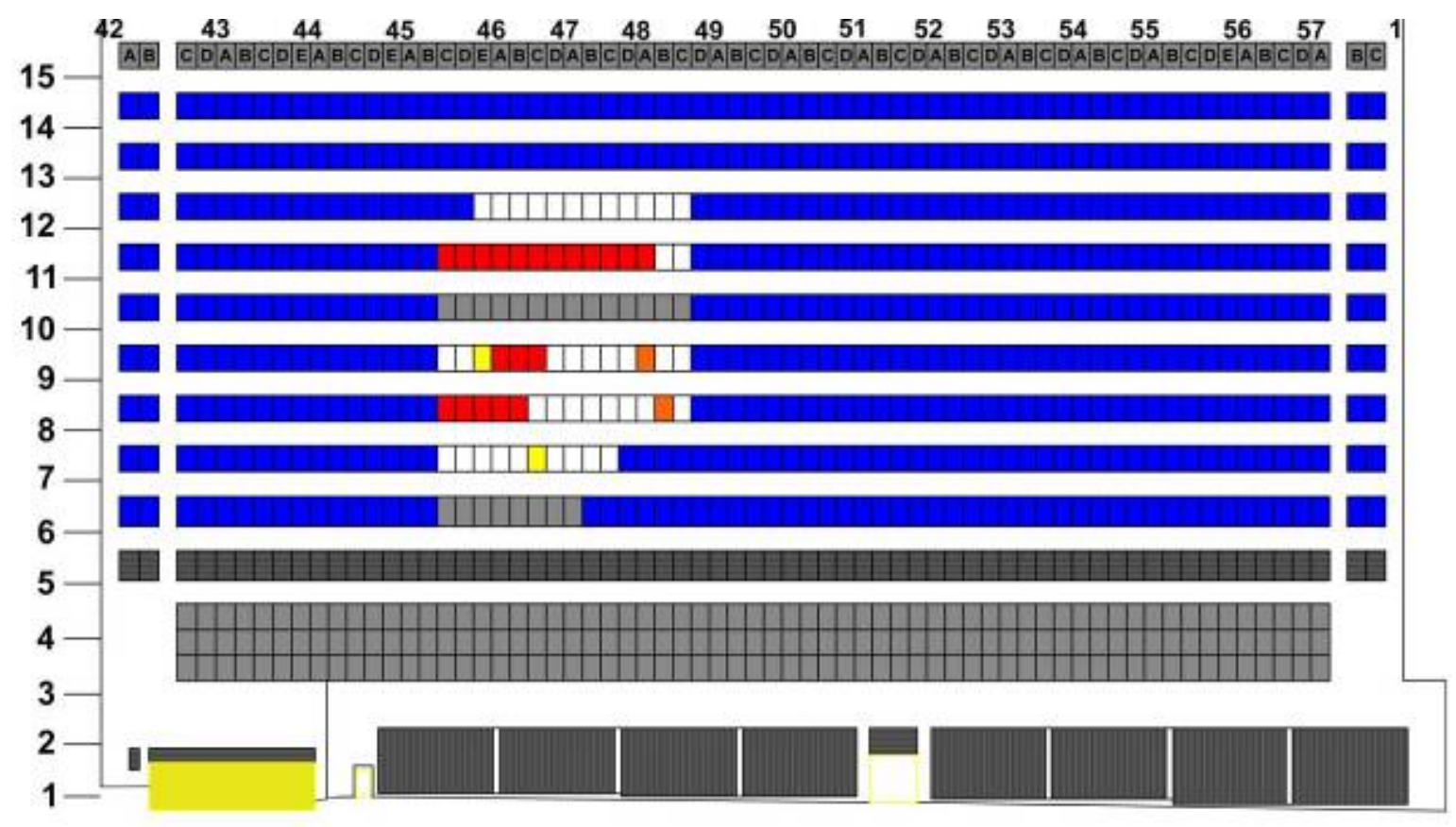

Figure 5-177. Façade map summarizing observations of fires and open windows on the north face of WTC 7 around 4:39 p.m.

Based on Figure 5-150.

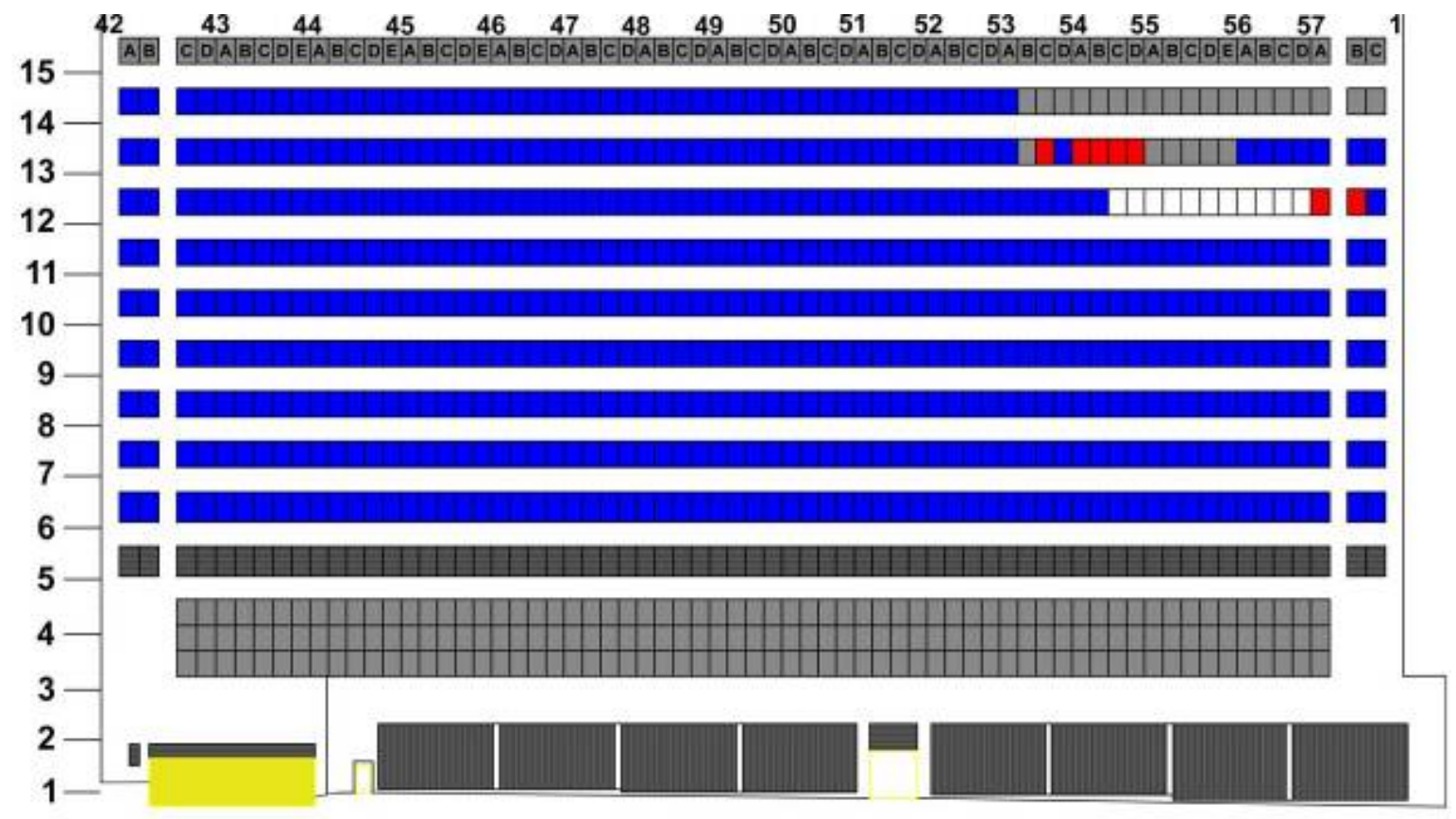

Figure 5-178. Façade map summarizing observations of fires and open windows on the north face of WTC 7 around 5:00 p.m.

Based on Figure 5-152 and the video clip from which it was taken. 


\section{West Face}

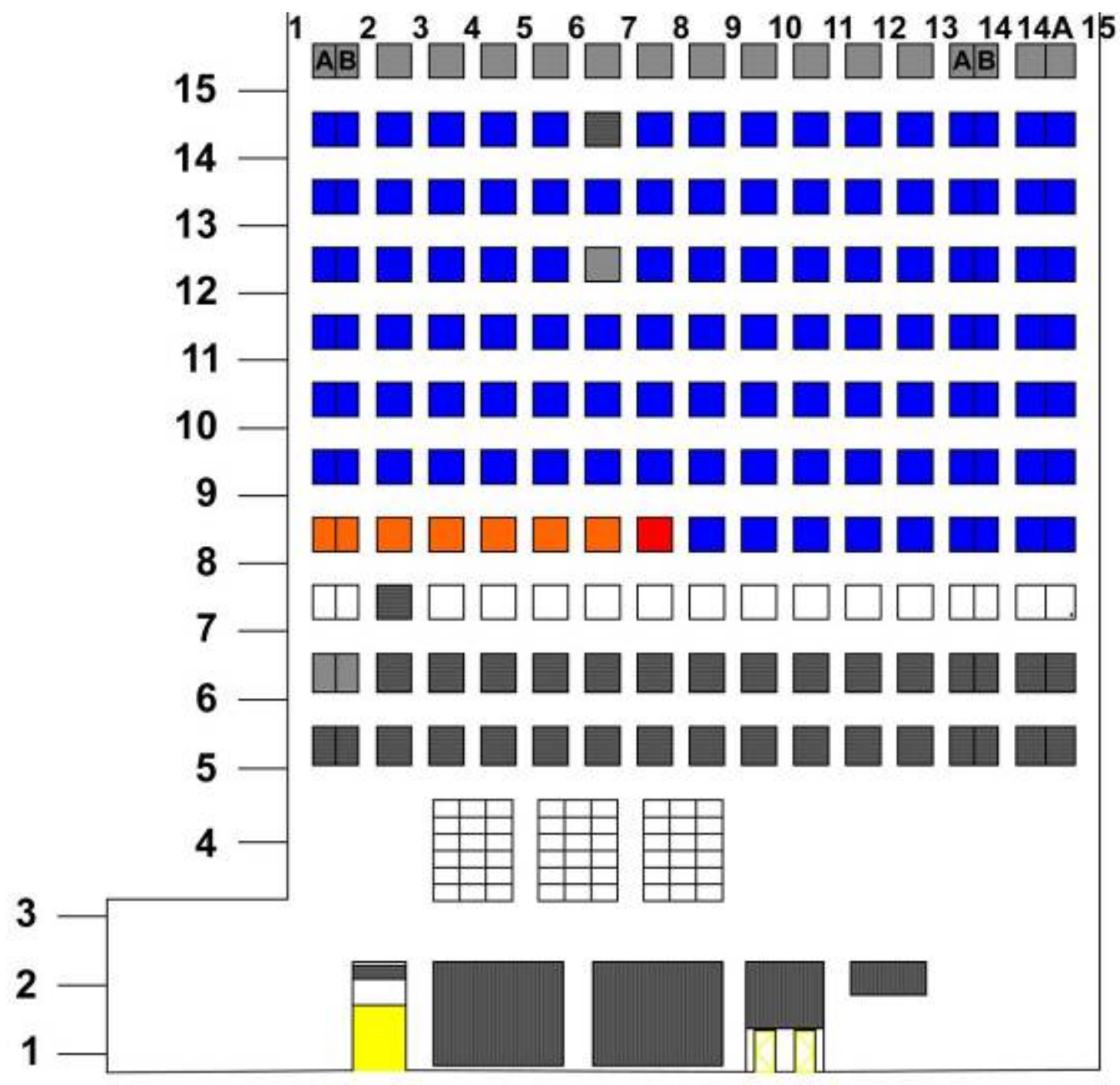

Figure 5-179. This façade map summarizes observations of fires and open windows on the west face of WTC 7 around 3:52 p.m.

Based on several video clips including the one from which Figure 5-132 and Figure 5-133 were taken. 


\subsubsection{Summary Graphics of Total Fire Extent in WTC 7}

In order to provide a better indication of the extent of the fires, three summary façade maps have been prepared. These maps utilize only two colors. Red represents windows where the glass was broken and/or fire was observed through the window. The remaining windows are colored blue, indicating that no direct evidence was observed for fires at these locations. It is very likely that fires burned adjacent to some of these windows, but, due to the limited imagery available, were not observed.

Each map was prepared by simply integrating the various data sheets available for this face and transposing the results onto the façade drawing and incorporating additional information discussed in the text.

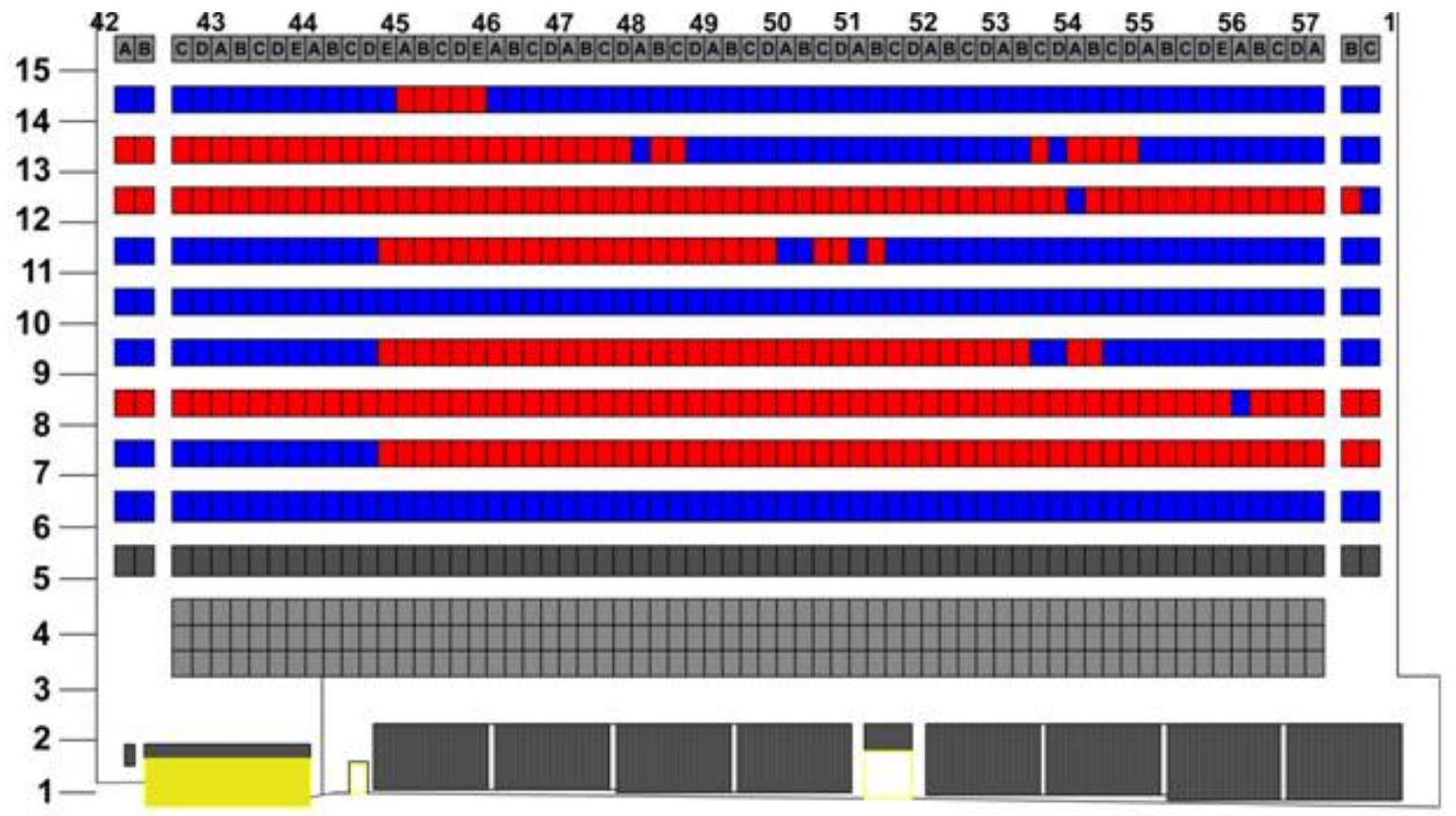

Figure 5-180. Façade map of the north face of WTC 7 showing where windows were broken and/or fire was observed during the period when fire first appeared on the face shortly before 3:00 p.m. until the building collapsed at 5:20:52 p.m. 


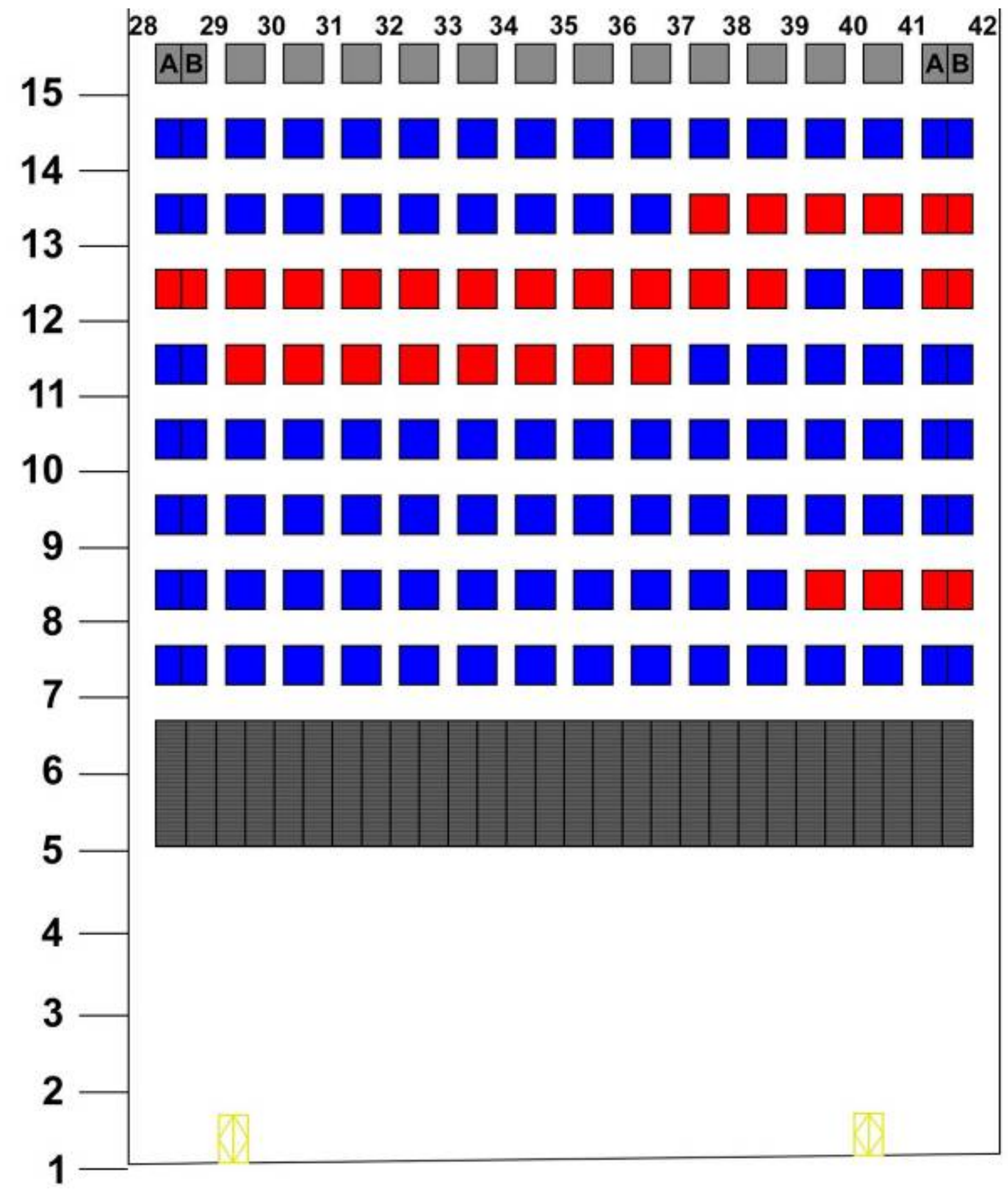

Figure 5-181. Façade map of the east face of WTC 7 showing locations where windows were broken and/or fire was observed during the period when fire first appeared on the face around 2:00 p.m. and the building collapsed at 5:20:52 p.m. 


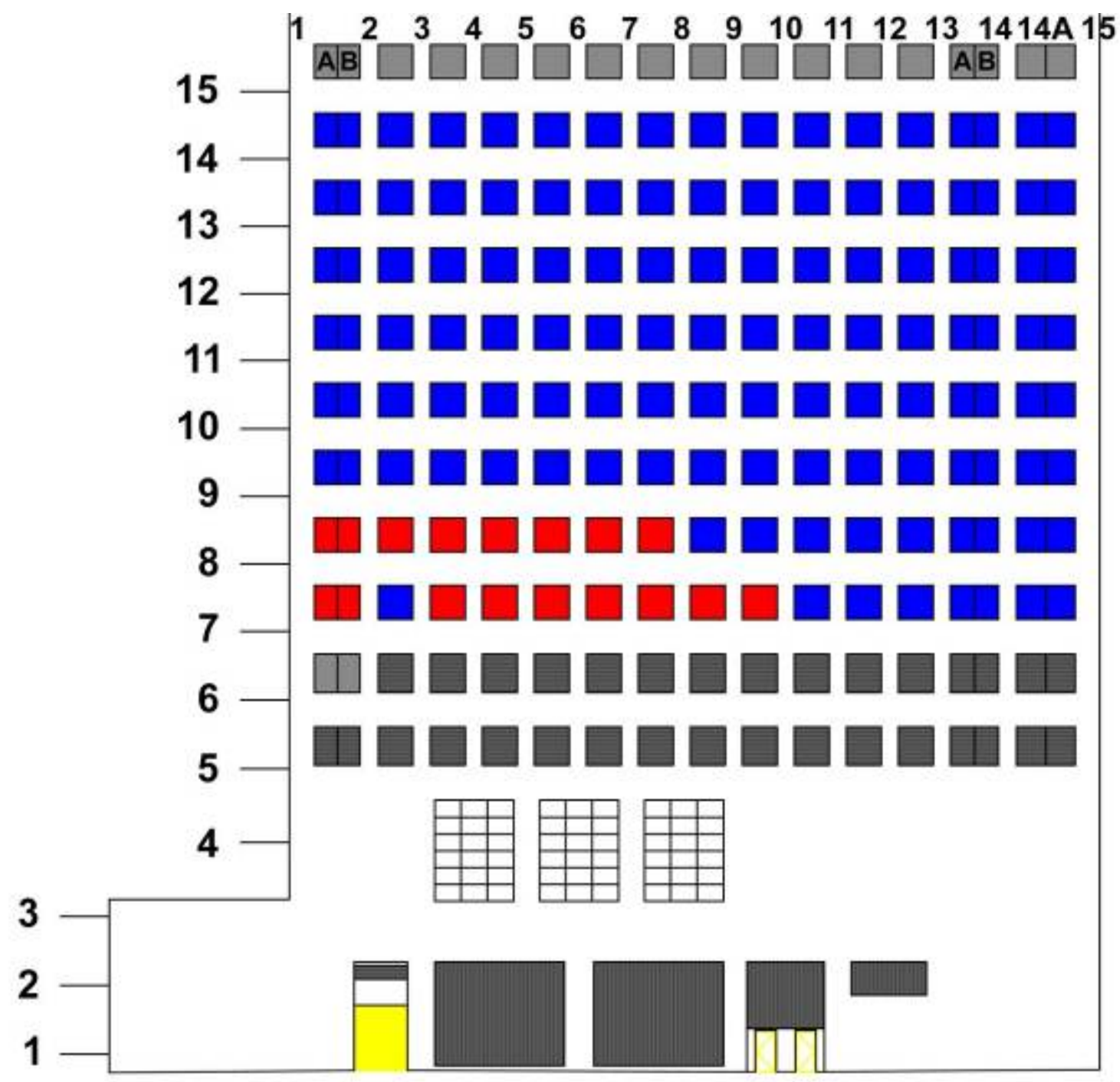

Figure 5-182. Façade map of the west face of WTC 7 showing locations where windows were broken and/or fire was observed during the period when fire first appeared on the face before 2:00 p.m. and the building collapsed at 5:20:52 p.m.

\subsection{OBSERVATIONS AND ANALYSIS OF THE WTC 7 COLLAPSE}

\subsubsection{The Nine Videos}

WTC 7 began to collapse at 5:20:52 p.m. The collapse time was defined as the time when the north face of the building first began to move downward. As will be shown, shortly before this time, the east penthouse descended into the roof of the building, with a break along the penthouse roof as it did so. As discussed in Appendix C, there was movement of the building just before the east penthouse began to descend.

The visual database contains 16 videos showing at least a portion of the collapse of WTC 7. Nine of these were selected for more detailed analysis; each of these nine cameras was primarily located to the 
north of the WTC complex. Attributes of these nine videos are listed in Table 5-2, and a map indicating the locations of the cameras relative to WTC 7 is shown in Figure 5-183.

Using video analysis software, the nine video clips were placed on a common timeline by matching various events, such as collapse initiation and window breakage. The maximum estimated uncertainty in assigning relative times is 6 frames or $0.2 \mathrm{~s}$. For the analyses that follow, $0 \mathrm{~s}$ is defined as the time when the east penthouse began to descend into WTC 7. Note that this event occurred prior to 5:20:52 p.m. The actual time will be provided below.

Table 5-2. Attributes of videos used for analysis of the collapse of WTC 7.

\begin{tabular}{|c|c|c|c|}
\hline $\begin{array}{l}\text { Camera } \\
\text { No. }\end{array}$ & Location & Coverage & Notes \\
\hline 1 & $\begin{array}{l}\text { High on building near midtown Manhattan, } \\
\text { slightly east of normal to the north face of } \\
\text { WTC } 7\end{array}$ & $\begin{array}{l}\text { Entire collapse } \\
\text { sequence }\end{array}$ & $\begin{array}{l}\text { News camera, trained on WTC } 7 \\
\text { for several minutes prior. }\end{array}$ \\
\hline 2 & $\begin{array}{l}\text { High on building near mid-town Manhattan, } \\
\text { due north of WTC } 7\end{array}$ & $\begin{array}{l}\text { Entire collapse } \\
\text { sequence }\end{array}$ & $\begin{array}{l}\text { News camera, trained on WTC } 7 \\
\text { for several minutes prior. Higher } \\
\text { magnification than Camera } 1 .\end{array}$ \\
\hline 3 & $\begin{array}{l}\text { Street level, west side of West Street, near } \\
\text { Harrison Street }\end{array}$ & $\begin{array}{l}\text { Entire collapse } \\
\text { sequence }\end{array}$ & $\begin{array}{l}\text { News camera, trained on WTC } 7 \\
\text { for several minutes prior. }\end{array}$ \\
\hline 4 & $\begin{array}{l}\text { Street level, near the corner of West } \\
\text { Broadway and Leonard Street }\end{array}$ & $\begin{array}{l}\text { Began after } \\
\text { descent of east } \\
\text { penthouse }\end{array}$ & $\begin{array}{l}\text { Hand-held news camera, was not } \\
\text { operating when east penthouse } \\
\text { descended. }\end{array}$ \\
\hline 5 & $\begin{array}{l}\text { Street level, near the corner of Franklin and } \\
\text { Hudson Streets }\end{array}$ & $\begin{array}{l}\text { Began after } \\
\text { descent of east } \\
\text { penthouse }\end{array}$ & Amateur recording \\
\hline 6 & $\begin{array}{l}\text { An elevated apartment to the northeast of the } \\
\text { corner of Church and Duane Streets }\end{array}$ & $\begin{array}{l}\text { Began after } \\
\text { descent of east } \\
\text { penthouse }\end{array}$ & $\begin{array}{l}\text { Figure 5-152, Figure } 5-157 \text {, and } \\
\text { Figure } 5-158 \text { are frames from } \\
\text { clips shot earlier from the same } \\
\text { location. }\end{array}$ \\
\hline 7 & $\begin{array}{l}\text { Street level, near the corner of Church and } \\
\text { Duane Streets }\end{array}$ & $\begin{array}{l}\text { Began after } \\
\text { descent of east } \\
\text { penthouse }\end{array}$ & Provided by news organization. \\
\hline 8 & $\begin{array}{l}\text { Street level, near the corner of Greenwich } \\
\text { and Jay Streets }\end{array}$ & $\begin{array}{l}\text { Began after } \\
\text { descent of east } \\
\text { penthouse }\end{array}$ & News camera. \\
\hline 9 & $\begin{array}{l}\text { Street level, near the corner of Greenwich } \\
\text { and Jay Streets }\end{array}$ & $\begin{array}{l}\text { Began after } \\
\text { descent of east } \\
\text { penthouse }\end{array}$ & News camera \\
\hline
\end{tabular}

The videos were used to derive a timeline for the collapse. Note that none of the video clips provide unobstructed views of the lower floors of WTC 7.

Figure 5-184, Figure 5-185, and Figure 5-186 show frames taken from Cameras 1, 2, and 3, respectively, just prior to the time when the east penthouse began to descend into the building. The earliest frames available from the six additional video clips are shown in Figure 5-187 through Figure 5-192. 


\subsubsection{Descent of the East Penthouse}

The first detectable indication of the WTC 7 east penthouse collapse was a downward movement of the eastern side of its roofline. As the downward motion developed, it quickly involved the entire penthouse and became most rapid 42 percent of the way across the roofline from the east. It appeared as if the penthouse almost immediately began to break into two separate sections along a north-south line, and the penthouse then began to "fold" into the main roof from either edge. Figure 5-193 through Figure 5-197 show a 3.5 s sequence of the descent as viewed from the Camera 2 and Camera 3 positions.

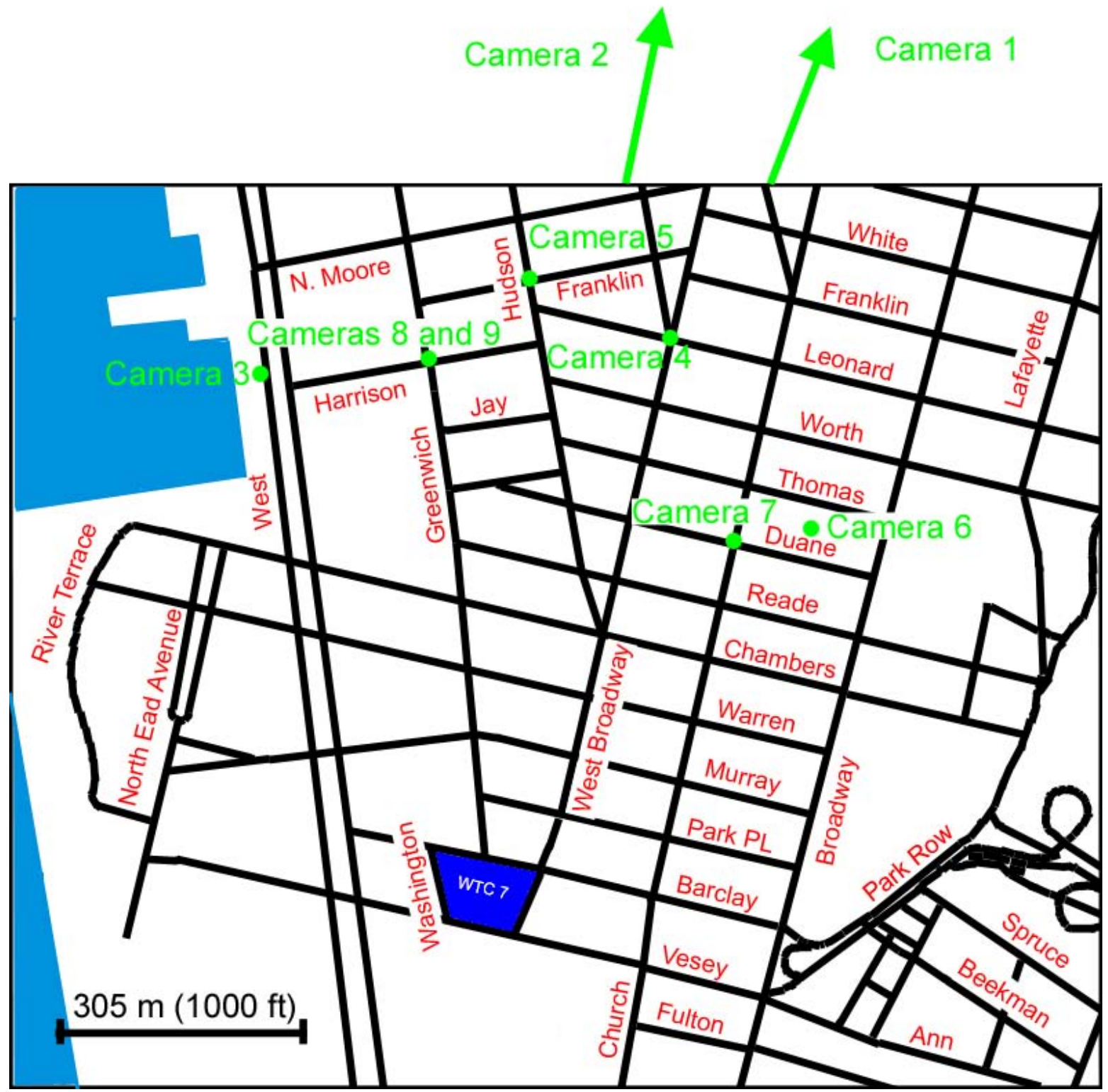

Figure 5-183. Locations of the nine video cameras used to analyze the WTC 7 collapse are shown relative to the location of WTC 7.

The arrows indicate the directions of Camera 1 and Camera 2 relative to WTC 7.

They were located approximately $5 \mathrm{~km}$ to $7 \mathrm{~km}$ ( 3 miles to 4 miles) from WTC 7. 


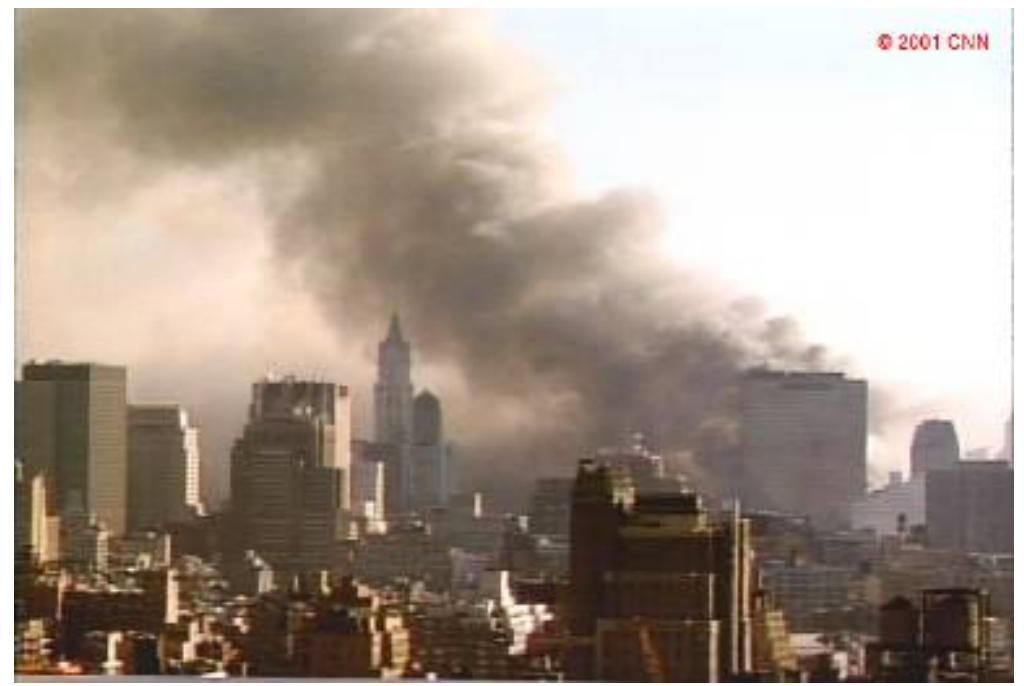

Figure 5-184. Frame from the Camera 1 video, showing the north face of WTC 7 (on right) seconds before the east penthouse began to fall into the building.

Figure 5-185. Frame from the Camera 2 video, showing the north face of WTC 7 (just right of center) seconds before the east penthouse began to fall into the building.

The intensity levels were adjusted.

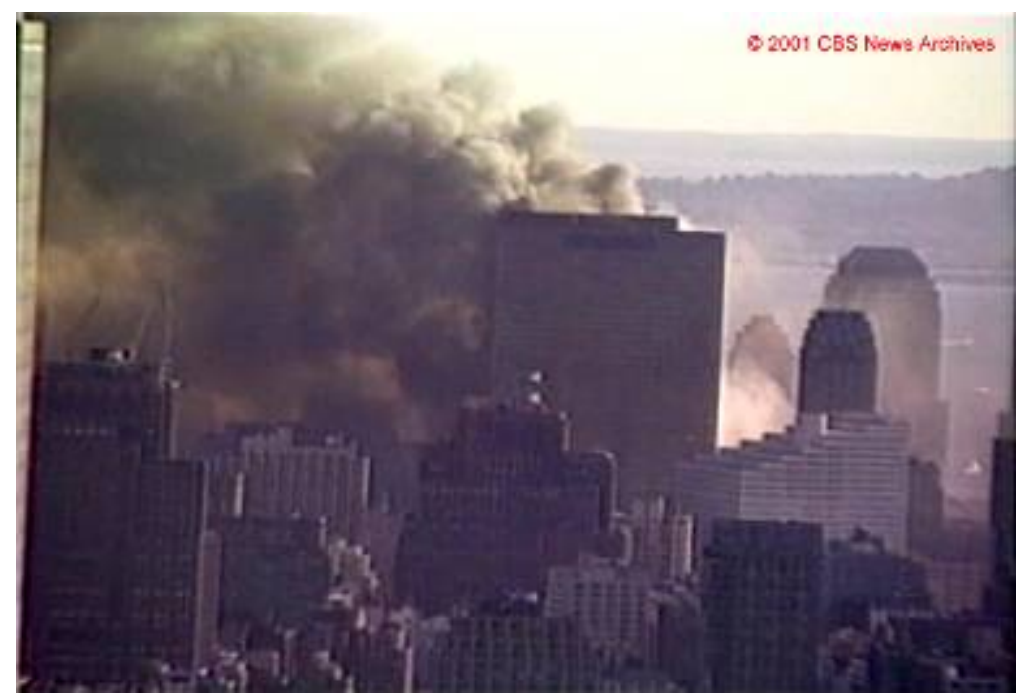

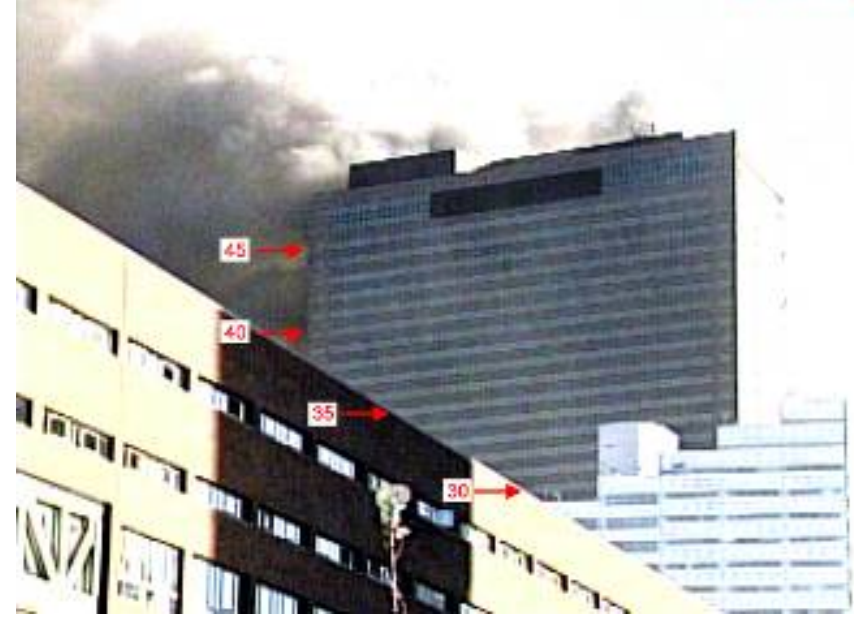

Figure 5-186. Frame from the Camera 3 video showing the north face of WTC 7 (in center) seconds before the east penthouse began to fall into the building.

The intensity levels were adjusted and floor numbers have been added. 


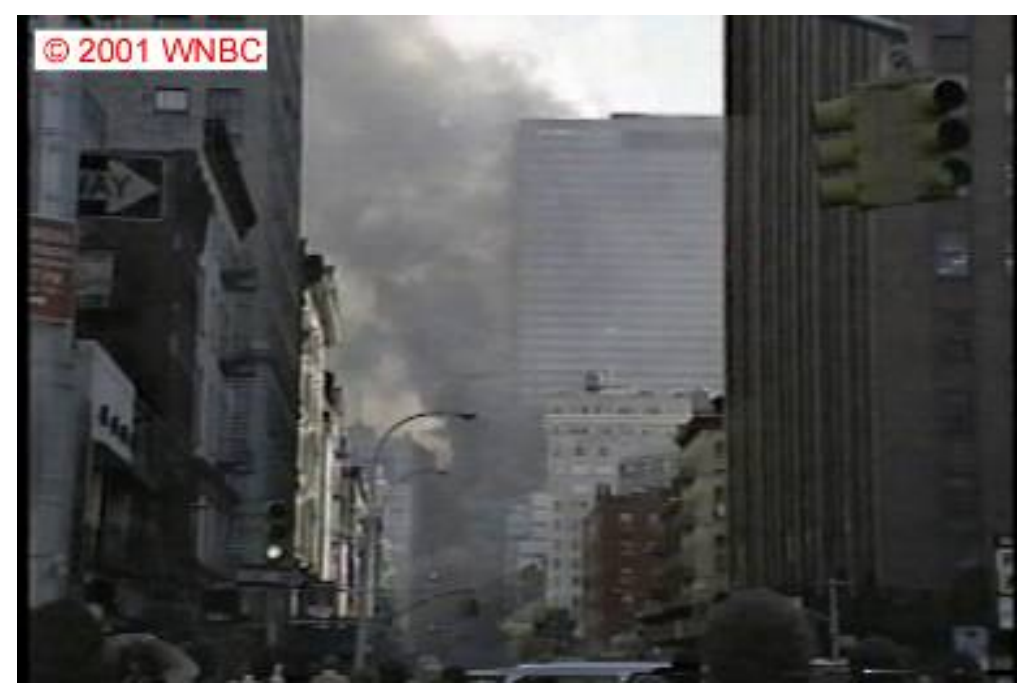

Figure 5-187. Earliest frame from the Camera 4 video, showing the north face of WTC 7.

It was shot $3.7 \mathrm{~s} \pm 0.2 \mathrm{~s}$ after the east penthouse began to sink into the building. The intensity levels have been adjusted.

Figure 5-188. Earliest frame from the Camera 5 video, showing the north face of WTC 7.

It was shot $6.1 \mathrm{~s} \pm 0.2 \mathrm{~s}$ after the east penthouse began to sink into the building.
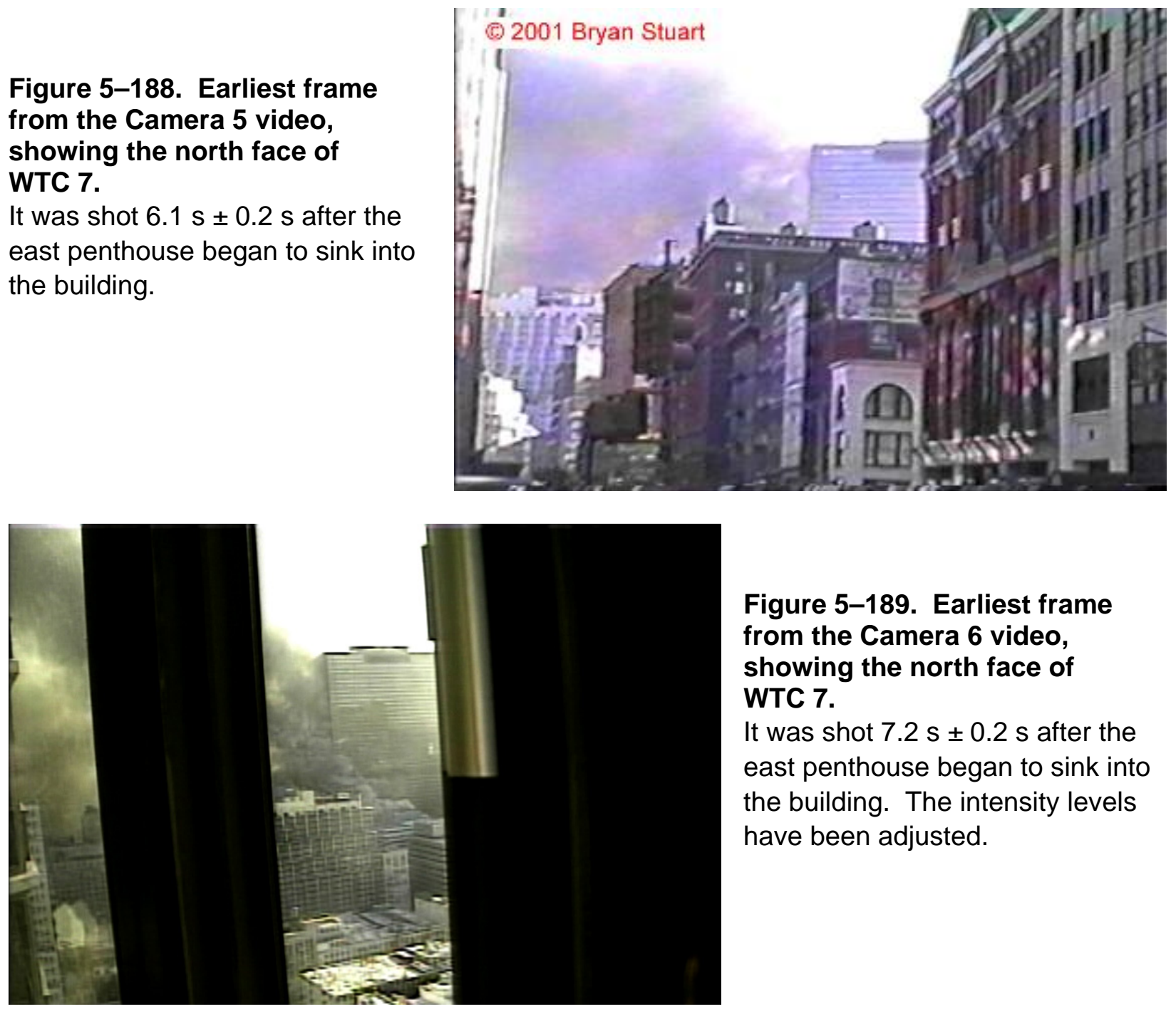

Figure 5-189. Earliest frame from the Camera 6 video, showing the north face of WTC 7.

It was shot $7.2 \mathrm{~s} \pm 0.2 \mathrm{~s}$ after the east penthouse began to sink into the building. The intensity levels have been adjusted.

Source: Unknown 


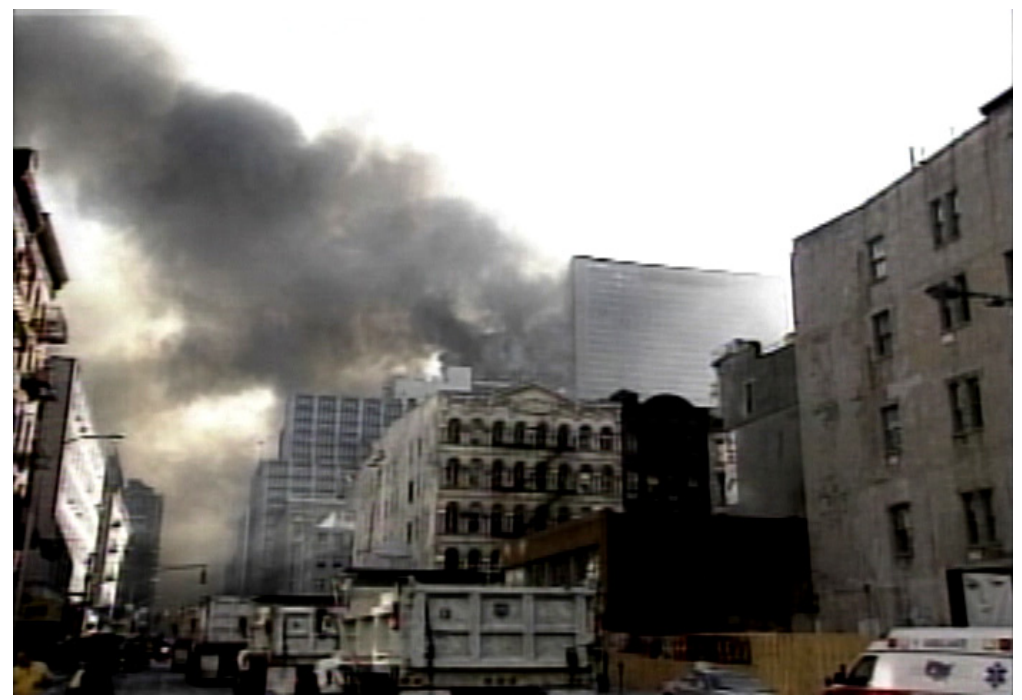

Figure 5-190. Earliest frame from the Camera 7 video, showing the north face of WTC 7.

It was shot $7.7 \mathrm{~s} \pm 0.2 \mathrm{~s}$ after the east penthouse began to sink into the building. The intensity levels have been adjusted.

Reproduced with the permission of $\mathrm{AP}$

Figure 5-191. Earliest frame from the Camera 8 video, showing the north face of WTC 7.

It was shot $8.8 \mathrm{~s} \pm .2 \mathrm{~s}$ after the east penthouse began to sink into the building. The intensities were adjusted.
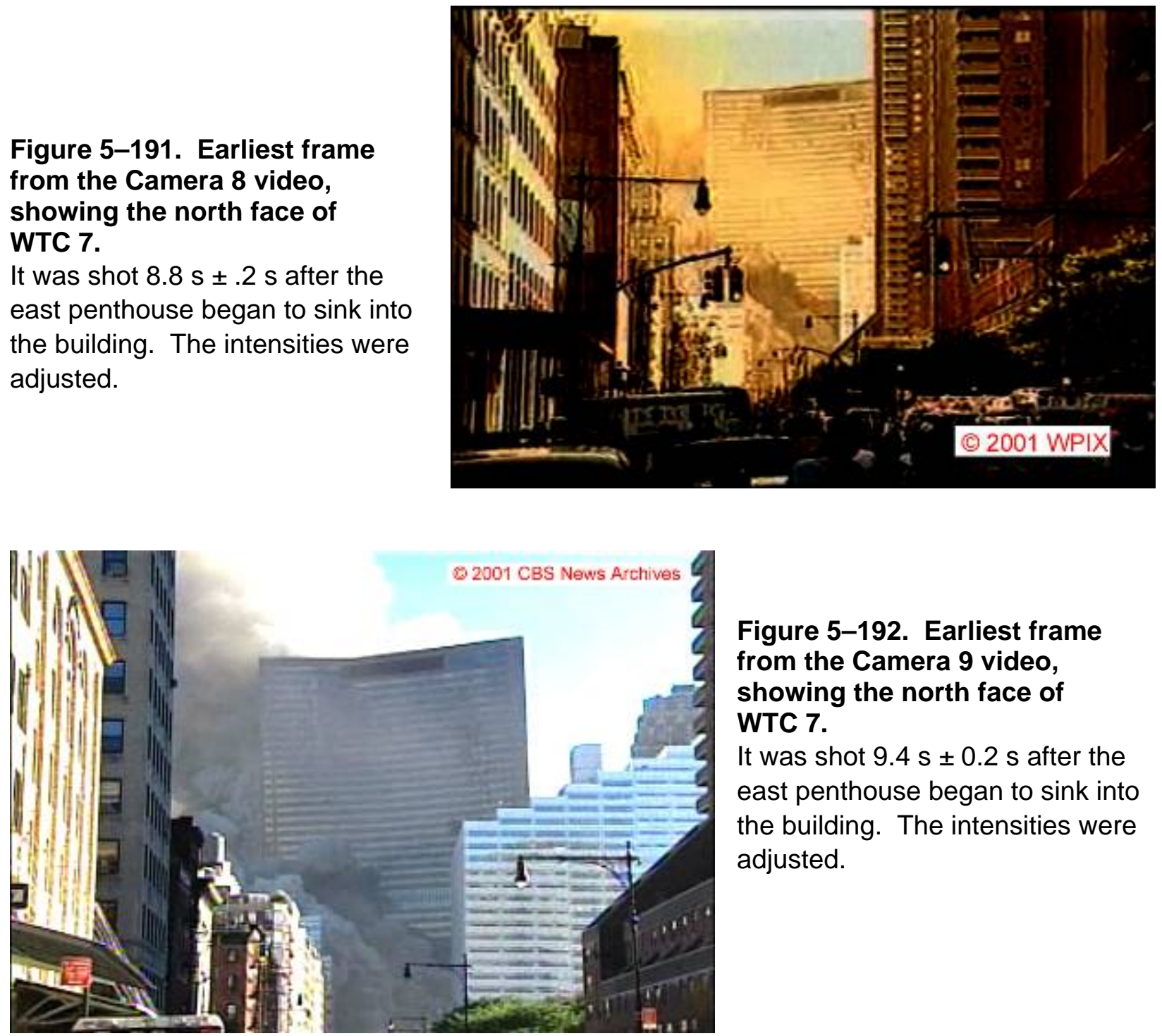

Figure 5-192. Earliest frame from the Camera 9 video, showing the north face of WTC 7.

It was shot $9.4 \mathrm{~s} \pm 0.2 \mathrm{~s}$ after the east penthouse began to sink into the building. The intensities were adjusted. 

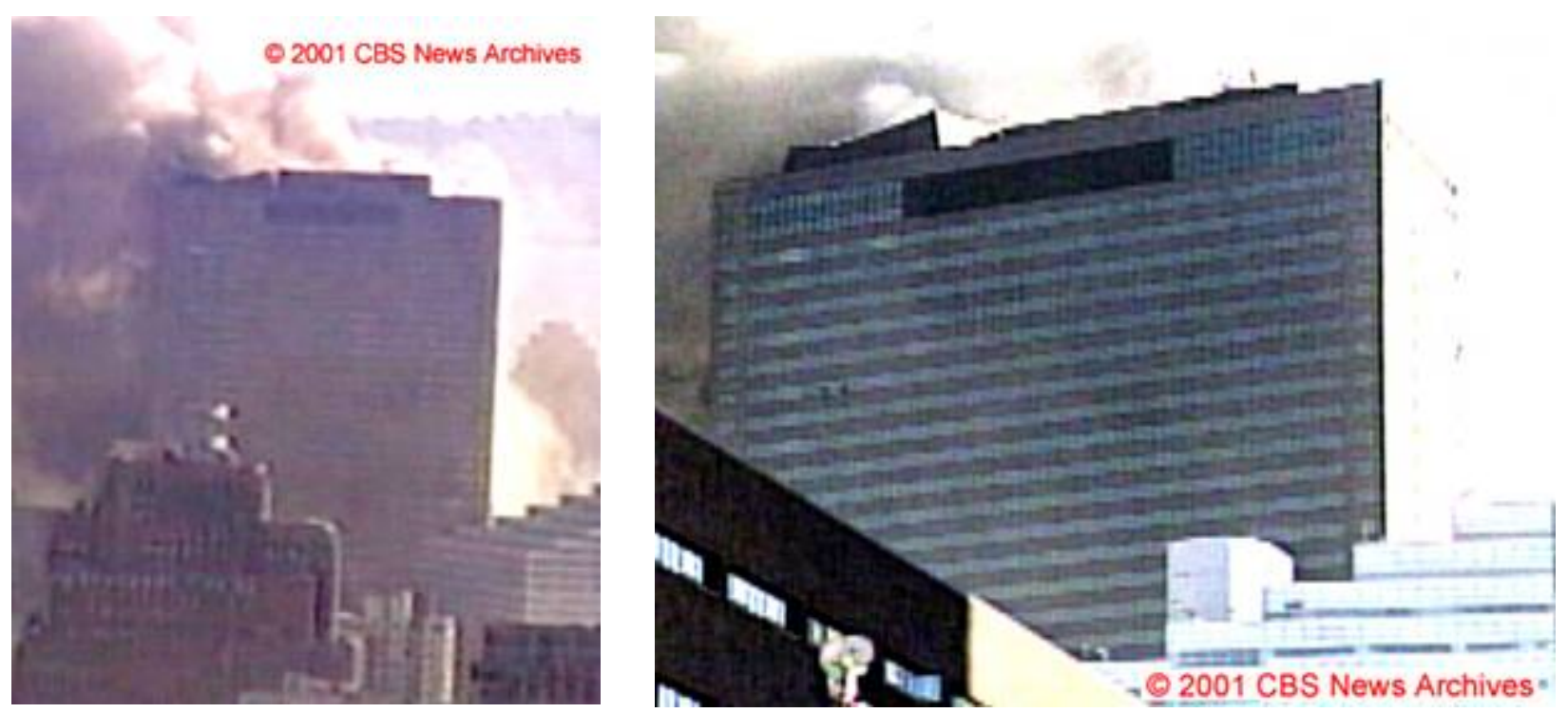

Figure 5-193. Cropped frames from the Camera 2 video clip and the Camera 3 video clip, showing the north face of WTC $71.0 \mathrm{~s} \pm 0.1 \mathrm{~s}$ after the east penthouse began to move downward.

The intensities have been adjusted.
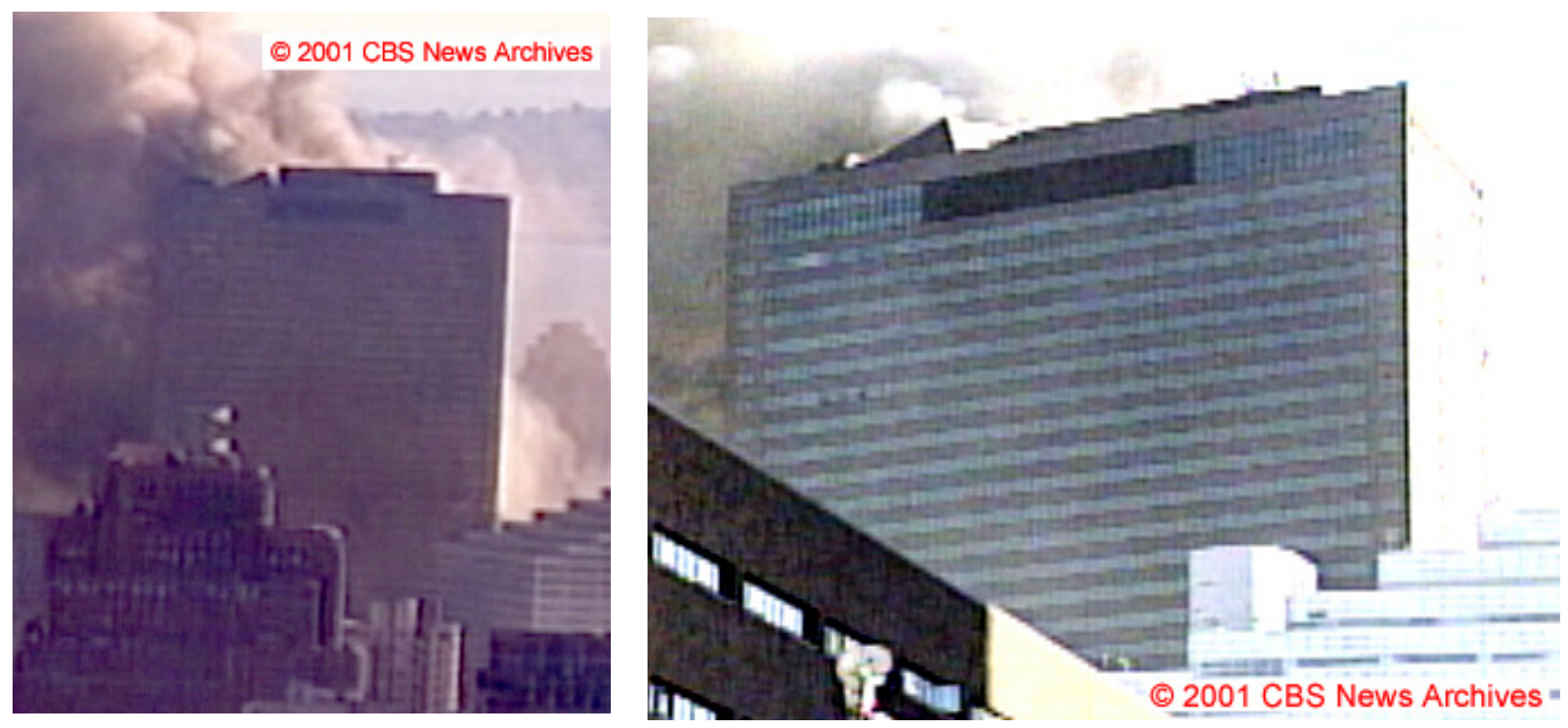

Figure 5-194. Cropped frames from the Camera 2 video clip and the Camera 3 video clip, showing the north face of WTC $71.3 \mathrm{~s} \pm 0.1 \mathrm{~s}$ after the east penthouse began to move downward.

The intensities have been adjusted. 

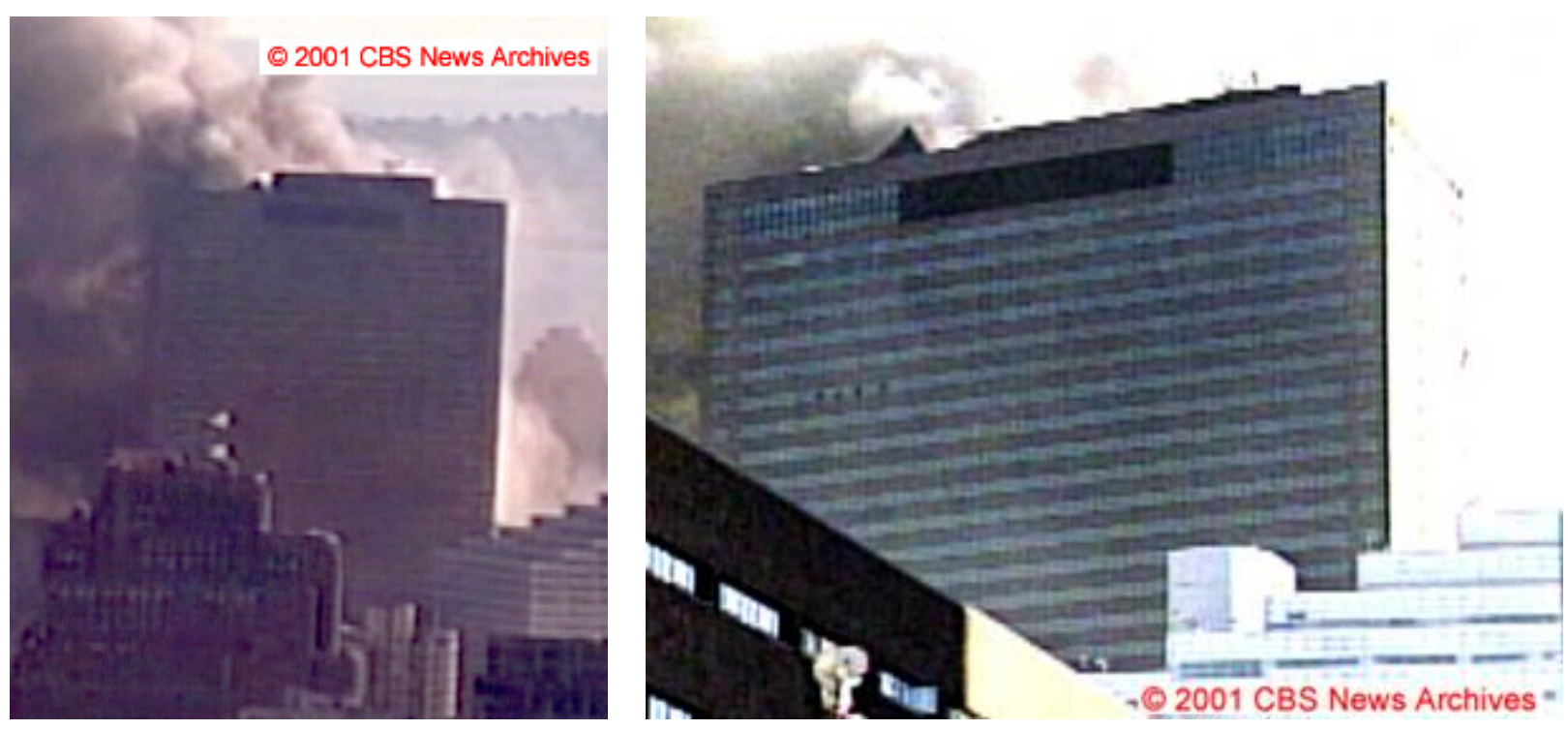

Figure 5-195. Cropped frames from the Camera 2 video clip and the Camera 3 video clip, showing the north face of WTC $71.7 \mathrm{~s} \pm 0.1 \mathrm{~s}$ after the east penthouse began to move downward.

The intensities have been adjusted.
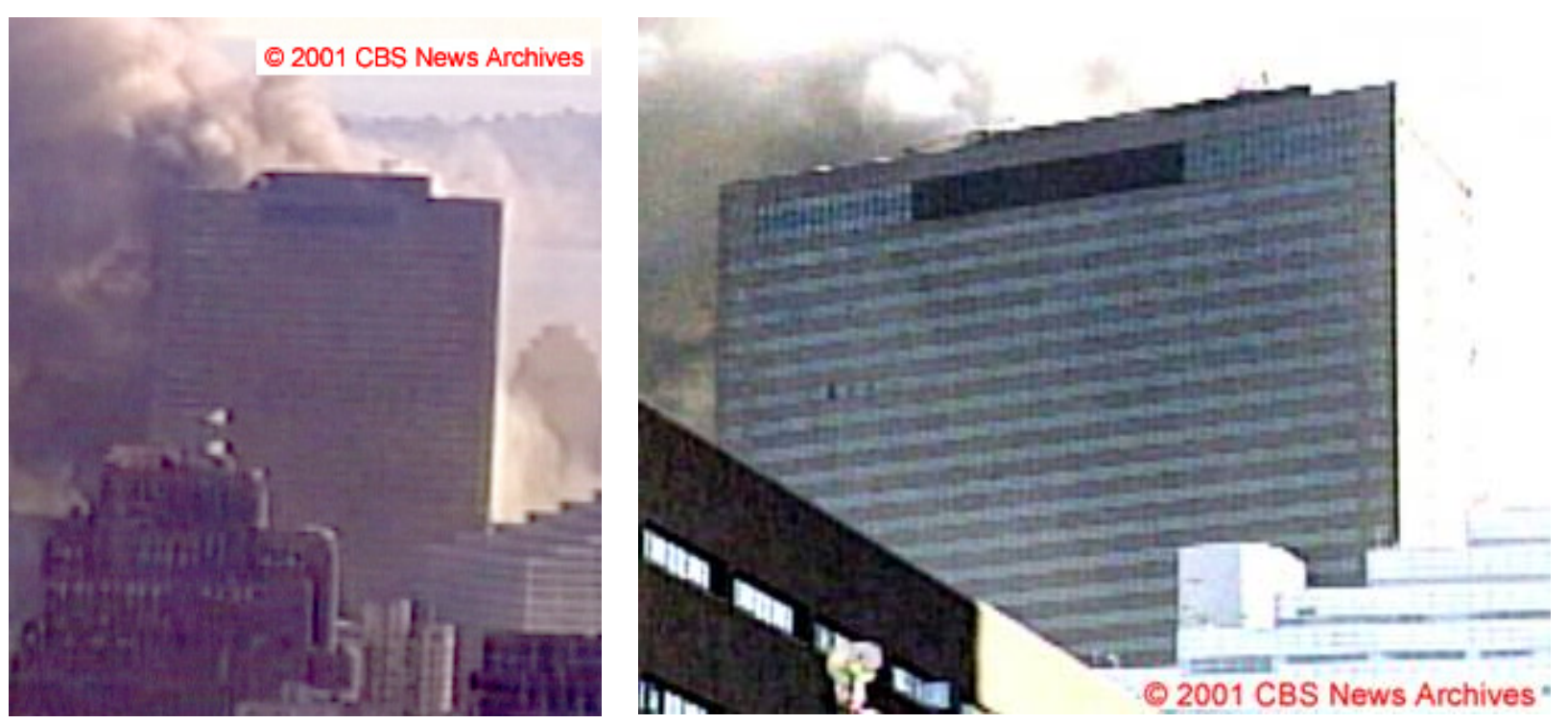

Figure 5-196. Cropped frames from the Camera 2 video clip and the Camera 3 video clip, showing the north face of WTC $72.0 \mathrm{~s} \pm 0.1 \mathrm{~s}$ after the east penthouse began to move downward.

The intensities have been adjusted. 

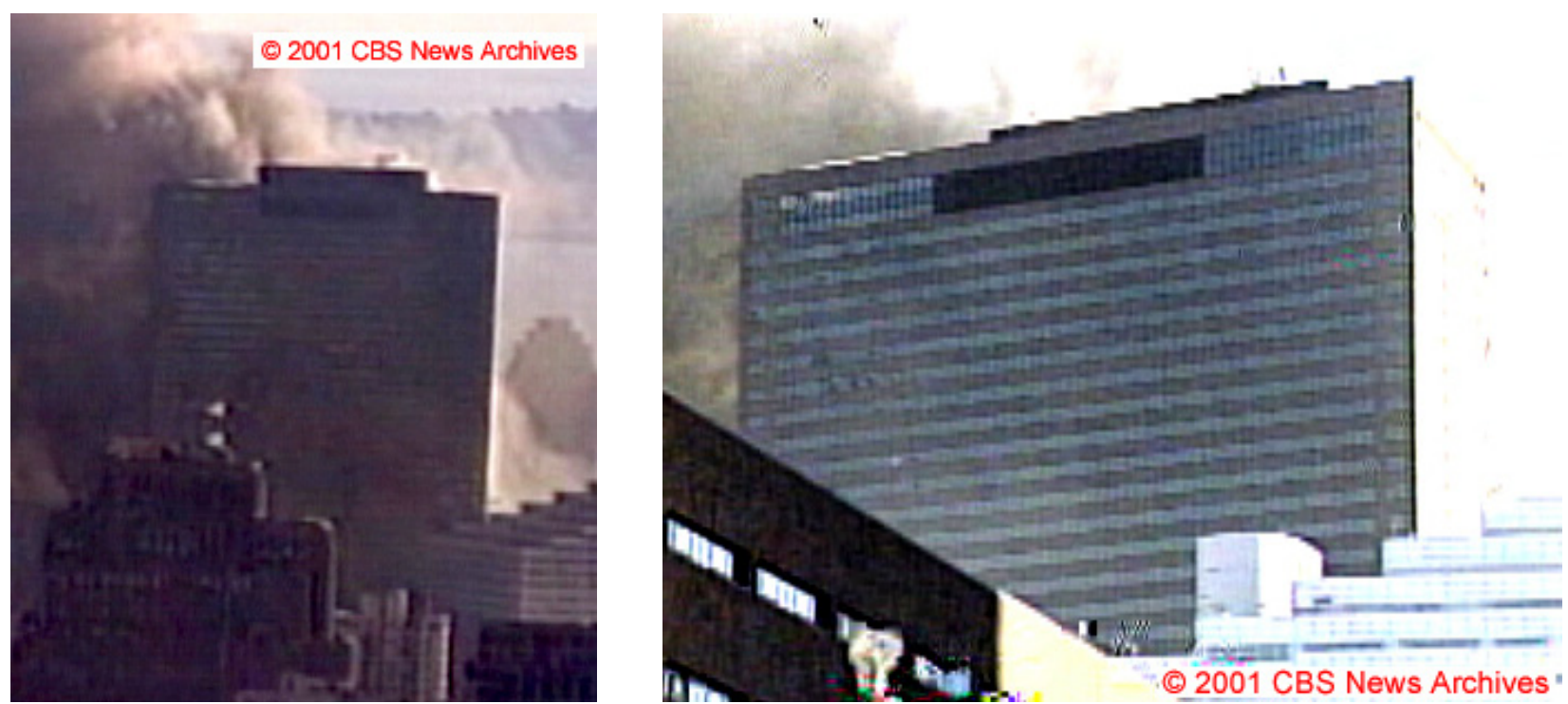

Figure 5-197. Cropped frames from the Camera 2 video clip and the Camera 3 video clip, showing the north face of WTC $73.5 \mathrm{~s} \pm 0.1 \mathrm{~s}$ after the east penthouse began to move downward.

The intensities have been adjusted.

Figure 5-193 shows the appearance of the east penthouse $1.0 \mathrm{~s}$ after it began to descend. A photograph recorded at roughly the same time is included in Figure 5-1. The east-west location where the penthouse split was estimated to be 42 percent of the way across the penthouse roofline using the Camera 2 video. A similar result was obtained from the photograph in Figure 5-1. This location lies close to the vertical line of windows on the north face numbered 44B.

From the two perspectives shown in Figure 5-193, the entire lengths of the east and west walls of the east penthouse began to rotate downward into an apparent opening in the roof of WTC 7. The west wall of the penthouse pulled away from the north and south screenwalls that connected the east and west penthouses as it rotated counterclockwise.

Comparison of the Camera 3 frame in Figure 5-193 with the earlier frame in Figure 5-186 reveals some subtle changes in the appearance of the north face of WTC 7. On the $40^{\text {th }}$ floor, it appears that two glass panes have broken out of windows 40-44B and 40-44D. In the video, window 40-44B began to break $0.6 \mathrm{~s}$ after the penthouse began to move downward, followed by window 40-44D $0.1 \mathrm{~s}$ later. On the $45^{\text {th }}$ floor, two brighter areas have appeared near windows 45-43D and 45-46A even though the window glass appears to be intact. These brighter areas developed nearly simultaneously with the downward movement of the penthouse roof. The changes in appearance are due to local variations in the light reflected from the façade, suggesting local distortions of the façade at these locations. Although faint, similar light variations are evident along a line running vertically near windows $43 \mathrm{D}$ and extending over the visible portion of the face from the $37^{\text {th }}$ to $45^{\text {th }}$ floors.

Figure 5-194 shows two frames from the same video clips, recorded 0.33 s later than those in Figure 5-193. The east penthouse has continued moving downward into the building. The Camera 3 video shows that the northeast corner of the penthouse was falling faster than the other three corners. In the Camera 3 view in Figure 5-194, a small section of the northeast corner, which appears to be black in the frame, is about 
to disappear below the upper edge of the building façade, while another part of the eastern section, which appears to be much higher, is visible further toward the center of the roof. The difference in heights is even larger than it appears, since the southern edge of the penthouse is considerably further away from the camera location. From the more distant Camera 2 view in Figure 5-194, it is clear that the eastern and western sections of the east penthouse have fully separated. In this view, the roofline of the eastern section appears to be parallel to the main roof, even though it lies well below the upper end of the western section and its original location (compare with Figure 5-185). Since the northern part of the eastern section is about to fully disappear into the roof, this observation suggests that the southern part is actually collapsing by rotating as a single unit toward the north, indicating that the eastern section of the penthouse had broken into at least two pieces.

A large fraction of the west wall of the east penthouse is rotating towards the east in the closer view from Camera 3 and appears to be intact. The appearance of this area in the Camera 2 view in Figure 5-194 is consistent with this interpretation.

The appearance of the north face recorded by Camera 3 in Figure 5-194 has changed somewhat over the 0.33 s since the frame in Figure 5-193 was taken. An additional window on the $40^{\text {th }}$ floor, 40-43E, has opened. The bright spot on the $45^{\text {th }}$ floor near Column 44 is still prominent, but the one near Column 46 has become much less distinct. The vertical line near Column 44 is no longer evident. In the Camera 2 view, a faint lighter area is visible near the $42^{\text {nd }}$ and $43^{\text {rd }}$ floors below the collapsing penthouse. This lighter area appeared as the penthouse began to sink into the roof and seems to be associated with changes in reflected light from the face at this location.

The two views of the collapsing penthouse 10 frames later (1.7 s after it began to descend) are shown in Figure 5-195. From the long distance Camera 2 view, it is clear that the eastern portion of the penthouse has disappeared completely below the parapet running around the building and has presumably fallen into the building, while the western half is still visible and continues to rotate into the opening. In the view from West Street (Camera 3), it appears as if the west wall of the east penthouse is still intact.

In the closer view, an additional window (40-45A) on the $40^{\text {th }}$ floor has opened. The bright spot near Column 43 is still prominent on the $45^{\text {th }}$ floor. A light area has appeared near the tops of the windows on the $46^{\text {th }}$ and $47^{\text {th }}$ floors below the collapsing penthouse. In the longer distance view, the lighter area on the north face below the collapsing penthouse has extended further down the face to the $41^{\text {st }}$ floor.

The videos show that it took $2.0 \mathrm{~s} \pm 0.2 \mathrm{~s}$ for the entire east penthouse to disappear from view. The last portion to disappear was the southwest corner. There is a small uncertainty in the timing because a small section of the north screenwall near the penthouse began to break away at $1.9 \mathrm{~s} \pm 0.1 \mathrm{~s}$ and rotated counterclockwise toward the collapsing penthouse. As it rotated, it blocked the view of the last section of the penthouse to disappear. Figure 5-196 shows the two views of WTC 7 taken $2.0 \mathrm{~s} \pm 0.1$ after the penthouse began to move downward. The small black object visible at the right side of the location where the penthouse had been is the section of the collapsing screenwall. The penthouse itself is no longer visible.

Except for the missing penthouse and broken windows, the north face of WTC 7 in the Camera 3 view from West Street is little changed from Figure 5-186. In the more distant view, the area of increased light reflection on the north face has continued to move downward. 


\subsubsection{Distortion of the North Façade}

After the east penthouse and a small section of the north screenwall disappeared, there was a short period during which structural changes were not apparent in the videos. Figure 5-197 shows two views of the north face of the building $3.5 \mathrm{~s}$ after the east penthouse began to move downward and $1.5 \mathrm{~s}$ later than Figure 5-196. In the close view, a number of windows have opened on the $40^{\text {th }}$ through $45^{\text {th }}$ floors between Columns 43 and 45 . A bright area is evident in the windows on the $46^{\text {th }}$ and $47^{\text {th }}$ floors. This bright area appeared as the east penthouse disappeared into the building, likely due to sunlight shining onto the windows through the opening created in the roof of WTC 7 by the collapsing penthouse. The same bright area near the top of WTC 7 is evident in the long distance view in Figure 5-197.

In this same frame, a faint tear-drop-shaped brighter area is also apparent, spread over multiple floors on the eastern side of the north face. This area extends downward to near the $33^{\text {rd }}$ floor. When this video clip was scrubbed (played back and forth at varying rates), it was possible to observe this lighter area moving downward on the face following the penthouse descent. It appeared near the top of the building at the same time the east penthouse disappeared into the building (Figure 5-194 through Figure 5-196) and moved downward in a single continuous motion, disappearing from view behind the building in the foreground, roughly $5 \mathrm{~s}$ after the penthouse began to descend. The same motion could be seen in the Camera 1 video clip from which the more distant view shown in Figure 5-184 was taken.

Since the majority of the window glass in the area of the movement was still intact, it is probable that the lighter area was the result of changing light reflections due to distortions of the façade, similar to those discussed earlier. Such distortions could be due to physical movement of the face or perhaps to pressure changes within the building. Whatever the cause, it seems clear that some type of disturbance began to move downward in the building at the same time as the east penthouse started descending.

Just prior to the time that Figure 5-196 was taken (at $3.5 \mathrm{~s} \pm 0.1 \mathrm{~s}$ ), an additional failure was observed on the roof of WTC 7 in the Camera 2 video clip. A relatively small piece of screenwall or mechanical equipment in the vicinity of the east end of the screenwalls began to move and appeared to rotate downward toward the south or west. It disappeared from view in about $2 \mathrm{~s}$.

When the Camera 3 video clip was scrubbed, it could be seen that the entire building moved as the east penthouse began to sink into WTC 7. This motion was most evident along the northwest corner. At first, there was a relatively small motion toward the west, followed by a larger movement toward the east. These motions were more easily identified by creating difference frames in which a single frame recorded prior to the start of the east penthouse movement was subtracted from each frame in the clip. Figure 5-198 includes three frames taken from such a difference video, with times following the start of downward motion for the east penthouse indicated. The variations in the brightness of the line along the northwest corner reveal that lateral motions were taking place. Details concerning these motions are provided in Appendix C, where a more sophisticated analysis is used to quantify the building movements. Note that other observations discussed previously, such as the appearance of broken windows and light coming through the upper windows at the top of the building, can be discerned in the difference frames.

Figure 5-187 was recorded $0.2 \mathrm{~s}$ after the images shown in Figure 5-197 and $3.7 \mathrm{~s}$ after the east penthouse began to move downward, looking down West Broadway. Much of the north face is visible for the $25^{\text {th }}$ floor and higher. Roughly seven additional lower floors are visible at the northeast corner. Some 
details concerning the north face can be gleaned from the image. For instance, the light coming through windows on the east side of the $46^{\text {th }}$ and $47^{\text {th }}$ floors can be seen.

Perhaps the most interesting feature of Figure 5-187 is the flow of what appears to be dark smoke across the visible part of the northeast corner as high as the $23^{\text {rd }}$ floor. The actual composition of the material is not known. It could have been smoke from the fires on lower floors and/or escaping dust generated within the building by ongoing structural changes. Later during the WTC 7 collapse, a debris flow similar to those generated by the collapses of the towers (see Figure 5-27, Figure 5-34, Figure 5-35, and Figure 5-42) formed due to the dust released by the collapse. Due to the shadowing of the area, the dust cloud had a very similar appearance to the dark flow in Figure 5-187. The flow in Figure 5-187 appears to extend out to and across West Broadway and perhaps even somewhat north along this street.
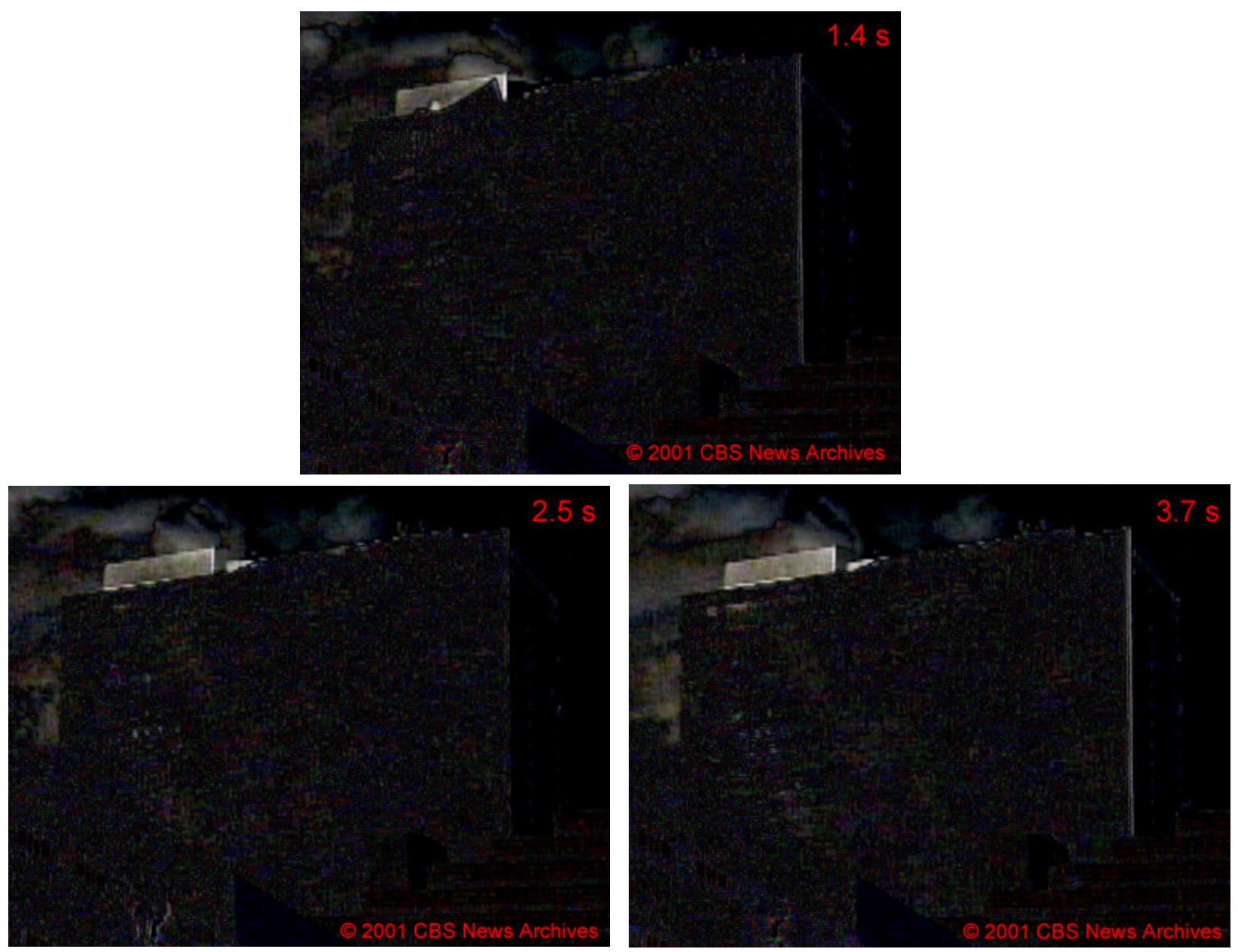

Figure 5-198. Three cropped difference frames based on the Camera 3 video clip shown in Figure 5-186 created by subtracting a frame from before the east penthouse started downward from each frame in the clip.

The indicated times are the periods since the east penthouse began to move.

The intensity levels were adjusted. 
Figure 5-199 shows the north face $5.0 \mathrm{~s}$ after the east penthouse began moving downward. These two frames were taken from the Camera 2 long distance and Camera 3 West Street views. The time is $1.5 \mathrm{~s}$ after the corresponding views shown in Figure 5-197. There have been relatively minor changes in the appearance of the north face over this period. In the Camera 3 shot, it can be seen that additional glass has broken out of windows on the east side of the face. Open windows are visible at multiple locations from the $37^{\text {th }}$ floor to the $43^{\text {rd }}$ floor. The light coming through the open roof is apparent for windows on the $46^{\text {th }}$ and $47^{\text {th }}$ floors. In the longer distance view, the top of the tear-drop shaped light area that was observed moving down the north face is just visible above the buildings in the foreground. Most of the shape has already moved out of view. No other major visible changes were evident over the $1.5 \mathrm{~s}$ period.
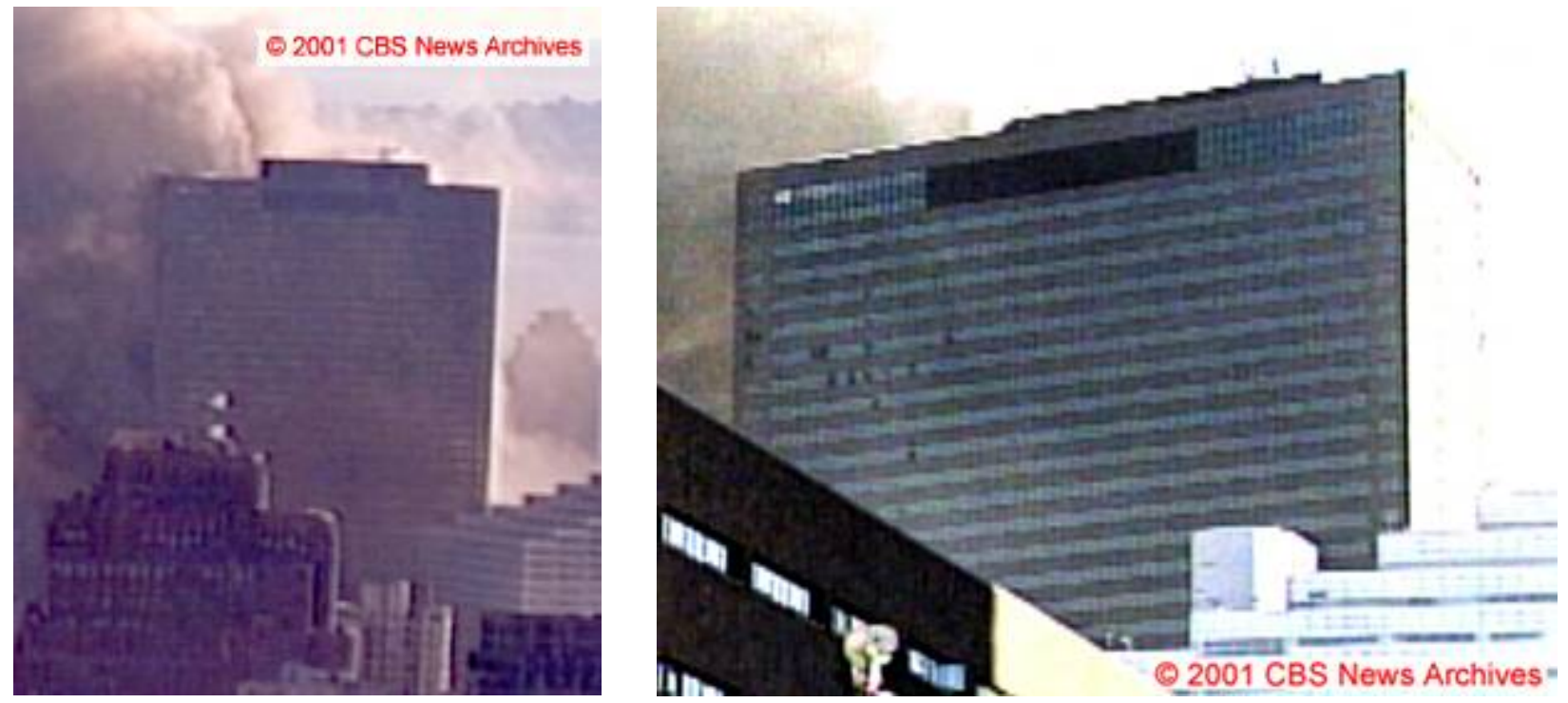

Figure 5-199. Cropped frames from the Camera 2 video clip in Figure 5-185 and the Camera 3 video clip in Figure 5-186, showing the north face of WTC 7 $5.0 \mathrm{~s} \pm 0.1 \mathrm{~s}$ after the east penthouse began to move downward.

The intensities have been adjusted.

\subsubsection{Global Collapse of WTC 7}

The global collapse of WTC 7 started $6.9 \mathrm{~s} \pm 0.1 \mathrm{~s}$ after the east penthouse began its descent into the building. Thus, the actual time when the east penthouse first began to descend into the roof of WTC 7 was 5:20:45 p.m. $\pm 1 \mathrm{~s}$. The initial movement of the north face occurred at the roofline at the east penthouse location and at the eastern side of the screenwalls on the roof. The most rapid initial descent was near the screenwall, and this structure appeared to be sinking into the building.

Figure 5-200 shows views of the north face, shot by Cameras 2 and 3, $0.6 \mathrm{~s}$ after this motion was first detectable. Comparison of the Camera 3 shot with the corresponding view in Figure 5-199 shows that the top of the north screenwall has moved downward on the east side. This is most easily seen by noting the variation in the height of the screenwall above the top of the north face parapet. In the more distant Camera 2 shot, the line running along the top of the north screenwall and the west penthouse appears to be slanted downward toward the east. 
A better idea of the motion can be obtained from Figure 5-201, which shows the result of subtracting the Camera 3 clip in Figure 5-199 from that shown in Figure 5-200. The white area along the top of the building is due to the building movement between the two frames. The largest change is along the eastern edge of the screenwall. There is a decided narrowing of the white band further west indicating that the eastern side of the line formed by the screenwall and west penthouse has descended further. Substantial movement of the building's upper edge is evident to the east of the screenwall. Interestingly, little movement of the northeast and northwest corners of the building is indicated.

Comparison of the Camera 3 frames in Figure 5-199 and Figure 5-200 shows that changes in the appearance of the visible upper floors of the north face were minimal during the $2.5 \mathrm{~s}$ between the frames. In particular, the number of broken windows appears to be unchanged.

Figure 5-188 shows a north face view of WTC 7 that was recorded by Camera 5 just prior to the initiation of the global collapse of the building. The east penthouse is no longer present on the roof, while the screenwall and west penthouse are still in place. This view provides little additional information concerning the state of the building. On the other hand, Figure 5-189 was taken by Camera 6 a few tenths of a second after the global collapse started and before the images in Figure 5-200 were taken. It provides a view of the center of the north face, down to the $15^{\text {th }}$ floor. Heavy smoke and/or dust are visible flowing across portions of the north face. The smoke and/or dust nearly reach to the $25^{\text {th }}$ floor at the northeast corner. It is likely that this flow is a continuation of the heavy smoke and/or dust flow first observed in Figure 5-187, i.e., prior to the initiation of apparent global collapse.
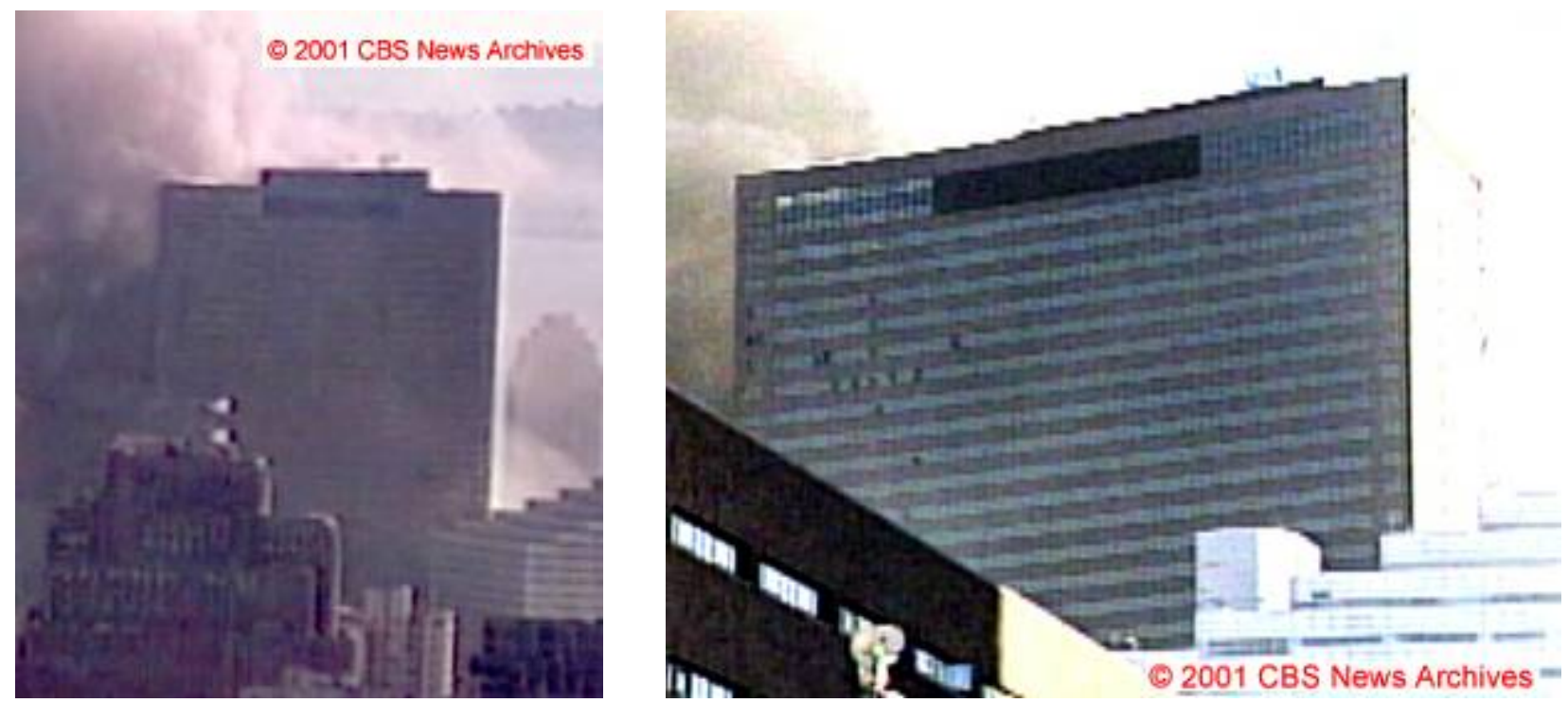

Figure 5-200. Cropped frames from the Camera 2 video clip in Figure 5-185 and the Camera 3 video clip in Figure 5-186, showing the north face of WTC 7 $7.5 \mathrm{~s} \pm 0.1 \mathrm{~s}$ after the east penthouse began to move downward.

The intensities have been adjusted. 


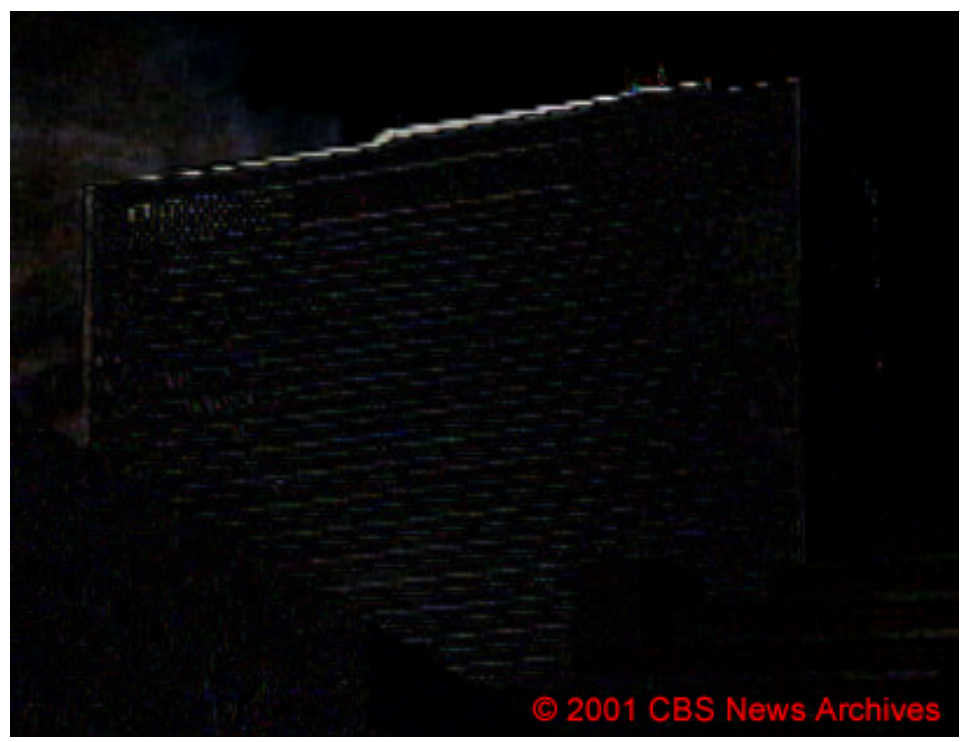

Figure 5-201. Cropped difference frame at $7.5 \mathrm{~s} \pm 0.1 \mathrm{~s}$ after the east penthouse began to move, created by subtracting the frame reproduced in Figure 5-199 from the Camera 3 video clip shown in Figure 5-200.

The intensity levels were adjusted.

Review of the Camera 3 video clip showed that the top of the screenwall and west penthouse rapidly disappeared from view behind the north parapet from east to west. The last section was seen $8.0 \mathrm{~s} \pm 0.1 \mathrm{~s}$ following the initial movement of the east penthouse. Note that this does not mean these structures had sunk completely through the roof, since they were set well back from the north face, and only their tops were visible over the parapet. At nearly the same time that the penthouse was lost from the Camera 3 view, multiple windows opened nearly simultaneously on several floors on the west side of the north face near Column 55. Shortly thereafter, in the long distance Camera 2 video, a relatively small object could be seen falling rapidly away from the east end of the screenwall starting at $8.3 \mathrm{~s} \pm 0.2 \mathrm{~s}$ after the east penthouse began moving down. It is likely that this object was part of the south screenwall that fell into the opening in the roof to the east.

Figure 5-202 shows Camera 2 distant and Camera 3 West Street views of the north face $8.1 \mathrm{~s}$ after the east penthouse began falling. In the closer view the west penthouse is no longer visible. The windows that opened $0.2 \mathrm{~s}$ earlier on the west side of the face near Column 55 extend over the $33^{\text {rd }}$ to $39^{\text {th }}$ floors in the West Street image. The distribution of open windows on the east side of the face appears to be unchanged from that in Figure 5-200.

Direct comparison of Figure 5-200 and Figure 5-202 shows that WTC 7 moved downward during the $0.6 \mathrm{~s}$ period between the images. It also appears that the east end of the north face is rotating to the north relative to the rest of the north face.

It is clear from the distant view in Figure 5-202 that, even though the screenwall and west penthouse have partially sunk into the building, they are still well above the roof and parapet. Close inspection of this image reveals a darker area at the eastern end of the sloping line formed by the screenwall and the west penthouse on the roof. This dark area is the falling object that is about to disappear into the building. On the east side there is a white cloud rising above the roofline. Later frames reveal that this is a dust cloud that is being pushed upward from the opening in the roof as the building collapses. 

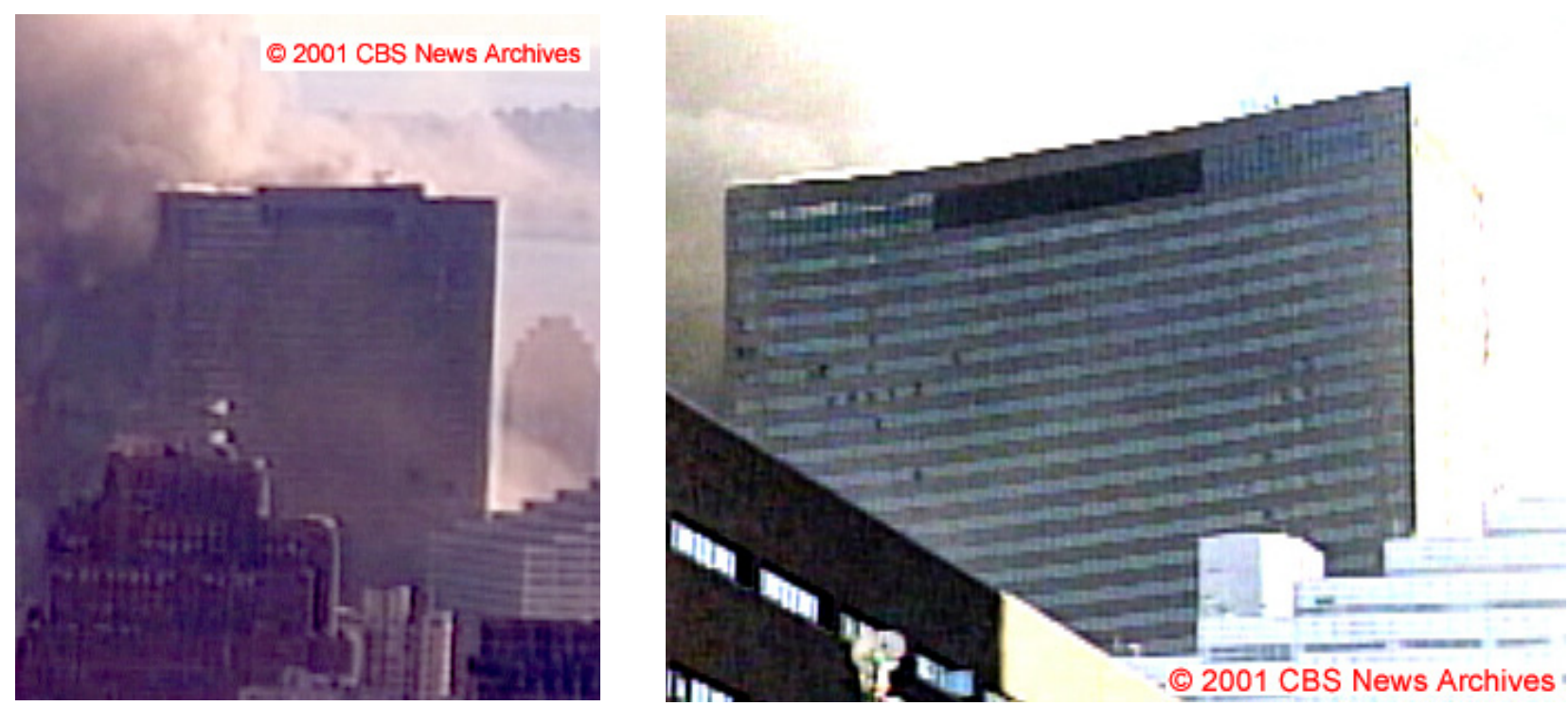

Figure 5-202. Cropped frames from the Camera 2 video clip in Figure 5-185 and the Camera 3 video clip in Figure 5-186, showing the north face of WTC $78.1 \mathrm{~s} \pm 0.1 \mathrm{~s}$ after the east penthouse began to move downward.

The intensities have been adjusted.

Camera 2 and Camera 3 views of the north face of WTC 7 recorded 0.9 s after those in Figure 5-202, i.e., $9.0 \mathrm{~s}$ after the east penthouse began to move, are shown in Figure 5-203. By this time, the entire north face that is visible above the foreground buildings was clearly falling as a unit. By counting the visible floors above the foreground building in the view from West Street, it was found that WTC 7 had fallen nearly two stories in the $2.1 \mathrm{~s}$ since the global collapse started. The façade damage on the west side of the face has increased and seems to extend over most of the visible floors between Columns 54 and 55 . What appears to be dust has begun to flow from the open windows. A few additional windows have opened near the center of the face since the frame in Figure 5-202 was taken. The distribution of open east-side windows looks similar at the two times. The rotation of the east edge of the north face has become more evident, and a distinct kink has begun to develop just to the left of the east end of the louvers on the $46^{\text {th }}$ and $47^{\text {th }}$ floors. This location is close to perimeter Column 47.

In the distant view in Figure 5-203 it can be seen that all of the screenwall and most of the west penthouse have disappeared below the north parapet. The roofline of the west penthouse that is still visible is sloping down steeply from its western edge. The dust cloud rising through the roof opening on the east side of the building has grown.

By utilizing video clips from the Camera 3 and Camera 4 videos it was possible to characterize the motions of the northeast and northwest edges of WTC 7 in more detail. A sequence of images from the Camera 4 video is shown in Figure 5-204. This camera was hand held, and during the collapse the camera moved and the operator began to zoom in. As a result, the line corresponding to the pre-collapse location of the northeast edge of WTC 7 moved within the video frames with time. However, the two buildings in the foreground were fixed and provided a means to identify this location in frames after the collapse began. In the first image of Figure 5-204, a vertical line has been drawn tracing the northeast edge of WTC 7, and a horizontal line was drawn to the two buildings in the foreground. Using the foreground building edges as guides, these same lines were imposed on subsequent frames, in effect 
identifying the original location of the northeast edge in the frame. Onto each subsequent image, the same lines have been added that trace the evolving location of the northeast edge of the building. In the first five frames the original line and the edge of WTC 7 at the later time coincide within the resolution of the image, showing that the visible northeast edge had not moved perpendicular to a line running between the camera position and the edge of the building. During this time, WTC 7 had begun to collapse, and the roofline had already descended about 10 stories. Thus, well into the building collapse, the northeast corner of the building fell either straight down, directly toward, or directly away from the video camera. In the next frame at $10.6 \mathrm{~s}$ following initial movement of the east penthouse, the top of the northeast corner of the building has tilted sharply to the west, and it appears that the building has begun to break apart. This motion continued to grow until the northeast edge became hidden by the rising dust cloud.
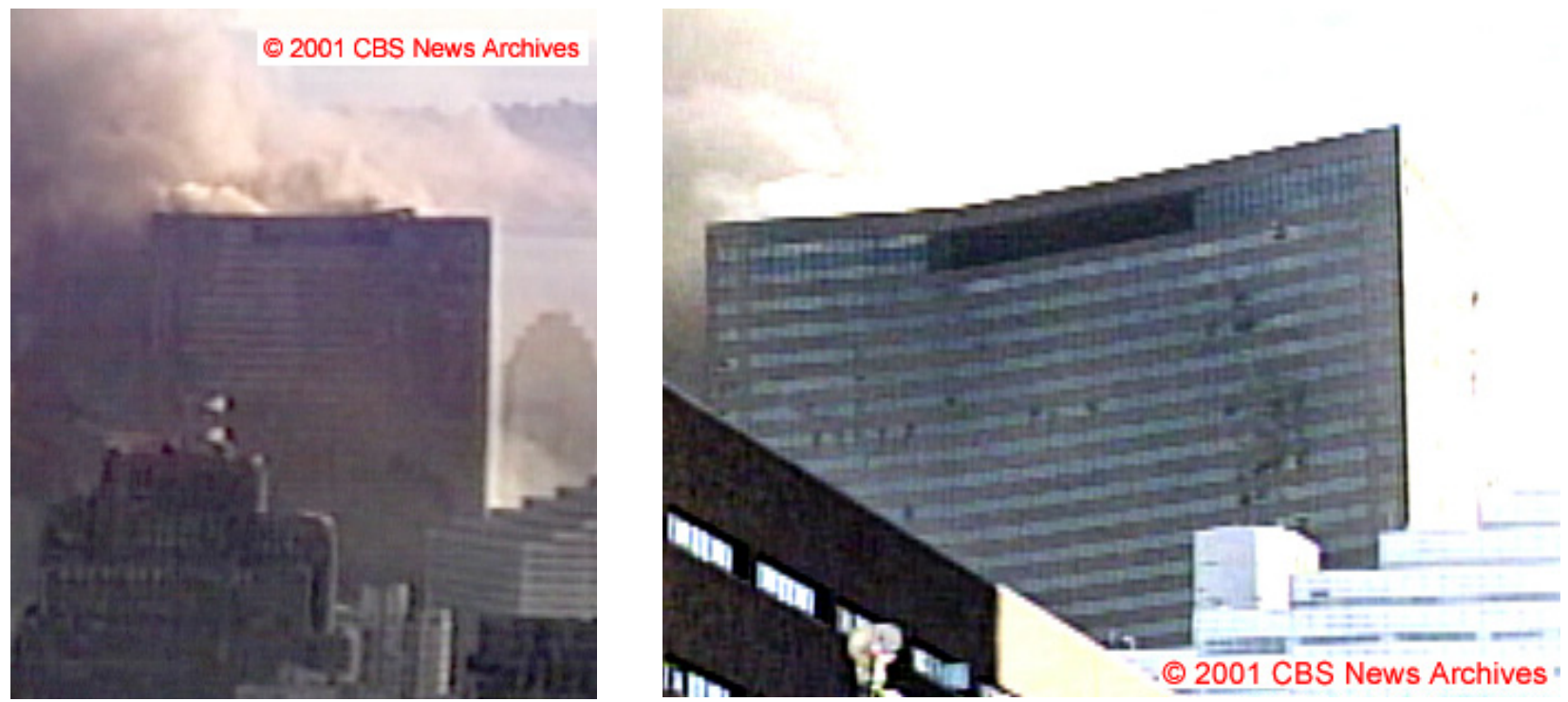

Figure 5-203. Cropped frames from the Camera 2 video clip in Figure 5-185 and the Camera 3 video clip in Figure 5-186, showing the north face of WTC 7 $9.0 \mathrm{~s} \pm 0.1 \mathrm{~s}$ after the east penthouse began to move downward.

The intensities have been adjusted.

The Camera 3 video provided additional information about the movement of the building edges due to its view of the full width of WTC 7 and a more oblique viewing angle. The image differencing technique used to visualize the movement of WTC 7 in Section 5.7.3 was again applied. Figure 5-205 shows several frames from the difference video at the indicated times following initiation of downward movement of the east penthouse. White lines denoting both the original and displaced edges of the building are drawn on the image to emphasize the relative displacement and rotation. In this sequence of images, both the northeast and northwest edges began to tilt toward the north shortly after the building began to move downward. The northeast edge tilt continued to increase until the edge was obscured by dust and smoke. The northwest edge initially tilted in a similar manner, but then settled back to its original line and fell nearly vertically (or directly toward or away from the camera). 

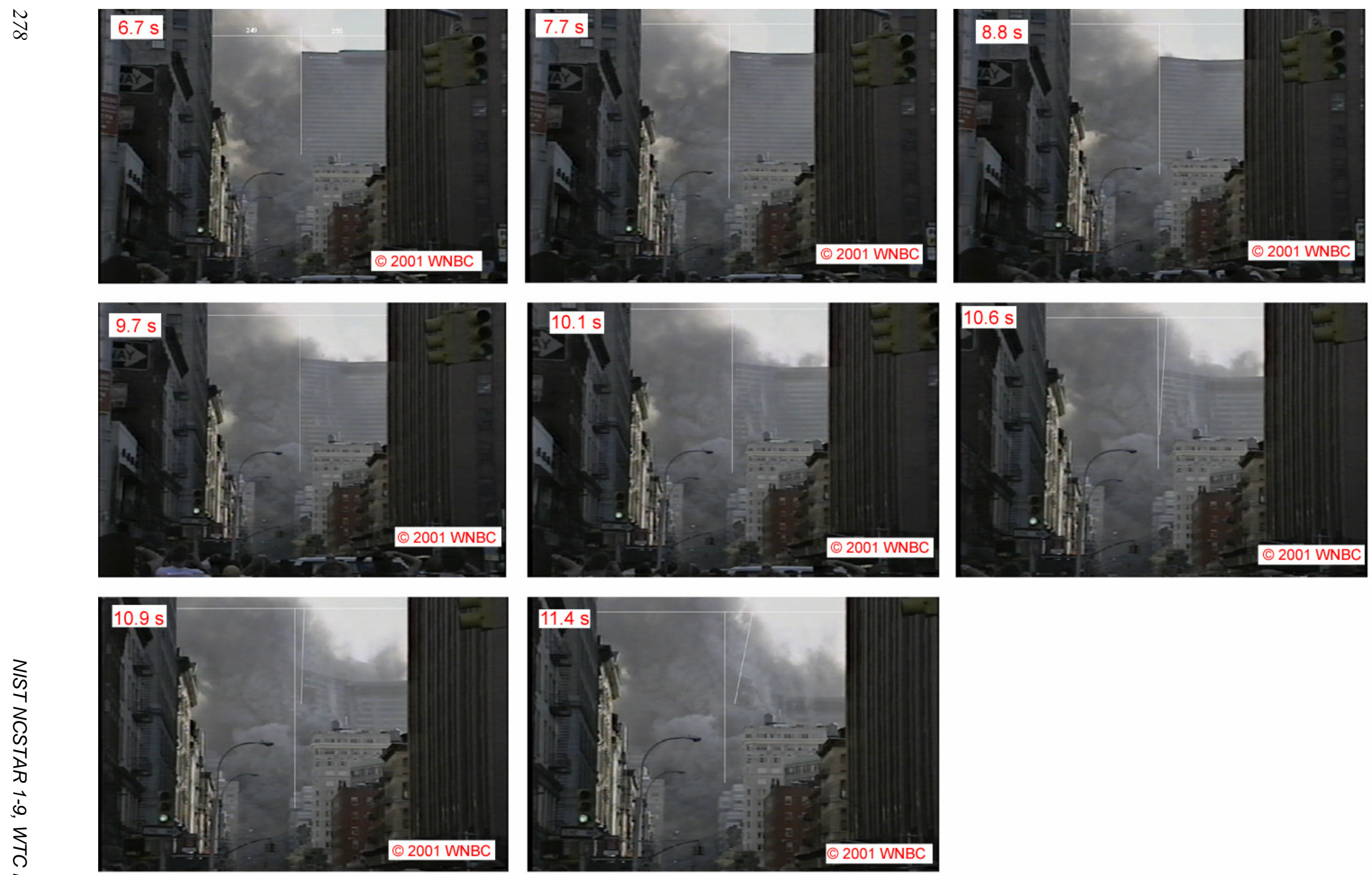

Figure 5-204. Images from the Camera 4 video clip showing relative movement of the northeast edge of WTC 7 during its global collapse. 

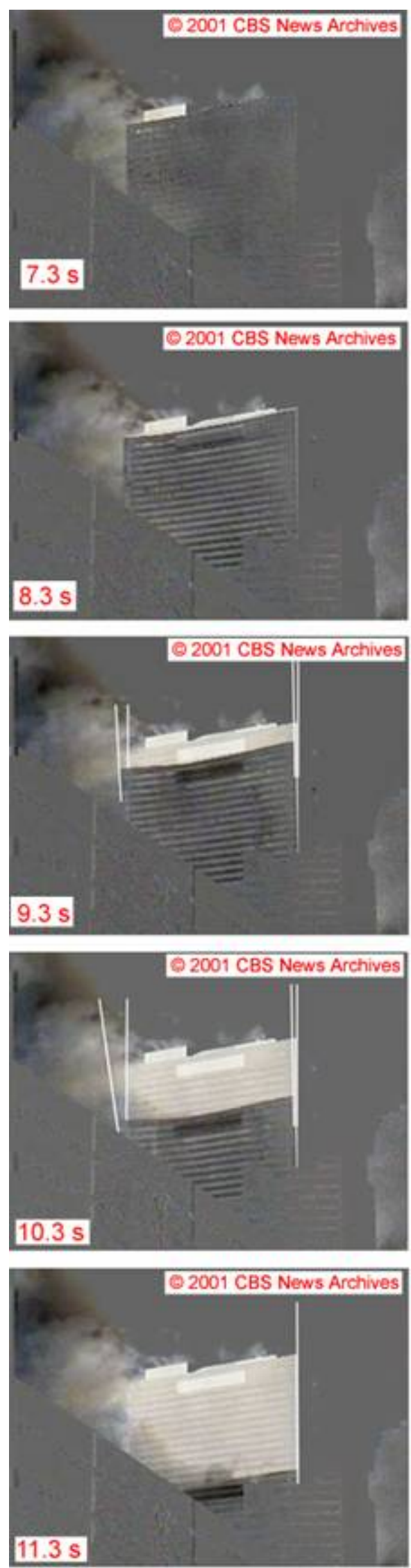
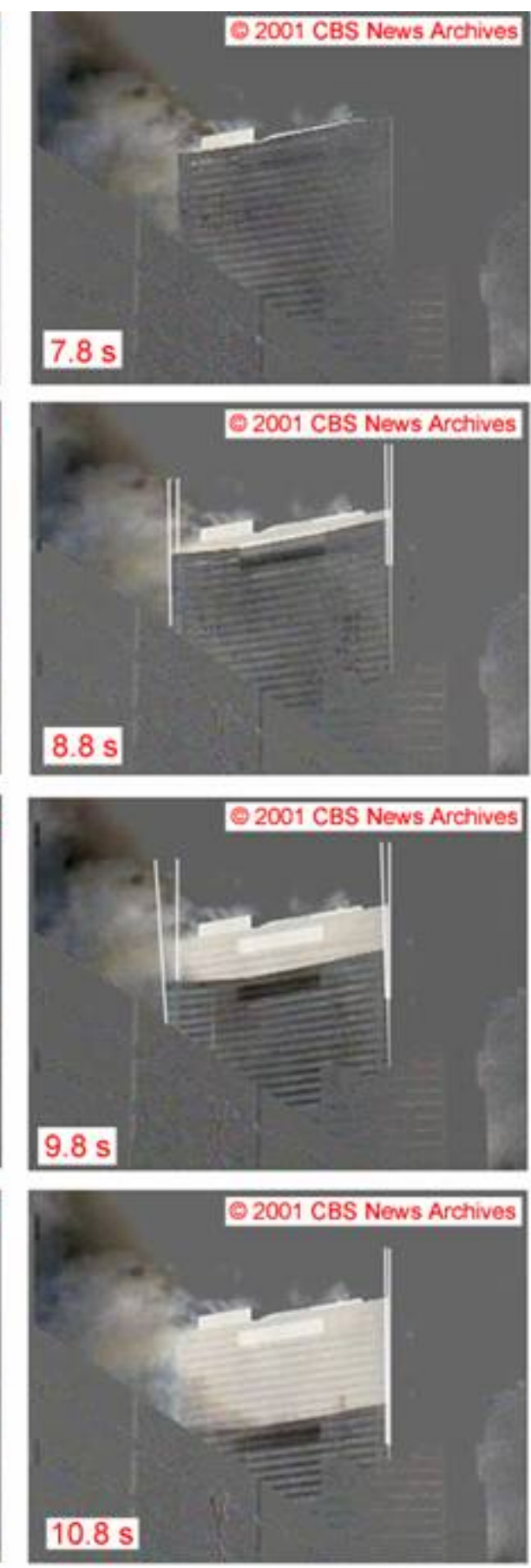

Figure 5-205.

Difference images from the Camera 3 video clip showing the rotation of the northeast edge of WTC 7 during the global collapse. Times are referenced to the time the east penthouse began to descend into the building. 
The extent of the northeast edge motion was estimated using the Camera 3 video frame in Figure 5-206, at which time the top of the building had descended about seven stories. The two red lines on the right trace the west roofline and the southwest edge of WTC 7. The red line at the left is parallel to the west roofline and passes through the top of the northeast corner of the descending roofline. A geometric calculation was performed, involving the angle between these two lines, the dimensions of the building, the distance between the camera and the building, and the viewing angles of the northeast and southwest corners. The calculation led to an estimate that, at this point in the collapse, the top of the northeast corner roofline was displaced $11 \mathrm{~m} \pm 3 \mathrm{~m}$ from its original footprint. In combination with observations from Figure 5-204, it is possible to determine that the motion was primarily due north.

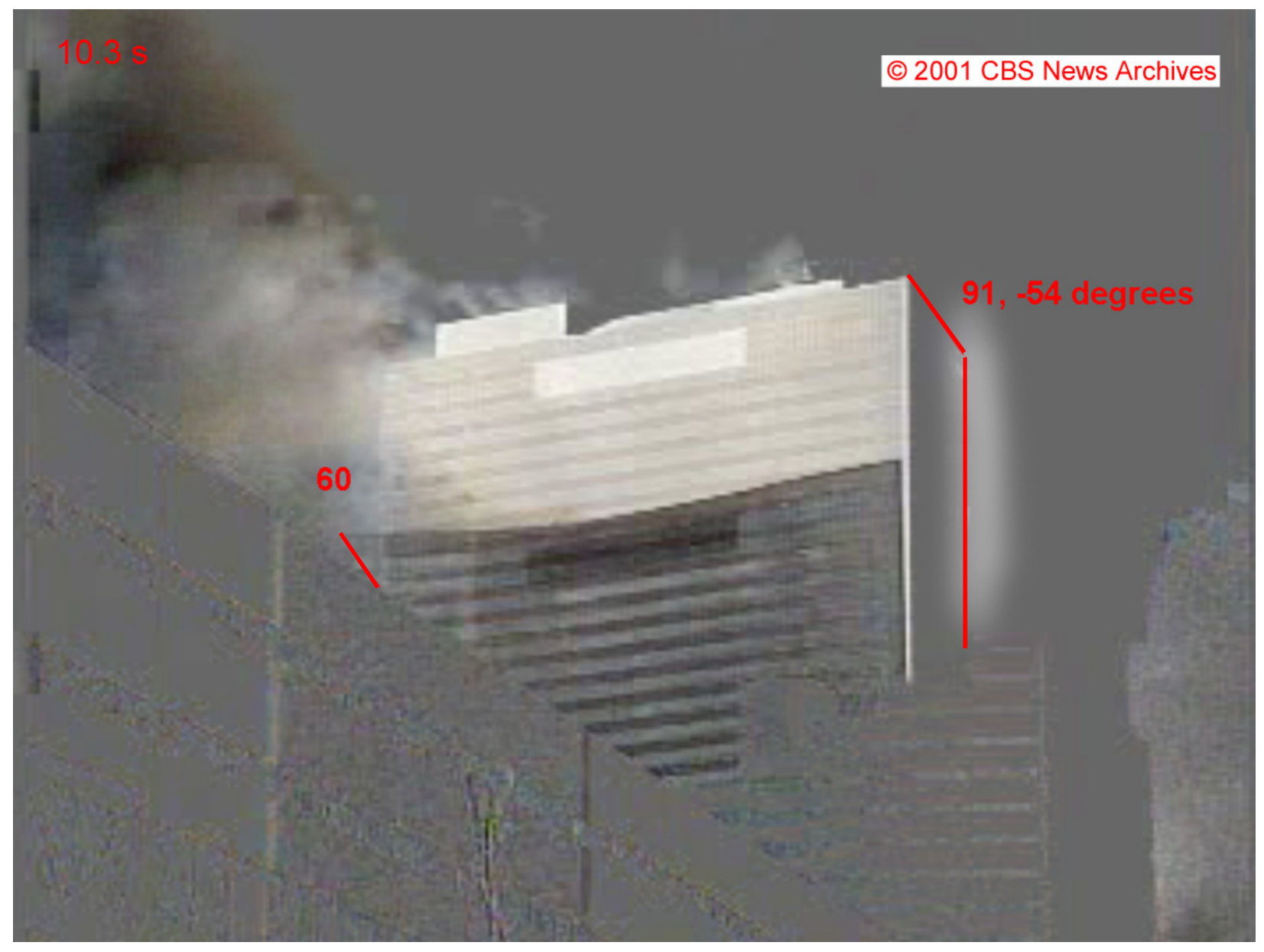

Figure 5-206. Heavily processed difference frame from the camera 3 video, used to estimate the lateral distance the northeast corner of WTC 7 moved from its original footprint during the collapse.

It was recorded $10.3 \mathrm{~s}$ after the east penthouse began to move down. 
The Camera 6 videographer, who shot the clip from which Figure 5-189 was taken, zoomed in on the north face of WTC 7 as it collapsed. Figure 5-207 shows a frame taken from this clip at about the same time ( $\pm 0.2 \mathrm{~s}$ ) that the frames in Figure 5-203 were recorded. In this image, there appears to be both smoke (black) and dust (white) flowing across the north face just above the building in the foreground. Most of the material appears to be dust. It is possible to make out the window damage on the west side of the face between Columns 54 and 55. This damage extends at least as far down as the $22^{\text {nd }}$ floor. Only a few open windows are visible on the east side of the face.

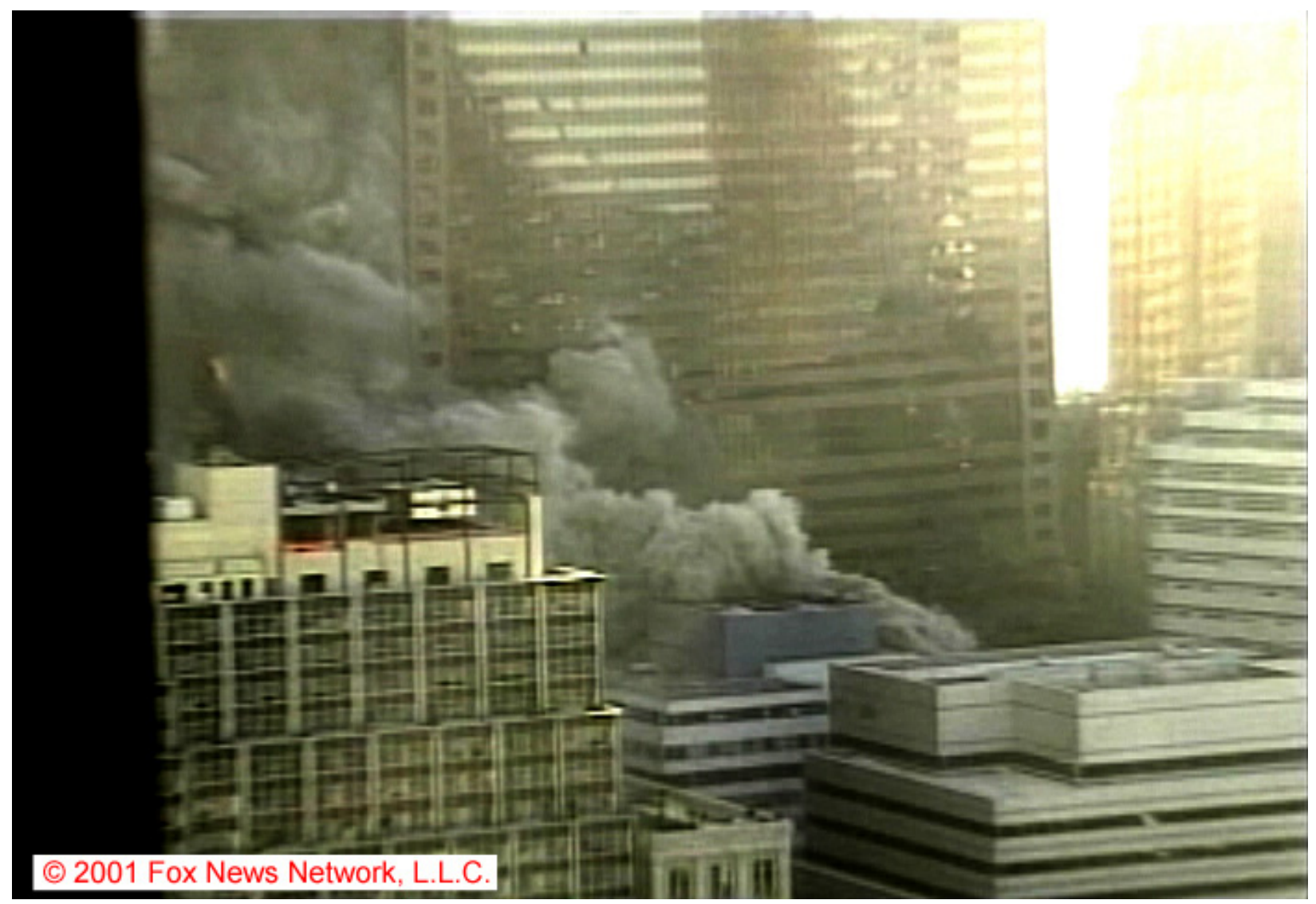

Figure 5-207. Frame from the Camera 6 video clip in Figure 5-189, showing the north face of WTC $79.0 \mathrm{~s} \pm 0.2 \mathrm{~s}$ after the east penthouse began to move downward.

The intensities have been adjusted.

Figure 5-191 and Figure 5-192 showed views of the north face of WTC 7 taken looking up Greenwich Street that were recorded just prior to and just after those shown in Figure 5-203 and Figure 5-207, respectively. The dust cloud is prominent in both images. It appears to extend down close to the ground. Figure 5-192 is the clearer of the two images. The damage on the west side of the north face between Columns 54 and 55 is discernable along with open windows on the east face. Streams of dust have appeared from several windows near Column 45.

During the period between $9.0 \mathrm{~s}$ and $10.0 \mathrm{~s}$ after the east penthouse began to descend, the north face fell downward slightly more than four stories. Camera 2 and Camera 3 views, recorded 10.0 s following the start of downward movement for the east penthouse, are shown in Figure 5-208. The West Street view shows a large amount of dust flowing from open windows on the face. This dust first appeared around 
$9.2 \mathrm{~s}$ after the east penthouse started moving. The kink near Column 47 is still prominent. The dust plume being forced from the roof opening on the east side of the building is visible. In the distant view, the entire west penthouse has disappeared below the north wall parapet. This took place around $9.3 \mathrm{~s}$. A dust cloud, similar to that being ejected from the opening in the roof on the east side, has begun to form just to the west of the center of the north face. This suggests that the roof has also opened at this location.
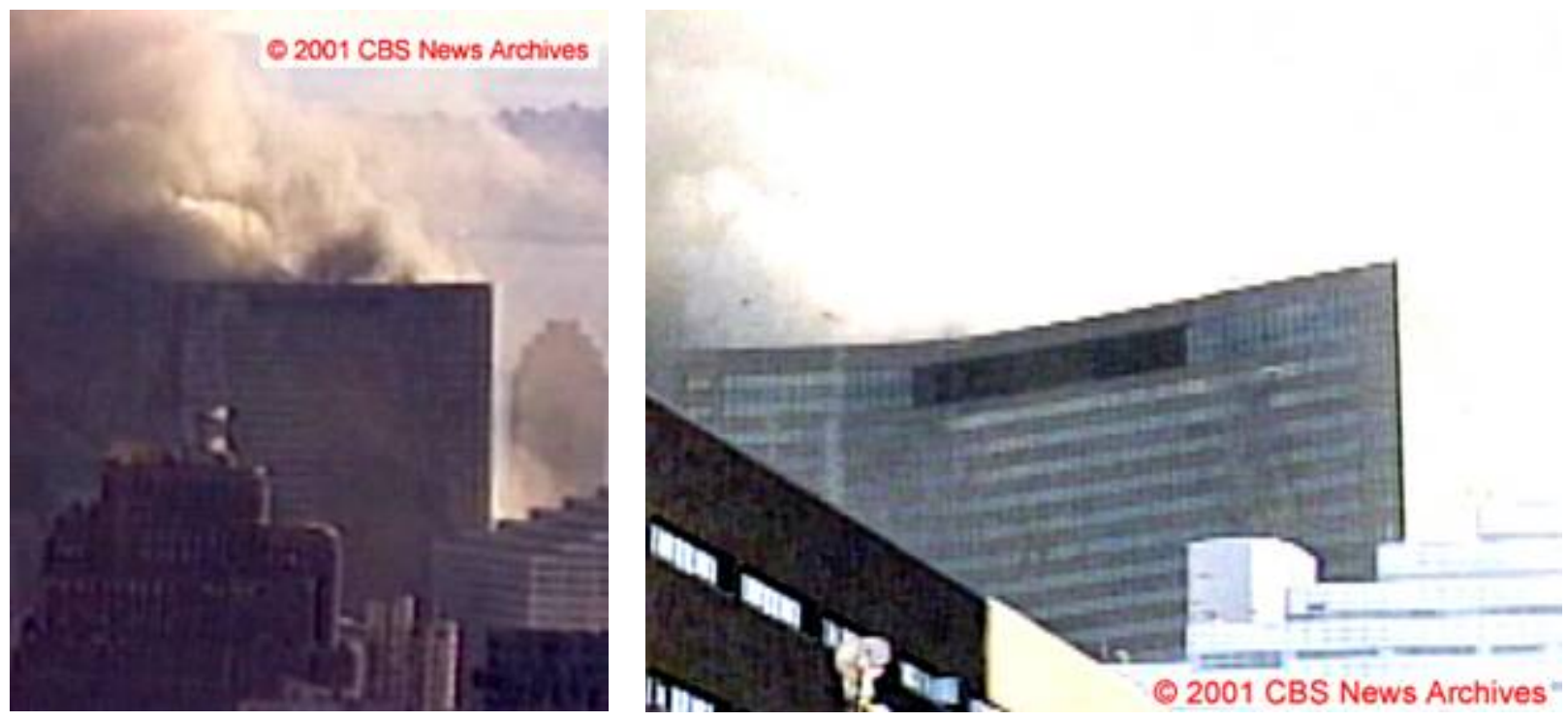

Figure 5-208. Cropped frames from the Camera 2 video clip in Figure 5-185 and the Camera 3 video clip in Figure 5-186, showing the north face of WTC 7 $10.0 \mathrm{~s} \pm 0.1 \mathrm{~s}$ after the east penthouse began to move downward.

The intensities have been adjusted.

Figure 5-209 shows a frame from Camera 6 of the north face of WTC 7 recorded $10.0 \mathrm{~s}$ after the east penthouse began to collapse. Dust trails are flowing from the open windows on the east and west sides of the building. Numerous windows are open near the center of the face, but no dust flows are evident from these windows. The kink in the face near Column 47 observed near the top of building in Figure 5-208 appears to extend at least as far down as the mechanical floors on the $22^{\text {nd }}$ and $23^{\text {rd }}$ floors.

Figure 5-210 is a frame from the Camera 9 video showing the collapse at the same time looking up Greenwich Street. The appearance of the collapsing north face is consistent with the descriptions above. The appearance of the dust cloud at the base of the building has not changed markedly from that seen in Figure 5-192.

During the next second, the north face of WTC 7 moved downward nearly 6 stories. Figure 5-211 shows the Camera 2 distant and Camera 3 West Street views at $11.0 \mathrm{~s}$ following the initial downward movement of the east penthouse. WTC 7 is just about to pass out of sight behind the foreground building in the West Street view. While dust clouds continue to pass over the face, it is remarkable how many windows are still intact at the top of the building. The amount of dust pouring from the open windows of the falling north face is more evident in the distant view. It is also clear that a large amount of dust has been ejected through the roof at the two locations on the east side and near the center. 


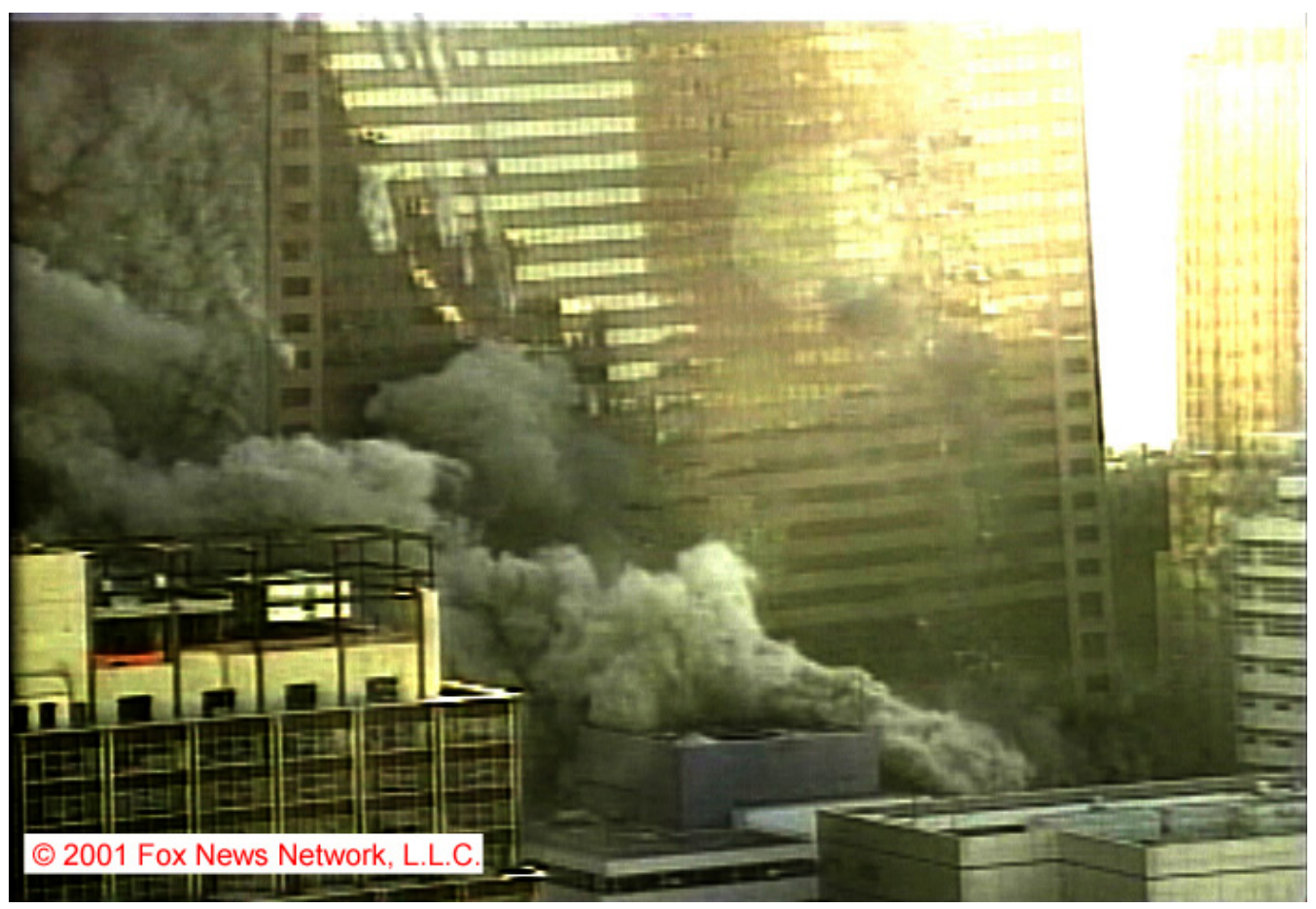

Figure 5-209. Frame from the Camera 6 video clip in Figure 5-189, showing the north face of WTC $710.0 \mathrm{~s} \pm 0.2 \mathrm{~s}$ after the east penthouse began to descend. The intensities have been adjusted.

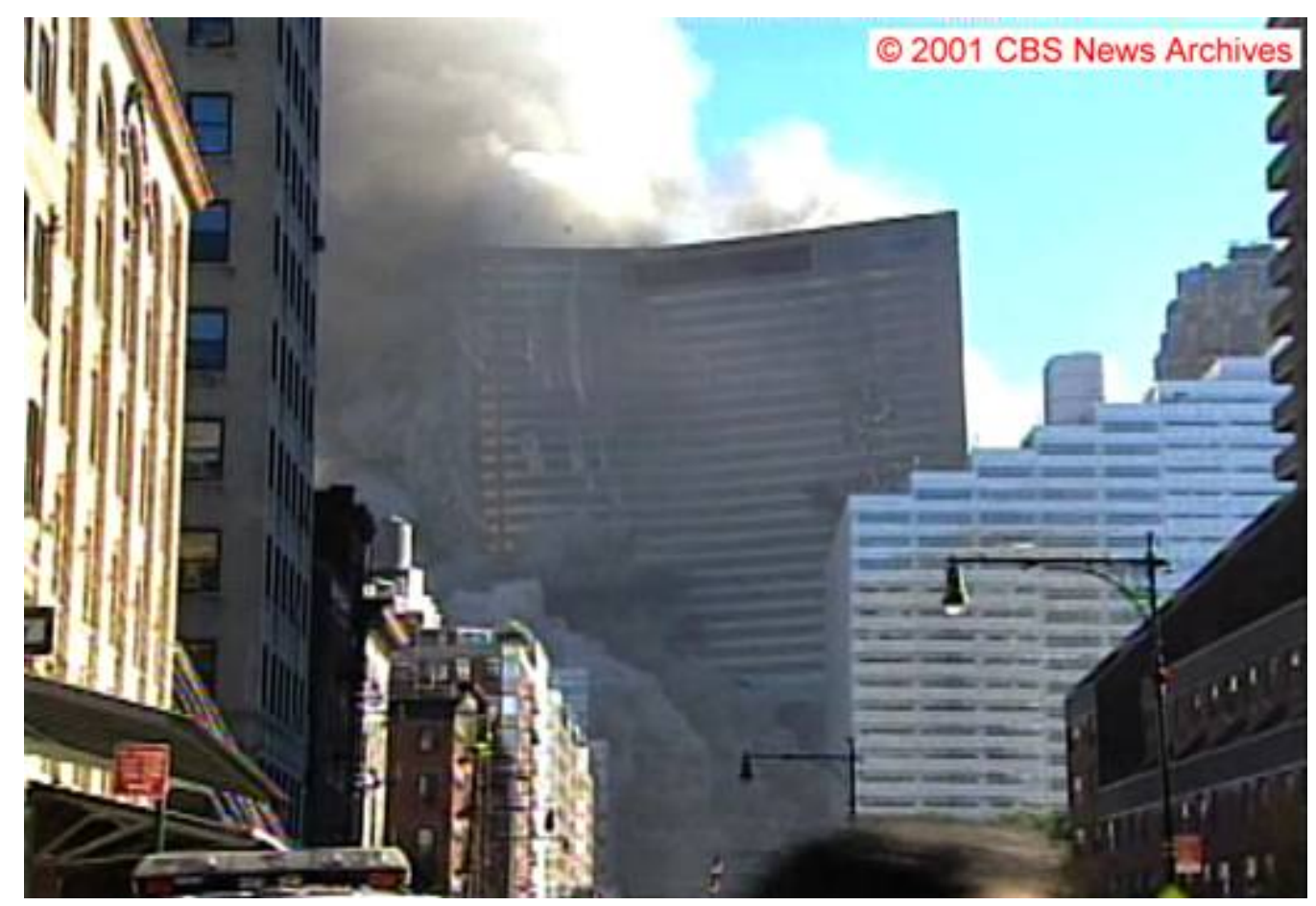

Figure 5-210. Frame from the Camera 9 video clip in Figure 5-192, showing the north face of WTC $710.0 \mathrm{~s} \pm 0.2 \mathrm{~s}$ after the east penthouse began to move downward. The intensities have been adjusted. 

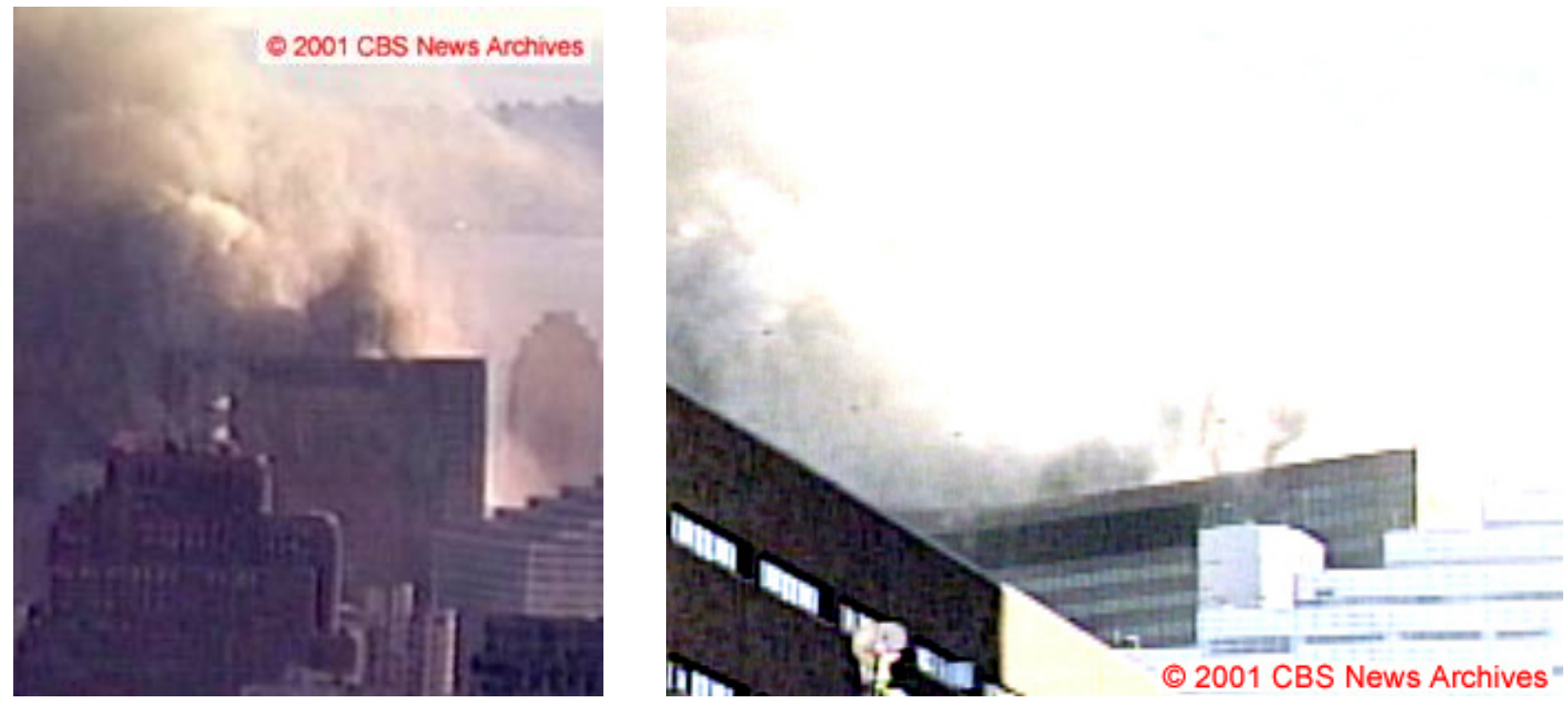

Figure 5-211. Cropped frames from the Camera 2 video clip in Figure 5-185 and the Camera 3 video clip in Figure 5-186, showing the north face of WTC 7 $11.0 \mathrm{~s} \pm 0.1 \mathrm{~s}$ after the east penthouse began to move downward.

The intensities have been adjusted.

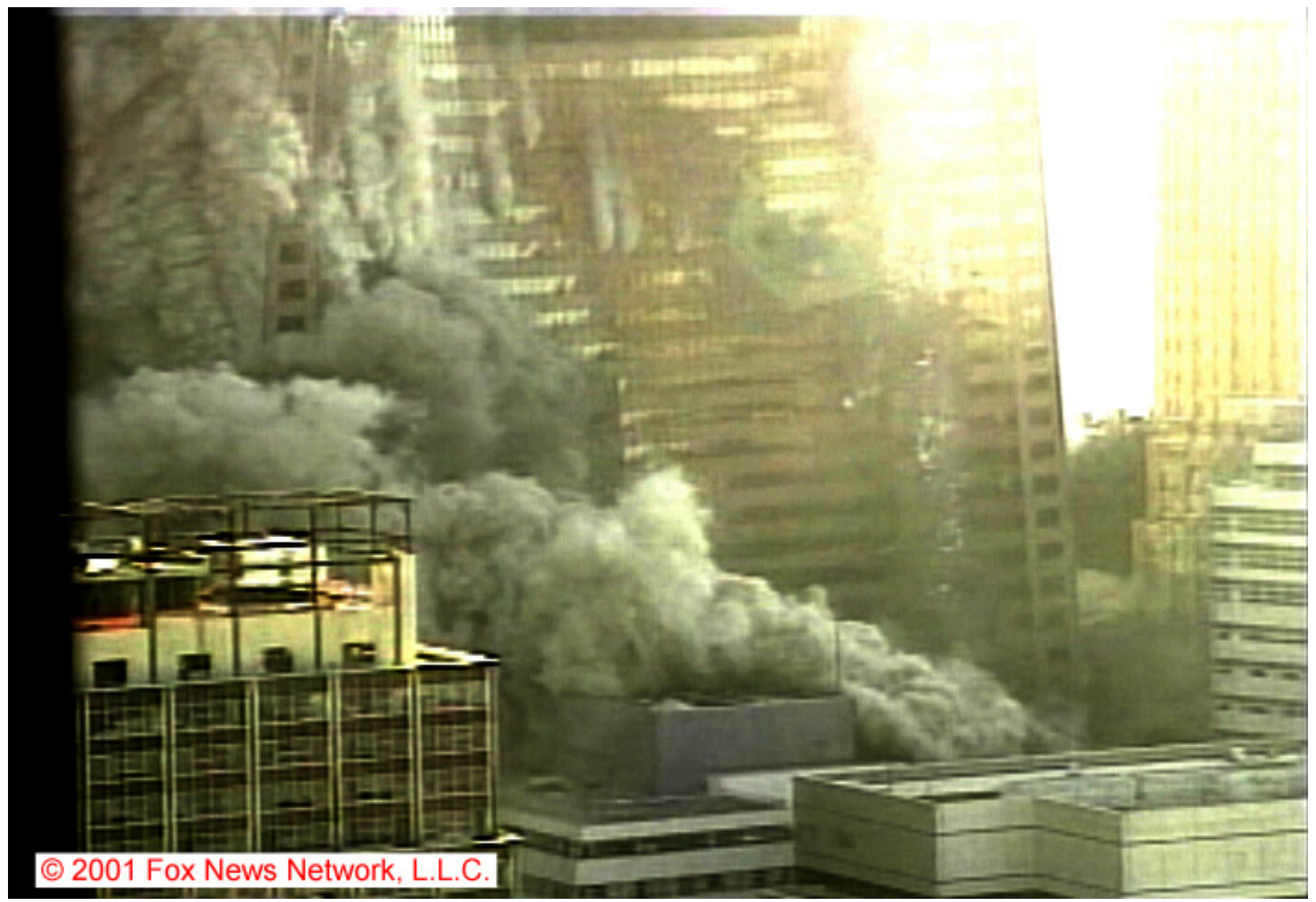

Figure 5-212. Frame from the Camera 6 video clip in Figure 5-189, showing the north face of WTC $711.0 \mathrm{~s} \pm 0.2 \mathrm{~s}$ after the east penthouse began to move downward. The intensities have been adjusted. 
Figure 5-212 and Figure 5-213 show frames from the northeast (Camera 6) and Greenwich Street (Camera 9) video clips for the same time as the images in Figure 5-211. In both frames, the distortions of the falling building stand out. The kink near Column 47 is prominent in Figure 5-213, while in Figure 5212, a strong distortion is present near the east edge of the north face. Both frames also show the large amount of dust being pushed out of open windows higher up in the building and the huge dust clouds forming near its base. In Figure 5-212, large amounts of dust have been pushed from near the base of the building on the east, north, and west sides. A prominent feature in Figure 5-213 is the large pulses of dust flowing upward through the roof on the east side and near the center.

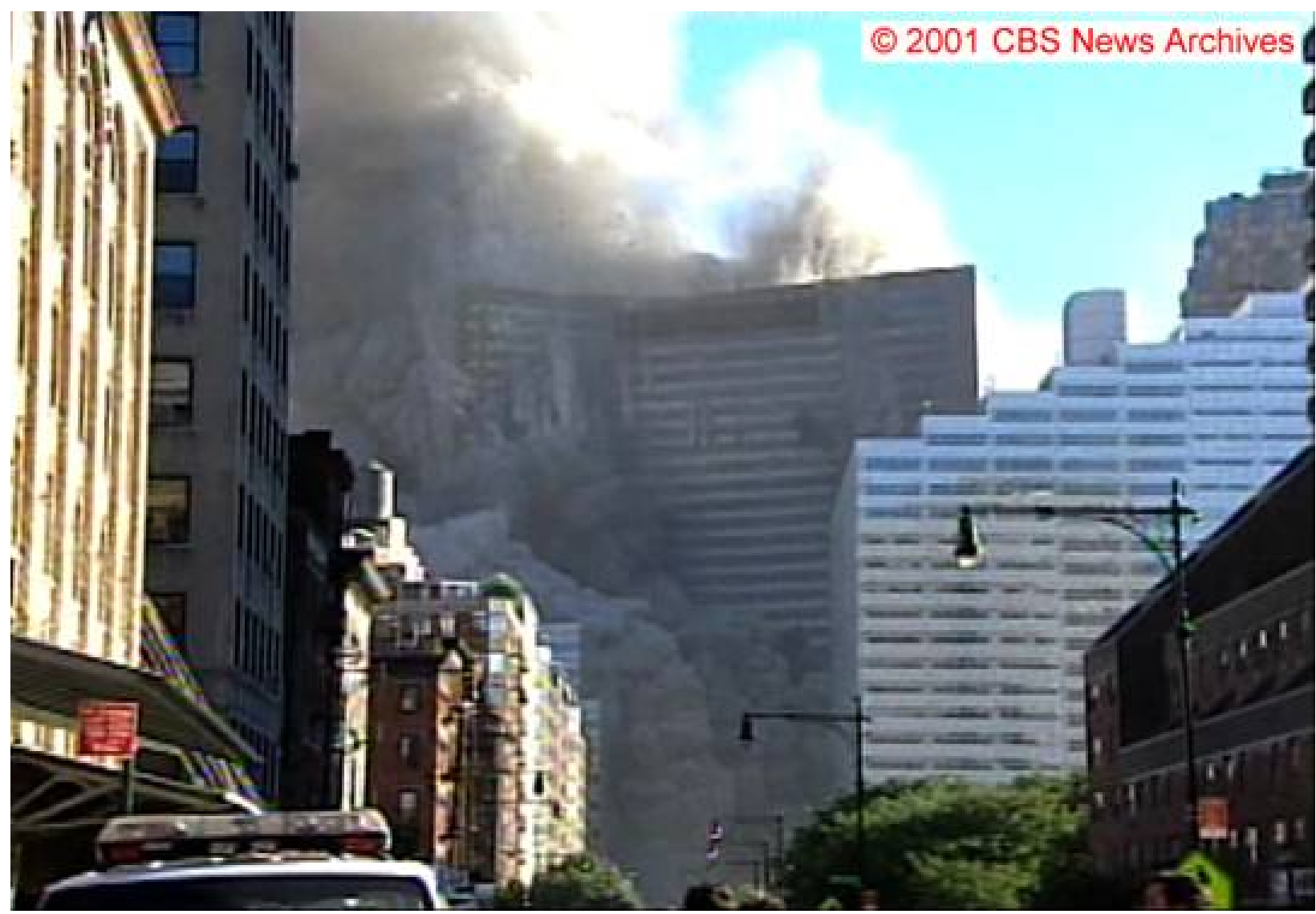

Figure 5-213. Frame from the Camera 9 video clip in Figure 5-192 shows the north face of WTC $711.0 \mathrm{~s} \pm 0.2 \mathrm{~s}$ after the east penthouse began to move downward.

The intensities have been adjusted.

Between $11 \mathrm{~s}$ and $12 \mathrm{~s}$ following the initial movement of the east penthouse, WTC 7 fell an additional eight stories. By 12 s, there is clear evidence that the collapsing building is breaking apart. Figure 5-214 shows the northeast Camera 6 view of the north face $12 \mathrm{~s}$ after the east penthouse began to move. Several sections of the parapet on the west side of the building are missing and light is streaming through the openings. The building appears to be breaking apart on the west side of the north face. A large amount of dust and debris is coming from this area. The Camera 9 view of the building from Greenwich Street at the same time is shown in Figure 5-215. A section of the northeast corner of WTC 7 (indicated by an arrow) is visible well above the remaining roofline for the building. As suggested by the image in Figure 5-212, this corner apparently separated from the remainder of the building and collapsed at a different rate. 
Figure 5-216 shows a frame taken from the Camera 6 video shot looking at WTC 7 from the northeast. It was recorded $13 \mathrm{~s}$ following the initiation of east penthouse movement. The remainder of WTC 7 is just about to disappear into the dust cloud. Shortly after most of the building disappeared into the dust cloud, a piece of debris several stories tall appeared from the east side (where it had been hidden by the dust cloud) and fell toward the center of the building. This section of WTC 7 may have come from the northeast corner which had earlier separated from the remainder of the building.

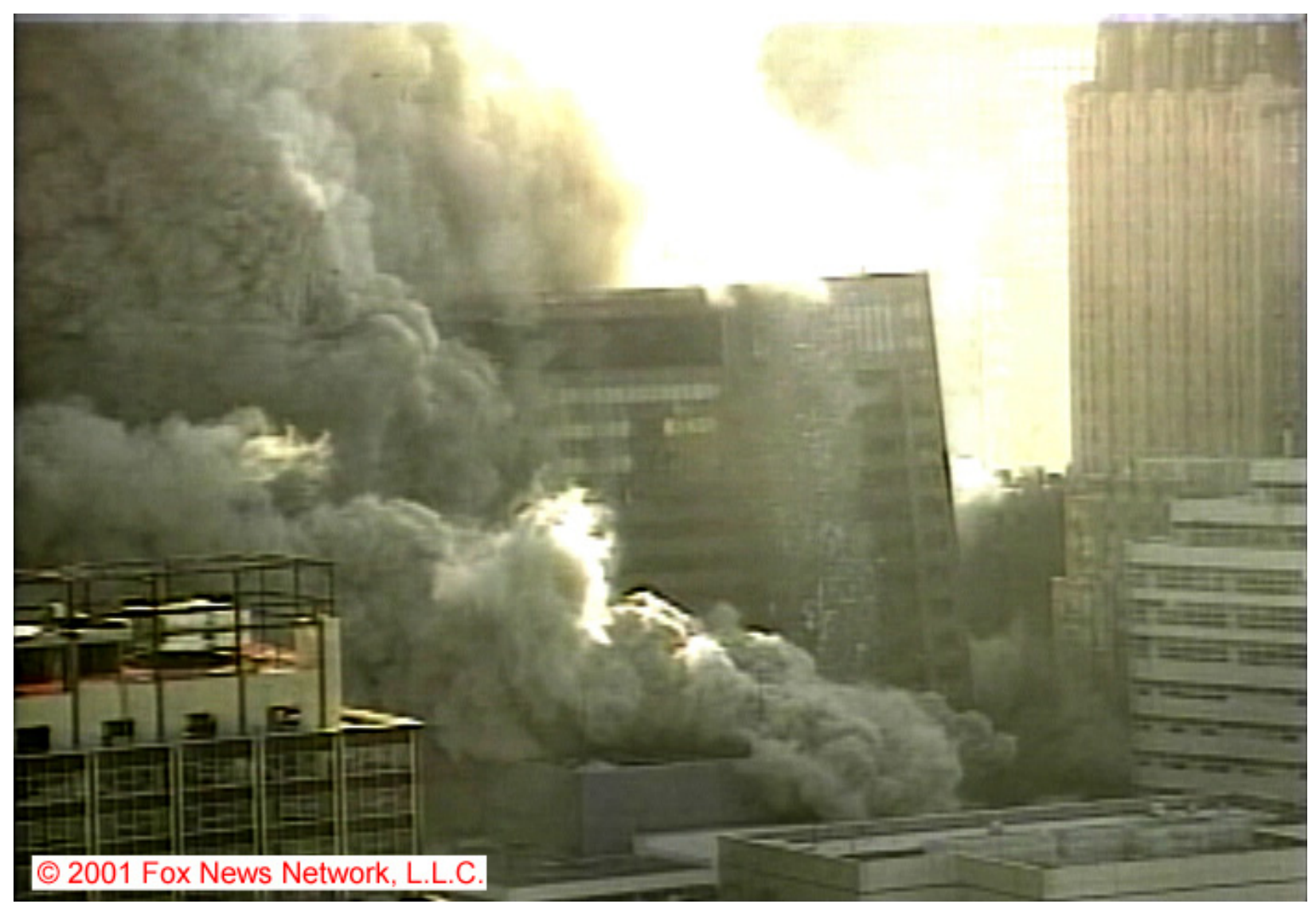

Figure 5-214. Frame from the Camera 6 video clip in Figure 5-189, showing the north face of WTC $712.0 \mathrm{~s} \pm 0.2 \mathrm{~s}$ after the east penthouse began to move downward. The intensities have been adjusted.

When WTC 7 collapsed, the dust that was generated mixed with air to create a dense mixture that flowed away from the site. The resulting dust- and debris-laden flow spread over many blocks of lower Manhattan. Figure 5-217 and Figure 5-218 show two views of the dust cloud as it spread northward along Greenwich Street after being channeled between the taller buildings at 123 Barclay Street on the west side and 30 West Broadway and 70 Murray Street on the east side. 


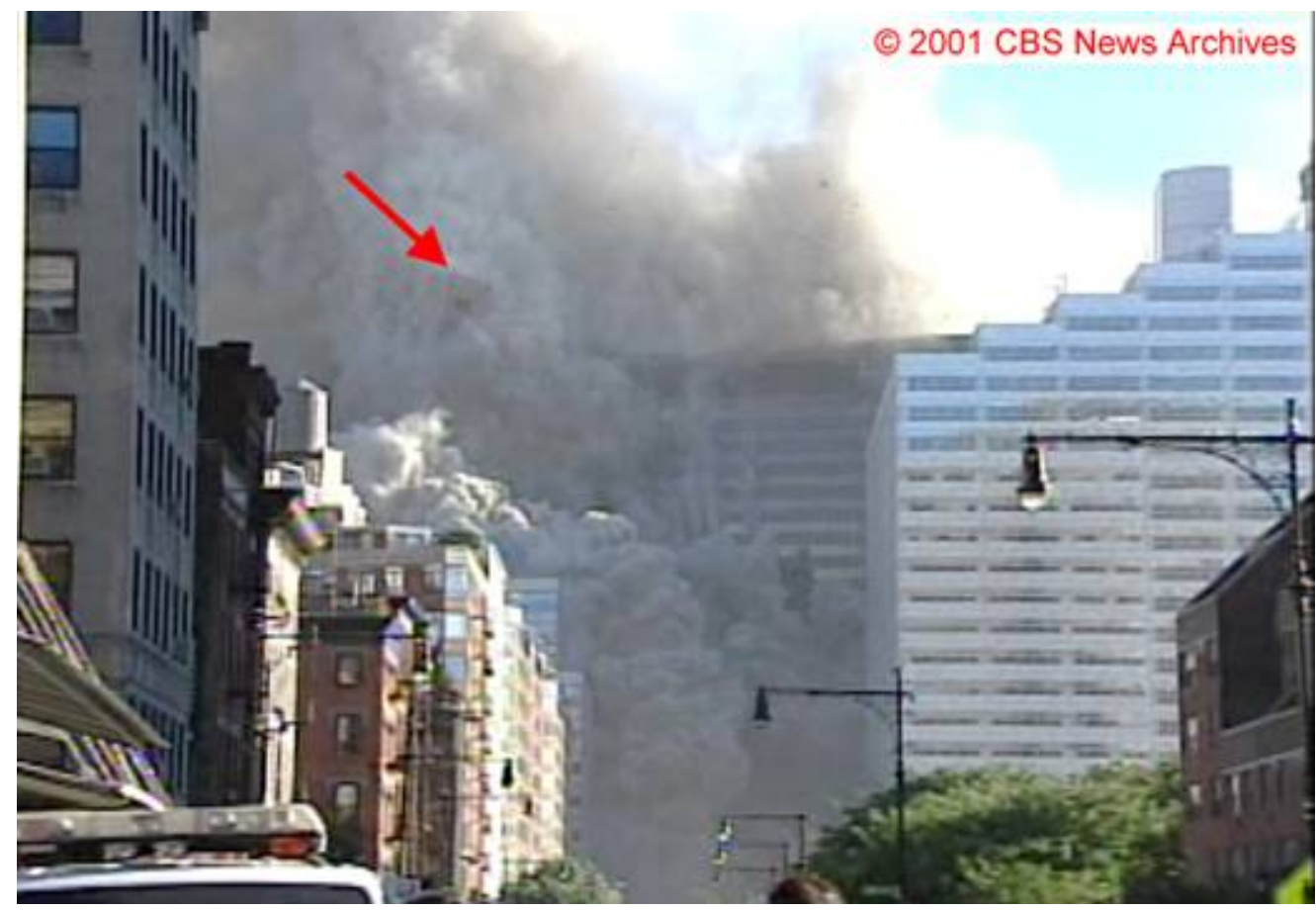

Figure 5-215. Frame from the Camera 9 video clip in Figure 5-192, showing the north face of WTC $712.0 \mathrm{~s} \pm 0.2 \mathrm{~s}$ after the east penthouse began to move downward. The arrow indicates a section of the northeast corner of the building that has broken away from the main section of the building. The intensities have been adjusted.

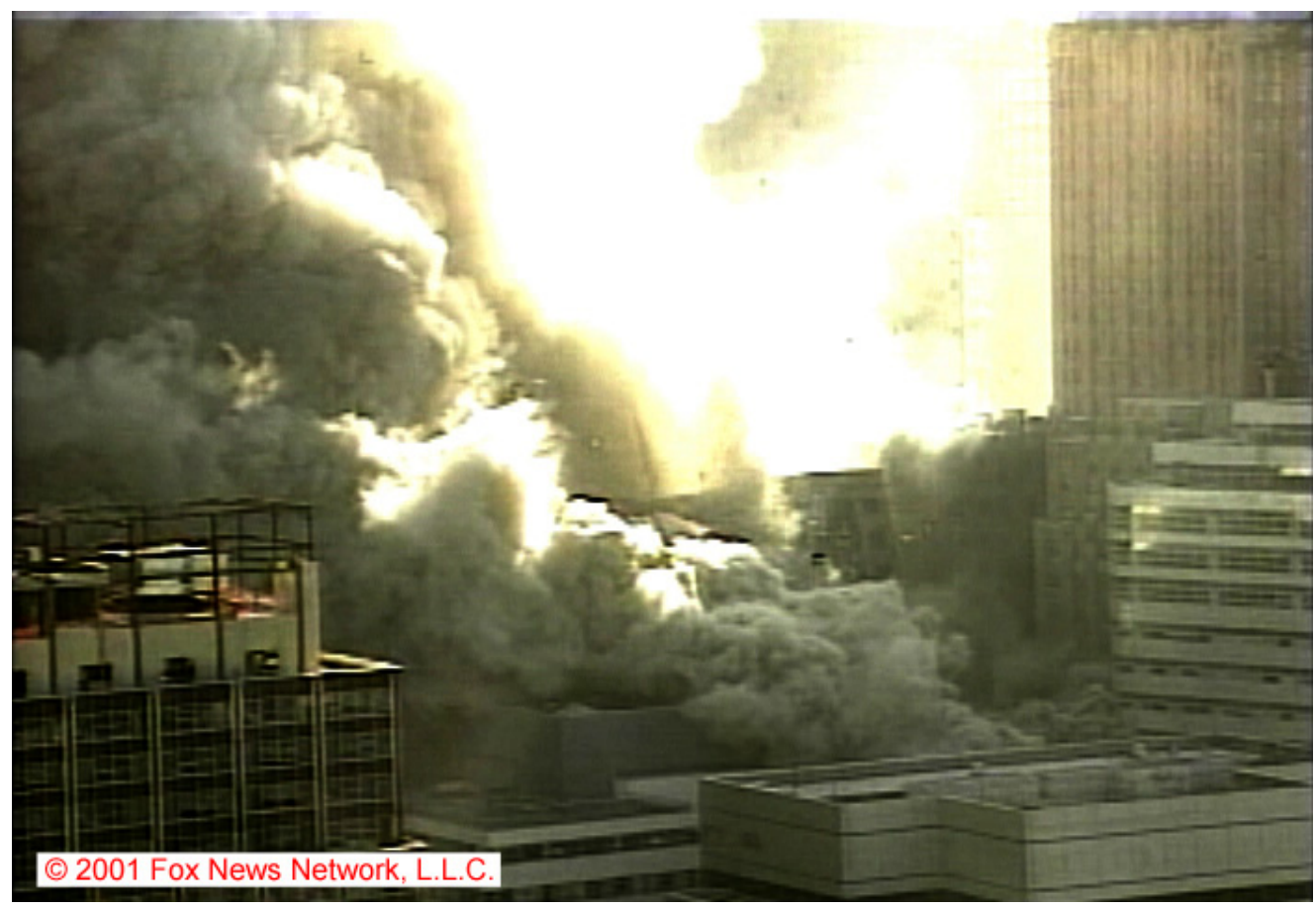

Figure 5-216. Frame from the Camera 6 video clip in Figure 5-189, showing the north face of WTC $713.0 \mathrm{~s} \pm 0.2 \mathrm{~s}$ after the east penthouse began to move downward.

The intensities have been adjusted. 


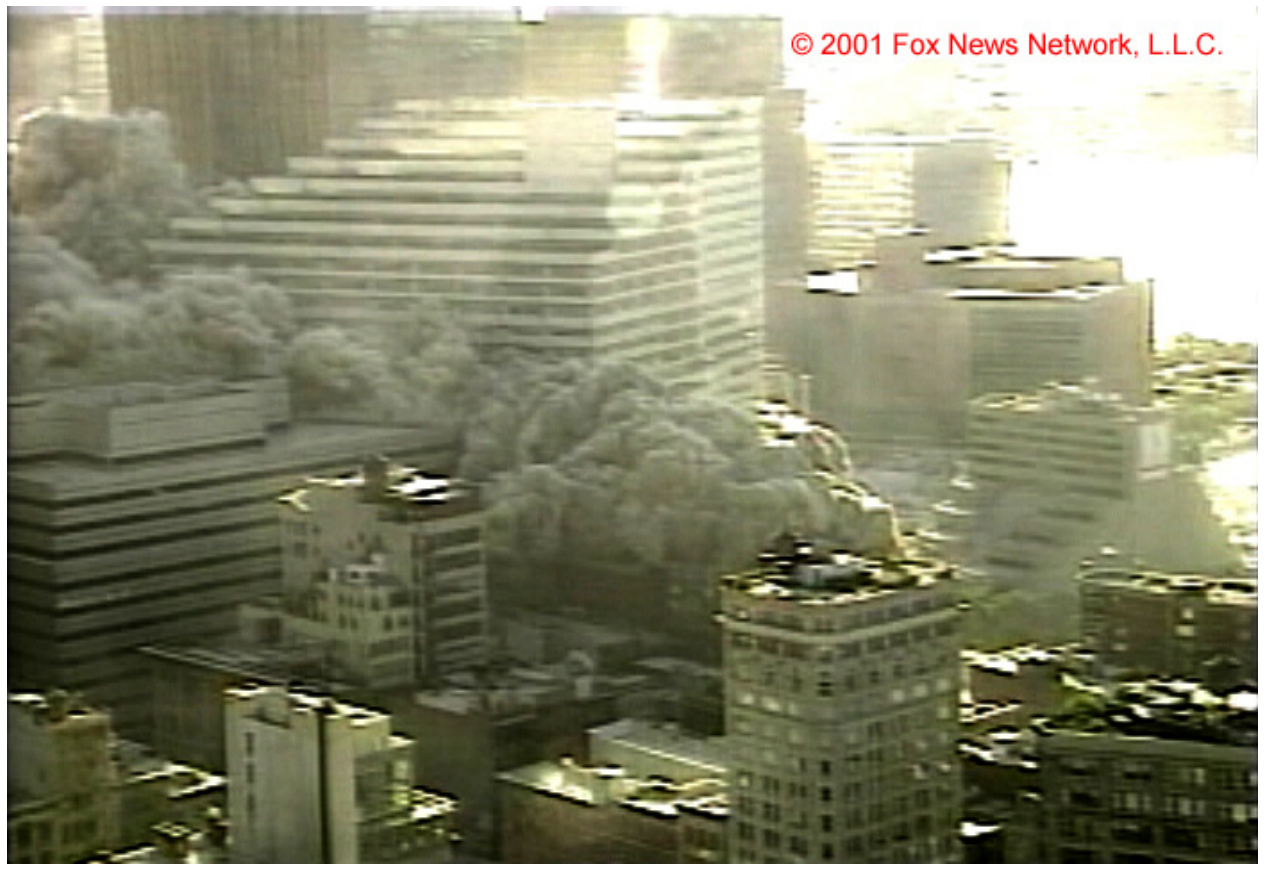

Figure 5-217. Frame from the Camera 6 video clip in Figure 5-189, showing the dust-laden flow generated by the collapse of WTC 7, $22.0 \mathrm{~s} \pm 0.2 \mathrm{~s}$ after the east penthouse began to move downward.

The intensities have been adjusted.

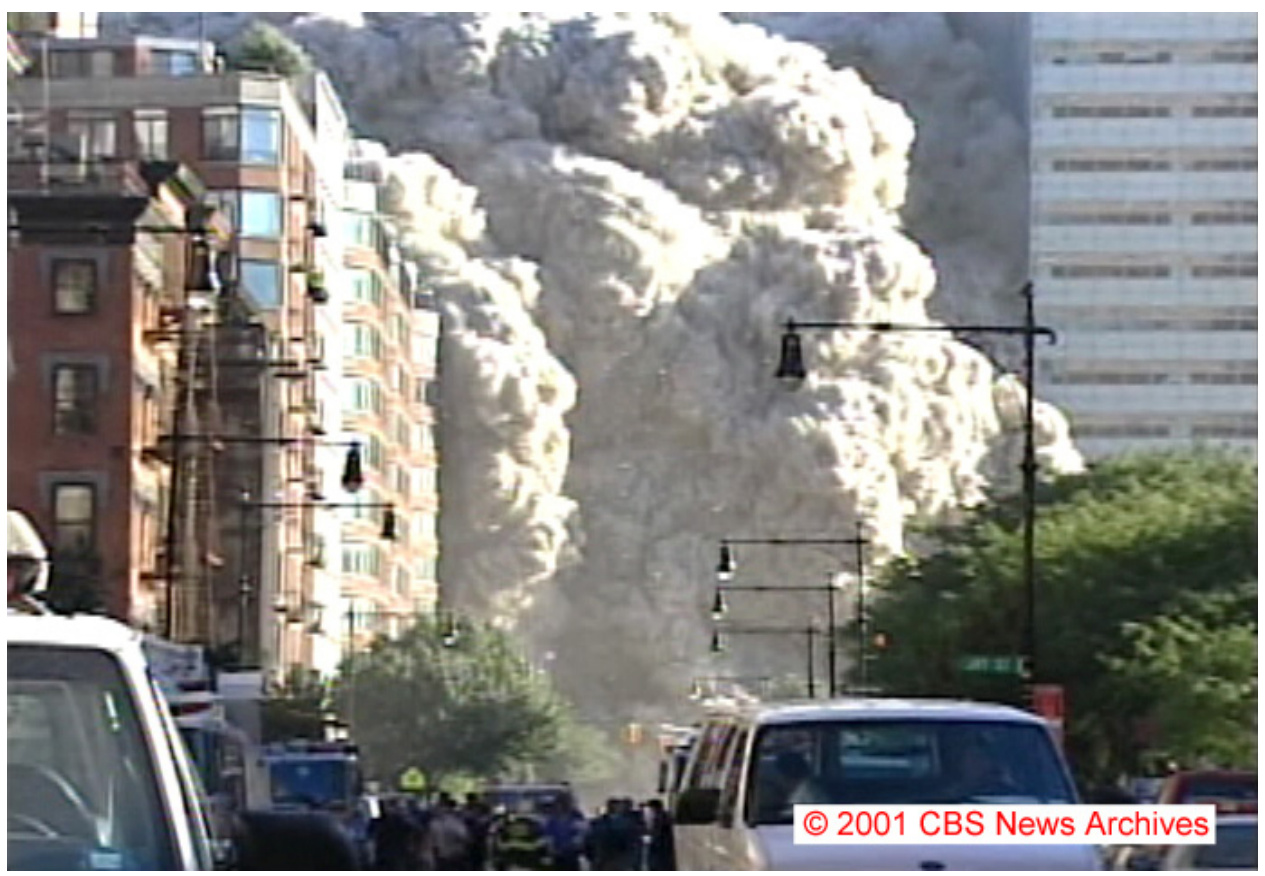

Figure 5-218. Frame from the Camera 9 video clip in Figure 5-192, showing the dust-laden flow created by the collapse of WTC 7, $22.0 \mathrm{~s} \pm 0.2 \mathrm{~s}$ after the east penthouse began to move downward.

The intensities have been adjusted. 


\subsubsection{Audio Characteristics Based on Video Soundtracks}

Three videos in the database included soundtracks that were used to investigate the audio signature associated with the period immediately prior to and during the collapse of WTC 7. All of these cameras were located at street level at least $640 \mathrm{~m}(2100 \mathrm{ft}) \mathrm{from}$ the building. Also, there were numerous other buildings between the cameras and WTC 7 .

The most usable soundtrack was recorded by Camera 3, with its West Street location. This video ran for many minutes prior to and during the collapse. Even though sound was recorded by the camera, no interviews or commentary were recorded, and the microphone tended to pick up low level street sounds, such as sirens, traffic, and distant conversations. Occasionally, the camera operators located nearby were recorded at a much louder level. Since the collapse was recorded on the video, it was possible to coordinate the sound recording with the actual WTC 7 collapse.

A careful review of the audio clip did not reveal any sounds that could be associated with WTC 7 until the global collapse began. A low-level audio analysis was performed by creating a video showing the waveform for the audio signal using Aftereffects software. This video also did not reveal any features that could be associated with the collapse until after the global collapse began. In the analysis, the roughly 2 s delay in sound transmission between WTC 7 and the camera was accounted for. The amplitude of the sound signal increased while the global collapse was taking place, but there were no loud, explosive sounds when the collapse began.

The response of the camera operators provides another indication of the audio environment. Even though the east penthouse began to descend into the building $6.9 \mathrm{~s}$ prior to initiation of global collapse, there was no verbal response from the camera operators until $2.5 \mathrm{~s}$ after the global collapse began, when a loud shout of "whoa, whoa, whoa, whoa" was heard. There is no evidence that the operators heard something that attracted their attention prior to this time.

At the same time the Camera 3 video was being shot, a recorded street interview was being conducted a short distance away on West Street. In this video clip of the interview, WTC 7 is visible in the upper left hand corner of the frame. Even though the east penthouse can be seen disappearing into the building, neither the camera operator, interviewer, nor interviewee responded in any way until just over $3 \mathrm{~s}$ after the global collapse began. Again, there was no indication that sounds loud enough to attract attention or cause alarm were heard by people at the interview location prior to global collapse initiation.

The third video clip reviewed was a second street interview being conducted at West Broadway and Leonard Street. This camera was located near the Camera 4 location, roughly $650 \mathrm{~m}$ (2100 ft) from WTC 7. This clip does not show WTC 7 collapsing, but, by comparing events in the clip with those seen in the Camera 4 clip, it was possible to place the two videos on a common timeline. Review of the interview clip showed that people in the video responded to the WTC 7 collapse $1.4 \mathrm{~s}$ before the clip from Camera 4 started, or $1.3 \mathrm{~s}$ after the east penthouse began to descend into the building. Allowing $2 \mathrm{~s}$ for sound to reach the camera location, this is very close to the time that the east penthouse began to descend. People at this location were able to hear the collapse of the east penthouse, while observers on West Street did not hear loud noises until the global collapse started.

In the interview clip, it is possible to see dust and/or smoke being pushed across West Broadway, starting around $3 \mathrm{~s}$ before the East Penthouse began to descend. This suggests that structural changes inside 
WTC 7 were occurring several seconds prior to the time when the east penthouse began to descend. Note that this is consistent with the seismic data discussed in Appendix B and the analysis of building motions discussed in Appendix C.

\subsubsection{Summary}

Most of the details concerning the collapse of WTC 7 are based on visual observations of the upper portions of the building. The timeline for the major events observed during the collapse shown in Table 5-3 was generated using the discussion and visual imagery presented above. Note that all times are relative to the initial downward motion of the east penthouse on the roof of WTC 7.

Table 5-3. Timeline for major WTC 7 collapse observations

\begin{tabular}{|c|c|}
\hline Time(s) & Observations \\
\hline-3 & $\begin{array}{l}\text { Dust and/or smoke are observed being pushed across West Broadway from the east side of the } \\
\text { building. }\end{array}$ \\
\hline 0 & $\begin{array}{l}\text { The east edge of the east penthouse starts to move downward; the east penthouse folds roughly } 40 \\
\text { percent of the way across from the east edge; the two sections of the east penthouse appear to rotate } \\
\text { into the roof, with the east section disappearing first. }\end{array}$ \\
\hline 0.6 & $\begin{array}{l}\text { Glass breaks in windows 40-44B and 40-44D; additional windows open on this floor over the next } \\
\text { couple of seconds. }\end{array}$ \\
\hline 1.3 & $\begin{array}{l}\text { The northeast corner of the east penthouse disappears from view; evidence suggests that the east } \\
\text { section of the east penthouse had broken into two additional pieces along an east-west line. }\end{array}$ \\
\hline 1.6 & $\begin{array}{l}\text { The southern part of the eastern section of the east penthouse disappears from view, appearing to } \\
\text { rotate into roof about an east-west line. }\end{array}$ \\
\hline 1.9 & $\begin{array}{l}\text { A small section at the east end of the north screenwall detaches and falls away; it may have fallen } \\
\text { through the opening in the roof created by the descending east penthouse. }\end{array}$ \\
\hline 2.0 & $\begin{array}{l}\text { The western section of the east penthouse disappears from view; it appears to rotate into the roof } \\
\text { about a north-south line; a tear-drop shaped light variation covering several floors on the building } \\
\text { façade begins to propagate downward on the north face; a bright area in the windows on the east side } \\
\text { of the } 46^{\text {th }} \text { and } 47^{\text {th }} \text { floors is attributed to sunlight shining through the open roof. }\end{array}$ \\
\hline 2.0 & Additional windows start to open between Columns 43 and 45 on the $40^{\text {th }}$ to $45^{\text {th }}$ floors. \\
\hline 3.4 & A small piece of debris falls away from an area at the eastern end of the screenwalls. \\
\hline 3.8 & $\begin{array}{l}\text { Earliest view of a small portion of the area at the base of WTC } 7 \text { indicates that a dust cloud has } \\
\text { already formed. }\end{array}$ \\
\hline$\approx 5$ & The tear drop shaped light variation on the north façade moves out of sight near the $33^{\text {rd }}$ floor. \\
\hline 6.9 & $\begin{array}{l}\text { The beginning of the global collapse of WTC } 7 \text { was detected on the north face; the roofline below the } \\
\text { east penthouse location and the eastern end of the screenwall start dropping simultaneously; the } \\
\text { eastern end of the north wall rotates northward and a kink develops near Column } 47 \text {. }\end{array}$ \\
\hline 8.0 & $\begin{array}{l}\text { Windows open over multiple floors on the west side near Column 55; the amount of damage grows } \\
\text { rapidly; dust flows from open windows }\end{array}$ \\
\hline 8.3 & A small object, likely part of the south wall, falls away from the east end of the screenwalls. \\
\hline 8.5 & The east end of the screenwall disappears behind the north face parapet. \\
\hline 9.2 & Dust begins to flow from open windows on the east side near the top of the building. \\
\hline 9.3 & The west penthouse disappears from view below the north face parapet. \\
\hline 12.0 & The upper portion of the building breaks up as it collapses. \\
\hline 13.5 & The upper portion of WTC 7 disappears into a dust cloud created by the collapse. \\
\hline
\end{tabular}




\section{$5.8 \quad$ REFERENCES}

Appendix L-Interim Report on WTC 7, in Progress Report on The Federal Building and Fire Safety Investigation of the World Trade Center Disaster, NIST-SP 1000-5, National Institute of Standards and Technology, Gaithersburg, MD, June 2004.

Cantor 1985. Irwin G. Cantor P.C., Structural Engineers, Structural Drawings, 7 World Trade Center.

McAllister, T., ed. 2002. World Trade Center Building Performance Study: Data Collection, Preliminary Observations, and Recommendations. FEMA 403. Federal Emergency Management Agency. Washington, DC, May.

May 2003 Progress Report on the Federal Building and Fire Safety Investigation of the World Trade Center Disaster, NIST Special Publication 1000-3, National Institute of Standards and Technology, Gaithersburg, MD.

Rehm, R. G., W. M. Pitts, H. R. Baum, D. D. Evans, K. Prasad, K. B. McGrattan, G. P. Forney. 2002. Initial Model for Fires in the World Trade Center Towers, Proceedings of the Seventh International Symposium on Fire Safety Science, International Association for Fire Safety Science, pp. 25-40. 
This page intentionally left blank. 


\section{Chapter 6 \\ EMERGENCY RESPONSE}

\subsection{CONTEXT}

Soon after the first aircraft impacted WTC 1 at 8:46:30 a.m., and before the full extent of the disaster unfolded, emergency services in New York City were functioning on the scene. Port Authority Police Department (PAPD) officers were already present performing their law enforcement duties, assisting with the evacuation, and helping the injured. By 8:50 a.m., the Fire Department of the City of New York (FDNY) was operating at the Fire Command Desk in the lobby of WTC 1. New York Police Department (NYPD) helicopters and ground staff reached the scene by 8:52 a.m. ${ }^{1}$ This early deployment is discussed in detail in NIST NCSTAR 1-8.

An additional, critical component of the New York City emergency response system, the New York City Office of Emergency Management (OEM), was located on the $7^{\text {th }}$ and $23^{\text {rd }}$ floors of WTC $7 .^{2}$ The OEM office on the $23^{\text {rd }}$ floor contained the emergency operations post for OEM and was designed to function as the primary command center to help coordinate multi-agency operations at incidents throughout the city ${ }^{2}$ (Sheirer 2004). The OEM office consisted of a communications center and management facilities staffed by OEM personnel, liaison personnel from each of the emergency response departments, and personnel from organizations who provide support to the city's critical infrastructure. The OEM facility also had meeting rooms available for use by the Mayor, senior emergency response personnel, personnel responsible for transportation systems, and personnel who managed other infrastructure critical to city operations.

WTC 7, on the north side of Vesey Street and across from the main WTC complex, was affected by the collapses of the two towers and was included in the total emergency response at the WTC site. This chapter describes the response operations in, near, and relating to WTC 7.

\subsection{DATA GATHERING}

The Investigation Team compiled first person accounts, conducted interviews, reviewed FDNY communications recordings (including radio communications with command posts and personnel), and examined recordings of dispatcher telephone communications. In addition, FDNY documents were analyzed as they related to operations at WTC 7. For details on the data gathering processes, see NIST NCSTAR 1-8.

\footnotetext{
${ }^{1}$ Some times listed in this chapter are based on times documented during the investigation and are written as actual times. However, these actual times are estimated to have a potential error of $\pm 2 \mathrm{~min}$. Other times listed in this chapter are estimated based on the best evidence available and are written as "at about" or "at approximately." These times may have an error of $\pm 8 \mathrm{~min}$, unless the potential time frame error is otherwise stated.

${ }^{2}$ FDNY Interview 54, winter 2004.
} 


\subsection{EMERGENCY RESOURCES}

\subsubsection{FDNY}

FDNY was in control of the overall site, since the incident at the WTC site had been identified as a fire incident. In the course of the day, roughly 1,000 firefighters were on the scene, about ten times the number that might have responded to a two alarm fire. To keep track of all these, there were three magnetic Fire Command Boards, located in the lobbies of WTC 1 and WTC 2, and at the incident Command post at West Street. These Boards became overwhelmed while the WTC towers were still burning; and, with the collapse of the towers, the difficult job of knowing who was where became even more difficult. The Boards were lost in the collapses of the buildings.

\subsubsection{NYPD}

There were about 50 NYPD personnel on the site. Their responsibilities were traffic control, perimeter security, security for the command posts, and building evacuation. Their primary mobilization point was at the corner of Church and Vesey streets.

\subsubsection{PAPD}

There were a few dozen PAPD personnel on site and on orders to report to the site. As they arrived, they reported to the Fire Command Desk in the lobby of WTC 1. With the collapse of WTC 2, the Fire Command Desk was abandoned.

\subsubsection{WTC 7 Resources}

\section{Fire Command Station}

The Fire Command Station, located at the security desk in the main lobby on the $3^{\text {rd }}$ floor, provided a command post from which building personnel could orchestrate the response and a convening point for key building personnel responding to the emergency. The NYC Building Code requires that the computer screen in the fire command station monitor and display information regarding manual fire alarms, smoke detection, sprinkler water flow, elevator lobby smoke detectors, fire signal activation, central office notification, fan system status, fail safe locked door status, fire system trouble, fire signal trouble, tamper switch alarm, power source, test/normal mode, and other information as desired, including elevator status.

\section{Fire Safety Director}

The Fire Safety Director is a position required by Local Law 5 (New York 1973). Local Law 5 required all buildings (new or existing) occupied by more than 100 persons above or below the street level, or with more than 500 people in the entire building to have a Fire Safety Director, one or more Deputy Fire Safety Directors, and a Building Evacuation Supervisor. People in the first two categories must possess certificates of fitness from the Commissioner qualifying the individual to conduct fire drills, evacuations, and related training. A certified individual is required to be on duty during normal working hours. 
Consistent with Local Law 5, the primary responsibility of the Fire Safety Director at the WTC site (according to the formal emergency procedures manual) was overall emergency management for a building incident (Fire Safety Plan, 1998).

\section{Floor Warden System}

Appendix C.2 of the WTC 7 Fire Safety Plan required each floor to designate a "responsible and dependable employee" for duty as Floor Warden to coordinate the evacuation of the floor, consistent with the NYC Building Code. Assisting the Floor Warden were Deputy Floor Wardens (one Deputy Floor Warden per $700 \mathrm{~m}^{2}, 7,500 \mathrm{ft}^{2}$ ) and Searchers, who constituted a tenant fire safety team. On multi-tenant floors, each tenant identified a Floor Warden for its space. The Floor Wardens were to be familiar with the Fire Safety Plan, the location of the exits, and the location and operation of the fire alarm system. Once the order to evacuate a floor was given, those with building authority had specific responsibilities to ensure an orderly evacuation:

- In the event of a fire or fire alarm, the Floor Warden was to ascertain the location of the fire and evacuate the floor in accordance with the fire safety plan.

- The Floor Warden was to determine that an alarm was transmitted.

- As soon as practicable, the Floor Warden and Deputy Floor Wardens reported the incident in detail to the Fire Command Station.

- The Floor Warden was responsible for notifying occupants of the floor that there was a fire and ensuring that the occupants executed the fire safety plan (PANYNJ 1995). In an emergency, searchers would round up employees, and the Deputy Fire Wardens would move them into the corridors and make sure all occupants were accounted for. In the event occupants were reluctant to evacuate, searchers were not required to force evacuation.

- Floor Wardens were to select the safest stairwell to use on the basis of the location of the fire and notify the Fire Command Station which stairwell was utilized.

\subsection{ACTIVITY AT WTC 7 FROM 8:46 A.M. TO 10:30 A.M. EDT}

At 8:46 a.m., the aircraft impact on the north side of WTC 1 showered debris onto the adjacent buildings and streets below. As a result of this impact, the electrical power went out for several seconds inside WTC 7. ${ }^{2}$ After learning of the situation at WTC 1, many occupants of WTC 7 immediately began leaving their building (Chapter 7). The OEM operations center also began receiving calls related to the emergency. ${ }^{2}$

At 9:03 a.m., a building engineer in a hallway on the $44^{\text {th }}$ floor heard glass breaking when the second aircraft struck WTC 2. ${ }^{3}$ Another interviewee stated that the second aircraft impact further indicated the possibility of a threat to WTC 7, and it quickly led to the first order to evacuate the building. ${ }^{4}$

${ }^{3}$ SSB Interview 1, January 2004.

${ }^{4}$ WTC 7 Interview 1110402, fall 2002. 
Shortly after WTC 2 was struck, there were numerous small fires outside WTC 7 at the street level. A firefighter entered WTC 7 from "the Washington Street and Vesey Street sides," connected a hose line to the "A" stairwell sprinkler riser, located on the west side of the building, and started the engine's pump. ${ }^{5}$

At 9:16 a.m., NYPD officers from Manhattan South began to establish a security perimeter extending two city blocks around the WTC site. ${ }^{6}$ This security perimeter contained WTC 7.

At 9:30 a.m., the FDNY Emergency Medical Service (EMS) established a Division at WTC 7 for assisting victims. ${ }^{7}$ An EMS triage center was established in the lobby of WTC 7 as occupants from WTC 1 and WTC 6 evacuated through WTC 7. ${ }^{8}$ In addition, at about 9:30 a.m., the building engineer mentioned above went up to the penthouse of WTC 7 to get supplies for the triage center. He reported that all mechanical and electrical equipment was operating, and that the building's air dampers were closed to control dust intake. As the evacuation continued, he had other building staff members check the tenant floors to make sure everyone was out of the building. ${ }^{3}$

At approximately 9:32 a.m., after a report of a third aircraft heading into the city, a second order was given in the OEM office to evacuate the WTC 7 facility. A number of personnel stayed in the OEM office and continued to work. Again, at approximately 9:44 a.m., following the news that the Pentagon had been attacked, a Deputy OEM Commissioner verbally ordered the complete evacuation of WTC 7 (Sheirer 2004). This order included the evacuation of the OEM operations center on the $23^{\text {rd }}$ floor. Before evacuating, OEM assigned personnel to work with each of the emergency responder command posts. Though this action reduced the impact of the loss of the OEM office, the loss did create difficulties related to the coordination of emergency responder operations and resources. ${ }^{8}$ As an example, shortly after WTC 7 was evacuated, the FDNY Fire Commissioner arrived, looking for the Mayor, who he believed to be at the OEM center on the $23^{\text {rd }}$ floor. A guard met the Commissioner in the lobby and ordered him and his staff out of the building. The guard told him, "This building has been evacuated," and “OEM, the mayor, they're all gone” (Von Essen 2002).

At 9:45 a.m. the NYPD Command and Control Center at One Police Plaza was activated. ${ }^{6}$

At 9:59 a.m., the triage center located in the lobby of WTC 7 was expanded. Operations were being set up on the loading dock of WTC 7 when WTC 2 collapsed. ${ }^{3}$

When WTC 2 collapsed at 9:59 a.m., light debris from the collapse struck the south face of WTC 7 (Section 5.5) ${ }^{8}$ This collapse caused the emergency battery-powered lighting to come on inside WTC 7. In addition, the emergency AC power generators began operating. The building engineer went up to the $4^{\text {th }}$ floor cafeteria. When he opened the east emergency exit door, he saw what he described as heavy smoke and dust, and there was a reddish glow from above. He also mentioned smelling fuel oil and feeling heat. ${ }^{3}$

At approximately 10:00 a.m., a WTC 7 security manager was concerned that he might still have personnel on the $44^{\text {th }}$ floor and started up the "A" (west) stairway to get his people out of the building. At 10:28 a.m.,

\footnotetext{
${ }^{5}$ WTC 7 Interview 2110402, fall 2002.

${ }^{6}$ McKinsey \& Company, Improving NYPD Emergency Preparedness and Response, New York, August 2002.

${ }^{7}$ McKinsey \& Company, Increasing FDNY's Preparedness, New York, August 2002.

${ }^{8}$ FDNY Interview 45, winter 2004.
} 
when WTC 1 collapsed, he had reached the $30^{\text {th }}$ floor, and then continued up the stairway. There was rubble just before the $44^{\text {th }}$ floor landing, and the stairway swayed or vibrated. Smoke or dust was swirling around. During this climb, he opened doors on the $23^{\text {rd }}$ floor to check for OEM staff, and the floor was full of smoke or dust. He also opened a door on the $26^{\text {th }}$ floor to check for occupants and found none.

NIST was unable to find any evidence that, by approximately 10:30 a.m., any of the original occupants who intended to leave WTC 7 had not already done so (Chapter 7).

\subsection{COLLAPSE OF THE TOWERS AND THE EMERGENCY RESPONSE}

With the collapse of the WTC towers, all emergency response operations at the site were disrupted. Each emergency response organization experienced significant difficulties maintaining communications and a functional command structure. For the next hour or so, activity focused on restoring operational capability and performing rescue operations.

\subsubsection{Restoration of Command Structure and Command Posts}

All FDNY, NYPD, and PAPD command posts at the site were lost or were seriously disrupted by the collapses of the towers (NIST NCSTAR 1-8). Officers of all emergency response organizations quickly began processes to reestablish command posts and the command structure. New command posts had to be established in safe locations and new personnel had to be assigned to take command where officers were either dead or missing. The command system of each emergency response organization was challenged during this time period as the emergency responders rebuilt the command structure. As a result, during the hour following the collapse of WTC 1 , there was only a poorly defined command structure, and operations were somewhat chaotic.

With the collapse of the first tower, WTC 2, FDNY began moving its West and Vesey Streets Command Post north on West Street towards Chambers Street. This was in progress when WTC 1 collapsed. ${ }^{7}$ A large dust cloud covered lower Manhattan, creating breathing difficulties for anyone in the area, and it totally obscured the view of the site for several minutes. Immediately following the collapse, emergency responders reported that there was a period where they heard no radio communications. ${ }^{9}$ As the smoke began to clear, many of the emergency responders found that their radio microphones and speakers were filled with dust and debris, and these radios had to be cleaned before they were functional again. ${ }^{8}$

As command posts were being relocated, several different FDNY officers took charge of operations. By approximately 10:35 a.m., the FDNY Division 6 Chief (who was in route to the scene) assumed incident command. He went to Park Row and Vesey Streets and established a command post. Shortly following the Division 6 Chief assuming incident command, an FDNY Executive Staff person identified as C5 assumed incident command and reestablished a command post at West and Vesey Streets. ${ }^{7}$ Within this same time period, a FDNY Citywide Tour Commander, designated as 4A, assumed incident command and established a command post at West and Chambers Streets. ${ }^{7}$ By 11:28 a.m., a FDNY Citywide Tour Commander, designated as 4C, assumed incident command at the West and Chambers Streets Command Post. $^{7}$ During this same period of time, NYPD established a Command Post at 222 Broadway, the Mayor and NYPD Police Commissioner arrived at the FDNY Firehouse at Houston Street, and by 10:50 a.m., an

\footnotetext{
${ }^{9}$ FDNY Interview 22, winter 2004.
} 
NYPD Command Post was established on Liberty Street. ${ }^{6}$ Following the collapse of WTC 2, the PAPD Police Desk that was located inside WTC 5 was abandoned. ${ }^{10}$

\subsubsection{Rescue Operations}

The initial response to the towers' collapses by emergency responders at the scene was to find lost members of their units and to conduct necessary rescue operations for personnel calling for help. Also, as the radio systems came back on line, emergency responders indicated that the radios became filled with Mayday distress messages, and surviving personnel began to respond to these calls for help. ${ }^{11}$ These statements are supported by numerous emergency responder comments during first-person interviews, as well as the numerous Mayday calls heard on the radios following the buildings collapsing. ${ }^{11}$ As a result of these calls, emergency responders initially were focused on rescuing trapped personnel and were not addressing any issues associated with the condition of WTC 7.

However, as the dust cloud continued to clear, it became apparent that WTC 7 had sustained damage and required immediate attention. ${ }^{12}$ The PAPD reported that the collapse of WTC 1 had done significant damage to WTC $7 .^{13}$ FDNY personnel at the scene reported that a large amount of debris from WTC 1 had crashed through the front center (south side) of WTC 7 from approximately the $10^{\text {th }}$ floor down to ground level, and debris ripped off part of the southwest corner from approximately the $8^{\text {th }}$ floor up to the $18^{\text {th }}$ floor. $^{12}$ The collapse of WTC 1 also was ascribed as responsible for starting fires inside of WTC 7. ${ }^{14,15}$

As all of the emergency responder restructuring operations were underway, three people became temporarily trapped inside WTC 7. Two New York City employees had gone to the OEM Center on the $23^{\text {rd }}$ floor and found no one there. ${ }^{16}$ As they went to get into an elevator to go downstairs, the lights inside WTC 7 flickered as WTC 2 collapsed. At that point, the elevator they were attempting to catch no longer worked, so they started down the staircase. When they got to the $6^{\text {th }}$ floor, WTC 1 collapsed, the lights went out in the staircase, the sprinklers (at an unspecified location) came on briefly, and the staircase filled with smoke and debris. The two men went back to the $8^{\text {th }}$ floor, broke out two windows, and called for help. Fire fighters on the ground saw them and went up the stairs.

A security officer for one of the businesses in the building headed back up to a floor in the 40s after WTC 2 collapsed to see if all his personnel were out of the building. He was accompanied by a police officer, but the police officer had trouble breathing around the $10^{\text {th }}$ floor and exited the building. The security officer had reached the $30^{\text {th }}$ floor when the building shook as WTC 1 collapsed, and the stairwell became dark. He began to descend and stopped at the $23^{\text {rd }}$ floor to see if anyone was on the OEM floor. He opened the door to check for staff that might have been present and saw that the area was filled with smoke. He made it down to the $7^{\text {th }}$ floor, where he stopped because he could not see or breathe at this

\footnotetext{
${ }^{10}$ PA Interview 3, fall 2003.

${ }^{11}$ FDNY Interviews 30 and 31, winter 2004.

${ }^{12}$ FDNY Interview 3, winter 2004.

${ }^{13}$ PAPD Interview 1, fall 2003.

${ }^{14}$ FDNY Interview 19, winter 2004.

${ }^{15}$ In some cases, the floors that were identified in the interviews were corroborated by a second interviewee or by a specific landmark, such as the cafeteria. In other cases, the floor assignments should be considered approximate.

${ }^{16}$ WTC 7 Interviews 2041604 and 1041704, spring 2004.
} 
point. He broke a window near the center of the north face to yell for help. A ladder truck pulled up, but could not reach the window because of the Con Edison building extension at the lower floors. Firemen came up the stairwell right away. Soon after WTC 1 collapsed, the security officer saw a fire on the west side of Floor 7 that he attempted to put out with an extinguisher, but he was unable to do so. ${ }^{17}$

As the firefighters went up, they vented the stairway and cleared some of the smoke. They first met the security officer on the $7^{\text {th }}$ floor, and fire fighters escorted him down the stairs. Other fire fighters from the group continued up the stairs, shined their flashlights through the staircase smoke and called out. The two trapped men on the $8^{\text {th }}$ floor saw the flashlight beams, heard the firefighters calling, and went down the stairway. The firefighters took the men outside and directed them away from the building. ${ }^{16}$

\subsection{ACTIVITY FROM 11:02 A.M. TO APPROXIMATELY 2:30 P.M. EDT}

At 11:02, the Mayor of New York City ordered the full evacuation of the city below Canal Street. ${ }^{6}$ At 11:30 a.m., NYPD established an outer perimeter security zone that extended to Canal and Houston Streets. ${ }^{6}$ No unauthorized individuals were allowed into lower Manhattan below Canal Street.

Between 11:00 a.m. and 12:00 noon, approximately 40 FDNY members arrived at WTC 7 with orders to put the fires out inside WTC $7 .^{18}$ Inside they surveyed conditions and reported seeing small fires in debris in the core area and on the west side of the same floor of the building. They did not identify the floor where they observed this. A Chief Officer inside the building ran into other firefighters who had searched the upper floors, and they reported that no one was inside the building. When the Chief Officer reached approximately the $9^{\text {th }}$ or $10^{\text {th }}$ floor $^{19}$, he had been inside the building about 20 min to $25 \mathrm{~min}$. He received a radio call from another Chief Officer outside the building ordering him out of WTC 7. The Chief Officer was ordering everyone to leave the building. ${ }^{18}$ The Chief Officer left the building and went to the FDNY Command Post and reported to the Command Post Chief that he believed the fires inside WTC 7 could be extinguished. Thus, the Chief assigned with firefighting tasks was sent back to extinguish the fires. When he got back to WTC 7, he met FDNY Superior Officers and an OEM staff member who were also assessing the building's condition. ${ }^{18}$

Multiple FDNY personnel reported seeing fires in WTC 7 from the exterior, some as early as about 11:00 a.m. Fires were observed on the west face around Floor $10^{20}$, and several fires were seen higher up in the building, around the 20s and 30s. ${ }^{21}$ These fires were seen from Vesey and West Street. A firefighter reported seeing fire near the center of the south face around Floor 14, which appeared to be a single office fire. Windows were broken, and smoke and fire were coming out of the building.

At approximately 11:30 a.m., FDNY assigned a different Chief Officer to take charge of operations at WTC 7. He was initially given orders to put the fires out in WTC $7 .^{22}$ From near the Command Post at West and Vesey Streets, a Chief reported that, looking toward the building, he could not see WTC 7

\footnotetext{
${ }^{17}$ SSB Interview 5, April, 2004.

${ }^{18}$ FDNY Interview 73, summer 2004.

${ }^{19}$ Most of the FDNY personnel interviewed about conditions in WTC 7 were not familiar with the layout of the building. The floor numbers they identified as part of their observations were a best estimate of the location, but the floor location should be considered accurate to within several floors and compared to the observed fire locations in Chapter 5.

${ }^{20}$ FDNY Interview 69, spring 2004.

${ }^{21}$ OEM Interviews 4 and 16, April 2004 \& July 2004.

${ }^{22}$ FDNY Interview 3, winter 2004.
} 
because of the large smoke and dust cloud. This Chief proceeded down the street to WTC 7 to gather information on conditions. He was able to negotiate the debris fields and get to the building, where he saw the WTC 7 logo on the building's south side. There were numerous burned-out FDNY vehicles around WTC 7. Fire was observed on the south face, on a single floor around Floor 10 to Floor 14, and appeared to be traveling from west to east. ${ }^{20}$ At the corner of Vesey and West Broadway, a Chief reported that a FDNY Engine was connected to a hydrant at the corner of WTC 7. Hose lines were stretched, and the engine's pump was still running even though the engine was on fire and was almost burned out. There was no water coming out of the hydrant system. ${ }^{12}$ One FDNY Chief, who had been inside WTC 7, reported to him that he had opened a standpipe on the $4^{\text {th }}$ floor of one stairway and found no water in the standpipe system. As they were leaving the building through a service door in the southeast corner, glass was breaking from overhead. After it stopped, they exited and saw that the fires on the south face had moved to the east face and were moving north. ${ }^{12,20}$ They reported that flames were coming out of the windows, and that the windows were breaking out sequentially in groups of two or three every $15 \mathrm{~min}$ to $20 \mathrm{~min}$. The rooms appeared to have reached a flashover condition, but no heavy smoke was being pushed out of the windows. By this time, a FDNY fire boat and the retired FDNY fire boat "Harvey" were operating at the shoreline on the Hudson River near the site, and they were stretching hoselines up to the WTC site. However, according to the FDNY first-person interviews, water was never an issue at WTC 7, since fire fighting was never started in the building. ${ }^{12}$

At 12:10 p.m. the Governor of New York State mobilized the State’s National Guard, and by 1:30 p.m., National Guard personnel and military police (MP) were assisting the NYPD with patrolling lower Manhattan. ${ }^{6}$

At approximately 1:00 p.m., an OEM staff member, a FDNY Deputy Chief, and a FDNY Battalion Chief entered WTC 7 to further evaluate conditions. ${ }^{21}$ The OEM staff member reported that they entered WTC 7 through the door near the southeast corner on West Broadway and proceeded up the B stairway on the east side. They stopped at the $3^{\text {rd }}$ floor level. The atrium was filled with dust but had no significant debris. As they observed the area, they heard the building creaking. Debris was piled up on the Vesey Street side between Columns 17 and 22. They checked the $4^{\text {th }}$ and $5^{\text {th }}$ floors and did not see much damage from their viewing location. At the $5^{\text {th }}$ floor, they moved to the A stairway and proceeded up. On the $8^{\text {th }}$ or $9^{\text {th }}$ floor, one of the group said he saw two elevator cars ejected from their shafts and in the hallway. Looking past the elevators, they could see a gaping hole in the south face from around the $6^{\text {th }}$ to the $9^{\text {th }}$ floors. They could see one floor below and two to three floors above that location. A lot of the core walls were destroyed, and one individual reported that he saw columns hanging from the floor above. They did not observe any fires at this time on the $8^{\text {th }}$ floor or $9^{\text {th }}$ floor, but the interviewee reported that they could hear fires burning well above where they were standing. Also, they continued to hear creaking noises in the building. ${ }^{21}$ As the FDNY Officers continued their inspection of WTC 7, they heard a loud noise, and a Chief decided that they should evacuate the building. ${ }^{18}$ They also met a Deputy Chief who had just returned from inside the building, and he reported that he had conducted an inspection up to the $7^{\text {th }}$ or $8^{\text {th }}$ floor. ${ }^{23}$ He indicated that the stairway he was in was filling with smoke and that there was a lot of fire inside the building.

When a Chief Officer got to Barclay Street and West Broadway, numerous firefighters and officers were exiting WTC 7. These firefighters indicated that several blocks needed to be cleared around WTC 7 because they thought that the building was going to collapse. ${ }^{12}$ In addition, there were numerous

\footnotetext{
${ }^{23}$ FDNY Interview 14, winter 2004.
} 
observations reported by other emergency responders who indicated that WTC 7 was considerably damaged by the collapse of WTC 1, and the potential for collapse of WTC 7 was taken seriously by these FDNY personnel. First-person interviews conducted by the news media, NIST, and FDNY communications recordings provide additional information on the building conditions, damage assessment, and emergency response operations at the scene. See the following statements:

- "There was a 10-story gash in the side of building 7. The southwest corner was taken out when Tower 1 came down.,24

- "Early on, we saw a bulge in the southwest corner between Floors 10 and 13, and we had put a transit on that, and we were pretty sure she [WTC 7] was going to collapse.”25

- “...you could see the structural members, literally 10 floors, were taken out. The corners were taken out." 26

- "You could see where the north tower was and we looked back at 7 WTC, it looked like someone ripped a big gouge out of the building. It looked like a big chunk of it was torn out right here in this corner, ripped right out, the south west corner. Yes, and I remember when the dust cleared and I looked back at 7 WTC, there was a huge gouge."27

- ' "We went to Vesey and Greenwich and didn’t see any damage on the north and east sides of WTC 7. When we looked on the south side of WTC 7, there had to be a hole 20 stories tall in the building, with fire on several floors." 28

- "We went out and around Building 6, down to the parking garage and to Vesey Street. We walked west. There was a 40-foot-high pile of steel in the street after Tower 1 collapsed." "The fire had entered building 7 . Fire was visible in 30 windows spread across four of the lower floors." 29

According to statements issued by Silverstein Properties, ${ }^{30}$

"In the afternoon of September 11, Mr. Silverstein spoke to the Fire Department Commander on site at Seven World Trade Center. The Commander told Mr. Silverstein that there were several firefighters in the building working to contain the fires. Mr. Silverstein expressed his view that the most important thing was to protect the safety of those firefighters, including, if necessary, to have them withdraw from the building.”

"With respect to Mr. Silverstein's statement, when recounting these events for a television documentary, that "I said, you know, we've had such terrible loss of life. Maybe the smartest thing to do is to pull it." (A Silverstein Properties

\footnotetext{
${ }^{24}$ Firehouse Magazine, July 2002, p. 46, Chief Mark Ferran, Battalion 12.

${ }^{25}$ Firehouse Magazine, April 2002, p. 97, Deputy Chief Peter Hayden.

${ }^{26}$ Firehouse Magazine, July 2002, p. 62, Lieutenant Pete Lund, Rescue 2.

${ }^{27}$ FDNY Interview 9, winter 2004.

${ }^{28}$ Firehouse Magazine, August 2002, pp. 90-92, Captain Chris Boyle, Engine 94.

${ }^{29}$ Firehouse Magazine, July 2002, p. 60, Lieutenant Glenn Rohan, Ladder 48.

${ }^{30}$ Letter from Silverstein Properties to NIST, March 24, 2006.
} 
spokesman) has said that by 'it,' Mr. Silverstein meant the contingent of firefighters remaining in the building.”

One Battalion Chief who had come from WTC 7 indicated that his unit had searched Floors 1 through 9 and found that the building was clear of people. ${ }^{31}$ In the process of the search, a Battalion Chief met the building's Fire Safety Director and former Deputy Fire Safety Director on the $9^{\text {th }}$ floor. The Fire Safety Director reported that the building's floors had been cleared from the top down. By this time, a Chief Officer reassessed the building again and determined that fires appeared to be burning on the following floors: $6,7,8,17,21$, and $30 .{ }^{12,15}$ No accurate time is available for these actions during the WTC 7 operations; however, the sequence of events indicates that it occurred during a time period from 12:30 p.m. to approximately 2:00 p.m.

At approximately 1:15 p.m. to 1:30 p.m., the FDNY Chief Officer in charge of operations at WTC 7 recommended to his Commanding Officer that they should give up on efforts to save WTC $7 .{ }^{12}$ It was reported that the group of FDNY Chiefs who discussed the building conditions and FDNY's capabilities for controlling the building fires formed the following conclusions concerning operations inside WTC $7:^{12,23}$

- The WTC 7 building had sustained damage from debris falling into it, and they were not sure about the structural stability of the building.

- The building had large fires burning on at least six floors. Any one of these six fires would have been considered a large incident during normal FDNY operations.

- There was no water immediately available for fighting the fires.

- They didn't have equipment, hose, standpipe kits, tools, and enough handie talkies for conducting operations inside the building.

- The reports that WTC 7 was making loud noises as it burned indicated to them that it might be unstable. $^{32}$

Fire conditions were also observed on the east face of WTC 7, and the fire was reported to be moving north through the $10^{\text {th }}$ or $11^{\text {th }}$ floor. Flames were coming out of the windows on this floor. The windows below the fire floor were intact. The windows on the fire floor were breaking out sequentially, in groups of two or three at a time, as the fire spread across the building. The rooms on the fire floor appeared to have reached a flashover condition. No heavy smoke was pushing out these windows. ${ }^{33}$

No accurate time is available for the following events during the WTC 7 operations; however, the sequence of events indicates that they occurred between approximately 12:00 noon and 2:00 p.m. Consolidated Edison (Con Edison) personnel arrived at the scene and consulted with FDNY. They wanted to know if they should cut off the power at the WTC 7 power station. At that point in time, it was decided to leave the power on and not allow Con Edison personnel to enter the substations in WTC 7 because it was not safe. The Con Edison personnel also indicated that fuel tanks were located in the

\footnotetext{
${ }^{31}$ FDNY Interview 26, winter 2004.

${ }^{32}$ FDNY Interview 29, winter 2004.

${ }^{33}$ WTC 7 FDNY Interview 70, April 2004.
} 
lower level of WTC 7. However, they could not determine if the fuel tanks were involved with the fires burning in the building. FDNY personnel reported that they did not see any indication of burning liquid fuels before the building collapsed. ${ }^{12}$

Following the collapse of the WTC towers large fires were burning in the rubble, WTC 5, and WTC 6 were burning and additional fires were scattered throughout the area. Damaged fire department apparatus and other vehicles were burning on the streets causing dangerous conditions for emergency responders with the possibility of fuel tank failures and explosions from burning tires. It is evident over the time period when WTC 7 was burning that FDNY was focused on preventing the loss of additional lives, providing medical assistance for the injured, and attempting to rescue trapped individuals. The fire department was actively working these issues and conducting fire suppression operations where it directly affected rescue operations in occupied buildings and the collapse debris field. ${ }^{11,12}$

Therefore, at approximately 2:30 p.m., FDNY officers who had evaluated the condition of WTC 7, the availability of fire fighting resources (including water supply) for operations at WTC 7, and the potential dangers for conducting operations inside WTC 7 decided that it was not worth the additional risk to human life. They decided to abandon the building completely, and the final order was given to evacuate the site around the building. ${ }^{12,23}$

\subsection{ACTIVITY AFTER APPROXIMATELY 2:30 P.M. EDT}

NIST was unable to find much information regarding the details of the emergency response activity after the decision to abandon WTC 7. This order also terminated the ongoing rescue and firefighting operations at WTC 6 and on the rubble pile of WTC 1. Firefighters and other emergency responders were withdrawn from the WTC 7 area, and the building continued to burn. As the day progressed, the safety zone was moved several city blocks further away from the building. Also, the FDNY Command Post was moved further north and was eventually established at West and Chambers Streets. ${ }^{34}$ The FDNY Field Command Unit was also operating at the same location. At this time, all FDNY operations relating to WTC 7 were now centered at this Command Post and with the Field Command Unit. No emergency responders were operating within the collapse zone of WTC 7.

According to Con Edison records, electric power to the lower Manhattan substation at WTC 7 was shut down at 4:33 p.m. (Appendix A).

\section{8 $\quad$ FINDINGS}

- The loss of numerous firefighters, company officers, and chief officers in the collapses of WTC 1 and WTC 2 led to a changing command structure for the rest of the morning, as new command posts were established and several different chief officers took command and relinquished command of operations at the WTC site.

- Following the collapses of the two towers, FDNY was focused on rescuing personnel trapped in the debris field and providing aid to the injured. At approximately 1:00 p.m., FDNY considered the possibility of fighting fires in WTC 7.

\footnotetext{
${ }^{34}$ FDNY Interview 20, winter 2004.
} 
- At approximately 2:30 p.m., FDNY gave the order to forego firefighting activity and for personnel to withdraw to a safe distance from the building. This was based on recognition that WTC 7 had already been evacuated, fires were growing in the building, the building had potentially sustained significant structural damage, the building was producing interior noise that indicated potential instability in the structure, FDNY had lost many of its assets that would be needed to fight the fires inside WTC 7, and there was no usable water in lower Manhattan's hydrant system to fight the fires.

- Soon after WTC 1 collapsed, and thus about 10:30 a.m., FDNY observed a fire on the west side of the $7^{\text {th }}$ floor.

- During their multiple reconnaissance trips to the interior of WTC 7, FDNY personnel reported that they did not see any indication of burning liquid fuels before the building collapsed.

- At 4:33 p.m., Con Edison shut off the power at the WTC 7 substation.

\subsection{REFERENCES}

Fire Safety Plan. Appendix A: Fire Safety Directors Duties. Approved 4/18/98. WTCI-13-NYC. Marked received by FDNY Nov 13, 2002).

New York 1973. Fire Safety in Office Buildings, New York City - Local Law 5, The City of New York. January 18.

PANYNJ Fire Safety Plan $1995-$ p.3.

Sheirer, Richard J., 2004. Testimony Before the National Commission on Terrorist Attacks upon the United States, May.

Von Essen, Thomas, 2002. Strong of Heart Life and Death in the Fire Department of New York, Regan Books, HarperCollins Publishers, New York. 


\section{Chapter 7 \\ EVACUATION OF WTC 7}

\subsection{OVERVIEW}

The occupants of WTC 7 had clear warnings about the serious nature of their situation. They could feel and hear the percussion from the aircraft impacts, and those with access to windows facing south had views of the fire and smoke emanating from WTC 1 and WTC 2. Modern communication channels were also utilized, as televisions and land and cellular phones brought information and awareness to occupants in the building. Obtaining this information led many people to leave the building prior to any formal orders to do so.

The evacuation experience in WTC 7 was markedly different from that of the occupants of the towers. WTC 7 was not struck by an aircraft, and extensive fires were not ignited early and simultaneously on multiple floors. There was no immediate damage to the stairwells, the elevators were in operation for occupant use, and no occupants were trapped above fire floors without means of escape. Finally, WTC 7 did not collapse for $81 / 2$ hours after the aircraft impact into WTC 1 . These factors provided more than ample time for people to leave the building safely. With the exception of a handful of officials who reported to the New York City Office of Emergency Management headquarters on the $23^{\text {rd }}$ floor, virtually all of the estimated 4,000 occupants (see below) evacuated prior to the collapse of WTC 2, the first of the two towers to collapse.

Thus, the examination of the evacuation of WTC 7 by the Investigation Team had a purpose different from the examination of the evacuation of the two towers, and required less thorough study. While the occupants left the building without encountering fires, emergency responders, or structural damage, their evacuation did take place during a perceived emergency. Moreover, there were multiple unexpected complications, such as might arise in any such emergency and affect management of the situation, including use of the lobby area as a triage center, the resulting constriction of egress flow, and limitation of expected exit paths due to the potential for debris injury outside the building.

\subsection{THE EMERGENCY EGRESS SYSTEM}

\subsubsection{Stairwell Design}

The principal components of the emergency egress system in WTC 7 were two 56 in. to 58 in. (1.42 m to $1.47 \mathrm{~m})$ wide stairwells. These were significantly wider than the conventional $44 \mathrm{in}$. (1.12 m) wide stairwells. The stairs had a typical tread depth of $9 \mathrm{in} .(23 \mathrm{~cm})$ and a typical riser height of $8 \mathrm{in} .(20 \mathrm{~cm}){ }^{1}$ Stairwell A (also referred to as the west stairwell), located in the west-center part of the building, was vertically continuous from the $47^{\text {th }}$ floor down to the $5^{\text {th }}$ floor. From there, an evacuee moved horizontally through a protected corridor to the west, where stairs led to the exit discharge at the $1^{\text {st }}$ floor

\footnotetext{
${ }^{1}$ Emory Roth architectural drawing for WTC 7 Floor 5, October 20, 1986.
} 
through the west wall onto Washington Street. Stairwell B (also referred to as the east stairwell), located slightly east of the geometric center of the building, was vertically continuous from the $47^{\text {th }}$ floor down to the $23^{\text {rd }}$ floor, where there was a horizontal transfer corridor. The transfer allowed use of the floor space above the easternmost elevator lobby and the elevator machinery on the $22^{\text {nd }}$ floor for the elevators below. From there, the stairwell continued down to the $5^{\text {th }}$ floor, where a second transfer corridor led south and east to the third leg of the stairwell (Figure 7-1), which ran from the $5^{\text {th }}$ floor to the $1^{\text {st }}$ floor, where the stair exited the building through the east wall to West Broadway (Figure 7-2). There were also two secondary exits located off the $3^{\text {rd }}$ floor lobby, leading south over Vesey Street to the Promenade and pedestrian bridge shown in Figure $7-3$ and exits from the $1^{\text {st }}$ floor lobby onto Vesey Street. The photographs in Figure 7-4 and Figure 7-5, taken prior to September 11, 2001, show the exterior of the south and east exits, respectively.

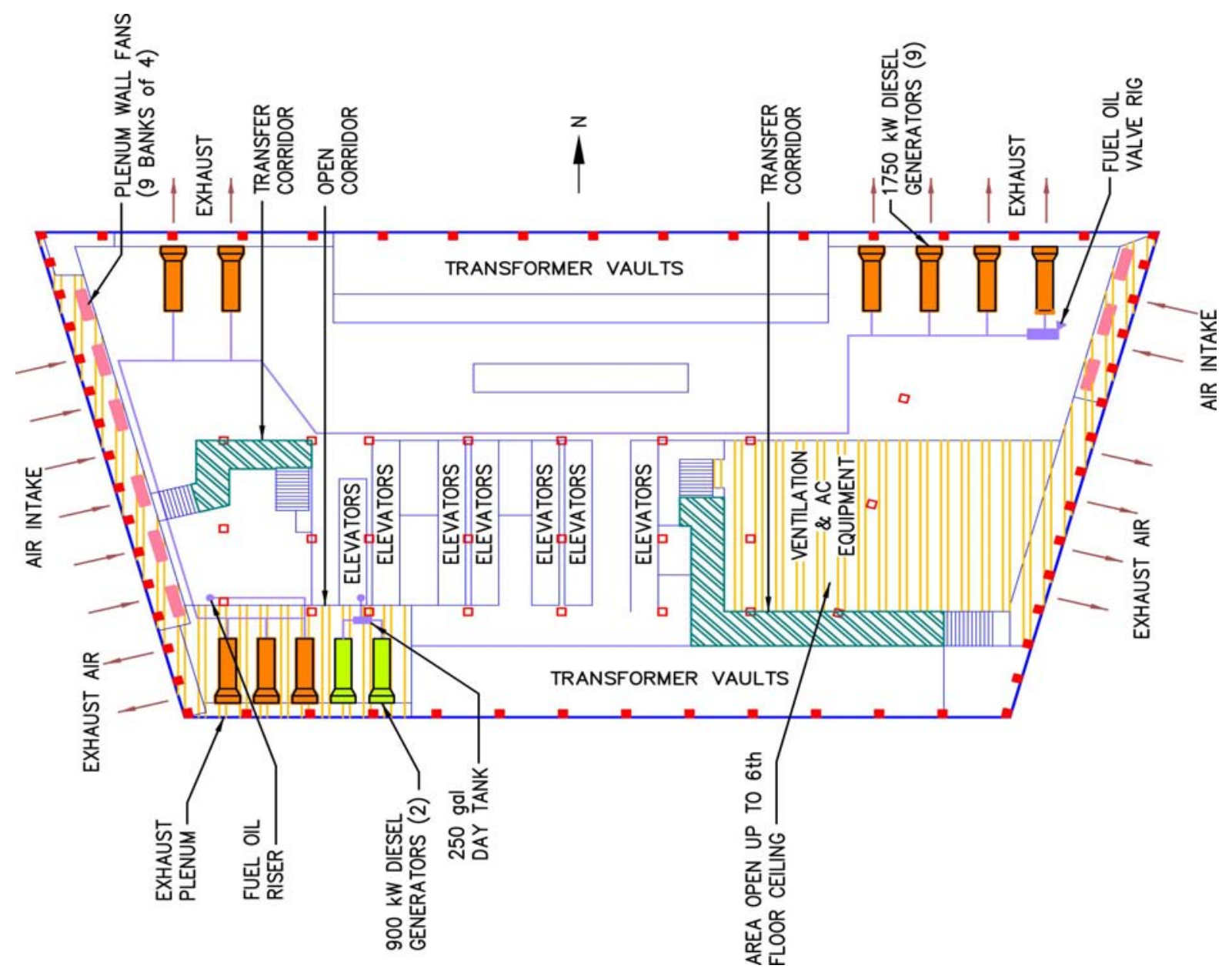

Figure 7-1. Fifth floor plan, indicating stairwell locations and the horizontal transfer corridors. $^{2}$

\footnotetext{
${ }^{2}$ The descriptions of the $5^{\text {th }}$ and $6^{\text {th }}$ floors were based on architectural and mechanical design drawings provided by Emery Roth \& Sons (1985), Cantor (1985), Syska \& Hennesy (1985), and Flack \& Kurtz (1988). Some of the details may differ from the actual layout on September 11, 2001.
} 


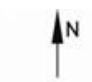

BARCLAY STREET

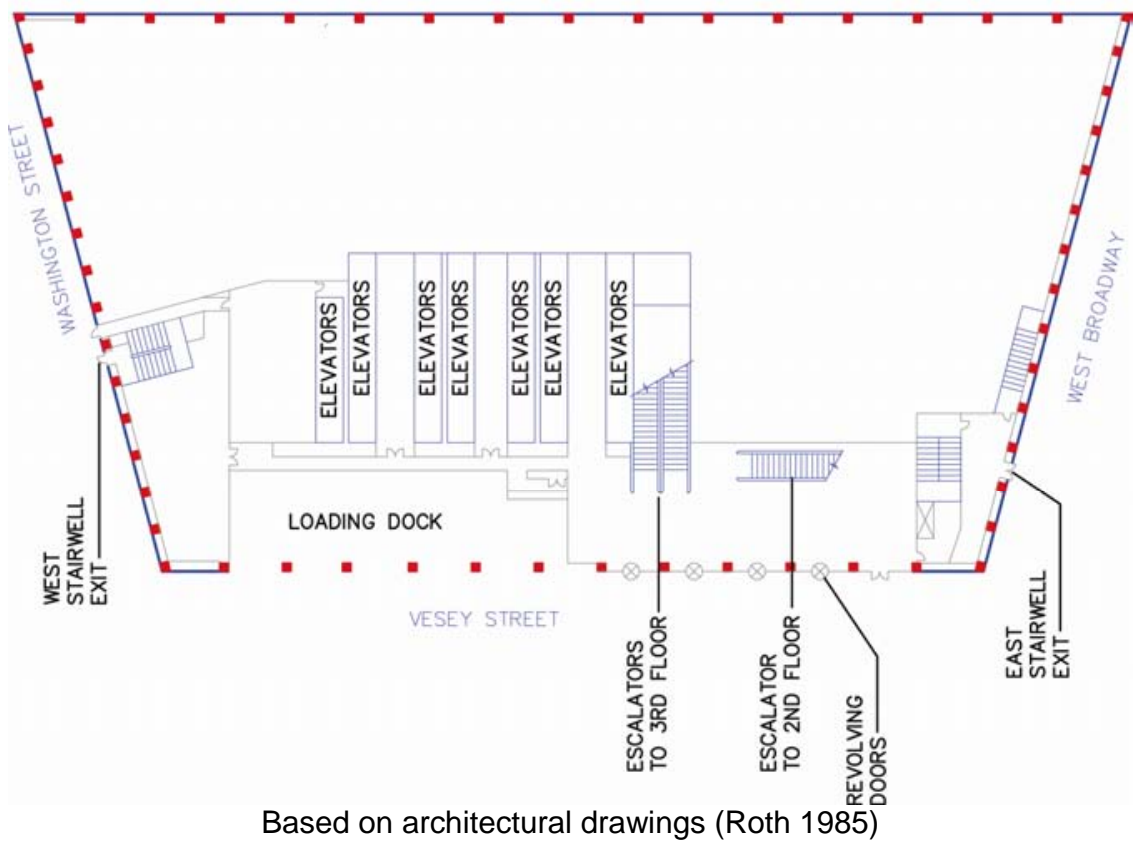

Figure 7-2. First floor plan, indicating the loading dock exit, stairwells, and escalators to and from the $3^{\text {rd }}$ floor.

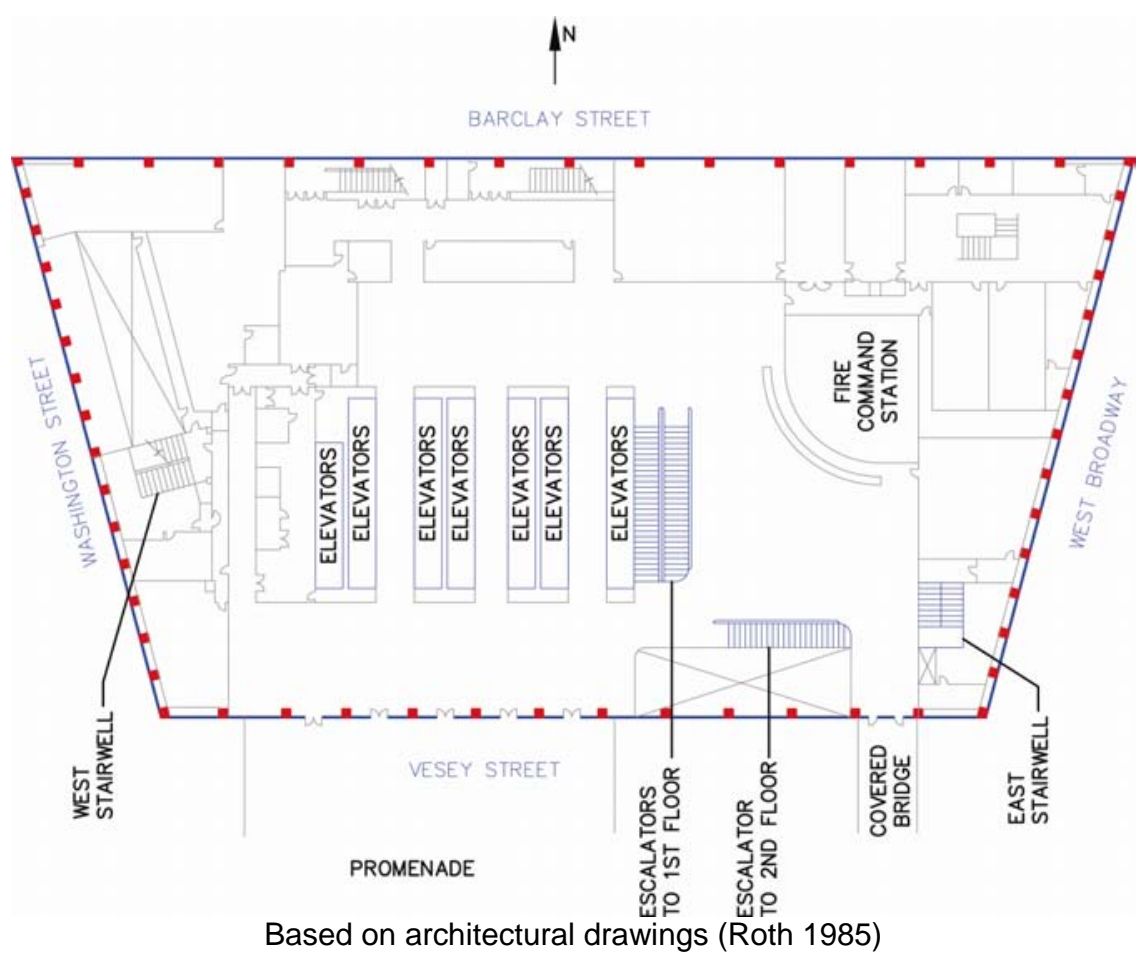

Figure 7-3. Third floor plan, indicating the elevators, stairs, escalators to and from the $1^{\text {st }}$ floor, and the exits to the Promenade and pedestrian bridge. 


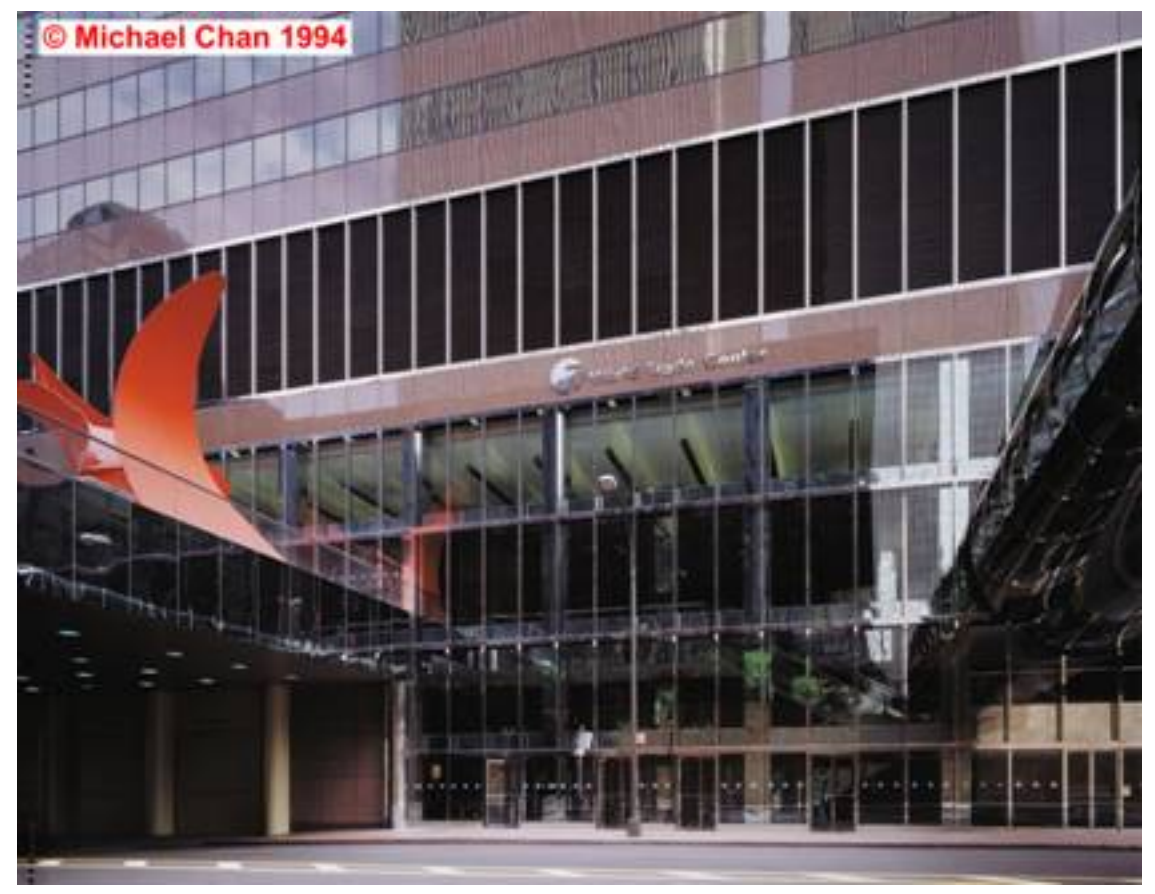

Figure 7-4. Photograph of the $3^{\text {rd }}$ floor exits from the south face of WTC 7. The Promenade is on the left and the enclosed pedestrian bridge is on the right.

Figure 7-5. Photograph of the east face of WTC 7 showing the east exit door. (indicated by the text and arrow).

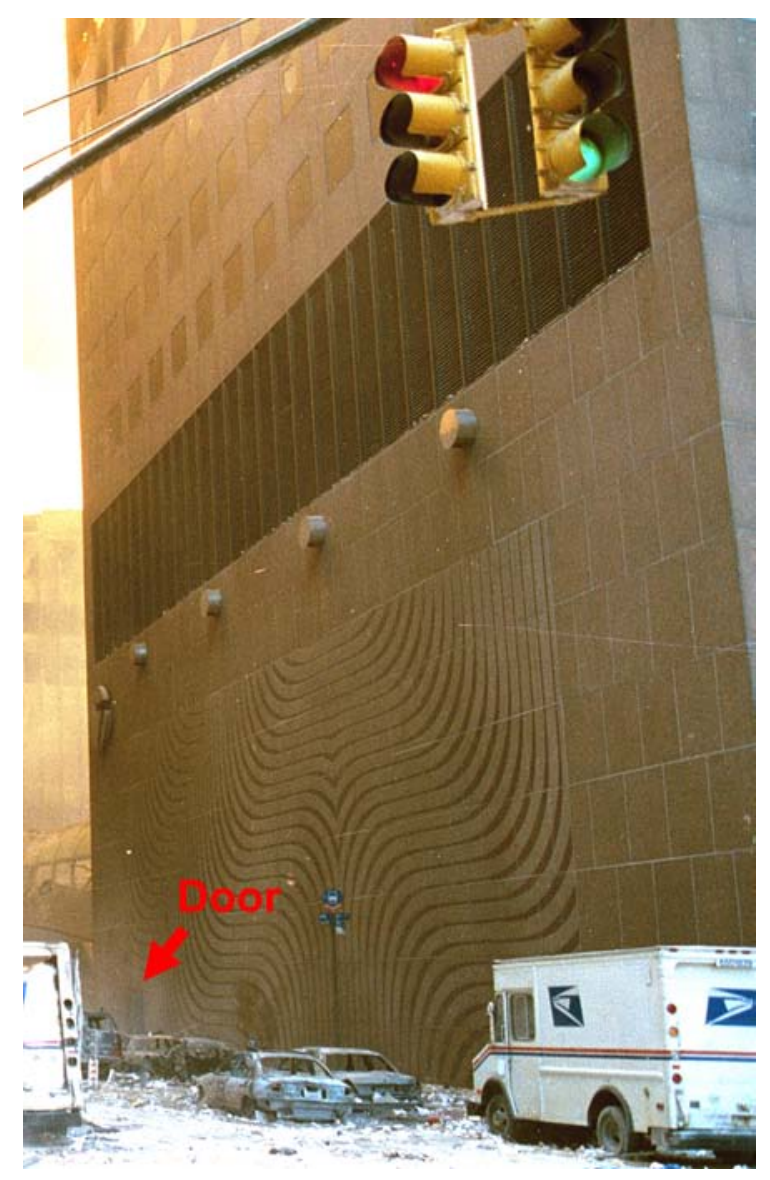

Source: George Miller, New York City Transit Authority (NYCTA) 


\subsubsection{Building Code Requirements for Stairwells}

\section{General}

The Investigation Team evaluated the capacity of the WTC 7 stairwells against various building code requirements. The codes considered were the building code in effect when WTC 7 was designed (New York City Building Code (NYCBC) of 1968) and the two current U.S. model building and fire codes (International Building Code of 2000, and NFPA 5000/Life Safety Code of 2003). In each case, the code provides formulas for calculating the nominal number of occupants per floor and the resulting stairwell capacity. (As presented in Section 7.5.2, the actual number of occupants per floor was considerably lower than these calculated values.) For WTC 7, the largest net floor area was approximately $34,800 \mathrm{ft}^{2}$, or $3,200 \mathrm{~m}^{2}$ (41,600 gross $\mathrm{ft}^{2}$ less $6,800 \mathrm{ft}^{2}$ of core space), when using conventional calculation methods which do not account for tenant-specific unoccupied space allowances. ${ }^{3}$

\section{New York City Building Code (1968)}

Table 6-2 in §C26-601 required $100 \mathrm{ft}^{2}$ per occupant (net) for business occupancies, yielding a design occupant floor load of 348 persons per floor in WTC $7 .^{4}$ For this number of people, there were two requirements for stairwells.

- The code required one $0.56 \mathrm{~m}$ (22 in.) unit of stairwell width for 60 people for business occupancies. Sufficient capacity for 348 persons would have required six units of exit width, or $3.35 \mathrm{~m}$ (132 in.).

- For an occupant load of fewer than 500 people, §C26-602 (Exits from Floors) required a minimum of two stairwells, each equally sized, as no more than 50 percent of the occupants can be served by a single exit. Two equally sized stairwells meeting the design requirements of the NYCBC would have been at least $1.68 \mathrm{~m}$ (66 in.) wide each. Three stairwells, each 44 in. wide, would also have provided the minimum egress capacity for business occupancy floors.

WTC 7 had two stairwells, each $1.42 \mathrm{~m}$ to $1.47 \mathrm{~m}$ (56 in. to $58 \mathrm{in.)}$ wide, which was not consistent with the NYCBC.

The NYCBC also included additional requirements.

- Each stairwell would be required to have a door at least $0.91 \mathrm{~m}$ (36 in.) wide. The actual doors were $1.10 \mathrm{~m}$ (44 in.) wide.

\footnotetext{
${ }^{3}$ When WTC 7 was being designed, many details of tenant spaces were unknown. Therefore, NIST used a conservative calculation of net floor area which does not account for tenant spaces which are normally unoccupied. While the NYCBC in effect at the time of design allowed for these reductions to net floor area calculations (spaces such as columns, fixed cabinets, furred-in spaces, equipment and accessory spaces would be subtracted from gross area), this calculation would require specific knowledge of tenant layout details and would preclude future changes to the floor layouts after stairwell construction.

${ }^{4}$ Conference rooms or other meeting spaces might have increased the calculated occupant load, but were not included in these analyses.
} 
- The sum of two risers and one tread depth was required to be not less than $0.61 \mathrm{~m}$ (24 in.) nor greater than $0.65 \mathrm{~m}$ (25.5 in.). ${ }^{5}$ Thus, the typical WTC 7 tread depth of $0.24 \mathrm{~m}$ (9.5 in.) and riser height of $0.20 \mathrm{~m}$ (7.7 in.) would satisfy this formula, at 25 in. However, according to Table 6-4 in the NYCBC, the stair riser may not exceed $0.20 \mathrm{~m}$ (7.75 in.) and the tread depth must be greater than $0.24 \mathrm{~m}$ (9.5 in.).

- New York City Local Law 16 (1984) modified the NYCBC minimum remoteness requirement to be $9 \mathrm{~m}$ (30 ft) or one-third the maximum travel distance of the floor (which was approximately $63 \mathrm{~m}, 205 \mathrm{ft}$, in WTC 7), whichever was greater. Therefore, the remoteness requirement would have been one-third of $63 \mathrm{~m}(205 \mathrm{ft}$.), or $21 \mathrm{~m}$ (68 ft). This was exceeded in WTC 7. The

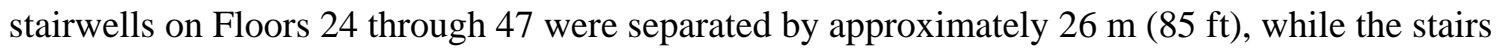
on Floors 5 through 23 were separated by $35 \mathrm{~m}$ (113 ft).

\section{International Building Code (2000)}

Chapter 10 of the 2000 International Building Code (IBC) requires $100 \mathrm{ft}^{2}$ per occupant (gross area), yielding a design occupant floor load of 416 persons per floor in WTC $7 .^{4}$ A minimum of two equally sized stairwells would have been required (for occupant load less than 500 persons (Table 1005.2.1)). As WTC 7 was fully sprinklered, Table 1003.2 .3 requires a minimum of $0.005 \mathrm{~m}$ (0.2 in.) per occupant, totaling $2.13 \mathrm{~m}$ (84 in.) of total stairwell width, or two $1.12 \mathrm{~m}$ (44 in.) stairwells. WTC 7 had two stairwells, each $1.42 \mathrm{~m}$ to $1.47 \mathrm{~m}$ (56 in. to 58 in.) wide.

Section 1003.3.1 requires that each stairwell have a door at least $0.81 \mathrm{~m}$ (32 in.) wide. As noted above, the actual doors were $1.1 \mathrm{~m}$ (44 in.) wide.

Section 1004.2.2.1 requires that for fully sprinklered buildings, the stairwell doors be located a distance of no less that one-third the length of the maximum overall diagonal dimension of the building or area to be served, which was $103 \mathrm{~m}$ (337 ft) for WTC 7. One-third of that is $34 \mathrm{~m} \mathrm{(112} \mathrm{ft).} \mathrm{This} \mathrm{was} \mathrm{not} \mathrm{exceeded}$ on all floors in WTC 7. There, the stairwells on Floors 24 through 47 were separated by approximately $26 \mathrm{~m}$ (85 ft), while the stairs on Floors 5 through 23 were separated by $35 \mathrm{~m}$ (113 ft).

\section{NFPA 5000 and NFPA 101 - Life Safety Code (2003)}

The gross square footage for WTC 7 was $41,600 \mathrm{ft}^{2}\left(3,875 \mathrm{~m}^{2}\right)$. Table 7.3.1.2 of the Life Safety Code requires $100 \mathrm{ft}^{2}$ per occupant (gross) for a business occupancy, yielding a design occupant floor load of 416 persons per floor in WTC $7 .{ }^{4}$ A minimum of two equally sized stairwells would be required for an occupant load of fewer than 500 persons (Section 7.4)). Table 7.3.3.1 requires a minimum of $0.0076 \mathrm{~m}$ (0.3 in.) per occupant, totaling $3.2 \mathrm{~m}$ (125 in.) of total stairwell width, which may be satisfied by two $1.6 \mathrm{~m}$ (63 in.) stairwells, or three stairwells, sized at $1.1 \mathrm{~m}$ (44 in.) each. The two WTC 7 stairwells were each $1.42 \mathrm{~m}$ to $1.47 \mathrm{~m}$ (56 in. to 58 in.) wide.

\footnotetext{
${ }^{5}$ From the NFPA Life Safety Code Handbook (2003 Edition), the following note was made about the formula formerly used by NFPA and currently used by NYC: "This requirement was deleted because it was based on a 300-year-old French formula in which an inch was a slightly larger unit of measure than it is today. Moreover, people's feet and stride length - the basis of the formula - were somewhat smaller at that time. Also, the requirement was originally intended only for stairs of moderate steepness or pitch.”
} 
Section 7.2.1.2 requires that each stairwell have a door at least $0.81 \mathrm{~m}$ (32 in.) wide. The doors in WTC 7 exceeded this requirement.

Section 7.5.1.3 addresses the remoteness of stairwells, with the purpose "to minimize the possibility that more than one has the potential to be blocked by any one fire or other emergency condition.”

Additionally, Section 7.5.1.3.3 requires that, for fully sprinklered buildings, the stairwell doors be located a distance of no less that one-third the length of the maximum overall diagonal dimension of the building

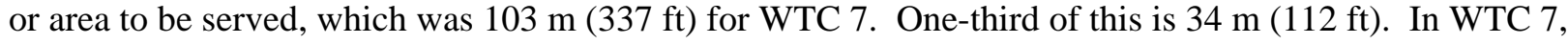
the stairwells on Floors 24 through 47 were separated by approximately $26 \mathrm{~m}$ (85 ft), while stairs on Floors 5 through 23 were separated by $34 \mathrm{~m}(113 \mathrm{ft})$.

\subsubsection{Elevators}

Building elevators are not conventionally considered part of the emergency egress system. However, on September 11, 2001, they were used extensively during the mass evacuation of the building. NIST estimated the service capacity of the elevator system.

Figure 7-2 shows the locations of the 31 elevators on the $3^{\text {rd }}$ floor. Figure 7-6 indicates the floors served by each elevator. All the elevators were passenger elevators (PE), except elevators 29 through 31, denoted by SE (service elevator) and FE (freight elevator). The lobby on the $3^{\text {rd }}$ floor was the primary access and discharge floor for the occupant elevator system. Two escalators transported people from the entrances on the street level $\left(1^{\text {st }}\right.$ floor) to the $3^{\text {rd }}$ floor. Two elevators (passenger elevators operated in parallel with the escalators, providing access for mobility impaired individuals or other individuals for whom the escalators were not safe or convenient (such as individuals with strollers, packages, or other objects).

The design parameters for the elevator system were included in the 1984 building specifications memo from the engineering design firm of Syska and Hennessy to PANYNJ. The three primary measures of elevator system performance used were the wait intervals, handling capacities, and the time-in-car.

- Wait intervals are the average amount of time between elevators leaving the $3^{\text {rd }}$ floor lobby during the morning rush period. They were specified to be $35 \mathrm{~s}$ or shorter.

- The handling capacities are the number of people the elevators are required to move during the 5 min busiest period in the morning. The requirement was that 12 percent of the population be served in this peak interval, after subtracting 10 percent for those likely to be absent during the rush period. The occupant load was defined uniquely for each elevator bank: 13.8 usable $\mathrm{m}^{2}$ $\left(149 \mathrm{ft}^{2}\right)$ per person for the elevators serving Floors 4 though 13 (called low-rise elevators), $13.7 \mathrm{~m}^{2}\left(147 \mathrm{ft}^{2}\right)$ per person for the mid-low elevators serving Floors 14 through 21$), 11.7 \mathrm{~m}^{2}$ $\left(126 \mathrm{ft}^{2}\right)$ per person for the mid-rise elevators serving Floors 22 through $28,12.5 \mathrm{~m}^{2}\left(135 \mathrm{ft}^{2}\right)$ per person for the mid-high elevators serving Floors 29 through 35, and $13.1 \mathrm{~m}^{2}\left(141 \mathrm{ft}^{2}\right)$ per person for the high-rise elevators serving Floors 36 through 45.

- The time-in-car parameter is the maximum period a person would spend in an elevator, from entering at the $3^{\text {rd }}$ lobby level to arriving at the top floor served. This time was not to exceed $170 \mathrm{~s}$. 
Using these values, the elevator system was designed to serve approximately 9,000 people. From the floor plans, the Investigation Team estimated that the building could house about 8,000 employees and visitors. (See Section 7.5.2.)

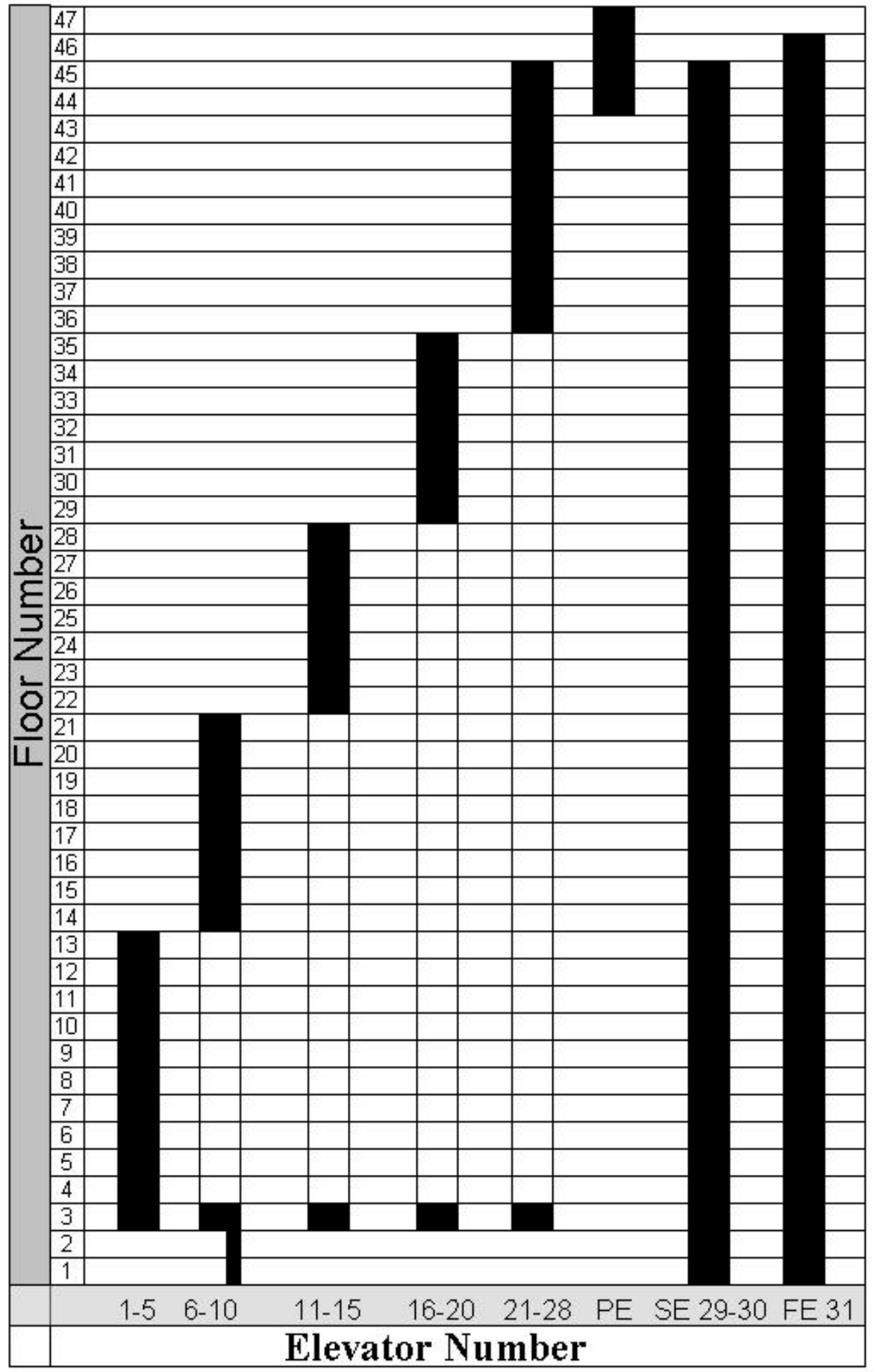

Figure 7-6: Schematic of the elevators in WTC 7.

The bars indicate the range of the elevators; the filled section of the bars indicates the floors at which they stopped. 


\subsection{EVACUATION RESOURCES AND PROCEDURES}

\subsubsection{Roles and Responsibility}

Silverstein Properties (SP) had been the leaseholder and property manager for WTC 7 since its construction.

As described in Section 6.3.4, on-scene emergency staff included the Fire Safety Director and a number of Floor Wardens. In addition, there were responsible managers from the tenant firms and agencies. Their roles in an emergency were spelled out in the 1998 Fire Safety Plan, as were all the policies presented in this Section.

\subsubsection{Elevator Usage During Emergencies}

While elevators were not considered in emergency evacuation planning, there were circumstances when their use was permitted. In particular, if the stairways serving a floor were unusable due to contamination from fire and/or smoke or if several floors involving large numbers of occupants were to be evacuated, the elevators were to be considered for use by occupants under the following conditions:

- If the elevator also serves the fire floor, that elevator must not be used. "However, elevators may be used if there is more than one bank of elevators and [the Floor Warden] is informed from the Fire Command Station that one bank is unaffected by the fire.”

- If elevators do not service the fire floor and there are no shaft openings to the fire floor, the elevators may be used.

- Elevators may be used by trained personnel or fire service.

The Floor Warden was to inform the Fire Command Station of the means employed by occupants for evacuation.

\subsubsection{Occupant and Tenant Training}

The Fire Safety Plan required that new tenants conduct fire drills every three months for the first two years, and then every six months after the first two years. During the fire drill the floor warden notifies the occupants on the floor using the public address system that the fire drill is about to begin. The occupants report to the designated stairway, where the Fire Safety Director and Assistants give a brief talk on the purpose and objectives of the fire drill program and answer any questions.

\subsubsection{Evacuation Procedures for Disabled Persons}

Upon notification of fire or odor of smoke, the fire brigade members were to be dispatched via manned freight elevator to a staging area one floor below the fire floor. The fire brigade would then use a stairway to ascend to the affected floor and assess the conditions. Based upon the assessment, the Fire Safety Director would then dispatch the elevator in order to evacuate disabled persons. Should elevator evacuation be considered dangerous, the fire brigade was to carry disabled persons down the stairs to 
areas of safe refuge. Security, maintenance, and other personnel trained in evacuation procedures were to be dispatched to assist, as necessary.

\subsection{DATA COLLECTION}

\subsubsection{Interview Methodology}

NIST gathered first-hand accounts and observations of the activities and events inside the buildings on the morning of September 11, evaluated technical hypotheses about channels of awareness, modes of evacuation, and evacuation speed, and explored conscious motivations for occupant behaviors. Further, the timing of critical events, such as an announcement of full-building evacuation, was investigated.

NIST used two interview methods during the investigation of WTC 7: (1) structured occupant interview techniques identical to the protocols used during occupant interviews with survivors from the WTC 1 and WTC 2 evacuations, and (2) unstructured open-ended interviews with selected building officials who may possess specific information about the building or evacuation process on September 11, 2001.

\subsubsection{Structured Occupant Interviews}

From the large number of structured interviews discussed in NIST NCSTAR 1-7, approximately 12 contained occupant experiences from WTC 7 from 8:46:30 a.m., when the first aircraft impacted WTC 1, until all the occupants had left the building.

The methodology for the face-to-face interviews is a synthesis of the Behavioral Sequence Interview Technique (BSIT), originally developed by Keating and Loftus (Keating and Loftus 1984), and the Cognitive Interviewing Method (CIM), originally developed by Fisher (Fisher et al. 2000) and Geiselman (Geiselman 1986). These two interviewing methodologies were developed with the purpose of assisting persons in retrieving more comprehensive and accurate memories of incidents and sharing important details. Both approaches begin by allowing the informant to retell an unimpeded account without interruption by the interviewer, and both initially employ a chronological retelling of information. However, BSIT was designed to yield a database of qualitative information that could be subjected to systematic analysis and consolidation, while CIM was designed to facilitate investigative interviews. Since the investigation is pursuing both goals (i.e., creation of a database of evacuation-related behaviors and an investigatory capture of information relevant to outcomes), the methodology combines these two approaches.

\subsubsection{Unstructured Interviews with Selected Personnel}

In addition, NIST staff conducted unstructured interviews with selected building officials over the course of the Investigation. Typically, these interviews were investigatory in nature, with NIST seeking answers to specific questions related to the expertise of the particular official. In addition, the interviews were open-ended to allow for the opportunity to explore new directions. While the majority of the interviews were face-to-face, some material was gathered by telephone or e-mail. Twelve officials were interviewed in this manner. 


\subsection{THE EVACUATION}

\subsubsection{General}

The full building evacuation of WTC 7 was unusual, due to the presence of an exterior threat to the occupants for the duration of the evacuation. Similar to the evacuation of WTC 2 prior to 9:03 a.m., elevators were available in WTC 7 for occupant use. However, unlike WTC 2, there was no underground concourse through which to direct the evacuees in order to avoid the debris emanating from WTC 1 and WTC 2. Therefore, while downward passage from the upper floors was relatively easy, safely exiting the building became a significant challenge to both the emergency management and occupants.

\subsubsection{Estimation of the Number of Occupants}

NIST made four separate estimates of the total building capacity using documents from PANYNJ and using the model building code design requirements:

- Appendix H of the WTC 7 Fire Safety Plan (1988) lists the daytime population of "persons normally employed in the Building" as 2,000. There is no substantiation for this number provided, and it is significantly lower than tenant floor plans and occupant loads calculated using the NYCBC or any other national model code.

- The elevator specifications were outlined in a 1984 memo from Syska and Hennessy to PANYNJ, as discussed in the section above. The specifications infer a design load of approximately 10000 total building occupants. The elevator design load was 9,000 occupants, as the memo assumed that 10 percent of the population would be absent at the peak demand.

- $\quad$ According to the NYCBC, the design occupant load for the building would have been 348 persons per floor. Assuming approximately 40 occupied floors (ignoring mechanical floors and lobbies), this would yield a rough occupant load of approximately 14,000 persons.

- From the architectural drawings, there were desks and chairs for about 8,000 people, including visitors. Using this number would presume that all the organizations in the building were fully staffed.

As no representative sampling method was applied to interviews of occupants of WTC 7, NIST cannot make a scientific estimate of the population of occupants inside the building at 8:46:30 a.m. on September 11, 2001. However, upon estimating the building capacity, two separate techniques for estimating the population of occupants on September 11, 2001 can be offered:

- During interviews with building officials responsible for emergency management operations inside the building that morning, NIST asked three officials to estimate the number of occupants present in the building at the time of the first attack. The consensus estimate of the three officials was that approximately 5,000 persons were present, including occupants who entered WTC 7 
from WTC 5 and WTC 6 across the pedestrian bridges after the attacks on WTC 1 and WTC $2{ }^{6}$ However, the estimate has a significant uncertainty.

- In WTC 1 and WTC 2, statistical techniques from the representative sampling of occupant interviews resulted in an estimate that the towers were between one-third and one-half full on September 11, 2001 (NCSTAR 1, 2005). Assuming the same rate of occupancy in WTC 7 would result in an estimated occupant load of 3,000 persons (one-third of 10,000) to 5,000 persons (onehalf of 10,000 persons).

Based on these numbers, NIST estimated a likely total building occupant load of up to 8,000 people (including visitors) on a typical day and estimated the building to have been half full (approximately 4,000 people) just before the first airplane attack on September 11, 2001. The uncertainty in each value was taken as about \pm 25 percent.

\subsubsection{Awareness of the Emergency: 8:46 a.m. EDT}

When the first aircraft hit WTC 1 at 8:46 a.m., occupants throughout WTC 7 reported hearing a loud explosion outside the building. A window washer on the north side of the roof of WTC 7 observed the impact and was knocked unconscious by it. A building employee on a low floor observed that the lights blinked and was concerned about the implications of a power interruption to the tenants who were financial firms and depended upon uninterrupted supply of power. ${ }^{6}$ Another building employee, upon seeing the lights flicker, assumed someone had detonated a truck bomb near the building, perhaps recalling the 1993 bomb incident at the WTC complex. ${ }^{6}$ Several occupants reported hearing an explosion and/or feeling the building shake. One occupant of WTC 7 on a floor in the teens said: "Our office went dark, as a shadow passed over us; and I wanted to see what it was. I put down my work and looked up [and then] I heard the noise of the first plane hitting." 7 The first reaction of many occupants was to discuss the proper course of action with others in order to decide whether to evacuate the building.

\subsubsection{Evacuation of the Tenant Floors}

The occupants' perceptions of risk defined their initial activity. None of the interviewed occupants indicated that they felt their lives were in immediate danger. As one occupant on a floor in the 10's said: "I went back to my office, packed my lunch, and shut down my computer. I didn't feel any sense of urgency; our building wasn’t in direct danger." Consistent with this low risk perception, most occupants chose to gather belongings prior to evacuation. One occupant reported that he/she went back to the task on which he/she was working prior to the attack, until he/she was instructed by a supervisor or floor warden to evacuate the floor. ${ }^{7}$ Other occupants gathered around a television to watch news coverage of the events in WTC 1.

Officials from Silverstein Properties (SP), Citigroup, the U.S. Secret Service (USSS), the Mayor's Office of Emergency Management (OEM), The Port Authority of New York and New Jersey (PANYNJ), and the Federal Bureau of Investigation (FBI) were involved at different times and places in deciding whether

\footnotetext{
${ }^{6}$ NIST Interview 11402.

${ }^{7}$ NIST Interview 1000045.

${ }^{8}$ NIST Interview 7000004.
} 
and when to evacuate WTC $7 .{ }^{9}$ While it is clear that several independent decisions were taken to order a full building evacuation, NIST found only one individual who stated that a public address announcement was actually delivered at approximately 9:45 a.m., ${ }^{9}$ but could not verify with a second source that such an order was communicated to the building occupants. However, NIST inferred from the limited interviews, and the total time it took to clear the building, that most of the occupants began moving to the stairwells and elevators within minutes of the aircraft impact on WTC 1.

- In the lobby of WTC 7, a tenant representative asked the building fire safety directors whether or not to issue an evacuation order. The preliminary decision, prior to WTC 2 being attacked, was not to evacuate WTC 7. Shortly after WTC 2 was attacked, however, the representative witnessed OEM order a SP manager to evacuate the building. The representative never heard an evacuation announcement over the PA system. ${ }^{10}$

- $\quad$ After WTC 2 and the Pentagon were attacked, an OEM manager had a conversation on the $23^{\text {rd }}$ floor of WTC 7 (OEM office) with unidentified representatives of the U.S. Secret Service, the U.S. Federal Bureau of Investigation, WTC security, and other OEM officials, and he personally ordered the evacuation of WTC 7, 15 min prior to the collapse of WTC $2 .{ }^{9}$ This corroborated the tenant representative's statement, establishing the time to have been about 9:45. (By all accounts, the building was essentially empty at this point, and he acknowledged that many had already selfevacuated.)

- Shortly before the attack on WTC 2, an SP manager reported that an OEM person was aware that there was a second plane in the air, that they didn't know where it was going, and that they had better evacuate WTC 7. Two engineers were dispatched to locate a missing window washer and were on the roof of WTC 7 when WTC 2 was hit, forcing them to take cover. There was no indication of whether the evacuation order was executed over the PA system. ${ }^{6}$

- All of the interviewed occupants were asked if they heard a PA announcement regarding building evacuation, and only one indicated hearing the announcement. NIST did confirm a building fire alarm was actively sounding a "whoop" siren in the lobby during the time period after WTC 2 collapsed, but prior to the collapse of WTC 1 (Section 5.5.1). This corroborated the readout from the alarm system, as reported in Section 4.2.3, which indicated that the alarm system was activated at 10:00 a.m., in response to the collapse of WTC 2.

\subsubsection{Congestion in the WTC 7 Lobby}

Occupants who evacuated to the lobby promptly after the attack on WTC 1 at 8:46 a.m. were able to exit the building using the primary exits to the west and east. Shortly after WTC 2 was attacked at 9:03 a.m., building officials (representatives from SP, SSB, USSS, and OEM) decided to prevent occupants from exiting the building due to a danger of being hit by debris from WTC 1. ${ }^{6,7}$ Hundreds of people began accumulating in the WTC 7 lobby, and were described as "packed like sardines." ${ }^{11}$ (See Figure 7-2 and Figure 7-3 for the locations of lobby entrances/exits.) The crowd included:

\footnotetext{
${ }^{9}$ NIST Interview 041504.

${ }^{10}$ NIST Interview 73347.

${ }^{11}$ NIST Interview 7000001.
} 
- $\quad$ Occupants from WTC 7 who had descended from the tenant floors using the elevators;

- Occupants who had descended the east stairwell of WTC 7, and were redirected into the lobby at the $3^{\text {rd }}$ floor by a security guard; ${ }^{6}$

- Occupants of WTC 5 and WTC 6 (described by eyewitnesses as a "flood"6), who had used the tubular and plaza bridges to cross Vesey Street (from the south) into WTC 7 in an effort to move away from WTC 1 and WTC 2; and

- Injured people from WTC 1 in a medical triage post, established by the OEM in the WTC 7 lobby. ${ }^{6}$

Initially, the crowd in the lobby was concentrated near the large south lobby windows, which faced toward WTC 1 . Once WTC 2 was attacked, the crowd recoiled, moving away from these windows. ${ }^{6}$

Shortly after the attack on WTC 2 , the escalators connecting the $3^{\text {rd }}$ floor lobby area and the $1^{\text {st }}$ floor lobby area were turned off in order to allow occupants to use both escalators to descend safely. ${ }^{6} \mathrm{~A}$ building manager raised the loading dock doors (not generally considered to be a part of the building egress system) on the west end of the south side of the building and directed the occupants to proceed west on Vesey Street and then north on the west side of Washington Street, away from WTC 1 and WTC 2. In addition to this exit being protected by the overhead Promenade Bridge on Vesey Street, the path was protected on Washington Street by scaffolding on the exterior of the Verizon building. Occupants were instructed to stay close to the building and proceed north and away from the WTC complex. ${ }^{6}$

By the time WTC 2 collapsed, it appears that all the building occupants who intended to leave WTC 7 had done so, except for those mentioned in Section 6.5.2.

\subsubsection{Occupancy after 10:00 a.m. EDT}

Several individuals were inside WTC 7 after the collapses of WTC 2 and WTC 1, respectively, each with varied reasons to be inside the building.

- Several people were still in the building at the time when WTC 2 collapsed 9:59:03 a.m. These included four representatives from Silverstein Properties, two U.S. Secret Service agents, and two other occupants with business inside the building. The rescue of these last two was recounted in Section 6.5.2.

- Video footage (Section 5.5) showed a reporter entering WTC 7 through the revolving doors from Vesey St. some time after WTC 2 collapsed, but prior to the WTC 1 collapse. The $1^{\text {st }}$ floor lobby, with substantial broken glass on the south façade, had a significant layer of dust and debris. The reporter ascended the escalator to the $3^{\text {rd }}$ floor lobby, where he interviewed an officer from the U.S. Secret Service. After panning the western and southern walls of the $3^{\text {rd }}$ floor lobby and discussing the collapse of WTC 2, the reporter descended the (stopped) escalator and exited WTC 7 through the broken glass wall. Of significant note was the "whoop" of the fire alarm audible in the lobbies (Section 5.5.1). 
- A firefighter entered WTC 7 shortly after the collapse of WTC 1 and remained inside for approximately $5 \mathrm{~min}$, until finding out that the building had been evacuated. Around 3:00 pm, while on the corner of Barclay Street and West Broadway, the firefighter was approached by six or seven law enforcement officers who requested assistance in rescuing police dogs from the underground level of WTC 7. Upon entering the basement and looking for the place where the dogs were kept, they observed several areas of significant collapse debris. After determining that the area where the dogs were kept was not safe, they quickly made their way out of the building using the same driveway ramp through which they had entered. ${ }^{12}$

\subsubsection{Estimation of the Minimum Required Evacuation Time}

All modes of evacuation were available to the occupants on September 11, 2001, including elevators and stairwells. However, it was not known what fraction of the occupants took each mode.

NIST estimated that, if everyone had used the elevators, assuming optimal car loading, and allowing about 5 min of activity before people began moving toward the elevator lobbies (see NIST NCSTAR 1-7, 2005), everyone could have been transported to the $3^{\text {rd }}$ floor lobby in about 30 minutes.

- The elevator system in WTC 7 was designed to move 12 percent of 90 percent of the building population in $5 \mathrm{~min}$. Had there been about 5,000 people (the upper limit of the actual occupancy estimate in Section 7.5.2) in the building at that time on September 11, 2001, it would have taken approximately $20 \mathrm{~min}$ for the elevators to have transferred everyone from their floor of origin to the $3^{\text {rd }}$ floor lobby. Even if the maximum estimate of 14,000 people had been present at the start of the evacuation, the elevators would have taken approximately $60 \mathrm{~min}$ to move all of the occupants to the $3^{\text {rd }}$ floor lobby.

- If the elevator evacuation were combined with stairwell evacuation, the estimate of overall evacuation time could be either reduced (if only people in the lower part of the building used the stairs) or increased (if people on the upper floors chose to use the stairs rather than the elevators).

The observed evacuation time from WTC 7 on September 11, 2001 was less than 75 min. However, the evacuation process had several atypical aspects, some slowing the evacuation process and some speeding the evacuation process:

- No building evacuation announcement was broadcast prior to approximately 9:45 a.m.

- Evacuation from the lobby and stairwells was interrupted while building management decided upon the safest path away from the building.

- Occupants from other buildings on the WTC site evacuated into the WTC 7 lobby, adding to the routine occupant load.

- Elevators were available and widely used for occupant evacuation.

${ }^{12}$ FDNY Interview 74, Spring 2004. 


\subsection{FINDINGS}

- The evacuation of WTC 7 was successful, as NIST identified no life-threatening injuries or fatalities of building occupants on September 11, 2001. Most of the occupants initiated their own evacuation shortly after WTC 1 was attacked, and the building was safely evacuated prior to the collapse of WTC 2. Evacuation took just over an hour to complete, which was somewhat longer than the minimum time expected if elevators and stairs were used to maximum advantage.

- While no occupants from WTC 7 were killed on September 11, 2001, evacuation management did not provide prompt evacuation instructions to building occupants during the event. Several key officials determined independently to evacuate WTC 7, from several minutes before WTC 2 was attacked $(\approx 9: 00$ a.m.) and shortly after WTC 2 was attacked $(\approx$ 9:05 a.m.), to shortly after the Pentagon was attacked ( $\approx 9: 45$ a.m.). The decisions appear not to have resulted in actually delivering specific guidance to the occupants via the public address system until approximately 9:45 a.m.

- Considerable crowding in the lobby of WTC 7 occurred. Occupants arrived in the lobby from both stairwells, from the elevators, and from other WTC buildings, and were held in the lobby until a safe exterior exit was identified by emergency management officials.

- The calculated stairwell capacity was insufficient to meet the requirements of the NYCBC in effect during the design and construction period, if the building were occupied at the calculated maximum level ( $\approx 14,000$ people). The capacity was sufficient for the normal occupancy of the building $((\approx 8,000$ workers plus visitors), estimated by NIST, and was more than sufficient for the occupancy on September 11, $2001(\approx 4,000$ people), also estimated by NIST. The stairwell capacity met the requirement of the (subsequent) 2006 edition of the IBC, but not the 2003 edition of NFPA 5000.

- The separation of the stairwell doors met the requirement of the 1968 NYCBC. On some floors, the separation of the stairwell doors was below the remoteness requirements in the 2000 IBC and the 2003 NFPA 5000.

- Some specific people actions likely contributed to the speed and overall success of the evacuation. Evacuation drills had been conducted every six months in WTC 7. On September 11, 2001, the decision to prevent occupants from exiting the stairwells out into the streets where they could be impacted by debris from WTC 1 and WTC 2 likely prevented injuries or deaths. Using the loading dock exit to provide overhead protection, combined with the scaffolding protection along the other side of Washington Street, was an example of spontaneous decisionmaking on the part of the building management which likely contributed to the positive outcome.

\subsection{REFERENCES}

Cantor 1985. Irwin G. Cantor P.C., Structural Engineers, Structural Drawings, 7 World Trade Center.

Fire Safety Plan. Appendix A: Fire Safety Directors Duties. Approved 4/18/98. WTCI-13-NYC.

Marked received by FDNY Nov 13, 2002). 
Fisher, R. P., K. L. Falkner, M. Trevisan, and M. R. McCauley. 2000. Adapting the cognitive interview to enhance long-term (35 years) recall of physical activities. Journal of Applied Psychology 85, no. 2:180-189.

Flack and Kurtz 1988. Flack and Kurtz Mechanical Engineers, Mechanical and Electrical Drawings for Salomon Brothers 7 World Trade Center Headquarters.

Geiselman, R. E., R. P. Fisher, D. Mackinnon, and H. Holland. 1986. Enhancement of eyewitness memory with the cognitive interview. American Journal of Psychology 99:385-401.

IBC (International Building Code). 2000. International Building Code, International Code Council, Falls Church, VA.

Keating, J. and E. Loftus. Post Fire Interviews. 1984. Development and Field Validation of the Behavioral Sequence Interview Technique. NBSIR 84-477. 1984. Nat. Bur. Stand. (U.S.).

NFPA (National Fire Protection Association). 2003. Building Construction and Safety Code, NFPA 5000, Quincy, MA.

NYCBC (New York City Building Code). 1968. Building Code-Local Law 76 of the City of New York, New York, NY.

Roth 1985. Emery Roth \& Sons P.C., Architects, Architectural Drawings, 7 World Trade Center.

Syska \& Hennessy Group Inc. 1984. 7 World Trade Center: Summary of Mechanical and Electrical Systems. New York, NY, May.

Syska \& Hennessy 1985. Syska \& Hennessy Engineers, Mechanical, Electrical, and Plumbing Drawings, 7 World Trade Center. 
This page intentionally left blank. 


\section{Chapter 8 \\ INITIATING EVENT HYPOTHESES}

\subsection{INTRODUCTION}

This chapter addresses the initiating event and collapse propagation hypotheses that formed the basis of the technical approach to determine why and how the 47 story WTC 7 building collapsed on September 11, 2001. Specifically, NIST considered (1) building contents fires on tenant floors, (2) fuel oil fires from leaks in the emergency generator fuel systems, (3) hypothetical blast events, and (4) fires in the Con Edison substation.

The leading collapse hypothesis will be presented first, followed by supporting evidence and calculations that led to the hypothesis. Prediction of the growth and spread of fires from fire simulation models, analysis of heating of the structural elements due to these fires, and structural analysis of the initiating event hypothesis and global response are presented in subsequent chapters.

\subsection{LEADING COLLAPSE HYPOTHESIS FOR WTC 7}

Based on observations and analyses of photographic and videographic records, critical study of the steel framing, and simplified and detailed analyses to investigate possible failure modes that could lead to an initiating event, the following leading collapse hypothesis was identified.

\section{Initial Local Failure for Collapse Initiation}

An initial local failure occurred at the lower floors (below Floor 14) of the building due to fire-induced floor failures, leading to buckling of a critical column (the initiating event) which supported a large-span floor bay with an area of about $200 \mathrm{~m}^{2}\left(2,000 \mathrm{ft}^{2}\right)$.

The leading hypothesis for the failure sequence that characterized the initial local failure was based on fire-induced failure events in the tenant floors. Floor beams, girders, slabs, and connections heated more quickly and to higher temperatures than the columns. Elevated temperatures in the floor elements led to thermal expansion, with or without thermal weakening and sagging, which resulted in failure of floor connections and/or buckling of floor beams. Sufficient floor component failures (connections and/or beams) resulted in at least one unsupported column over multiple floors at the lower floors. This column buckled and led to the initiation of global collapse.

\section{Vertical Progression of Failure}

Vertical progression of the initial local failure occurred up to the east penthouse, and as the large floor bays became unable to redistribute the loads, this initial local failure brought down the interior structure below the east penthouse. 


\section{Horizontal Progression of Failure}

Triggered by damage due to the vertical failure below the east penthouse, the failure progressed horizontally across the lower floors (in the region of Floors 5 and 7 that were much thicker and more heavily reinforced than the rest of the floors), resulting in a progressive collapse of the entire structure.

\section{Other Collapse-Related Possibilities}

The leading hypothesis was based on an initial local failure caused by ordinary building contents fires, not fires from leaking pressurized fuel lines or fuel from day tanks. These other factors were considered as possible collapse hypotheses, but were ruled out, as discussed subsequently in Section 8.9.1.

While NIST found no evidence of a blast or controlled demolition event, it evaluated the consequences of hypothetical blast scenarios that could have led to the structural failure of one or more critical elements (Section 8.9.2).

The Con Edison substation was also found to have had no role in the collapse of WTC 7 (Section 8.9.3).

\subsection{WTC 7 COLLAPSE OBSERVATIONS}

\subsubsection{Visual Images}

The collapse of WTC 7 was recorded on several videos taken from various locations, and the study of these videos was reported in Section 5.7. Table 5-3 shows the timeline for major WTC 7 collapse observations. Several of the collapse observations are repeated here with specific reference to annotated figures, which also appear in Section 5.7.

- East edge of the east penthouse started to move downward, roofline quickly "kinked" roughly 40 percent of the way from the east side of the penthouse (Figure 8-1).

- Two sections of the east penthouse rotated inward as the roof below gave way and the east section disappeared below the roof parapet wall (Figure 8-2). Window breakage occurred on the north face of the building near Columns 43 and 45 as the penthouse collapsed.

- Horizontal motion of the northwest corner of the building was detected during the collapse of the east penthouse and vertical progression of failure, as evidenced by video frame subtraction, as explained in Section 5.7 (Figure 8-3).

- Daylight was visible through the windows on the $47^{\text {th }}$ floor after the entire east side of roof collapsed (Figure 8-4).

- Beginning of global collapse of WTC 7 was detected as the building roofline below the east penthouse location and the eastern end of the screenwall started dropping simultaneously, and the east edge of the north wall rotated northward and developed a kink near Column 47 (Figure 8-5).

- The entire upper portion of the building, i.e., all floors visible in the videos, began to move downward, and window breakage occurred on the west side of the north face between Columns 
53 and 55 as the building collapsed (Figure 8-6). The dashed red lines in Figure 8-6 are the silhouette of the building from Figure 8-1. They are included to provide a qualitative indication of the extent to which the upper portion of WTC 7 had descended.

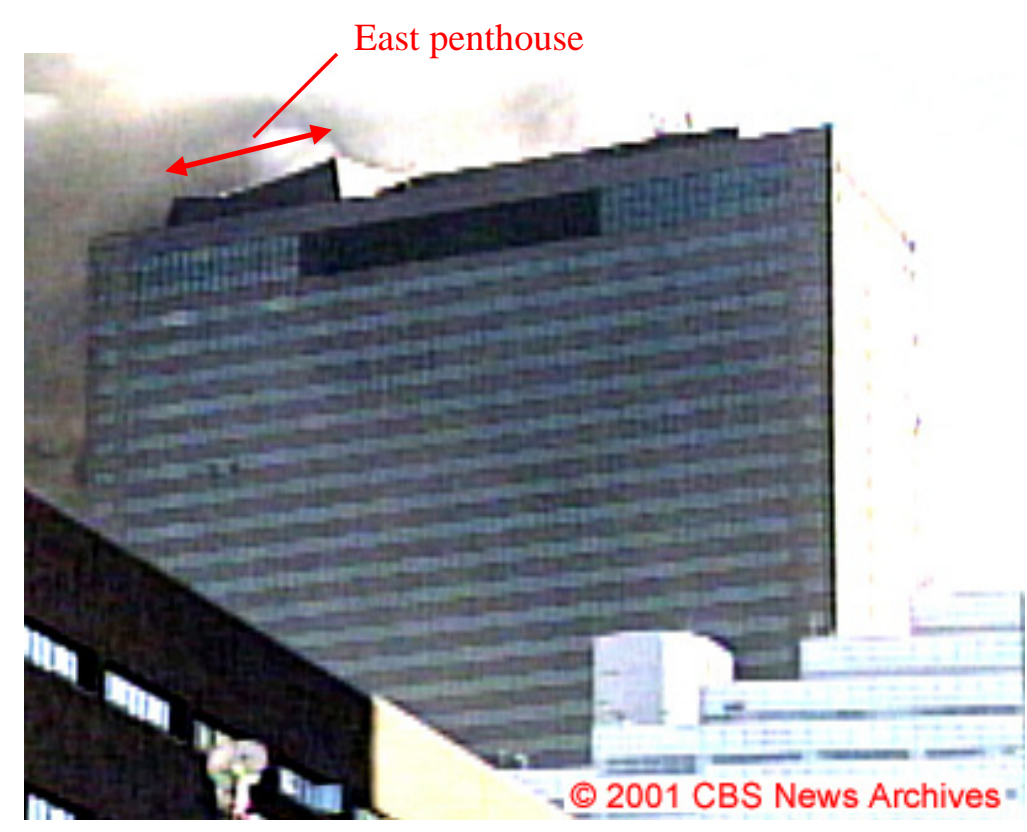

Figure 8-1. East penthouse kinks and begins to collapse.

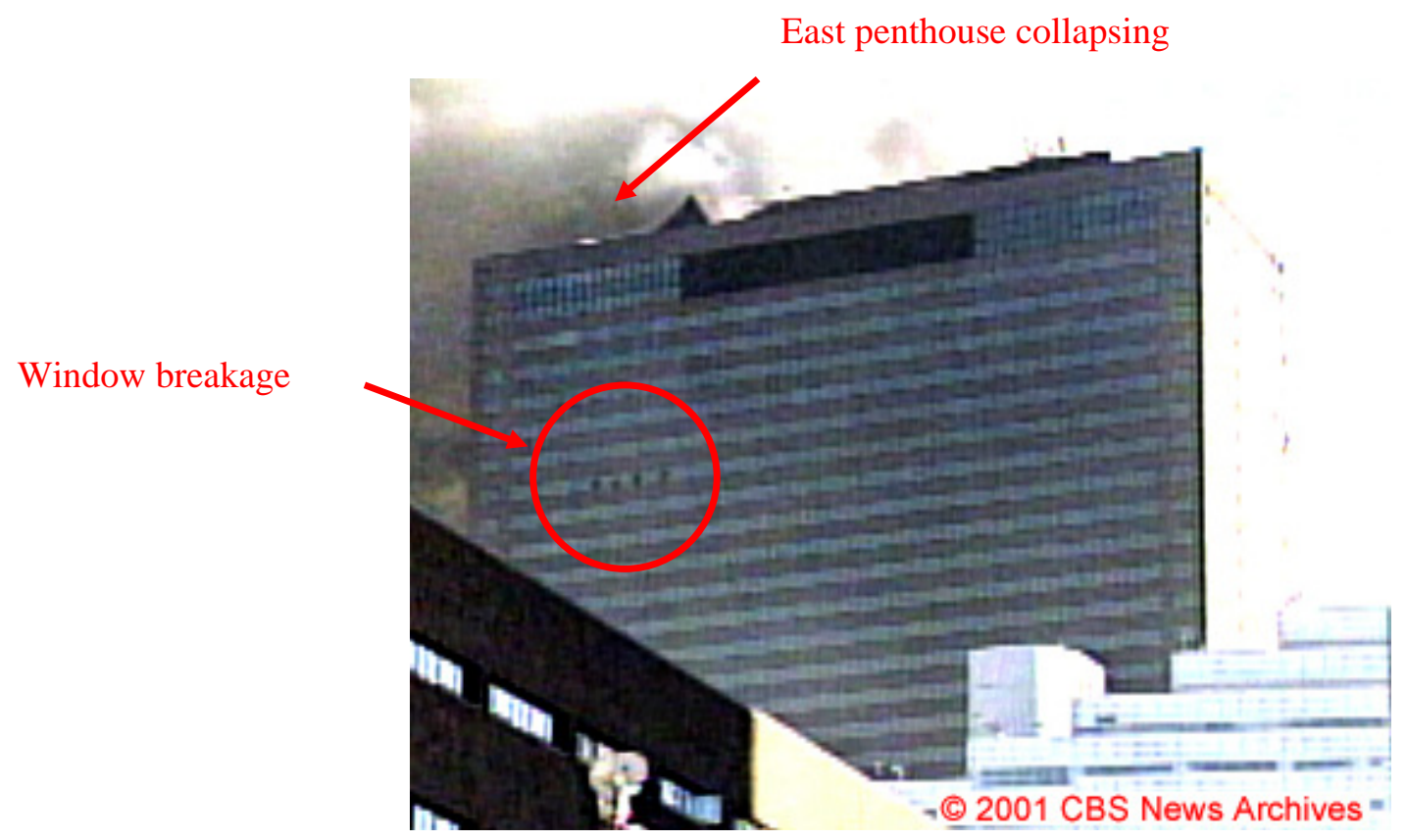

Figure 8-2. East penthouse collapses as roof gives way - windows break between column lines 43 and 45. 


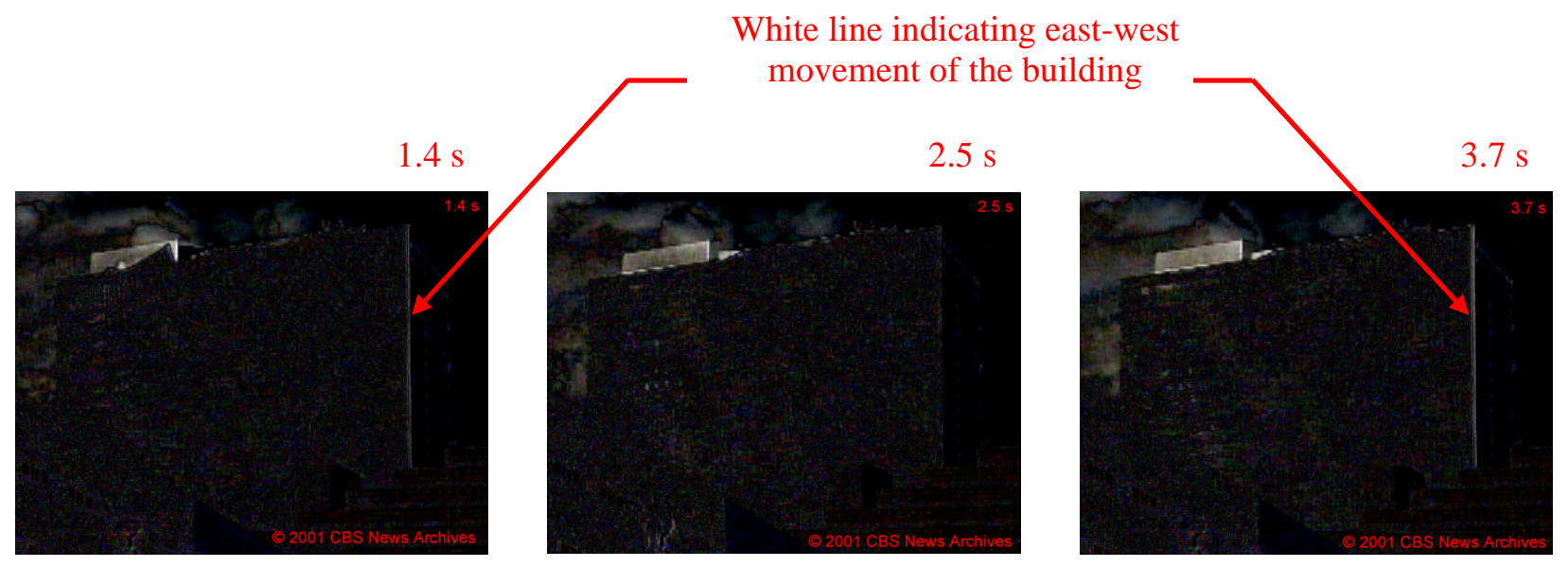

Figure 8-3. Motion of northwest edge of building detected by video frame subtraction.

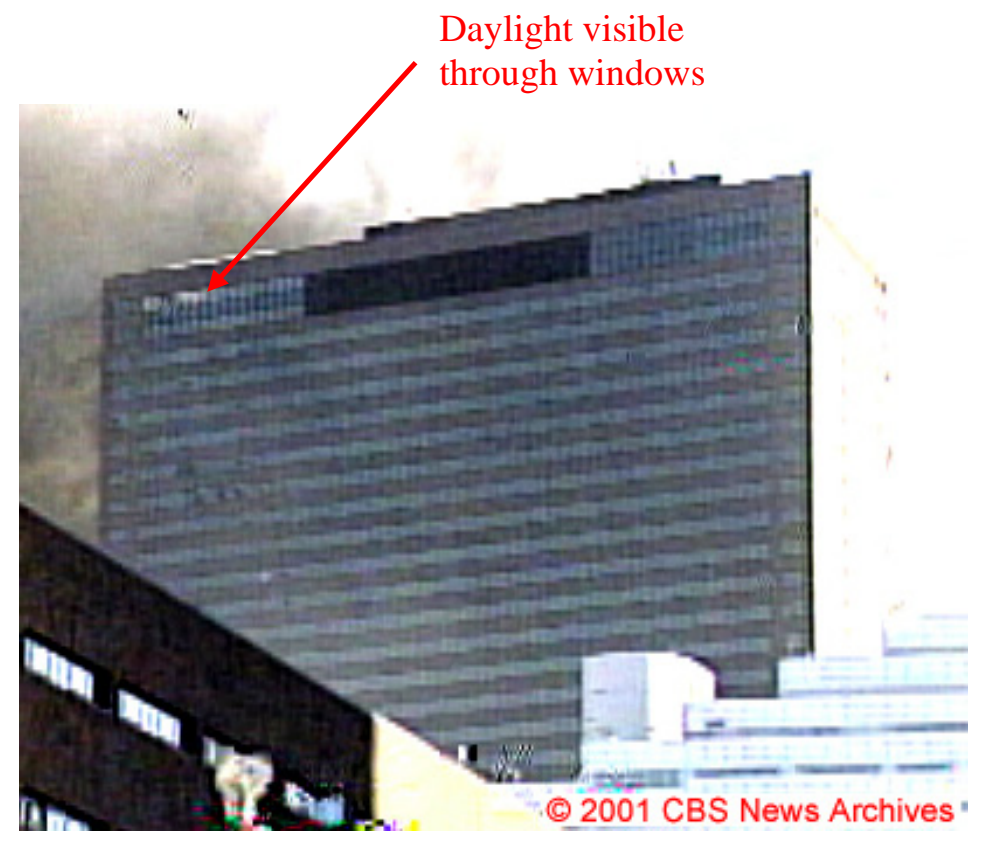

Figure 8-4. Daylight visible where roof collapsed on east side of building. 


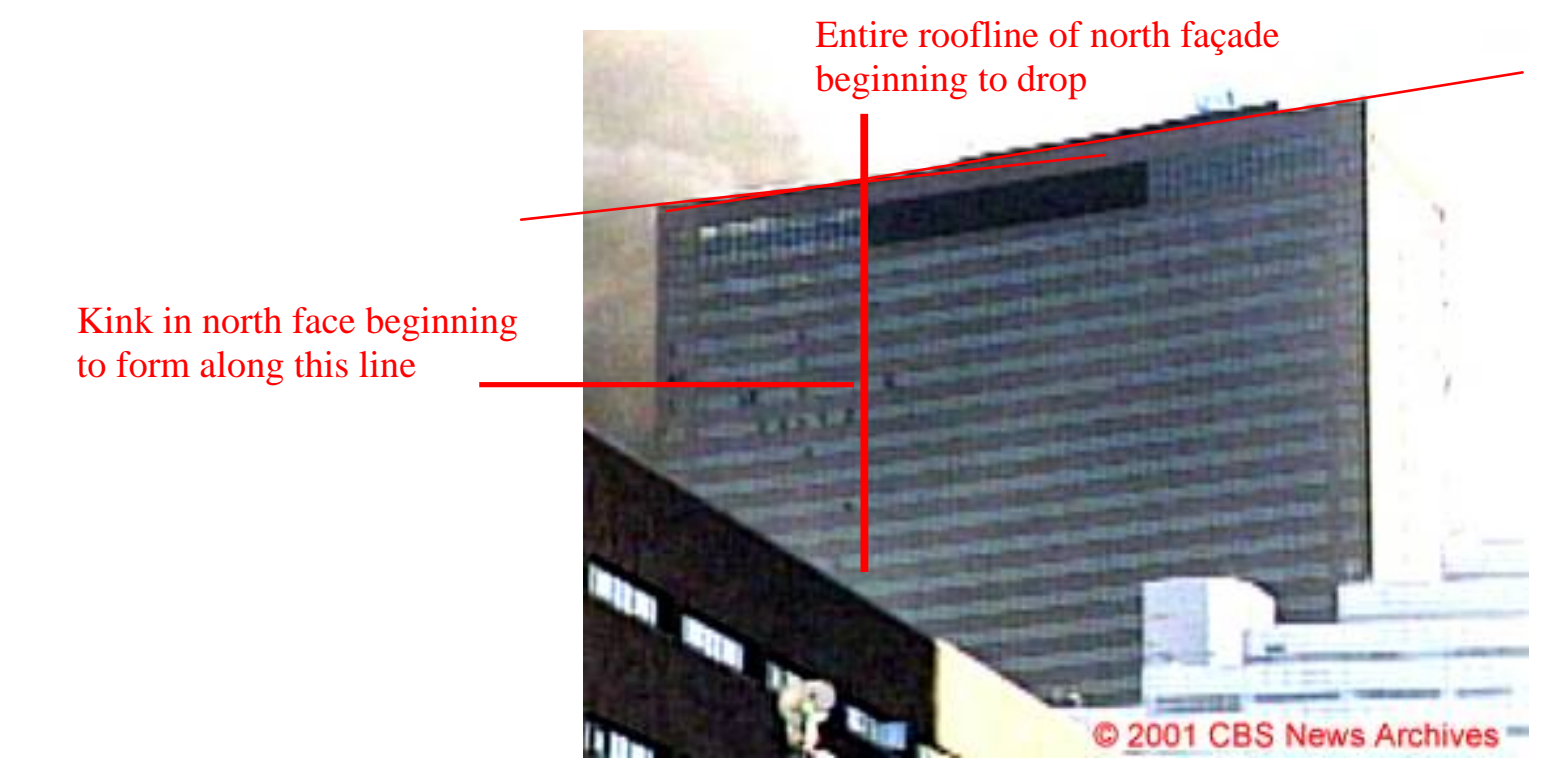

Figure 8-5. Global collapse of WTC 7 begins about seven seconds after the onset of collapse of the east penthouse.

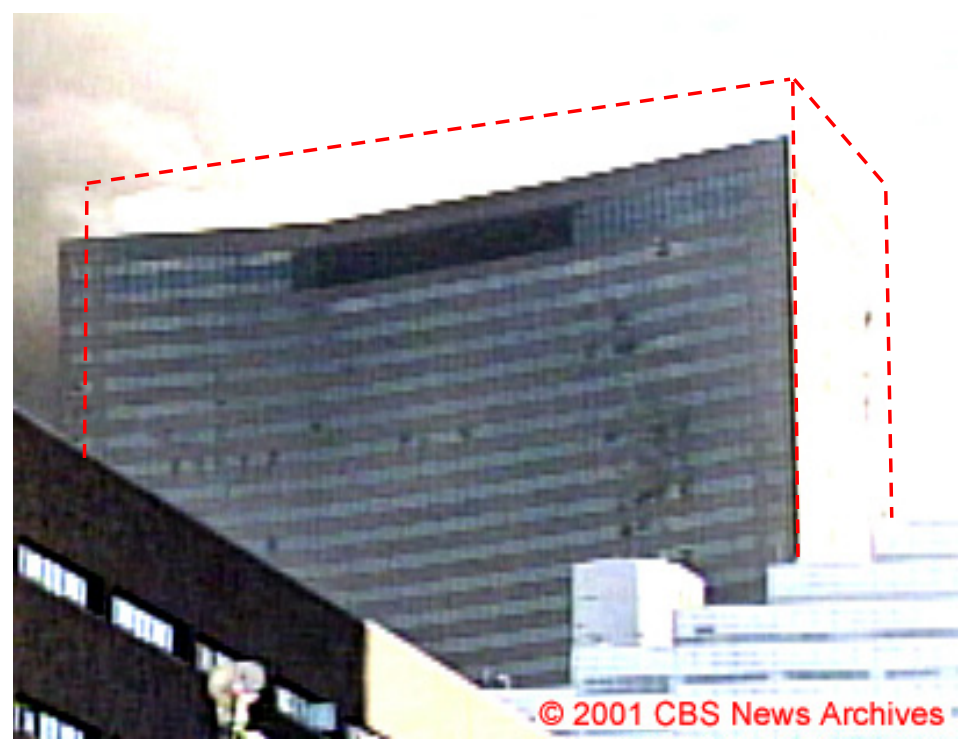

Figure 8-6. Entire building continues to collapse.

\subsubsection{Implications of Collapse Observations}

In this section, the key observations noted above are considered in the context of the building's framing to understand their relevance to the collapse initiation. 


\section{Onset of Collapse of the East Penthouse}

A video taken from essentially due north was used to measure the location of the kink that formed in the roof of the east penthouse at the onset of collapse (Section 5.7.2). The kink formed approximately 40 percent of the distance from the east edge of the penthouse to the west edge of the penthouse (Figure 81). Plotting this location on the penthouse framing plan shows that the kink was located essentially at Post 17 (indicated as "P17" in Figure 8-7). This post was supported directly on the roof girder spanning between Column 79 and Column 44. Since exterior Column 44 was observed in the video to not fail, and the entire penthouse moved downward, not just the north portion, it was likely that initiation of the collapse of the east penthouse was preceded by the initial local failure of Column 79.

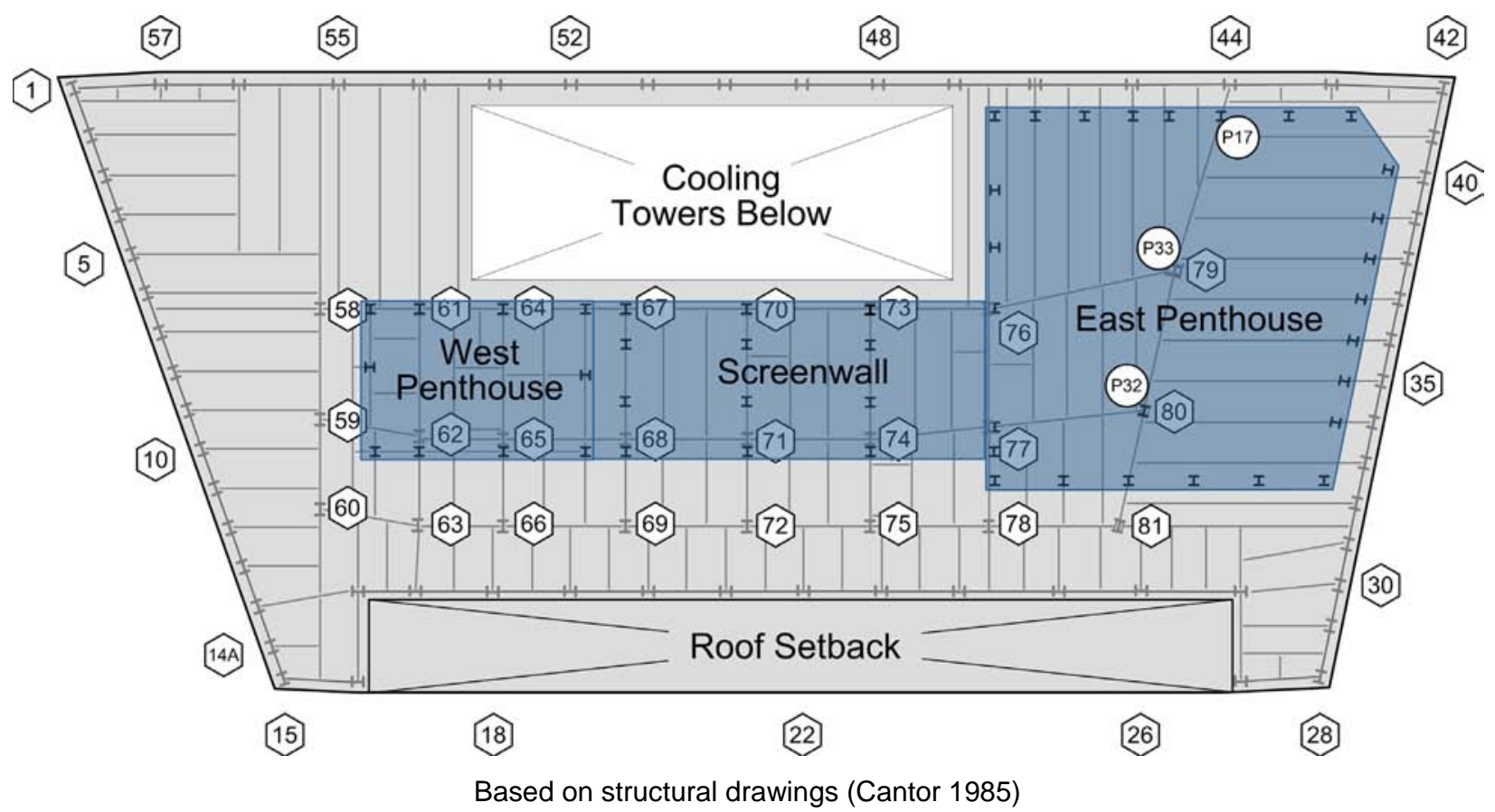

Figure 8-7. Framing of east penthouse.

\section{Inward Rotation of the East Penthouse as the Roof Below Gave Way}

For the widespread failure of the roof on the east side of the building to occur, as evidenced by daylight visible through the upper story windows (Figure 8-4), it appeared likely that Column 79 failed along with the girders that framed into it (including the one that spanned to Column 44) and the surrounding roof beams. The east side of the east penthouse was observed to first move downward before rotating inward, which would be consistent with loss of support of the failed roof beams. The west side of the east penthouse did not move downward initially (Figure 8-2), but rather rotated about its base, which aligned with the east edge of the core along Columns 76, 77 and 78 (Figure 8-7). Thus, at the time of collapse of the east penthouse, it is likely that at least the east edge of the core was still supporting load. 


\section{East-west Motion of the Building as the East Penthouse Collapsed}

As evidenced by the breaking glass in the upper stories (Figure 8-2 and Figure 8-4), collapse on the east side of the building was not limited to the roof and penthouse. Failures were likely occurring on many floors below with sufficient energy to cause the 47 story building to move laterally in its strong (eastwest) direction (Figure 8-3). An analysis of one of the videos using frame subtraction to highlight differences between two video frames (Appendix C), revealed that the northwest edge of the building showed horizontal motion of around 15 in. peak-to-peak oscillation as the east penthouse collapsed (Figure 8-8). Measurable, though smaller, vibrations (about \pm 2 in.) were detected at least 6 s before the east penthouse began to collapse. This suggested that a major disturbance occurred within the building prior to visible evidence of collapse (movement of the east penthouse) from available video recordings.

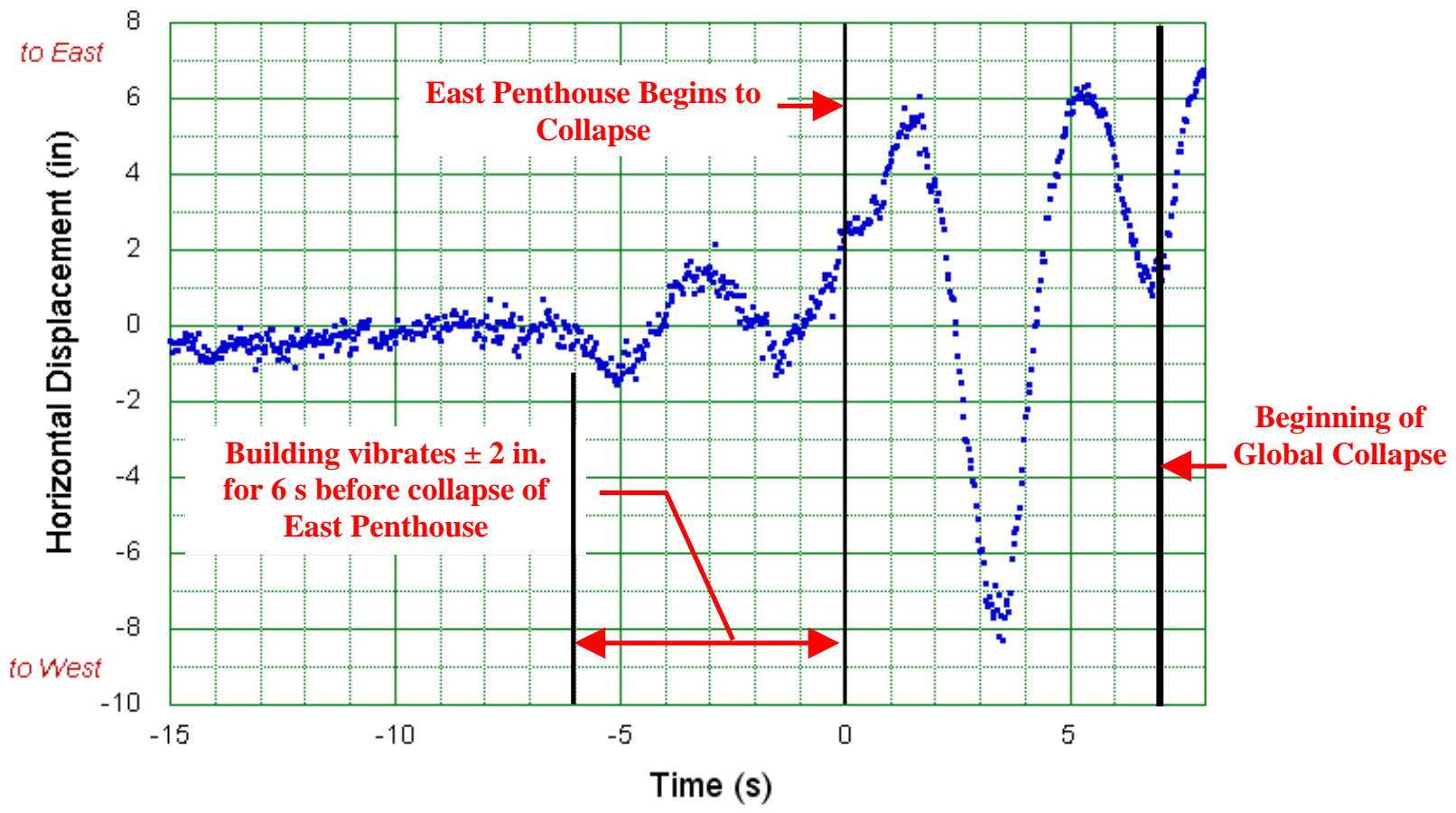

Figure C-8 (Appendix C) with annotations

Figure 8-8. Horizontal motion detected on the northwest edge of the building.

\section{Collapse of the Entire Building}

The global collapse of WTC 7 began approximately $7 \mathrm{~s}$ after the onset of downward movement of the east penthouse (Figure 8-5). At this time, the entire upper section of the building - all floors visible in the videos - moved downward together, suggesting widespread failure of the support structure (columns and/or transfer trusses) in the lower levels of the building (Figure 8-6).

\subsection{BUILDING CONTENTS FIRES}

If, as identified above, the failure of Column 79 were consistent with the observations and interpretations of the photographic and videographic evidence, then the possible causes of failure of Column 79 needed to be investigated. 
Steel column failure is generally characterized by inelastic buckling and, as a consequence, is a function of inelastic material behavior (i.e., yielding) and local and/or global instability. The strength of a column is related to the properties of the steel (in this case, possibly at elevated temperatures), the shape of the cross section, and the unbraced length (i.e., the distance between points of lateral support). In a building frame, a column is considered to be braced where each floor frames into the column and, thus, the unbraced length would be the floor-to-floor height. Since a column's cross section is not likely to change, a column subject to fire could fail (1) if its material properties are diminished by fire exposure sufficient to result in column instability, or (2) if failures of floor framing increase the unbraced length sufficient to result in column instability. Both of these possible hypotheses were investigated.

\subsubsection{Column Failure by Heating}

Heating of a column could occur as a result of a building contents fire, or as had been suggested, from a diesel fire resulting from rupture of a fuel line supplying one of several emergency generators in the building. Prediction of growth and spread of building contents fires (Section 9.3.2) indicated that such fires moved from one location to the next (e.g., from one office cubicle to the next) and burned intensely in any one location for roughly $20 \mathrm{~min}$ to $30 \mathrm{~min}$. However, the large floor area surrounding Column 79 would have had sufficient combustibles (i.e., cubicles) to support fires in that area for two to three hours. A diesel fuel fire could also have occurred in the vicinity of Column 79, but analyses have shown (Section 9.2) that the duration of such a fire would be limited to less than two hours.

A thermal analysis was conducted of Column 79, typical of the geometry found on lower floors, i.e., a W14x730 section with cover plates and thermal insulation (see Chapter 9). Based on the knowledge that the yield strength of steel is reduced to roughly 50 percent of its room temperature value at steel temperatures of around $500{ }^{\circ} \mathrm{C}$ to $600{ }^{\circ} \mathrm{C}$, it was found that it would take roughly $6 \mathrm{~h}$ of continuous exposure from a fully developed fire (gas temperatures of around $1100^{\circ} \mathrm{C}$ ) to reach these temperatures. Therefore, it would not have been possible for a building contents fire to have heated a massive, insulated column such as Column 79 to the point of failure.

Sections 9.2 and 8.9.1 show that the worst-case scenarios associated with ruptured fuel lines generated fires that could not be sustained long enough, would have produced too little heat to raise the temperatures of the steel to the point of significant loss of strength, and/or would have led to the flowing of smoke out the ventilation louvers, which contradicts the visual evidence.

\subsubsection{Column Failure by Loss of Lateral Support (increased unbraced length)}

Floors that frame into a column provide lateral support to the column. If a building had a regular floor-tofloor height, h, then failure of one floor would result in an unbraced column length of $2 \mathrm{~h}$. Likewise, failure of two floors would result in an unbraced column length of 3h, and so on. If a sufficient number of floors were to fail, the column could buckle even if it were not weakened by heating. This simple explanation assumes that the load on a column remains constant. In reality, the load on a column can change as fires grow and spread and non-uniformly heat the steel frame. Such load redistribution is accounted for in the analyses conducted in this investigation. The possibility of floor failure in fire is explored in detail in later sections of this chapter. 
Failure of a floor beam in fire is an infrequent event, and, indeed, there have been many building fires that have not resulted in even local failures of the floor system. The challenge was to determine if a fireinduced floor system failure could occur in WTC 7 under an ordinary building contents fire.

\subsection{LESONS FROM HISTORIC HIGH-RISE FIRES}

To determine whether there were aspects of the design or construction of the building that could have contributed to column failure by loss of lateral support, NIST considered other buildings that had survived multiple-floor fires, particularly those for which there is documentation on the performance of the structural system as well as characterization of the fire conditions. Three buildings were considered: One Meridian Plaza building in Philadelphia, the First Interstate Bank building in Los Angeles, and the eight story steel frame building used in some Cardington Tests in England. The Cardington Test structure was not subjected to fires on multiple floors, but the fires were well characterized (gas temperatures measured) and the structural performance well documented. The other two buildings had building contents fires that were not suppressed initially by sprinklers and grew to involve multiple floors before they were extinguished.

\subsubsection{One Meridian Plaza}

At approximately 8:30 p.m., February 23, 1991, a fire was reported at One Meridian Plaza, a 38 story office building in Philadelphia (Figure 8-9). The fire, which started on the $22^{\text {nd }}$ floor, ultimately consumed the $21^{\text {st }}$ through $29^{\text {th }}$ floors. Fire fighting operations were suspended when it was determined that there was a possibility of a major structural collapse; the fire was extinguished only when it reached the $30^{\text {th }}$ floor, which had a functioning automatic sprinkler system. Information regarding this fire, taken largely from Eisner and Manning (1991), Klem (1991), and Routley et al. (1991), is summarized here.

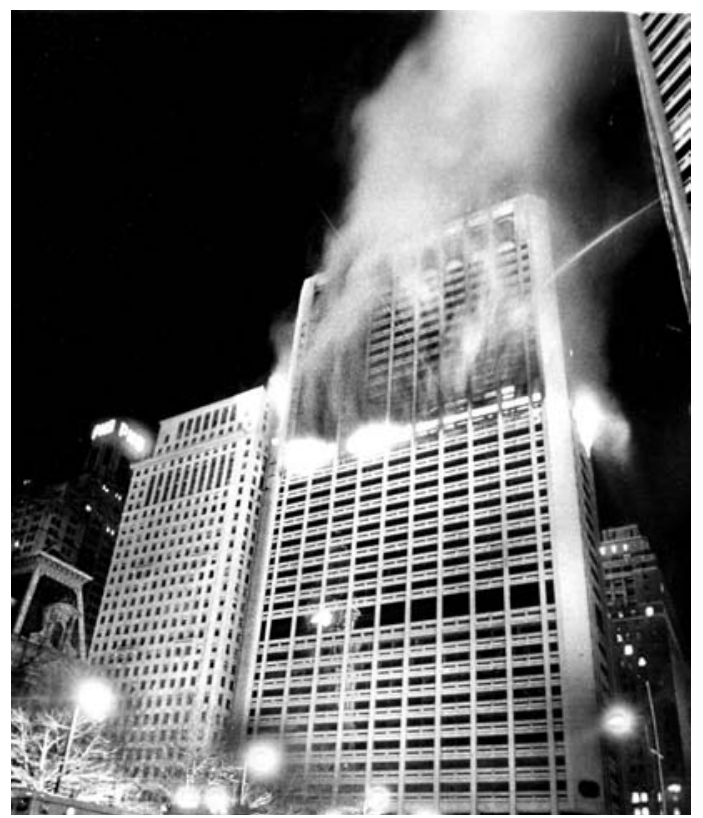

Source: Michael Wirtz/Philadelphia Inquirer, used with permission

Figure 8-9. One Meridian Plaza fire, Philadelphia, 1991. 


\section{The Building}

The One Meridian Plaza office building was designed and built to the 1949 Philadelphia Building Code and was completed in 1969. It was classified as "Type 1B" construction requiring $3 \mathrm{~h}$ fire-rated columns, and $2 \mathrm{~h}$ fire-rated beams. The building was steel frame construction with non-composite concrete slab floors over metal deck. It had moment frame construction with all girder-to-column connections moment resisting , i.e., what would today be termed "fully restrained." Beams were protected with cementitious sprayed fire-resistive material (SFRM), and the columns were encased in plaster and gypsum. Columns were reported to have a $4 \mathrm{~h}$ fire resistance rating, which exceeded the $3 \mathrm{~h}$ code requirement.

The building was approximately $68 \mathrm{~m}$ by $29 \mathrm{~m}$ (223 ft by $94 \mathrm{ft}$ ) in plan and had an open-plan floor layout with offices around the periphery (Figure 8-10). There was a service core located on the south side of the building leaving roughly $1,600 \mathrm{~m}^{2}\left(17,000 \mathrm{ft}^{2}\right)$ of tenant space per floor. The $22^{\text {nd }}$ floor, where the fire started, had a "convenience stairway" to the $21^{\text {st }}$ floor which was open (i.e., not separated by fire-rated partitions and doors). There was a similar stairway connecting the $24^{\text {th }}$ and $25^{\text {th }}$ floors, allowing for easy vertical fire spread.

\section{Fire Protection Systems}

An automatic sprinkler system was being installed in the building, and tenant floors were sprinklered or would have been sprinklered as they became vacant or were renovated. At the time of the fire, sprinklers had been installed on Floors 30, 31, 34, and 35, and parts of Floors 11 and 15, with installation scheduled for completion by 1993. There were three stairways, two served by 6 in. "wet” risers. Pressureregulating valves on Floors 13 through 25 had not been properly calibrated on installation and initially limited available water for fire fighting operations.

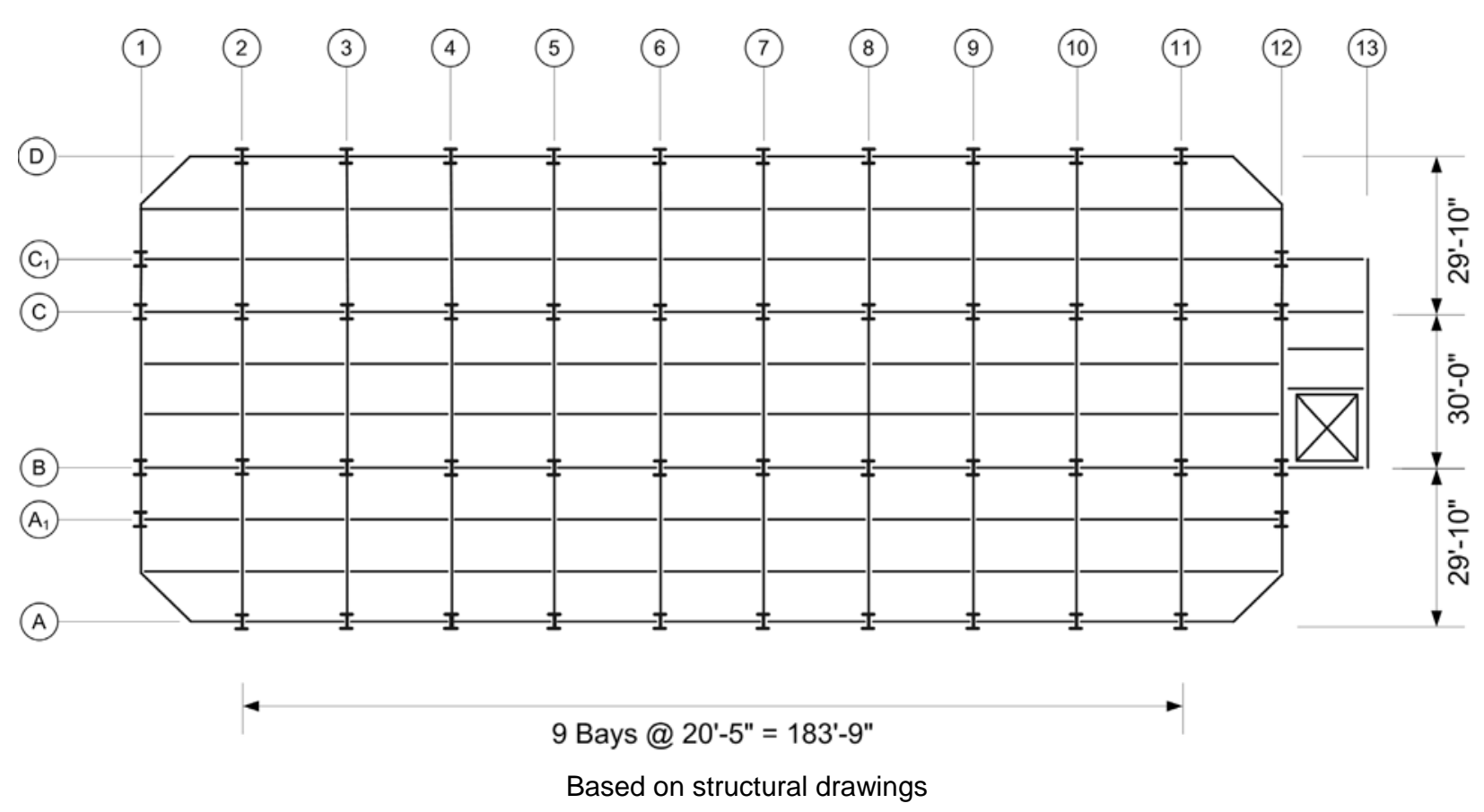

Figure 8-10. Floor framing plan for One Meridian Plaza. 


\section{Combustible Load}

The building tenants were law offices, and brokerage, banking and accounting firms. The fire load was characterized as "heavy" in the USFA Technical Report (Routley 1991) with "heavy wood paneling, heavy wood furniture, and an abundance of office machinery."

\section{Growth and Spread of Fire}

The fire was determined by the Fire Marshal of the City of Philadelphia (Eisner and Manning 1991) to have started by spontaneous heating, resulting in the ignition of oily rags left in an office where wood paneling was being refinished. The fire was first detected by a smoke alarm that activated at approximately 8:23 p.m. The Philadelphia Fire department was notified at 8:27 p.m. and the first unit arrived within $4 \mathrm{~min}$, at which time heavy smoke was reported, with fire observed from one window on the $22^{\text {nd }}$ floor.

The fire on the $22^{\text {nd }}$ floor spread to the $23^{\text {rd }}$ floor. It was reported that "Vertical fire extension resulted from unprotected openings in floor and shaft assemblies, failure of fire-resistance rated floor assemblies, and the lapping of flames through windows on the outside of the building” (Routley et al. 1991). Fire fighting efforts were severely hampered by low pressure in the standpipe water supply system and loss of electrical power, allowing uncontrolled fires to continue to spread vertically.

About six hours after the fire started, at 2:15 a.m. the next day, "fire was reported to be burning on the $24^{\text {th }}$ and $25^{\text {th }}$ floors and extending to the $26^{\text {th }}$ floor" (Routley et al.1991). Thus, fires were burning simultaneously on at least two floors at a time, and the vertical fire spread rate was approximately $90 \mathrm{~min}$ per floor. Fire fighters reported (Eisner and Manning 1991),

“...continual movement and cracking [of concrete] in all three [stair] towers. Floors had moved as much as three feet...and beam flanges were cracked. SFRM on beams in stairways had fallen off and the now-unprotected members were twisting, moving, and starting to elongate. Main structural elements were beginning to fail.”

A structural engineer advised the fire department of the potential for structural collapse, and a decision was made to pull back firefighters. The order to evacuate the building was issued at about 7:00 a.m. on February 24. Fire continued to spread vertically until, at the $30^{\text {th }}$ floor, it was stopped by automatic sprinklers.

\section{Structural Fire Damage}

The USFA report (Routley et al. 1991) indicated that, “After the fire, there was evident significant structural damage to horizontal steel members and floor sections on most of the fire damaged floors. Beams and girders sagged and twisted — some as much as three feet—under severe fire exposures, and fissures developed in the reinforced concrete floor assemblies in many places." It was reported that the columns continued to support their loads without obvious damage. The Philadelphia Fire Commissioner later commented that, "vertical member protection was a major factor in preventing a total collapse of upper floors" (Eisner and Manning 1991). Recall that the fire protection for the columns was reported to exceed the code requirements. 


\subsubsection{First Interstate Bank Building}

On May 4, 1988, fire broke out in the First Interstate Bank Building in downtown Los Angeles, burning out four floors and damaging a fifth (Figure 8-11). Fire originated on the $12^{\text {th }}$ floor and was believed to have been caused by an electrical problem, although the source of ignition was never determined (Routley 1988). The fire was eventually controlled by the Los Angeles City Fire Department that had summoned 64 companies, totaling 383 firefighters and support personnel. Information regarding this fire has been reported in United States Fire Administration Technical Report USFA-TR-022 (Routley 1988) and in (Nelson 1989) and is summarized here.

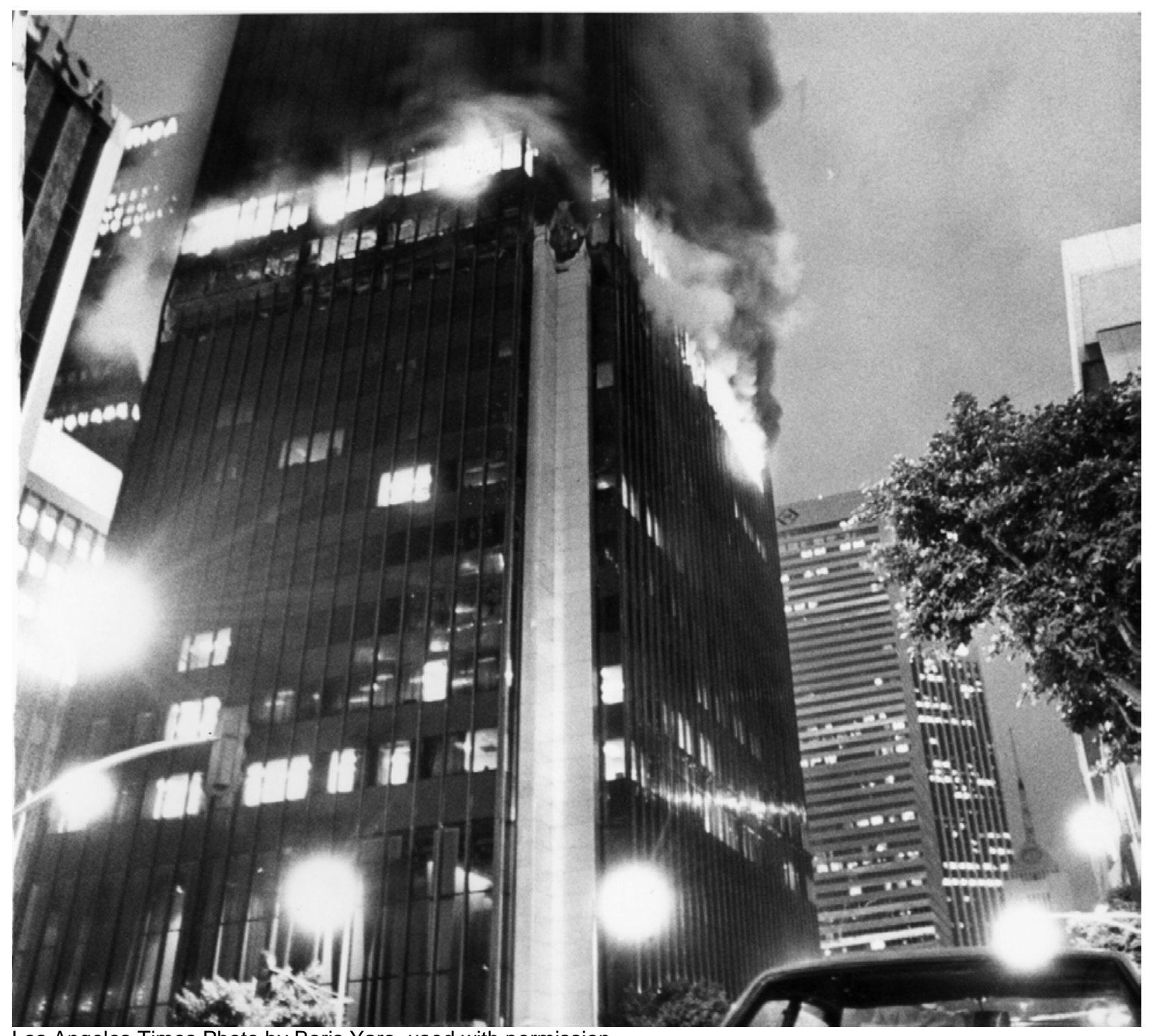

Los Angeles Times Photo by Boris Yaro, used with permission

Figure 8-11. First Interstate Bank fire, Los Angeles, 1988. 


\section{The Building}

The 62 floor office building, completed in 1973, was a steel moment frame structure with lightweight composite concrete floors over metal deck. The steel was protected with sprayed fire-resistive material. The building had a floor plan measuring $38 \mathrm{~m}$ by $68 \mathrm{~m}$ (124 ft by $184 \mathrm{ft})$, a central core, and approximately $1,600 \mathrm{~m}^{2}\left(17,500 \mathrm{ft}^{3}\right)$ of office space per floor. The tenant space was largely open-plan office space.

An automatic sprinkler system was being installed at the time of the fire. Installation was about 90 percent complete and included piping and sprinkler heads on the five floors affected by fires (Floors 12 through 16). Valves controlling the system, however, had been closed until installation of water flow alarms was to be completed. The building was served by a standpipe system with four risers - one on each stairway - providing water for fire fighting operations. While it was determined that activating the automatic sprinkler system on the fire floors would overwhelm the system and, thereby, limit the available water for fire fighting operations, the sprinklers on Floors 17 through 19 were activated in the event that fire extended above the $16^{\text {th }}$ floor.

\section{Combustible Load}

The building was occupied by the headquarters of the bank corporation, with several floors occupied by other tenants. The $12^{\text {th }}$ floor, where the fire was believed to have started in the open-plan office area, had modular furniture with personal computers and terminals, typical of those used in securities exchange activities.

\section{Growth and Spread of Fire}

A smoke detector on the $12^{\text {th }}$ floor was activated at 10:30 p.m., and the first alarm was called in at 10:37 p.m. The first fire company arrived on the scene at 10:41 p.m., at which time the Battalion Chief indicated "the entire east side and three-fourths of the south side of the $12^{\text {th }}$ floor [were] fully involved with fire” (Routley 1989).

The fire spread vertically, mostly as flames extended $30 \mathrm{ft}$ up the face of the building and through the space between the floor and glass curtain wall. Additionally, some extension was reported as occurring through floor penetrations, ventilation shafts and by conduction through the slabs (Routley 1988). The fire was eventually brought under control by the fire department at about 2:19 a.m., nearly $4 \mathrm{~h}$ after smoke was first detected at 10:30 p.m. the previous night.

The USFA report (Routley 1988) indicated that:

"The fire extended at a rate estimated at 45 minutes per floor and burned intensely for approximately 90 minutes on each level. This resulted in two floors being heavily involved at any point during the fire." 


\section{Structural Fire Damage}

According to the United States Fire Administration (Routley 1988), "in spite of the total burnout of four and a half floors, there was no damage to the main structural members and only minor damage to one secondary beam and a small number of floor pans. ... It was noted that quality control in the application of the sprayed-on fire protection was unusually good.”

\subsubsection{Multi-Story Test Building at Cardington (Test No. 6)}

An eight story test building was constructed by the British Research Establishment (BRE) at its Cardington Laboratory for the purpose of conducting a series of fire tests. The steel braced-frame building was designed and constructed to represent a typical office building, and was completed in 1993. The floor framing had simple shear connections and a rectangular grid. A series of seven tests were conducted, two of which are discussed in this section. Information regarding the various fire tests at the Cardington facility has been reported (British Steel 1999). Here, Test No. 3 is referenced in qualitative terms, and Test No. 6 is compared with the One Meridian, First Interstate Bank and WTC 7 fires.

\section{The Building}

The test building was rectangular in plan measuring approximately $21 \mathrm{~m}$ by $45 \mathrm{~m}$ ( $69 \mathrm{ft}$ by $148 \mathrm{ft}$ ) for a total floor area of $880 \mathrm{~m}^{2}\left(9500 \mathrm{ft}^{2}\right)$ excluding the service core areas. There were five equally spaced bays along the length at $9.0 \mathrm{~m}(29.5 \mathrm{ft})$ each, and bays of $6.6 \mathrm{~m}, 9.0 \mathrm{~m}$, and $6.0 \mathrm{~m}(19.7 \mathrm{ft}, 29.5 \mathrm{ft}$, and $19.7 \mathrm{ft})$ across the width (Figure 8-12). The building was 8 stories high, for a total height of $33 \mathrm{~m}(108 \mathrm{ft}$ ).

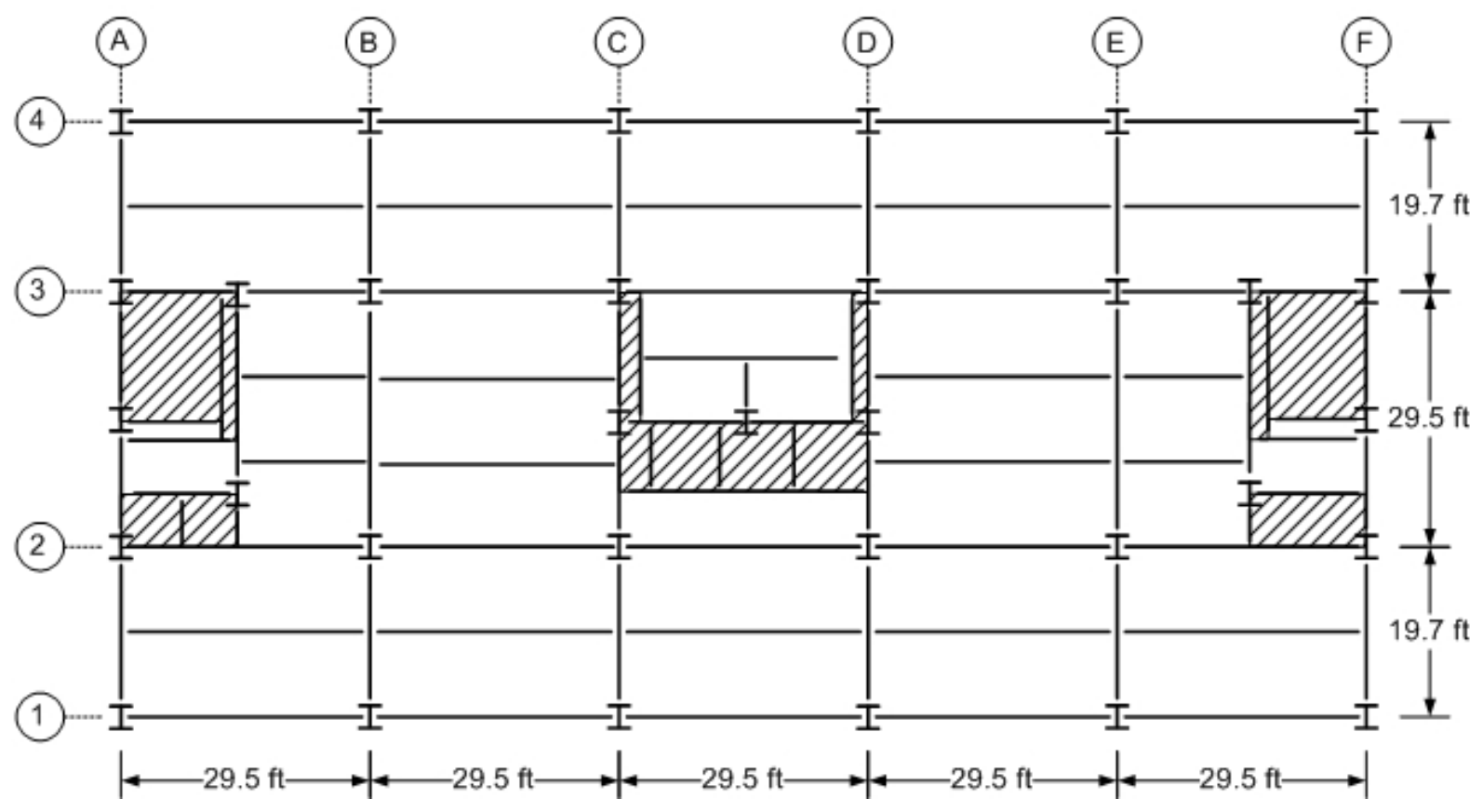

Reproduced from British Steel 1999

Figure 8-12. Floor framing plan of Cardington test building. 
Test No. 6 (Simulated Office Test) was designed to investigate the behavior of a fire covering a large floor area fueled by typical office furnishings to produce a severe fire. It involved a test area of $135 \mathrm{~m}^{2}$ $\left(1,450 \mathrm{ft}^{2}\right)$, as shown in Figure 8-13. Because it represented a large (although single floor) fire and realistic fuel load, results of Test No. 6 were used in the comparison below. Test No. 3 ( $1^{\text {st }}$ Corner) is also of qualitative interest. This test was designed to investigate a single bay of the floor system under a severe fire, and involved a test area of $76 \mathrm{~m}^{2}\left(820 \mathrm{ft}^{2}\right)$, as shown in Figure 8-13. Results of this test were used to illustrate qualitatively the effect of floor framing configuration on the behavior of floor beams and their connections to girders (Section 8.7).

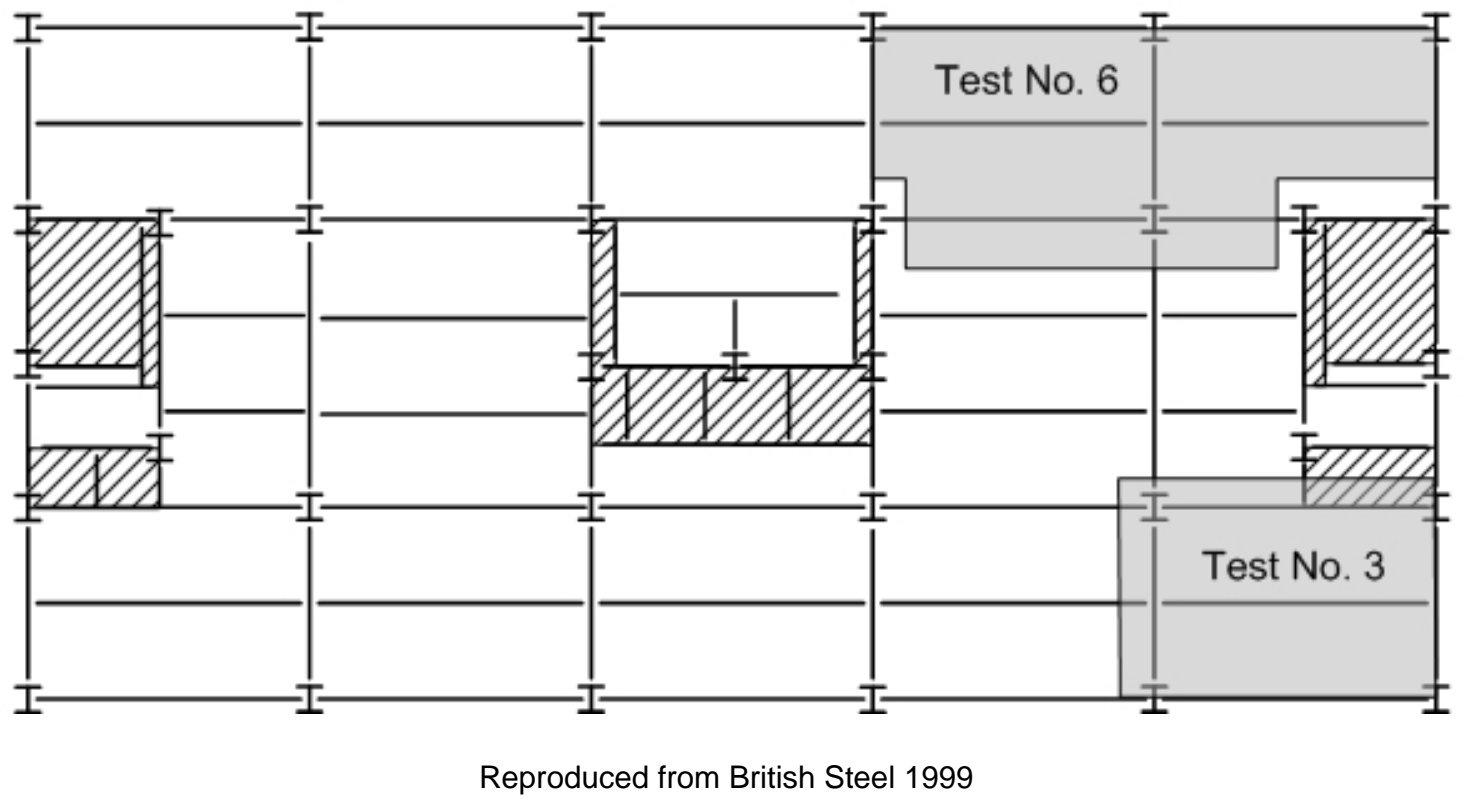

Figure 8-13. Test areas for Test No. 3 and Test No. 6.

\section{Combustible Load}

Test No. 6 involved an open-plan compartment that contained work stations consisting of modern day furnishings, computers, and filing systems. The total combustible loading was equivalent to $46 \mathrm{~kg} / \mathrm{m}^{2}$ $\left(9.2 \mathrm{lb} / \mathrm{ft}^{2}\right)$.

\section{Growth and Spread of Fire}

Test conditions (quantity and make-up of combustibles, ventilation, etc.) were designed to create the most severe fire possible. Within 10 minutes of ignition, hot gas temperatures exceeded $900{ }^{\circ} \mathrm{C}$ and reached a maximum of just over $1200{ }^{\circ} \mathrm{C}$ within $40 \mathrm{~min}$. The combustibles were nearly all consumed in $1 \mathrm{~h}$. At its maximum, the heat release rate was calculated to be $58 \mathrm{MW}$. Complete burnout, including contents of the filing cabinets, was achieved.

\section{Structural Fire Damage}

No structural failures were reported in Test No. 6, but the maximum floor sag was reported to be $0.64 \mathrm{~m}$ (25 in.) in a span of $9 \mathrm{~m}(29.5 \mathrm{ft})$. In Test No. 3, where the maximum compartment temperatures was 
approximately $960^{\circ} \mathrm{C}\left(1760{ }^{\circ} \mathrm{F}\right)$, the maximum floor beam deflection was $428 \mathrm{~mm}$ (16.8 in.), also in a span of $9 \mathrm{~m}(29.5 \mathrm{ft})$.

\subsubsection{Other Structural Failures in Fire}

Structural damage due to fire has been reported for several other steel frame office buildings in the United States in the last few decades. Two instances are mentioned here: the One New York Plaza fire that occurred in 1970, and the fire and partial collapse of World Trade Center 5 on September 11, 2001.

\section{One New York Plaza}

On August 5, 1970, fire broke out on the $33^{\text {rd }}$ floor of One New York Plaza, a 50 story office building in New York City (Powers 1970). Fire spread to the $34^{\text {th }}$ floor and then to the $35^{\text {th }}$ floor. Damage to the structural steel was reported on the $33^{\text {rd }}$ and $34^{\text {th }}$ floors. The official report on the fire, conducted by The New York Board of Fire Underwriters (Powers 1970), stated,

"Steel beams in the south corner and west center section of the $33^{\text {rd }}$ floor were twisted or deflected several inches and the connecting bolts sheared off or failed allowing the beams in some sections to rest on the flange of the girder."

"Beams [on the $34^{\text {th }}$ floor] were severely deflected and distorted and the most severe structural damage occurred in the west section of this floor."

While there were no floor collapses in this case, there were connection failures, and deflection and distortion of floor beams.

\section{World Trade Center 5}

The World Trade Center Building 5 (WTC 5) was a 9 story office building located on the northeast corner of the World Trade Center Plaza. The collapse of WTC 1 caused damage to WTC 5 and started fires in it (McAllister 2002). The uncontrolled fires resulted in complete burnout of most floors and partial collapse of four floors. The building was steel frame construction with field-bolted connections between floor beams and column tree assemblies. Failure of large sections of floor, in areas not damaged by falling debris from WTC 1, resulted from bolt tear-out at these connections as a result of the uncontrolled fires (Figure 8-14). Photographs of two recovered samples of floor beams (Figure 8-15) show how the field bolts tore out from the beam web weakened by the fires (McAllister 2002). 


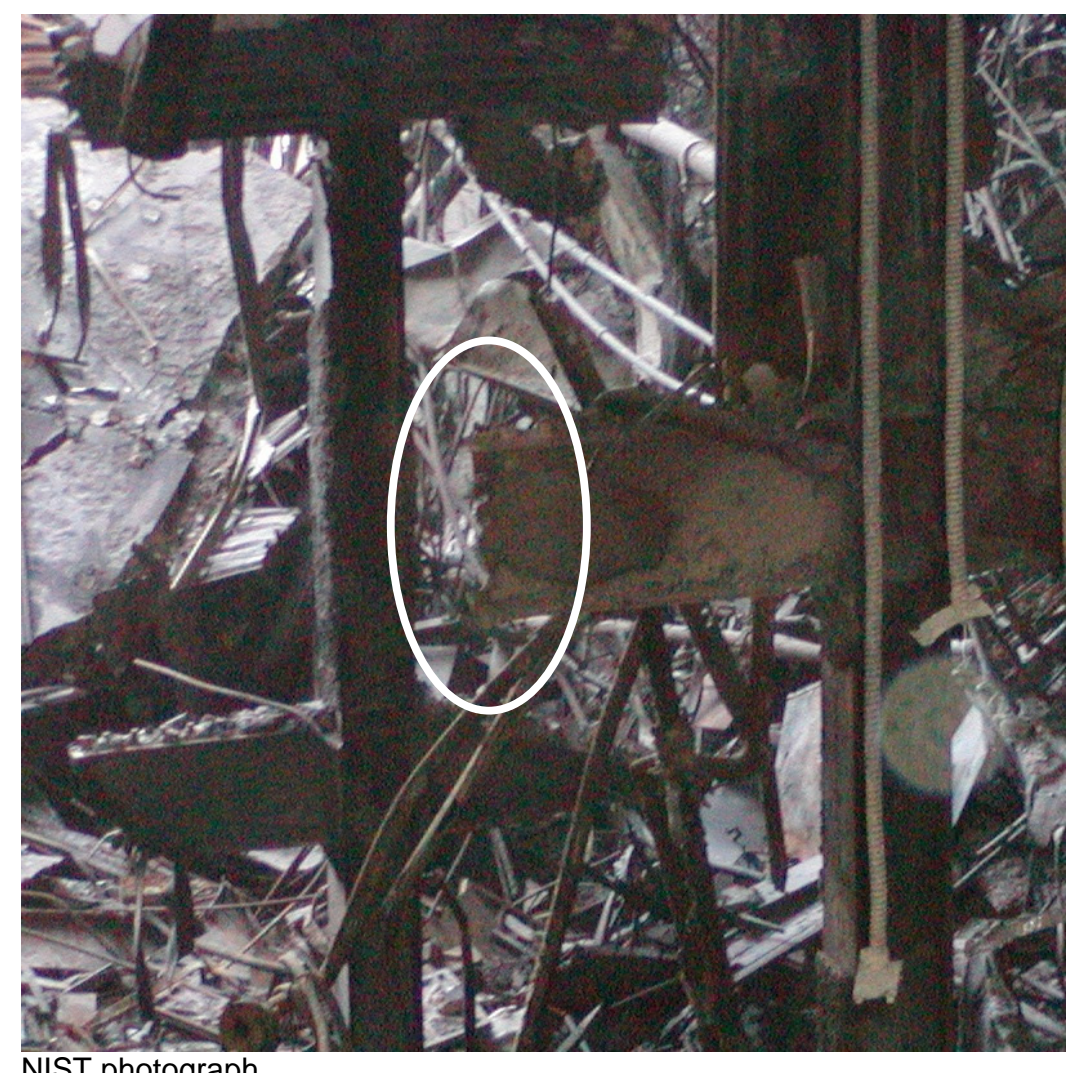

NIST photograph

Figure 8-14. Tear-out of beam web due to uncontrolled fires.
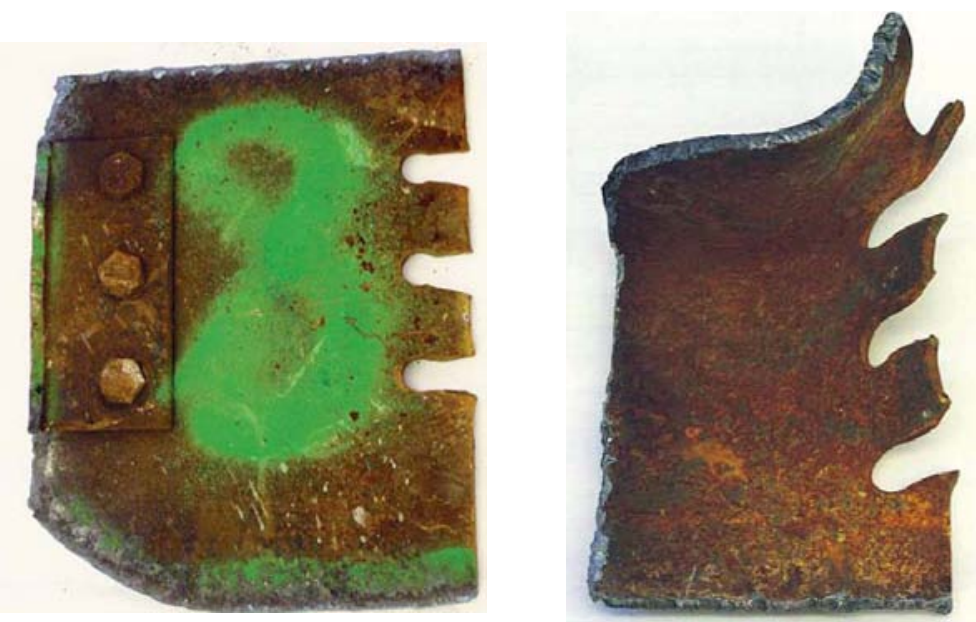

Source: McAllister 2002

Figure 8-15. Steel samples recovered from WTC 5, showing tear-out of beam web.

\subsubsection{Comparisons Among Building Fires}

Information provided in the above summaries, extracted from the USFA Technical Reports and documentation of the BRE Cardington Tests, is summarized here. 
Table 8-1. Comparison of building fires.

\begin{tabular}{|c|c|c|c|c|}
\hline & $\begin{array}{l}\text { First Interstate } \\
\text { Bank Building }\end{array}$ & $\begin{array}{c}\text { One Meridian } \\
\text { Plaza }\end{array}$ & $\begin{array}{c}\text { Cardington Test } \\
\text { No. } 6\end{array}$ & WTC 7 \\
\hline \multicolumn{5}{|c|}{ Building } \\
\hline Year Built & 1973 & 1969 & 1993 & 1987 \\
\hline Occupancy & office & office & office & office \\
\hline Number of Stories & 62 & 38 & 8 & 47 \\
\hline Plan Dimensions (ft) & $124 \times 184$ & $94 \times 223$ & $69 \times 148$ & $144 \times 329^{a}$ \\
\hline $\begin{array}{l}\text { Floor Area - excluding service } \\
\text { core }\left(\mathrm{ft}^{2}\right)\end{array}$ & 17,500 & 17,000 & $1450^{b}$ & 31,250 \\
\hline Floor Layout & open & $\begin{array}{l}\text { Open w/ offices on } \\
\text { periphery }\end{array}$ & open & open \\
\hline \multicolumn{5}{|c|}{ Construction } \\
\hline Steel Structure & $\begin{array}{l}\text { Moment-Resisting } \\
\text { Space Frame }\end{array}$ & $\begin{array}{l}\text { Moment-Resisting } \\
\text { Space Frame }\end{array}$ & Braced Frame & $\begin{array}{l}\text { Exterior Moment } \\
\text { Frame, Unbraced } \\
\text { Core }\end{array}$ \\
\hline Floor Framing & $\begin{array}{l}\text { Regular } \\
\text { grid }\end{array}$ & $\begin{array}{l}\text { Regular } \\
\text { grid }\end{array}$ & $\begin{array}{l}\text { Regular } \\
\text { grid }\end{array}$ & Asymmetric \\
\hline Bay spacing (ft) (approx.) & $30 \times 30$ & $20 \times 30$ & $20 \times 30$ & $44 \times 54^{c}$ \\
\hline Floor Slab & $\begin{array}{c}\text { Lightweight } \\
\text { concrete on metal } \\
\text { deck }\end{array}$ & $\begin{array}{l}\text { Concrete on metal } \\
\text { deck }^{\mathrm{d}}\end{array}$ & $\begin{array}{c}\text { Lightweight } \\
\text { concrete on metal } \\
\text { deck }\end{array}$ & $\begin{array}{l}\text { Concrete on metal } \\
\text { deck }\end{array}$ \\
\hline Primary Beams & composite & Non-composite & composite & Non-composite \\
\hline Secondary Beams & composite & Non-composite & composite & composite \\
\hline \multicolumn{5}{|l|}{ Floor Framing Connections } \\
\hline Beam-to-Column & $\begin{array}{l}\text { Fully restrained } \\
\text { moment }\end{array}$ & $\begin{array}{l}\text { Fully restrained } \\
\text { moment }\end{array}$ & $\begin{array}{l}\text { Simple (end- } \\
\text { plate) }\end{array}$ & $\begin{array}{l}\text { Simple (double } \\
\text { angle or seat) }\end{array}$ \\
\hline Beam-to-Girders & Unknown & simple & $\begin{array}{c}\text { Simple } \\
\text { (fin plate) }\end{array}$ & $\begin{array}{c}\text { Simple (fin plate, } \\
\text { double angle, or seat) }\end{array}$ \\
\hline \multicolumn{5}{|c|}{ Fire Protection (hourly rating) } \\
\hline Columns & $3 \mathrm{~h}$ & $4 \mathrm{~h}$ & $1 \frac{1 / 2^{e}}{}$ & $3 \mathrm{~h}$ \\
\hline Primary Beams & $2 \mathrm{~h}$ & $2 \mathrm{~h}$ & none & $2 \mathrm{~h}$ \\
\hline Secondary Beams & $2 \mathrm{~h}$ & $2 \mathrm{~h}$ & none & $2 \mathrm{~h}$ \\
\hline \multicolumn{5}{|c|}{ Fire Conditions } \\
\hline Duration of Fire (hours) & 4 & 18 & 1 & 5 \\
\hline No. of Fire Floors & 5 & 9 & 1 & 6 \\
\hline Max atmosphere (gas) temp & Unknown & Unknown & $1213^{\circ} \mathrm{C}$ & $1100^{\circ} \mathrm{C}^{\mathrm{f}}$ \\
\hline \multicolumn{5}{|c|}{ Structural Performance } \\
\hline Max steel temperature & Unknown & Unknown & $1150^{\circ} \mathrm{C}^{\mathrm{g}}$ & $740^{\circ} \mathrm{C}$ \\
\hline Structural Damage & no & yes & yes & yes \\
\hline $\begin{array}{l}\text { Max vertical displacement of } \\
\text { floor beams (in) }\end{array}$ & N/A & 36 & 25 & N/A \\
\hline Floor Collapse & no & no & no & yes \\
\hline
\end{tabular}

N/A means not applicable

a Overall plan dimensions

b The building floor area was $9500 \mathrm{ft}^{2}$ but the compartment tested was approximately $1450 \mathrm{ft}^{2}$

c Represents largest spans (in NE corner)

d May be lightweight concrete but USFA report indicates only "concrete"

e British Code requirement -1 in. ceramic fiber blanket was used on columns

f Estimated using fire simulation models (Chapter 9) and measured in office furnishing burn tests (NCSTAR 1-5E)

g Unprotected steel 
First Interstate Bank and One Meridian Plaza, both commercial office buildings, had fires that fully involved entire floors. In both buildings, vertical spread of fire was by external flame exposure, breaking glass windows from the outside and igniting office furnishings in the floor above. By contrast, the fires in WTC 7 spread across several floors, but did not involve an entire floor at any given time. Additionally, in WTC 7 there was no evidence of floor-to-floor fire spread in the photographic and videographic records. Finally, the combustible load was likely similar in First Interstate Bank, One Meridian Plaza, and WTC 7, with the combustible load in One Meridian Plaza perhaps even greater as it was described subjectively as "heavy." NIST therefore concluded that the fires in First Interstate Bank and One Meridian Plaza were at least as severe, and probably more severe, than the fires in WTC 7.

The maximum gas temperature for large, open-floor plan burning of office furnishings is approximately $1200^{\circ} \mathrm{C}\left(2200^{\circ} \mathrm{F}\right)$, as measured in Cardington Test No. 6. Note that Cardington Test No. 3, which was also characterized as a severe fire, produced maximum gas temperatures of approximately $1000^{\circ} \mathrm{C}$ $\left(1800^{\circ} \mathrm{F}\right)$. These maximum temperatures were consistent with the maximum gas temperatures of $1100^{\circ} \mathrm{C}$ $\left(2000^{\circ} \mathrm{F}\right.$ ) determined by fire simulations and measured experimentally for fires of workstations similar to those in WTC 7 (NIST NCSTAR 1-5E).

If the fires in First Interstate Bank, One Meridian Plaza, the Cardington Test Building and WTC 7 generated comparable gas temperatures, and of the four buildings cited only the WTC 7 building collapsed, the reason for the different outcomes likely lay in differences in the structural systems and the details of how the steel frames were constructed. ${ }^{1}$ Although all four buildings have been described as "steel frame structures," comparison of construction features between the three buildings that did not collapse in an uncontrolled fire and WTC 7 revealed the following differences:

- Simple framing connections for girders in WTC 7 vs. fully restrained moment connections of girders-to-columns in the One Meridian Plaza and First Interstate Bank buildings;

- Floor beam spans up to $16 \mathrm{~m}$ (52 ft) in WTC 7, rather than a maximum of $9 \mathrm{~m}$ (30 ft) in the other structures;

- Asymmetric framing in WTC 7 (providing one-sided lateral support to girders) rather than regular floor framing (providing two-sided lateral support to girders) in the other three structures (Section 8.6);

- Non-composite girders in WTC 7 rather than composite girders (presence or absence of shear studs) in two of the other three structures; and

- Seated connections used for girder-to-column connections in WTC 7; NIST found no evidence that such connections were used in the First Interstate Bank and Cardington buildings.

The implications of these differences are discussed in the following section.

\footnotetext{
${ }^{1}$ WTC 7 sustained damage to its exterior as a result of falling debris from the collapse of WTC 1, but this damage was found to have no effect on the collapse initiating event.
} 


\subsection{STRUCTURAL FRAMING OF WTC 7}

The exterior of WTC 7 was a moment frame with relatively closely spaced columns. The core structure was simply connected and derived its lateral support from the moment frame through diaphragm action of the floors. Simply-connected floor beams and girders spanned between the exterior moment frame and the core. Where the spans between the exterior and core were large (on the east side), intermediate-size columns $(79,80$, and 81$)$, designed to carry gravity loads only were used.

The floor framing layout was somewhat unique due, in part, to the unusual trapezoidal shape of the building, but also to the need to match existing column layout in the Con Edison substation (Chapter 2). The result was that, in some locations, floor beams framed into girders on only one side of the girder, denoted in Figure 8-16 as "asymmetric" floor framing. The use of single shear plates and double angles is typical for steel floor framing connections. Seated connections, though generally less common, are nevertheless found in high-rise construction and have advantages during steel erection.

In general, the concrete slab and metal deck are considered to provide continuous lateral support of the compression flange (top flange) of the floor beams and girders thereby providing bracing against lateraltorsional buckling. Welding of the metal deck to the flanges of the supporting beams and the use of shear studs to provide composite action with the concrete floor generally achieve the required bracing.

Except for the moment frame exterior, simple framing connections using high strength bolts were used. These connections were either shear connections using a single shear plate or double angles, or seated connections. See Chapter 2 for a description of the floor framing connections.

\subsection{IMPLICATIONS OF STRUCTURAL FRAMING DETAILS IN WTC 7}

Figure 8-16 is a partial floor framing plan of the northeast corner of WTC $7^{2}$, which contains interior

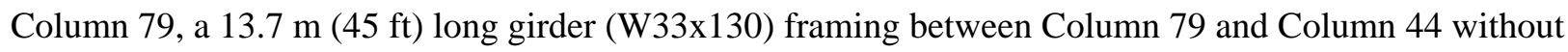
shear studs ${ }^{3}$, seat connections at both ends of this girder, and $15.8 \mathrm{~m}$ (52 ft) floor beams with shear studs that frame into the girder from only one side (the east side). The northeast corner framing of a typical tenant floor was used to explore the implications of various construction features (details) of interest.

\subsubsection{Fully Restrained Moment Connections vs. Simple Connections for Girders}

Two of the high-rise buildings that did not collapse in uncontrolled fires (First Interstate Bank and One Meridian Plaza) had moment frames, wherein fully restrained moment connections were used to connect all girders to the columns. Moment connections are considerably more robust than simple connections as they connect the beam flanges as well as the web to the column. Thus, column failure by loss of lateral support due to failure of primary beams (as discussed previously) is less likely. In contrast, WTC 7 had a "gravity frame" for the core above Floor 7, which used simple connections to connect the webs of the floor beams to the girders and girders to the columns. Single shear plate (or fin plate) connections and seated connections, in particular, (as described above) are more vulnerable to the effects of fire than moment connections. The behavior in fire of a simply connected floor system is further affected by long

2 Taken from Erection Drawings, Sheet E12/13, $12^{\text {th }} \& 13^{\text {th }}$ Floor Framing Plan.

3 The number of shear studs on a floor beam is indicated on erection drawings between brackets “ $\langle\ldots\rangle$,” as shown in Figure 8-16. 
spans, the absence of shear studs, and asymmetric floor framing. These aspects are addressed in the following sections. Note that the Cardington building used simple floor framing connections but had fire on only one floor, not multiple floors, and had considerably shorter spans.

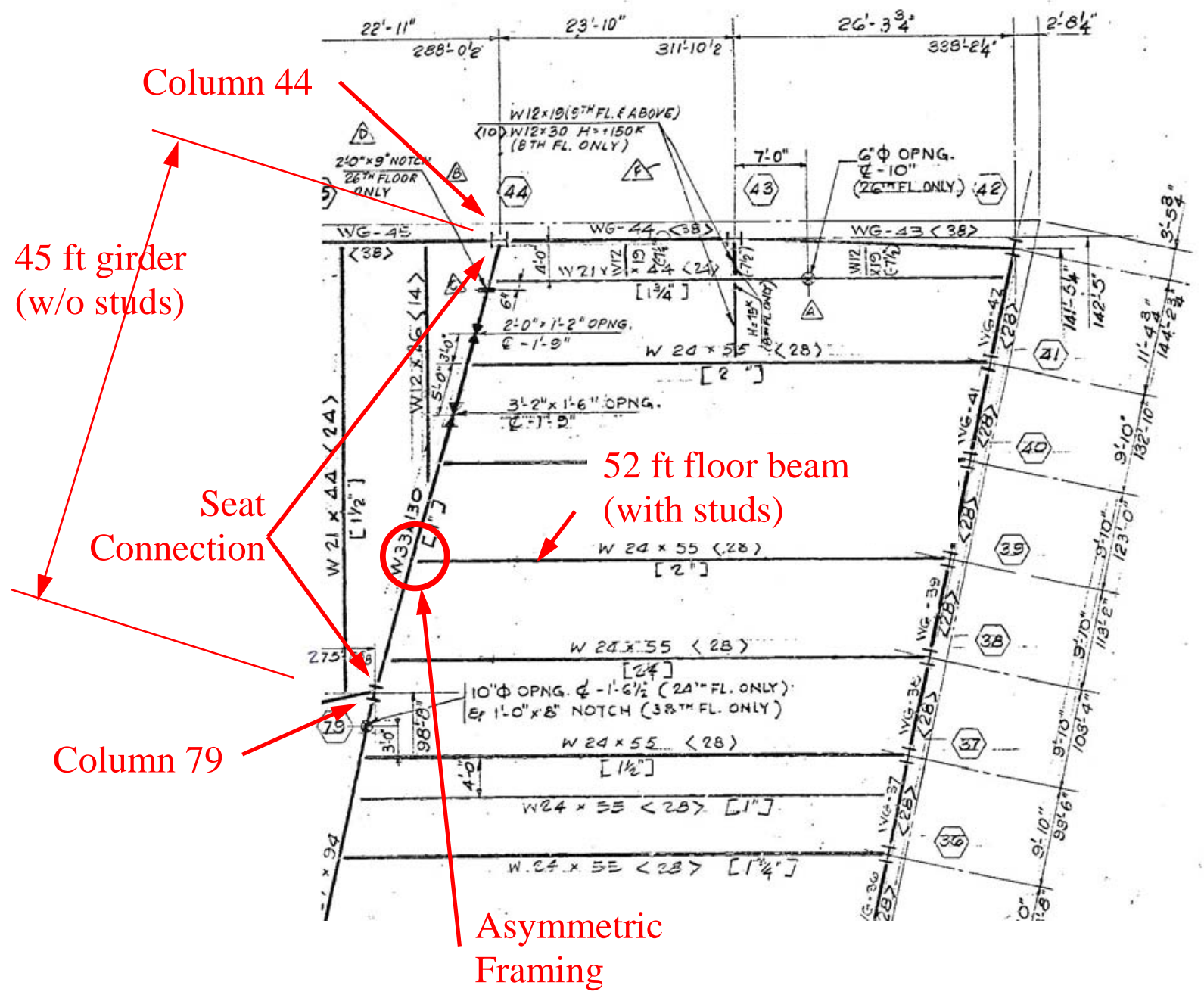

Based on erection drawing of Floors 12/13 (Frankel Steel 1985)

Figure 8-16. Partial floor framing plan showing northeast corner.

\subsubsection{Long Span Beams and Girders}

As a steel beam or girder is heated by a fire, it undergoes thermal expansion and elongates in proportion to its length and the temperature increase. With no restraint to thermal expansion, the change in length due to uniform heating, $\delta_{T}$, is computed as

$$
\delta_{T}=\alpha \Delta T L
$$

where

$\alpha \quad$ is the coefficient of thermal expansion $\left({ }^{\circ} \mathrm{C}\right)^{-1}$

$\Delta T \quad$ is the increase in temperature, ${ }^{\circ} \mathrm{C}$ 
$L \quad$ is the length if the member (in.)

For example, if a $13.7 \mathrm{~m}$ (540 in.) long girder is heated so as to uniformly increase its temperature by $600{ }^{\circ} \mathrm{C}$, and the coefficient of thermal expansion is taken to be $1.4 \times 10^{-5} /{ }^{\circ} \mathrm{C}$, the elongation would be,

$$
\delta_{T}=\left(1.4 \times 10^{-5} /{ }^{\circ} \mathrm{C}\right) \times\left(600{ }^{\circ} \mathrm{C}\right) \times(540 \text { in. })=4.5 \text { in. }
$$

Often this free thermal expansion is resisted by the steel structure that the beam or girder frames into, or by attachment to the concrete floor slab that it supports. The force required to resist completely the free thermal expansion (elongation) of a beam or girder, $Q_{\Delta T}$, is given by

$$
Q_{\Delta T}=A E(T) \alpha \Delta T
$$

where

A is the cross sectional area of the beam or girder (in. ${ }^{2}$ )

$E(T) \quad$ is the modulus of elasticity at temperature, $T(\mathrm{ksi})$

The temperature-dependent modulus of elasticity can be computed as (see NCSTAR 1-3D),

$$
E(T)=145 \times\left(206-4.3 \times 10^{-2} \mathrm{~T}-3.5 \times 10^{-5} \mathrm{~T}^{2}-6.6 \times 10^{-8} \mathrm{~T}^{3}\right)
$$

Assume a steel beam or girder heats up to $600{ }^{\circ} \mathrm{C}$. The modulus of elasticity by the above equation would be approximately $22,000 \mathrm{ksi}$, or roughly 75 percent of its room temperature value of 30,000 ksi.

Consider again a $13.7 \mathrm{~m}$ (540 in.) long W33x130 girder that is heated uniformly to $600{ }^{\circ} \mathrm{C}$. Substituting $A=38.3$ in. $^{2}, E(T)=22,235 \mathrm{ksi}, \alpha=1.4 \times 10^{-5} /{ }^{\circ} \mathrm{C}, \Delta T=580{ }^{\circ} \mathrm{C}\left(600{ }^{\circ} \mathrm{C}-20^{\circ} \mathrm{C}\right)$, one obtains a force of

$$
Q_{\Delta T}=\left(38.3 \mathrm{in} .^{2}\right) \times(22,235 \mathrm{ksi}) \times\left(1.4 \times 10^{-5} /{ }^{\circ} \mathrm{C}\right) \times\left(580{ }^{\circ} \mathrm{C}\right) \cong 6900 \mathrm{kip} .
$$

If, for example, this force to resist free thermal expansion could be developed, the axial stress in the member would be $6900 \mathrm{kip} / 38.3 \mathrm{in}^{2}=180 \mathrm{ksi}$ which greatly exceeds the yield strength of the steel used (approximately $50 \mathrm{ksi}$ ). Alternatively, consider the case in which this 6900 kip force is exerted on a bolted connection. Since the single shear capacity of a one bolt is approximately 45 kip (Section 11.2.4), it is clear that the force exerted by the expanding girder far exceeds the capacity of, e.g., four bolts found in a seated connection which together have a shear capacity at room temperature of roughly 180 kip.

These two aspects, (1) the magnitude of elongation due to free-thermal expansion, and (2) force required to resist this elongation, will be shown to be of importance in the following discussions. These two aspects are of particular importance for long members and for the heavy sections required for long spans.

\subsubsection{Asymmetrical Framing of Floor Beams into Girders}

In all three buildings, One Meridian Plaza, First Interstate Bank, and the Cardington Test Building, in which large uncontrolled fires did not lead to local or global collapse, the floor framing formed a rectangular grid and, except at the building's exterior, floor beams framed into both sides of the girders or columns. (See, for example, the floor framing of the Cardington Test Building in Figure 8-12.) Behavior of the floor beam and girder is influenced by the end restraint conditions under fire exposure. For 
example, Cardington Test No. 3 exposed one bay to a wood crib fire resulting in gas temperatures that reached almost $1000{ }^{\circ} \mathrm{C}$. The floor beam in this test framed into a girder on column line E, and into a spandrel beam on the building exterior on column line F (Figure 8-17). Thermal expansion of the floor beam framing into the girder on column line $\mathrm{E}$ was resisted by a floor beam framing from the opposite side (the floor beam spanning between column lines D and E), resulting in forces sufficient to buckle the bottom flange. The top flange of the beam did not buckle, since both the primary and secondary beams were tied to the slab using shear studs.

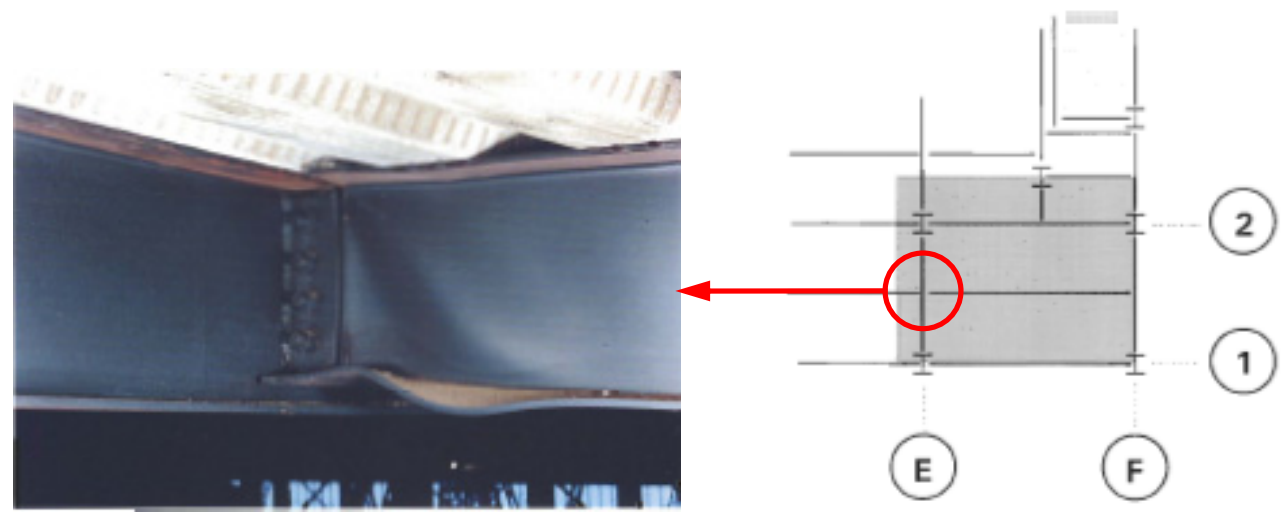

Source: British Steel 1999

Figure 8-17. Floor beam buckling at symmetrical framing to girder.

Floor beams framed into only one side of a girder in several locations in WTC 7, as shown in the highlighted areas in Figure 8-18. (Arrows indicate directions that the metal deck spanned.) Of particular interest was the northeast corner of the building. The relevance of this framing condition, in concert with the presence (or absence) of shear studs, and the use of seated connections under the effect of fire-induced thermal expansion is covered next.

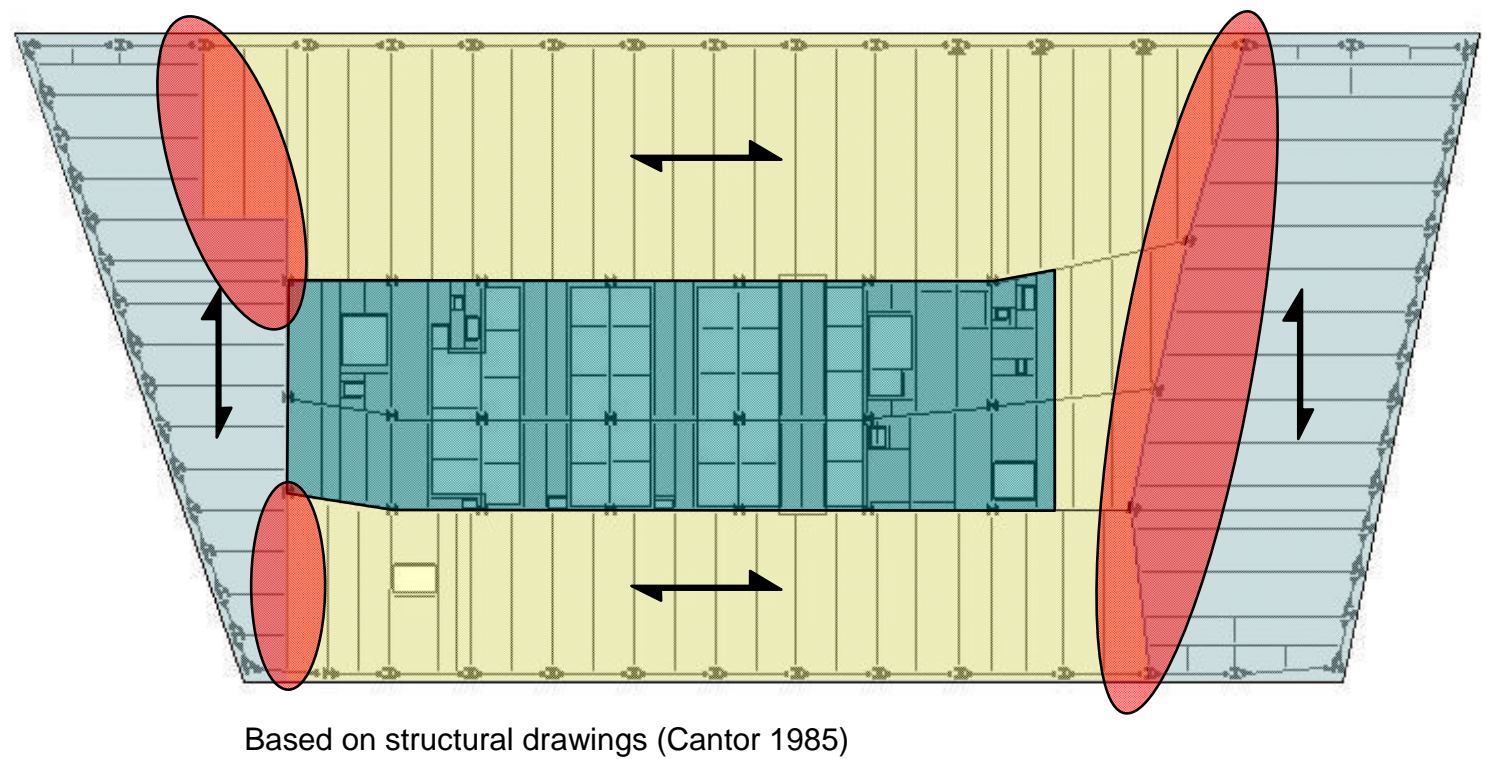

Figure 8-18. Floor framing where beams frame into only one side of the girder. 


\subsubsection{Absence of Shear Studs on Girders}

In WTC 7, no studs were installed on the girders (Cantor 1985). Thus, in those locations where there were no opposing beams, resistance to the thermal expansion of the floor beams would have been provided primarily by the lateral stiffness of the girder (neglecting the minor contribution of the puddle welds attaching the metal deck to the girder).

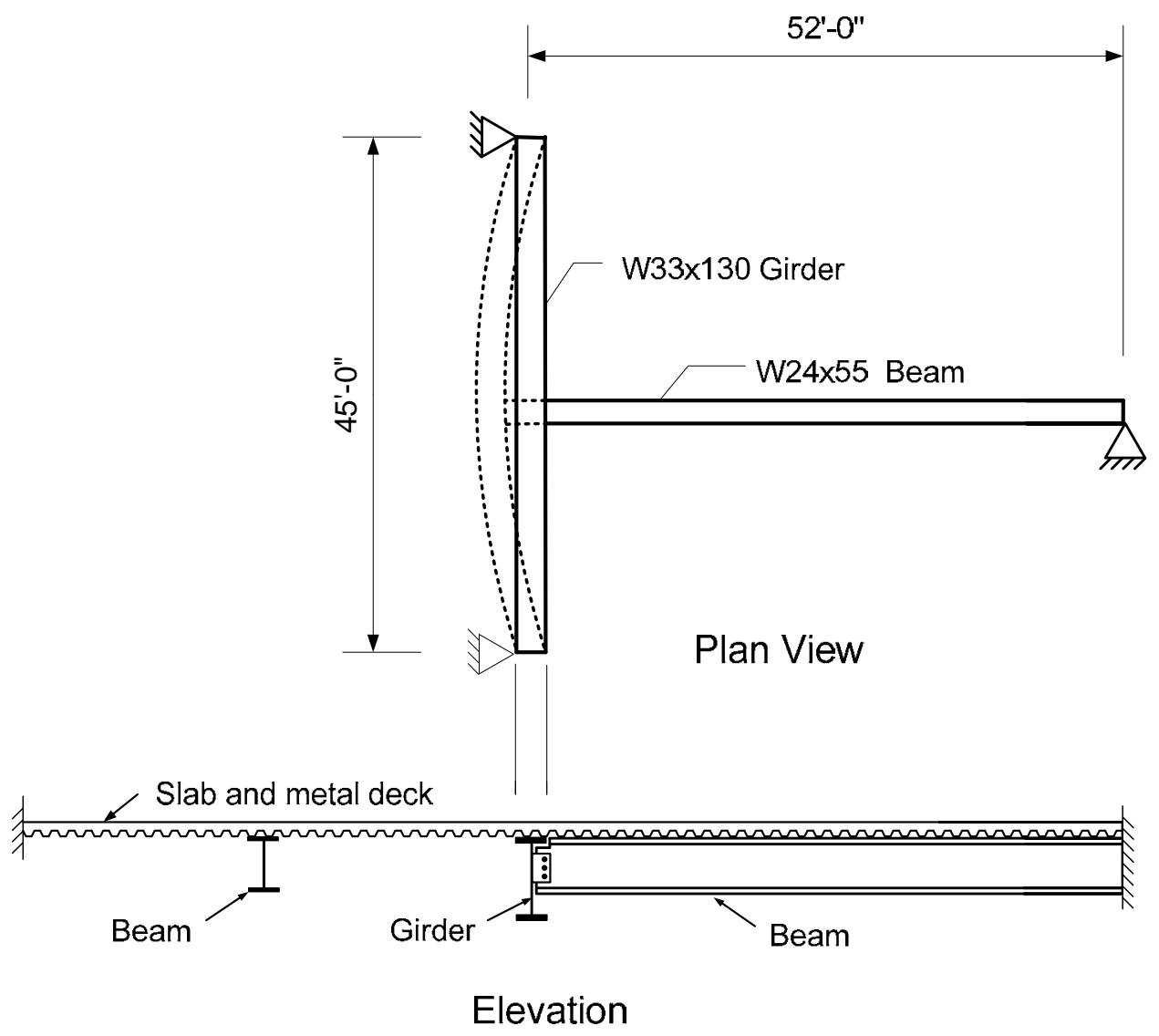

Based on structural drawings (Cantor 1985)

Figure 8-19. Thermal expansion of floor beams

Consider a simple floor beam-to-girder arrangement as found in the northeast corner of WTC 7 (Figure 8-19). In this example, the floor slab was restrained at both ends and the floor beam was restrained at the exterior column. In-plane restraint of the floor slab assumes that either the slab was not heated or that surrounding cooler sections of floor slab restrained expansion. This boundary condition is assumed for illustrative purposes and to produce a maximum force in the shear studs. This simple analysis helped to determine whether or not the failure of shear studs needed to be accounted for in the detailed ANSYS analysis of the lower 16 stories of WTC 7 (Chapter 11). In the detailed finite element analysis, the floor slabs were not restrained and the heating of the concrete slab and steel beams was determined by thermal analysis (Chapter 10).

The displacement of the connection between the floor beam and girder is a function of the lateral stiffness of the girder and the axial stiffness of the floor beam, and is given by, 


$$
u_{x}=\frac{-A E \alpha \Delta T}{\frac{A E}{L_{1}}+\frac{48 E I_{y}}{L_{2}^{3}}}
$$

$$
\text { where } \begin{array}{ll}
A & =\text { cross sectional area of floor beam } \\
E & =\text { modulus of elasticity } \\
\alpha & =\text { coefficient of thermal expansion } \\
\Delta T & =\text { temperature increase of floor beam } \\
I_{y} & =\text { moment of inertia of girder weak-axis } \\
L_{1} & =\text { length of floor beam } \\
L_{2} & =\text { length of girder }
\end{array}
$$

The ratio of the lateral stiffness of the girder to the axial stiffness of the beam (ratio of the second term in the denominator to the first term) is

$$
\frac{\frac{48 E I_{y}}{L_{2}^{3}}}{\frac{A E}{L_{1}}}=\frac{48 I_{y} L_{1}}{A L_{2}{ }^{3}}
$$

Substituting $A=16.2$ in. ${ }^{2}, I_{y}=218$ in. ${ }^{4}, L_{1}=52 \mathrm{ft}=624 \mathrm{in}$., and $L_{2}=45 \mathrm{ft}=540 \mathrm{in}$., one finds that this ratio was approximately $2.6 \times 10^{-3}$, or, in other words, the lateral stiffness of the girder was about three orders of magnitude smaller than the axial stiffness of the floor beam. Thus, in this simplified example, the girder provided almost no lateral resistance to the thermal expansion of the floor beam.

Now consider the force carried by the shear studs attaching the floor beam to the floor slab when there was little or no lateral resistance provided by the girder. If the floor beam was heated due to fire exposure, its tendency would have been to elongate by the amount, $\alpha \Delta T L_{1}$ where the terms are described above. Resistance to this free thermal expansion would have been provided only by the shear studs, if the lateral stiffness of the girder were neglected as illustrated above. The force on a single stud on the floor beam due to thermal elongation is

$$
Q_{s}=\frac{A E(T) \alpha \Delta T}{n}
$$

where $\mathrm{n}$ is the number of shear studs along the beam and the other terms are as defined above noting that the modulus of elasticity is a function of the temperature, $T$.

Assume that the steel heated to $600{ }^{\circ} \mathrm{C} . E\left(600^{\circ} \mathrm{C}\right)$ is approximately 22,000 ksi (Figure 3-3 in NCSTAR 16C). Substituting $A=16.2$ in. $^{2}$ (W24x55), $E(T)=22,000 \mathrm{ksi}, \alpha=1.4 \times 10^{-5} /{ }^{\circ} \mathrm{C}, \Delta T=600{ }^{\circ} \mathrm{C}$, and $n=22$ (number of shear studs on the W24x55 floor beam in the northwest corner), one obtains,

$$
Q_{s}=\frac{(16.2) \times(22000) \times\left(1.4 \times 10^{2}\right)(600)}{22} \cong 135 \mathrm{kip}
$$

The nominal capacity of a $3 / 4$ in. stud is roughly 20 kip at room temperature (Chapter 11); thus, one would expect that, when a floor beam is not restrained from thermally expanding, while the floor slab to which it 
is attached with shear studs is restrained due to its in-plane stiffness, the shear studs will fail and the floor beam will have little resistance to thermal expansion or to lateral-torsional buckling.

In those locations where there is asymmetric framing of the floor beams into the girders, an absence of shear studs on the girders combined with the failure of shear studs on the floor beams, leads to a floor system which has little restraint to free thermal expansion and little resistance to lateral-torsional buckling.

\subsubsection{Seats Used for Floor System Connections}

Floor beams and girders that framed into exterior columns, and in some instances, girders that framed into interior columns, had seated connections. For example, the girder that framed between interior Column 79 and exterior Column 44 had such connections at both ends.

Seat connections to exterior columns where the floor beam framing was perpendicular to the exterior moment frame were as shown in Figure 8-20. Where the floor beam framed into an exterior column at a skew angle, the seat angle was replaced by a plate. Figure 8-21 shows the seat connection at Column 79 that supported the girder spanning to Column 44 on the exterior. The details of the connections of the other two girders that framed into Column 79 are not shown.

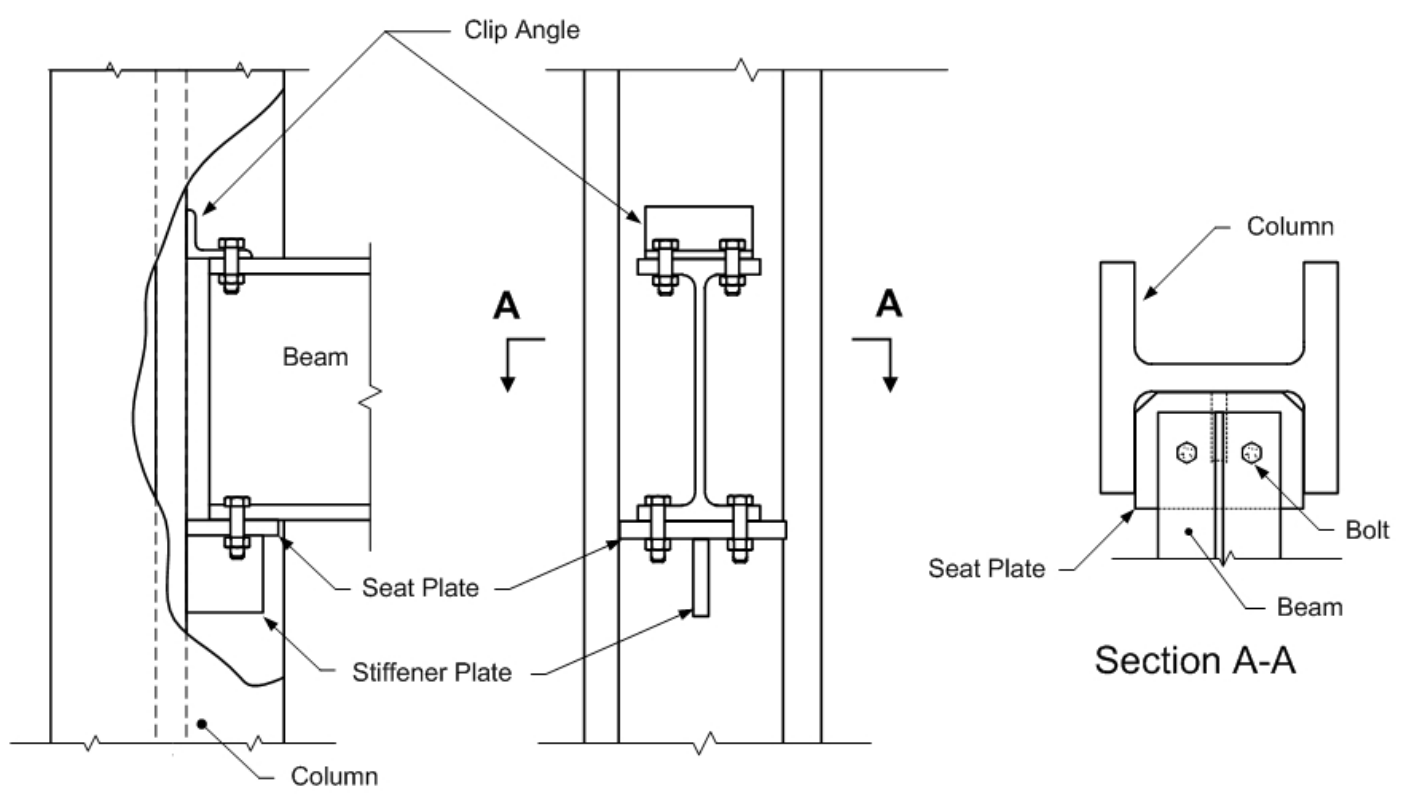

Based on fabrication shop drawings (Frankel 1985)

Figure 8-20. Seat connection at exterior column on the north face.

In a seated connection, the beam or girder was supported by the seat, which was welded to the column. Bolts were installed that fasten the beam or girder to the seat for erection purposes. These erection bolts did not carry any gravity load; rather, they were installed to insure that the beam or girder was held in place during erection. NIST found no evidence that the girders or beams in WTC 7 were welded to the seats. In a similar way, an angle or plate was bolted to the top flange to prevent the beam or girder from twisting, but there was little restraint to bending in the plane of the beam. 
Consider the girder that spanned between Column 79 on the interior of the building and Column 44 on the exterior. Thermal expansion of this girder would have loaded the erection bolts in shear, since (1) there were no shear studs anchoring the girder to the slab (and thereby restraining elongation), and (2) the columns were prevented from lateral movement because they were embedded in the floor slabs which had considerable in-plane stiffness. Additionally, the expansion of floor beams that framed into this girder, because the framing was asymmetrical, tended to add additional shear load to the erection bolts. The combination of these two shear loads could have failed the bolts in shear. If the erection bolts were to fail, then there would be no positive attachment preventing the girder from being pushed off the seat.

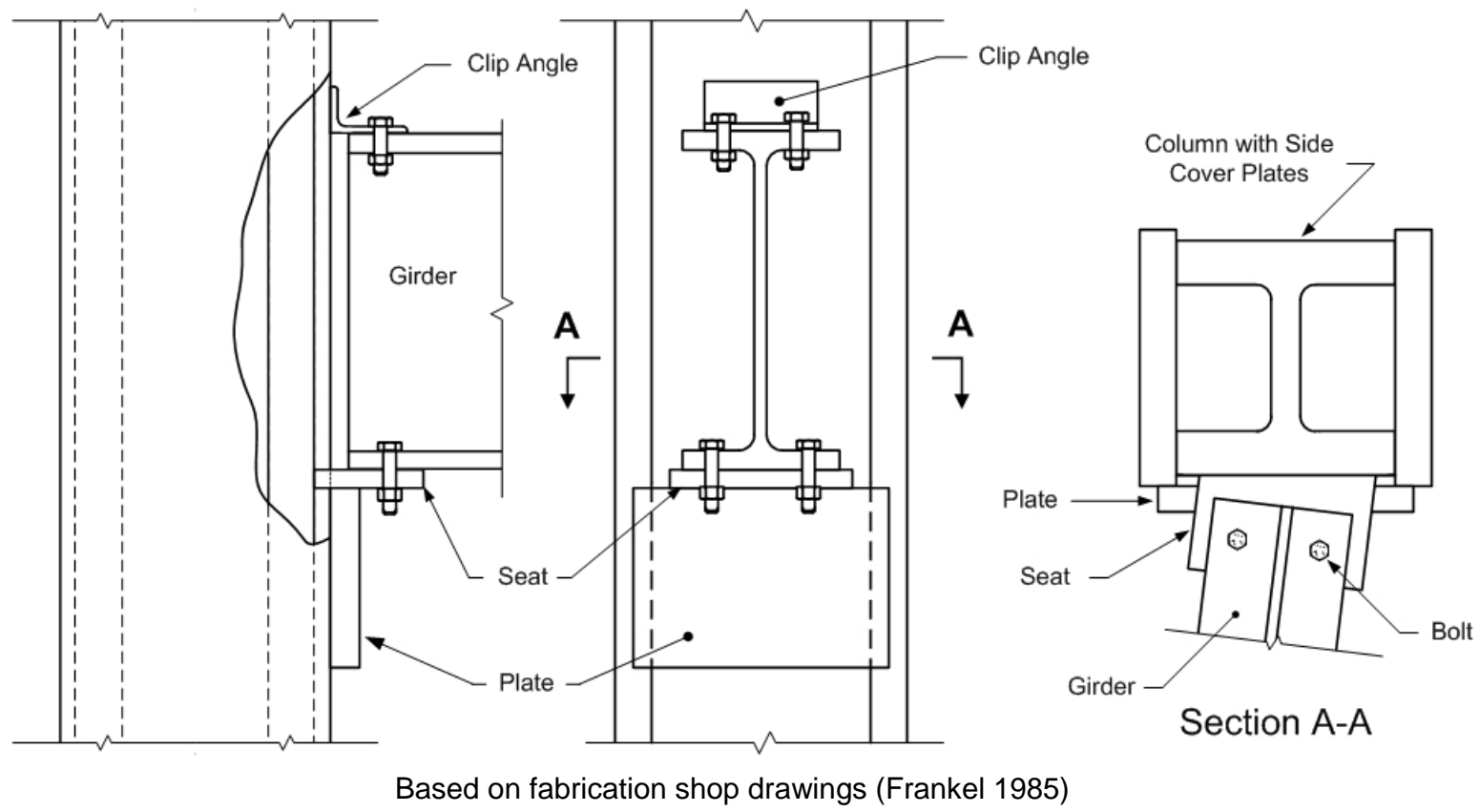

Figure 8-21. Seat connection at Column 79.

\subsection{FINITE ELEMENT ANALYSIS OF THE NORTHEAST FLOOR FRAMING SYSTEM}

A finite element analysis of the northeast corner floor system was conducted to evaluate its response to elevated temperatures and to confirm which failure modes needed to be accounted for in the 16-story ANSYS model. A finite element model of the northeast corner was developed using the LS-DYNA software that included the design details described in the previous section such as shear studs on the beams and seat connections at the girder ends and exterior ends of the beams.

The structural framing was modeled in detail using shell elements. The boundary conditions were selected to approximate the remaining portion of the structure that was not included in the model. The girder and beam temperatures were assumed to be $500{ }^{\circ} \mathrm{C}$ and $600{ }^{\circ} \mathrm{C}$, respectively, and the slab was assumed to remain unheated. The boundary conditions and temperatures were selected to create maximum shear forces on the stud connectors and beam and girder connections. Note that, in the detailed finite element analyses of the 16-story ANSYS model (see Chapter 11), no boundary conditions were 
applied to the floor slabs, and the temperatures of both the steel and concrete were derived from a thermal analysis based on fire dynamics calculations.

The finite element model, shown in Figure 8-22, included the floor beams, girder, bolted single shear plate connections of floor beams to girder, and seat connections at both ends of the girder and at the exterior ends of the floor beams. Short sections of Columns 79 and 44 and the exterior columns on the east side were modeled to provide axial restraint of the girder and beams through contact after bolt failure, as well as lateral and torsional restraint by the girder and beam flanges where applicable. Figure 8-23 shows a closeup view of the connections near Column 79, including the seat connection of the girder to Column 79 and the single shear plate connection of a floor beam to the girder. Bolts were modeled explicitly, both in the shear connections and erection bolts in the seated connections. The metal deck and concrete slab were modeled, as were the headed shear studs on the floor beams.

(a)

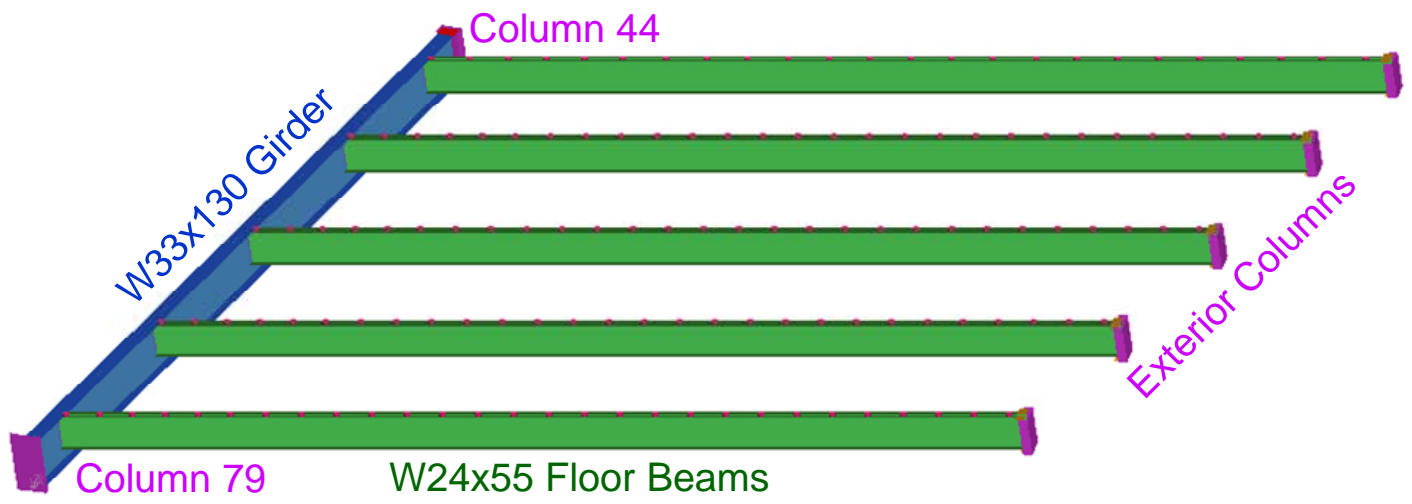

(b)

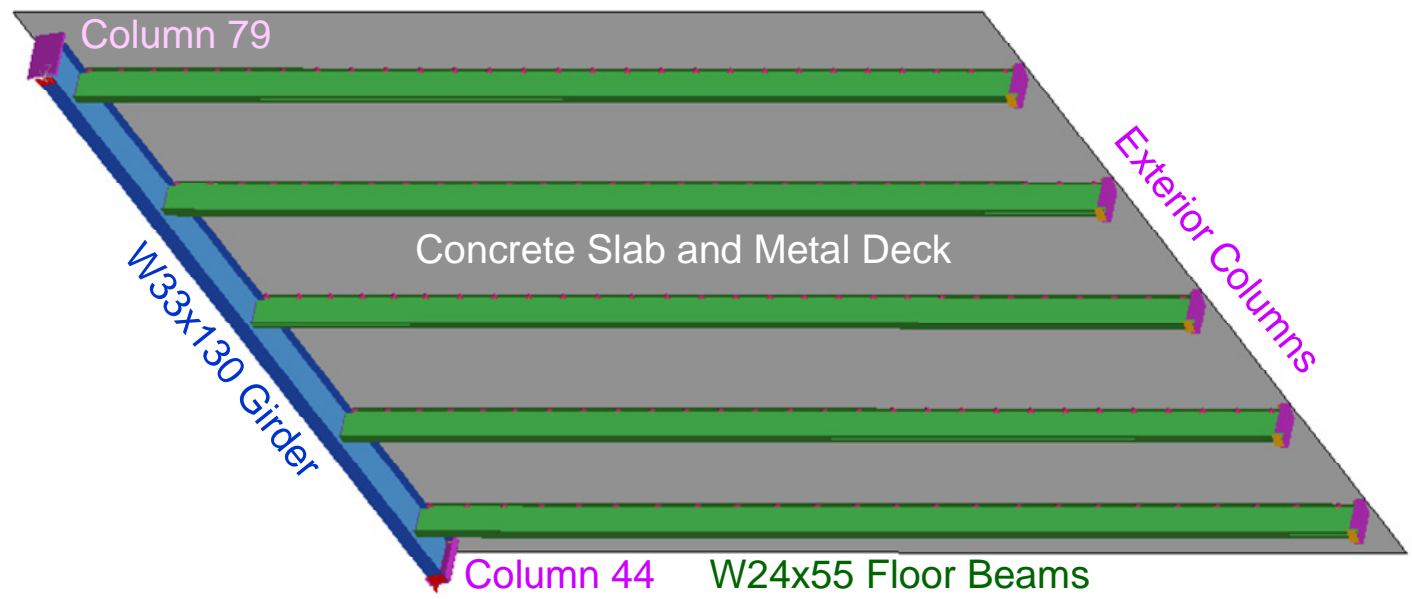

Figure 8-22. Finite element model of northeast corner as viewed from the southeast.

(a) Top view, with deck removed; (b) bottom view.

The model consisted primarily of shell elements. Fully integrated shell elements were used, with five integration points through the thickness. Typical element sizes for the beams, girders, and plates were 1.8 in., while the concrete slab and metal deck were meshed more coarsely with typical element sizes of $7.5 \mathrm{in}$. A single layer of shell elements was used to represent the concrete slab and metal deck, using a material model that allowed for different stress-strain behavior in tension and compression. The contribution of the welded wire fabric to the tensile capacity of the concrete slab was accounted for in this 
model using a smearing approach. The bolts and shear studs were modeled using nonlinear discrete spring elements. Separate spring elements were used to model the shear and axial behavior of the bolts.

Vertical support for the beams and girders was provided by contact with the seats, which were explicitly modeled using shell elements. The seat at Column 44 was supported from below by a vertical stiffener, which was explicitly modeled. Top plates and clip angles, where present, were also modeled, and contact with the beams and girders was defined.

For Column 79, the flange on the north face and the extending portions of the side cover plates were modeled to allow for contact with the girder. For Column 44 and the exterior columns, the column web and the flanges on the near side were modeled, and contact with the girder and the floor beams was defined. The welded edges of the seats, top plates, and clip angles were modeled as perfectly fixed. The columns were modeled as perfectly fixed along the edges of intersection between the webs and flanges and between the flange and side plates. Contact was also defined between the concrete slab and the girders to allow for transfer of the gravity loads. This contact also provided some rotational restraint for the girders and floor beams.

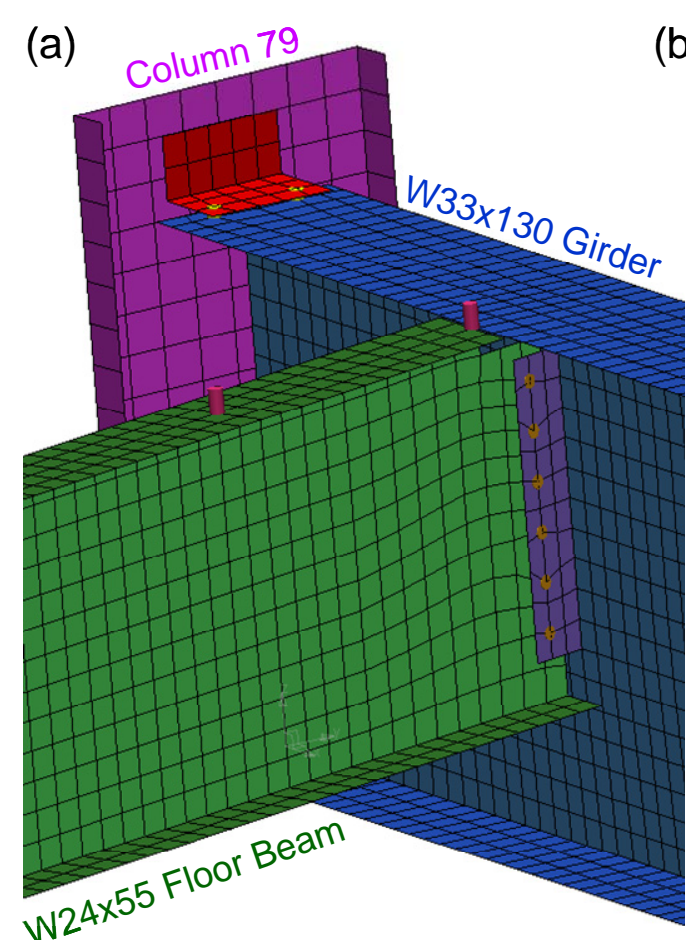

(b)

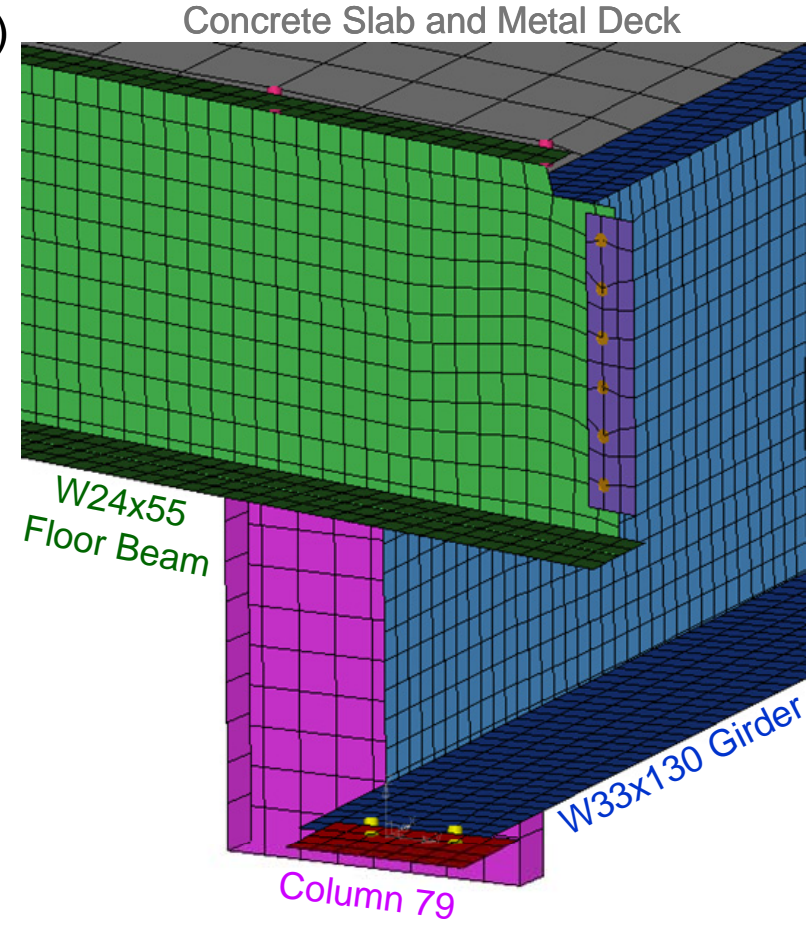

Figure 8-23. Views from northeast showing seat connection at Column 79 and bolted shear plate connection of floor beam to girder.

For the concrete slab, all translational degrees of freedom were constrained along the north and east edges, which would have been attached to the exterior girders by closely spaced shear studs. Rotations were permitted along these edges. The south edge of the concrete slab in the model was defined as the midline between two floor beams, and a symmetry boundary condition was imposed along this edge, allowing vertical displacements but no rotations about the edge axis and no north-south displacements. Similarly along the west edge, no in-plane displacements and no rotations about the edge axis were permitted. Constraining the in-plane displacements along the south and west edges accounted for the in- 
plane stiffness of the adjoining slab that was not included in the model. The west edge of the slab in the model was parallel to the W33x130 girder and was extended approximately $8 \mathrm{in}$. beyond the edge of the girder flange, to allow for contact between the girder and the slab to be maintained even if the girder were pushed laterally due to thermal expansion of the beams.

To avoid dynamic effects, the gravity loading was ramped up smoothly over a period of $1 \mathrm{~s}$, as shown in Figure 8-24. Ramping of the temperatures for the beams and the girder then commenced at $1.1 \mathrm{~s}$, as shown in Figure 8-25, leveling off at temperatures of $600{ }^{\circ} \mathrm{C}$ for the beams and $500{ }^{\circ} \mathrm{C}$ for the girder at $2.6 \mathrm{~s}$. These temperature histories were prescribed uniformly for all nodes of the beams and the girder, respectively. The material model for the steel beams and girders incorporated temperature dependence in the stress-strain behavior and accounted for thermal expansion. No thermal expansion or material degradation was considered for the slab, as the slab was not heated in this analysis.

The predicted response of the system is summarized in Table 8-2. The first failures observed were of the shear studs, which were produced by axial expansion of the floor beams, and which began to occur at fairly low beam temperature of $103^{\circ} \mathrm{C}$. Axial expansion of the girder then led to shear failure of the bolts at the connection to Column 79; and, at a girder temperature of $164{ }^{\circ} \mathrm{C}$, all four erection bolts had failed, leaving that end of the girder essentially unrestrained against rotation. Continued axial expansion of the floor beams pushed the girder laterally at Column 79, as shown in Figure 8-26, in which failed shear studs and bolts were evident. When the beam temperatures had reached $300{ }^{\circ} \mathrm{C}$, all but three shear studs in the model had failed due to axial expansion of the beams, leaving the top flanges of the beams essentially unrestrained laterally. Continued axial expansion of the girder caused it to bear against the face of Column 79, generating large axial forces that led to failure of the bolts connecting the girder to Column 44. When the girder temperature had reached $398^{\circ} \mathrm{C}$, all four erection bolts at Column 44 had

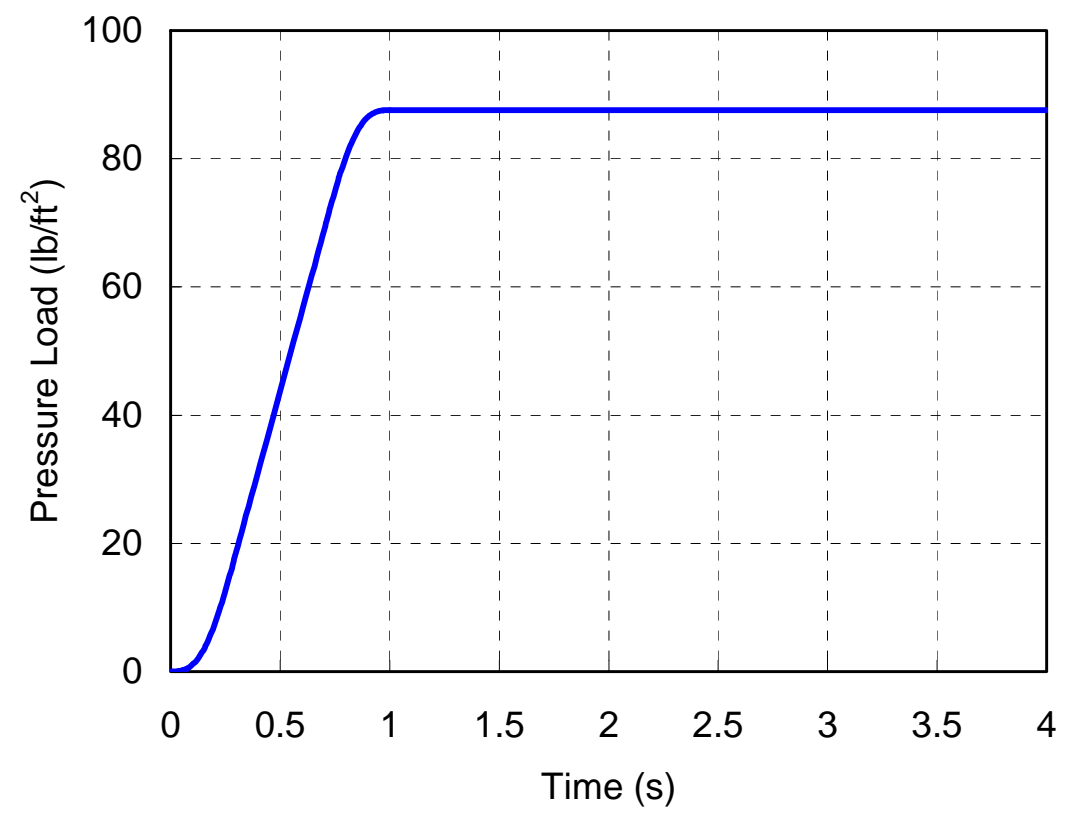

Figure 8-24. Time history of gravity loading, applied as a downward pressure on the concrete slab and metal deck. 
failed, leaving the girder essentially unrestrained against rotation at both ends. After failure of the erection bolts in the seat at Column 44, continued axial expansion of the floor beams pushed the girder laterally, where it came to bear against the inside of the column flange. Axial compression then increased in the floor beams, and at a beam temperature of $436{ }^{\circ} \mathrm{C}$, the northmost beam began to buckle laterally. Buckling of other floor beams followed as shown in Figure 8-27 (a), leading to collapse of the floor system, and rocking of the girder off its seat at Column 79 as shown in Figure 8-27 (b). The collapse process took time to occur in the LS-DYNA analysis, during which the temperatures had ramped up to their maximum values in the simulation.

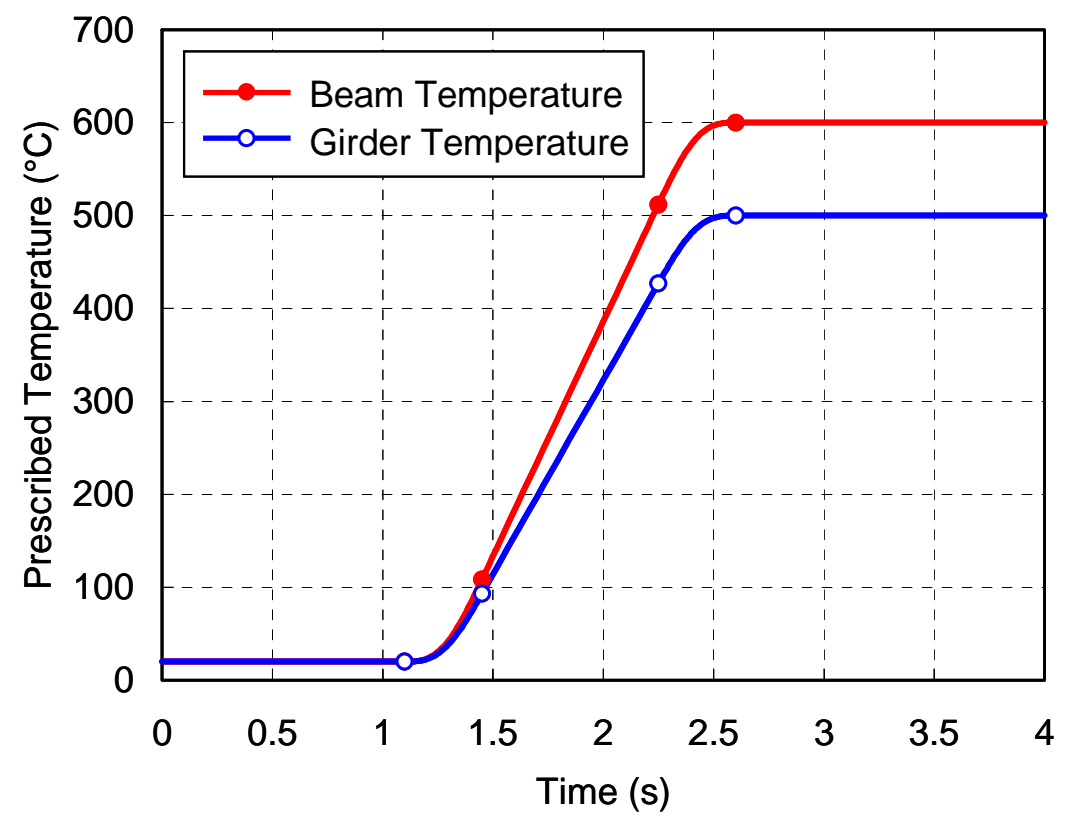

Figure 8-25. Time histories of temperatures prescribed for girders and beams.

Table 8-2 Progression of observed failures.

\begin{tabular}{|c|c|c|l|}
\hline \multirow{2}{*}{ Time (s) } & \multicolumn{2}{|c|}{ Temperature $\left({ }^{\circ} \mathbf{C}\right.$ ) } & \multirow{2}{*}{ Event } \\
\cline { 2 - 3 } & Beam & Girder & \\
\hline 1.44 & 103 & 89 & First shear stud failure \\
\hline 1.54 & 154 & 131 & Both seat bolts of girder to Column 79 had failed \\
\hline 1.62 & 194 & 164 & Both top clip bolts of girder to Column 79 had failed \\
\hline 1.83 & 300 & 252 & All but three shear studs had failed \\
\hline 2.04 & 406 & 339 & Both seat bolts of girder to Column 44 had failed \\
\hline 2.10 & 436 & 364 & Northmost floor beam began to buckle laterally \\
\hline 2.18 & 476 & 398 & Both top plate bolts of girder to Column 44 had failed \\
\hline 2.90 & 600 & 500 & All floor beams began to buckle \\
\hline
\end{tabular}

This analysis demonstrated possible failure mechanisms that were used to develop the leading collapse hypothesis further. The failure modes in this model were incorporated into the 16 story ANSYS and 47 story LS-DYNA analyses. 


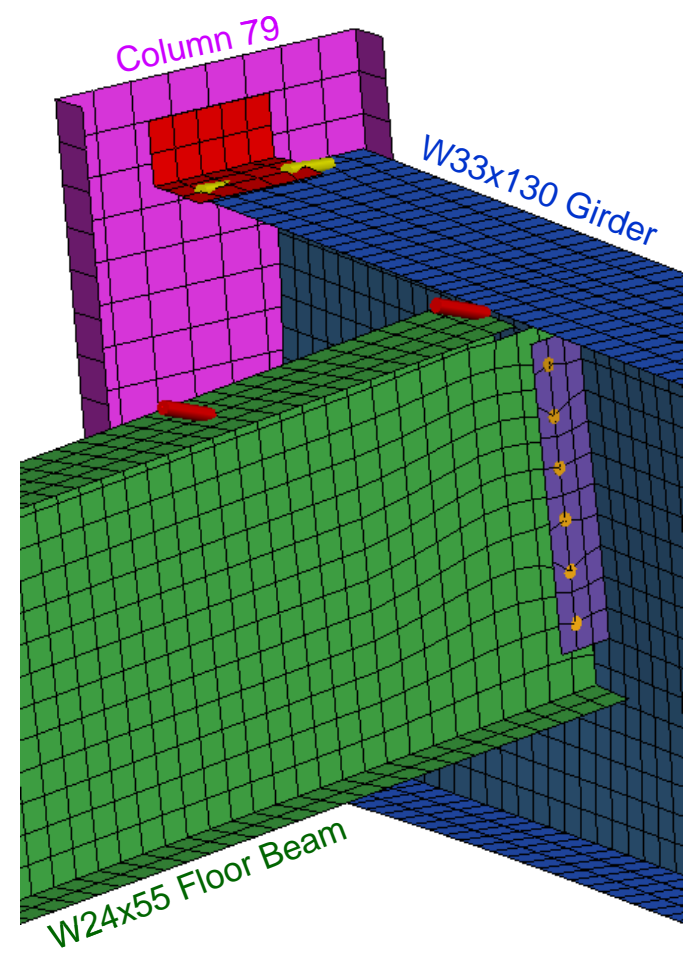

Figure 8-26. Lateral displacement of girder due to thermal expansion of floor beam. Note: failed bolts and shear studs
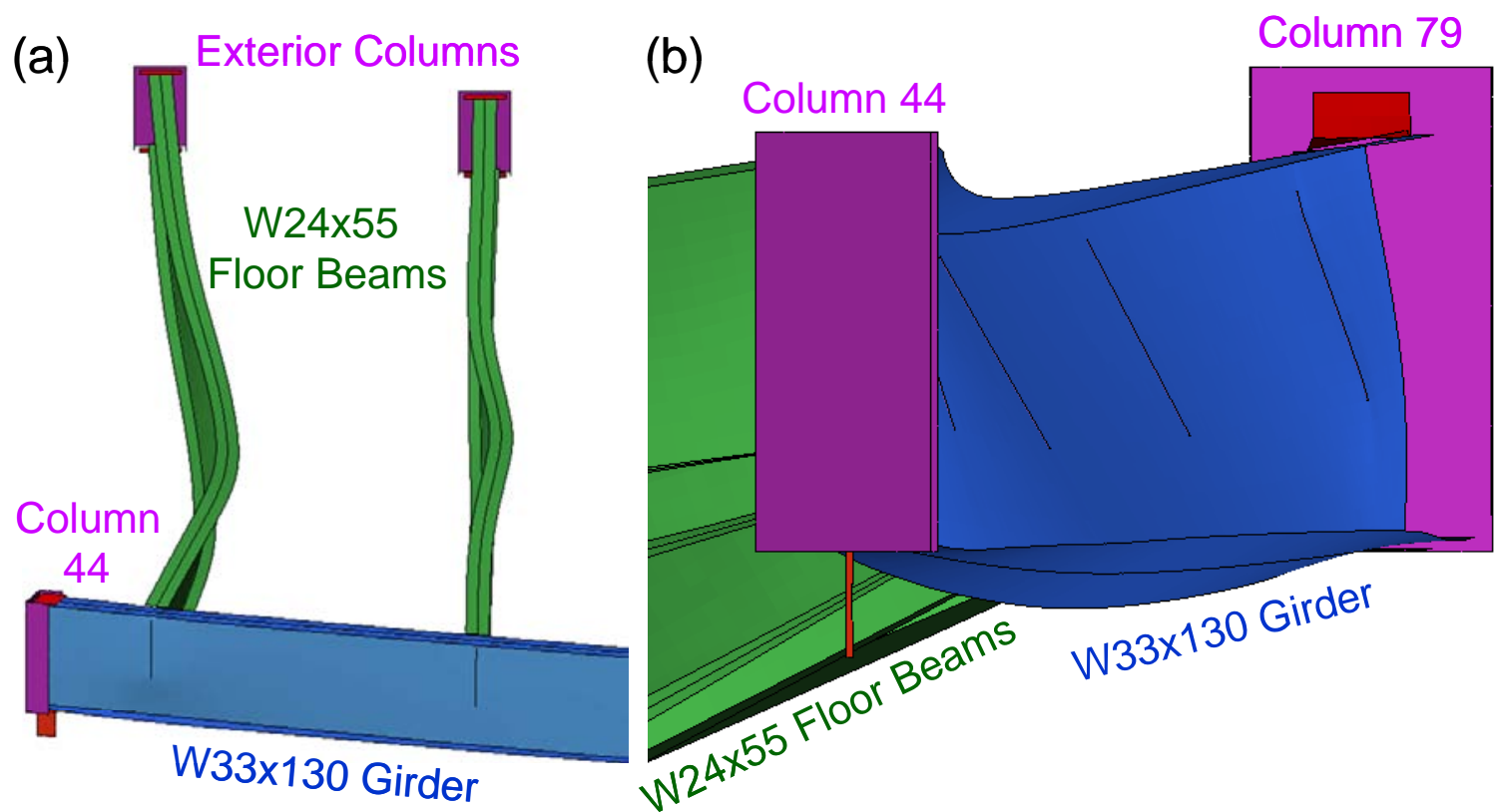

Figure 8-27. Buckled floor beams shown from above (a) and along girder (b). 


\section{$8.9 \quad$ OTHER COLLAPSE-RELATED POSSIBILITIES}

\subsubsection{Fuel Oil Fires}

There were several emergency generator installations located on several different floors of WTC 7 which were supplied by either day tanks or pressurized loop fuel delivery systems. NIST investigated the possibility that rupture of one of the fuel lines might have provided a continuous supply of sufficient fuel to affect a critical column or floor system. Section 3.4.2 describes the fuel systems and their status on September 11, 2001. Section 9.2 describes a set of hypothetical, extreme diesel fuel fire scenarios and their potential consequences. Simulations showed that pool fires associated with ruptured diesel fuel lines (a) would have raised the temperatures near the generators to the point where the generators would have failed, cutting off power to the fuel pumps, (b) could not be sustained long enough or generated too little heat to raise the temperatures of the steel and concrete structure to the point of significant loss of strength or stiffness, and/or (c) would have exhausted smoke from the exhaust louvers, in conflict with the photographic evidence which showed none.

NIST also found that the day tanks on Floors 5, 7, and 9 that supplied the emergency generators on those floors did not contain enough fuel to be significant contributors to the combustible load on the fire floors, and it was unlikely that the tanks could have been be re-supplied because of multiple safeguards in the fuel delivery system. Further, none of the day tanks were located near the location of critical Column 79.

Thus, it was concluded that the hypothetical fuel oil fires on the $5^{\text {th }}$ floor, or hypothetical fires on Floors 5 , 7, and 9 involving day tanks, did not contribute to the collapse of WTC 7.

\subsubsection{Hypothetical Blast Events}

To determine whether explosives could have been used to cause the collapse of WTC 7, a hypothetical blast event was considered. This work is reported in detail in Appendix D and is summarized here.

Scenarios of a hypothetical blast event that could have occurred in WTC 7 on September 11, 2001, were assessed, including blast location, size, and timing. Identification and analysis of hypothetical blast scenarios was conducted in three phases, with the results from each phase being used as input to the next phase. The three phases were:

- Phase I: Identify hypothetical blast scenarios to initiate structural collapse.

- Phase II: Assess the blast wave propagation inside the building and the corresponding response of the WTC 7 windows.

- $\quad$ Phase III: Assess the approximate distance from the building that the blast would have been audible in an urban setting.

In Phase I, hypothetical blast scenarios to initiate structural collapse were identified. A scenario with the minimum amount of required explosive was identified, which included cutting of columns sections as part of the preparations. Other scenarios were considered, but the amount of explosive material would have been larger, with the amount depending on the type and degree of column preparations conducted. 
The minimum charge scenario and was used in the Phase II blast analyses. This scenario proposed a linear shaped charge blast consisting of $9 \mathrm{lb}$ of RDX. The Phase II analysis centered on Column 79, as the observations in Section 5.7 indicated that the collapse initiated at this location. The recommended column preparation for use of this shape charge required at least $30 \mathrm{~min}$, plus additional time for preparations required to clear the column for cutting, such as removing walls or other coverings that might have restricted access to bare steel at a column section.

In Phase II, 2-D SHAMRC (Crepeau et al. 2001) blast propagation calculations were performed for the minimum explosive case identified in Phase I. Calculations were performed for a lesser charge size of $2 \mathrm{lb}$ to evaluate threshold explosive requirements for the windows. There were four blast analyses performed in total, consisting of two different charge sizes (2 lb or $9 \mathrm{lb}$ of RDX) and two floor layouts with differing partition layouts in the tenant areas. The primary conclusion from the Phase II analyses was that windows were expected to fail on the north and east faces for even the most conservative blast loading case considered (the densely-partitioned layout with a $2 \mathrm{lb}$ charge). Other scenario and charge size combinations resulted in greater predicted window damage.

In Phase III, an acoustic analysis was performed to assess the distance from the building that the blast would have been audible. Adjacent buildings and their effect on the sound propagation was not considered in this analysis. Analyses were performed for both layout scenarios, using the pressure history and window failure locations from Phase II. For all four scenarios, significant audible sound was predicted from all building faces. If propagation were unobstructed (e.g., up Greenwich Street from the north face), the sound level from all building perimeter openings at $1 \mathrm{~km}$ would be approximately $130 \mathrm{~dB}$ to $140 \mathrm{~dB}$. For comparison, sound levels generated by various sources of noise are shown in Table 8-3 (Bearden 2000).

Table 8-3 Sound Levels Generated by Various Sources of Noise.

\begin{tabular}{|l|c|}
\hline Noise Source & Sound Level (dB) \\
\hline Quiet library, soft whispers & 30 \\
\hline Living room, refrigerator & 50 \\
\hline Light traffic, normal conversation, quiet office & 60 \\
\hline Air conditioner at 20 ft, sewing machine & 70 \\
\hline Vacuum cleaner, hair dryer, noisy restaurant & 80 \\
\hline Average city traffic, garbage disposals, alarm clock at 2 ft & \\
\hline $\begin{array}{l}\text { Constant exposure to the following sound levels can lead to } \\
\text { hearing loss }\end{array}$ & 90 \\
\hline Subway, motorcycle, truck traffic, lawn mower & 100 \\
\hline Garbage truck, chain saw, pneumatic drill & 120 \\
\hline Rock band concert in front of speakers, thunderclap & 140 \\
\hline Gunshot blast, jet plane & 180 \\
\hline Rocket launching pad & \\
\hline
\end{tabular}

Source: Bearden (2000). 
In summary, the minimum charge (lower bound) required to fail a critical column (i.e., Column 79) would have produced a pressure wave that would have broken windows on the north and east faces of the building near Column 79. The visual evidence did not show such a breakage pattern on any floor of WTC 7 as late as about 4:00 p.m. or above the $25^{\text {th }}$ floor at the time of the building collapse initiation. Views of the northeast corner at the time of the collapse were obstructed by other buildings. The other scenarios considered would have required much more explosive material, which would have generated much more window breakage and a higher sound level, or were generally considered infeasible to carry out without detection.

Preparations for a blast scenario would have been almost impossible to carry out on any floor in the building without detection. While the selected blast scenario considered one column, demolition with explosive charges usually requires the preparation of many columns in a building. Preparations would have included removal of column enclosures or walls, use of weld torches to cut column sections, installation of charges, and placement of wires for detonation. Occupants, support staff, and visitors would have noticed evidence of such activities, particularly since they likely would have occurred around more than one column. It is highly doubtful that such activities would have not been detected.

Furthermore, for a shaped charge with an explosive weight equivalent to or higher than $9 \mathrm{lb}$ (detonated in a single delay), the noise level at a distance of $1 / 2$ mile would have been on the order of $130 \mathrm{~dB}$ to $140 \mathrm{~dB},{ }^{4,5}$ roughly equivalent to that of a thunderclap directly overhead or an adjacent jet engine. The sound blast in an urban setting would have propagated by being reflected and channeled down streets with minimum attenuation. The hard building exteriors would have acted as nearly perfect reflectors, with little to no absorption. The sound would have been attenuated behind buildings, but it would also generate multiple echoes. This could have extended the time period over which the sound could possibly have had an additive effect if multiple in-phase reflections met. ${ }^{4}$

People on the street would have heard $9 \mathrm{lb}$ of RDX go off a mile away in air (and even further away if the wind were blowing in their direction). ${ }^{5}$ There were no witness reports of such a loud noise, nor was such a noise heard on audio tracks of video tapes that recorded the WTC 7 collapse. Thus, from this study, NIST concluded that blast events could not have occurred and found no evidence of any blast events.

\subsubsection{Fires within the Con Edison Substation}

NIST considered the possibility of fire in the Con Edison Substation (Chapter 2). Eyewitness accounts and off-site monitoring of the substation operation and alarm signals provided the basis for the assessment. Details are provided in Appendix A.

Con Edison employees were present at the substation when WTC 1 was impacted by the aircraft, and additional personnel were summoned to assist in dealing with the emergency. No fire or significant physical damage was noted prior to the time the substation building was evacuated at about 10:20 a.m. NIST found no evidence that significant physical damage to the Con Edison portion of WTC 7 occurred due to the collapse of WTC 1 at 10:29 a.m.

\footnotetext{
${ }^{4}$ Email correspondence from Applied Research Associates to NIST, 31 July 2008.

${ }^{5}$ Email correspondence from Loizeaux Group International to NIST, 5 August 2008.
} 
After the building was evacuated, signals from the Con Edison substation continued to be monitored offsite throughout the day on the supervisory control and data acquisition logs. One fire detector within the Con Edison substation went into alarm mode when WTC 1 collapsed, and stayed in the alarm mode until the substation was totally isolated from incoming feeders at 4:33 p.m. However, there were no other indications (e.g., no high temperature alarms from the transformers, no visible smoke emanating from the Con Edison building) that there were significant fires within the substations during that period of time. Logical sources of the fire detector alarm were the smoke and dust dispersed in the area of the substation from the collapse of WTC 1. While several transformers uncovered during site clean-up showed clear evidence of thermal damage, from the information gathered, NIST was unable to determine whether the thermal damage to the transformers occurred due to electrical overheating, due to a fire in the Con Edison substation, or due to burning within the rubble pile subsequent to the collapse of WTC 7. Based on this evidence, NIST concluded that fire within the Con Edison substation was not a factor in the collapse of WTC 7.

\subsection{SUMMARY}

The leading hypothesis for the initiation of the collapse of WTC 7 involved:

- Initial local fire-induced floor failures initiating in the tenant floors,

- At least one long unsupported column at the lower floors,

- Buckling of a critical column (the initiating event), which supported a large-span floor bay,

- An initial local failure that brought down the interior structure below the east penthouse, and

- Horizontal progression of the failure across the lower floors that resulted in a progressive collapse of the entire structure.

This hypothesis was supported by photographic and videographic evidence showing the collapse of the east section of the roof and the kinking of the east penthouse.

A critical look at the steel framing that supported the concrete floors in WTC 7 and, in general, the overall framing of the building, revealed several characteristics that warranted further consideration:

- Simple framing connections for girders,

- Long-span floor beams and girders,

- Asymmetric framing (one-sided lateral support to girders),

- Absence of shear studs, and

- Girder-to-column seat connections

Simple analyses revealed that, alone or in combination, these construction framing features had the potential to produce initial local fire-induced failures resulting from ordinary building contents fires on a tenant floor. The east side of WTC 7 had columns that supported large floor areas and many of the 
construction details were identified as being important. A finite element analysis of the northeast corner of the building, representing the framing of a lower tenant floor, verified that the following fire-induced failures were possible:

- Significant lateral deflections (movement) of the girder produced by thermal elongation of the floor beams,

- Failure of shear studs on the floor beams,

- Shear failure of the erection bolts fastening the girder to the seated connections,

- Failure of single shear plate (fin) connections attaching the floor beams to the girder,

- Buckling of floor beams, and

- Girder sliding off its seat connection.

Analysis of the northeast floor system showed that the fire-induced failure modes predicted by simple analyses were, indeed, realized for the case of uniformly increased temperatures. These results helped to guide the development of special connection elements that used a combination of break elements, rigid links, contact elements and elastic elements, that captured the salient features and failure modes of the various types of connections used in the floor system of WTC 7. These features and failure modes included individual bolt failure, weld failure, shear stud failure, contact between floor slab and girder (without shear studs), gap closing and contact, slip-off of seated connections, etc. In Chapter 11, the structural models that capture these features of the floor framing and connections, and their failure modes, are described in detail.

It was also concluded in this chapter, that neither a fuel oil fire, a hypothetical blast, nor fires in the Con Edison substation was a valid hypothesis for initiating collapse.

\subsection{REFERENCES}

Bearden, David M. 2000. Noise Abatement and Control: An Overview of Federal Standards and Regulations, Report No. RS20531, National Council for Science and the Environment, Congressional Research Service, Environmental Information Analyst Resources Science, and Industry Division, April 7, 2000.

British Steel. 1999. The Behavior of Multi-Storey Steel Framed Buildings in Fire, British Steel plc, Swinden Technology Centre, South Yorkshire, UK.

Cantor 1985. Irwin G. Cantor P.C., Structural Engineers, Structural Drawings, 7 World Trade Center.

Crepeau, J., Needham, C. and Hikida, S., 2001. SHAMRC second-order hydrodynamic automatic mesh refinement code, Methodology, 2001, Applied Research Associates, Albuquerque, NM.

Eisner, Harvey, and Manning, Bill, 1991. One Meridian Plaza Fire, Fire Engineering, V. 144, N. 8, August, 1991. 
Frankel 1985. Frankel Steel Limited, Erection Drawings, 7 World Trade Center.

Frankel 1985a. Frankel Steel Limited, Fabrication Shop Drawings, 7 World Trade Center (drawing set was not sealed).

Klem, Thomas, 1991. Preliminary Investigation Report: One Meridian Plaza, National Fire Protection Association, Quincy, Massachusetts, 1991.

McAllister, T., ed. 2002. World Trade Center Building Performance Study: Data Collection, Preliminary Observations, and Recommendations. FEMA 403. Federal Emergency Management Agency. Washington, DC, May.

Nelson, Harold, 1989. An Engineering View of the Fire at the First Interstate Bank Building, Fire Journal, V. 83, N. 4, July/August 1989.

Powers, R. W., 1970. One New York Plaza Fire, The New York Board of Fire Underwriters, New York, New York.

Routley, Gordon, 1988. First Interstate Bank Building Fire, Los Angeles, California, May 4, 1988, United States Fire Administration, Technical Report USFA-TR-022/May 1988, Emmitsburg, Maryland.

Routley, J. G., Jennings, C., and Chubb, M., 1991. High-Rise Office Building Fire: One Meridian Plaza, Philadelphia, Pennsylvania (February 23, 1991), United States Fire Administration, Emmitsburg, Maryland. 
NIST NCSTAR 1-9

Federal Building and Fire Safety Investigation of the World Trade Center Disaster

\section{Structural Fire Response and}

Probable Collapse Sequence of

World Trade Center Building 7

\section{VOLUME 2}





\section{TABLE OF CONTENTS}

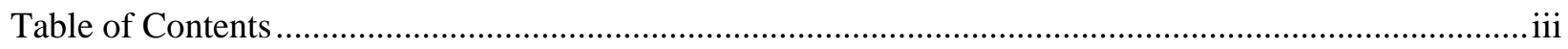

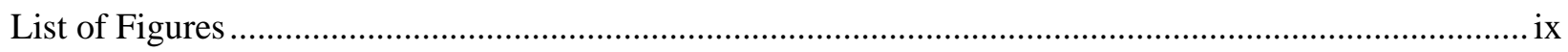

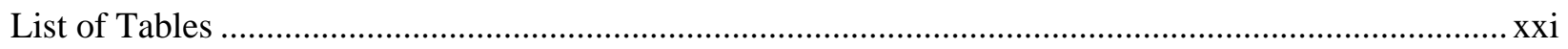

\section{Chapter 9}

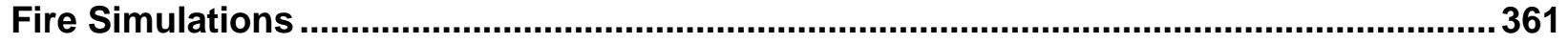

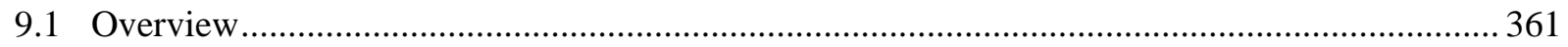

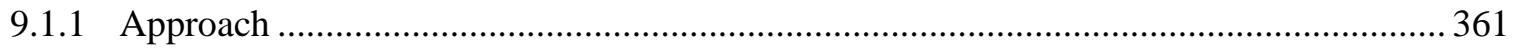

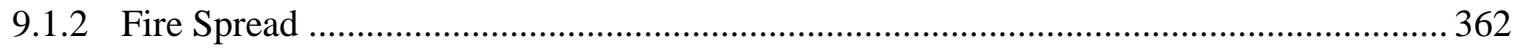

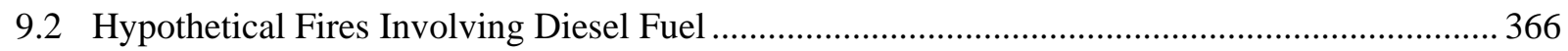

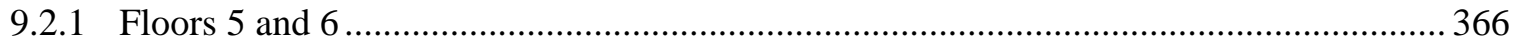

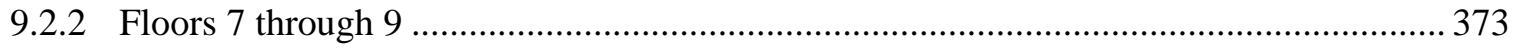

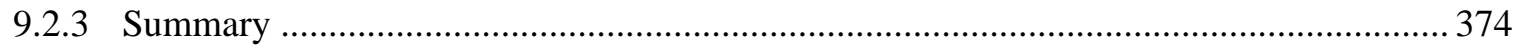

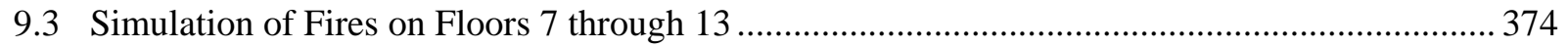

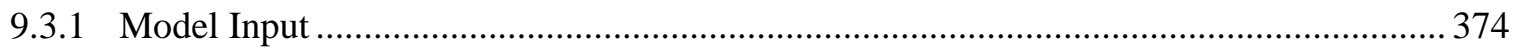

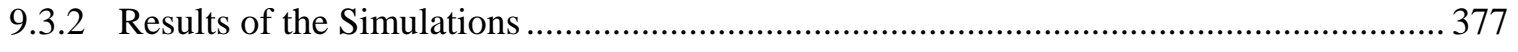

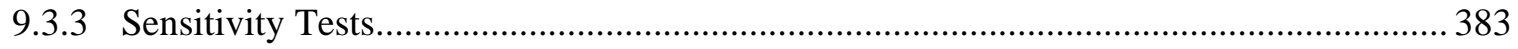

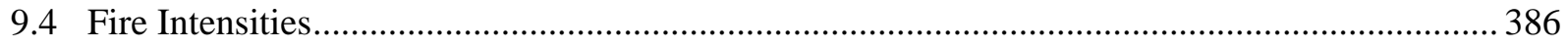

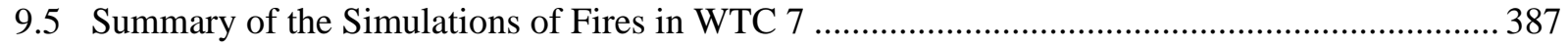

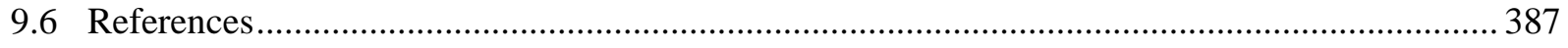

\section{Chapter 10}

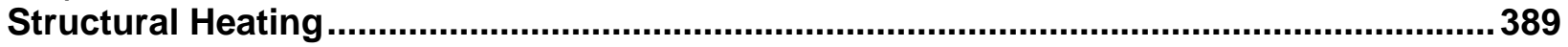

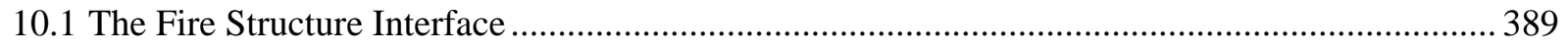

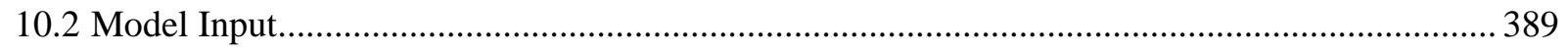

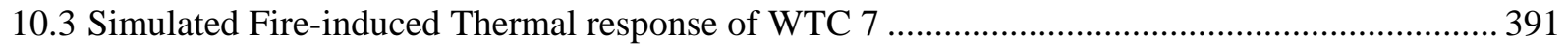

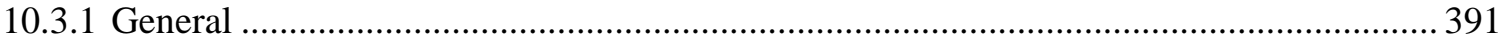

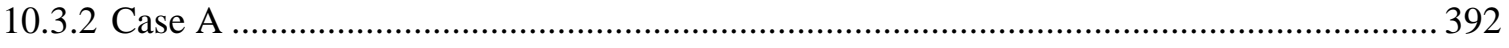

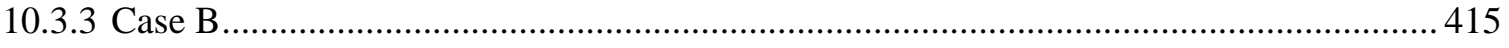

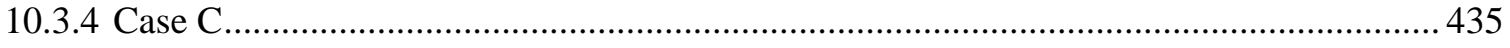

10.4 Findings from the Calculated Fire-induced Thermal Response of WTC 7............................... 455 


\section{Chapter 11}

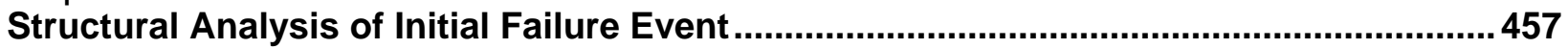

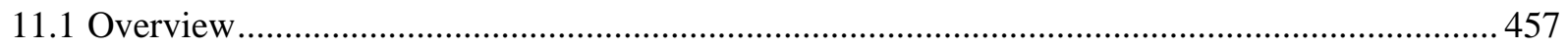

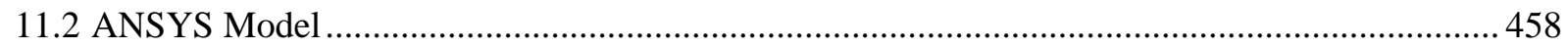

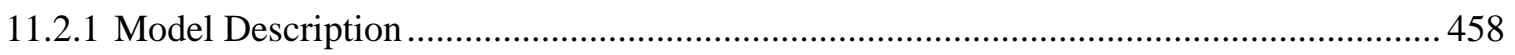

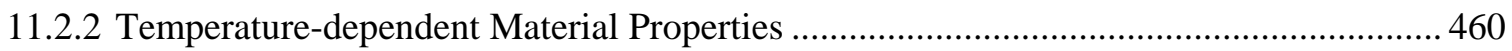

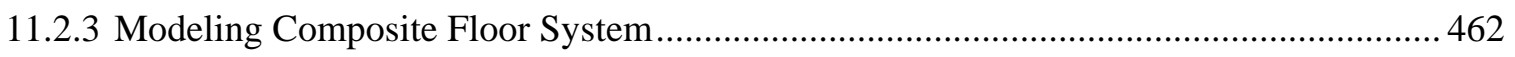

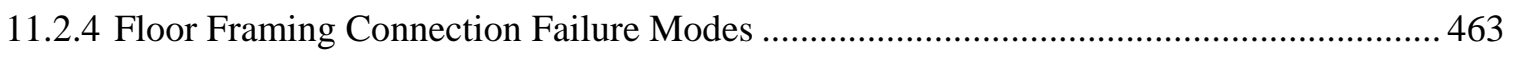

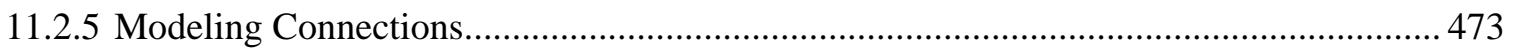

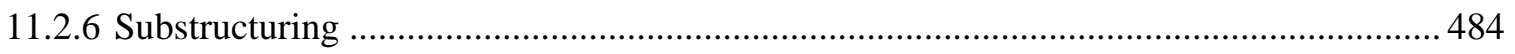

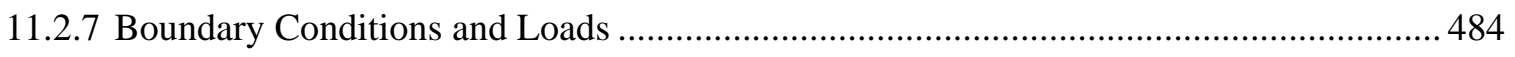

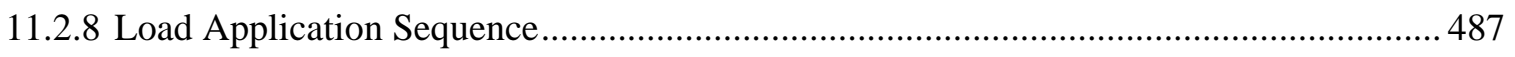

11.2.9 Criterion to Determine Component Failures ................................................................. 487

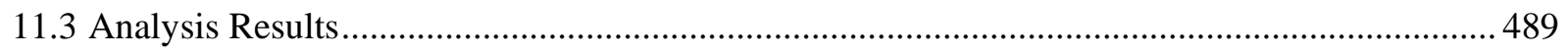

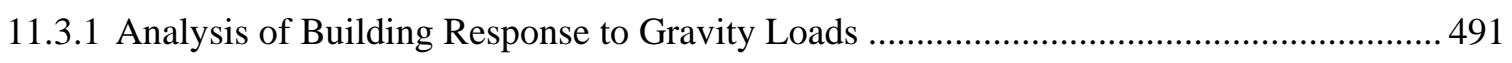

11.3.2 Analysis of Building Response for Case B Temperatures................................................ 493

11.3.3 Analysis of Building Response for Case C Temperatures.............................................. 513

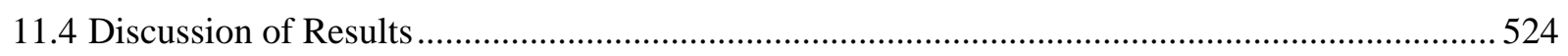

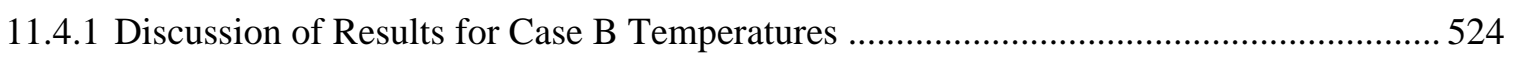

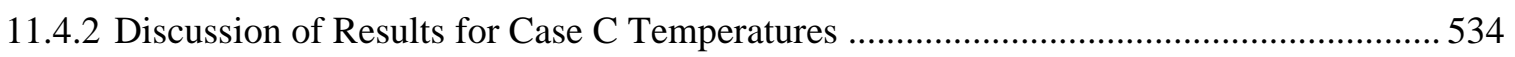

11.5 Transfer of ANSYS Results to the LS-DYNA Analysis ......................................................... 535

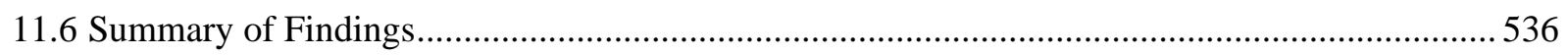

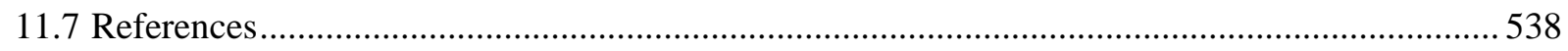

\section{Chapter 12}

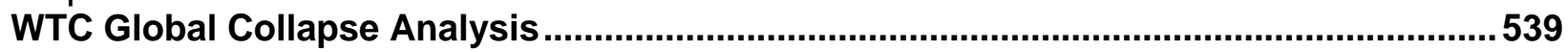

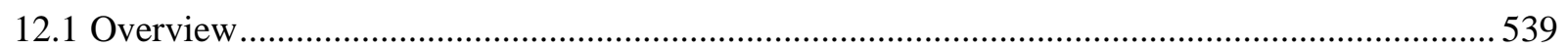

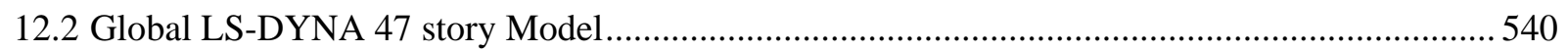

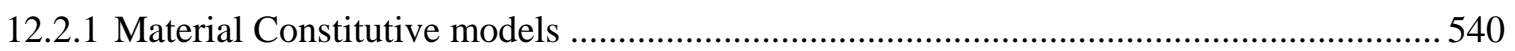

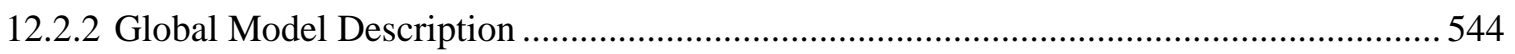

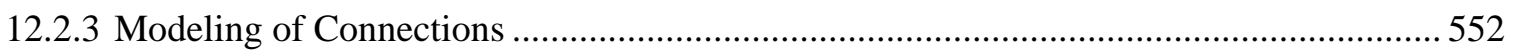

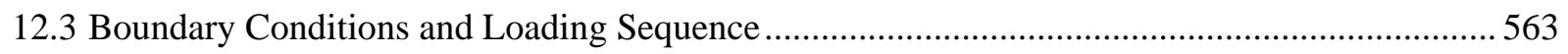

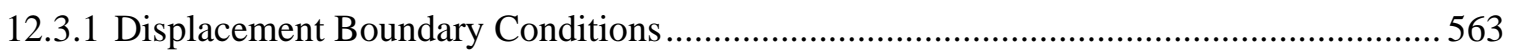

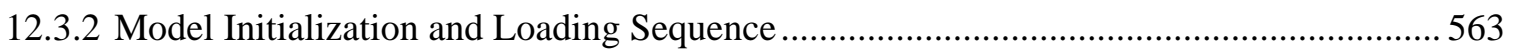

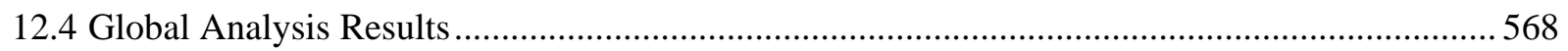

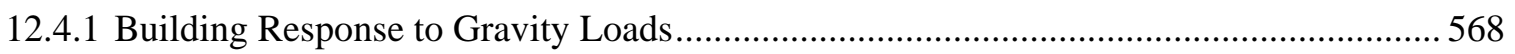




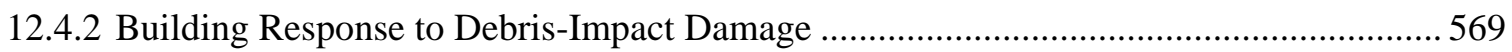

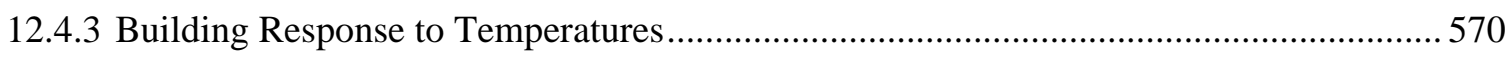

12.4.4 Global Analysis Results with Best Estimate Debris Impact Damage .............................. 571

12.4.5 Global Analysis Results with Fire Induced Damage at $3.5 \mathrm{~h} \mathrm{........................................} 589$

12.4.6 Global Analysis Results without Debris Impact Damage ................................................ 591

12.4.7 Classic Global Progressive Collapse Analysis Results Without Debris Impact and Fire-

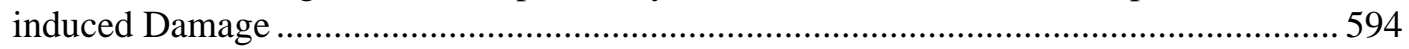

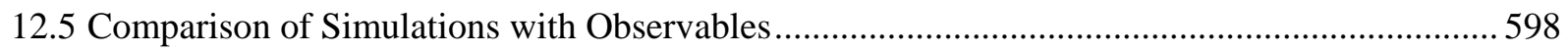

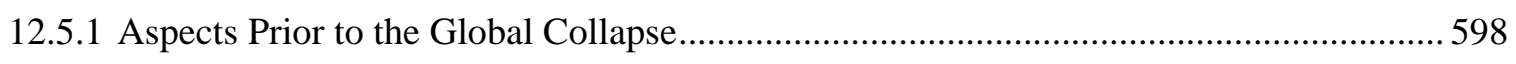

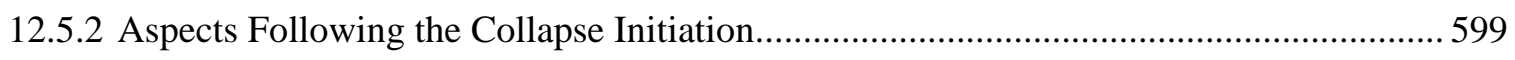

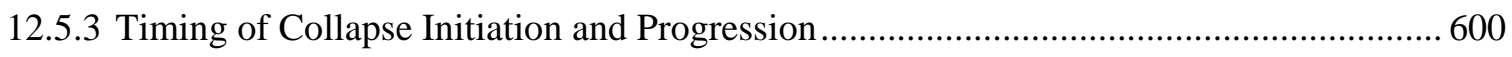

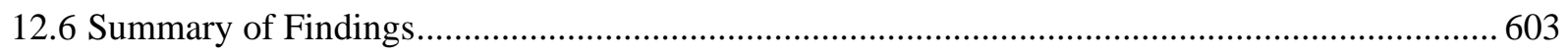

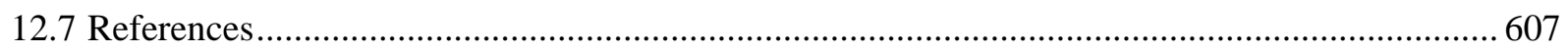

\section{Chapter 13}

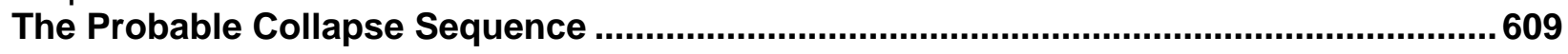

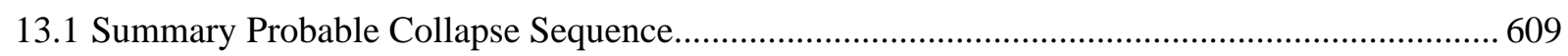

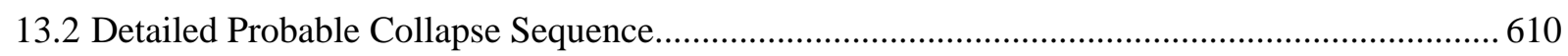

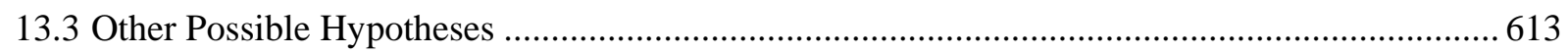

\section{Chapter 14}

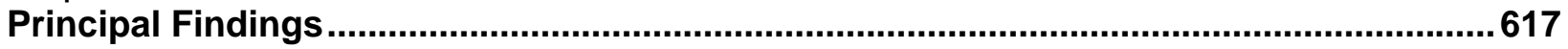

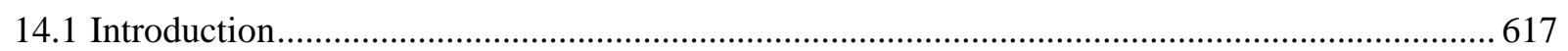

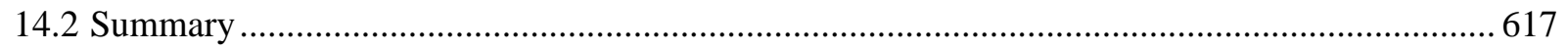

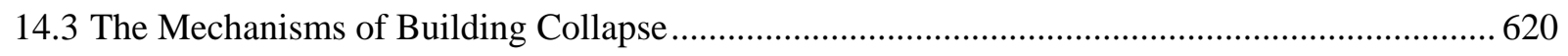

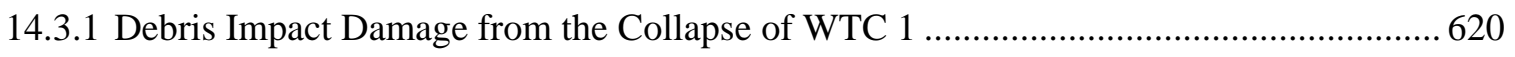

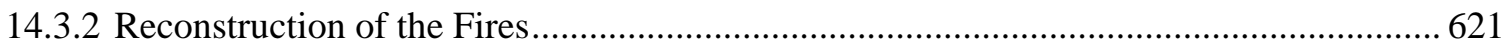

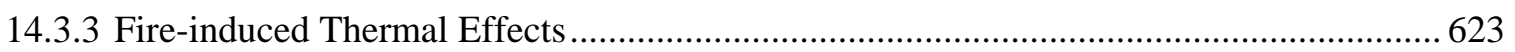

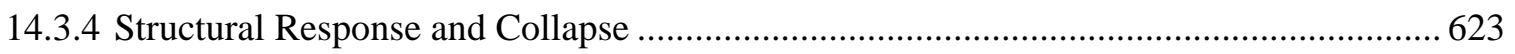

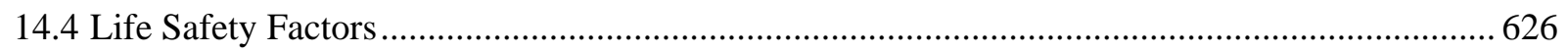

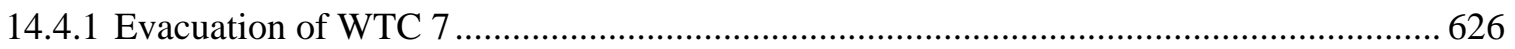

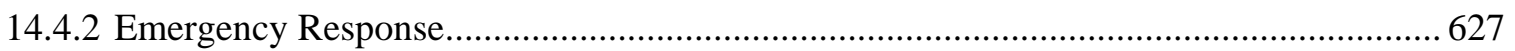

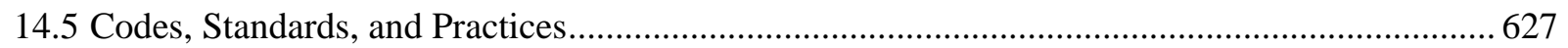

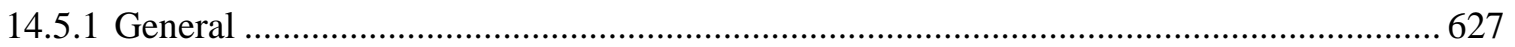

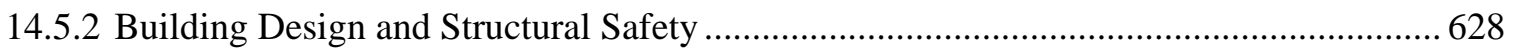

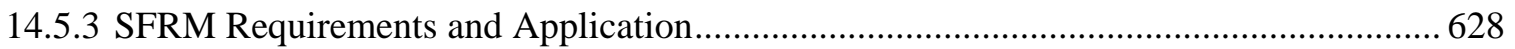




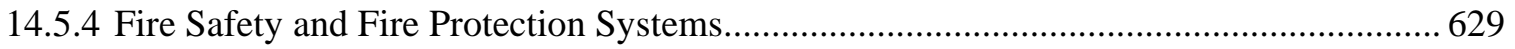

14.6 Future Factors That Could Have Mitigated Structural Collapse...............................................630

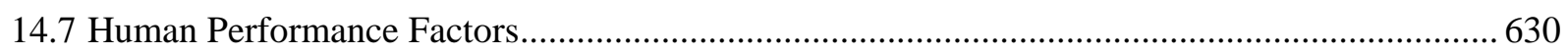

\section{Appendix A}

The Con Edison Substation in World Trade Center 7................................................633

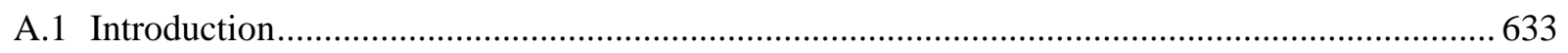

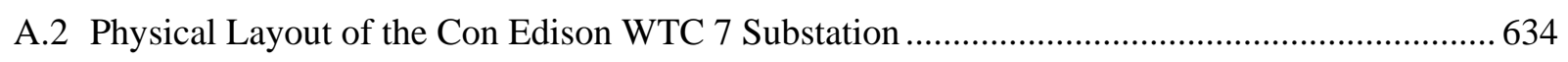

A.3 Overview of the Electric Power Networks Supplying Lower Manhattan................................. 636

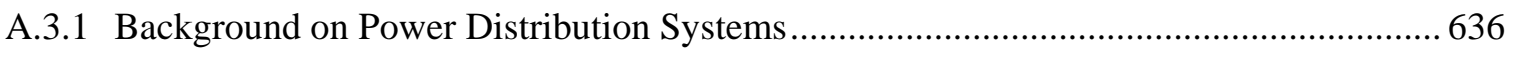

A.3.2 Supply of the WTC Complex from the Con Edison System ........................................... 639

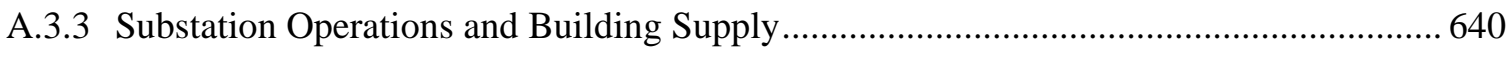

A.3.4 Description of the Power Supply for the Remaining WTC Complex .............................. 642

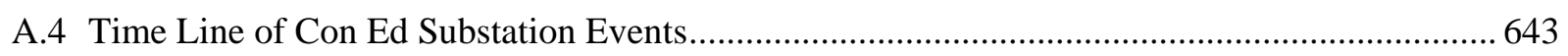

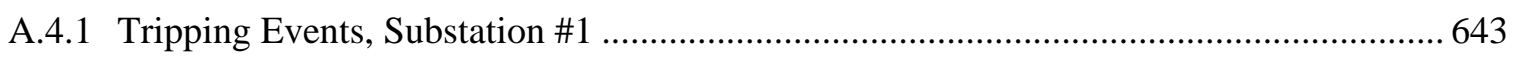

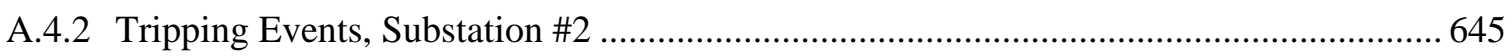

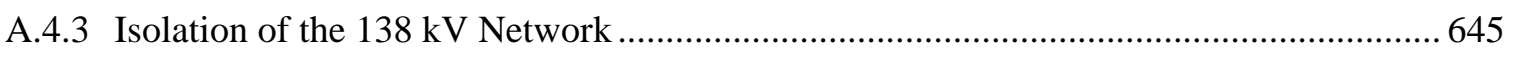

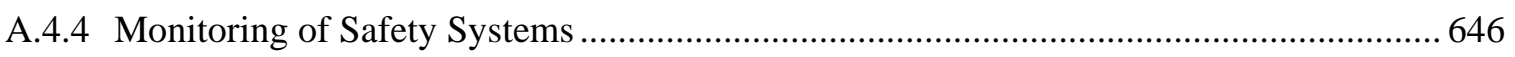

A.5 Physical Condition of the Con Edison Building Following the Collapse of WTC 1................. 648

A.6 Power Sources From Other Than Con-Edison...................................................................... 652

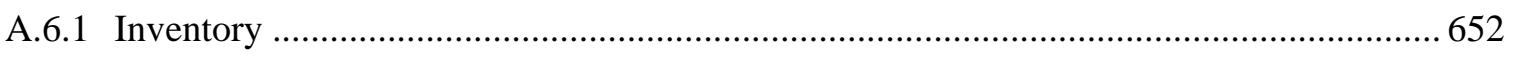

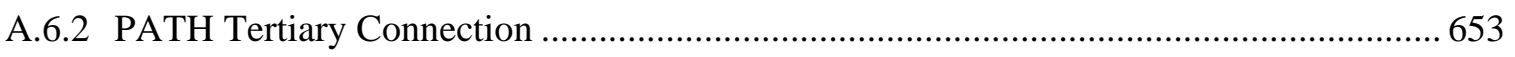

A.6.3 Emergency Generation for Local Use ........................................................................ 653

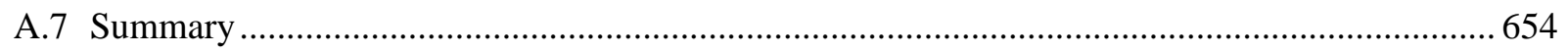

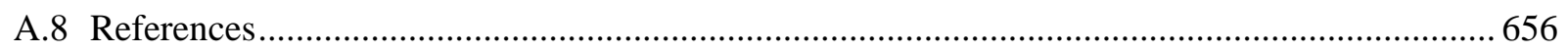

\section{Appendix B}

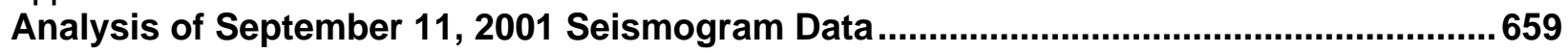

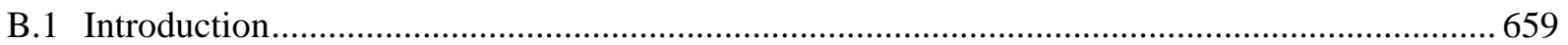

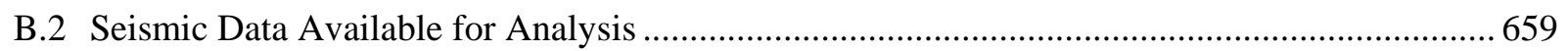

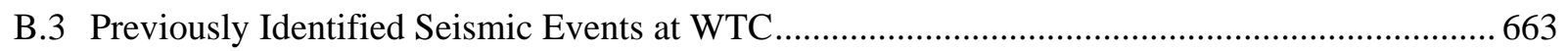

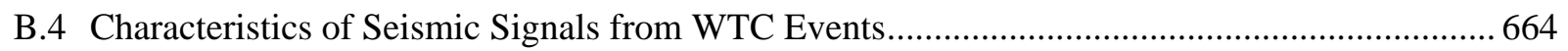

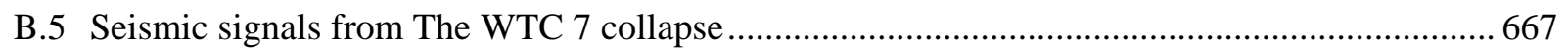

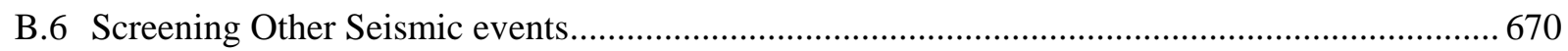

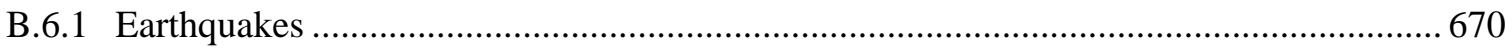

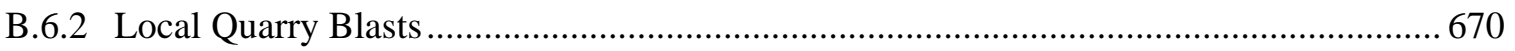




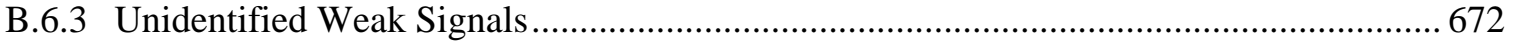

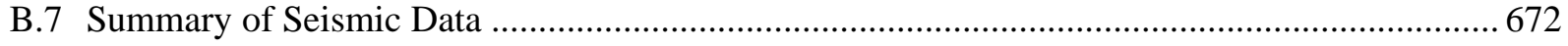

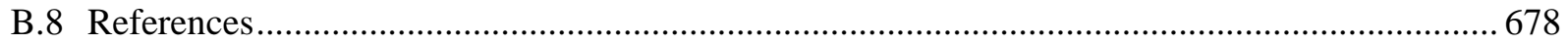

\section{Appendix C}

Video Analysis of WTC 7 Building Vibrations Before Collapse.......................................679

C.1 Determination of Building Vibration Data ............................................................................ 679

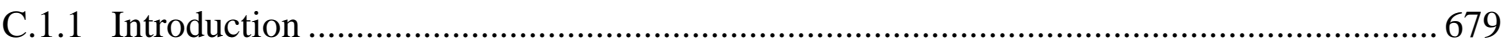

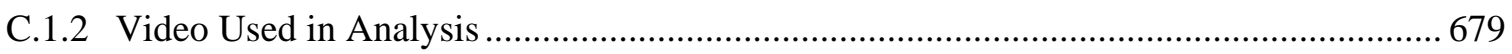

C.1.3 Moiré Technique for a Single Marker Point................................................................. 680

C.1.4 Conversion of Magnitude from Vertical Pixels to Distance............................................ 683

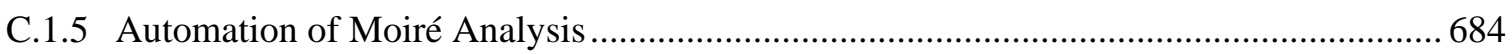

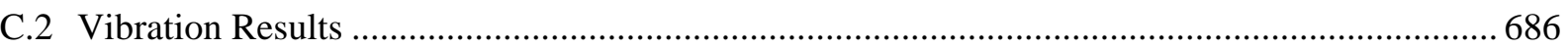

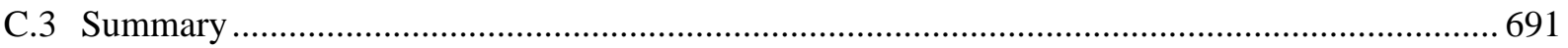

\section{Appendix D}

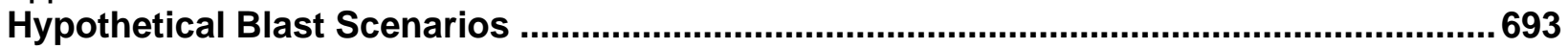

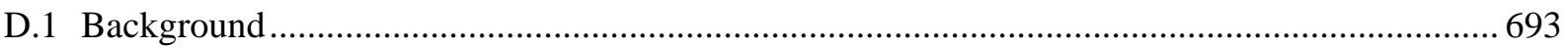

D.2 Phase I: Expert Recommended Preparations for Explosively Controlled Demolition ................ 693

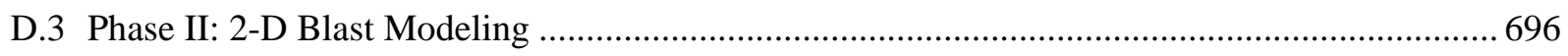

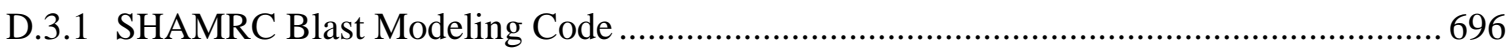

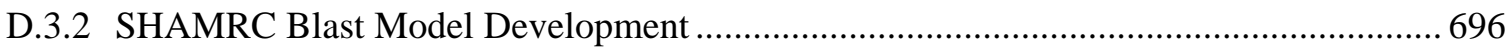

D.3.3 Estimation of WTC 7 Perimeter Window Fragility....................................................... 699

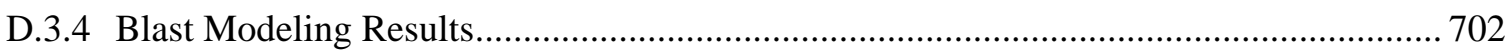

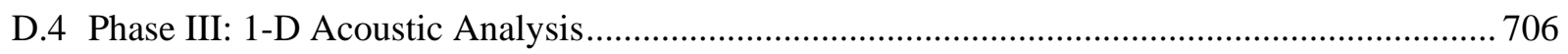

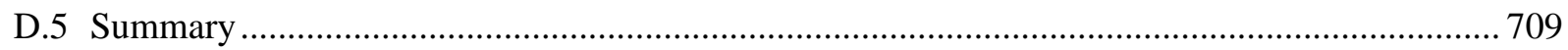

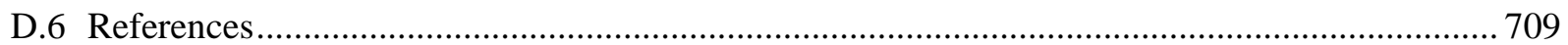

\section{Appendix E}

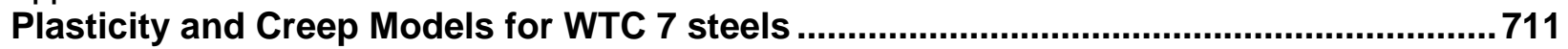

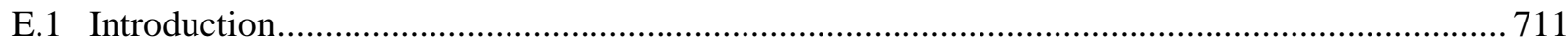

E.2 Method for Creating High-temperature Stress-strain Curves .................................................. 711

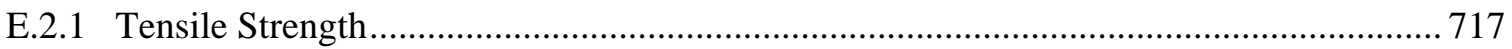

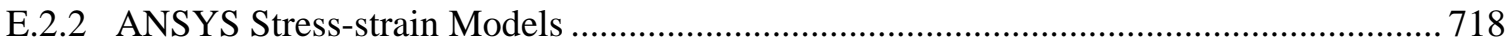

E.3 Method for Creating High-temperature Creep Curves ….......................................................... 718

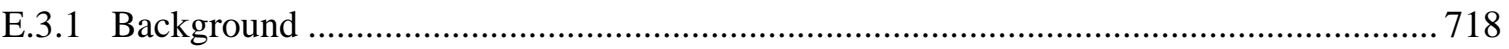

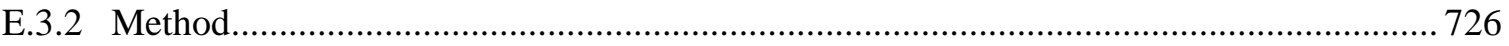




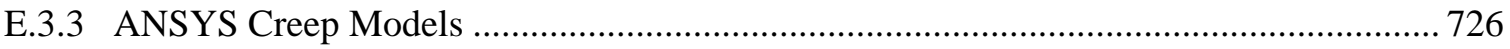

E.4 Elevated Temperature Strength of Bolts ................................................................................... 728

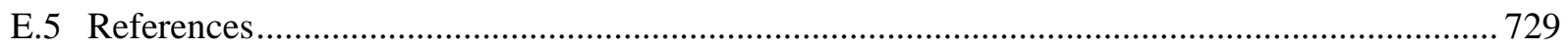




\section{LIST OF FIGURES}

Figure 9-1. Plan view of the $5^{\text {th }}$ floor, including estimated debris damage from WTC 1 ..................... 366

Figure 9-2. Plan view of the $6^{\text {th }}$ floor, including estimated debris damage from WTC 1.….................. 367

Figure 9-3. Minimum heating of reinforced heavy columns to initiate global collapse.......................... 368

Figure 9-4. Gas temperatures near the $5^{\text {th }}$ floor ceiling for the hypothetical maximum duration, over-ventilated diesel fuel pool fire after $7 \mathrm{~h}$ (Scenario 1.a)...

Figure 9-5. Gas temperatures near the $5^{\text {th }}$ floor ceiling for the hypothetical maximum intensity, over-ventilated diesel fuel pool fire after $3.5 \mathrm{~h}$ (Scenario 1.b).....

Figure 9-6. Gas temperatures near the $5^{\text {th }}$ floor ceiling for a hypothetical under-ventilated diesel fuel pool fire with the louvers closed (Scenario 1.c); (a) after $15 \mathrm{~min}$; (b) after $3 \mathrm{~h}$.

Figure 9-7. Gas temperatures near the $5^{\text {th }}$ floor ceiling for a hypothetical diesel fuel pool fire in the southeast generator room in steady-state (Scenario 2).

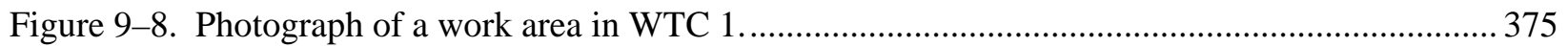

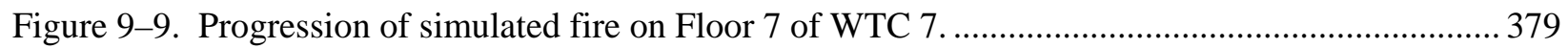

Figure 9-10. Progression of simulated fire on Floor 8 of WTC 7....................................................... 381

Figure 9-11. Progression of simulated fire on Floor 12 of WTC 7 ....................................................... 384

Figure 9-12. Progression of simulated fire on Floor 12 of WTC 7, with more durable ceiling tile

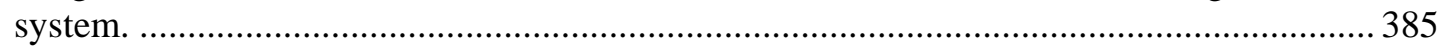

Figure 9-13. Rates of heat release of simulated fires in WTC 7. 386

Figure 10-1 Gas temperature time history for Floor 12 near the ceiling by Column 79 and the northeast corner.

Figure 10-2. View from the southeast of the computed thermal loading of the 16 lower floors of WTC 7 at 5:00 p.m. (Case A).

Figure 10-3. View from the northeast of the computed thermal loading of the 16 lower floors of WTC 7 at 5:00 p.m. (Case A, floor slabs removed).

Figure 10-4. View from the southeast of the computed thermal loading of the lower 16 floors of WTC 7 at 12 different instants in time (Case A).

Figure 10-5. View from the northeast of the computed thermal loading of the lower 16 floors of WTC 7 at 12 different instants in time (Case A, floor slabs removed). 398

Figure 10-6. Computed temperature distribution $\left({ }^{\circ} \mathrm{C}\right)$ in the top layer of the concrete slab of Floor 7 at 12 different instants in time (Case A).

Figure 10-7. Computed temperature distribution $\left({ }^{\circ} \mathrm{C}\right)$ on the floor beams of Floor 7 at 12 different instants in time (Case A, floor slab removed).

Figure 10-8. Computed temperature distribution $\left({ }^{\circ} \mathrm{C}\right)$ in the top layer of the concrete slab of Floor 8 at 12 different instants in time (Case A). 
Figure 10-9. Computed temperature distribution $\left({ }^{\circ} \mathrm{C}\right)$ on the floor beams of Floor 8 at 12 different instants in time (Case A, floor slab removed).

Figure 10-10. Computed temperature distribution $\left({ }^{\circ} \mathrm{C}\right)$ in the top layer of the concrete slab of Floor

9 at 12 different instants in time (Case A).

Figure 10-11. Computed temperature distribution $\left({ }^{\circ} \mathrm{C}\right)$ on the floor beams of Floor 9 of WTC 7 at 12 different instants in time (Case A, floor slab removed).

Figure 10-12. Computed temperature distribution $\left({ }^{\circ} \mathrm{C}\right)$ in the top layer of the concrete slab of Floor 10 at 12 different instants in time (Case A).

Figure 10-13. Computed temperature distribution $\left({ }^{\circ} \mathrm{C}\right)$ on the floor beams of Floor 10 of WTC 7 at 12 different instants in time (Case A, floor slab removed).

Figure 10-14. Computed temperature distribution $\left({ }^{\circ} \mathrm{C}\right)$ in the top layer of the concrete slab of Floor 11 at 12 different instants in time (Case A).

Figure 10-15. Computed temperature distribution $\left({ }^{\circ} \mathrm{C}\right)$ on the floor beams of Floor 11 at 12 different instants in time (Case A, floor slab removed).

Figure 10-16. Computed temperature distribution $\left({ }^{\circ} \mathrm{C}\right)$ in the top layer of the concrete slab of Floor 12 at 12 different instants in time (Case A).

Figure 10-17. Computed temperature distribution $\left({ }^{\circ} \mathrm{C}\right)$ on the floor beams of Floor 12 at 12 different instants in time (Case A, floor slab removed).

Figure 10-18. Computed temperature distribution $\left({ }^{\circ} \mathrm{C}\right)$ in the top layer of the concrete slab of Floor 13 at 12 different instants in time (Case A).

Figure 10-19. Computed temperature distribution $\left({ }^{\circ} \mathrm{C}\right)$ on the floor beams of Floor 13 at 12 different instants in time (Case A, floor slab removed).

Figure 10-20. Computed temperature distribution $\left({ }^{\circ} \mathrm{C}\right)$ in the top layer of the concrete slab of Floor 14 at 12 different instants in time (Case A).

Figure 10-21. Computed temperature distribution $\left({ }^{\circ} \mathrm{C}\right)$ on the floor beams of Floor 14 at 12 different instants in time (Case A, floor slab removed).

Figure 10-22. View from the southeast of the 16 lower floors of WTC 7, comparing Case A (left) and Case B (right) temperatures at two different times.

Figure 10-23. View from the northeast of the 16 lower floors of WTC 7, comparing Case A (left) and Case B (right) temperatures at two different times (floor slabs removed).

Figure 10-24. View from the southeast of the computed thermal loading of the lower 16 floors of WTC 7 at 12 instants in time (Case B).

Figure 10-25. View from the northeast of the computed thermal loading of the lower 16 floors of WTC 7 at 12 different instants in time (Case B, floor slabs removed).

Figure 10-26. Computed temperature distribution $\left({ }^{\circ} \mathrm{C}\right)$ in the top layer of the concrete slab on Floor 7 at 12 instants in time (Case B).

Figure 10-27. Computed temperature distribution $\left({ }^{\circ} \mathrm{C}\right)$ on the floor beams of Floor 7 at 12 different instants in time (Case B, floor slab removed).

Figure 10-28. Computed temperature distribution $\left({ }^{\circ} \mathrm{C}\right)$ in the top layer of the concrete slab on Floor 8 at 12 instants in time (Case B). 
Figure 10-29. Computed temperature distribution $\left({ }^{\circ} \mathrm{C}\right)$ on the floor beams of Floor 8 at 12 different instants in time (Case B, floor slabs removed)....

Figure 10-30. Computed temperature distribution $\left({ }^{\circ} \mathrm{C}\right)$ in the top layer of the concrete slab of Floor 9 at 12 different instants in time (Case B).

Figure 10-31. Computed temperature distribution $\left({ }^{\circ} \mathrm{C}\right)$ on the floor beams of Floor 9 at 12 different instants in time (Case $\mathrm{B}$, floor slabs removed)

Figure 10-32. Computed temperature distribution $\left({ }^{\circ} \mathrm{C}\right)$ in the top layer of the concrete slab of Floor 10 at 12 different instants in time (Case B)

Figure 10-33. Computed temperature distribution $\left({ }^{\circ} \mathrm{C}\right)$ on floor beams of Floor 10 of WTC 7 at 12 different instants in time (Case $\mathrm{B}$, floor slabs removed).

Figure 10-34. Computed temperature distribution $\left({ }^{\circ} \mathrm{C}\right)$ in the top layer of the concrete slab of Floor 11 at 12 different instants in time (Case B)

Figure 10-35. Computed temperature distribution $\left({ }^{\circ} \mathrm{C}\right)$ on the floor beams of Floor 11 at 12 different instants in time (Case $\mathrm{B}$, floor slabs removed).

Figure 10-36. Computed temperature distribution $\left({ }^{\circ} \mathrm{C}\right)$ in the top layer of the concrete slab of Floor 12 at 12 different instants in time (Case B)

Figure 10-37. Computed temperature distribution $\left({ }^{\circ} \mathrm{C}\right)$ on the floor beams of Floor 12 of WTC 7 at 12 different instants in time (Case $\mathrm{B}$, floor slabs removed).

Figure 10-38. Computed temperature distribution $\left({ }^{\circ} \mathrm{C}\right)$ in the top layer of the concrete slab of Floor 13 at 12 different instants in time (Case B)

Figure 10-39. Computed temperature distribution $\left({ }^{\circ} \mathrm{C}\right)$ on the floor beams of Floor 13 at 12 different instants in time (Case $\mathrm{B}$, floor slabs removed).

Figure 10-40. Computed temperature distribution $\left({ }^{\circ} \mathrm{C}\right)$ in the top layer of the concrete slab of Floor 14 at 12 different instants in time (Case B)

Figure 10-41. Computed temperature distribution $\left({ }^{\circ} \mathrm{C}\right)$ on the floor beams of Floor 14 at 12 different instants in time (Case B, floor slabs removed).

Figure 10-42. View from the southeast of the 16 lower floors of WTC 7, comparing Case A (left) and Case $\mathrm{C}$ (right) temperatures at two different times.

Figure 10-43. View from the northeast of the 16 lower floors of WTC 7, comparing Case A (left) and Case $\mathrm{C}$ (right) temperatures at two different times (floor slabs removed).

Figure 10-44. View from the southeast of the computed thermal loading of the lower 16 floors of WTC 7 at 12 instants in time (Case C).

Figure 10-45. View from the northeast of the computed thermal loading of the lower 16 floors of WTC 7 at 12 different instants in time (Case C, floor slabs removed).

Figure 10-46. Computed temperature distribution $\left({ }^{\circ} \mathrm{C}\right)$ in the top layer of the concrete slab on Floor 7 at 12 instants in time (Case C).

Figure 10-47. Computed temperature distribution $\left({ }^{\circ} \mathrm{C}\right)$ on the floor beams of Floor 7 at 12 different instants in time (Case $\mathrm{C}$, floor slabs removed).

Figure 10-48. Computed temperature distribution $\left({ }^{\circ} \mathrm{C}\right)$ in the top layer of the concrete slab on Floor 8 at 12 instants in time (Case C). 441 
Figure 10-49. Computed temperature distribution $\left({ }^{\circ} \mathrm{C}\right)$ on the floor beams of Floor 8 at 12 different instants in time (Case $\mathrm{C}$, floor slabs removed)

Figure 10-50. Computed temperature distribution $\left({ }^{\circ} \mathrm{C}\right)$ in the top layer of the concrete slab on Floor 9 at 12 instants in time (Case C).

Figure 10-51. Computed temperature distribution $\left({ }^{\circ} \mathrm{C}\right)$ on the floor beams of Floor 9 at 12 different instants in time (Case $\mathrm{C}$, floor slabs removed)

Figure 10-52. Computed temperature distribution $\left({ }^{\circ} \mathrm{C}\right)$ in the top layer of the concrete slab on Floor 10 at 12 instants in time (Case C).

Figure 10-53. Computed temperature distribution $\left({ }^{\circ} \mathrm{C}\right)$ on the floor beams of Floor 10 at 12 different instants in time (Case $\mathrm{C}$, floor slabs removed).

Figure 10-54. Computed temperature distribution $\left({ }^{\circ} \mathrm{C}\right)$ in the top layer of the concrete slab on Floor 11 at 12 instants in time (Case C).

Figure 10-55. Computed temperature distribution $\left({ }^{\circ} \mathrm{C}\right)$ on the floor beams of Floor 11 at 12 different instants in time (Case $\mathrm{C}$, floor slabs removed).

Figure 10-56. Computed temperature distribution $\left({ }^{\circ} \mathrm{C}\right)$ in the top layer of the concrete slab on Floor 12 at 12 instants in time (Case C).

Figure 10-57. Computed temperature distribution $\left({ }^{\circ} \mathrm{C}\right)$ on the floor beams of Floor 12 at 12 different instants in time (Case $\mathrm{C}$, floor slabs removed).

Figure 10-58. Computed temperature distribution $\left({ }^{\circ} \mathrm{C}\right)$ in the top layer of the concrete slab on Floor 13 at 12 instants in time (Case C).

Figure 10-59. Computed temperature distribution $\left({ }^{\circ} \mathrm{C}\right)$ on the floor beams of Floor 13 at 12 different instants in time (Case $\mathrm{C}$, floor slabs removed).

Figure 10-60. Computed temperature distribution $\left({ }^{\circ} \mathrm{C}\right)$ in the top layer of the concrete slab on Floor 14 at 12 instants in time (Case C).

Figure 10-61. Computed temperature distribution $\left({ }^{\circ} \mathrm{C}\right)$ on the floor beams of Floor 14 at 12 different instants in time (Case $\mathrm{C}$, floor slabs removed).

Figure 11-1. 16 story model representing lower 16 floors of the WTC 7 building.

Figure 11-2. ANSYS multilinear isotropic hardening (MISO) model for temperature-dependent behavior of ASTM A572 grade 50 steel.

Figure 11-3. ANSYS multilinear isotropic hardening (MISO) model for temperature-dependent behavior of 4000 psi normal weight concrete slab.

Figure 11-4. Finite element representation of the composite floor system.

Figure 11-5. Tear-out mode of failure 466

Figure 11-6. Block shear failure planes for vertical shear forces. 467

Figure 11-7. Block shear failure planes for horizontal tension force. 467

Figure 11-8. Schematic of shear stud placement relative to the metal deck. 468

Figure 11-9. Area of the floor where connection failures were modeled. 476

Figure 11-11. Analytical model for a fin connection. 477 


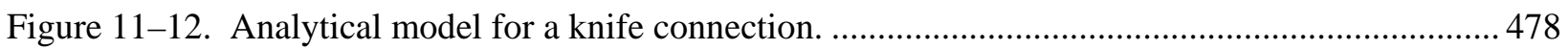

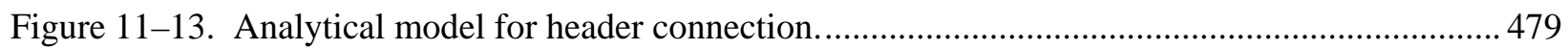

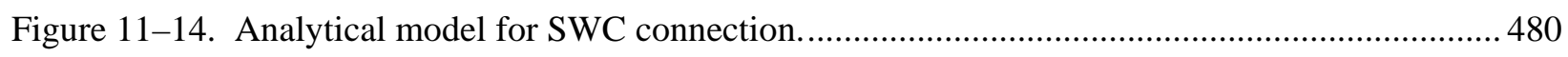

Figure 11-15 Analytical model for seated connections at exterior columns. ....................................... 481

Figure 11-16 Analytical model for the seated connection at Column 79............................................ 483

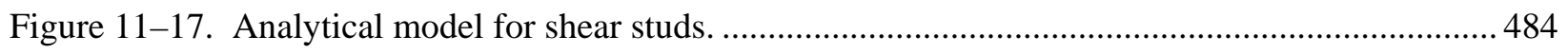

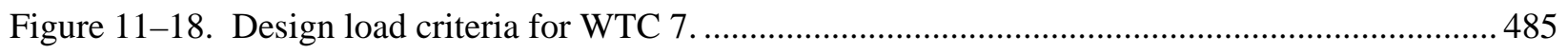

Figure 11-19. Detailed thermal analysis showing the gradient between girders, Column 79, and

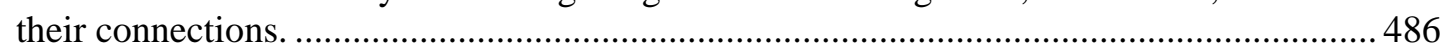

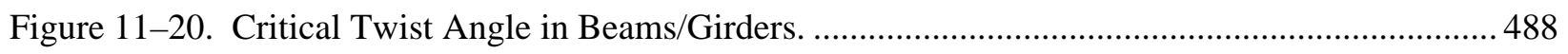

Figure 11-21. Structural response of Floor 8 to gravity loads............................................................... 492

Figure 11-22. Column forces (kip) above Floor 8 for gravity loads. ................................................... 493

Figure 11-23. Damage state of connections, beams, and girders in Floor 8 at $3.5 \mathrm{~h}$ for Case B

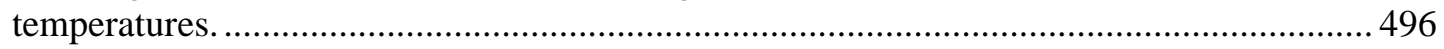

Figure 11-24. Damage state of connections, beams, and girders in Floor 9 at $3.5 \mathrm{~h}$ for Case B temperatures.

Figure 11-25. Damage state of connections, beams, and girders in Floor 10 at $3.5 \mathrm{~h}$ for Case B. temperatures.

Figure 11-26. Damage state of connections, beams, and girders in Floor 11 at $3.5 \mathrm{~h}$ for Case B temperatures.

Figure 11-27. Damage state of connections, beams, and girders in Floor 12 at $3.5 \mathrm{~h}$ for Case B temperatures.

Figure 11-28. Damage state of connections, beams, and girders in Floor 13 at $3.5 \mathrm{~h}$ for Case B temperatures.

Figure 11-29. Damage state of connections, beams, and girders in Floor 14 at $3.5 \mathrm{~h}$ for Case B temperatures.

Figure 11-30. Column forces (in kip) above Floor 8 at $3.5 \mathrm{~h}$ for Case B temperatures.

Figure 11-31. Damage state of connections, beams, and girders in Floor 8 at $4.0 \mathrm{~h}$ for Case B temperatures.

Figure 11-32. Damage state of connections, beams, and girders in Floor 9 at $4.0 \mathrm{~h}$ for Case B temperatures.

Figure 11-33. Damage state of connections, beams, and girders in Floor 10 at $4.0 \mathrm{~h}$ for Case B temperatures.

Figure 11-34. Damage state of connections, beams, and girders in Floor 11 at $4.0 \mathrm{~h}$ for Case B temperatures.

Figure 11-35. Damage state of connections, beams, and girders in Floor 12 at $4.0 \mathrm{~h}$ for Case B temperatures.

Figure 11-36. Damage state of connections, beams, and girders in Floor 13 at $4.0 \mathrm{~h}$ for Case B temperatures. 
Figure 11-37. Damage state of connections, beams, and girders in Floor 14 at $4.0 \mathrm{~h}$ for Case B temperatures.

Figure 11-38. Column forces (in kip) above Floor 8 at t $=4.0 \mathrm{~h}$ for Case B temperatures.

Figure 11-39. Damage state of connections, beams, and girders in Floor 8 at 4.0 h for Case C temperatures.

Figure 11-40. Damage state of connections, beams, and girders in Floor 9 at $4.0 \mathrm{~h}$ for Case C temperatures.

Figure 11-41. Damage state of connections, beams, and girders in Floor 10 at $4.0 \mathrm{~h}$ for Case C temperatures.

Figure 11-42. Damage state of connections, beams, and girders in Floor 11 at $4.0 \mathrm{~h}$ for Case C temperatures

Figure 11-43. Damage state of connections, beams, and girders in Floor 12 at $4.0 \mathrm{~h}$ for Case C temperatures.

Figure 11-44. Damage state of connections, beams, and girders in Floor 13 at $4.0 \mathrm{~h}$ for Case C temperatures

Figure 11-45. Damage state of connections, beams, and girders in Floor 14 at $4.0 \mathrm{~h}$ for Case C temperatures. 523

Figure 11-46. Column forces (in kip) above Floor 8 at $\mathrm{t}=4.0 \mathrm{~h}$ for Case $\mathrm{C}$ temperatures. 524

Figure 11-47. Floor 13 Case B temperatures at 3.0 h, 3.5 h, and 4.0 h.............................................. 528

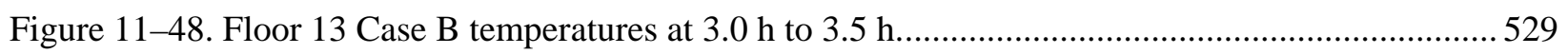

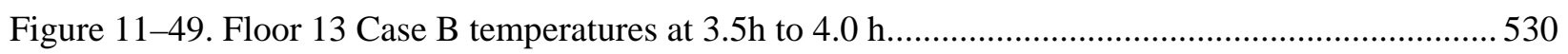

Figure 11-50. Beam and girder failures around Columns 79, 80, and 81 at $4.0 \mathrm{~h}$ for Case B temperatures.

Figure 11-51. Heating of a typical floor beam (W24 x 55) subject to an ASTM E 119 temperature profile for different SFRM thicknesses.

Figure 11-52. Heating of a typical floor beam (W24 x 55) subject to a uniform $1100{ }^{\circ} \mathrm{C}$ gas temperature for different SFRM thicknesses.

Figure 12-1. Tabular true stress-true strain constitutive model curves for WTC 7 steels.

Figure 12-2. Temperature-dependent strength of the ASTM A572 Grade 50 structural steel as a function of temperature.

Figure 12-3. Typical composite floor construction detail (along strong direction)

Figure 12-4. Typical composite floor construction detail (along weak direction).

Figure 12-5. Calculated composite slab behaviors in tension and compression.

Figure 12-6. Global model of WTC 7, viewed from the southwest. 545

Figure 12-7. Global model of WTC 7, viewed from the northeast. 546

Figure 12-8. Typical tenant floor structural framing and slab model (Floors 8 to 20, 24 to 45)........ 547

Figure 12-9. Floor 5 structural framing and slab model. 548 
Figure 12-10. Model of the $5^{\text {th }}$ floor diaphragm framing plan. .........................................................548

Figure 12-11. Detail of Truss 1 in the WTC 7 global model. ............................................................... 549

Figure 12-12. Detail of Truss 2 in the WTC 7 global model. .......................................................... 549

Figure 12-13. Exterior wind bracing in the lower floors of the global model...................................... 550

Figure 12-14. Core wind bracing in the lower floors of the global model, viewed from the

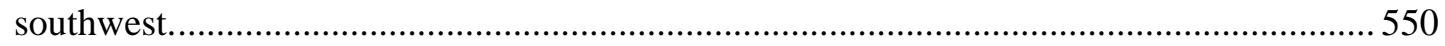

Figure 12-15. Belt truss cross-bracing in the global model............................................................... 551

Figure 12-16. Beam element model of the penthouse structure........................................................... 551

Figure 12-17. Fin, header, and knife shear connection schematics.................................................... 553

Figure 12-18. Component model used to develop the fin, header, and knife (FHK) shear connection

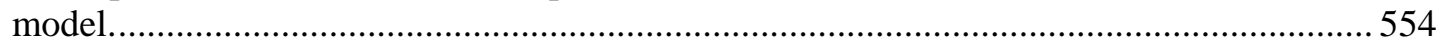

Figure 12-19. Comparison of the spring element and shell element models of the fin connections........ 554

Figure 12-20. Generic LS-DYNA model of a FHK shear connection. ................................................. 555

Figure 12-21. Schematic of seated connections at exterior columns. .................................................... 556

Figure 12-22. Model of seated connection at exterior column..........................................................557

Figure 12-23. STP connection in global model, view of southwest corner above Floor 9. .................... 557

Figure 12-24. Schematic of the STC connection at Column 79.......................................................... 558

Figure 12-25. Seat connection in global model, Column 79............................................................ 559

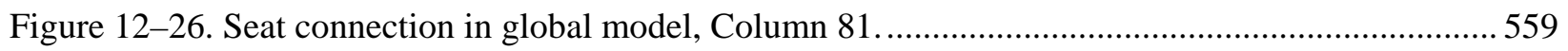

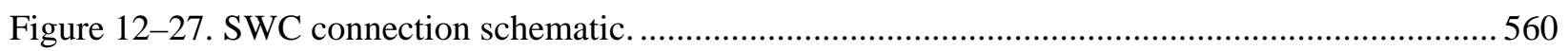

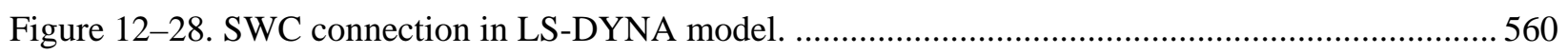

Figure 12-29. Moment connection model for a wind girder. ................................................................ 561

Figure 12-30. Column splice connection in LS-DYNA model.......................................................... 562

Figure 12-31. Modeling of shear stud connection between beams and slabs....................................... 562

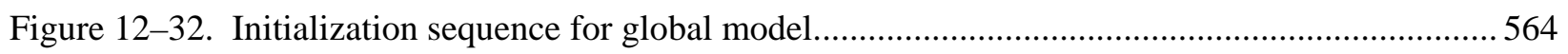

Figure 12-33. Debris impact damage application to the global LS-DYNA model. ................................ 565

Figure 12-34. Temperature profile in Floors 7 through 14. ............................................................... 565

Figure 12-35. Approach used to model buckled beams in LS-DYNA model........................................ 567

Figure 12-36. Shear connection damage application in LS-DYNA model..........................................567

Figure 12-37. Calculated global vertical displacements after gravity initialization............................... 569

Figure 12-38. Total load history above Floor 8 during gravity initialization........................................569

Figure 12-39. Calculated vertical displacements after impact damage.................................................5 570

Figure 12-40. Calculated vertical displacements after temperature initialization..................................570

Figure 12-41. Detailed comparison of vertical displacements after damage and temperature

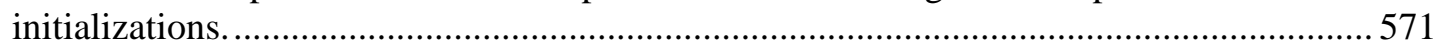

Figure 12-42. The collapse of Floors 13 and 14 in the northeast region [Time: -6.5 (9.5) s] .................573 


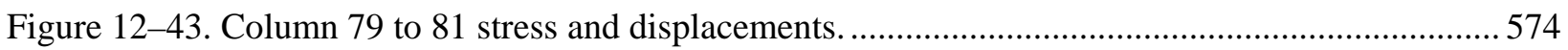

Figure 12-44. Column 79 lateral support status at time of buckling initiation...................................... 575

Figure 12-45. Column 79-81 vertical displacement with contours from $-0.5 \mathrm{~m}$ to $0 \mathrm{~m}$........................ 577

Figure 12-46. Kink on east penthouse as it moves downward [Time 0.2 (16.2) s]. View from north..... 578

Figure 12-47. Columns 80 and 81 lateral support status at time of buckling initiation. ........................ 578

Figure 12-48. Vertical progression of failures on the east side of the building [Time: 0.5 (16.5) s] ......579

Figure 12-49. Debris from the vertical progression falling onto the lower floors, Trusses 1 and 2,

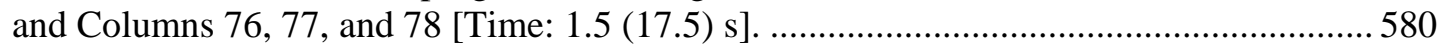

Figure 12-50. Failure of Truss 2 east diagonal. View from southeast and above. ................................ 580

Figure 12-51. Truss 2 collapse. View from south (most of debris removed from view). ..................... 581

Figure 12-52. Failure of Columns 77 and 78 due to failure of Truss 2 from debris impact [Time:

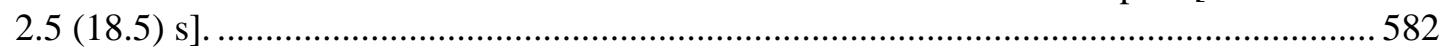

Figure 12-53. Buckling of Column 76 from the load transfer and debris impact from the buckling

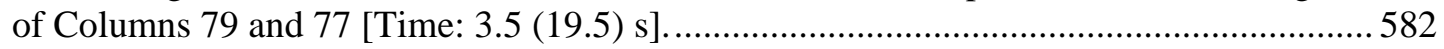

Figure 12-54. Failure of Columns 73 to 75 from the load redistribution and debris impact [Time:

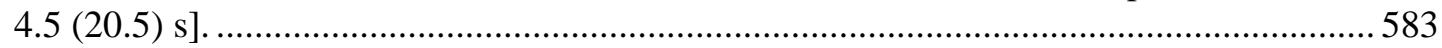

Figure 12-55. Buckling of all interior columns [Time: 6.5 (22.5) s] ..................................................... 583

Figure 12-56. Western core column vertical displacements (contours: -0.5 to $0 \mathrm{~m}$ ).............................. 584

Figure 12-57. Horizontal progression of column buckling and interior column groupings.................... 584

Figure 12-58. Interior column loads illustrating east to west collapse progression. .............................. 585

Figure 12-59. West interior column loads illustrating progression of failure. ...................................... 585

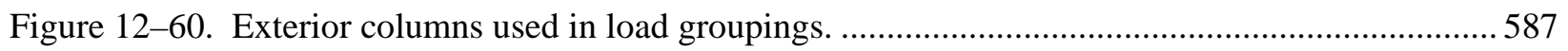

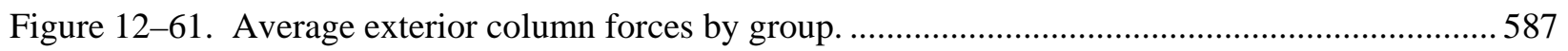

Figure 12-62. Exterior column buckling after initiation of global collapse with debris impact and fire-induced damage (slabs removed from view)............................................................... 588

Figure 12-63. Detailed view of exterior column buckling at lower floors (slabs removed from view).

Figure 12-64. Floor framing damage around Columns 76 to 81 after stability has been reached $3.24 \mathrm{~s}(12.76 \mathrm{~s})$. Contours of vertical displacement shown -39 to 0 in. $(-1$ to $0 \mathrm{~m})$.............. 590

Figure 12-65. Lower floor damage in stable structure at -3.8 s (12.2 s). View from southwest. ............. 590

Figure 12-66. Core collapse sequence viewed from the south. Time: $-5.8 \mathrm{~s}$ to $-1.3 \mathrm{~s}$ (7.5 s to $12.0 \mathrm{~s}$ ). Contours of resultant lateral displacement 0 in. to -20 in. $(0 \mathrm{~m}$ to $-0.5 \mathrm{~m})$.

Figure 12-67. Core collapse sequence viewed from south. Time: $0.7 \mathrm{~s}$ to $3.2 \mathrm{~s}$ (14.0 s to $17.5 \mathrm{~s}$ ). Contours of resultant lateral displacement 0 in. to -20 in. $(0 \mathrm{~m}$ to $-0.5 \mathrm{~m})$.

Figure 12-68. Core collapse sequence. Time: 5.5 to 7.8 s (21.5 to 23.8 s). Contours of resultant lateral displacement 0 to -20 in. (0 to $-0.5 \mathrm{~m})$.

Figure 12-69 Core collapse sequence viewed from the south. Time: 10.8 to $15.5 \mathrm{~s}$ (24.1 to $28.8 \mathrm{~s}$ ). Contours of resultant lateral displacement 0 in. to -20 in. ( $0 \mathrm{~m}$ to $-0.5 \mathrm{~m})$. 593 
Figure 12-70. Exterior column buckling after initiation of global collapse with fire-induced damage and without debris impact damage (slabs removed from view).

Figure 12-71. Collapse of the north interior columns from $0.7 \mathrm{~s}(6.0 \mathrm{~s})$ to $12.7 \mathrm{~s}(18.0 \mathrm{~s})$. Contours of resultant lateral displacement 0 in. to 16 in. ( $0 \mathrm{~m}$ to $0.4 \mathrm{~m})$.

Figure 12-72. Collapse of the north interior columns from $15.7 \mathrm{~s}(21.0 \mathrm{~s})$ to $21.2 \mathrm{~s}$ (26.5 s). Contours of resultant lateral displacement 0 in. to 16 in. $(0 \mathrm{~m}$ to $0.4 \mathrm{~m})$. 596

Figure 12-73. Exterior column buckling after initiation of global collapse for progressive collapse analysis without debris impact and fire-induced damage (slabs removed from view). ...... 597

Figure 12-74. Global kinetic energy during the analysis without fire or debris impact damage. ........... 598

Figure 12-75 Brightness of a pixel on the north face roofline as WTC 7 began to collapse................... 601

Figure 12-76 Downward displacement of north face roofline as WTC 7 began to collapse.................... 602

Figure 12-77 Downward velocity of north face roofline as WTC 7 began to collapse.

Figure A-1. WTC site indicating the Con Edison substation location within WTC 7.

Figure A-2. Aerial view from the north side of WTC 7 showing the Con Edison substation along Barclay Street. (Photo taken prior to September 11, 2001.)

Figure A-3. Simplified diagram of the World Trade Center power supply.

Figure A-4. Northwest corner of the Con Edison substation (building on left), showing light damage from WTC 1 debris. (Photo taken sometime in the afternoon on Sept. 11, 2001.).

Figure A-5. Aerial view of the middle of the north side of the Con Edison substation, taken at 2:57 p.m. \pm 5 min on September 11, 2001.

Figure A-6. Debris pile from collapse of WTC 7 onto the Con Edison substation, viewed looking south from Greenwich Street, date undetermined.

Figure A-7. Photographs taken on mid-October, 2001, showing Con Edison transformer \#4 (or \#8 or \#9) uncovered from the debris pile of WTC 7.

Figure A-8. Photograph taken in mid-October, 2001, showing Con Edison transformers \#6 and \#1 uncovered from debris pile of WTC 7.

Figure A-9. Con Edison transformer \#7 (or \#5) uncovered from debris pile of WTC 7; photo taken mid-October, 2001.

Figure B-1. Seismographic stations (solid triangles) that recorded events at WTC. 661

Figure B-2. PAL seismic recordings (nm/s) on EW component, beginning at 10:00 EDT. 662

Figure B-3. Three-component seismic records at stations PAL and BRNJ from the collapse of WTC 1. 665

Figure B-4. Vertical-component seismic records at local stations PAL, BRNJ, TBR, MANY and ARNY from collapse of WTC 1. 666

Figure B-5. East-west (BHE) and vertical (EHZ) component seismic records, $0.6 \mathrm{~Hz}$ to $5 \mathrm{~Hz}$ filtered, at PAL, BRNJ, TBR, MANY and ARNY from collapse of WTC 7. 668 
Figure B-6. Three-component seismic records, $1 \mathrm{~Hz}$ to $10 \mathrm{~Hz}$ filtered, at PAL from collapse of WTC 7

Figure B-7. Vertical component seismic records from quarry blast (ID \#8) recorded at seismographic stations around New York City (PKP is ID \#6).

Figure B-8. Epicenters of local quarry blasts on Sept. 11, 2001.

Figure B-9. Events identified on PAL seismogram.

Figure C-1. A single frame from the Camera 3 news video shot on September 11.

Figure C-2. Demonstration of moiré fringe pattern resulting from two gratings superimposed at a slight angle.

Figure C-3. Effect of a small shift of one grating on the location of the moiré fringe pattern. 680

Figure C-4. Pixel grid of the north face of WTC 7, showing that the northwest edge was nearly vertical.

Figure C-5. Enlargement of northwest edge of WTC 7 from Figure C-4.

Figure C-6. Marker point data for final $18 \mathrm{~s}$ (left) and the final minute (right) prior to the collapse of WTC 7.

Figure C-7. Automated determination of intersection point. a) close-up of northeast edge of WTC 7 in grayscale, b) plot of pixel intensity vs. vertical pixel number for pixel columns 517 and 519, and c) polynomial fit showing the intersection point.

Figure C-8. Horizontal displacement of northwest corner of WTC 7 and marker point location for final $22 \mathrm{~s}$ before the start of penthouse downward movement.

Figure C-9. Horizontal displacement of northwest corner of WTC 7 and marker point location for full $7 \frac{1}{2} \mathrm{~min}$ duration of video before collapse initiation.

Figure C-10. a) Comparison of oscillation mode with data for $6 \mathrm{~s}$ period before the east penthouse began to move downward, b) residual after mode was subtracted from data.

Figure C-11. a) Comparison of mode with data for period from $t=2.0 \mathrm{~s}$ to $t=6.9 \mathrm{~s}$, and $\mathrm{b}$ ) residual.

Figure C-12. a) Comparison of secondary mode with residual for period from $t=2.0 \mathrm{~s}$ to $\mathrm{t}=6.9 \mathrm{~s}$, and $b$ ) residual after both modes were subtracted from original data.

Figure C-13. a) Comparison of mode with data for period from $t=1.0 \mathrm{~s}$ to $\mathrm{t}=6.9 \mathrm{~s}$, and $\mathrm{b}$ ) residual...... 690

Figure C-14. Comparison of data with modes before and after penthouse fall.

Figure D-1. Column side plate attachment details.

Figure D-2. Layout 2 floor plan layout and SHAMRC model.

Figure D-3. Layout 3 floor plan layout and SHAMRC model.

Figure D-4. WTC 7 Architectural Drawing 38, Detail A: Typical Southwall and Southeast Corner Elevation.

Figure D-5. WTC 7 Architectural Drawing 38, Section C: Typical Plan at Exterior Southwall and Southeast Corner. 
Figure D-6. WTC 7 Architectural Drawing 38, Section G: Typical Exterior Wall Section.................... 700

Figure D-7. WTC 7 Architectural Drawing 40, Section A: Typical Exterior Wall at Window............... 701

Figure D-8. Pressure-impulse requirements for WTC 7 window breakage.......................................... 702

Figure D-9. Layout 2 pressure-impulse values at window locations compared to predicted failure

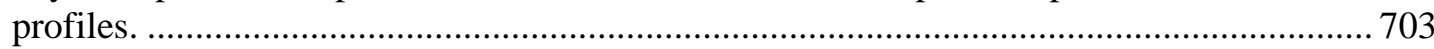

Figure D-10. Layout 3 pressure-impulse values at window locations compared to predicted failure

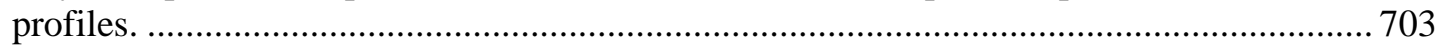

Figure D-11. Layout 2 peak overpressure and broken window locations, 9 lb charge........................... 704

Figure D-12. Layout 2 peak overpressure and broken window locations, 2 lb charge............................ 704

Figure D-13. Layout 3 peak overpressure and broken window locations, 9 lb charge............................ 705

Figure D-14. Layout 3 peak overpressure and broken window locations, 2 lb charge............................ 705

Figure D-15. Typical waveform and corresponding Fourier transformation at a broken window

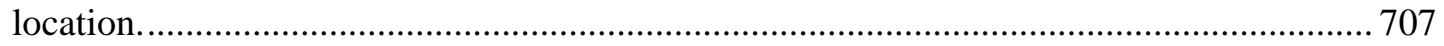

Figure D-16. Typical waveform in the southwest corner near the debris damaged windows. ................. 707

Figure D-17. Layout 2 acoustic overpressure-distance predictions. ..................................................... 708

Figure D-18. Layout 3 acoustic overpressure-distance predictions. ....................................................... 708

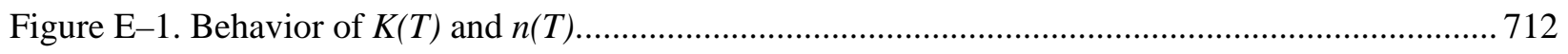

Figure E-2. Base and modeled stress-strain behavior at $20^{\circ} \mathrm{C}$ for A 36 and A 572 steels...................... 715

Figure E-3. "Yield strength" evaluated from the high-temperature stress strain curves and the

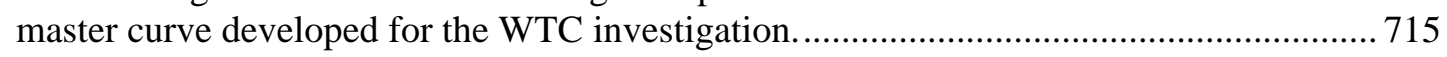

Figure E-4. Elevated-temperature stress-strain curves for $d \varepsilon / d t=10^{-2} \mathrm{~s}^{-1}$ for A 36 steel...................... 716

Figure E-5. Elevated temperature stress-strain curves for $d \varepsilon / d t=10^{-2} \mathrm{~s}^{-1}$ for A 572 steel.................... 716

Figure E-6. Elevated-temperature stress-strain curves for $d \varepsilon / d t=10^{-2} \mathrm{~s}^{-1}$ for CSA G40.21-44W

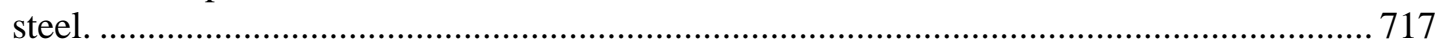

Figure E-7. Creep curves for various 36 ksi steels, from the fits of Williams-Leir, evaluated at convenient temperatures and stresses.

Figure E-8. Creep curves for various high-strength structural steels, evaluated at other convenient

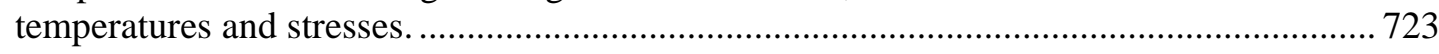

Figure E-9. Comparison of A 572 creep with predictions for AS149 steel............................................ 724

Figure E-10. Comparison of AS149 creep data with predicted data based on A 572 data and tensile strength scaling. 
This page intentionally left blank. 


\section{LIST OF TABLES}

Table 10-1. Regions in WTC 7 in which computed temperatures of structural components exceeded $600{ }^{\circ} \mathrm{C}$.

Table 11-1. Element types used in 16 story model. 460

Table 11-2. Ratio of vertical capacity to design shear load of shear connections for floor beams and girders on a typical tenant floor.

Table 11-3. Ratio of vertical capacity to design shear load of shear connections for core floor beams on a typical tenant floor.

Table 11-4. Ratio of vertical capacity to design shear load of shear connections for core floor girders on a typical tenant floor.

Table 11-5. Types of break elements defined in ANSYS. 474

Table 11-6. Structural response of WTC 7 to Case B and Case C temperatures. 515

Table 11-7. Connection damage level estimate for data transfer to the LS-DYNA model. .535

Table 12-1. Summary of the size of the global 47 story model of WTC 7. 544

Table 12-2. Comparison of major collapse events: observable versus analysis timeline. 599

Table A-1. Times for major events on September 11, 2001 (Chapter 5). 634

Table A-2. Glossary of Technical Terms Associated with Electrical Power Networks. 637

Table A-3. WTC Substation \#1 tripping sequence. 644

Table A-4. Con Edison WTC Substation \#2 tripping sequence... 647

Table A-5. Inventory of Distributed Generation in Lower Manhattan. (Con Edison 2005j). 652

Table A-6. Emergency generation available in WTC 7. (NIST NCSTAR 1-1J 2005) 654

Table B-1. List of seismic stations around New York City used in this study. 661

Table B-2. Major seismic events previously reported. 664

Table B-3. Minor seismic signals recorded around New York City on Sept. 11, 2001, and examined in this study. 671

Table B-4. Summary of seismic events recorded 8:46 to 17:21 on Sept. 11, 2001. 676

Table C-1. Modes from nonlinear least squares analysis for WTC 7 data... 688

Table D-1. Basic wide flange column parameters. (Dimensions in in.) 694 


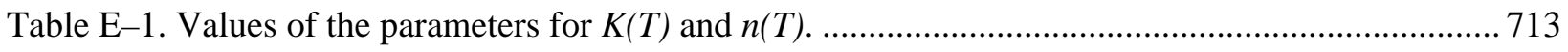

Table E-2. Values of the tensile strength, TS, of A 36, CSA G40.21-44W, and A 572........................ 718

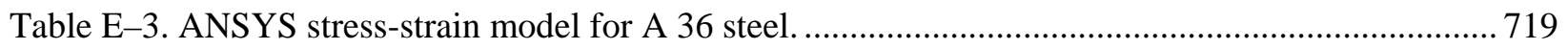

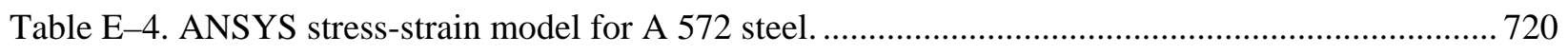

Table E-5. ANSYS stress-strain model for CSA G40.21-44W steel. .................................................... 721

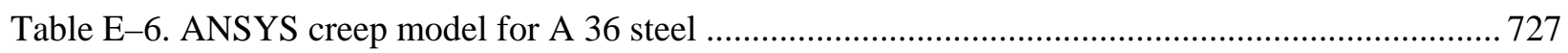

Table E-7. ANSYS creep model for A 572 and CSA G4012 steels....................................................... 728

Table E-8. Recommended values for the parameters in the strength reduction equations (Equations

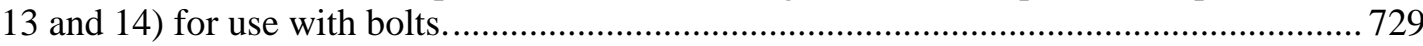




\section{Chapter 9 \\ FIRE SiMULATIONS}

\section{$9.1 \quad$ OVERVIEW}

\subsubsection{Approach}

The major fires in WTC 7 were simulated using the Fire Dynamics Simulator, version 4 (McGrattan 2004), the same software that NIST used to simulate the fires in the World Trade Center towers (NIST NCSTAR 1-5F). These simulations were part of a sequence of estimates that included the debris damage from WTC 1, the subsequent fires, the heating of the structural elements, the structural response, and the eventual collapse. Temperature predictions from the fire model were passed to the structural model via the Fire Structure Interface, again using the same process as in the reconstruction of the collapse of the World Trade Center towers (NIST NCSTAR 1-5G).

As described in Chapter 5, sustained and/or late fires were observed on Floors 7 through 9 and 11 through 13 of WTC 7. There was a single observation of a late, small fire on Floor 14. In addition, there might have been concealed fires in the mechanical spaces on Floors 5 and 6 . No fire was observed on the $10^{\text {th }}$ floor. The fires on the upper floors $(19,22,29$, and 30) died out well before the collapse of WTC 7.

The fire simulations for WTC 7 were conducted for each floor individually. Section 5.6 showed that there were no externally visible observations of flames passing from one floor to another, aside from what might have remained hidden in the debris-damaged area in the southwest of the building. The only floorto-floor connection within the tenant spaces was a flight of convenience stairs connecting the $11^{\text {th }}$ and $12^{\text {th }}$ floors. It was located near the southwest corner of the building, near the multi-floor debris damage zone, and essentially acted as an enlargement of the debris damage zone. The stairs were thus not included in the FDS simulations. The analysis described in Section 9.1.2 found that any late developing floor breaches would not have had a major effect on the structural heating.

It would have been difficult to observe fires on the $5^{\text {th }}$ and $6^{\text {th }}$ floors, due to the partitions just behind the various windows or louvers (Chapter 3). Thus, the Investigation Team simulated a variety of fire scenarios and examined the outcome of each to determine whether it would have produced a visible telltale or whether it would have been severe enough to weaken any structural elements on those floors.

The actual fires on Floors 7 through 9 and 11 through 13 were likely initiated when WTC 1 collapsed (Section 5.6). However, there was limited photographic evidence or on-site personal observation upon which to base simulation of the early development of these fires. While use was made of the appearance of flames and window breakage in photographs and videos in formulating the simulations, the Investigation Team realized that the absolute timing of the simulations might not align exactly with the timing of the fires on September 11, 2001.

Using a timeline reconstructed from the limited photographic evidence and eyewitness testimony, fire simulations were conducted for Floors 7 and 8 . For the simulations, the fires on these two floors were assumed to have initiated at a time designated as noon. There was no evidence of visible fire growth on 
these floors during the morning; and, even at 2:00 p.m., the fire on the $7^{\text {th }}$ floor was still in the southwest section of the building. The computations were continued for six hours, since the time in the structural simulations at which the building would become structurally unstable was not yet known.

The fire on the $9^{\text {th }}$ floor was not observed until about 4:00 p.m., approximately one hour after fire was first observed on the $8^{\text {th }}$ floor. Since there was no information about the history of the $9^{\text {th }}$ floor fire prior to 4:00 p.m., and since there was limited knowledge of the layout of combustible materials on this floor, this fire was approximated by displacing the $8^{\text {th }}$ floor fire one hour later.

The layouts of the $11^{\text {th }}$ and $12^{\text {th }}$ floors were essentially identical. The observation of fires on the $11^{\text {th }}$ floor indicated that they were similar to those on the $12^{\text {th }}$ floor, but lagged by about an hour in reaching equivalent positions along the building perimeter. The intense fires on the $13^{\text {th }}$ floor appeared after about 2:30 p.m. on the east face and the east side of the north face. These fires also appeared similar to those on the $12^{\text {th }}$ floor, but lagged behind them by about a half hour. Thus, these fires were simulated using the $12^{\text {th }}$ floor fires, suitably offset in time.

On the $14^{\text {th }}$ floor, a small fire was observed at the far east of the north face at about 5:03 p.m. It was not observed at 4:52 p.m., nor at 5:09 p.m. On September 11, 2001, the $14^{\text {th }}$ floor was unoccupied and should have had a very small combustible fuel load. From this evidence, the Investigation Team deduced that it was unlikely that there had been a sustained fire of appreciable heat output. Thus, no fire simulation was performed for this floor.

The calculations were very similar to those conducted for WTC 1 and WTC 2 (NIST NCSTAR 1-5F) and, therefore, only a brief description of the major assumptions is included. It should be remembered that there were far fewer photographs of WTC 7 than of the towers. Thus, while the severity of the simulated WTC 7 fires (as established from the visual evidence) is reasonable, the details of these fires are not as precise as for the fires in the towers.

\subsubsection{Fire Spread}

\section{Ventilation Effects}

If each floor of WTC 7 had been airtight (i.e., no broken windows or breach in the exterior from debris impact damage), a fire starting on a particular floor would have been limited to a size that would not likely have threatened the building for the following reasons:

- The volume of a floor was approximately $1 \times 10^{4} \mathrm{~m}^{3}\left(4 \times 10^{5} \mathrm{ft}^{3}\right)$. The mass of air contained in that volume was $1.7 \times 10^{4} \mathrm{~kg}$; the mass of oxygen was $3 \times 10^{3} \mathrm{~kg}$. The heat release from combustion of typical combustibles is $13.1 \mathrm{MJ}$ per kg of oxygen consumed (Huggett 1980). Only about half the oxygen could have been consumed, since that would have resulted in an oxygen level below which flame spread would slow considerably and soon halt. Thus, a fire on this airtight floor would have generated about $2 \times 10^{4} \mathrm{MJ}$.

- If the density of combustible materials able to burn were $20 \mathrm{~kg} / \mathrm{m}^{2}\left(4 \mathrm{lb} / \mathrm{ft}^{2}\right)$, there would have been approximately $6 \times 10^{4} \mathrm{~kg}$ of combustibles on a given floor. If they were wood-like in heat of combustion (heat of combustion approximately $20 \mathrm{~kJ} / \mathrm{g}$ (Drysdale 2002)), they would have generated $1 \times 10^{6} \mathrm{MJ}$, given sufficient oxygen. Since an airtight floor would have only 
enough usable oxygen to generate $2 \times 10^{4} \mathrm{MJ}$, only about 2 percent of the combustibles would have burned.

- Even if a fire burned over as short a duration as $1 \mathrm{~h}(3,600 \mathrm{~s})$, the fire would have averaged only about $6 \mathrm{MW}$ in intensity. This would not have been sufficient to heat enough of the insulated structural steel or the concrete floor slab to a temperature that would have led to significant thermal expansion or weakening.

The fires burned for up to $7 \mathrm{~h}$ and, on some floors, had sustained intensities estimated to have exceeded 100 MW (Section 9.4). Thus, the rate at which fresh air became available played a major role in determining the intensity and duration of the fires. The locations from which air became available determined the direction of fire growth.

Initially, the intake air supply for the fires came from the south side of the building. As noted in Section 5.5, the debris from the collapse of WTC 1 created a gash in the west side of the south face of the building that stretched from the $17^{\text {th }}$ floor down to the $5^{\text {th }}$ floor. Photographs also showed that windows in this vicinity were broken by the percussion and debris impact (Section 5.5). Fires on the interior of the tenant spaces would have had to draw and vent air through these openings. Section 5.6 also documents additional window breakage by the fires as they reached the building façade. Only a very few (about three) windows were known to have been broken by building occupants. ${ }^{1}$ These occurred well before fires reached these locations, and were too few to affect the fire ventilation or spread rate significantly.

\section{Floor-to-floor Fire Spread}

Initially, the Investigation Team hypothesized that it was unlikely that fires, once ignited on a given floor but prior to the initiation of the total building collapse, would have spread to an adjacent floor once they had moved past the gash in the south face. There were several bases for this reasoning:

- There was only one constructed opening connecting adjacent fire floors in the tenant spaces, which was a convenience stair between the $11^{\text {th }}$ and $12^{\text {th }}$ floors in the southwest corner. This was in the immediate vicinity of the gash created by debris impact and would have been little more than an extension of the debris-caused opening between these two floors.

- There was no visual evidence of floors collapsing prior to the beginning of the building collapse itself.

- There was no visual evidence of a fire having spread from floor to floor on the inside of the curtain wall, i.e., through gaps in the firestopping. However, such spread would have been difficult to verify.

- There were no photographs or videos indicating flames had emanated from a window and ignited a fire on the floor above through the windows located directly above.

Subsequently, thermostructural calculations (Chapter 11) indicated that approximately 15 min prior to the total building collapse, it was likely that the following floor sections had failed:

\footnotetext{
${ }^{1}$ NYC Housing Authority Interview 8, April 2004.
} 
- $10^{\text {th }}$ and $11^{\text {th }}$ floors: a section of the north side, east of center.

- $12^{\text {th }}$ and $14^{\text {th }}$ floors: the same section as on the two lower floors, plus the southeast corner.

- $13^{\text {th }}$ floor: the full east section of the floor.

In addition, the thermostructural simulations indicated that a small section east of center on the north side of the $8^{\text {th }}$ floor had failed approximately $20 \mathrm{~min}$ to $45 \mathrm{~min}$ before the building collapse.

These support failures would have led to openings in the floor and could have altered the thermal profiles as follows.

- Hot gases from the lower floor would have vented to the upper floor. This would have slowed further heating of the ceiling of the lower floor. The hot gases would have increased the heating of the upper floor.

- Had a sizable hole opened in the floor slab, some combustibles from the upper floor could have fallen to the lower floor. Flames from the lower floor could have ignited combustibles adjacent to the hole on the upper floor. If portions of the floor slab actually separated and fell, they would have smothered some of the burning combustibles on the floor below.

The breaches in Floors 10 through 14 would have only had a modest effect on the heating of the steel and concrete, since the holes would have been there for only a relatively short time. In addition:

- Prior to the breaches in the $8^{\text {th }}, 12^{\text {th }}$ and $13^{\text {th }}$ floor slabs, there had been significant burning above and below the vicinity of the breach. Thus, the combustibles on the upper floors had already been ignited, and only a small fraction of the combustibles remained, potentially to fall to the floor below. In about $15 \mathrm{~min}$, hot gas penetration to the already hot upper floor would not likely have had a major effect on the fire intensity or duration there.

- There were essentially no combustibles on the $14^{\text {th }}$ floor. Thus, the only effect of the breach in the $14^{\text {th }}$ floor slab would have been the short-term decrease in the heating of the $13^{\text {th }}$ floor ceiling. The separation of this floor might have allowed for flames from the $13^{\text {th }}$ floor to appear in the $14^{\text {th }}$ floor windows, explaining the brief, late fire observed in the east end of the north face at 5:03 p.m.

- The floor collapses on the $10^{\text {th }}$ and $11^{\text {th }}$ floors resulted from thermal expansion of the support girders due to prolonged exposure to the hot gases from fires on the floors above and below.

o No fire was observed on the $10^{\text {th }}$ floor, and the fire on the $9^{\text {th }}$ floor had just reached the area of the floor breach. Thus, the effects of the breach in the $10^{\text {th }}$ floor would have been the short-term decrease in the heating of the $9^{\text {th }}$ floor ceiling and the addition of (unignited) combustibles to the $9^{\text {th }}$ floor fire, which had no shortage of fuel already.

o There had already been a prominent fire on the east side of the $11^{\text {th }}$ floor. Thus, a breach of its floor would not have affected the fire on the $11^{\text {th }}$ floor significantly. Since no fire was observed on the $10^{\text {th }}$ floor, there had been no significant effect of any combustibles falling from the floor above. 
In light of the lack of visual evidence with which to validate the highly complex coupling of the fire and thermostructural models, the Investigation Team did not pursue simulating the modest effect of these late floor failures on the progress of the fires.

The Investigation Team was able to develop a qualitative estimate of the effect of not including floor-tofloor fire spread through possible gaps in the firestopping on the accuracy of the thermal environment in the fire simulations. The estimates were for fire spread from Floor 7 to Floor 8, Floor 8 to Floor 9, Floor 11 to Floor 12, and Floor 12 to Floor 13. No sustained fires were observed on any other pairs of floors (Section 5.6).

At about 3:40 p.m. there were fires above each other on the $7^{\text {th }}$ and $8^{\text {th }}$ floors. No fire had been observed on the $8^{\text {th }}$ floor prior to $3: 22$ p.m. The $8^{\text {th }}$ floor fire simulation assumed that the fire had begun in the southwest corner and calculated that it moved northward on the west side of the building. If the fire had actually started $n$ the $8^{\text {th }}$ floor by spreading from the $7^{\text {th }}$ floor around 3: 30 p.m., the simulation of the fire on the $8^{\text {th }}$ floor would have overestimated the thermal environment in the southwest region of this floor. However, Figure 9-10 shows that the calculated air temperatures at the southwest region of the $8^{\text {th }}$ floor were below about $300{ }^{\circ} \mathrm{C}$ after about $3 \mathrm{~h}$ of simulation time; and the ANSYS simulations (Chapter 11), which included this potential overheating, indicated minor fire-induced structural damage in this region. The LS-DYNA simulations (Chapter 12) indicated that complete removal of the more serious, debrisinduced structural damage still resulted in the collapse of WTC 7. Thus, it appeared that any overestimation of the thermal environment due to the assumption of no floor-to-floor fire spread was not consequential.

The fire on the $9^{\text {th }}$ floor, which was not observed in the imagery until about 4:00 p.m., was simulated by displacing the $8^{\text {th }}$ floor fire one hour later. The effect of overestimation of the temperatures in the fire simulation would have been similar to that for the hypothetical spread from the $7^{\text {th }}$ floor to the $8^{\text {th }}$ floor.

The fires on the $11^{\text {th }}, 12^{\text {th }}$, and $13^{\text {th }}$ floors were all first observed between 2:08 p.m. and 2:30 p.m. near the southeast corner of WTC 7. Thus, it is conceivable that a single fire started on the $11^{\text {th }}$ floor following the collapse of WTC 1 and that the fire had spread to the $12^{\text {th }}$ and $13^{\text {th }}$ floors by the time the fires emerged from the dust-blocked south side of the building. The fires on the $11^{\text {th }}$ and $13^{\text {th }}$ floors were simulated as delayed equivalents of the $12^{\text {th }}$ floor fire. As shown in Figure 9-13, nearly all of the heat released in these simulated fires occurred after these initial observation times (i.e., after about 2:00 p.m.), even though the simulations had been started over $2 \mathrm{~h}$ earlier. Thus, any overestimation of structural heating (from assuming three fires burning in the late morning rather than just one) would have been small compared to the effects of the far larger fires in the northeast region of the floors later in the afternoon..

The Investigation Team concluded that it was unlikely that hypothetical spread of fire through gaps in the firestopping would have changed the simulated thermal environment substantially. 


\subsection{HYPOTHETICAL FIRES INVOLVING DIESEL FUEL}

\subsubsection{Floors 5 and 6}

\section{Fire Conditions and Limits to Fire Intensity}

Figure 9-1 and Figure 9-2 are schematic diagrams of the layout of the $5^{\text {th }}$ and $6^{\text {th }}$ floors, respectively. They include the locations of the diesel generators, the fuel lines that fed them, the intake and exhaust ports, and any interior partitions. These figures show that Column 79 was located in the same space as

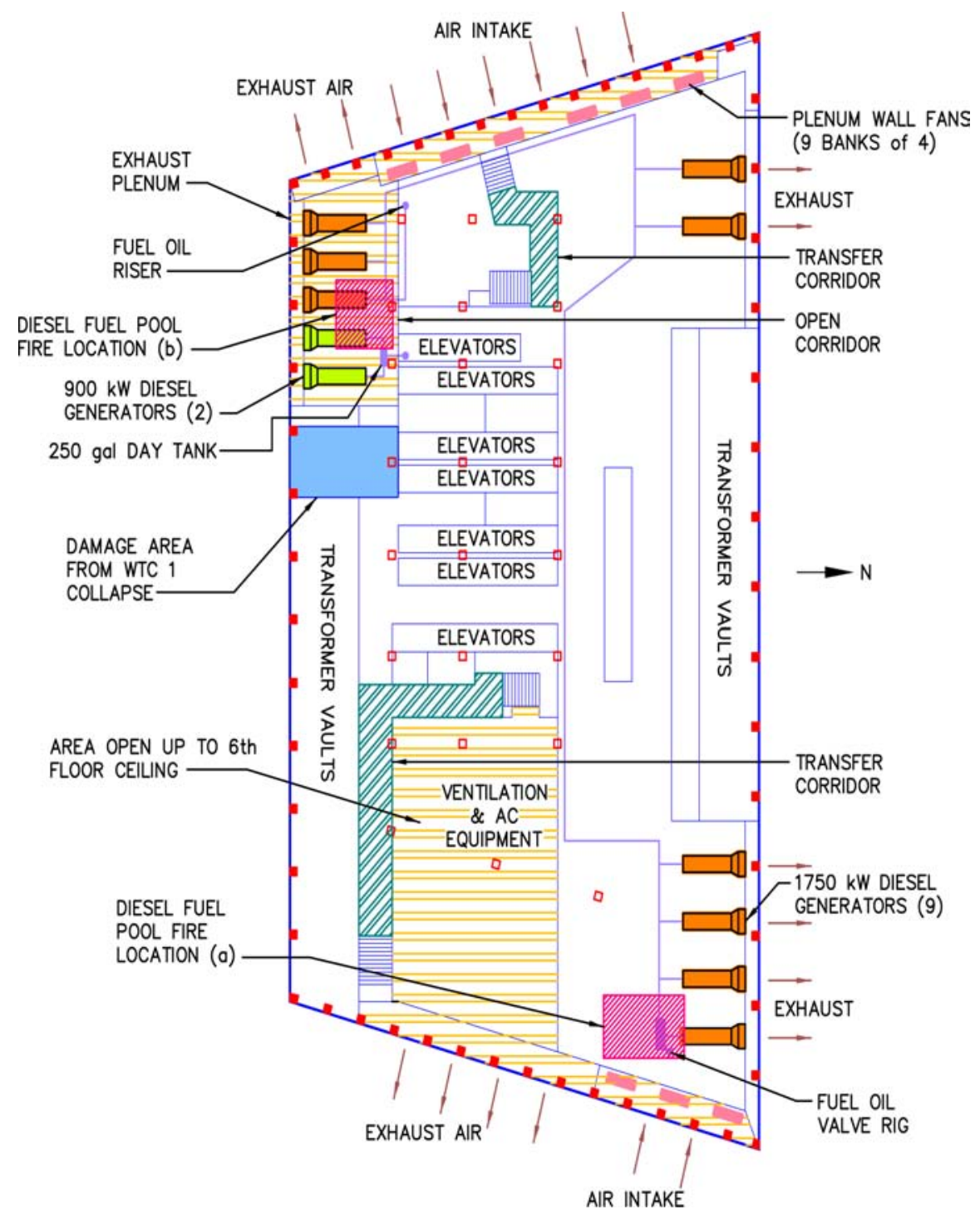

Figure 9-1. Plan view of the $5^{\text {th }}$ floor, including estimated debris damage from WTC $1^{2}$

\footnotetext{
2 The descriptions of the $5^{\text {th }}$ and $6^{\text {th }}$ floors were derived from architectural and mechanical design drawings provided by Emery Roth \& Sons (Roth 1985), Irwin G. Cantor (Cantor 1985), Syska \& Hennesy (1985), and Flack \& Kurtz (1988). Some of the details may differ from the actual layout on September 11, 2001.
} 


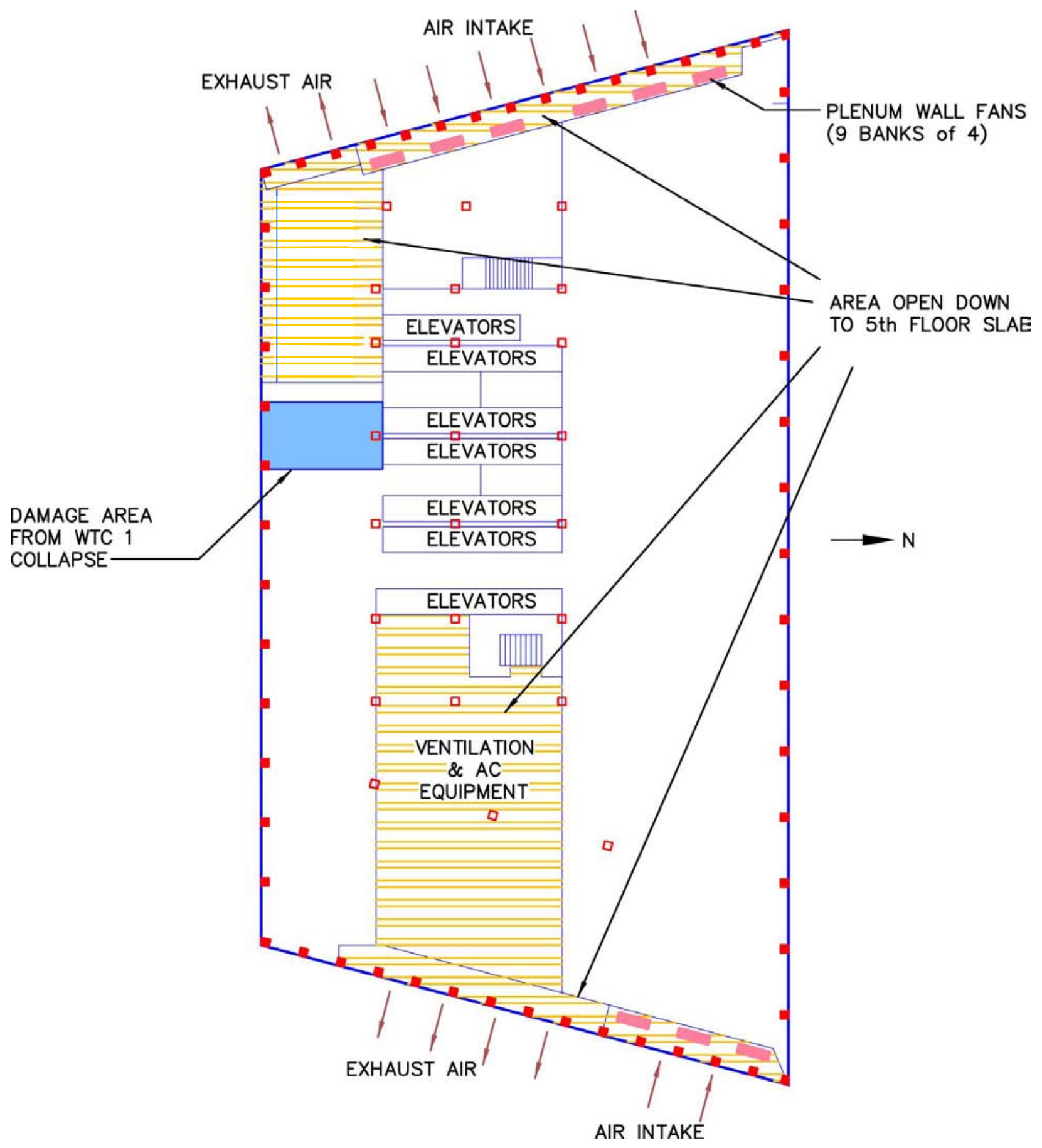

Figure 9-2. Plan view of the $6^{\text {th }}$ floor, including estimated debris damage from WTC $1 .^{2,}$ 
the four generators in the northeast quadrant. Column 80, Truss 1, and Truss 2 were located in the Ventilation and AC Equipment space, which was enclosed with masonry walls. Column 81 was located within the transfer corridor. Thus, of these critical structural components, only Column 79 could have been exposed to heating from a diesel fuel fire on Floor 5.

As presented in Chapter 5 of this report, there was no visual evidence of a fire in this space. However, as presented in Section 3.3.2, louvers and blocked windows would have obscured views of a fire on the $5^{\text {th }}$ floor from the north, east, and west. A fire on the north or west side of the core on the $6^{\text {th }}$ floor would have been visible through the $6^{\text {th }}$ floor windows; the two story louvers that extended up from the $5^{\text {th }}$ floor would have obscured a fire on the $6^{\text {th }}$ floor viewed from the east. Had a large, sustained fire occurred on the $5^{\text {th }}$ floor, the partitions separating the exhaust and air intake plenums could have been breached, discharging visible smoke through the louvers to the west, east or north.

Chapter 8 suggests that the initial effect of a fire weakening the building structure would have occurred on the east side of the building. The interior columns that might have been affected were Columns 79, 80, and/or 81. Figure 9-3 shows the developing thermal conditions for these heavy columns, insulated with $9 / 16$ in. of thermal insulation ${ }^{3}$, when exposed to a uniform temperature of $1100^{\circ} \mathrm{C}$. It would have required a continuous, fully developed fire at the location of a column for approximately $7 \mathrm{~h}$ for a 50 percent reduction in its strength to occur (Section 4.1.2, NIST NCSTAR 1-6).

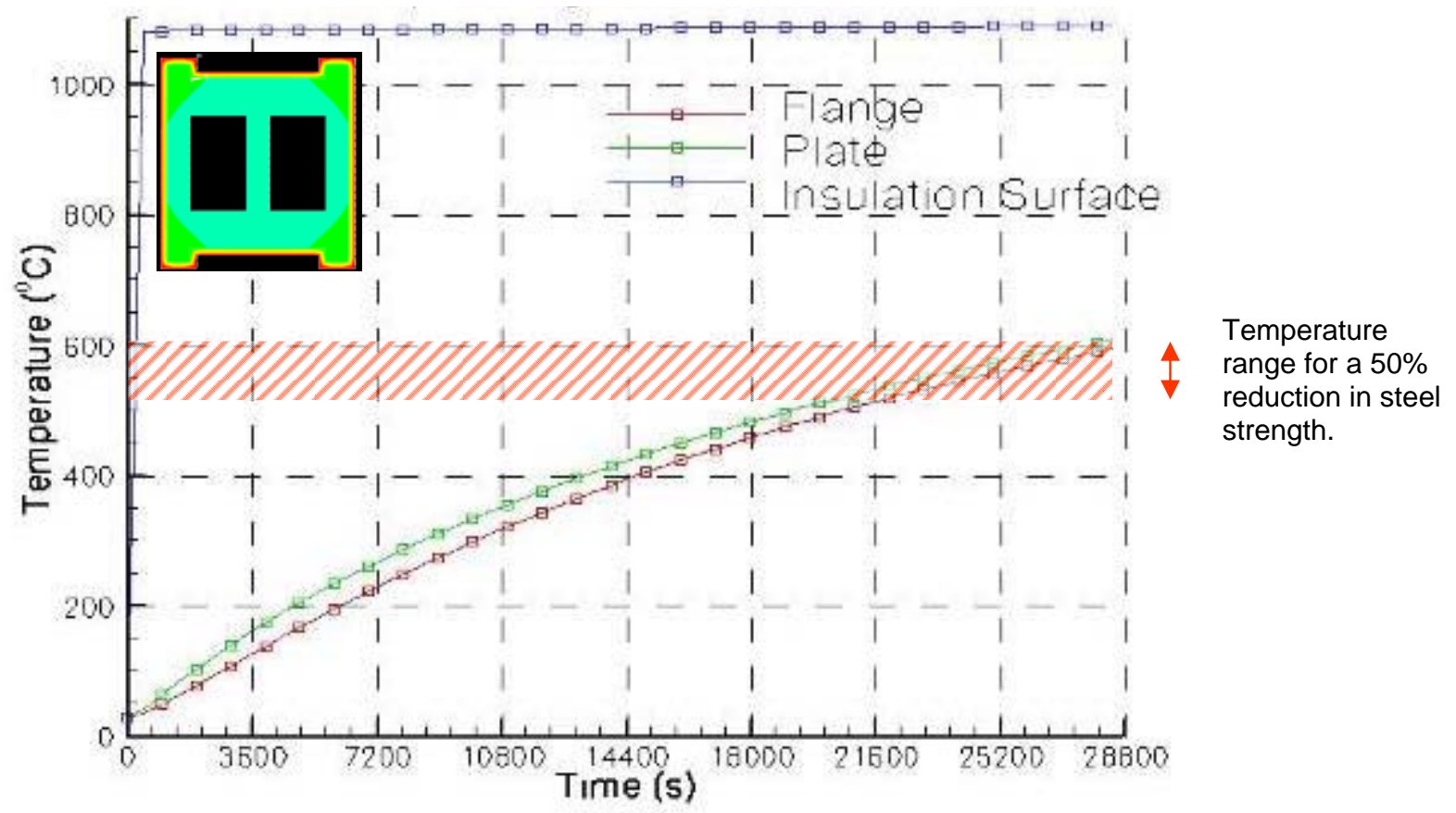

Figure 9-3. Minimum heating of reinforced heavy columns to initiate global collapse. The column modeled is a W14×730 with 9/16 in. of thermal insulation.

There was very little in the way of solid combustibles on the $5^{\text {th }}$ and $6^{\text {th }}$ floors. Therefore, any sizable fires would have involved the diesel fuel that could have been delivered to the floor by fuel pumps

\footnotetext{
${ }^{3}$ The nominal column insulation thickness for columns larger than a W14x228 was nominally 7/8 in. (Chapter 2). As part of determining the rate of heating in Column 79, a reduced thickness was evaluated.
} 
(Section 3.4.2). NIST evaluated a set of hypothetical, extreme fire scenarios to determine whether the outcomes could have contributed to the weakening of the WTC 7 structure and whether the outcomes were consistent with the available evidence.

\section{Hypothetical Fire Scenarios and Results}

\section{Fire Scenario Set 1}

The fires in scenario set 1 would have originated in the northeast quadrant of the $5^{\text {th }}$ floor (Figure 9-1). The scenarios presumed a rupture of the diesel fuel supply piping, possibly where it was rigidly attached to the ceiling-mounted valve rig (refer to Figure 9-1 for location and Section 12.3 of NIST NCSTAR 1-1 for a fuller description of the piping), as the building responded to being struck by debris from the collapse of WTC 1 at 10:28:22 a.m. The maximum total fuel supply for the fires would have been the 55 $\mathrm{m}^{3}$ (12,000 gal) from the SSB system (Section 4.3.2). The maximum flow from the circulating pump was $4.4 \mathrm{~L} / \mathrm{s}$ (70 gal/min). Ignition of the fuel would have occurred at approximately the same time as the pipe rupture.

Scenario 1.a, maximum duration, over-ventilated fire: To be sustained for the approximately $7 \mathrm{~h}$ between the collapse of WTC 1 and the collapse of WTC 7, the fuel would have had to be pumped at about $1.8 \mathrm{~L} / \mathrm{s}$ ( $29 \mathrm{gal} / \mathrm{min})$, which was well within the capacity of the pumps. A large open pool of diesel fuel burns at a surface regression rate of about $4 \mathrm{~mm} / \mathrm{min}$ (Gottuk and White 2002). A pool fire that burned the fuel at the same rate as it was being pumped would have had a surface area of about $30 \mathrm{~m}^{2}$. For the purpose of the simulation, the pool was assumed to be a square, $6 \mathrm{~m}$ on a side, sited underneath the valve rig at location (a) in Figure 9-1. The needed air would have been supplied by continuously operating fans ( $\left.95 \mathrm{~m}^{3} / \mathrm{s}, 200,000 \mathrm{ft}^{3} / \mathrm{min}\right)$ and through breached partitions at elevator lobbies and the large gap on the south face. The steady state heat release rate from the over-ventilated fire would have been $50 \mathrm{MW}$ to $60 \mathrm{MW}$. As suggested by the FEMA Building Performance Study Report (McAllister 2002), this fire scenario could have heated critical structural elements to high enough temperatures that the structural elements would have become incapable of maintaining the required load.

Result: Figure 9-4 shows the gas temperatures near the ceiling after $7 \mathrm{~h}$ for Scenario 1.a. as predicted by the FDS computer model. Maximum gas temperatures of approximately $1000{ }^{\circ} \mathrm{C}$ are indicated in the vicinity of Column 79. These temperatures, had they existed the entire $7 \mathrm{~h}$, would have been sufficient to weaken this column substantially. However, the simulation also indicated that the gas temperatures above all of the nine water-cooled diesel generators would have exceeded their operating limit of about $100{ }^{\circ} \mathrm{C}$ (the boiling point of water) in the northeast, northwest, and southwest quadrants in less than an hour. The emergency electrical distribution cables, which connected the various transformer vaults and the diesel generators, were protected by $2 \mathrm{~h}$ fire resistance rated partitions (Flack and Kurtz 1987). These cables would have been threatened by a sustained fire. Thus, with all nine generators and/or the electrical distribution system out of commission, there would have been no power to operate the fuel pumps for more than an hour or two, and the fires would have burned out well before the column experienced significant loss of strength or the 8 in. composite floor system at the $7^{\text {th }}$ floor was damaged by the fire. 
Scenario 1.b, maximum intensity, over-ventilated fire: This northeast fire location was the same as in Scenario 1.a. However, the fuel flow was doubled, which cut the possible fire duration in half, to $3.5 \mathrm{~h}$. The forced air flow remained the same $\left(95 \mathrm{~m}^{3} / \mathrm{s}, 200,000 \mathrm{ft}^{3} / \mathrm{min}\right)$, which was more than enough to maintain an over-ventilated fire.

Result: The predicted temperatures of the upper layer of the $5^{\text {th }}$ floor about $3.5 \mathrm{~h}$ into the fire are shown in Figure 9-5. The temperatures were somewhat higher across the floor as compared to Scenario 1.a, even though the total energy content was the same (that is, $100 \mathrm{MW}$ to $120 \mathrm{MW}$ heat release rate for half the time). The higher temperatures were due to the reduced amount of time for heat to be lost through the walls. The outcomes for Scenarios 1.a and 1.b were the same: the high temperatures near Column 79 could not be sustained because the environment around all the diesel generators and the electrical distribution system would likely have caused the electrical power to the fuel pumps to fail. Neither Column 79 nor the $7^{\text {th }}$ floor composite floor system would have been thermally weakened.

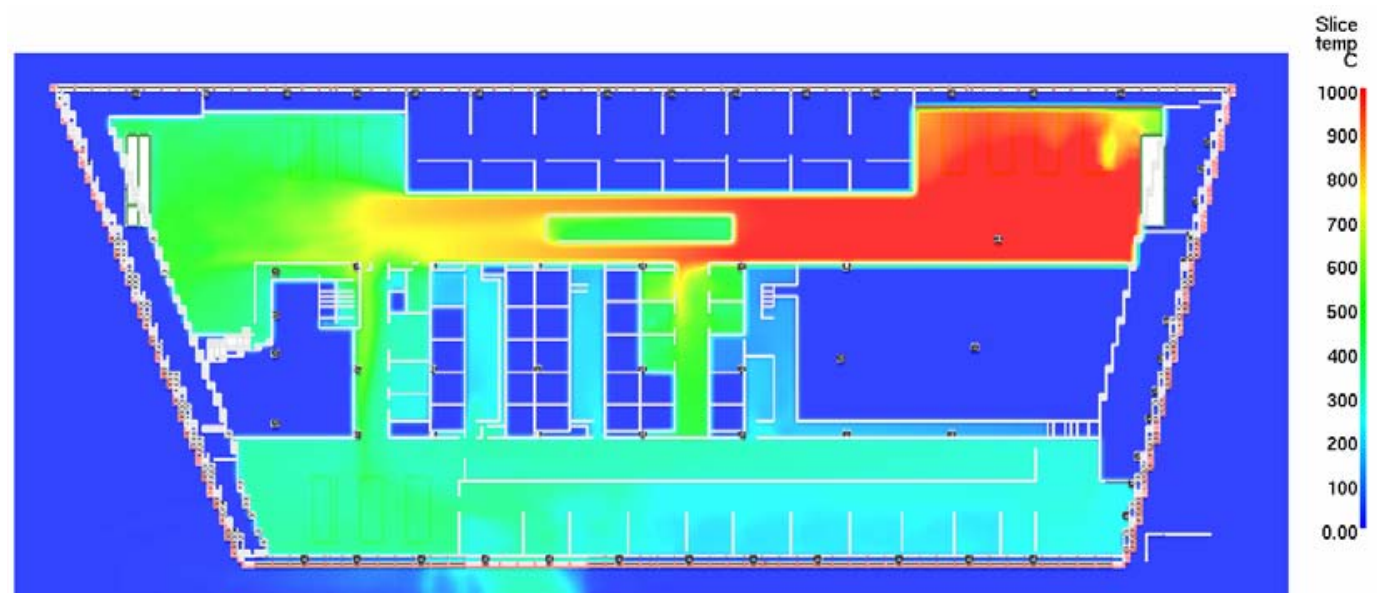

Figure 9-4. Gas temperatures near the $5^{\text {th }}$ floor ceiling for the hypothetical maximum duration, over-ventilated diesel fuel pool fire after $7 \mathrm{~h}$ (Scenario 1.a).

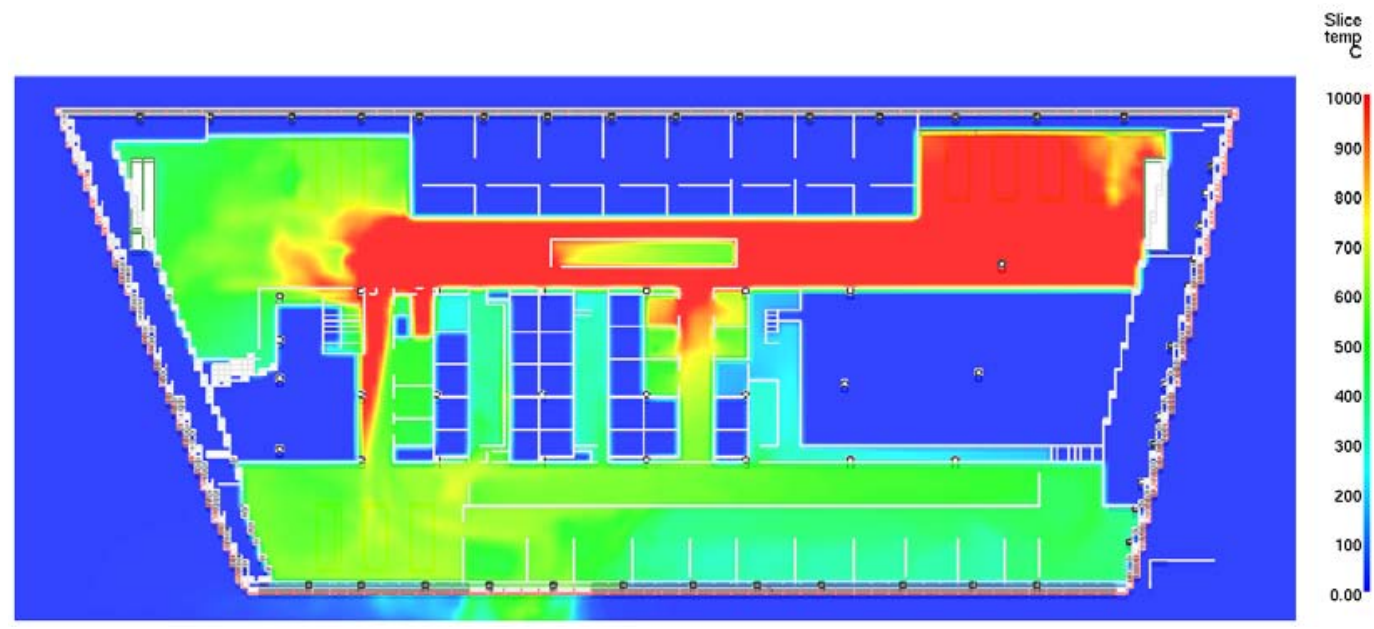

Figure 9-5. Gas temperatures near the $5^{\text {th }}$ floor ceiling for the hypothetical maximum intensity, over-ventilated diesel fuel pool fire after $3.5 \mathrm{~h}$ (Scenario 1.b). 
Scenario 1.c, maximum duration, under-ventilated fire: This fire location and pool size were the same as in Scenario 1.a. The louvers were assumed to be closed on the east and west sides of the $5^{\text {th }}$ and $6^{\text {th }}$ floors (preventing flames and smoke from escaping either side). Hence, air flow was limited to what could be entrained through breached partitions and the large gap in the south wall. The fuel flow was assumed to be $1 \mathrm{~L} / \mathrm{s}(16.4 \mathrm{gal} / \mathrm{min}$ ), which led to an underventilated fire. (Note that that this was a bit less than the fuel flow in scenario 1.a; however, additional fuel would only have served to cool the interior of the $5^{\text {th }}$ floor because it would have exceeded what the available air could burn.). The fire was located at the fuel source until the oxygen in that vicinity was consumed. It then traveled around the floor in search of a sufficient fresh supply of oxygen. The fire intensity in the vicinity of Column 79, about $40 \mathrm{MW}$ initially, would have decreased with time.

Result: An FDS simulation showed gas temperatures near the ceiling ranging between $300{ }^{\circ} \mathrm{C}$ and $400{ }^{\circ} \mathrm{C}$ after about $15 \mathrm{~min}$. A map of the temperatures near the ceiling for this time is shown in Figure 9-6a. Figure 9-6b shows the estimated gas temperatures near the ceiling more than two hours later,
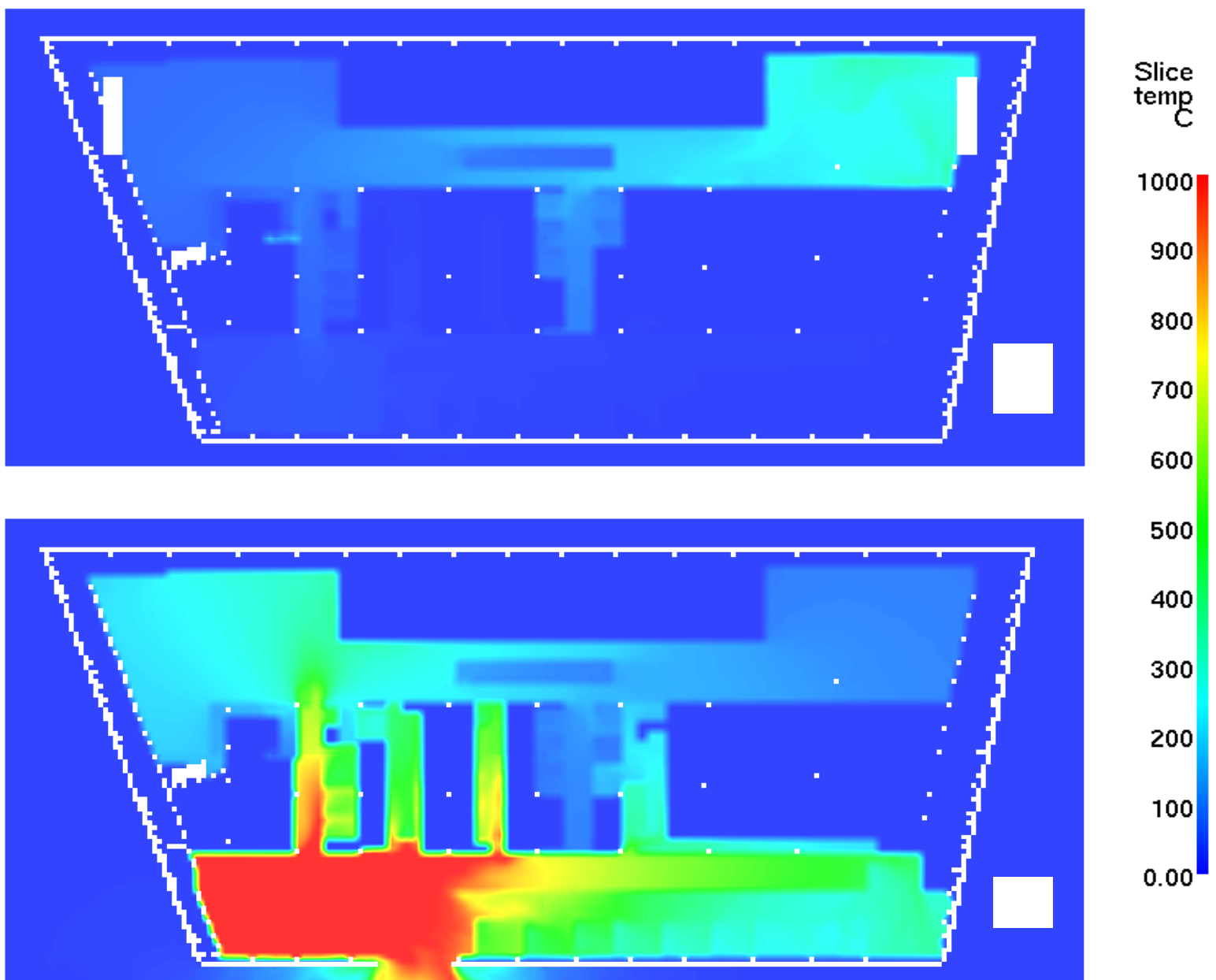

Figure 9-6. Gas temperatures near the $5^{\text {th }}$ floor ceiling for a hypothetical underventilated diesel fuel pool fire with the louvers closed (Scenario 1.c); (a) after 15 min; (b) after $3 \mathbf{h}$. 
when the oxygen in the vicinity of the liquid fuel had been consumed and the flames were forced to find a fresh supply in the southwest corner of the building. This stage of the fire was highly speculative since the flames were no longer available to provide the heat needed to vaporize the diesel fuel in the pool. At any rate, the sustained temperature in the vicinity of Column 79 did not exceed $400{ }^{\circ} \mathrm{C}$. Thus, the column temperature would not have risen to the point where significant loss of strength could have occurred. The generators in the northeast, northwest, and southwest sections would likely have all ceased to operate at these temperatures. Neither Column 79 nor the $7^{\text {th }}$ floor composite floor system would have been thermally weakened.

Scenario 1.d, louvers open, fans inoperable: This fire was similar to Scenario 1.c, in that there was no forced air from the fans, but the louvers were open, augmenting the convection. The steady fire intensity would have been about $30 \mathrm{MW}$ to $40 \mathrm{MW}$.

Result: The FDS simulation showed that the natural flow from the fire plume would have been out of the louvered openings on the east side of the building in a very short time. Significant plumes of smoke would have been seen emerging from the building within a few minutes of ignition, contradicting the visual evidence.

\section{Fire Scenario 2}

The pool of diesel fuel was located in the southwest generator room (location (b) in Figure 9-1) and assumed to be about the same size as in Scenario 1.a: $6 \mathrm{~m}$ square, with a fuel flow of $1.8 \mathrm{~L} / \mathrm{s}$. The corridor on the west side of the core was assumed to be open, along with the louvers on the east and west sides of the $5^{\text {th }}$ floor; the ventilation fans were assumed to be off.

Result: The air flow through the breach in the south wall was sufficient to consume the fuel and support an approximately $60 \mathrm{MW}$ fire. The temperatures near the ceiling of the $5^{\text {th }}$ floor above the southwest corner generator room quickly exceed $1000{ }^{\circ} \mathrm{C}$, which would have caused the generators in this corner to fail soon after the fires would have begun. The generators on the north side would not have been able to operate after their fuel supply line was broken. However, if, somehow, enough fuel was able to keep at least one generator operating, the temperatures near the ceiling of the $5^{\text {th }}$ floor might have reached the close-to-steady state shown in Figure 9-7. Note that the ceiling in the generator room was the bottom of the $7^{\text {th }}$ floor slab. The plume from the fire was predicted to extend well outside the breach on the south wall. There was no photographic evidence of fires originating from this area; however, the actual fire would have been difficult to distinguish from the plumes of other fires and dust on the south side of WTC 7. The nearby columns, especially those whose insulation was damaged by the debris from WTC 1, likely would have reached temperatures high enough to decrease their strength substantially. However, this scenario provided no open path for the hot gases to reach Columns 79. Any weakening of the $7^{\text {th }}$ floor composite floor system would have been on the south side of the building, in the same region as the debris damage from the collapse of WTC 1. 

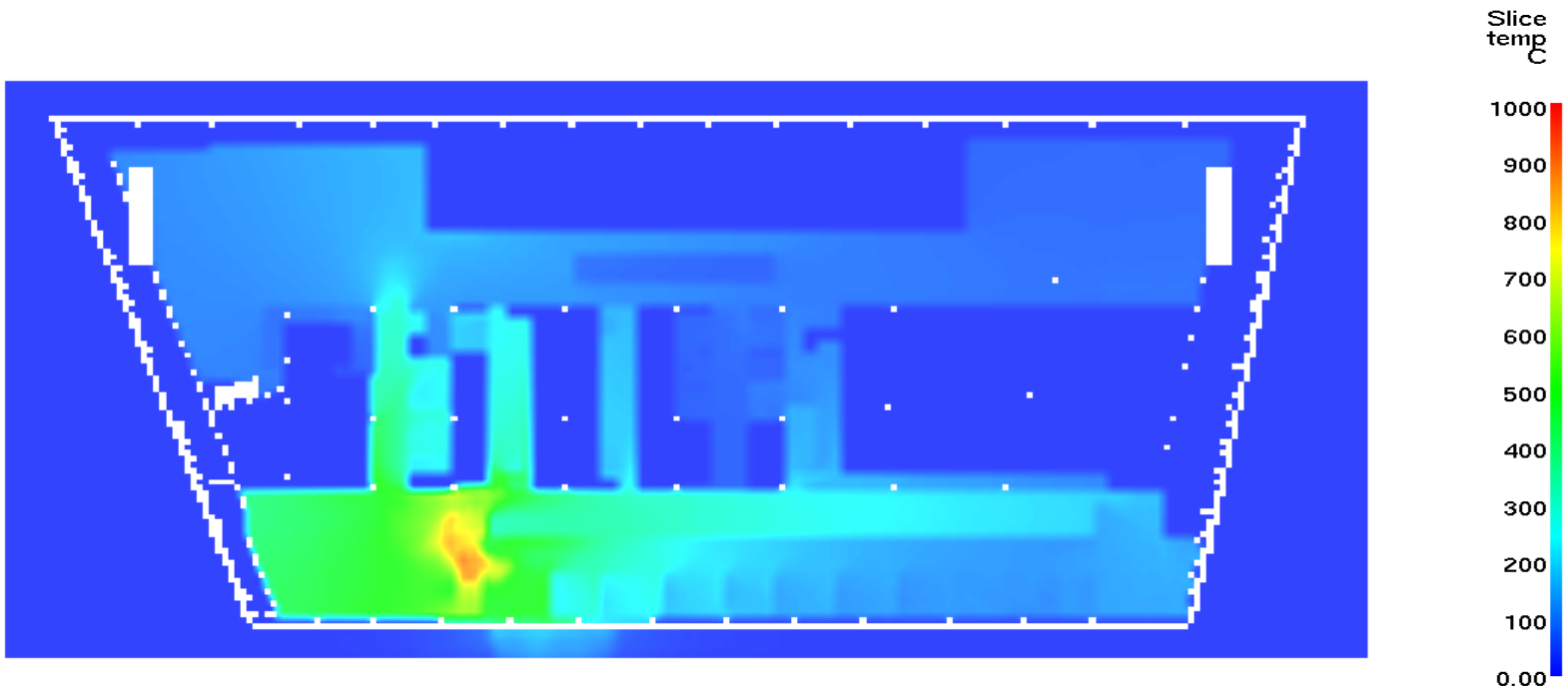

\section{Figure 9-7. Gas temperatures near the $5^{\text {th }}$ floor ceiling for a hypothetical diesel fuel pool fire in the southeast generator room in steady-state (Scenario 2).}

\subsubsection{Floors 7 through 9}

Diesel generators were also located on the $7^{\text {th }}$ and $9^{\text {th }}$ floors of WTC 7 (Figure 3-11). The day tank that was on Floor 8 had been removed in $2000 .{ }^{4}$ Had the base emergency generators on the $5^{\text {th }}$ floor operated as designed following loss of power to the building, the fuel pumps located on the first floor and the large storage tanks located underground could have continued for many hours to replenish the day tanks on Floors 7 and 9.

Three $500 \mathrm{~kW}$ generators were located on the south side of Floor 7 to support the OEM in an emergency. The $27 \mathrm{~m}^{3}\left(6,000\right.$ gal) storage tank on the $1^{\text {st }}$ floor was kept full by an automatic pump connected to the below-ground base storage tanks. The $1.25 \mathrm{~m}^{3}$ (275 gal) day tank, located within a $2.5 \mathrm{~m}^{3}$ (550 gal) rupture basin, was supplied through a riser by two $0.9 \mathrm{~L} / \mathrm{s}(11.7 \mathrm{gal} / \mathrm{min}), 50 \mathrm{psi}$ pumps. There was a horizontal run of the diesel fuel return line along the south and west sides of the core on the $7^{\text {th }}$ floor. The collapse of WTC 1 might have damaged the horizontal run in a way that allowed diesel fuel to be pumped onto the $7^{\text {th }}$ floor (and somehow did not trigger the leak alarm), contributing to the severity of the fires in the southwest portion of these floors. The maximum pumping rate (which could have been maintained for over $4 \mathrm{~h}$ ) would have been sufficient for a steady $50 \mathrm{MW}$ fire along the south side of Floor 7. Smoke and flames from a fire in this region might not have been noticeable within the massive smoke and dust plume that shrouded the south side of WTC 7 for most of the day; however, the heat on Floor 7 from such a fire would have been isolated from the north and east side of the core.

The $125 \mathrm{~kW}$ emergency generator in the northwest corner of the $9^{\text {th }}$ floor supplied power to the U.S. Secret Service. A $0.23 \mathrm{~m}^{3}$ (50 gal) tank was mounted on the diesel engine. It was replenished with two $0.17 \mathrm{~L} / \mathrm{s}$ (2.4 gal/min), $100 \mathrm{psi}$ pumps, connected to the base fuel storage system. The fuel oil supply and return risers were located in the same shaft as the American Express risers. A horizontal pipe ran along the outside of the core on the $9^{\text {th }}$ floor from the diesel engine to the riser shaft, and could have been

\footnotetext{
${ }^{4}$ Letter from Trammel Crow Company (as manager for American Express) to Silverstein Properties, April 12, 2002.
} 
vulnerable to debris from the collapse of WTC 1, contributing up to $10 \mathrm{MW}$ to the fire along the west side of Floor 9; however, there was no evidence of a fire on Floor 9 until late in the day.

The day tanks themselves on Floors 7 and 9 contained a total of 325 gal of diesel fuel, roughly equivalent to $975 \mathrm{~kg}(2,167 \mathrm{lb})$ of combustible furnishings. If spread evenly over the areas of the $7^{\text {th }}$ and $9^{\text {th }}$ floors, this amount of fuel was equivalent to one percent of the estimated combustible material on these floors.

\subsubsection{Summary}

A broad range of hypothetical, extreme fires on the $5^{\text {th }}$ floor did not produce a fire scenario that was consistent with the visual evidence that would have threatened the load bearing capacity of Columns 79, 80, or 81. Additionally, these hypothetical fires were likely to have caused collateral damage to the electrical and fuel supplies. This conclusion was also consistent with the information from interviews that sometime after 1:00 p.m., OEM and FDNY staff climbed the east stairway of WTC 7 and did not see much damage on the lower floors from their viewing location (Chapter 6). They made no mention of fire, heat or smoke.

The possible contribution of diesel fuel to the fires that were observed on Floors 7 and 9 was also considered. The amount of fuel available within the day tanks was insignificant compared to the normal combustible load on these floors, but the diesel fuel could have contributed to the initial ignition and spread of the fires on the south side of Floor 7 and on the west side of Floor 9. Had a rupture occurred in the horizontal runs of the fuel supply line, and had the base emergency generators on the $5^{\text {th }}$ floor operated as designed, a significant fire on the south side of Floor 7 could have occurred without being distinguishable within the smoke and dust plume. Lesser fires on the west and southwest portions of the $9^{\text {th }}$ floor might also have been possible under very special circumstances. These fires would have been well away from critical structural systems on the east side of WTC 7.

Based on the result of these analyses and the review of the numerous interview transcripts, the Investigation Team concluded that it was highly unlikely that any fires on the $5^{\text {th }}$ floor contributed significantly to the collapse of WTC 7. Accordingly, in the structural modeling of the collapse initiation (Chapter 11), it was assumed that the temperatures on Floors 5 and 6 began at ambient values and only rose due to conductive heating from the fires on the floors above. For the reasons discussed above, the Investigation Team concluded that it was appropriate not to include diesel fuel explicitly in the simulation of the fires on Floors 7 and 9.

\subsection{SIMULATION OF FIRES ON FLOORS 7 THROUGH 13}

\subsubsection{Model Input}

\section{Numerical Grid}

As discussed in Section 9.1, independent fire simulations were carried out for the $7^{\text {th }}, 8^{\text {th }}$, and $12^{\text {th }}$ floors. The layouts of these floors can be found in Chapter 3 of this report.

The numerical grid dimensions for each floor of WTC 7 were the same as for the WTC towers. Grid cells of $0.5 \mathrm{~m}$ by $0.5 \mathrm{~m}$ by $0.4 \mathrm{~m}$ (vertical) were used, with a slab-to-slab height of $3.6 \mathrm{~m}$. Although this grid 
was relatively coarse for a computational fluid dynamics (CFD) calculation, it was determined from validation experiments (NIST NCSTAR 1-5E) that it could adequately capture the peak temperatures, heat release rate, and burning duration of a fully engulfing workstation fire. The coarse grid would not be appropriate to describing the very early stages of the fires on each floor, nor would it help determine how the fires started. Much of this is unknown anyway, because it occurred in the damaged and heavily smoke-shrouded southern portion of the building. For this reason, the simulated fires were specified as having originated near the southern face of the building with a size of about $2 \mathrm{MW}$. This is roughly the equivalent of a single office workstation burning. As the fires grew and spread to other workstations, the coarse grid did reproduce qualitatively the observed fire activity.

\section{Floor Layouts and Combustible Load}

Once the spatial resolution of the numerical grid was chosen, architectural drawings were needed at a level of detail consistent with the underlying numerical grid. These were generally obtained from the tenants and augmented with interviews (Chapter 3).

Most of the drawings indicated large areas of open landscaping, mainly occupied by workstations, also referred to as cubicles. These were assumed to be similar to those in WTC 1 and WTC 2. Figure 9-8 shows a typical office environment in the WTC. (This photograph was taken in WTC 1, but the array is typical of the layout in the open spaces of WTC 7.) Despite varying appearances, these workstations typically contained about $250 \mathrm{~kg}$ of combustible material, mostly a mix of wood products, paper, and plastic (NIST NCSTAR 1-5C). In the numerical simulations, the modeled workstations were distributed on each floor, following the architectural plans.

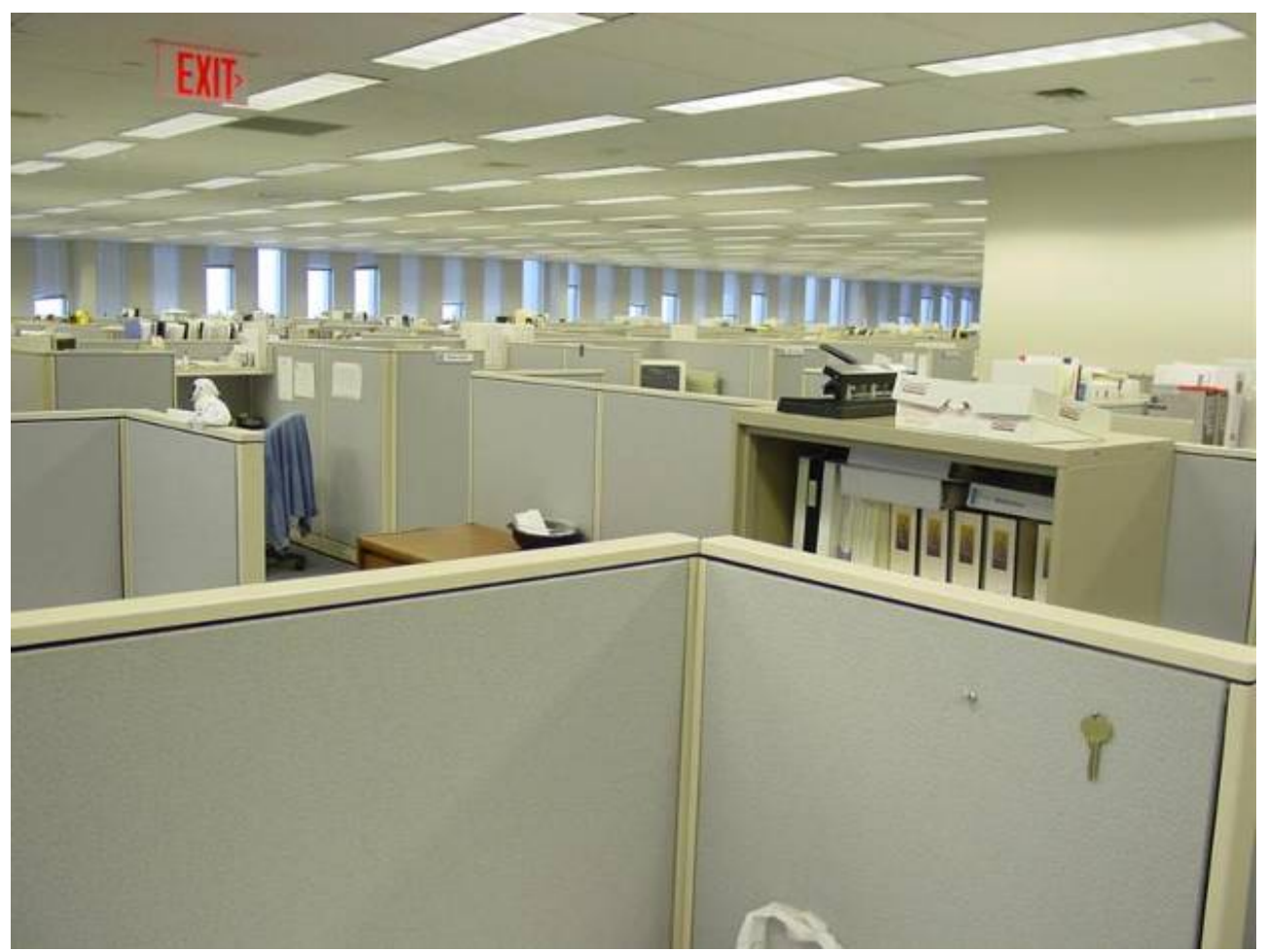

Source: The Port Authority of New York and New Jersey.

Figure 9-8. Photograph of a work area in WTC 1. 
For the simulation of fires in the WTC towers, NIST had estimated the combustible fuel load that was accessible to the fires in the cubicle-dominated tenant spaces to have been approximately $20 \mathrm{~kg} / \mathrm{m}^{2}$ $\left(4 \mathrm{lb} / \mathrm{ft}^{2}\right)$ (NIST NCSTAR 1-5). ${ }^{5}$ There was little information on the specific types of workstations in WTC 7, and the combustible mass had been found to vary only modestly among several types of workstations. Thus, the FDS simulations of the fires on the $7^{\text {th }}$ and $8^{\text {th }}$ floors of WTC 7 (which were mostly populated by cubicles) assumed similar fuel loads. As discussed in Chapter 3 , the $11^{\text {th }}$ and $12^{\text {th }}$ floors of WTC 7 were mainly partitioned into offices. The combustible loading of office furnishings was estimated as follows. There were approximately 150 cubicles on the $8^{\text {th }}$ floor and about 120 offices on the $12^{\text {th }}$ floor. NIST assumed that the combustible mass of the furniture was about the same in an office as in a cubicle. Since the loading of other combustibles was reported to have been high on the $11^{\text {th }}$ and $12^{\text {th }}$ floors (Chapter 3), NIST assumed that the total combustible mass in an office was about double that of a cubicle. Thus, the average combustible fuel load on the $11^{\text {th }}$ and $12^{\text {th }}$ floors was estimated as $32 \mathrm{~kg} / \mathrm{m}^{2}$ $\left(6.4 \mathrm{lb} / \mathrm{ft}^{2}\right)$. The density of combustibles on the $13^{\text {th }}$ floor was varied and not well known. The average value was assumed to be the same as on the $12^{\text {th }}$ floor. As noted later in this chapter, calculations were performed to estimate the sensitivity of the fire simulations to the combustible mass loading.

The core area contained elevator and HVAC shafts, stairwells, storage rooms, toilets, and various other support facilities. The magnitude of the combustible load in the various core areas was unclear, although it was likely to have been small. As a first approximation, the carpet that was assumed to be spread over the floor of the tenant spaces was extended into the core area. This was not necessarily meant to imply that the core was carpeted, but was to represent some light load of combustible objects that might have been found there.

For the suspended ceiling tile system, the best information available was that given in NCSTAR 1-5, Section 3.1.3, which estimated that the ceiling tiles would have failed after 5 to 15 minutes of exposure to a fire, depending on the whether the ceiling grids and supports were made with aluminum or steel. It was assumed that, except for the immediate damage area in the south of the building, the tile systems were intact following the debris impact. The tiles were assigned the same thermal properties as those for the systems in the WTC towers, and it was assumed that a tile became dislodged from its supports when its surface temperature reached $400{ }^{\circ} \mathrm{C}$.

Ceiling tiles were included in the FDS simulations. They were modeled as thin obstructions tied to virtual "heat detectors" with a response time index (RTI) of $400(\mathrm{~m}-\mathrm{s})^{1 / 2}$ and activation temperature of $400{ }^{\circ} \mathrm{C}$. These values were chosen simply to cause the tiles to disappear in roughly 10 to $15 \mathrm{~min}$ of exposure to high temperatures. Various simulations were performed with and without the tiles, and with various values of the RTI and activation temperature. The results of the simulations were not sensitive to either the presence, or specific thermal properties, of the ceiling tiles.

\section{Exterior Damage}

An important component of the fire simulations was the damage to the exterior of the building, both from the debris impact from WTC 1 and from the heat of the fires breaking windows. Exterior damage was

\footnotetext{
${ }^{5}$ As discussed in NIST NCSTAR 1-5, this fuel loading may appear to be lower than that in the surveys of actual offices. In this Investigation, the combustible mass cited in the FDS simulations is the fully burned mass. However, in the multi-cubicle tests reported in NIST NCSTAR 1-5E, a sizable fraction of the paper in file cabinets, shelves, and desk drawers did not combust fully.
} 
input directly into the model from the assessment in Chapter 5. There were no attempts to predict window breakage with the model, nor was there any effort to assess the sensitivity of the calculations to the degree of exterior damage.

The window breakage input for the simulations of the floors of WTC 7 was obtained from available photographs. In the absence of photographic evidence, it was assumed that the windows broke out linearly in time following the observed pattern of the fire. For example, a photograph of the north face taken at 1:52 pm shows no window breakage on Floor 7, yet another photograph taken at 3:00 pm shows window breakage extending from the west end halfway towards the east end. Fires were observed on the west side of Floor 7 prior to 2:00 pm; thus, it was assumed in the model that the windows broke out at regular time intervals starting at the west end, beginning at 2:00 pm. Similar assumptions were made for all times when photographs were unavailable.

\section{Ignition}

For the simulations of the WTC 1 and WTC 2 fires, the initial ignition of furnishings was clearly a result of flaming jet fuel, and this effect was reproduced in the simulations using evaporating liquid droplets. For WTC 7, however, the ignition and early course of the fires were unknown because they were presumed to have occurred in the damaged and heavily smoke-shrouded southern portion of the building. For this reason, on each floor, a specified fire of $2 \mathrm{MW}$ was positioned near the southern face of the building. This was roughly the equivalent of a small, single office workstation burning.

The choice of a 2 MW fire at 12:00 noon was a somewhat arbitrary initialization of the simulations, but there is little visual evidence of how the fires behaved in the time period between 10:28:22 a.m. and 2:00 p.m. There was a direct observation of a workstation fire in the southwest corner of Floor 7 around noon. This observation supported the assumption that the fire on that floor had slowly grown to about $2 \mathrm{MW}$ by noon. In addition, starting the calculations at noon was convenient in that the simulation time was the same as the actual clock time, and that the fires were allowed, in the model, to spread naturally to a point where they could be compared to photographic evidence, much of which focused on the north face of the building. The early history of the fires played a minor role in their eventual progression, at least in the simulations.

Furnishings near the originally specified fire were assigned thermal properties obtained from small scale experiments (NIST NCSTAR 1-5F). Fire spread was predicted by the model as a natural consequence of surrounding objects heating and burning. The exception was that, for the simulation of the $8^{\text {th }}$ floor, a second specified fire was needed to spread the fire to the north face of the building, where it was observed from about 3:00 p.m. until as late as 4:40 p.m. All of the simulations were carried out for six hours of elapsed time.

\subsubsection{Results of the Simulations}

The aim of the fire simulations for WTC 7 was to replicate the major features of the fires, given the limited knowledge of the debris impact damage and interior contents, while exploiting as much as possible the visual evidence contained within the few photographs and videotapes taken of WTC 7 following the collapse of the towers. As noted in the discussion of the individual floors below, the simulations generally replicated the major fire features, including the rate of spread of the fires at the building perimeter (the 
photographs could not show interior burning) and the overall burn time for each of the affected floors. There was some variability in simulation of the duration of fire activity in a given perimeter location on some highly partitioned floors. The descriptions of the actual fires are from Chapter 5 of this report.

Note that only the window glass breaking times were prescribed in the fire model. The observed fire activity gleaned from the photographs and videos was not a model input, and thus one should not expect a perfect correspondence between predicted high temperatures and observed fire activity.

\section{Floor 7}

A cubicle fire was observed on Floor 7 at about 12:15 p.m., near the southwest corner of the building. The fire spread north along the west face. By 3:00 p.m., the fire had progressed from the west side of the building past the halfway point of the north face. Shortly after this time, the fire on the north face appeared to stop and was not observed to progress further. About 4:25 p.m., a fire flared just east of this and died down within about another $15 \mathrm{~min}$. As late as 4:45 p.m., fire was observed near the middle of the north face on Floor 7.

To simulate the fire on Floor 7, a 2 MW fire was prescribed near the southwest corner at an assigned time of 12:00 noon, which became the starting "time" of the simulation. This fire was chosen to initiate spread along the west face of the building. No other fires were prescribed, and the spread of this fire beyond its point of origin was predicted by the model. Windows were removed from the calculation at times observed in the (infrequent) photographs and videos. For the time periods between photographs, windows were removed in a linear fashion, consistent with the assumption that the fires spread at a nearly constant rate.

Figure 9-9 displays hourly snapshots of the upper layer temperatures predicted by the model. The simulations indicated that the clusters of workstations burned out in about $20 \mathrm{~min}$ to $30 \mathrm{~min}$. The cold, rectilinear areas along the south wall and the east wall are the mechanical areas described in Chapter 3. Their fire-rated walls would have effectively resisted any significant heating of the contained space. The walls also impeded fire spread along the south face, explaining the clockwise movement of the fire. Figure 9-1 shows the location of Columns 79, 80, and 81 relative to the mechanical area on the east side of the building.

The spread rate and intensity of the observed fire and the simulated fire were similar. The simulated fire reached the north face of the building a little later and spread a little more slowly to the east than the visuals indicated. (Note that the start time of the simulated fires was defined as 12:00 p.m., for lack of visual evidence, and that the visuals only indicated burning near the windows, not in the building interior.) The principal difference between the photographs and the simulation was that, unlike the actual fire on Floor 7, which stopped and then flared up to the east, the simulated fire slowed briefly near the middle of the north face and then continued toward the east. (There were office walls in this vicinity, but doors were left open in the simulation, and the fire eventually passed through the middle section of the building and moved to the east face, where it finally consumed the remainder of the furnishings.) The effect of these differences on the thermal environment would have been small. 


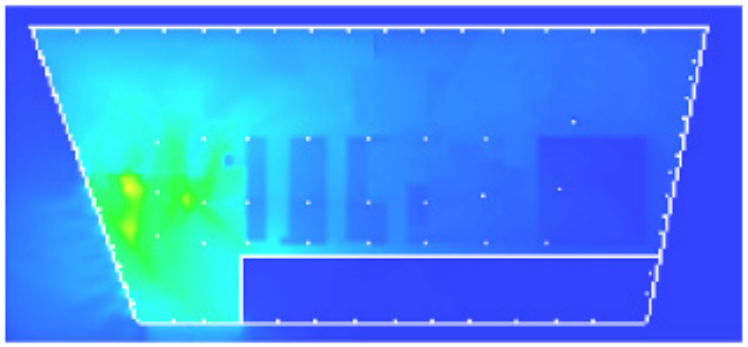

1:00 p.m.
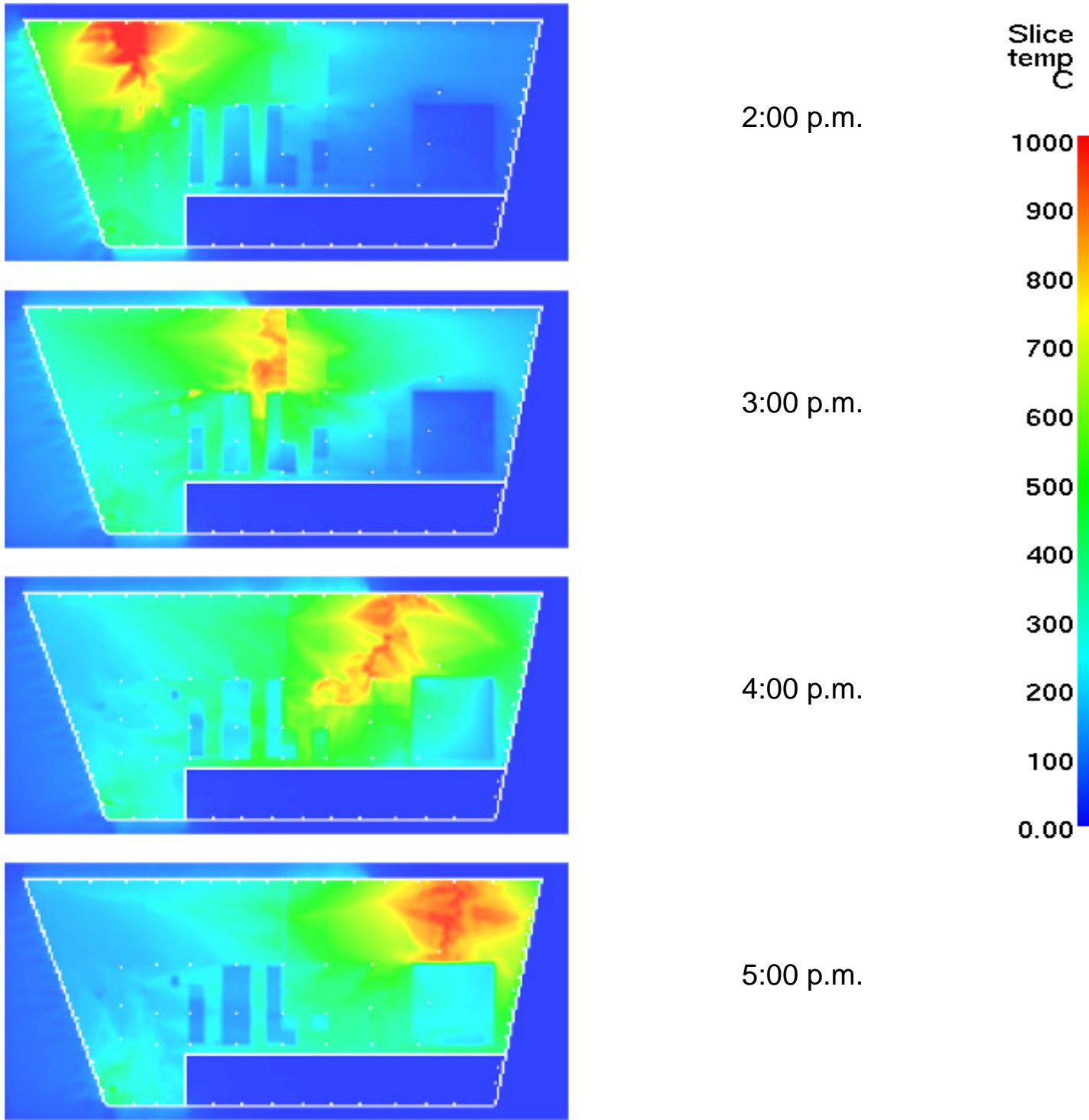

5:00 p.m.

Figure 9-9. Progression of simulated fire on Floor 7 of WTC 7. Upper layer gas temperatures are shown. 


\section{Floor 8}

At 12:15 p.m., when the cubicle fire was observed on Floor 7, people being led from Floors 7 and 8 out of the building reported no fires, heavy dust, or smoke on Floor 8. Between 12:15 p.m. and 2:30 p.m., fire activity on Floor 8 was observed at the south face by eyewitnesses near the southwest corner of the building. At 3:15 p.m., fire was observed on Floors 7 and 12 at the north face, but not Floor 8 . At about 3:40 p.m., fire was observed near the center of the north face of Floor 8 at roughly the same time fires were burning on the west face and in the northeast corner. Earlier fires between the western edge and the center of the north face appeared to have died down. Unlike the fire on Floor 7, the fire on Floor 8 continued to move east on the north face fairly steadily, reaching the northeast corner and moving to the east face around 4:00 p.m., then moving onto the east face. Low intensity interior fires were still present on Floor 8 to the east of the center of the north face around 4:45 p.m.

In the simulation, a $2 \mathrm{MW}$ fire was prescribed near the middle of the south face at about 12: 30 p.m., $30 \mathrm{~min}$ after the start of the fire on Floor 7. Although there is no direct photographic evidence for it, in the model, windows were intentionally broken out along the west face, starting from the southwest corner, as a means of directing the simulated fire spread in the observed clockwise direction.

This fire did not spread to the north face in preliminary simulations. The cause was a partition (shown in the architectural drawing of the floor) that partially blocked the path from the southwest corner to the northwest corner. Thus, a second $2 \mathrm{MW}$ fire was prescribed near the northwest corner at 3:00 p.m., based on the photographic evidence.

Figure 9-10 displays hourly snapshots of the upper layer temperatures predicted by the model. As with the fires on the $7^{\text {th }}$ floor, the burning time and spread rate of the $8^{\text {th }}$ floor fires were similar in the photographs and the simulation. The fire spread rate over the clusters of workstations was the same as on Floor 7. The principal difference between the simulations and the observations was that the simulated fires spread from the western edge to the east, while the imagery suggested the fire first appeared somewhere on the western side of the north face and then spread both west and east, first burning to the western edge and along the west side and reaching the eastern edge at a later time. In other words, the difference was the order in which the northwest corner and the west end of the north face burned. Since all the fuel in this region was consumed in about a half hour, the order of burning was not likely to have had a significant effect on the heating of the structure in that vicinity.

\section{Floor 9}

The first observations of fire on the $9^{\text {th }}$ floor were soon after 4:00 p.m., on the west side of the north face. The fire spread eastward, reaching four-fifths of the way across the face by 4:15 p.m. Images showing further progress to the east were not available. The intensity of the fire had decreased markedly by 4:40 p.m. Since observations of fire on the $9^{\text {th }}$ floor were at times similar to those on the $8^{\text {th }}$ floor about one hour earlier, the $9^{\text {th }}$ floor fire was simulated by transposing the $8^{\text {th }}$ floor fire one hour later.

Between 4:00 p.m. and 4:40 p.m., the progress of the simulated fire matched the visual evidence. The simulation added descriptions of the fires prior to and subsequent to this period. Since the fire physics should have been similar to that on the $7^{\text {th }}$ and $8^{\text {th }}$ floors, the overall fire progress on the $9^{\text {th }}$ floor was assumed to be of the same accuracy as the fires on the two floors immediately below, despite the lack of visual corroboration. 


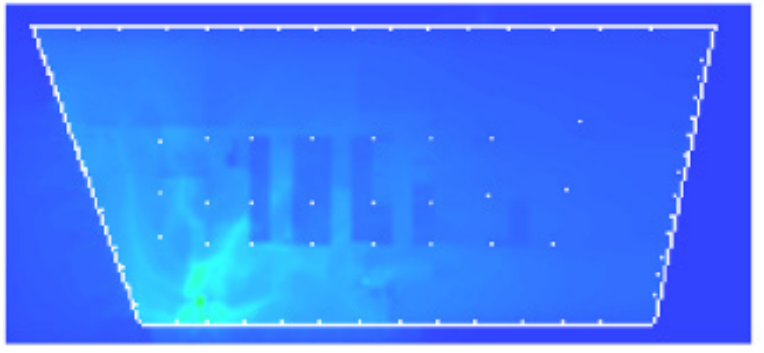

1:00 p.m.
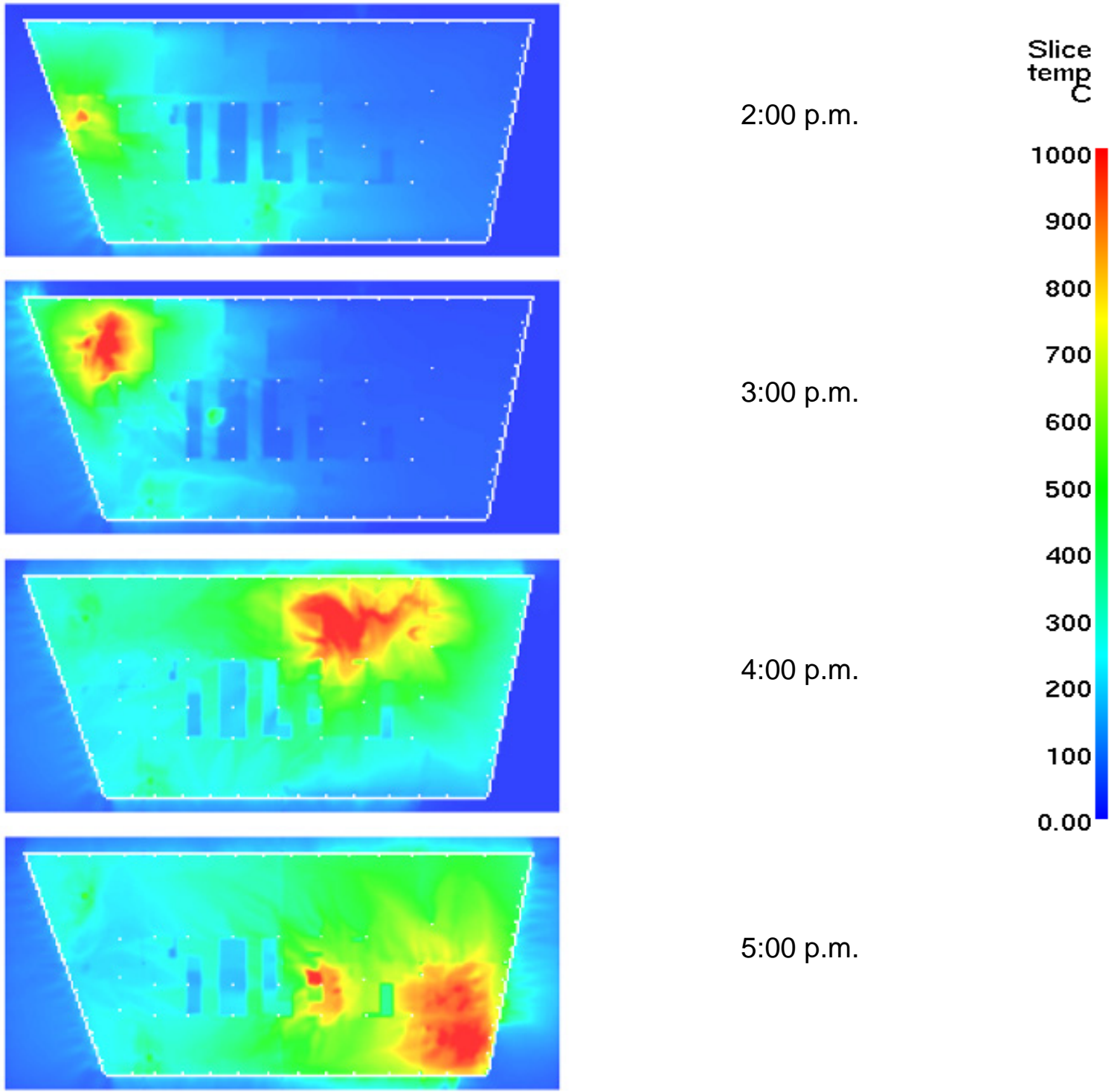

Figure 9-10. Progression of simulated fire on Floor 8 of WTC 7. Upper layer gas temperatures are shown. 


\section{Floor 12}

Fire was first observed on the $12^{\text {th }}$ floor, on the south side of the east face, at about 2:10 p.m. Intact windows at the south edge indicated that the fire likely had bypassed the southeast corner as it moved from the south face onto the east. By around 2:30 p.m., the intense flames originally seen on the east face were dying down, while the fire had spread both south into the southeast corner and two-thirds of the way to the northeast corner. Just before 3:00 p.m., there were flames east of center on the north face. The fire had apparently bypassed the northeast corner of the floor and spread internally to the north face. By 3:15 p.m., the fire had spread to the east to engulf the northeast corner and to the west, reaching near the center of the face. By around 3:55 p.m., flames had reached west of the center of the north face. Around 5:00 p.m., the fire had continued spreading west to the northwest corner.

The simulation reflected the high partitioned floor layout and higher estimated fuel load, compared to Floors 7 and 8 (Chapter 3). In the simulation, a 2 MW fire was prescribed near the center of the south face at an assigned time of 12:00 noon. No other fires were prescribed, and the spread of this fire beyond its point of origin was predicted by the model. Windows were removed from the calculation at times observed in the photographs and videos, which were well spaced from about 2:30 p.m. until about 5:00 p.m. For the time periods between photographs, windows were removed in a linear fashion, consistent with the assumption that the fires spread at a nearly constant rate. Figure 9-11 displays hourly snapshots of the upper layer temperatures predicted by the model for the $12^{\text {th }}$ floor.

The prescribed window breakage pattern in the model drove the fires in a counter-clockwise direction, consistent with the visual evidence. The fires also spread along the south face in the simulation, although there is no evidence to confirm this observation. The spread rate was about one-third to one-half slower than that on the lower floors due to the higher fuel load. The burning time near the north face was longer in the simulation than in the visual evidence, suggesting that (a) additional gasified fuel from the building interior was burning near the windows in the simulation, (b) the input fuel load was too high, and/or (c) the office partitions were more effective at slowing the fire progress in the simulation than in the actual fires. The first possibility would lead to overestimated temperatures near the north curtain wall, but not necessarily between the curtain wall and the building core. The second possibility would imply reduced heat release, which, in turn, would lead to overestimates of structural temperatures throughout the area between the north curtain wall and the building core. The third possibility would lead to heating of the northeast corner slightly earlier than in the actual fires. Explanations (a) and (c) are more likely the cause of longer apparent burning time than (b). (See Section 9.3.3.)

\section{Floor 11}

Fire on the $11^{\text {th }}$ floor was first observed at about 2:10 p.m. near the southeast corner on the east face. The smoke patterns suggested intense flames prior to this time. The fires reached the midpoint of the east face about 2:30 p.m. There had been no indication of burning along the entire north face as late as 4:00 p.m. The next images of fire on this floor were about 4:40 p.m., showing burning just east of the center of the north face. By around 4:52 p.m., the flames in the original fire area had apparently died down. The fire continued to spread slowly across the north face toward the west until WTC 7 collapsed, having reached about 60 percent of the distance across the face. 
The fire behavior on Floor 11 followed the pattern on Floor 12. The fires on the two floors occurred at similar times on the east face, prior to 2:30 p.m. The appearance times of the fires on the north face of the $11^{\text {th }}$ floor were about $1 \frac{1}{2} \mathrm{~h}$ later than those on the $12^{\text {th }}$ floor. Since the floor layouts had the same arrays of partitioned offices, and since it was unknown which office doors were open or closed, the Investigation Team decided that additional simulations of Floor 11 would not have provided any more meaningful results than time-offsetting the temperatures predicted for Floor 12. The Floor 11 fires were represented by the Floor 12 fires delayed by $1 \mathrm{~h}$. This resulted in a westward fire spread rate along the north face that was faster and a burn duration that was longer than observed in the photographs. Combined, these effects could have led to a mild overestimate of the heating on the north side of the floor.

\section{Floor 13}

The visual evidence suggests that the fire, first seen about 2:30 p.m., burned along the east face, turned at the northeast corner, and was east of the center of the north face about 3:40 p.m. Around 4:00 p.m., flames had reached the center of the north face. Forty minutes later, any fires on the east side of the north face were no longer visible. At about 5:00 p.m., the fires had extended west of the center of the north face and were still there just prior to the building collapse.

The fire on this floor generally followed the pattern of the fire that was observed for the $12^{\text {th }}$ floor. The timing of the fire on the east side was roughly one-half hour behind that of the fire on the $12^{\text {th }}$ floor. The $13^{\text {th }}$ floor fire arrived in the northeast corner about one-half hour later than the $12^{\text {th }}$ floor fire and was about one-half hour slower in approaching the west section of the north face. Since the floor layout and fuel load on the east side of the $13^{\text {th }}$ floor were highly uncertain, the Investigation Team decided that additional simulations of Floor 13 would not have provided any more meaningful results than timeoffsetting the temperatures predicted for Floor 12. The Floor 13 fires were represented by the Floor 12 fires delayed by one-half hour. The westward fire rate along the north face was moderately faster, and the burn duration was longer than in the visual evidence. Combined, these effects could have led to a mild overestimate of the heating on the north side of the floor.

\subsubsection{Sensitivity Tests}

The paucity of visual evidence did not support an extensive series of tests of the sensitivity of the simulations to the various assumptions noted above. However, a small number of checks of important input parameters were performed to improve confidence in the fire behavior obtained from the initial simulations. The following are the result of those sensitivity checks.

- Doubling the combustible load on the $8^{\text {th }}$ floor from $20 \mathrm{~kg} / \mathrm{m}^{2}$ to $40 \mathrm{~kg} / \mathrm{m}^{2}$. This caused the fires to burn in place longer, until the fuel was consumed, before advancing. As a result, the fires moved distinctly more slowly than in the visual evidence.

- Decreasing the combustible load on the $12^{\text {th }}$ floor from $32 \mathrm{~kg} / \mathrm{m}^{2}$ to $20 \mathrm{~kg} / \mathrm{m}^{2}$, the value used for the floors whose combustible load was not described as high (Chapter 3). This showed little effect on the rate of fire progression. This suggests that the input combustible fuel load was not the principal factor in the longer burn duration (see above). 
- Decreasing the combustible load on the $12^{\text {th }}$ floor from $32 \mathrm{~kg} / \mathrm{m}^{2}$ to $20 \mathrm{~kg} / \mathrm{m}^{2}$ and doubling the strength of the ceiling tiles (Figure 9-12). This floor was heavily segmented into individual offices, and this change effectively slowed the fire movement past the walls and into adjacent offices. This fire spread rate was lower than in the visual evidence.

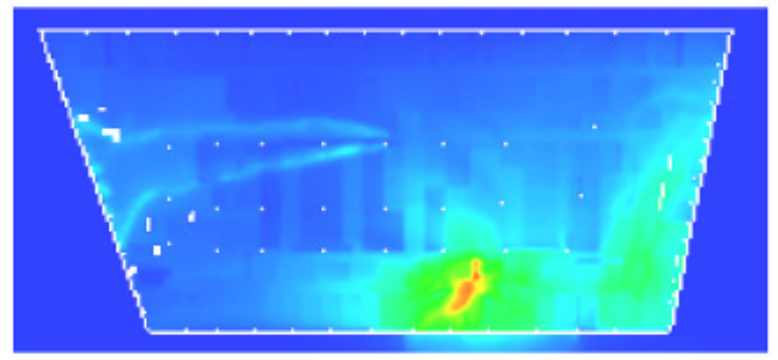

1:00 p.m.
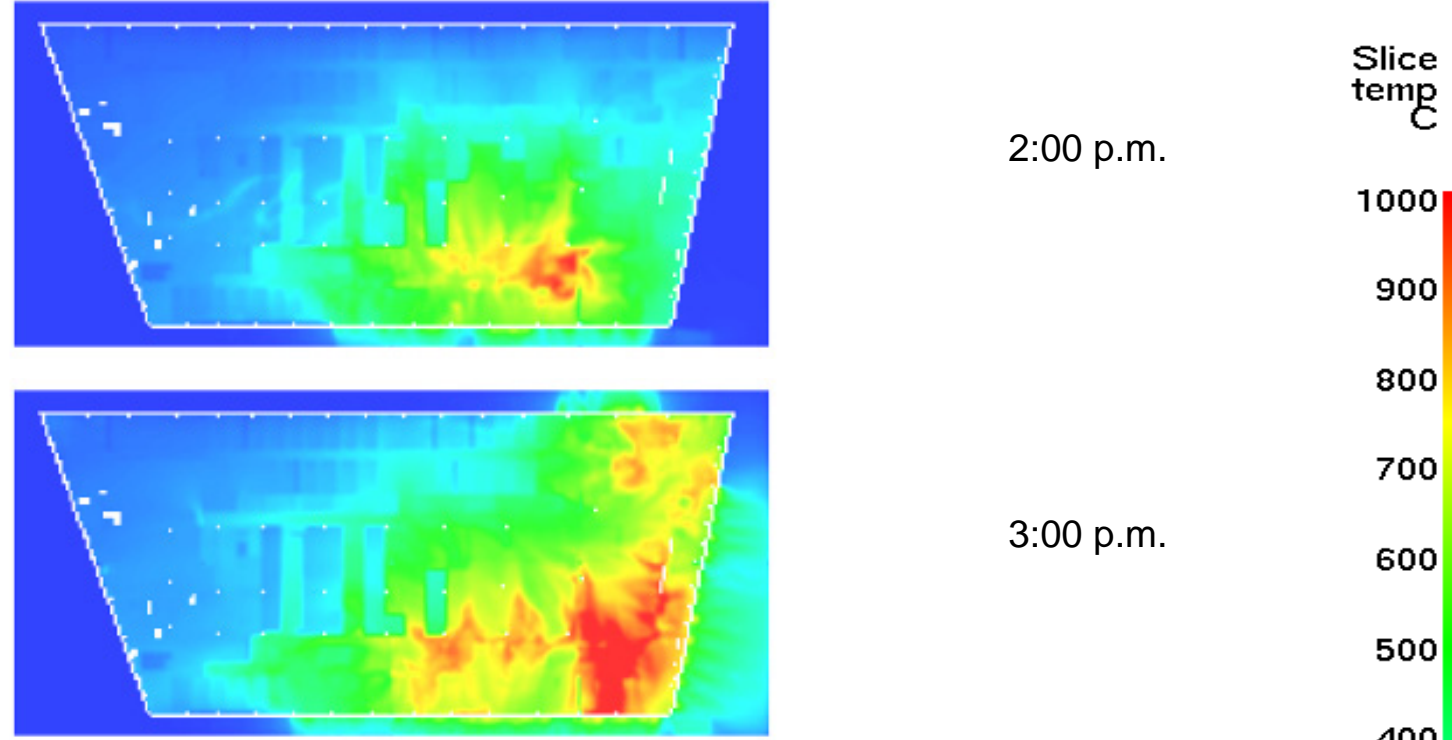

2:00 p.m.

temp
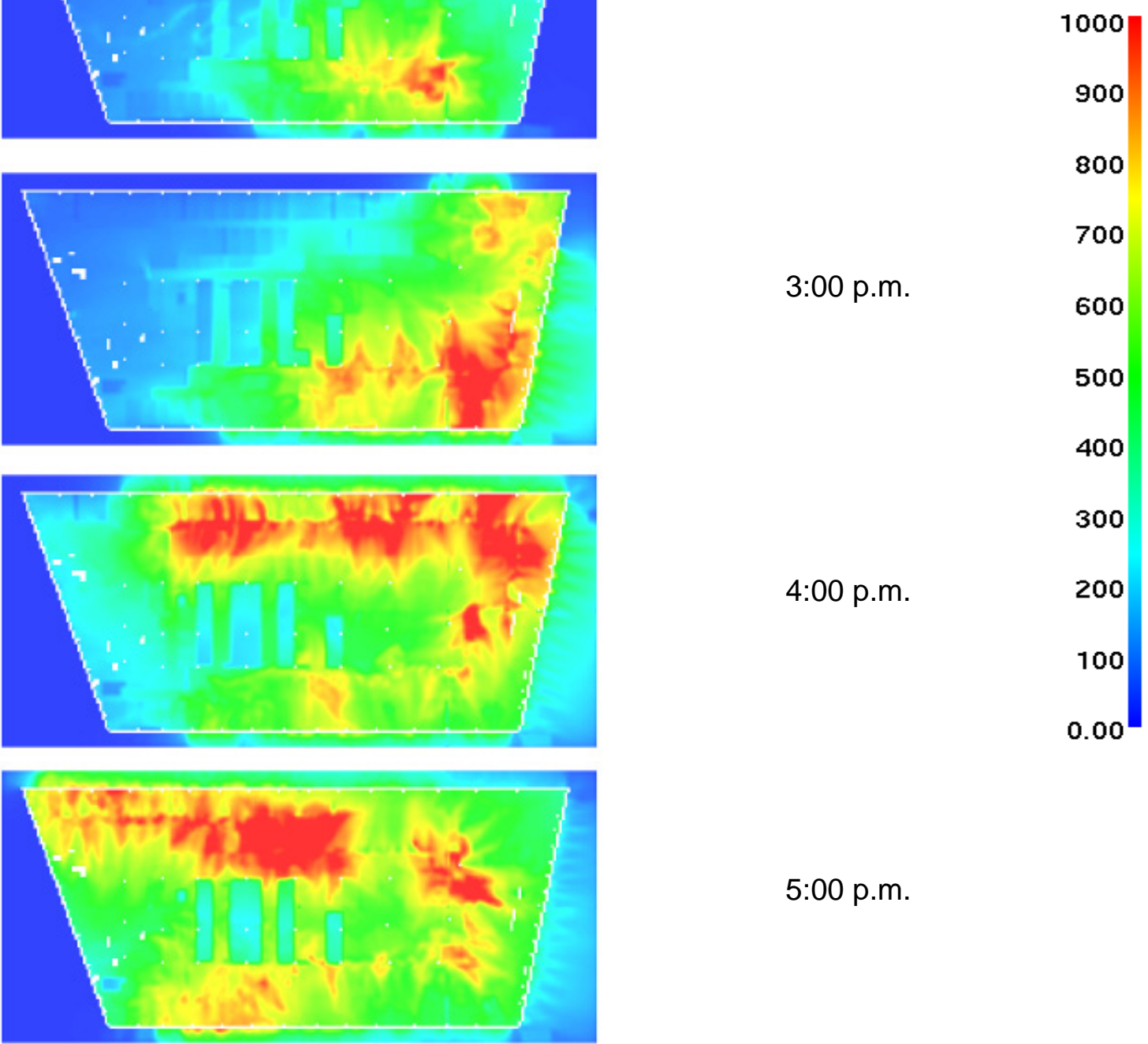

5:00 p.m.

Figure 9-11. Progression of simulated fire on Floor 12 of WTC 7. Upper layer gas temperatures are shown. 


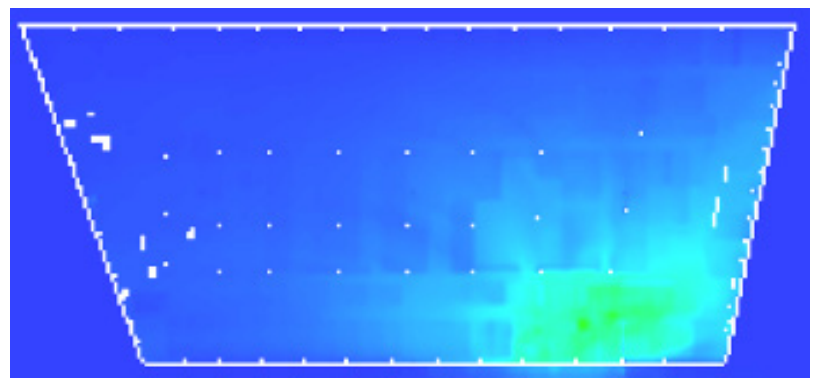

1:00 p.m.

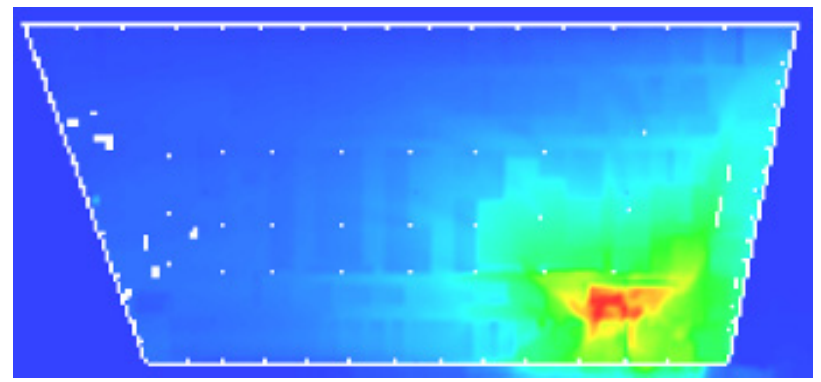

Slice

2:00 p.m.

temp
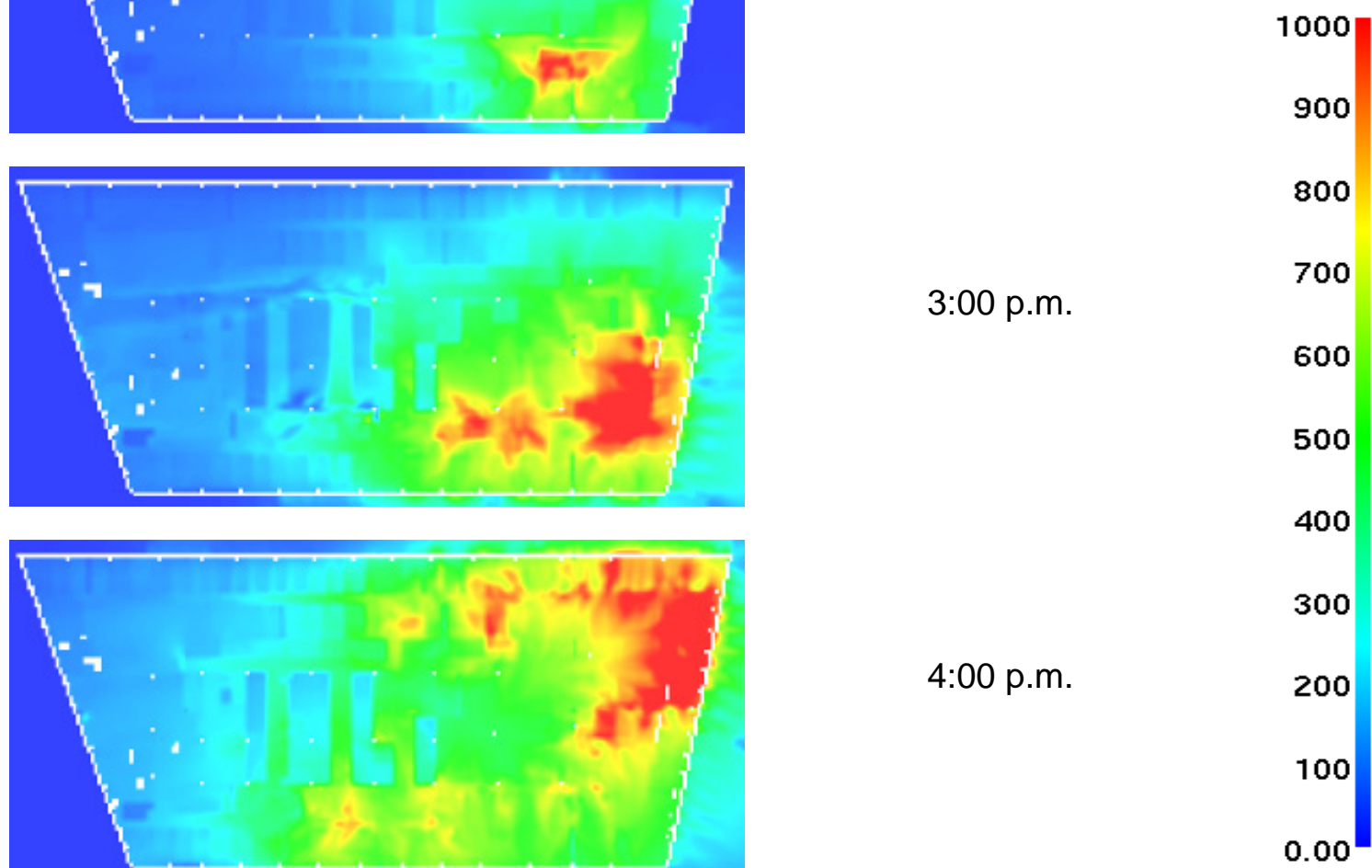

5:00 p.m.

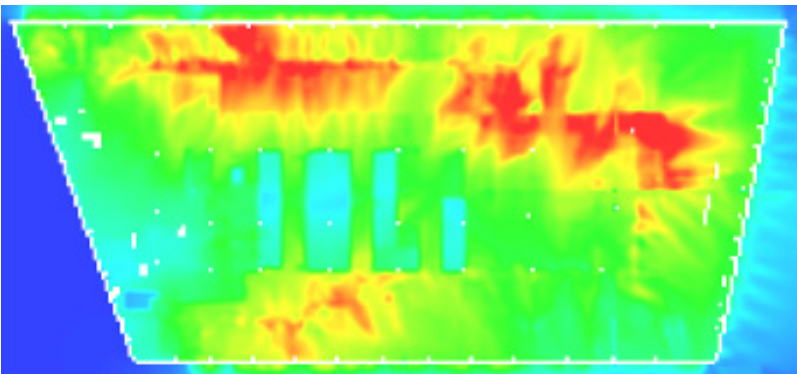

Figure 9-12. Progression of simulated fire on Floor 12 of WTC 7, with more durable ceiling tile system.

Upper layer gas temperatures are shown. 


\subsection{FIRE INTENSITIES}

Figure 9-13 shows the rates of heat release for the simulated fires on the $7^{\text {th }}, 8^{\text {th }}$, and $12^{\text {th }}$ floors. The time of $0 \mathrm{~h}$ corresponds roughly to noon on September 11, 2001. There was only a single observation of a (small) fire on Floors 7 through 13 from 10:28:22 a.m., when it is likely that the actual fires started, until about 2:00 p.m. Thus, it is probable that the fires were no more intense during the interval from 10:28:22 a.m. to noon than the early intensities in Figure 9-13.

The simulated fires on the $7^{\text {th }}$ and $8^{\text {th }}$ floors occurred in open landscaped areas, with free access to fresh air. Therefore, the shapes of the heat release curves do not reflect the additional window breakage. The jump in heat release rate for the $8^{\text {th }}$ floor at $3 \mathrm{~h}$ is a result of a second fire having been started in the already heated northwest section of the floor.

In the computations, the fire on the $12^{\text {th }}$ floor, and thus the derivative fires on the $11^{\text {th }}$ and $13^{\text {th }}$ floors, generated significantly more heat than the fire on the $7^{\text {th }}$ or $8^{\text {th }}$ floor. This was in large part due to the higher fuel load in the simulations of the $11^{\text {th }}, 12^{\text {th }}$, and $13^{\text {th }}$ floors and the larger burning area of the fires on these floors (i.e., the west and north floor areas on the $7^{\text {th }}$ and $8^{\text {th }}$ floors were smaller than the south and east areas of the $11^{\text {th }}, 12^{\text {th }}$, and $13^{\text {th }}$ floors).

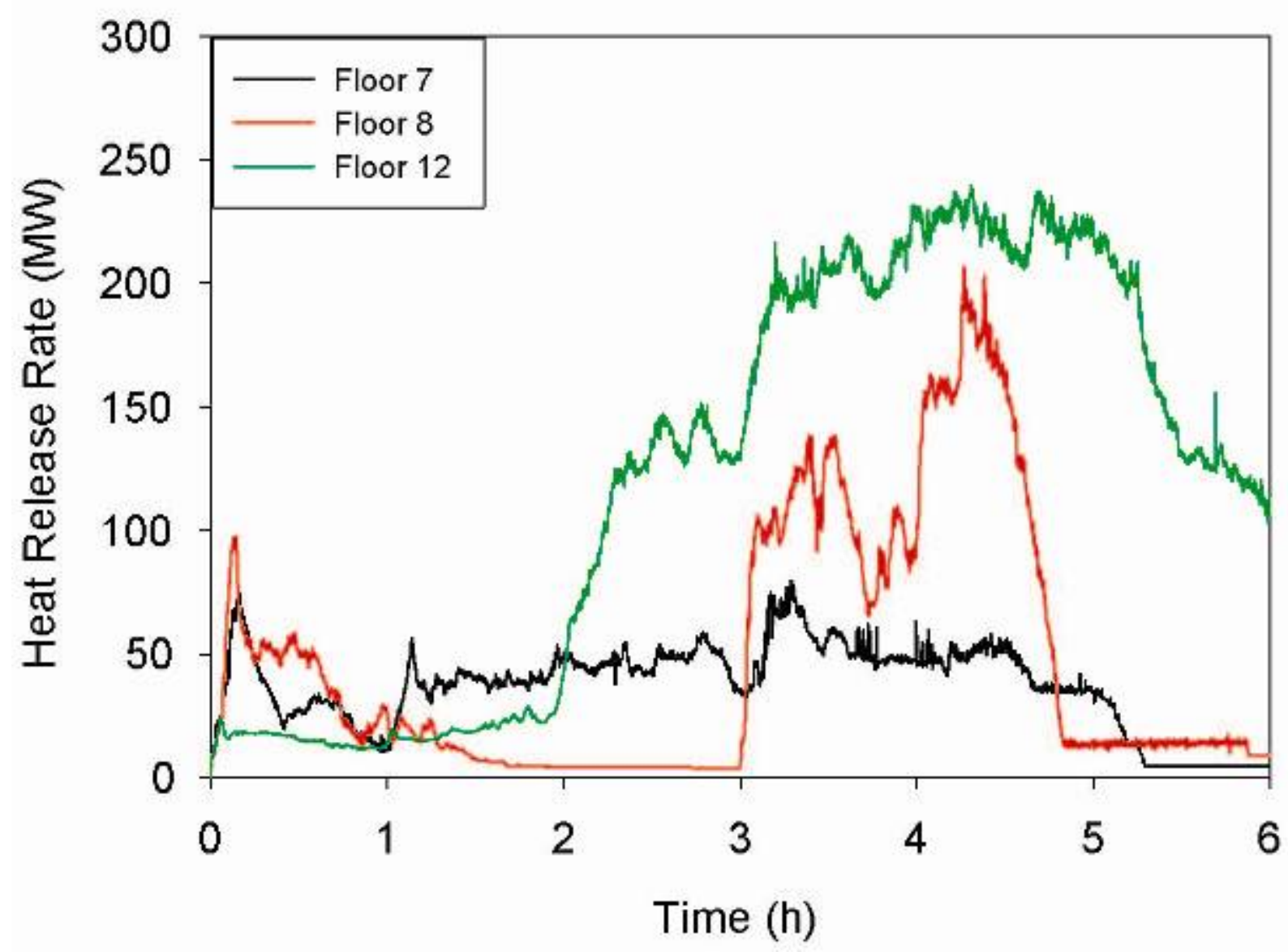

Figure 9-13. Rates of heat release of simulated fires in WTC 7. 
The rate of heat release shown in Figure 9-13 indicates only what the FDS analysis predicted to have burned. All the combustibles were not consumed in the simulations. Floors 7 and 8 had nominally the same fuel load, but the layout of furnishings was different, the window breakage history was different, and consequently the total amount of combustibles consumed was different. Floor 12 was assumed to have a higher combustible loading, and the layout of the floor was different from Floors 7 and 8. Also, the simulated fires spread along the south face of Floor 12, as well as along the east and north faces, whereas the simulated fires on Floors 7 and 8 spread along the west, then north, then east faces. There is no visual evidence to confirm that there was any substantial fire spread along the south face, but nothing was deliberately added to the model to spread or not spread fire along the south face.

\subsection{SUMMARY OF THE SIMULATIONS OF FIRES IN WTC 7}

The Investigation Team concluded that possible diesel fuel fires on the $5^{\text {th }}$ or $6^{\text {th }}$ floors were not likely to have been significant contributors to the eventual collapse of the building. The worst-case scenarios associated with ruptured fuel lines generated fires that could not be sustained long enough, or generated too little heat, to raise the temperatures of the steel and concrete structure to the point of significant loss of strength or stiffness, or these fires would have exhausted smoke from the exhaust louvers. No such emanation was observed.

Although the visual evidence for WTC 7 was not nearly as extensive as for WTC 1 and WTC 2, the fire simulations did exploit as much as possible the few photographs showing the location of severe fire activity in WTC 7 at various times during the afternoon of September 11, 2001. Compared to the actual fires, the simulated fires followed the same general paths and, as evidenced by the validation experiments reported in NIST NCSTAR 1-5E, generated comparable temperatures to those in the fire tests. The simulations of the $12^{\text {th }}$ floor fires (and thus the derivative $11^{\text {th }}$ and $13^{\text {th }}$ floor fires) may have mildly overestimated the duration of the fires and the fraction of the burning near the north face windows, relative to the burning in the interior of the tenant space.

The output from the fire simulations of the $7^{\text {th }}, 8^{\text {th }}$, and $12^{\text {th }}$ floors, along with the time-shifted output for the $9^{\text {th }}, 11^{\text {th }}$, and $13^{\text {th }}$ floors, was used as the input for the building thermal response calculations presented in the next chapter.

\subsection{REFERENCES}

Cantor. 1985. Irwin G. Cantor P.C., Structural Engineers, Structural Drawings, 7 World Trade Center.

Drysdale, D.D. 2002. Thermochemistry, P.J. DiNenno, ed., The SFPE Handbook of Fire Protection Engineering, NFPA International, Quincy, MA, p. 1-93.

Flack and Kurtz. 1987. Design Criteria for Mechanical, Electrical, Plumbing, Salomon Brothers 7 World Trade Center Headquarters, April 20.

Flack and Kurtz. 1988. Flack and Kurtz Mechanical Engineers, Mechanical and Electrical Drawings for Salomon Brothers 7 World Trade Center Headquarters.

Gottuk, D.T., and White, D.A. Liquid Pool Fires, P.J. DiNenno, ed., The SFPE Handbook of Fire Protection Engineering, NFPA International, Quincy, MA, p. 2-309. 
Huggett, C. 1980. Estimation of the Rate of Heat release by Means of Oxygen Consumption, Fire and Materials, Vol. 12, p. 61-65.

McAllister, T., ed. 2002. World Trade Center Building performance Study: Data Collection, Preliminary Observations, and Recommendations, FEMA 403, Federal Emergency Management Agency, Washington, DC. May.

McGrattan, K. B., ed. 2004. Fire Dynamics Simulator (Version 4), Technical Reference Guide, NIST Special Publication 1018. National Institute of Standards and Technology, Gaithersburg, MD, July.

Roth. 1985. Emery Roth \& Sons P.C., Architects, Architectural Drawings, 7 World Trade Center.

Syska \& Hennessy. 1985. Syska \& Hennessy Engineers, Mechanical, Electrical, and Plumbing Drawings, 7 World Trade Center. 


\section{Chapter 10 \\ Structural HeAting}

\subsection{THE FIRE STRUCTURE INTERFACE}

The Fire Structure Interface (FSI) was used to impose the air temperatures from the FDS simulations (Chapter 9) on the structural components of WTC 7 (Chapter 2) to predict the evolving thermal state of the building. The FSI also linked the thermal analysis and structural analysis by creating thermal loading data in a format that was consistent with the structural models that were used to predict the collapse of the building (Chapters 11 and 12). The structural response analysis of WTC 7 to understand the collapse initiation mechanism was performed using the thermal data presented in this section. The approach was similar to that used to predict the fire induced thermal response of WTC 1 and WTC 2 described in NCSTAR 1-5G, and therefore, only a brief description of the major assumptions is included.

The FSI converts the rapidly changing, three-dimensional FDS gas temperature profiles into slowly varying upper gas layer and lower gas layer temperatures. These temperatures were time averaged over

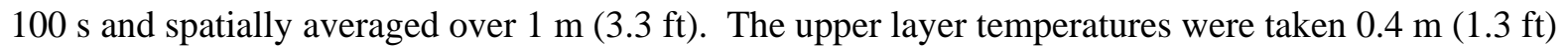
(one grid cell) below the ceiling. The lower layer temperatures were taken $0.4 \mathrm{~m}(1.3) \mathrm{ft}$ above the floor. Under this plane layer approximation, a simplified form of the radiative transport equation was solved to predict the radiative fluxes incident on the sub-grid scale structural elements. The incident radiative fluxes were functions of space and time and depended on the location and orientation of the structural elements. The radiative fluxes were also related to the local instantaneous properties of the hot layer as defined by the upper and lower layer temperature, absorption coefficient, and depth of the hot layer as computed in the fire simulations.

\subsection{MODEL INPUT}

As indicated in the preceding chapter, the fire simulations for the $7^{\text {th }}, 8^{\text {th }}$ and $12^{\text {th }}$ floors were used to create thermal environments on Floors 7 through 13 . The simulated fire on the $8^{\text {th }}$ floor was transposed one hour later and used to represent the fire on the $9^{\text {th }}$ floor. Similarly, the simulated fire on the $12^{\text {th }}$ floor was transposed one hour later to represent the fire on the $11^{\text {th }}$ floor and one-half hour later to represent the fire on the $13^{\text {th }}$ floor. The FSI source term for the remaining floors in the building was ambient temperature. Figure 10-1 shows the gas temperature time history for Floor 12 near the ceiling by Column 79 and the northeast corner. 


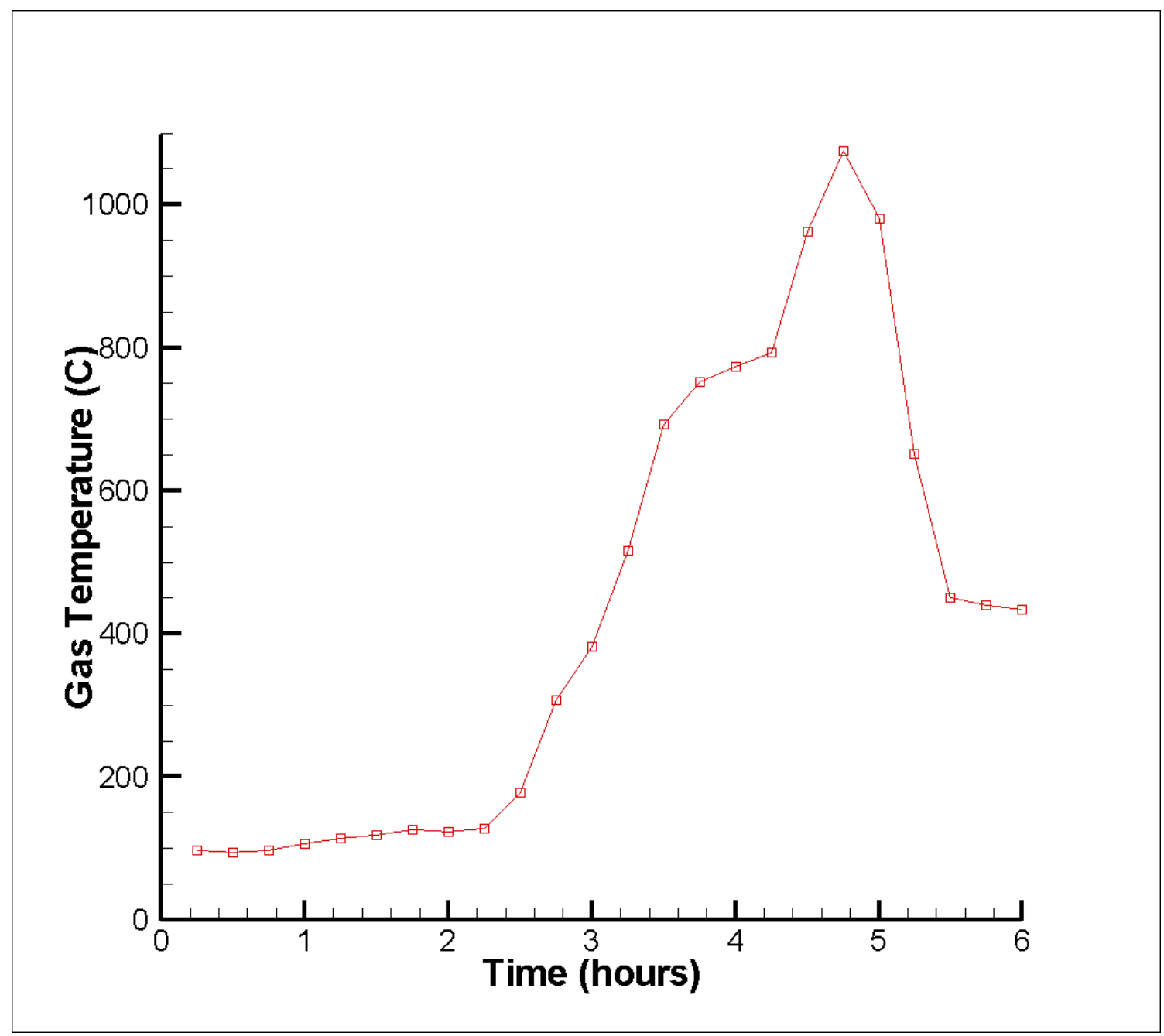

\section{Figure 10-1 Gas temperature time history for Floor 12 near the ceiling by Column 79 and the northeast corner.}

The thermal analysis performed for the reconstruction of the WTC 1 and WTC 2 fires indicated that significant heat transport from a floor with a flashed over fire did not extend past the adjacent floor. As indicated in Chapter 9, no fires were simulated on the $14^{\text {th }}$ floor, and the analysis in Section 9.2.1 indicated that there was no significant fire on the $5^{\text {th }}$ or $6^{\text {th }}$ floor. Thus, it was expected that the output from the FSI would indicate heating from the $6^{\text {th }}$ floor to the $14^{\text {th }}$ floor.

The dimensions and structural formulation of the exterior and core columns and the concrete floor slabs were those provided for WTC 7 (Chapter 2). The exterior surfaces of the exterior and core columns were covered with a mean Monokote MK-5 insulation thickness of $22 \mathrm{~mm}$ (7/8 in.); the concrete slabs were protected by $9.5 \mathrm{~mm}$ (3/8 in.) thick Monokote MK-5 on their bottom face only; the beams and girders were protected by $13 \mathrm{~mm}$ ( $0.5 \mathrm{in}$.) of Monokote MK-5 (Chapter 2). The damage from the debris from the collapse of the towers was not included in the simulations. This was because the thermal effect of the damage would have been local to the southwest portion of the building, while the eventual collapse initiated in the northeast region of the building. Otherwise, the thermal response modeling of WTC 7 was identical to that performed for the WTC towers. 


\subsection{SIMULATED FIRE-INDUCED THERMAL RESPONSE OF WTC 7}

\subsubsection{General}

It was assumed that the structure was initially at $23{ }^{\circ} \mathrm{C}$. The thermal analysis covered the approximately 21,600 s (6 h) period over which the FDS fires were present on Floors 7, 8, 9, 11, 12, and 13. The minimum time step for the thermal analysis was $1 \mathrm{~ms}$, while the maximum time step was limited to $50 \mathrm{~s}$. As was done for the towers, the output file for use in the structural analysis contained thermal data at 12 instants in time, spaced at 30 min (1,800 s) intervals, beginning at 12:30 p.m.

The modeling of the steel elements was similar to that in NIST NCSTAR 1-5G. However, in WTC 7, there was no evidence of damage to the thermal insulation (away from the immediate impact area of debris from WTC 1). Since heat transport across the insulation layer was much slower than heat transport into the depth of the steel, temperatures across column sections differed by less than $1{ }^{\circ} \mathrm{C}$. Temperature gradients through the depth of the steel beams and girders were affected by the presence of the floor slab. Temperatures were uniform (within $1^{\circ} \mathrm{C}$ ) across the bottom flange and web, but the top flange temperature was less by up to several hundred degrees, because the slab acted as a heat sink (see Figure 4-6 to Figure 4-8).

As described in Chapter 2, the floor systems had a concrete slab on a corrugated steel deck. For Floor 8 and above, the overall concrete thickness was $140 \mathrm{~mm}$ (5.5 in.), with the corrugations being $75 \mathrm{~mm}$ (3 in.) deep. The FSI simulated these slabs as uniformly $100 \mathrm{~mm}$ (4 in.) thick. The thickness was subdivided into eight elements, each $12.7 \mathrm{~mm}\left(0.5 \mathrm{in}\right.$.) thick. For the north side of the $7^{\text {th }}$ floor, the overall concrete thickness was $200 \mathrm{~mm}$ ( $8 \mathrm{in}$.), with the corrugations being $75 \mathrm{~mm}$ (3 in.) deep. The south side had a formed $200 \mathrm{~mm}$ (8 in.) slab without a metal deck. The FSI simulated this slab as uniformly $200 \mathrm{~mm}$ (8 in.) thick. This thickness was also subdivided into eight elements, each 25 mm (1 in.) thick.

For each step, a set of thermal load data was generated to completely specify the thermal state of the lower 16 stories of the building. The thermal load data were in a format that was consistent with the structural models and could be readily read with the ANSYS finite element software to specify body loads (temperature and temperature gradient information) on the entire structure, for use in the simulations recounted in Chapter 11. ANSYS performed a linear interpolation between two consecutive thermal load steps. A second set of thermal load data was generated as input for the LS-DYNA simulations of the building collapse (Chapter 12).

The Investigation Team estimated the sensitivity of the thermostructural simulations to the temperatures developed from the fires. Accordingly, three different thermal response computations were performed that were consistent with a realistic and reasonable range of expected fires. Case A used the temperature data as obtained from the FDS simulation. Case B incremented the Case A gas temperatures by 10 percent. This increased the severity of the fire in three ways. It increased the local heat transfer to the structural members, it increased the area over which the structural members were heated, and it increased the chance of hot zone overlap on adjacent floors. A 10 percent increase or decrease in gas temperatures resulted in a roughly 30 percent increase or decrease in the heat flux to structural members. For example, a gas temperature of $1000{ }^{\circ} \mathrm{C}$ results in a heat flux to nearby objects of about $150 \mathrm{~kW} / \mathrm{m}^{2}$. A 10 percent increase in gas temperatures to $1100^{\circ} \mathrm{C}$ leads to a heat flux of about $200 \mathrm{~kW} / \mathrm{m}^{2}$; a $10 \%$ decrease in temperature leads to a heat flux of just over $100 \mathrm{~kW} / \mathrm{m}^{2}$. This range of thermal exposure is fairly broad, 
and typical of fully engulfing enclosure fires. Given the limited guidance from the visual evidence, the Investigation Team estimated that a 10 percent change was within the uncertainty in the extent and intensity of the fires. In Case $\mathrm{C}$, the Case A gas temperatures were decreased by 10 percent, again consistent with the expected range of realistic and reasonable fires in WTC 7 on September 11, 2001.

\subsubsection{Case A}

Two visualizations of the results were developed: with and without the opaque concrete floor slabs. Note that the simulations themselves always included the slabs.

Figure 10-2 shows the thermal data generated with FSI and subsequently transferred to the ANSYS and LS-DYNA structural models for analysis (Chapters 11 and 12). The figure shows the exterior and core columns extending from the ground level to Floor 16. The figure also shows the beams and concrete floor slabs. Only a fraction of the entire model is visible because of the concrete slabs. As noted above, the simulations showed essentially no thermal gradient across the thickness of the steel components. The depicted slab temperatures are in the midpoint of the uppermost thermal element. For the $7^{\text {th }}$ floor slab, this was approximately $12.5 \mathrm{~mm}$ ( $0.5 \mathrm{in}$.) below the top surface; for the other floors, this was approximately $6 \mathrm{~mm}(0.25 \mathrm{in}$.) below the top surface.

FSI generated temperature histories at 30 min intervals for the ANSYS structural analyses and at a single point in time (corresponding to the collapse initiating event) for the LSDYNA analyses. Due to differences in the ANSYS and LS-DYNA models, the thermal data were prepared separately for each analysis.

The ANSYS model, which was specifically developed to capture the effects of fire on the structural system of Floors 7 to 14, used beam elements to model the steel framing and shell elements with 5 layers to model the concrete slab (see Chapter 11). Five temperatures, evenly spaced through the slab depth, were provided at each node in the concrete slab shell elements to capture the nonlinear temperature profile through the depth of the slab. Since steel temperatures were nearly the same across column sections, a uniform temperature was supplied at each node of the columns. The beam elements could model a linear temperature gradient across the section, but a uniform temperature was determined to be a reasonable approximation for the temperature profile in the beam and girder sections. A linear gradient across the beam depth would have either underestimated the temperature across the web or would have overestimated the temperature in the bottom flange. Additionally, the top flange of the floor beams was located near the neutral axis of the composite floor section, and had little influence on the flexural response of the floor system. For these reasons, a uniform temperature across the depth of the beam and girder sections was selected.

The LS-DYNA model, which was specifically developed to capture the response of the 47 story building to an initiating event, primarily used shell elements to model the steel framing and concrete slab (see Chapter 12). The LS-DYNA model used the structural temperatures as an initial condition for the collapse progression analysis. A single set of temperatures was provided at the time that the ANSYS analysis predicted that a collapse initiating event was imminent. Since steel temperatures were nearly the same across column sections and approximated as uniform across the beam and girder sections, a single temperature was supplied for each node of the columns, girders, and floor beams. Since the LS-DYNA 
shell elements for the concrete slab had a single layer, the average slab temperature for the slab thickness was provided.

Figure 10-3 shows a view of the same 16 floor simulation from the northeast corner. Here, the concrete slabs have been removed in the image to allow a better view of the internal floor beams and columns.

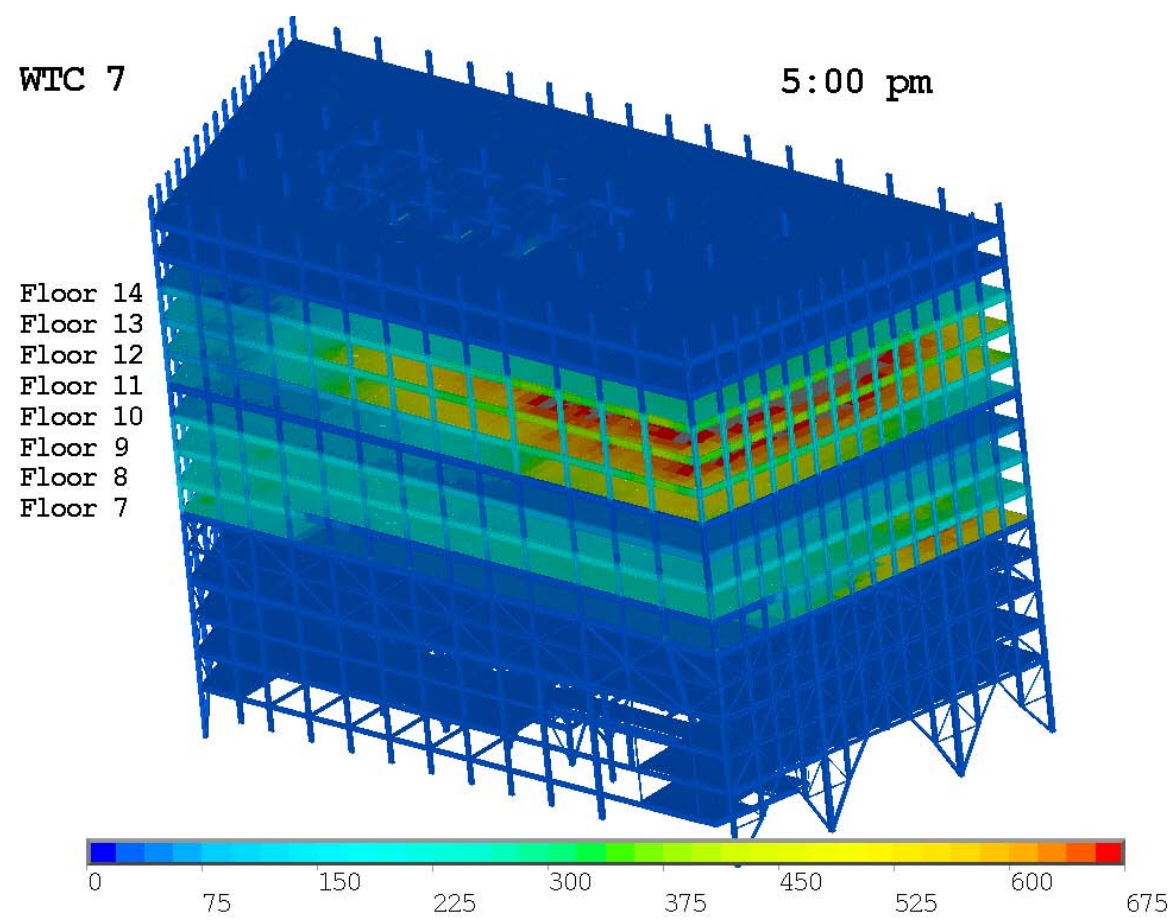

Figure 10-2. View from the southeast of the computed thermal loading of the 16 lower floors of WTC 7 at 5:00 p.m. (Case A).

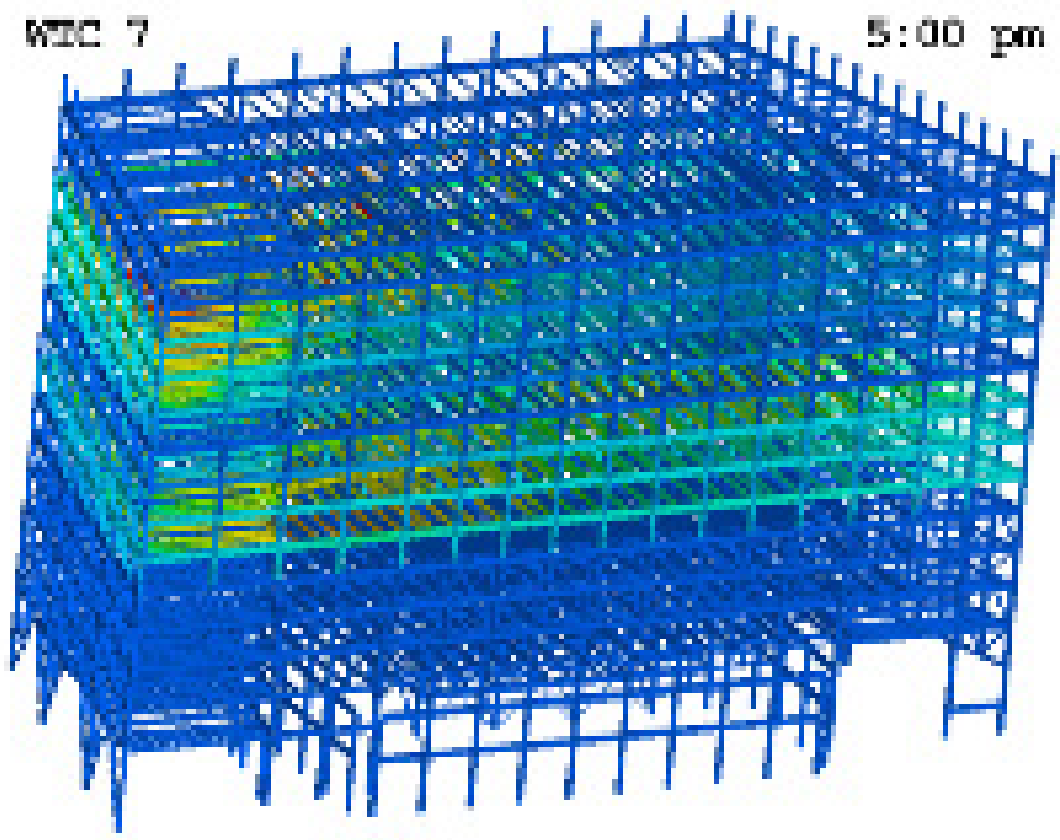

Figure 10-3. View from the northeast of the computed thermal loading of the 16 lower floors of WTC 7 at 5:00 p.m. (Case A, floor slabs removed). 
Figure 10-4 shows the thermal loading on the 16 floor model at 12 different instants in time. Each subfigure shows a view of the WTC 7 model from the southeast corner, similar to that shown in Figure 10-2. Each sub-figure shows the thermal state at the time stamp noted in the top right hand corner. The results are presented at half hour intervals, with the first sub-figure showing the thermal loading at 12:30 p.m.

Figure 10-5 shows the thermal loading on the 16 floor model as viewed from the northeast corner. Each sub-figure is similar to that shown in Figure 10-3. Thermal loading data are visually shown at half hour intervals, starting at 12:30 p.m. The concrete slab has been removed from the images to allow a more detailed view of the interior beams and columns.

The simulation results shown in Figure 10-4 and Figure 10-5 indicate that there was significant heating of the floor systems on Floors 7, 8, 9, 11, 12, 13 and 14. ${ }^{1}$ The floors below Floor 7, Floor 10, and the floors above Floor 14 did not heat significantly due to the absence of fire activity. The exterior columns and core columns also did not heat significantly on the fire floors. The results indicated that there was intense heating of the floor beams in the northeast corner after 3:30 pm, especially those on Floors 7, 8, 11,12 and 13.

In the following sections, FSI results are described on a floor-by-floor basis. The figures in each of the following sections are visual representations of the thermal state of that floor at specific instants in time.

\section{Floor 7}

Figure 10-6 and Figure 10-7 show the thermal response of Floor 7 at 12 different instants in time ranging from 12:30 p.m. to 6:00 p.m. at half hour intervals. The exterior and core columns above the $7^{\text {th }}$ floor were subjected to fires on the $7^{\text {th }}$ floor, while the columns below the $7^{\text {th }}$ floor were subjected to the thermal environment on the $6^{\text {th }}$ floor. The floor beams for the $7^{\text {th }}$ floor were also subject to the thermal environment on the $6^{\text {th }}$ floor. As indicated earlier in this Chapter, it is unlikely that there was a significant fire on the $6^{\text {th }}$ floor, so the floor beams and the columns below the $7^{\text {th }}$ floor would have been at about ambient temperature, and the concrete slab would have been subjected to heating only from a fire on the $7^{\text {th }}$ floor.

Late in the day, the most intense heating was in the northeast sector and the center of the south wall, just east of where there was extensive debris damage.

The thermal response of the exterior and core columns was highly dependent on the thickness of the insulation, the shape and size of the column, and, to a lesser extent, on the fire growth and spread pattern. The simulated exterior and core columns were covered with a mean insulation thickness of $22 \mathrm{~mm}$ (7/8 in.), which resulted in only a small increase in the temperature of the columns. The maximum temperature in the exterior and core column simulations at 6:00 p.m. was $100{ }^{\circ} \mathrm{C}$ to $200{ }^{\circ} \mathrm{C}$.

The $100 \mathrm{~mm}$ (4 in.) thick concrete slab was protected by $9.5 \mathrm{~mm}$ (3/8 in.) thick insulation on its bottom face. The top surface of the concrete slab indicated high temperatures, above $675^{\circ} \mathrm{C}$, during the course of the simulation. Since the concrete slab had low thermal conductivity, there was a sharp temperature

\footnotetext{
${ }^{1}$ In the graphics, a concrete floor slab is labeled with the number of its floor. The beams that support $\mathrm{t}$ he slab are labeled with the number of the floor below. Thus, e.g., the $11^{\text {th }}$ floor beams stay cool because there was no fire on the $10^{\text {th }}$ floor, while the $11^{\text {th }}$ floor slab is heated by the fire on the $11^{\text {th }}$ floor.
} 
gradient through the thickness of the concrete slab. The computed temperatures on the bottom of the slab and in the floor beams were barely above ambient.

\section{Floor 8}

Figure 10-8 and Figure 10-9 show the thermal response of Floor 8 at 12 different instants in time ranging from 12:30 p.m. to 6:00 p.m. at half hour intervals. The pattern of the heated structural components was similar to the $7^{\text {th }}$ floor, but the temperature increases in the concrete slab were much smaller. This was a result of the fire on the west side of the $8^{\text {th }}$ floor being less intense until midafternoon.

During the course of the simulation, the $8^{\text {th }}$ floor beams heated up significantly due to the fire on the $7^{\text {th }}$ floor. Initial heating of the floor beams was observed in the southwest corner at 1:00 p.m. At approximately 2:00 p.m., the floor beams in the northwest corner exhibited temperatures in the range of $500^{\circ}$ to $550^{\circ} \mathrm{C}$. As the fires evolved and spread on Floor 7, the central portion of the floor beams heated up as observed at 4:00 p.m. Toward the end of the simulation, the fires were concentrated in the northeast corner, in the vicinity of Column 79.

The increased temperatures on the top of the floor slab followed the fire as it moved across the north face from west to east. The temperatures in the northeast corner floor beams were above $675{ }^{\circ} \mathrm{C}$ near 5:00 p.m.

The insulation on the interior and exterior columns functioned as intended. The column temperatures rose by less than $100{ }^{\circ} \mathrm{C}$ in the simulation.

\section{Floor 9}

Figure 10-10 and Figure 10-11 show the thermal response of Floor 9. The timing and intensity of the floor slab heating relative to the $8^{\text {th }}$ floor heating were consistent with the FDS simulation of the $9^{\text {th }}$ floor fire being the same as for the $8^{\text {th }}$ floor, but delayed by one hour. The column temperatures rose less than $100{ }^{\circ} \mathrm{C}$. The temperature rise in the floor beams was lower than that on the $8^{\text {th }}$ floor, reflecting the shorter duration $8^{\text {th }}$ floor fire having less time to heat the steel through the insulation layer.

\section{Floor 10}

Figure 10-12 and Figure 10-13 show the thermal response of the $10^{\text {th }}$ floor. Due to the absence of a fire on this floor, the floor slab and the columns were heated only by conduction and remain relatively cool. The peak floor beam temperatures, resulting from the fire on the $9^{\text {th }}$ floor, did not exceed about $400{ }^{\circ} \mathrm{C}$.

\section{Floor 11}

Figure $10-14$ and Figure $10-15$ show the thermal response of the $11^{\text {th }}$ floor. In Figure $10-15$, the cold floor beams reflected the absence of a fire on the $10^{\text {th }}$ floor. The fire on the $11^{\text {th }}$ floor caused only a modest temperature rise in the insulated columns. The temperature on the top of the floor slab approached $600{ }^{\circ} \mathrm{C}$ on the east side of the floor. 


\section{Floor 12}

Figure 10-16 shows that the intense fire on this floor resulted in the most severe heating of a floor slab. Peak temperatures reached over $675^{\circ} \mathrm{C}$ on much of the east side and the east portion of the south side of the floor. These temperatures remained high for about $2 \mathrm{~h}$. Figure 10-17 shows that the floor beams, heated by the fire on the $11^{\text {th }}$ floor below, reached similar temperatures in these same locations.

\section{Floor 13}

Figure 10-18 shows the severe heating of the top of the $13^{\text {th }}$ floor slab. The temperature pattern was similar to that on the $12^{\text {th }}$ floor slab one-half hour earlier, as expected from the manner in which the $13^{\text {th }}$ floor fire was simulated. The highest column temperatures were about $300^{\circ} \mathrm{C}$, reflecting the effectiveness of the insulation. Figure 10-19 shows that many of the floor beams in the southeast half of the floor reached temperatures around $600{ }^{\circ} \mathrm{C}$ and remained that hot for over an hour.

The computed thermal response of the perimeter and core columns was highly dependent on the thickness of the insulation, the shape and size of the column, and to a lesser extent, on the fire growth and spread pattern. The perimeter and core columns were covered with a mean fireproofing thickness of 7/8 in., which resulted in only a very moderate increase in the temperature of the columns. The maximum perimeter and core column temperature at 5:00 p.m. was between $100{ }^{\circ} \mathrm{C}$ to $200{ }^{\circ} \mathrm{C}$, depending on its location.

\section{Floor 14}

Figure 10-20 provides an example of the degree of conductive heat transfer through the floor slab. With no fire on the $14^{\text {th }}$ floor, but a severe fire on the $13^{\text {th }}$ floor, the temperature on the top of the slab rose only about $100{ }^{\circ} \mathrm{C}$ by the end of the simulation. The temperature rise in the floor beams in Figure 10-21 was as expected from a fire on the $13^{\text {th }}$ floor that was equal to the $12^{\text {th }}$ floor fire displaced one-half hour earlier. 


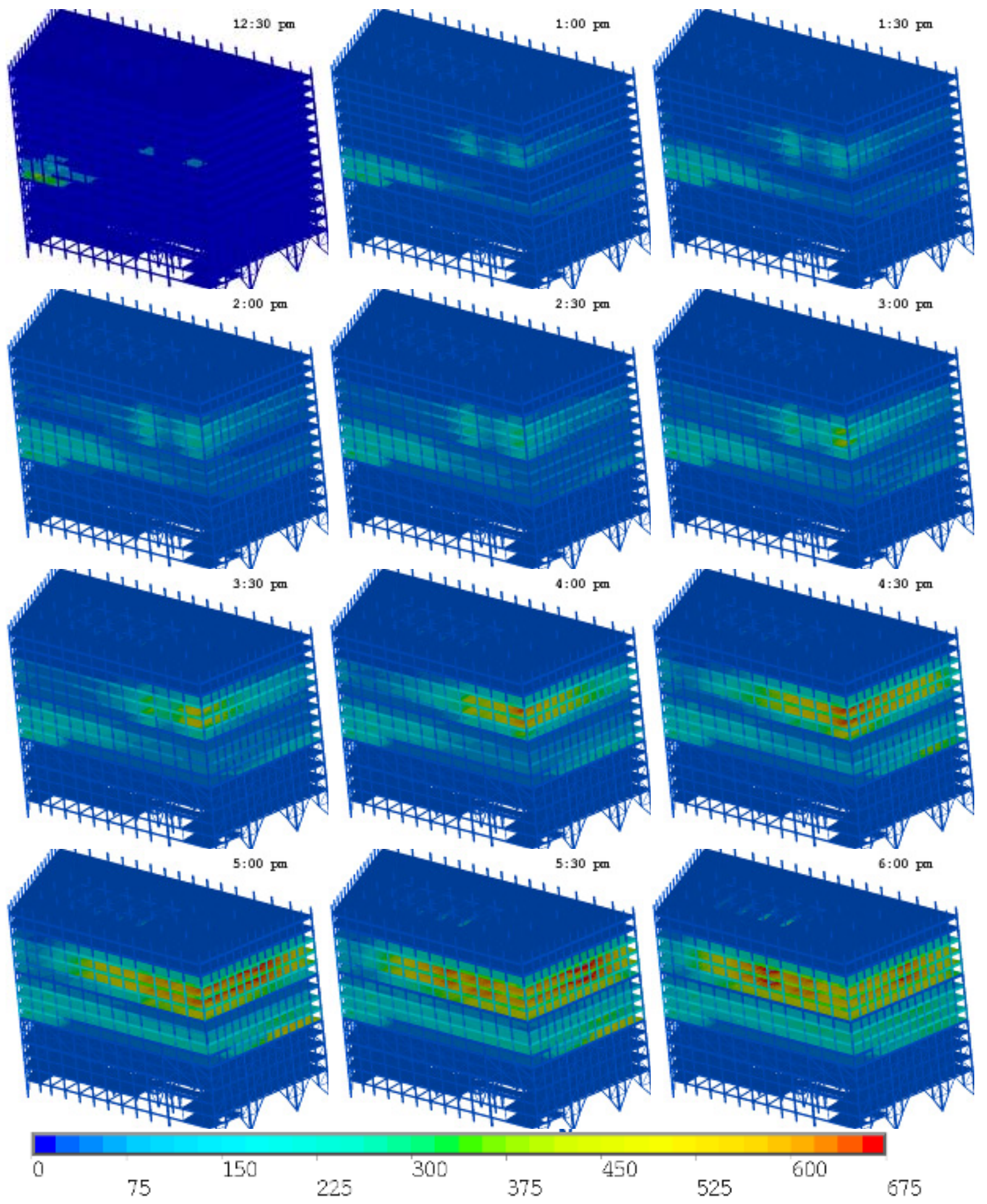

Figure 10-4. View from the southeast of the computed thermal loading of the lower 16 floors of WTC 7 at 12 different instants in time (Case A). 

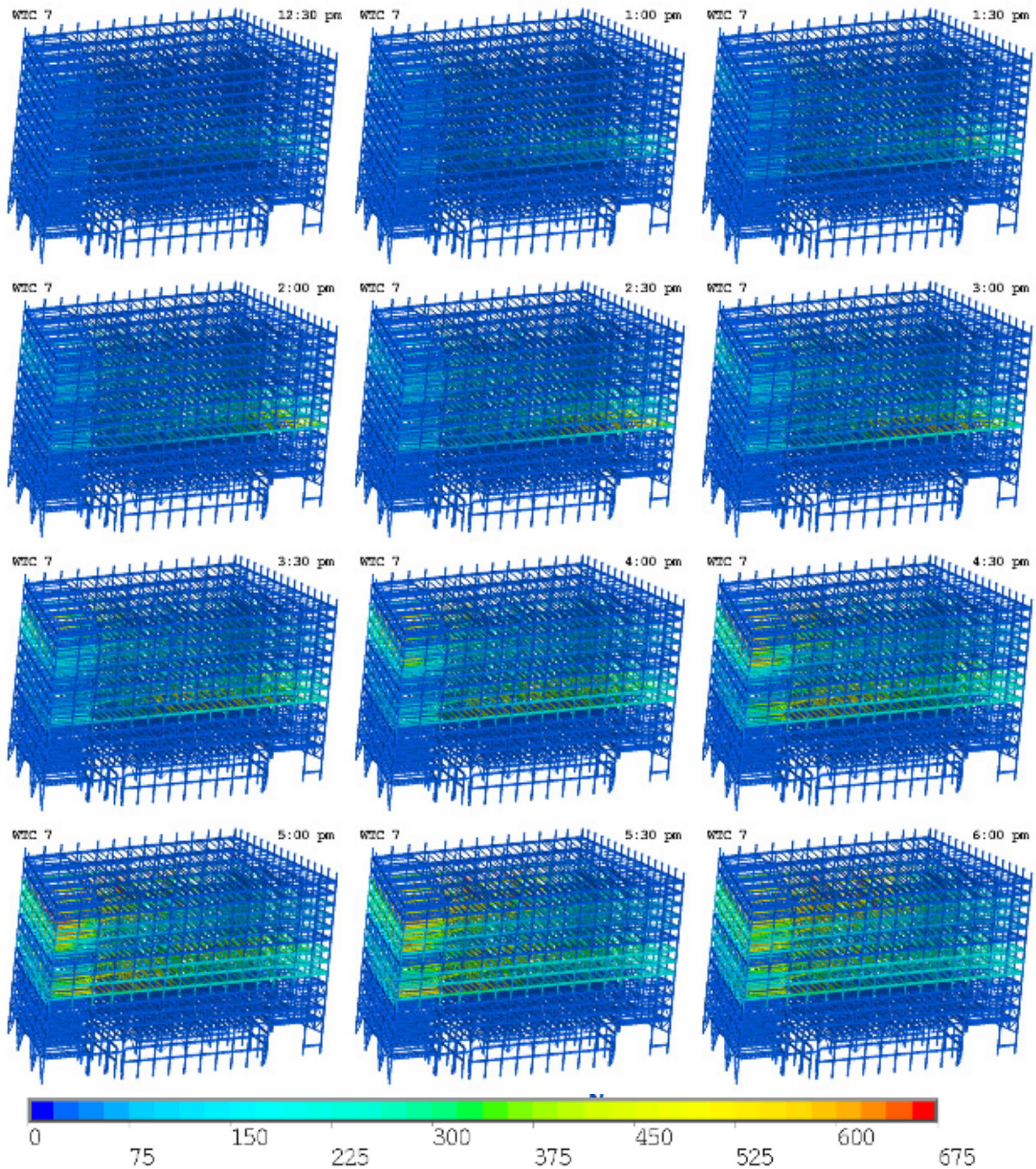

225

300

375

450

525

600

675

Figure 10-5. View from the northeast of the computed thermal loading of the lower 16 floors of WTC 7 at 12 different instants in time (Case A, floor slabs removed). 


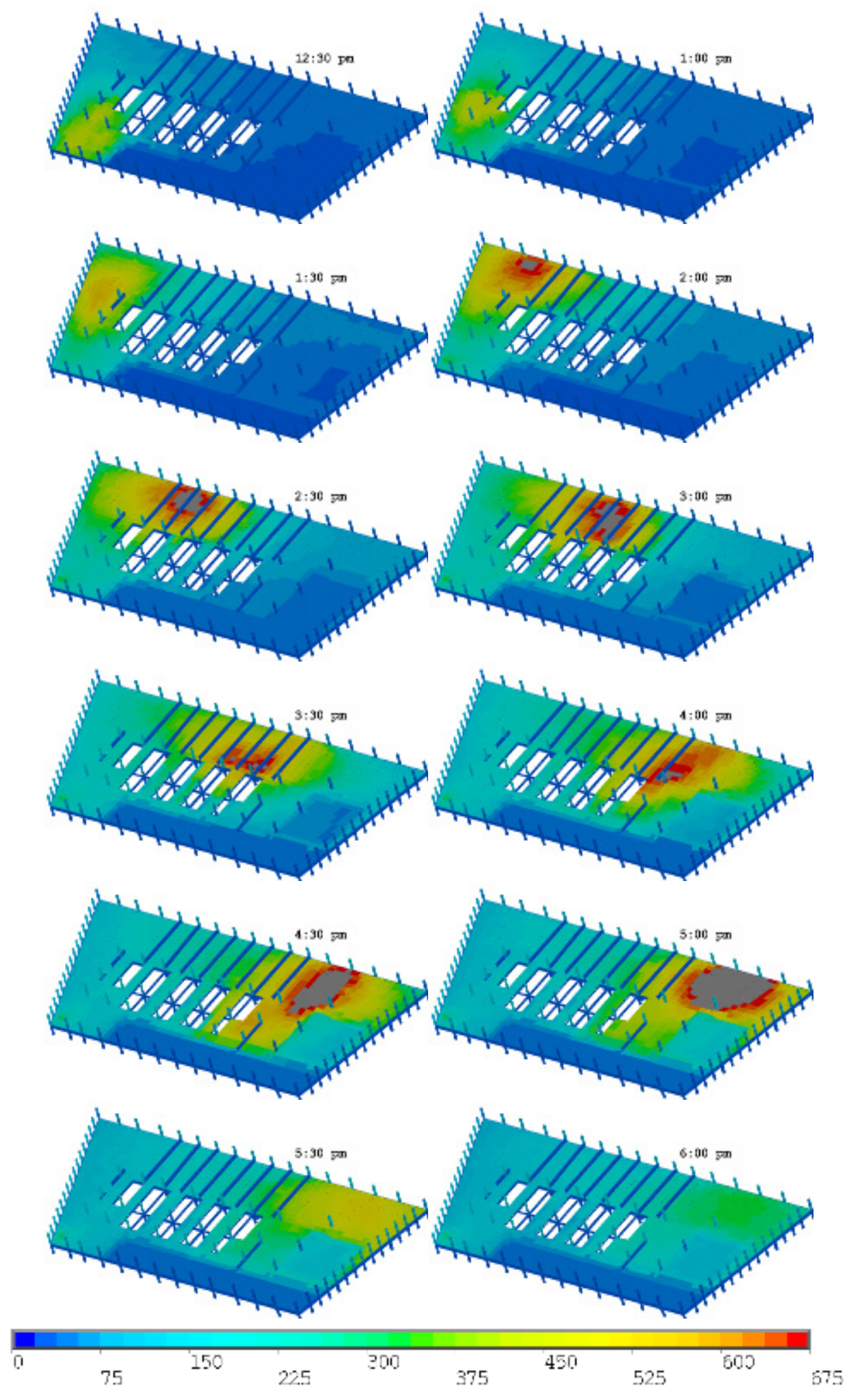

Figure 10-6. Computed temperature distribution $\left({ }^{\circ} \mathrm{C}\right)$ in the top layer of the concrete slab of Floor 7 at 12 different instants in time (Case A). 


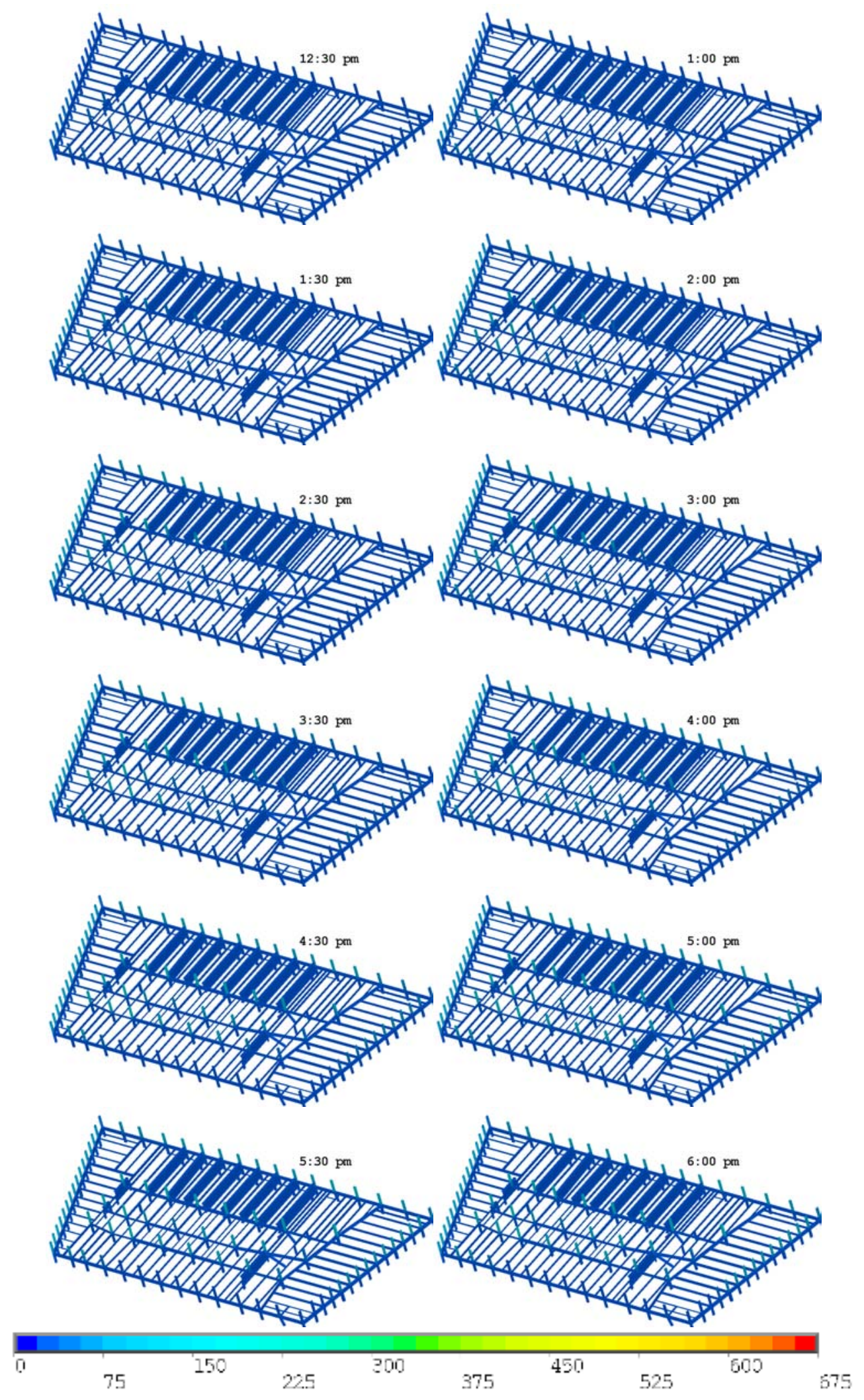

Figure 10-7. Computed temperature distribution $\left({ }^{\circ} \mathrm{C}\right)$ on the floor beams of Floor 7 at 12 different instants in time (Case $A$, floor slab removed). 


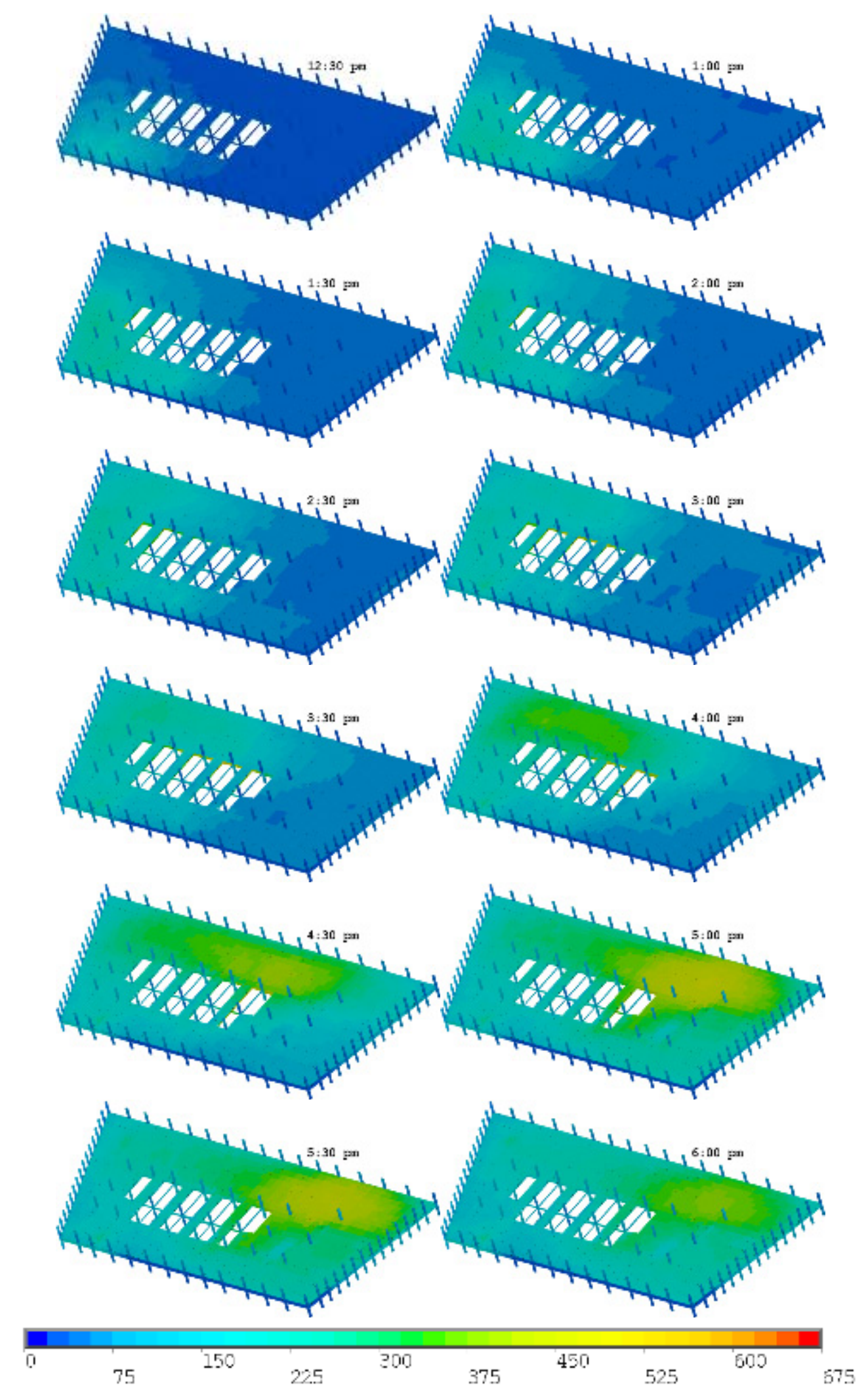

Figure 10-8. Computed temperature distribution $\left({ }^{\circ} \mathrm{C}\right)$ in the top layer of the concrete slab of Floor 8 at 12 different instants in time (Case A). 


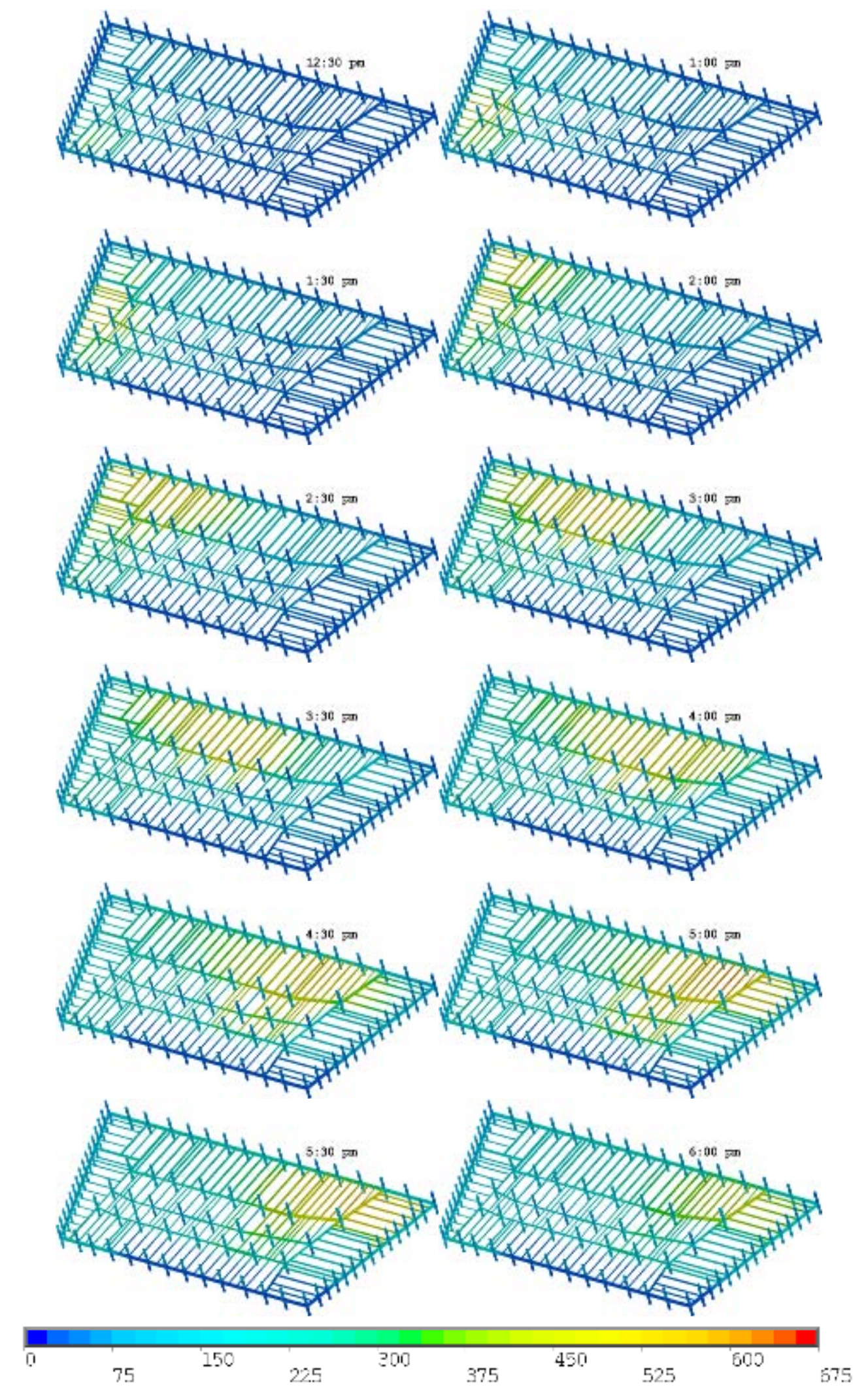

Figure 10-9. Computed temperature distribution $\left({ }^{\circ} \mathrm{C}\right)$ on the floor beams of Floor 8 at 12 different instants in time (Case A, floor slab removed). 


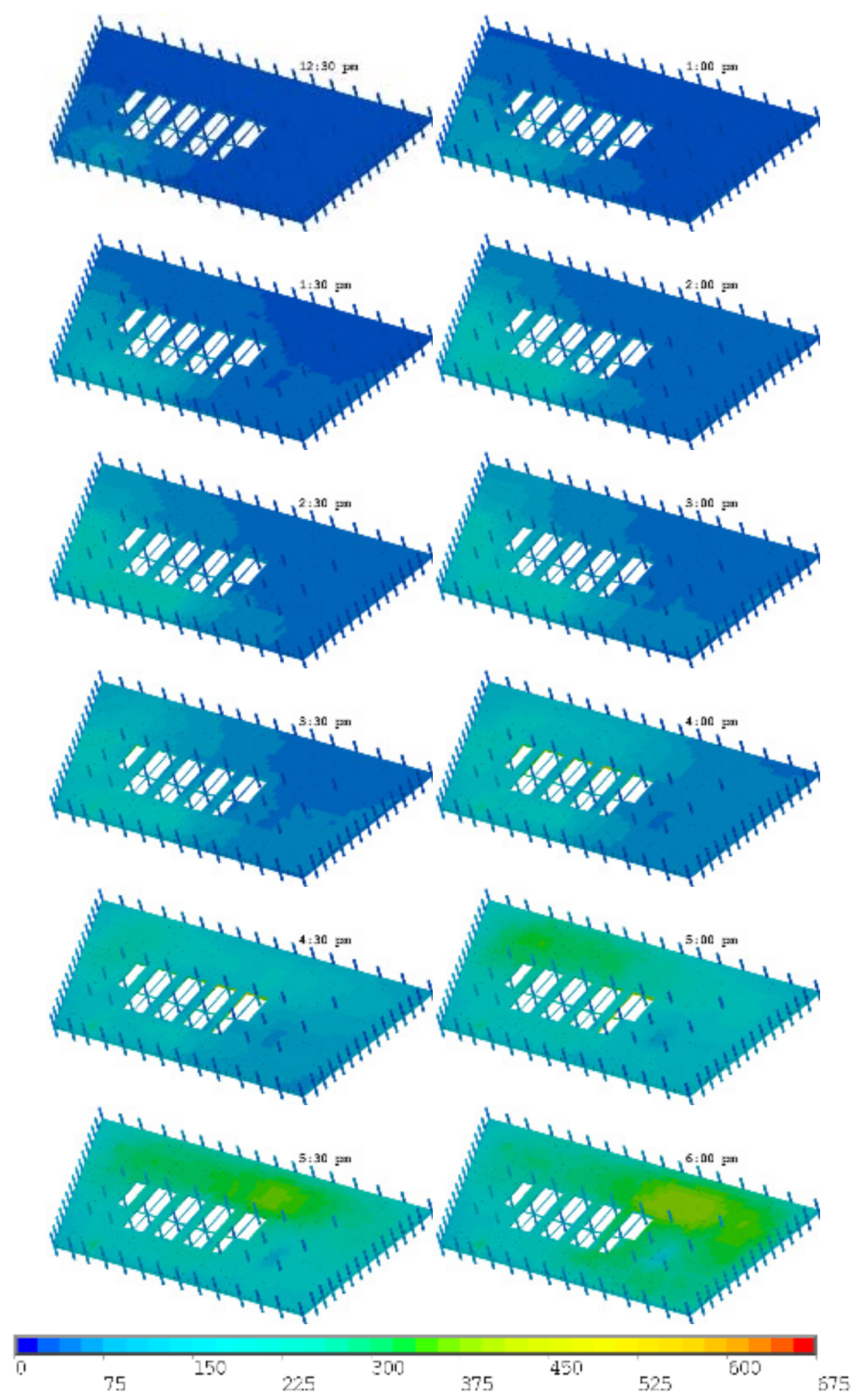

Figure 10-10. Computed temperature distribution $\left({ }^{\circ} \mathrm{C}\right)$ in the top layer of the concrete slab of Floor 9 at 12 different instants in time (Case A). 


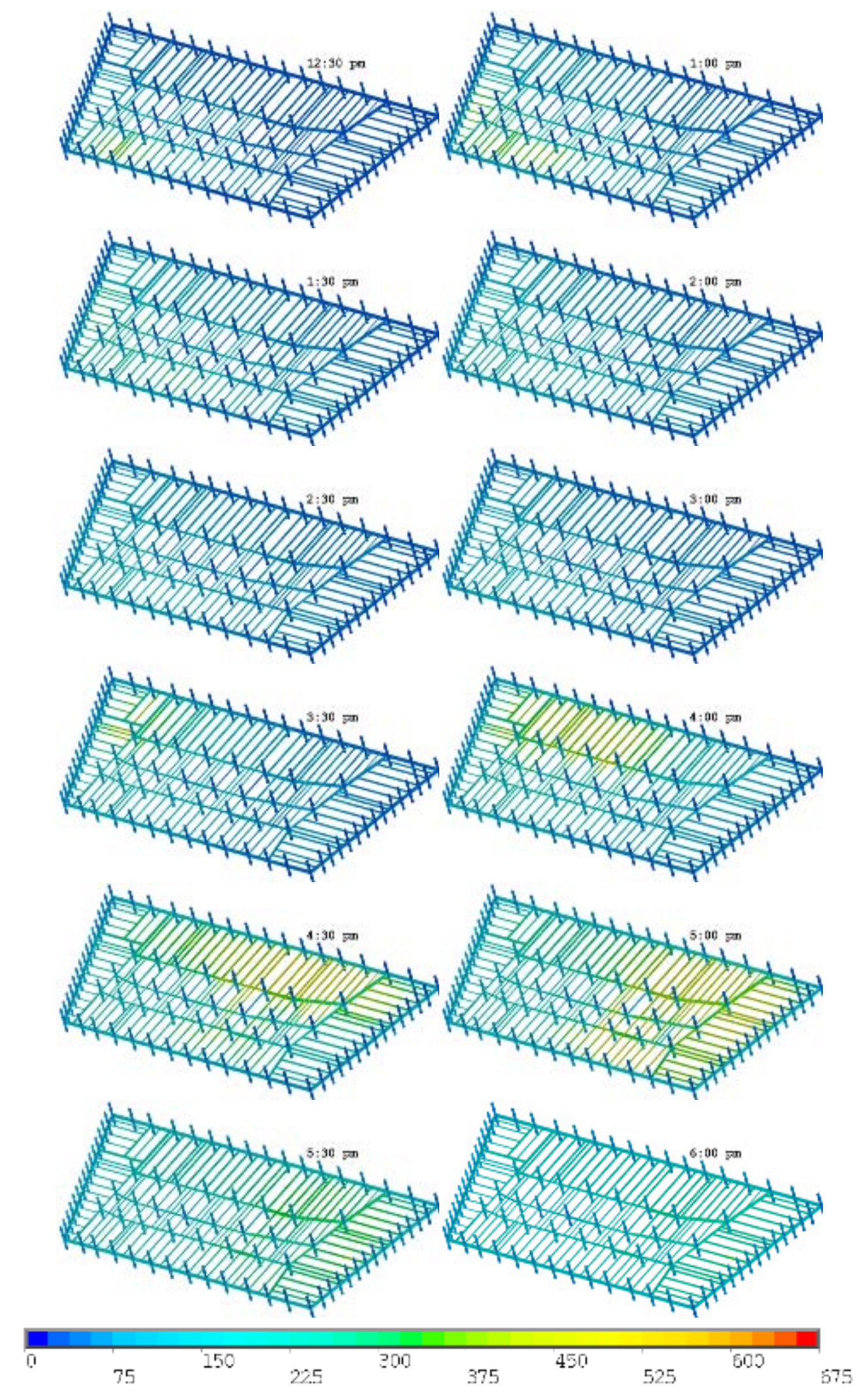

Figure 10-11. Computed temperature distribution $\left({ }^{\circ} \mathrm{C}\right)$ on the floor beams of Floor 9 of WTC 7 at 12 different instants in time (Case A, floor slab removed). 

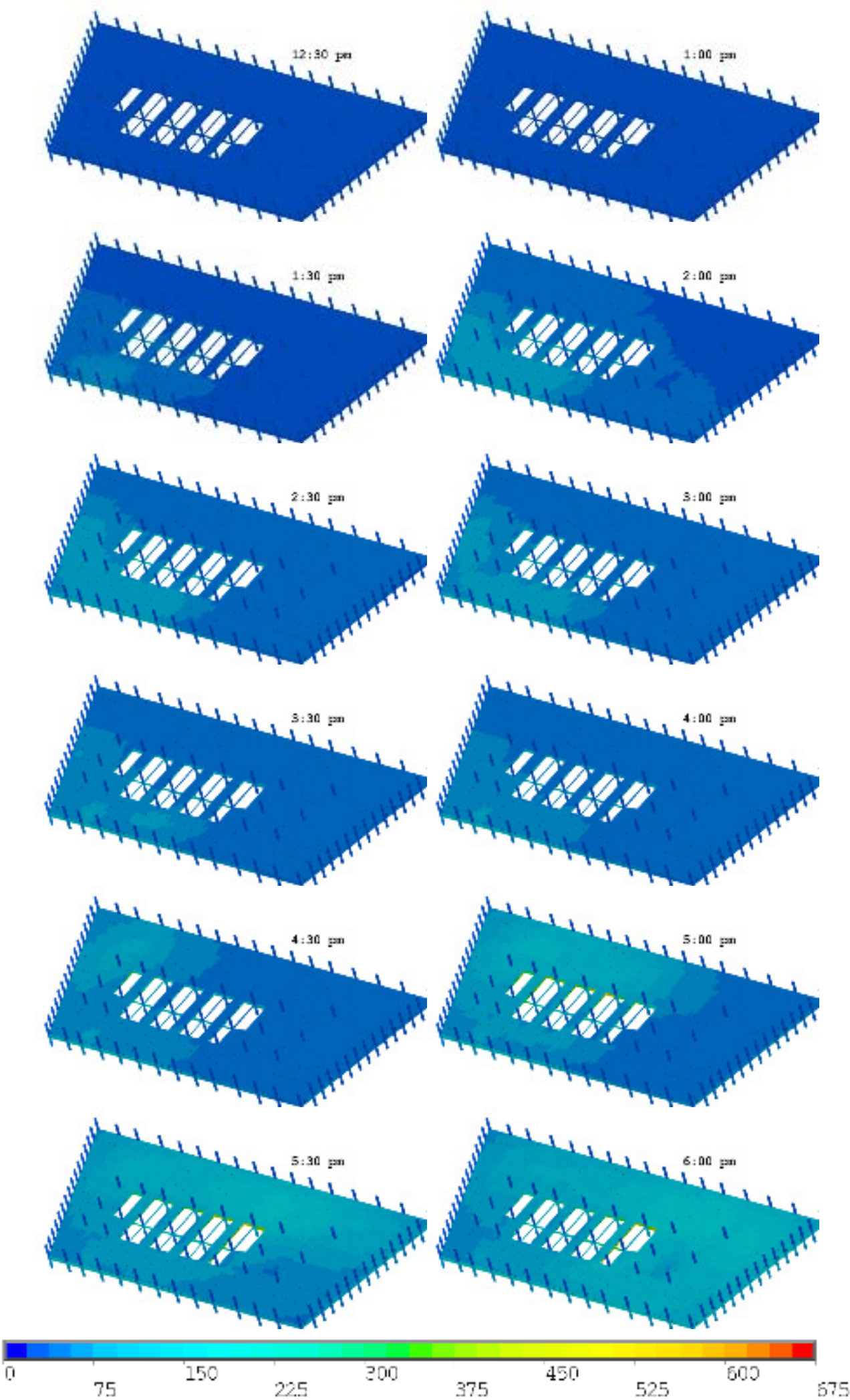

Figure 10-12. Computed temperature distribution $\left({ }^{\circ} \mathrm{C}\right)$ in the top layer of the concrete slab of Floor 10 at 12 different instants in time (Case A). 


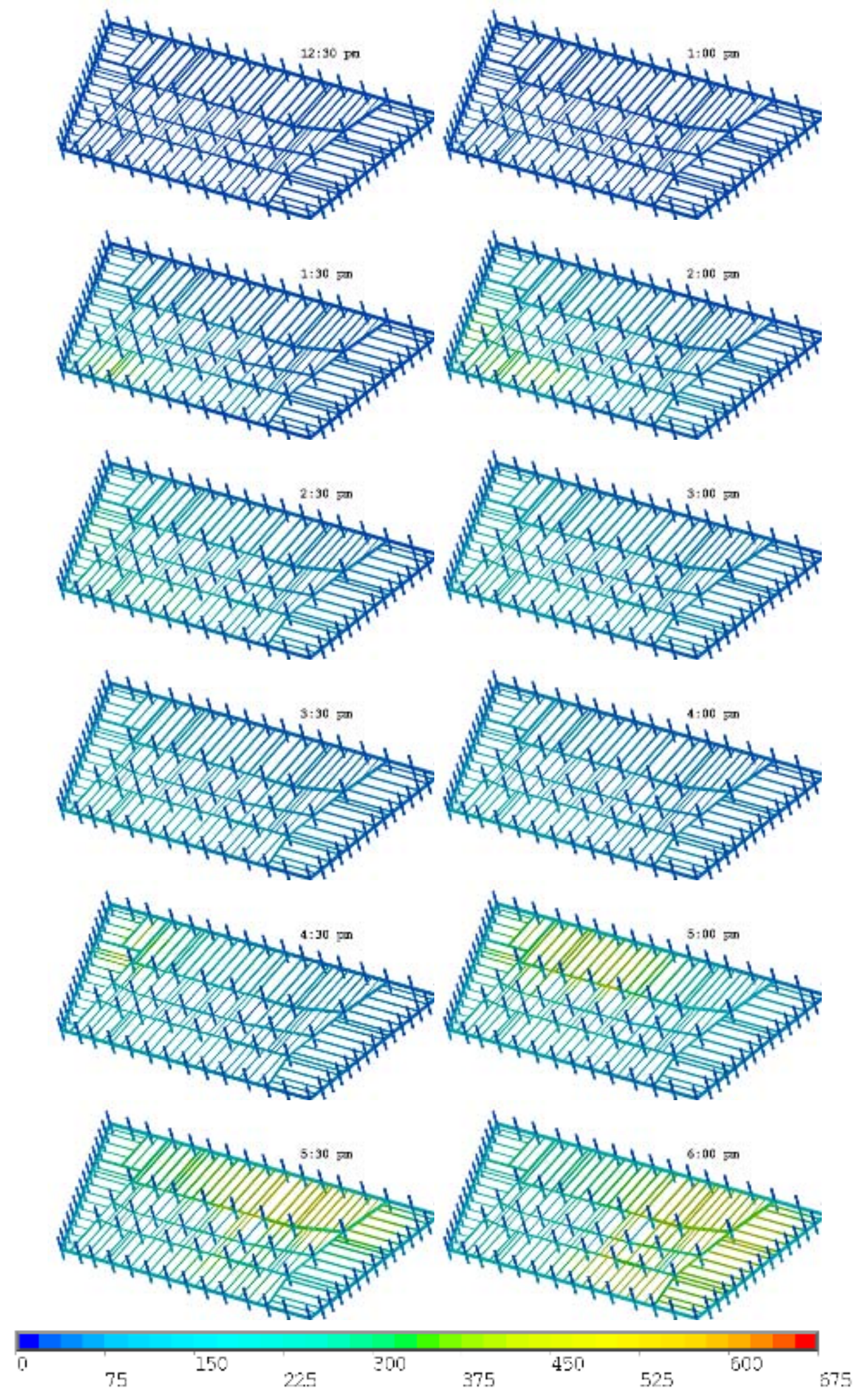

Figure 10-13. Computed temperature distribution $\left({ }^{\circ} \mathrm{C}\right)$ on the floor beams of Floor 10 of WTC 7 at 12 different instants in time (Case A, floor slab removed). 


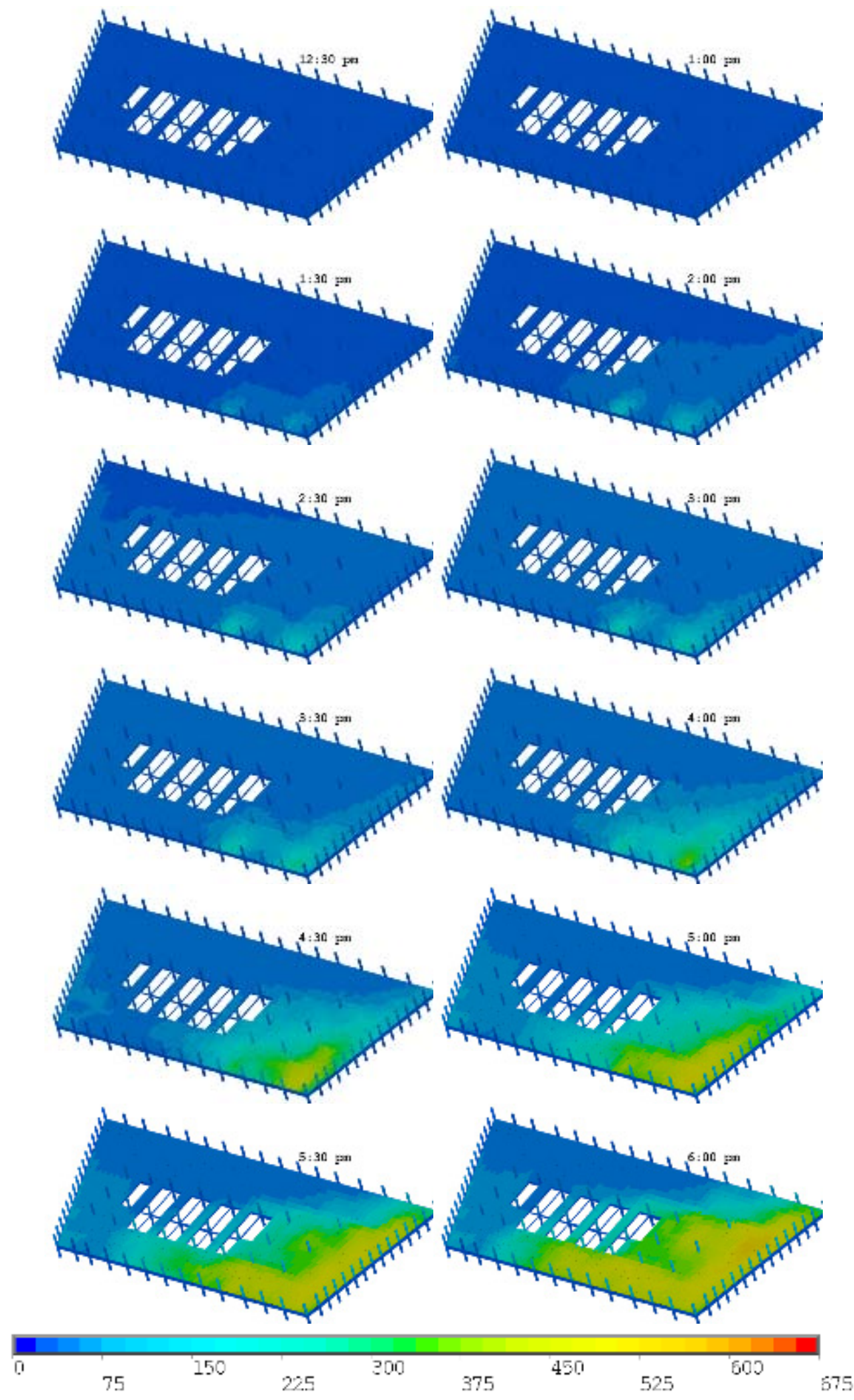

Figure 10-14. Computed temperature distribution $\left({ }^{\circ} \mathrm{C}\right)$ in the top layer of the concrete slab of Floor 11 at 12 different instants in time (Case A). 


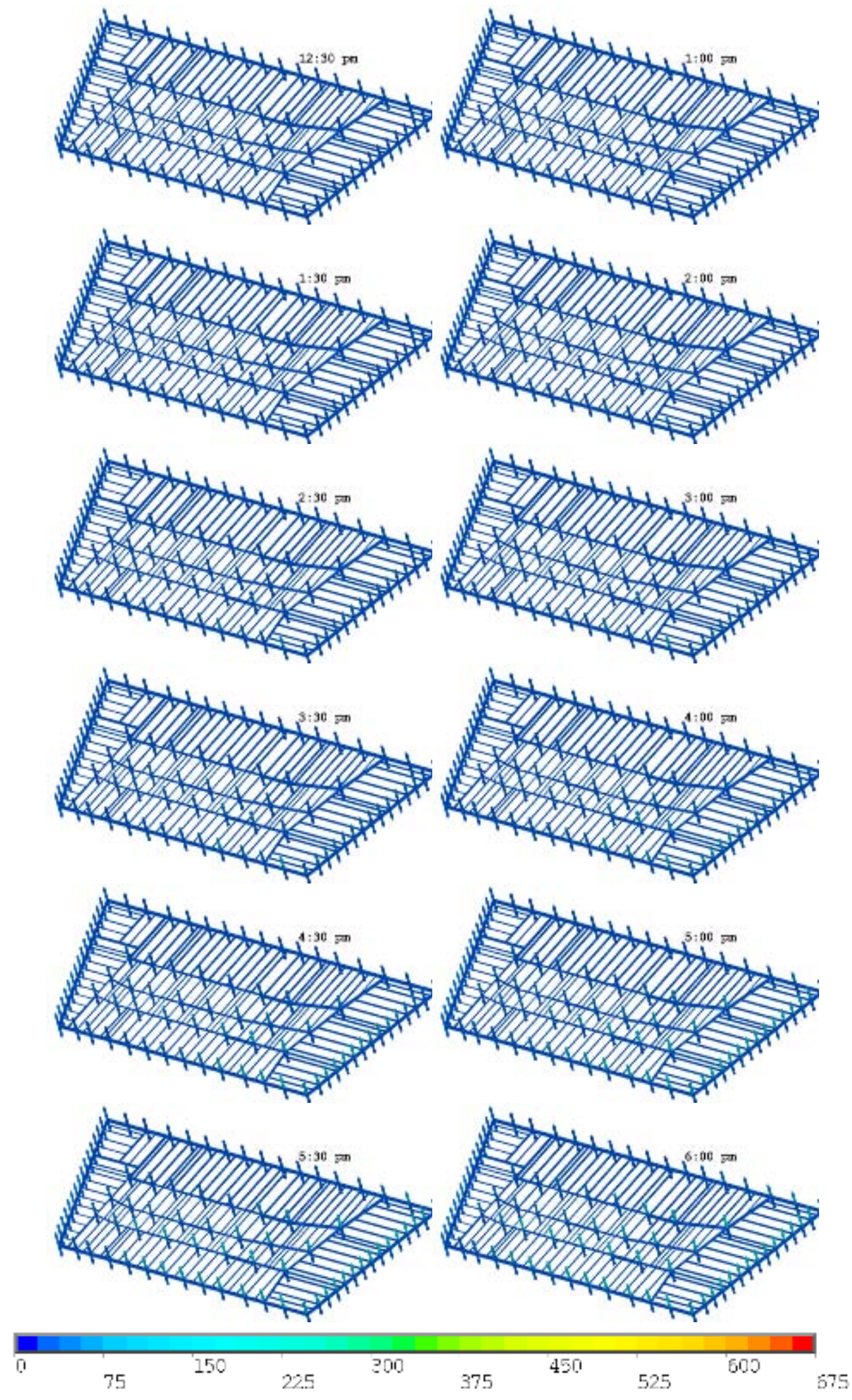

Figure 10-15. Computed temperature distribution $\left({ }^{\circ} \mathrm{C}\right)$ on the floor beams of Floor 11 at 12 different instants in time (Case $A$, floor slab removed). 

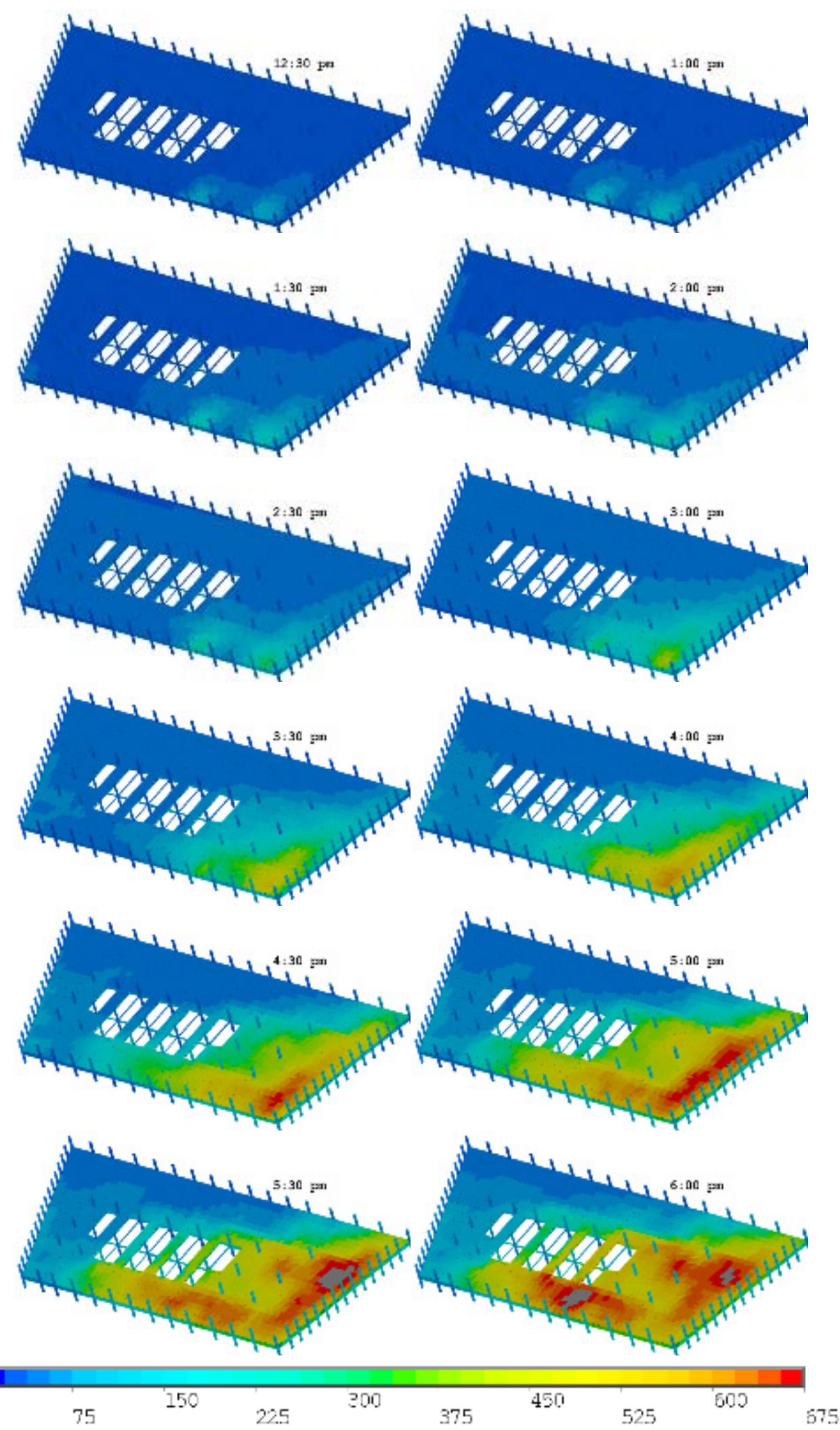

Figure 10-16. Computed temperature distribution $\left({ }^{\circ} \mathrm{C}\right)$ in the top layer of the concrete slab of Floor 12 at 12 different instants in time (Case A). 


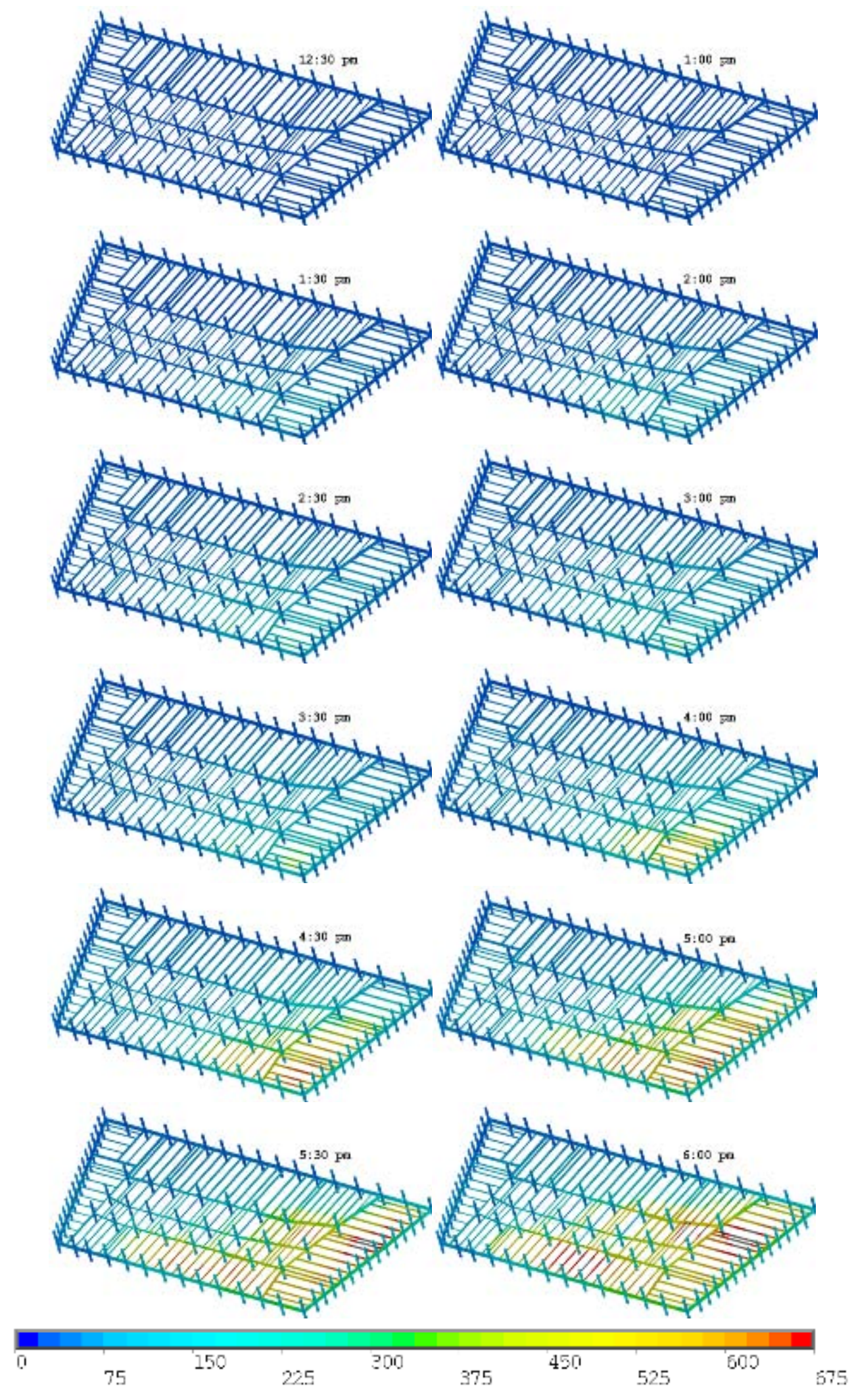

Figure 10-17. Computed temperature distribution $\left({ }^{\circ} \mathrm{C}\right)$ on the floor beams of Floor 12 at 12 different instants in time (Case $A$, floor slab removed). 

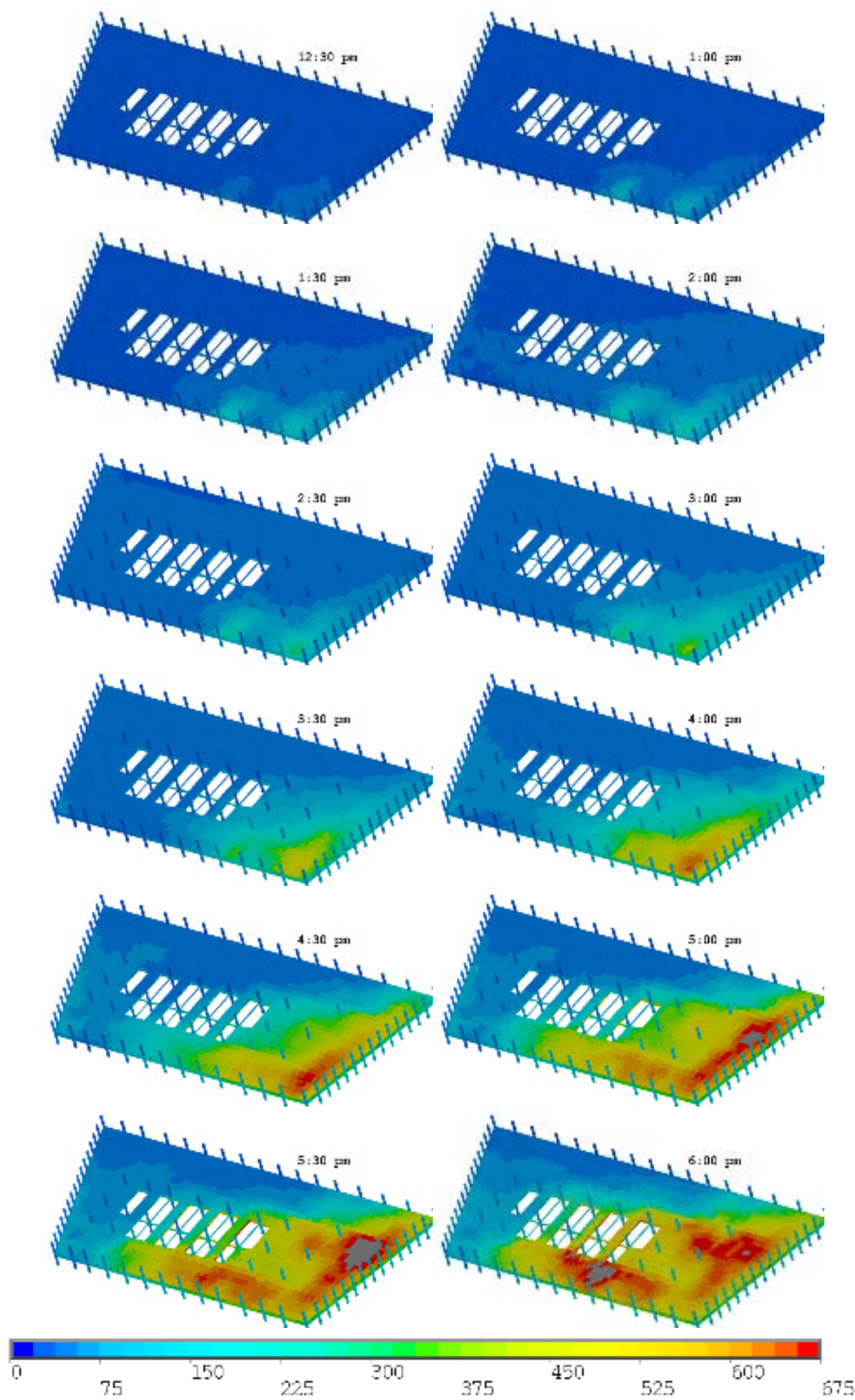

Figure 10-18. Computed temperature distribution $\left({ }^{\circ} \mathrm{C}\right)$ in the top layer of the concrete slab of Floor 13 at 12 different instants in time (Case A). 


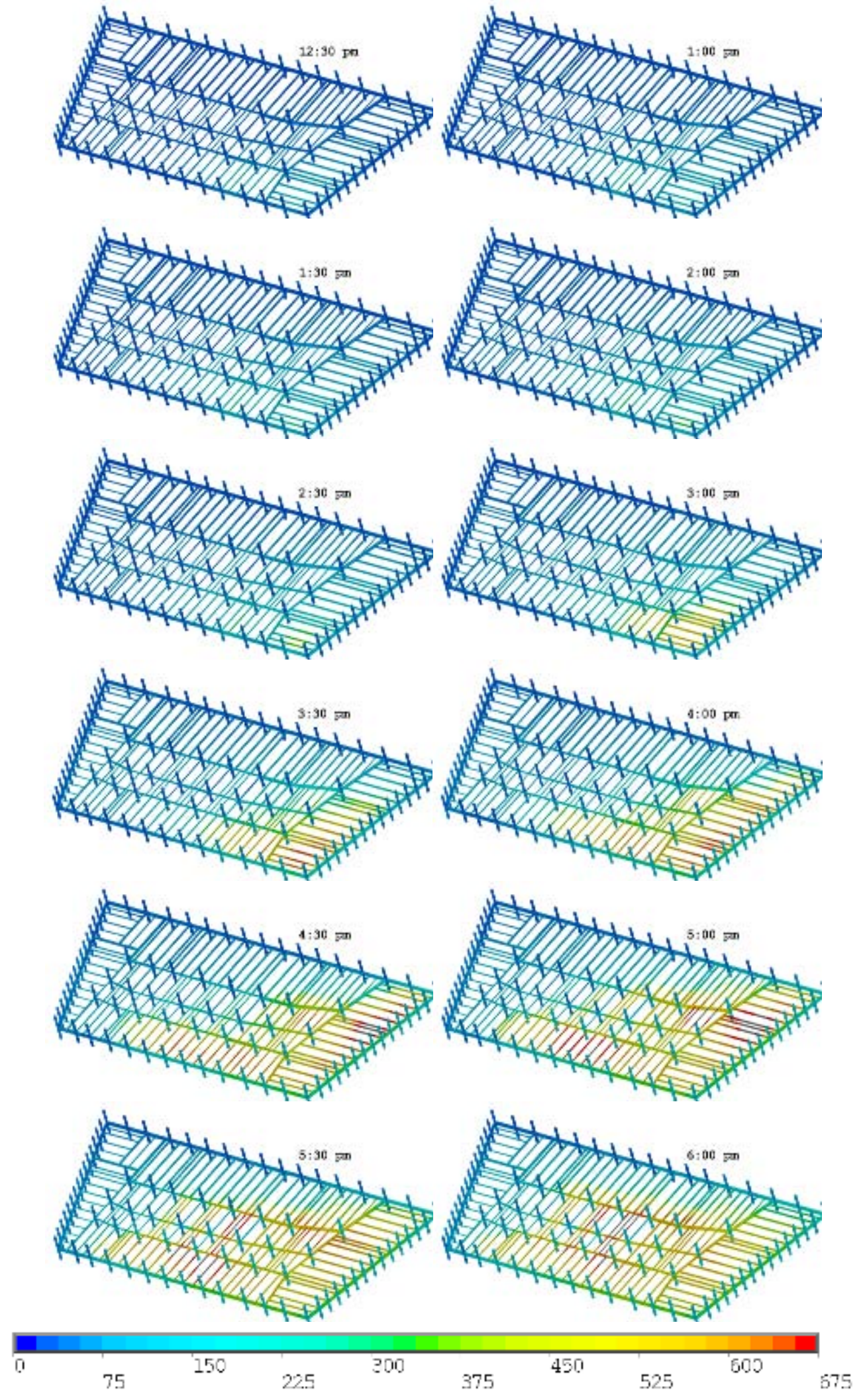

Figure 10-19. Computed temperature distribution $\left({ }^{\circ} \mathrm{C}\right)$ on the floor beams of Floor 13 at 12 different instants in time (Case $A$, floor slab removed). 


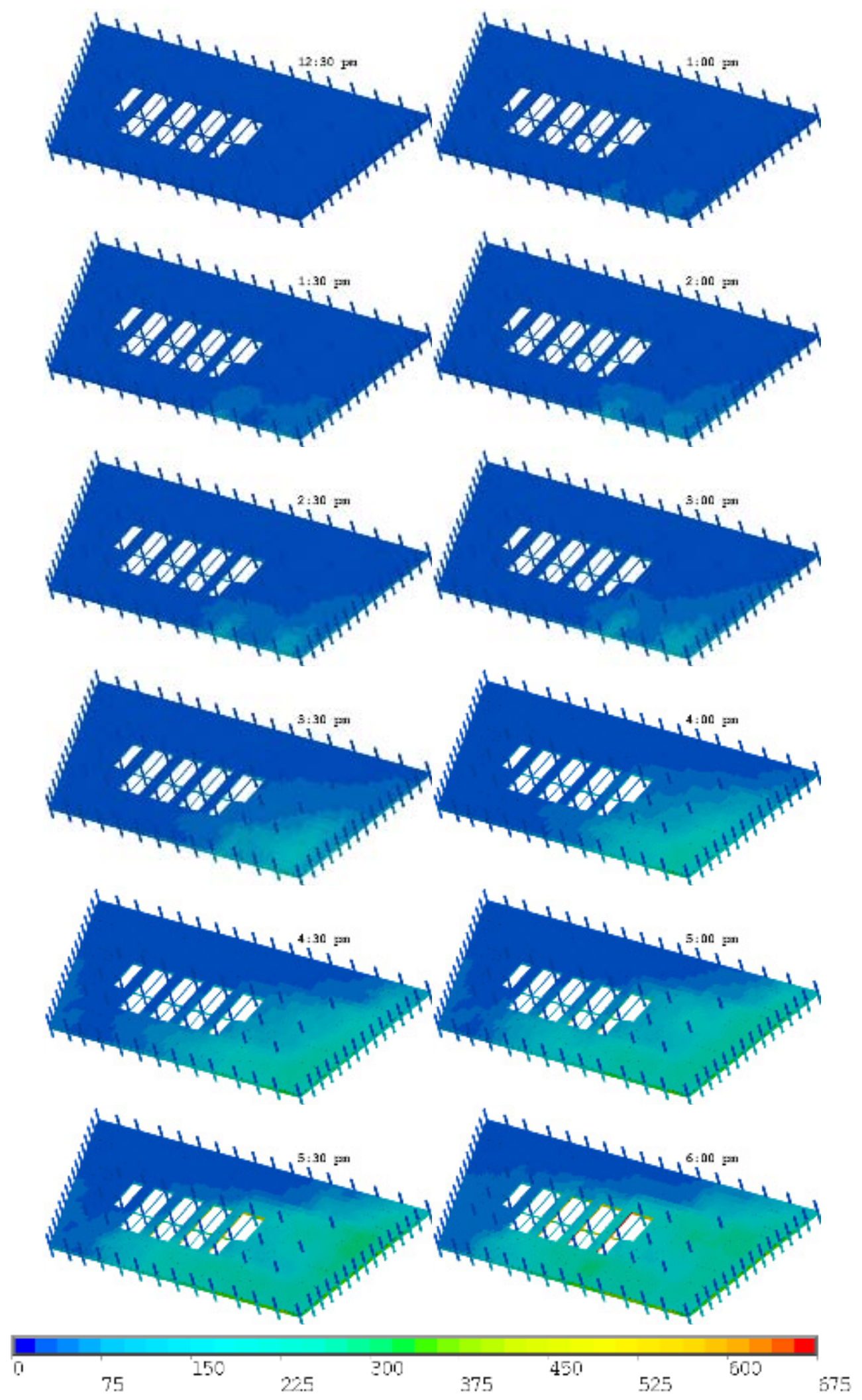

Figure 10-20. Computed temperature distribution $\left({ }^{\circ} \mathrm{C}\right)$ in the top layer of the concrete slab of Floor 14 at 12 different instants in time (Case A). 


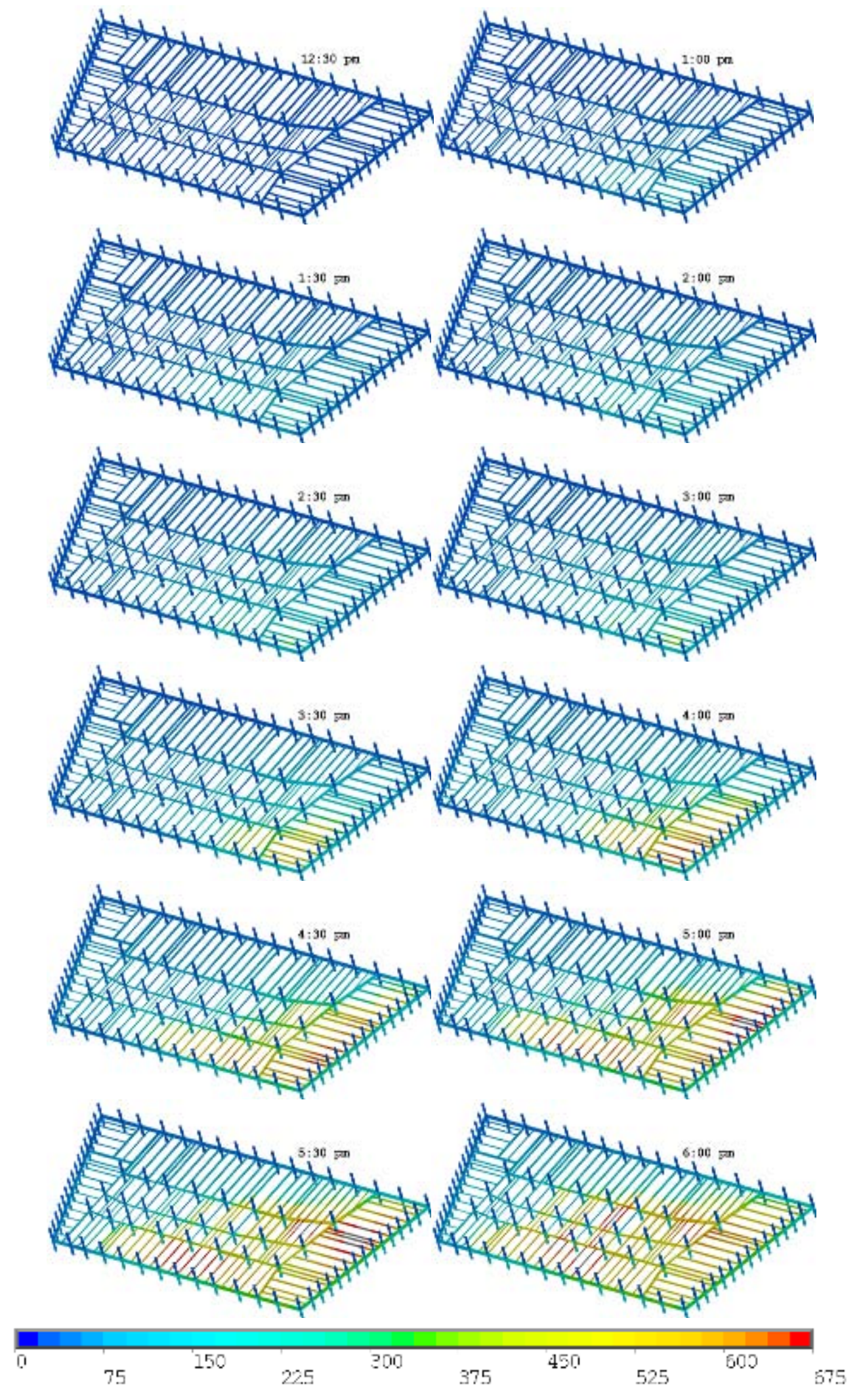

Figure 10-21. Computed temperature distribution $\left({ }^{\circ} \mathrm{C}\right)$ on the floor beams of Floor 14 at 12 different instants in time (Case $A$, floor slab removed). 


\subsubsection{Case B}

For Case B, the temperature increase at each location on Floors 7 through 14 was assumed to be 10 percent higher than that computed from the FDS simulation of Case A, which was within the expected range of reasonable and realistic fire-generated temperatures. Figure 10-22 and Figure 10-23 compare the temperatures of the building at two times for these two cases. Case A is on the left, and Case B is on the right. As expected, Case B resulted in mildly higher temperatures in the steel and concrete, wider hot zones, and greater overlap of hot zones between adjacent floors.
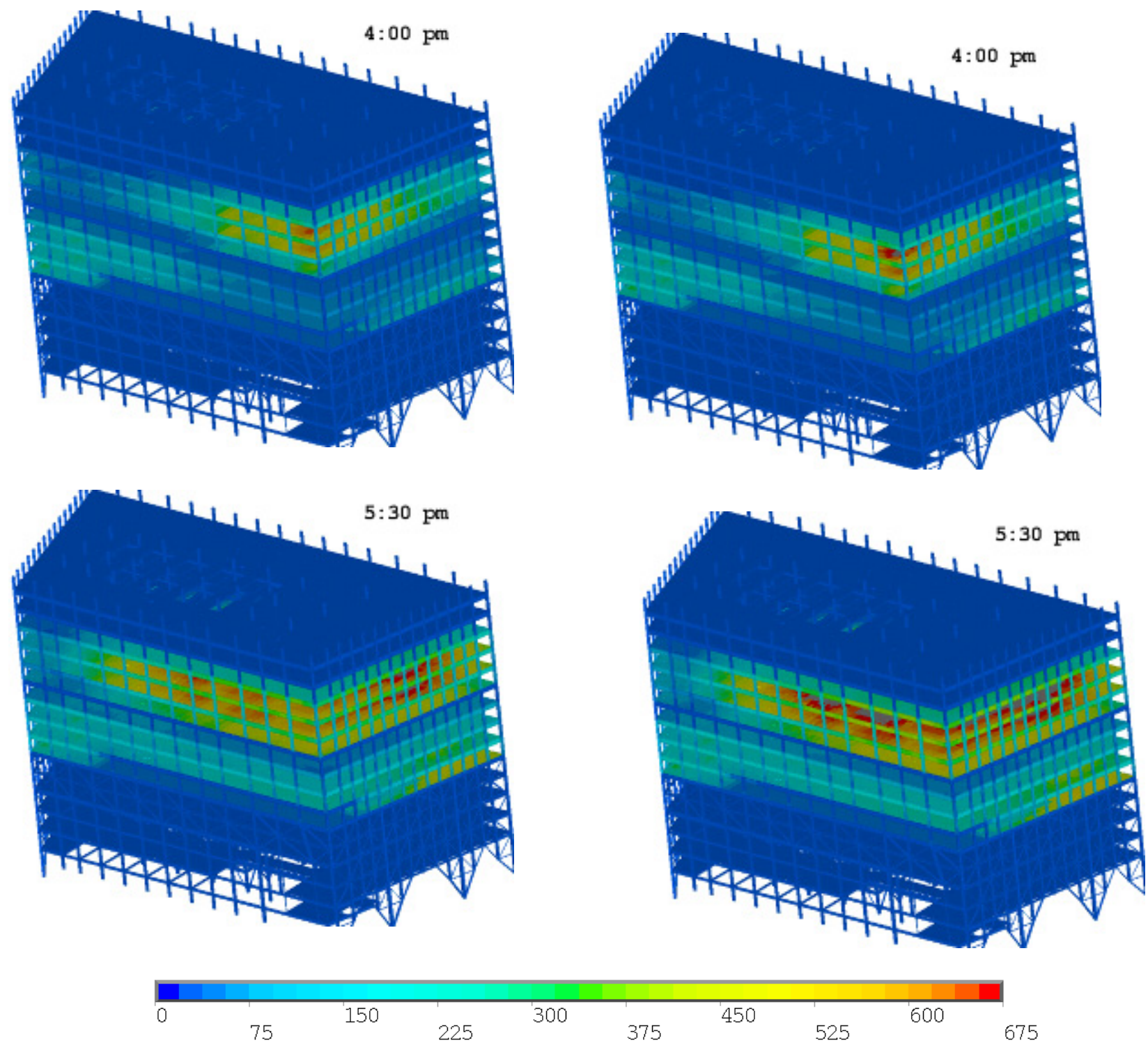

Figure 10-22. View from the southeast of the 16 lower floors of WTC 7, comparing Case A (left) and Case B (right) temperatures at two different times. 

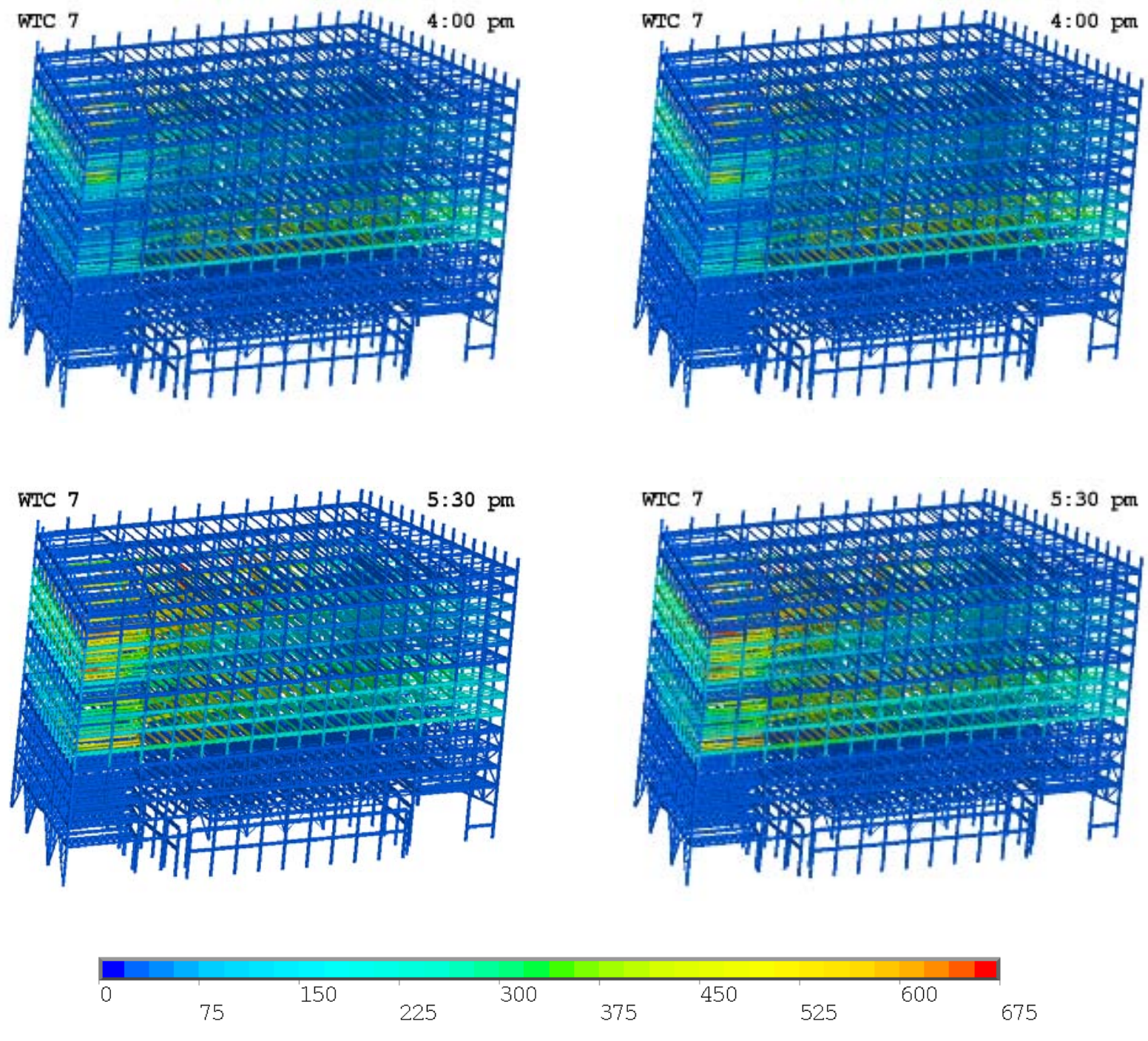

Figure 10-23. View from the northeast of the 16 lower floors of WTC 7, comparing Case A (left) and Case B (right) temperatures at two different times (floor slabs removed).

Figure 10-24 and Figure 10-25 show the full timed Case B sequence from which these examples were drawn. (The Case A sequences were shown in Figure 10-4 and Figure 10-5.) Figure 10-26 through Figure 10-41 show the floor-by-floor heating for Case B. 


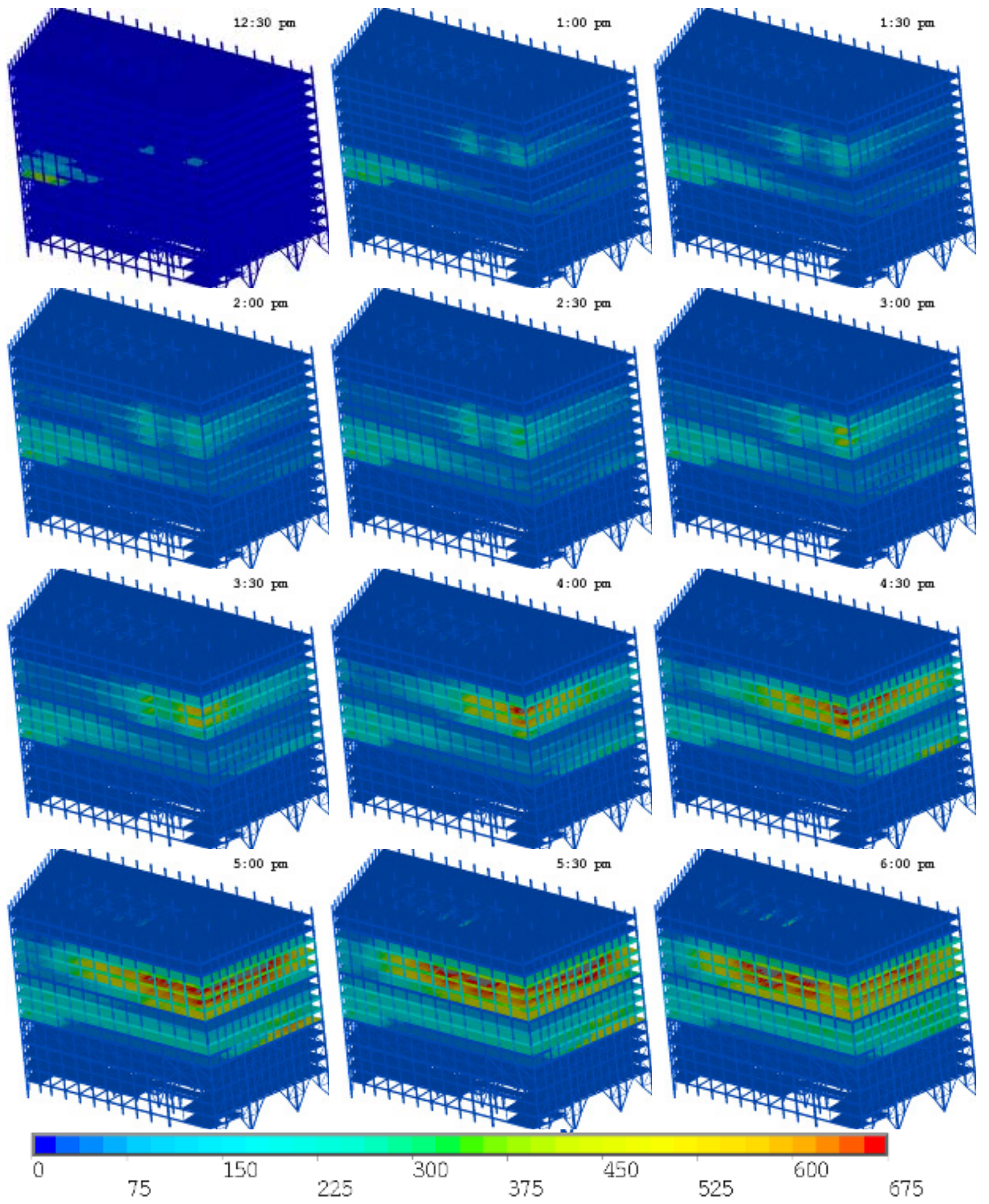

Figure 10-24. View from the southeast of the computed thermal loading of the lower 16 floors of WTC 7 at 12 instants in time (Case B). 

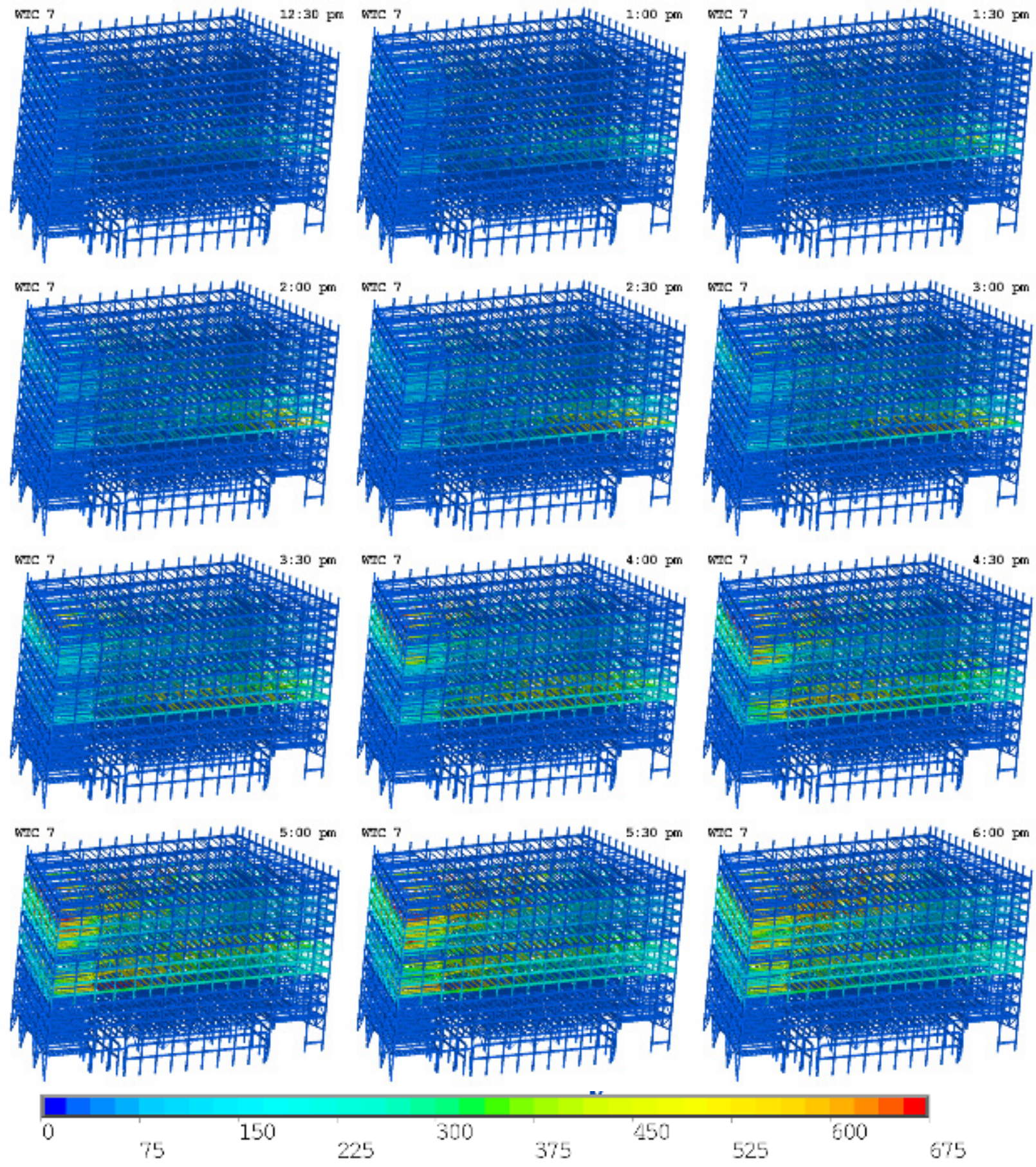

Figure 10-25. View from the northeast of the computed thermal loading of the lower 16 floors of WTC 7 at 12 different instants in time (Case B, floor slabs removed). 


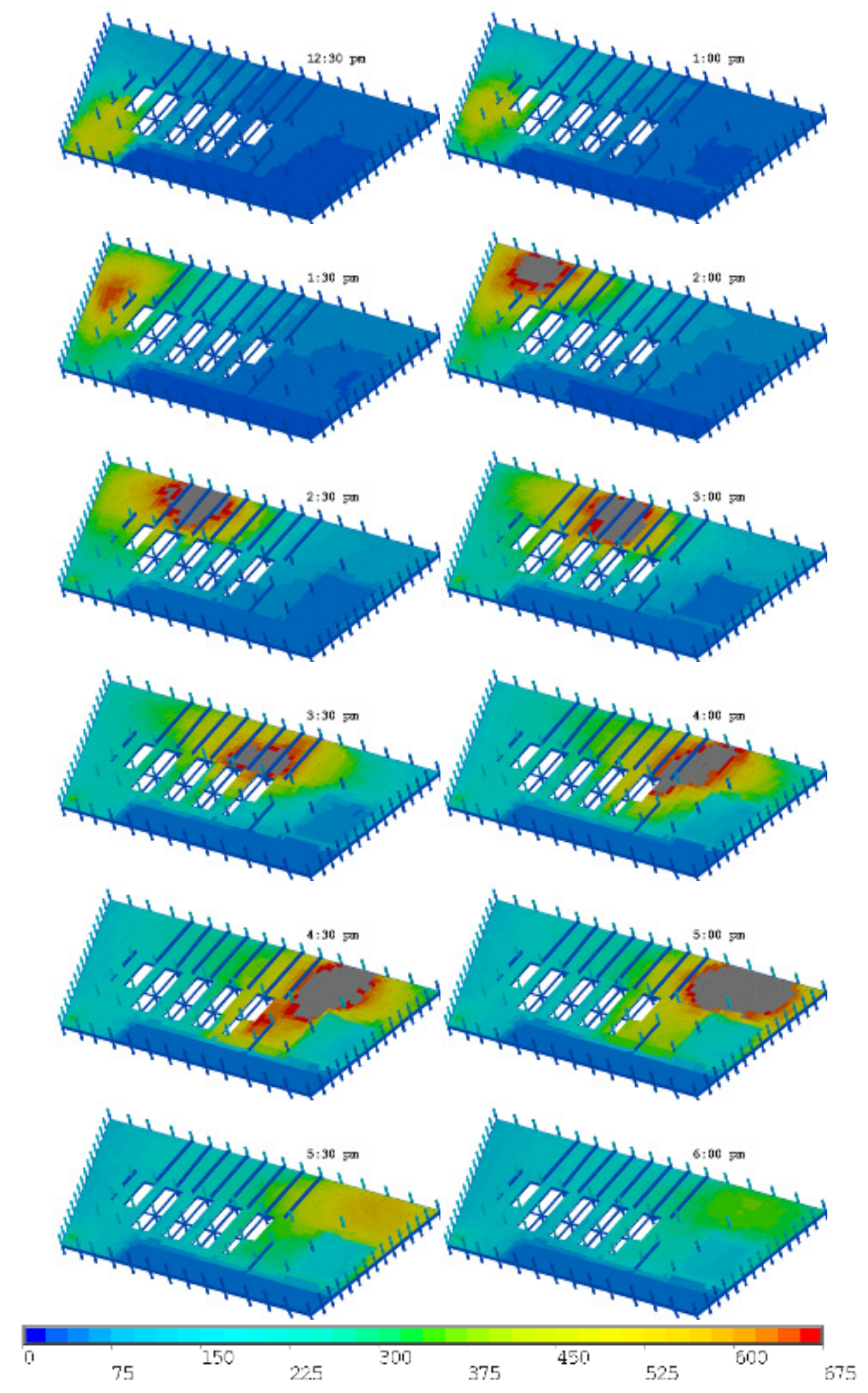

Figure 10-26. Computed temperature distribution $\left({ }^{\circ} \mathrm{C}\right)$ in the top layer of the concrete slab on Floor 7 at 12 instants in time (Case B). 


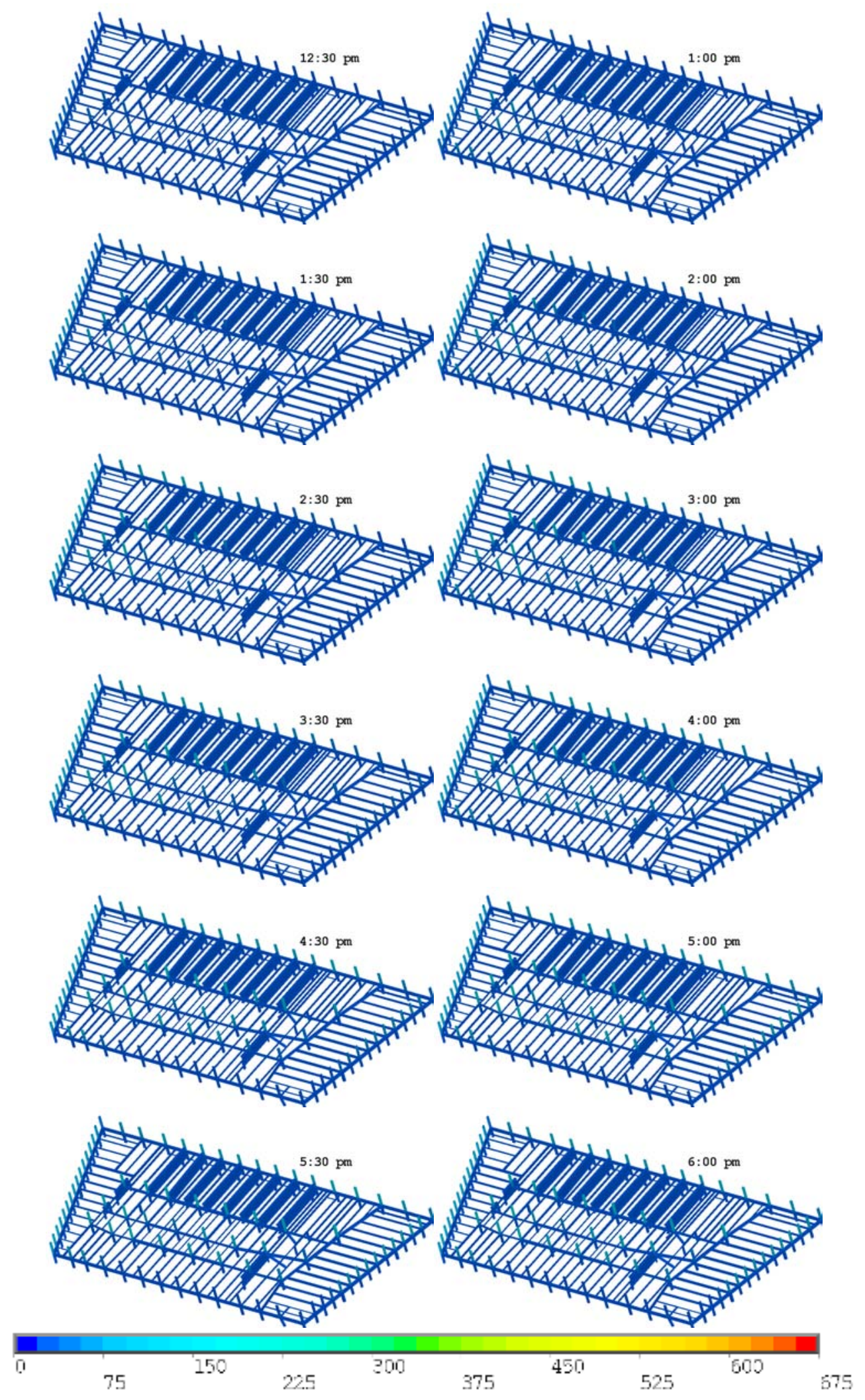

Figure 10-27. Computed temperature distribution $\left({ }^{\circ} \mathrm{C}\right)$ on the floor beams of Floor 7 at 12 different instants in time (Case $B$, floor slab removed). 


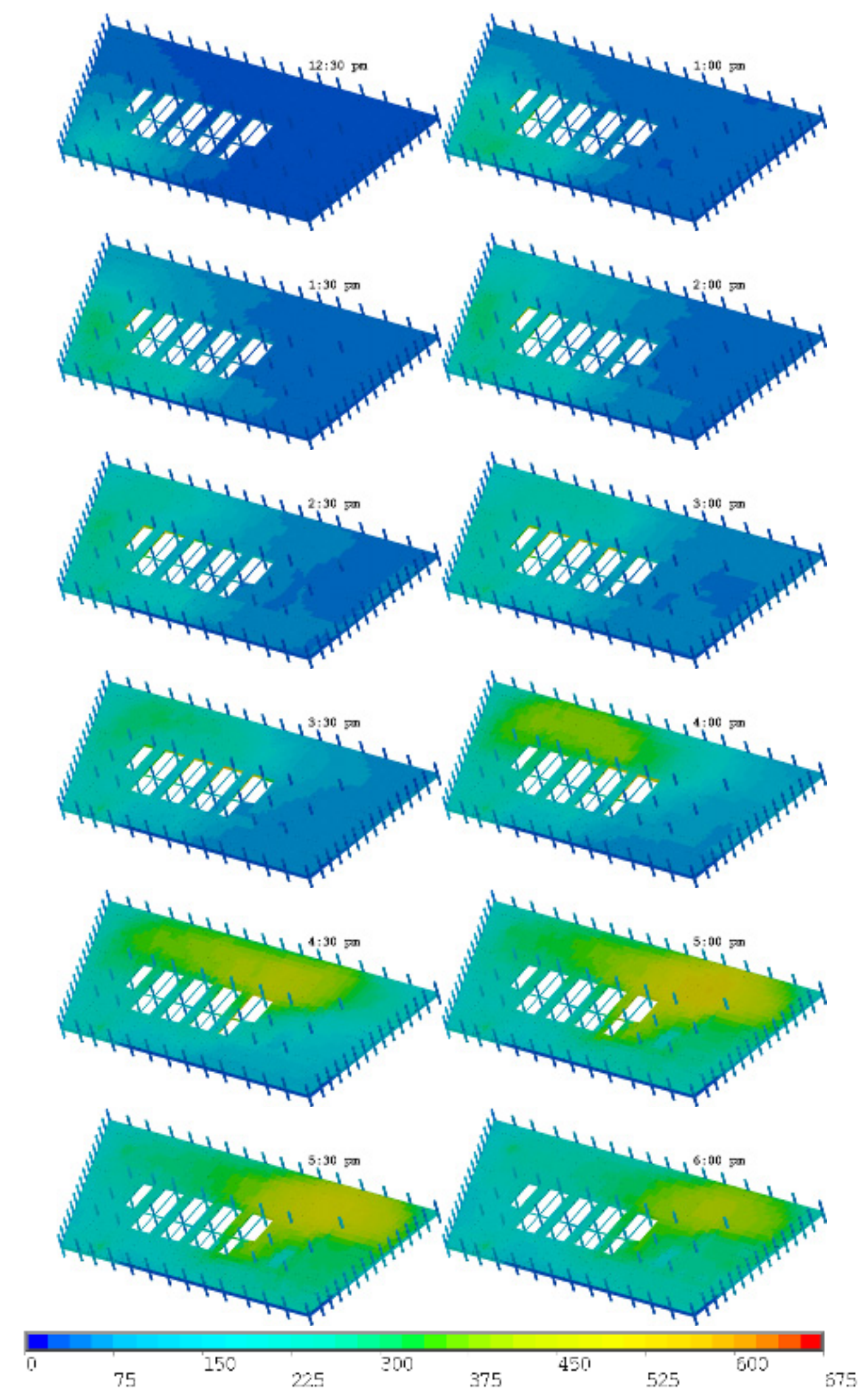

Figure 10-28. Computed temperature distribution $\left({ }^{\circ} \mathrm{C}\right)$ in the top layer of the concrete slab on Floor 8 at 12 instants in time (Case B). 


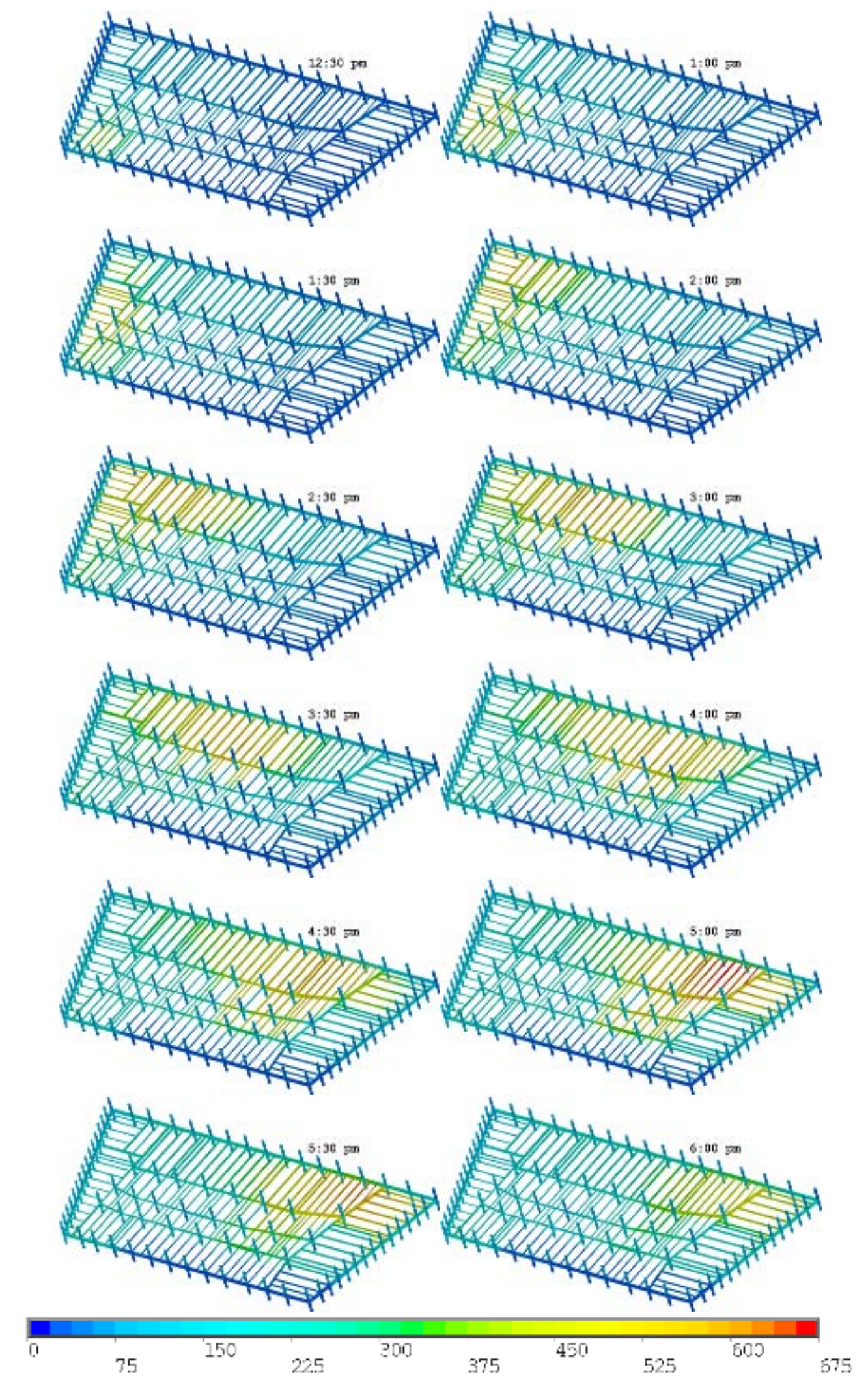

Figure 10-29. Computed temperature distribution $\left({ }^{\circ} \mathrm{C}\right)$ on the floor beams of Floor 8 at 12 different instants in time (Case B, floor slabs removed). 


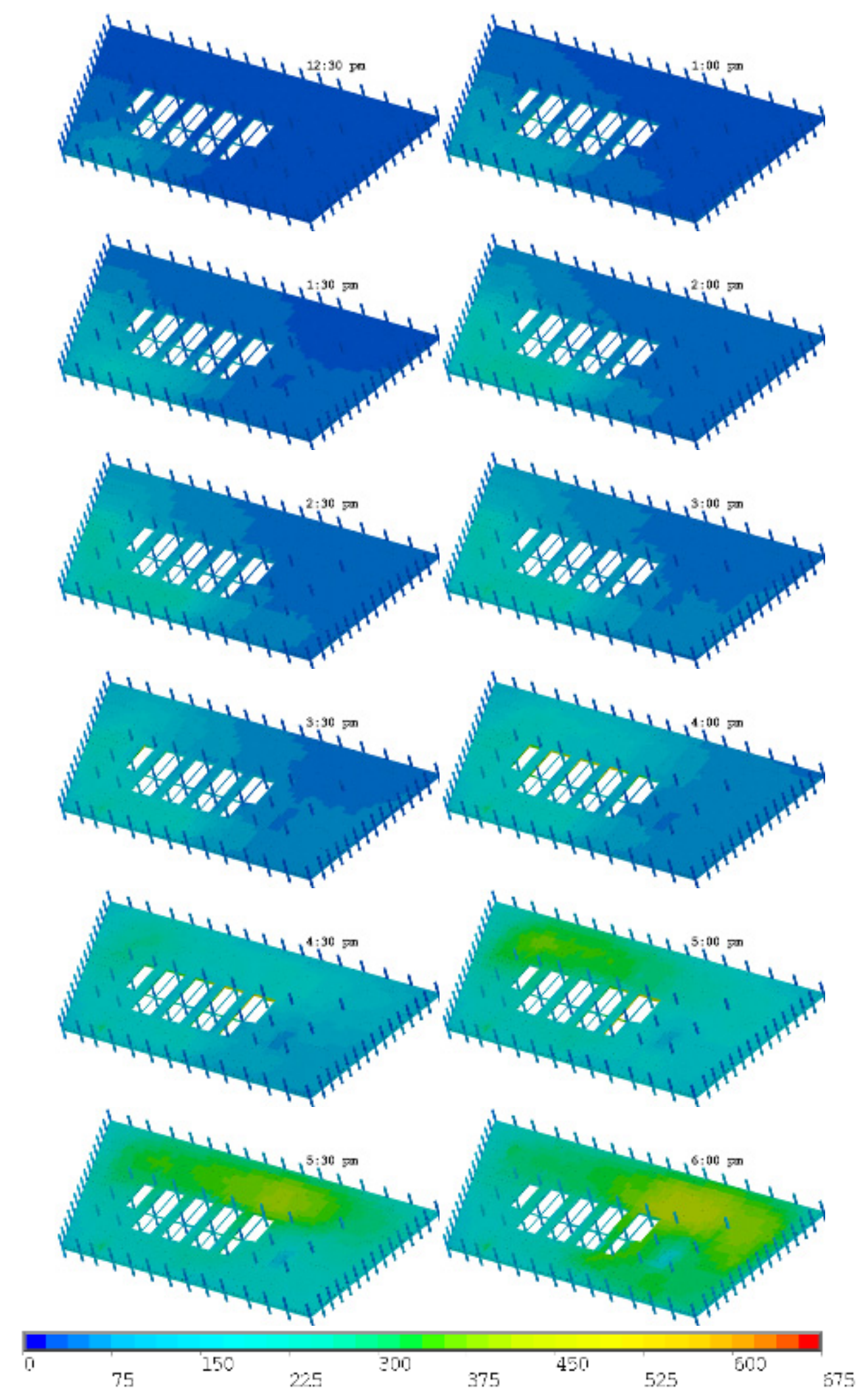

Figure 10-30. Computed temperature distribution $\left({ }^{\circ} \mathrm{C}\right)$ in the top layer of the concrete slab of Floor 9 at 12 different instants in time (Case B). 


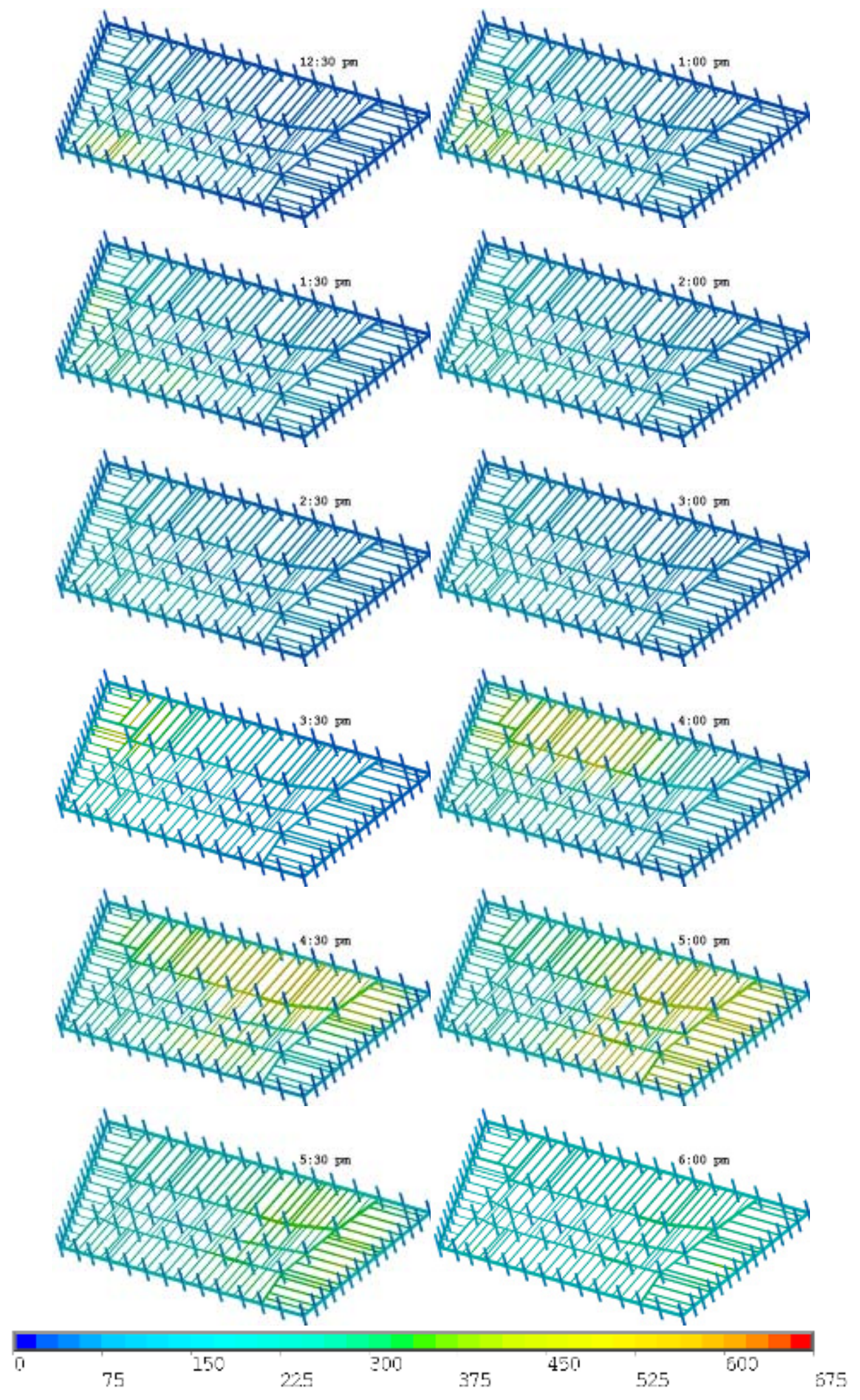

Figure 10-31. Computed temperature distribution $\left({ }^{\circ} \mathrm{C}\right)$ on the floor beams of Floor 9 at 12 different instants in time (Case B, floor slabs removed). 

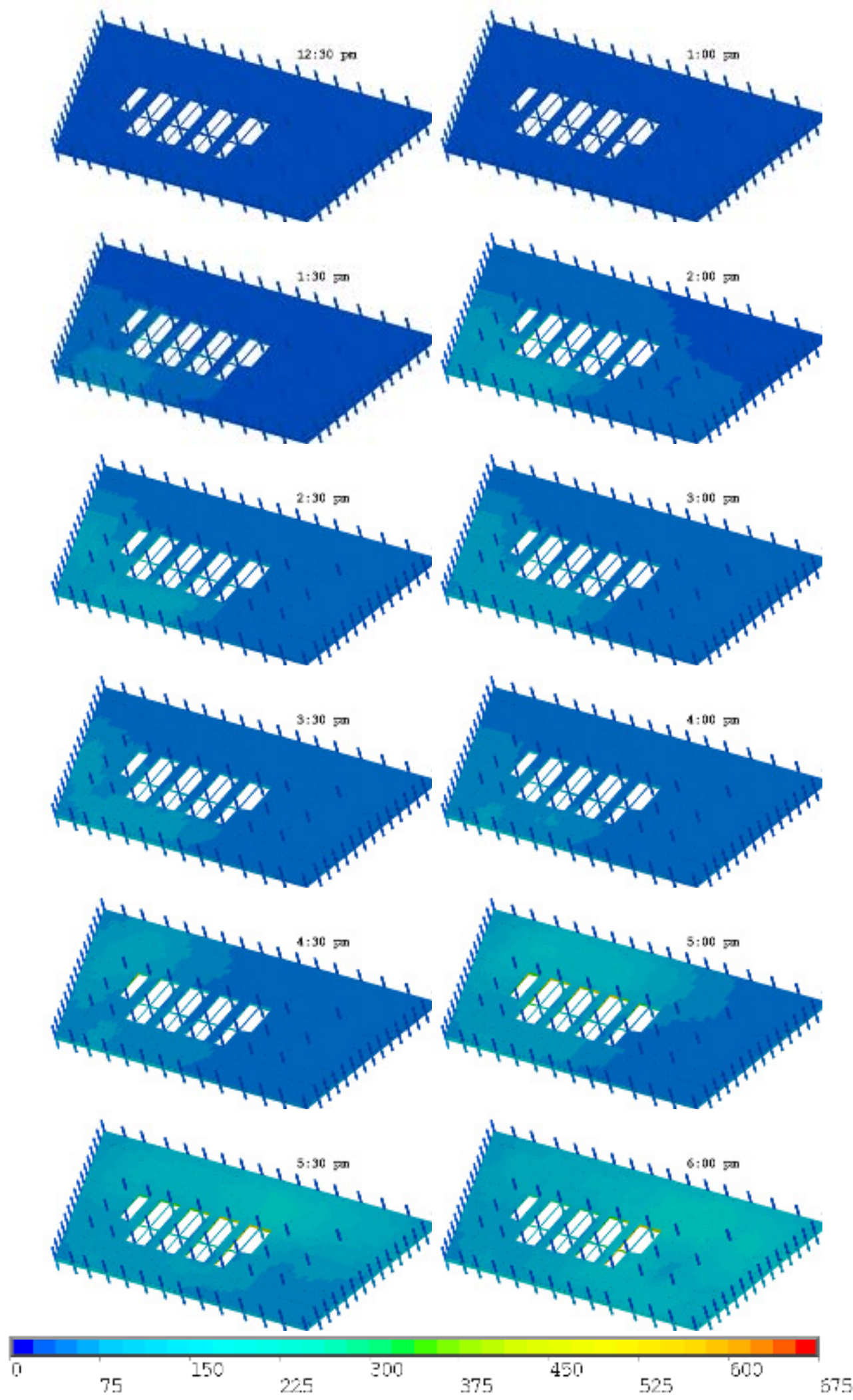

Figure 10-32. Computed temperature distribution $\left({ }^{\circ} \mathrm{C}\right)$ in the top layer of the concrete slab of Floor 10 at 12 different instants in time (Case B). 


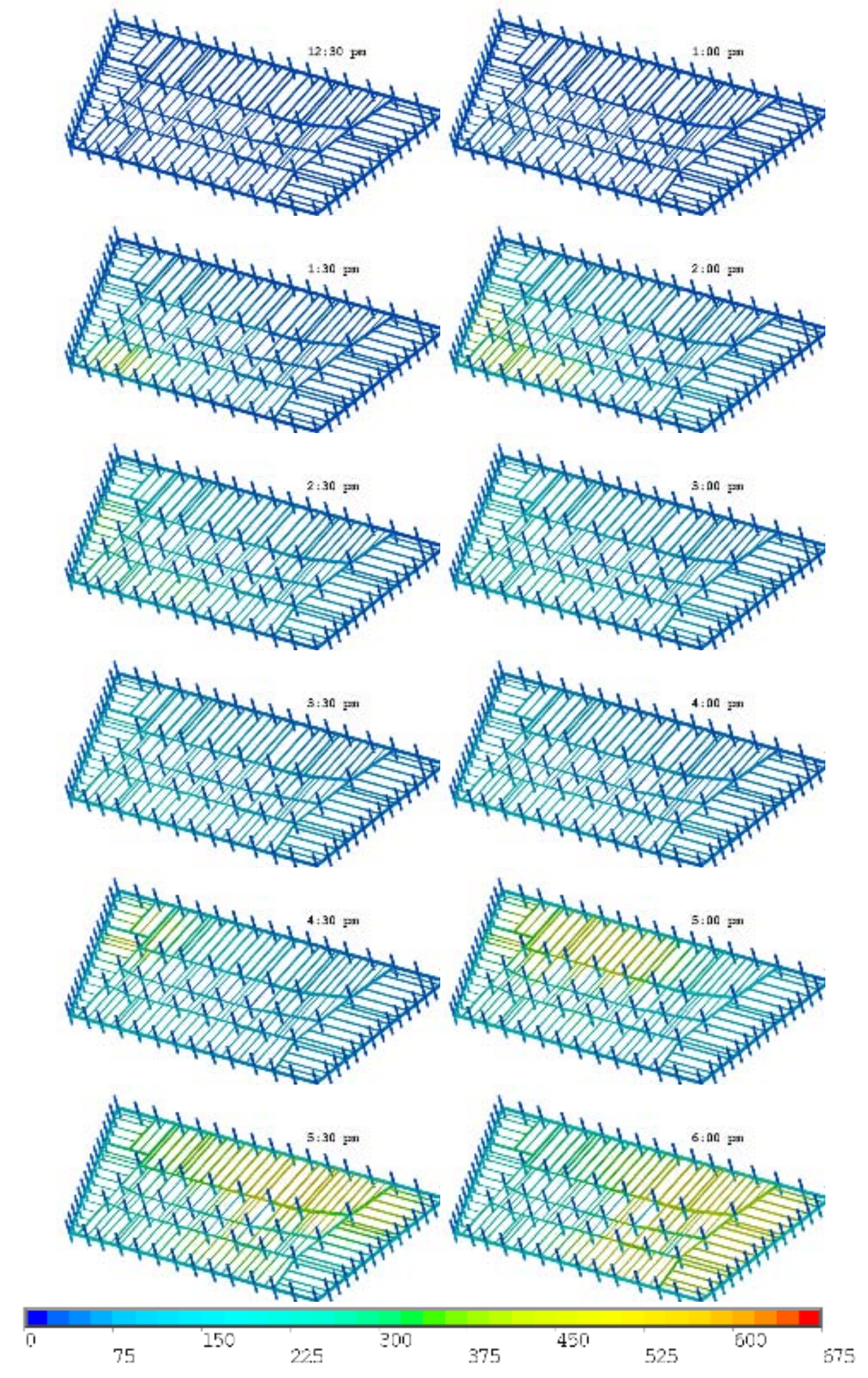

Figure 10-33. Computed temperature distribution $\left({ }^{\circ} \mathrm{C}\right)$ on floor beams of Floor 10 of WTC 7 at 12 different instants in time (Case B, floor slabs removed). 


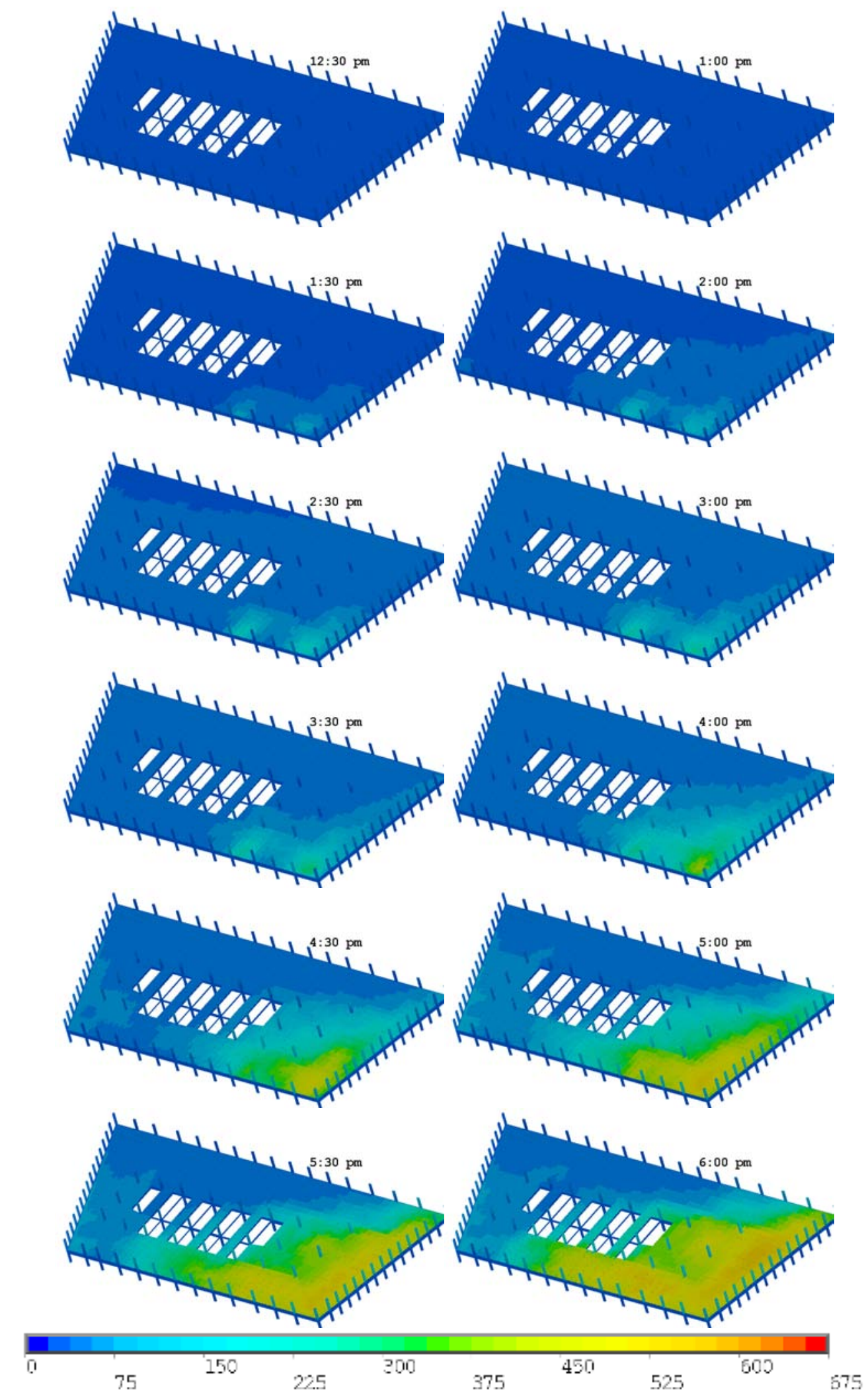

Figure 10-34. Computed temperature distribution $\left({ }^{\circ} \mathrm{C}\right)$ in the top layer of the concrete slab of Floor 11 at 12 different instants in time (Case B). 


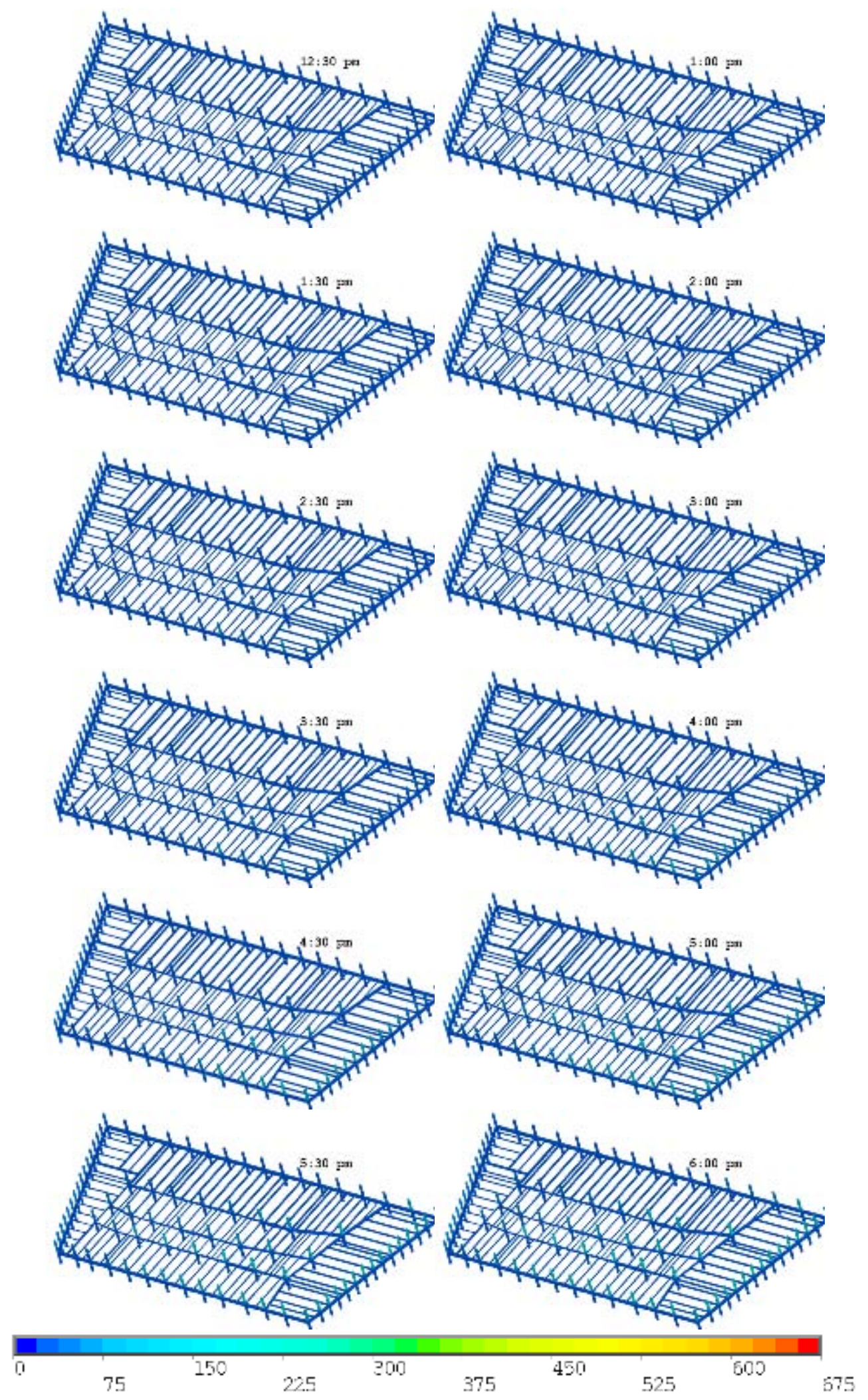

Figure 10-35. Computed temperature distribution $\left({ }^{\circ} \mathrm{C}\right)$ on the floor beams of Floor 11 at 12 different instants in time (Case B, floor slabs removed). 


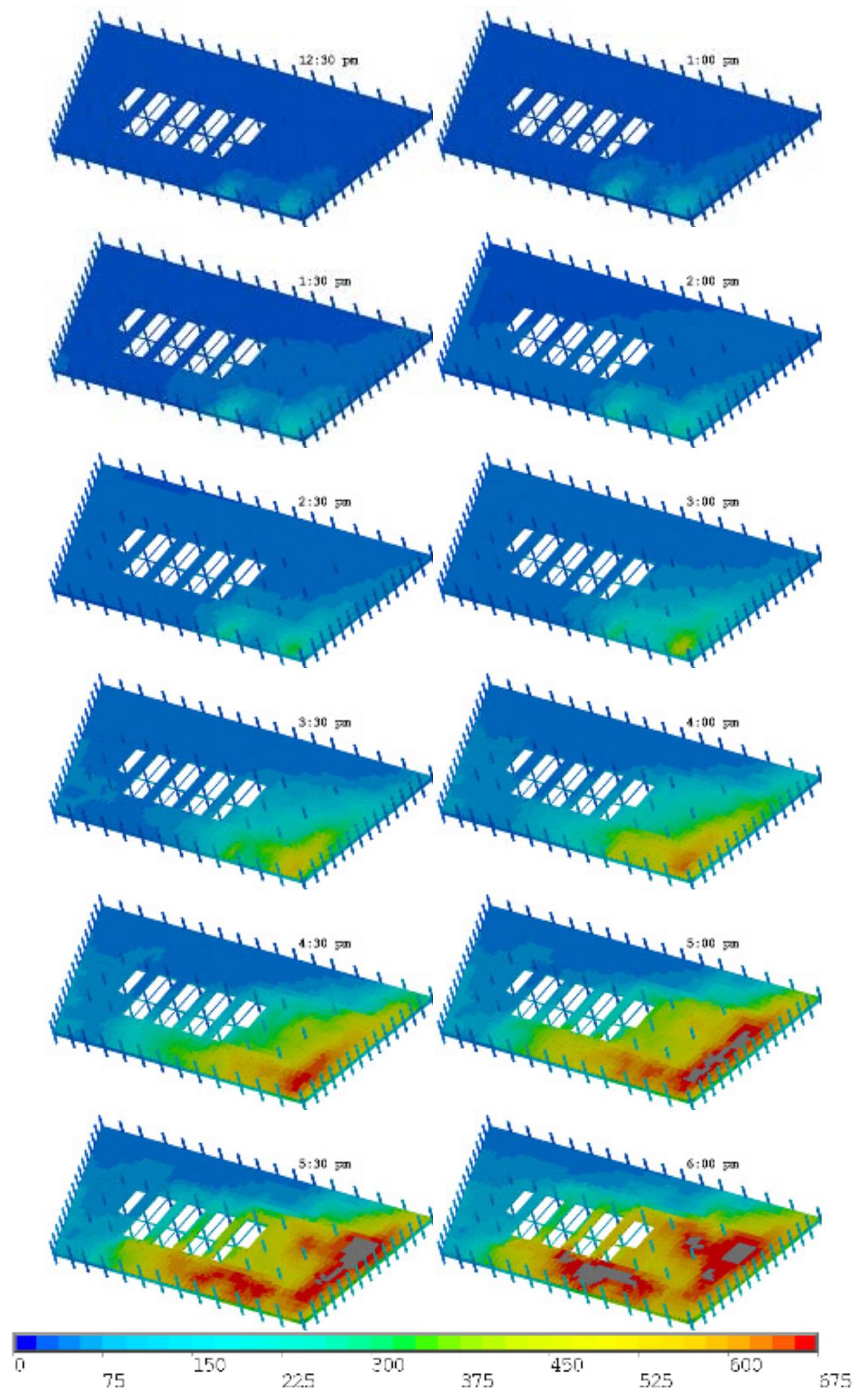

Figure 10-36. Computed temperature distribution $\left({ }^{\circ} \mathrm{C}\right)$ in the top layer of the concrete slab of Floor 12 at 12 different instants in time (Case B). 


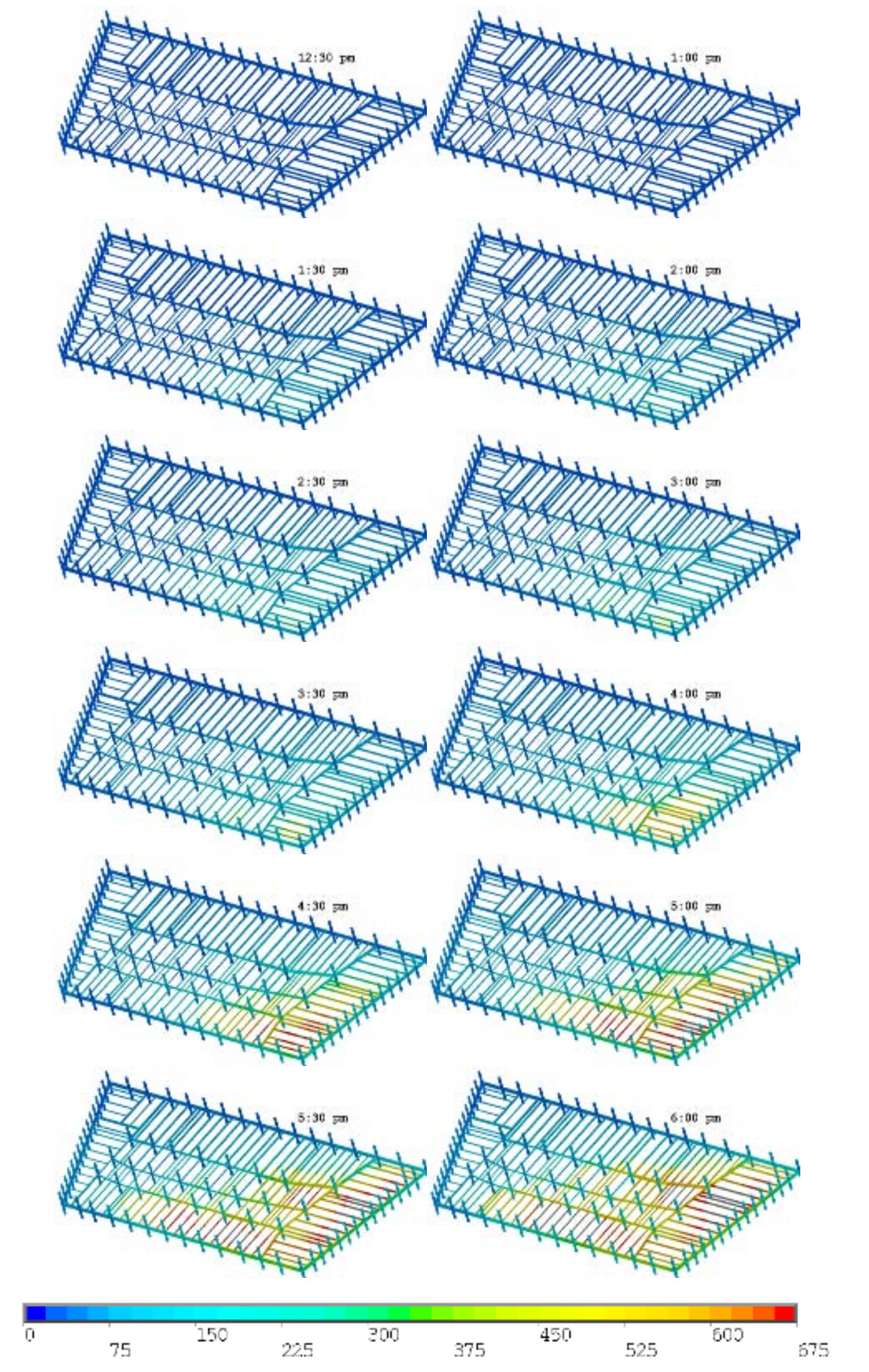

Figure 10-37. Computed temperature distribution $\left({ }^{\circ} \mathrm{C}\right)$ on the floor beams of Floor 12 of WTC 7 at 12 different instants in time (Case B, floor slabs removed). 

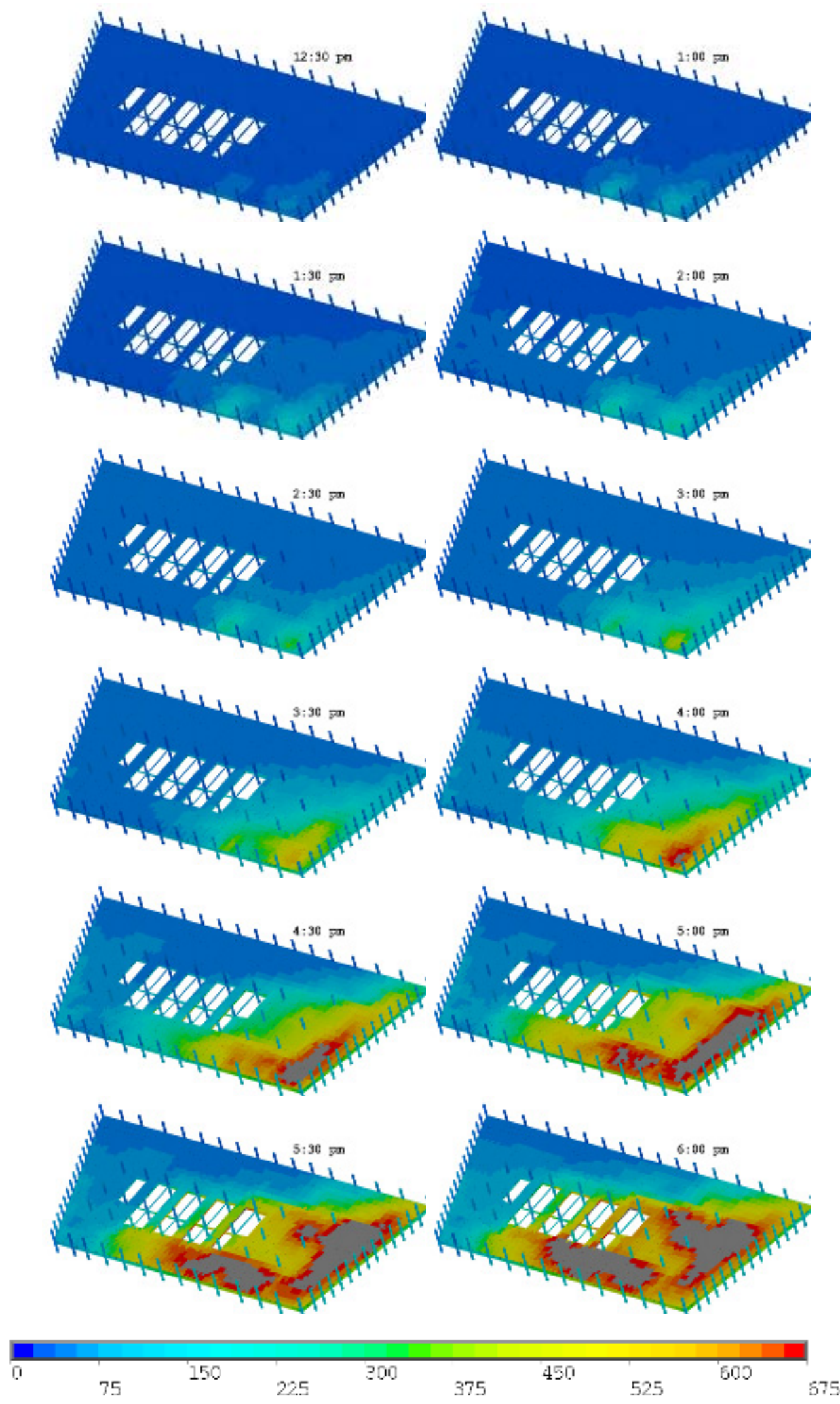

Figure 10-38. Computed temperature distribution $\left({ }^{\circ} \mathrm{C}\right)$ in the top layer of the concrete slab of Floor 13 at 12 different instants in time (Case B). 


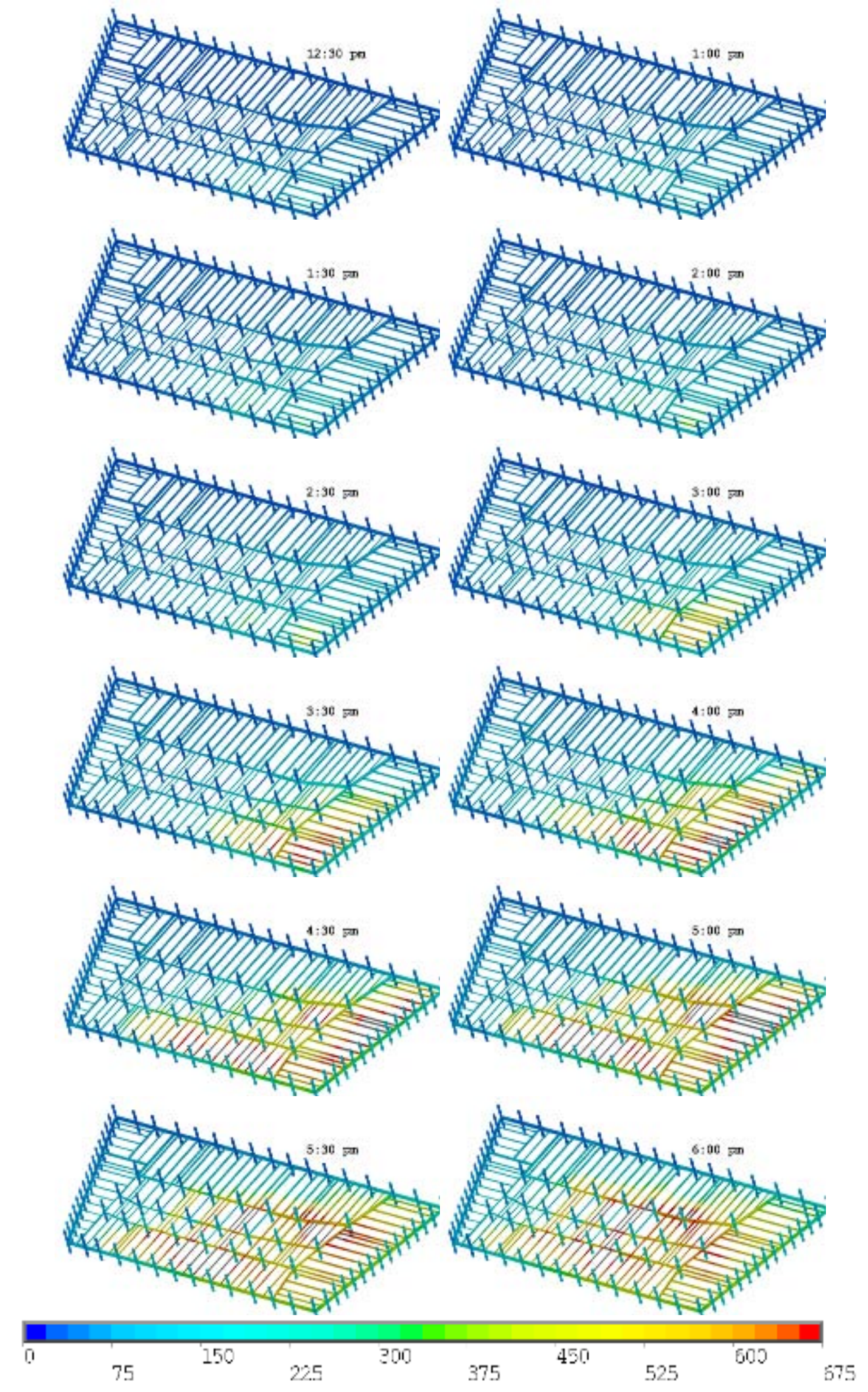

Figure 10-39. Computed temperature distribution $\left({ }^{\circ} \mathrm{C}\right)$ on the floor beams of Floor 13 at 12 different instants in time (Case B, floor slabs removed). 


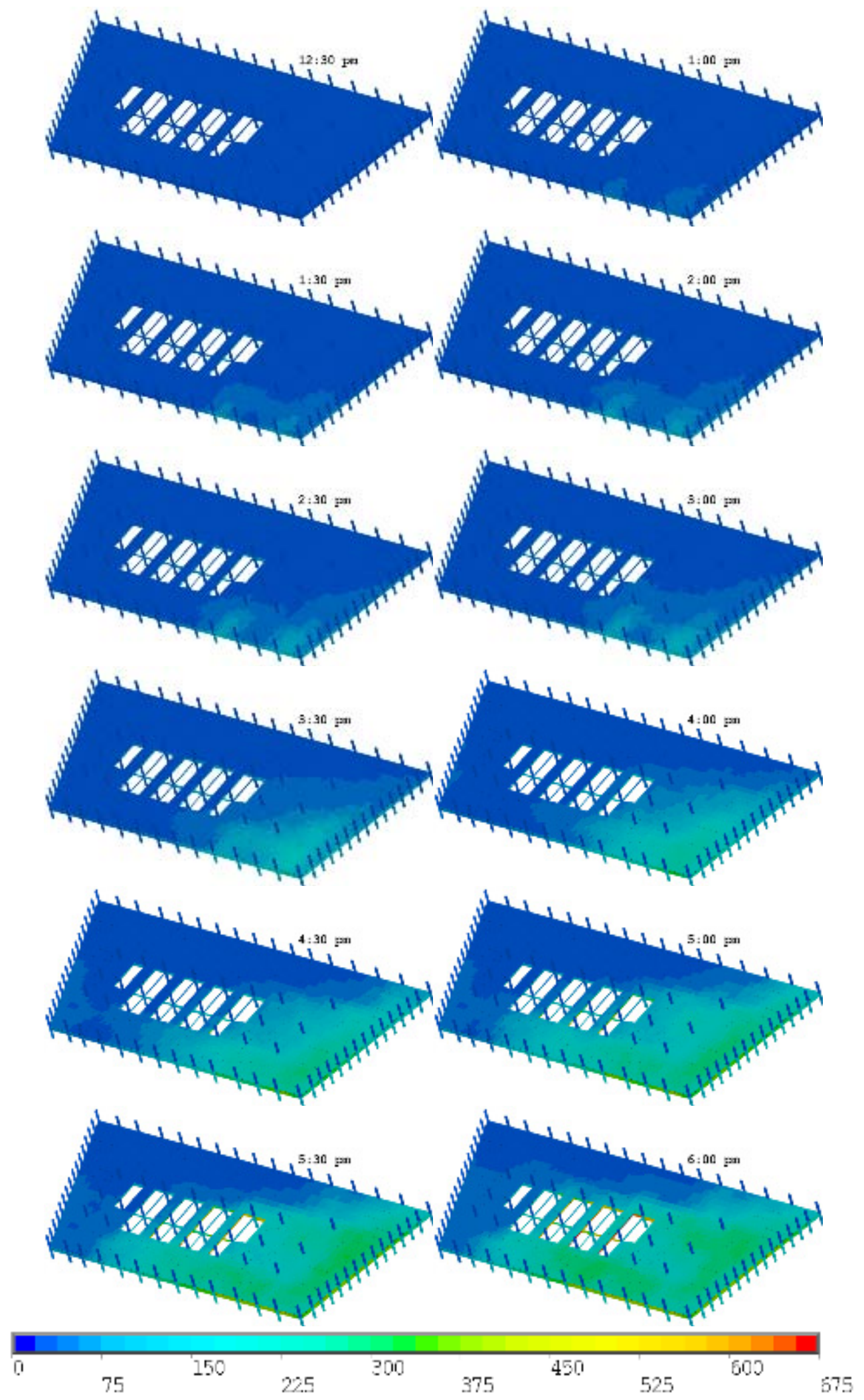

Figure 10-40. Computed temperature distribution $\left({ }^{\circ} \mathrm{C}\right)$ in the top layer of the concrete slab of Floor 14 at 12 different instants in time (Case B). 


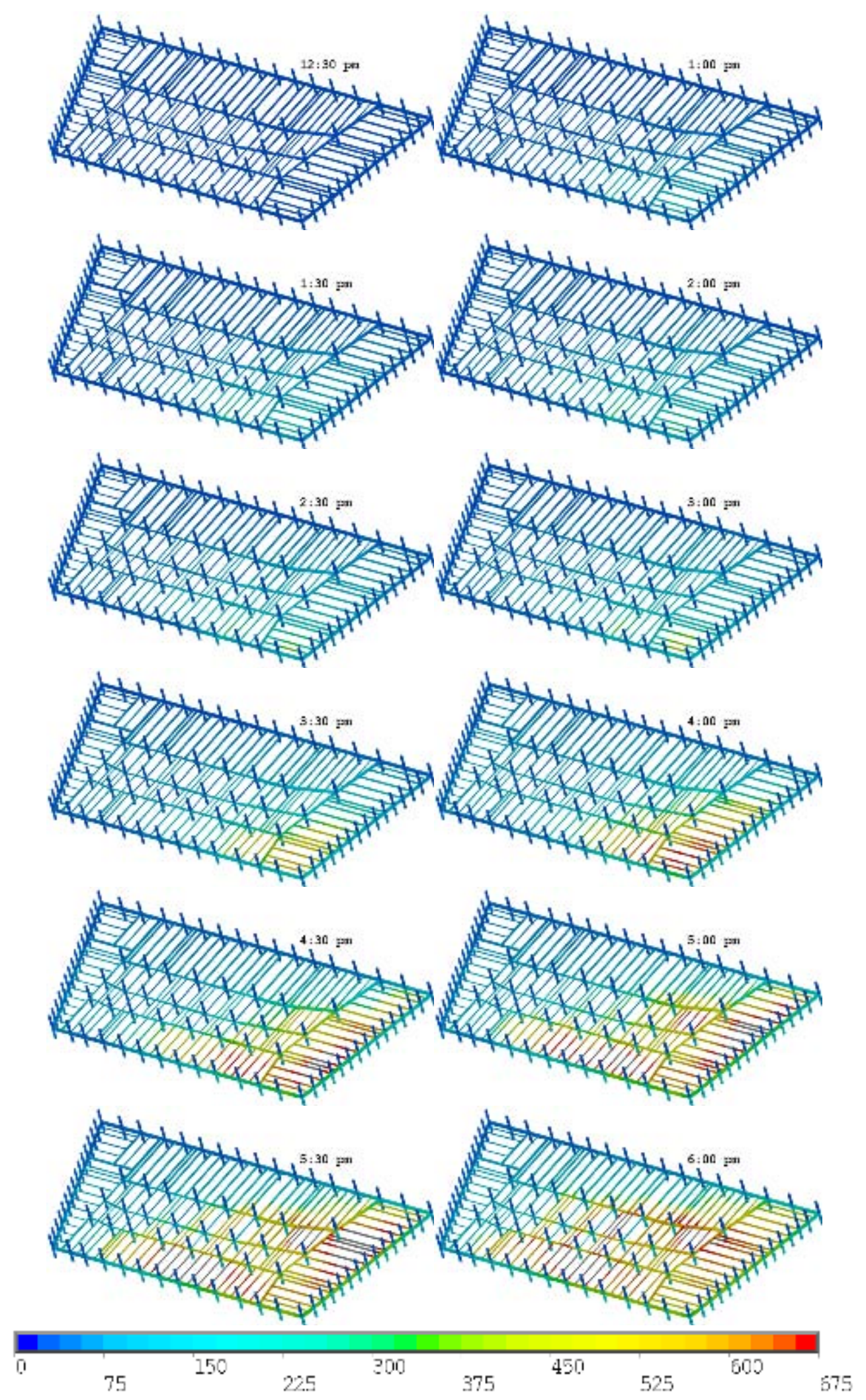

Figure 10-41. Computed temperature distribution $\left({ }^{\circ} \mathrm{C}\right)$ on the floor beams of Floor 14 at 12 different instants in time (Case $B$, floor slabs removed). 


\subsubsection{Case C}

For Case C, the air temperature increase at each location on Floors 7 through 14 was assumed to be 10 percent lower than that computed from the FDS simulation of Case A, which was within the expected range of reasonable and realistic fire-generated temperatures. Figure 10-42 and Figure 10-43 compare the temperatures of the building at two times for these two cases. Case A is on the left, and Case C is on the right. As expected, Case $\mathrm{C}$ resulted in mildly lower temperatures in the steel and concrete, narrower hot zones, and lesser overlap of hot zones between adjacent floors.
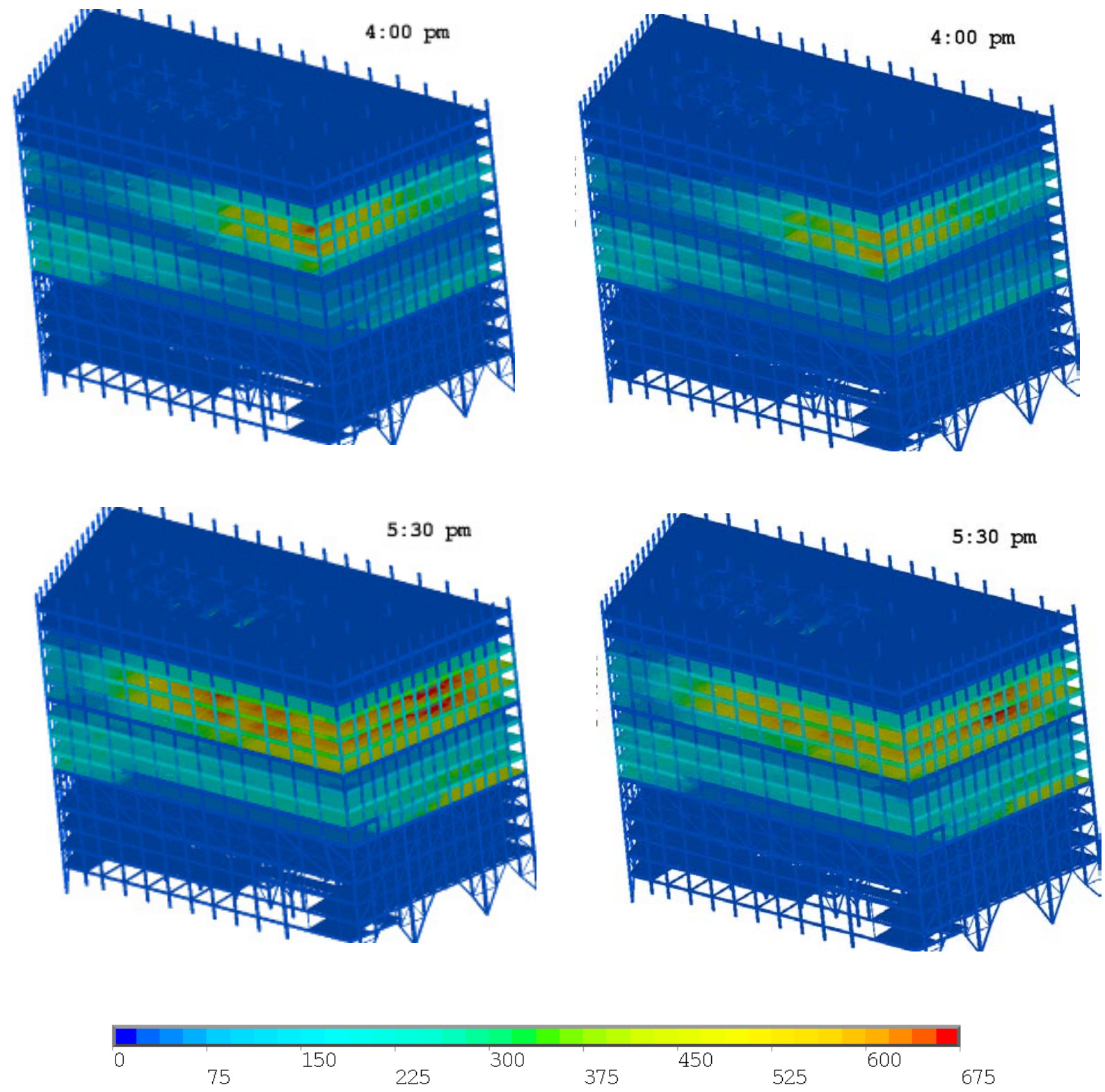

Figure 10-42. View from the southeast of the 16 lower floors of WTC 7, comparing Case A (left) and Case C (right) temperatures at two different times. 

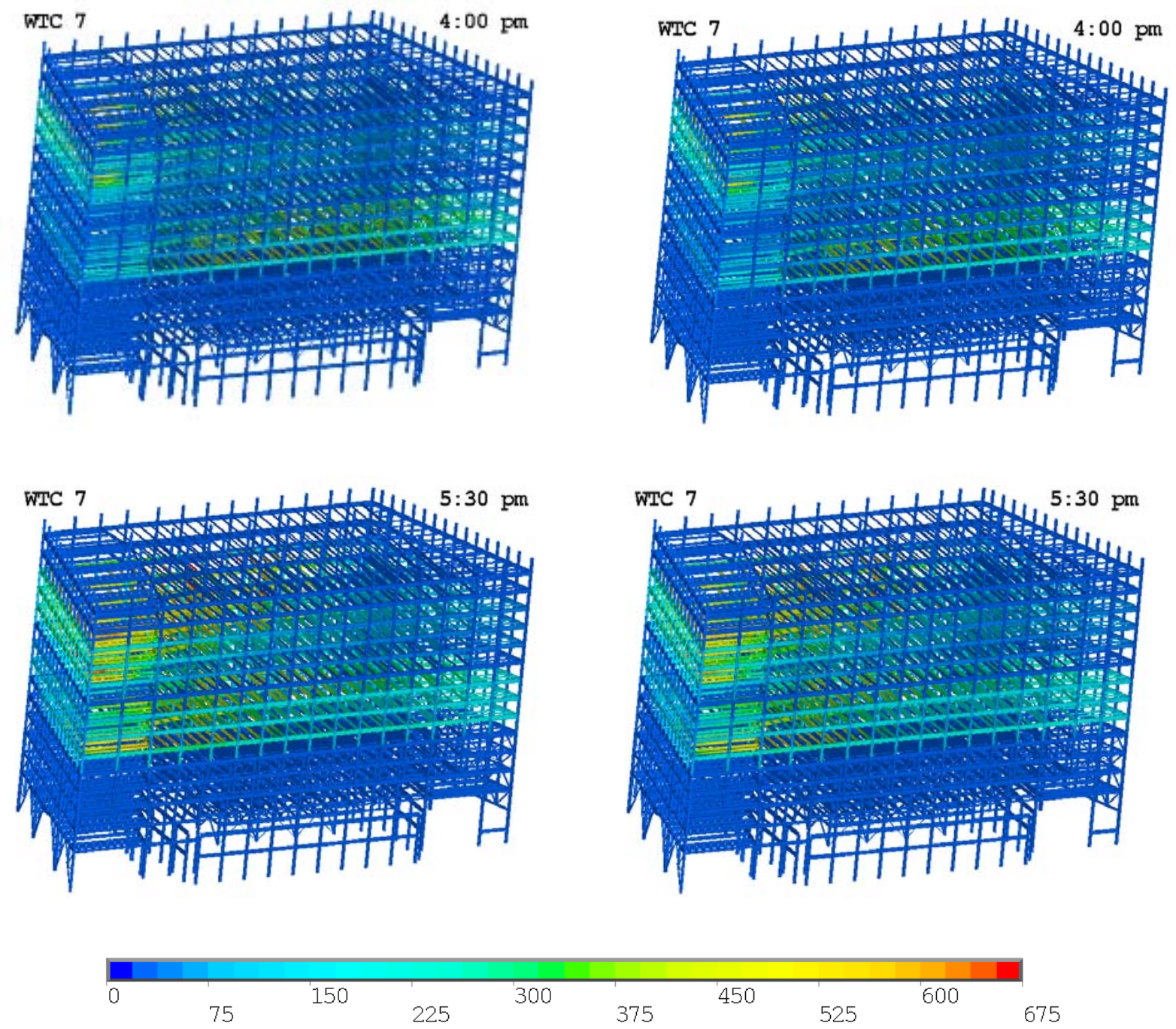

Figure 10-43. View from the northeast of the 16 lower floors of WTC 7, comparing Case A (left) and Case C (right) temperatures at two different times (floor slabs removed).

Figure 10-44 and Figure 10-45 show the full timed Case $\mathrm{C}$ sequence from which these examples were drawn. (The Case A sequences were shown in Figure 10-4 and Figure 10-5.) Figure 10-46 through Figure 10-61 show the floor-by-floor heating for Case C. 


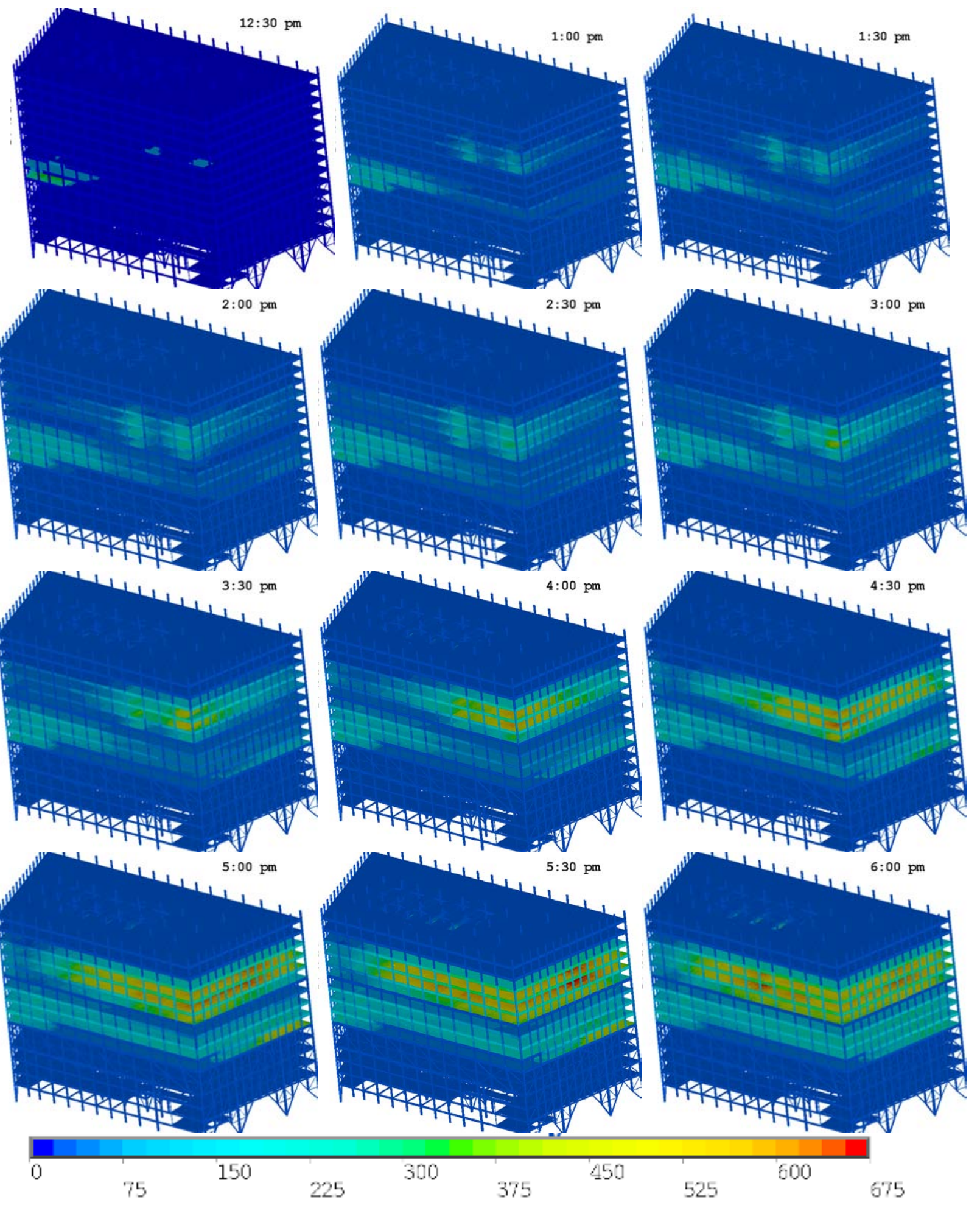

Figure 10-44. View from the southeast of the computed thermal loading of the lower 16 floors of WTC 7 at 12 instants in time (Case C). 

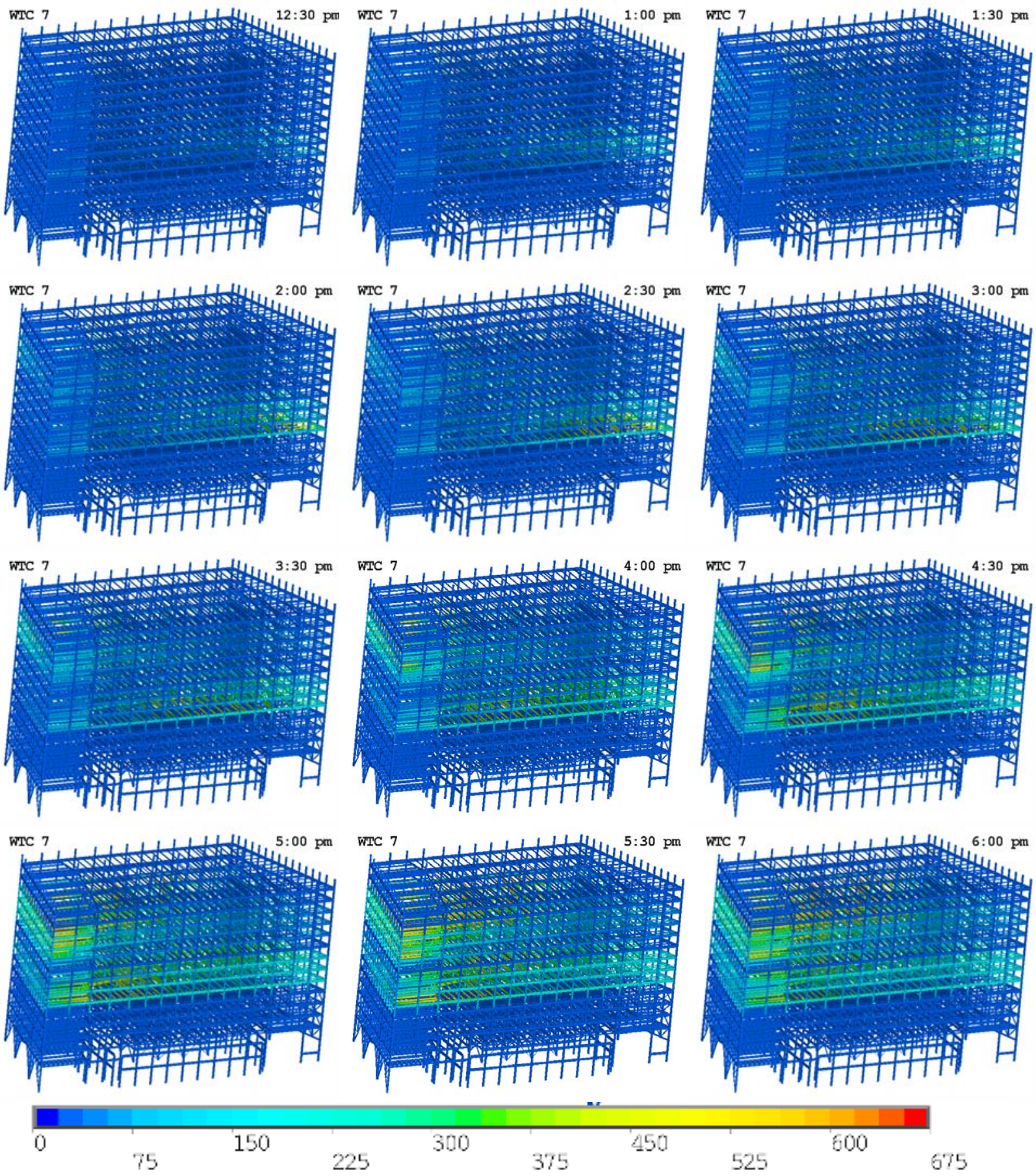

Figure 10-45. View from the northeast of the computed thermal loading of the lower 16 floors of WTC 7 at 12 different instants in time (Case C, floor slabs removed). 

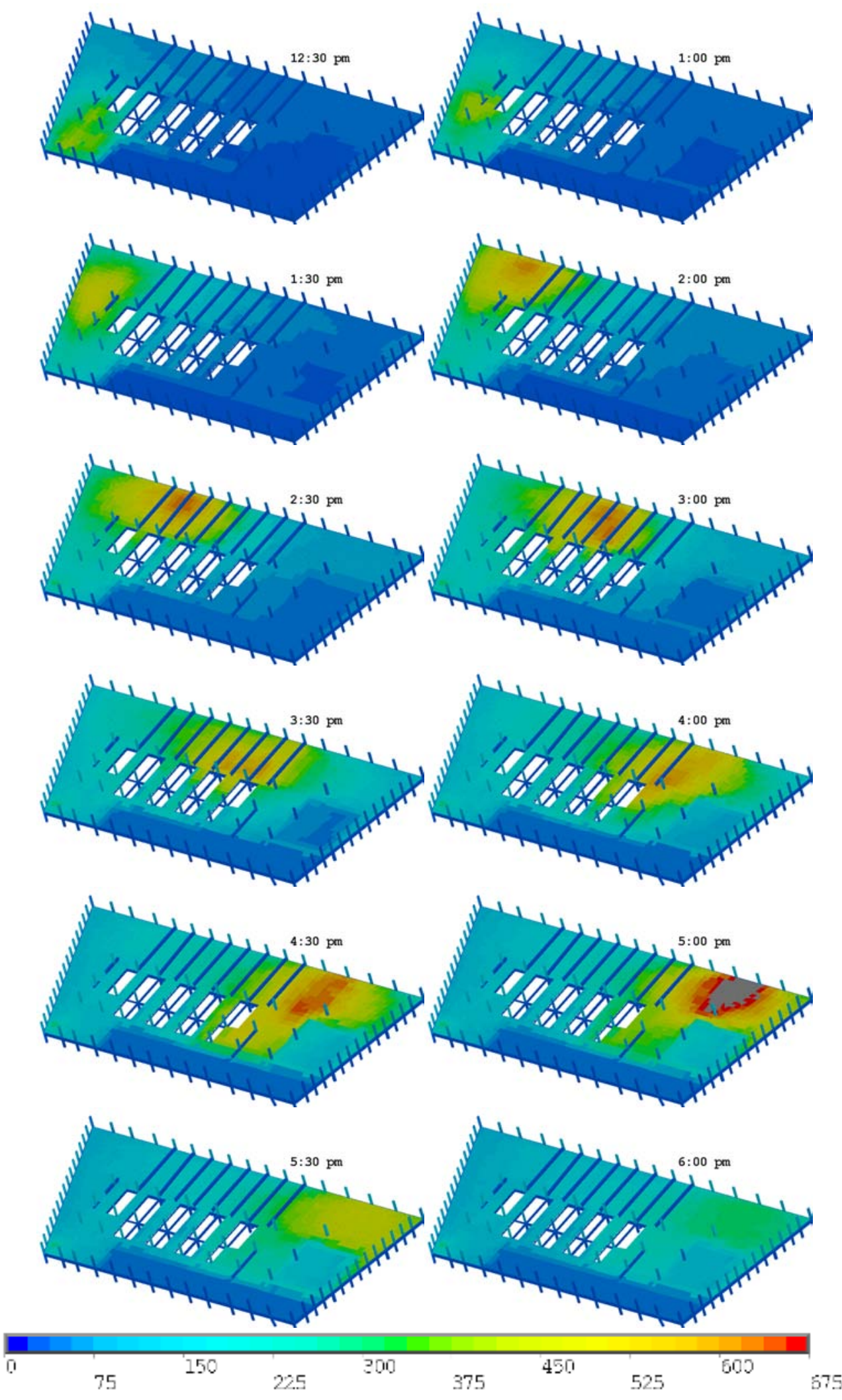

Figure 10-46. Computed temperature distribution $\left({ }^{\circ} \mathrm{C}\right)$ in the top layer of the concrete slab on Floor 7 at 12 instants in time (Case C). 


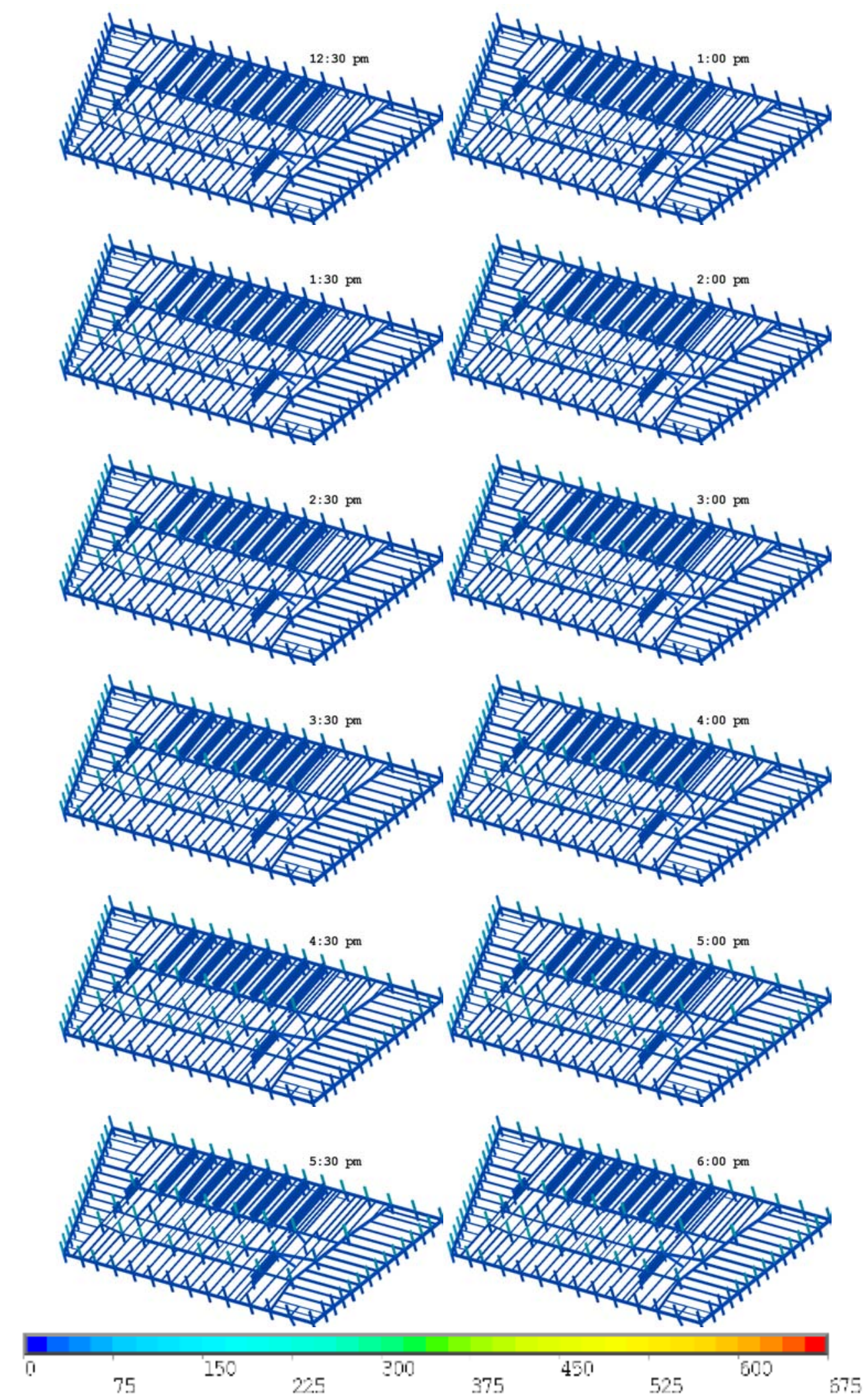

Figure 10-47. Computed temperature distribution $\left({ }^{\circ} \mathrm{C}\right)$ on the floor beams of Floor 7 at 12 different instants in time (Case C, floor slabs removed). 


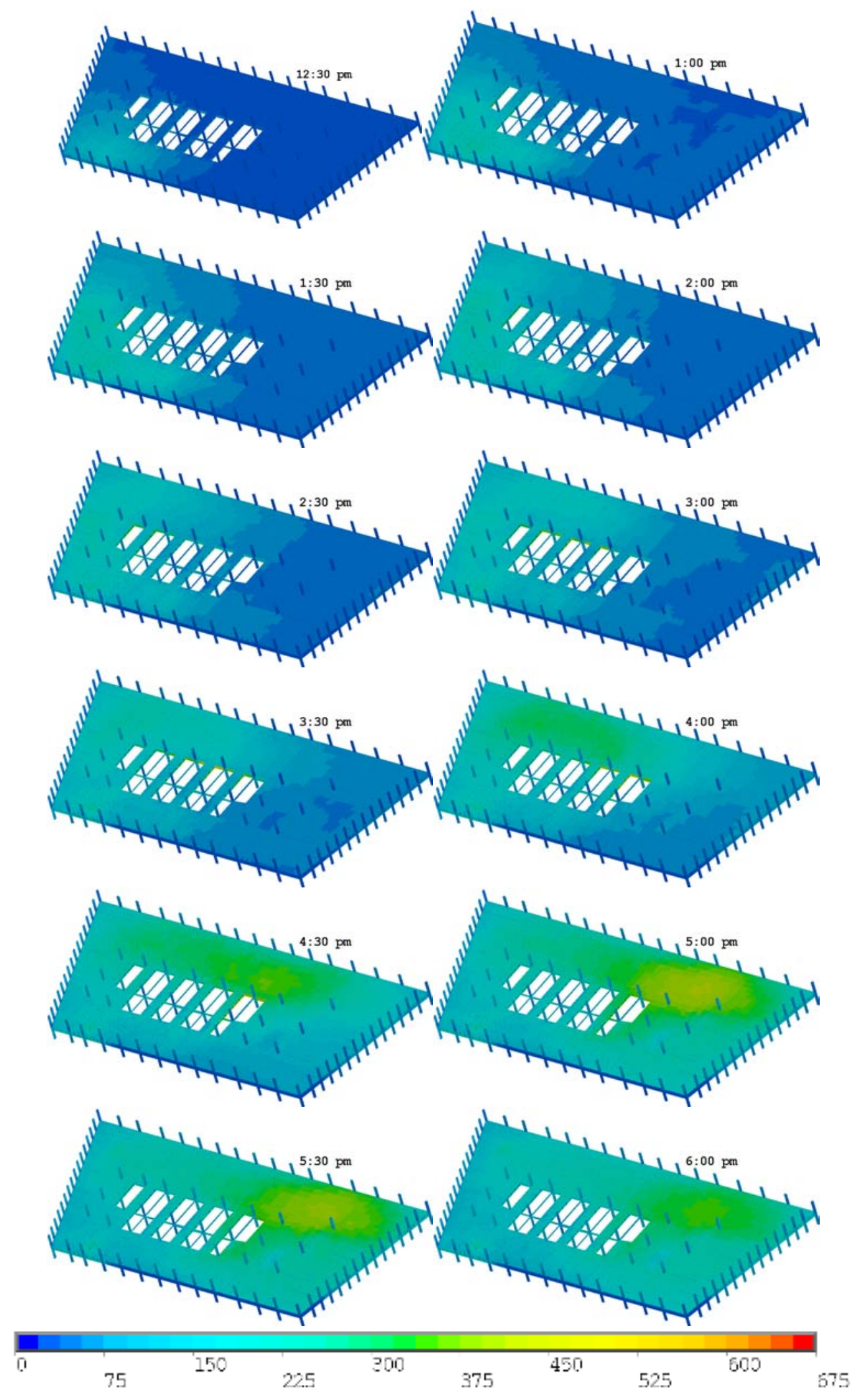

Figure 10-48. Computed temperature distribution $\left({ }^{\circ} \mathrm{C}\right)$ in the top layer of the concrete slab on Floor 8 at 12 instants in time (Case C). 


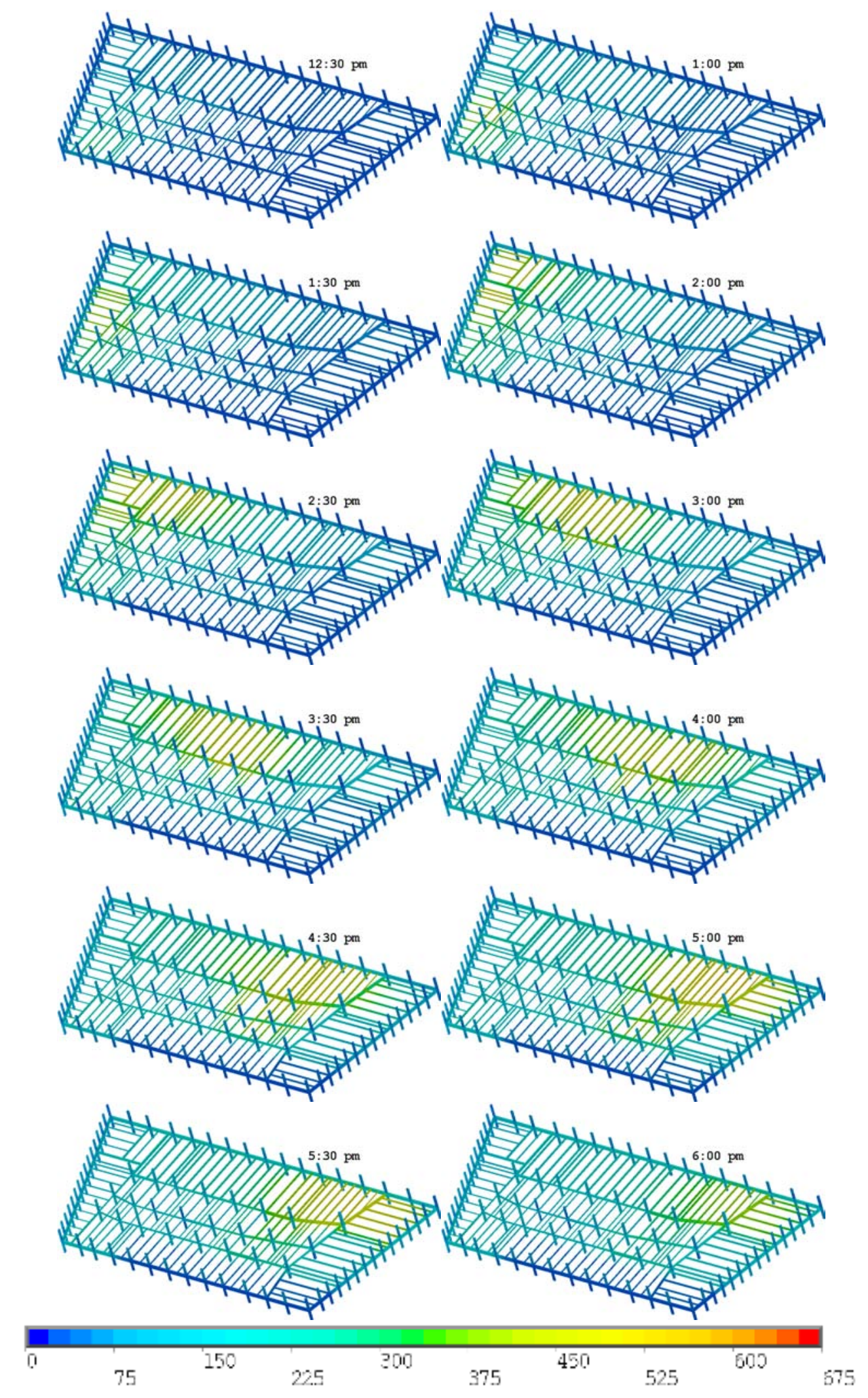

Figure 10-49. Computed temperature distribution $\left({ }^{\circ} \mathrm{C}\right)$ on the floor beams of Floor 8 at 12 different instants in time (Case $\mathrm{C}$, floor slabs removed). 


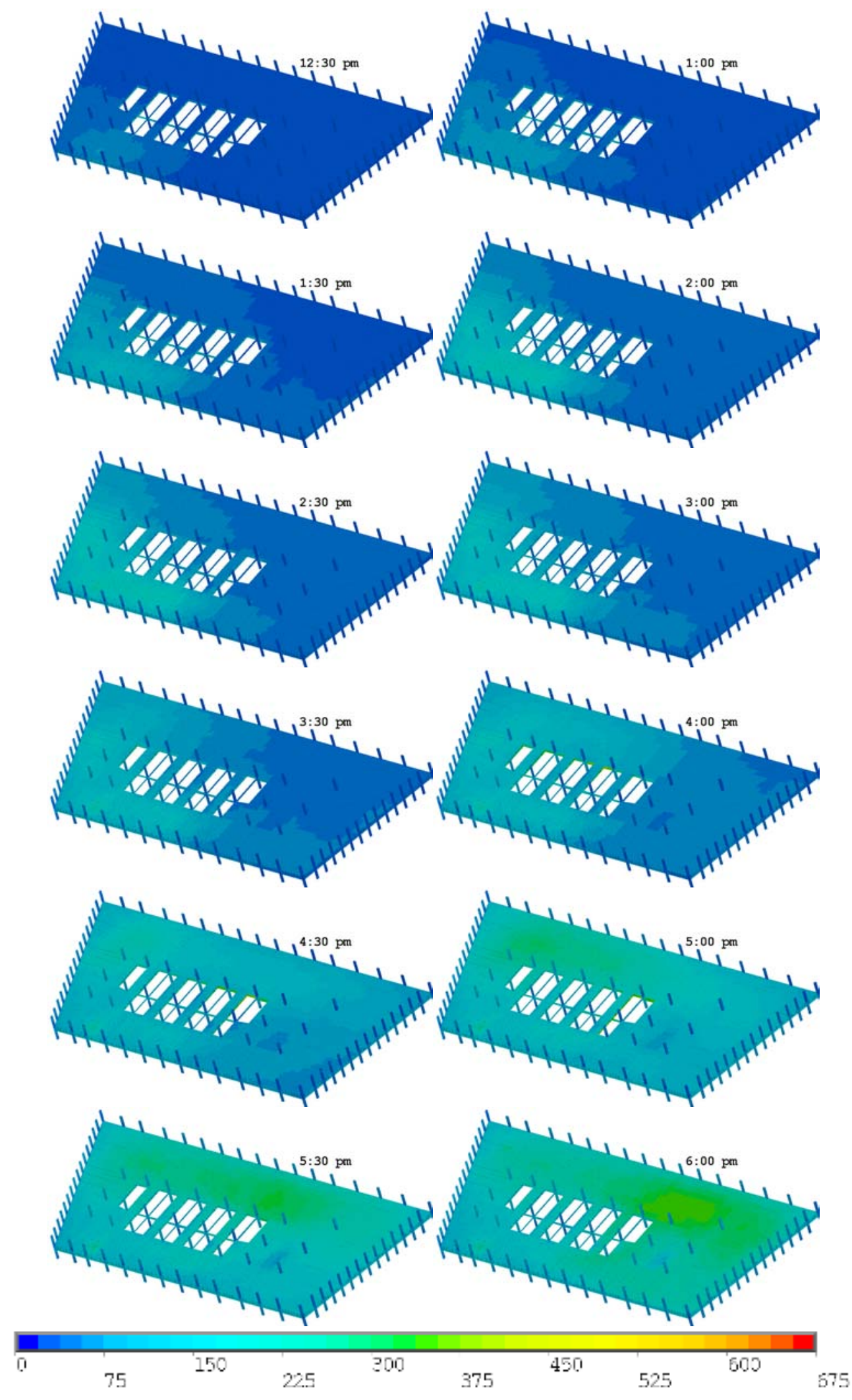

Figure 10-50. Computed temperature distribution $\left({ }^{\circ} \mathrm{C}\right)$ in the top layer of the concrete slab on Floor 9 at 12 instants in time (Case C). 


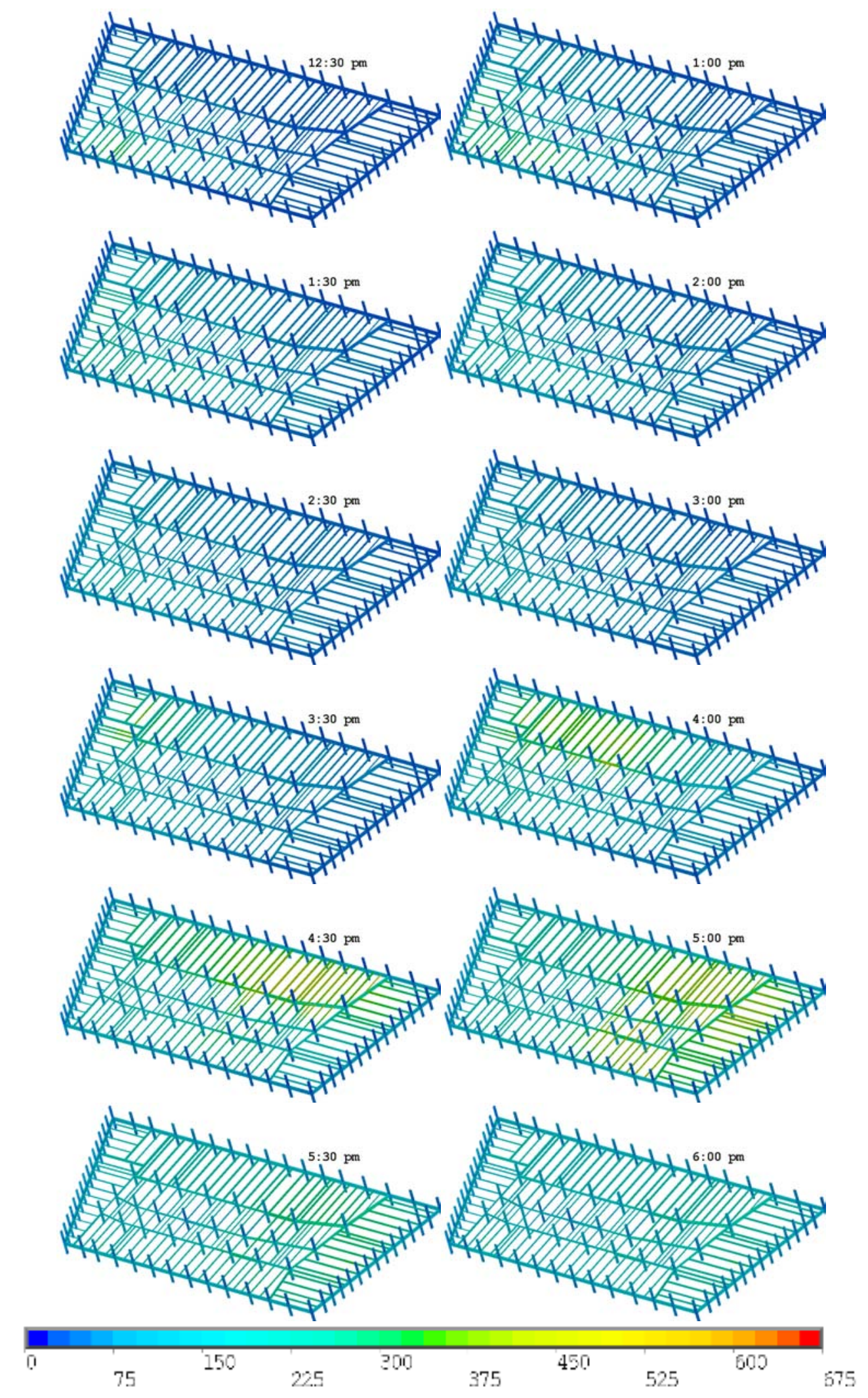

Figure 10-51. Computed temperature distribution $\left({ }^{\circ} \mathrm{C}\right)$ on the floor beams of Floor 9 at 12 different instants in time (Case $\mathrm{C}$, floor slabs removed). 

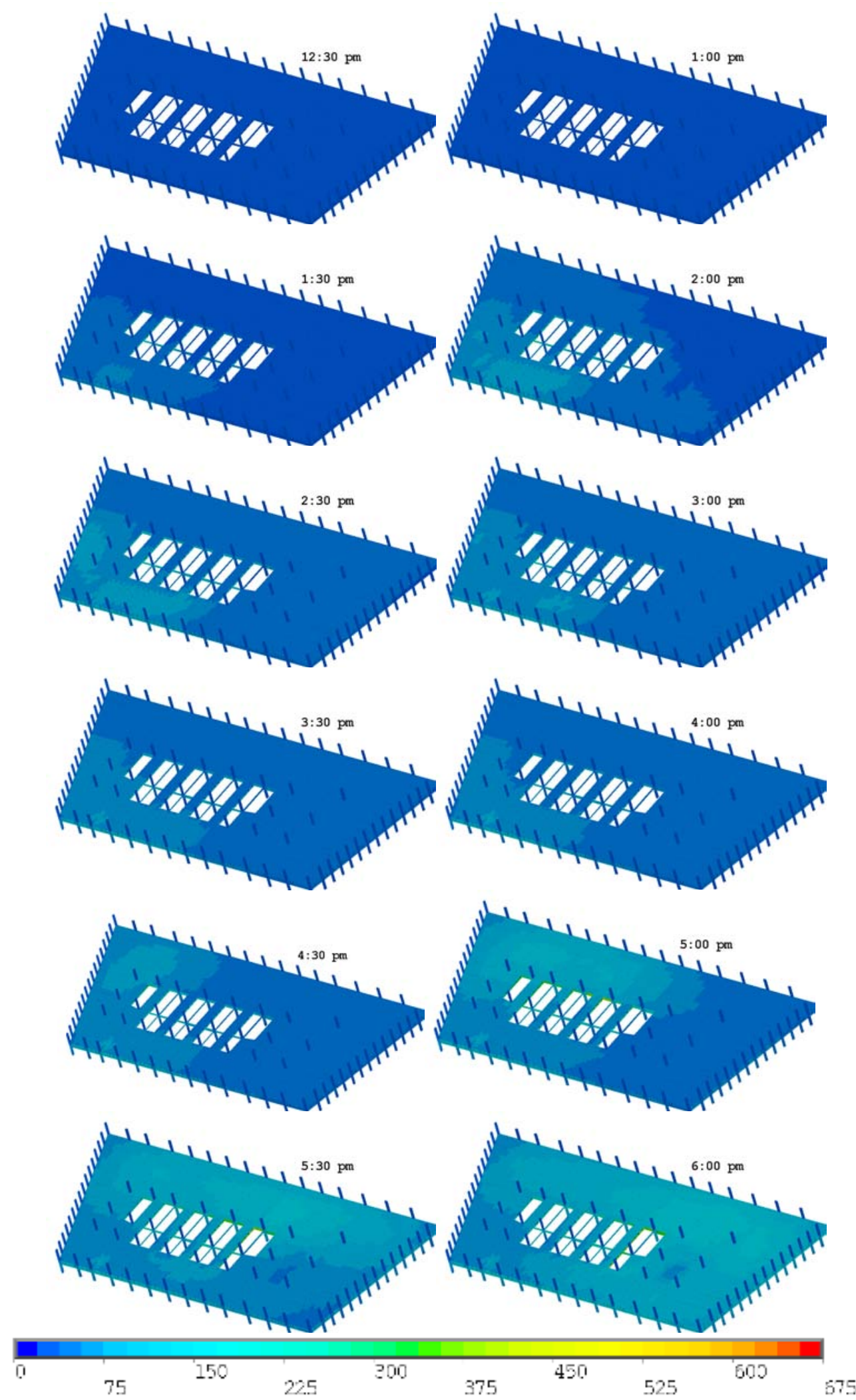

Figure 10-52. Computed temperature distribution $\left({ }^{\circ} \mathrm{C}\right)$ in the top layer of the concrete slab on Floor 10 at 12 instants in time (Case C). 


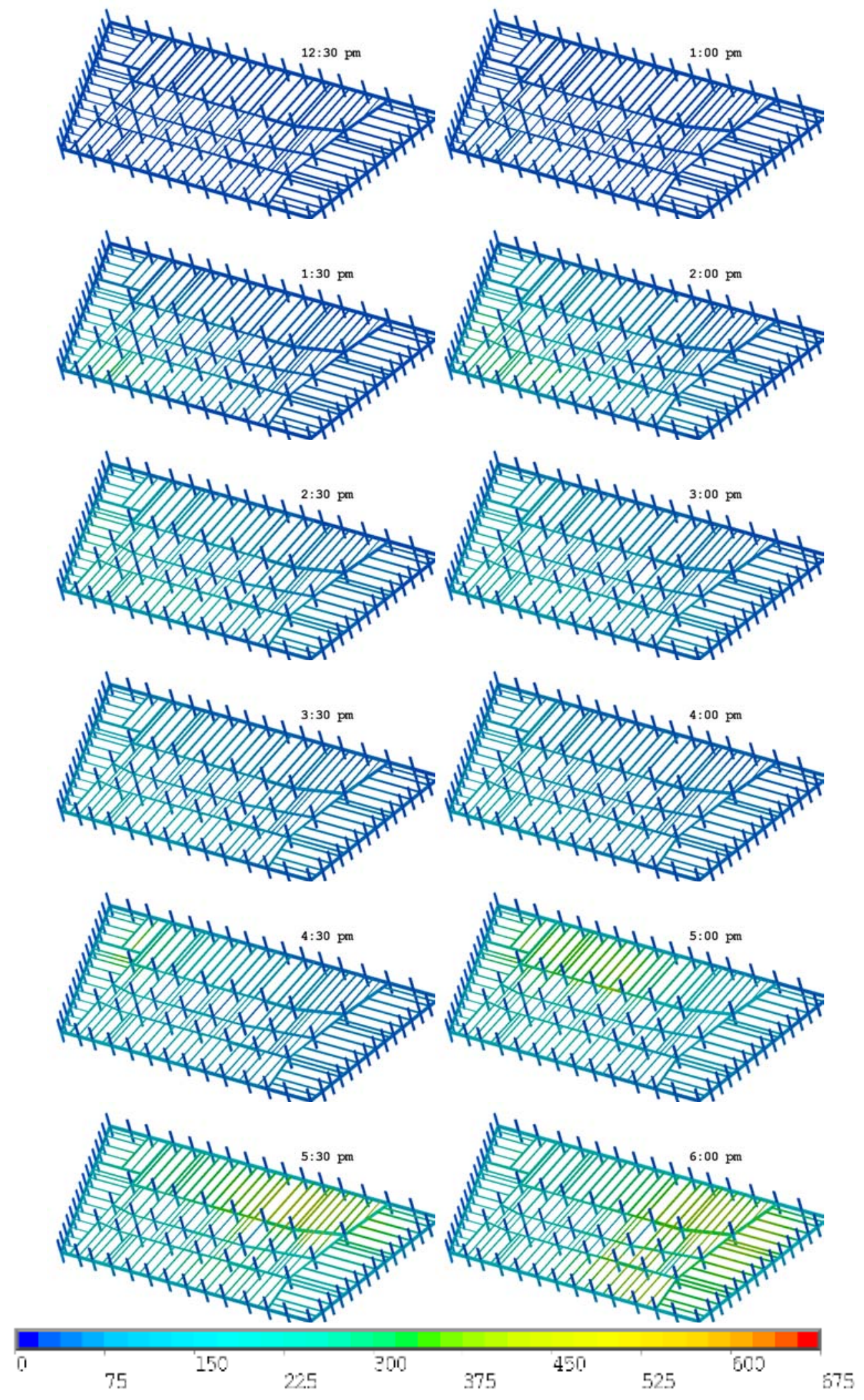

Figure 10-53. Computed temperature distribution $\left({ }^{\circ} \mathrm{C}\right)$ on the floor beams of Floor 10 at 12 different instants in time (Case $C$, floor slabs removed). 


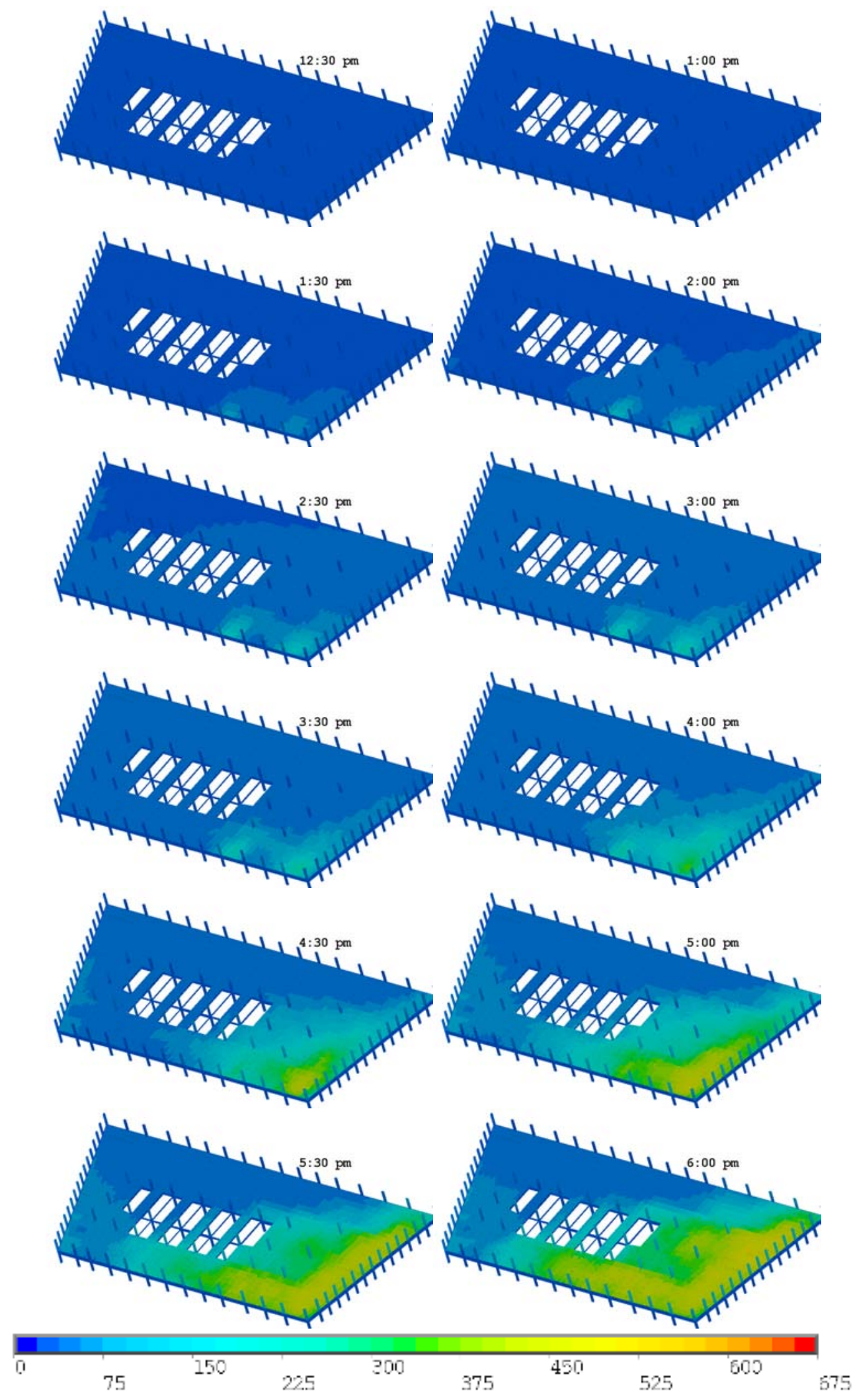

Figure 10-54. Computed temperature distribution $\left({ }^{\circ} \mathrm{C}\right)$ in the top layer of the concrete slab on Floor 11 at 12 instants in time (Case C). 


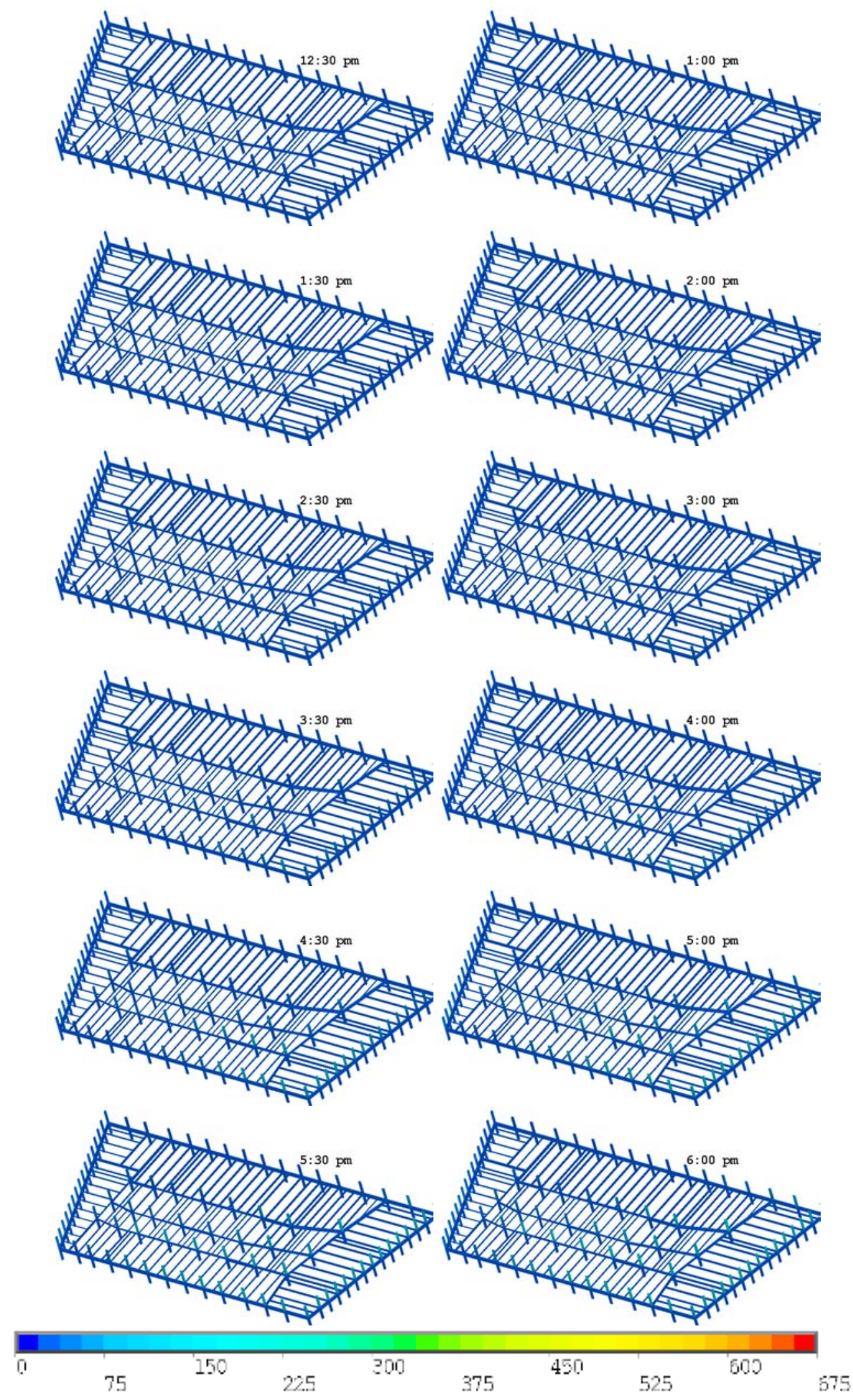

Figure 10-55. Computed temperature distribution $\left({ }^{\circ} \mathrm{C}\right)$ on the floor beams of Floor 11 at 12 different instants in time (Case $\mathrm{C}$, floor slabs removed). 


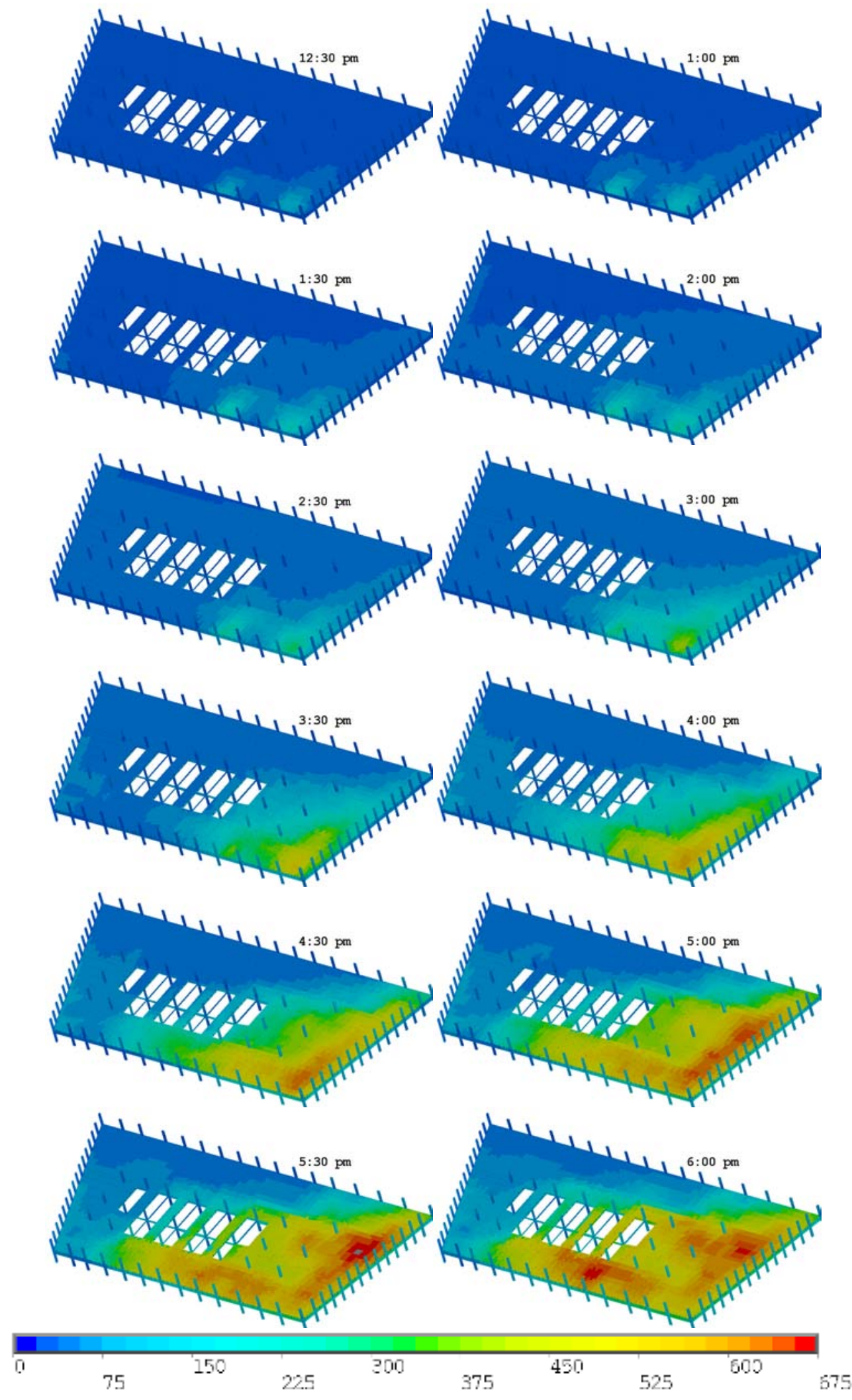

Figure 10-56. Computed temperature distribution $\left({ }^{\circ} \mathrm{C}\right)$ in the top layer of the concrete slab on Floor 12 at 12 instants in time (Case C). 


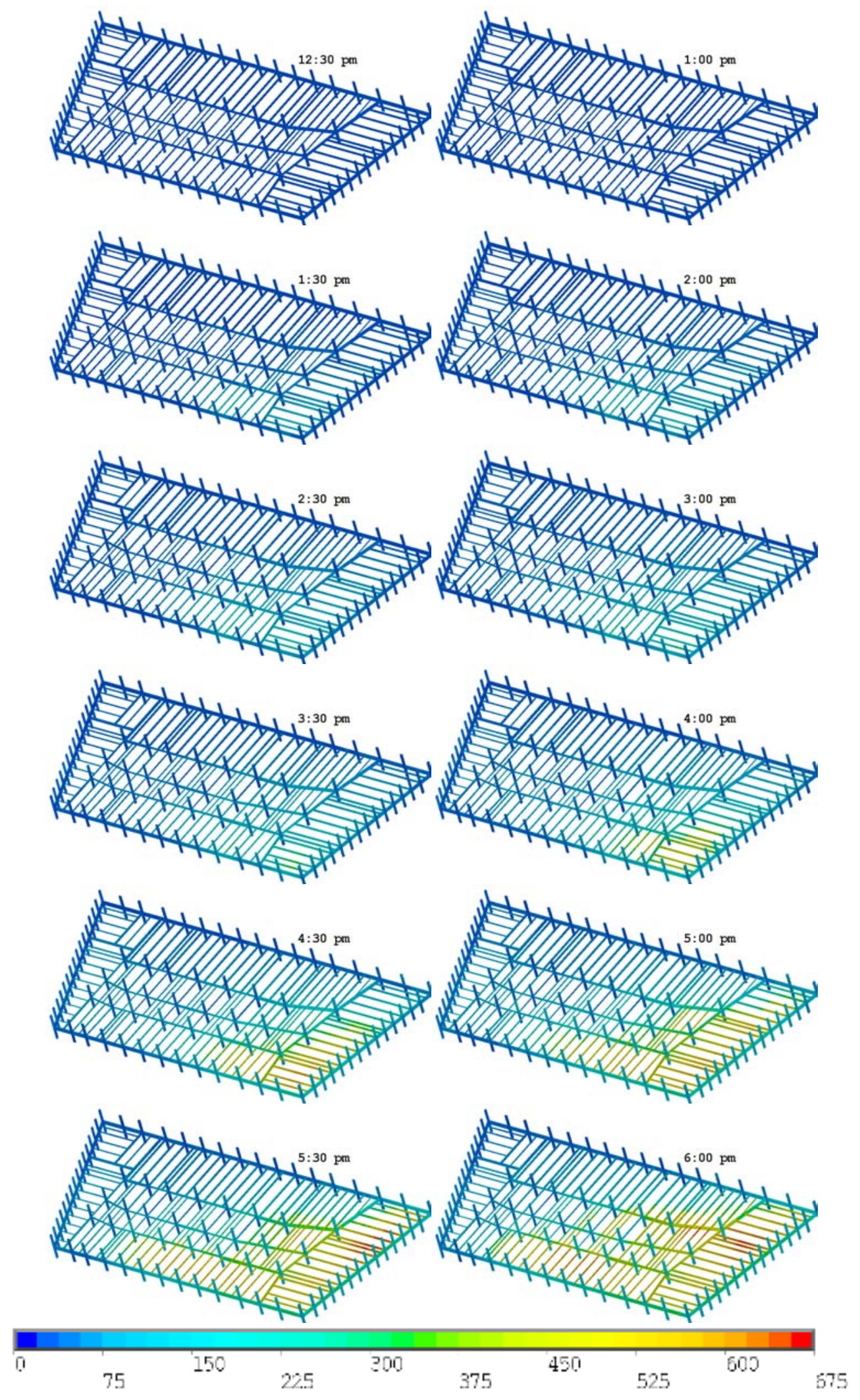

Figure 10-57. Computed temperature distribution $\left({ }^{\circ} \mathrm{C}\right)$ on the floor beams of Floor 12 at 12 different instants in time (Case $\mathrm{C}$, floor slabs removed). 

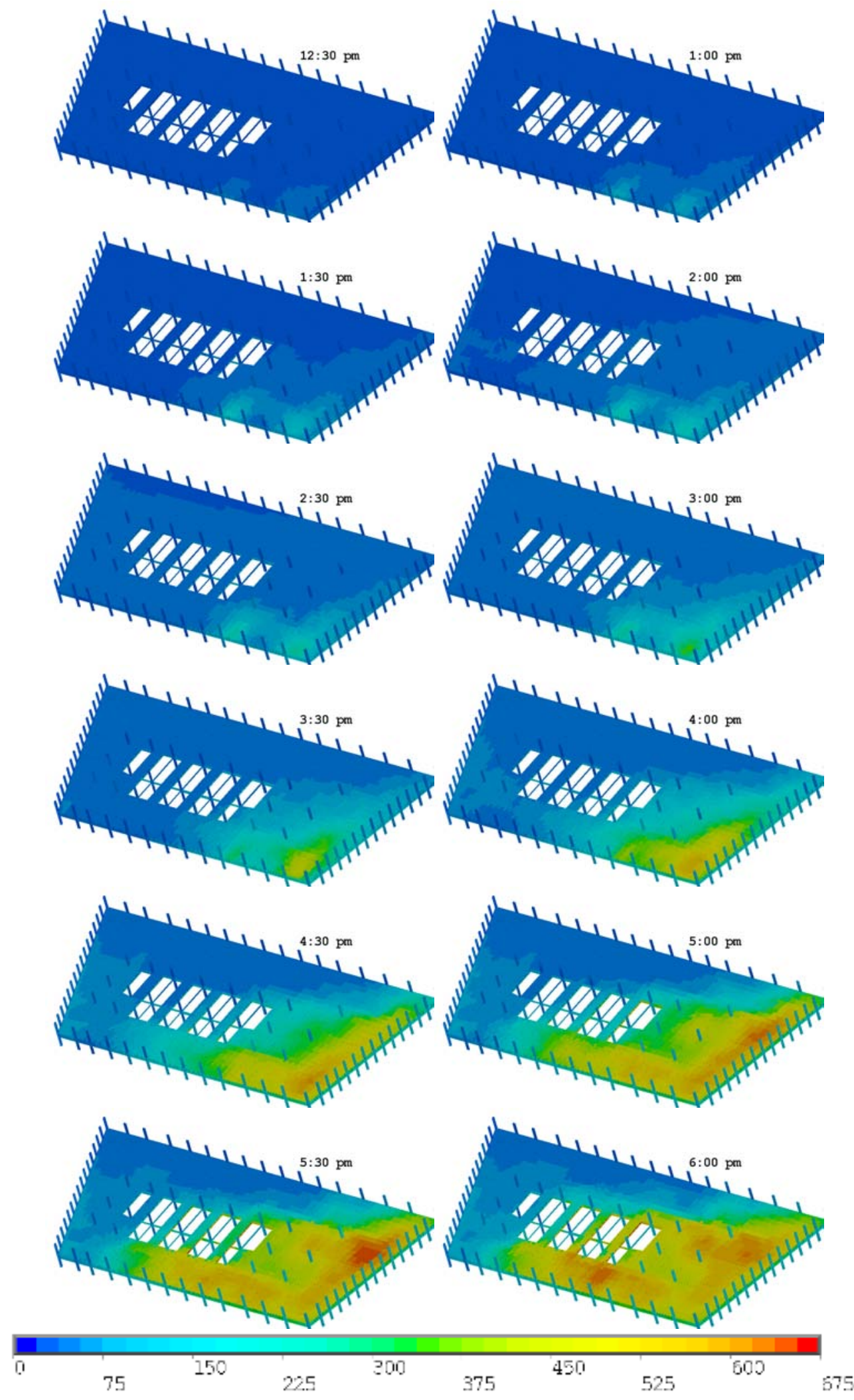

Figure 10-58. Computed temperature distribution $\left({ }^{\circ} \mathrm{C}\right)$ in the top layer of the concrete slab on Floor 13 at 12 instants in time (Case C). 


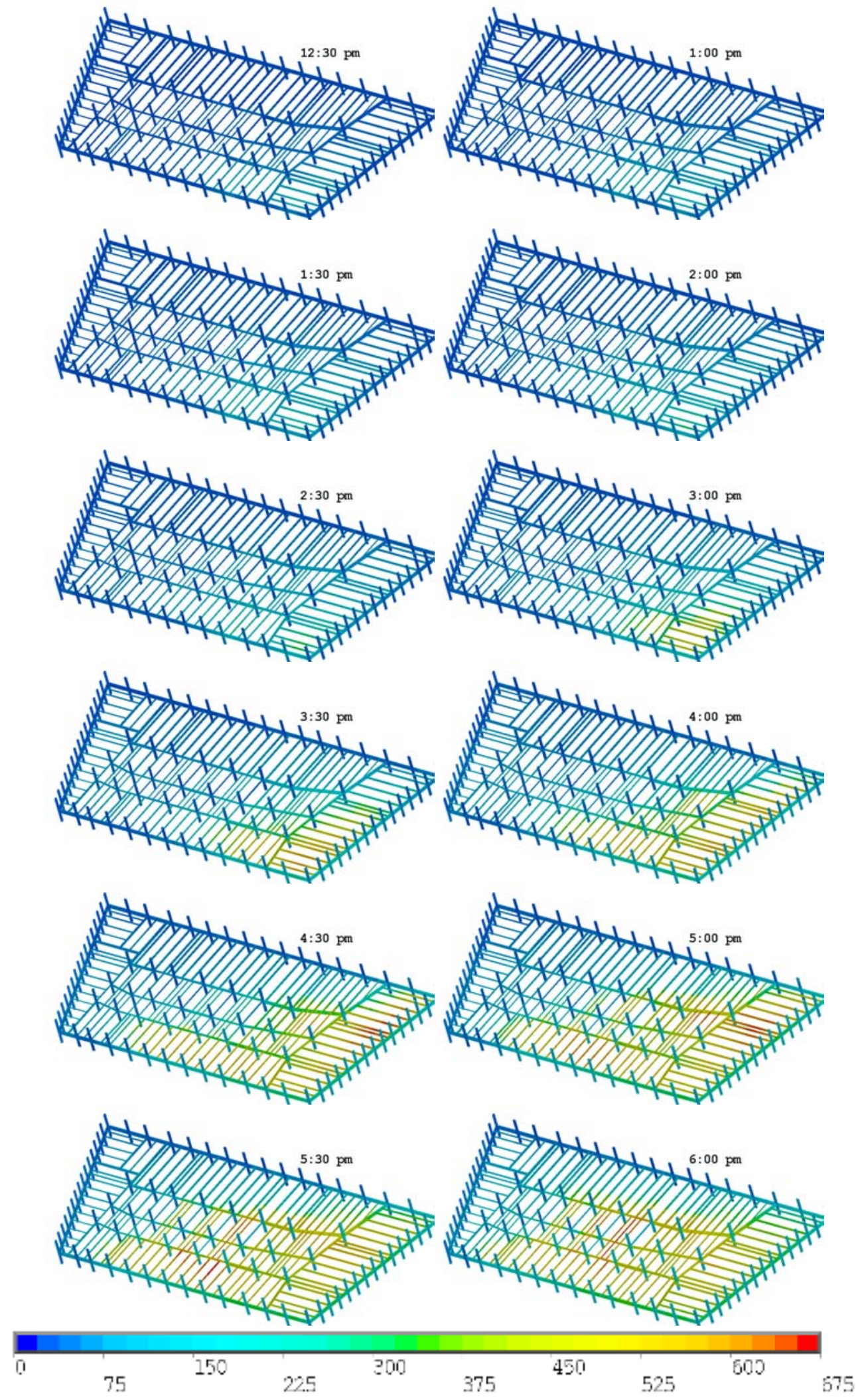

Figure 10-59. Computed temperature distribution $\left({ }^{\circ} \mathrm{C}\right)$ on the floor beams of Floor 13 at 12 different instants in time (Case $\mathrm{C}$, floor slabs removed). 

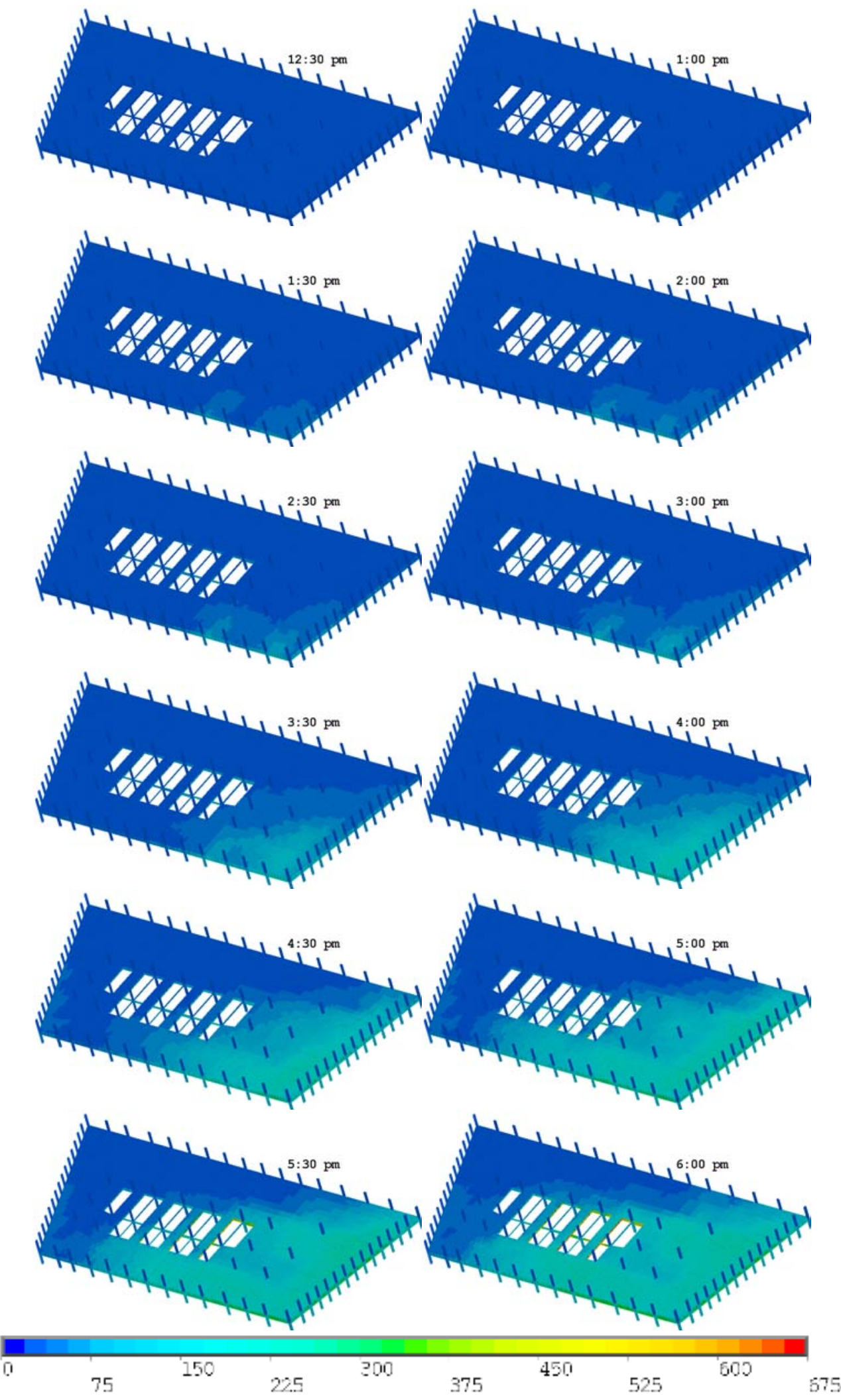

Figure 10-60. Computed temperature distribution $\left({ }^{\circ} \mathrm{C}\right)$ in the top layer of the concrete slab on Floor 14 at 12 instants in time (Case C). 


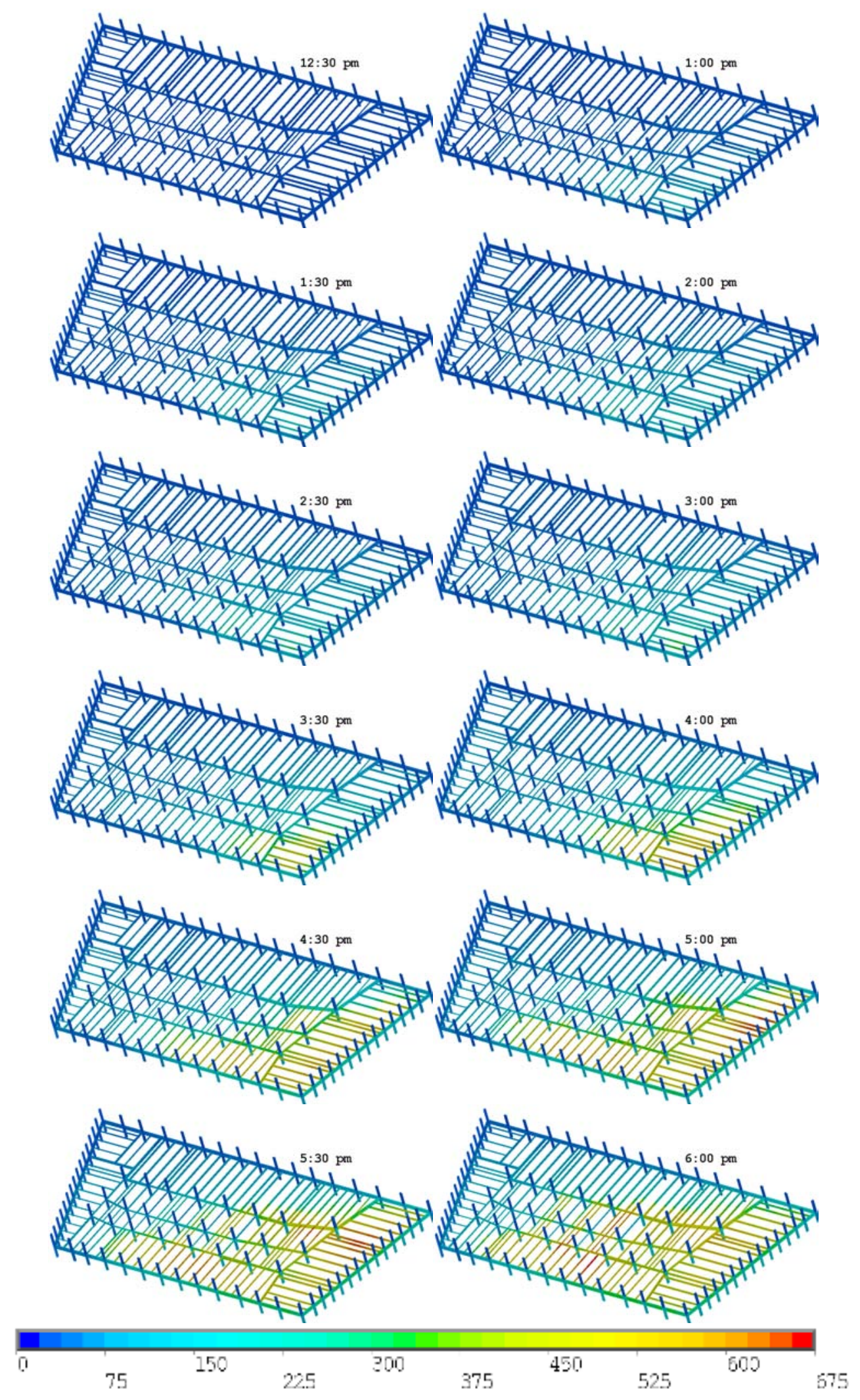

Figure 10-61. Computed temperature distribution $\left({ }^{\circ} \mathrm{C}\right)$ on the floor beams of Floor 14 at 12 different instants in time (Case $\mathrm{C}$, floor slabs removed). 


\subsection{FINDINGS FROM THE CALCULATED FIRE-INDUCED THERMAL RESPONSE OF WTC 7}

Imposing the heat from the simulated WTC 7 fires floor on the building structure led to significant heating of some structural components. Other structural components, particularly columns, remained relatively cool. FSI calculations were performed using the temperatures directly from the FDS simulations (Case A), temperatures that were 10 percent larger than the FDS temperatures (Case B), and temperatures that were 10 percent lower than the FDS temperatures (Case $\mathrm{C}$ ). The temperatures in the latter two Cases were within the expected range of realistic and reasonable fire-generated temperatures.

The following is a list of findings common to the three Cases:

- In none of the Cases did any of the columns, all of which were insulated, reach temperatures sufficiently high for significant loss of strength or stiffness.

o The temperatures of Columns 79,80 , and 81 stayed below $200{ }^{\circ} \mathrm{C}$ on all of the floors.

o Only on Floors 12 and 13 did any of the exterior column temperatures exceed $150^{\circ} \mathrm{C}$. On these floors, the temperatures on the east and south exterior columns reached $300^{\circ} \mathrm{C}$.

- The fires on the $7^{\text {th }}, 12^{\text {th }}$, and $13^{\text {th }}$ floors heated portions of the tops of the floor slabs to over $900^{\circ} \mathrm{C}$. In all cases, significant temperature gradients were observed through the thickness of the concrete slab.

- The temperatures of some sections of the floor beams supporting the $8^{\text {th }}, 12^{\text {th }}, 13^{\text {th }}$, and $14^{\text {th }}$ floor slabs exceeded $600{ }^{\circ} \mathrm{C}$, except for the $8^{\text {th }}$ floor beams in Case C. The temperatures of some sections of the floor beams supporting the $9^{\text {th }}$ and $10^{\text {th }}$ floors reached $400{ }^{\circ} \mathrm{C}$.

For each of the three cases, Table 10-1 indicates, in blue, those regions of the steel structure that reached a temperature at which nominally half the steel strength remains. It also indicates, in blue, the regions where the tops of the floor slabs reached a similar temperature. An arrow connecting two regions indicates a moving hot zone; a comma connecting two regions indicates both were heated simultaneously.

For the Case B computation, the following characteristics were observed relative to Case A results.

- The peak temperatures in the tops of the floor slabs increased by about $80^{\circ} \mathrm{C}$. The peak temperatures in the floor beams increased by about $75^{\circ} \mathrm{C}$.

- The floor area over which the temperatures of the supporting beams exceeded $600{ }^{\circ} \mathrm{C}$ increased significantly.

- The overlap between adjacent floors of these $>600^{\circ} \mathrm{C}$ zones increased significantly.

- The change in the temperatures of the exterior and core columns was not significant. 
For the Case $\mathrm{C}$ computation, the following characteristics were observed relative to Case A results:

- $\quad$ The peak temperatures in the tops of the floor slabs decreased by about $80{ }^{\circ} \mathrm{C}$. The peak temperatures in the floor beams decreased by about $60^{\circ} \mathrm{C}$

- The floor area over which the temperatures of the supporting beams exceeded $600{ }^{\circ} \mathrm{C}$ decreased significantly.

- The overlap between adjacent floors of these $>600{ }^{\circ} \mathrm{C}$ zones decreased significantly.

- The change in the temperature of the exterior and core columns was not significant.

Table 10-1. Regions in WTC 7 in which computed temperatures of structural components exceeded $600^{\circ} \mathrm{C}$.

\begin{tabular}{|c|c|c|c|c|c|c|c|c|c|}
\hline Floor $\rightarrow$ & Case & 7 & 8 & 9 & 10 & 11 & 12 & 13 & 14 \\
\hline \multirow{3}{*}{ Floor Beams } & A & None & $\mathrm{NE}$ & None & None & None & $\mathrm{E} \rightarrow \mathrm{S}$ & $\mathrm{E}, \mathrm{SE}$ & E,S \\
\hline & B & None & $\mathrm{NE}$ & None & None & None & $\mathrm{E} \rightarrow \mathrm{S}$ & $\mathrm{E}, \mathrm{SE}$ & $\mathrm{E}, \mathrm{S}$ \\
\hline & $\mathrm{C}$ & None & None & None & None & None & $\mathrm{E} \rightarrow \mathrm{S}$ & $\mathrm{E}, \mathrm{SE}$ & $\mathrm{E}, \mathrm{S}$ \\
\hline \multirow{3}{*}{ Floor Slabs } & A & $\mathrm{NW} \rightarrow \mathrm{NE}$ & None & None & None & E, SE & E,S & $\mathrm{E}, \mathrm{SE}$ & None \\
\hline & B & $\mathrm{NW} \rightarrow \mathrm{NE}$ & None & None & None & E, SE & $\mathrm{E}, \mathrm{S}$ & $\mathrm{E}, \mathrm{SE}$ & None \\
\hline & $\mathrm{C}$ & $\mathrm{NW} \rightarrow \mathrm{NE}$ & None & None & None & E, SE & E,S & E,SE & None \\
\hline \multirow{3}{*}{$\begin{array}{l}\text { Perimeter } \\
\text { Columns }\end{array}$} & A & None & None & None & None & None & None & None & None \\
\hline & B & None & None & None & None & None & None & None & None \\
\hline & $\mathrm{C}$ & None & None & None & None & None & None & None & None \\
\hline \multirow{3}{*}{$\begin{array}{l}\text { Interior } \\
\text { Columns }\end{array}$} & A & None & None & None & None & None & None & None & None \\
\hline & B & None & None & None & None & None & None & None & None \\
\hline & C & None & None & None & None & None & None & None & None \\
\hline
\end{tabular}




\section{Chapter 11 \\ STRUCTURAL ANALYSIS OF INITIAL FAILURE EVENT}

\subsection{OVERVIEW}

Two global structural models of WTC 7 were developed to simulate the response of the building to debris impact damage from the collapse of WTC 1 and subsequent fire effects, and to evaluate the collapse hypothesis.

The first model, developed in ANSYS (2007), was used to determine how and where the building failure began, which is referred to as the initial failure event or collapse initiation event. The model accounted for nonlinear geometric effects, temperature dependent behavior of members and connections (including thermal expansion and stiffness and strength degradation), the sequential failure of structural framing and connections under fire conditions, and removal of failed elements (with user intervention). The ANSYS model estimated the structural response to elevated temperatures of the lower 16 stories of the building, where the fires grew and spread, until an initial failure event became imminent following a series of local structural failures in the floor systems. Since the spatial and temporal changes in the temperature of structural members were slow relative to the dynamic characteristics (i.e., natural frequencies) of the building, the structural response to thermal loads was static in nature. Thus, the ANSYS analysis used a non-linear static procedure with an implicit solution algorithm that guaranteed force equilibrium at each time step. The ANSYS analyses are presented in this chapter.

The second model, developed in LS-DYNA, analyzed the collapse propagation phase by accounting for the structural response of the full 47 story structure to the initial failure event due to fire (from the 16 story ANSYS model) up to the collapse of WTC 7, and is presented in Chapter 12. This model accounted for the possibility for the development of progressive collapse of the entire building, including buckling instability of columns due to loss of lateral support, dynamic effects associated with failure progression, and debris impact from falling floors. The fire-induced damage from the ANSYS model were input into the LS-DYNA model as initial conditions.

The floor framing geometry, member sizes, and gravity loads for both models were obtained from structural and architectural drawings, as well as erection and fabrication shop drawings of connections for the steel framing (Section 2.4.2). Mechanical properties of steel and concrete materials, which included room and elevated temperature behaviors, were based on the relevant information developed during the investigation of the WTC towers.

An important feature of the WTC 7 ANSYS model was the user-defined elements that were developed to model the behavior and failure of floor framing connections at elevated temperatures. The structural floor connections were analyzed for all possible failure modes. The failure modes and their associated capacities were modeled with user-defined connection elements, which are also referred to as break elements. Break elements were used on the east side of Floors 7 to 14, where the fires were dominant prior to collapse. Including break elements at every connection location on these floors would have 
greatly increased the model size and affected the rate of solution convergence. Since the collapse of WTC 7 clearly initiated on the east side of the structure (Chapters 5 and 8), the break elements were only used in the east side of the model.

Debris impact damage from the collapse of WTC 1 was included in the LS-DYNA model, but not in the ANSYS model. The structural damage that was observed following the collapse of WTC 1 was between Floors 7 and 17 in the southwest quadrant of the building (Chapter 5). The WTC 7 structure redistributed loads around this damage through the Vierendeel truss action ${ }^{1}$ provided by the exterior moment frame. The ANSYS model, which modeled the structure from ground level to Floor 16, did not include a sufficient number of floors to capture the load redistribution following the debris impact damage. Inclusion of debris damage was unnecessary for analyzing the initiating event which occurred in the northeast region of the building.

The ANSYS analysis included the effects of gravity and temperature loads. Gravity loads included: the dead load of the structure; superimposed dead loads consisting of the weight of ceilings, mechanical and electrical equipment, thermal insulation, and floor finishes; and service live load, which was taken as 25 percent of the design live load specified in the original design documents. The gravity loads from the floors above Floor 16 were applied to the top of the columns in the model. Wind loads were not considered in the analyses, as the wind speeds on September 11, 2001, were not structurally significant.

Temperature data were input at 30 min intervals for the fires observed on Floors 7 to 9, and 11 to 13 . The temperature data were obtained from the FSI analysis (Chapter 10), which was based on the FDS analysis of the fires (Chapter 9). Three different thermal cases were developed and used in the ANSYS analysis. These cases were within the range of realistic and reasonable fires in WTC 7 on September 11, 2001. Case A used the temperature data as obtained from the FDS simulations. Cases B and C increased and decreased, respectively, the Case A gas temperature by 10 percent, which was judged to be within the range of uncertainty for these fires.

\subsection{ANSYS MODEL}

\subsubsection{Model Description}

A finite element model, referred to hereafter as the 16 story model, was developed and is illustrated in Figure 11-1. As fires were observed on Floors 7 to 9 and 11 to 13, the floors and columns in these areas were subject to heating and possible thermally induced failures, while floors and columns above Floor 14 and below Floor 7 were not. Floor framing between Floors 8 and 14 and columns between Floors 7 and 14 were explicitly modeled, while Floor 7 and below and Floors 15 and 16 were modeled using superelements. Superelements reduce the degrees of freedom, and hence, computational time, while appropriately representing the stiffness at the top and bottom of the model.

The gravity load was applied in stages to represent the effects of construction sequence. The thermal loading was applied in the form of temperature-time histories. Examination of temporal changes in structural elements temperatures with time during the FSI analysis found that the temperature state of

\footnotetext{
${ }^{1}$ Most trusses have a triangular shape and pinned joints that can transfer forces but not bending moments. A Vierendeel truss has a rectangular shape and fixed joints that can transfer and resist forces and bending moments.
} 
steel and concrete members could be provided at 30 min intervals to the ANSYS model, and linearly interpolated between these intervals, to reasonably model the spatial and temporal temperature changes in the structural system.

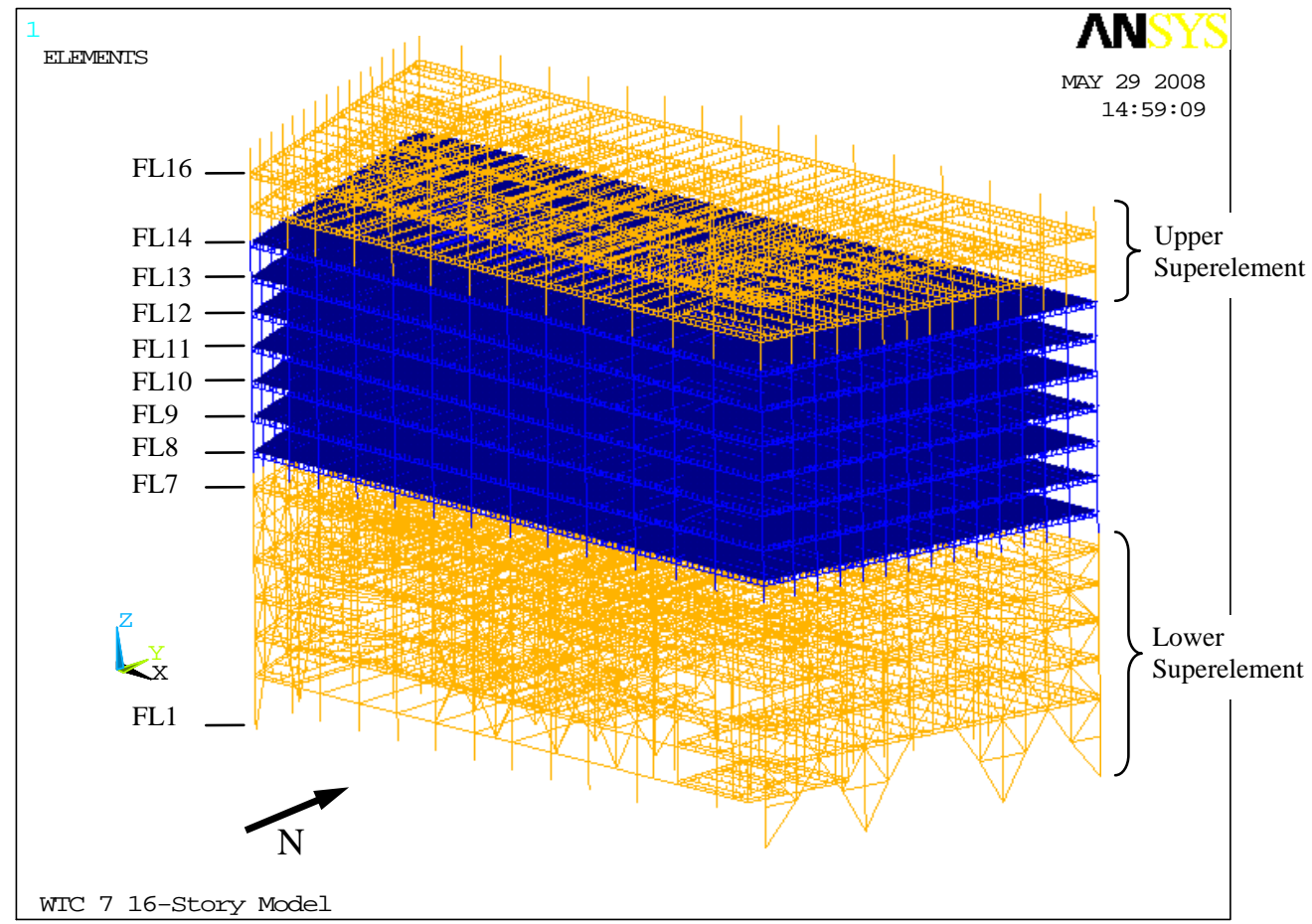

Figure 11-1. 16 story model representing lower 16 floors of the WTC 7 building.

In developing the 16 story model, various subsystems were analyzed to (1) evaluate the performance of connection element models, (2) evaluate the performance of a model with a composite floor beam and connections under temperature effects, and (3) determine the number of elements needed to capture lateral-torsional buckling of beams and girders and buckling of columns. Results of the subsystem analyses were used in the development of the 16 story model.

Element types used in developing the 16 story model are summarized in Table 11-1. Beams and girders for floor framing and columns were modeled using ANSYS BEAM188 element type with temperaturedependent inelastic material properties. Typically, the columns were meshed with $2 \mathrm{ft}$ long elements, and beams were meshed with $3 \mathrm{ft}$ long elements. Typical mesh size for the floor slab was selected as $3 \mathrm{ft} \times 3$ ft. BEAM188 elements are suitable for analyzing slender to moderately stubby/thick beam structures, are based on Timoshenko beam theory, and include shear deformation effects. The floor slab was modeled using SHELL181 element type with temperature-dependent inelastic material properties.

Rigid beams were typically used in connection models between beams and girders, girders and columns, and shear studs between floor beams and the floor slab to simulate composite action in the floor system. BEAM4 element type was used to model the rigid beams. The CONTA178 element type was used to model contact and sliding between two nodes in floor beam, girder, floor slab, and connection components. COMBIN37, COMBIN39, USER102, USER103, and USER104 element types were used to model beam-to-girder and girder-to-column connections. COMBIN37 is a unidirectional element with 
the capability of turning on and off during an analysis. COMBIN39 is a unidirectional element with nonlinear generalized force-deflection capability. USER103 and USER104 elements were used to model shear connections. USER105 element type was used to model failure of shear studs. Details of how these connections were modeled are discussed in Section 11.2.5.

Nonlinearities in the analysis, especially sequential local failures, required small time steps (e.g. ranging from $10^{-6}$ seconds to 10 seconds) to complete one equilibrium iteration. For this reason, simulation of a 30 min temperature time history sometimes took several weeks to complete and a complete ANSYS analysis for a given thermal case took approximately six months to complete on a 64 bit workstation with a quad-core, 3.0 GHz processor, and 64 GB of Random Access Memory (RAM). The inclusion of userdefined elements prevented parallel processing on a Linux cluster.

Table 11-1. Element types used in 16 story model.

\begin{tabular}{|l|c|c|l|}
\hline \multicolumn{1}{|c|}{ Element Type } & Number of Elements & \multicolumn{1}{c|}{$\begin{array}{c}\text { Material } \\
\text { Model }\end{array}$} & \multicolumn{1}{c|}{ Application } \\
\hline BEAM188 & 21,095 & Inelastic & Beams, girders, and columns \\
\hline BEAM4 & 28,182 & Elastic & $\begin{array}{l}\text { Beams between floor slab and } \\
\text { beams and in modeling connections }\end{array}$ \\
\hline SHELL181 & 34,461 & Inelastic & Floor slab \\
\hline CONTA178 & 6,342 & Inelastic & $\begin{array}{l}\text { Contact between floor beams/girders } \\
\text { and floor slab }\end{array}$ \\
\hline COMBIN37 & 504 & Inelastic & User-defined connections \\
\hline COMBIN39 & 812 & Inelastic & User-defined connections \\
\hline USER102 (Break Element) & 1,176 & Inelastic & User-defined connections \\
\hline USER103 (Break Element) & 2,520 & Inelastic & User-defined connections \\
\hline USER104 (Break Element) & 1,512 & Inelastic & User-defined connections \\
\hline USER105 (Break Element) & 4,753 & Inelastic & User-defined shear stud connections \\
\hline Total Number of elements = 101,357 & & & \\
\hline Total number of nodes = 93,413 & & & \\
\hline
\end{tabular}

\subsubsection{Temperature-dependent Material Properties}

The mechanical properties of steel are affected significantly by elevated temperatures. The steel for all beams and interior columns was ASTM A572 Grade 50, and the steel for exterior moment frames was ASTM A36. Material specifications for cover plates on the interior columns were based on plate thickness t (in.), where:

$$
\begin{aligned}
& 2<\mathrm{t}<4 \quad \text { ASTM A588 Grade } 50 \\
& 4<\mathrm{t}<6 \quad \text { ASTM A572 Grade } 42 \\
& \mathrm{t}>6 \quad \text { ASTM A588 Grade } 42
\end{aligned}
$$


The steel used for the connections was a Canadian Algoma steel plate, specified as CSA G40.21-44W with a nominal yield strength of $44 \mathrm{ksi}$.

The same procedure used for the WTC towers to develop temperature dependent material properties was used for the WTC 7 steel (see Appendix E). For the WTC 7 analysis, material properties were developed for the Algoma 44W steel plate and temperature dependent material properties were developed for ASTM A325 and A490 bolts.

No test data existed for the CSA G40.21-44W steel. The true stress-strain behavior was modeled as an average of the A572 and A36 behaviors, but chemically the steel is more like A572 than A36. Therefore, the estimated tensile strength was developed with strain criteria for A572. The yield and tensile strength of bolts degrade more rapidly with increasing temperature than do ordinary structural steels (Yu 2006). A separate relationship to describe their yield and tensile behavior, based on limited data available in the literature, was developed. The development of these data is described in Appendix E.

The analysis used the ANSYS multilinear isotropic hardening model (MISO) for temperature dependent material properties for steel and concrete. MISO defines piecewise linear stress-strain curves at specified temperatures. The slope of the first segment between the implied $(0,0)$ and the first point, which is the yield strength, must equal the elastic modulus for the specified temperature. The stress-strain curves were expressed as eleven data files at specific temperatures: (20, 400, 450, 500, 550, 600, 650, 700, 750, 800, $850)^{\circ} \mathrm{C}$. The piecewise linear MISO models for A572 steel and the concrete slab are shown in Figure 11-2 and Figure 11-3, respectively.

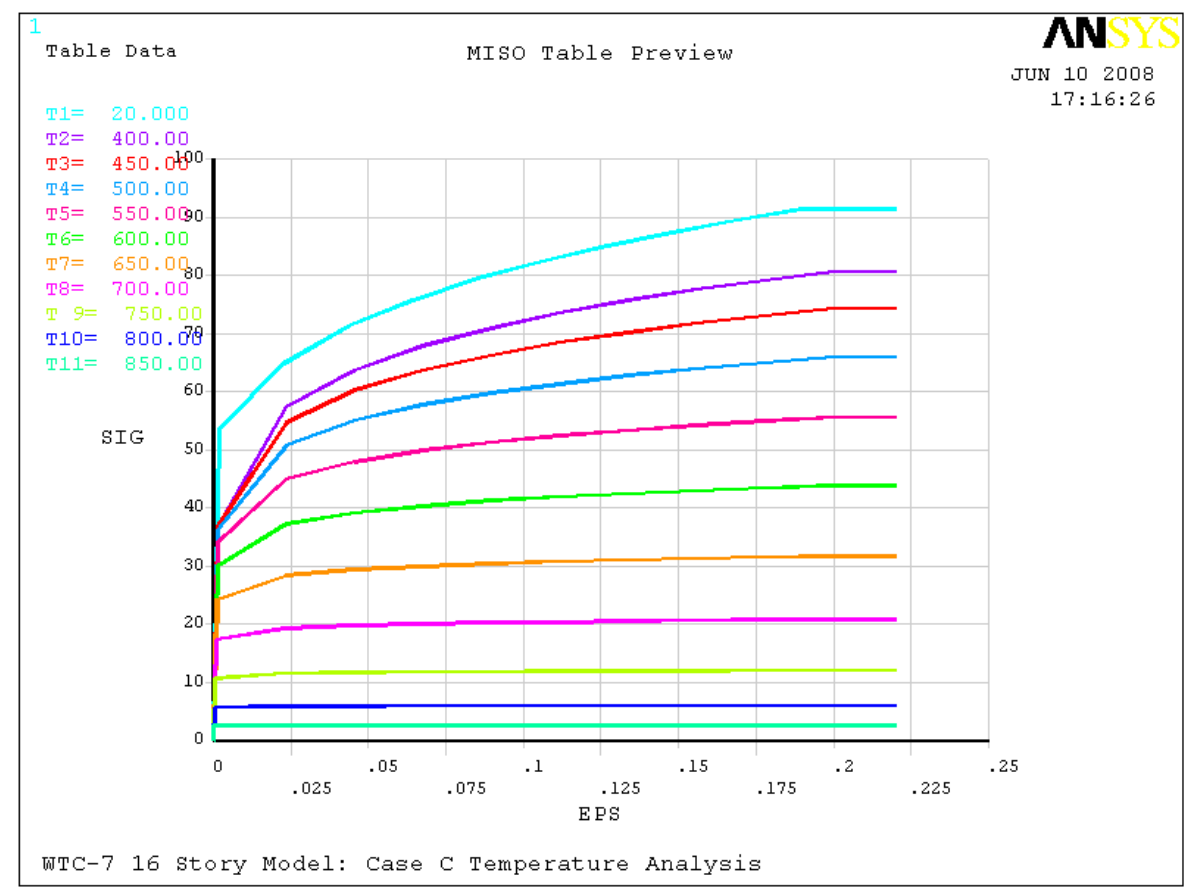

Figure 11-2. ANSYS multilinear isotropic hardening (MISO) model for temperature-dependent behavior of ASTM A572 grade 50 steel. 
The floor slabs had a normal weight concrete with a specified 28-day compressive strength of 3,500 psi. Even though concrete behavior is different in compression and tension, ANSYS did not have a material model that could input different compression and tension stress-strain curves for the SHELL181 element type. The only element that supported the concrete material model was SOLID65 which, if used, would significantly increase the number of degrees of freedom and, hence, the computation time. Therefore, SHELL181 elements were used to model the concrete slab and concrete using a compressive stress-strain relationship for both tension and compression (compressive failures occur at approximately 4,000 psi relative to tensile failures at approximately $500 \mathrm{psi}$ ). Concrete failure by crushing in compression and cracking in tension were accounted for by checking element strains against limiting strain criteria. Once these strain criteria were met, elements were either softened or removed as described in Section 11.2.9.

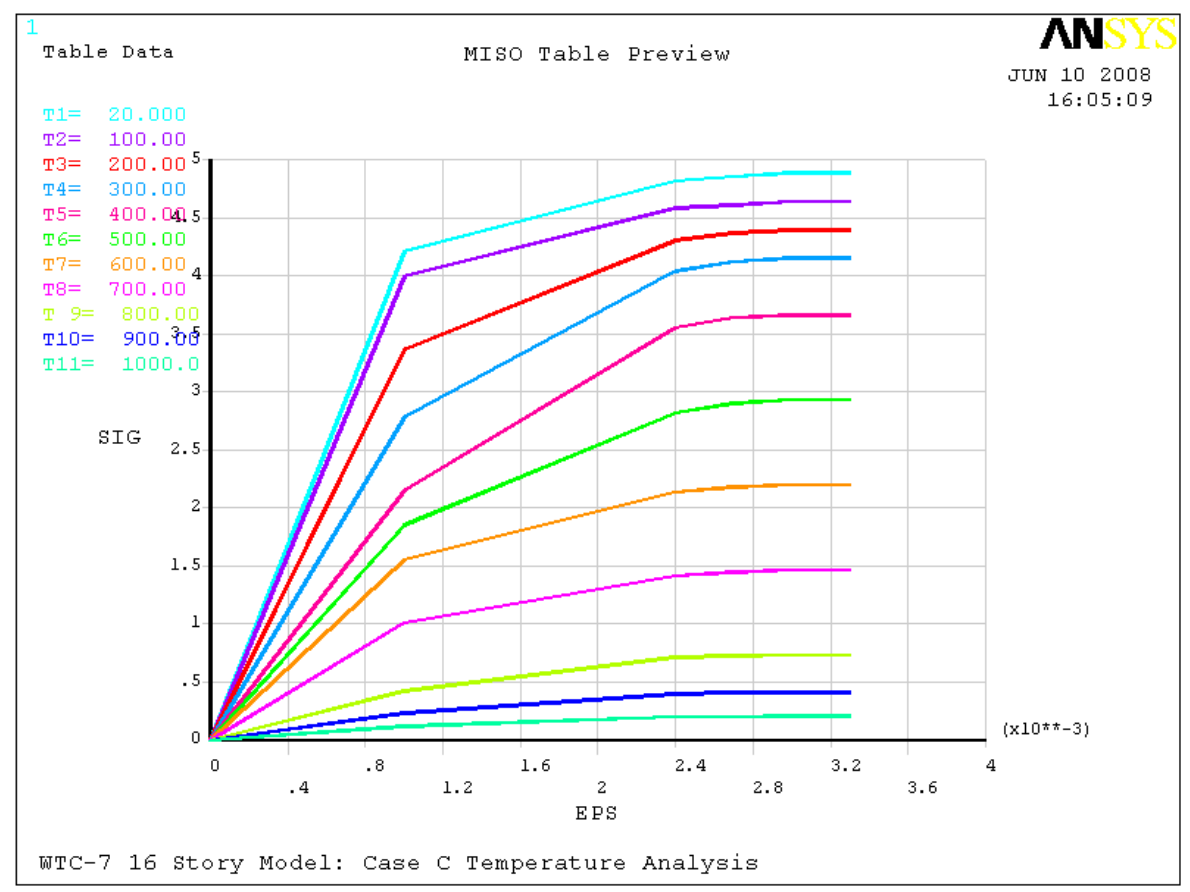

\section{Figure 11-3. ANSYS multilinear isotropic hardening (MISO) model for temperature-dependent behavior of 4000 psi normal weight concrete slab.}

\subsubsection{Modeling Composite Floor System}

In WTC 7, the floor system was designed for composite behavior between the floor beams and the slab (Chapter 2). Composite behavior was achieved through shear studs that were welded to the top flanges of the beams and embedded in the concrete slab. The shear studs transferred shear loads between the slab and beams. Floor beams and exterior spandrel beams had shear studs, but the girders that supported the floor beams did not have shear studs.

The composite floor system was modeled as shown in Figure 11-4. The floor slab was modeled at the centerline elevation of the slab, using the SHELL181 element type. Beams and girders of the floor framing were modeled at their section centroid, using the BEAM188 element type. The mesh of the floor slab was aligned with that of beams and girders. 


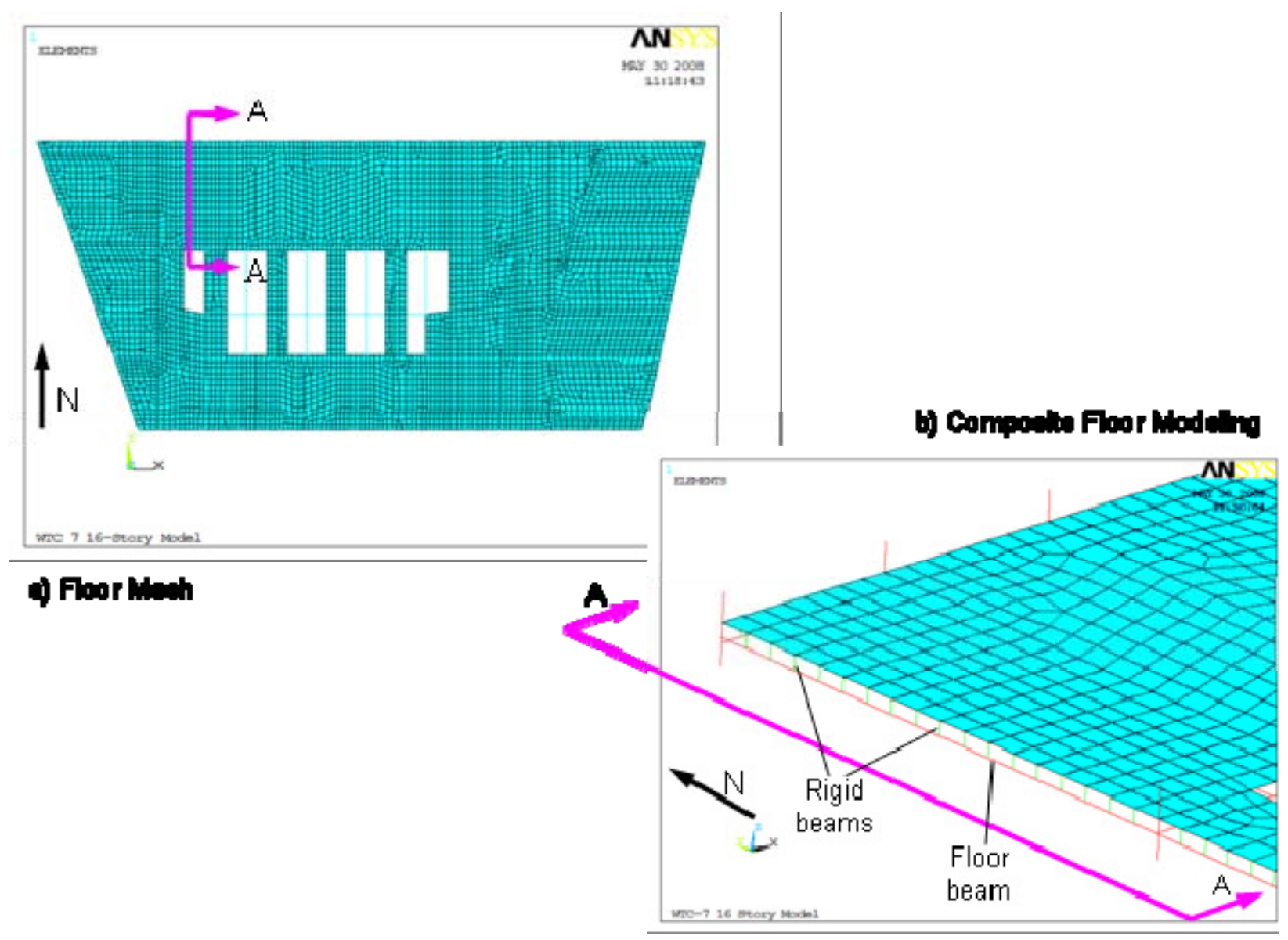

Figure 11-4. Finite element representation of the composite floor system.

Contact elements were used between the slab and girder to allow the slab to transfer gravity loads, but not lateral shear forces to the girder. Contact elements also allowed the girders to deflect independently of the floor slab, and prevented slab penetration through the girder. To model composite action between floor beams and slabs, break elements were used to represent shear stud connectors. The break elements represented the temperature-dependent shear stud capacity and captured shear failures between the concrete slab and the shear stud. Details of modeling the shear studs using break elements are discussed in Section 11.2.5.

The gravity load on the floor slab was transferred to the floor beams, then to the girders, and finally to the columns. The floor slab did not have structural connections to the girders or columns.

\subsubsection{Floor Framing Connection Failure Modes}

To determine the capacities of the various types of floor connections (Chapter 2), failure modes were evaluated for each connection type. Failure modes included weld failure, bolt failure (both shear and tension), plate tear-out, and block shear failure. Capacities, also referred to as failure loads or ultimate strength, were based on the AISC LRFD design provisions (AISC 2005). To determine failure loads instead of design loads, resistance factors were set to 1.0. 


\section{Weld Failure}

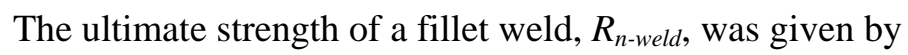

$$
R_{n \text {-weld }}=F_{w} A_{w} \quad \text { (Eq. J2-4, LRFD) }
$$

where

$$
F_{w}=0.60 F_{E X X}\left(1.0+0.50 \sin ^{1.5} \theta\right) \quad(\text { Eq. J2-5, LRFD) }
$$

and

$F_{E X X} \quad=$ electrode classification number, ksi

$\theta \quad=$ angle of loading measured from the weld longitudinal axis, degrees

$A_{w} \quad=$ effective area of the weld, in. ${ }^{2}$

The area of a fillet weld was taken as the throat $\times$ length, or

$$
\begin{aligned}
& A_{w}=L_{w} \times(\sqrt{ } 2 / 2)(\mathrm{D} / 16) \\
& \text { where } \\
& L_{w} \quad=\text { length of weld, in. } \\
& \mathrm{D} \quad=\text { size of fillet weld (leg) in 16ths of an inch. }
\end{aligned}
$$

Weld electrodes were specified as E70xx, for which $F_{E X X}=70 \mathrm{ksi}$. Therefore, the nominal weld strength was given by

$$
R_{n-\text { weld }}=1.86\left(1+0.50 \sin ^{1.5} \theta\right) L_{w} \times \mathrm{D}
$$

When a weld group was loaded eccentrically, as occurred in the header connections under a vertical shear force, there was a combined effect of the shear force and the moment resulting from the eccentric application of the shear force to the weld group ${ }^{2}$. To account for this combined effect, the "instantaneous center of rotation” method, found in AISC Manual (AISC 2005), was used to determine the weld group ultimate capacity.

\section{Bolt Shear Failure}

Bolt shear failure occurs when two surfaces, such as a connector plate and a beam web, are displaced relative to each other and sever the bolt across its cross section. The ultimate shear strength of a single

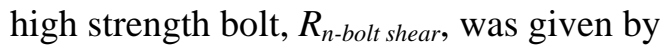

\footnotetext{
${ }^{2}$ A weld group is a set of several welds in a single connection. The welds typically are oriented perpendicular to each other and may have different lengths. For instance, to weld a connector plate to a beam web, a weld group consisting of a weld along the end and both sides of the plate may be used.
} 
$R_{n \text {-bolt shear }}=A_{b} \times F_{n v} \quad$ (Eq. J3-1, LRFD)

where

$$
\begin{aligned}
& A_{b} \quad=\text { area of the bolt shank, in. }{ }^{2} \\
& F_{n v} \quad=\text { nominal bolt shear stress, ksi. }
\end{aligned}
$$

For determination of bolt shear capacity, the threads were assumed to be excluded from the shear plane. This is a conservative assumption since the bolt section with threads has a reduced cross-sectional area. In bearing-type connections, the nominal shear stress of ASTM A325 bolts is 60 ksi (AISC 2005, Table J3.2). Kulak (2002) stated that the values in Table J3.2 were decreased by 20 percent to account for the uneven load distribution that occurs in splice connections, where a line of bolts are parallel to the applied load. However, in shear connections, the loads are distributed evenly among all bolts under both vertical and horizontal loading. Thus, the nominal shear stress was adjusted (divided by 0.8 ) to give

$$
F_{n v-A 325}=60 / 0.8=75 \mathrm{ksi}
$$

For a 7/8 in. A325 bolt, the bolt shear capacity was

$$
R_{n-\text { bolt shear }}=0.601 \mathrm{in}^{2} \times 75 \mathrm{ksi}=45 \mathrm{kip}
$$

Similarly, the ultimate shear strength of ASTM A490 bolts is 75 ksi (AISC 2005, Table J3.2), so following the same procedure gave

$$
F_{n v-A 490}=75 / 0.8=93.75 \mathrm{ksi} \text {. }
$$

In determining the shear strength of a bolt group, it was possible that the last bolt in a line would result in plate tear out before its shear strength was developed. Thus, tear-out failure, as described below, had to be accounted for in determining the shear strength of a bolt group.

\section{Bolt Tension Failure}

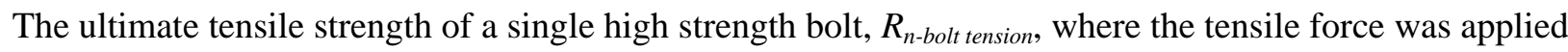
along the length of the bolt, was given by

$$
R_{n \text {-bolt tension }}=A_{b} \times F_{n t} \quad \text { (Eq. J3-1, LRFD) }
$$

where

$$
\begin{aligned}
& A_{b} \quad=\text { area of the bolt shank, in. }{ }^{2} \\
& F_{n t} \quad=\text { nominal bolt tensile strength, ksi. }
\end{aligned}
$$

For ASTM A325 bolts, $F_{n t-325}$ is 90 ksi and for ASTM A490 bolts, $F_{n t-490}$ is 113 ksi (from AISC 2005, Table J3.2). 


\section{Tear-out Failure}

Tear-out failure occurs along two shear planes in the connector plate, as indicated in Figure 11-5. The ultimate tear-out strength, $R_{u \text {-tearout, }}$ was given by

$$
R_{u-\text { tearout }}=1.5 L_{c} t F_{u} \quad(\mathrm{~J} 3-6 \mathrm{c}, \mathrm{LRFD})
$$

where $L_{c}$ is the clear distance between the edge of the hole and the edge of the plate, $t$ is the plate thickness, and $F_{u}$ is the ultimate tensile stress. Ultimate strengths for tear-out failure were calculated for both the beam web and the connection plate.

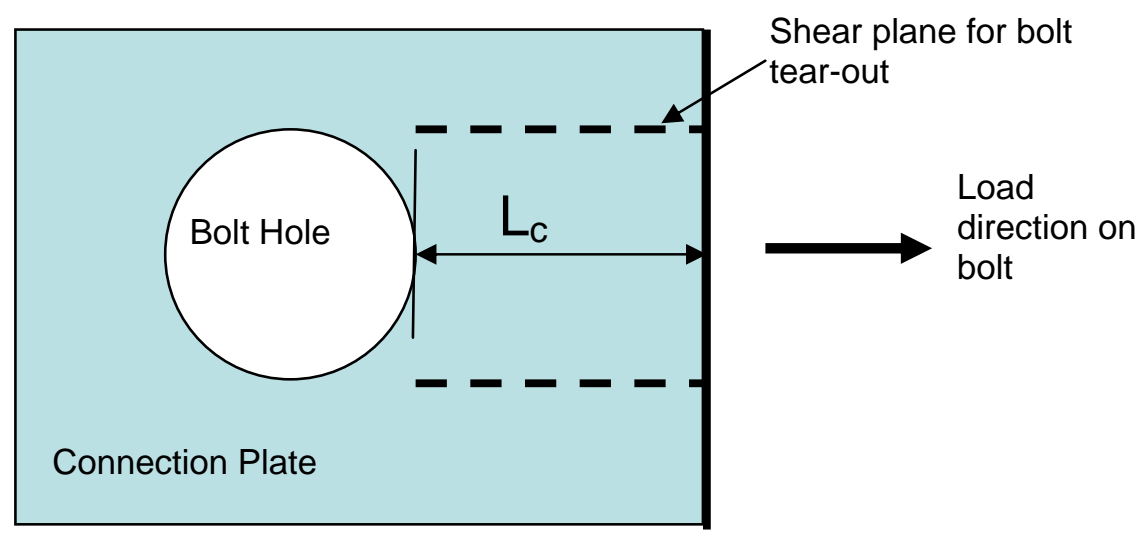

Figure 11-5. Tear-out mode of failure.

\section{Block Shear Failure}

Block shear is a rupture or tearing phenomenon, where the ultimate strength is computed as the sum of the shear strength and tensile rupture strength along a failure path. Block shear under a vertical load is a possible failure mechanism in single shear plate (fin) connections in both the coped beam web and the shear plate, as shown in Figure 11-6. Figure 11-7 shows possible shear failure paths when a double angle connection is subjected to horizontal loading. Cases 1, 2, and 3 have failure in the connection angles and Case 4 corresponds to failure in the beam web. Note that in Figure 11-6 and Figure 11-7 the failed block is cross-hatched.

All possible failure paths in the connected elements (beam web, angles, or plates) were checked and the block shear failure strength of the connection was determined from the lowest value obtained. The nominal block shear strength along a shear failure path and a perpendicular tension failure path was given by

$$
R_{u-b l o c k \text { shear }}=0.6 F_{u} A_{n v}+U_{b s} F_{u} A_{n t} \leq 0.6 F_{y} A_{g v}+U_{b s} F_{u} A_{n t} \quad \text { (J4-5, LRFD) }
$$

where,

$$
\begin{aligned}
& A_{g v} \quad=\text { gross area subject to shear, } \text { in }^{2} \\
& A_{n t} \quad=\text { net area subject to tension, } \text { in }^{2} \\
& A_{n v} \quad=\text { net area subject to shear, } \mathrm{in}^{2}
\end{aligned}
$$


and, for uniform tension stress (assumed here), $U_{b s}=1$. Note that the gross area subjected to shear was used for the yield limit state and the net area subjected to shear (i.e., the gross area less the area of the bolt holes) was used for the rupture limit state. Both the yield and rupture limit states were computed and the smaller (minimum) value was used. Thus, Equation J4-5 was rewritten as:

$R_{u-\text { block shear }}=F_{u} A_{n t}+\min \left(0.6 F_{y} A_{g v}, 0.6 F_{u} A_{n v}\right)$
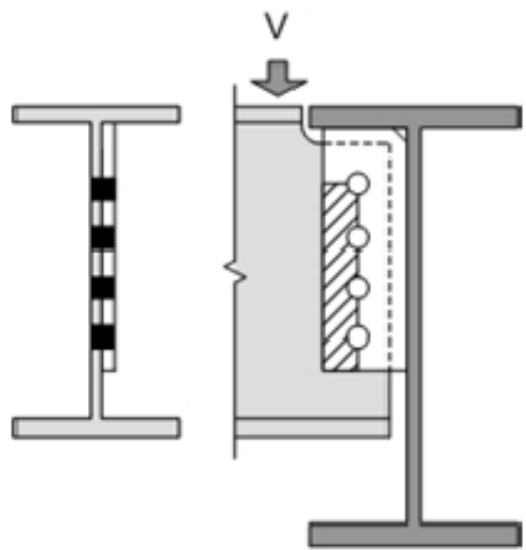

Failure in Shear Plate
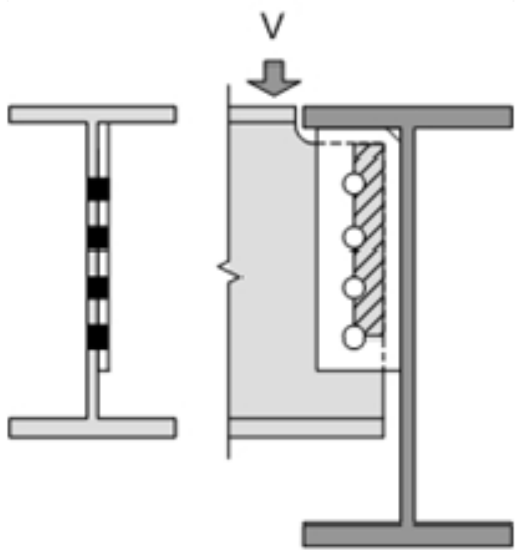

Failure in Beam Web

Figure 11-6. Block shear failure planes for vertical shear forces.
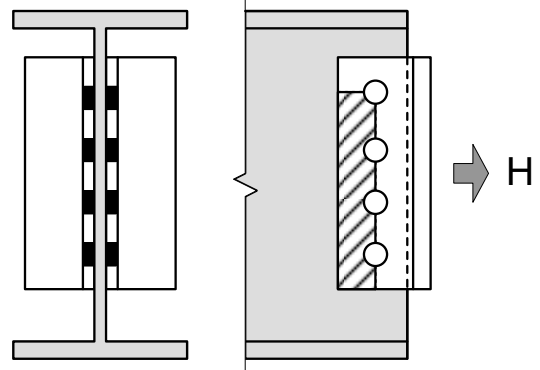

Case 1
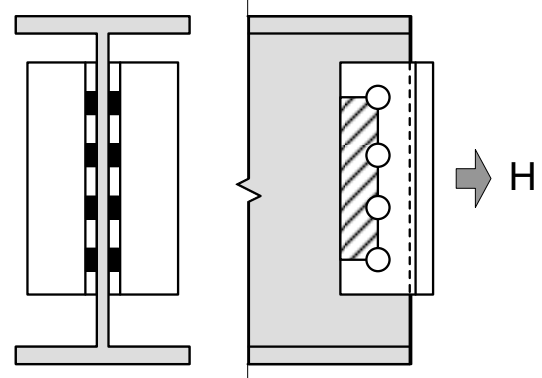

Case 3

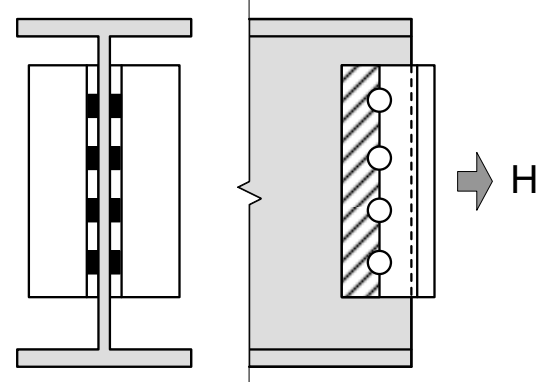

Case 2
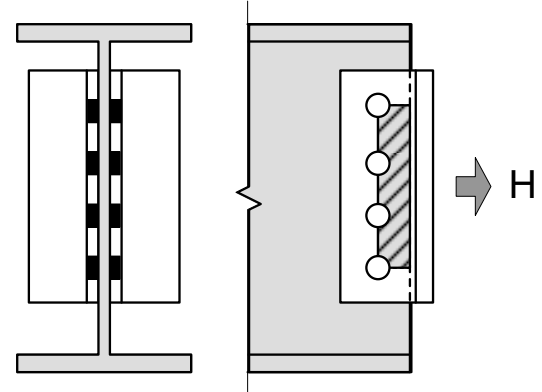

Case 4

Figure 11-7. Block shear failure planes for horizontal tension force. 


\section{Shear Stud Connector Failure}

Shear stud failure in a composite floor system occurs when the concrete slab is either crushed or cracks around the shear stud, or the shear stud separates from the floor beam. Shear stud failure in a composite floor system depends on a number of variables, including the depth and rib geometry of the metal deck, slab thickness, concrete properties, location of the studs relative to the beam axis, and the stud strength.

Metal decks typically have stiffeners in the center of the rib section that rests on the steel beam flange, as shown in Figure 11-8. The stiffener requires that the shear stud be placed off center from the center of the rib, which affects the strength of the shear connection perpendicular to the span of the metal deck. This is because the amount of concrete between the steel deck and the stud depends on the direction of the load that the stud can bear on when transferring the shear load between the slab and the floor beam. The direction of load transfer is termed "strong" or "weak" to refer to the relative load capacity associated with each direction, as shown in Figure 11-8.

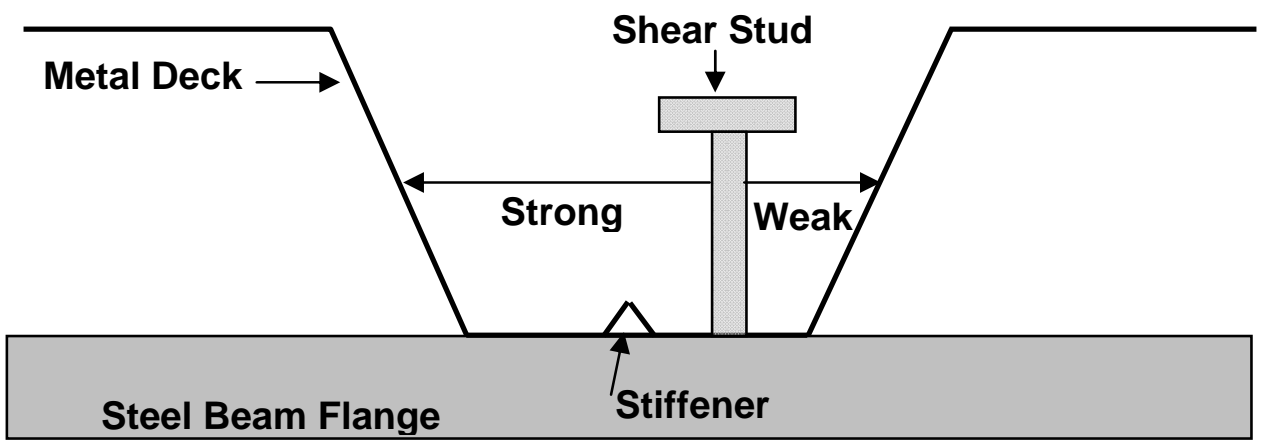

\section{Figure 11-8. Schematic of shear stud placement relative to the metal deck.}

Two sources were found for predicting shear stud strength in a composite floor system with a metal deck. For shear studs in a 3 in. metal deck, where the applied load is perpendicular to the metal deck ribs, the shear stud strength, $\mathrm{Q}_{\mathrm{sc}}$, is given by (Rambo-Rodenberry, 2002)

$$
Q_{s c}=R_{p} R_{n} R_{d} A_{s} F_{u}=19.5 \mathrm{kip}
$$

where

$R_{p}=0.68$ for $\mathrm{e} \geq 2.2$ in. (e is the distance from center of stud to mid-height of deck web on the loaded side) for strong position studs

$R_{n}=1.0$ for one stud per rib or staggered position studs

$R_{d}=1.0$ for all strong position studs

$A_{s}=0.44$ in. $^{2}$ for 0.75 in. shear stud cross sectional area

$F_{u}=65 \mathrm{ksi}$ (this ultimate strength value has been shown to accurately predict published experimental results for shear stud failure in a composite floor system) 
Values given by AISC (2005) using Table 3-21 for metal deck ribs that are perpendicular to the floor beam are given as

$$
\begin{aligned}
& Q_{n}=21.5 \text { kip Strong studs per rib } \\
& \text { and } \\
& Q_{n}=17.2 \text { kip Weak studs per rib }
\end{aligned}
$$

Since a shear stud could have been placed on either side of the rib along the beam length, the average of the strong and weak directions was used to give a shear stud strength of

$$
Q_{n}=19.4 \text { kip Average of strong and weak }
$$

The shear stud capacity was taken as $Q_{s c}=19.5$ kip. This value was used for forces that were both perpendicular and parallel to the metal deck ribs.

\section{Arc Spot Weld Failure}

Metal decks are used as stay-in-place formwork for composite floor construction, and are generally fastened to the beams and girders with arc spot welds (often referred to as a puddle welds). The shear strength of an arc spot weld, $Q_{f}$, can be estimated using the following equation (SDI 2007):

$$
Q_{f}=2.2 t F_{u}(d-t)
$$

Where

$$
\begin{aligned}
& t=\quad \text { thickness of metal deck (in.) } \\
& F_{u}=\quad \text { ultimate tensile strength of steel } \\
& d=\quad \text { nominal diameter of weld puddle }
\end{aligned}
$$

For a 5/8 in. diameter puddle weld, 20 gauge ( $t=0.0358$ in.) metal deck, and taking $F_{u}$ equal to $45 \mathrm{ksi}$, one obtains a strength of approximately 2 kip per weld. As noted in Chapter 8, restraint of thermal expansion produces forces substantially greater than $2 \mathrm{kip}$, and, for this reason, the puddle welds attaching the metal deck to the girder top flange were neglected in the ANSYS finite element analyses.

\section{Failure Loads of Shear Connections}

The shear connections in WTC 7 were designed to support design gravity loads, but they were not designed for horizontal loads from the floor beams due to thermal expansion or other fire effects. Shear connections on the typical tenant floors were evaluated for horizontal and vertical failure loads for room temperature material properties, using the failure modes previously described in this section. The seated connections with a top clip (STC) and seated connection with a top plate (STP) were evaluated for horizontal loads only, as the vertical capacity of the welded seat plates for these connections (i.e., at Columns 79 and 81) was much greater than the applied vertical loads, even for full design loads. The 
seated connections with web clip (SWC) were evaluated for horizontal and vertical failure loads, but the web clip and the seat capacities were evaluated separately.

The ratio of vertical failure load (no load or resistance factors) to the design load was determined for fin, header, and knife connections, as shown in Table 11-2, Table 11-3, and Table 11-4. The average vertical failure load-to-design load ratio was approximately 3.2 for the core floor beams and girders and 4.4 for the tenant floor beams and girders; the values ranged from a minimum of 1.9 to a maximum of 7.2. A vertical failure load to design load ratio of approximately 2.0 to 4.0 is within the typical range expected for these types of connections.

Failure loads for forces applied in the horizontal direction depended on the direction of load. For instance, if a knife connection was subject to a compressive axial load, the failure mode would be bolt shear, but if it were subject to a tensile load, the failure mode would be fracture of the weld at the column face. Since the shear connections were not designed for a horizontal load, no comparison of horizontal load capacity to design load could be made.

Table 11-2. Ratio of vertical capacity to design shear load of shear connections for floor beams and girders on a typical tenant floor.

\begin{tabular}{|c|c|c|c|c|c|}
\hline $\begin{array}{c}\text { Tenant Floor Beams } \\
\text { and Girders }\end{array}$ & $\begin{array}{c}\text { Connection } \\
\text { Type }\end{array}$ & $\begin{array}{c}\text { Failure } \\
\text { Load (kip) }\end{array}$ & Failure Mode & $\begin{array}{c}\text { Design } \\
\text { Shear Load } \\
\text { (kip) }\end{array}$ & $\begin{array}{c}\text { Failure } \\
\text { Load/ } \\
\text { Design } \\
\text { Shear Load }\end{array}$ \\
\hline \multicolumn{6}{|l|}{ Floors 8 to 20,24 to 45} \\
\hline \multicolumn{6}{|l|}{ South Tenant Floor } \\
\hline W24x62 & $\mathrm{H} 4$ & 217 & Block Shear-plate & 69 & 3.1 \\
\hline W24x62 & K4 & 190 & Block Shear-web & 69 & 2.7 \\
\hline W16x77 & F4 & 166 & Block Shear-plate & 73.4 & 2.3 \\
\hline W16x26 & F4 & 123 & Block Shear-web & 23 & 5.3 \\
\hline W16x31 & F4 & 135 & Block Shear-web & 28 & 4.8 \\
\hline W18x40 & F5 & 185 & Block Shear-web & 41 & 4.5 \\
\hline \multicolumn{6}{|l|}{ East Tenant Floor } \\
\hline W21x44 & F6 & 229 & Block Shear-plate & 40 & 5.7 \\
\hline W24X55 & F6 & 229 & Block Shear-plate & 46 & 4.9 \\
\hline \multicolumn{6}{|l|}{ North Tenant Floor } \\
\hline W12x26 & F3 & 91 & Block Shear-web & 15 & 6.0 \\
\hline W12x26 & $\mathrm{H} 2$ & 100 & Weld & 15 & 6.7 \\
\hline W21x44 & F5 & 200 & Block Shear-plate & 41 & 4.9 \\
\hline W24X55 & F6 & 229 & Block Shear-plate & 48 & 4.7 \\
\hline W24X55 & F7 & 309 & Block Shear-web & 48 & 6.4 \\
\hline W30x116 & H5 & 267 & Block Shear-plate & 109 & 2.5 \\
\hline W16x31 & $\mathrm{F} 4$ & 135 & Block Shear-web & 26 & 5.1 \\
\hline W24x76 & H4 & 223 & Block Shear-plate & 73 & 3.0 \\
\hline
\end{tabular}




\begin{tabular}{|l|l|l|l|l|c|}
\hline $\begin{array}{c}\text { Tenant Floor Beams } \\
\text { and Girders }\end{array}$ & $\begin{array}{c}\text { Connection } \\
\text { Type }\end{array}$ & $\begin{array}{c}\text { Failure } \\
\text { Load (kip) }\end{array}$ & Failure Mode & $\begin{array}{c}\text { cesign } \\
\text { Shear Load } \\
\text { (kip) }\end{array}$ & $\begin{array}{c}\text { Failure } \\
\text { Load/ } \\
\text { Design } \\
\text { Shear Load }\end{array}$ \\
\hline West Tenant Floor \\
\hline W16x26 & F4 & 123 & Block Shear-web & 25 & 4.9 \\
\hline W16X31 & F4 & 135 & Block Shear-web & 28 & 4.9 \\
\hline W14x22 & H2 & 118 & Block Shear-plate & 36 & 3.3 \\
\hline W30X99 & H5 & 267 & Block Shear-plate & 100 & 2.7 \\
\hline W18x35 & F5 & 176 & Block Shear-web & 52 & 3.4 \\
\hline W12X19 & H2 & 118 & Block Shear-plate & 23 & 5.0 \\
\hline & & & & Average & 4.4 \\
\hline & & & & Minimum & 2.3 \\
\hline & & & Maximum & 6.7 \\
\hline
\end{tabular}

Table 11-3. Ratio of vertical capacity to design shear load of shear connections for core floor beams on a typical tenant floor.

\begin{tabular}{|c|c|c|c|c|c|}
\hline Core Floor Beams & $\begin{array}{c}\text { Connection } \\
\text { Type }\end{array}$ & $\begin{array}{c}\text { Failure } \\
\text { Load (kip) }\end{array}$ & Failure Mode & $\begin{array}{c}\text { Design } \\
\text { Shear Load } \\
\text { (kip) }\end{array}$ & $\begin{array}{c}\text { Failure } \\
\text { Load/ Design } \\
\text { Shear Load }\end{array}$ \\
\hline \multicolumn{6}{|c|}{ Floors 8 to 20,24 to 45} \\
\hline \multicolumn{6}{|l|}{ South Floor } \\
\hline W12X14 & F3 & 79 & Block Shear-web & 16 & 5.1 \\
\hline W12X19 & K3 & 81 & Block Shear-web & 22 & 3.6 \\
\hline W16x26 & K3 & 87 & Block Shear-web & 40 & 2.2 \\
\hline W16x31 & K3 & 95 & Block Shear-web & 50 & 1.9 \\
\hline W18x35 & H3 & 168 & Block Shear-plate & 60 & 2.8 \\
\hline \multicolumn{6}{|l|}{ North Floor } \\
\hline W16x31 & F4 & 135 & Block Shear-web & 36 & 3.8 \\
\hline W18x40 & K4 & 140 & Block Shear-web & 50 & 2.8 \\
\hline W18x35 & F5 & 176 & Block Shear-web & 42 & 4.2 \\
\hline W12X35 & K3 & 104 & Block Shear-web & 33 & 3.1 \\
\hline W14x26 & K3 & 68 & Block Shear-web & 26 & 2.6 \\
\hline W16x40 & K3 & 106 & Block Shear-web & 47 & 2.2 \\
\hline W21x50 & $\mathrm{H} 4$ & 217 & Block Shear-plate & 69 & 3.1 \\
\hline \multirow[t]{4}{*}{ W21x44 } & $\mathrm{H} 4$ & 217 & Block Shear-plate & 60 & 3.6 \\
\hline & & & & Average & 3.2 \\
\hline & & & & Minimum & 1.9 \\
\hline & & & & Maximum & 5.1 \\
\hline
\end{tabular}


Table 11-4. Ratio of vertical capacity to design shear load of shear connections for core floor girders on a typical tenant floor.

\begin{tabular}{|c|c|c|c|c|c|}
\hline Core Girders & $\begin{array}{c}\text { Connection } \\
\text { Type }\end{array}$ & $\begin{array}{c}\text { Failure } \\
\text { Load (kip) }\end{array}$ & Failure Mode & $\begin{array}{c}\text { Design } \\
\text { Shear Load } \\
\text { (kip) }\end{array}$ & $\begin{array}{c}\text { Failure } \\
\text { Load/ Design } \\
\text { Shear Load }\end{array}$ \\
\hline \multicolumn{6}{|c|}{ Floors 8 to 20, 24 to 45} \\
\hline \multicolumn{6}{|l|}{ South Floor } \\
\hline W16X31 & K3 & 95 & Block Shear-web & 19 & 4.9 \\
\hline W24x62 & K4 & 190 & Block Shear-plate & 79 & 2.4 \\
\hline \multicolumn{6}{|l|}{ North Floor } \\
\hline W21x44 & K4 & 155 & Block Shear-plate & 48 & 3.2 \\
\hline W27x94 & K5 & 264 & Block Shear-plate & 118 & 2.2 \\
\hline \multicolumn{6}{|l|}{ South Girders } \\
\hline W21x50 & $\mathrm{H} 4$ & 217 & Block Shear-plate & 65 & 3.3 \\
\hline W18x40 & H3 & 168 & Block Shear-plate & 56 & 3.0 \\
\hline W21X68 & $\mathrm{H} 4$ & 217 & Block Shear-plate & 72 & 3.0 \\
\hline W24x62 & $\mathrm{H} 4$ & 217 & Block Shear-plate & 75 & 2.9 \\
\hline 40 in girder 'S' & H8 & 415 & Block Shear-plate & 75 & 5.5 \\
\hline W27x84 & H5 & 267 & Block Shear-plate & 113 & 2.3 \\
\hline \multicolumn{6}{|l|}{ Middle Girders } \\
\hline W21x44 & $\mathrm{H} 4$ & 217 & Block Shear-plate & 56 & 3.8 \\
\hline W18x40 & $\mathrm{H} 4$ & 217 & Block Shear-plate & 56 & 3.9 \\
\hline W21x57 & H5 & 253 & Weld & 63 & 4.0 \\
\hline MG-141 (14) & $\mathrm{H} 4$ & 217 & Block Shear-plate & 30 & 7.2 \\
\hline W27x84 & H5 & 267 & Block Shear-plate & 122 & 2.2 \\
\hline W27x94 & H5 & 267 & Block Shear-plate & 108 & 2.5 \\
\hline \multicolumn{6}{|l|}{ North Girders } \\
\hline W24X55 & $\mathrm{H} 4$ & 217 & Block Shear-plate & 80 & 2.7 \\
\hline W21x50 & $\mathrm{H} 4$ & 217 & Block Shear-plate & 77 & 2.8 \\
\hline W24x76 & $\mathrm{H} 4$ & 217 & Block Shear-plate & 100 & 2.2 \\
\hline \multirow[t]{4}{*}{ W36x135 } & K8 & 436 & Weld & 168 & 2.6 \\
\hline & & & & Average & 3.3 \\
\hline & & & & Minimum & 2.2 \\
\hline & & & & Maximum & 7.2 \\
\hline
\end{tabular}




\subsubsection{Modeling Connections}

As illustrated in Chapter 8, the simple floor framing connections and shear studs are critical to the behavior of a structure subject to the effects of fire. The modeling of connection failure modes is covered in this section.

User-defined connection models were developed with break elements for each connection type. These connection models used the various temperature dependent failure modes described in Section 11.2.4. Failure in connections was determined by exceedance of either a limiting force or a deformation limit (for example, "walking off" the seat). The inclusion of contact elements in the connection models allowed for slip and construction clearances (gaps) to be taken into account and for a different response in horizontal tension and compression.

The temperature of connections and shear stud connectors was taken as the average of the temperature between two components (e.g., a girder and a column). Shear stud temperatures were modeled as the average of the slab temperature at mid-depth and the floor beam temperature. Connection and shear stud capacity at elevated temperature were modeled using room temperature capacity and the tensile strength reduction factor for steel. The temperature dependent strength reduction of the shear studs was applied when temperatures became greater than $300^{\circ} \mathrm{C}$. At this temperature in the shear studs, differential thermal expansion of the floor beams and floor slab resulted in significant shear force in the shear studs and caused them to fail. The temperatures assigned to shear studs did not significantly affect the time and sequence of shear stud failures.

\section{Modeling Failure with Break Elements}

User-defined finite elements, or break elements, were developed to capture complex modes of failure in connections, including temperature-dependence, with relatively few degrees of freedom. A user-define break element is a multi-degree of freedom elastic spring element with the capability of turning "off" once its capacity is reached. The stiffness of the element in the off mode was reduced to a predefined post-failure stiffness, which was set to a significantly small value, $10^{-6}$ to $10^{-9}$ times the initial stiffness. The force and moment capacity of the element were defined as temperature-dependent properties. Different tension and compression force capacities were assigned where appropriate.

Connections with multiple failure modes required use of several break elements connected in series and/or parallel. To model independent failure modes, that is, one failure mode that did not cause other failures, break elements were connected in parallel so that when one break element turned "off", the other break elements remained "on". For example, in a seated connection, failure of the bolts in shear did not lead to vertical failure of the connection. To model dependent failure modes, break elements were connected in series so that when one break element turned off, all elements turned off. For example, bolt shear and tear-out were modeled as two break elements in series, where failure by either bolt shear or tear-out caused a disconnect. A list of break element types developed in ANSYS is summarized in Table $11-5$. 
Table 11-5. Types of break elements defined in ANSYS.

\begin{tabular}{|c|c|c|c|c|}
\hline Type & $\begin{array}{l}\text { Degree of } \\
\text { Freedom }\end{array}$ & $\begin{array}{l}\text { Capacities to } \\
\text { be defined }\end{array}$ & Stiffness to be defined & Description \\
\hline 102 & $\begin{array}{l}\text { UX } \\
\text { UY } \\
\text { UZ } \\
\text { ROTX } \\
\text { ROTY } \\
\text { ROTZ }\end{array}$ & $\begin{array}{l}\text { Positive FX } \\
\text { Negative FX } \\
\text { Positive FY } \\
\text { Negative FY } \\
\text { Positive FZ } \\
\text { Negative FZ } \\
\text { MX } \\
\text { MY } \\
\text { MZ }\end{array}$ & $\begin{array}{l}\text { Initial stiffness for UX } \\
\text { Post-failure stiffness for UX } \\
\text { Initial stiffness for UY } \\
\text { Post-failure stiffness for UY } \\
\text { Initial stiffness for UZ } \\
\text { Post-failure stiffness for UZ } \\
\text { Initial stiffness for ROTX } \\
\text { Post-failure stiffness for ROTX } \\
\text { Initial stiffness for ROTY } \\
\text { Post-failure stiffness for ROTY } \\
\text { Initial stiffness for ROTZ } \\
\text { Post-failure stiffness for ROTZ }\end{array}$ & $\begin{array}{l}\text { All force and moment } \\
\text { components are checked with } \\
\text { corresponding capacities. }\end{array}$ \\
\hline $\begin{array}{c}103 \\
\mathrm{~K} 1=0\end{array}$ & $\begin{array}{l}\text { UX } \\
\text { UY } \\
\text { UZ }\end{array}$ & $\begin{array}{l}\text { Positive F } \\
\text { Negative F }\end{array}$ & $\begin{array}{l}\text { Initial stiffness for UX, UY, and UZ } \\
\text { Post-failure stiffness for UX, UY, and UZ }\end{array}$ & $\begin{array}{l}\text { SRSS* of three force } \\
\text { components is checked with } \\
\text { the capacity. The sign of } \\
\text { force is determined by the } \\
\text { direction specified by the user. }\end{array}$ \\
\hline $\begin{array}{c}103 \\
\mathrm{~K} 1=1\end{array}$ & $\begin{array}{l}\text { UX } \\
\text { UY } \\
\text { UZ }\end{array}$ & $\begin{array}{l}\text { Positive F } \\
\text { Negative F }\end{array}$ & $\begin{array}{l}\text { Initial stiffness for UX, UY, and UZ } \\
\text { Post-failure stiffness for UX, UY, and UZ }\end{array}$ & $\begin{array}{l}\text { SRSS* of force components } \\
\text { FX and FY is checked with the } \\
\text { capacity. The sign of force is } \\
\text { determined by the direction } \\
\text { specified by the user. }\end{array}$ \\
\hline 104 & $\begin{array}{l}\text { UX } \\
\text { UY } \\
\text { UZ }\end{array}$ & $\begin{array}{l}\text { Positive FX } \\
\text { Negative FX } \\
\text { Positive FY } \\
\text { Negative FY } \\
\text { Positive FZ } \\
\text { Negative FZ }\end{array}$ & $\begin{array}{l}\text { Initial stiffness for UX } \\
\text { Post-failure stiffness for UX } \\
\text { Initial stiffness for UY } \\
\text { Post-failure stiffness for UY } \\
\text { Initial stiffness for UZ } \\
\text { Post-failure stiffness for UZ }\end{array}$ & $\begin{array}{l}\text { All force components are } \\
\text { checked with corresponding } \\
\text { capacities. }\end{array}$ \\
\hline $\begin{array}{c}105 \\
\mathrm{~K} 1=0\end{array}$ & $\begin{array}{l}\text { UX } \\
\text { UY } \\
\text { UZ } \\
\text { ROTX } \\
\text { ROTY } \\
\text { ROTZ }\end{array}$ & $\begin{array}{l}\text { Positive } F \\
\text { Negative F }\end{array}$ & $\begin{array}{l}\text { Initial stiffness for UX, UY, and UZ } \\
\text { Post-failure stiffness for UX, UY, and UZ } \\
\text { Initial stiffness for ROTX, ROTY, and ROTZ } \\
\text { Post-failure stiffness for ROTX, ROTY, and ROTZ }\end{array}$ & $\begin{array}{l}\text { SRSS* of three force }^{*} \text { components is checked with } \\
\text { the capacity. The sign of } \\
\text { force is determined by the } \\
\text { direction specified by the user. }\end{array}$ \\
\hline $\begin{array}{c}105 \\
K 1=1\end{array}$ & $\begin{array}{l}\text { UX } \\
\text { UY } \\
\text { UZ } \\
\text { ROTX } \\
\text { ROTY } \\
\text { ROTZ }\end{array}$ & $\begin{array}{l}\text { Positive } F \\
\text { Negative F }\end{array}$ & $\begin{array}{l}\text { Initial stiffness for UX, UY, and UZ } \\
\text { Post-failure stiffness for UX, UY, and UZ } \\
\text { Initial stiffness for ROTX, ROTY, and ROTZ } \\
\text { Post-failure stiffness for ROTX, ROTY, and ROTZ }\end{array}$ & $\begin{array}{l}\text { SRSS* of force components } \\
\text { FX and FY is checked with the } \\
\text { capacity. The sign of force is } \\
\text { determined by the direction } \\
\text { specified by the user. }\end{array}$ \\
\hline
\end{tabular}

*SRSS: square-root-of-sum-of-square 


\section{Analytical Modeling of Connections Using Break Elements}

A connection model was developed for each of the following connection types, using the break elements in Table 11-5 in series or in parallel, as needed, to model the appropriate failure modes:

- Single shear plate

o Fin (beam-to-girder)

- Double angle shear connections

o Knife (beam or girder-to-column)

o Header (beam-to-girder or girder-to-column)

- Seat with web clip (SWC) connection

o Seat with web clip (core beam-to-core girder)

- $\quad$ Seat with top plate (STP) connections

o Seat connection at columns on the east face (beam or girder-to-exterior column)

- $\quad$ Seat with top clip (STC) connections

o Seat connection at columns on the north and south face (beam or girder-to-exterior column)

o Seat connection at Columns 79 and 81 (girder-to-interior column)

The floor area where failure of floor framing connections and shear studs ${ }^{3}$ was modeled with break elements on Floors 8 to 14 is shown in Figure 11-9. This area is east of the north-south line passing through Column 76 and the core area east of Column 73.

Outside the selected area, structural damage-such as buckling of the steel frame and crushing and cracking of the concrete slab-was modeled over the entire floor, but connection failures were not modeled. The extent of the area with detailed connection models was based on the results of single floor fire simulations, where connection damage west of Columns 73 through 76 were not found to contribute to an initial failure event on the east side of the structure. The area where break elements were modeled was selected to reduce the model size without biasing the results for simulating the initial failure event.

\footnotetext{
${ }^{3}$ The shear stud capacity was scaled so that the total capacity of the modeled studs equaled the total capacity of the actual number of studs for each floor beam. For instance, if a floor beam in ANSYS had 17 shear stud connections (due to mesh sizing), the capacity of each stud connector would be scaled by 28/17, because the floor beam as constructed had 28 shear studs.
} 
Framing connections outside of the selected area, or on other floors not subjected to fire, were modeled as either fixed or pinned, using typical modeling approaches. Connections were not modeled in the exterior moment frame, as no failures were observed there prior to the onset of global collapse. Column splices were also not modeled for interior columns, as the purpose of the ANSYS model was to accumulate local failures up to the point of buckling in a column. When column buckling appeared to be imminent, the analyses were continued in the LS-DYNA 47 story model.

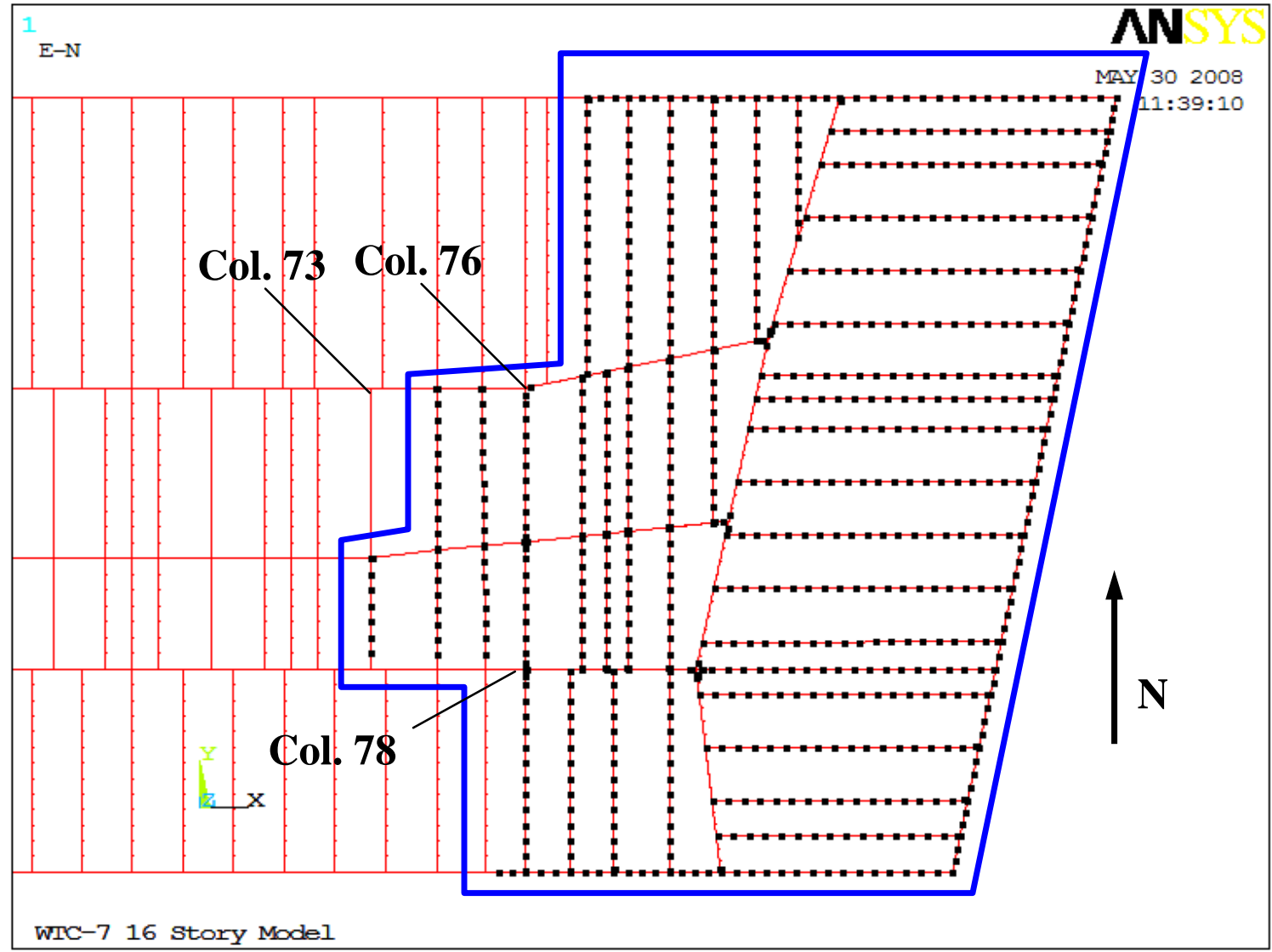

Note: Black colored dots show the location of shear studs and connections modeled with break elements.

Figure 11-9. Area of the floor where connection failures were modeled.

\section{Analytical Model for Fin Connections}

The analytical model used for the fin connection is depicted in Figure 11-10. The girder is located on the right side in each diagram in Figure 11-10. The model shown has three bolts, but a fin connection in WTC 7 had up to 6 bolts. The connection model accounted for: (1) shear failure of individual bolts, (2) tear-out failure at each bolt location, (3) vertical block shear failure of the connection plate, (4) horizontal block shear failure of the web or connection plate, and (5) vertical and horizontal failure of the connection plate-to-column weld. 


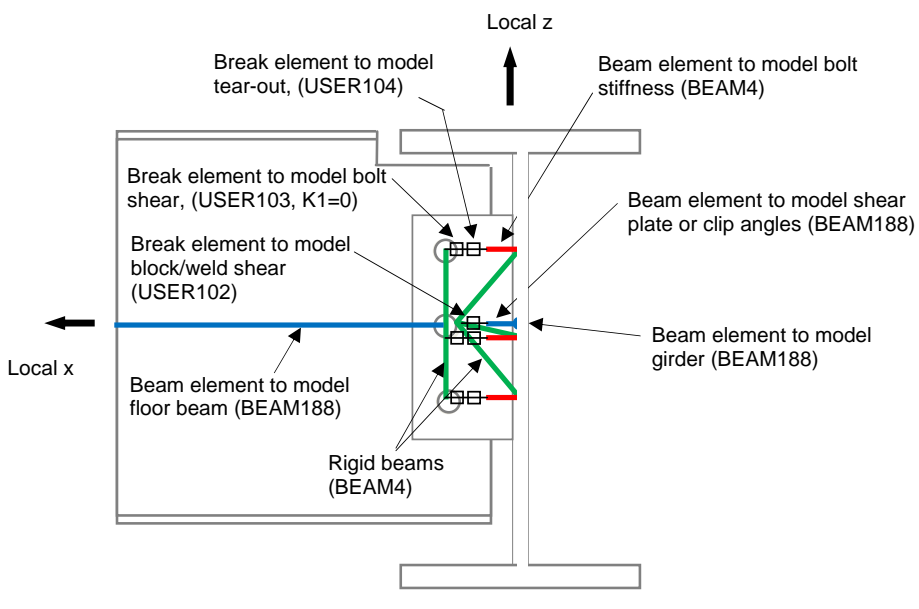

Beam-to-Girder Fin Connection

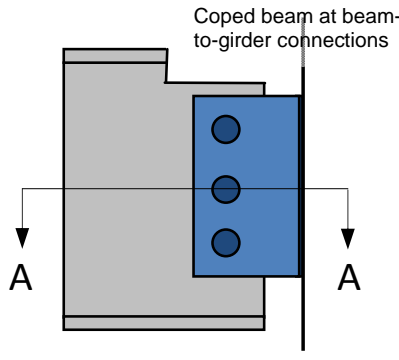

Elevation View of Fin Connections

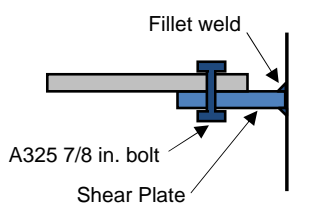

Section A-A Based on fabrication shop drawings (Frankel 1985)

Figure 11-10. Analytical model for a fin connection.

At each bolt location two break elements and one elastic beam were defined. The break elements represented the shear strength of the bolt and the tear-out strength of the connection plate. These break elements were defined at the centerline of each bolt. The bolt shear strength was modeled with break element type USER103 with K1 = 0 (see Table 11-5), i.e., failure occurred when the square-root-of-sumof-squares (SRSS) of the force components in the $\mathrm{x}$ - $\mathrm{y}$ - and $\mathrm{z}$-directions in the break element exceeded the temperature-dependent shear strength of the bolt. The tear-out strength of the connection plate was modeled with break element type USER104. The properties of this break element were defined such that the failure occurred only in the positive local $\mathrm{x}$-direction when the force exceeded the temperaturedependent tear-out strength of the connection plate. The elastic beam represented the stiffness of each bolt in shear. The axial stiffness of the beam was set equal to the secant stiffness of the non-linear forcedisplacement relationship for a bolt in shear at the ultimate strength. Bending and torsional stiffness of the beam were set equal to a large value to prevent any deformation due to bending and torsion.

Block shear and weld failure of the connection plate were modeled using break element type USER102. This break element was defined at the centroid of the connection plate. Failure in the vertical direction occurred when the force in the z-direction exceeded the temperature-dependent strength of the weld or plate block shear. Failure in the horizontal direction occurred when the force in the positive x-direction exceeded the temperature-dependent strength of the weld.

\section{Analytical Model for Knife Connections}

The analytical model used for the knife connection is depicted in Figure 11-11. The model shown has three bolts, but knife connections in WTC 7 had up to 8 bolts. The connection model accounted for: (1) shear failure of individual bolts, (2) tear-out failure at each bolt location, (3) vertical block shear failure of the double angles, (4) horizontal block shear failure of the web or angles, and 5) vertical and horizontal failure of the angle-to-column fillet welds. 
The analytical model for the knife connection was the same as that for the fin connection. The only differences were that the two outstanding legs of the angles, and fillet welds at the toes of the angles that replaced the double-sided fillet weld at the connection plate.

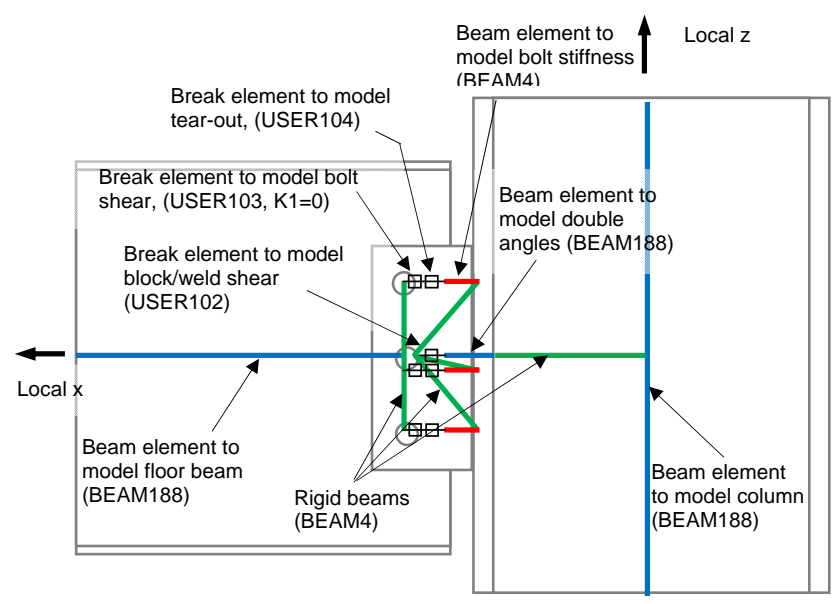

Beam or Girder-to-Column Knife
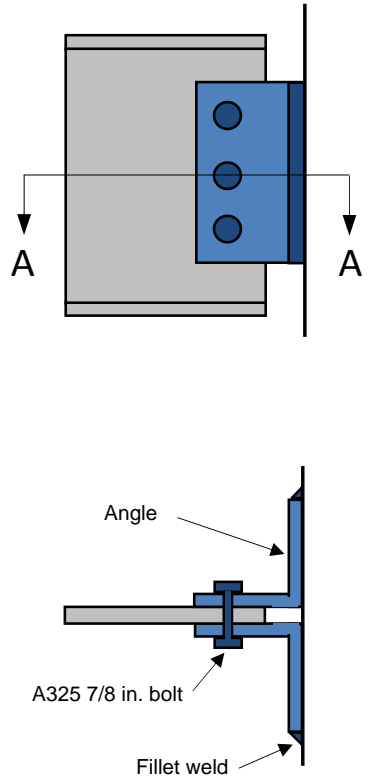

Section A-A

Based on fabrication shop drawings (Frankel 1985)

Figure 11-11. Analytical model for a knife connection.

\section{Analytical Model for Header Connections}

The analytical model for the header connection is depicted in Figure 11-12. The model shown has six bolts (three per row), but a header connection had up to 10 bolts (five per row). The connection model accounted for: (1) shear failure of individual bolts, (2) tension failure of individual bolts, and (3) vertical and horizontal failure of the fillet weld connecting the angles to a girder web or column.

At each bolt location one break element, one elastic beam element, and one node-to-node contact element were defined. The break element represented the shear and tension strength of the bolt. The bolt shear and tension strength was modeled with break element type USER102, i.e., failure occurred when the force in the z-direction exceeded the temperature-dependent shear capacity of the bolt, and also failed if the force in the x-direction exceeded the temperature-dependent tensile capacity of the bolt. The properties of this break element were defined such that the failure did not occur in the negative x-direction. The elastic beam represented the stiffness of each bolt. The node-to-node contact element (CONTA178) represented contact interaction between the angles and girder web or column flange. Initially, full contact was assumed between the angles and column flange. In the case of bolt failure, either due to vertical shear or horizontal tension, the contact element became active and allowed separation when a beam or girder end pulled away from the girder or column. The contact element also and prevented penetration of the angles into the column when a beam or girder end moved toward the girder or column. 


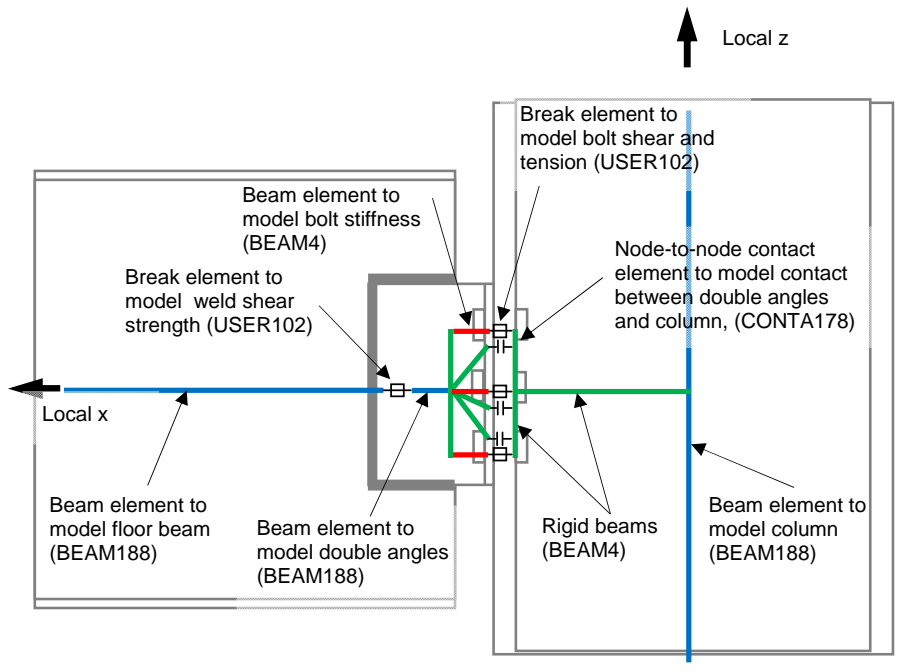

Header Connection

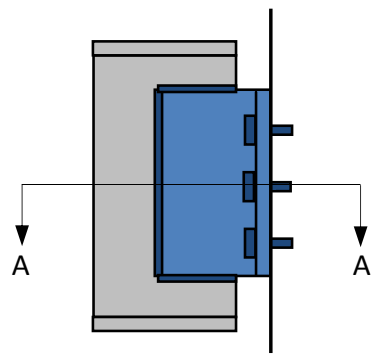

Elevation View

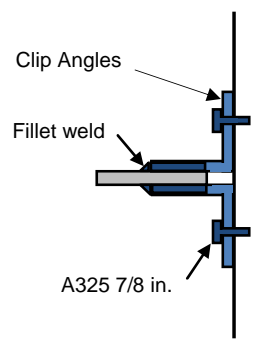

Section A-A

Based on fabrication shop drawings (Frankel 1985)

Figure 11-12. Analytical model for header connection.

The vertical and horizontal weld failure of the connection plate was modeled using break element type USER102. This break element was defined at the centroid of the connection plate. Failure in the vertical direction occurred when the force in the z-direction exceeded the temperature-dependent strength of the weld. Failure in the horizontal direction occurred when the force in the positive x-direction exceeded the temperature-dependent strength of the weld.

\section{Analytical Model for SWC Connections}

The analytical model used for a seat with a web clip (SWC) connection is depicted in Figure 11-13. The connection model accounted for: (1) shear failure of individual bolts, (2) vertical and horizontal failure of weld connection at web clip angle, (3) vertical and horizontal failure of weld connection at seat angle, and (4) the beam walking off the seat.

At each bolt location one break element and one elastic beam element were defined at the bolt centerlines. The shear strength of the bolt at the web clip was modeled with break element type USER103 with $\mathrm{K} 1=0$, i.e., failure occurred when the SRSS of the force components in the $\mathrm{x}$ - $\mathrm{y}$ - and $\mathrm{z}$-directions exceeded the temperature-dependent shear capacity of the bolt. The bolt attaching the beam to the seat was modeled with break element type USER103 with K1 = 1, i.e., failure occurred when the SRSS of the horizontal force components in the $\mathrm{x}$ - and $\mathrm{y}$-directions exceeded the temperature-dependent shear capacity of the bolt. The elastic beam represented the stiffness of each bolt. Contact interaction between end of beam or girder was modeled using node-to-node contact element (CONTA178) with a defined initial gap.

Vertical and horizontal weld failure at the web clip and at the seat were modeled using break element type USER102. Failure in the vertical direction occurred when the force in the z-direction exceeded the 
temperature-dependent strength of the weld. Failure in the horizontal direction occurred when the force in the positive x-direction exceeded the temperature-dependent strength of the weld.

If the web clip failed and the bolts that attached the beam to the seat were sheared, the beam could either walk off the seat laterally or be pulled off the seat. Failure of the web clip and shearing of the bolts did not cause the beam to lose vertical support, but a prerequisite for the beam end walking off the seat. The travel distance for a beam to walk off a seat was $2.5 \mathrm{in}$. A control element (COMBIN37), a unidirectional linear spring element with the capability of turning on and off during an analysis, was used to model walk-off.

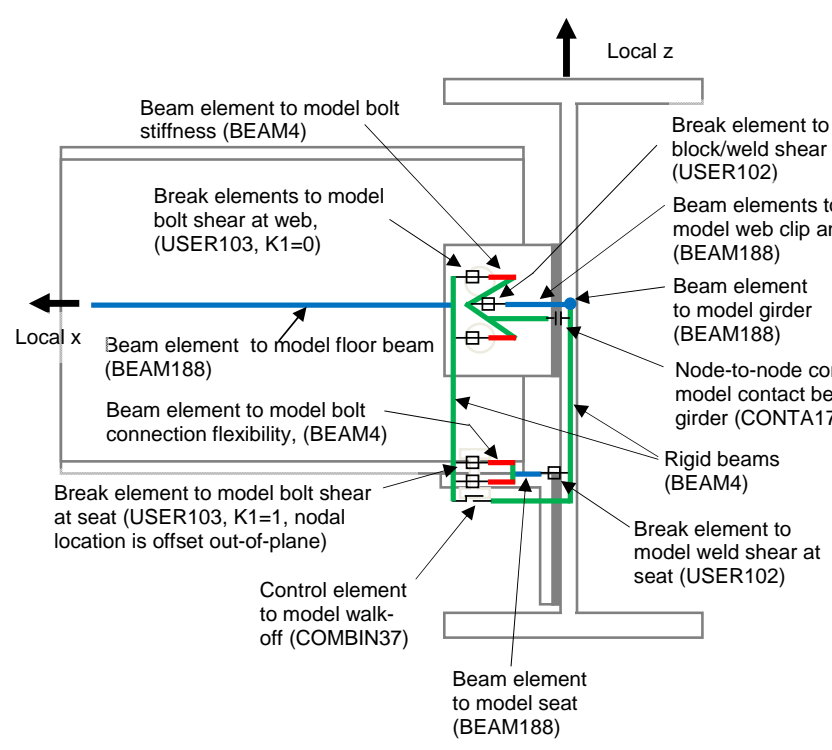

Seat with Web Clip

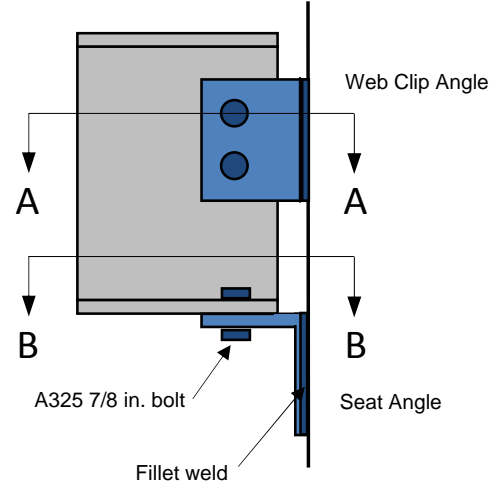

Elevation View

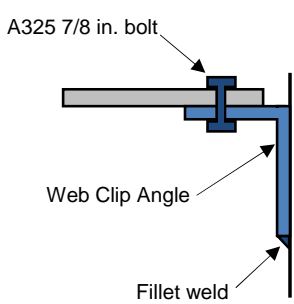

Section A-A

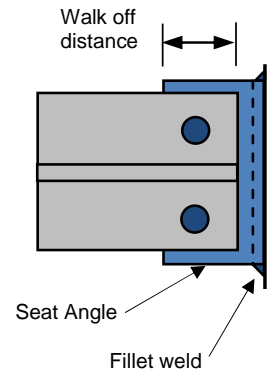

Section B-B

Based on fabrication shop drawings (Frankel 1985)

Figure 11-13. Analytical model for SWC connection.

\section{Analytical Model for Seated Connections at Exterior Columns}

The analytical model for seated connections at exterior columns is depicted in Figure 11-14. The north and south face columns had STC connections and the east face columns had STP connections. The STC connection at Column 26 and the STP connection at Column 44 were slightly different, as the girder framed into the column at a different angle and the bolts had a different location. Other differences, such as the use of a top plate in lieu of a clip angle at the top of beam, did not affect the structural response of the connection, because both the top plate and clip angle were welded along their side edges to the column flanges of the exterior columns. The shear strength of the clip angle or the top plate was much greater than the shear strength of the bolts, so only the bolt shear failure mode was included at the top of the beam. Therefore, the failure of the seated connection at the exterior columns was governed by bolt 
shear, followed by beam walk off of the seat. The analytical model accounted for: 1) shear failure of individual bolts, and 2) beam walk off of the seat.

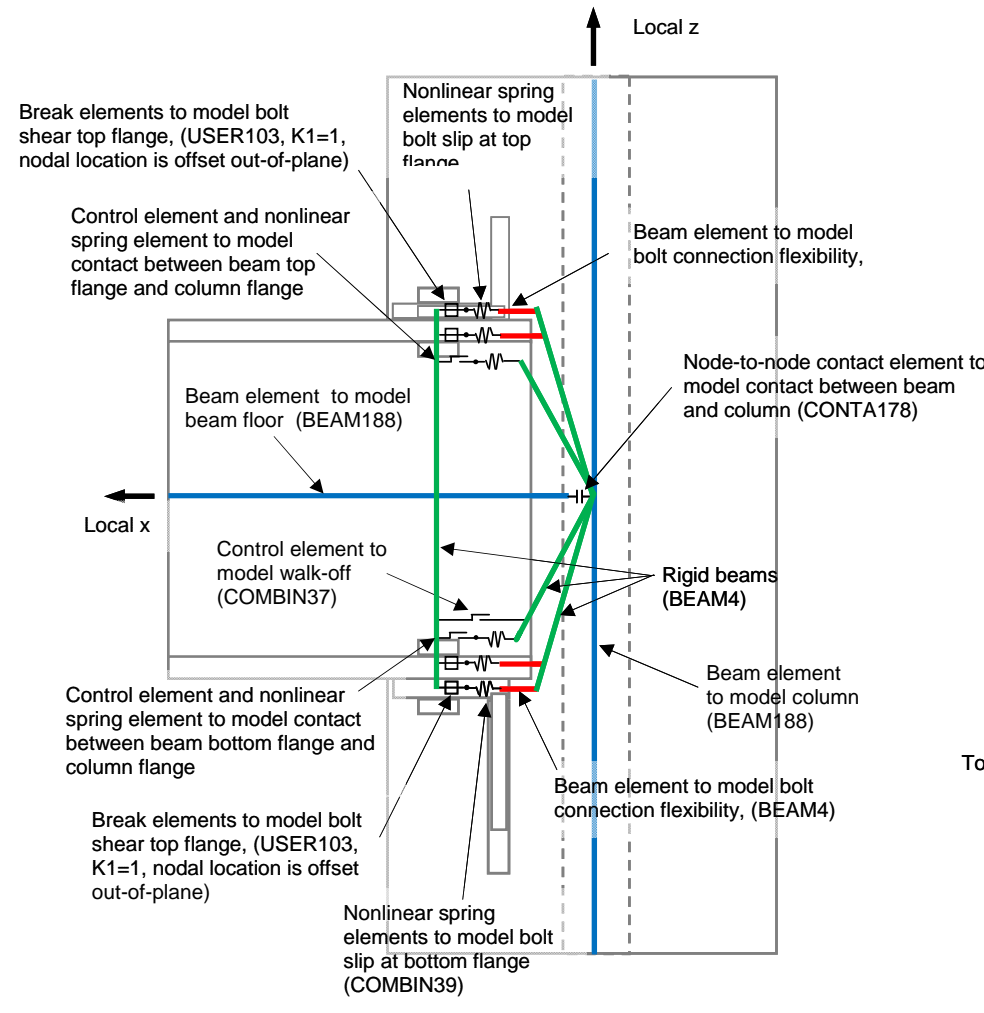

a) Analytical Model

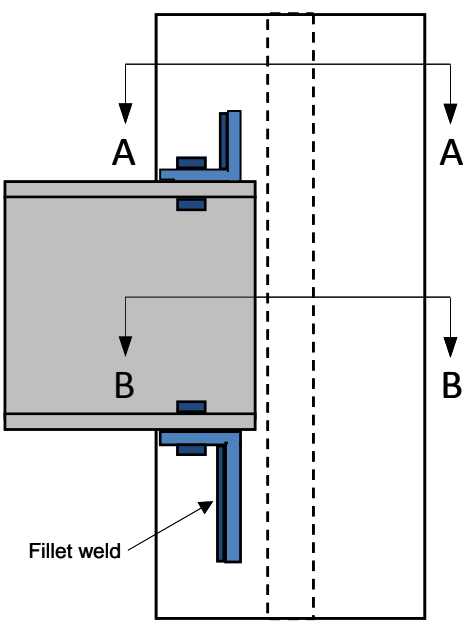

b) Elevation View

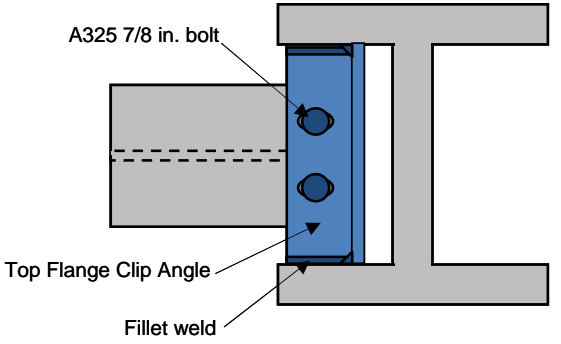

c) Section A-A

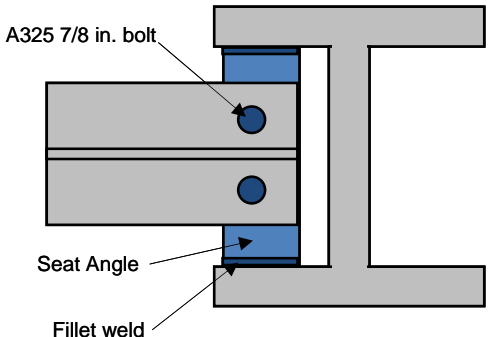

d) Section B-B

Based on fabrication shop drawings (Frankel 1985)

Figure 11-14 Analytical model for seated connections at exterior columns.

At each bolt location one break element, one elastic beam, and one non-linear spring were defined. The bolt shear strength was modeled with break element type USER103 with $\mathrm{K} 1=1$, i.e. failure occurred when the SRSS of the horizontal force components in the $\mathrm{x}$ - and $\mathrm{y}$-directions exceeded the temperaturedependent shear capacity of the bolt. The elastic beam element represented the flexibility of bolt connection in shear. The non-linear spring was used to capture slip in the connection before bolt bearing occurred against the hole edge. Slotted bolt holes were used at the top flange clip angle while standard bolt holes were used at the bottom seat angle. 
A node-to-node contact element with an initial gap representing the clearance between the end of the beam and the column was used to model the contact between the beam and the column when the bolts sheared off and the beam moved enough to touch the surface of the column. The bolts could fail in shear under tensile, compressive or lateral force, but the beam would only walk off the seat under a tensile force. The shear strength of the bolts controlled the connection's horizontal capacity. A control element was used to model walk-off. The travel distance for a beam to walk off a seat is $4.5 \mathrm{in}$.

When the connection was subjected to a lateral horizontal force (perpendicular to the beam axis) or a twisting moment at the beam end causing bolt shear, the beam end was restrained from lateral motion or twisting by the exterior column flanges. One nonlinear spring element and one control element were used at the top and bottom flanges of the beam to model beam and column contact interaction. Control elements were used to remove the lateral restraint after beam walk-off of from its seat.

\section{Analytical Model for Seated Connection at Columns 79 and 81}

The analytical model for the seated connection at Column 79 is shown in Figure 11-15. The same model was used for Column 81, but the girder was connected to the column at a different angle. Also note the difference in the location of the fillet weld-it was at the top of the top clip angle for Column 79-relative to the fillet weld along the sides of the angle in the STC connections at the exterior columns. The top clip angle used in STC connection at Column 79 and Column 81 was weak in tension and needed to be explicitly represented in the connection model. Therefore, the failure of the connection was governed by tension failure of the top clip angle or bolt shear followed by beam walking-off the seat and loss of vertical support. The analytical model accounted for: 1) shear failure of individual bolts, 2) beam walking off of the seat, and 3) horizontal weld failure of the top flange clip angle. The failure of the connection was governed by bolt shear followed by walk-off before loss in vertical support.

At each bolt location one break element, one elastic beam, and one non-linear spring were defined. The bolt shear strength was modeled with break element type USER103 with K1 = 1, i.e., failure occurred when the SRSS of the horizontal force components in the $\mathrm{x}$ - and $\mathrm{y}$-directions exceeded the temperaturedependent shear capacity of the bolt. The elastic beam represented the stiffness of the bolt connection. The non-linear spring was used to capture slip in the connection before bolt bearing against the hole edge. Slotted bolt holes were used at the top flange clip angle while standard bolt holes were used at the bottom seat plate.

A node-to-node contact element with an initial gap representing the clearance between the end of the beam and the column was used to model the contact between the beam and the column when the bolts sheared off and the beam moved enough to touch the surface of the column. The bolts could fail in shear under a tensile, compressive or lateral force, but the beam would only walk off the seat under a tensile or lateral force. The failure of the bolts and weld was a prerequisite for the beam end walking off the seat. The travel distance for walk off was $6.25 \mathrm{in}$. along the axis of the beam and $5.5 \mathrm{in}$. lateral to the beam. A walk off failure occurred when the bolts sheared at the seat connection, the bolts sheared or the weld failed at the top clip angle, and the beam walked off the seat. A control element was used to model beam walk-off in the axial direction. Beam walk off in the lateral direction was monitored during the analysis. 


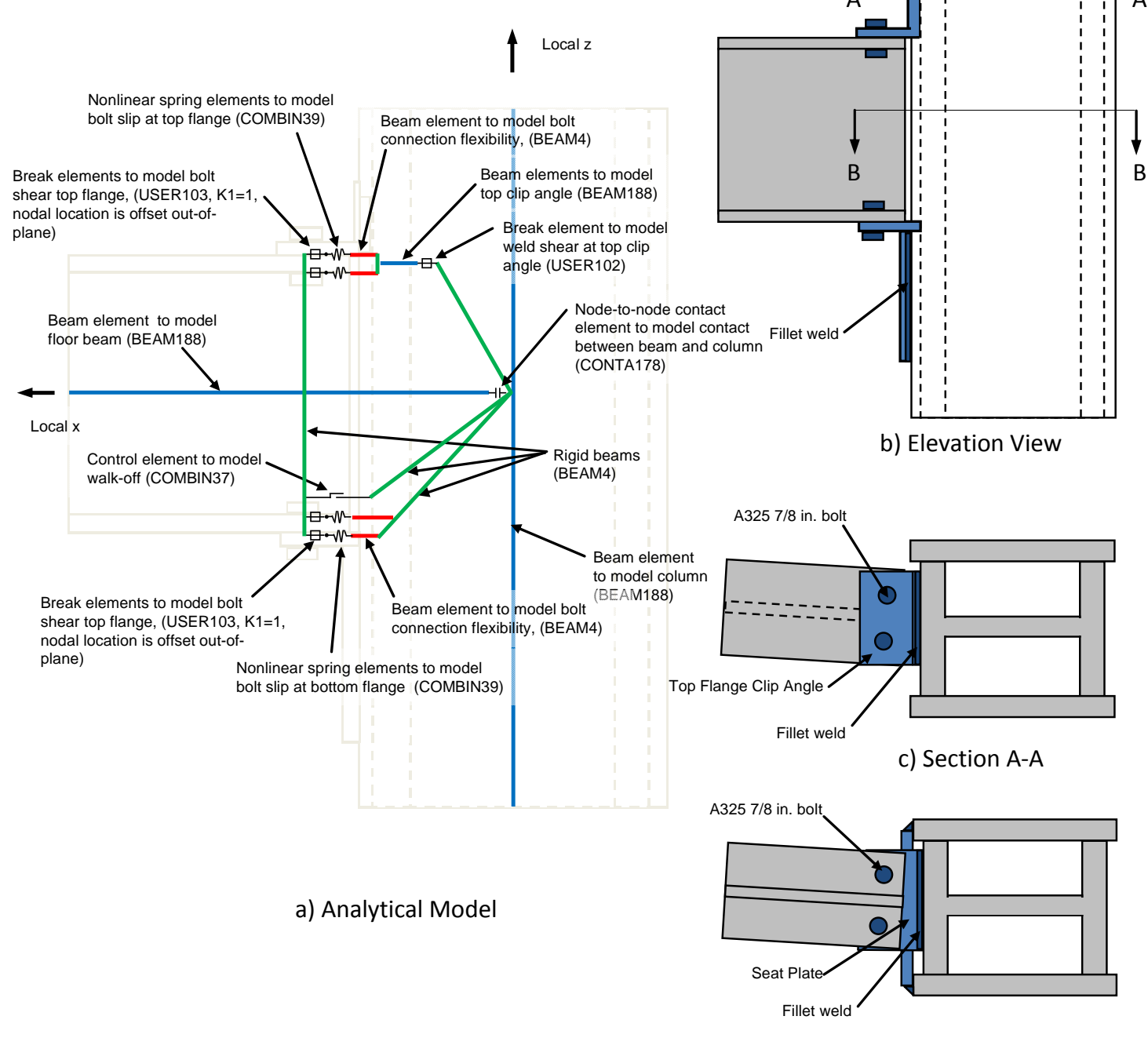

d) Section B-B

Based on fabrication shop drawings (Frankel 1985)

Figure 11-15 Analytical model for the seated connection at Column 79.

\section{Analytical Model for Shear Stud Connections}

The analytical model for shear stud connections is depicted in Figure 11-16. Each shear stud was represented by one break element and one node-to-node contact element. Break element type USER105 with K1 = 1 (Table 11-5) was used, wherein failure occurred when the SRSS of the force components in the $\mathrm{x}$ - and $\mathrm{y}$-directions (i.e., in the plane of the floor slab) exceeded the temperature-dependent shear capacity of the stud. After shear failure of the stud connection, node-to-node contact elements ensured gravity load transfer from the slab to the floor beam, allowed the beam to sag independently of the floor slab, and prevented slab penetration into the beam. 


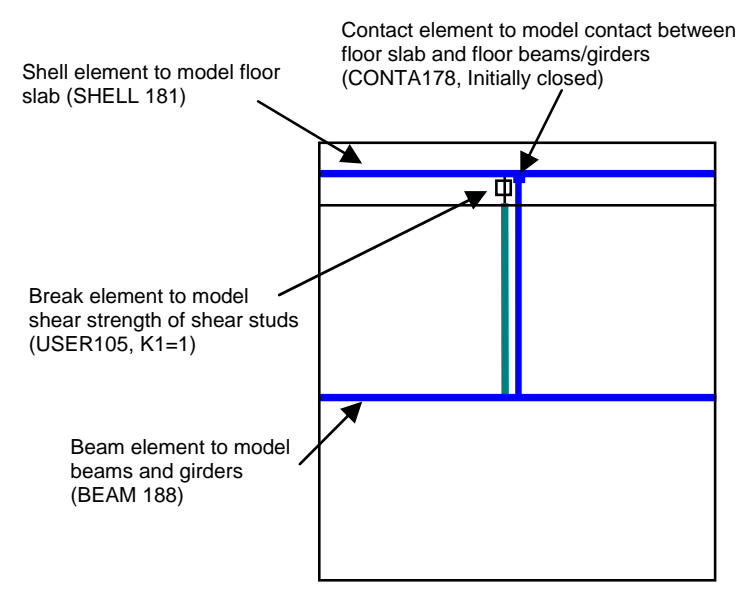

Shear Stud Connection

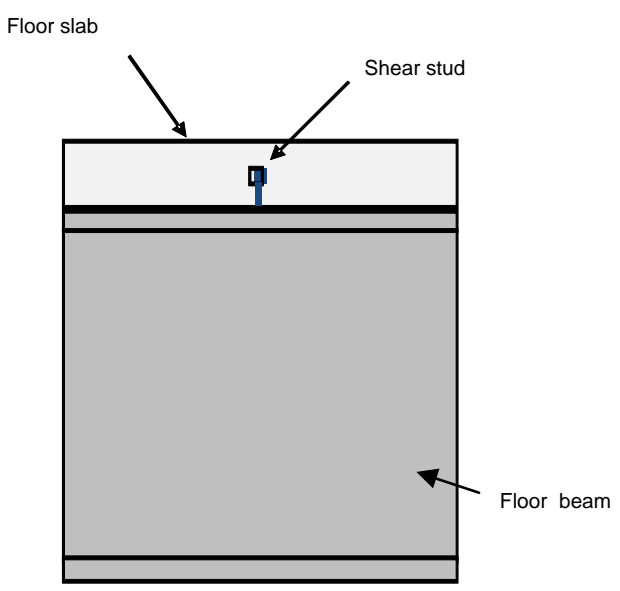

Elevation View

Figure 11-16. Analytical model for shear studs.

\subsubsection{Substructuring}

To improve the computational efficiency of the 16 story model, the lower 7 floors and Floors 15 and 16 were replaced with "superelements" to reduce the size of the model. Superelement is the term used for sub-structuring, where static condensation of the elastic stiffness matrix eliminates interior degrees of freedom while preserving the degrees of freedom on the boundaries of the superelement. This modification was made since these floors remained elastic, as there was no fire on these floors.

\subsubsection{Boundary Conditions and Loads}

\section{Displacement Boundary Conditions}

The column nodes at the base of the 16 story model were fully fixed to model the rigidity of the grillage and foundation (Chapter 2). The top of the columns at Floor 16 were fixed in the global x- and ydirections, to prevent lateral displacements, and were free in the global z-direction, to allow vertical displacement of the columns in response to gravity loads and thermal expansion. The purpose of the ANSYS model was to simulate the accumulation of local damages and failures up to the initiation of overall global collapse due to fire. The building was not expected to displace significantly in the $\mathrm{x}$ - and $\mathrm{y}$-directions outside of the floors with no fire and there was no interaction between adjacent columns for relatively small motions in the z-direction, due to limited load re-distribution mechanisms.

\section{Structural Loads}

The 16 story model was analyzed for the effects of gravity and temperature loads. Gravity loads were based on the WTC 7 design loads, shown in Figure 11-17, and included:

- $\quad$ the dead load (self-weight) of the structural steel and concrete floor slabs; 
- $\quad$ superimposed dead load consisting of the estimated weights of ceilings, mechanical and electrical equipment, thermal insulation, and floor finishes; and

- $\quad$ service live load, taken as 25 percent of the design live load.

The gravity loads from the portion of the building above Floor 16 were applied as concentrated forces to each column at Floor 16. Wind loads on September 11, 2001, were not structurally significant and, therefore, not considered.

\begin{tabular}{|c|c|c|c|c|c|c|c|c|c|}
\hline & & & LOAL & $D I N G$ & $5 \mathrm{CHEDL}$ & $J \mathbf{L E}$ & & & \\
\hline AREA & $\begin{array}{c}\text { CONCRETE } \\
\text { SLAB }\end{array}$ & $\begin{array}{l}\text { F/UL, } \\
\text { FINISH, } \\
\text { ROOFING }\end{array}$ & $\begin{array}{l}\text { CEILING } \\
\text { DUCTWOKK }\end{array}$ & PARTITIONS & FLOORING & \begin{tabular}{c|} 
BEAMS \\
ENCASEMENT \\
FRREPAOOFINS
\end{tabular} & $\begin{array}{l}\text { TOTAL } \\
D E A D \\
\angle O A D \\
\end{array}$ & $\begin{array}{l}\angle I V E \\
\angle O A D\end{array}$ & $\begin{array}{l}\text { TOTAL } \\
\angle O A D\end{array}$ \\
\hline \begin{tabular}{|l|} 
MAIN ROOF, \\
BULKHEAD \\
ROOF
\end{tabular} & 50 & 10 & . 8 & & 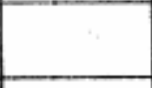 & 7 & 75 & 30 & 105 \\
\hline $\begin{array}{l}8^{T H}-20^{7 H} \mathrm{Fl} . \\
24^{T H}-46^{T H} \mathrm{FL} .\end{array}$ & 50 & $\cdot$ & 5 & 12 & & 8 & 75 & 50 & 125 \\
\hline $2^{5 T}-23^{N 0} / \mathrm{FL}$. & 50 & & 5 & 12 & 15 & 8 & 90 & 75 & 165 \\
\hline $\begin{array}{l}7 \text { TH FLOOR } \\
\text { NORTH SIOE }\end{array}$ & 80 & & 5 & 12 & 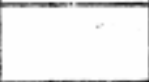 & 93 & 190 & 50 & 240 \\
\hline \begin{tabular}{|l} 
TH FLOOR \\
SOUTH SIDE
\end{tabular} & 80 & 38 & 8 & 12 & ... & 27 & 165 & 50 & $2 / 5$ \\
\hline $\begin{array}{l}\text { GW FLOOR } \\
\text { OFFICE SPACE }\end{array}$ & 56 & & 5 & 12 & & $\therefore 7$ & 80 & 50 & 130 \\
\hline \begin{tabular}{|c|} 
EW FLOOR \\
SWICHBOARD \\
ROOM
\end{tabular} & 62 & 38 & f & & & 55 & 155 & 100 & 255 \\
\hline \begin{tabular}{|l} 
STHFLOOR \\
OFF/CE \\
SPACE \\
\end{tabular} & 150 & 38 & 5 & & & 17 & 210 & 50 & 260 \\
\hline $\begin{array}{l}\text { STHFLOOR } \\
\text { MECHANICAL } \\
\text { SPACE } \\
\end{array}$ & 150 & 38 & 5 & . & & 17 & 210 & 150 & -360 \\
\hline $4^{T N}$ FLOOR & 56 & 75 & 5 & & & 10 & 146 & 100 & 246 \\
\hline \begin{tabular}{|c|} 
SRDFLOOR \\
NEW \\
CONSTRUCTIOW
\end{tabular} & 56 & 75 & 5 & & & 10 & 546 & 100 & 246 \\
\hline \begin{tabular}{|l|} 
3RO FLOOR \\
OVER EXISTIUG \\
SUBSTATION
\end{tabular} & . & & & & & , & 240 & 100 & 340 \\
\hline $\begin{array}{l}\text { 2ND FLOOR } \\
\text { NEW } \\
\text { CONSTRUCTION }\end{array}$ & 56. & 60 & 5 & & . & 10 & $\mathrm{fBt}$ & 150 & 281 \\
\hline \begin{tabular}{|l|} 
2NO FLOOR \\
EXISTING \\
SUESTATION \\
\end{tabular} & & & & & & $\because$ & 240 & 150 & 390 \\
\hline $\begin{array}{l}1 \text { ST FLOOR } \\
\angle O B B Y\end{array}$ & 175 & 90 & & & & 50 & $3 / 5$ & 100 & 415 \\
\hline $\begin{array}{l}\text { IST FLOOR } \\
\text { EXISTING } \\
\text { SUBSTATION }\end{array}$ & & & & & & & 300 & 225 & 525 \\
\hline
\end{tabular}

Source: Reproduced with permission of The Port Authority of New York and New Jersey. Figure 5-4 in NIST NCSTAR 1-1

Figure 11-17. Design load criteria for WTC 7.

\section{Thermal Loads}

Three thermal cases (A, B, and C) were developed in the thermal analyses (Section 10.3.1) that were within the range of realistic and reasonable fires in WTC 7 on September 11, 2001. Case A was based on the temperature data obtained from the FDS simulations. Cases B and C increased and decreased, 
relatively, the gas temperatures from Case A by 10 percent. A 10 percent variation from Case A gas temperatures was consistent with the expected range of realistic and reasonable fires in WTC 7 on September 11, 2001. The thermal data were input at each $30 \mathrm{~min}$ time step as nodal temperatures for the structural elements.

The concrete slab had temperatures applied to the shell element nodes at fire locations evenly spaced through the slab thickness and included temperature gradients through the slab. Each beam and column was assigned a single temperature (i.e., no thermal gradients across the section). Component studies had shown that columns were not heated sufficiently to warrant inclusion of a gradient, and that steel beams in the tenant floors heated at a nearly uniform rate, with the exception of the top flange which was adjacent to the floor slab. A uniform temperature gradient was determined to be a reasonable approximation for the temperature profile in the beam and girder sections (Section 10.3.2).

The temperature at beam-to-girder or girder-to-column connections was taken as the average of the temperatures of the nodes where the connection was located. Similarly, the temperature of a shear stud connection was computed as the average of the temperatures at the beam and slab nodes at the ends of the shear stud.

These modeling approaches were based on detailed thermal analyses, such as the analysis of Column 79 shown in Figure 11-18, which demonstrated that (1) the web and bottom flange of the girders heated at a nearly uniform rate at a given point along the girder length (except where girders were connected at their ends) and (2) the connection temperatures were approximately midway between the temperature of the end beam node and the column node.

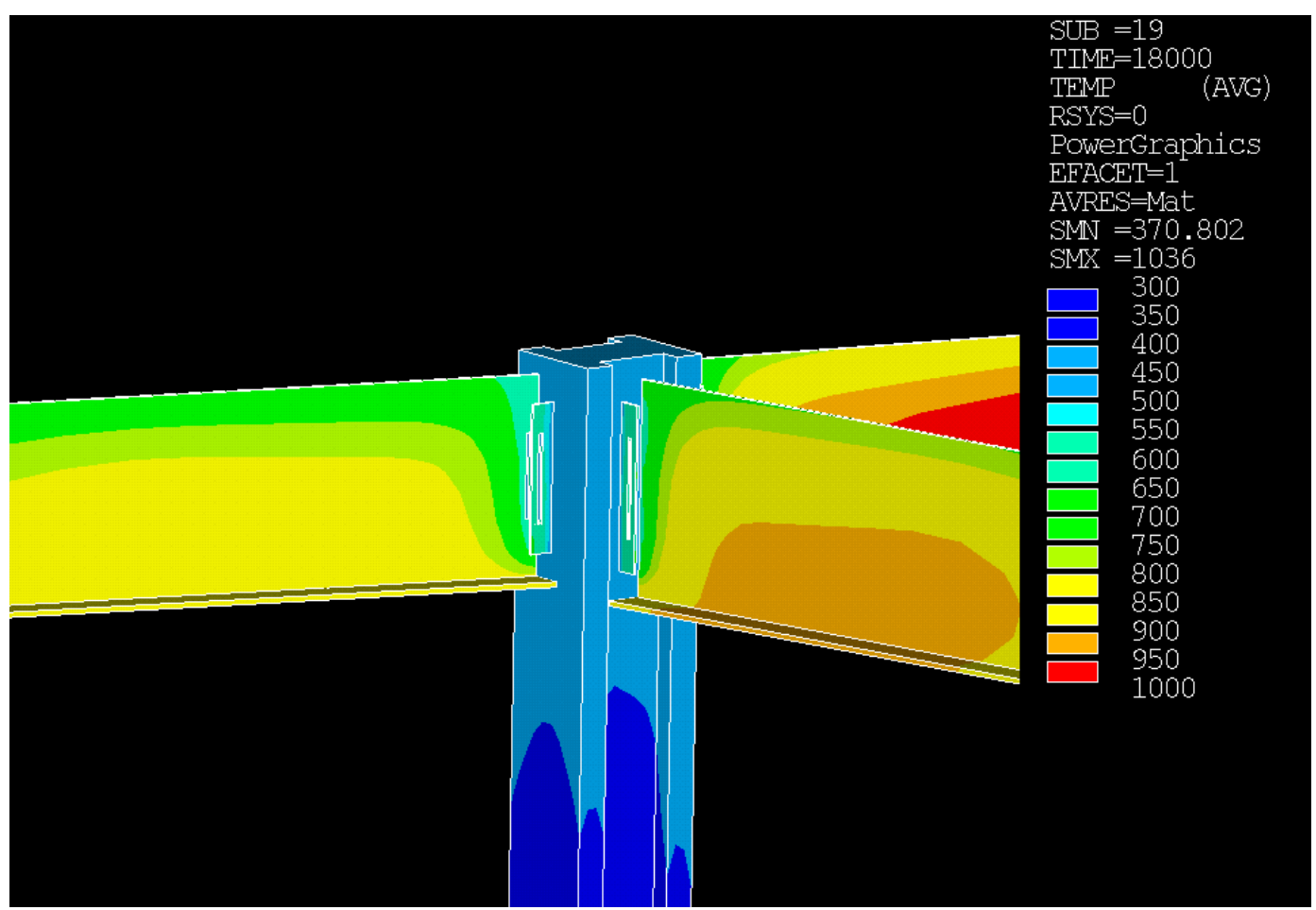

Figure 11-18. Detailed thermal analysis showing the gradient between girders, Column 79, and their connections. 


\subsubsection{Load Application Sequence}

\section{Gravity Load Sequence}

The gravity loads were applied in steps to simulate the effects of construction sequence. During construction, the floor framing deflects under the weight of poured concrete, but the concrete does not have the stiffness to participate in supporting its self-weight. After the concrete has hardened and gained strength, the concrete slab acts compositely with the steel beams (through the shear studs) to support the superimposed dead and live loads, but not the dead weight of the concrete slab.

The analysis of the gravity loads was performed in two steps. In the first step, the stiffness of the slab was set to zero and all simple shear connections were assumed to provide no bending while the model was subjected to the self weights of the floor framing, concrete slab, and floors above Floor 16 (applied as concentrated forces to Floor 16 columns).

In the second step, the stiffness of the slab was activated (the floor became fully composite with the supporting frame) and the simple shear connections at the ends of the floor beams were assumed to provide the resistance to beam end rotations in accordance with their connection models, before subjecting the model to the superimposed dead and service live loads.

\section{Temperature Load Sequence}

Thermal loading was applied in the form of temperature-time histories. Each temperature-time history was defined discretely at 30 min intervals. Temperatures were linearly interpolated for times between consecutive intervals.

\subsubsection{Criterion to Determine Component Failures}

A procedure was developed for addressing buckled and/or failed components so that any member that did not structurally contribute to the response of the building was removed from the analysis to improve computational efficiency and avoid convergence problems. This procedure was used to modify the model at the end of each 30 min interval, or as necessary when the analysis halted due to non-convergence.

The removal of framing and slab elements from the model was performed in ANSYS by reducing the stiffness and mass of the selected elements to a very small fraction of the original values. These elements remained part of the stiffness matrix and solution process, but they did not contribute to the structural response of the model. When elements were removed, any temperature, distributed load, or concentrated forces that were assigned to these elements were automatically set to zero.

\section{Criteria to Determine Lateral-Torsional Buckling of Beams and Girders}

When lateral support of the top (compression) flange was lost, floor beams and girders could laterally displace and buckle in a lateral-torsional mode. In the ANSYS analysis, buckling of flexural members led to convergence difficulties. To improve analysis progress, buckled members were removed from the analysis. The criterion used for removal of buckled beams or girders was based on the destabilizing effect of gravity loads on laterally displaced beams or girders. If a beam or girder twisted half of its flange 
width laterally, it would not be able to support its gravity loads and would be removed from the analysis. The rotation corresponding to this condition is shown in Figure 11-19 and is expressed as follows:

$$
\theta_{\text {critical }}=\tan ^{-1}\left(b_{f} / d\right)
$$

where, $b_{f}=$ flange width

$d=$ depth of beam/girder

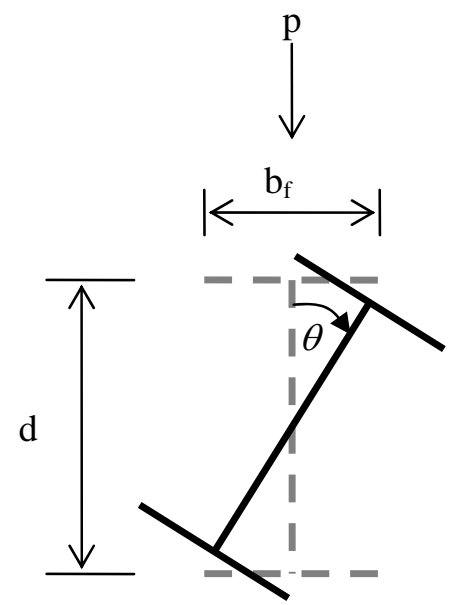

Figure 11-19. Critical Twist Angle in Beams/Girders.

\section{Criteria to Remove Locally Unstable Members Due to Loss of Vertical Support}

Under elevated temperatures, a beam could lose vertical support at one end through connection failure. Loss of vertical support occurred when a fin, knife, or header connection failed or when a beam or girder walked off of a bearing seat in a SWC, STC, or STP connection. Walk-off failure of beams and girders was defined to occur when (1) the end of the beam or girder moved along the axis of the beam until it was no longer supported by the bearing seat, or (2) the beam or girder was pushed laterally until its web was no longer supported by the bearing seat. Gravity shear loads in a beam were transferred to the bearing seat primarily in the proximity of the web on the bottom flange. Therefore, when the web was no longer supported by the bearing seat, the beam was assumed to have lost support, as the flexural stiffness of the bottom flange was assumed to be insufficient for transferring the gravity loads. Under such conditions, the beam would fall to the floor below under its self weight. When this occurred in the ANSYS analysis, the beam was removed. When a girder failed in this manner, the floor beams that it supported were removed at the same time.

\section{Criteria to Determine Cracking and Crushing of Floor Slab}

Temperature effects and failure of supporting beams and girders caused slab elements to undergo large tensile or compressive strains. The ANSYS material model used for slabs was based on an isotropic plasticity formulation without strength degradation at high strains and, hence, it could not represent cracking under tensile strains or crushing under compressive strains. To address this issue, slab elements that reached the tensile or compressive failure strains were softened. Any slab element with a principal tensile strain equal to or greater than 0.0015 at mid-depth of the section was assumed to be fully cracked 
in tension. ${ }^{4}$ Similarly, any slab element with a principal in-plane compressive strain equal to or less than -0.004 was considered fully crushed in compression.

When these strain levels were reached in the slab, that portion of the slab was softened. Softening of slab elements refers to replacing the material property of concrete with a reduced elastic modulus. The reduced elastic modulus was equivalent to the in-plane stiffness that would be provided by the weldedwire-mesh in the slab at high temperatures $\left(\mathrm{T} \geq 700^{\circ} \mathrm{C}\right)$. Softening of a section of the slab, and not removing it from the analysis, allowed the service live loads that were applied to the slab elements to be transferred to the remaining beams, girders, or spandrel beams without affecting the stiffness of the remaining floor system. Additionally, the floor slab continued to provide lateral support even after slab strains exceeded the cracking and crushing strains of concrete.

After softening, the compressive strain in the concrete slab was allowed to increase to more than 3.0\%. As the analysis progressed, some floors had large areas where the floor beams and girders had failed and had been removed. In these areas the softened floor slab caused rotation in the exterior spandrel beams as the sagging slab applied a torque to the spandrel beam causing it to undergo severe torsional buckling. This behavior created numerical difficulties in the analysis, which were not likely to occur in the structure. When this situation occurred in the analysis, the slab elements were removed from the analysis. Typically at the time of removal of the slab, the strains were greater than $3.0 \%$.

\subsection{ANALYSIS RESULTS}

The three different thermal response cases (Cases A, B, and C) were used as input to the ANSYS analysis. It became apparent as the ANSYS analyses progressed that the connection, beam, and girder failures occurred essentially at the same locations and with similar failure mechanisms, but shifted in time between the three cases. Case B failures occurred at the earliest time, followed by Case A, and then Case C. The results of the Case $B$ and Case $C$ analyses are presented to show the similarity in failures and locations and the time lag between Case B and Case C, since Case A results fall between these two Cases.

The analysis of the structural response of WTC 7 to the effects of elevated temperatures produced a large volume of output data. Results for Floors 2 to 7 and Floors 15 and 16 are not presented as they were subject only to gravity loads and were not subjected to thermal loads. The analysis results for Floors 8 to 14 were first examined graphically for a selected response, such as vertical displacement or strains. Areas of interest were then examined in more detail by listing the results of interest.

Heating of structural components resulted in several possible structural responses, depending on the temperature of the components, amount of thermal expansion, end restraint, and degradation of stiffness and strength. Structural parameters that were monitored and evaluated to determine the structural thermal response included:

- Vertical displacements of the floor framing and the slab

- Axial stresses in floor beams and columns

\footnotetext{
${ }^{4}$ Concrete starts to microcrack at a tensile strain of approximately $1.4 \times 10^{-4}$. Beyond this strain level, the microcracking will grow and coalesce, and the concrete will soften with increasing strain. At a strain level of about $1.5 \times 10^{-3}$, the concrete can no longer support any tensile force.
} 
- In-plane strains of the floor slab

- Degree of damage in connections

- Lateral displacement and rotation of floor beams and girders

Damage to the floor framing depended primarily on the heating from fires on the floor below, whereas the slab was affected by fires on the top of the slab as well as from the floor below. The vertical displacements generally increased as the temperature of the structural framing increased.

In general, the steel framing heated more quickly than the concrete slab. Thus, even though steel and concrete have similar coefficients of thermal expansion, differential thermal expansion occurred between the steel floor beams and concrete slab when the composite floor was subjected to fire.

Axial stresses in the floor beams increased as the beam temperatures increased due to restrained thermal expansion, but the column axial stresses remained relatively constant during the response. Interior columns were not thermally restrained and were free to expand. Exterior columns had some thermal restraint due to the moment framing, but their temperatures remained low. Axial column stresses remained essentially constant because (1) interior column temperatures were less than $200{ }^{\circ} \mathrm{C}$ and exterior column temperatures were less than $150{ }^{\circ} \mathrm{C}$, except for a few columns in the $12^{\text {th }}$ and $13^{\text {th }}$ floors which were less than $300^{\circ} \mathrm{C}$; and (2) the failure of girders in a floor did not noticeably decrease the column load. The change in column load following a girder failure at any given floor was small compared to the total column loads from the tenant floors above. Additionally, the only path for redistribution of gravity loads in WTC 7 between interior columns was through the floor framing. Any load redistribution would have occurred until the beam or girder connections failed at the column.

A damage index was computed for the horizontal and vertical direction (shear and axial loads) for each connection. Failure of fin, knife, and header connections resulted in a loss of support for both horizontal and vertical directions, whereas, loss of horizontal and vertical support in the seated connections (SWC, STC, and STP) occurred separately. For example, if all the bolts in a fin connection were sheared, the connection would be fully damaged (failed with a damage level of 1.0) in both the horizontal and vertical directions. However, if all the bolts of a seated connection were sheared, the connection would be fully damaged in the horizontal direction, but not in the vertical direction as the beam or girder would still be resting on the seat. Failure in the vertical direction would occur when either the member supported by the connection walked off the seat or the weld at the seat failed.

The damage state of connections, floor beams, and girders for each floor is illustrated in Sections 11.3.2 and 11.3.3. Connection damage is shown separately for the horizontal and vertical directions. For example, in Figure 11-22 (first graphic in Section 11.3.2), tan dots represent connections without any damage and black dots represent connections with full damage for a given direction. The other colors indicate the degree of damage to the connection at a given time in the analysis. For example, a blue dot, with the degree of damage labeled as " 0.5 to 0.74 ," represents a 6-bolt fin connection with 4 failed bolts, which gives a damage index of 0.66. Connection damage was typically gradual, with bolts and/or welds failing sequentially over time. In addition to showing connection damage, these graphics also present the floor beam and girder damage, where buckled beams are pink lines and failed end connections are red lines. Prior to end connection failure, many, if not all, of the shear stud connections had failed along the 
floor beams due to thermal expansion effects. Any beam connected to a girder that lost vertical support also lost vertical support at the girder, and is indicated with a red line.

Graphics are presented in Sections 11.3.1, 11.3.2, and 11.3.3 to describe key observations for the building response to gravity loads (Figure 11-20 and Figure 11-21), Case B temperatures at $3.5 \mathrm{~h}$ (Figure 11-22 through Figure 11-29) and 4.0 h (Figure 11-30 through Figure 11-37), and Case C temperatures at $4.0 \mathrm{~h}$ (Figure 11-38 to Figure 11-45). The Case B temperatures at $4.0 \mathrm{~h}$ resulted in significant damage to the floors subjected to fires relative to the damage at $3.5 \mathrm{~h}$. The Case $\mathrm{C}$ temperatures at $4.0 \mathrm{~h}$ show how the structural response was similar to the Case B response, but with a time lag.

Section 11.4 has a general discussion of results for Case B at $3.5 \mathrm{~h}$ and $4.0 \mathrm{~h}$ and for Case C at $4.0 \mathrm{~h}$.

\subsubsection{Analysis of Building Response to Gravity Loads}

The structural response to gravity loads was the same for all tenant floors in the ANSYS model. Figure 11-20 shows the vertical displacements in the floor framing and slab, the axial stresses in the floor framing and columns, and the in-plane strains of the floor slab for Floor 8.

Displacements. The typical vertical floor displacement on the tenant floors was about 3.5 in., as shown in Figure 11-20a. The maximum vertical deflection of $4.5 \mathrm{in}$. occurred in the northwest corner of the tenant floor. The floor beams were shown to be cambered from 1.0 in. to $2.75 \mathrm{in}$. in the design drawings. Beam camber could not be modeled in ANSYS. Thus, the actual vertical floor displacements would have been about one to two inches, if the camber was subtracted from the computed displacements.

Axial stresses from axial forces in the floor beams and in-plane slab strains were small, as expected for gravity load conditions. The stress in the floor beams due to axial loads was less than $1 \mathrm{ksi}$ (floor beams had a nominal yield strength of $50 \mathrm{ksi}$ ). The in-plane slab strains were less than $-5 \times 10^{-5}$ (concrete failure strain in compression was $-4 \times 10^{-3}$ and failure strain in tension was $1.5 \times 10^{-3}$ ).

Axial column stresses (Figure 11-20c) ranged from 15 to $28 \mathrm{ksi}$ in the interior columns and in exterior Columns 44 and 55 on the north face. The axial column stress in the other exterior columns ranged from 8 to $15 \mathrm{ksi}$.

Column Forces. The column forces at Floor 8 are presented for comparison to the column forces at $3.5 \mathrm{~h}$ and $4.0 \mathrm{~h}$ of heating, which are presented at the end of Sections 11.3.2 and 11.3.3. Axial forces in the columns at Floor 8 are shown in Figure 11-21. The size of the circle at each column indicates the magnitude of the load. The maximum column force of 7,525 kip was at Column 79. The axial force ranged from 2,000 kip to 5,000 kip in the rest of the interior columns and 1,000 kip to 3,000 kip in the exterior columns. The sum of all column forces was 176,500 kip, with the interior and exterior columns carrying these forces in about equal parts. Based on the design drawings, the sum of all column forces for a loading condition of dead loads and service live loads was 174,100 kip. 


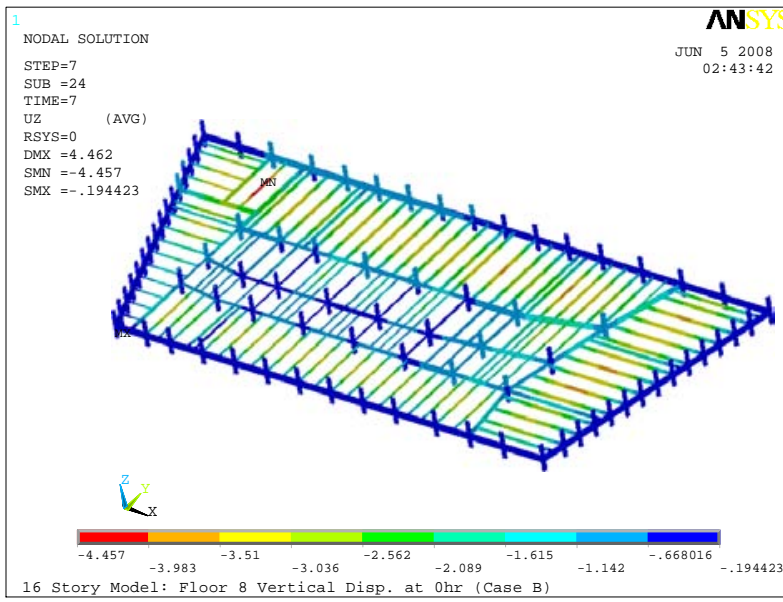

a) Vertical displacements in floor framing.

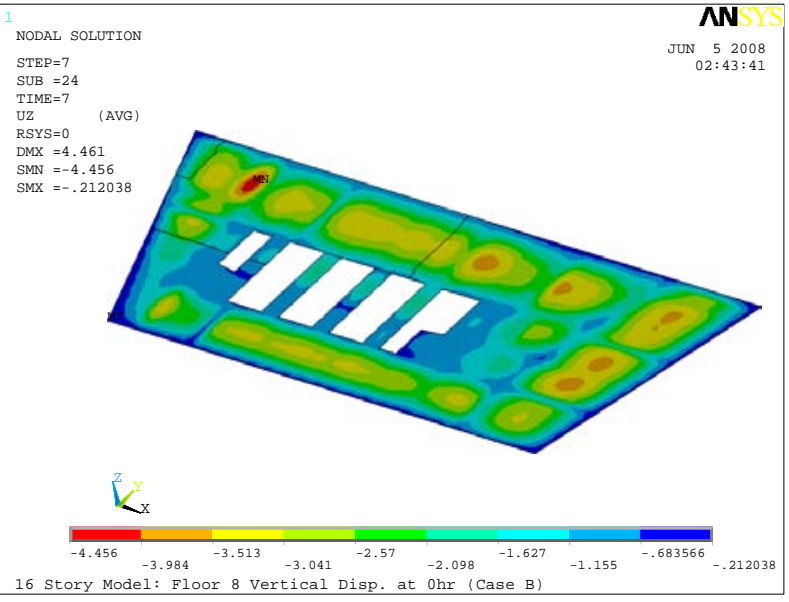

b) Vertical displacements in floor slab.

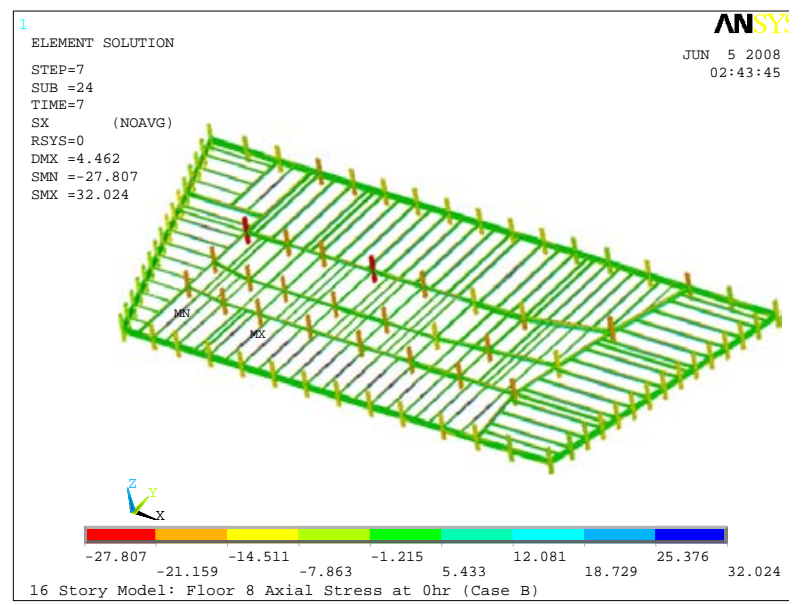

c) Axial stress in floor framing and columns.

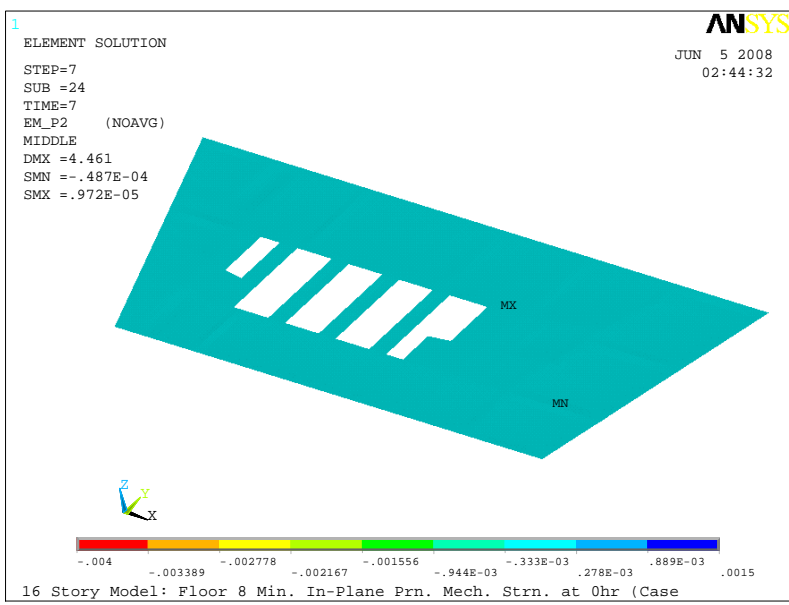

d) Minimum in-plane principal strains in floor slab.

Grey color indicates areas with $\varepsilon<-0.004$ and purple color indicates areas with $\varepsilon>0.0015$.

Figure 11-20. Structural response of Floor 8 to gravity loads. 


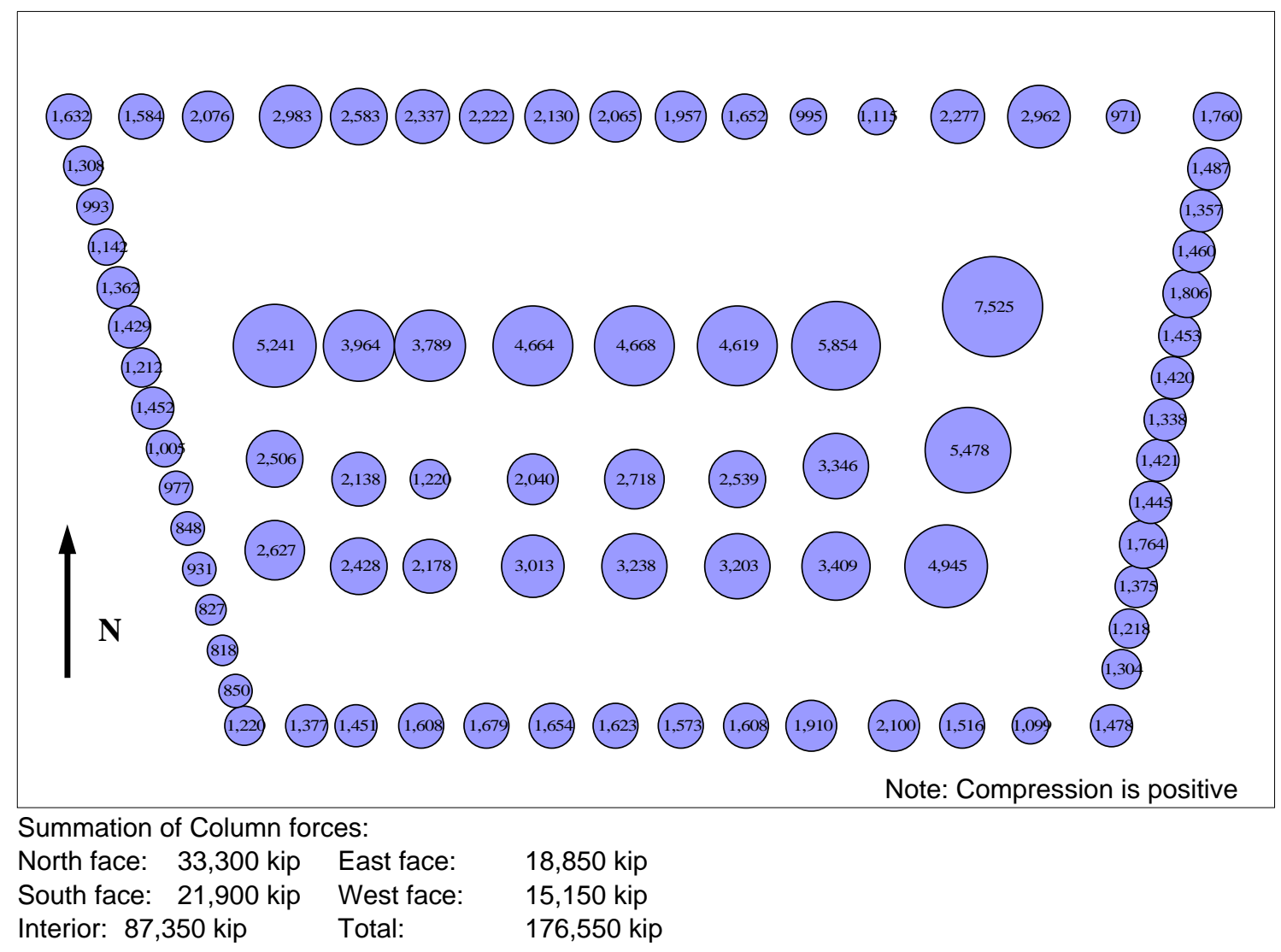

Figure 11-21. Column forces (kip) above Floor 8 for gravity loads.

\subsubsection{Analysis of Building Response for Case B Temperatures}

The fires on Floors 11, 12, and 13 generated significantly more heat than the fire on Floors 7, 8, and 9. This was due in large part due to the higher fuel load and the window breakage on Floors 11, 12, and 13 (see Section 10.4). The difference in the heating of the structural elements is reflected in the location and extent of fire-induced damage to the floor systems described below. (As a reminder, a fire on a given floor, such as Floor 12, will primarily heat the top of the slab on Floor 12 and the floor framing and bottom of the slab on Floor 13).

The building response is examined at $3.5 \mathrm{~h}$ and $4.0 \mathrm{~h}$ of heating. At $3.5 \mathrm{~h}$, the floor systems had fireinduced damage and failures of some connections, beams, and girders. After $4.0 \mathrm{~h}$ of heating, there was substantially more damage and failures in the WTC 7 structural floor system, particularly in the northeast region surrounding Column 79. The structural condition at these two times illustrates how the structure developed sufficient fire-induced damage to reach the collapse initiation event.

\section{Building Response at $3.5 \mathrm{~h}$}

Figure 11-22 to Figure 11-28 show the damage to the connections, beams and girders of Floors 8 to 14, respectively. 
After $3.5 \mathrm{~h}$ of heating, there were failures of floor beams, girders, and floor slab sections on Floors 8, 12, 13, and 14 due to the fires. The fires on Floors 7, 8, and 9 had primarily heated the north tenant floor area from west to east. The fires on Floors 11, 12, and 13 had heated the south tenant floor area and the southern region of the east tenant floor area. Figure 10-27 to Figure 10-40 in Section 10.3.3 show the temperatures of structural members on these floors ${ }^{5}$.

Floors 8, 13, and 14 had the most damage in response to the fires at $3.5 \mathrm{~h}$, with the greatest vertical deflections and axial stresses in beams and girders, and the greatest areas of crushed slab and failed beams and girders. Floor 12 also had thermally induced damage, but to a lesser degree than Floors 8, 13, and 14. Results for Floors 8, 12, 13, and 14 are discussed here.

Floor 8. Elevated temperatures in the $8^{\text {th }}$ floor framing on the north side ranged from about $150{ }^{\circ} \mathrm{C}$ at the east side to $500{ }^{\circ} \mathrm{C}$ at the west side. The downward (vertical) floor deflections had increased to 19 in. in the north floor beams on the west side. Axial compression had increased to between $20 \mathrm{ksi}$ and $30 \mathrm{ksi}$ in many of the core and north floor beams, from less than $1 \mathrm{ksi}$ due to gravity loads alone, due to restrained thermal expansion. The slab in the northwest region had reached the crushing strain limit and was softened.

Fin connections failed where the north floor beams were attached to the girder between Columns 76 and 79 (see Figure 2-4 for column locations), as the bolts sheared due to thermal expansion. Figure 11-22 shows the connection and floor framing damage that occurred. The northeast beam-to-girder fin connections had a 0.75 to 0.99 damage level between Columns 44 and 79 and a 0.25 to 0.49 damage level at the east exterior columns. The header connections failed at Columns 74 and 78, due to thermal expansion of the girder. The beams that were supported by these girders are also considered to have failed, since they would fall with the girder.

Floors 9 to 11. Floors 9 to 11 had downward displacements ranging from 9 in. to 15 in. The largest downward displacements tended to be adjacent to failed floor beams, as the remaining intact beams were loaded by the slab.

Floors 12, 13, and 14. Elevated temperatures of the floor framing in the southeast region on Floors 12, 13, and 14 ranged from $150{ }^{\circ} \mathrm{C}$ to $350{ }^{\circ} \mathrm{C}$ in Floor $12,500{ }^{\circ} \mathrm{C}$ to $700{ }^{\circ} \mathrm{C}$ in Floor 13 , and $300{ }^{\circ} \mathrm{C}$ to $500{ }^{\circ} \mathrm{C}$ in Floor 14. However, the thermal analysis did not account for failed floor framing as the structure was heated. Figure 11-26, Figure 11-27, and Figure 11-28, based on the ANSYS analysis of the structural response to heating, show that floor beams had failed in areas where the steel temperatures were greater than $400{ }^{\circ} \mathrm{C}$ to $500{ }^{\circ} \mathrm{C}$. The following beam and girder failures occurred:

- Floor 12 had six floor beam failures by Columns 78, 80, and 81, due to either buckling of the floor beam near Column 80 or connection failures (Figure 11-26). The beam on the east side of Column 81 had a weld failure in the header connection to the exterior spandrel beam. The remaining failed beams either buckled or lost vertical support when all of the connection bolts were sheared.

\footnotetext{
${ }^{5}$ The thermal analysis in Chapter 10 determined the temperature of structural members when subjected to the gas temperatures from the FDS analysis, but it did not account for thermally-induced damage. During the ANSYS analysis of structural response, structural members or their connections may have failed before reaching the temperatures shown in Chapter 10.
} 
- Floor 13 had failure of all tenant floor beams near Columns 78, 80, and 81 (Figure 11-27) and Floor 14 framing had failure of all tenant floor beams near Columns 78 and 81 (Figure 11-28). The floor beams either buckled (i.e., the east floor beam that framed into Column 80) or had connection failures (i.e., all the bolts were sheared) at the girder or spandrel beam, as a result of thermal expansion of the beams.

- At Floors 13 and 14, the girder between exterior Column 26 and interior Column 81 buckled and walked off the bearing seat due to the combined effects of (1) gravity loads, (2) lateral westward displacement due to the thermal expansion in the east floor beams prior to their failures, and (3) thermal expansion in the girder.

Axial beam stresses had increased in the south and east floor beams on Floors 12 to 14, due to restrained thermal expansion. The southeast floor slab was softened, on Floors 12 and 13, due to the local thermal expansion and crushing of concrete from the fires on those floors.

Figure 11-26, Figure 11-27, and Figure 11-28 show the connection and floor framing damage that occurred in Floor 12, 13, and 14, primarily due to the effects of thermal expansion. The east beam-togirder fin connections had a 0.75 to 0.99 damage level between the south face (Column 26) and Column 79 at most of the floor beams. This level of connection damage also extended toward the north face (Column 44) on Floor 13, where only two connections remained undamaged. The seated connection at Column 79 had horizontal connection damage, with shear failure of all the erection bolts on Floor 13 and two to three bolts on Floors 12 and 14, respectively

Column Forces. Figure 11-29 shows the axial force in the columns at Floor 8 at $3.5 \mathrm{~h}$. The axial force decreased slightly ( 0.04 percent) after removing some of the beams from the analysis. The change in axial forces in columns and redistribution of loads among floor columns was negligible.

Summary. The connections between the girders and interior columns were all intact, except for the girder connections between exterior Column 26 and interior Column 81 on Floors 13 and 14. At the seated connection at Column 79, all the bolts had sheared on Floor 13 and 2 to 3 bolts had sheared on Floors 12 and 14. Approximately one-half to three-quarters of the east floor beams had a connection damage level of $0.75-0.99$ on Floors $11,12,13$, and 14 . The floor systems had fire-induced damage to connections, beams, and girders after $3.5 \mathrm{~h}$ of heating, primarily due to the effects of thermal expansion, on the north floor and east side of the core on Floor 8 and the south and east floor area of Floors 12, 13, and 14. 


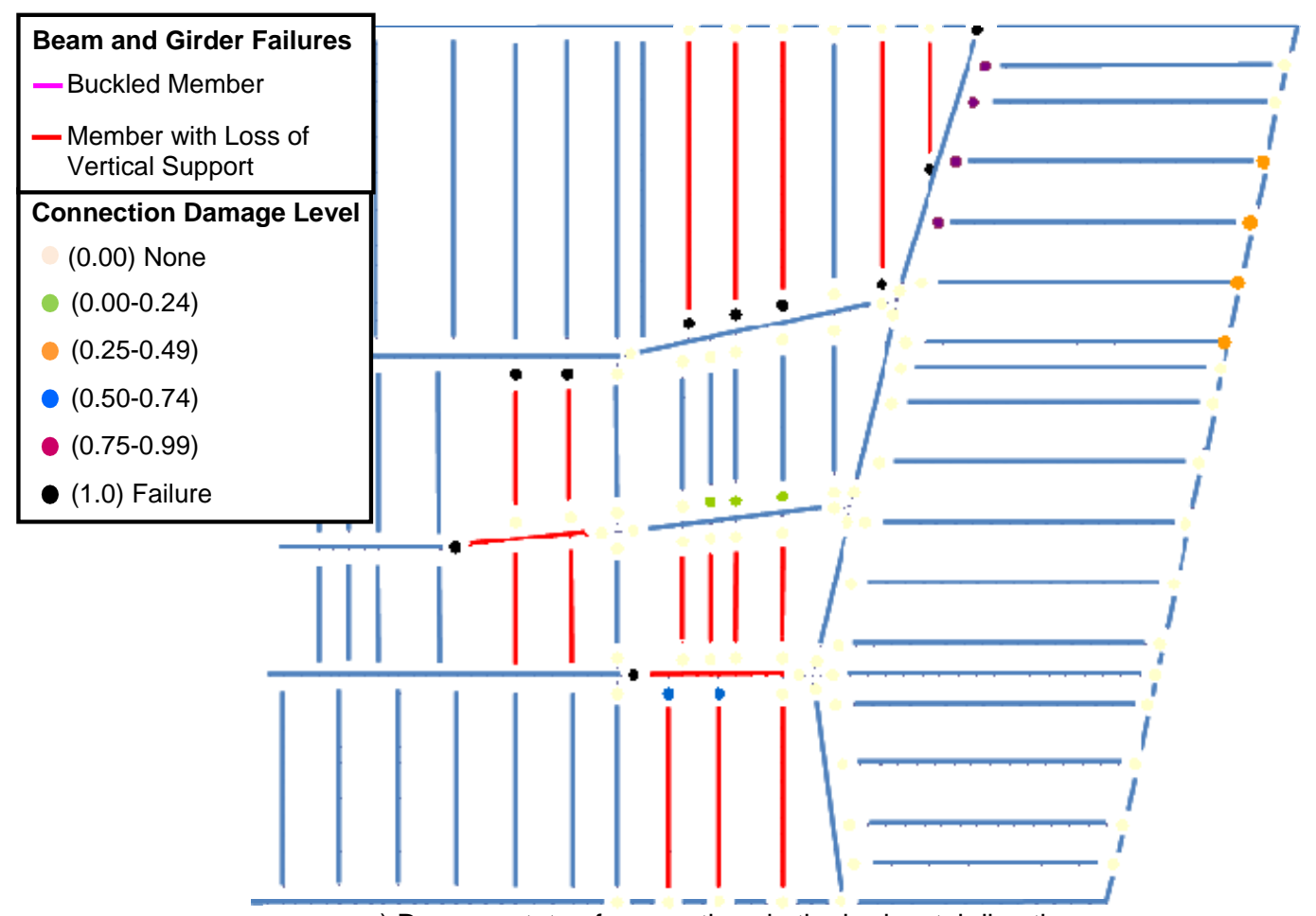

a) Damage state of connections in the horizontal direction

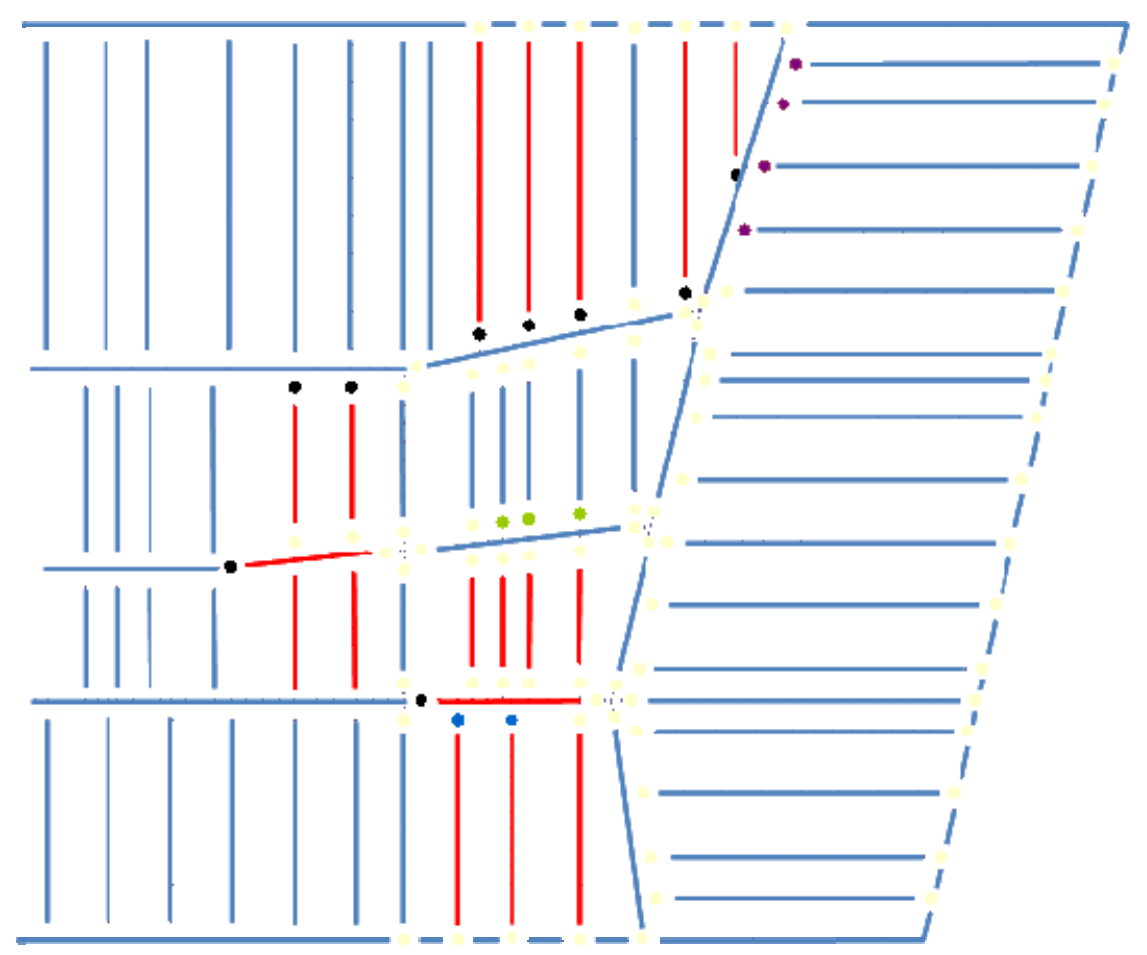

b) Damage state of connections in the vertical direction

Figure 11-22. Damage state of connections, beams, and girders in Floor 8 at $3.5 \mathrm{~h}$ for Case B temperatures. 


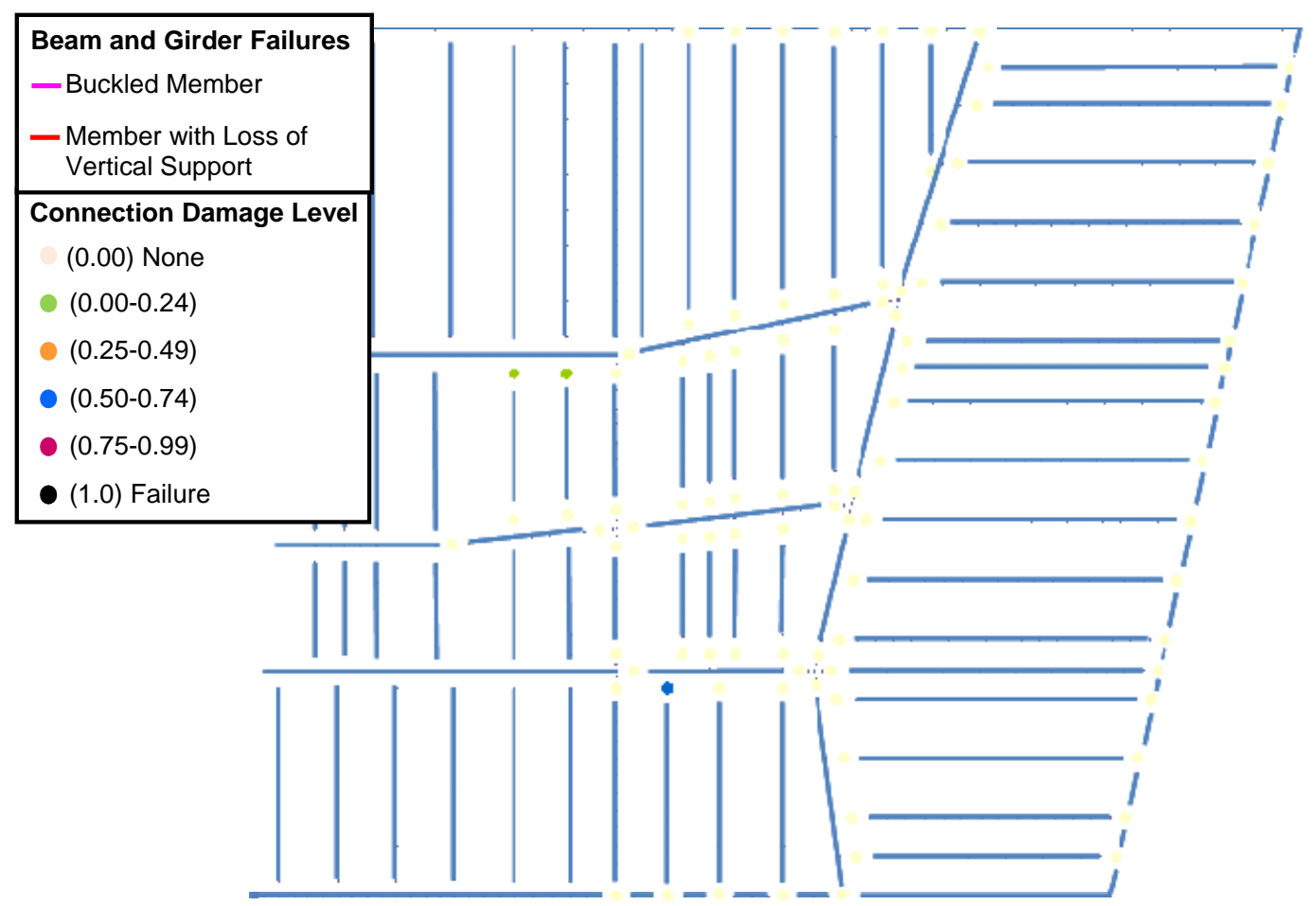

a) Damage state of connectıons in the norizontal dırectıon

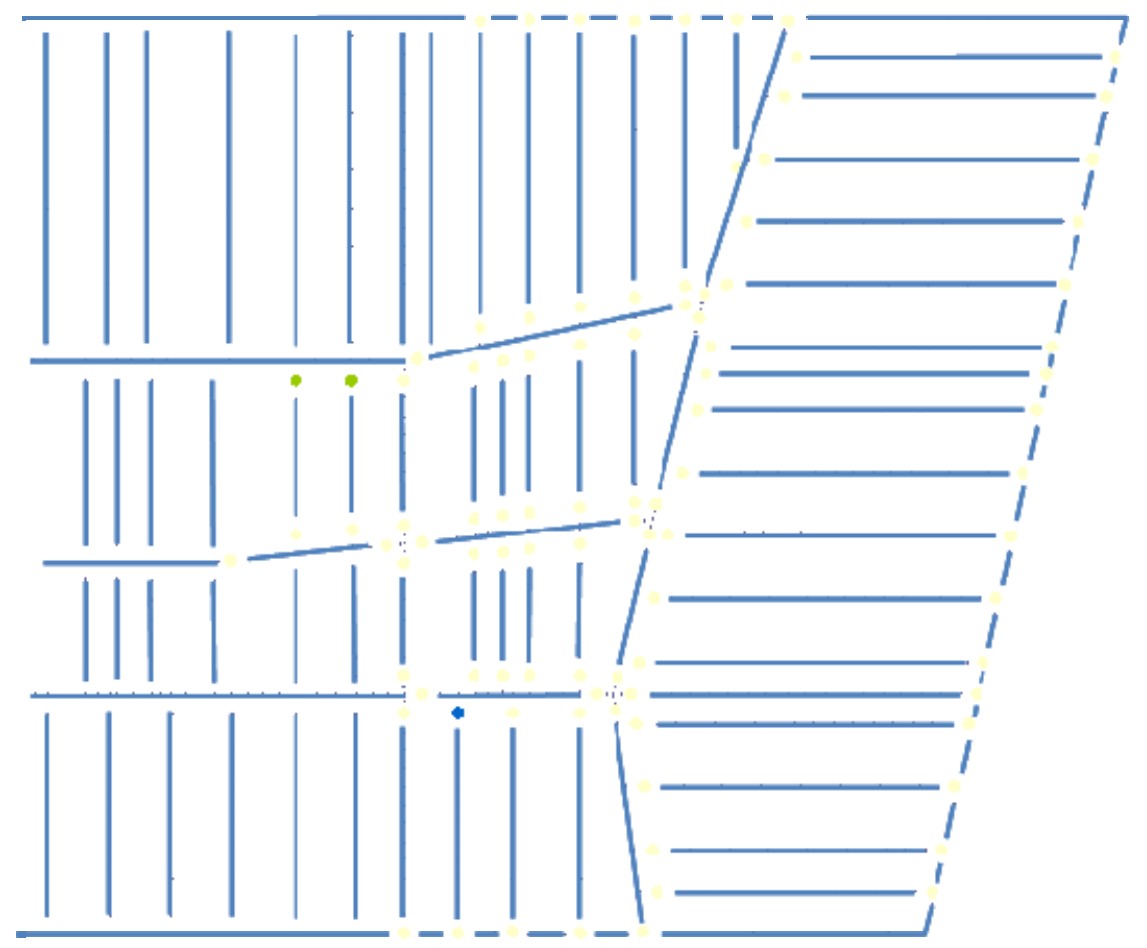

b) Damage state of connections in the vertical direction

Figure 11-23. Damage state of connections, beams, and girders in Floor 9 at $3.5 \mathrm{~h}$ for Case B temperatures. 


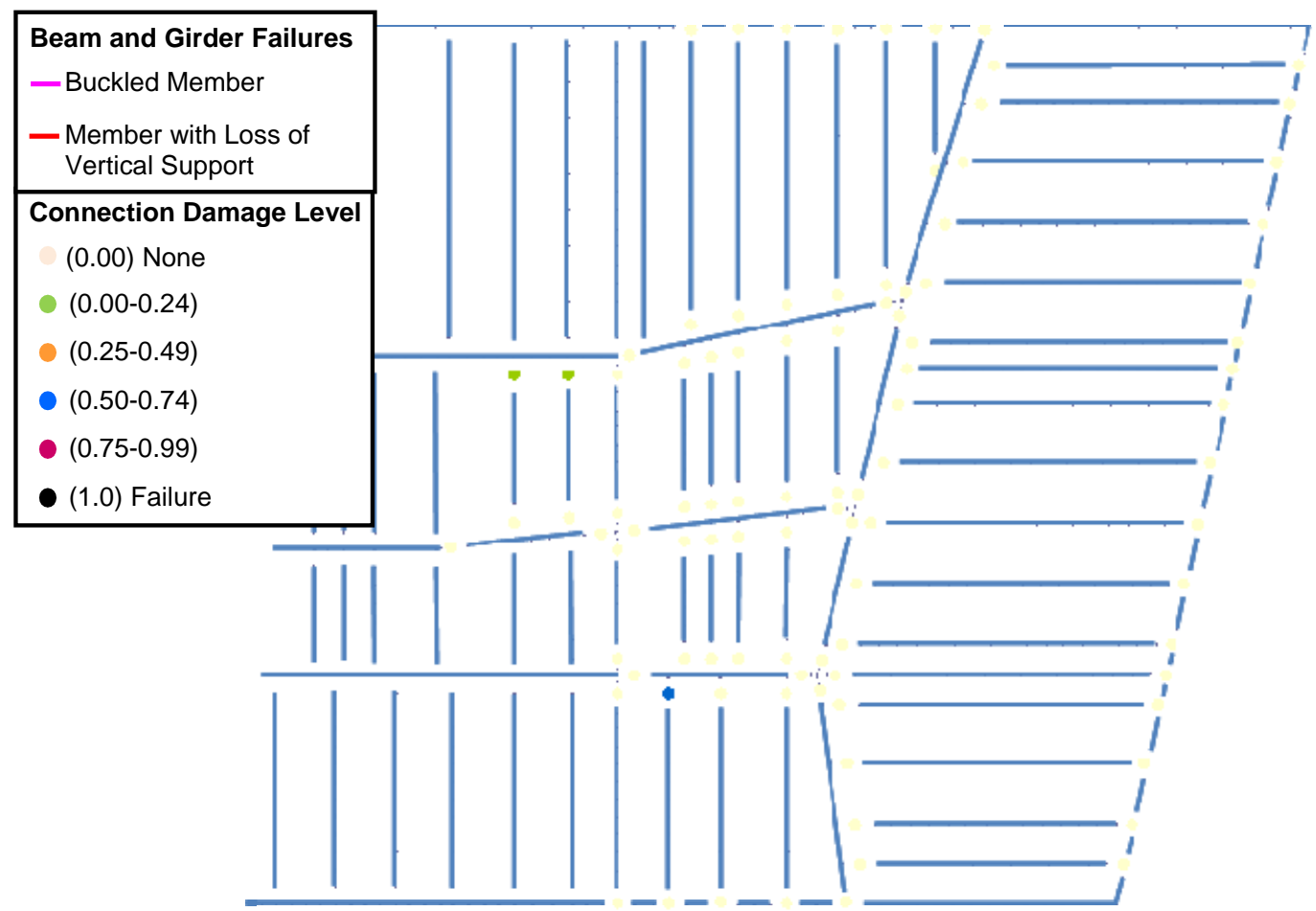

a) Damage state of connectıons in the norızontal aırectıon

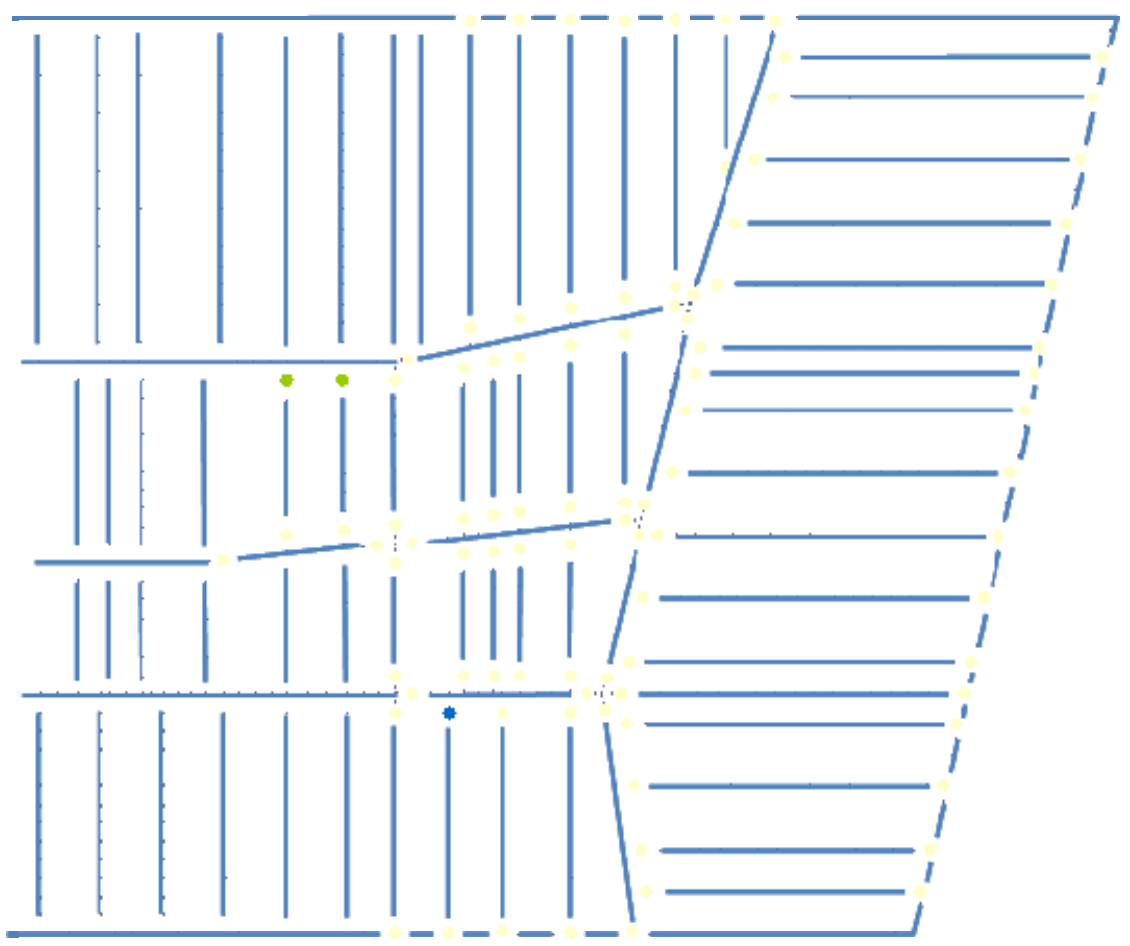

b) Damage state of connections in the vertical direction

Figure 11-24. Damage state of connections, beams, and girders in Floor $\mathbf{1 0}$ at $\mathbf{3 . 5} \mathrm{h}$ for Case B. temperatures. 


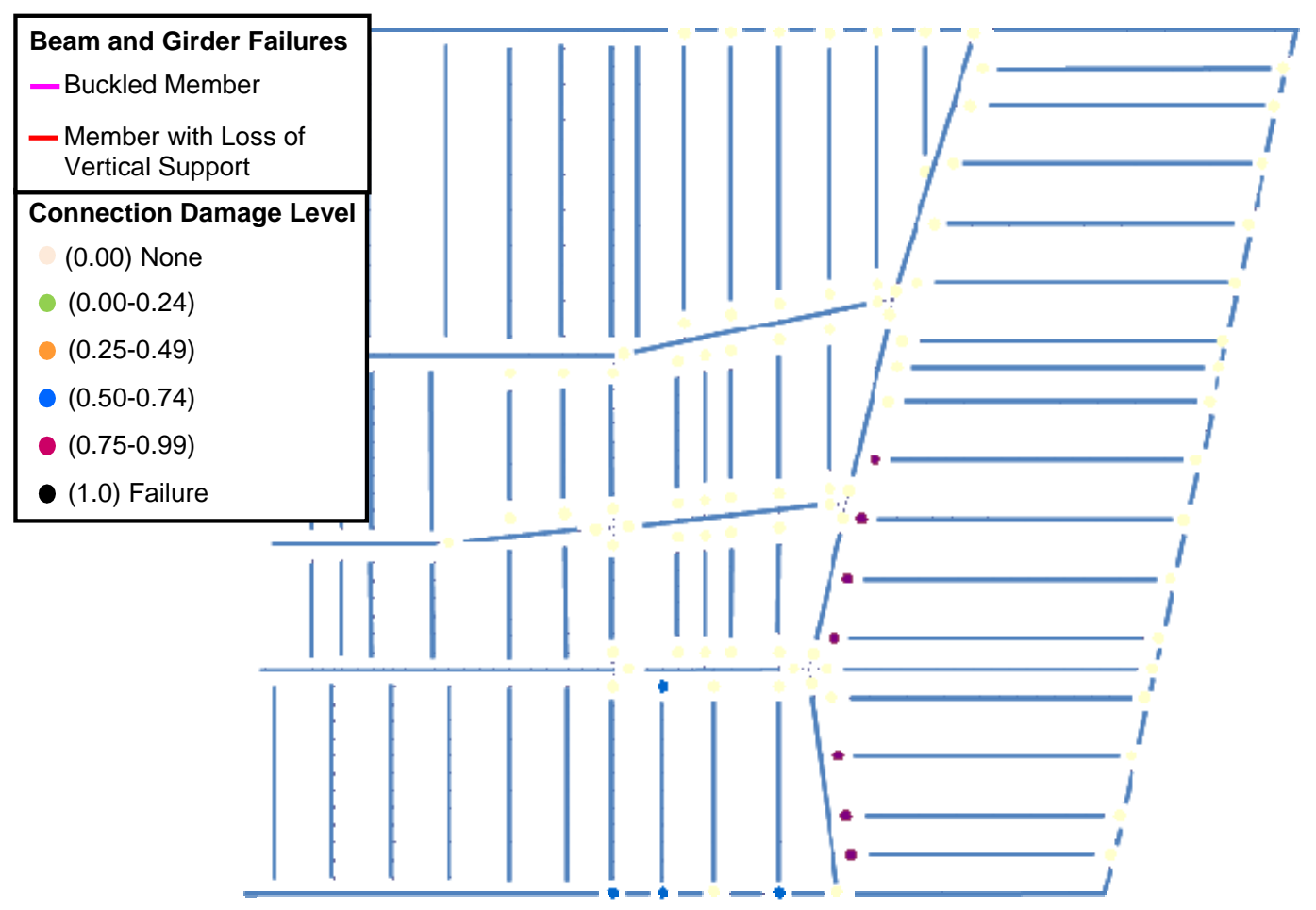

a) Damaqe state of connections in the horizontal direction

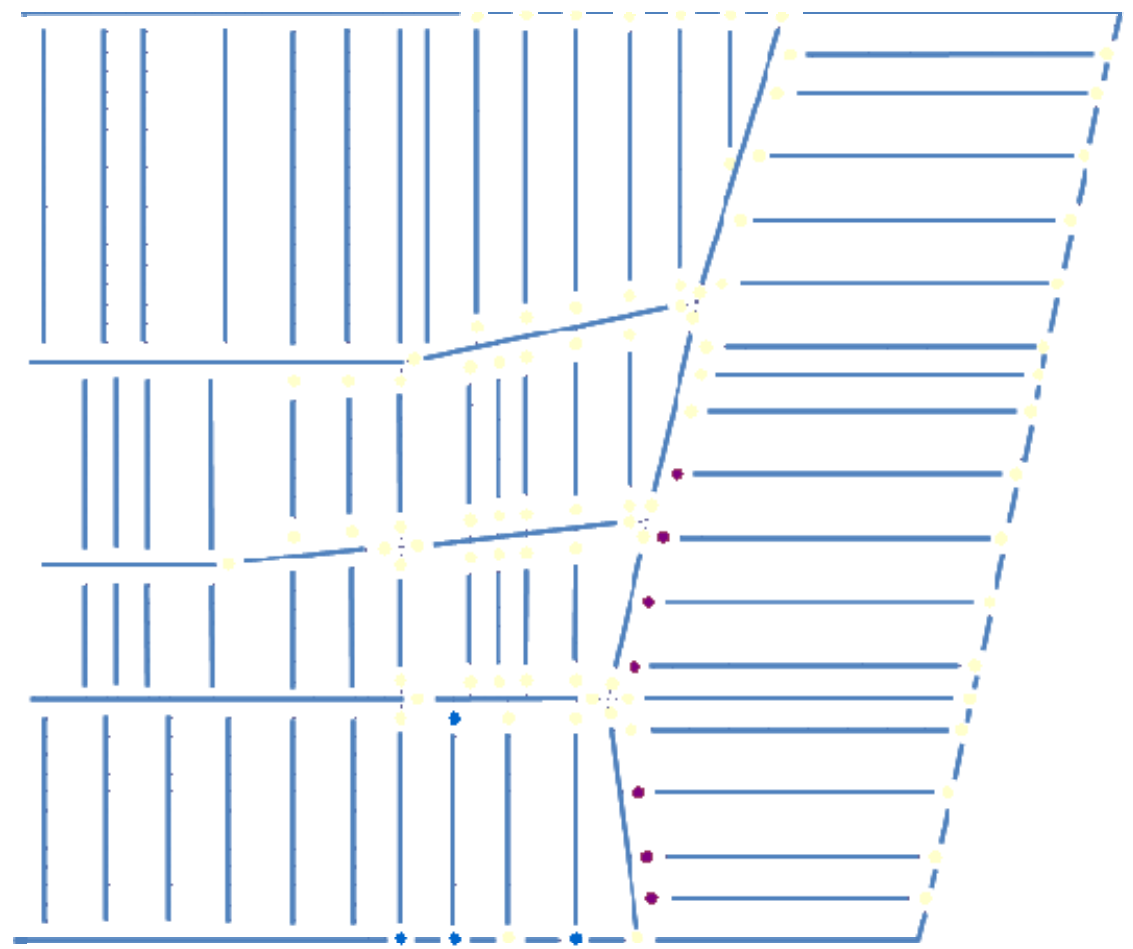

b) Damage state of connections in the vertical direction

Figure 11-25. Damage state of connections, beams, and girders in Floor 11 at $3.5 \mathrm{~h}$ for Case B temperatures. 


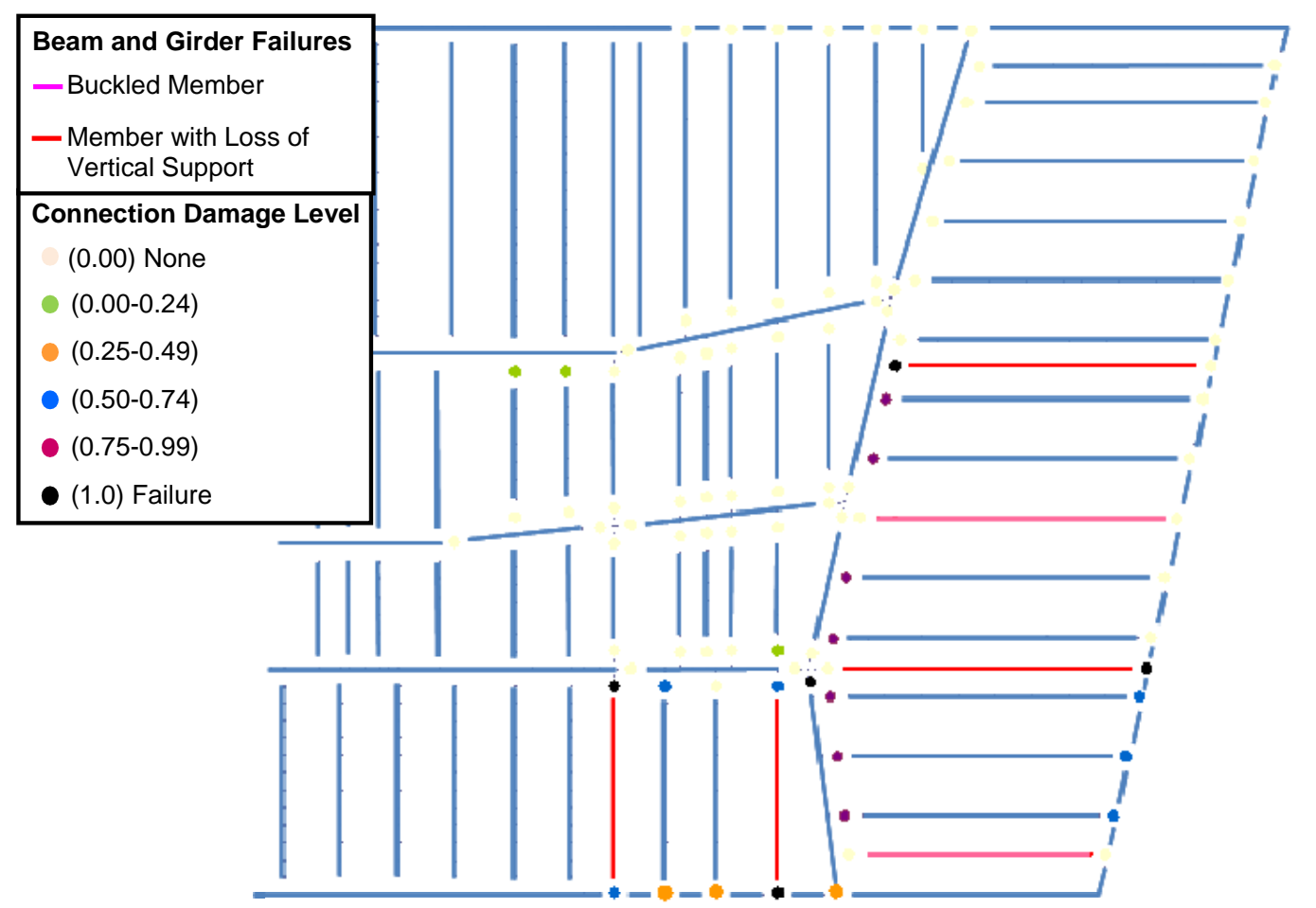

a) Damage state of connections in the horizontal direction

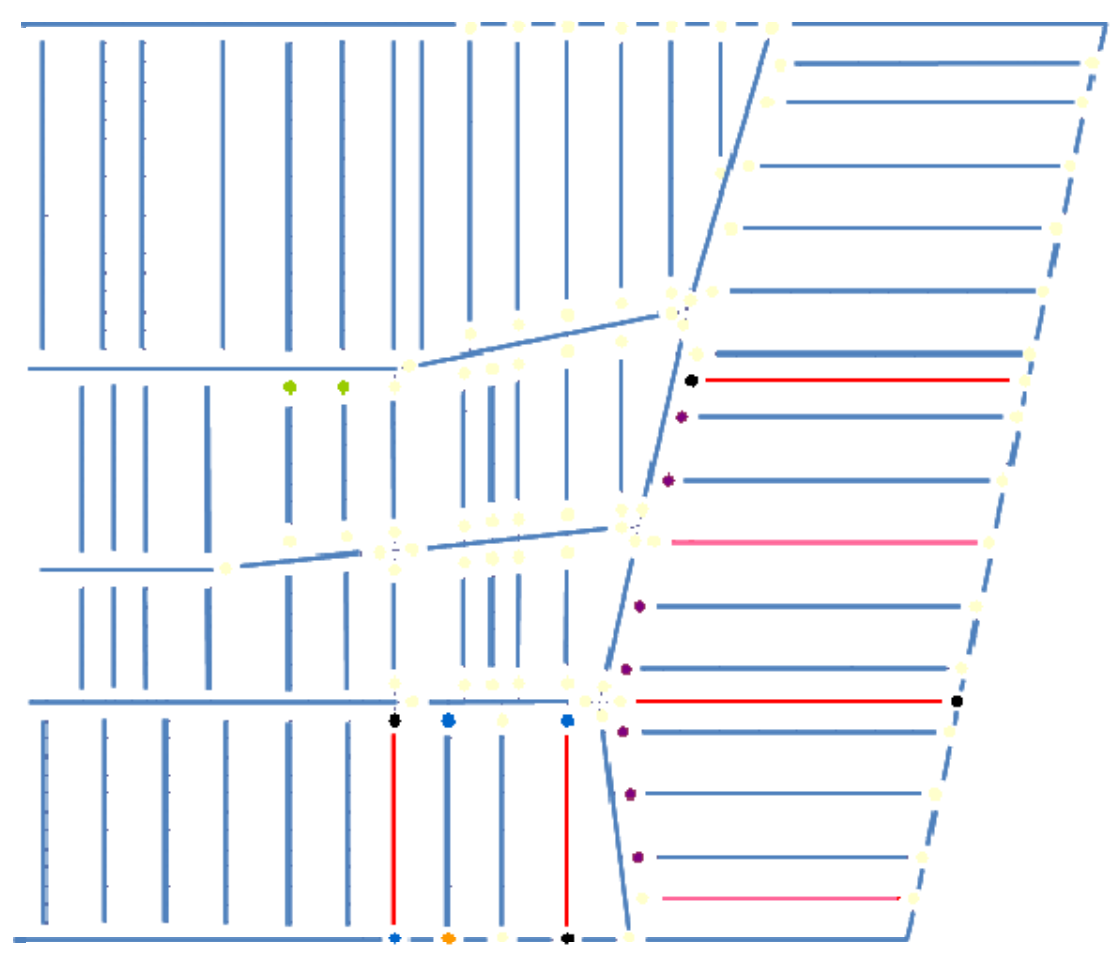

b) Damage state of connections in the vertical direction

Figure 11-26. Damage state of connections, beams, and girders in Floor 12 at $3.5 \mathrm{~h}$ for Case B temperatures. 


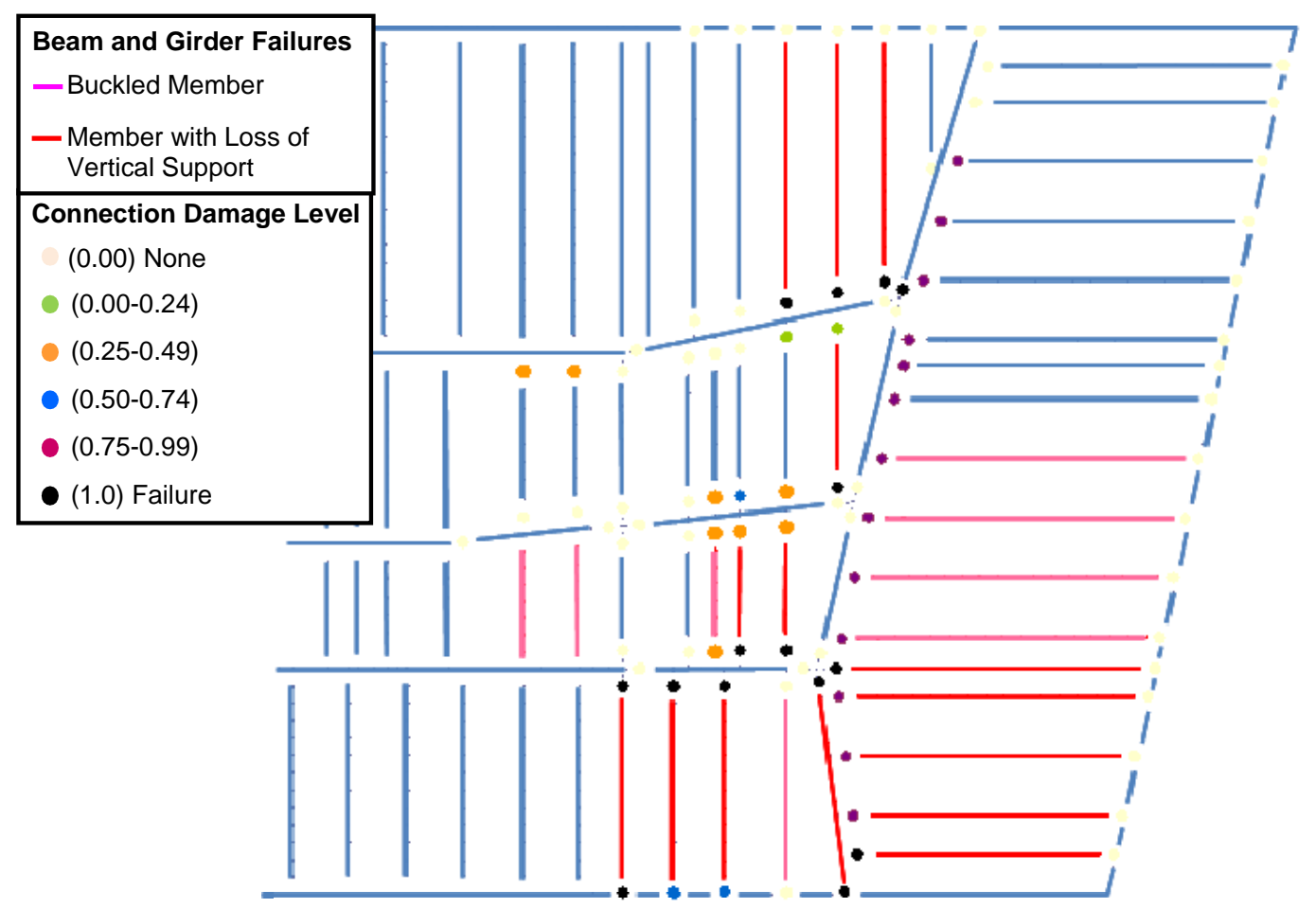

a) Damage state of connections in the horizontal direction

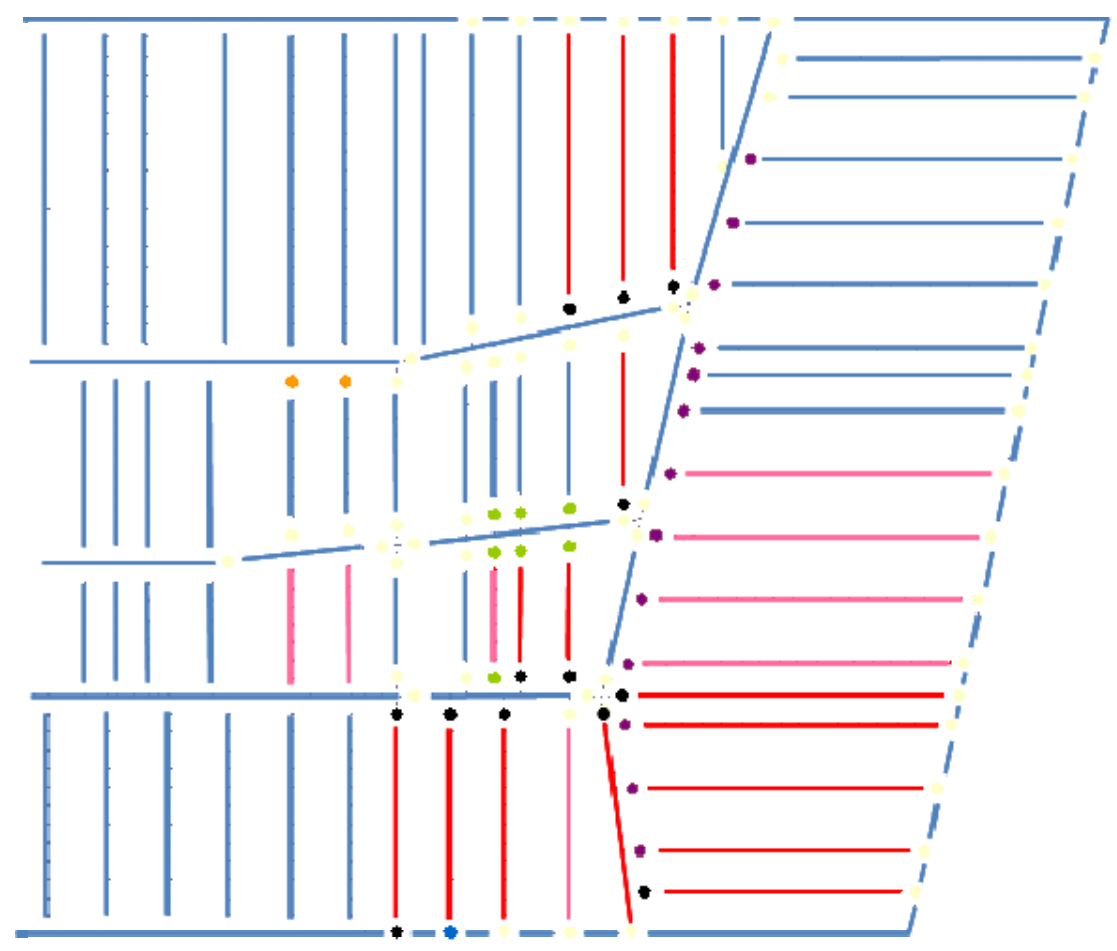

b) Damage state of connections in the vertical direction

Figure 11-27. Damage state of connections, beams, and girders in Floor 13 at $3.5 \mathrm{~h}$ for Case B temperatures. 


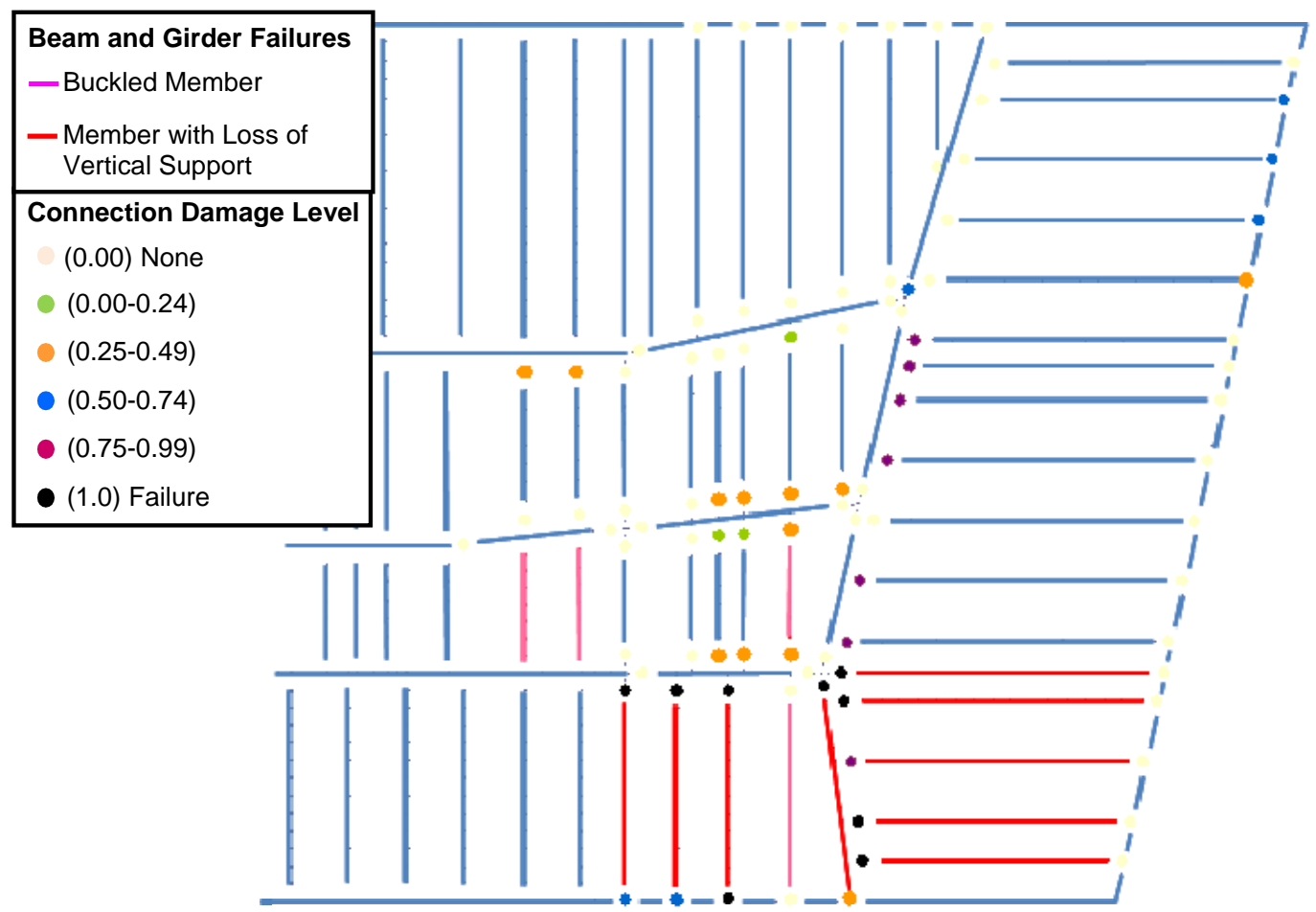

a) Damage state of connections in the horizontal direction

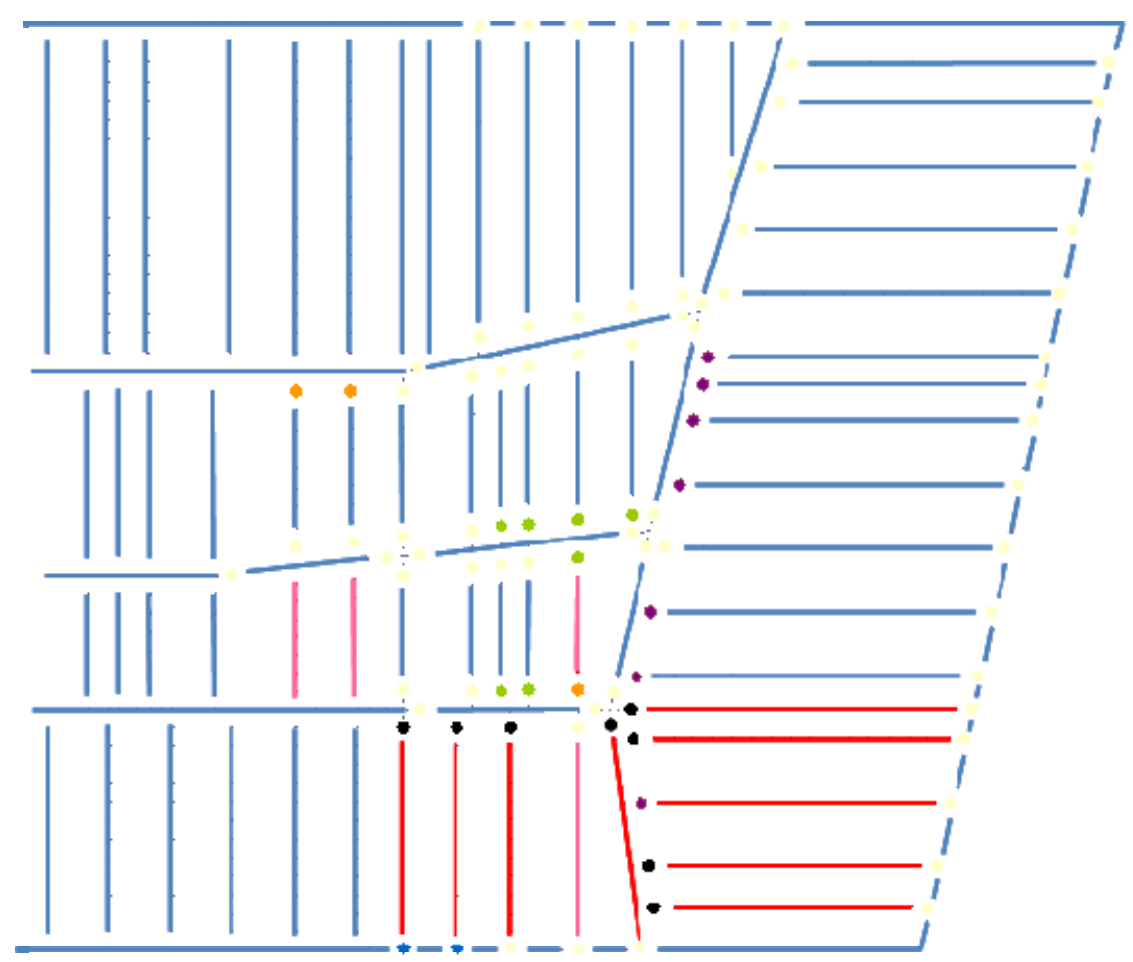

b) Damage state of connections in the vertical direction

Figure 11-28. Damage state of connections, beams, and girders in Floor 14 at $3.5 \mathrm{~h}$ for Case B temperatures. 


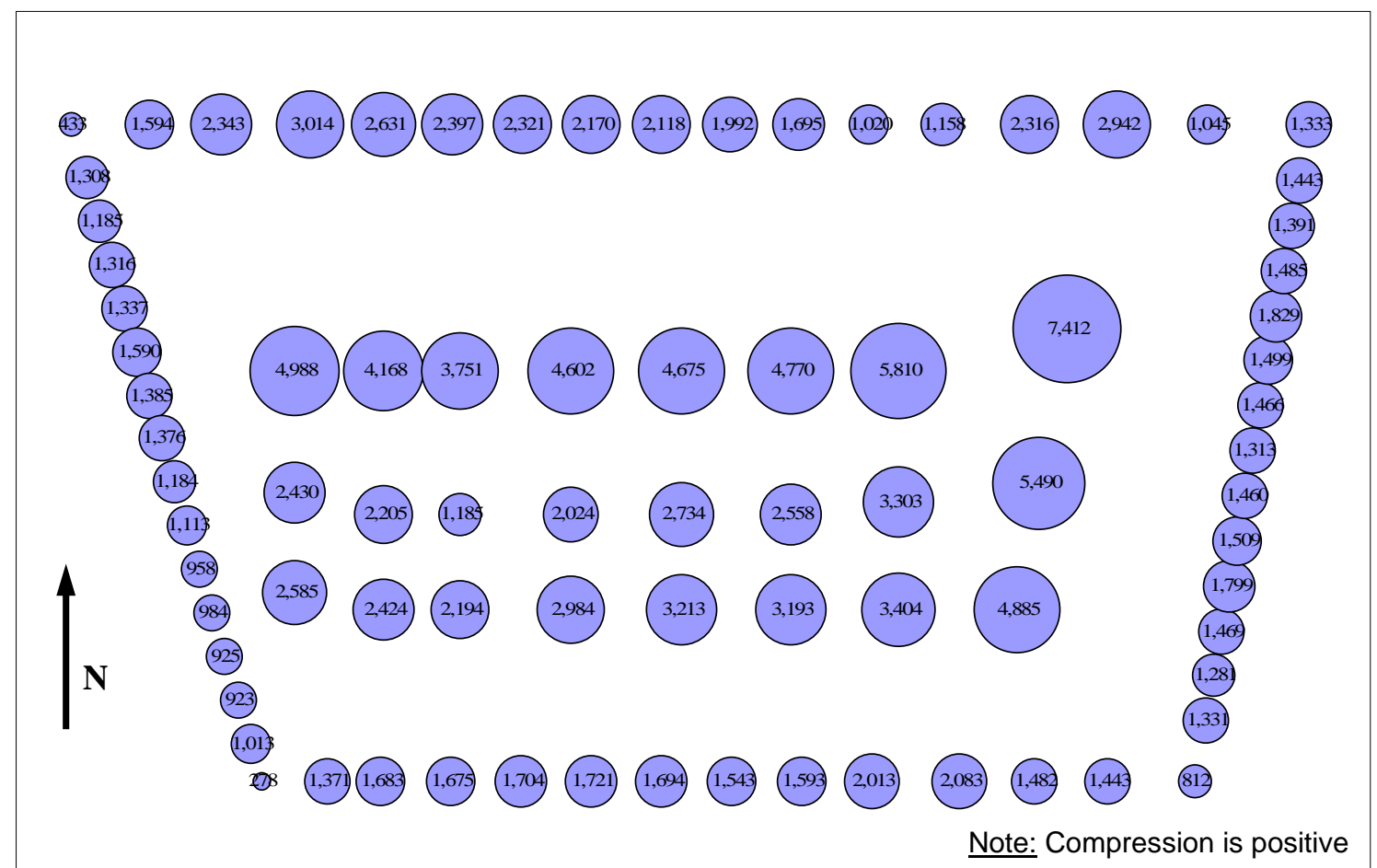

\begin{tabular}{llll}
\multicolumn{4}{l}{ Summation of Column forces: } \\
North: $\quad 32,500$ kip & East: & 19,300 kip \\
South: & 21,100 kip & West: & 16,600 kip \\
Interior: 87,000 kip & Total: & 176,500 kip
\end{tabular}

Figure 11-29. Column forces (in kip) above Floor 8 at $3.5 \mathrm{~h}$ for Case B temperatures.

\section{Building Response at $4.0 \mathrm{~h}$}

After $4.0 \mathrm{~h}$ of heating, there were considerably more failures of floor beams, girders, and floor slab sections at Floors 8, 10, 11, 12, 13, and 14. Fire-induced damage on Floor 9 was limited to the failure of three floor beams and several connections. Figure 11-30 to Figure 11-36 show the failures in the connections, beams, and girders. Figure 10-27 to Figure 10-40 in Section 10.3.3 show the temperatures of structural members.

Floors $8,12,13$, and 14 had the most damage, with the greatest vertical deflections, axial stresses in beams and girders, areas of crushed slab, and areas of failed beams and girders. Floors 10 and 11 had girder and beam failures at the east side of the north floor area, near Column 79. The damage that occurred between $3.5 \mathrm{~h}$ and $4.0 \mathrm{~h}$ is described below.

Floor 8. Elevated temperatures in the north floor framing on Floor 8 ranged from about $550{ }^{\circ} \mathrm{C}$ at the east side to $300{ }^{\circ} \mathrm{C}$ at the west side. Axial stresses were compressive and remained around $20 \mathrm{ksi}$ to $30 \mathrm{ksi}$ in many of the core and north floor beams, but had increased to $52 \mathrm{ksi}$ in some locations in the core near the failed floor framing. Figure 11-2 shows that the yield strength for the A572 Grade 50 steel used for the beams was $54 \mathrm{ksi}$ at room temperature. As the temperature in these beams was less than $400{ }^{\circ} \mathrm{C}$, the beam strength and stiffness was not reduced appreciably. 
As before, beams and girders failed by loss of vertical support at connections or by buckling of beams or girders. The girder between Columns 70 and 73 and Columns 73 and 76 buckled, as shown in Figure 1130. The floor beams that were supported by the girder between Columns 78 and 81 and Columns 71 and 74 also failed when the girder lost vertical support at an end connection, due to the effects of thermal expansion. Seven fin connections in the east tenant floor between Columns 44 and 80 had a 0.75 to 0.99 damage level.

Floors 10, 11, and 12. On Floors 10, 11, and 12 (Figure 11-32, Figure 11-33, and Figure 11-34), the girder between Columns 76 and 79 failed due to a tensile weld failure in the knife connection on the west side of Column 79. Temperatures in this region were less than $100{ }^{\circ} \mathrm{C}$ on these floors. The tensile force in the connection was due to an eastward lateral displacement of Column 79, which was primarily caused by thermal expansion of the girder between Column 76 and Column 79 at Floor 13.

There was connection damage and beam buckling around the southeast corner of Floor 11, but there were no fires on Floor 10 to heat the steel framing from below. The fires on Floor 11 caused heating and thermal expansion of the Floor 11 slab in this area. The concrete slab thermally expanded until it exceeded the compressive strain criteria, so that the floor system no longer acted as a composite system. As a result, the floor beams began to act independently, and connection damage and beam buckling occurred.

Floors 12, 13, and 14. Elevated temperatures in the southeast and east floor framing on Floors 12, 13, and 14 ranged from $150{ }^{\circ} \mathrm{C}$ to $550{ }^{\circ} \mathrm{C}$ in Floor $12,300{ }^{\circ} \mathrm{C}$ to $700{ }^{\circ} \mathrm{C}$ in Floor 13, and $150{ }^{\circ} \mathrm{C}$ to $700{ }^{\circ} \mathrm{C}$ in Floor 14. However, the thermal analysis did not account for thermally induced damage to floor framing or slabs as the structure was heated. Figure 11-34, Figure 11-35, and Figure 11-36 show that the floor beams had failed by connection failures or buckling of beams or girders in areas where the steel temperatures were greater than $400{ }^{\circ} \mathrm{C}$ to $500{ }^{\circ} \mathrm{C}$. The following beam and girder failures occurred:

- On Floors 12 and 14, most of the floor beams on the south and east floor areas near Columns 78, 81, and 80 (Figure 11-34 and Figure 11-36) had failed. The floor beams had either buckled or lost vertical support when all the fin connection bolts were sheared off due to thermal expansion. Both Floors 12 and 14 had a 0.75 to 0.99 damage level in several east floor beam connections near Column 79.

- On Floor 12, the girder between Column 26 and Column 81 had failed due to buckling, followed by walk off of the bearing seat, at Column 81 .

- On Floor 13 (Figure 11-35), all four of the north-south girders attached to Columns 79, 80, and 81 had failed, due to either buckling or girder walk off of the bearing seat at Columns 79 and 81.

- On Floor 14, all four of the erection bolts in the seated connection at Column 79 on Floor 14 had failed due to the effects of thermal expansion.

- On Floor 14, the header connection for the girder west of Column 80 had failed at the weld to the girder web. 
The compressive strains in the southeast area of the slab for Floor 12 gradually increased to exceed the crushing criterion $(\varepsilon>0.004)$ and covered the full east side and half of the south side of the tenant floor area. The compressive strains in the southeast and east slab areas for Floor 13 exceeded the crushing criterion, and the damage to the slab extended westward on the south face. As a result, slab elements were removed from the model. Due to the large area of failed floor beams, the slab was unsupported over a large area and was not able to carry its loads. A portion of the slab was removed, and the mechanical strains were set to zero.

Column Forces. Figure 11-37 shows the axial force in columns at Floor 8 at $4.0 \mathrm{~h}$. The axial forces in columns were reduced by less than 0.50 percent relative to the gravity load analysis. This reduction was due to the self-weight of the removed beams. At the end of $4.0 \mathrm{~h}$, the change in axial column forces was still negligible, as expected.

Summary. After $4.0 \mathrm{~h}$ of heating, Columns 79, 80, and 81 had lost lateral support in the north-south direction at Floor 13, due to failure of the girders between the columns. The girders between Columns 80 and 81 had buckled and the girders between Columns 79 and 44 and Columns 26 and 81 had walked off the bearing seat at Column 79 and 81, respectively. In addition, all of the bolts had sheared at Column 79 on Floor 14, and two to three bolts had sheared on Floor 12. Approximately one-half to three-quarters of the east floor beams had a connection damage index of 0.75-0.99 on Floors 11, 12, and 14 and all of the east floor beams had failed on Floor 13 . After $4.0 \mathrm{~h}$ of heating, there was substantially more damage and failures in the WTC 7 structural system than after 3.5 h of heating. Columns 79, 80, and 81 had lost lateral support at one or more floors.

The impact of a floor section falling on the floor below was not analyzed in the 16 story ANSYS model, but was simulated in the 47 story LS-DYNA model (Chapter 12). 


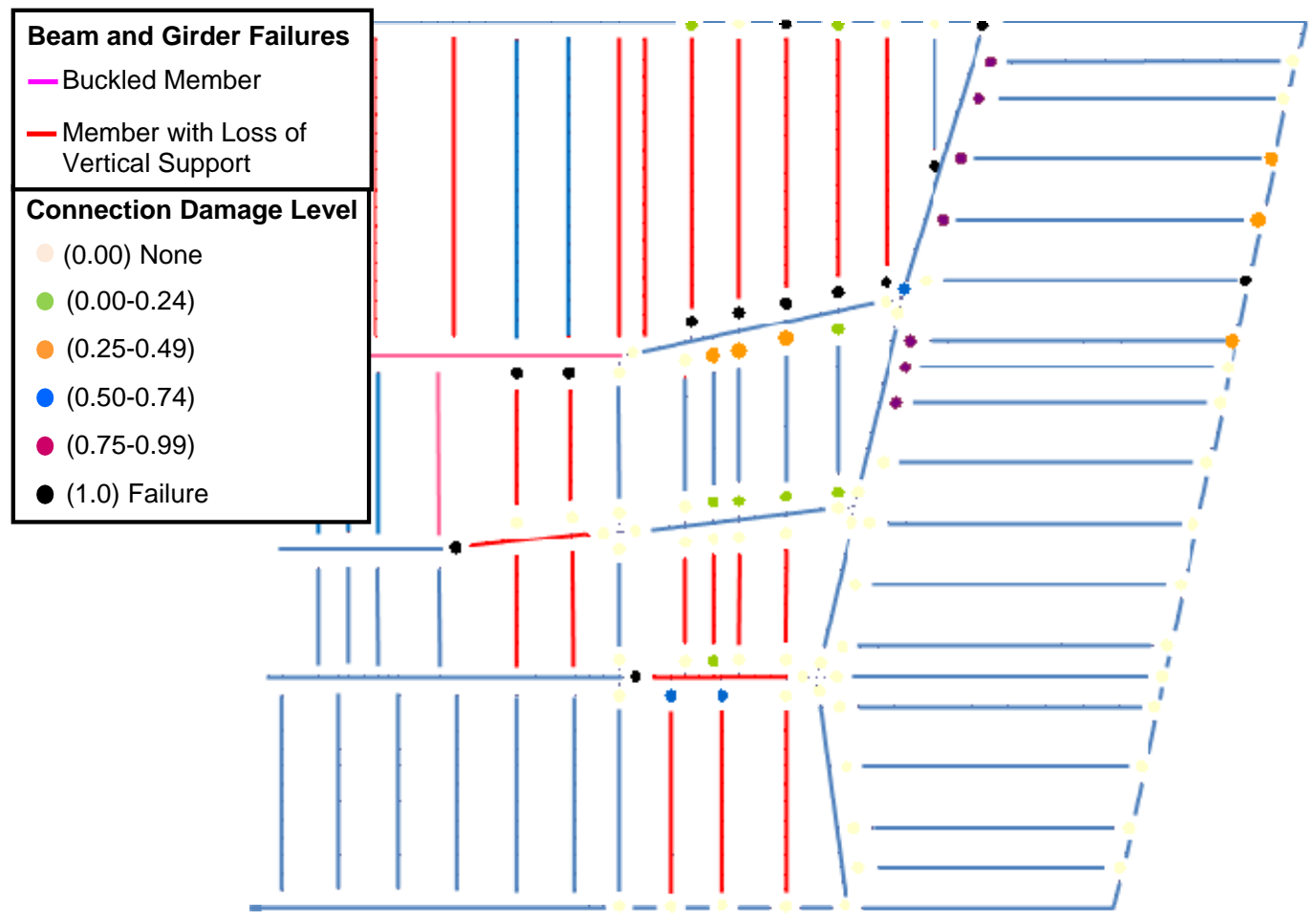

a) Damage state of connections in the horizontal direction

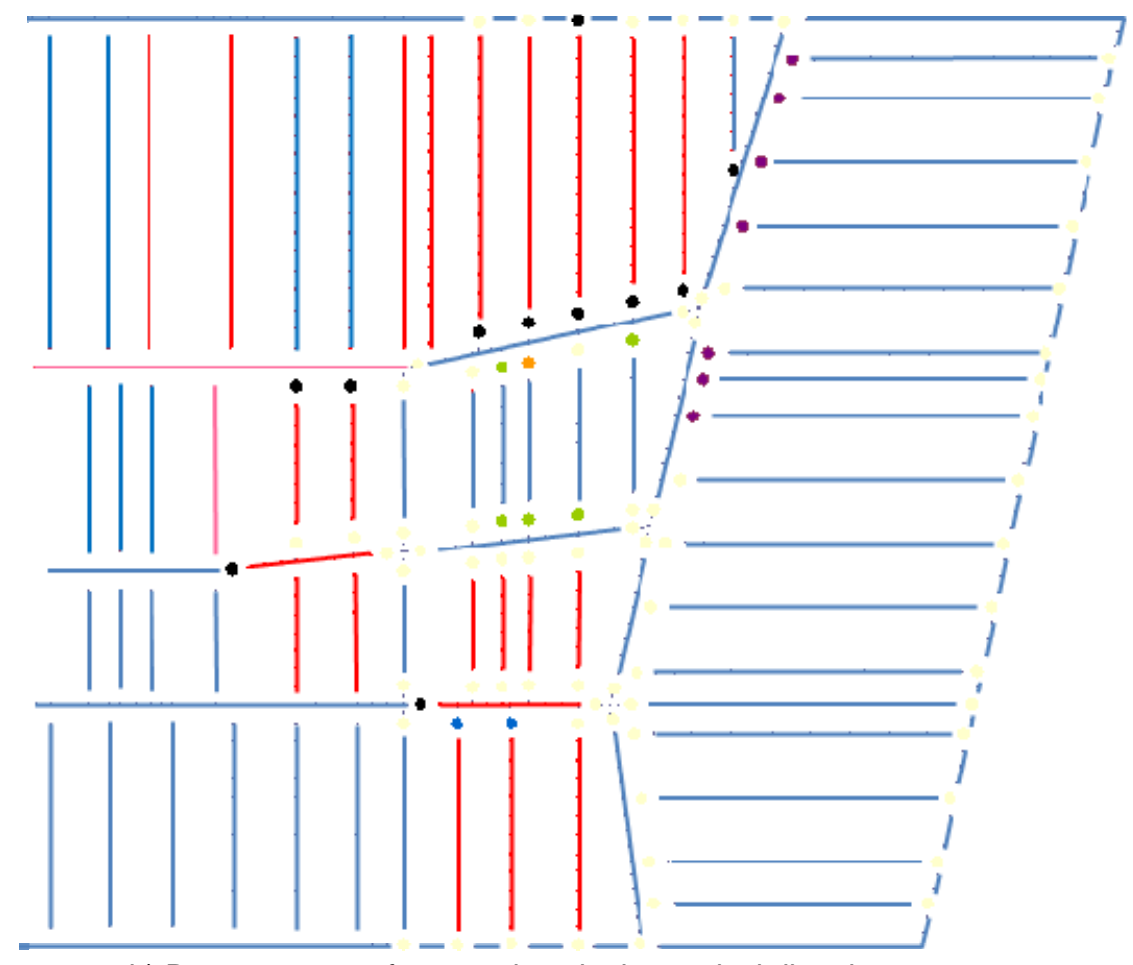

b) Damage state of connections in the vertical direction

Figure 11-30. Damage state of connections, beams, and girders in Floor 8 at $4.0 \mathrm{~h}$ for Case B temperatures. 


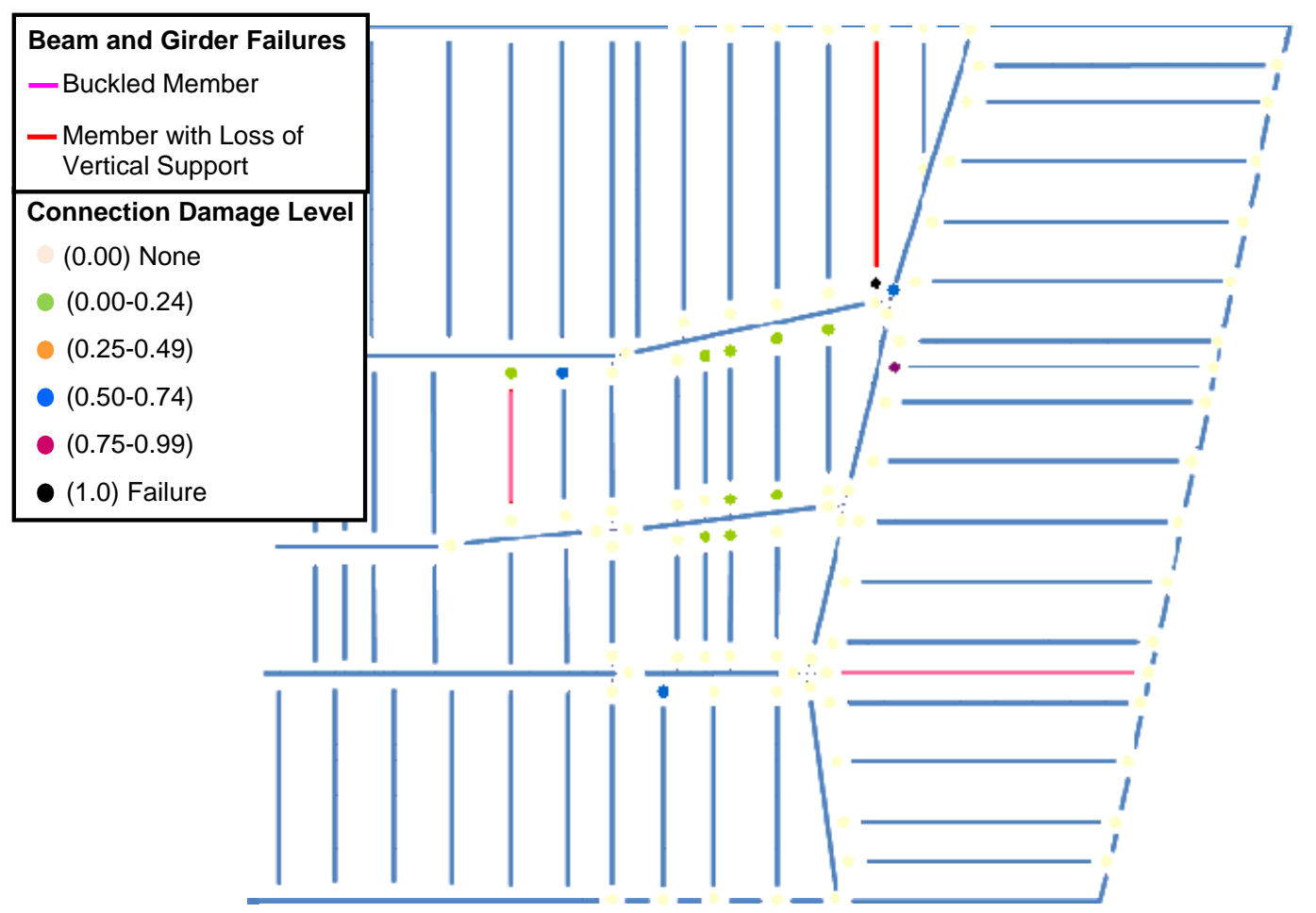

a) Damage state of connections in the horizontal direction

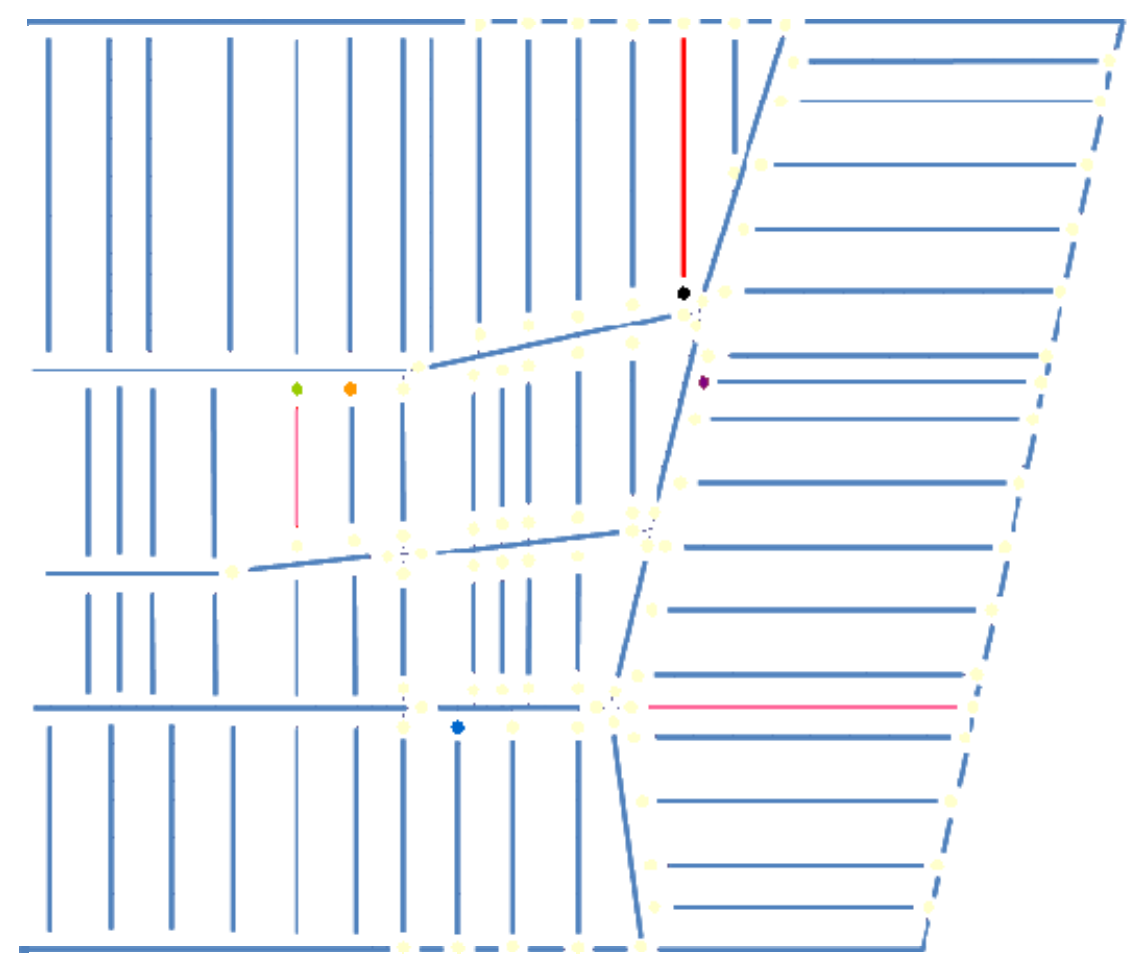

b) Damage state of connections in the vertical direction

Figure 11-31. Damage state of connections, beams, and girders in Floor 9 at $4.0 \mathrm{~h}$ for Case B temperatures. 


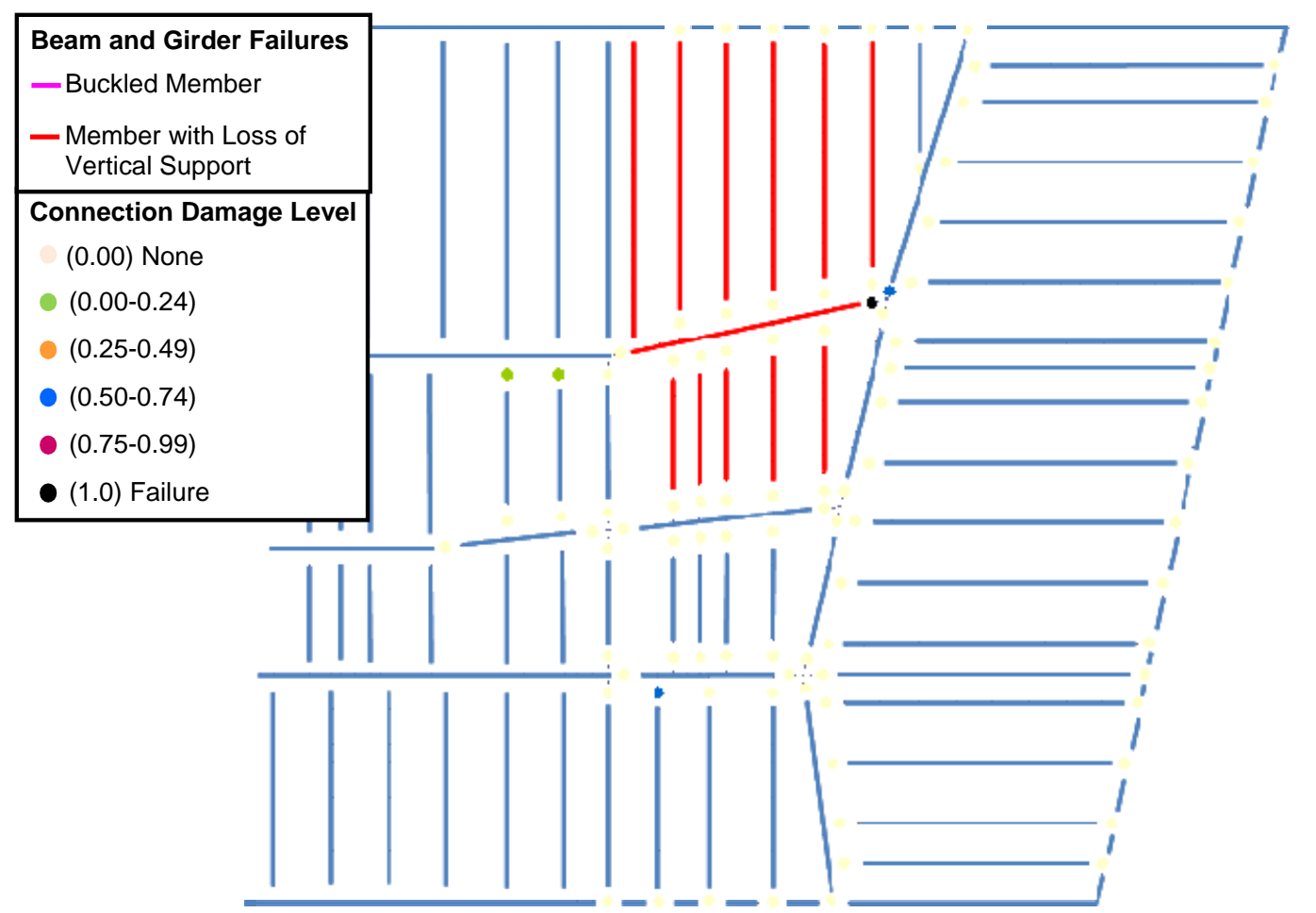

a) Damage state of connections in the horizontal direction

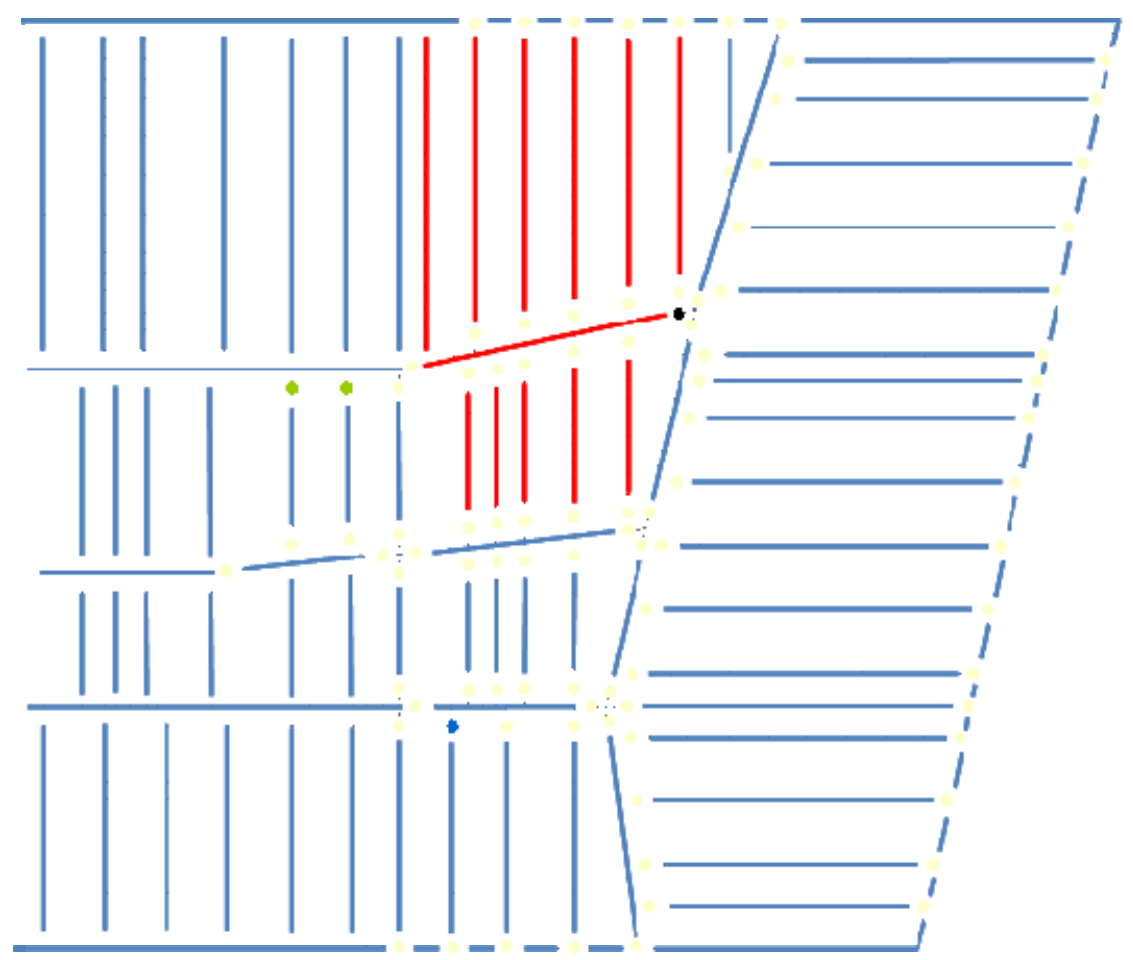

b) Damage state of connections in the vertical direction

Figure 11-32. Damage state of connections, beams, and girders in Floor 10 at $4.0 \mathrm{~h}$ for Case B temperatures. 


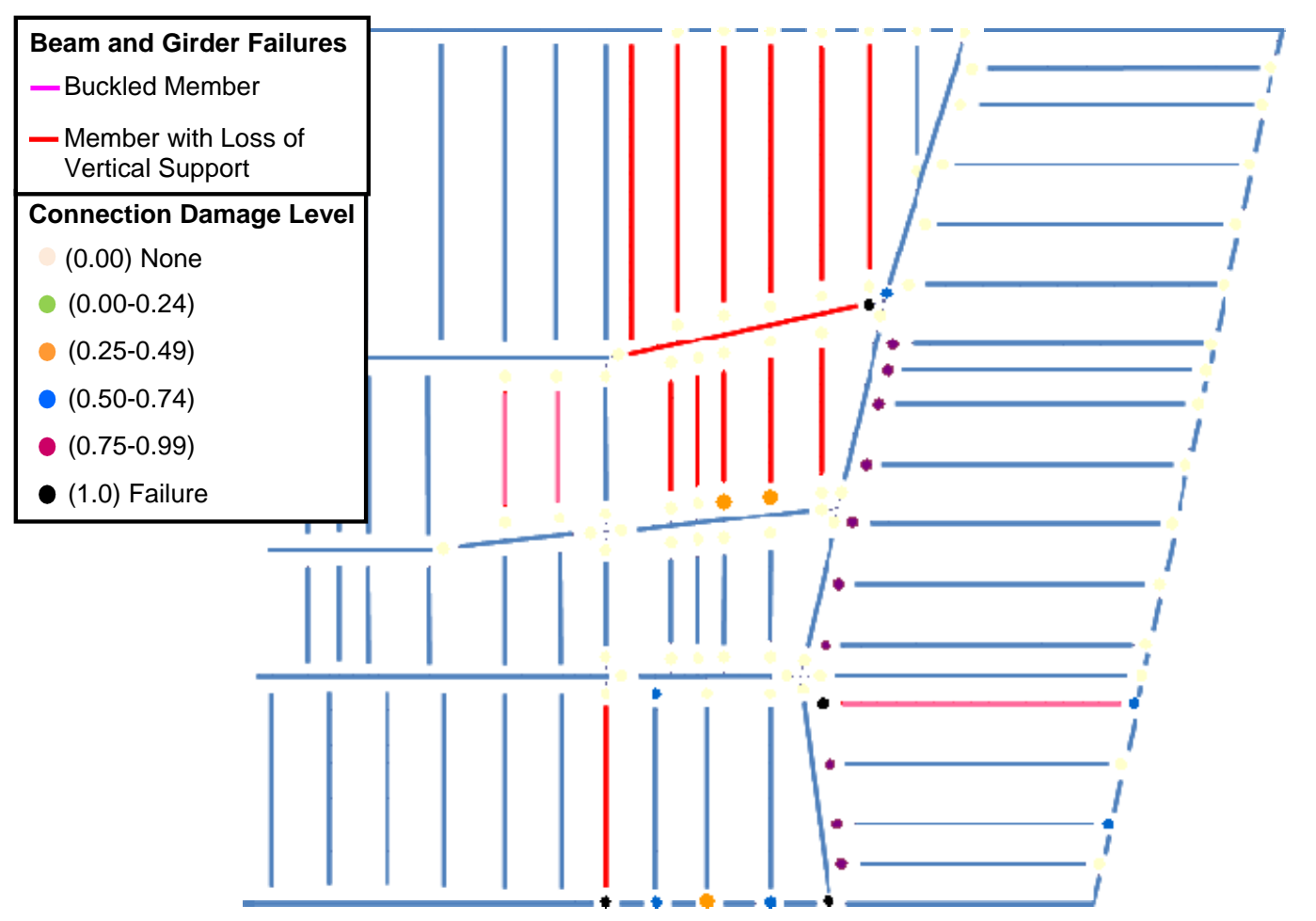

a) Damage state of connections in the horizontal direction

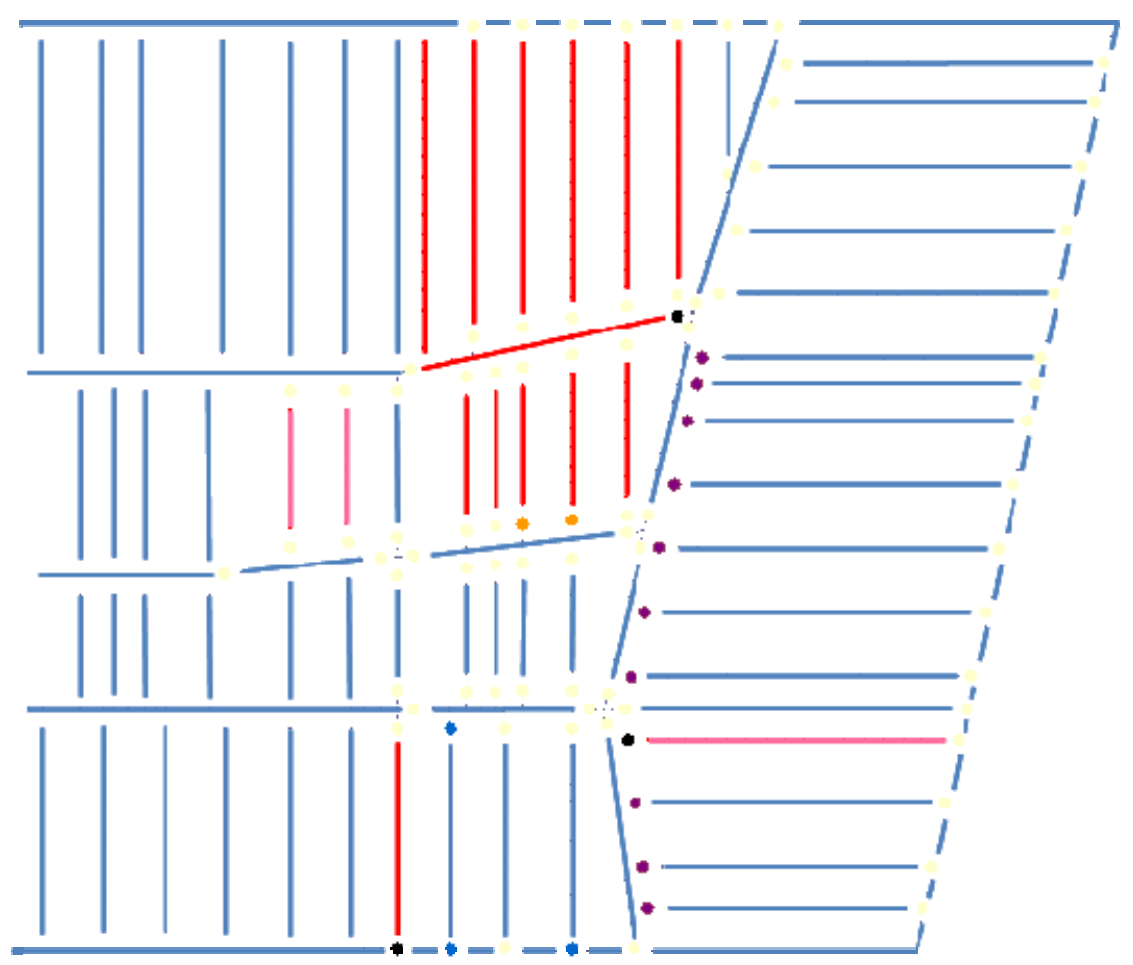

b) Damage state of connections in the vertical direction

Figure 11-33. Damage state of connections, beams, and girders in Floor 11 at $4.0 \mathrm{~h}$ for Case B temperatures. 


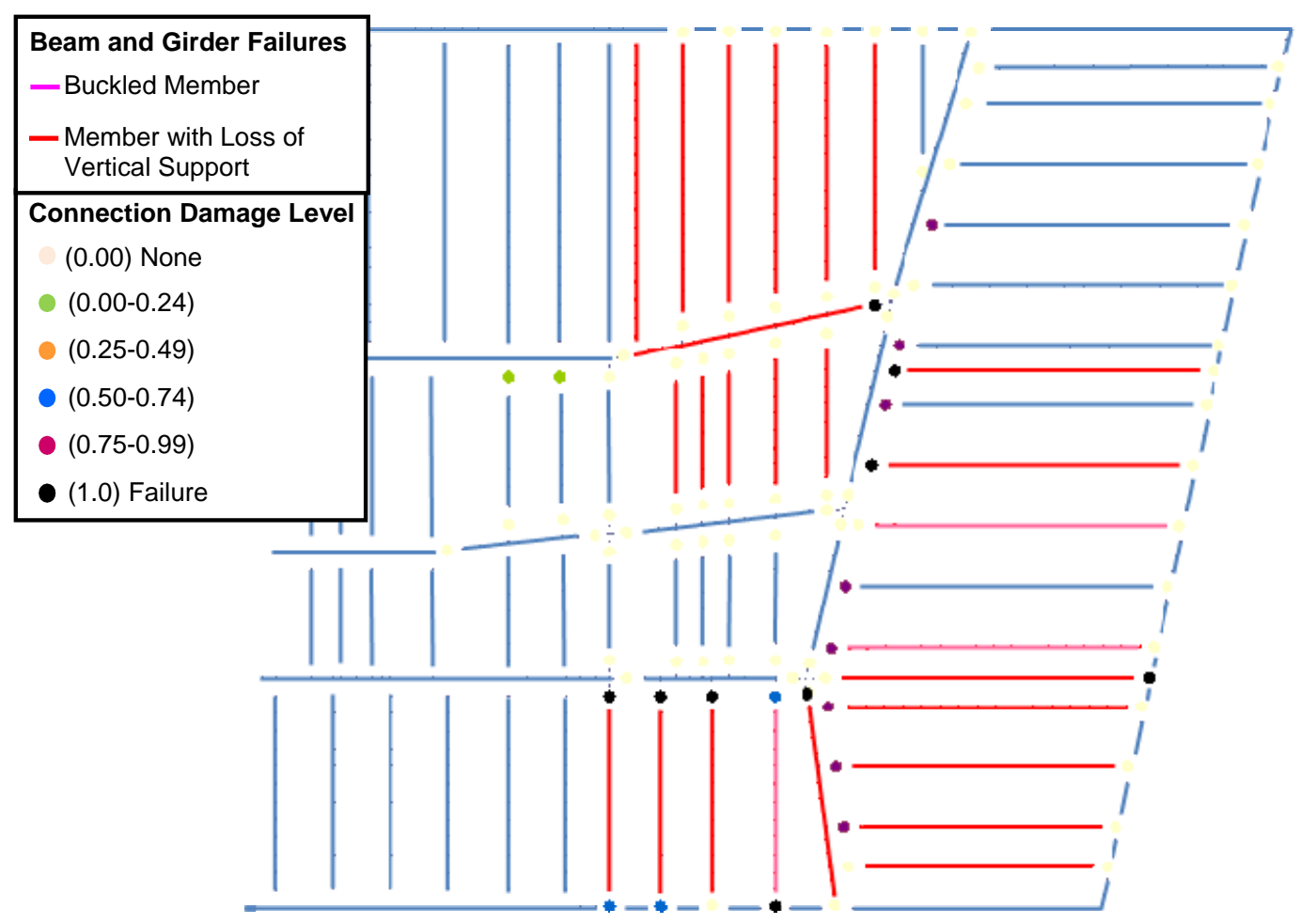

a) Damage state of connection in the horizontal direction

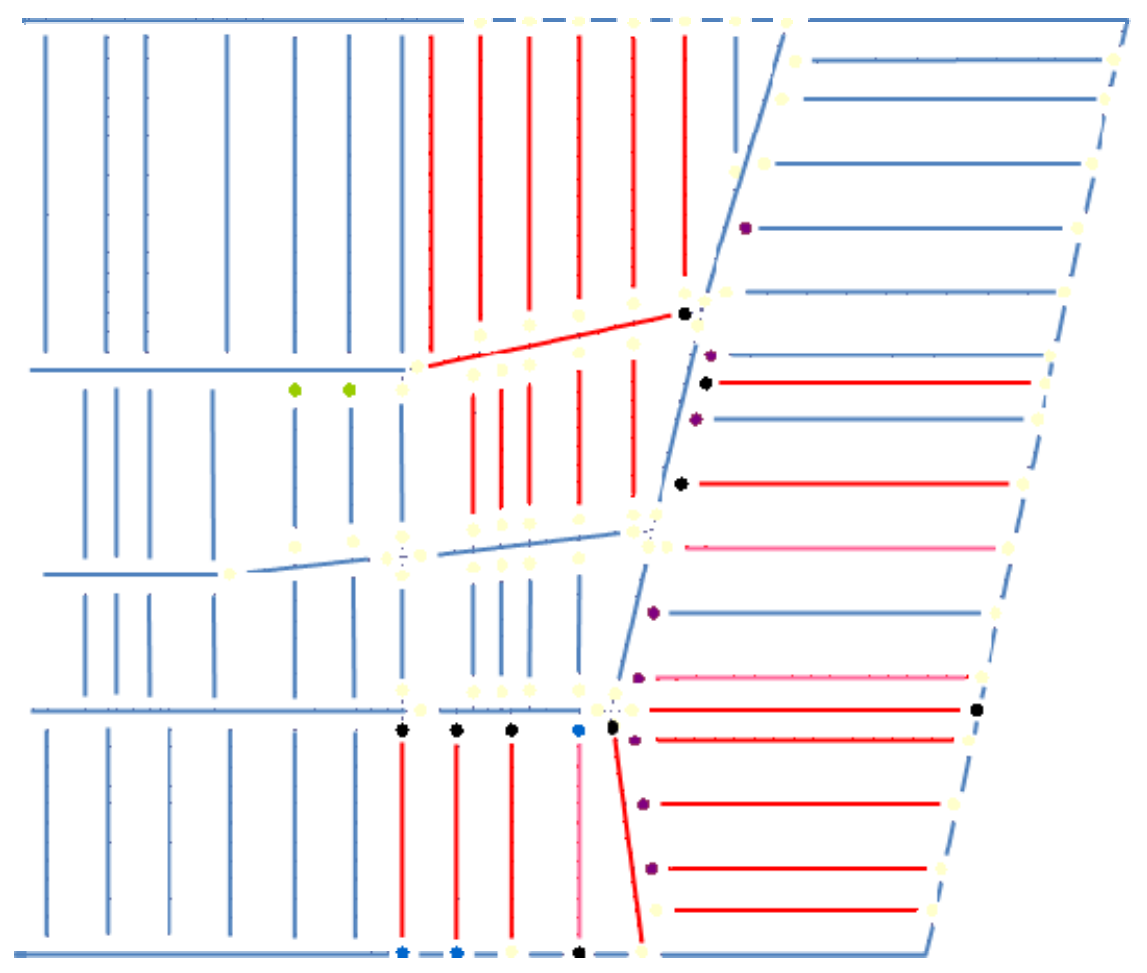

b) Damage state of connection in the vertical direction

Figure 11-34. Damage state of connections, beams, and girders in Floor 12 at $4.0 \mathrm{~h}$ for Case B temperatures. 


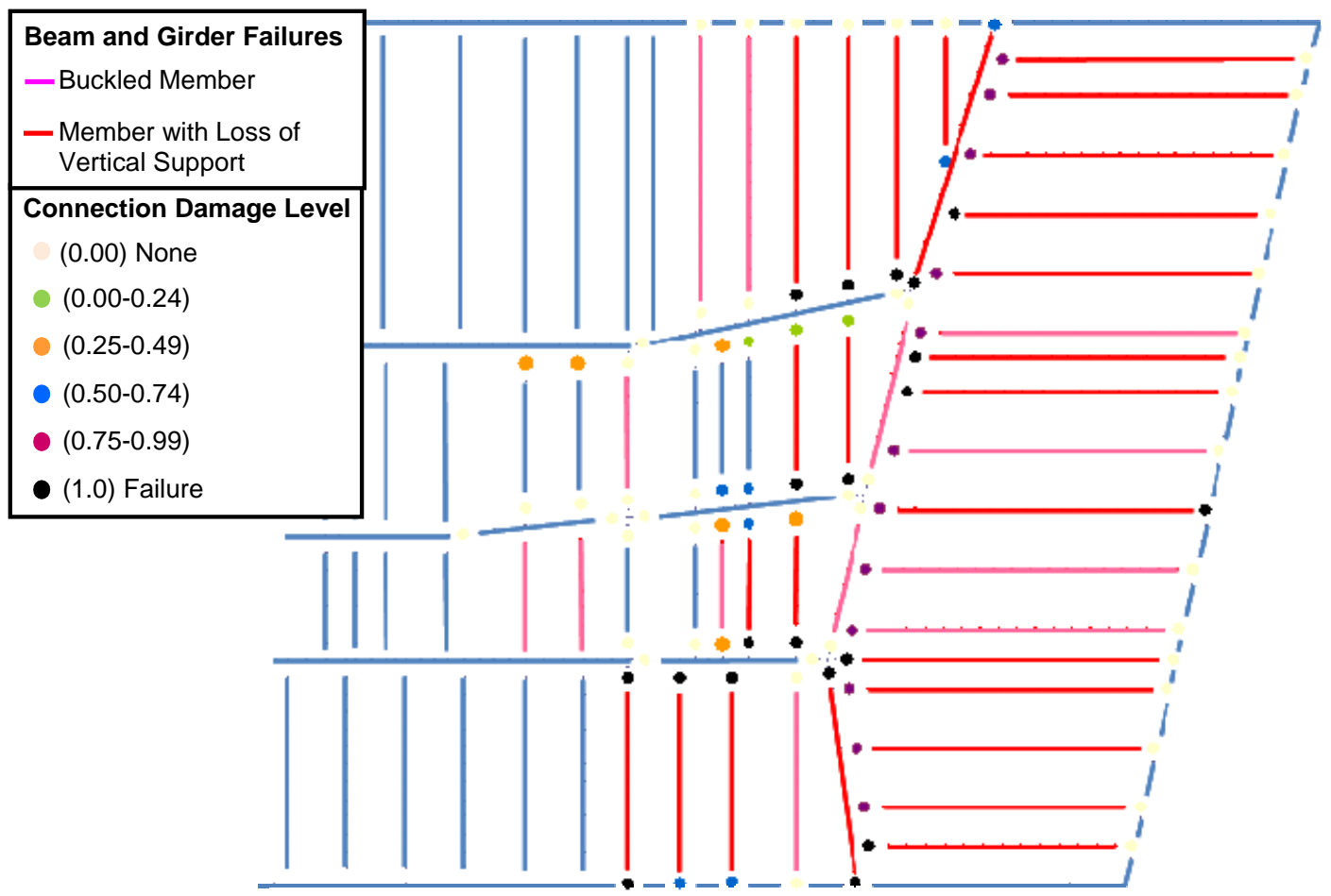

a) Damage state of connection in the horizontal direction

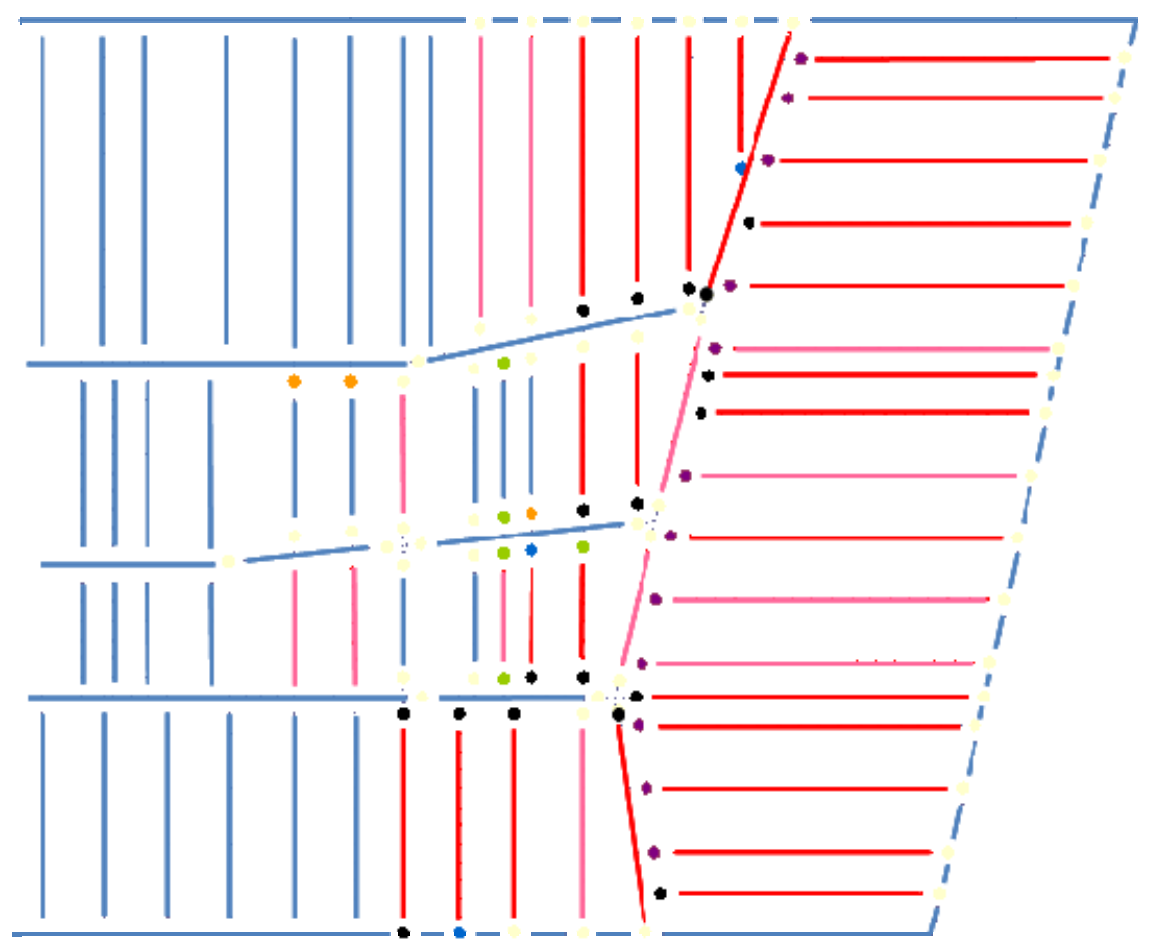

b) Damage state of connectıon in the vertıcal directıon

Figure 11-35. Damage state of connections, beams, and girders in Floor 13 at $4.0 \mathrm{~h}$ for Case B temperatures. 


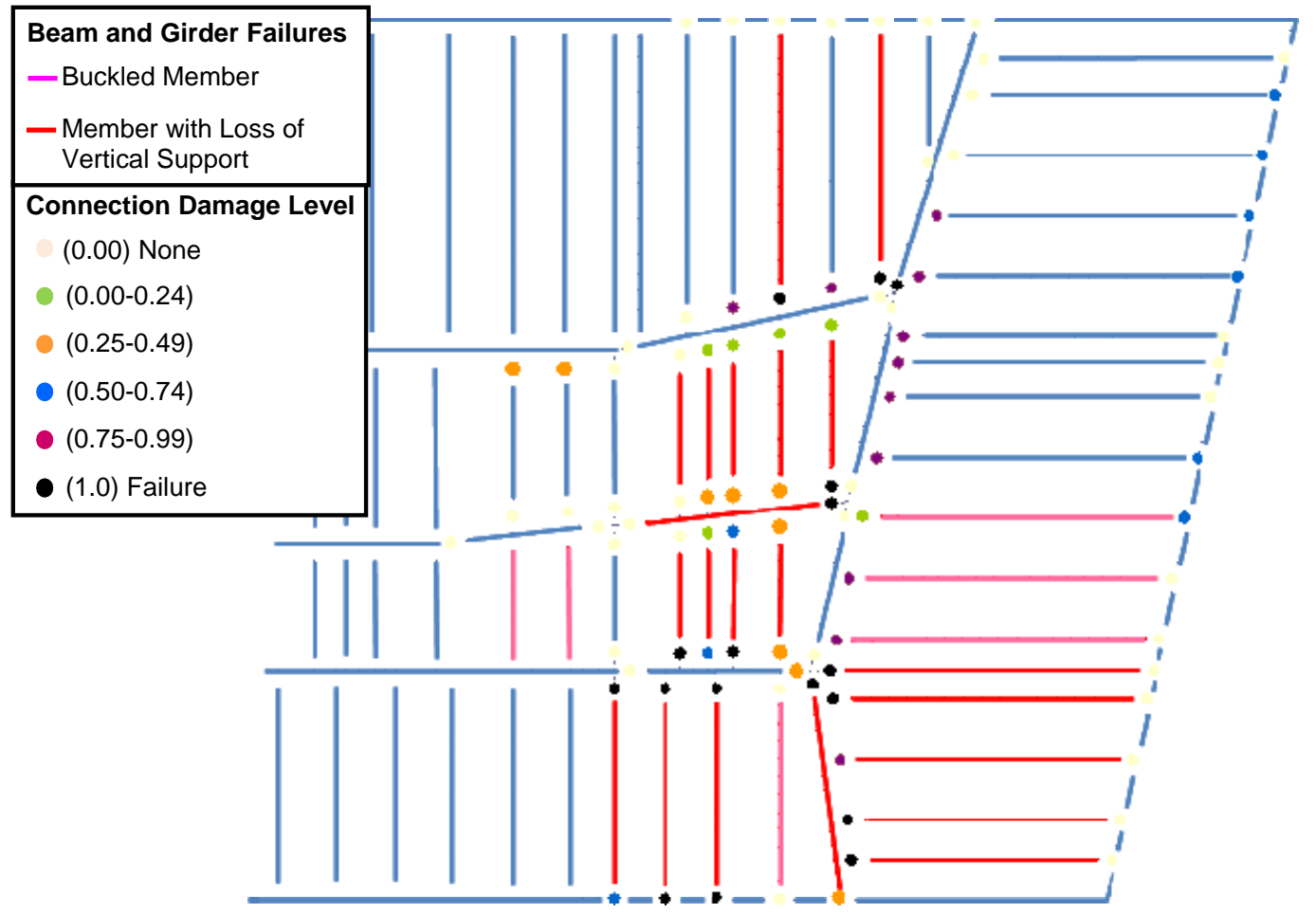

a) Damage state of connection in the horizontal direction

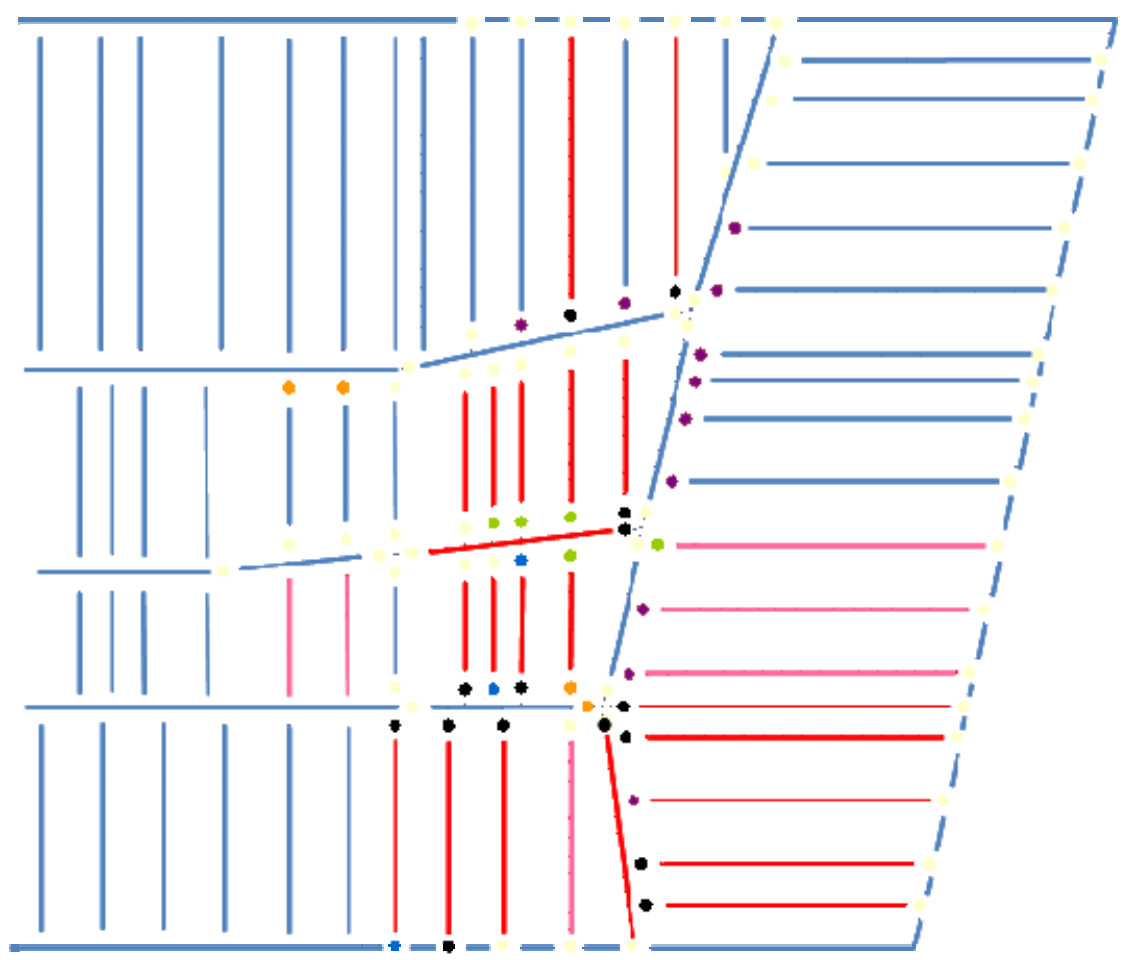

b) Damage state of connection in the vertical direction

Figure 11-36. Damage state of connections, beams, and girders in Floor 14 at $4.0 \mathrm{~h}$ for Case B temperatures. 


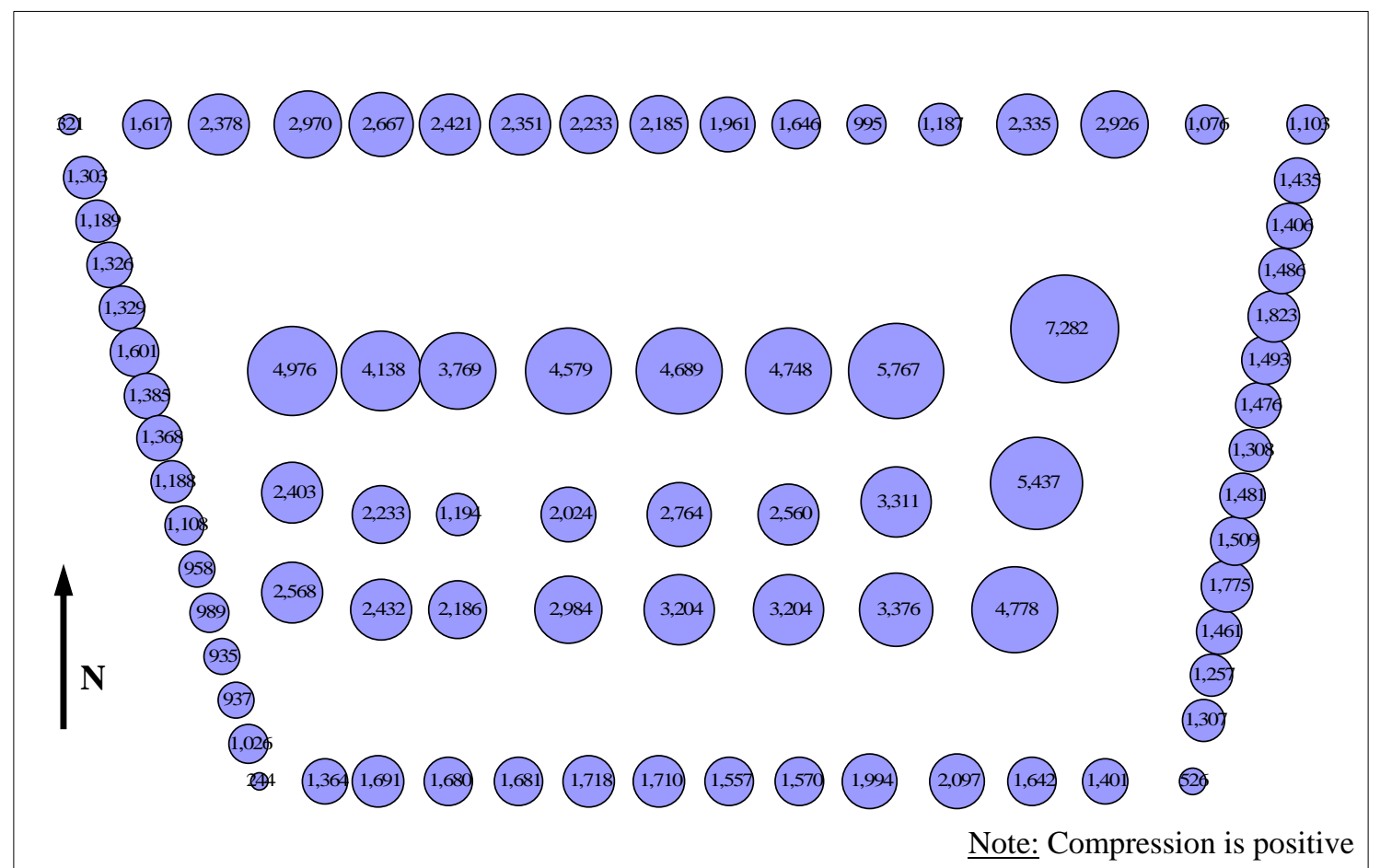

Summation of Column forces:

$\begin{array}{llll}\text { North: } & 32,400 \text { kip } & \text { East: } & 19,200 \text { kip } \\ \text { South: } & 20,850 \text { kip } & \text { West: } & 16,650 \text { kip } \\ \text { Core: } & 86,600 \text { kip } & \text { Total: } & 175,700 \text { kip }\end{array}$

Figure 11-37. Column forces (in kip) above Floor 8 at $\mathrm{t}=4.0 \mathrm{~h}$ for Case $\mathrm{B}$ temperatures.

\subsubsection{Analysis of Building Response for Case C Temperatures}

The structural response of WTC 7 to Case $\mathrm{C}$ temperatures at $4.0 \mathrm{~h}$ produced essentially the same damage and failures as the Case B temperatures at $3.5 \mathrm{~h}$ and $4.0 \mathrm{~h}$, with a time lag of approximately 10 to $30 \mathrm{~min}$.

\section{Building Response at $4.0 \mathrm{~h}$}

The structural damage from Case $\mathrm{C}$ temperatures at $4.0 \mathrm{~h}$ relative to Case $\mathrm{B}$ temperatures at $3.5 \mathrm{~h}$ and $4.0 \mathrm{~h}$ is summarized in Table 11-6. The thermally-induced damage for Case $\mathrm{C}$ temperatures at $4.0 \mathrm{~h}$ is shown in Figure 11-38 to Figure 11-45. Figure 10-47 to Figure 10-60 in Section 10.3.4 show the temperatures of the structural framing.

Elevated temperatures in Floors 12, 13, and 14 in the southeast and east region of the floor framing ranged from $300{ }^{\circ} \mathrm{C}$ to $550{ }^{\circ} \mathrm{C}$ in Floor $12,300{ }^{\circ} \mathrm{C}$ to $700{ }^{\circ} \mathrm{C}$ in Floor 13 , and $300{ }^{\circ} \mathrm{C}$ to $700{ }^{\circ} \mathrm{C}$ in Floor 14. As before, Figure 11-42, Figure 11-43, and Figure 11-44 show that the floor beams had already failed in areas where the steel temperatures were greater than $400^{\circ} \mathrm{C}$ to $500{ }^{\circ} \mathrm{C}$. The following beam and girder failures occurred: 
Floor 8. Figure 11-38 shows connection and floor framing damage that occurred. Fin connections attaching the floor beams to the girder between Columns 76 and 79 (see Figure 2-4 for column locations), failed by shearing the bolts due to thermal expansion of the beams. The northeast beam-to-girder fin connections had a 0.75 to 0.99 damage level between Columns 44 and 79 . The header connections at Columns 74 and 78 failed, due to thermal expansion of the girder. The beams that were supported by these girders are also indicated as failed, since they would fall with the girder.

Floors 9 and 10. On Floor 9, SWC connections in the core area between Columns 73 and 79 had damage levels of 0.0 to 0.24 and 0.50 to 0.74 , depending on the number of bolts that had sheared (Figure 11-39). Floor 10 had no damage from fire (Figure 11-40).

Floor 11. On Floor 11, (Figure 11-41), the girder between Columns 76 and 79 failed due to a tensile weld failure in the knife connection on the west side of Column 79. Temperatures in this region were less than $100{ }^{\circ} \mathrm{C}$. The tensile force in the connection was due to an eastward lateral displacement of Column 79, which was primarily caused by thermal expansion of the girder between Column 76 and Column 79 at Floor 13.

Floors 12, 13, and 14. On Floors 12 and 14, most of the floor beams on the south and east floor areas near Columns 78, 81, and 80 had failed. The floor beams either buckled or lost vertical support when all the fin connection bolts had sheared off due to thermal expansion. Both floors had a damage level of 0.75-0.99 in floor beam fin connections extending past Column 79 in the east floor beams (Figure 11-42 and Figure 11-44). The girder between Columns 26 and 81 buckled on Floors 12 and 14 and the girder between Columns 80 and 81 buckled on Floor 14. All four of the erection bolts in the seated connection at Column 79 on Floor 14 had failed.

On Floor 13, the girders between Columns 26 and 81 and Columns 80 and 81 had buckled. The girder between Columns 79 and 80 had walked off of the bearing seat at Column 79 due to the effects of thermal expansion.

Summary. After $4.0 \mathrm{~h}$ of heating, Column 81 had lost lateral support in the north-south direction at Floor 13, due to failure of the girders framing into Column 81. The girders between Columns 26 and 81 and Columns 80 and 81 had buckled and the girder between Columns 79 and 44 had walked off the seated connection at Column 79. In addition, all 4 bolts had failed at the seated connection at Column 79 on Floor 14. Approximately one-half to three-quarters of the east floor beams had a connection damage level of 0.75 to 1.0 on Floors 11, 12, and 14. All of the east floor beams, except for one, had failed on Floor 13.

\section{Comparison of Case C at $4 \mathrm{~h}$ to Case B at $4 \mathrm{~h}$}

Similar to the Case B results, the Case $\mathrm{C}$ results at $4.0 \mathrm{~h}$ had the most failures of floor beams, girders, and floor slab sections at Floors 8, 11, 12, 13, and 14. Floor 9 had partial damage to several beam connections in the northeast area of the core, and Floor 10 had no damage. 
Table 11-6. Structural response of WTC 7 to Case B and Case C temperatures.

\begin{tabular}{|c|c|c|c|}
\hline Floor & Case C Response & Case B Response & Comment \\
\hline \multicolumn{4}{|l|}{ Floor 8} \\
\hline $\begin{array}{l}\text { Floor framing (beams, } \\
\text { girders, and } \\
\text { connections) }\end{array}$ & $\begin{array}{l}\text { Nearly the same as Case B } \\
3.5 \mathrm{~h}\end{array}$ & & \\
\hline Concrete slab & $\begin{array}{l}\text { Area of compression } \\
\text { failure is less than Case B } \\
3.5 \mathrm{~h}\end{array}$ & & $\begin{array}{l}\text { Case C fire (gas } \\
\text { temperatures) was less } \\
\text { severe than Case B }\end{array}$ \\
\hline \multicolumn{4}{|l|}{ Floor 9} \\
\hline Floor framing & $\begin{array}{l}\text { Between Case B } 3.5 \mathrm{~h} \text { and } \\
4.0 \mathrm{~h}\end{array}$ & & $\begin{array}{l}\text { Frame deflections } \\
\text { Case B }-8 \text { in. to }-12 \text { in. } \\
\text { Case C }-10 \text { in. }\end{array}$ \\
\hline Concrete slab & None & None & \\
\hline \multicolumn{4}{|l|}{ Floor 10} \\
\hline Floor framing & None & $\begin{array}{l}3 \text { connections damaged at } \\
3.5 \mathrm{~h} \\
\text { Girder failed at Col 76-79 } \\
\text { at Case B } 4.0 \mathrm{~h}\end{array}$ & $\begin{array}{l}\text { Frame deflections } \\
\text { Case B }-6 \text { in. } \\
\text { Case C }-6 \text { in. }\end{array}$ \\
\hline Concrete slab & None & None & \\
\hline \multicolumn{4}{|l|}{ Floor 11} \\
\hline Floor framing & $\begin{array}{l}\text { Nearly the same as Case B } \\
4.0 \mathrm{~h}\end{array}$ & & \\
\hline Concrete slab & $\begin{array}{l}\text { Between Case B } 3.5 \mathrm{~h} \text { and } \\
4.0 \mathrm{~h}\end{array}$ & & \\
\hline \multicolumn{4}{|l|}{ Floor 12} \\
\hline Floor framing & $\begin{array}{l}\text { Between Case B } 3.5 \mathrm{~h} \text { and } \\
4.0 \mathrm{~h} \\
\text { Girder not failed at Col } \\
76-79 \text { at Case C } 4.0 \mathrm{~h}\end{array}$ & $\begin{array}{l}\text { Girder failed at Col 76-79 } \\
\text { at Case B } 4.0 \mathrm{~h}\end{array}$ & \\
\hline Concrete slab & $\begin{array}{l}\text { Nearly the same as Case B } \\
4.0 \mathrm{~h}\end{array}$ & & \\
\hline \multicolumn{4}{|l|}{ Floor 13} \\
\hline Floor framing & $\begin{array}{l}\text { Nearly the same as Case B } \\
4.0 \mathrm{~h}\end{array}$ & & \\
\hline Concrete slab & $\begin{array}{l}\text { Nearly the same as Case B } \\
4.0 \mathrm{~h}\end{array}$ & & \\
\hline \multicolumn{4}{|l|}{ Floor 14} \\
\hline Floor framing & $\begin{array}{l}\text { Nearly the same as Case B } \\
4.0 \mathrm{~h} \\
\text { Girder failed at Col } 80-81 \\
\text { at } 4.0 \mathrm{~h}\end{array}$ & & \\
\hline Concrete slab & None & None & \\
\hline
\end{tabular}


The same type of failures in the connections, beams, and girders occurred on each floor, with the extent of damage falling somewhere between the damage that occurred between $3.5 \mathrm{~h}$ and $4.0 \mathrm{~h}$ for Case B temperatures. The exceptions, which are minor, are noted below.

- Case $\mathbf{C}$ at $\mathbf{4} \mathbf{h}$. The girder between Columns 76 and 79 failed due to tensile weld failure of the knife connection at Column 79 on Floor 11 (Figure 11-33).

Case B at $4 \mathbf{~ h}$. After $4 \mathrm{~h}$ of heating, the girder between Columns 76 to 79 had failed due to tensile forces on Floors 10, 11, and 12 (Figure 11-32, Figure 11-33, and Figure 11-34).

- Case C at $4 \mathbf{h}$. The girder between Columns 80 and 81 on Floor 14 failed (Figure 11-44). Case $\mathbf{B}$ at $\mathbf{4} \mathbf{h}$. This girder had not yet failed (Figure 11-36).

Table 11-6 lists the structural response for each floor components (floor framing and concrete slab). The second column indicates how the Case $\mathrm{C}$ response at $4.0 \mathrm{~h}$ compares to the Case $\mathrm{B}$ response at either $3.5 \mathrm{~h}$ or $4.0 \mathrm{~h}$. The third column lists damage from the Case B response that did not occur in the Case $\mathrm{C}$ response at $4.0 \mathrm{~h}$. The fourth column provides comments regarding the basis for noted differences.

Table 11-6 shows that the damage for Case $C$ temperatures at $4.0 \mathrm{~h}$ on Floors 8, 9, and 10 more closely matched the damage for Case B at 3.5 h, and that the damage for Case C on Floors 11, 12, 13, and 14 more closely matched the damage for Case B at $4.0 \mathrm{~h}$. The fires on Floors 11, 12, and 13 generated significantly more heat than the fire on Floors 7, 8, and 9. Even though the temperatures were lower in Case $\mathrm{C}$ relative to Case B, there was still a substantial amount of heating taking place on Floors 11, 12, 13 , and 14 for both cases. 


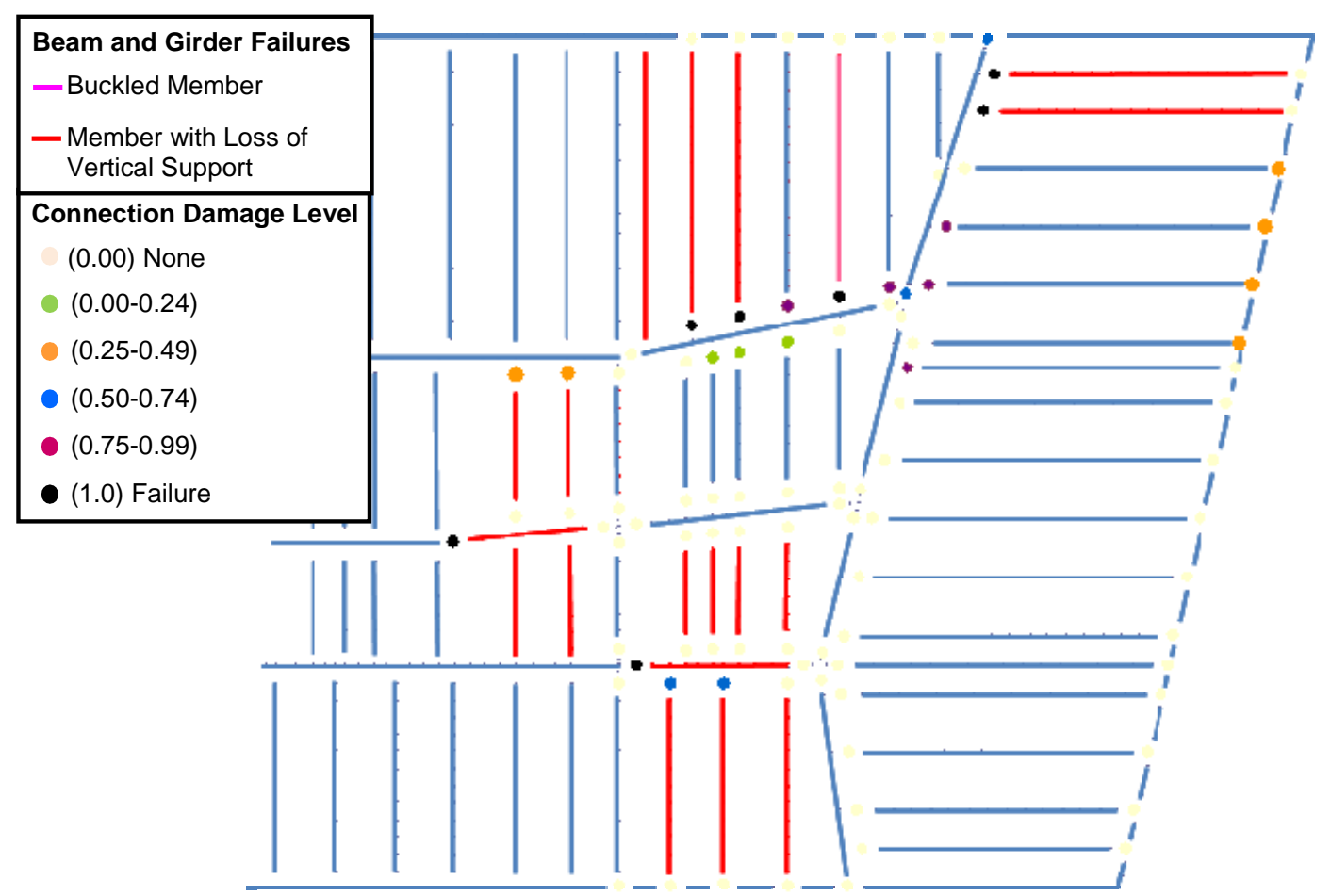

a) Damage state of connections in the horizontal direction

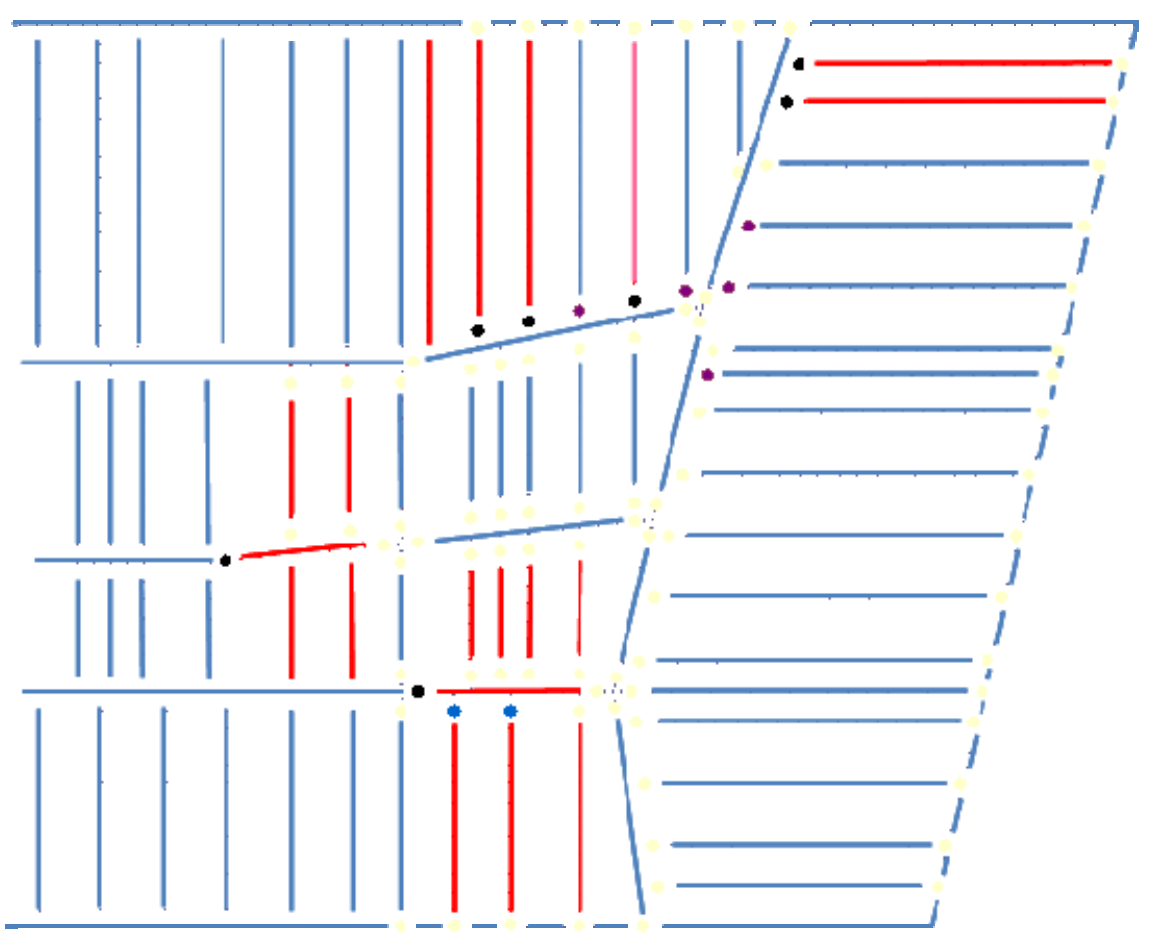

b) Damage state of connections in the vertical direction

Figure 11-38. Damage state of connections, beams, and girders in Floor 8 at $4.0 \mathrm{~h}$ for Case $\mathrm{C}$ temperatures. 


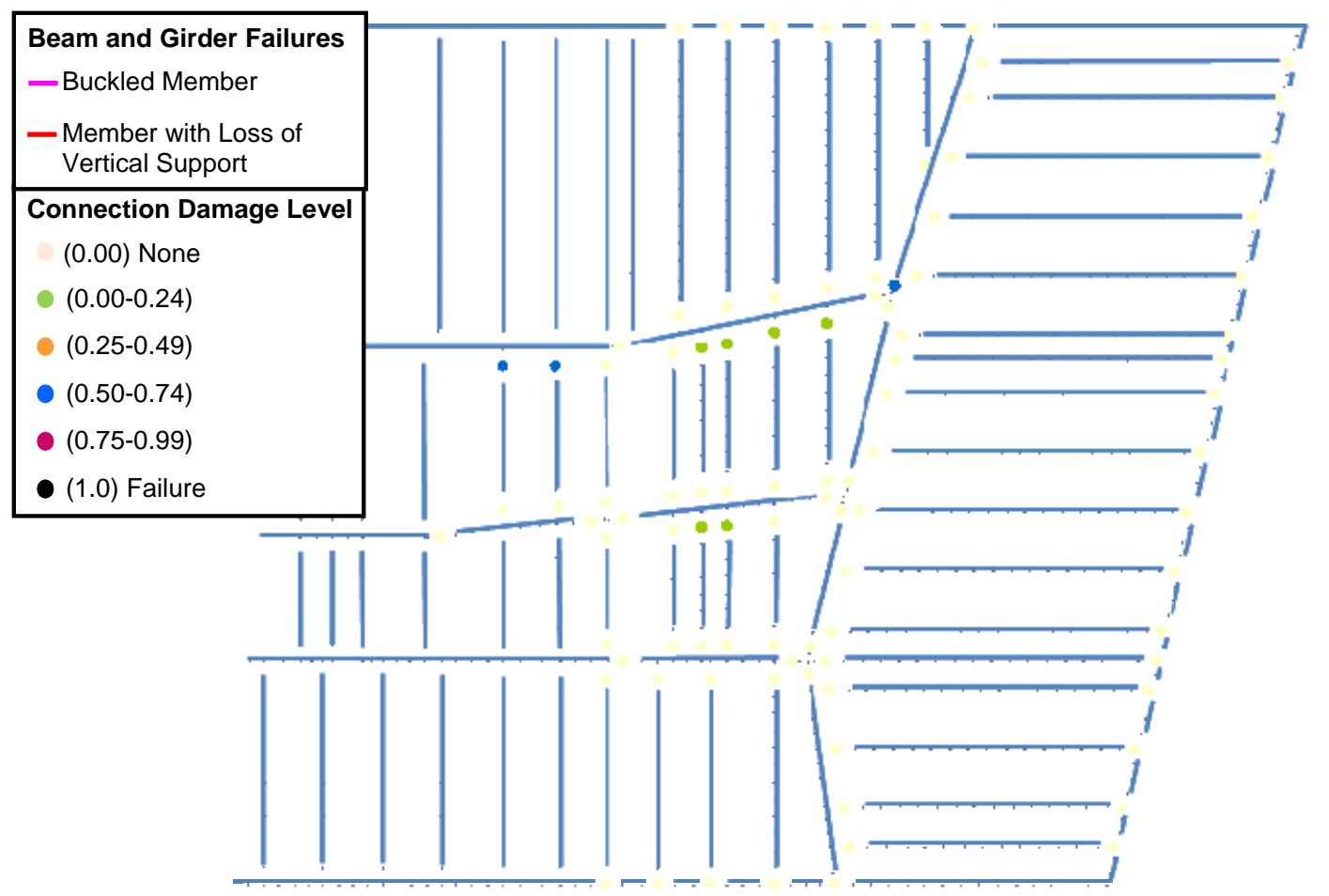

a) Damage state of connections in the horizontal direction

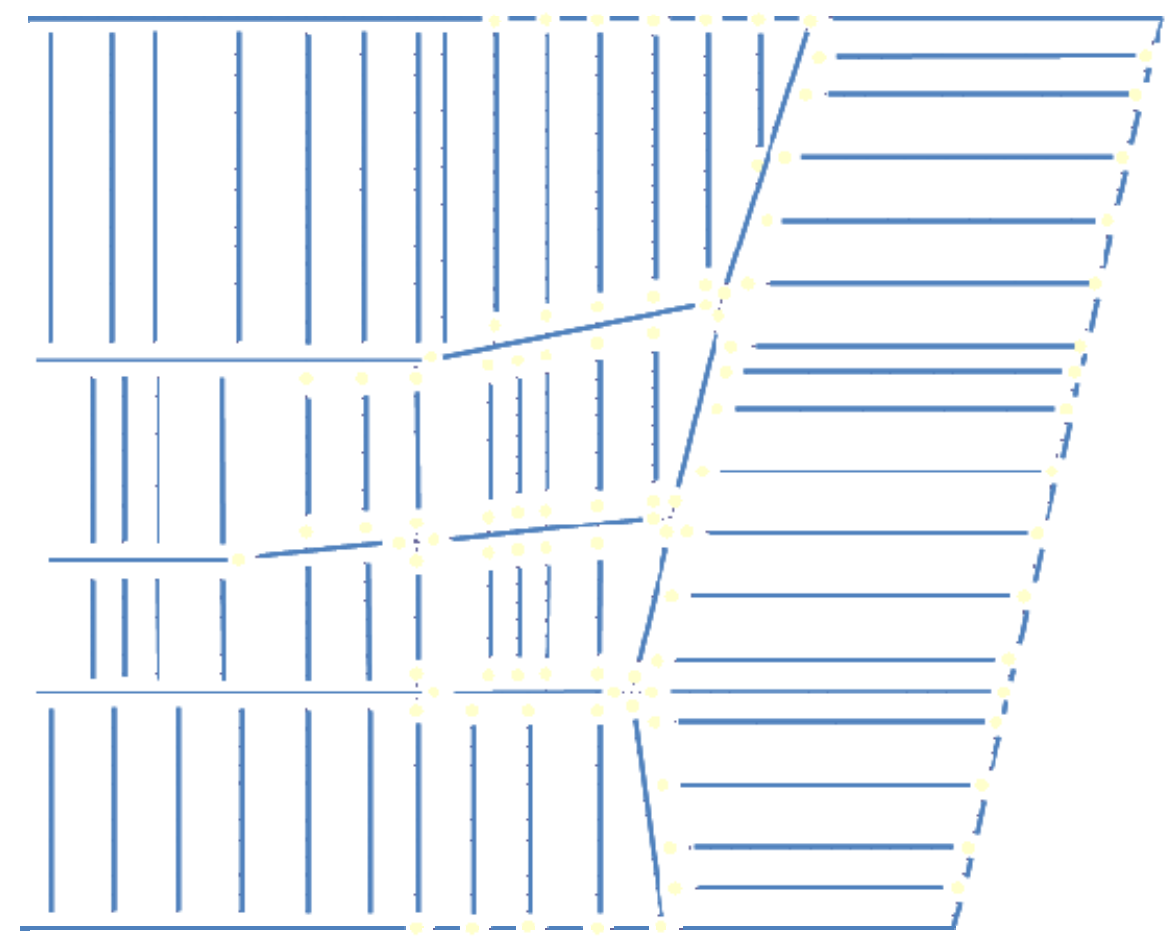

b) Damage state of connections in the vertical direction

Figure 11-39. Damage state of connections, beams, and girders in Floor 9 at $4.0 \mathrm{~h}$ for Case $\mathrm{C}$ temperatures. 


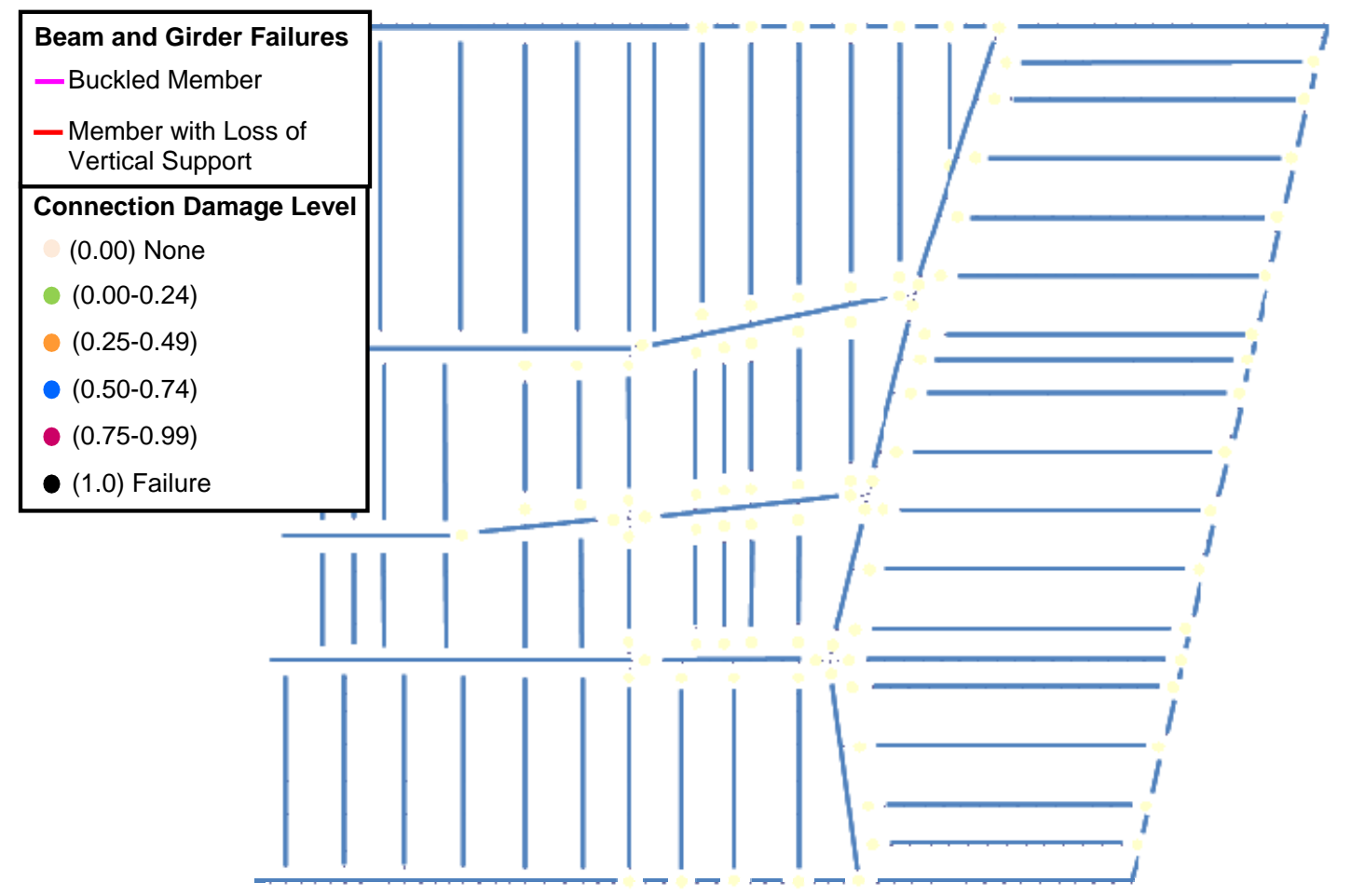

a) Damage state of connections in the horizontal direction

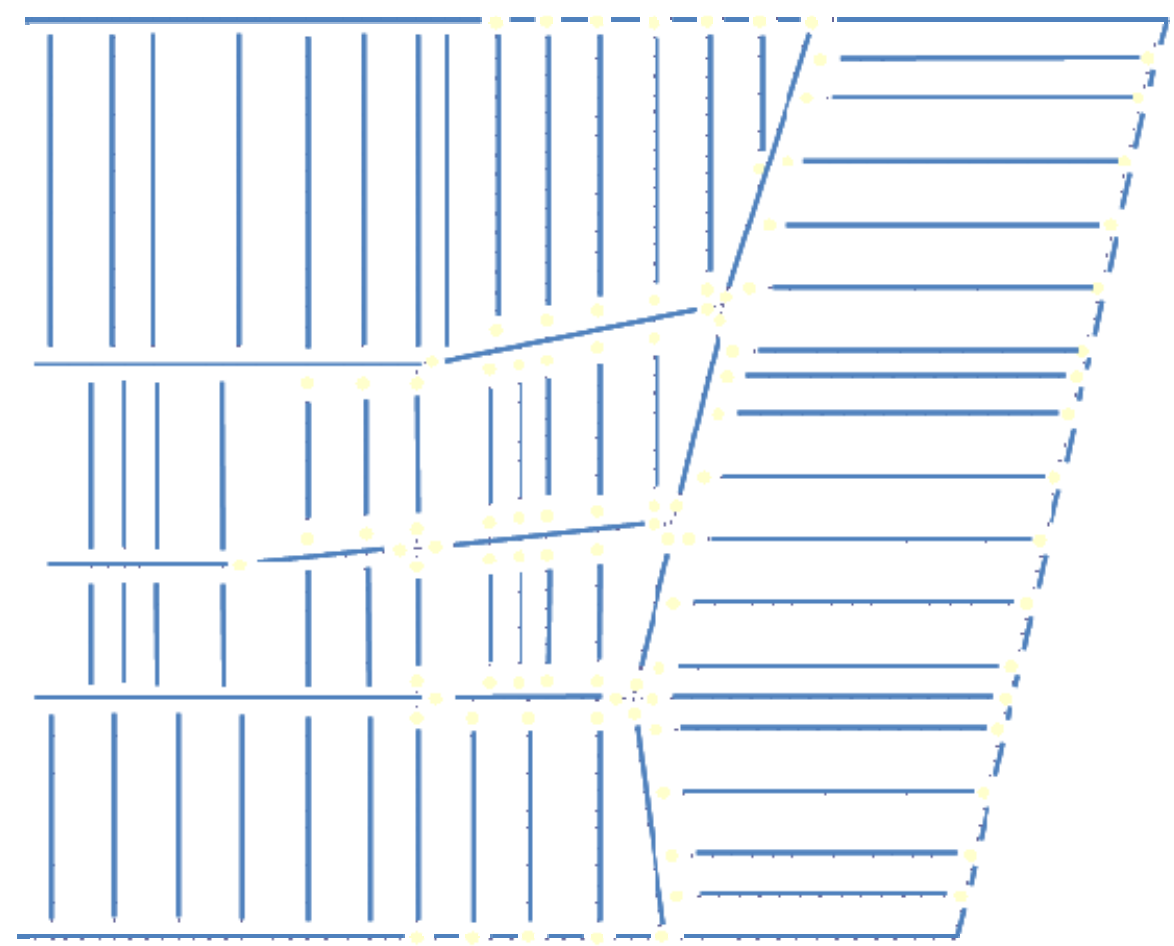

b) Damage state of connections in the vertical direction

Figure 11-40. Damage state of connections, beams, and girders in Floor $\mathbf{1 0}$ at $\mathbf{4 . 0} \mathrm{h}$ for Case $\mathrm{C}$ temperatures. 


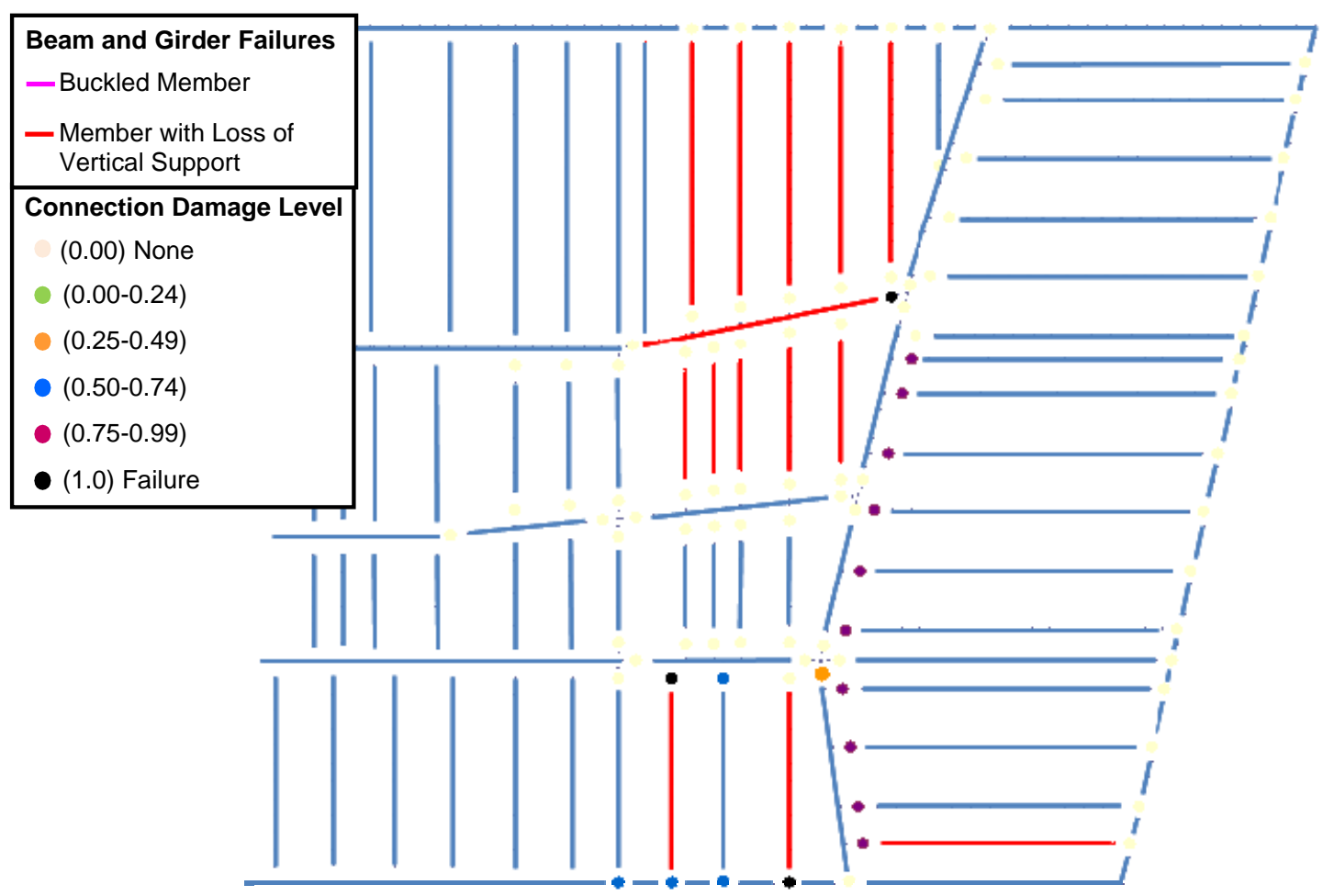

a) Damage state of connections in the horizontal direction

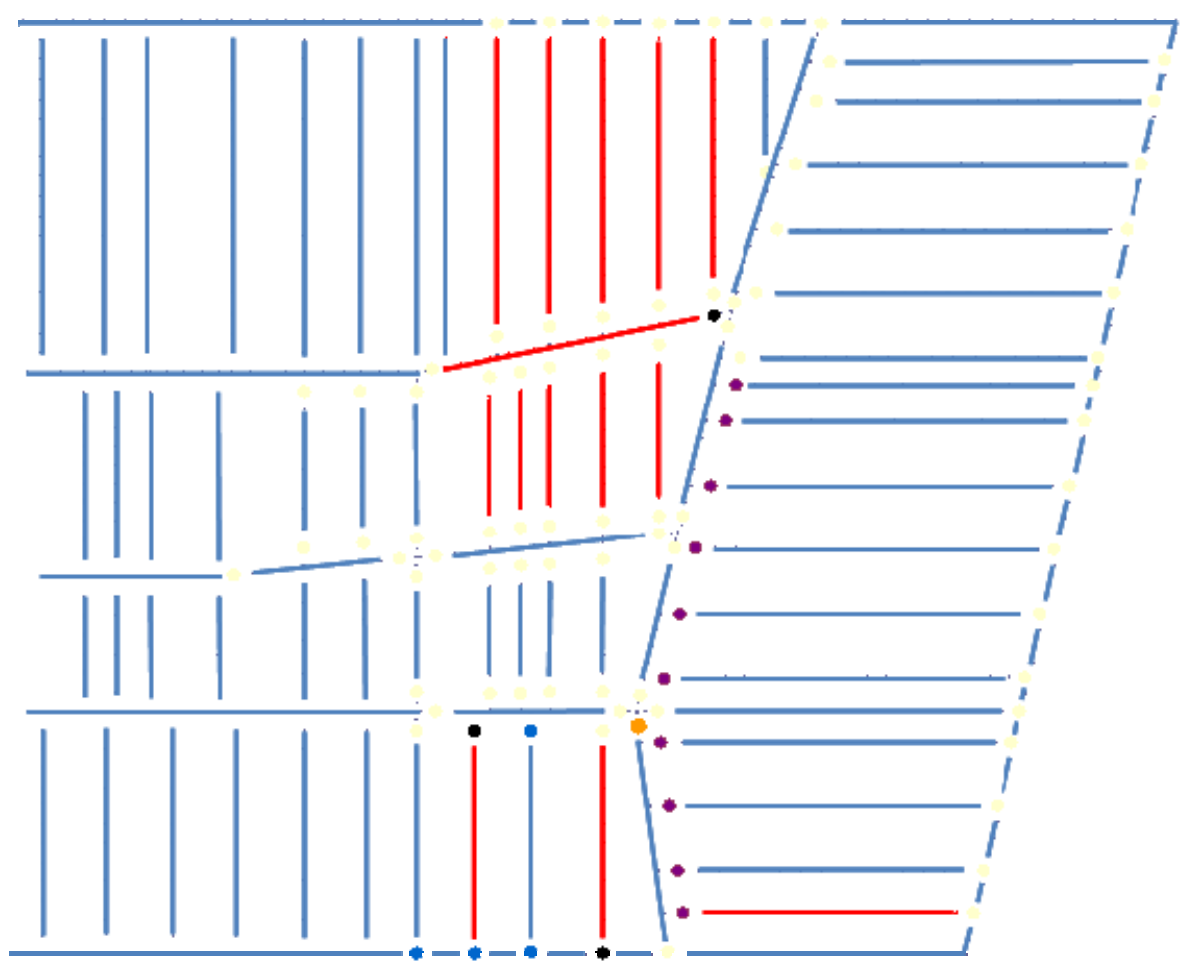

b) Damage state of connections in the vertical direction

Figure 11-41. Damage state of connections, beams, and girders in Floor 11 at $4.0 \mathrm{~h}$ for Case $\mathrm{C}$ temperatures. 


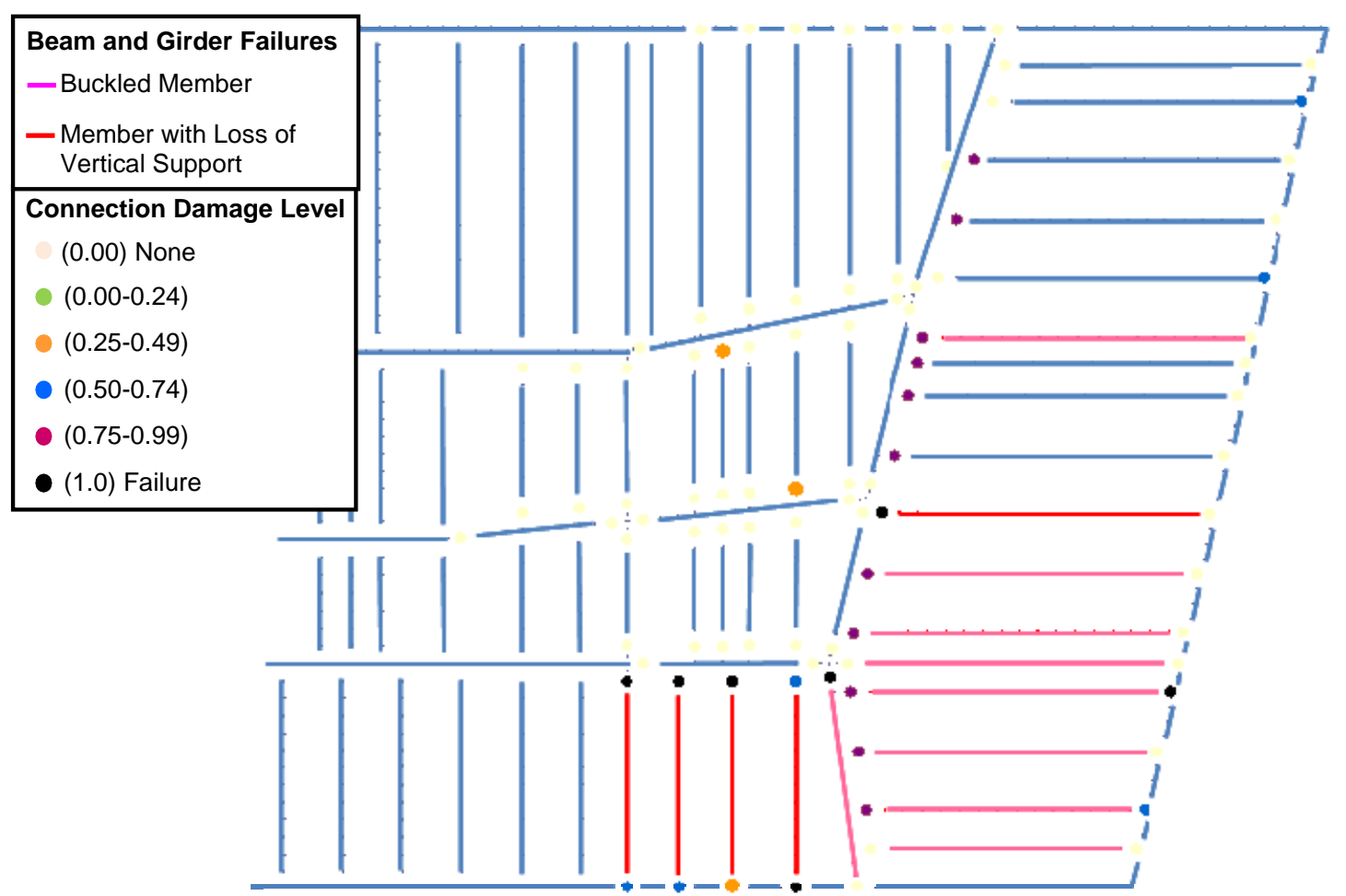

a) Damage state of connection in the horizontal direction

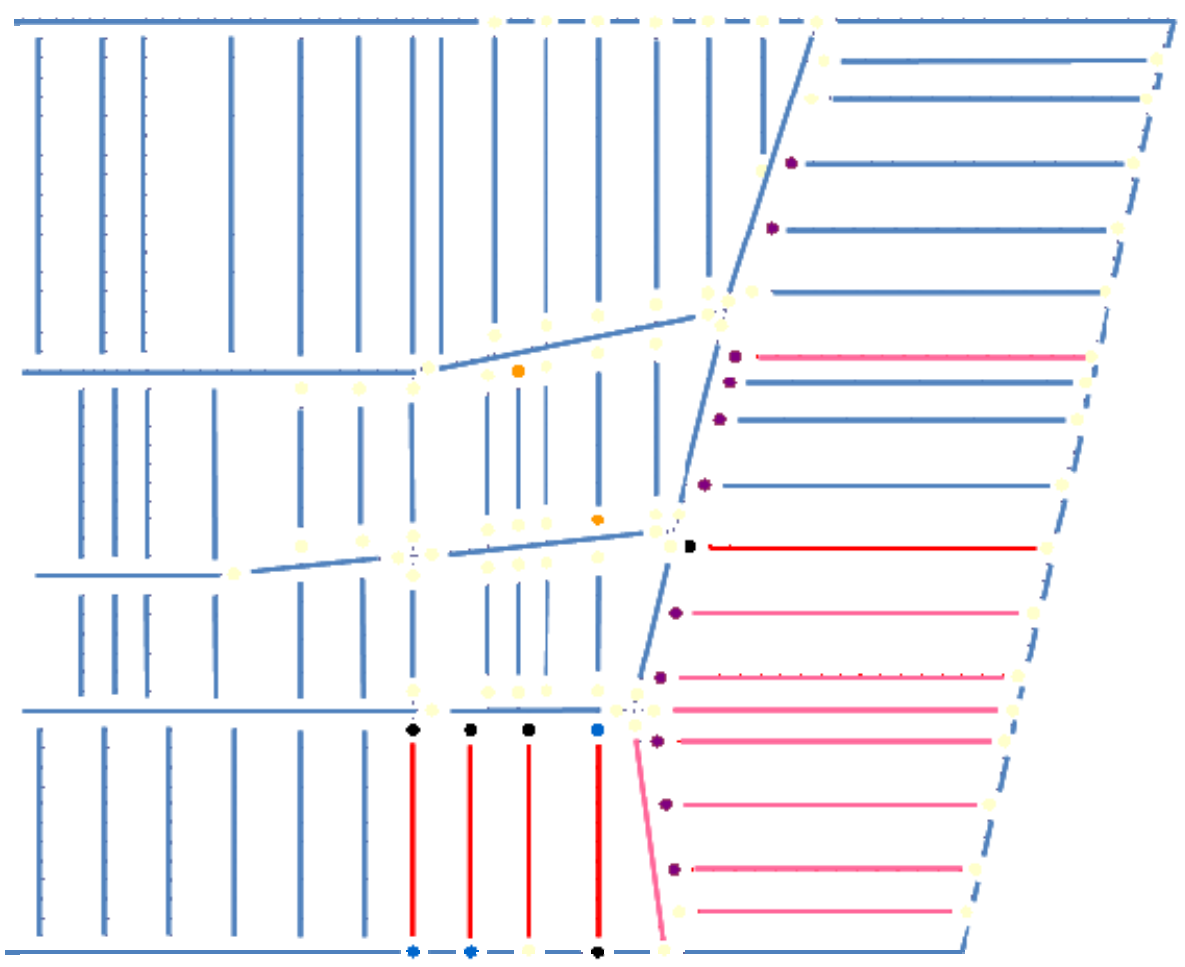

b) Damage state of connection in the vertical direction

Figure 11-42. Damage state of connections, beams, and girders in Floor 12 at $4.0 \mathrm{~h}$ for Case $\mathrm{C}$ temperatures. 


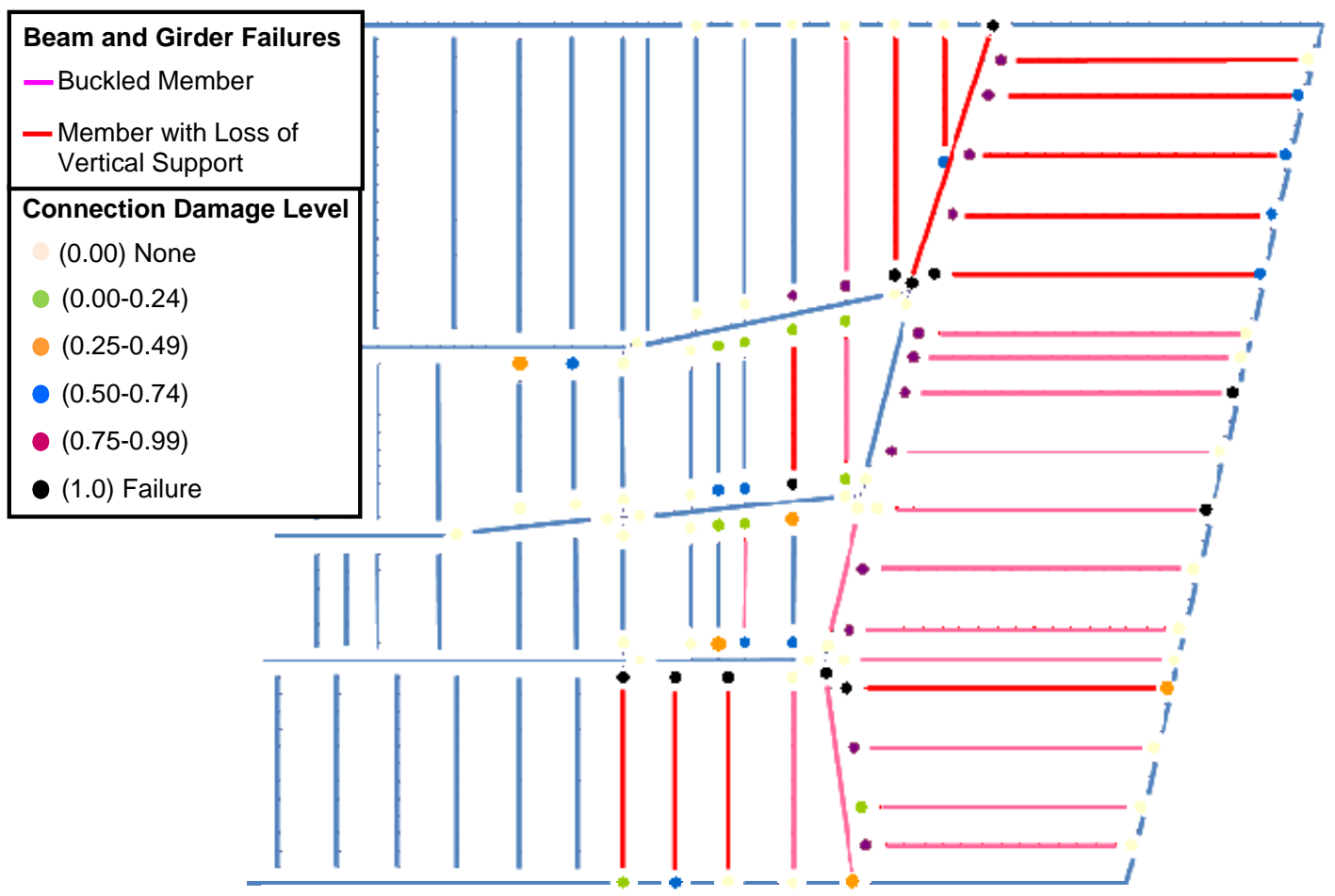

a) Damage state of connection in the horizontal direction

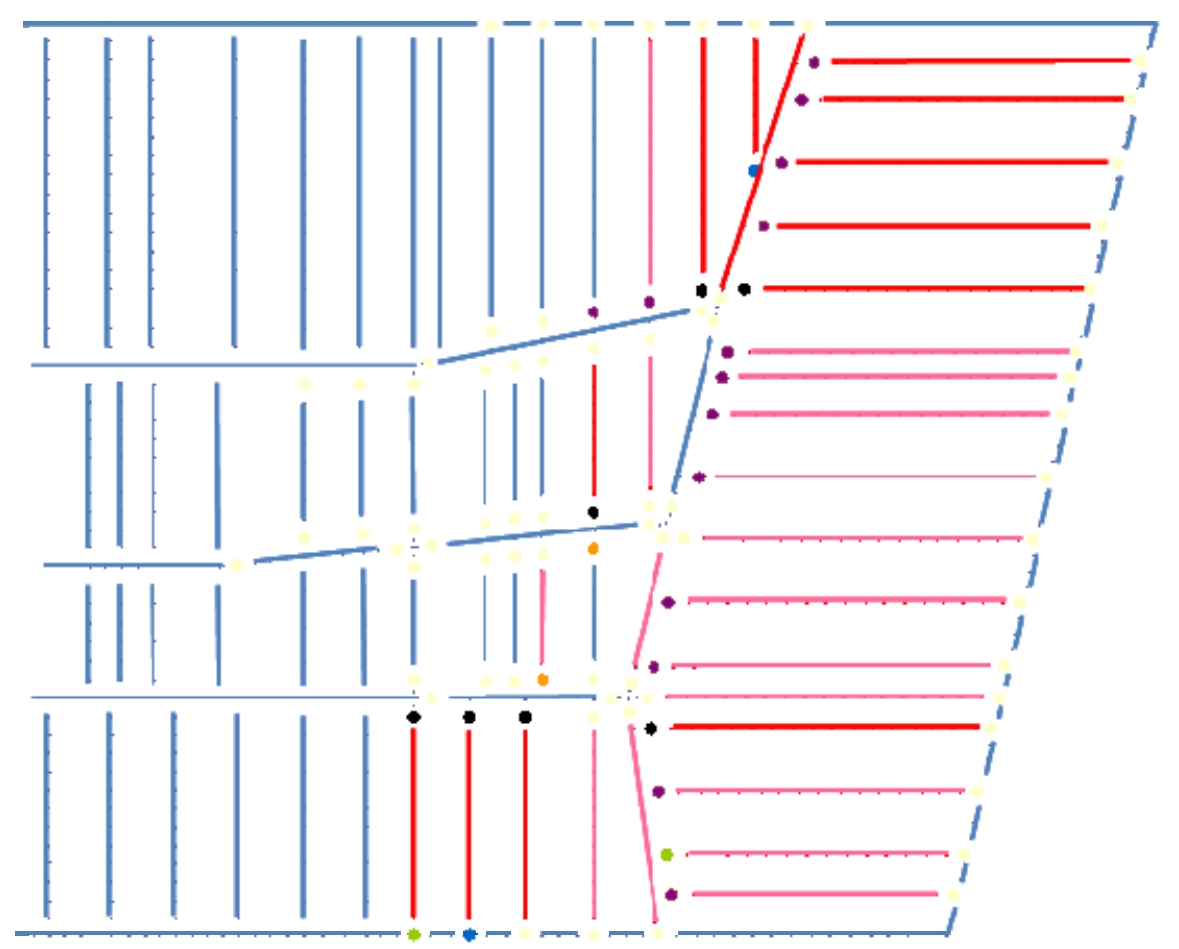

b) Damage state of connection in the vertical direction

Figure 11-43. Damage state of connections, beams, and girders in Floor 13 at $4.0 \mathrm{~h}$ for Case $\mathrm{C}$ temperatures. 


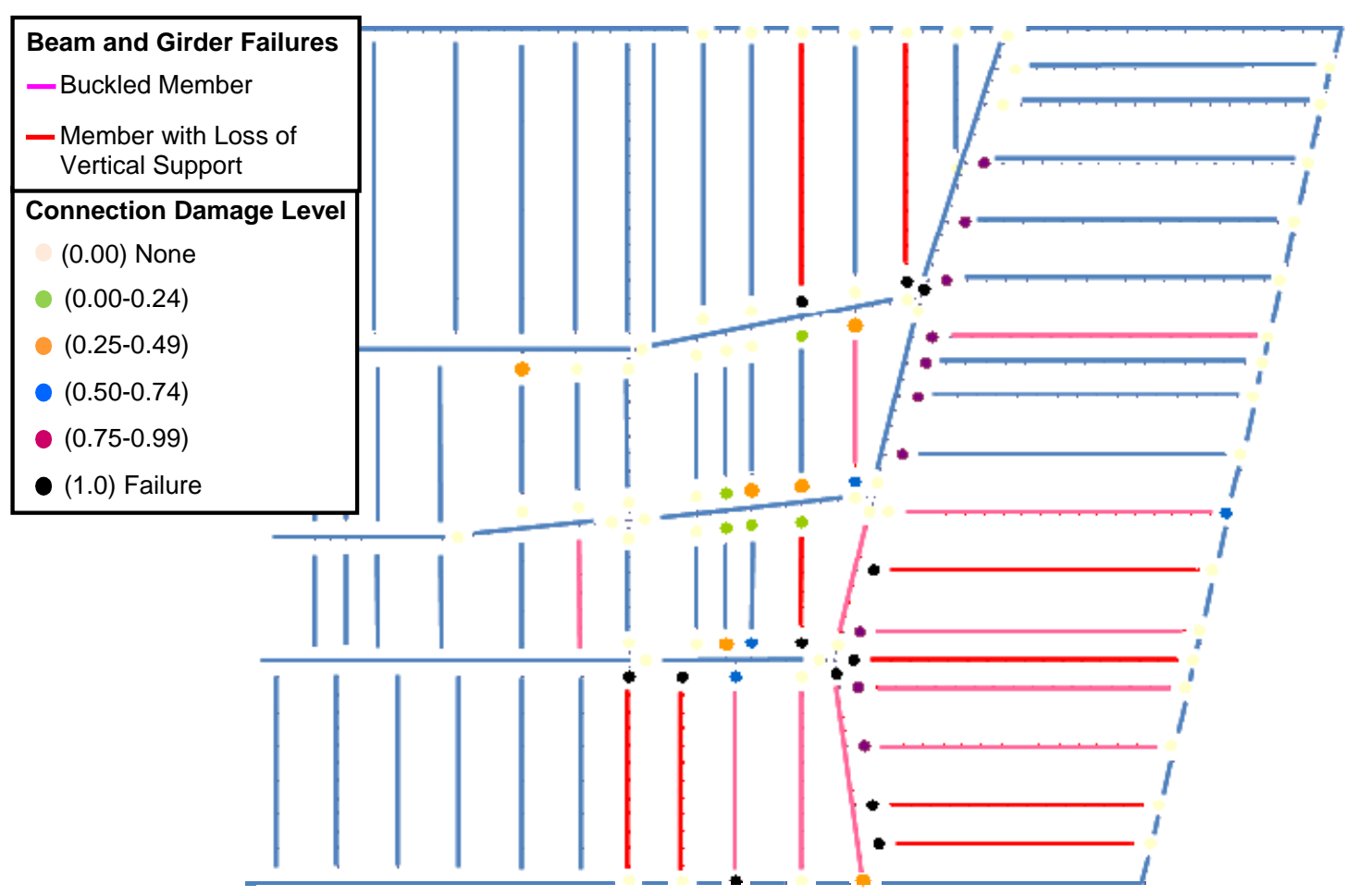

a) Damage state of connection in the horizontal direction

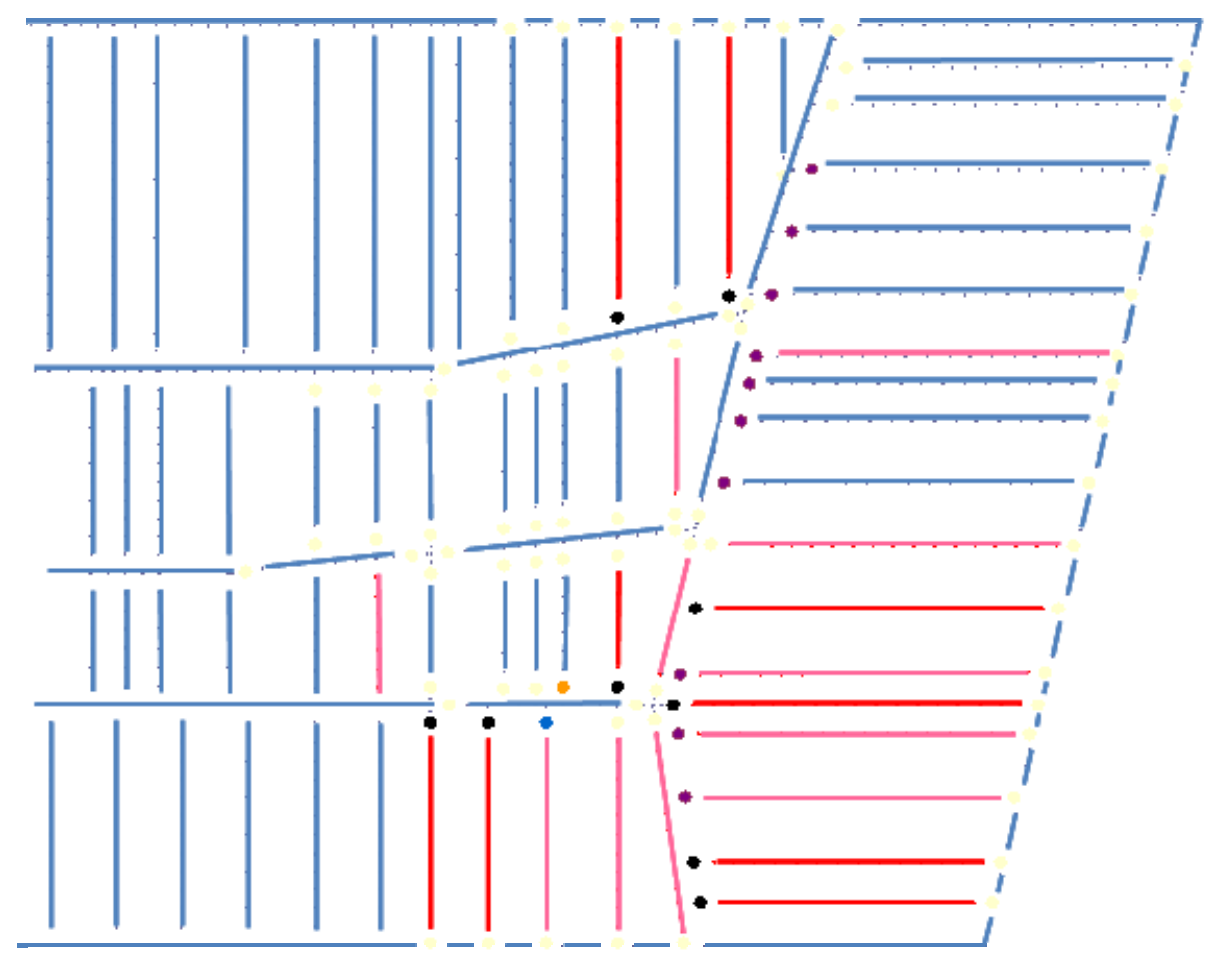

b) Damage state of connection in the vertical direction

Figure 11-44. Damage state of connections, beams, and girders in Floor 14 at $4.0 \mathrm{~h}$ for Case $\mathrm{C}$ temperatures. 


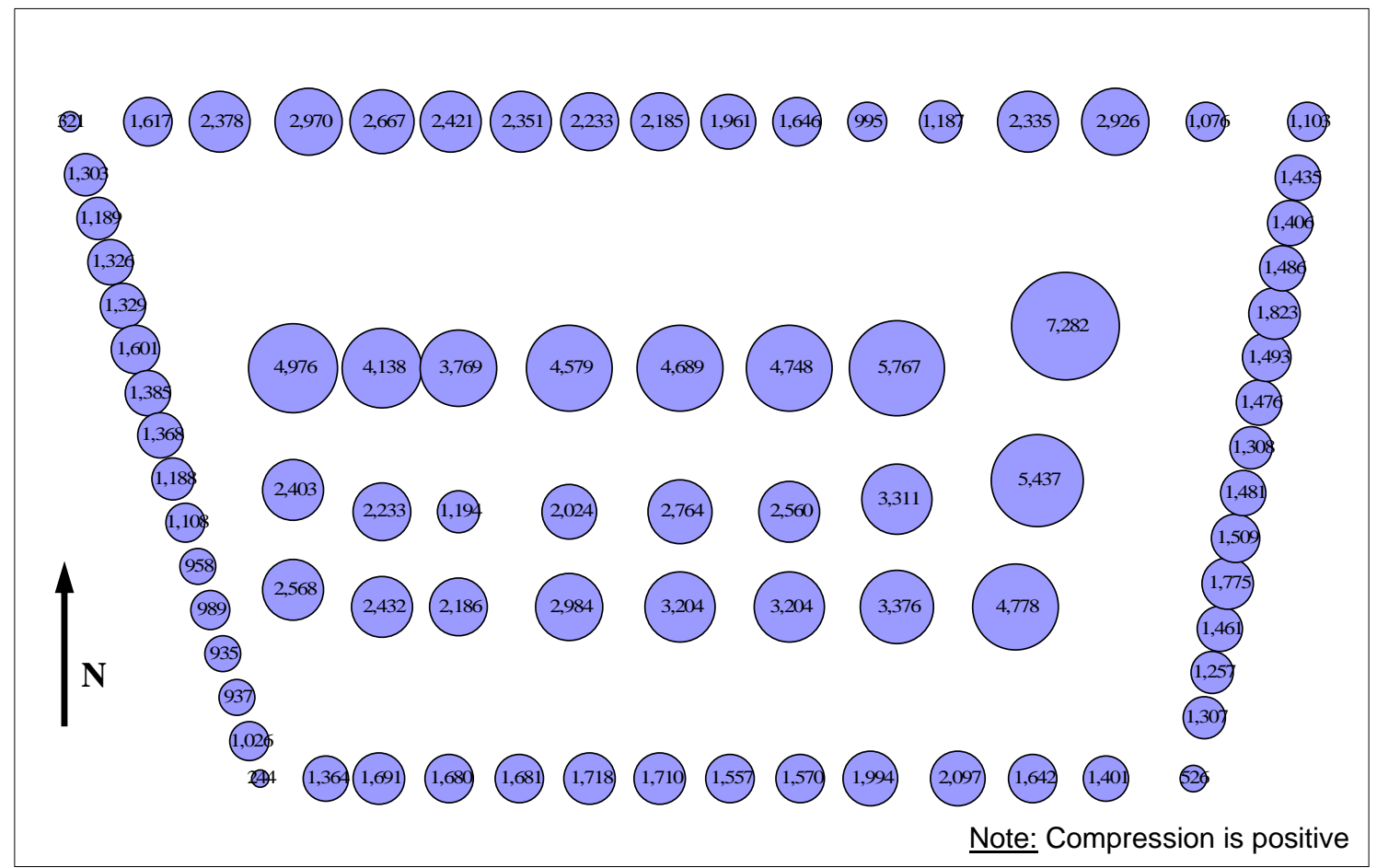

Summation of Column forces:

North: 32,400 kip East: 19,200 kip

South: 20,850 kip West: 16,650 kip

Interior: $86,600 \mathrm{kip} \quad$ Total: $175,700 \mathrm{kip}$

Figure 11-45. Column forces (in kip) above Floor 8 at $\mathrm{t}=4.0 \mathrm{~h}$ for Case $\mathrm{C}$ temperatures.

\subsection{DISCUSSION OF RESULTS}

The structural response of WTC 7 to Case B temperatures is presented in Section 11.4.1. The structural response of WTC 7 to Case $C$ temperatures is presented in Section 11.4.2.

\subsubsection{Discussion of Results for Case B Temperatures}

The fires on Floors 11, 12, and 13 generated significantly more heat than the fires on Floors 7, 8, and 9. This was in large part due to the higher fuel load and the larger concurrent burning area on Floors 11, 12, and 13.

After $3.5 \mathrm{~h}$ of heating, the fire had damaged the floor beams, girders and floor slab sections on Floors 8, 12, 13, and 14. The girders bracing interior Columns 79, 80, and 81 were still intact, except for the girder between exterior Column 26 and interior Column 81, which had buckled and walked off of the bearing seat on Floors 13 and 14. At the seated connection at Column 79, all the bolts had sheared on Floor 13 and two to three bolts had sheared on Floors 12 and 14. Approximately one-half to three-quarters of the east floor beams had a connection damage level of 0.75-0.99 on Floors 11, 12, 13, and 14. 
By $4.0 \mathrm{~h}$ of heating, there was substantially more damage in the WTC 7 structural system, particularly the loss of lateral support to Column 79 after the failure of girder connections at Floors 10, 11, 12, and 13. Floor beams, girders and floor slab sections at Floors 8, 10, 11, 12, 13, and 14 were damaged in the vicinity of Column 79, primarily from the effects of thermal expansion within the structural system. All the north-south girders framing into Columns 79, 80, and 81 on Floor 13, and the east floor beams, had been damaged. The girder between Columns 44 and 79 had walked off the bearing seat at Column 79 on Floor 13, and all 4 bolts had failed on Floor 14 and two to three bolts had failed on Floor 12 at this seated connection. The girder between Columns 79 and 80 and Columns 80 and 81 had buckled on Floor 13. The girder between Columns 81 and 26 had buckled and walked off the bearing seat on Floor 12 . Approximately one-half to three-quarters of the east floor beams had a connection damage level of 0.750.99 on Floors 11, 12, and 14.

\section{Thermal Effects on Columns}

None of the columns reached temperatures over $300{ }^{\circ} \mathrm{C}$ and, therefore, did not buckle due to fire-induced thermal weakening (thermal weakening occurs at temperatures greater than about $500{ }^{\circ} \mathrm{C}$ ). The interior columns were not thermally restrained, so they could not develop increased loads due to thermal expansion. The exterior columns had some restraint to thermal expansion, due to the moment frame construction of the exterior framing. However, the exterior columns tended to have lower temperatures than the interior columns as they were only heated on one side and the heat was dissipated to the outside. Thermal expansion of either interior or exterior columns had little or no effect on the failure mechanisms that occurred in the floor systems.

\section{Thermal Expansion Effects on Shear Studs}

Before the floor beams could exert an axial force on the interior girders, the shear studs had to have failed. Shear stud failures in WTC 7 were found to be primarily due to differential thermal expansion effects as the floor beams heated more quickly than the concrete slab. The capacity of a shear stud connector in a concrete slab was found to be 19.4 kip (Section 11.2.3). For 28 shear studs on each floor beam, the shear force required to fail all of the shear studs was approximately 545 kip.

The interior girders connecting Columns 44, 79, 80, 81, and 26 were non-composite and floor beams framed into one side of these girders. The less stiff interior girders allowed the floor beams to thermally expand toward the girders, but the concrete slab was restrained by the surrounding floor slab. When a northeast corner floor beam was heated to an average temperature of $100{ }^{\circ} \mathrm{C}$, the floor beam exerted an axial force of up to 950 kip on its shear studs, significantly grater than the capacity of 545 kip.

Shear stud failures also occurred when fires caused local thermal expansion in the concrete slab (the floor surface where the fire was burning) such that compressive failure by concrete crushing occurred in the slab, causing the shear studs to became ineffective. This type of failure occurred in the southwest floor slab of Floor 11 where fires burned on the slab surface. There were fin connection failures along the girder between Columns 26 and 81 and a buckled floor beam, even though there were no fires on Floor 10.

Once the shear studs failed, the floor beams were no longer laterally restrained. Clearly, this was the case if the shear stud connector failed at its weld. If a shear connector failed through crushing of the concrete 
surrounding the stud, there would also be little resistance to lateral movement as the cone of failed concrete would pull out of the slab when the beam rotated about its flange tip.

Review of the literature did not find much data that documented shear stud failure in composite floor assemblies subjected to fire. Fire tests of composite floor assemblies typically have the same, highly restrained boundary conditions for the floor slab and the steel floor beams. It is not likely that shear stud failures would be observed in Standard Fire Tests of floor assemblies since the beam is wedged tightly to the reaction frame and the concrete slab is cast against the frame, resulting in the condition where neither the beam nor slab can expand. Thus, there is no differential displacement between the beam and the slab, and no shear transfer.

If such tests had been conducted where the concrete slab was laterally restrained (representing the restraint of the surrounding slab) but the floor beams were allowed to elongate thermally with minimal restraint (representing the weak axis of the wide flange girder), the shear studs would likely have failed. The behaviour of composite floor assemblies when exposed to fire is strongly dependent on the boundary conditions and degree of thermal restraint imposed by the member connections and surrounding structure.

\section{Thermal Effects on Floor Beams and Girders}

Figure 11-46 shows temperatures in the steel framing for Floor 13 at $3.0 \mathrm{~h}, 3.5 \mathrm{~h}$, and $4.0 \mathrm{~h}$ (graphics are from Chapter 10). Figure 11-47 and Figure 11-48 show the floor beams and girders that had failed at different points in time as the temperatures were applied. Beams and girders subject to fires were loaded and/or displaced by the combined effects of gravity loads from the floor slab and compressive axial forces from restrained thermal expansion. At temperatures below approximately $400{ }^{\circ} \mathrm{C}$ (when averaged over the beam length), thermal expansion effects caused two types of failures in the floor beams and girders: the buckling of beams and girders and the failure of end connections (discussed in the next section). At temperatures greater than $400{ }^{\circ} \mathrm{C}$, the strength and stiffness of the steel floor beams, girders, and their connections began to degrade.

Figure 11-47 shows the east floor beam failures, due to buckling and connection failures, that occurred between $3.25 \mathrm{~h}$ and $3.5 \mathrm{~h}$ on Floor 13. Comparison of Figure 11-46 and Figure 11-47 shows that floor beams had failed prior to the beam temperature reaching $400{ }^{\circ} \mathrm{C}$.

Buckling in the floor beams was due to the combined effects of (1) loss of lateral restraint, (2) increased axial loads due to thermal expansion effects, and (3) gravity loads from the floor slab. Floor beams lost lateral restraint when the majority of their shear stud connections failed, either by differential thermal expansion between the steel beams and the concrete slab, or by local concrete failure due to fires on the floor slab.

Primarily for the east tenant floor, when a floor beam thermally expanded, the beam displaced the girder at the interior end of the floor beam but did not displace the exterior frame at the other end of the floor beam. The exterior frame underwent minimal lateral displacement when floor beams thermally expanded, since the exterior framing with moment connections was much stiffer than the interior girders. In comparison, the girders were simply supported, laterally restrained by the floor beams only as they did not have shear stud connections to the slab, and laterally loaded by the floor beams in their weak axis (Section 8.7.4). Many of the east floor beams on Floors 12, 13, and 14 failed by buckling, as shown in Figure 11-27 and Figure 11-35. 
The girder between Columns 26 and 81 buckled and walked off the bearing seat between $3.25 \mathrm{~h}$ and $3.5 \mathrm{~h}$. In a similar fashion, the girders between Columns 79 and 80 and Columns 80 and 81 buckled and the girder between Columns 44 and 79 buckled and walked off the bearing seat between $3.7 \mathrm{~h}$ and $4.0 \mathrm{~h}$. Girder buckling was due to the combined effects of (1) gravity loads from the floor beams, (2) lateral westward displacement due to the thermal expansion in the east floor beams, and (3) increased axial loads due to thermal expansion in the girder.

\section{Thermal Effects on Connections for Floor Beams and Girders}

Thermal expansion of beams and girders also caused connection failures. Restrained thermal expansion of steel beams and girder within the structural system resulted in (1) bolt shear due to increased axial forces, (2) walk off of seated connections after bolts had sheared, and (3) failure of connection welds in shear.

Shear failure of all the bolts in fin and knife connections, or failure of the weld at the beam and girder web in header connections, resulted in a loss of horizontal and vertical support to the beam or girder. In seated connections (SWC, STP, and STC), the shear failure of bolts at the bearing seat and top clip or plate, caused loss of horizontal support but not vertical support. When four bolts at the seated connection were sheared due to thermal expansion effects in the east floor beams and girders, there was a loss of horizontal support at the connection. Loss of vertical support occurred when the beam or girder walked off the bearing seat or when the bearing seat weld failed.

Walk off occurred when beams that framed into the girders from one side thermally expanded and the resulting compressive forces in the beams pushed laterally on the girder from one side, sheared the bolts at the seated connection, and then continued to push the girder laterally until it walked off the bearing seat. A girder was considered to have lost vertical support when its web was no longer supported by the bearing seat. The bearing seat at Column 79 was 11 in. wide. Thus, when the girder end at Column 79 had been pushed laterally at least 5.5 in., it was no longer supported by the bearing seat. Additional factors that contributed to this failure were the absence of shear studs on the girders that would have provided lateral restraint and the one-sided framing of the northeast corner floor beams that allowed the floor beams to push laterally on the girder due to thermal expansion.

On Floors 10, 11, and 12, tensile failure of knife connections occurred in the girder between Columns 76 and 79. The temperature of the girder between Columns 76 and 79 on Floor 13 was sufficient to displace Column 76 to the west and Column 79 to the east. The forced displacements at Floors 10, 11, and 12 created a tensile load in the girder knife connections to the columns, and failed the connection fillet weld to the column. 
WTC 7 : Floor 13

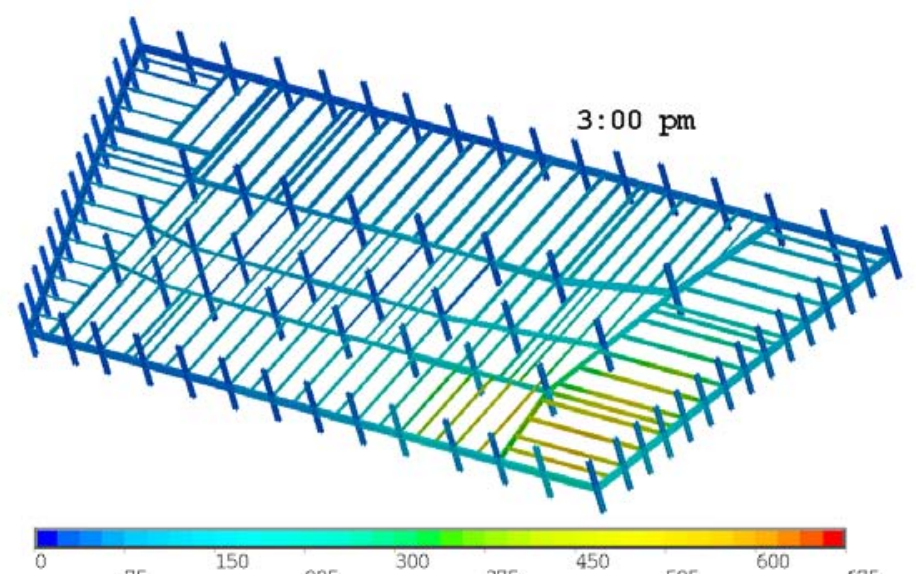

WIC 7 : Floor 13
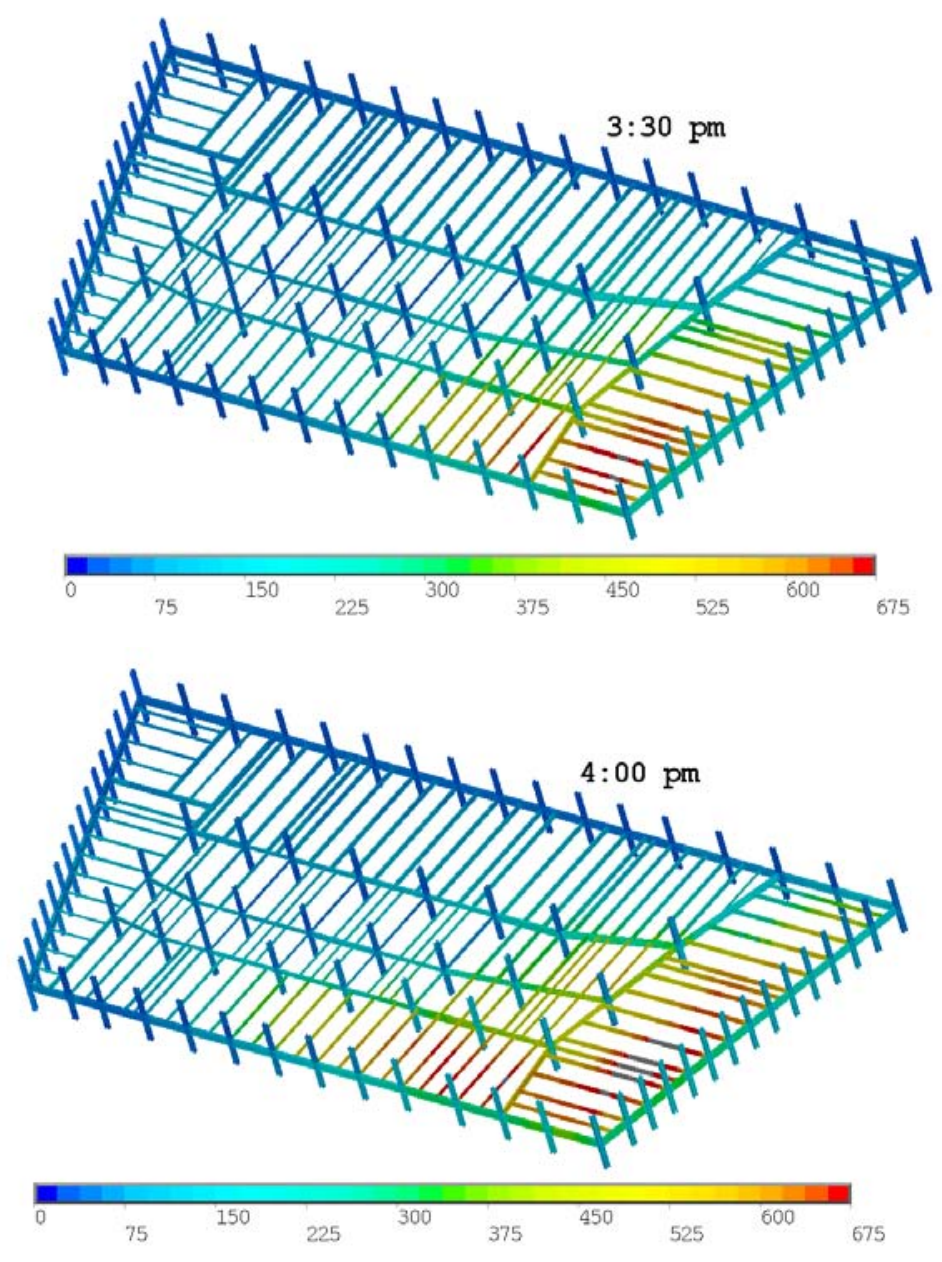

Figure 11-46. Floor 13 Case B temperatures at $3.0 \mathrm{~h}, 3.5 \mathrm{~h}$, and $4.0 \mathrm{~h}$. 

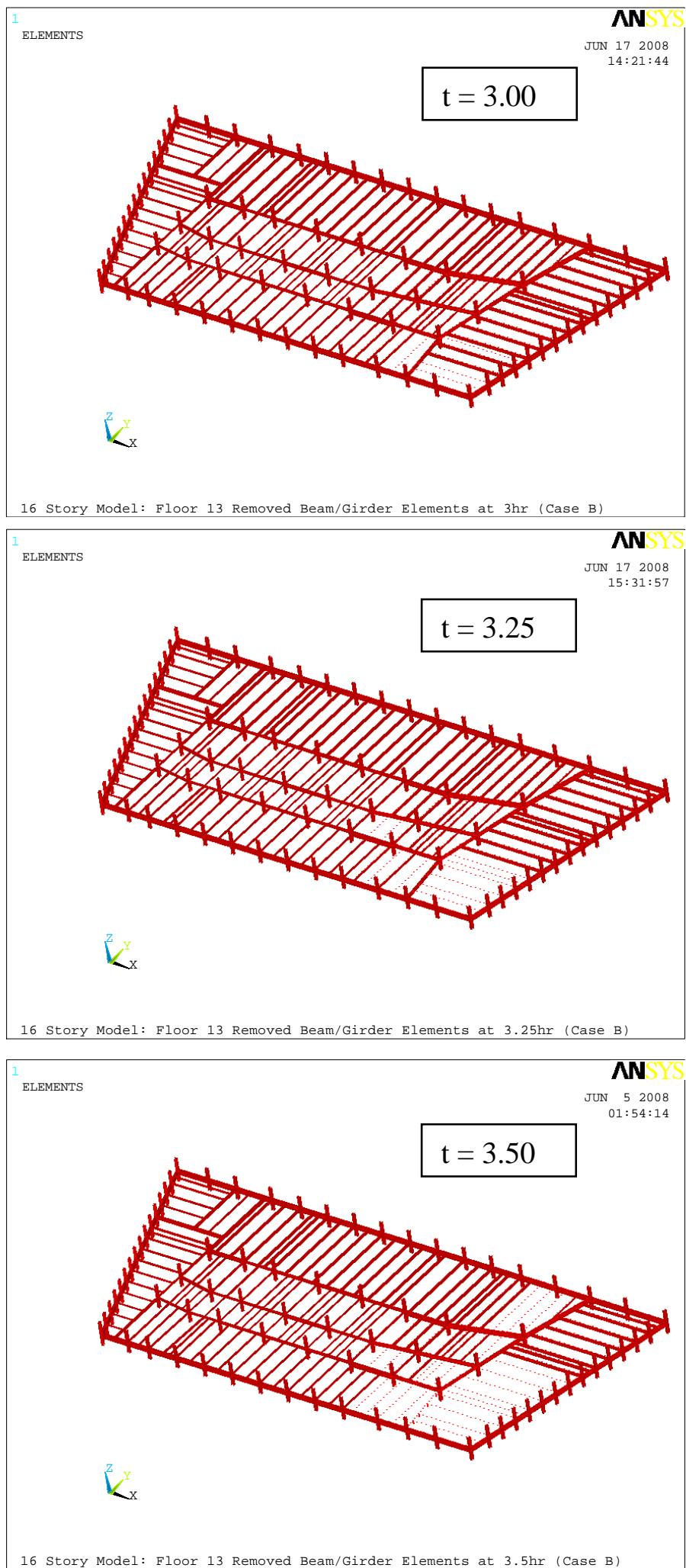

Beams and girders that buckled or had end connection damage are indicated with dotted lines.

Figure 11-47. Floor 13 Case B temperatures at $3.0 \mathrm{~h}$ to $3.5 \mathrm{~h}$. 

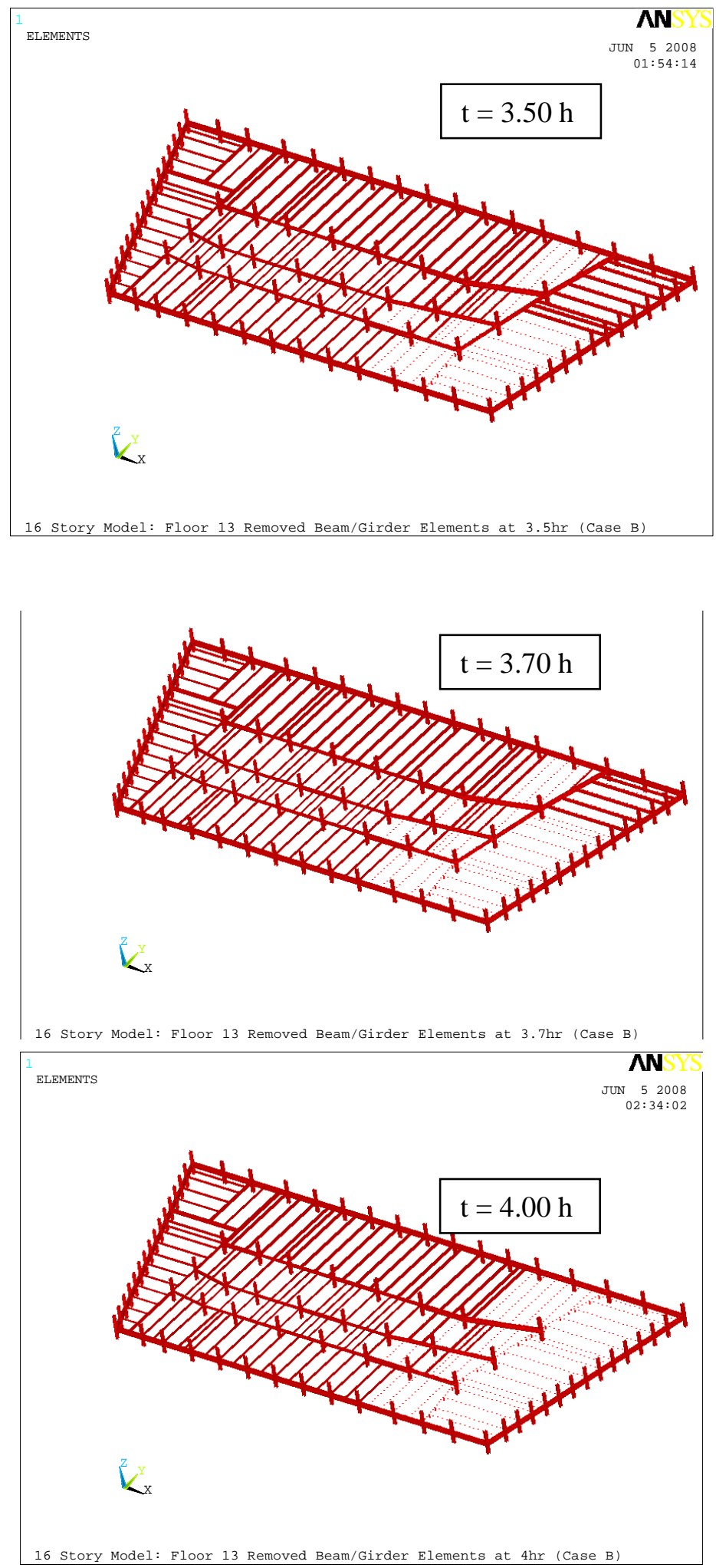

Beams and girders that buckled or had end connection damage are indicated with dotted lines.

Figure 11-48. Floor 13 Case B temperatures at $3.5 \mathrm{~h}$ to $4.0 \mathrm{~h}$. 


\section{Thermal Effects on Concrete Floors}

Thermal expansion of concrete floors was restrained by the surrounding unheated slab sections, the interior and exterior columns, and shear studs at the floor beams and exterior spandrel beams. Restraint of thermal expansion led to compressive failure of the concrete slab through crushing, which softened the slab in tenant floor areas, and also led to loss of composite action with the floor beams. This failure mechanism usually occurred at slab surface locations where fires were burning, which led to much higher slab temperatures in a localized area.

Slab tensile failures were related to the response of floor beams and girders to thermal effects. When beams and girders failed at their connections, affected slab section cracked under tensile stresses where reverse curvature in the slab occurred over adjacent intact girders.

\section{Floor Failures Leading to an Initial Failure Event}

After $4.0 \mathrm{~h}$ of heating, the floor framing and slabs at Floors 8 to 14 were weakened by fires, and Columns 79,80 , and 81 had lost lateral support at several floors due to the failure of connections, floor beams, and girders. The fire-induced failures of the floor framing resulted in increased unsupported column lengths for Columns 79, 80, and 81, as shown in Figure 11-49, where floor beams or girders that failed (by either buckling or end connection failure) are shown as red and intact members are shown as blue.

In the east-west direction, Columns 79 and 80 were laterally supported by one member that was directly connected to the columns at each floor, while Column 81 had two members providing lateral support, as shown in Figure 11-49. The east floor beams could only provide lateral support to Columns 79, 80, and 81 as long as the girders were intact. The floor beams with fin connections provided indirect lateral bracing to Columns 79 and 80, as the beams framed into the girders at locations close to the columns. In the north-south direction, Columns 79, 80, and 81 were laterally supported by two girders that were directly connected to the columns. Neglecting the lateral support provided by the east floor beams at Columns 79 and 80, the unsupported lengths for these columns at $4.0 \mathrm{~h}$ can be described as follows: Column 79 was laterally unsupported at three floors in the east-west direction and one floor in the northsouth direction, Column 80 was laterally unsupported at one floor in the east-west and north-south directions, and Column 81 was laterally unsupported at one floor in the north-south direction. (Even though there were three failed girders on the south side, there was one failed girder on the north side, so lateral support was still provided at the floors above and below the failed girder.)

As noted previously, the ANSYS analysis used a non-linear static procedure with an implicit solution algorithm that solved for equilibrium at each time step, but did not account for the dynamic effects of falling debris from framing failures in the floor systems. Based on engineering judgment and preliminary analyses in LS-DYNA, which included the effects of dynamics caused by debris impact from failed floor sections, the level of failures, damage, and thermal weakening in ANSYS at $4.0 \mathrm{~h}$ was identified as likely to result in an initiating event in an LS-DYNA analysis. The procedures used for transferring the ANSYS data to LS-DYNA are discussed in Section 11.5. 


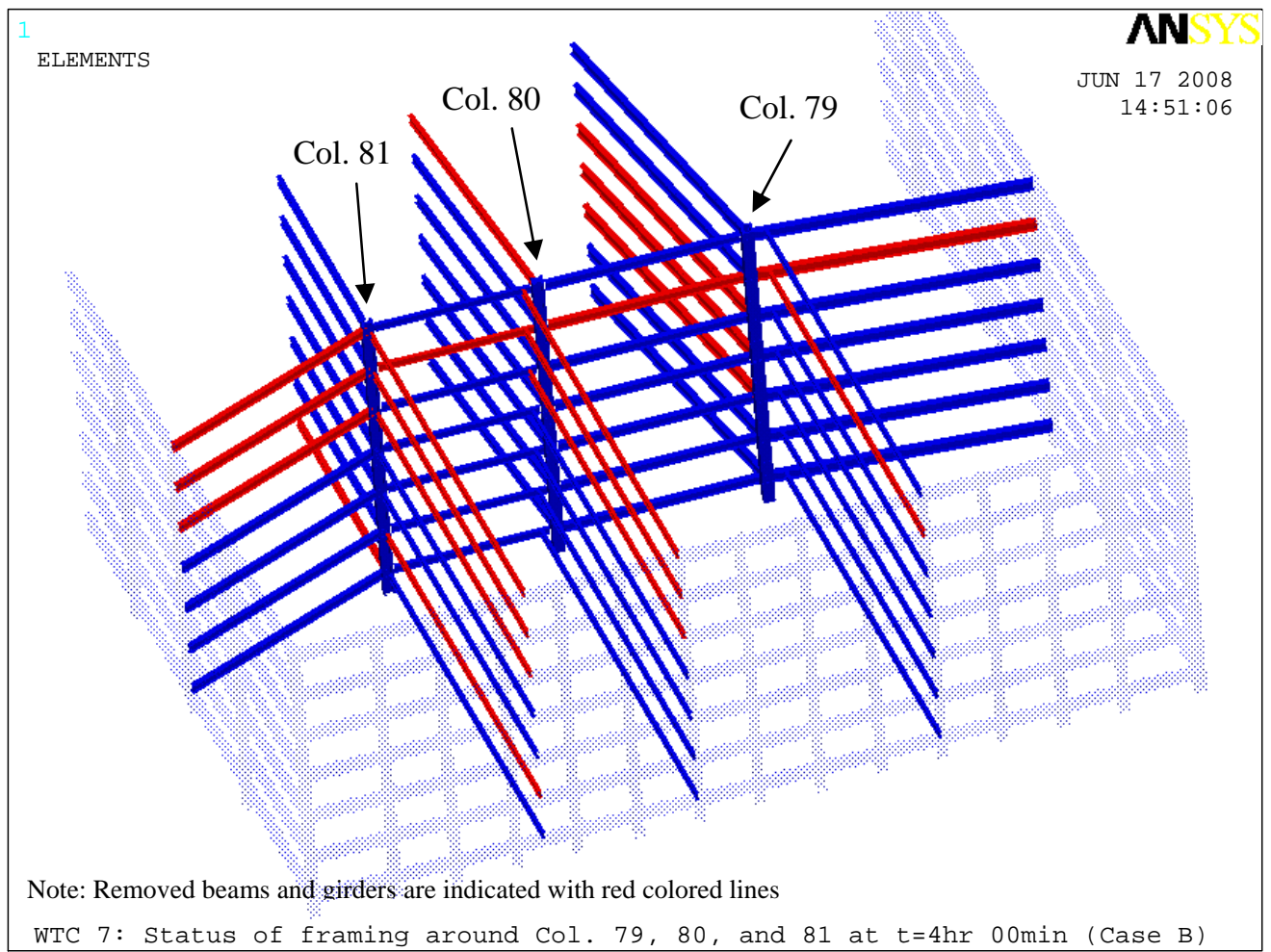

Figure 11-49. Beam and girder failures around Columns 79, 80, and 81 at $4.0 \mathrm{~h}$ for Case B temperatures.

\section{Effects of SFRM Thickness}

A SFRM thickness of $0.5 \mathrm{in}$. was specified for the floor beams in the composite floor system and independent testing found that the floor beams had an average applied thickness of $0.53 \mathrm{in}$. To evaluate the effect of increasing the SFRM thickness on the floor beams, by 25 percent to $0.625 \mathrm{in}$. (5/8 in.) and by 50 percent to $0.75 \mathrm{in}$. (3/4 in.), was examined with the ANSYS analyses described below.

Figure 11-50 and Figure 11-51 show the temperature versus time for a typical floor beam in the north and east tenant floor areas for two different fire exposures, the ASTM E 119 temperature curve and a uniform $1100{ }^{\circ} \mathrm{C}$ gas temperature, respectively, and four different SFRM thicknesses:

- $0.4375(7 / 16)$ in.

- 0.53 in. (average applied SFRM thickness)

- $0.625(5 / 8)$ in.

- $0.75(3 / 4)$ in.

The uniform $1100{ }^{\circ} \mathrm{C}$ gas temperature and the ASTM E 119 temperature curve were selected as bounding conditions for the floor beam when subjected to the fires in WTC 7 (i.e., typical floor fires). Thus, the 
actual rate of heating of the W24x55 floor beam in a composite floor would be expected to fall between the times shown in the figures.

When the steel beam reached $600{ }^{\circ} \mathrm{C}$ under the ASTM E 119 temperature curve, the additional protection provided by increasing the SFRM thickness to $0.625 \mathrm{in.} \mathrm{(5/8} \mathrm{in.)} \mathrm{or} 0.75 \mathrm{in.}(3 / 4 \mathrm{in}$.) was approximately $8 \mathrm{~min}$ to $15 \mathrm{~min}$, as shown in Figure 11-50. The ASTM E 119 tests for floors and roofs allow the temperature criteria to apply for one half of the classification of the assembly or $1 \mathrm{~h}$, whichever is greater. For instance, for a $2 \mathrm{~h}$ fire rating for a floor assembly, the floor beams cannot exceed the temperature criteria of $1300^{\circ} \mathrm{F}\left(704^{\circ} \mathrm{C}\right)$ at any one location or $1100^{\circ} \mathrm{F}\left(593^{\circ} \mathrm{C}\right)$ for the average temperature at a cross section for $1 \mathrm{~h}$.

When the steel beam reached $600{ }^{\circ} \mathrm{C}$ under the uniform $1100{ }^{\circ} \mathrm{C}$ gas temperature, the additional protection provided by increasing the SFRM thickness to 0.625 in. (5/8 in.) or 0.75 in. ( $3 / 4$ in.) was approximately $10 \mathrm{~min}$ to $20 \mathrm{~min}$, as shown in Figure 11-51.

Comparing Figure $11-51^{*}$ to Figure 4-7, it can be seen that the temperature rise in the lower flange and web is similar. Figure 4-7 shows the temperature of a W24x55 floor beam with 0.5 in. of SFRM in a composite floor assembly for a constant $1100{ }^{\circ} \mathrm{C}$ gas temperature below the concrete slab. Figure 11-51* shows the temperature of a W24x55 beam (no concrete slab) with 0.53 in. of SFRM for a constant $1100{ }^{\circ} \mathrm{C}$ gas temperature. The beam without a slab analysis was conducted to evaluate the effect of SFRM thickness on steel temperature for a floor beam. The lower flange and web in Figure 4-7 and the beam in Figure $11-51^{*}$ both reached $600{ }^{\circ} \mathrm{C}$ in 25 to 30 min.

Thus, an increase in the SFRM thickness on the floor beams would have delayed heating of the floor beams by $10 \mathrm{~min}$ to $20 \mathrm{~min}$, but would not ${ }^{*}$ have altered the outcome.

Figure 11-50.

Heating of a typical floor beam (W24 x 55) subject to an ASTM E 119 temperature profile for different SFRM thicknesses.

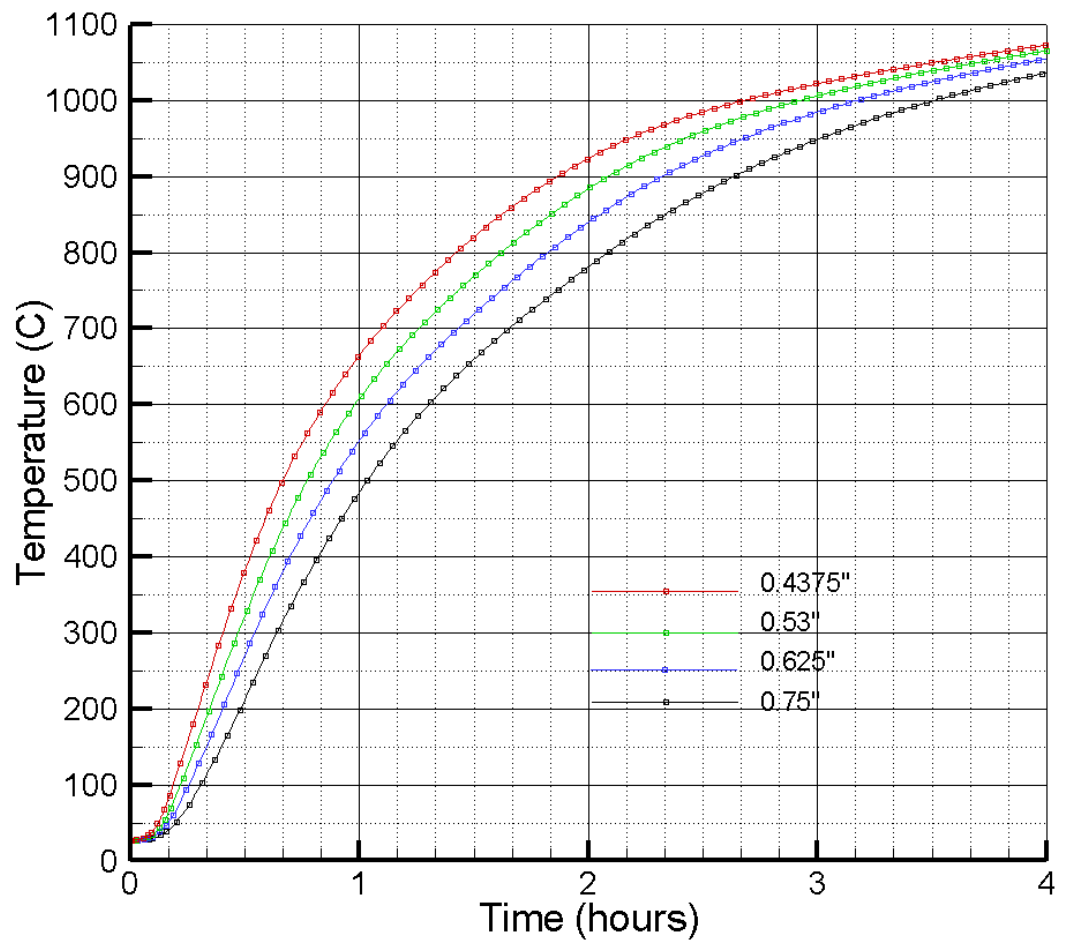

* Corrected text January 2009. Changes were made to this page only. Similar statements are correct in the original text for Chapter 11 Summary and in the findings and recommendations in NIST NCSTAR 1A. 


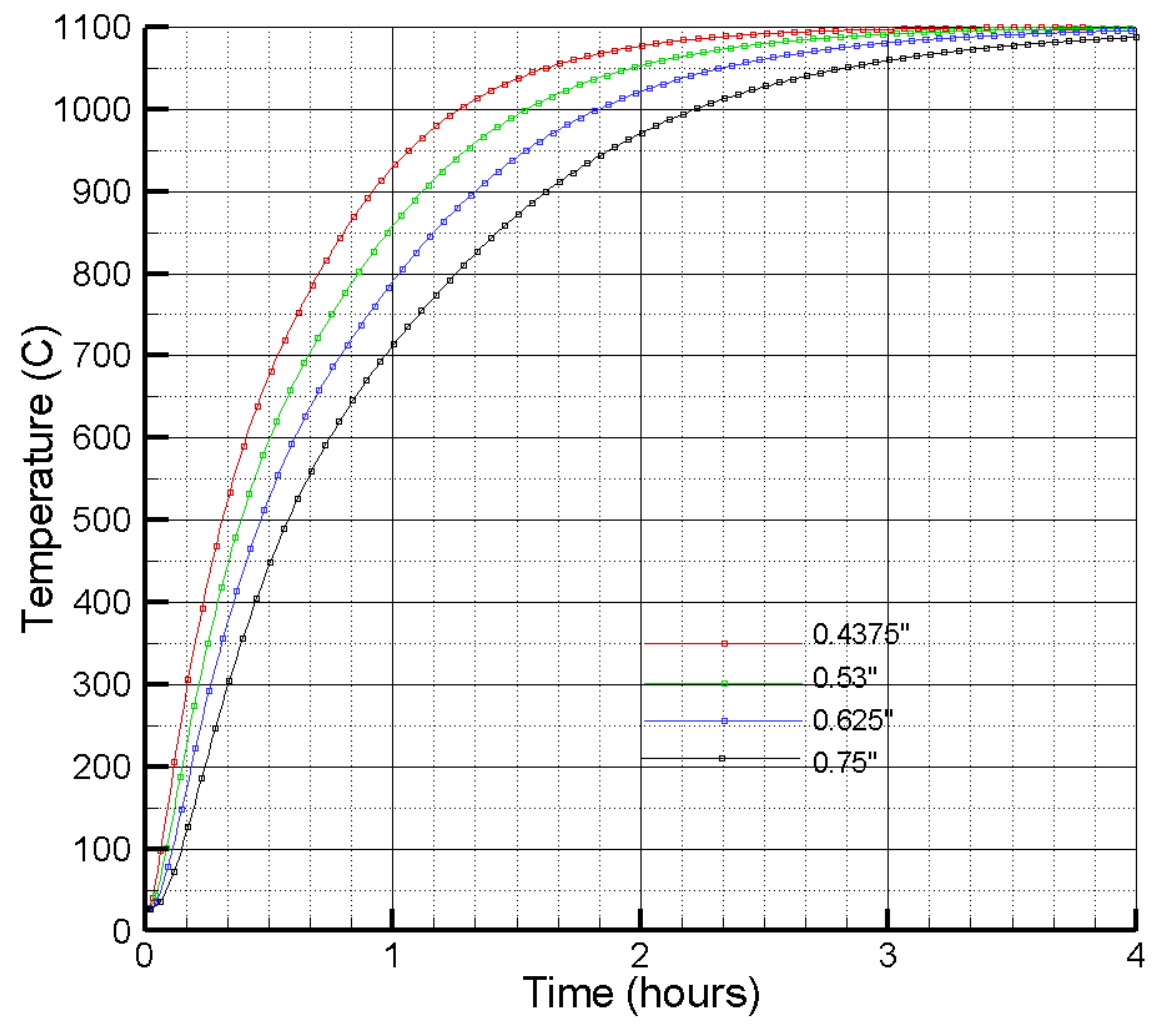

Figure 11-51. Heating of a typical floor beam (W24 x 55) subject to a uniform $1100{ }^{\circ} \mathrm{C}$ gas temperature for different SFRM thicknesses.

\subsubsection{Discussion of Results for Case C Temperatures}

As the Case B and Case C analyses progressed, essentially the same sequence of damage and failures occurred, but they were shifted in time (i.e., Case $\mathrm{C}$ failures occurred at a later time than Case B failures) as a consequence of the difference between the Case $\mathrm{B}$ and Case $\mathrm{C}$ temperatures. However, even though the temperatures were lower in Case $\mathrm{C}$ relative to Case $\mathrm{B}$, there was still a substantial amount of heating taking place on Floors 11, 12, 13, and 14.

The same type of failures in the connections, beams and girders occurred on each floor in Case C, with the timing (and hence, extent) of damage falling somewhere between the damage that occurred between $3.5 \mathrm{~h}$ and $4.0 \mathrm{~h}$ for Case B. Similar to the Case B results, the Case $\mathrm{C}$ results at $4.0 \mathrm{~h}$ had considerably more damage in the beams, girders, and portions of floor slabs at Floors 8, 11, 12, 13, and 14 than at $3.5 \mathrm{~h}$.

The time lag in damage was not uniform over Floors 8 to 14. The damage in Floors 8, 9, and 10 was closer to the Case B damage at 3.5 h, but the damage for Case C on Floors 11, 12, 13, and 14 was closer to the Case B damage at $4.0 \mathrm{~h}$.

The comparison of Case B and Case C results at $4 \mathrm{~h}$ (Section 11.3.3) showed that the Case $\mathrm{C}$ structural response would be nearly identical to the Case B structural response at a time between $4.0 \mathrm{~h}$ and $4.5 \mathrm{~h}$. Thus, the temperature differences between Case B and C were not sufficient to produce different failure patterns, and both cases provided the same damage (i.e. location and degree) to the floors with a time lag between the two solutions. 
As a result, it was not necessary to input more than one solution to the global analysis of the collapse. The fire-induced damage produced by Case B temperatures at $4.0 \mathrm{~h}$ was carried forward as the initial condition for the LS-DYNA analysis (Chapter 12).

\subsection{TRANSFER OF ANSYS RESULTS TO THE LS-DYNA ANALYSIS}

The fire-induced floor damage was input to the LS-DYNA model to determine if the predicted floor failures would lead to an initiating collapse event, followed by a failure progression to global collapse.

When the ANSYS analysis had reached a point where buckling instability of columns appeared imminent, the accumulated damage due to thermally-induced failures of floor framing was summarized as input for the LS-DYNA model. The transferred data also included the temperature of structural components at that time and buckled beams and girders.

The damage state of the connections was indicated by a numerical value ranging between 0.0 for no damage and 1.0 for full damage (i.e., there was no remaining strength). The damage state of each connection type was defined as shown in Table 11-7:

Table 11-7. Connection damage level estimate for data transfer to the LS-DYNA model.

\begin{tabular}{|c|c|c|}
\hline Support Direction & $\begin{array}{c}\text { Damage Level } \\
\text { (0: no damage, } 1: \text { full damage) }\end{array}$ & Conditions \\
\hline \multicolumn{3}{|l|}{ Fin and Knife Connections } \\
\hline Horizontal Damage & (\# of Failed Bolts)/(Total \# of Bolts) & \\
\hline Vertical Damage & (\# of Failed Bolts)/(Total \# of Bolts) & \\
\hline \multicolumn{3}{|l|}{ Header Connections } \\
\hline \multirow[t]{2}{*}{ Horizontal Damage } & 1.0 & if there was weld failure \\
\hline & (\# of Failed Bolts)/(Total \# of Bolts) & if there was no weld failure \\
\hline \multirow[t]{2}{*}{ Vertical Damage } & 1.0 & if there was weld failure \\
\hline & (\# of Failed Bolts)/(Total \# of Bolts) & if there was no weld failure \\
\hline \multicolumn{3}{|l|}{$\begin{array}{l}\text { SWC Connections } \\
\text { (SWC connections always } \\
\text { have } 2 \text { welds and } 4 \text { bolts) }\end{array}$} \\
\hline Horizontal Damage & $\begin{array}{l}\max \{(\# \text { of Failed Bolts }) /(4), \text { (\# of Weld } \\
\text { Failures }) /(2)\}\end{array}$ & \\
\hline Vertical Damage & (\# of Weld Failures)/(2) & \\
\hline \multicolumn{3}{|l|}{ STC and STP Connections } \\
\hline \multirow[t]{2}{*}{ Horizontal Damage } & 1.0 & if there was walk off \\
\hline & (\# of Failed Bolts)/(Total \# of Bolts) & if there was no walk off \\
\hline \multirow[t]{2}{*}{ Vertical Damage } & 1.0 & if there was walk off \\
\hline & 0 & if there was no walk off \\
\hline
\end{tabular}




\subsection{SUMMARY OF FINDINGS}

A finite element model of WTC 7 was developed in ANSYS to evaluate the building structural response to the fire environment and to determine the sequence of events that led to an initial failure event (or collapse initiation event). The ANSYS model consisted of the lower 16 stories of the building. The ANSYS model included nonlinear effects, such as: nonlinear temperature-dependent material properties including thermal expansion, plasticity and creep; nonlinear geometry; and user-defined elements that captured the details of temperature dependent connection failures. The following findings are based on the ANSYS finite-element analysis of the structural response of WTC 7 to the fires observed between Floors 7 to 14:

- The failures in the floor systems were caused by the following structural responses to elevated temperatures:

o At temperatures less than approximately $400^{\circ} \mathrm{C}$, restrained thermal expansion of beams and girders caused axial compressive forces to develop in the beams and girders, which led to the following connection failures:

- bolt shear failure in fin, knife, and seated connections,

- girder walk off of seated connections after all the bolts had sheared at Columns 79 and 81 , and

- failure of header connection welds.

o The failure of the girder-to-column seated connection at Columns 79 and 81 occurred in two stages: (1) horizontal loss of support occurred when the bolts at the seated connection were sheared, primarily due to thermal expansion of the floor beams in the east floor system, and (2) further thermal expansion of the floor beams pushed the girder off the bearing seat.

o Many floor beams on Floors 12, 13, and 14 in the east floor region had buckled prior to beam temperatures reaching $400{ }^{\circ} \mathrm{C}$ (averaged over the beam length). Floor beams buckled under the combined effects of

- loss of lateral restraint due to failure of the majority of shear studs,

- increased axial loads due to thermal expansion that was restrained by the exterior and interior structural frame, and

- gravity loads from the floor slab.

o The girders that framed into interior columns on Floor 12, 13, and 14 failed by either

- buckling due to the combined effects of gravity loads from the floor beams, lateral displacement due to the thermal expansion in the floor beams, and increasing axial loads due to thermal expansion in the girder, or 
- loss of vertical support due to girder walk off the bearing seat, or due to thermallyinduced failure of a connection.

o Loss of lateral support to Columns 79, 80, and 81 resulted from the failures of the girders to the north, west, and south, and the floor beams to the east, where

- girders between Columns 79 and 80 and Columns 80 and 81 buckled on Floor 13, due to the combined effects of thermal expansion and the lateral displacement caused by the thermal expansion in the east floor beams,

- girders west of Column 79 failed due to tensile weld failures in the knife connections on Floors 10, 11, and 12 from restrained thermal expansion on other floors,

- girder west of Column 80 failed due to weld failures in the header connections on Floor 14,

- girders between Columns 44 and 79 and Column 26 and 81 failed due to girder walk off of the bearing seat,

- The buckling failure of the east floor beams and exterior columns was caused by restrained thermal expansion and failure of the shear studs along the beam length.

o Restrained thermal expansion of slabs, particularly in locations where fires were directly heating the slab, resulted in a compressive failure of the concrete slab (crushing) and reduced slab stiffness.

- The simple shear connections used in the typical floor framing were not able to resist the axial compressive forces that developed in the floor framing due to thermal expansion effects that were restrained by the structural system.

- The failure of the girder-to-column seated connection at Columns 79 and 81 was primarily caused by thermal expansion of the long span floor beams in the east tenant floor.

- Additional factors that contributed to the girder failures were the absence of shear studs that would have provided lateral restraint and the one-sided framing of the east floor beams, which pushed laterally on the girders.

- Columns 79, 80, and 81 were not thermally weakened by elevated temperatures since temperatures in the columns rarely exceeded $300^{\circ} \mathrm{C}$.

- An increase in the SFRM thickness on the floor beams, from 0.53 in. to 0.625 in. or 0.75 in., would have delayed heating of the floor beams by $10 \mathrm{~min}$ to $20 \mathrm{~min}$, which was unlikely to have prevented the heating, thermal expansion, and damage of the floor system that led to collapse initiation.

- The temperature differences between Case B and C were not sufficient to produce different failure patterns, and both cases resulted in similar damage (i.e., location and degree) to the floors with a time lag between the two solutions. 


\subsection{REFERENCES}

AISC. 2005. American Institute of Steel Construction Inc., Manual of Steel Construction, Thirteenth Edition, Chicago, IL.

ANSYS. 2007. ANSYS Mechanical Release 11.0, ANSYS Inc., Southpointe, 275 Technology Drive, Canonsburg, PA 15317

Rambo-Roddenberry, M. D. 2002. Behavior and Strength of Welded Stud Shear Connectors, Dissertation submitted to the faculty of the Virginia Polytechnic Institute and State University, April 8, 2002.

SDI. 2007. Arc-puddle Welds and Weld Washers for Attachments in Steel Deck, Steel Deck Institute, Fox River Grove, IL, January 17, 2007.

The University of Edinburgh. 2000. Behavior of Steel Framed Structures Under Fire Conditions, Main Report, PIT Project, School of Civil \& Environmental Engineering, June 2000.

Yu, Liang. 2006. Behavior of Bolted Connections During and After a Fire, Dissertation Submitted to the Faculty of the University of Texas at Austin, August 2006. 


\section{Chapter 12 \\ WTC GLobal ColLapse ANALYsis}

\subsection{OVERVIEW}

This chapter presents the description and analysis results of the global model, which was developed to determine the collapse sequence of the World Trade Center (WTC) 7 building and to test the leading collapse hypothesis presented in Chapter 8 . The response of the full 47 story structure to initial failure events due to fire was analyzed to determine the events that led to the global collapse of WTC 7.

The nonlinear dynamic collapse analyses were performed using LS-DYNA, which was capable of explicitly modeling sequential failures, falling debris, and debris impact on other structural components. LS-DYNA was well suited for this type of analysis, since it can model dynamic failure processes, including nonlinear material properties, nonlinear geometry, material failures, contact between collapsing structural components, and element erosion based on a defined failure criterion. In addition, LS-DYNA has capabilities to include thermal softening of materials and thermal expansion.

The global LS-DYNA model had the following input data:

- Extent of initial damage to the building due to debris impact from the collapse of WTC 1 (Chapter 5).

- Mechanical properties of steel (Appendix E and NIST NCSTAR 1-3D) and concrete (NCSTAR NIST 1-6A) used in the construction of WTC 7.

- $\quad$ Temperature-dependent mechanical properties of steel (Appendix E and NIST NCSTAR 13D).

- Temperatures of structural components and connections, at the time when the ANSYS results were transferred to the LS-DYNA analysis (Chapter 10).

- Fire-induced damage to floor beams, girders, and their connections from the 16 story ANSYS analysis (Chapter 11).

The floor framing geometry, component sizes, connection details, and gravity loads were obtained from structural and architectural drawings, as well as erection and fabrication shop drawings of connections for the steel framing (Chapter 2). The global LS-DYNA model analyzed the effects of gravity and temperature loads. Gravity loads included: the dead load of the structure; superimposed dead loads consisting of the weight of ceilings, mechanical and electrical equipment, thermal insulation, and floor finishes; and service live load, which was taken as 25 percent of the design live load specified in the original design documents.

Four simulations were performed with the global LS-DYNA model. 
- The first was based on the best estimate of both the debris impact damage from the collapse of WTC 1 and the fire-induced damage based on the ANSYS analyses (Case B at $4 \mathrm{~h}$ ).

- The second simulation differed only in the input of an earlier state of fire-induced damage with Case B at $3.5 \mathrm{~h}$. The purpose of this LS-DYNA simulation was to determine whether a lesser degree of fire-induced damage could lead to the collapse of WTC 7.

- The third simulation was the same as the first, except that no debris impact damage was included. The purpose of this analysis was to determine the contribution of debris impact to the WTC 7 global collapse sequence and whether WTC 7 would have collapsed solely due to the effects of the fires.

- In the fourth simulation, the building experienced no debris or fire-induced damage. A section of Column 79 between Floors 11 and 13 was removed. The purpose of this analysis was to determine the potential for a classic progressive collapse, i.e., disproportionate structural damage from a single failure, regardless of the cause of that failure.

Section 12.2 provides a description of the global 47 story model, including material constitutive models, floor framing, truss and column transfers, penthouse structures on the roof, and modeling of floor system connections. Section 12.3 describes the model boundary conditions and loading sequence applied during the execution of the model. Section 12.4 presents the three simulations and their outcomes. Section 12.5 compares the simulation outcomes with the photographic and videographic observations and the calculated time of descent of WTC 7 with an estimate of the hypothetical free fall time.

\subsection{GLOBAL LS-DYNA 47 STORY MODEL}

\subsubsection{Material Constitutive models}

The structural materials in the WTC 7 global model were the steels used in the framing of WTC 7 and the concrete floor slabs. Brief descriptions of the constitutive models for the steels and concrete slabs are provided (see Chapter 2 of NIST NCSTAR 1-9A for further details).

\section{Structural Steel Constitutive Models}

The primary constitutive model used for modeling the steel in the framing of WTC 7 was the Piecewise Linear Plasticity model (material type 24 in LS-DYNA). This model captured the nonlinear behavior and failure of steel, with an effective stress versus effective strain curve and a pre-defined strain to failure to simulate fracture.

The constitutive models for the WTC 7 steels were based on those developed for the WTC tower steels. (Appendix E and NIST NCSTAR 1-3D). The steels used to construct WTC 7 were ASTM A36 (nominal yield strength Fy $=36 \mathrm{ksi})$, A572 grade $50(\mathrm{Fy}=50 \mathrm{ksi}$ ), and steel plates produced by Algoma (CSA $\mathrm{G} 40.21-44 \mathrm{~W}, \mathrm{Fy}=44 \mathrm{ksi}$ ) for the fabrication of all shear connections in the floor framing. The Algoma steel had not been used in the WTC towers, and a stress-strain curve was developed for the analysis of WTC 7. The true stress-strain curves for these grades of steel at room temperature are shown in Figure $12-1$. 


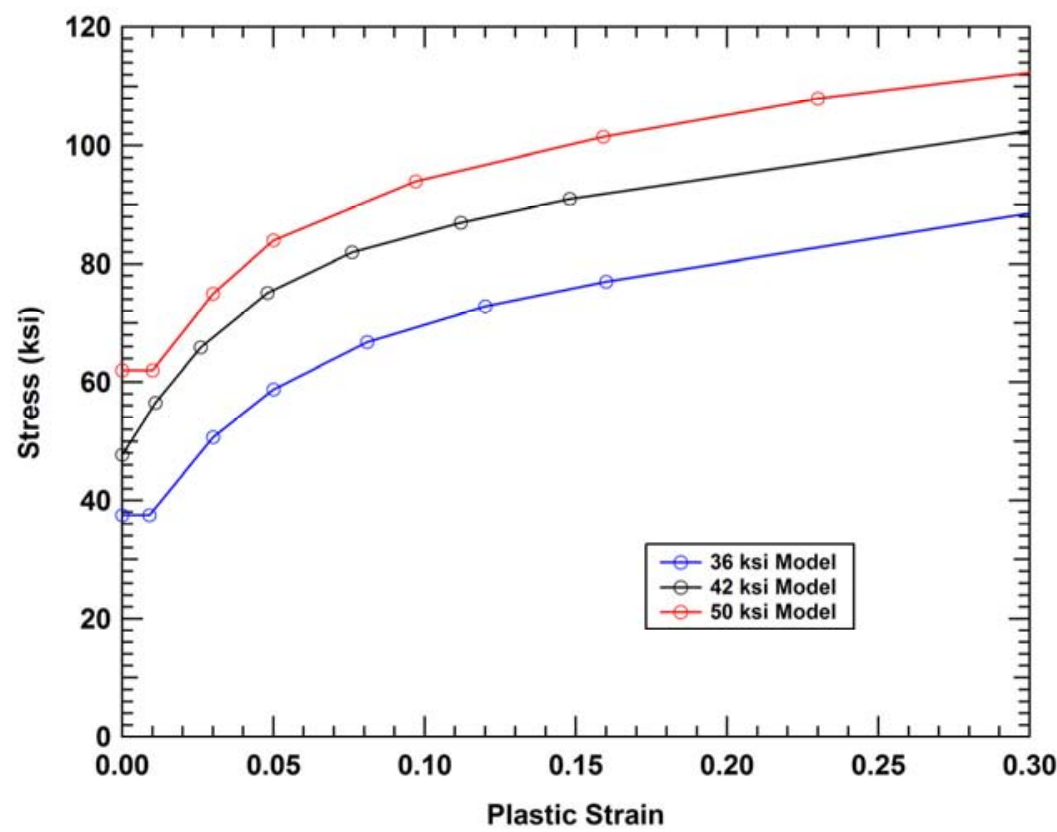

Figure 12-1. Tabular true stress-true strain constitutive model curves for WTC 7 steels.

For the regions of WTC 7 subjected to heating by fires (between Floors 7 and 14), temperature-dependent material models were used for the framing. The material model used for the steel in the fire-affected floors was the Elastic-Viscoplastic Thermal (Type 106) model in LS-DYNA, which included thermal expansion and thermal degradation in material stiffness and strength. This model used the same parameters to define the nonlinear material behavior of steel at room temperature as the Type 24 model, but included additional parameters to define temperature dependence. The yield strength, elastic modulus, Poisson's ratio, and thermal expansion coefficient were all specified as a function of temperature. The temperature-dependent models used the same failure criterion as that applied at room temperature. The temperature-dependent material properties and constitutive model parameters for the steels and bolts used in WTC 7 are presented in Appendix E. Example of the stress-strain curves for the 50 ksi steel at various temperatures is shown in Figure 12-2.

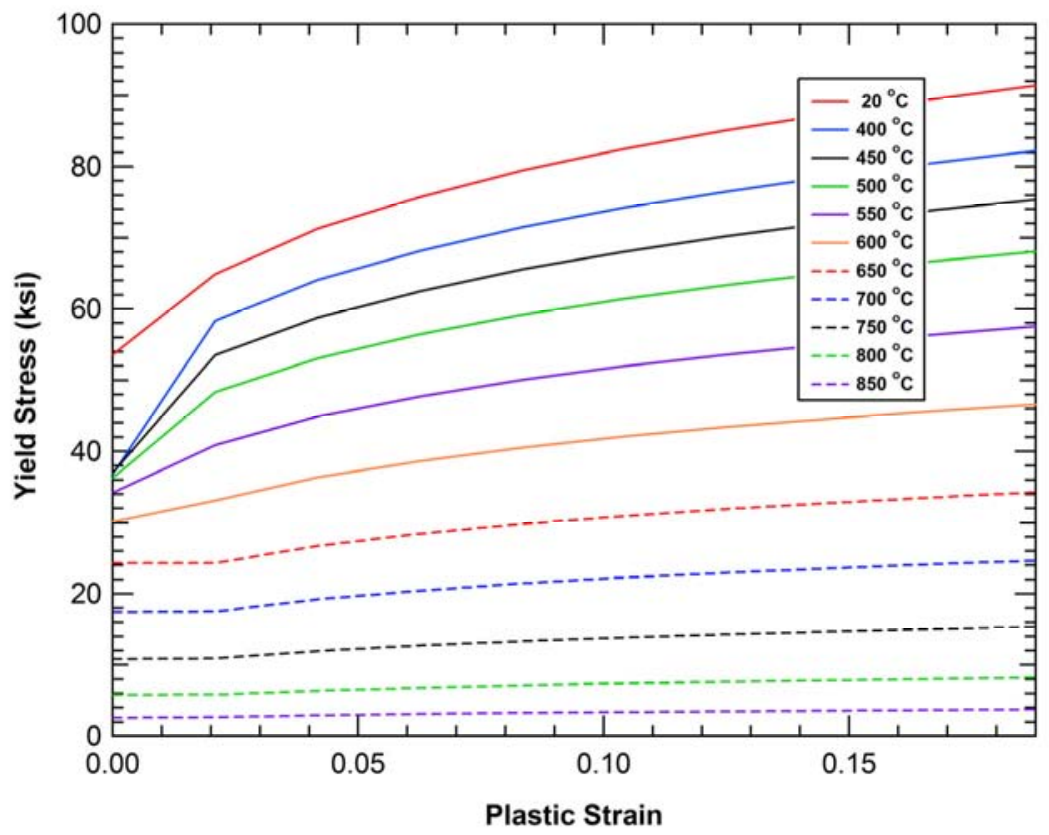

Figure 12-2. Temperaturedependent strength of the ASTM A572 Grade 50 structural steel as a function of temperature. 
The properties obtained for the Algoma steel were a yield nominal strength of $44 \mathrm{ksi}$ and an ultimate tensile strength of $75^{1} \mathrm{ksi}$ corresponding to a true strain of 16 percent. With this limited information, a bilinear constitutive model was generated that had a yield strength of $44 \mathrm{ksi}$ and a plastic hardening modulus of $194 \mathrm{ksi}$. The temperature-dependent material properties were developed with the same procedure used for the WTC towers (see Appendix E).

\section{Floor Slab Constitutive Model}

The floor slabs in WTC 7 consisted of a 3 in. corrugated metal deck topped with 2.5 in. of normal weight concrete, giving an average thickness of approximately 4 in. The slab had a specified (28 day) compressive strength of 3500 psi. The analysis used a compressive strength of 4900 psi to account for strength gain with age (see NIST NCSTAR 1-9A). Welded wire fabric was placed with a 3/4 in. cover to reinforce the slab. Cross sections of the typical floor slab construction details are shown in Figure 12-3 and Figure 12-4.

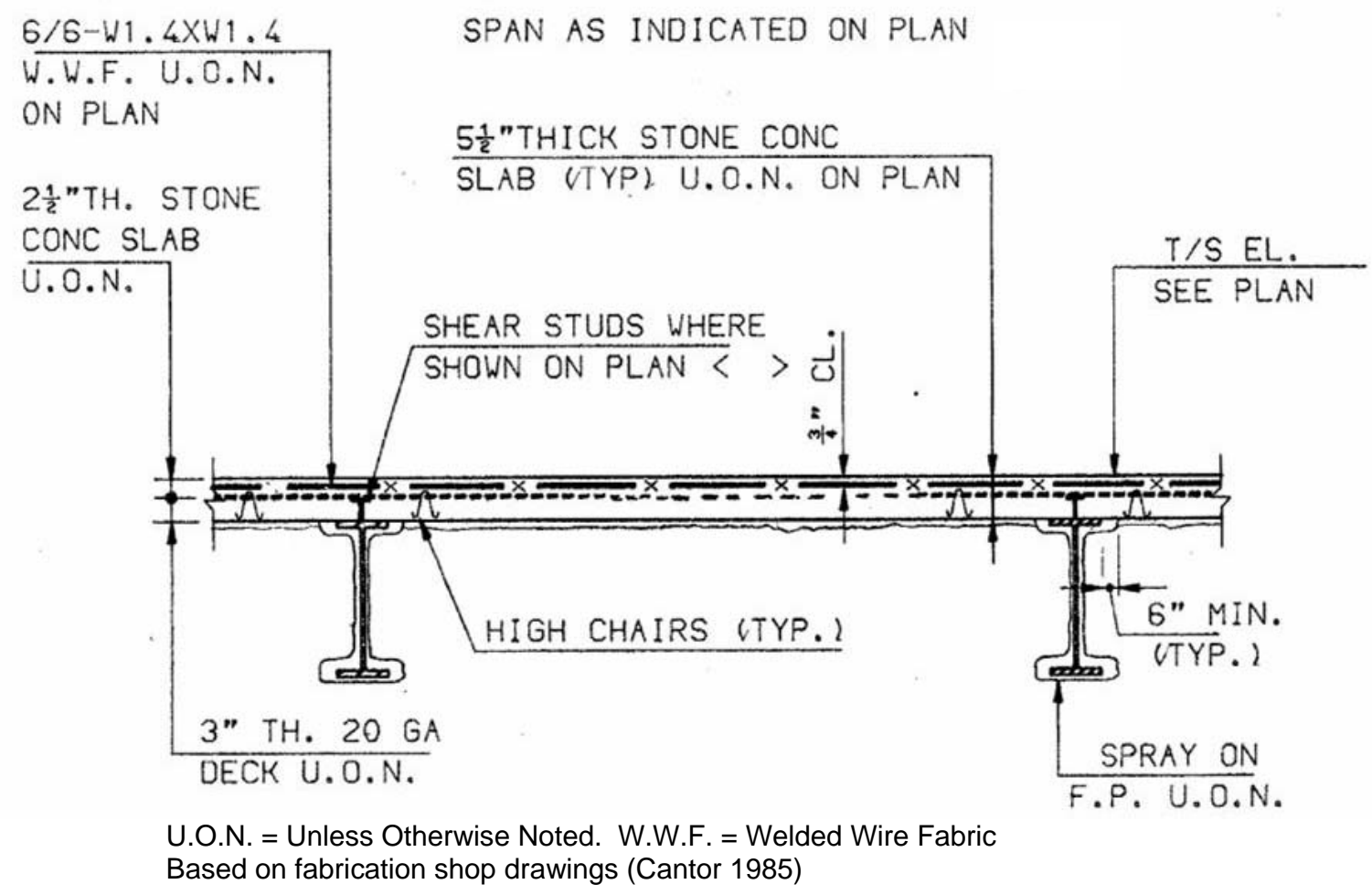

Figure 12-3. Typical composite floor construction detail (along strong direction).

\footnotetext{
${ }^{1}$ The ultimate tensile strength for the Algoma steel was estimated to be 70.6 ksi (see Appendix E), but 75 ksi was used in the LSDYNA analyses. However, the Algoma steel model was only applied to the seats of the seated connections. The other connection components used custom material models that were developed to capture the appropriate connection strengths.
} 


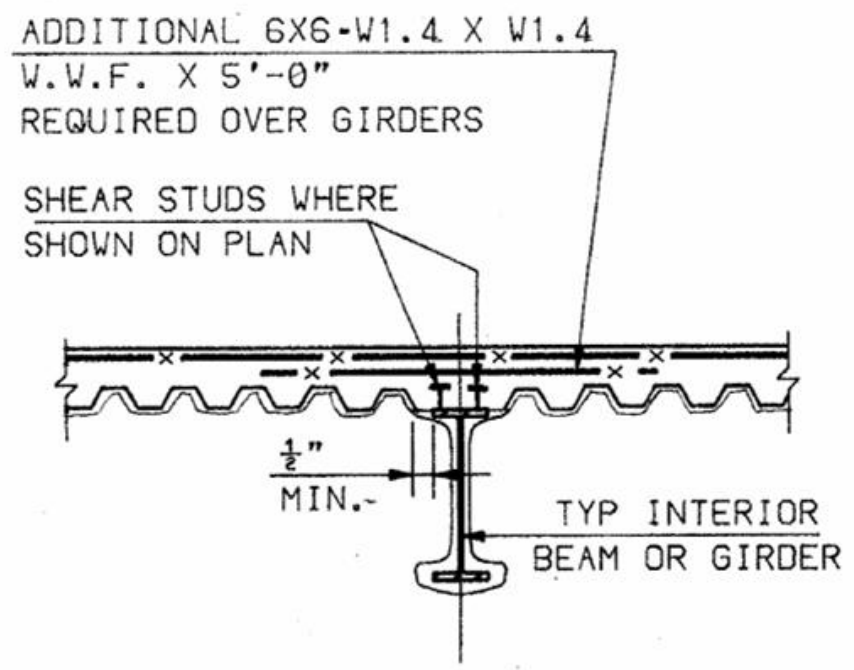

Based on fabrication shop drawings (Cantor 1985)

Figure 12-4. Typical composite floor construction detail (along weak direction).

The primary feature required in modeling the composite slab was the different slab behavior in tension and compression, as concrete cracks under tensile loads at relatively low stresses. By comparison, the tensile strength of the metal reinforcement was an order of magnitude higher than the concrete compressive strength and two orders of magnitude higher than the concrete tensile strength.

The composite slabs in the WTC 7 global model were modeled with shell elements. The constitutive model used in LS-DYNA for the composite floor slab was material type 124 (Mat_Plasticity_Compression_Tension). This material model allowed the specification of separate tabular plastic stress-strain curves in compression and tension. The separate tension and compression curves for the composite slab were obtained by using the rule of mixtures, which provided average properties of the composite slab based on the volume fraction of the concrete, metal deck, and reinforcement (Chapter 2, NIST NCSTAR 1-9A). The calculated tensile and compressive behaviors for the composite slab are shown in Figure 12-5.

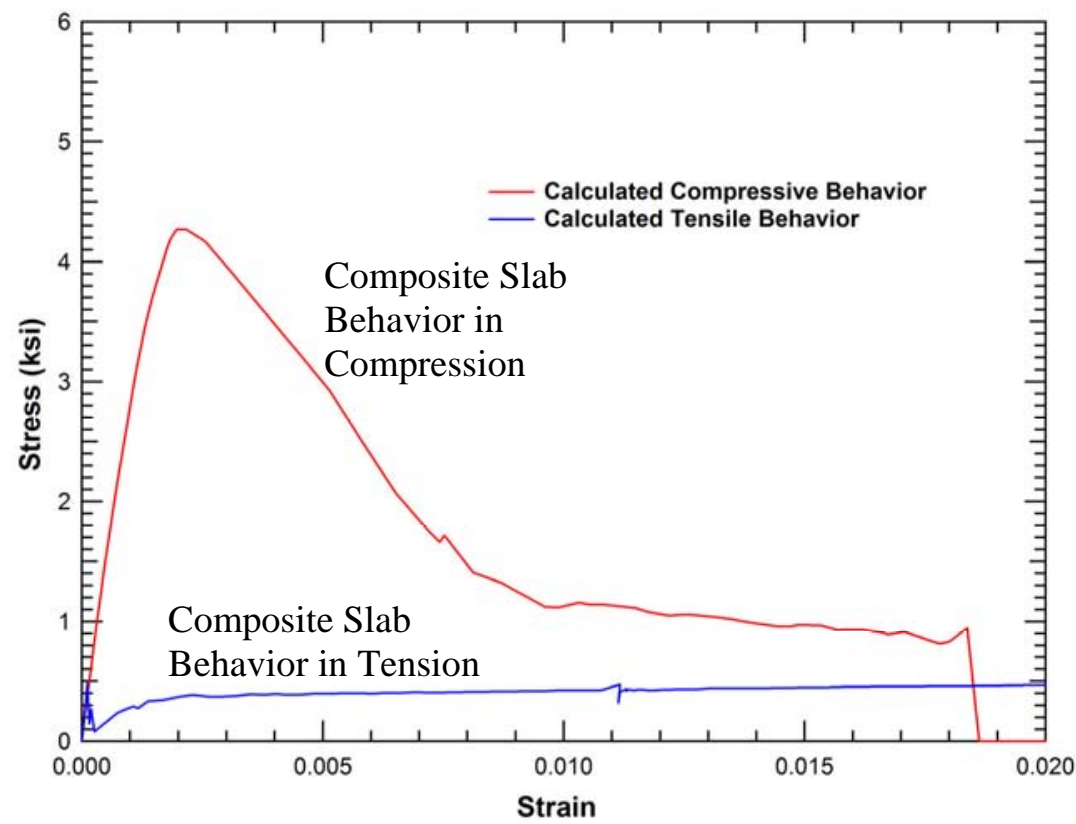

Figure 12-5. Calculated composite slab behaviors in tension and compression. 


\subsubsection{Global Model Description}

This section provides a brief description of the construction of the global 47 story model. Strategies for modeling the various connections in the building are explained in Section 12.2.3. Additional details of the global model development can be found in Chapter 3 of NIST NCSTAR 1-9A.

The WTC 7 global model was constructed mainly with shell elements, which were used to model the floor beams, girders, slabs, and columns. Typical shell element dimensions were between 6 in. and 12 in. Beam elements were used to model the diagonal bracing elements in the structural frame and the frame of the penthouse structures. Nonlinear discrete (spring) elements were used for the connection components (see Section 12.2.3). Solid (brick) elements were used for some of the foundation structures and for some rigid masses representing large equipment. A summary of the size of the global model of WTC 7 is presented in Table 12-1. Two views of the global model are shown in Figure 12-6 and Figure 12-7.

To model the damage and sequence of failures in WTC 7 following the initial failure event, failure models were used within the framework of the LS-DYNA finite element analyses. For the global collapse analyses of WTC 7, shell element sizes were 6 in. to 12 in. to maintain a model size of approximately 3 million elements (see Table 12-1). With this resolution, the gradients around a fracture could not be accurately resolved, and the damage criteria required adjustment to obtain the appropriate strength and ductility of the structures (see NIST NCSTAR 1-2B). Simulating the global response of WTC 7 required the same level of refinement throughout the model.

All simulations were run on a high speed Linux Beowulf compute cluster. The head node had two 64 bit AMD Opteron $2502.4 \mathrm{GHz}$ processors, $4 \mathrm{~GB}$ of RAM, and 1.5 terabytes of RAID 5 disk storage. Each compute node had two 64 bit AMD Opteron Dual-core $2852.6 \mathrm{GHz}$ processors. Six of the compute nodes had 8 GB of RAM and the remaining two nodes had 16 GB RAM.

The global simulation was first initialized under gravity loading over $4.5 \mathrm{~s}$ of simulation time. Then damage and temperature initialization states were applied over 4 additional seconds. Collapse propagation in the global model required approximately 16 additional seconds after initialization, for a total of about $25 \mathrm{~s}$ of simulated time, which generally took up to 8 weeks using 12 cores across three nodes. The analysis was performed using the double precision version of LS-DYNA for better computational accuracy.

Table 12-1. Summary of the size of the global 47 story model of WTC 7.

\begin{tabular}{|l|c|}
\hline & WTC 7 Tower Model \\
\hline Number of Nodes & $3,593,049$ \\
\hline Hughes-Liu Beam Elements & 3,190 \\
\hline Belytschko-Tsay Shell Elements & $3,006,910$ \\
\hline Constant Stress Solid Elements & 2,461 \\
\hline Nonlinear Discrete Elements & 33,364 \\
\hline Total Number of Elements & $3,045,925$ \\
\hline
\end{tabular}




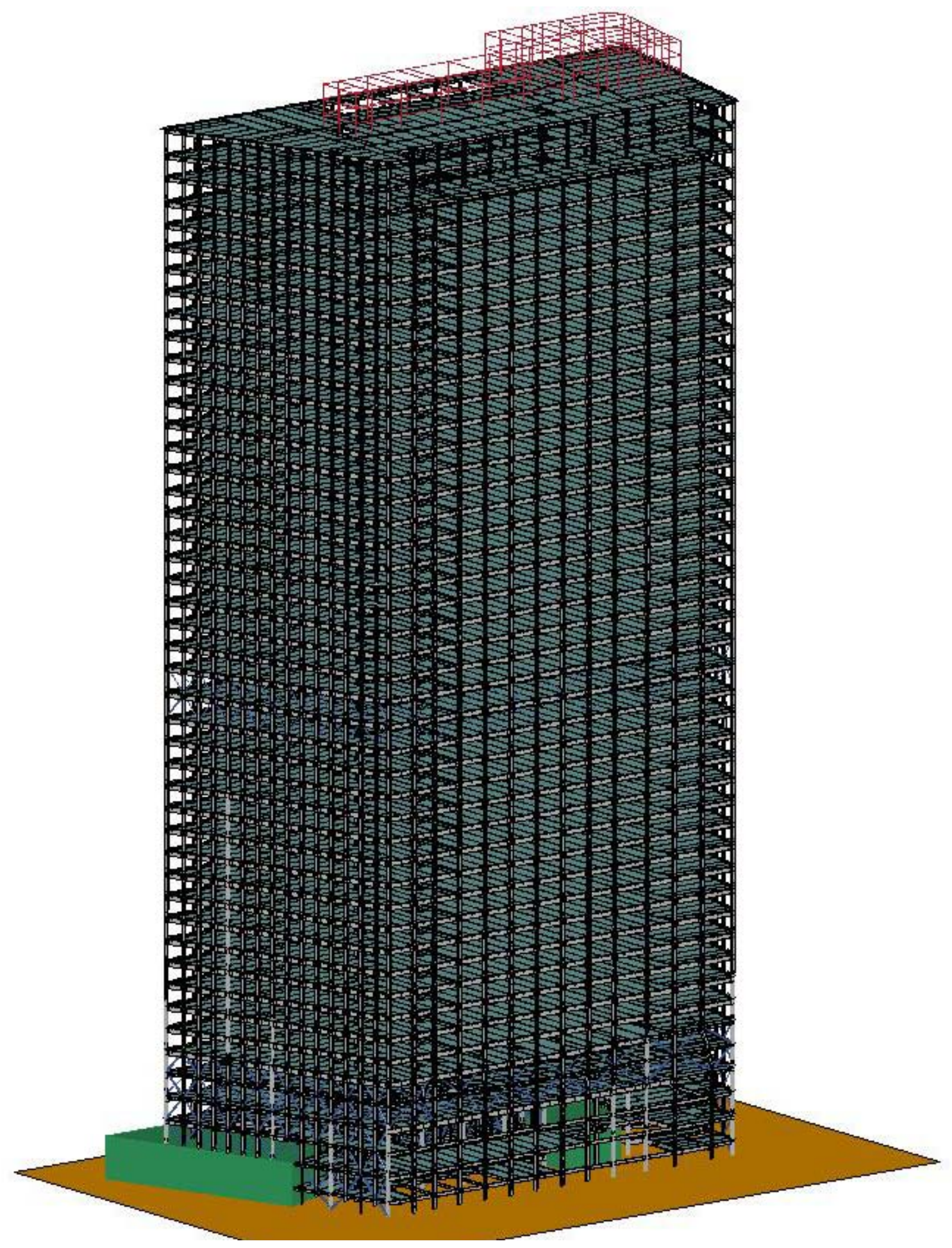

Figure 12-6. Global model of WTC 7, viewed from the southwest. 


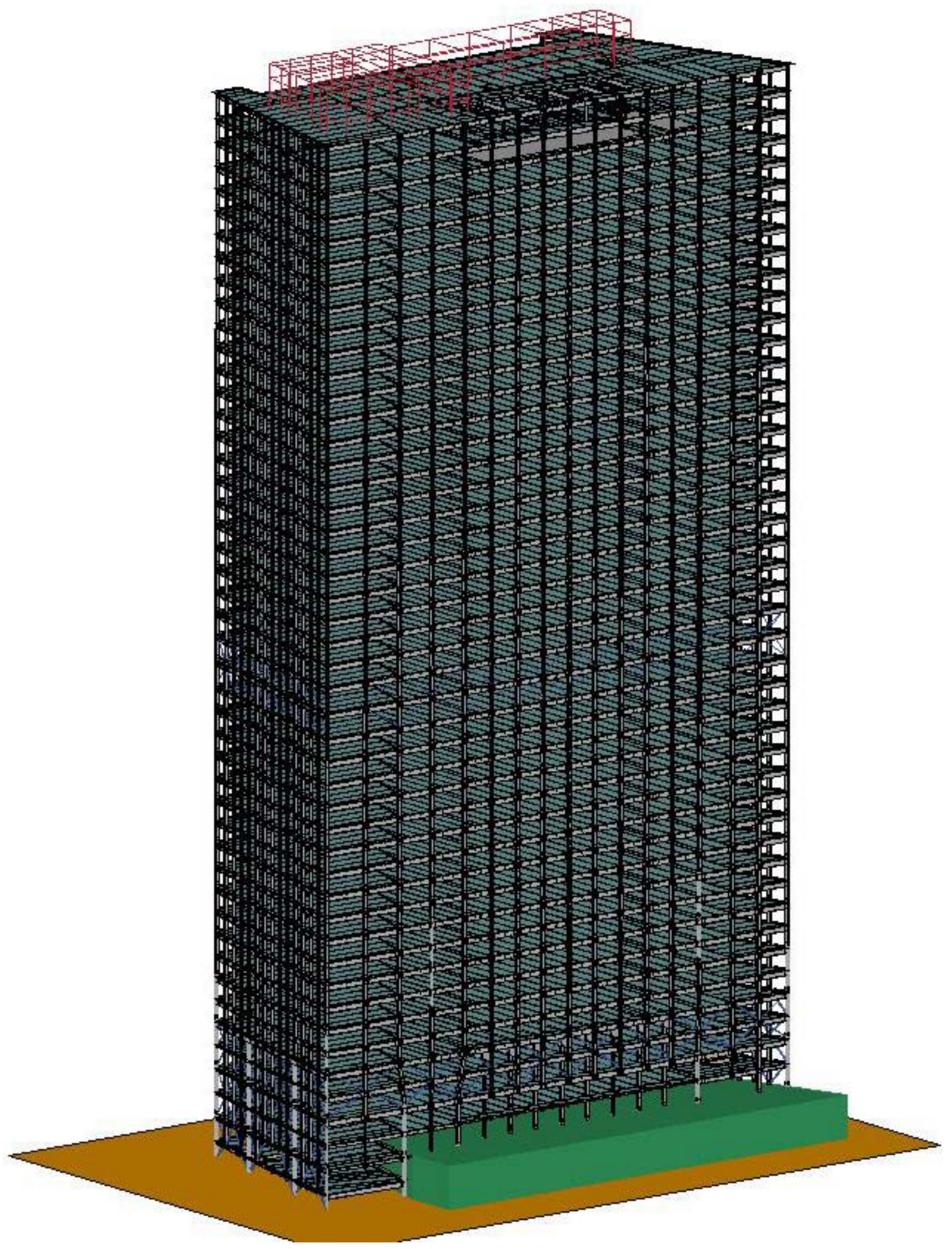

Figure 12-7. Global model of WTC 7, viewed from the northeast. 
The global model was constructed in accordance with the structural drawings. All floor beams, girders, and columns were included except for a few non-critical, small beams in the core. Figure 12-8 shows a view of the model of a typical tenant floor (Floors 8 to 20 and 24 to 45).

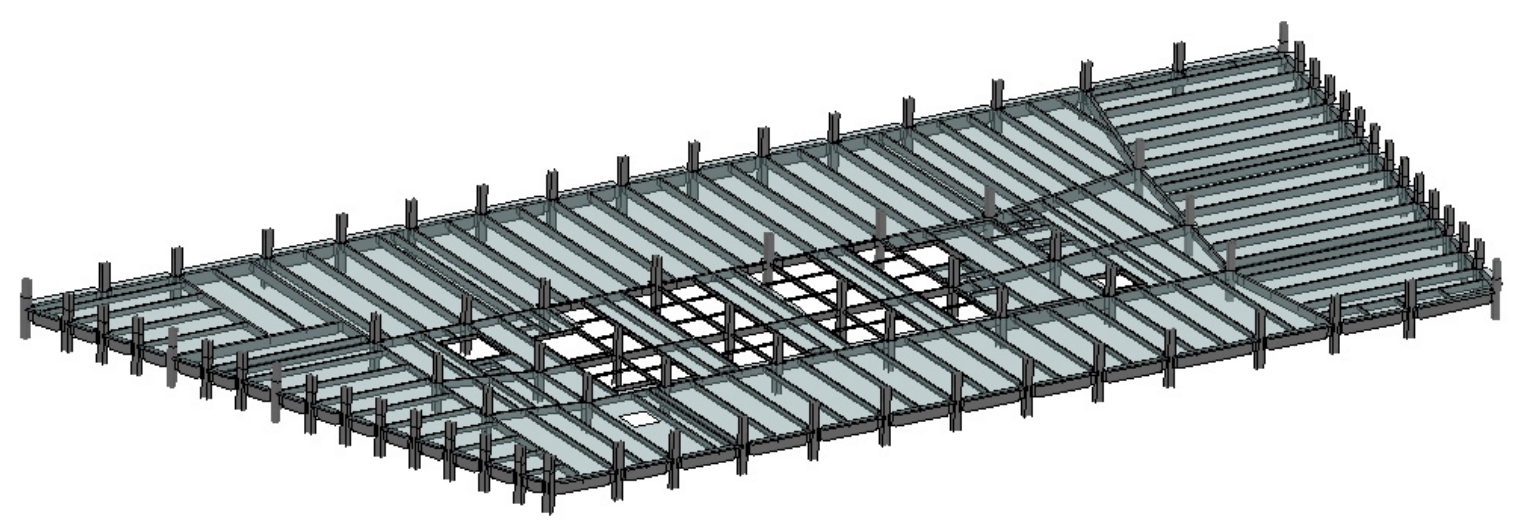

Figure 12-8. Typical tenant floor structural framing and slab model (Floors 8 to 20, 24 to 45).

As described in Chapter 2, the structure of WTC 7 between Floors 5 and 7 included a number of transitions in the column layout due to the presence of the Con Edison substation. As a result, there were a number of load transfer mechanisms in these floors that needed to be considered in the global model. The global model also accounted for variations from the typical tenant floors. For example, Floors 21 to 23 had similar floor layouts to the typical tenant floors, except for several framing members that were slightly larger to support computer equipment. Also, Floor 46 had heavier framing to support the cooling towers on the north region of the floor (see Figure 2-13 of Chapter 2), while Floor 47 had a double height space extending from the $46^{\text {th }}$ floor to the underside of the roof for the cooling towers on the north side (see Figure 2-14 of Chapter 2).

Figure 12-9 shows Floor 5, which had a heavily reinforced 15 in. concrete slab and acted as a diaphragm. The slab reinforcement, which were WTs, was approximated in the LS-DYNA model with beam elements. Unlike the actual construction, the beam elements in the model were not embedded in the slab since shear studs were not used between the WTs and the floor slab. The major horizontal truss elements that were part of the diaphragm framing layout were included in the model, as shown in Figure 12-10.

The column models were generated in two-story lengths, as in the actual building construction, and connected with models of the splice plates. 


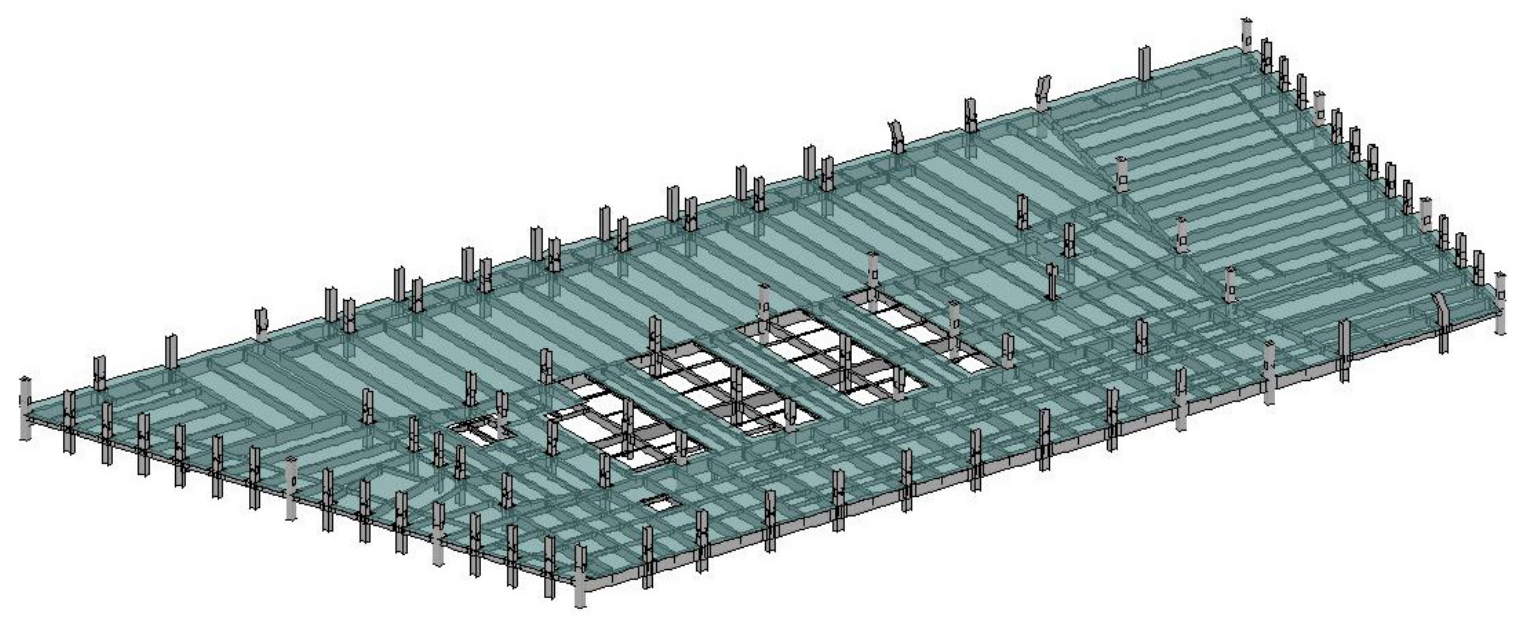

Figure 12-9. Floor 5 structural framing and slab model.

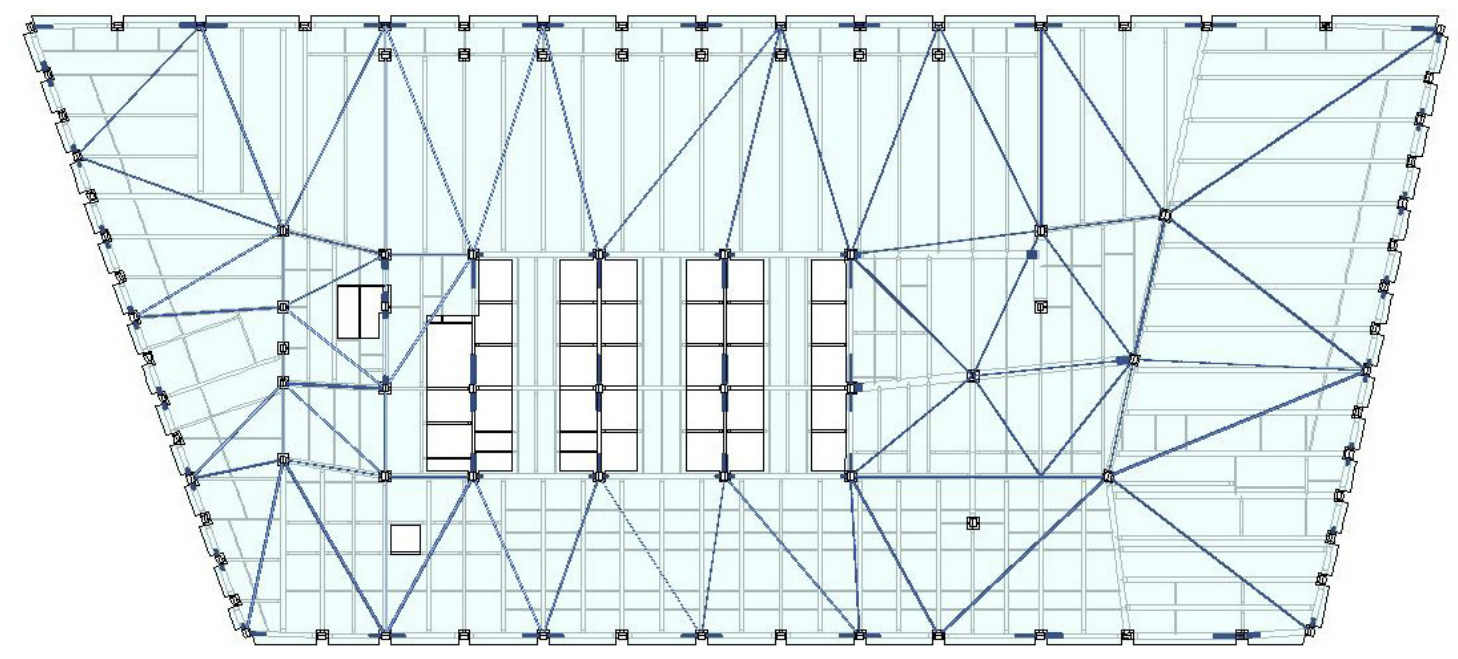

Figure 12-10. Model of the $5^{\text {th }}$ floor diaphragm framing plan.

\section{Column Transfer Structures}

There were a number of column transfer structures between Floors 5 and 7. All of them were included in the LS-DYNA model, but only Truss 1 and Truss 2 are described here due to their proximity to the global collapse initiation mechanism. See Chapter 3 of NIST NCSTAR 1-9A for the description of all of the transfer structures.

Truss 1 is shown in Figure 12-11. The truss supported Column 76 and transferred its loads to Column 73 to the west and to Columns E3 and E4 to the east. Columns E3 and E4 both extended from Floor 7 to the foundation. Moment connections were used to connect the east-west beam at Floor 5 to Column 73 and girder MG-53. ${ }^{2}$

\footnotetext{
${ }^{2}$ Built-up girders were referred to in the design drawings as MG.
} 
Truss 2 is shown in Figure 12-12. Truss 2 supported Column 77 and transferred its loads to Columns 74 and 80. Girder MG-23 supported Column 78 and transferred its loads to Columns 77 and 78A. Column 78A extended from Floor 7 to the foundation. Moment connections were used in the Floor 5 girder framing between Columns 74 and 80 .

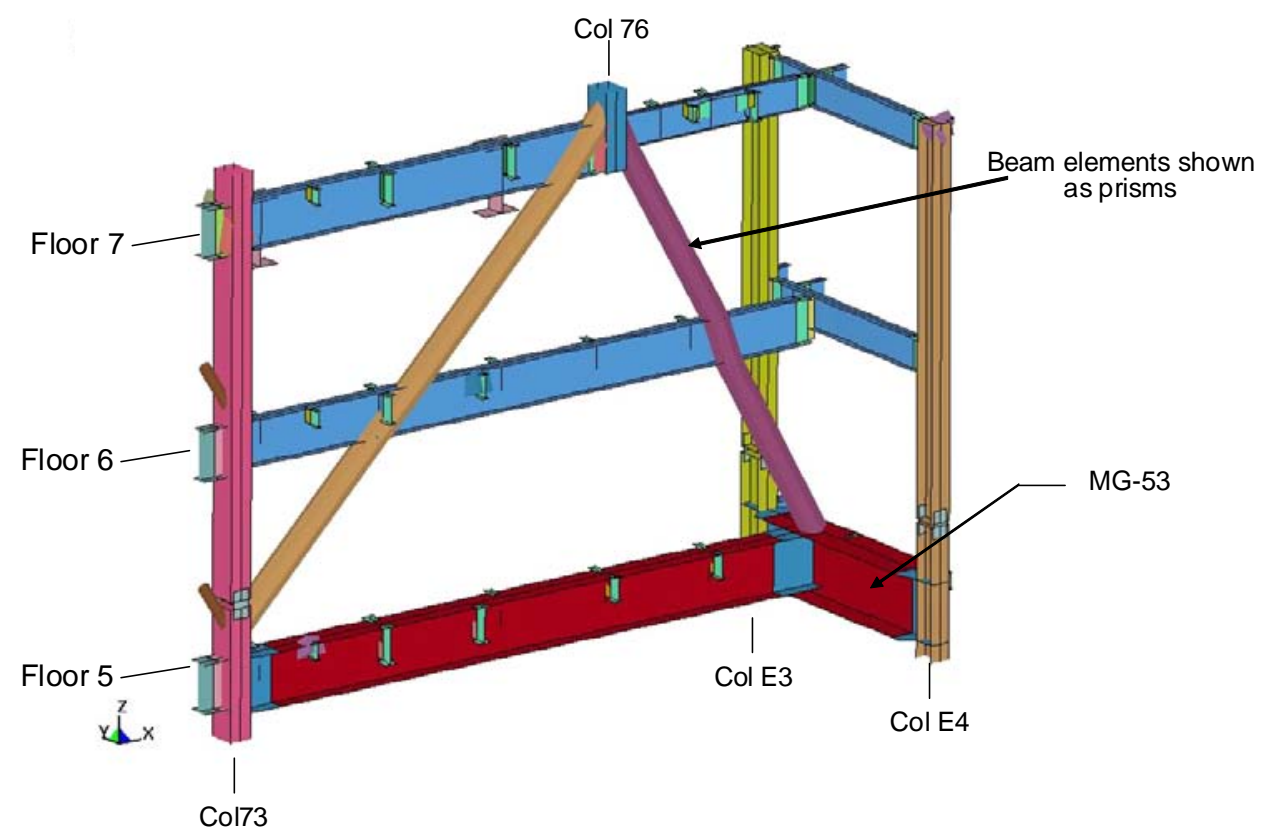

Figure 12-11. Detail of Truss 1 in the WTC 7 global model.

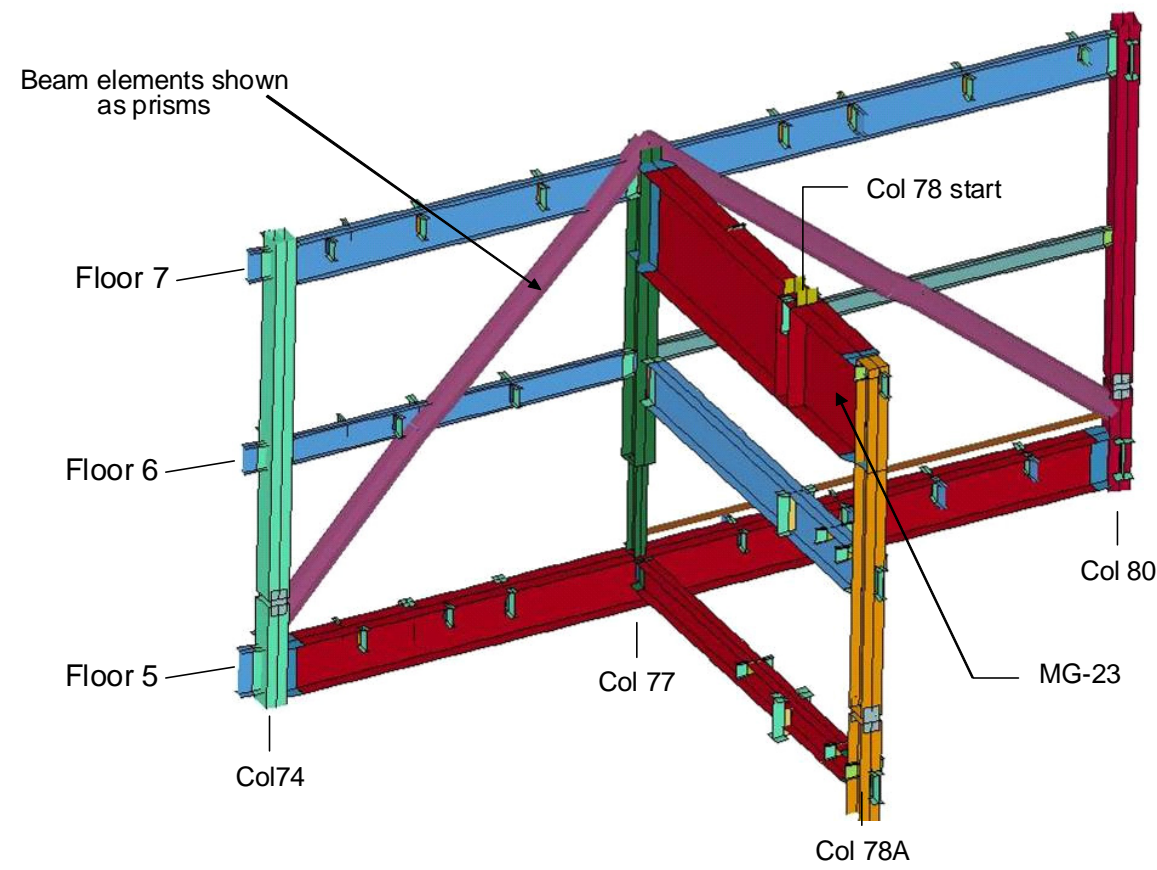

Figure 12-12. Detail of Truss 2 in the WTC 7 global model. 


\section{Exterior and Core Wind Bracing}

Wind bracing trusses were added to the lower core and exterior walls of WTC 7 and were included in the global model. The belt truss at Floors 22 to 24, which was part of the exterior framing, was also included. Truss members were included as beam elements, and were merged directly into the columns.

The exterior wind bracing at the lower floors in the global model is shown in Figure 12-13. Core wind bracing is shown in Figure 12-14. The belt truss is shown in Figure 12-15.

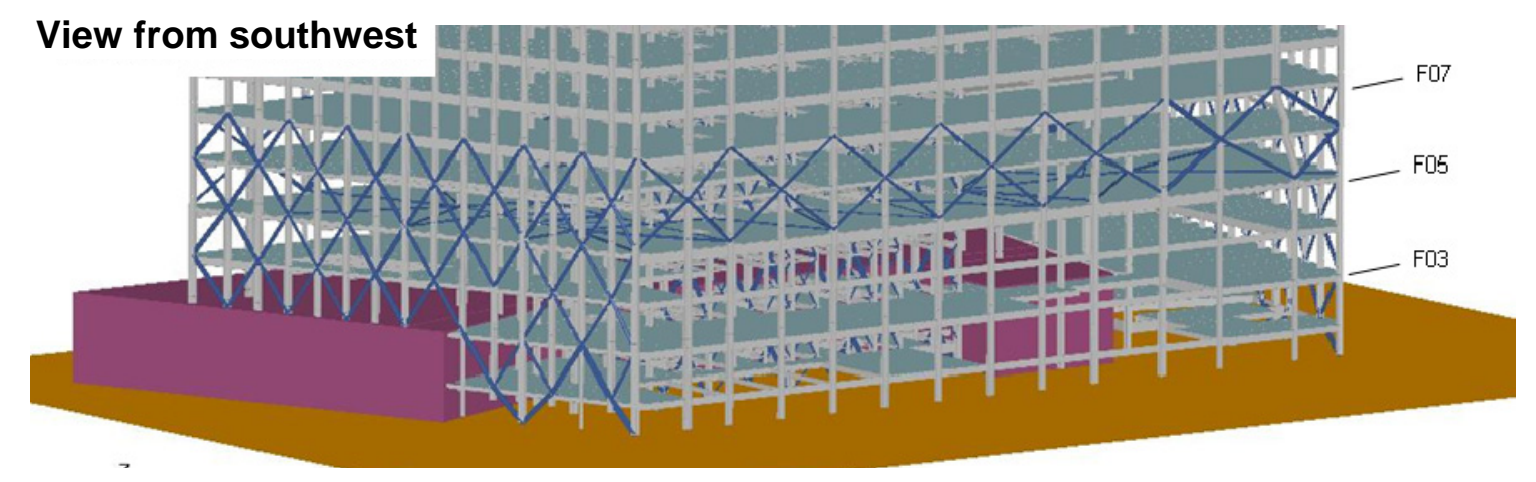

Figure 12-13. Exterior wind bracing in the lower floors of the global model.

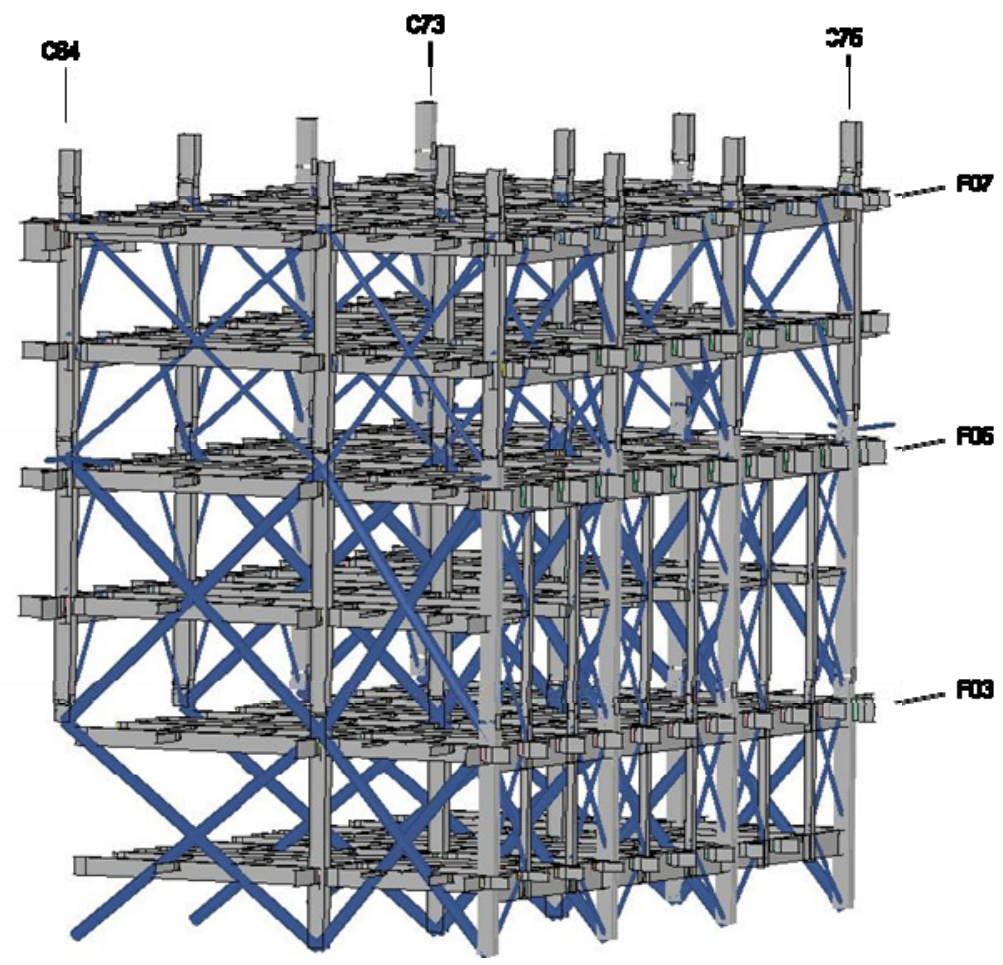

Figure 12-14. Core wind bracing in the lower floors of the global model, viewed from the southwest. 


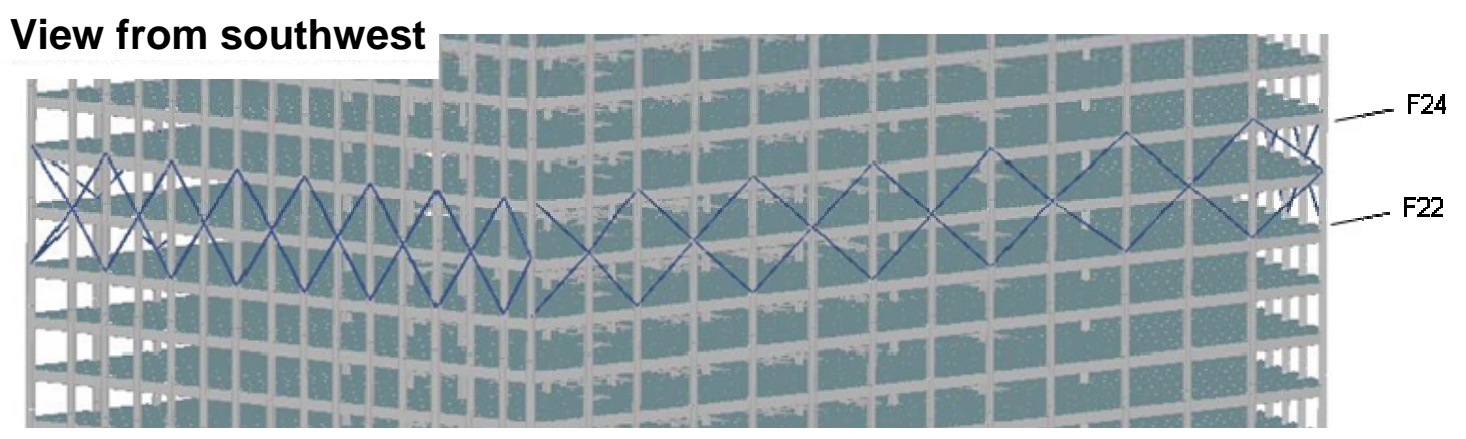

Figure 12-15. Belt truss cross-bracing in the global model.

\section{Penthouses}

A simplified model of the penthouse structures was developed using beam elements. The penthouse and the roof model are shown in Figure 12-16. Attachment of the penthouse structure to the global WTC 7 model was achieved by merging the beam ends into supporting columns or other framing in the roof structure. To approximate the weak connections between the east penthouse and the screening wall section of the western penthouse, the two structures were decoupled.

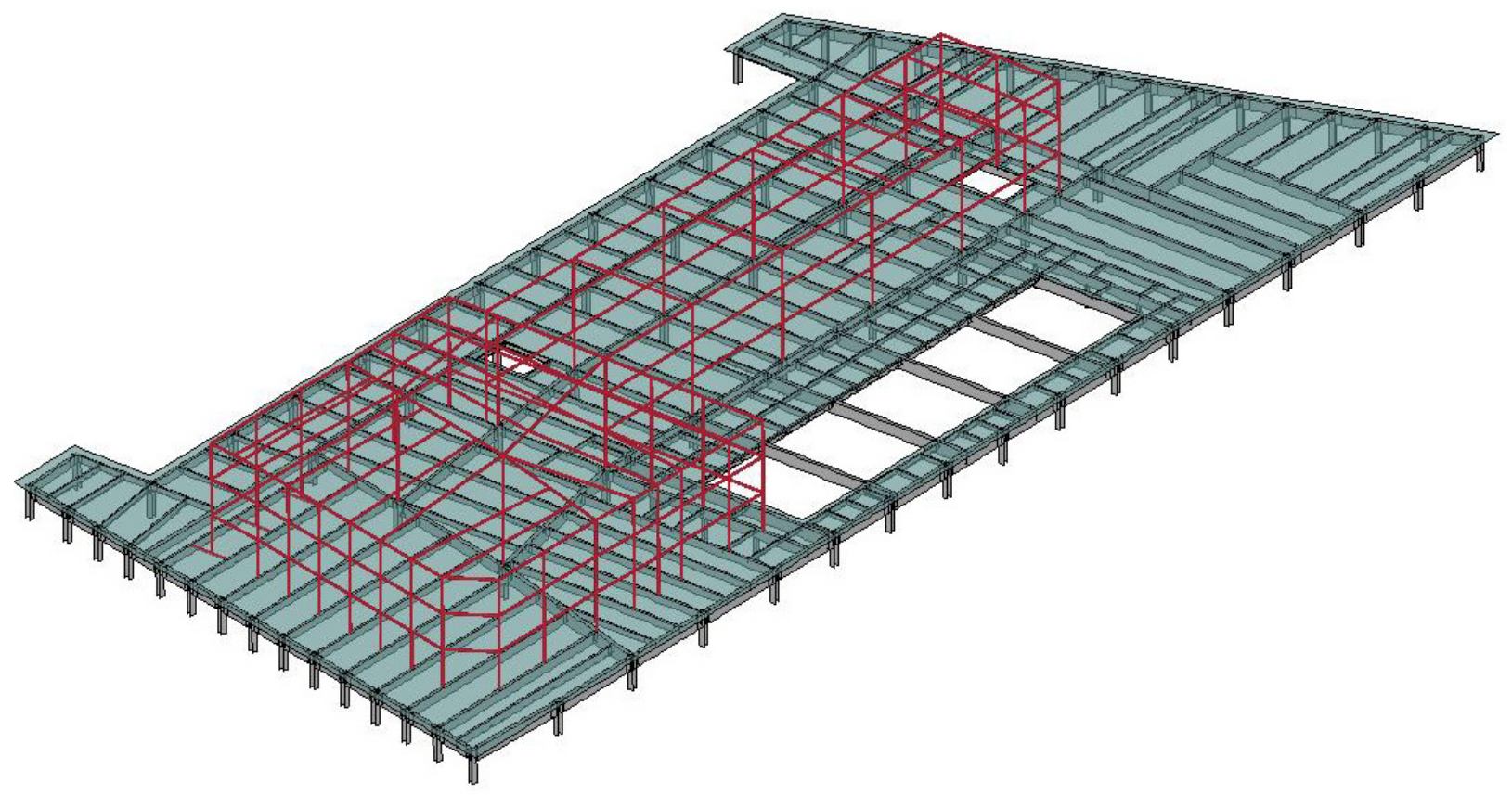

Figure 12-16. Beam element model of the penthouse structure. 


\subsubsection{Modeling of Connections}

A key aspect of modeling the structural response of WTC 7 for collapse progression was the behavior of the floor connections in the building. Similar to the 16 story ANSYS model, a significant portion of the modeling effort was spent developing connection models that accurately captured the dominant behaviors and failure modes. The strengths and failure modes of the connections were highly dependent on the connection details (e.g., whether the connection had welds or bolts) and the loading condition and direction (e.g., connection behavior under shear or axial load).

Given a target element size of 6 in. to 12 in. within the global model, it was not possible to explicitly model connections in fine details. The connections were modeled with a simplified geometry, and connection material models were developed to provide the expected load capacity and ductility. The connection models were based on information extracted from the WTC 7 fabrication shop drawings and structural drawings.

The floor framing connections in WTC 7 (i.e., beam-to-girder and girder-to-column) included a variety of connection types. Simple shear connections were used at all interior floor framing connections. There were six types of shear connections in the floor system: fin $(\mathrm{F})$, header $(\mathrm{H})$, knife $(\mathrm{K})$, seated top plate (STP), seated top clip (STC), and seated web clip (SWC). For the details of these connections, see Section 2.4.3. Fin, header, and knife connections attached interior floor beams to girders and girders to interior columns, except for the seated connections at Columns 79 and 81. Seated connections attached floor beams and girders to exterior columns and to the north side of Column 79 and the south side of Column 81. Moment connections were used in the exterior frame to attach spandrel beams to exterior columns, and portions of the core framing at Floors 5 and 7, as part of the lateral load resisting system.

The floor framing connections, column splices, and moment connections included in the model are described in the following subsections.

\section{Fin, Knife, and Header Shear Connections}

A single model was used to represent fin, header, and knife connections in the global model. A schematic of each connection type is shown in Figure 12-17. In the LS-DYNA model, fin connections, were developed first. Fin connections were grouped by the depth of the beam web, which generally determined the number of bolts in the fin connection.

A series of component calculations were performed to develop fin connection models for the depth-based groupings. The idealized strength and ductility of the connection were obtained from a connection spring element model developed by Sadek el al. (2008). In that study, the connection model used an arrangement of spring elements to model the behavior and failure of the bolted connection. The spring elements accounted for a variety of failure modes including (1) bolt shear, (2) fillet weld failure under transverse load, (3) block shear failure, and (4) tear-out (bearing at bolt holes) of beam web or shear tab. Based on this simplified spring element model, a simple LS-DYNA beam-column connection model was developed using shell elements, as shown in Figure 12-18.

The shell element LS-DYNA fin model was calibrated to match the connection behavior obtained from the spring element model in Sadek et al. (2008). In this analysis, the unsupported center column was pushed down vertically, as shown in Figure 12-18, until the connection failed. The appropriate 
connection strength and ductility in the shell element model were obtained by adjusting the material behavior and failure strain for the connection to match the spring element model. A comparison of vertical load-deflection curves from the shell element model with the spring model for the set of connections considered is shown in Figure 12-19. Good agreement between the results of the spring and shell element fin models was obtained.
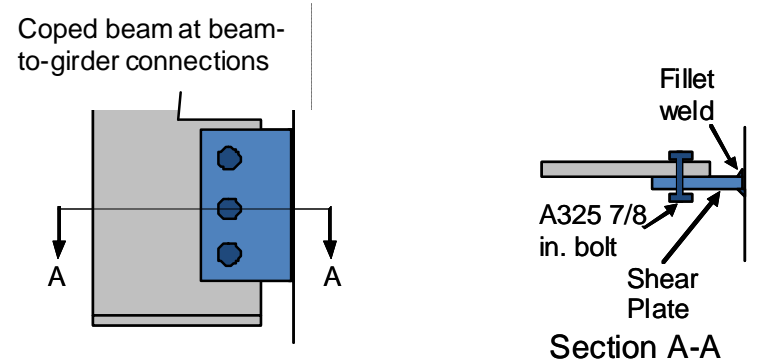

a) Fin (F) connection
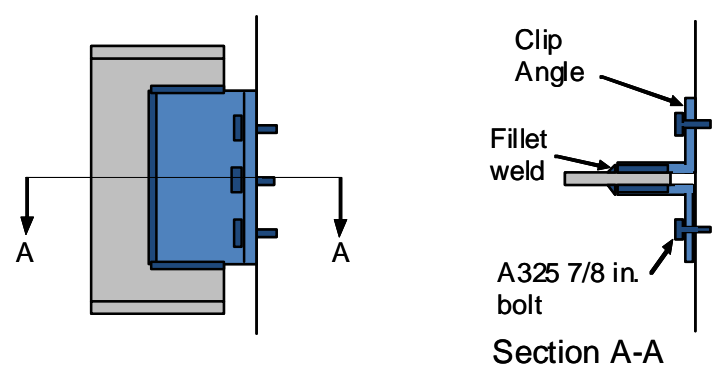

b) Header $(\mathrm{H})$ connection
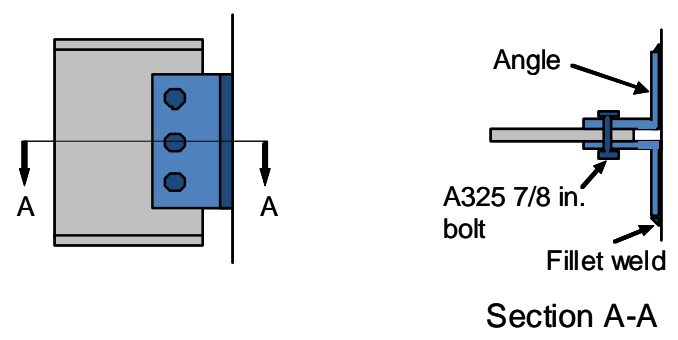

c) Knife (K) connection

Based on fabrication shop drawings (Frankel 1985)

Figure 12-17. Fin, header, and knife shear connection schematics. 
Symmetry boundary

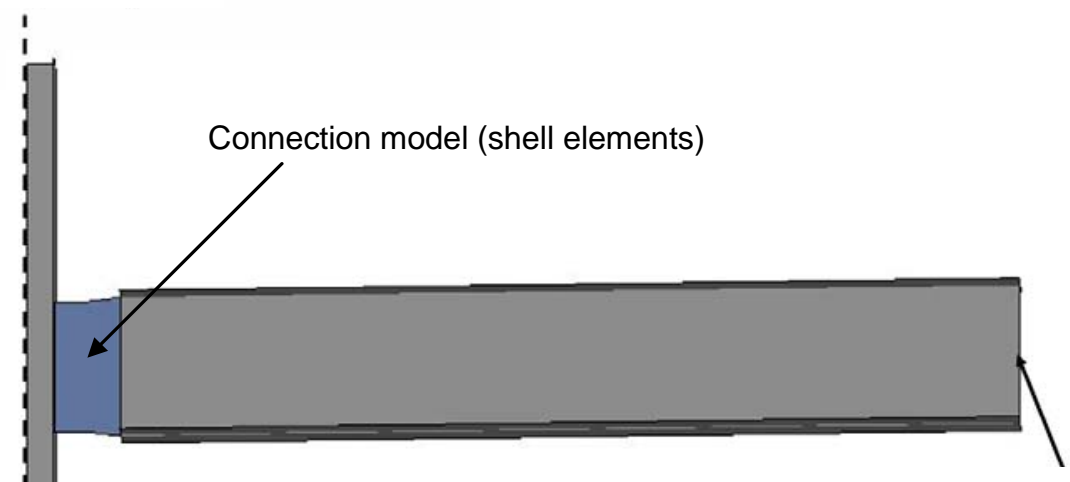

Fixed point of rotation

I. Column moved
if

Figure 12-18. Component model used to develop the fin, header, and knife (FHK) shear connection model.

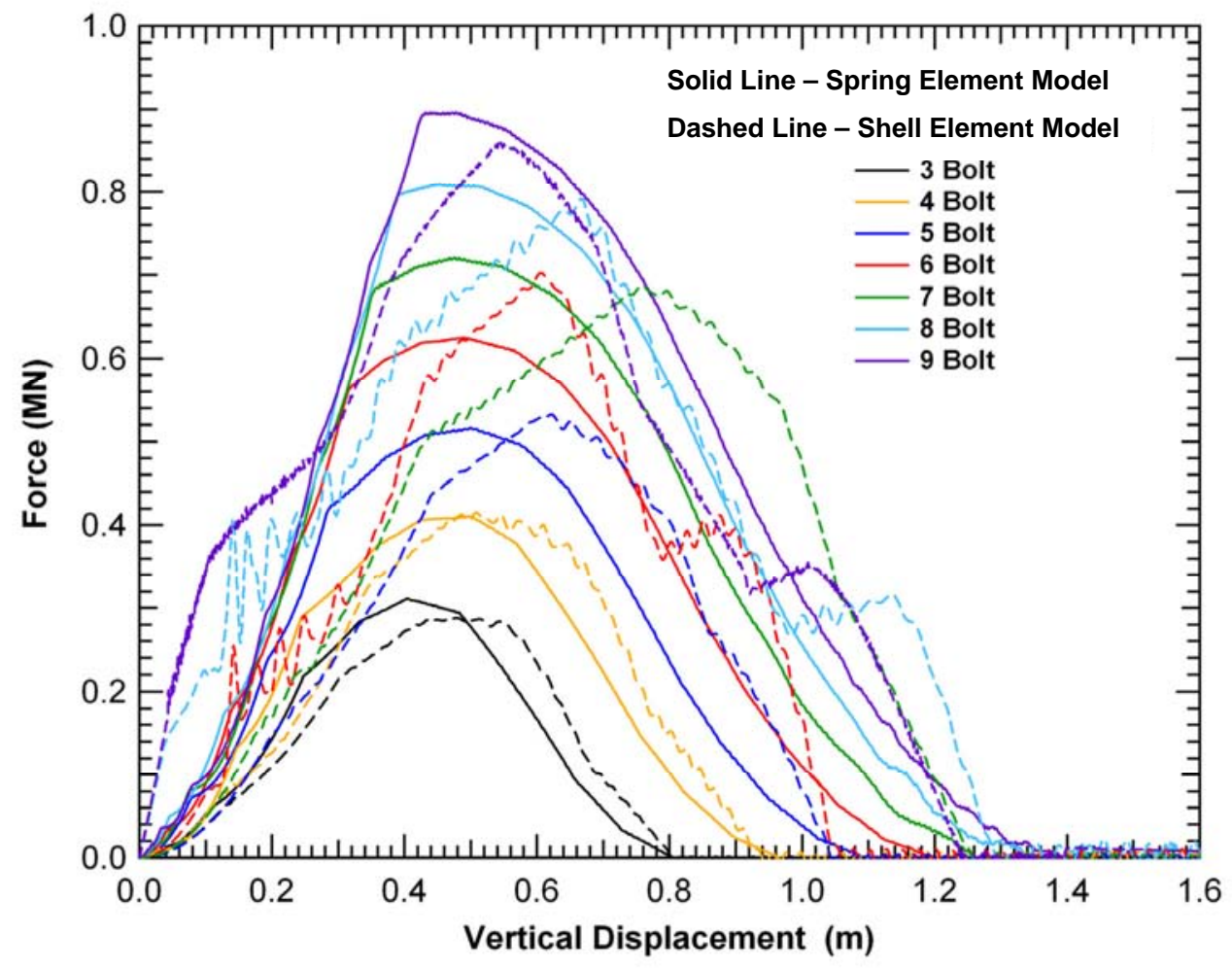

Figure 12-19. Comparison of the spring element and shell element models of the fin connections. 
The knife and header connections were developed in a manner similar to that described for the fin connection. A grouping strategy was devised to map the information within the existing framework of the LS-DYNA model based on section depth and critical geometry properties such as weld size and plate thickness. First, the connection information was sorted into groupings by section depth (W12 through W36), then divided into subgroups by connection type (F, H, or K). The groupings revealed that horizontal and vertical failure strengths were dependent on the geometric features of the connections. All horizontal and vertical load capacities within a group were normalized by geometric features (weld size or plate thickness, as appropriate) and averaged to formulate a standard, normalized strength for each group. A coefficient of variation of 0.3 was used as a guideline to indicate an appropriately tight grouping of connection strengths. Outliers not conforming to the grouping strategy were handled separately to obtain the correct strength. Shear connection models were generated using the same methodology for approximately 20 unique groups. To obtain the original, non-normalized strength of a given connection in the WTC 7 model, the geometric parameter specific to each connection was input at each location and used as a multiplier for that connection.

The model shown in Figure 12-18 was used to develop the specific connection properties for the connection groupings. During the component analyses, horizontal capacity was calibrated first by pulling on the beam and loading the shell element-based connection in tension. A discrete (spring) element was added to augment the vertical load capacity of each connection to achieve the appropriate vertical strength. The discrete element provided vertical strength while contributing minimally to horizontal capacity, see Figure 12-20.

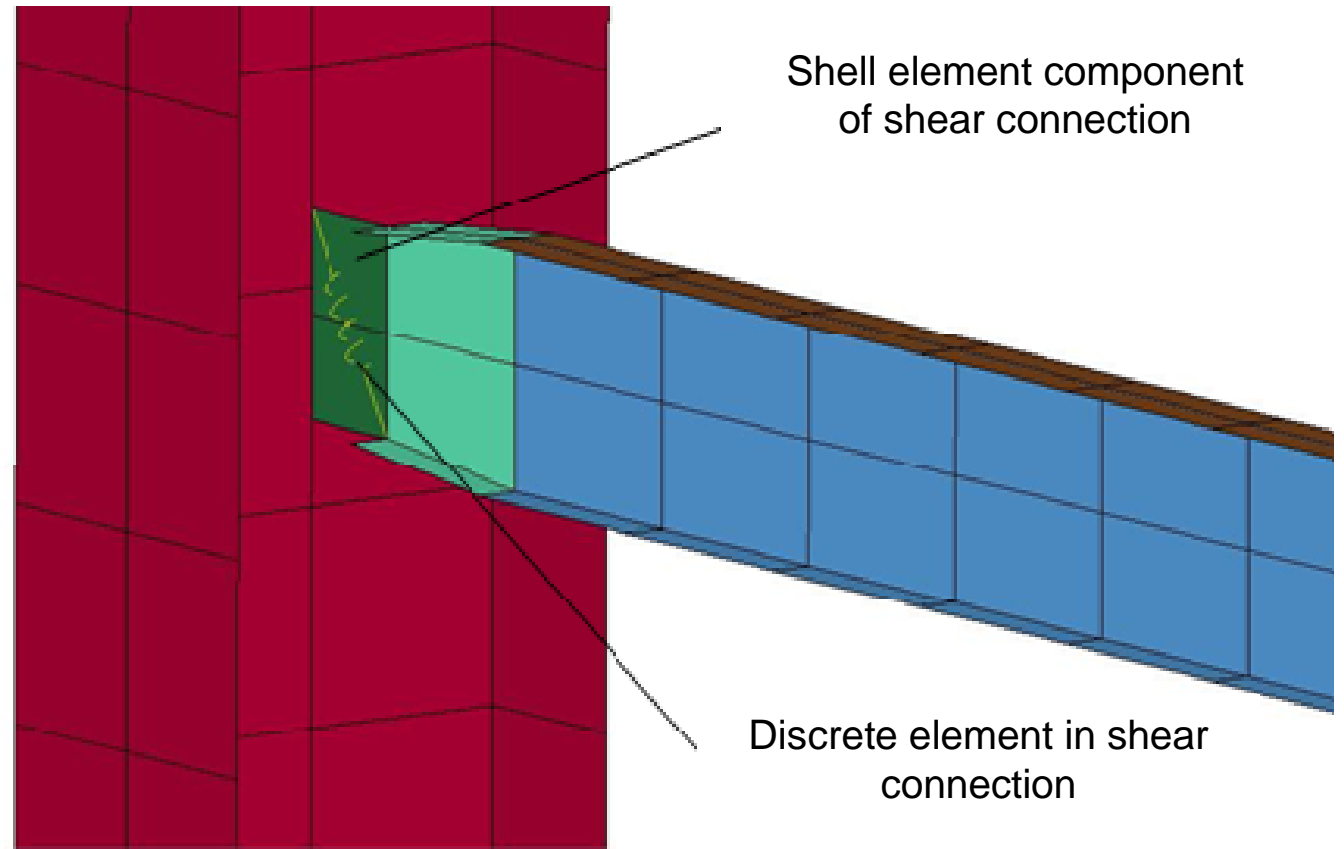

Figure 12-20. Generic LS-DYNA model of a FHK shear connection.

A comparison was performed between the LS-DYNA and ANSYS FHK shear connection models. The ANSYS model used beam and break elements to model the connection failure mechanisms. The comparison showed good agreement for selected connections, which increased confidence in both of the separately developed modeling approaches. 


\section{Seated Connections at Exterior Columns}

Seated connections attached interior beams and girders to the exterior columns of WTC 7. A schematic of a typical connection is shown in Figure 12-21. The connections included plates welded between the column flanges above and below the framing member. During construction, the beam was bolted to the plates with two 7/8 in. A325 bolts per plate. The shear force-deflection behavior of an individual bolt is shown in the figure. The geometry varied slightly in the actual details for north/south and east/west bearing connections. In the model, the same basic geometry was used to approximate both.

The LS-DYNA model for seated connections at exterior columns is shown in Figure 12-22. The model included the plates above and below the beam, which provided vertical constraint. The plates were attached to the columns with an edge-to-surface tied interface. Sliding contact was required between the beams and plates. Bolts in the LS-DYNA model were represented with discrete elements. The properties of the discrete elements were tailored to match the bolt resistance in shear (shown in Figure 12-21). Examples showing the seated connections along the building perimeter are shown in Figure 12-23.

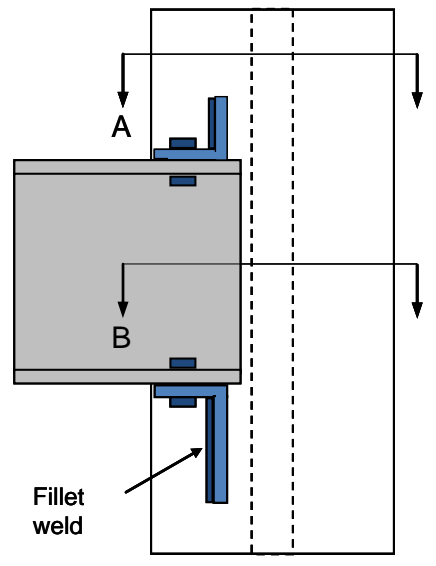

Elevation View

\section{A325 7/8 in.}

$$
\text { bolt }
$$

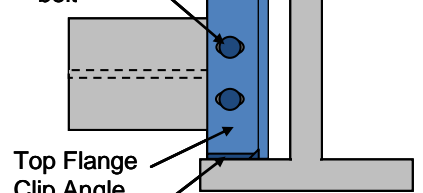

Clip Angle

Fillet weld

Section A-A

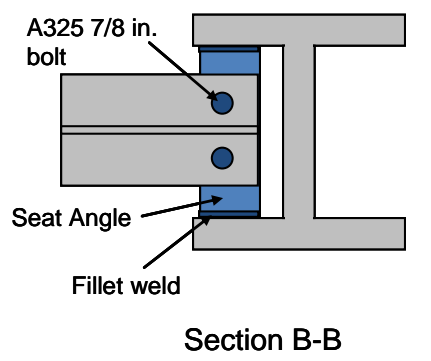

Bolt Strength

- $45 \mathrm{~K}$ Shear capacity / bolt

-Relatively ductile

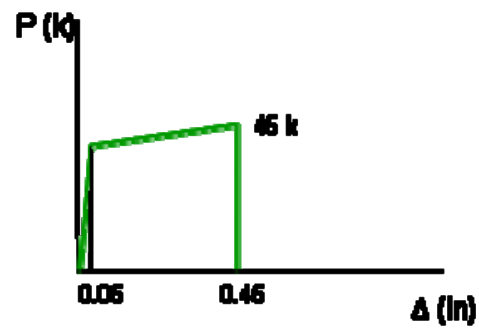

79h. Asps bol h aher

Based on fabrication shop drawings (Frankel 1985)

Figure 12-21. Schematic of seated connections at exterior columns. 


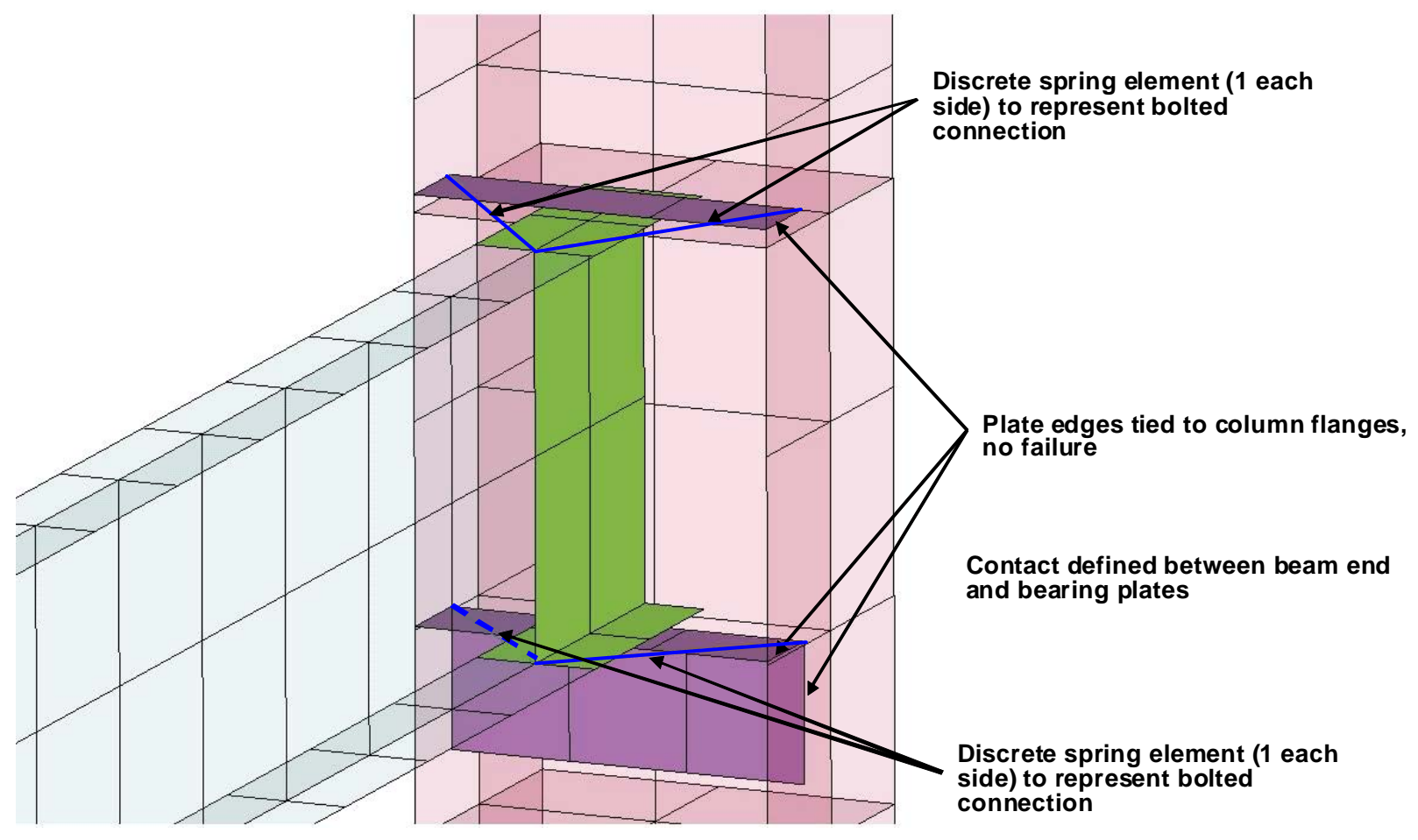

Figure 12-22. Model of seated connection at exterior column.

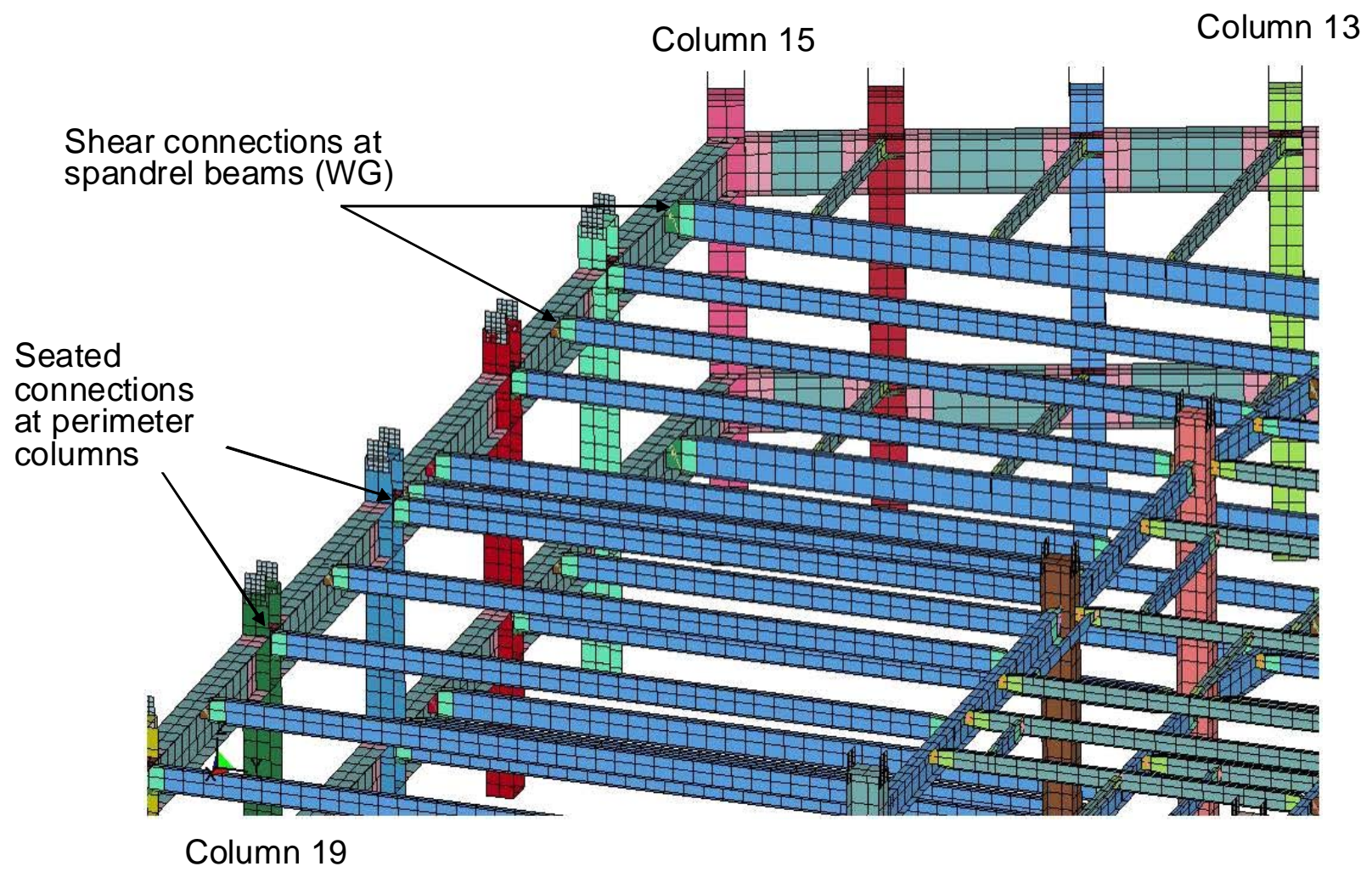

Figure 12-23. STP connection in global model, view of southwest corner above Floor 9. 


\section{Seated Connection at Columns 79 and 81}

The girders that framed into the north side of Column 79 and into the south side of Column 81 were connected with STC connections. A schematic of the Column 79 seated connection is shown in Figure 12-24. The connection had a seat, which constrained vertical motion of the girder, and an angle clip above the girder. Four bolts provided lateral restraint during construction until the floor beams were connected to the girder. The seated connection at Column 81 was similar to that for Column 79, except for the angle of the girder axis relative to the column.

In the model, seat and clip plates were constructed with shell elements and tied to the column elements and discrete elements representing bolts. The same A325 force-deflection properties for the bolts and the same contact strategy used in the seated connections at exterior columns were used for the seated STC connection model at Columns 79 and 81. Models of the Column 79 and Column 81 seated connections are shown in Figure 12-25 and Figure 12-26, respectively. Since vertical failure of the seat was not considered (Section 11.2.5), the connections at Columns 79 and 81 were both modeled as stiffened seats.
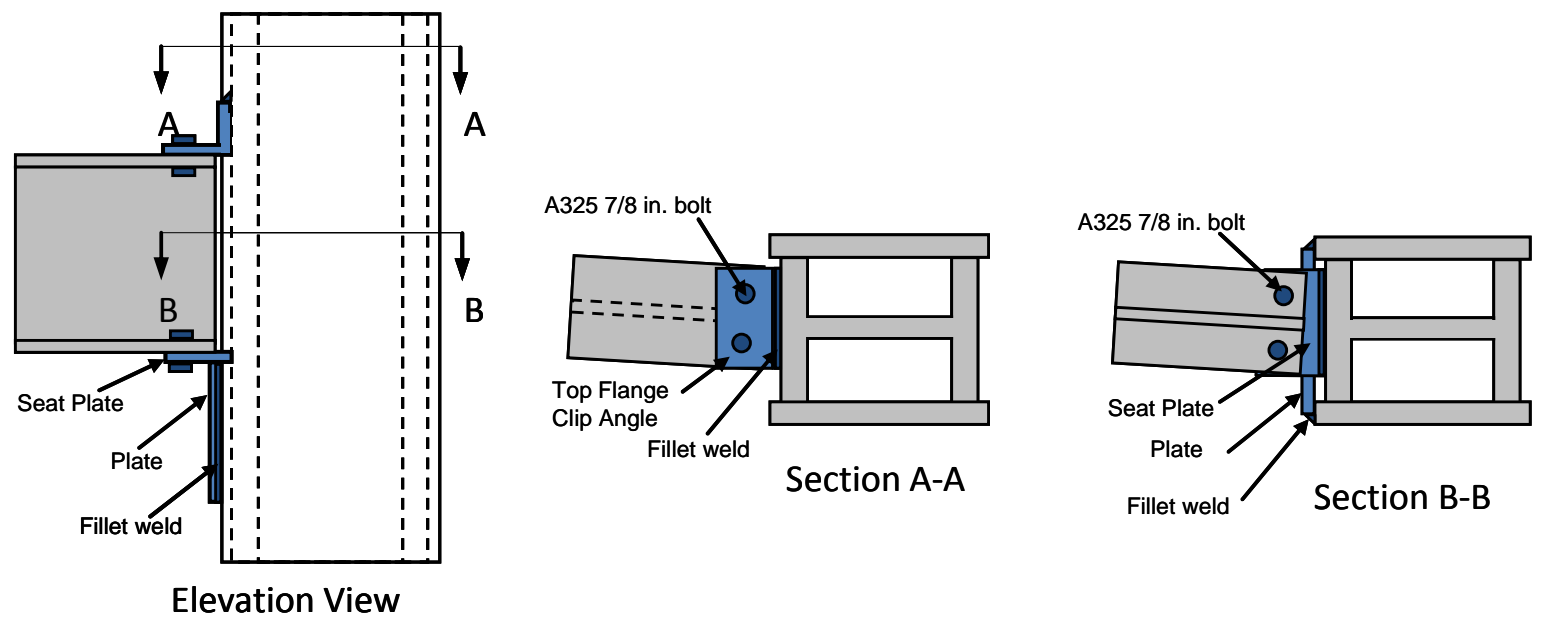

Based on fabrication shop drawings (Frankel 1985)

Figure 12-24. Schematic of the STC connection at Column 79. 


\section{Column 79 seated connection}

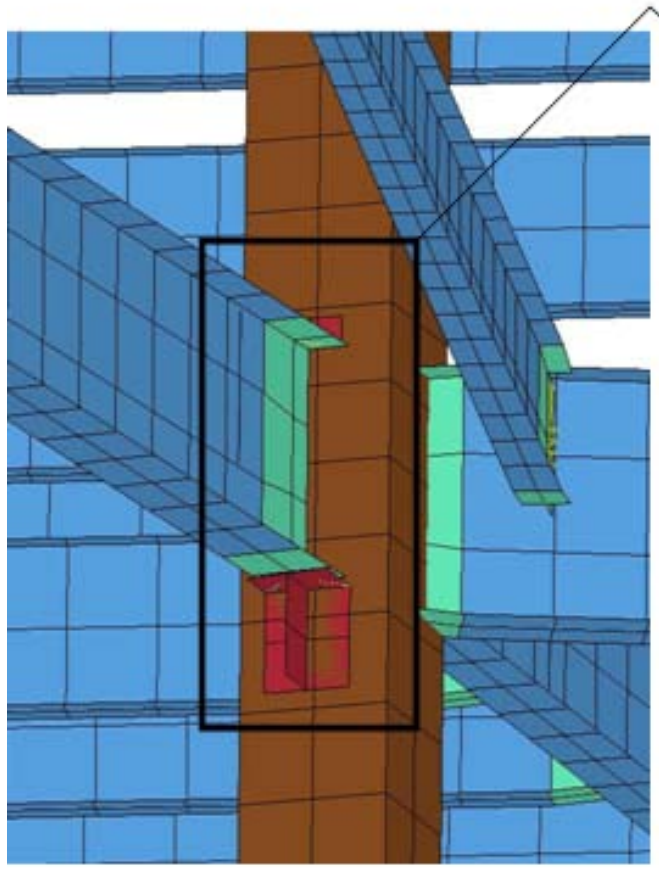

From below

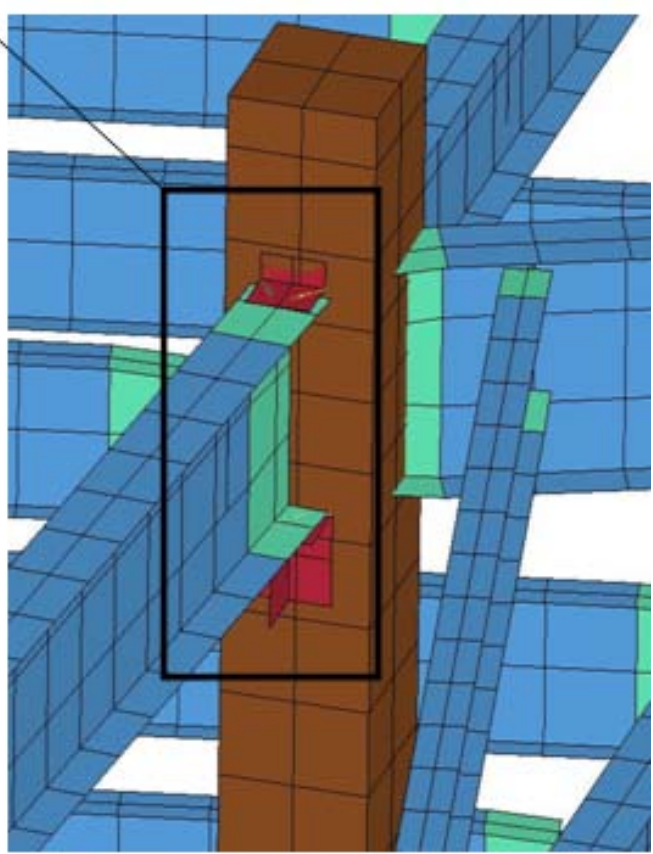

From above

Figure 12-25. Seat connection in global model, Column 79.

Column 81 seated connection

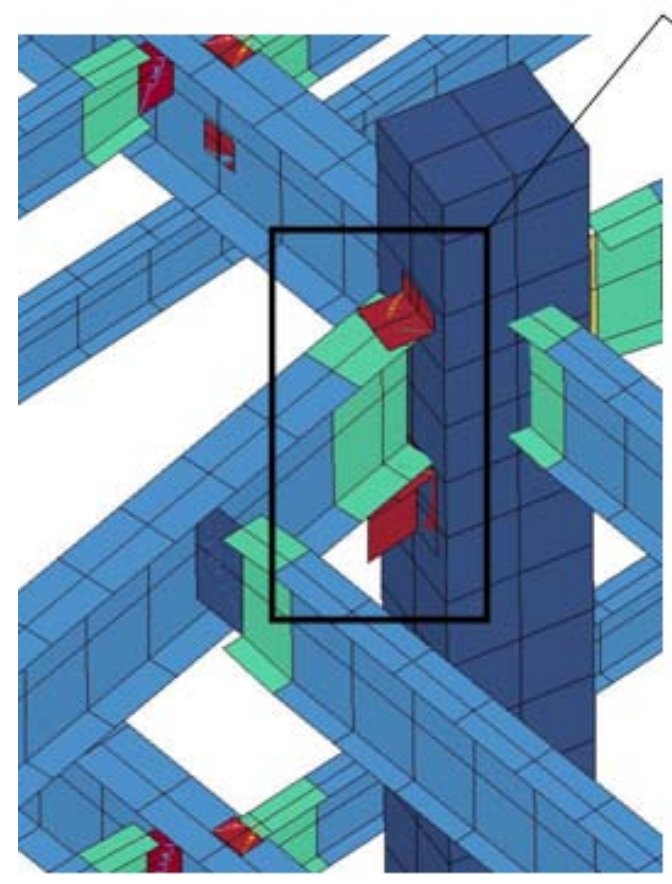

From above

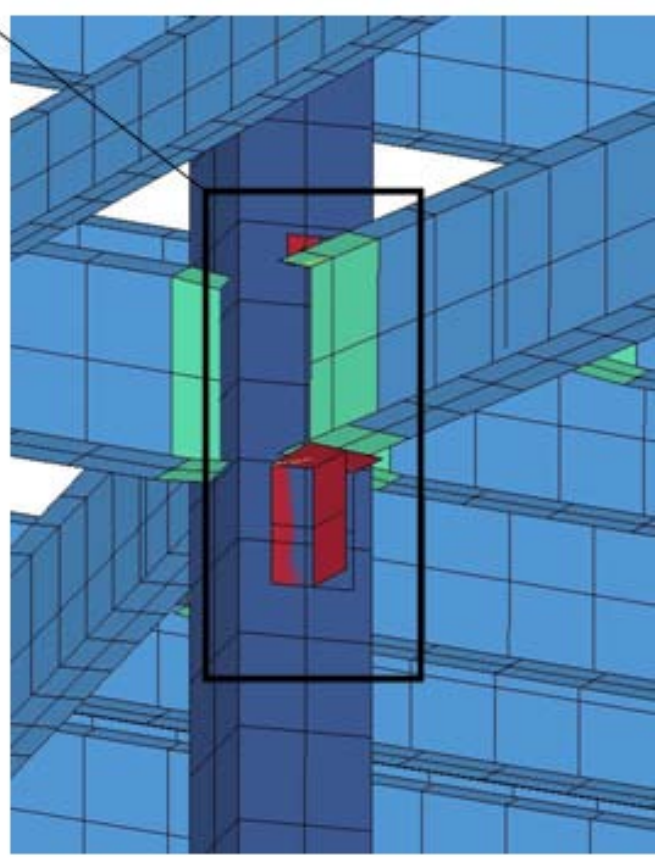

From below

Figure 12-26. Seat connection in global model, Column 81. 


\section{Seated Web Clip (SWC) Connections}

SWC connections were used to connect some floor beams to girders in the core of WTC 7. This connection had a web clip (angle) instead of a top flange clip, along with an angle seat supporting the beam. As with other seated connections in the building, two 7/8 in. A325 erection bolts were used at the seat angle and web clip. A schematic of the connection is shown in Figure 12-27.

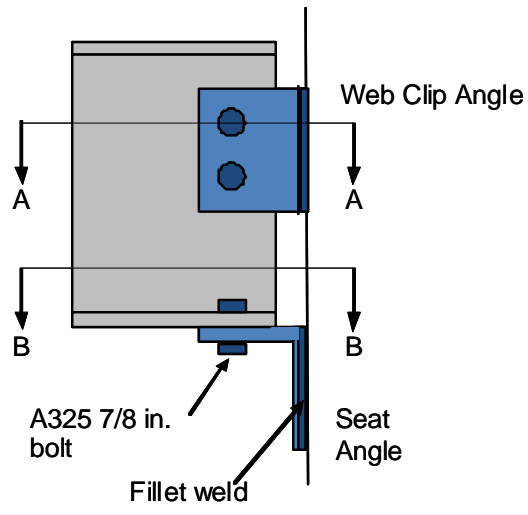

Elevation View

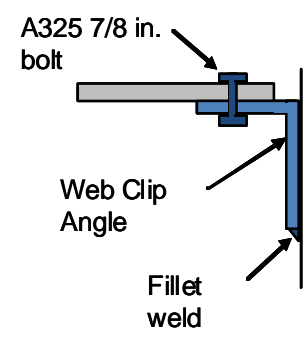

Section A-A

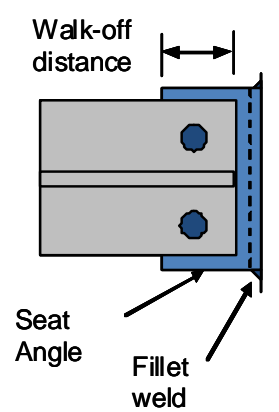

Section B-B

Based on fabrication shop drawings (Frankel 1985)

Figure 12-27. SWC connection schematic.

A modified version of the STC connection model was used to represent the SWC connection. In the global model, the web clip was approximated as a flange clip. The same discrete element properties as in other seated connections were used to approximate the bolt's behavior. An example of the SWC implementation in the LS-DYNA model is shown in Figure 12-28.

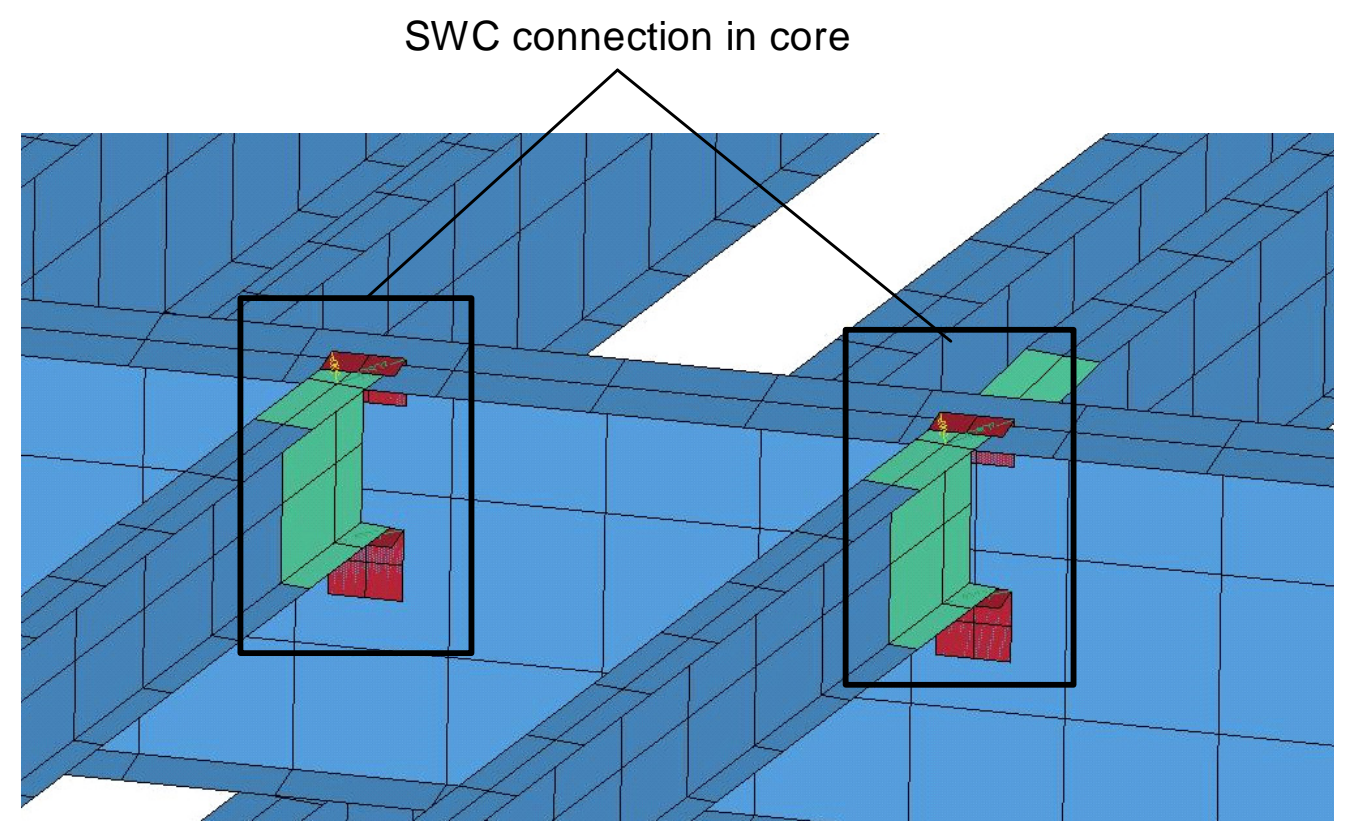

Figure 12-28. SWC connection in LS-DYNA model. 


\section{Moment Connections}

In the construction of WTC 7, moment connections were used for wind girders (WG, also referred to as spandrel beams) between exterior columns. Moment connections were also used at several core girder locations on Floors 5 and 7. Figure 12-29 illustrates a moment connection model in the LS-DYNA model. The connection between the girder and column flanges was assumed to have the same material properties as the WG, except the failure strain was lowered by 30 percent to approximate the less ductile weld zone at the connection to the column. For all moment connections, continuity plates (also referred to as stiffener plates) were added between the exterior column flanges (at the level of the beam flanges) to resist local crippling of the column.

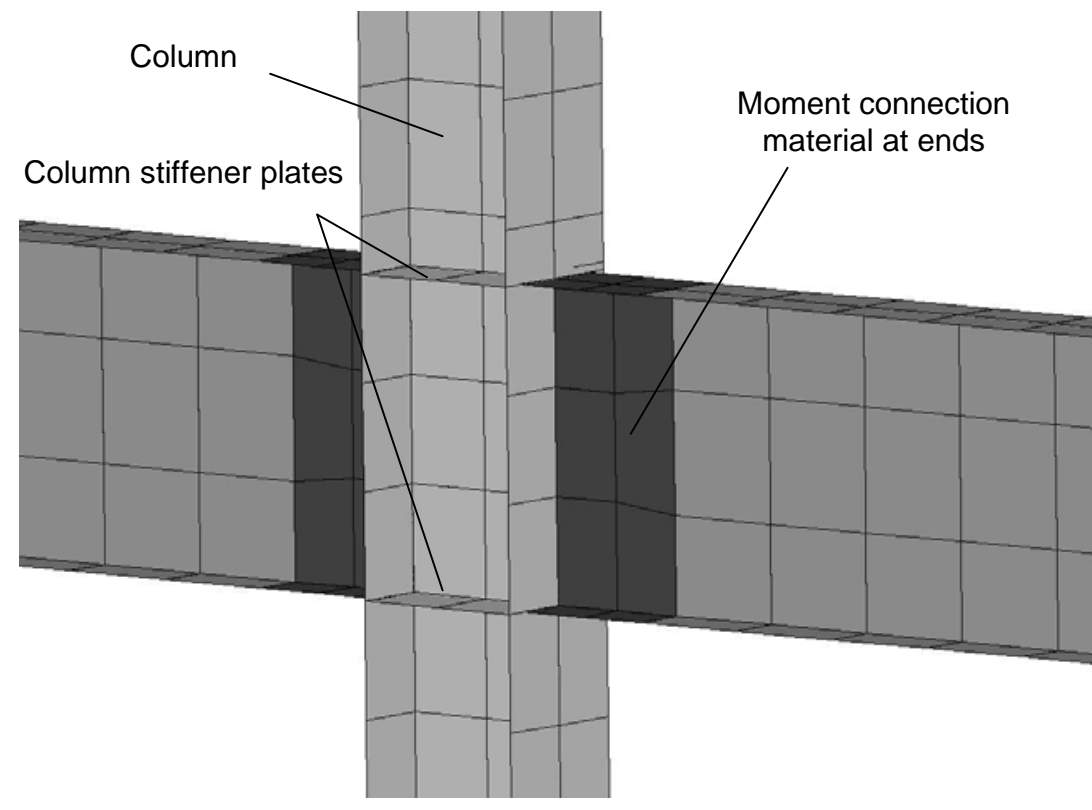

Figure 12-29. Moment connection model for a wind girder.

\section{Column Splices}

In WTC 7, columns were spliced at every other floor. Column splices used bolted and/or welded flange plates. In the global model, all column splices were explicitly represented with shell element models of the splice plates. An example of a column splice in the model is shown in Figure 12-30.

Splice plates were connected to the column flanges with a tied contact interface. Changes in column section dimensions were compensated for by using an offset tied interface between the columns and splice plates. This allowed for gaps between the splice plate and columns when a larger section column below was attached to a smaller section column above.

To avoid contact instability common with shell edge-to-edge contacts, a plate was added to column section ends to produce a more numerically stable surface-to-surface contact condition between column ends. Thickness of the end plate was equivalent to the flange thickness for a given column section. In Figure 12-30, a gap can be seen between column end plates. This gap was created by a half shell thickness offset between the column end plates to improve contact stability. The end plates were not expected to alter the structural response, and they were necessary to ensure contact stability in the model. 


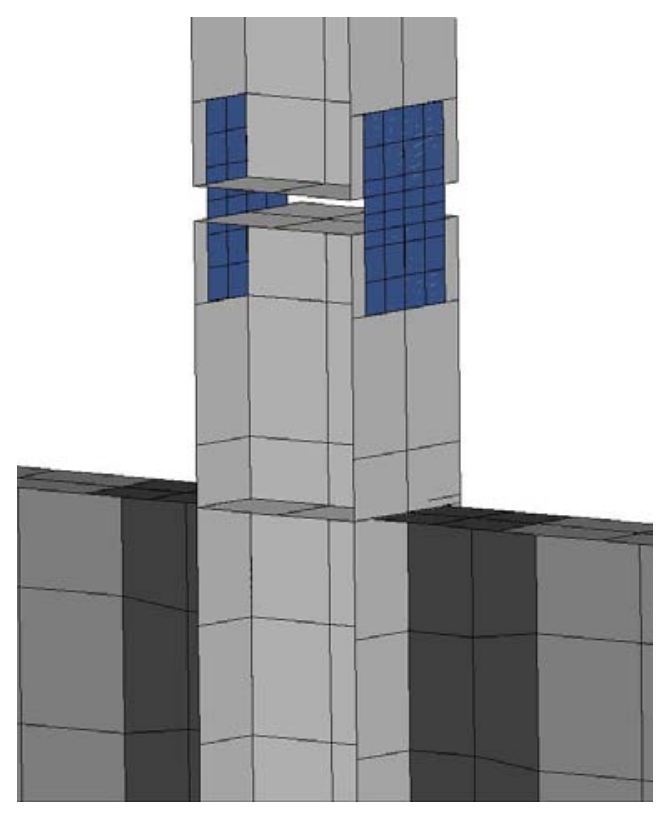

Figure 12-30. Column splice connection in LS-DYNA model.

\section{Shear Stud Connections}

The floor slab acted compositely with the floor beams by transferring shear loads through the shear studs. Shear stud connectors were modeled with a tied contact interface, where the center nodes along top flange of beams were tied to surface slab shell element nodes. The contact interface approach is illustrated in Figure 12-31. No failure was allowed in the tied contact. Individual connections failed when a node or shell element in the contact list exceeded its material failure criteria. This usually occurred when the composite slab material failed. Once a node or element was freed from the tied contact, it could interact with other contacting materials. The slab-to-beam tied contact was applied only to the interior floor beams and spandrel beams (WGs) where shear studs were located. Interior girders and MG sections did not have shear studs.

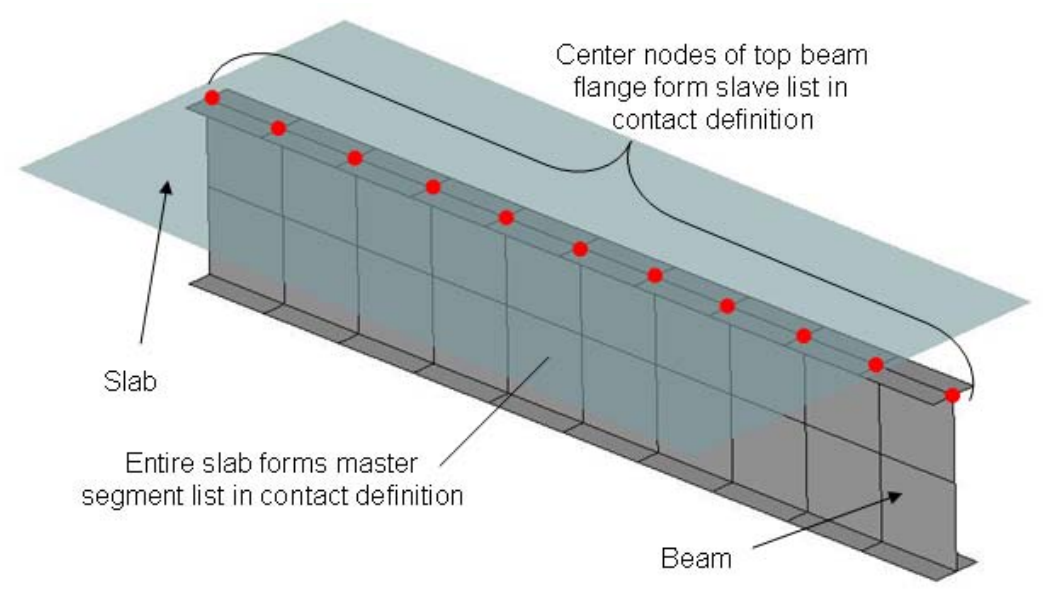

Figure 12-31. Modeling of shear stud connection between beams and slabs. 


\subsection{BOUNDARY CONDITIONS AND LOADING SEQUENCE}

\subsubsection{Displacement Boundary Conditions}

To approximate the connection of the columns to the foundation, the free column ends below the second floor framing were fully constrained in translation and rotation. The base of the Con Edison substation was fully fixed and the substation model was treated as a rigid (non-deformable) body. The columns originating from the top of the substation were, therefore, fully constrained with a tied contact interface between the base of the columns and the substation. Several lateral members in Floors 2 and 3 framed directly to the substation. The ends of the framing members were connected to the substation with a tied interface to the rigid substation. Connections were modeled at the beam ends and connection failure was allowed, but the connected edge was fixed to the rigidly constrained substation.

\subsubsection{Model Initialization and Loading Sequence}

The global model was initialized as follows to minimize any dynamic effects associated with loading sequence.

- First, gravity was applied slowly to the 47 floor structure over $4.5 \mathrm{~s}$ of elapsed simulation time to damp residual vibrations and eliminate dynamic response. The loads were applied smoothly with a sinusoidal load curve.

- Then, the debris impact damage from the collapse of WTC 1 was applied to the structure instantaneously by removing damaged elements from the model that were no longer capable of bearing their loads. The structure was then allowed to damp residual vibrations for $2 \mathrm{~s}$.

- Next, the structural temperatures were applied smoothly with a sinusoidal curve and allowed to damp residual vibrations for $2 \mathrm{~s}$.

- Last, the fire-induced damage obtained from the 16 story ANSYS analysis, including damage to floor beams, girders, and connections, was applied instantaneously. The heated, damaged structure was then free to react.

Figure $12-32$ presents the initialization sequence with the load curve profiles. The individual initialization steps are described in the following subsections. 


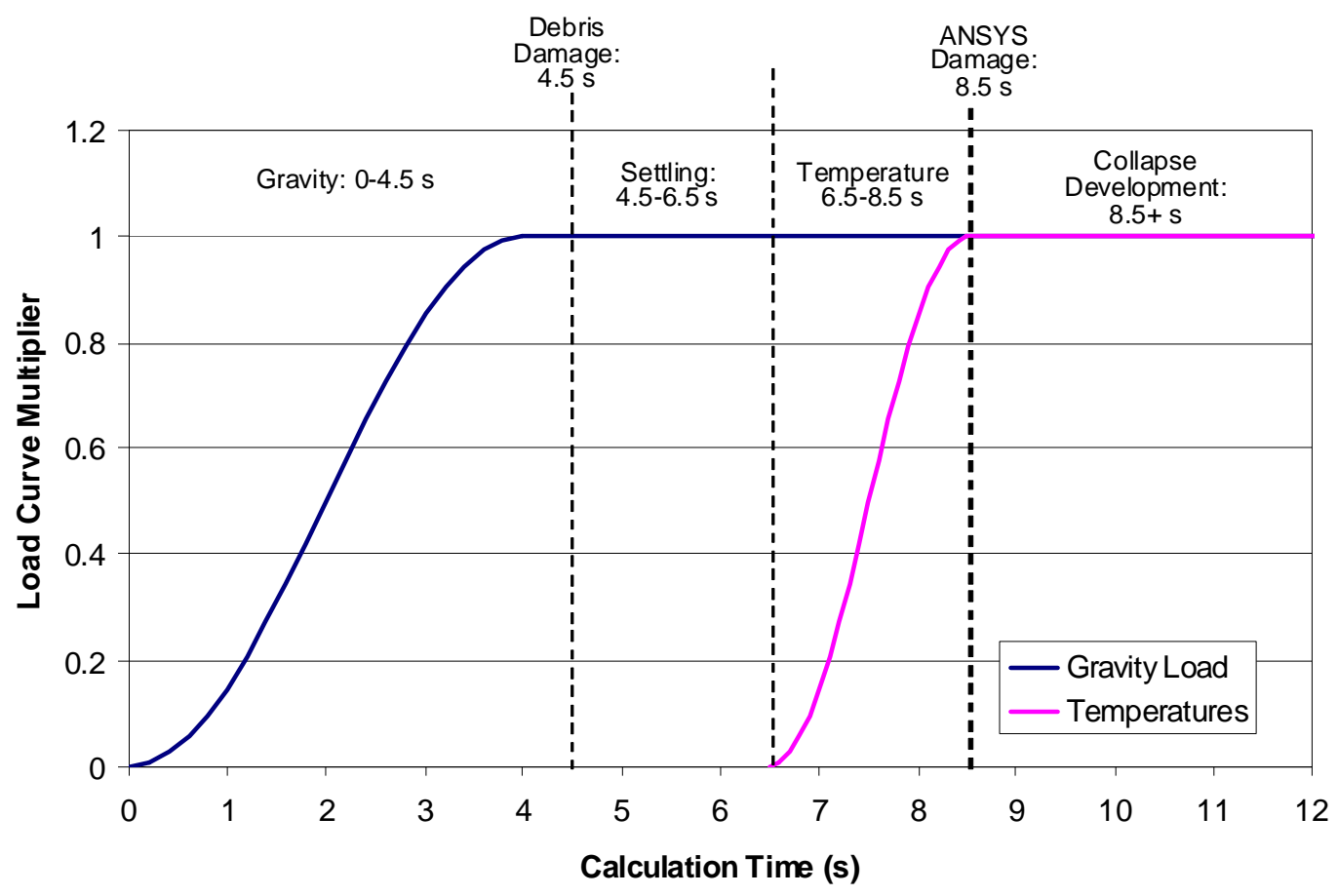

Figure 12-32. Initialization sequence for global model.

\section{Gravity Loads}

Similar to the 16 story ANSYS analysis (Chapter 11), gravity loads included: the dead load of the structure; superimposed dead loads consisting of the weight of ceilings, mechanical and electrical equipment, thermal insulation, and floor finishes; and service live load, which was taken as 25 percent of the design live load specified in the original design documents. The dead load of the structure, which was the self-weight of the steel and concrete slabs, was applied throughout the structure. At Floors 7 and 46, discrete loads were added to model the heavy localized weights of mechanical equipment. Live loads were applied by multiplying the modeled material densities with a scale factor to achieve a 25 percent live load. Gravity loads were applied as a smooth sinusoidal load curve over a duration of $4.5 \mathrm{~s}$ as shown in Figure 12-32.

\section{Debris impact damage}

After gravity initialization, debris impact damage due to the collapse of WTC 1 (Section 5.5.3) was applied to the global model instantaneously. The damage was applied to the building through the sudden removal of a number of elements from the model. The damage included two zones, as shown in Figure 12-33. Zone 1 was in the lower southwest quadrant of the building and included damage to the exterior columns and floor framing extending to the south core perimeter. In Zone 1, exterior Columns 14A through 20 were severed above Floor 7. Some floor sections in the debris zone that were not removed cantilevered out from the core. Damage to Zone 2 at the upper floors along the central-southern face was less extensive. Column 20 and some floor structure extending to the core perimeter were removed from the calculation above Floor 43. After the damage was instantaneously applied to the model, the calculation was allowed to progress for $2 \mathrm{~s}$ prior to temperature application. 


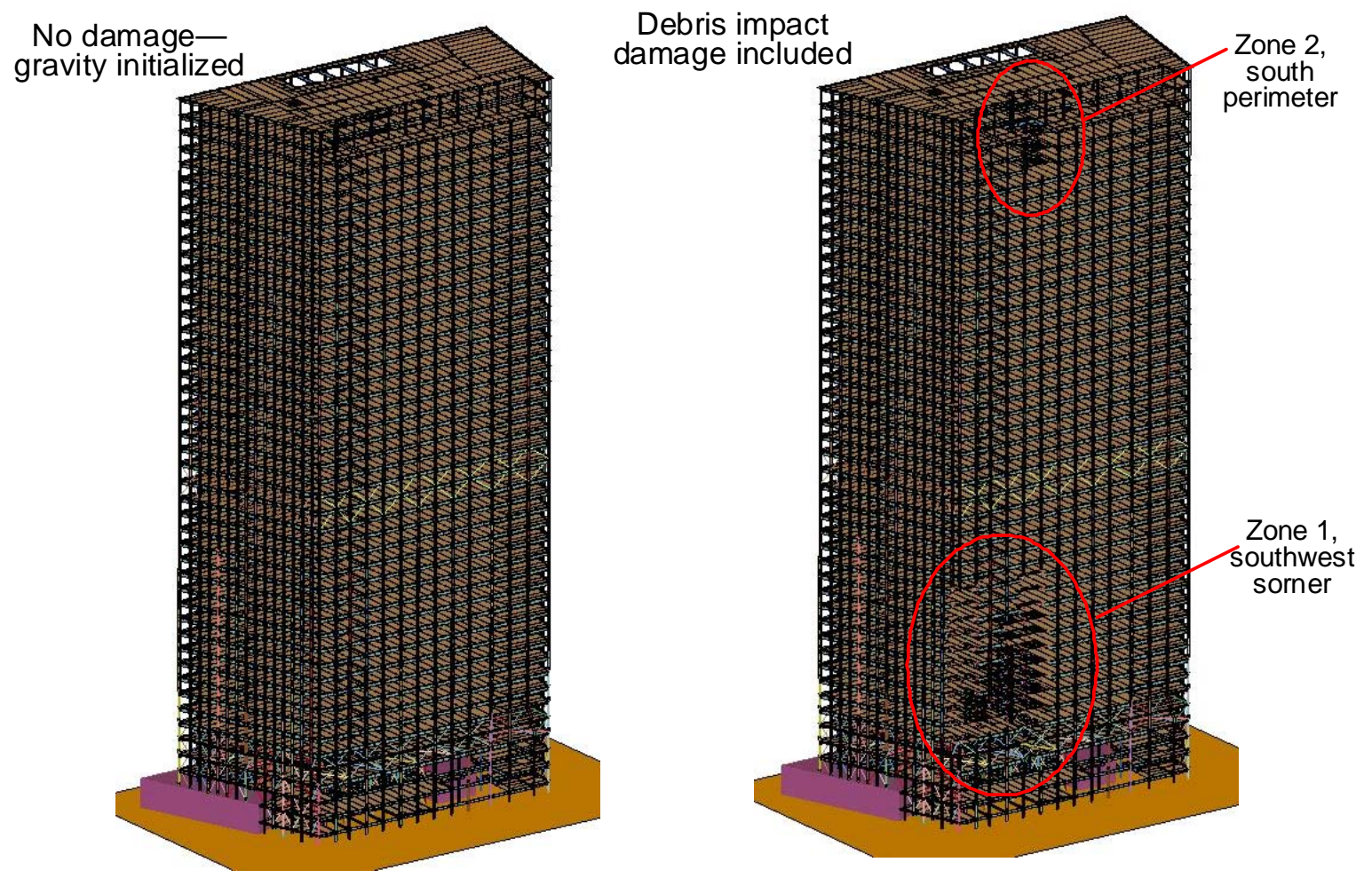

Figure 12-33. Debris impact damage application to the global LS-DYNA model.

\section{Thermal Loading}

As shown in Figure 12-32, temperatures were applied to the model smoothly over the duration of $2 \mathrm{~s}$. Temperatures applied to the fire-affected zone in the global model were Case B temperatures at 4.0 hours (Section 10.3.3). The affected zone was between Floors 7 and 14. The temperatures were applied to the nodes in the model and followed the prescribed time-dependent load curve. The final temperature distribution applied to Floor 7 to 14 in the global model is shown in Figure 12-34.

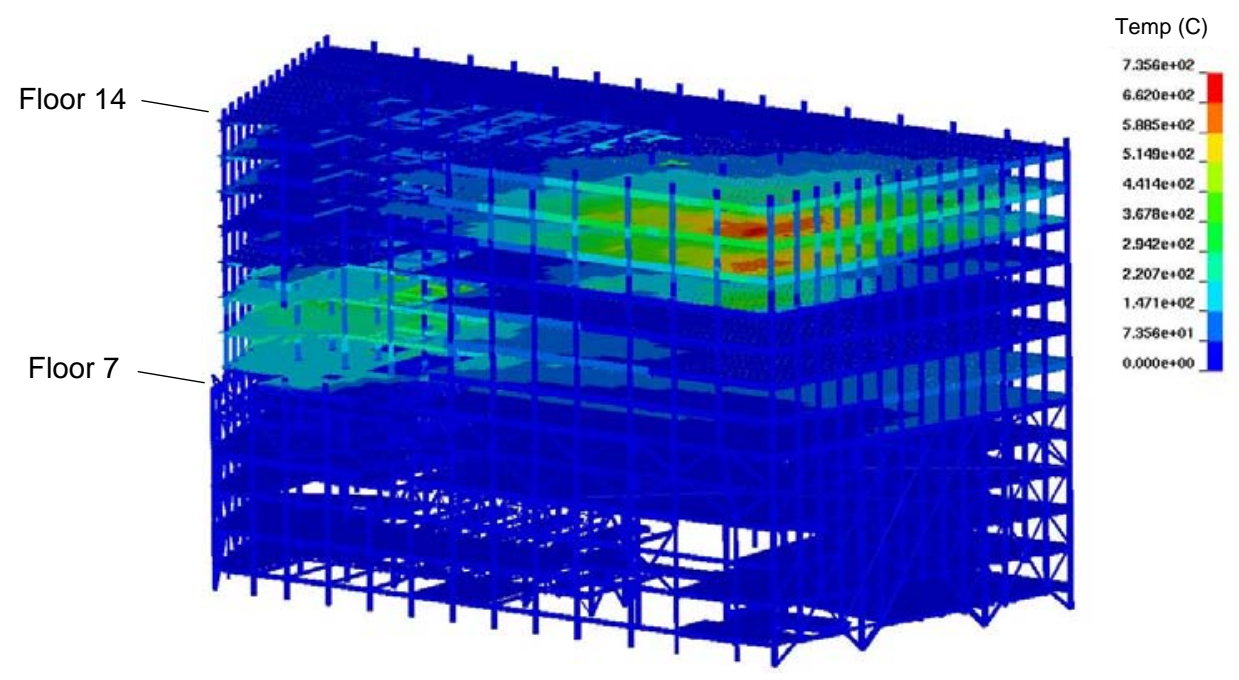

Figure 12-34. Temperature profile in Floors 7 through 14. 


\section{Fire-induced Damage}

The final step in the initialization process was to apply the fire-induced damage obtained from the 16 story ANSYS model (Chapter 11). The ANSYS model estimated the damage that occurred as the fires grew and spread on Floors 7, 8, and 9 and Floors 11, 12, and 13. The LS-DYNA model, by comparison, used one temperature profile at the time when damage was transferred from the ANSYS model.

The ANSYS model was capable of capturing the progression of accumulated damage over a long period of time, as fires spread through the lower floors. In contrast, the LS-DYNA model was able to predict damage due to the temperatures for a specific point in time and the subsequent dynamic progression of failures leading to the global collapse of WTC 7.

The fire-induced damage estimated from the ANSYS model was, therefore, input to the LS-DYNA model as the final step before analyzing the structural response. The damage was applied immediately after the temperatures were applied, by a sudden removal of damaged or failed elements calculated in the ANSYS analysis.

The fire-induced damage included buckled beams and connection damage. Buckled beams were modeled by removing a few flange and web elements, such that the beam would lose its axial and flexural strength, but the weight of the beam would remain in the calculation. An example of how buckled beams were modeled at the southeast corner in Floor 14 of the global model is shown in Figure 12-35. Contours shown are steel temperatures with a range of $0{ }^{\circ} \mathrm{C}$ to $736^{\circ} \mathrm{C}$.

The connection damage data from ANSYS was transferred to the LS-DYNA global model using a damage index (Section 11.5). The damage index described the degree of connection damage according to the following groups: 0 to $0.25,0.25$ to $0.5,0.5$ to 0.75 , and 0.75 to 1.0 , where 0 was no damage and 1.0 was failure. Horizontal support and vertical support were specified separately. Due to the coarseness of the shell element modeling of the fin, knife, and header connections in the LS-DYNA model, approximations of the damage state were made as shown in Figure 12-36.

Damage application to the seated connections was more straightforward. Discrete elements corresponding to the calculated number of failed bolts were removed for a given connection. Also, specified seat or clip angle damage was applied directly in the global model.

After the application of the fire-induced damage, further damage and failure progression were predicted by allowing the model to progress without further input. 


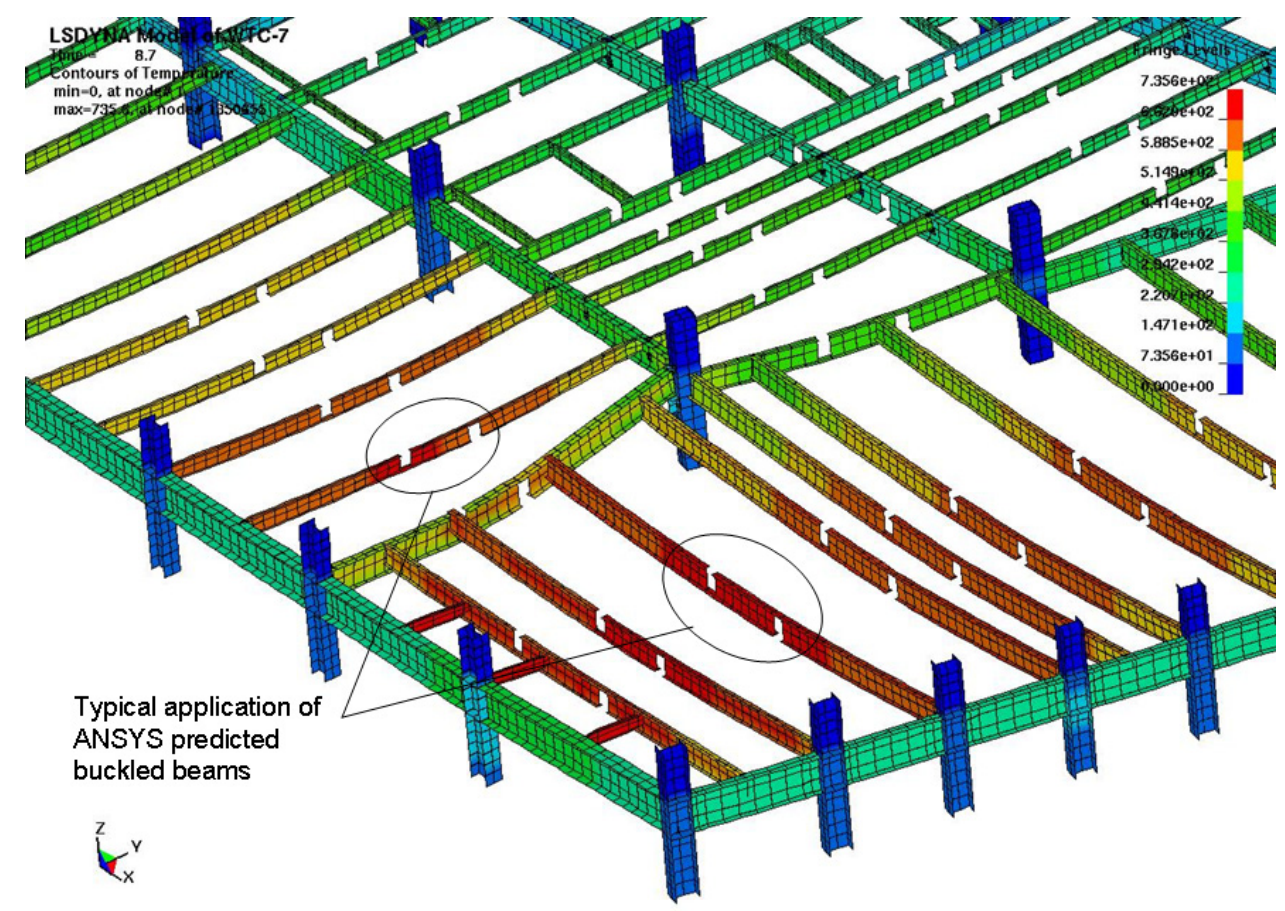

Figure 12-35. Approach used to model buckled beams in LS-DYNA model.
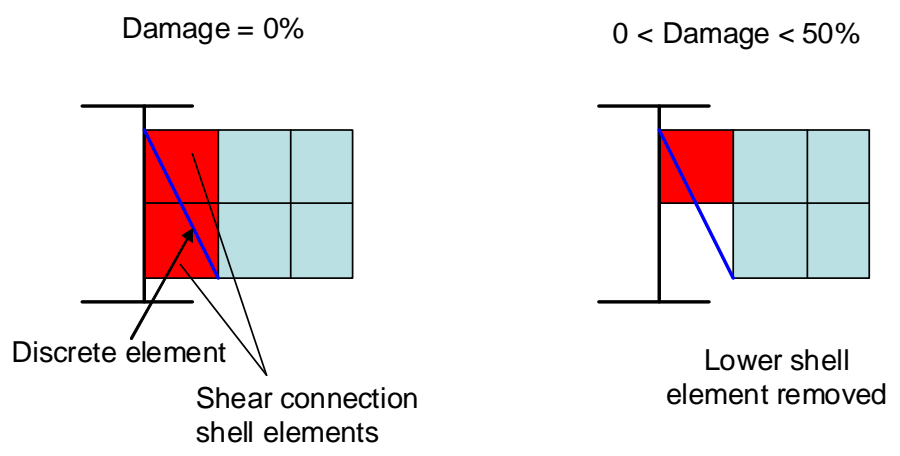

$50=$ Damage $=75 \%$

$75 \%<$ Damage $=100 \%$

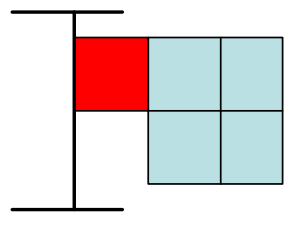

Discrete and lower shell element removed

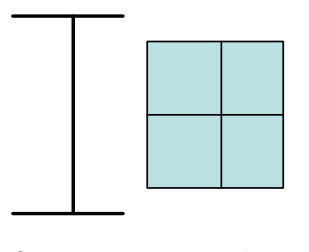

Shear connection failed

Figure 12-36. Shear connection damage application in LS-DYNA model. 


\subsection{GLOBAL ANALYSIS RESULTS}

This section presents the response of the global model of WTC 7 to gravity loading, debris impact damage, thermal loading, and fire-induced damage from the ANSYS analysis (Chapter 11). The global analyses simulated the response of the full 47 story structure to the initial failure event due to fire and the resulting component and subsystem failures to determine the events that led to the global collapse of WTC 7.

The following analysis results are presented:

Section 12.4.1 describes the building response to gravity loads.

Section 12.4.2 describes the building response to the debris-impact damage from the collapse of WTC 1.

Section 12.4.3 describes the building response to the application of fire-induced temperatures in the structural components.

Section 12.4.4 describes the building response to debris impact damage, temperature effects (Case B, $4.0 \mathrm{~h}$ temperatures), and fire-induced damage based on the 16 story ANSYS analysis (Case B, 4.0 h damage).

Section 12.4.5 describes the building response to debris impact damage, temperature effects (Case B, $4.0 \mathrm{~h}$ temperatures), and fire-induced damage based on the 16 story ANSYS analysis (Case B, 3.5 h damage).

Section 12.4.6 describes the building response to temperature effects (Case B, $4.0 \mathrm{~h}$ temperatures), and fire-induced damage based on the 16 story ANSYS analysis (Case B, $4.0 \mathrm{~h}$ damage), but without debris impact damage.

Section 12.4.7 describes the building response to a classic progressive collapse analysis, where a section of Column 79 between Floors 11 and 13 was removed. There was no debris impact or fire-induced damage.

The global analysis at $4.0 \mathrm{~h}$ had the best estimate of debris impact damage and fire-induced damage. The global analysis with fire-induced damage at $3.5 \mathrm{~h}$ was conducted to determine if an earlier fire-induced damage state was sufficient to initiate a global collapse of WTC 7. The global analysis without debris impact damage was conducted to determine the contribution of debris impact damage to the global collapse sequence of WTC 7.

\subsubsection{Building Response to Gravity Loads}

Figure 12-37 shows the vertical displacements calculated at the end of the application of the gravity loads. The figure shows that the largest floor displacements were estimated at the northeast quadrant of the building. A check on the accuracy of the applied loads was performed. The expected load due to dead, superimposed dead, and service live loads above Floor 8 based on the design drawings (after adjusting for service live loads instead of design live loads) was about 174,100 kip. The initialized model 
showed a total load of 172,900 kip, for a difference of about 0.7 percent. Figure 12-38 presents the total load above Floor 8 in the model during gravity initialization. The load increased smoothly as expected and without dynamic effects, indicating the gravity initialization duration of $4.5 \mathrm{~s}$ to full load was adequate.

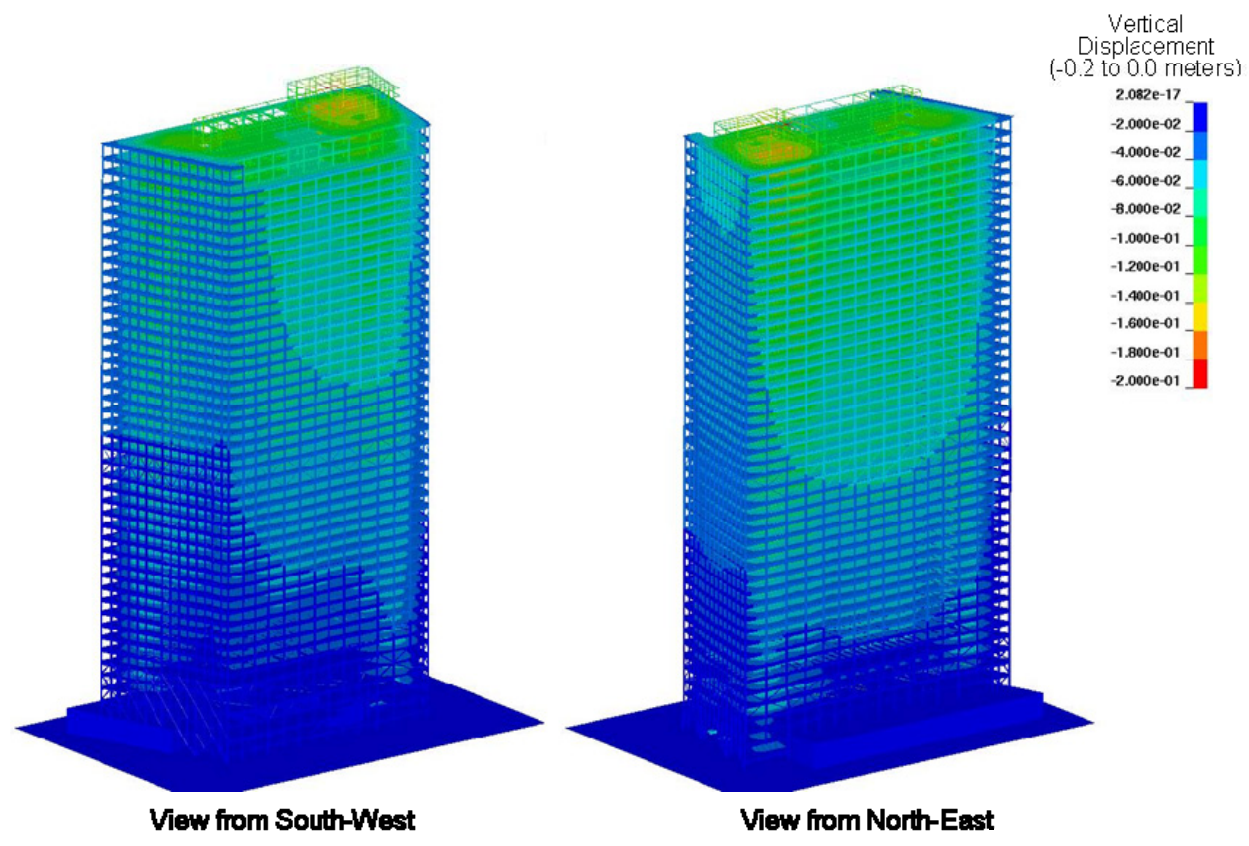

Figure 12-37. Calculated global vertical displacements after gravity initialization.

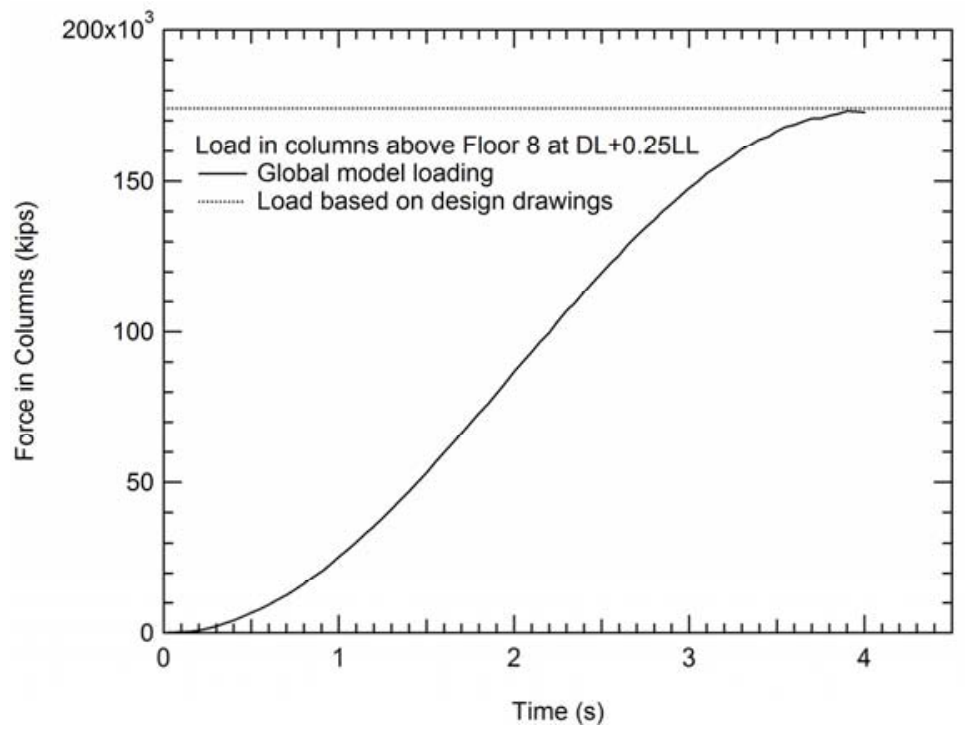

Figure 12-38. Total load history above Floor 8 during gravity initialization.

\subsubsection{Building Response to Debris-Impact Damage}

Subsequent to the application of the gravity loads, damage due to debris impact from the collapse of WTC 1 was applied to the global 47 story model. Figure 12-39 presents the vertical displacements due to 
debris impact damage application. The figure shows a downward displacement of up to 8 in. (about $1 / 900$ of the total building height) on the south face toward Zone 1 damage due to column removal. The analysis shows that the building remained stable and that columns and floors above the damaged zone were able to redistribute the loads through Vierendeel truss action.
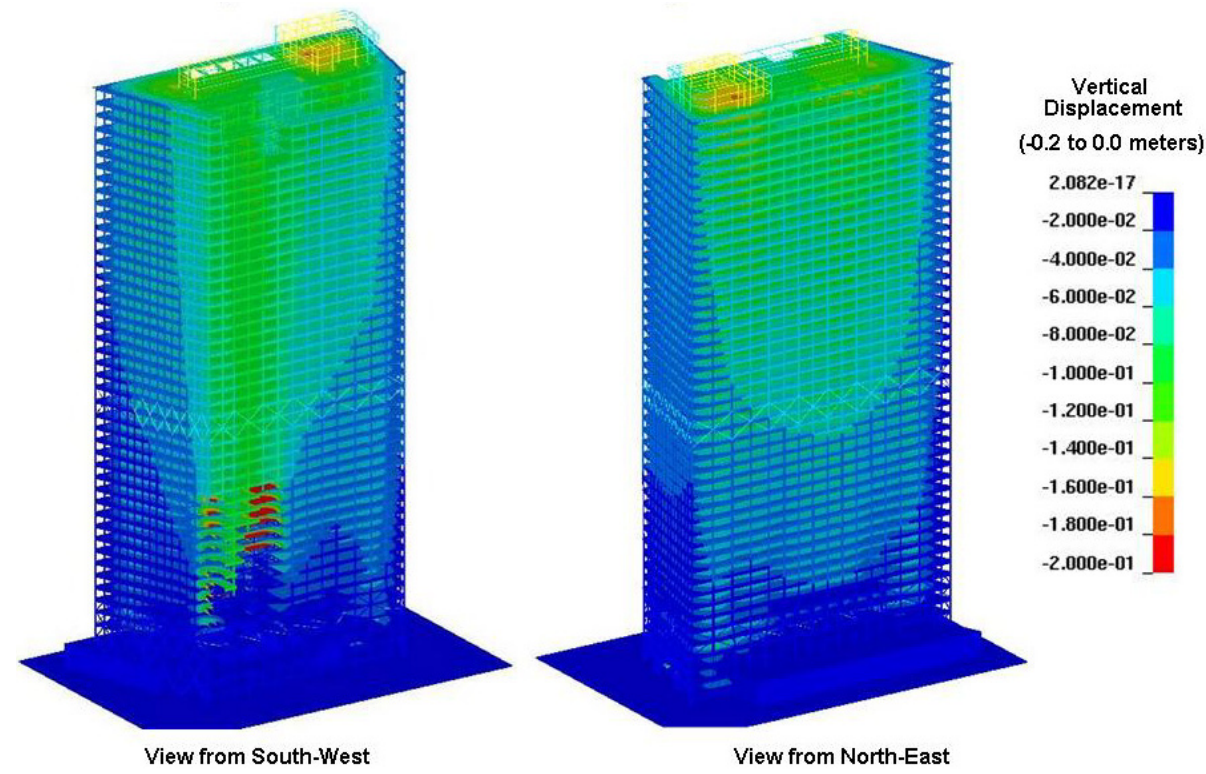

Figure 12-39. Calculated vertical displacements after impact damage.

\subsubsection{Building Response to Temperatures}

Figure 12-40 shows the subsequent change in vertical displacement after Case B, 4.0 hour temperatures were applied. Detail views illustrating the vertical displacements of the lower floors, up to Floor 14, are shown in Figure 12-41 (a) after debris impact damage application and Figure 12-41(b) after full

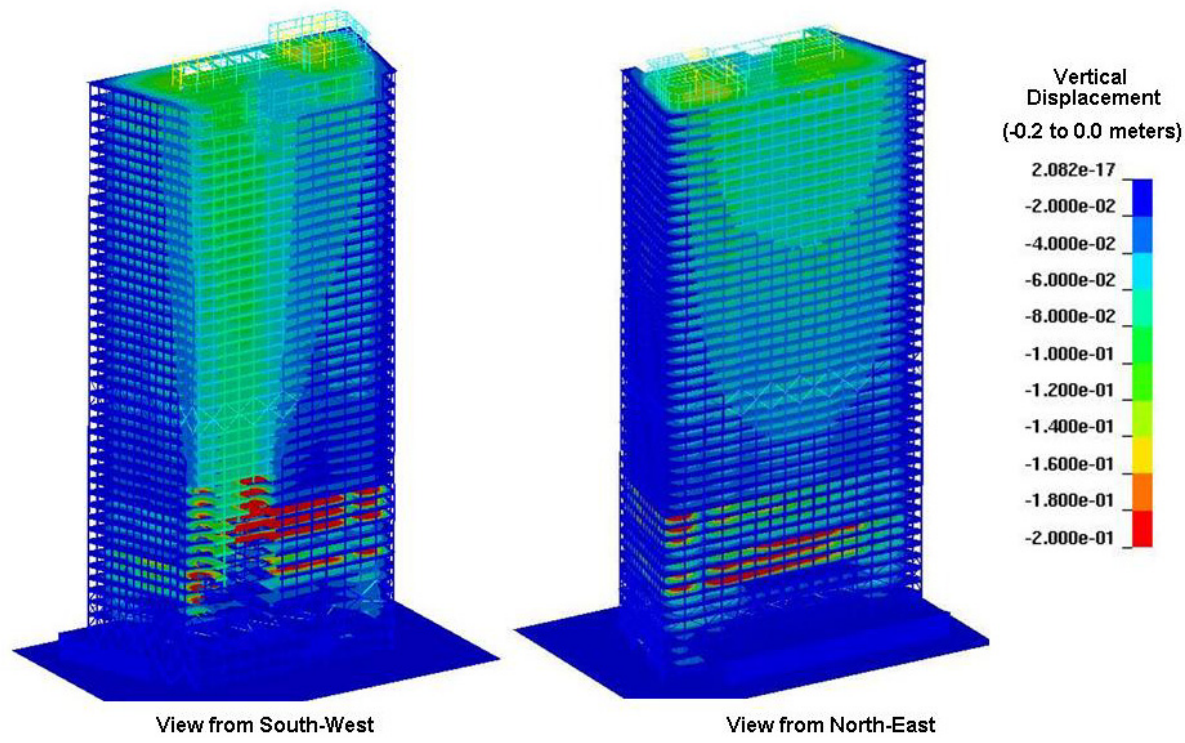

Figure 12-40. Calculated vertical displacements after temperature initialization. 
temperature application. This figure illustrates where the heated floors displaced vertically due to damaged floor framing and connections. The analysis also showed that the combination of the impact damage and thermal loading produced significantly higher stress states throughout the lower floors of the building.

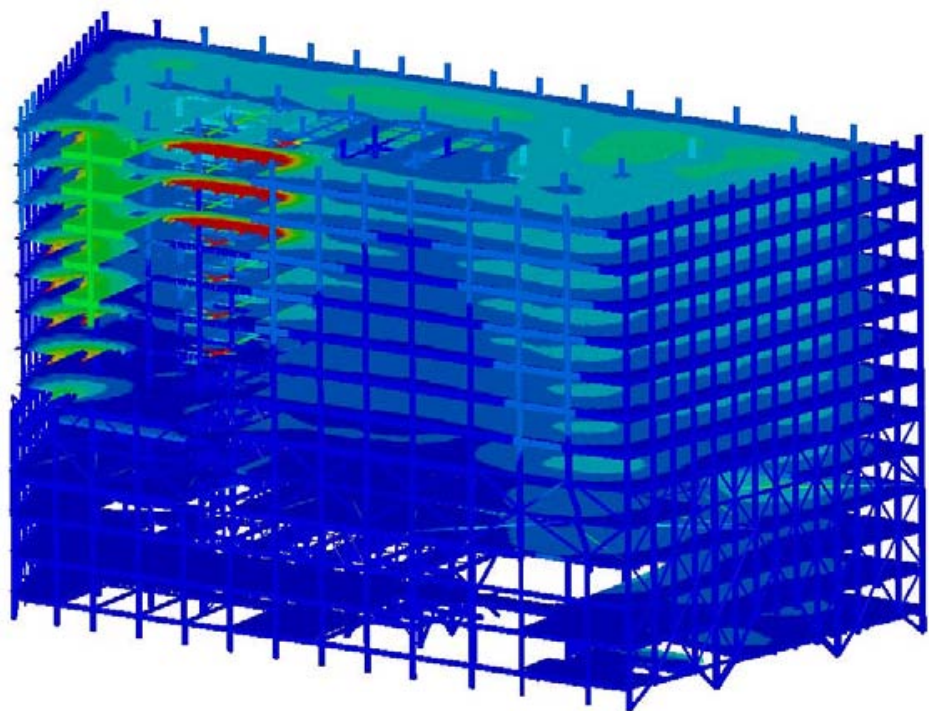

(a) After debris impact damage initialization

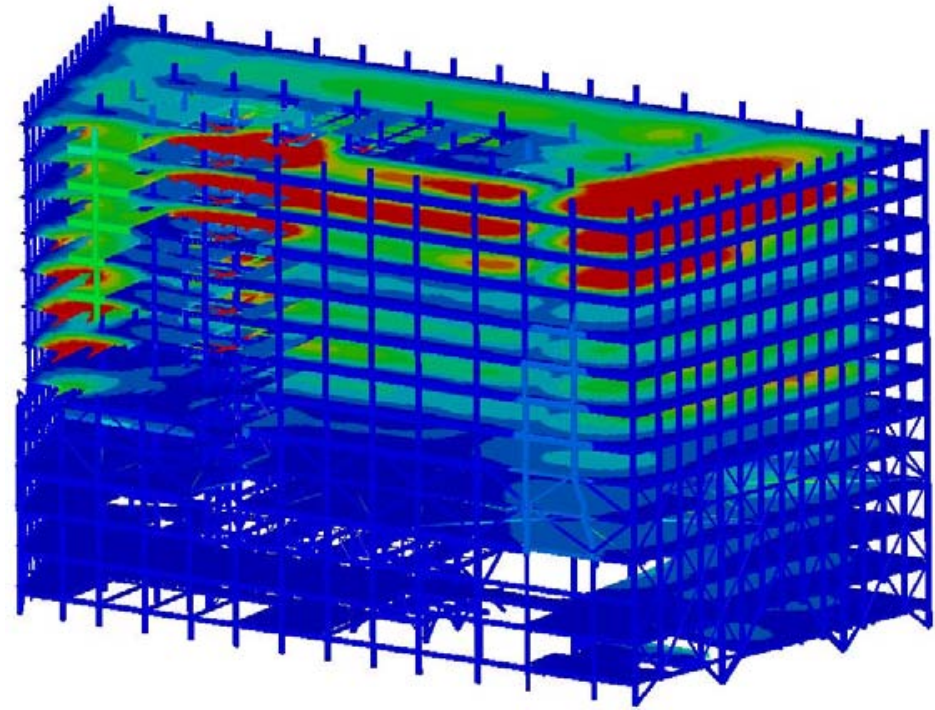

(b) After temperature initialization
Vertical

Displacement

-0.2 to $0 \mathrm{~m}$

(-8 to 0 in)

2.082e-17

$-2.000 \mathrm{e}-02$

$-4.000 \mathrm{e}-02$

$-6.000 \mathrm{e}-02$

$8.000 \mathrm{e}-02$

$-1.000 \mathrm{e}-01$

$-1.200 \mathrm{e}-01$

$-1.400 \mathrm{e}-01$

$-1.600 \mathrm{e}-01$

$-1.800 \mathrm{e}-01$

$-2.000 \mathrm{e}-01$

Vertical

Displacement

-0.2 to $0 \mathrm{~m}$

(-8 to 0 in)

2.082e-17

$-2.000 \mathrm{e}-02$

$-4.000 \mathrm{e}-02$

$-6.000 \mathrm{e}-02$

$8.000 \mathrm{e}-02$

$-1.000 \mathrm{e}-01$

$-1.200 \mathrm{e}-01$

$-1.400 \mathrm{e}-01$

$-1.600 \mathrm{e}-01$

$-1.800 \mathrm{e}-01$

$-2.000 \mathrm{e}-01$

\section{Figure 12-41. Detailed comparison of vertical displacements after damage and temperature initializations.}

\subsubsection{Global Analysis Results with Best Estimate Debris Impact Damage}

Following the application of gravity loading, debris impact damage, thermal loading, and fire-induced damage to floor framing and connections, the global analysis of the WTC 7 collapse progressed to calculate the response of the building. The analysis showed that a global collapse of WTC 7 occurred under the applied loading and damage conditions. 
Two timing reference frames are used when discussing global model results: a calculation reference frame and a collapse reference frame. The LS-DYNA calculation reference frame is described in Section 12.3.2. The collapse reference frame is based on observation times from photographic and videographic records (Chapter 5). The collapse reference time of $0.0 \mathrm{~s}$ starts when a kink was observed in the roofline of the east penthouse, as viewed from the north. In the global analysis results, the kink in the roofline of the east penthouse occurred at $16.0 \mathrm{~s}$ in the calculation reference time. In the following graphics, when both times are quoted, the syntax used is "collapse reference frame (calculation reference frame).”

A series of snapshots of the interior columns and floor systems up to Floor 18 taken, viewed from the southwest (see Figure 12-42, Figure 12-48, Figure 12-49, and Figure 12-52 to Figure 12-55) illustrates the progression of failures in the floors and interior columns of WTC 7. Exterior columns and some of the tenant floor structure spanning between the core and the exterior have been removed from the views to illustrate the damage to the interior of the building. In each figure, contours of resultant lateral displacements are shown. For comparison between snapshots, a constant range of $0 \mathrm{in}$. to $6 \mathrm{in}$. (0 m to $0.15 \mathrm{~m}$ ) was used. Since a resultant lateral displacement is presented, negative and positive values can not be distinguished, and only absolute values are displayed. Any value greater than 6 in. $(0.15 \mathrm{~m})$ remains red in the figure.

The following sequence of events was observed in the analysis, after the application of the loads and damage, which led to the global collapse of WTC 7. For each step, an overview highlighting the major events is presented first, followed by a discussion detailing these events. For further details on the global analysis results, see Chapter 4 of NIST NCSTAR 1-9A.

\section{Initial Local Failure for Collapse Initiation}

The global collapse analysis calculated a sequence of events that resulted in the buckling of critical Column 79.

The floor framing structure was thermally weakened at Floors 8 to 14, with the most substantial fireinduced damage occurring in the east region of Floors 12, 13, and 14. Even though each floor had been weakened over hours of exposure to separate and independent fires, it was not until there was substantial damage to the long span floors in the northeast region of Floor 13 that the initial failure event, i.e., buckling of Column 79, was triggered.

After the fire-induced ANSYS damage was applied, floor sections surrounding Columns 79 to 81 on Floors 13 and 14 collapsed to the floors below, as shown in Figure 12-42. The LS-DYNA analysis calculated the dynamic response of the structure to the floor failures and resulting debris impact loads on the surrounding structure. The thermally weakened floors below Floors 13 and 14 could not withstand the impact from the collapsing floors, resulting in sequential floor collapses. The floor systems progressively failed down to Floor 5, where the debris accumulated, as shown in Figure 12-43.

Figure 12-43 shows a cutaway view that illustrates the structural condition surrounding Column 79 as it buckled to the east. Figure 12-43 includes resultant lateral displacements and column axial stress histories for Columns 79 to 81 . The plots show that Column 79 buckled $1.3 \mathrm{~s}$ before the kink was observed in the east penthouse roof framing (which occurred at $0 \mathrm{~s}(16.0 \mathrm{~s})$ in the analysis). The rapid increase in lateral displacement indicates column buckling. Likewise, the axial column stresses indicated a rapid loss of stress at the time, signifying column buckling. Column 79 was laterally unsupported in the 
east-west and south directions between Floors 5 and 14. There was still some lateral support in the north direction at Floors 8 to 12 and Floor 14, as the erection bolts in the seated connections had all failed at these girder ends, but the girders had not walked off the bearing seats. Thus, these girder connections possibly prevented lateral displacement in the north direction, but did not resist lateral displacements in the east, west, or south direction. At Floor 14, the girder to the west of Column 79 (between Column 79 and 76) was still attached and provided lateral restraint from the west. Figure 12-44 illustrates the girderto-column connection status at the time of buckling of Column 79.

A separate global analysis of the structure with the same gravity loading, debris impact damage, and thermal loading, but with fire-induced damage from the ANSYS analysis at $3.5 \mathrm{~h}$ (instead of $4.0 \mathrm{~h}$ ) showed that interior columns did not buckle (Section 12.4.5). The damage state at $3.5 \mathrm{~h}$ primarily included failure to beams and connections at the south and southeast regions of the affected floors. This global analysis, therefore, indicated that thermally-induced damage in the southeast floor region was not sufficient to cause an initial failure event.

The buckling failure of Column 79 was the initial failure event that led to the global collapse of WTC 7, as will be shown in the subsequent sections.

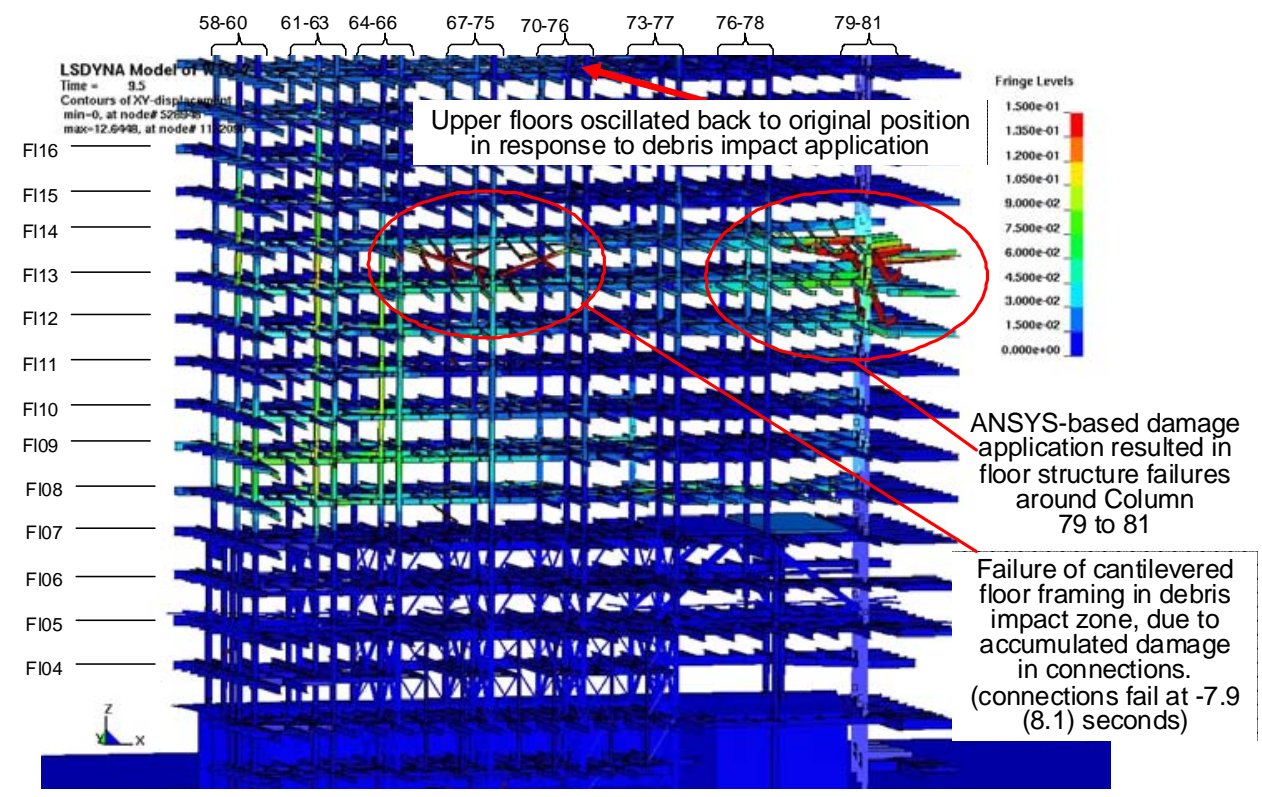

Figure 12-42. The collapse of Floors 13 and 14 in the northeast region [Time: $-6.5(9.5) \mathrm{s}]$ 


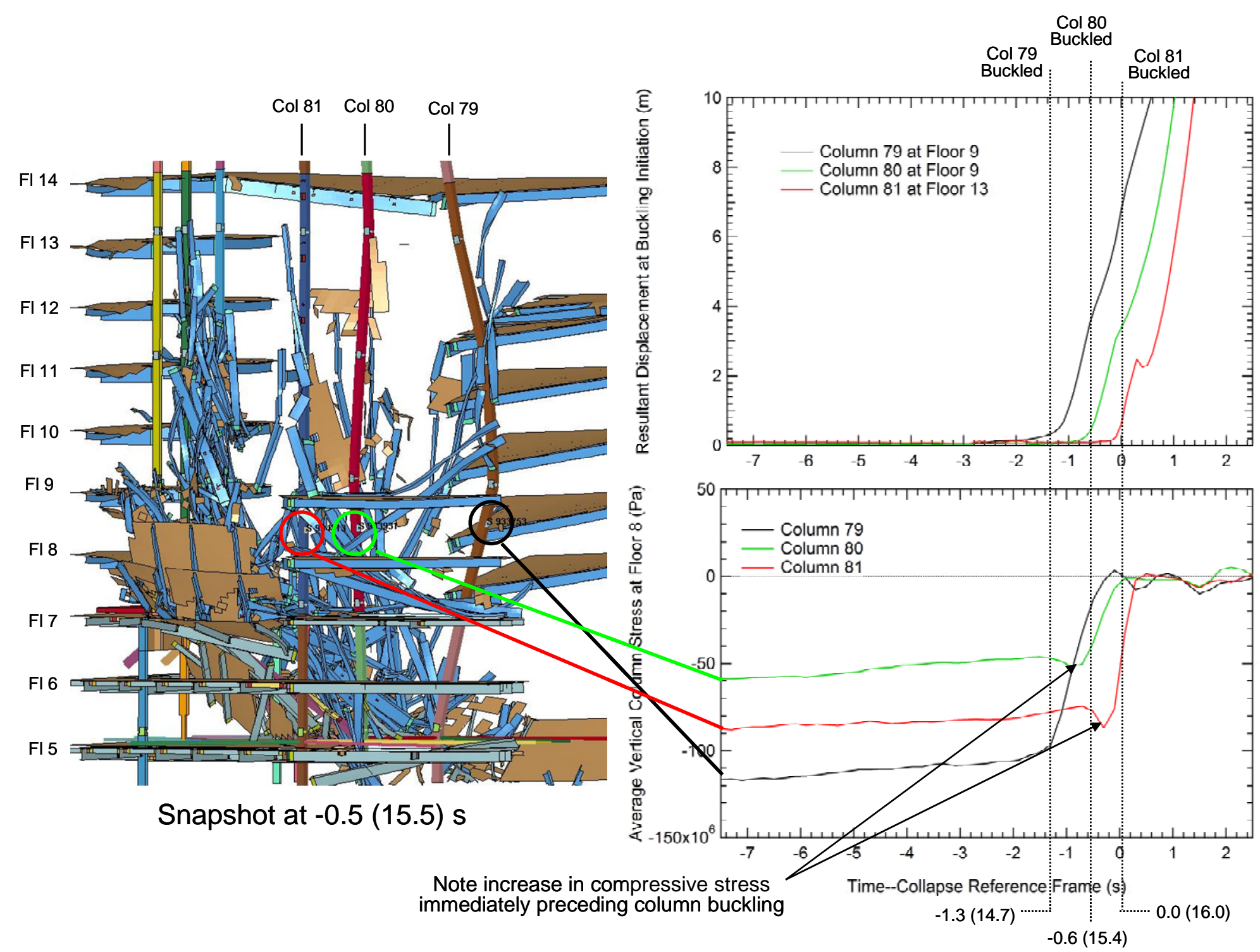

Figure 12-43. Column 79 to 81 stress and displacements. 


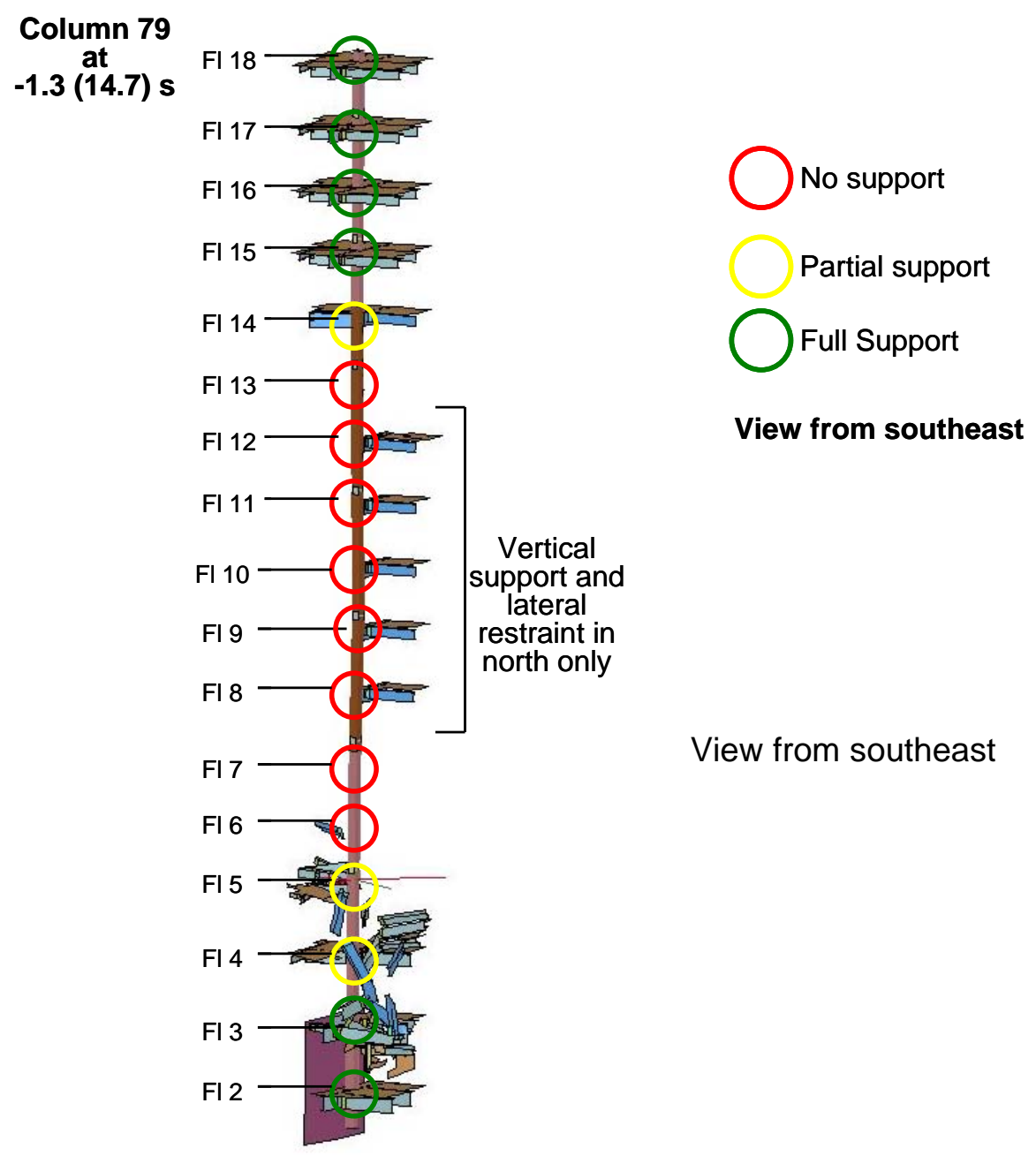

Figure 12-44. Column 79 lateral support status at time of buckling initiation.

\section{Vertical Progression of Failure}

The global collapse analysis showed that the buckling of Column 79 (the collapse initiation event) initiated vertical progression of failure of the floor systems on the east side all the way up to the top of the building. Buckling of Column 79 led to a cascading failure of adjacent interior Columns 80 and 81 on the east side of the building.

Figure 12-45 shows that after Column 79 buckled, it started moving downward at the roof level $0.2 \mathrm{~s}$ later. This led to a kink in the east penthouse roof framing, as shown in Figure 12-46, that was visible in videos taken from the north $1.1 \mathrm{~s}$ later.

The cascading failures of the floors surrounding Column 79 on Floors 6 to 14 led to increased unsupported length in Column 80. Column 80 became laterally unsupported, as shown in Figure 12-47. Column 80 buckled about 0.8 s after Column 79 buckled, as shown in Figure 12-43. 
In a similar fashion, Column 81 became laterally unsupported in both directions between Floors 7 to 15 , as a result of the progressive floor system failures that occurred as both Columns 79 and 80 buckled (Figure 12-47). Column 81 buckled about $1.3 \mathrm{~s}$ after Column 79 buckled, as shown in Figure 12-43. In addition to axial compressive loads that could cause buckling, the columns were subject to lateral loads from falling debris and failure of girder connections occurred. These lateral perturbations aided the onset of column buckling. Note that Columns 80 and 81 buckled after the vertical progression of floor failures around Column 79.

As Columns 79, 80, and 81 each buckled in turn, their column sections above Floor 14 began to descend downward and pulled the floor structures downward with them, thereby creating a vertical progression of floor collapses across the entire east region of WTC 7. The east penthouse, which was supported by Columns 79, 80, and 81, fell downward.

Figure 12-48 shows a view of the interior of WTC 7 from the southwest from the ground up to Floor 18. The figure shows the vertical progression of floor and column failures on the east side of the building, following the buckling of Columns 79, 80, and 81. 


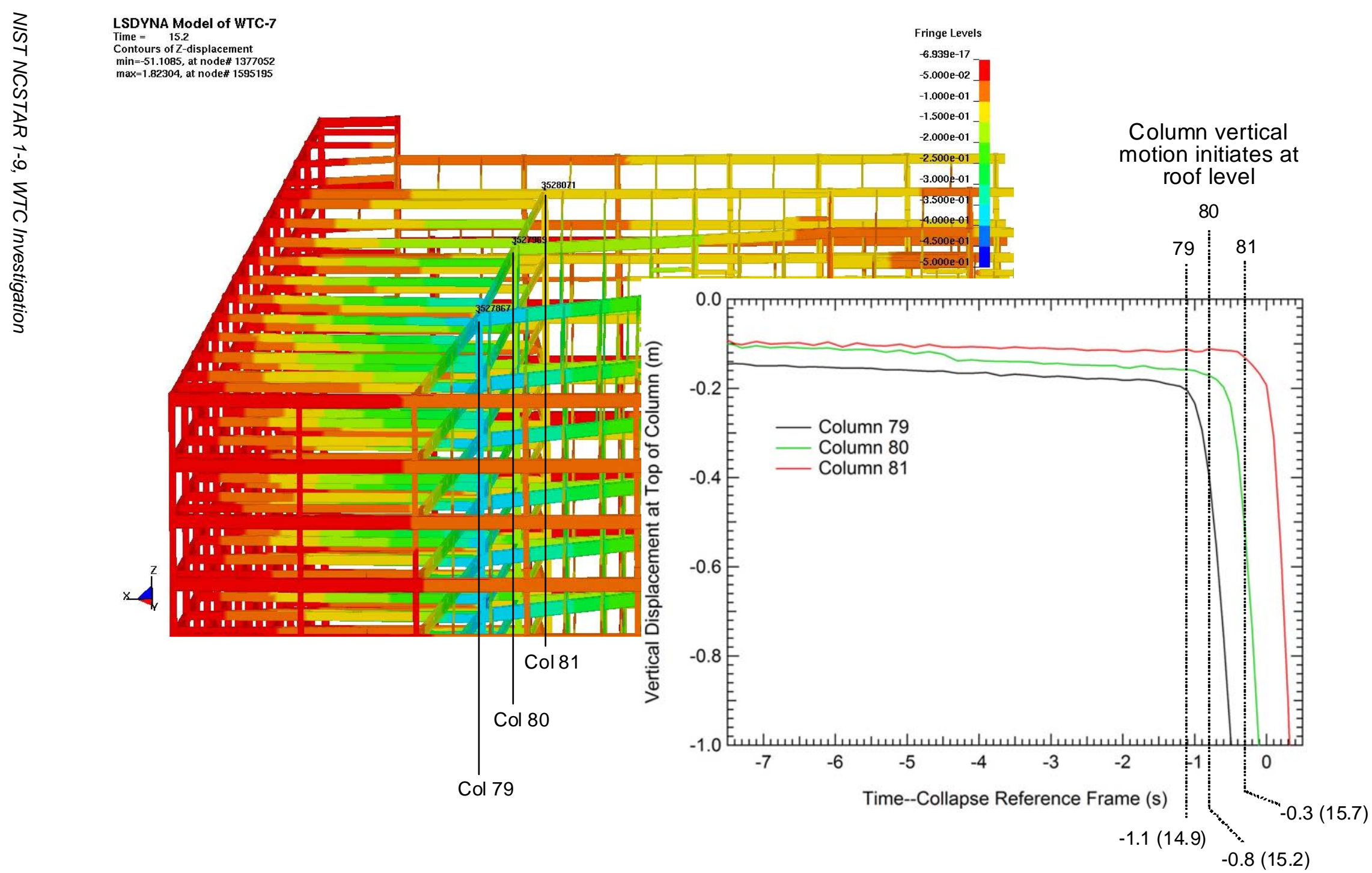

Figure 12-45. Column 79-81 vertical displacement with contours from $-0.5 \mathrm{~m}$ to $0 \mathrm{~m}$. 


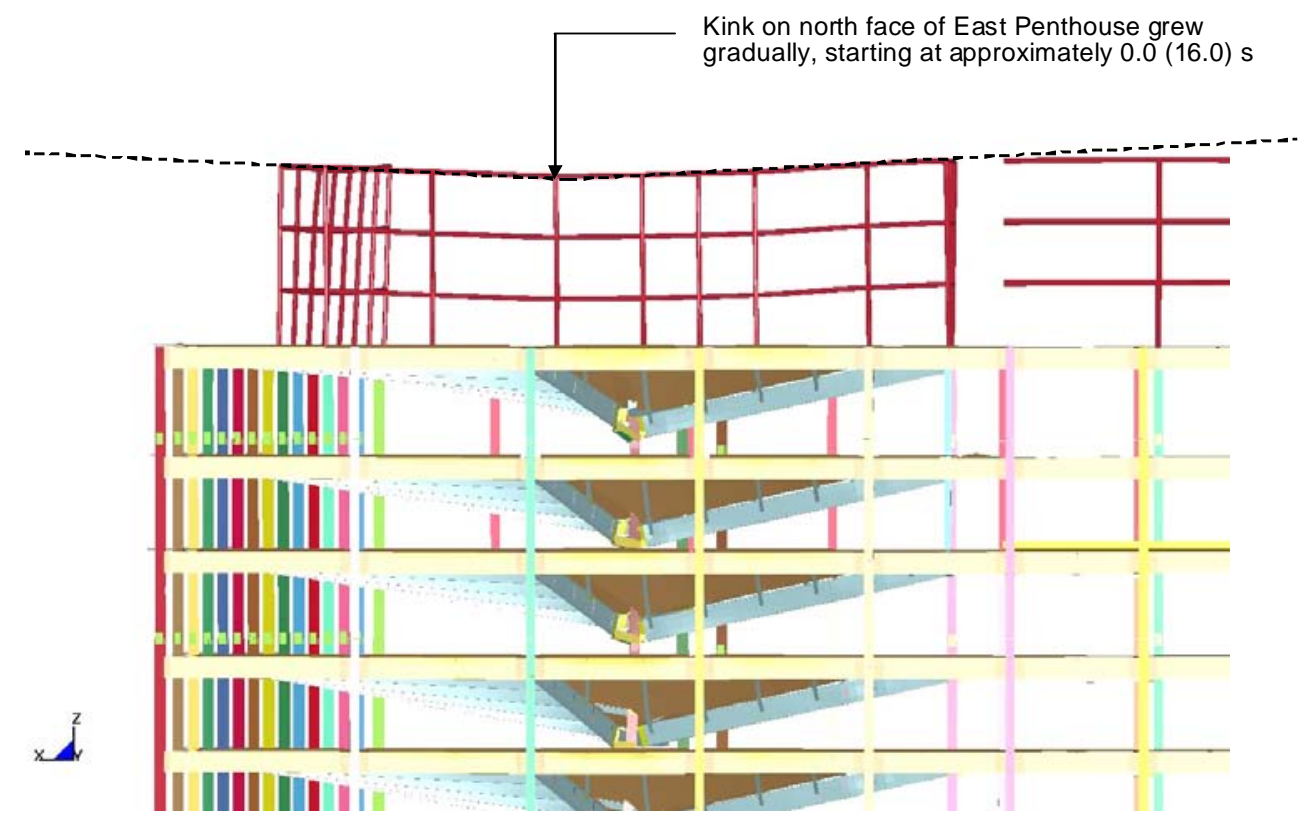

Figure 12-46. Kink on east penthouse as it moves downward [Time 0.2 (16.2) s]. View from north.

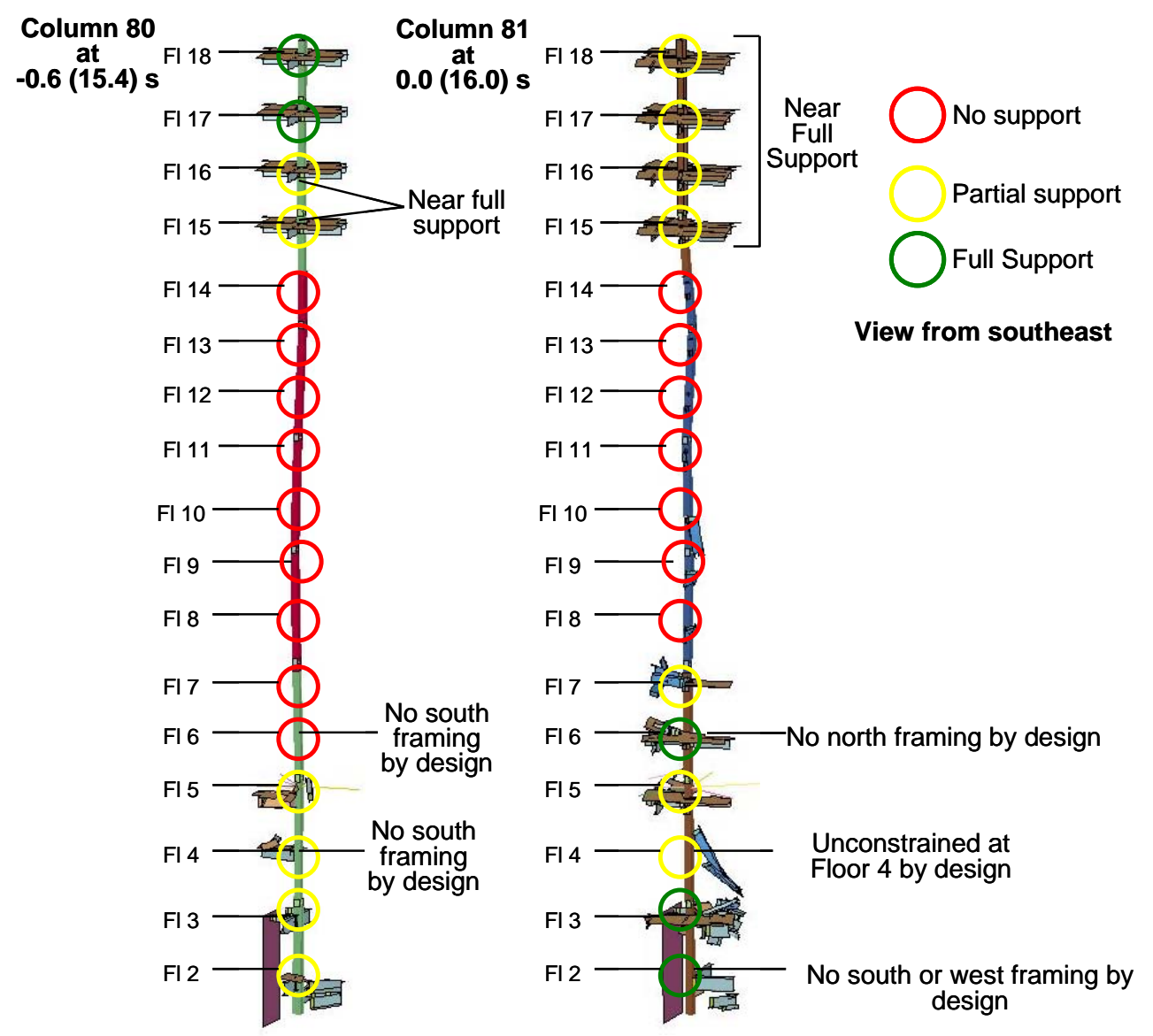

Figure 12-47. Columns 80 and 81 lateral support status at time of buckling initiation. 


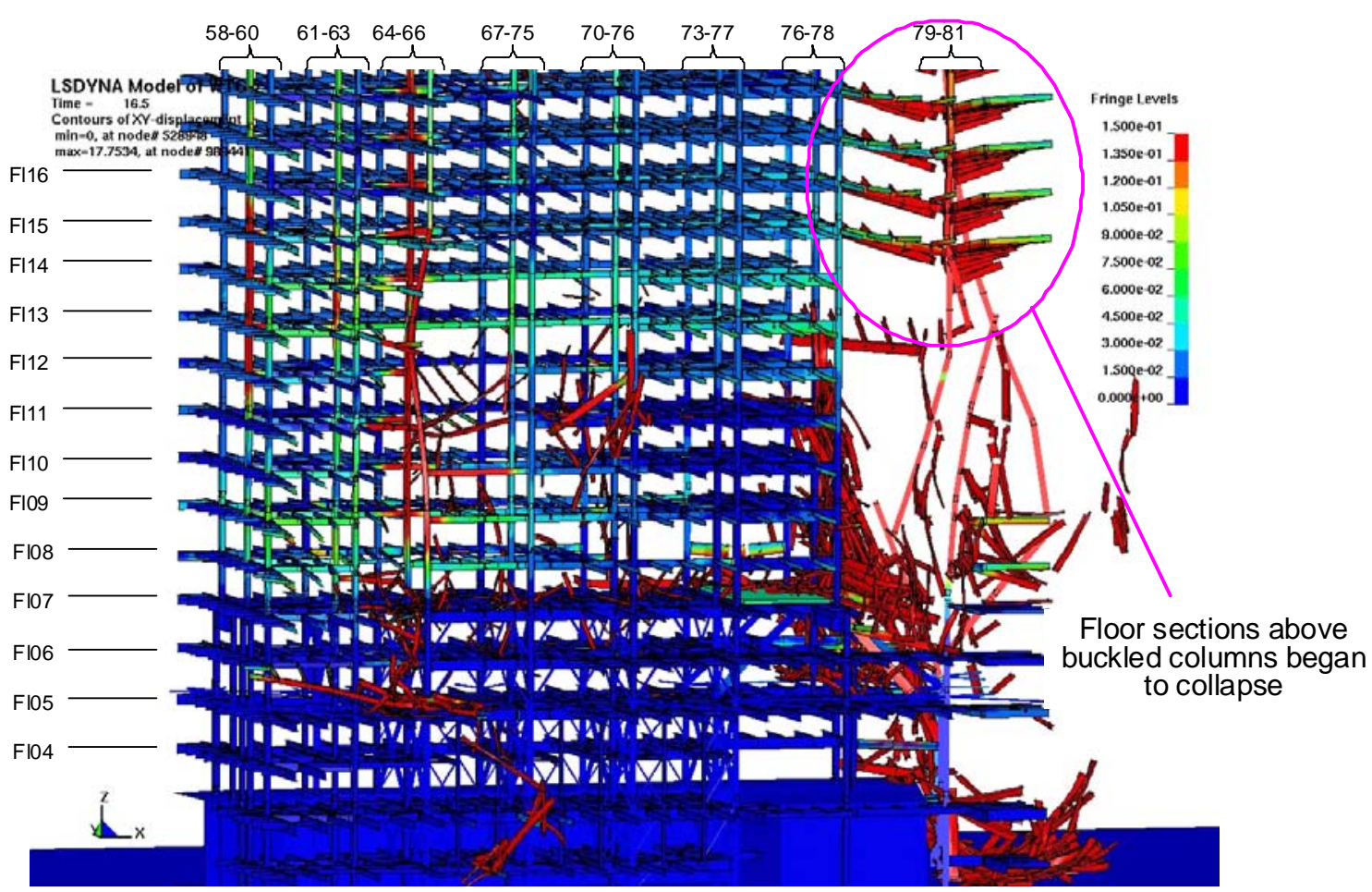

Figure 12-48. Vertical progression of failures on the east side of the building [Time: 0.5 (16.5) s].

\section{Horizontal Progression of Failure}

Following the collapse initiation event and vertical collapse progression, the failures progressed westward.

During the vertical failure progression, the falling floors pulled on adjacent columns until the floor connections failed on the east side of Columns 76, 77, and 78, resulting in a loss of lateral support on the east side, as shown in Figure 12-49. Additionally, debris from floor systems and columns fell from the upper floors, and impacted adjacent intact columns and floors, including Truss 1 and Truss 2 . The accumulation of debris and debris impacts eventually caused Truss 2 to fail, as shown in Figure 12-50 and Figure 12-51.

Figure 12-50 shows the failure of the Truss 2 east diagonal between Columns 77 and 80 . Most of the fallen debris is removed from view for clarity. Truss 2 supported Column 77 and girder MG-23, which was connected to Columns 77 and 78A and supported Column 78 (see Figure 12-12). Truss 1, which can be seen behind Truss 2, had similar construction with diagonal members, and supported Column 76 (see Figure 12-11). Unlike Truss 2, Truss 1 did not collapse in the analysis.

Figure 12-51 illustrates the structure after the diagonal member of Truss 2 failed and shows the axial force in the diagonal member. The plot shows two large debris impacts that caused sudden changes in axial force. The first event is associated with the initial collapse of Floors 8 to 14. The second impact event was caused by the debris impact from the floors above Floor 14. 


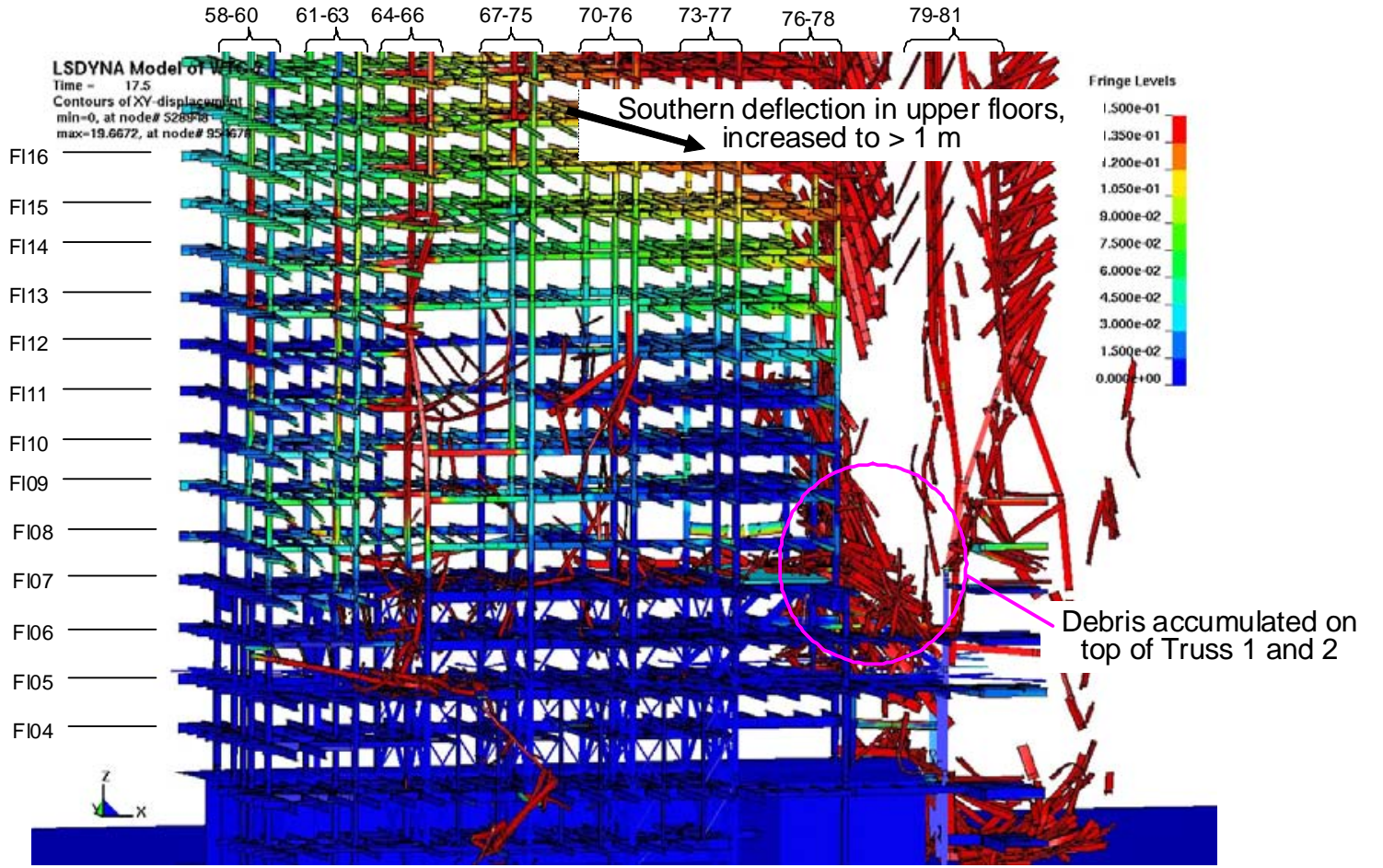

Figure 12-49. Debris from the vertical progression falling onto the lower floors, Trusses 1 and 2, and Columns 76, 77, and 78 [Time: $1.5(17.5) \mathrm{s}$ ].

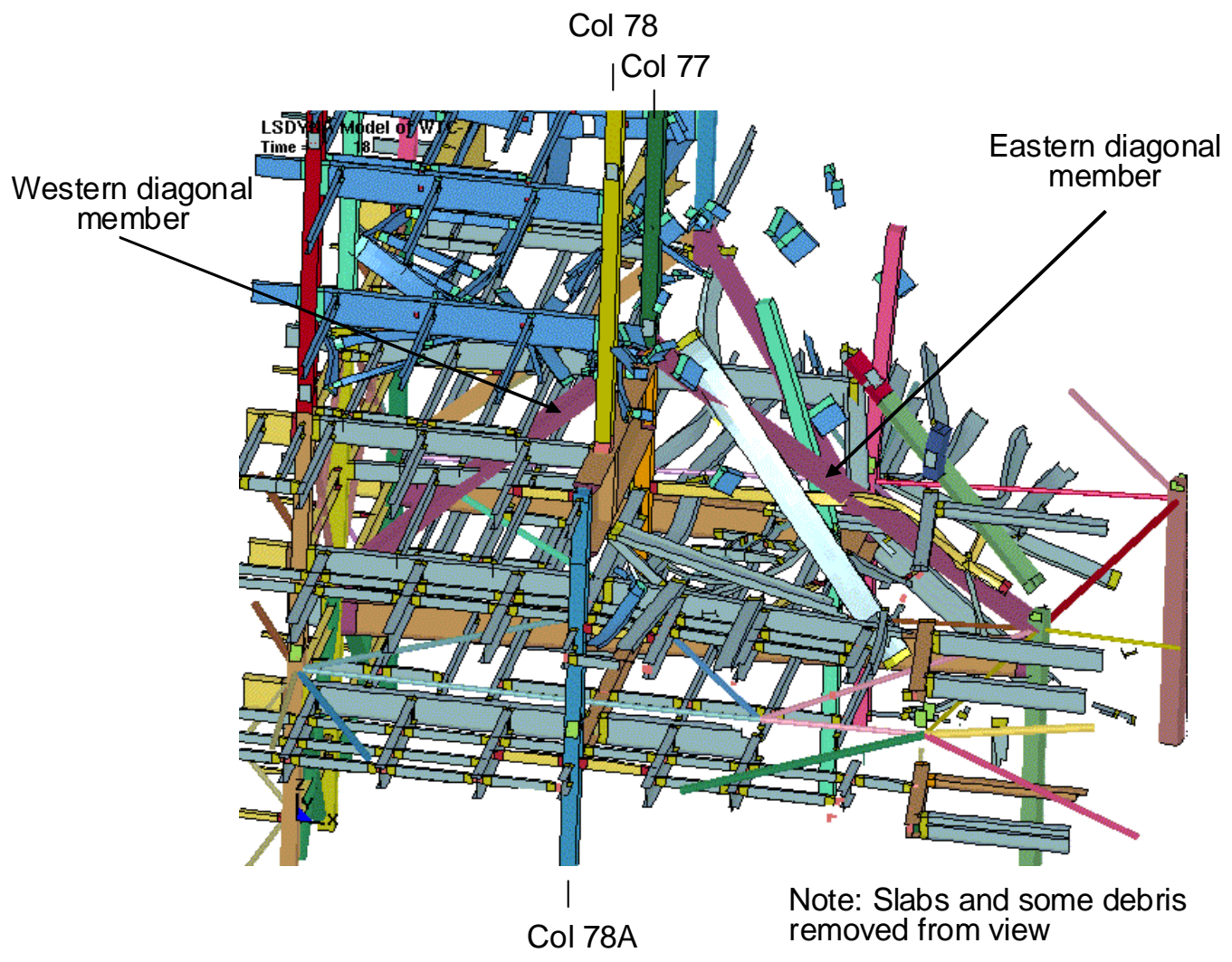

Figure 12-50. Failure of Truss 2 east diagonal. View from southeast and above. 


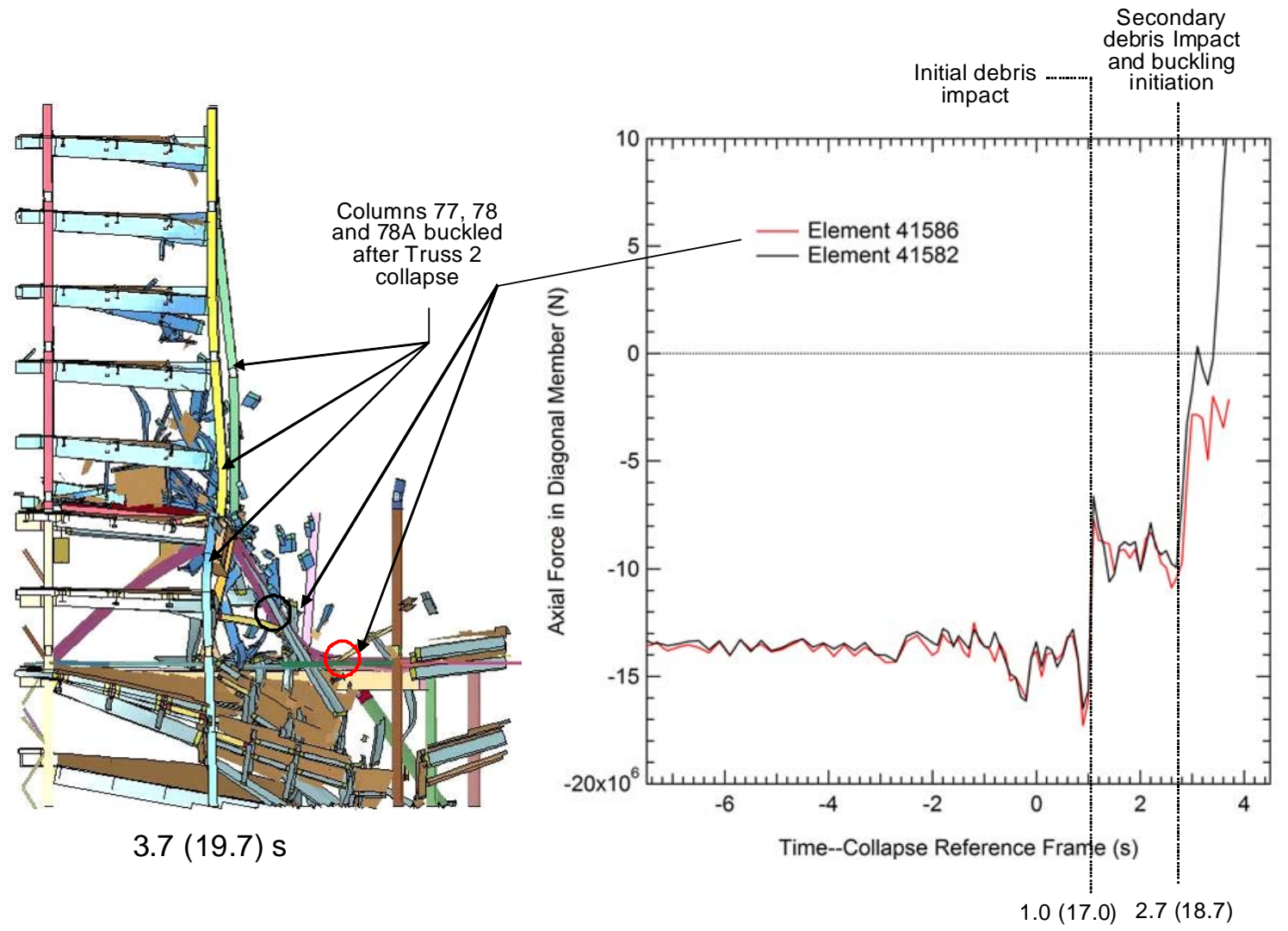

Figure 12-51. Truss 2 collapse. View from south (most of debris removed from view).

The failure of Truss 2 precipitated the buckling of Columns 77 and 78, as shown in Figure 12-52. The loss of the Truss 2 diagonal resulted in a loss of support for Column 77. When the Truss 2 diagonal member failed, support for the girder MG-23 at Column 77 was also lost, which subsequently led to loss of support for Columns 78.

Column 76 failed in the next second, as indicated in Figure 12-53, due to loss of lateral support as the floor connections failed, the impact of falling debris, and load redistribution from adjacent columns.

Columns 73 to 75 buckled in the next second, as shown in Figure 12-54, as the process continued where there were sequential failures of each north-south row of interior columns, due to loss of lateral support as floor connections failed, impact of falling debris, and load redistribution from adjacent failing columns.

Column buckling and floor failures continued to propagate from east to west across the core in the lower floors, until all the interior columns buckled between Floors 9 and 14. This occurred $6.5 \mathrm{~s}$ after the kink was observed in the east penthouse, and $6.7 \mathrm{~s}$ after Column 79 buckled, as indicated by Figure 12-55.

Figure 12-56 shows that west interior Columns 59, 62, 65, and 66, which had damaged floor connections after the debris impact by WTC 1 and by the fires, did not buckle until $4.7 \mathrm{~s}$ after the kink was observed in the east penthouse, or $6 \mathrm{~s}$ after Column 79 buckled. The west interior columns did not buckle until they were affected by the horizontal progression of failures. They also buckled due to loss of lateral support as floor connections failed, impact of falling debris, and the load redistribution from adjacent failing columns. 
The westward progression of column failures also indicated that the failure of Truss 2 was not essential to the failure of Columns 77 and 78, as they would have buckled similar to the other interior columns.

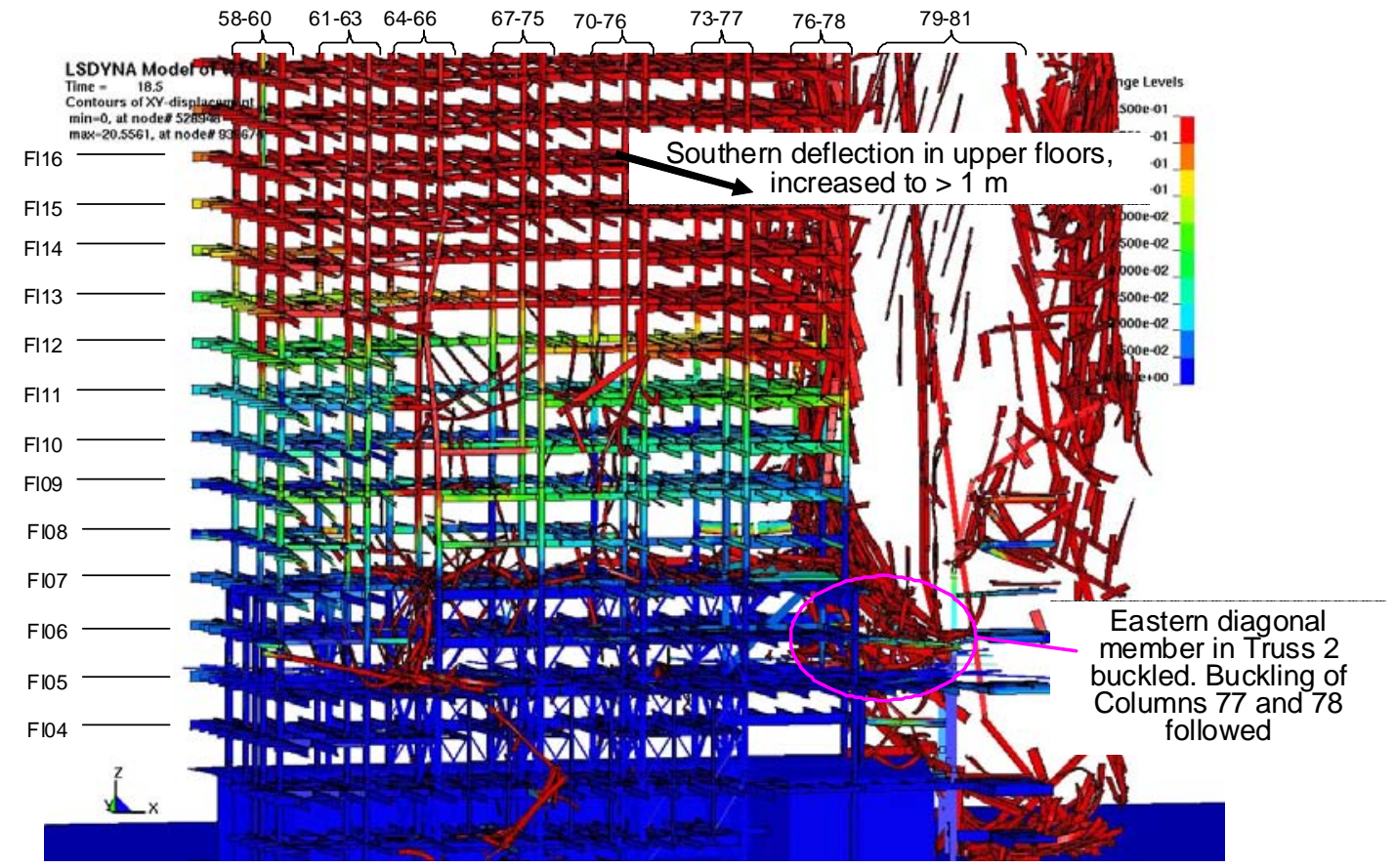

Figure 12-52. Failure of Columns 77 and 78 due to failure of Truss 2 from debris impact [Time: 2.5 (18.5) s].

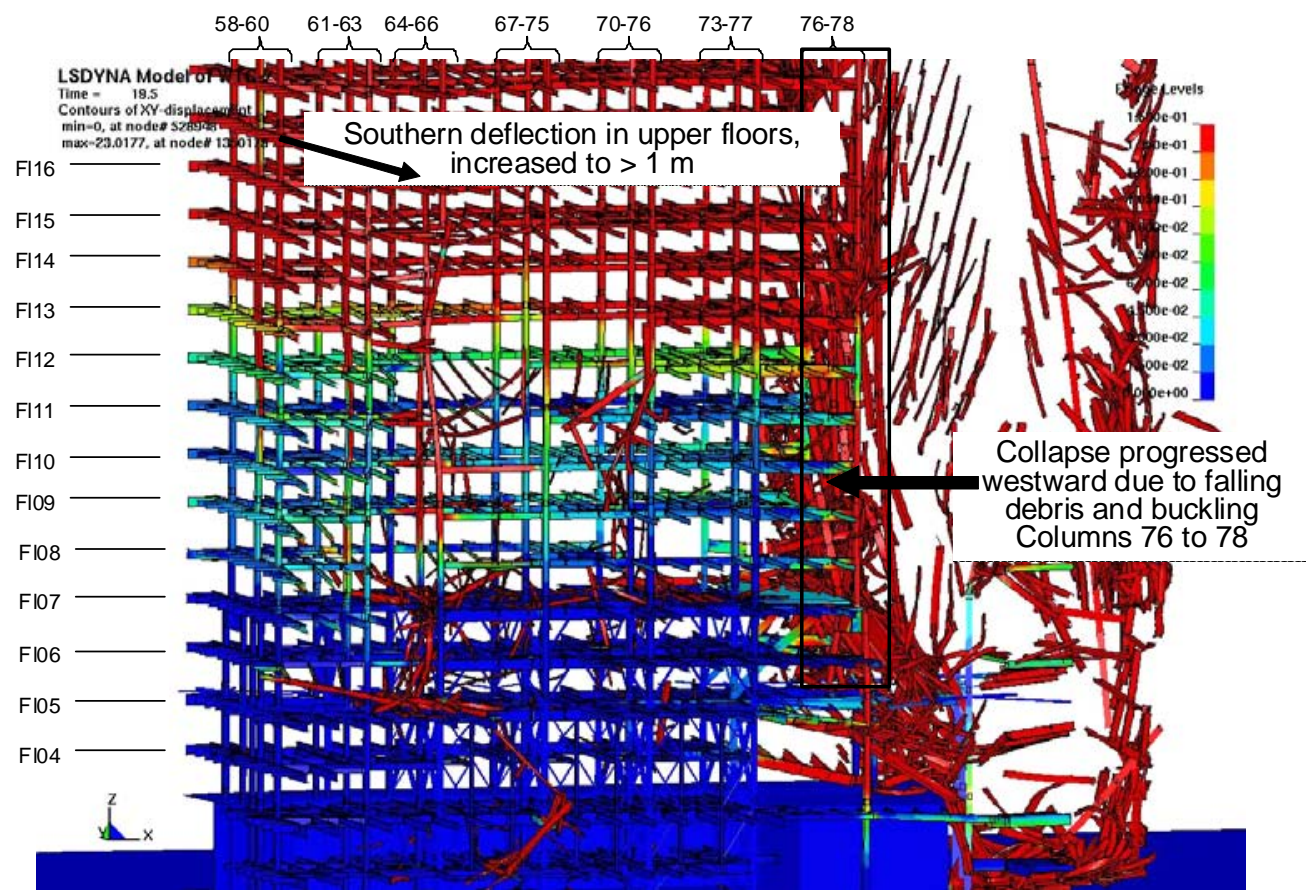

Figure 12-53. Buckling of Column 76 from the load transfer and debris impact from the buckling of Columns 79 and 77 [Time: 3.5 (19.5) s]. 


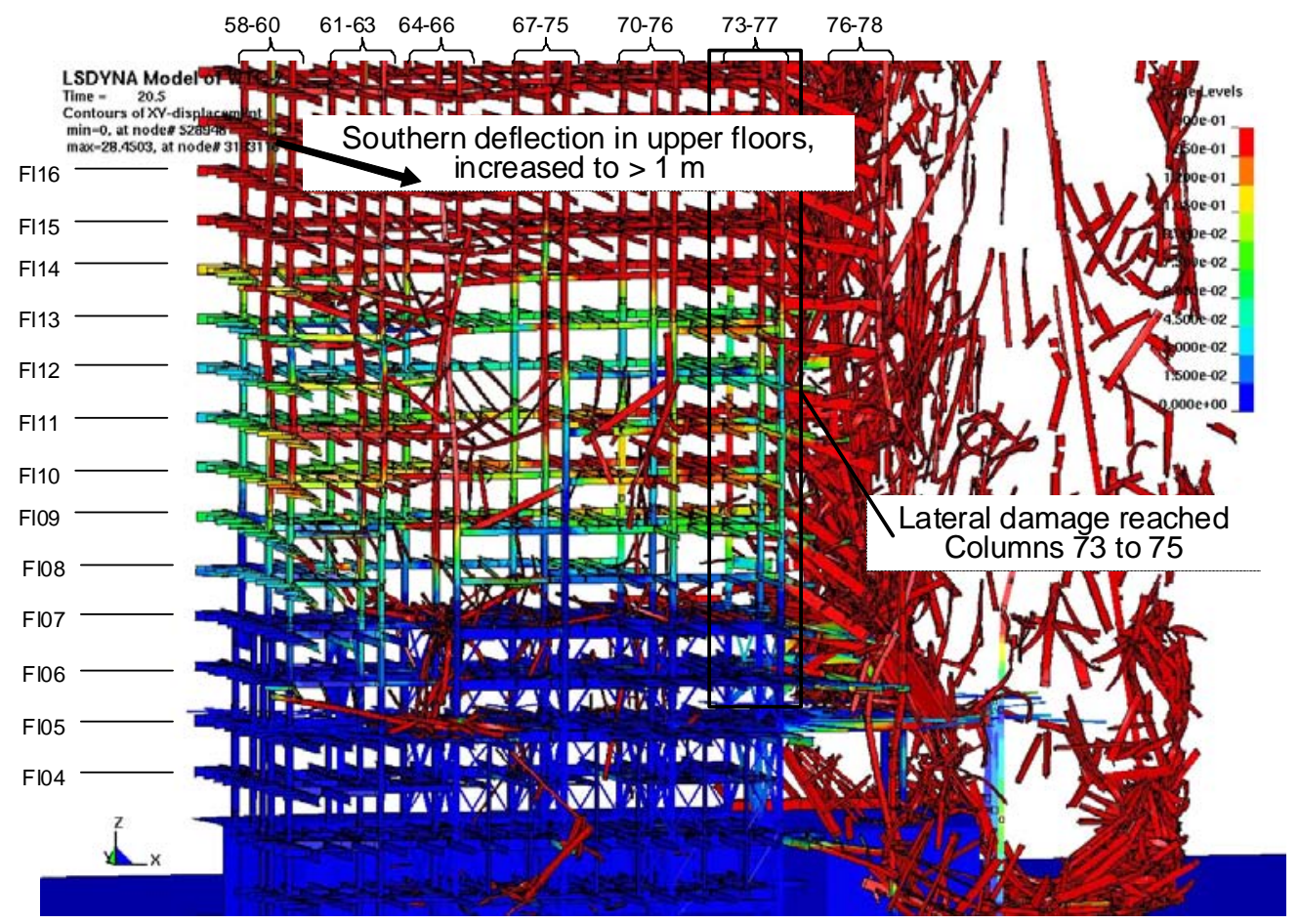

Figure 12-54. Failure of Columns 73 to 75 from the load redistribution and debris impact [Time: $4.5(20.5) \mathrm{s}$ ].

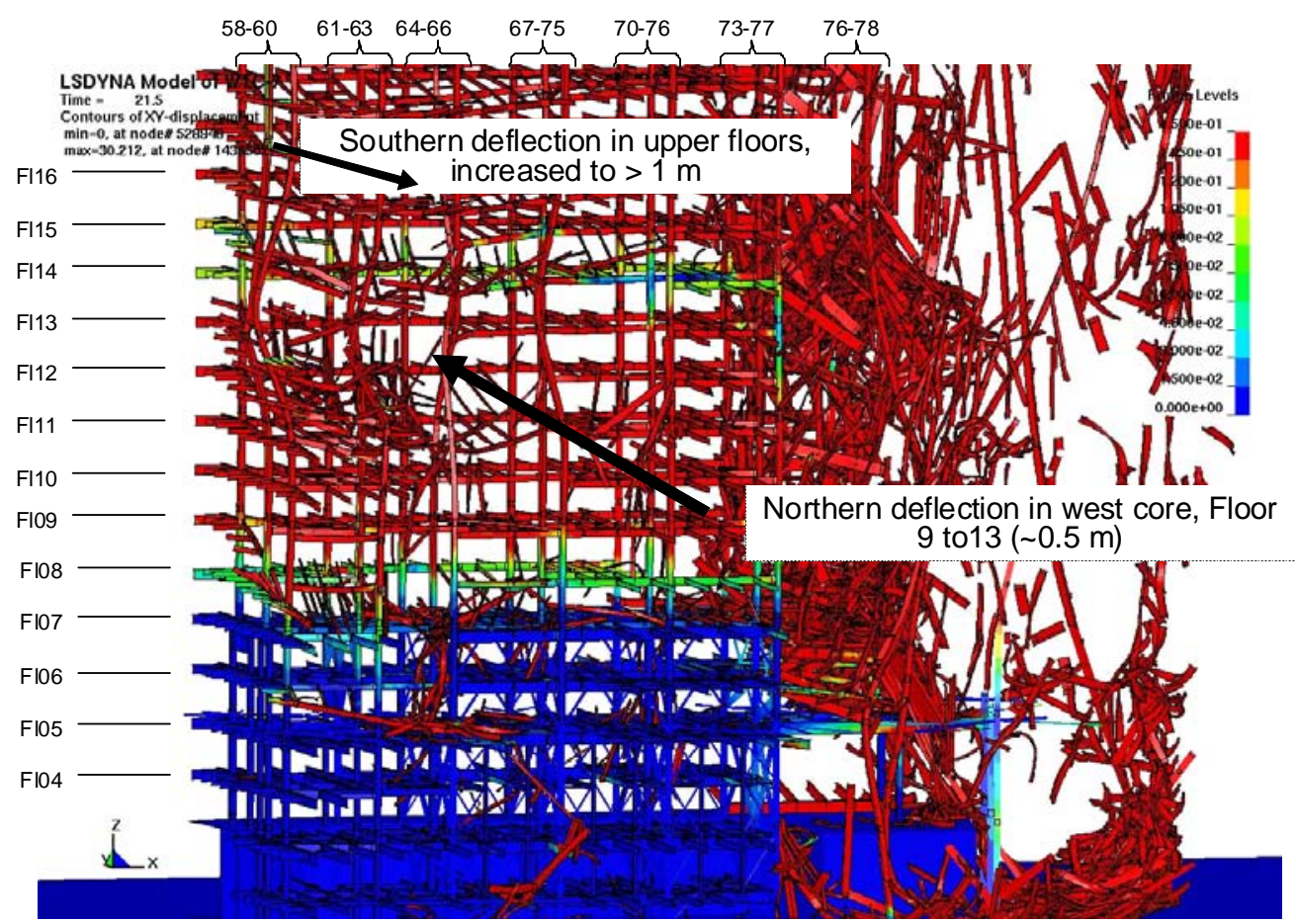

Figure 12-55. Buckling of all interior columns [Time: $6.5(22.5) \mathrm{s}$ ]. 


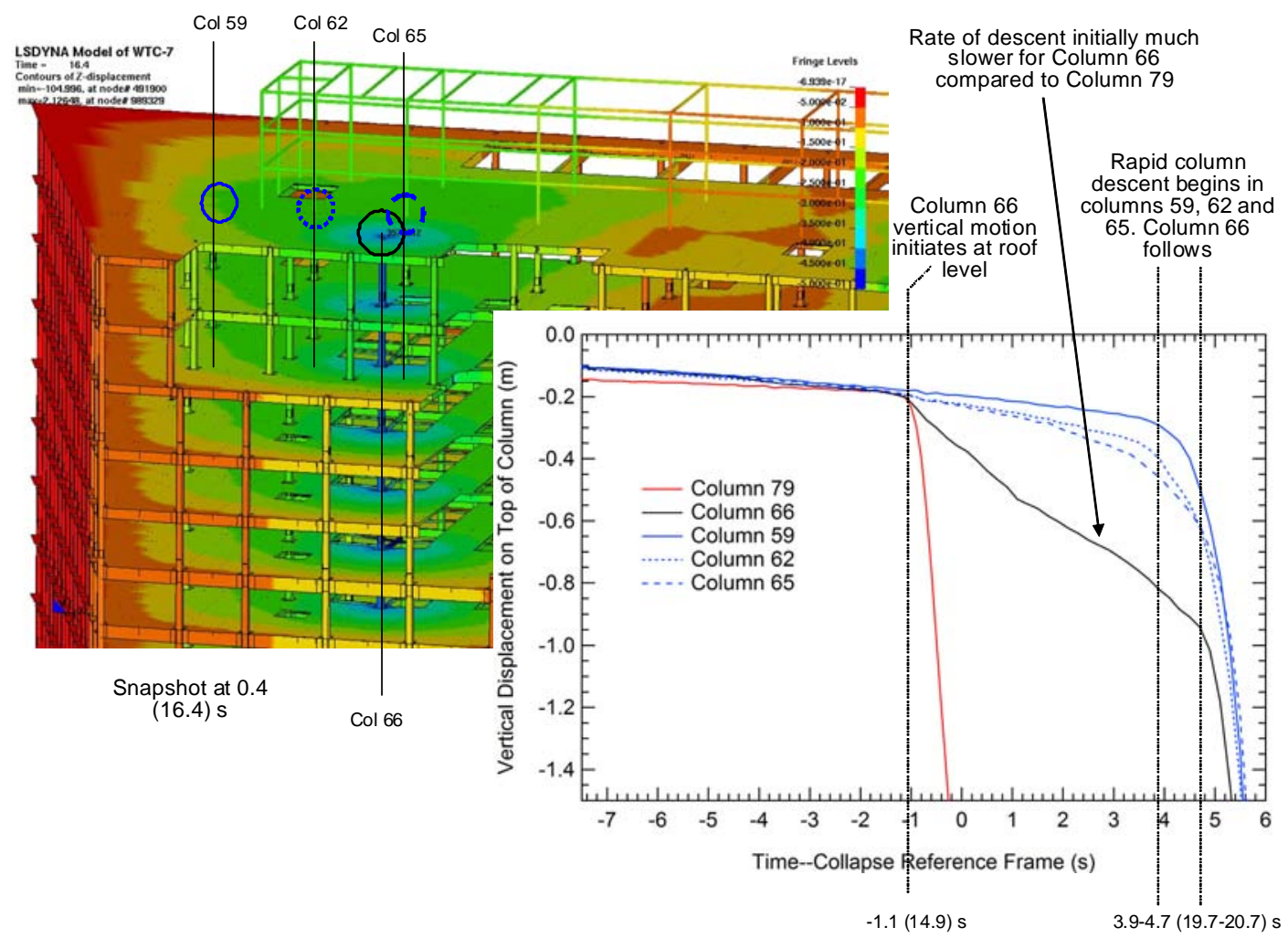

Figure 12-56. Western core column vertical displacements (contours: -0.5 to $0 \mathrm{~m}$ ).

To better understand the progression of interior column failures, the change in column loads with time in the global collapse analysis was examined. Figure 12-57 shows column groups to indicate the general westward progression of interior column failures. Corresponding loads for the column groups 1 to 5 during the horizontal progression of buckling are shown in Figure 12-58. Column group 1 (Columns 79, 80, and 81) failed at $-0.5 \mathrm{~s}$ before the kink was observed in the east penthouse, and column groups 1 to 5 had failed by $6.3 \mathrm{~s}$. Column loads for column groups 6 to 8 are shown in Figure 12-59. Column group 7 failed at $4.3 \mathrm{~s}$ and column groups 6 to 8 had failed by $6.3 \mathrm{~s}$. At this time, all the interior columns had buckled.

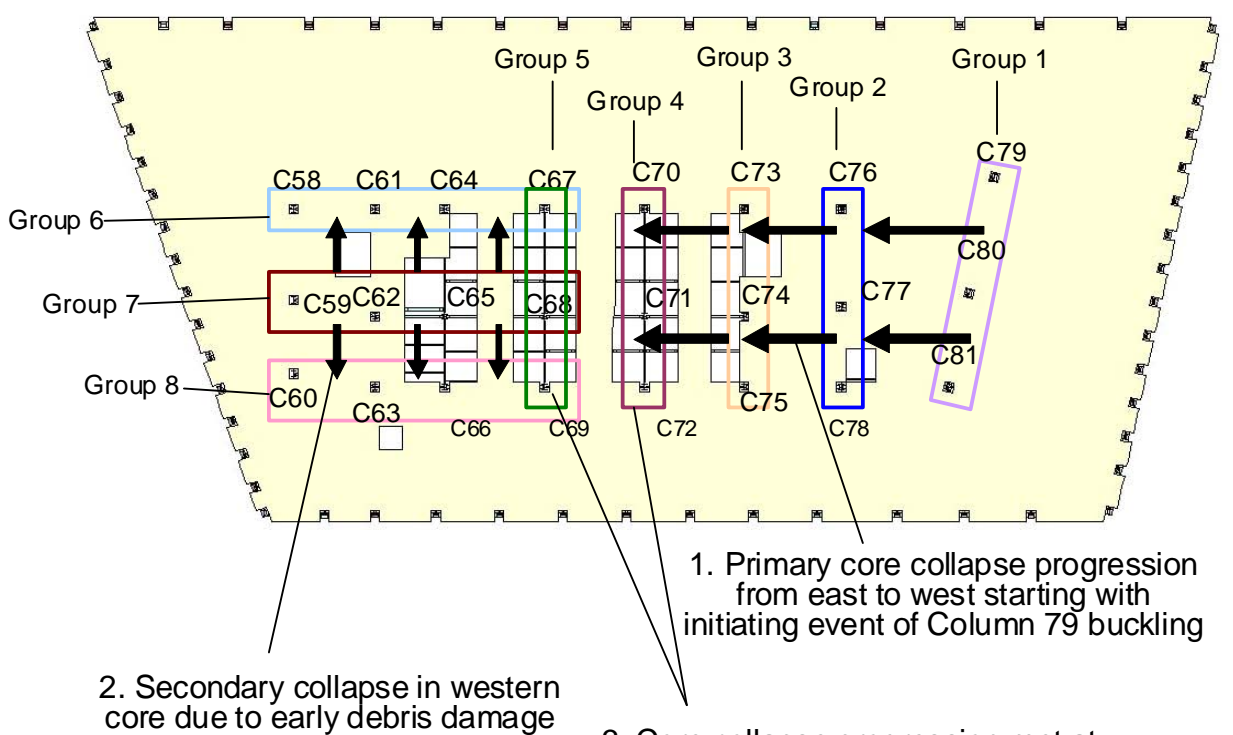

3. Core collapse progression met at Group 4 to 5 collapse
Figure 12-57. Horizontal progression of column buckling and interior column groupings. 


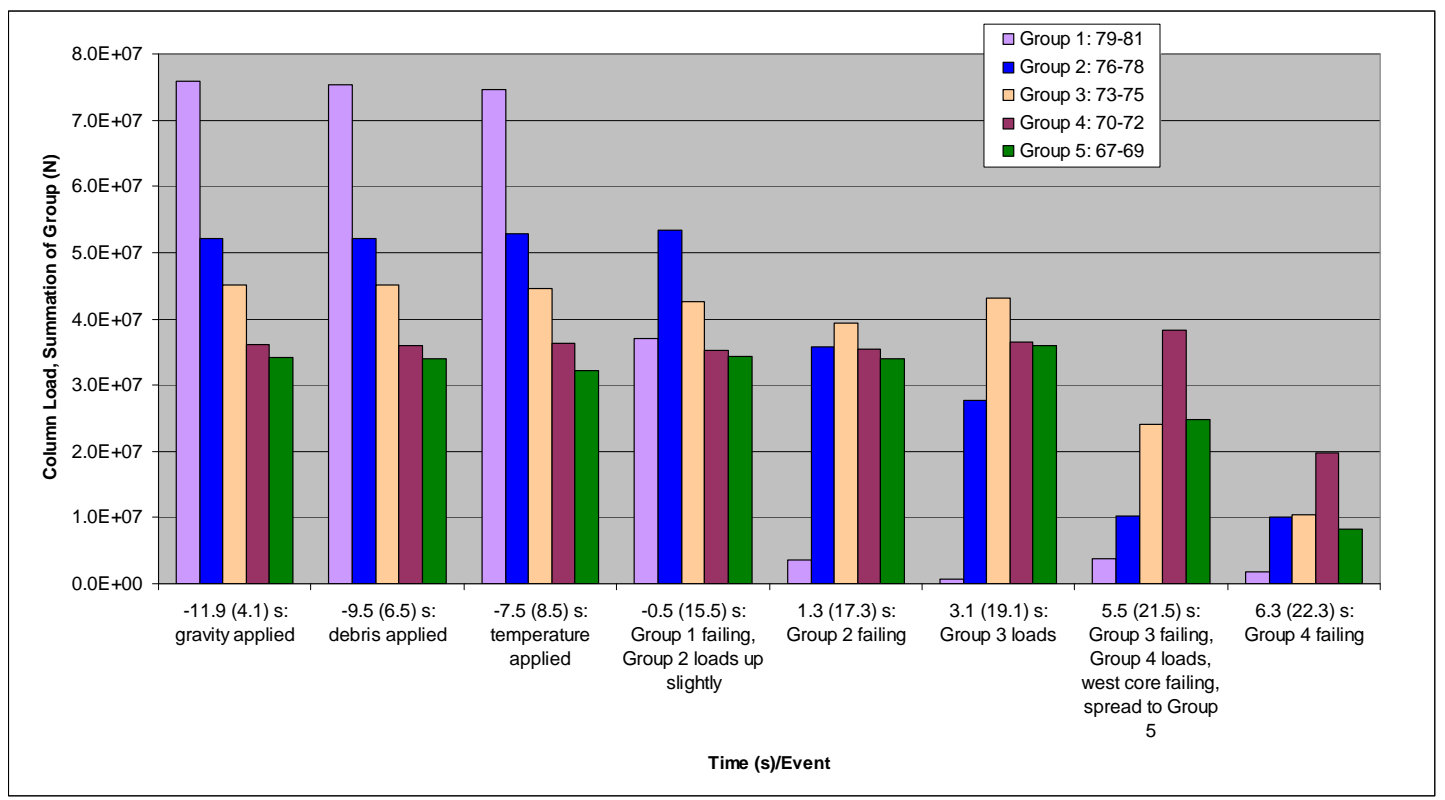

Figure 12-58. Interior column loads illustrating east to west collapse progression.

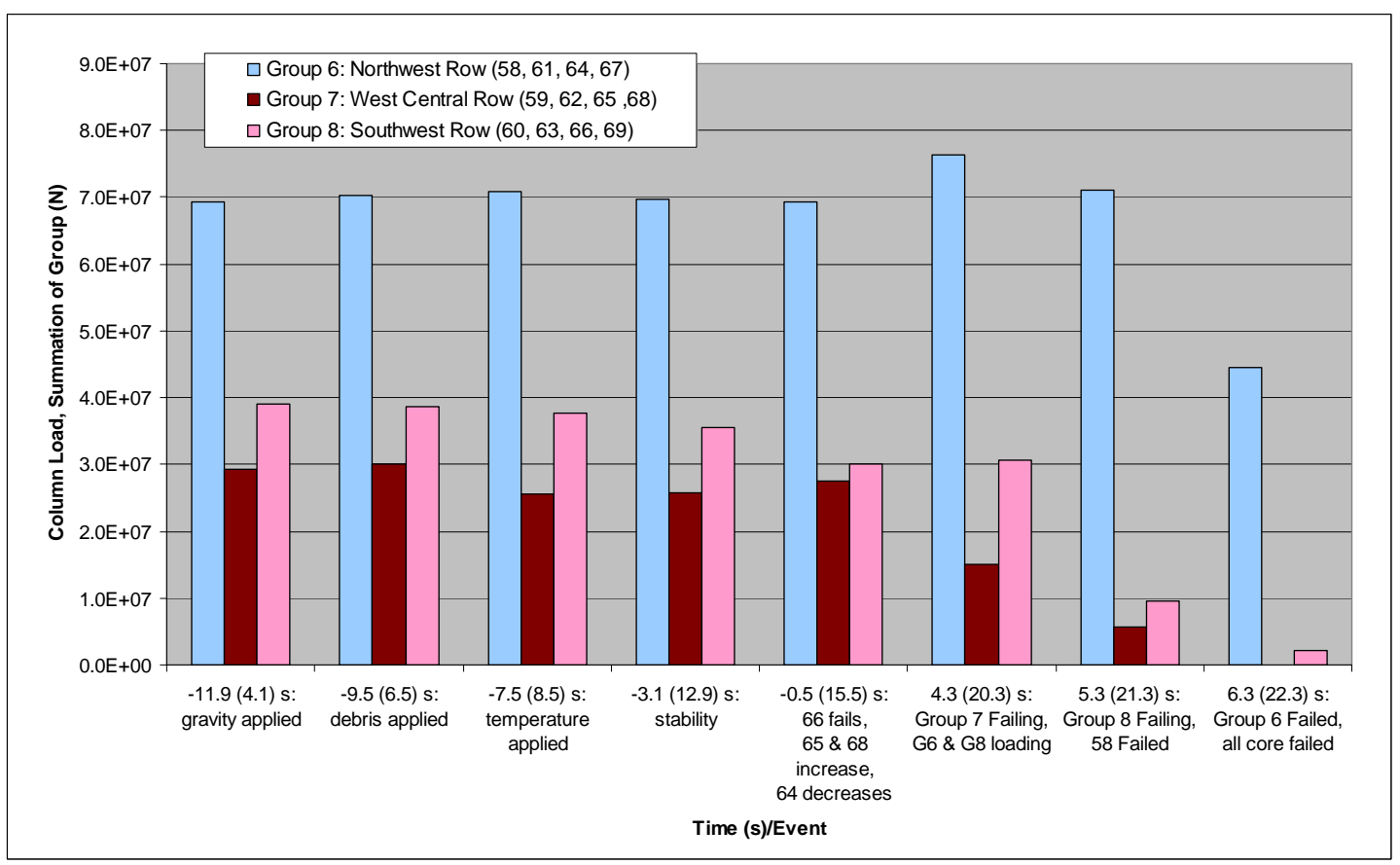

Figure 12-59. West interior column loads illustrating progression of failure. 


\section{Global Collapse}

After the horizontal progression of column buckling in the core of WTC 7, the exterior columns buckled at the lower floors, completing the global collapse sequence as follows:

- As the interior columns failed, the exterior columns on the west face buckled inward at the lower floors as a result of floor pull-in forces due to the downward movement of the building core. The floor connections to the columns had not failed in this region because there were no fires observed on the west side on Floors 10 through 14 at any time during the day, and the intact floors were able to pull the exterior columns inward.

- Exterior column buckling began at Column 14, adjacent to the debris impact zone near the southwest corner, between Floors 10 and 12. The exterior columns adjacent to the seven columns severed in the southwest region due to the collapse of WTC 1 were the first to buckle because additional load was distributed to them following the debris impact damage.

- The south and west exterior columns buckled first, followed by the north and east face columns.

- $\quad$ All exterior columns buckled between approximately Floors 7 and 14.

- Once column support was lost in the lower floors, the remaining exterior structure above began to fall vertically as a single unit.

The buckling of the interior columns in the global collapse analysis was followed by the buckling of the exterior columns.

Figure 12-60 shows a schematic view of Floor 8 that highlights the exterior columns that were used to track the column load history for each face. Also noted on the figure is the debris impact zone from the collapse of WTC 1, which shows the southwest columns that were severed. Loads were extracted just above Floor 8 for three columns per face and were averaged to generate the loads shown in Figure 12-61.

Figure 12-61 shows that selected exterior column forces increased as gravity loads were applied (compressive loads are negative). As indicated at $4.5 \mathrm{~s}$ (LS-DYNA calculation time), there was an increase in compressive forces on the west and south faces of the building after debris impact damage was applied. As Columns 79, 80, and 81 buckled and the floor systems failed on the east side of the building (at $15 \mathrm{~s}$ to $16 \mathrm{~s}$ ), column forces reduced in the north and east faces. The west face column forces were dominated by the forces in Column 14, which was adjacent to the severed columns in the southwest corner. At 21.5 s, exterior column buckling began at Column 14, between Floors 10 and 12. The exterior columns adjacent to the (seven) columns severed in the southwest region due to the collapse of WTC 1 were the first to buckle due to the increased forces in these columns following the debris impact damage. The south and west face columns buckled first, followed by the north and east face columns. 


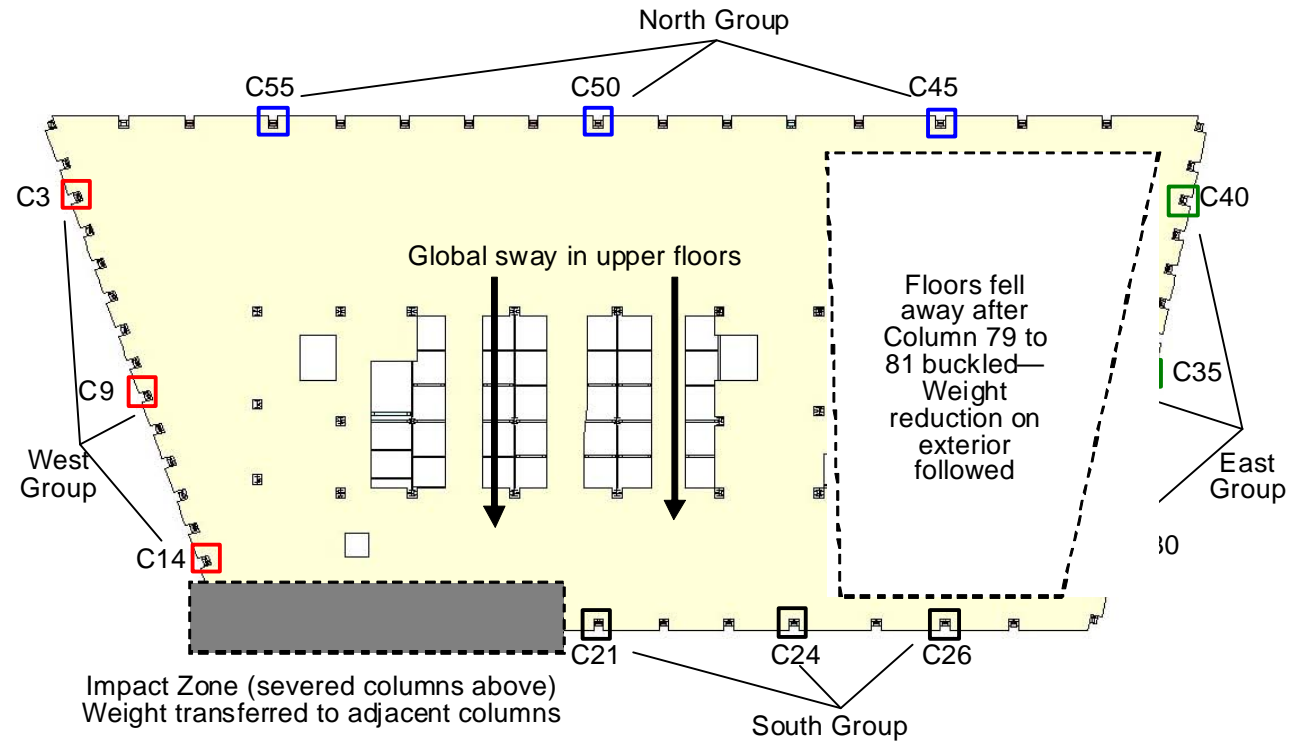

Figure 12-60. Exterior columns used in load groupings.

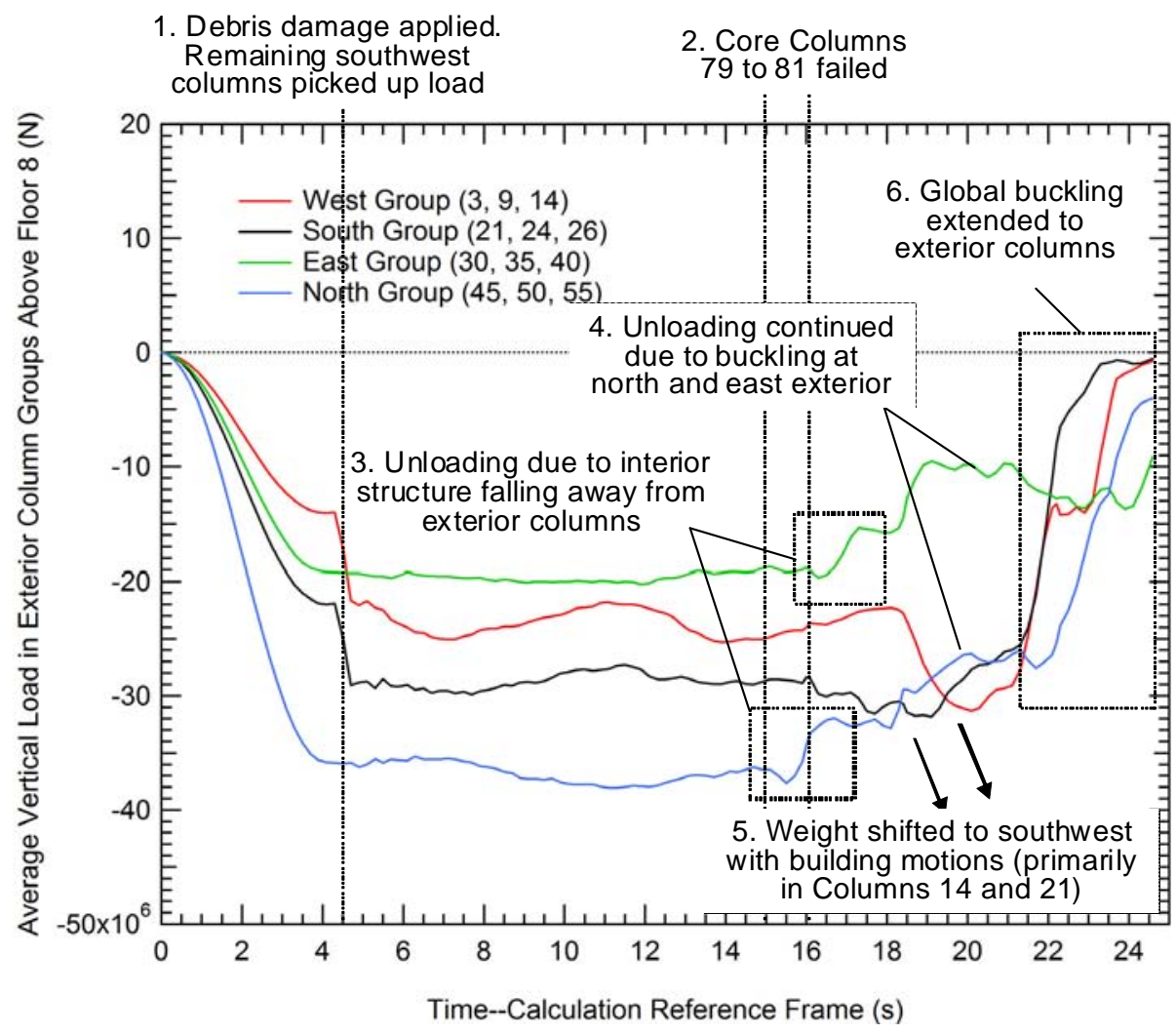

Figure 12-61. Average exterior column forces by group. 
The floor connections to the west face columns had not failed above Floor 9 because no fires were observed on the west side of Floors 10 through 14. The intact floor framing pulled the exterior columns inward as the interior columns fell downward during the horizontal progression of failure stage and the floors pulled on the exterior columns. As the interior columns buckled across the building, the exterior columns were left laterally unsupported normal to the east, south, and north faces. Exterior column buckling spread from column to column, as loads were redistributed, until all the exterior columns had buckled between Floors 7 and 14 within approximately 2 s.

When all the exterior columns had buckled, as shown in Figure 12-62, the entire building above the buckled-column region moved downward as a single unit, resulting in the global collapse of WTC 7. Detailed views of the lower exterior column buckling are shown in Figure 12-63.

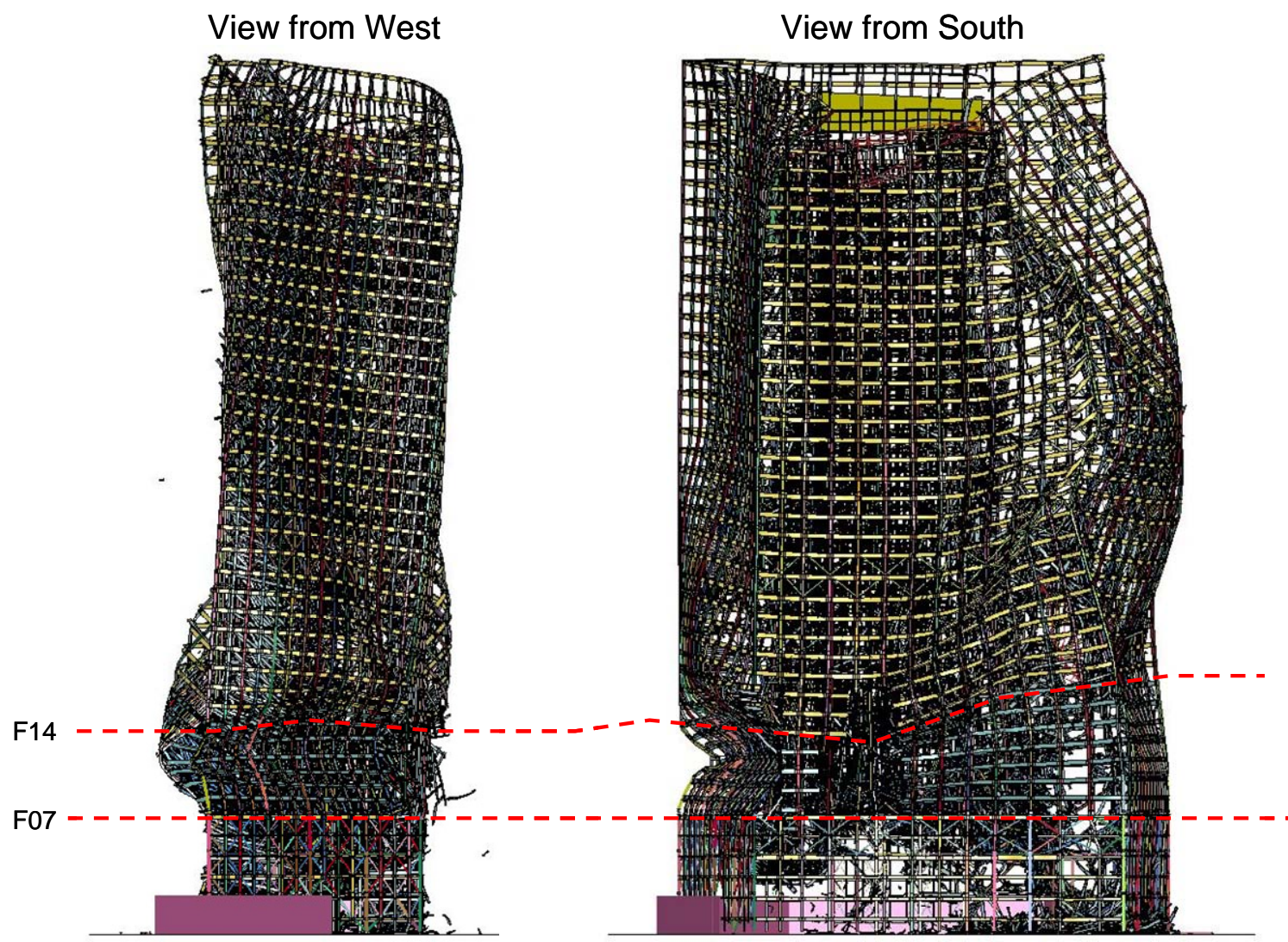

Figure 12-62. Exterior column buckling after initiation of global collapse with debris impact and fire-induced damage (slabs removed from view). 


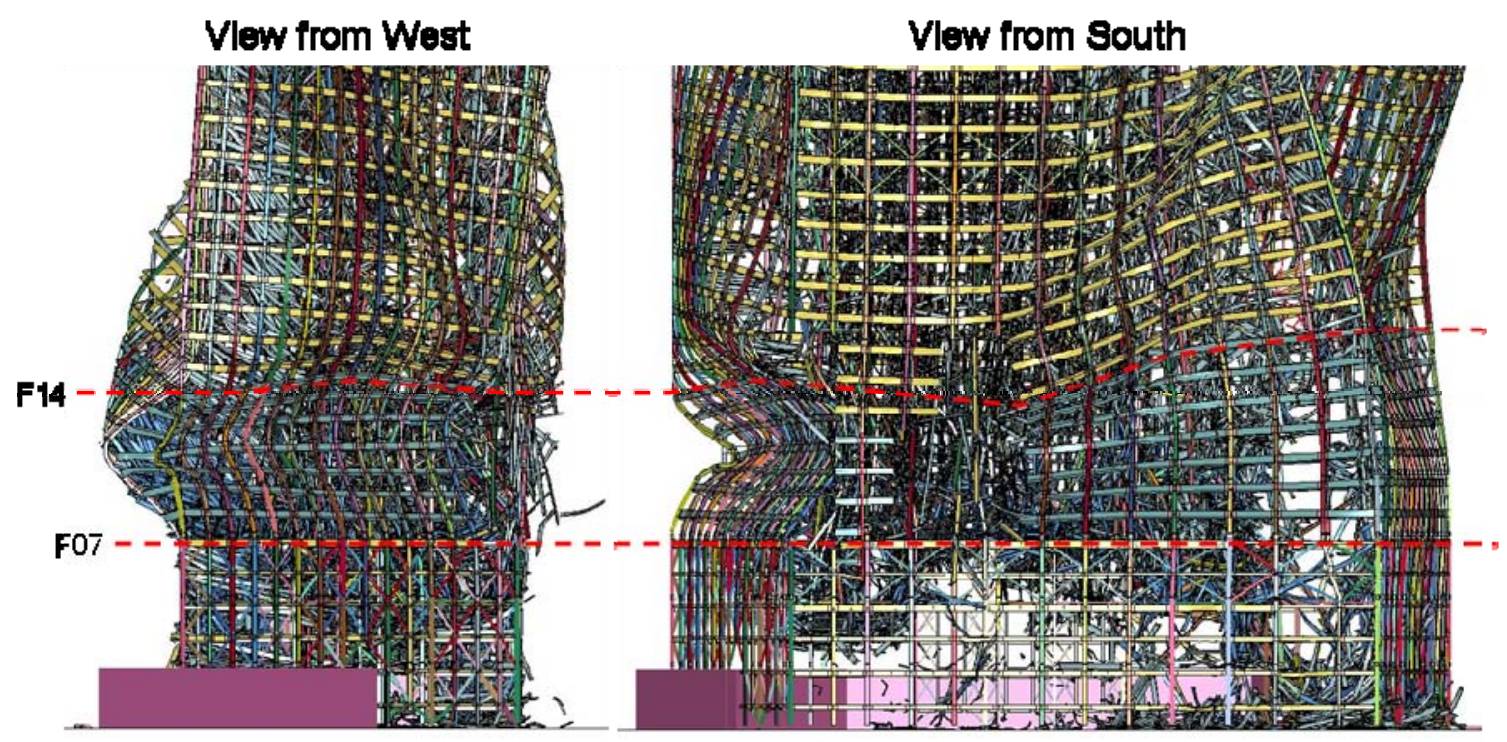

Figure 12-63. Detailed view of exterior column buckling at lower floors (slabs removed from view).

\subsubsection{Global Analysis Results with Fire Induced Damage at $3.5 \mathrm{~h}$}

A global analysis, similar to the analysis described in Section 12.4.4 was conducted with the same loading sequence and parameters, except that the fire-induced damage from the 16 story ANSYS analysis at $3.5 \mathrm{~h}$ (Chapter 11) was input to determine if a lesser fire-induced damage state was sufficient to initiate a global collapse of WTC 7.

The structural damage at $3.5 \mathrm{~h}$ in the ANSYS analysis had floor failures in the southeast corner at Floors 8, 13, and 14 and connection damage at Floor 12. After applying the $3.5 \mathrm{~h}$ ANSYS damage at $8.5 \mathrm{~s}$, a few girders connected to Columns 79, 80 and 81 in Floors 12 to 14 fell to floors below, as shown in Figure 12-64. However, the damage was not sufficient to fail other floor structures below Floor 12 or to initiate a vertical collapse. Vertical displacement contours in Figure 12-64 show some significant vertical displacements, but the structure was stable at the end of the analysis. Comparison to Figure 12-43 from the $4.0 \mathrm{~h}$ damage case (Section 12.4.4) shows that, for the $3.5 \mathrm{~h}$ damage case, the overall damage was significantly less extensive in the floors surrounding Columns 76 to 81.

Figure 12-65 illustrates the structural failures across the lower floors after the application of the fireinduced damage at $3.5 \mathrm{~h}$. Similar to the $4.0 \mathrm{~h}$ ANSYS analysis with debris damage (Figure 12-42), there was damage to connections at several west core column over 11 stories, which occurred during the application of the WTC 1 debris impact damage. However, the structure remained stable due to the lack of an initiating event (i.e., buckling of an interior column). The response of WTC 7 to the fire-induced damage at $3.5 \mathrm{~h}$ was not sufficient to cause an initiating event that would lead to global collapse. 


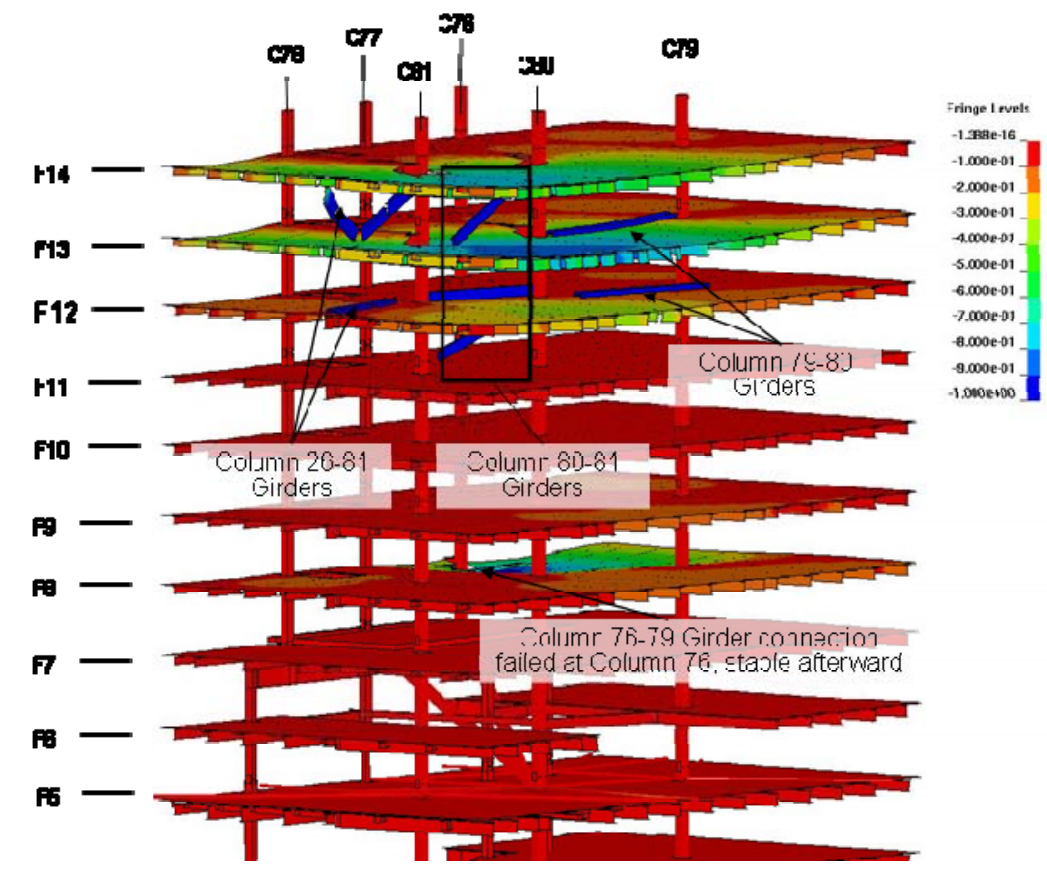

Figure 12-64. Floor framing damage around Columns 76 to 81 after stability has been reached $-3.24 \mathrm{~s}(12.76 \mathrm{~s})$. Contours of vertical displacement shown -39 to 0 in. (-1 to $0 \mathrm{~m})$.

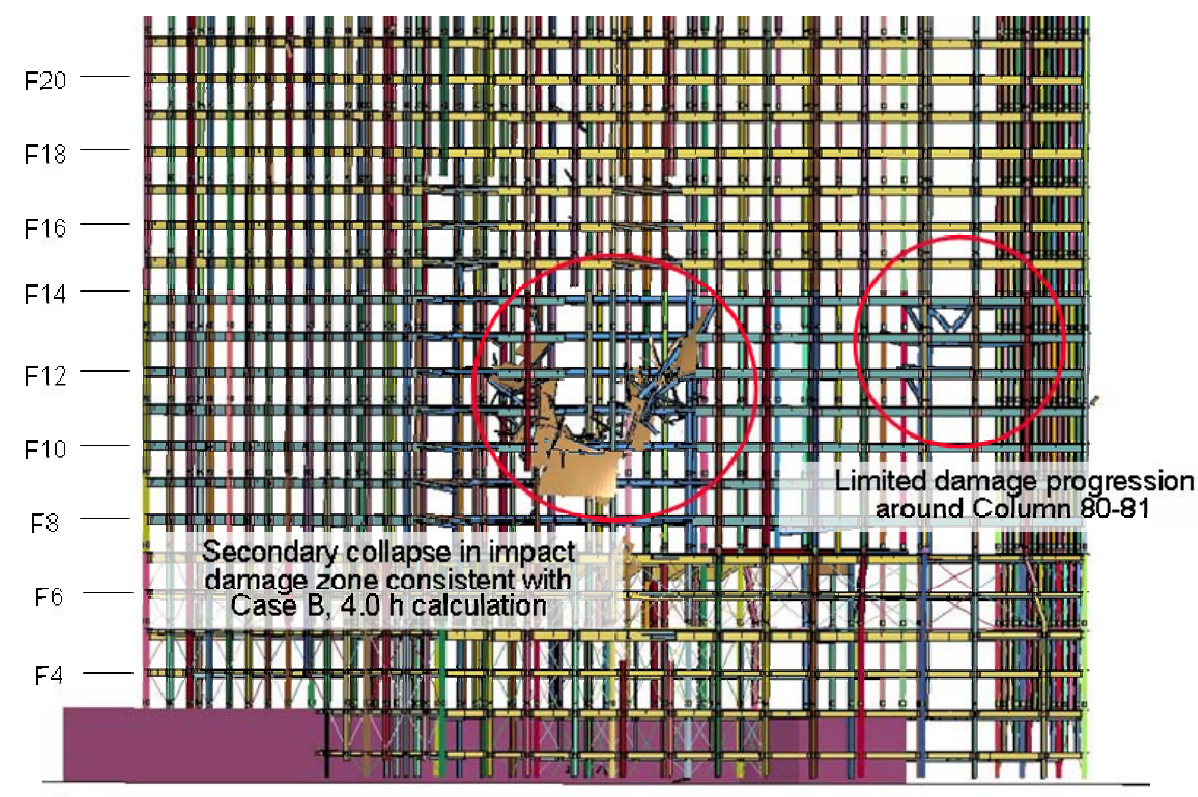

Figure 12-65. Lower floor damage in stable structure at -3.8 s (12.2 s). View from southwest. 


\subsubsection{Global Analysis Results without Debris Impact Damage}

This global analysis was similar to the analysis described in Section 12.4.4, except that the debris impact damage due to the collapse of WTC 1 was not included. The purpose of the analysis was to determine the contribution of debris impact damage to the global collapse sequence of WTC 7 and whether WTC 7 would have collapsed solely due to the effects of the fires.

As with the analysis in Section 12.4.4, the collapse reference frame is timed from the observed start of the downward motion of the east penthouse. The timing reported in this section is shorter because the debris impact damage was not applied during initialization of the global analysis, thereby eliminating $2.0 \mathrm{~s}$ from the initialization process. The removal of the debris impact step shifted the east penthouse kink time to $13.3 \mathrm{~s}$ in this analysis, compared to $16.0 \mathrm{~s}$ in the Section 12.4 .4 calculation.

The initial failure event, vertical progression of failure, and early stages of the horizontal progression of failure occurred in the same order and at essentially the same times as those described for the global analysis in Section 12.4.4. This is illustrated in Figure 12-66 and Figure 12-67 which show the sequence of failure progression from $1.0 \mathrm{~s}$ after the application of fire-induced damage at $-5.8 \mathrm{~s}$ (7.5 s) to $4.2 \mathrm{~s}$ after the kink in the east penthouse was observed, or $3.2 \mathrm{~s}$ (17.5 s).

Figure 12-66 shows the structural response from just after application of the fire-induced damage to $1.3 \mathrm{~s}$ prior to the kink formation in the east penthouse. The left and center images show the failures that started in Floors 13 and 14, and the cascade of floor failures that occurred subsequently, due to the thermally weakened condition. The right image shows the loss of lateral support around Column 79 and the start of Column 79 buckling. Similar response was shown in Figure 12-42 for the global analysis with impact damage. Note that in this stage of the analysis, relative to the analysis with debris impact damage, there was no early development of western core column buckling that was caused by the application of debris impact damage.

Figure 12-67 shows the structural response from $0.7 \mathrm{~s}(14.0 \mathrm{~s})$, shortly after the east penthouse kink was observed, to $3.2 \mathrm{~s}$ (17.5 s), when Columns 76 to 78 buckled as the horizontal progression of failure began. The left image shows the vertical progression of failure. The center image shows the loss of lateral support to Columns 76 to 78, as well as the failure of Truss 2, due to the effects of debris accumulation and impact during the vertical progression of failure. The right image shows the buckling of Columns 76 to 78. Similar responses were shown in Figure 11-48, Figure 12-49, and Figure 12-53 for the global analysis with impact damage.

The right image in Figure 12-68 shows that the screening wall fell downward prior to the west penthouse (view is from the southwest), which is consistent with the observed sequence of events. The horizontal progression continued to move westward.

As the horizontal progression moved from east to west, some differences were observed relative to the analysis with impact damage, as shown in Figure 12-68 and Figure 12-69. Some floors failed at midheight of the building around Columns 73 to 75, leading to the buckling of some interior columns at this location, rather than at lower floors. Between $6.2 \mathrm{~s}$ (19.5 s) s and $13.5 \mathrm{~s}$ (26.8 s), the damage progressed westward and downward across the core as floor structures failed and fell onto the floors below. The horizontal progression in the analysis without debris impact damage moved from east to west over a longer duration. This was due to the lack of western core damage that occurred in the analysis with debris impact damage. 


\section{$-5.8(7.5) \mathrm{s}$}

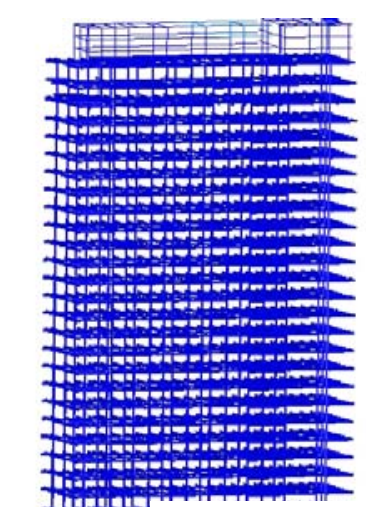

Floor collaps

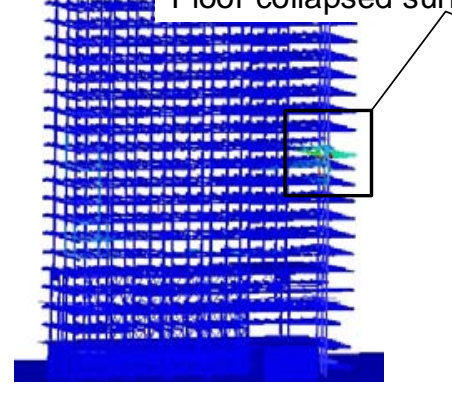

$-3.8(9.5) \mathrm{s}$
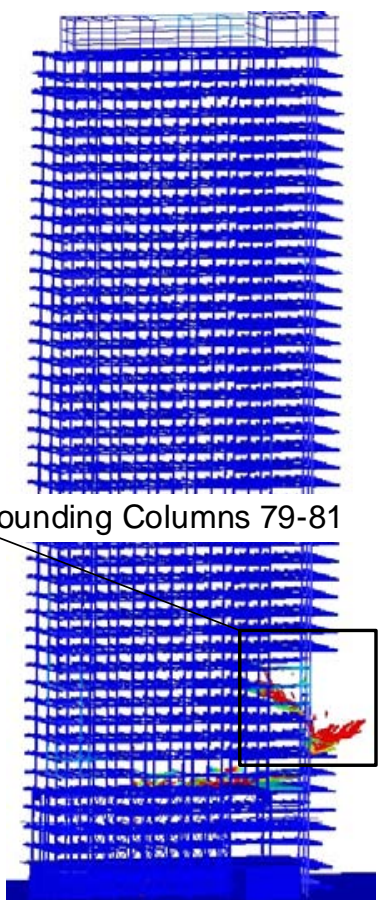

$-1.3(12.0) \mathrm{s}$

Lateral $(\mathrm{XY})$
Displacement $(\mathrm{m})$

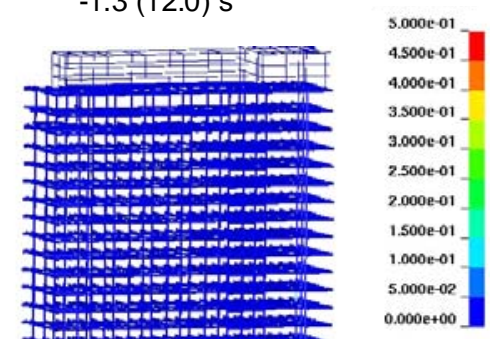

Columns 79 buckled quickly followed by Column 80 and 81

Figure 12-66. Core collapse sequence viewed from the south. Time: $-5.8 \mathrm{~s}$ to $-1.3 \mathrm{~s}(7.5 \mathrm{~s}$ to $12.0 \mathrm{~s})$. Contours of resultant lateral displacement 0 in. to $-20 \mathrm{in}$. $(0 \mathrm{~m}$ to $-0.5 \mathrm{~m})$.
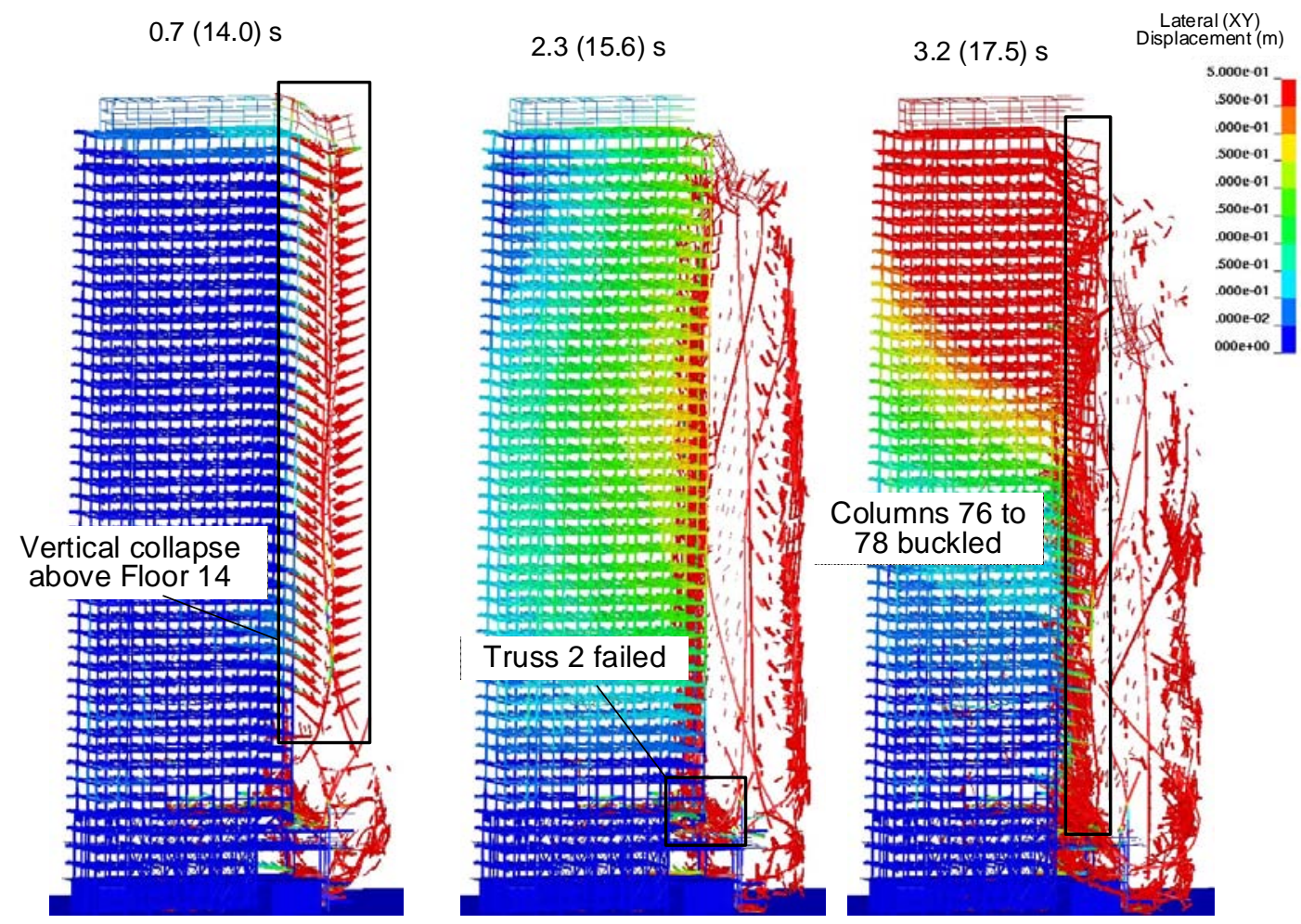

Figure 12-67. Core collapse sequence viewed from south. Time: $0.7 \mathrm{~s}$ to $3.2 \mathrm{~s}(14.0 \mathrm{~s}$ to $17.5 \mathrm{~s})$. Contours of resultant lateral displacement 0 in. to -20 in. ( $0 \mathrm{~m}$ to $-0.5 \mathrm{~m})$. 
$6.2(19.5) \mathrm{s}$

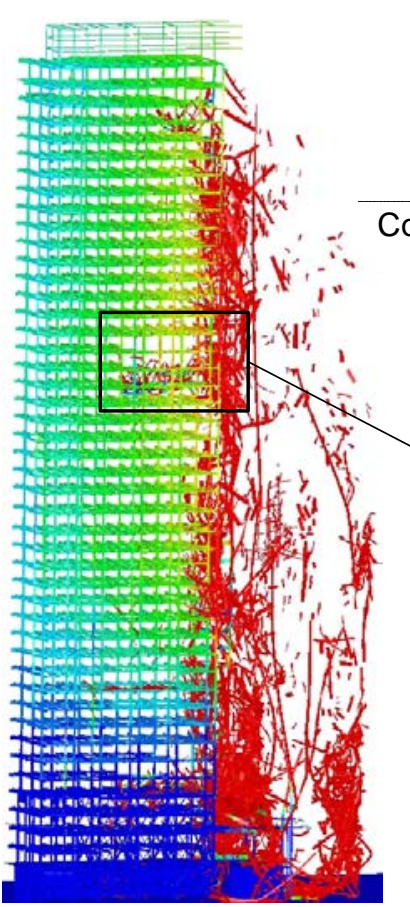

$7.4(20.7) \mathrm{s}$
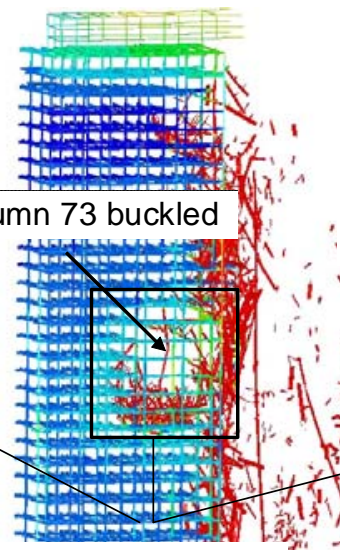

Lateral collapse in middle floors

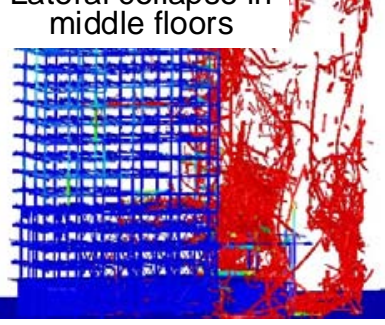

$8.5(21.8 \mathrm{~s}$

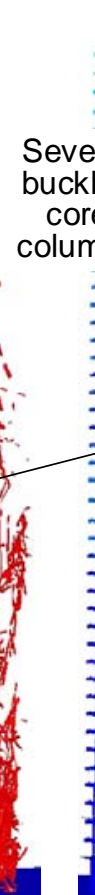

Lateral (XY)
Displacement (m)

$$
\begin{gathered}
5.000 \mathrm{e}-01 \\
500 \mathrm{e}-01 \\
.000 \mathrm{e}-01 \\
.500 \mathrm{e}-01 \\
.000 \mathrm{e}-01
\end{gathered}
$$
inimant Pischiconits
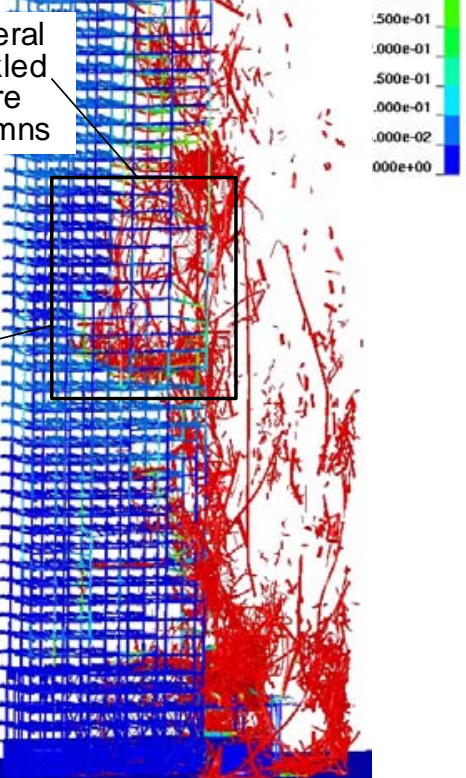

Figure 12-68. Core collapse sequence. Time: 5.5 to $7.8 \mathrm{~s}$ (21.5 to $23.8 \mathrm{~s})$. Contours of resultant lateral displacement 0 to -20 in. (0 to $-0.5 \mathrm{~m})$.
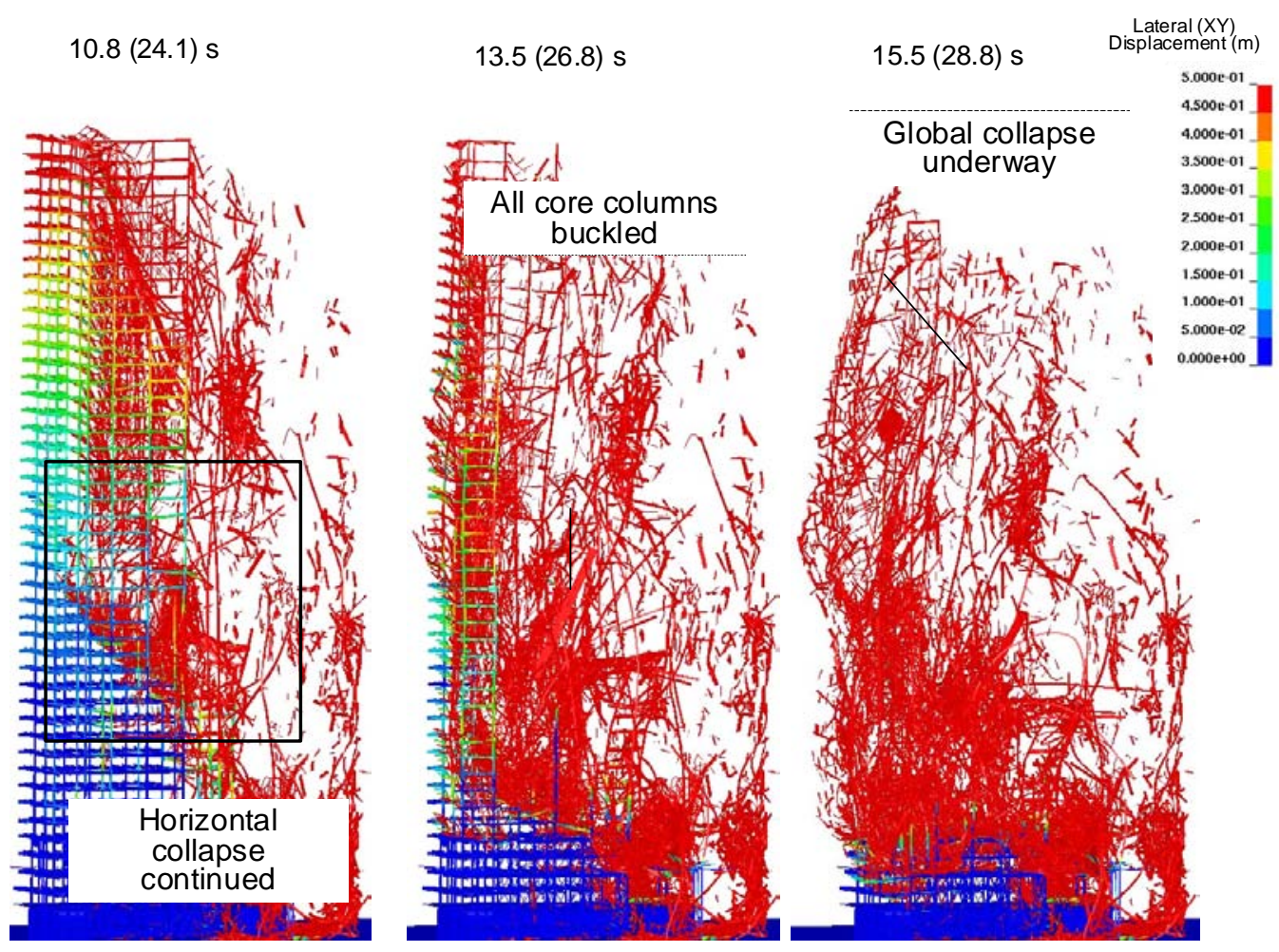

Figure 12-69 Core collapse sequence viewed from the south. Time: 10.8 to $15.5 \mathrm{~s}$ (24.1 to $28.8 \mathrm{~s}$ ). Contours of resultant lateral displacement 0 in. to -20 in. $(0 \mathrm{~m}$ to $-0.5 \mathrm{~m}$ ). 
By 13.5 s (26.8 s), all the interior columns had buckled and, at 15.5 s (28.8 s), the global collapse (i.e., buckling of exterior columns) was underway, as shown in Figure 12-70. The exterior columns buckled near mid-height of the building, approximately between Floors 17 and 29.

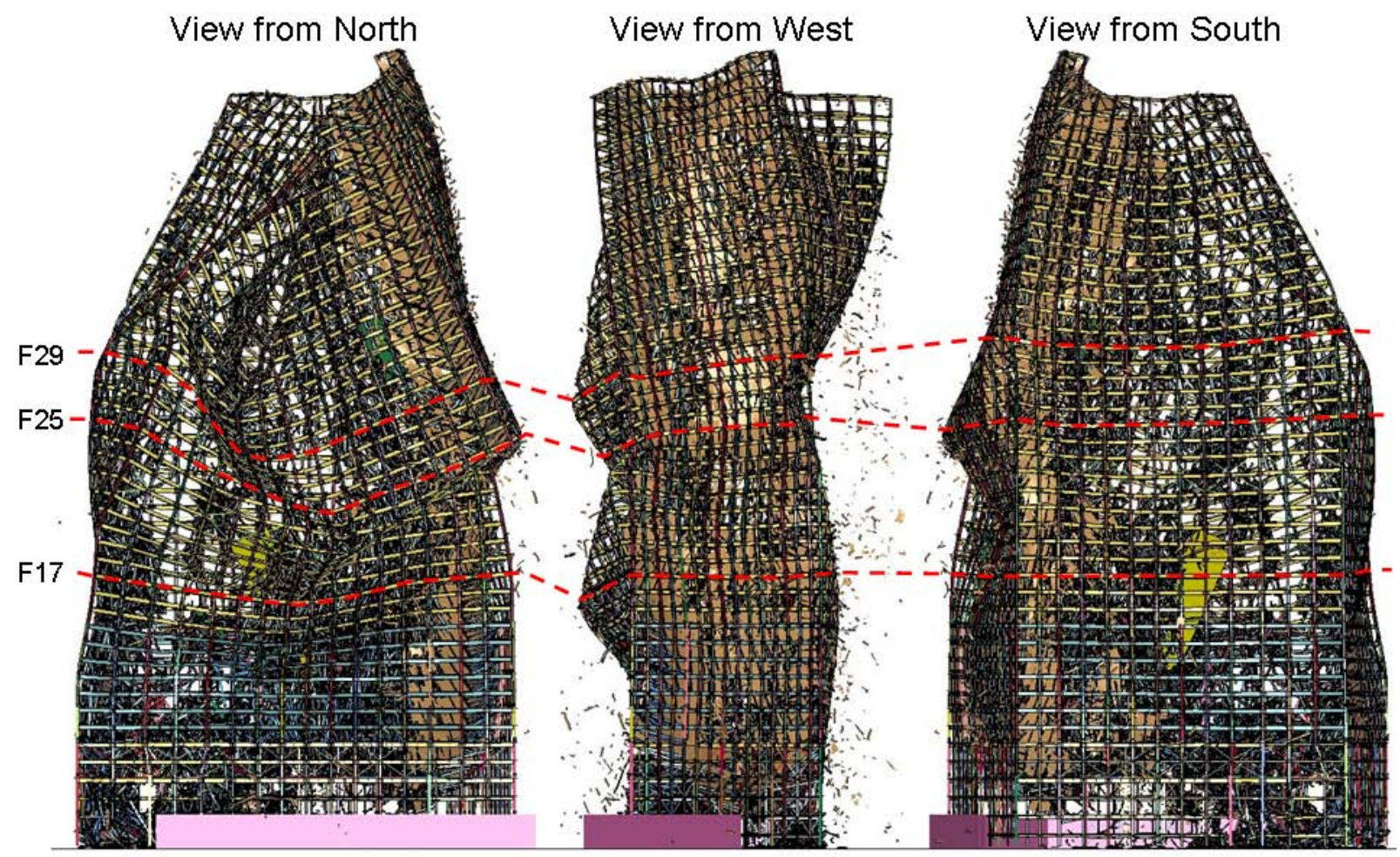

Figure 12-70. Exterior column buckling after initiation of global collapse with fire-induced damage and without debris impact damage (slabs removed from view).

\subsubsection{Classic Global Progressive Collapse Analysis Results Without Debris Impact and Fire-induced Damage}

A global analysis was conducted to determine whether a progressive collapse might occur, due to the removal of a section of Column 79, in the absence of debris impact and fire-induced damage.

The General Services Administration (GSA 2003) and the Unified Facilities Criteria (UFC 2005) provide guidance for conducting a progressive collapse analysis for new and existing multi-story buildings.

Typically, interior columns are considered for removal in progressive collapse analyses for facilities with underground parking and/or uncontrolled public ground floor areas. However, the guidelines also recommend that buildings with generally unique or distinguishing structural features be evaluated for other scenarios where loss of a vertical support could lead to disproportionate damage. For WTC 7, Column 79 would have been a possible candidate for such an analysis, given its large tributary floor area of approximately $2000 \mathrm{ft}^{2}$ per floor, had such guidance existed in the $1980 \mathrm{~s}$.

The only imposed damage in this analysis was the removal of Column 79 between Floors 11 and 13 after gravity loads were imposed. After removing the two-story segment of Column 79 at $-0.8 \mathrm{~s}$ (4.5 s), the floors around Column 79 collapsed all the way to the roof. A kink formed in the east penthouse roof framing at $0 \mathrm{~s}(5.3 \mathrm{~s})$. Column 80 buckled between Floors 37 and 39 at $6.6 \mathrm{~s}$, followed by sections of 
Column 81 failing at the roof level due to lateral loads. As Column 81 buckled at lower stories, there was a sharp reduction in its axial load (at Floor 8) between about $2.6 \mathrm{~s}$ (7.9 s) and $5.1 \mathrm{~s}$ (10.4 s), followed by a continued but more gradual reduction in load.

The Truss 2 diagonal partially buckled at 4.9 s (10.2 s) due to falling debris from the failure of Columns 79, 80, and 81. However, the Truss 2 damage did not lead to buckling of Columns 77 and 78.

Figure 12-71 shows the structural response of the interior columns between $0.7 \mathrm{~s}(6.0 \mathrm{~s})$ and $12.7 \mathrm{~s}$ (18.0 s). The east penthouse fell into the building at $7.5 \mathrm{~s}$ (12.8 s). Most of the east penthouse above Columns 79 and 80 sagged into the building after Columns 79 and 80 buckled, but the east penthouse did not fall into the building until the upper sections of Column 81 failed. The east penthouse was not disconnected from the screening wall structure until $7.5 \mathrm{~s}(12.8 \mathrm{~s})$. Column 76 was impacted by the east penthouse and other structural debris around Floor 35 at about $10.8 \mathrm{~s}$ (16.1 s), causing the column to deflect northward. Column 77 buckled at about 11.0 s (16.3 s) around Floor 36. Column 78 then buckled at about $9.5 \mathrm{~s}$ (19.3 s) between Floors 25 and 33.

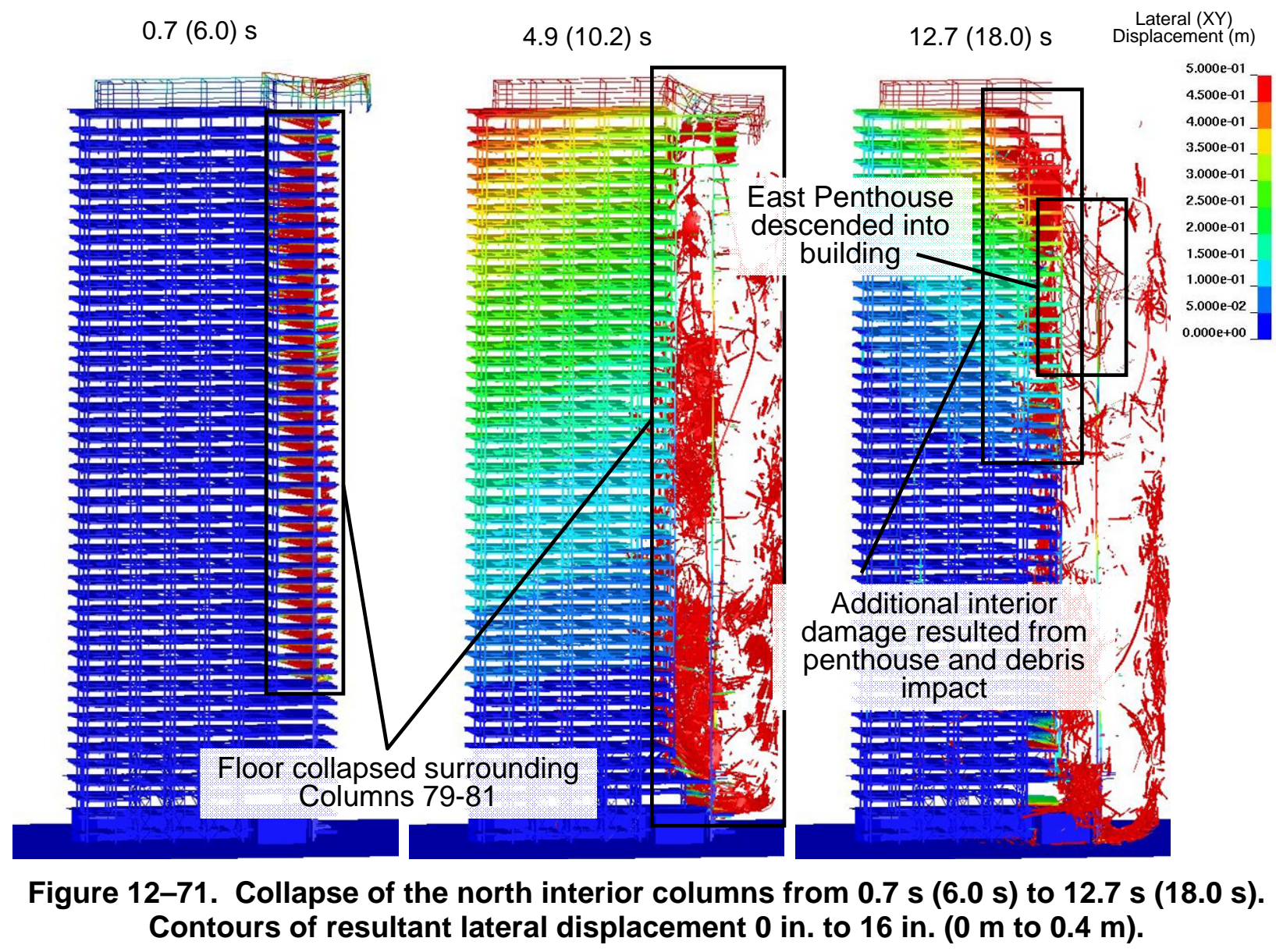


Figure 12-72 shows the structural response of the interior columns between $15.7 \mathrm{~s}(21.0 \mathrm{~s})$ and $21.2 \mathrm{~s}$ (26.5 s). Column damage continued to spread westward with Column 73 buckling at about $15.0 \mathrm{~s}$ (20.3 s) between Floors 35 and 37. Column 58 buckled at 14.7 s (20.0 s), following a column splice failure at Floor 31 that occurred $8 \mathrm{~s}$ earlier, at about $6.9 \mathrm{~s}$ (12.2 s), but did not cause column failure. The column splice initially failed due to relative twisting and shearing motions between floors that were most acute in the northwest corner of the building. The global building motions grew in response to the column and floor structure failures in the eastern interior. The relative motions at the Column 58 splice were magnified compared to other surrounding columns due to the relatively large area supported by Column 58 and the limited shear stud connections in the northwest corner of the building, which together provided relatively less twisting resistance from the composite floor slab. As a result, the Column 58 splice above Floor 31 and some surrounding framing connections sustained damage, which continued to accumulate with subsequent building motions.

$15.7(21.0) \mathrm{s}$

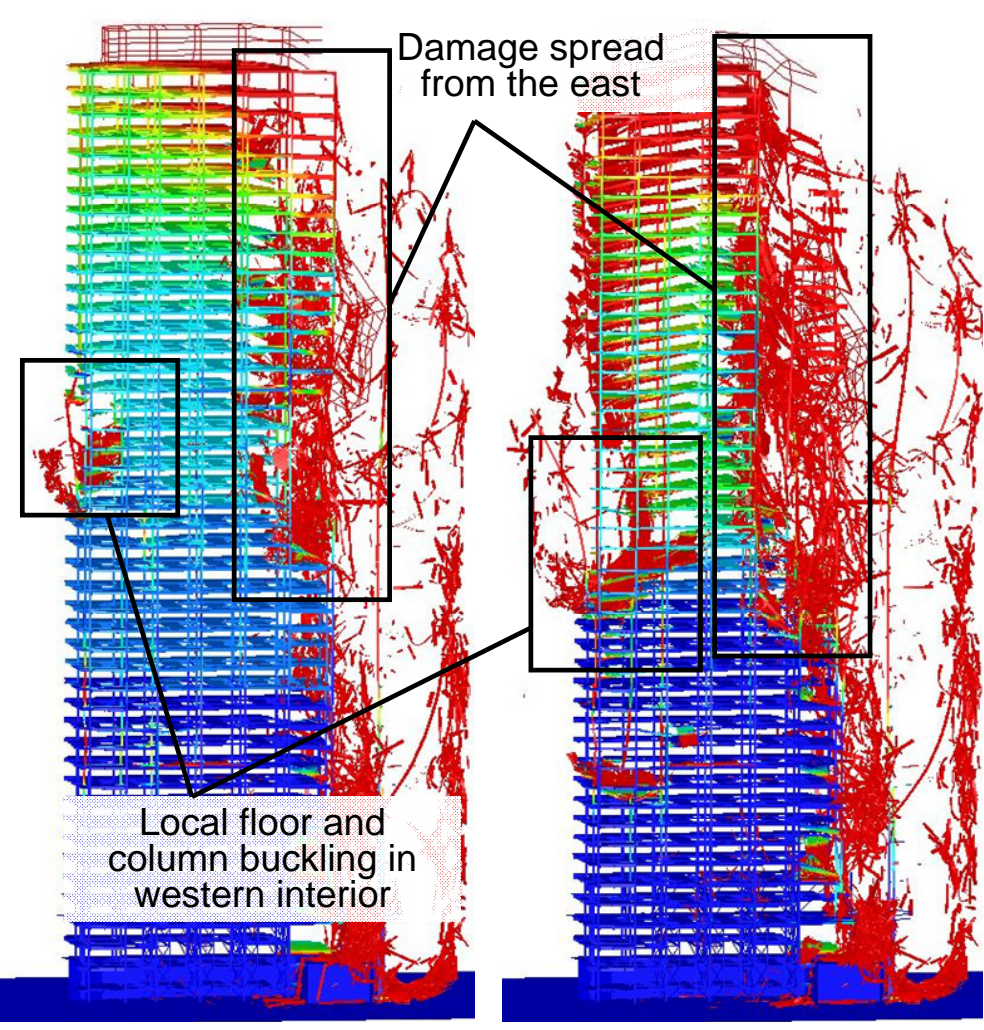

$21.2(26.5) \mathrm{s} \quad \begin{gathered}\text { Lateral }(\mathrm{XY}) \\ \text { Displacement }(\mathrm{m})\end{gathered}$

\section{Collapse spread throughout interior until all columns buckled}

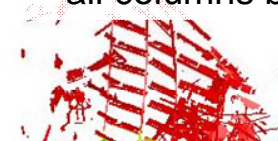

13

13

in

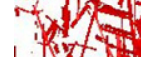

$5.000 \mathrm{e}-01$ $4.500 \mathrm{e}-01$ 4.000e-01 $3.500 \mathrm{e}-01$ $3.000 \mathrm{e}-01$ 2.500e-01 2.000e-01 $1.500 \mathrm{e}-01$ $1.000 \mathrm{e}-01$ $5.000 \mathrm{e}-02$

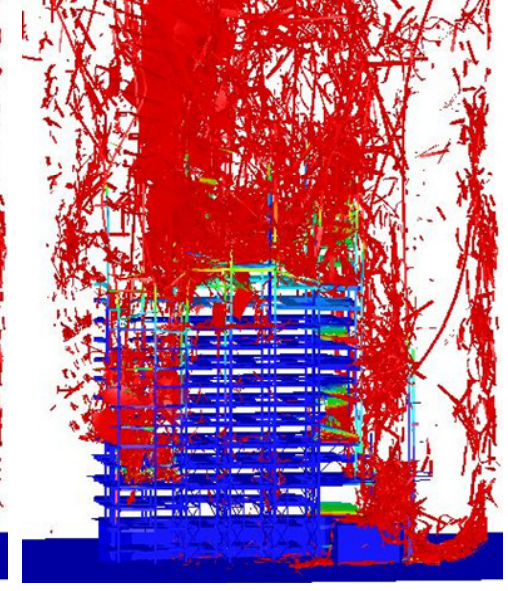

Figure 12-72. Collapse of the north interior columns from $15.7 \mathrm{~s}(21.0 \mathrm{~s})$ to $21.2 \mathrm{~s}$ (26.5 s). Contours of resultant lateral displacement 0 in. to 16 in. ( $0 \mathrm{~m}$ to $0.4 \mathrm{~m}$ ).

After Column 58 buckled, floor and column collapse propagated horizontally throughout the interior. By $21.2 \mathrm{~s}$ (26.5 s), all the interior columns had buckled above Floor 23, and the west penthouse and screening wall had fallen into the building, as indicated in Figure 12-73. Vertical motion at the roofline indicated buckling of the exterior columns, and the start of global collapse. 


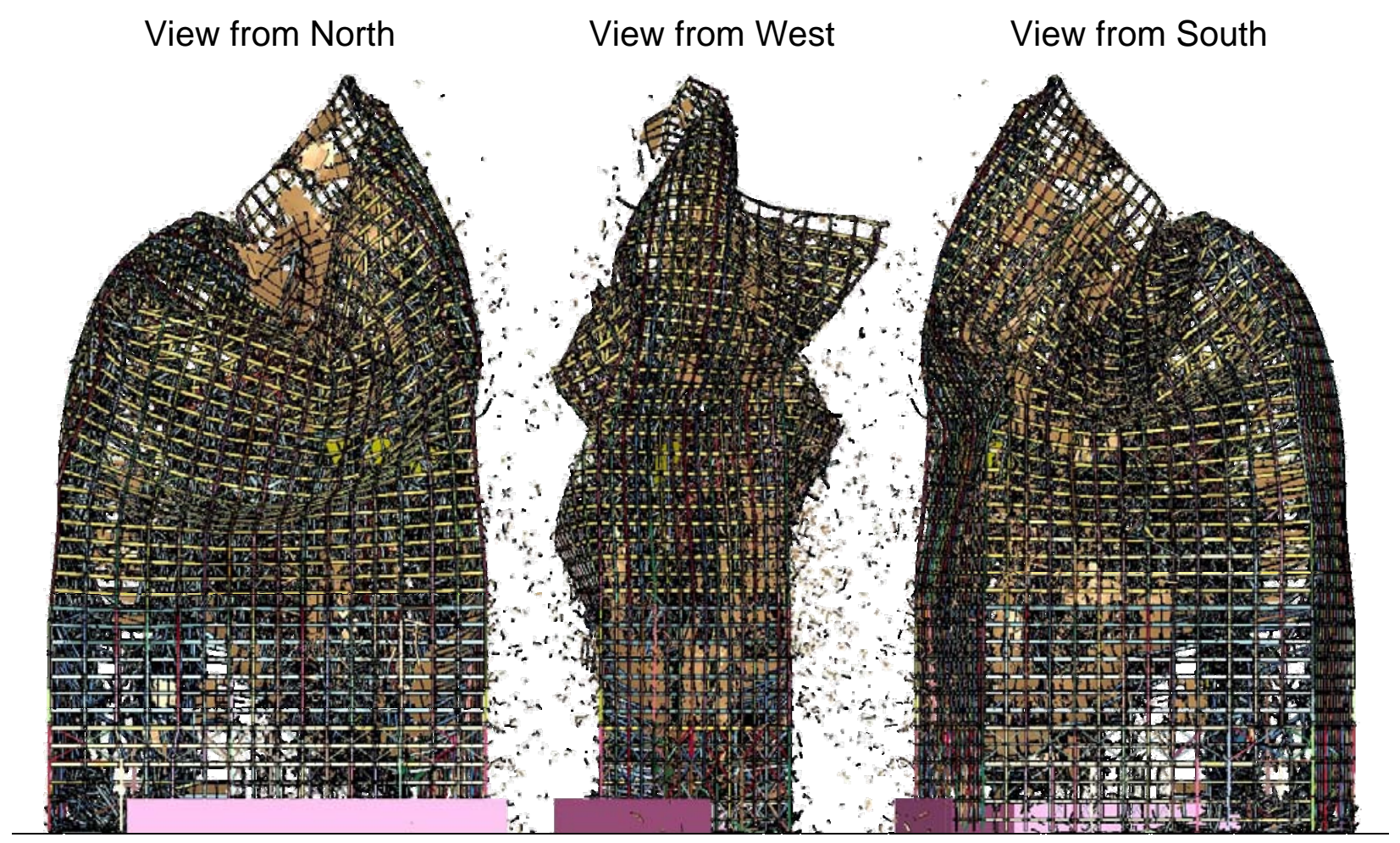

Figure 12-73. Exterior column buckling after initiation of global collapse for progressive collapse analysis without debris impact and fire-induced damage (slabs removed from view).

Figure 12-74 is a plot of the kinetic energy in the global model during the analysis, where the kinetic energy is due to falling debris and debris impact. An initial peak kinetic energy occurred around $3.7 \mathrm{~s}$ (9.0 s), when Columns 79, 80, and 81 had buckled between $1.3 \mathrm{~s}$ (6.6 s) to $5.1 \mathrm{~s}$ (10.4 s) and the surrounding floors and columns were falling. After the debris had fallen, the collapse progression slowed, as Columns 76, 77, and 78 did not buckle until $10.8 \mathrm{~s}$ (16.1 s) to $14.0 \mathrm{~s}$ (19.3 s), respectively. The kinetic energy levels decreased during this period until between $14.7 \mathrm{~s}$ (20.0 s) to $16.7 \mathrm{~s}$ (22.0 s), after which all the interior columns buckled and led to a sharp increase in kinetic energy.

The bi-modal kinetic energy plot illustrates the complex structural system interactions that affected global stability of the building. Had the analysis been stopped at some time between $6.7 \mathrm{~s}(12.0 \mathrm{~s})$ and $14.7 \mathrm{~s}$ (20.0 s), an incorrect and non-conservative conclusion would have been drawn that the structural damage would have been limited to the east side of the building. This type of analysis should be continued until the structure reaches a point of equilibrium (i.e., global stability) and the kinetic energy drops to zero.

This global analysis showed both a vertical and horizontal progression of failure, following the removal of a two-floor section of Column 79, as well as subsequent downward movement at the roofline due to the buckling of exterior columns. The analysis results were similar to the sequence of events shown for the results of the global analyses with debris impact damage and/or fire-induced damage, where the failure of Column 79 was due to the fire-induced damage at $4.0 \mathrm{~h}$. The results of this analysis more closely matched the results for the global analysis with fire-induced damage but without debris impact damage, as the buckling of columns took place near the center of the building height. 
This analysis showed that WTC 7 was prone to classic progressive collapse upon the failure of Column 79. WTC 7 was not evaluated for progressive collapse, as it was not (and still is not) standard practice to evaluate commercial office buildings for such an event. Unless a potential hazard is known, a typical progressive collapse analysis includes a critical failure location and identifies areas where the structural design could be strengthened or made more redundant to mitigate against a global or disproportionately large collapse.

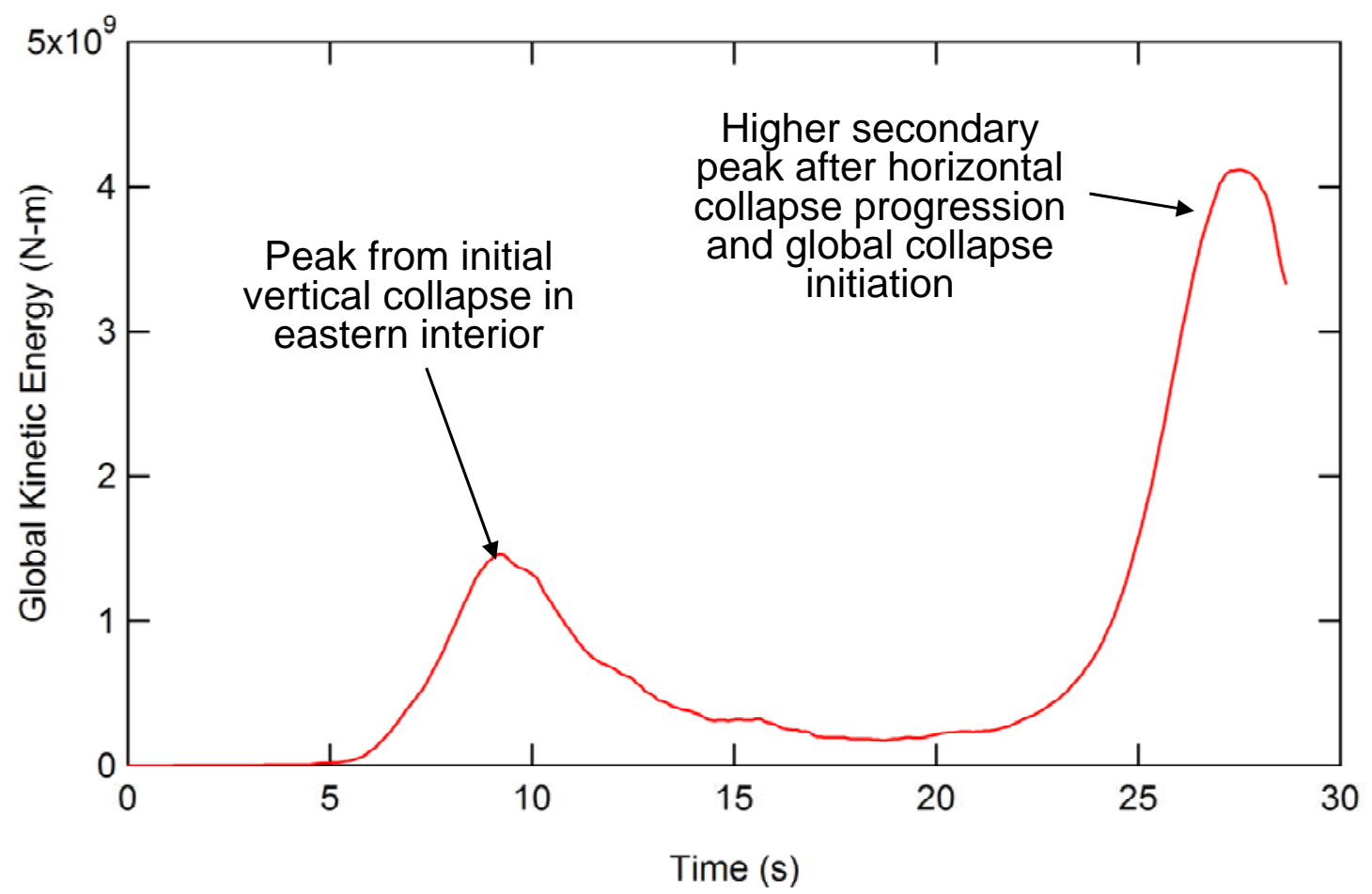

Figure 12-74. Global kinetic energy during the analysis without fire or debris impact damage.

\subsection{COMPARISON OF SIMULATIONS WITH OBSERVABLES}

\subsubsection{Aspects Prior to the Global Collapse}

Table 12-2 lists the major observed collapse events with corresponding times (collapse reference time frame) from the observable events and from the two global analyses, with and without debris impact damage, for Case B temperatures at $4.0 \mathrm{~h}$. As shown in the table, the calculated time for the buckling of Columns 79, 80, and 81, the calculated and observed times for the start of the east penthouse downward movement due to the vertical collapse progression, and the calculated and observed times for the descent of the east penthouse below the roofline were quite similar, and independent of the debris impact damage.

The cascading failure of floors surrounding Column 79 and the buckling of Column 79 could not be ascertained from any videographic evidence. However, analysis of the east-west vibration of the building prior to collapse (Chapter 5 and Appendix C) revealed horizontal motion ( \pm 2 in.) 6 s before the east penthouse began to move downward. The horizontal building motion started at nearly the same time as the cascading floor failures started in the LS-DYNA analysis (-6.5 s), which preceded the buckling failure 
of Column 79. The LS-DYNA analyses indicated that Column 79 buckled approximately $1.3 \mathrm{~s}$ prior to the downward motion of the east penthouse.

Table 12-2. Comparison of major collapse events: observable versus analysis timeline.

\begin{tabular}{|c|c|c|c|}
\hline $\begin{array}{l}\text { Observation } \\
\text { Time (s) }\end{array}$ & $\begin{array}{c}\text { Analysis Time (s) } \\
\text { with Debris Impact } \\
\text { Damage }\end{array}$ & $\begin{array}{c}\text { Analysis Time (s) } \\
\text { without Debris Impact } \\
\text { Damage }\end{array}$ & Event \\
\hline$\approx-6 \mathrm{~s}^{\mathrm{a}}$ & $-6.6 \mathrm{~s}$ & $-6.6 s$ & $\begin{array}{l}\text { Start of cascading failure of floors } \\
\text { surrounding Column } 79\end{array}$ \\
\hline$N / A^{b}$ & -1.3 & -1.4 & $\begin{array}{l}\text { Buckling of Column 79, quickly followed } \\
\text { by buckling of Columns } 80 \text { and } 81\end{array}$ \\
\hline 0 & $\equiv 0$ & $\equiv 0$ & Start of descent of east penthouse \\
\hline 2.0 & $2.4-2.7$ & $2.3-2.6$ & $\begin{array}{l}\text { Descent of east penthouse below roofline } \\
\text { (first value: observed from the northwest } \\
\text { and below, second value: observed from the } \\
\text { north at the roofline) }\end{array}$ \\
\hline N/A & $3.5-6.1$ & $3.2-13.5$ & $\begin{array}{l}\text { Buckling of columns across core, starting } \\
\text { with Column } 76\end{array}$ \\
\hline 6.9 & 6.3 & 9.8 & $\begin{array}{l}\text { Initial downward motion of the north face } \\
\text { roofline at the eastern section of building }\end{array}$ \\
\hline 8.5 & 7.3-7.7 & $8.7-9.2$ & $\begin{array}{l}\text { Descent of the east end of the screenwall } \\
\text { below the roofline (first value: observed } \\
\text { from the northwest and below, second } \\
\text { value: observed from the north at the } \\
\text { roofline) }\end{array}$ \\
\hline 9.3 & $6.9,7.3$ & $10.6,10.9$ & $\begin{array}{l}\text { Descent of the west penthouse below the } \\
\text { roofline (first value: observed from the } \\
\text { northwest and below, second value: } \\
\text { observed from the north at roofline) }\end{array}$ \\
\hline
\end{tabular}

a: From Appendix C; also see Chapter 8.

b: Not available

The horizontal progression of buckling interior columns could not have been observed from the street. The process occurred over a longer duration of $10.3 \mathrm{~s}$ (13.5 s minus $3.2 \mathrm{~s}$ ) for the analysis without debris impact damage than for the duration of $2.6 \mathrm{~s}$ (6.1 s minus $3.5 \mathrm{~s}$ ) for the analysis with impact damage. In the analysis without debris impact damage, the lack of core framing damage on the west side resulted in a sequence of interior column failures from east to west that occurred at a more uniform rate. In the analysis with debris impact damage, the core framing damage on the west side resulted in a more rapid failure of the west interior columns in the last stages of the horizontal progression.

The initial downward movement of the north face from the northeast corner to the east side of the screen wall was observed at $6.9 \mathrm{~s}$ after the initial downward motion of the east penthouse. The LS-DYNA analyses with and without impact damage straddled that value.

\subsubsection{Aspects Following the Collapse Initiation}

Once simulation of the global collapse of WTC 7 was underway, there was a great increase in the uncertainty in the progression of the collapse sequence, due to the random nature of the interaction, break up, disintegration, and falling of the debris. The uncertainties deriving from these random processes 
increasingly influenced the deterministic physics-based collapse process, and the details of the progression of the horizontal failure and final global collapse were increasingly less precise.

Thus, while the two predictions of the time of descent of the west penthouse also straddled the observed time, the mechanisms of building decay were quite different. In the analysis without debris impact damage, the exterior columns buckled near mid-height of the building, approximately between Floors 17 and 29. In the analysis with debris impact damage, the exterior columns buckled between Floors 7 to 14, due to the influence of the exterior damage near the southwest corner. In both analyses, the eastern exterior wall deflected inward at the roof level as the structure became unsupported after the vertical collapse event. The western wall also deflected inward in the analysis without debris impact damage, as it was pulled inward as the last line of core columns failed.

There was another observable feature that occurred after the global collapse was underway and, thus, could not be captured accurately in the simulation. After the exterior facade began to fall downward at $6.9 \mathrm{~s}$, the north face developed a line or "kink" near the end of the core at Column 76. As shown in Figure 5-205, the northeast corner began to displace to the north at about $8.8 \mathrm{~s}$, and the kink was visible at $9.3 \mathrm{~s}$. The kink and rotation of the northeast façade occurred $2 \mathrm{~s}$ to $3 \mathrm{~s}$ after the exterior façade had begun to move downward, as a result of the global collapse.

Given the complexity of the modeled behavior, the global collapse analyses matched the observed behavior reasonably well. The global collapse analyses confirmed the leading collapse hypothesis, which was based on the available evidence.

\subsubsection{Timing of Collapse Initiation and Progression}

The timing of global collapse of WTC 7, as indicated by downward motion of the north wall, was investigated using a video of the collapse taken from the vantage point of West Street near Harrison Street (Camera No. 3, Figure 5-183). The pertinent building dimensions were determined using architectural drawings (Roth 1985). An initial analysis compared the observed time for the roofline to fall approximately 18 stories to the free fall time under the force of gravity. A more detailed analysis examined the vertical displacement, velocity, and acceleration through different stages of the collapse process.

The initial analysis required two quantities: (1) the distance that some feature of the building descended and (2) the time it took to fall that distance. The chosen feature was the top of the parapet wall on the roofline aligned with the east edge of the louvers on the north face. The distance was the difference between the elevation of the roofline prior to the collapse and the last elevation where the roofline could be observed before it was obstructed by a building in the foreground.

The elevation of the top of the parapet wall was $+925 \mathrm{ft} 4 \mathrm{in}$. The lowest point on the north face of WTC 7 that was visible on the Camera 3 video, prior to any downward movement, was the tops of the windows on Floor 29, which had an approximate elevation of $+683 \mathrm{ft} 6 \mathrm{in}$. Thus, the distance that the roofline moved downward before it disappeared from view was about $242 \mathrm{ft}$.

It was difficult to detect the exact instant that the north wall began to collapse because of the resolution of the video image and because, as columns buckled, vertical movement was initially very small. The instant of initial movement was estimated by analyzing changes in the color of a pixel in the video 
recording over time. A single pixel close to the center of the north face roofline was selected and the color of the pixel, expressed as values of hue, saturation, and brightness, was recorded for each frame between $6.0 \mathrm{~s}$ and $7.8 \mathrm{~s}$, where $t=0 \mathrm{~s}$ corresponds to the start of descent of the east penthouse (see Table 5-3). The brightness was found to provide the best indicator of change since the brightness of a pixel representing the sky above the building had a value of 100 percent while a pixel representing the roofline of the building (granite façade) had a brightness of roughly 60 percent for the pixel selected. The brightness of the selected pixel, expressed as a percent, is plotted versus time in Figure 12-75. From $6.0 \mathrm{~s}$ to $6.9 \mathrm{~s}$, the brightness is seen to oscillate around a value of 60 percent indicating no vertical movement. Beginning at roughly $6.9 \mathrm{~s}$ the brightness increases irreversibly to a value of 100 percent at which time the pixel under study represents the sky. Thus, the relative time at which the roofline began to move was estimated as $6.9 \mathrm{~s}$. The time when the roofline dropped from view behind the buildings in the foreground was $12.3 \mathrm{~s}$. Thus, the time the roofline took to fall 18 stories was approximately $5.4 \mathrm{~s}$.

The theoretical time for free fall (i.e., at gravitational acceleration) was computed from,

$$
t=\sqrt{\frac{2 h}{g}}
$$

where $t=$ time (s), $h=$ distance $(\mathrm{ft})$, and $g=$ gravitational acceleration $\left(32.2 \mathrm{ft} / \mathrm{s}^{2}\right)$. Upon substitution of $h=242 \mathrm{ft}$ in the above equation, the estimated free fall time for the roofline to descend 18 stories was approximately $3.9 \mathrm{~s}$. Thus, the average time for the upper 18 stories to collapse, based on video evidence, was approximately 40 percent longer than the computed free fall time.

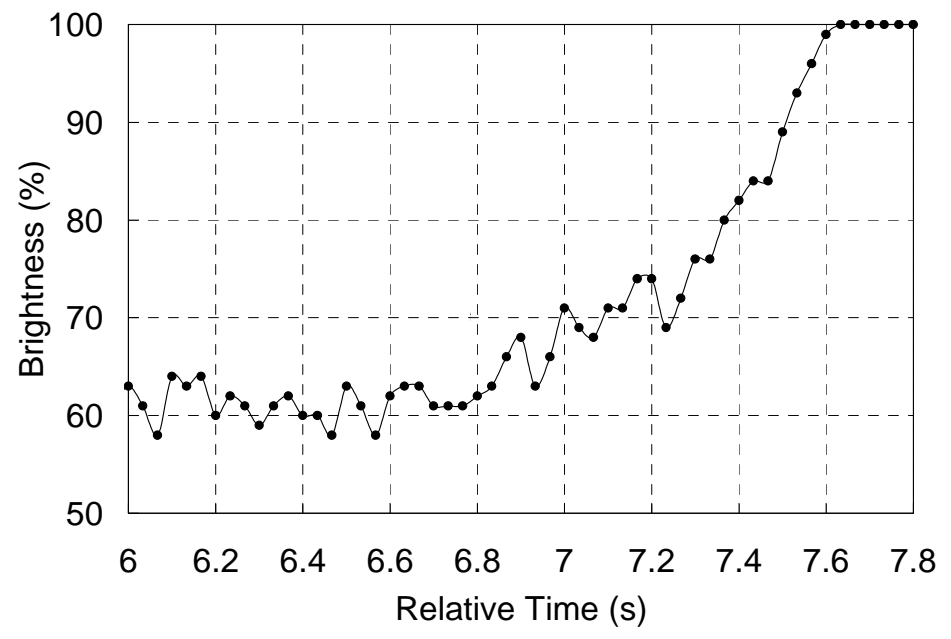

Figure 12-75 Brightness of a pixel on the north face roofline as WTC 7 began to collapse.

To obtain a better understanding of the vertical motion of the building in the first several seconds of descent, the motion of the north face was studied in more detail by tracking the vertical position of a point near the center of the roofline using the same video. In the following discussion, the time at which motion of the roofline was first perceived (6.9 s) is taken as time zero.

Figure 12-76 presents a plot of the downward displacement data shown as solid circles. A curve fit is also plotted with these data as a solid line. A function of the form $z(t)=A\left\{1-\exp \left[-(t / \lambda)^{k}\right]\right\}$ was selected 
because it is flexible and well-behaved, and because it satisfies the initial conditions of zero displacement, zero velocity, and zero acceleration. The constants $A, \lambda$, and $k$ were determined using least squares fitting. The fitted displacement function was differentiated to estimate the downward velocity as a function of time, shown as a solid curve in Figure 12-77. Velocity data points (solid circles) were also determined from the displacement data using a central difference approximation ${ }^{1}$. The slope of the velocity curve is approximately constant between about $1.75 \mathrm{~s}$ and $4.0 \mathrm{~s}$. To estimate the downward acceleration ${ }^{2}$ during this stage, a straight line was fit to the open-circled velocity data points using linear regression (shown as a straight line in Figure 12-77). The slope of the straight line, which represents a constant acceleration, was found to be $32.2 \mathrm{ft} / \mathrm{s}^{2}$ (with a coefficient of regression $R^{2}=0.991$ ), equivalent to the acceleration of gravity $g$. Note that this line closely matches the velocity curve between about $1.75 \mathrm{~s}$ and $4.0 \mathrm{~s}$.

For discussion purposes, three stages were defined, as denoted in Figure 12-77:

- In Stage 1, the descent was slow and the acceleration was less than that of gravity. This stage corresponds to the initial buckling of the exterior columns in the lower stories of the north face, as seen in Figure 12-62. By 1.75 s, the north face had descended approximately $7 \mathrm{ft}$.

- In Stage 2, the north face descended at gravitational acceleration, as exterior column buckling progressed and the columns provided negligible support to the upper portion of the north face. This free fall drop continued for approximately 8 stories $(105 \mathrm{ft})$, the distance traveled between times $t=1.75 \mathrm{~s}$ and $t=4.0 \mathrm{~s}$.

- In Stage 3, the acceleration decreased somewhat as the upper portion of the north face encountered resistance from the collapsed structure and the debris pile below. Between $4.0 \mathrm{~s}$ and $5.4 \mathrm{~s}$, the northwest corner fell an additional $130 \mathrm{ft}$.

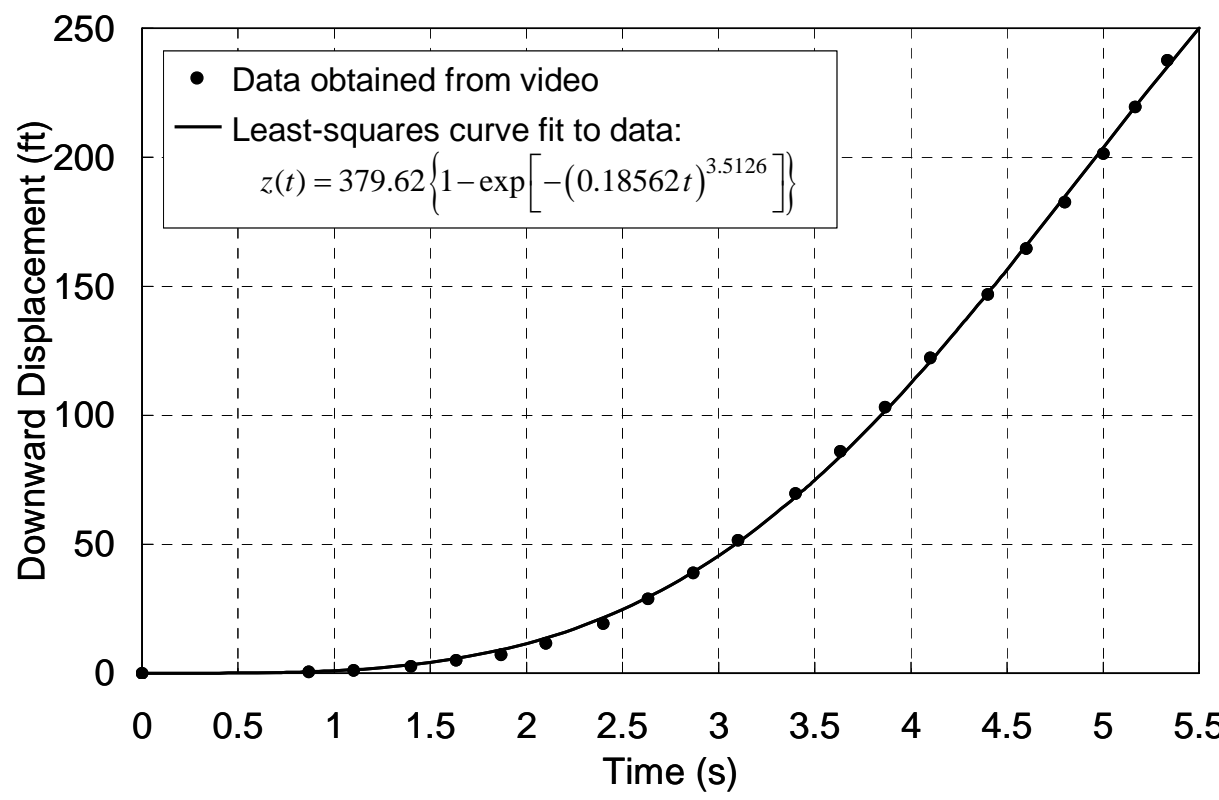

Figure 12-76 Downward displacement of north face roofline as WTC 7 began to collapse.

\footnotetext{
${ }^{1}$ The central difference approximation is given by $v_{i+1 / 2} \approx\left(z_{i}-z_{i+1}\right) /\left(t_{i}-t_{i+1}\right)$, where $z_{i}$ and $z_{i+1}$ denote the displacement at time $t_{i}$ and $t_{i+1}$, respectively

${ }^{2}$ Acceleration, or rate of change of velocity, is equal to the slope of a velocity versus time curve.
} 
As noted above, the collapse time was approximately 40 percent longer than that of free fall for the first 18 stories of descent. The detailed analysis shows that this increase in time is due primarily to Stage 1 , in which column buckling was just beginning and gradual increases in displacement and velocity were observed. The three stages of collapse progression described above are consistent with the results of the global collapse analyses discussed earlier in this chapter.

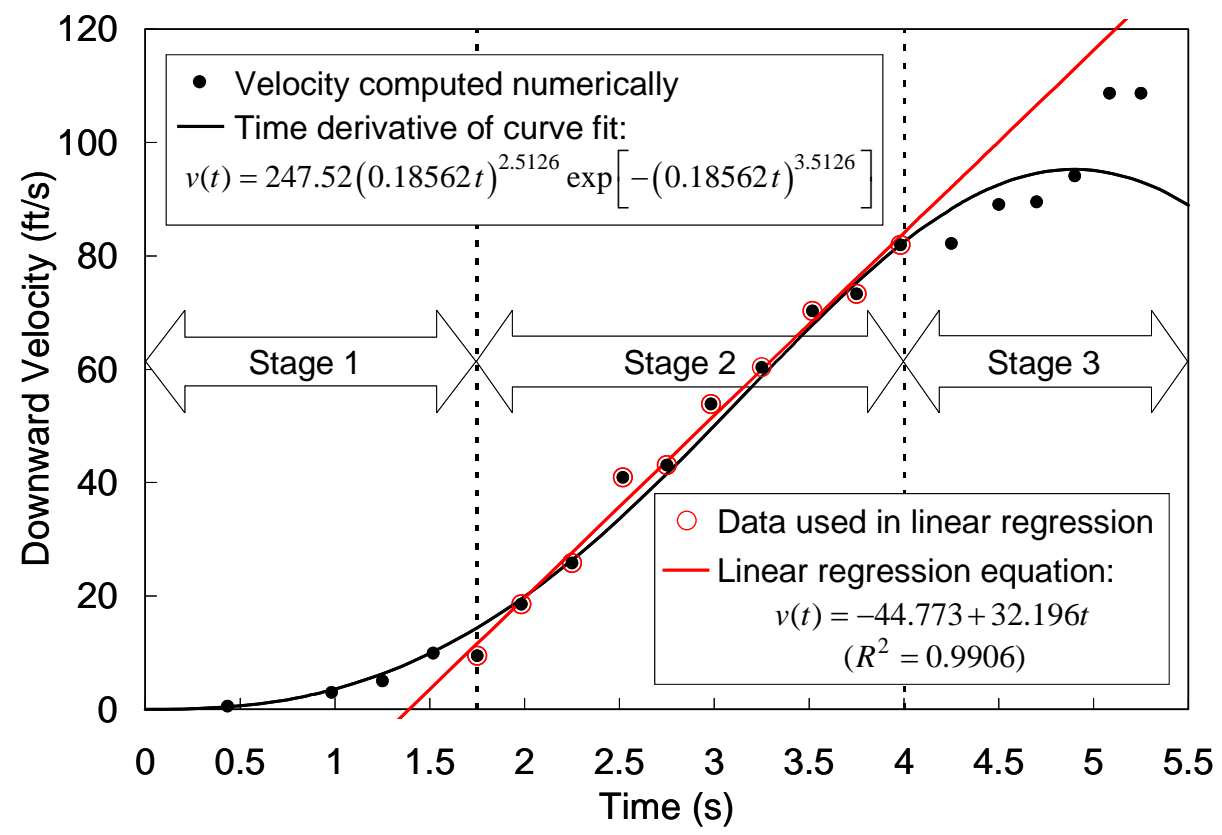

Figure 12-77

Downward velocity of north face roofline as WTC 7 began to collapse.

\subsection{SUMMARY OF FINDINGS}

A global finite element model of WTC 7 was developed using LS-DYNA to calculate the structural response of WTC 7 to a fire-induced initial failure event and to determine the sequence and timing of the events that led to the global collapse of the building. Four simulations were performed with this model.

- The first was based on NIST's best estimate of both the debris impact damage from WTC 1 and the fire-induced damage, from the ANSYS analysis. This occurred at $4 \mathrm{~h}$ in the ANSYS computation.

- The second simulation differed only in the input of a lesser degree of fire-induced damage at $3.5 \mathrm{~h}$ in the ANSYS computation. The purpose of this simulation was to determine whether a lesser degree of fire-induced damage could lead to the collapse of WTC 7.

- The third simulation was the same as the first, except that no debris impact damage was included. The purpose of this analysis was to determine the contribution of debris impact to the WTC 7 global collapse sequence and whether WTC 7 would have collapsed solely due to the effects of the fires.

- In the fourth simulation, the building experienced no debris or fire-induced damage. A section of Column 79 between Floors 11 and 13 was removed. The purpose of this analysis 
was to determine the potential for a classic progressive collapse, i.e., disproportionate structural damage from a single failure, regardless of the cause of that failure.

The following are the principal findings from these simulations.

- The best estimate simulation led to global collapse of WTC 7 and provided a reasonable sequence and timing of the events leading to the initiation of global collapse. As expected, there were some deviations from the observable evidence at computation times after the global collapse was underway.

- The simulation with identical debris impact damage, but reduced fire damage, did not lead to a collapse-initiating event or to collapse itself. This result indicated that the debris impact damage, by itself, was not sufficient to initiate global collapse. It also indicated that the long duration of the multiple floor fires was the primary cause of the eventual collapse.

- The simulation with the same fire-induced damage as the best estimate simulation, but with no debris impact damage, identified the same initiating event and timing of that event as did the best estimate simulation. This simulation also led to global collapse of the building, further indicating that the debris impact damage was not a principal contributor to the occurrence of collapse. However, the mechanics of the collapse differed from the best estimate simulation in the later stages of the horizontal progression of failure.

- WTC 7 was prone to classic progressive collapse in the absence of debris impact and fireinduced damage when a section of Column 79 between Floors 11 and 13 was removed. The collapse sequence demonstrated a vertical and horizontal progression of failure upon the removal of the Column 79 section, followed by buckling of exterior columns, which led to the collapse of the entire building.

The simulations supported the leading collapse hypothesis and provided the following additional insights into the sequence of events leading to the global collapse of WTC 7. Except as noted, these findings were derived from the best estimate simulation.

\section{Initial Local Failure for Collapse Initiation}

- The collapse of Floor 13 onto the floors below, some of which were already weakened by fires, triggered a cascade of floor failures in the northeast region of the building.

- The floor failures progressed down to Floor 5, where debris accumulated, and spread across the east floor area, due to the effects of impact loads from falling debris on thermally weakened floor areas.

- Critical Column 79 became laterally unsupported between Floors 5 and 14 in the east-west and south directions as a result of the progression of floor system failures. There was still some lateral support in the north direction at Floors 8 to 12 and Floor 14, as the erection bolts in the seated connections had all failed at these girder ends, but the girders had not walked off the bearing seat. 
- The increase in unsupported length led to the buckling failure of Column 79, which was the collapse initiation event for WTC 7.

\section{Vertical Progression of Failure}

- Once Column 79 buckled between Floors 5 and 14, the column section above began to descend. Column 79 began moving downward at the roof level approximately $0.2 \mathrm{~s}$ after Column 79 buckled and 0.6 s before Column 80 buckled.

- As Column 79 moved downward, the floor framing adjacent to Column 79 was pulled downward up to the roof and east penthouse, which led to the observed kink in the east penthouse roof framing on the north side.

- As Column 79 moved downward, the floor framing connections to interior Columns 76 and 80 and exterior Column 44 failed under increasing tensile in-plane floor forces, resulting in a vertical progression of failure of the floor systems around Column 79.

- Column 80 became laterally unsupported in both directions between Floors 5 and 15, as a result of the progressive floor system failures. Column 80 buckled about $0.7 \mathrm{~s}$ after Column 79 buckled.

- Column 81 became laterally unsupported in both directions between Floors 7 and 15, as a result of the progressive floor system failures. Column 81 buckled about $1.3 \mathrm{~s}$ after Column 79 buckled.

- As Columns 79, 80, and 81 each buckled, their column sections above Floor 14 began to descend downward and pulled the floor structures downward with them, thereby creating a vertical progression of floor collapses that spread across the entire east region of WTC 7.

- The east penthouse, which was supported by Columns 79, 80, and 81, fell downward.

\section{Horizontal Progression of Failure}

- Interior column buckling failures continued to propagate across the core in the lower floors from east to west, due to (1) loss of lateral support from floor system failures, (2) impact of falling debris from adjacent floors and columns, and (3) load redistributed from other buckled columns.

- During the vertical progression, the falling floors pulled on adjacent columns until the floor connections failed on the east side of Columns 76, 77, and 78.

- Truss 2 collapsed due to accumulated weight and impact loads from falling debris. The collapse of Truss 2 precipitated the buckling of Columns 77 and 78, which together with Column 76 had already lost lateral support. 
- The occurrence of this westward progression indicates that the failure of Truss 2 was not essential to the failure of Columns 77 and 78, as they would have buckled in a similar fashion as the other columns.

- The horizontal progression of failure was sensitive to the extent of the estimated initial structural damage in WTC 7 due to debris impact from the collapse of WTC 1.

o For the debris impact damage scenario, some of the interior columns on the west began buckling as the horizontal progression of interior column failures approached the middle of the core. For example, the middle line of interior columns directly behind the initially severed exterior columns buckled before the two north-south lines of columns immediately to their east. The middle line of interior columns lost lateral support in the north-south direction over 11 floors in response to the structural damage that was imposed.

o For the no debris impact damage scenario, the horizontal progression of column failures occurred in order from east to west after collapse initiation (i.e., buckling of Column 79) and the vertical progression of failures on the east side. This scenario matched the observations where the screenwall on the roof fell downward before the west penthouse. This suggests that the damage scenario that was imposed in the best estimate analysis was slightly more severe than actually occurred.

\section{Global Collapse}

- The exterior column failures were sensitive to the extent of the estimated initial structural damage in WTC 7 due to debris impact from the collapse of WTC 1.

o For the debris impact damage scenario, the exterior column buckling began at the southwest corner Column 14, adjacent to the WTC 1 debris impact zone, between Floors 10 and 12. The exterior columns adjacent to the (seven) columns severed in the southwest region due to the collapse of WTC 1 were the first to buckle because additional load was distributed to them as a result of the damage. The analysis with debris impact damage closely simulated the observed failure of the exterior façade, where the façade moved downward as a single unit.

o For the no debris impact damage scenario, the exterior columns buckled near mid-height of the building, approximately between Floors 17 and 29. If the exterior columns had buckled at mid-height, it would have been visible in the videographic records. The analysis without debris impact damage did not closely simulate the observed failure of the exterior façade.

- The observed behavior of the exterior columns during the global collapse was more closely simulated by the analysis with debris impact damage.

- As the interior columns buckled at the lower floors and the corresponding upper column sections began to move downward, the exterior columns buckled inward at the lower floors as a result of floor pull-in forces caused by the downward movement of the building core. The 
floor connections to the columns had not yet failed in this region, as there were no fires observed on the west side of Floors 10 through 14 at any time during the day, so the floors were intact and able to pull the exterior columns inward.

- The south and west exterior columns buckled first, followed by the north and east face columns.

- All exterior columns buckled between approximately Floors 7 and 14.

- Once column support was lost in the lower floors, the remaining exterior structure above began to fall vertically as a single unit.

- WTC 7 was prone to classic progressive collapse in the absence of fire-induced damage and debris impact damage when a section of Column 79 between Floors 11 and 13 was removed. The collapse sequence demonstrated a vertical and horizontal progression of failure upon the removal of the Column 79 section, followed by downward movement at the roofline due to buckling of exterior columns, which led to the collapse of the entire building.

- The observed descent time of the upper 18 stories of the north face of WTC 7 (the floors clearly visible in the video evidence) was 40 percent greater than the computed free fall time. A more detailed analysis of the descent of the north face found three stages: (1) a slow descent with acceleration less than that of gravity that corresponded to the buckling of the exterior columns at the lower floors, (2) a freefall descent over approximately eight stories at gravitational acceleration for approximately $2.25 \mathrm{~s}$, and (3) a decreasing acceleration as the north face encountered resistance from the structure below.

\subsection{REFERENCES}

Cantor 1985. Irwin G. Cantor P.C., Structural Engineers. 1985. Structural Design Drawings, 7 World Trade Center.

GSA. 2003. U.S. General Services Administration, Progressive Collapse Analysis and Design Guidelines for Federal Office Buildings and Major Modernization Projects, June.

Livermore 2007. LS-DYNA Keyword User's Manual, Livermore Software Technology Corporation, Version 971, May.

Sadek, F., El-Tawil, S., Lew, H.S. 2008. Robustness of Composite Floor Systems with Shear Connections: Modeling, Simulation, and Evaluation, J. Struct. Eng., ASCE, Vol 134, No. 11, pg 1717-1725.

UFC. 2005. Unified Facilities Criteria, Design of Buildings to Resist Progressive Collapse, U.S. Department of Defense UFC 4-023-03, 25 January. 


\section{Chapter 13 \\ The Probable Collapse Sequence}

\subsection{SUMMARY PROBABLE COLLAPSE SEQUENCE}

1. Collapse of the WTC Towers. The collapse of WTC 2 did not cause any structural damage or start any fires in WTC 7. The collapse of WTC 1 damaged seven exterior columns on the lower floors of the south and west faces and initiated fires on at least 10 floors between Floors 7 and 30.

2. Growth and Spread of Fires. Fires on the lower floors (Floors 7 to 9 and 11 to 13) grew and spread since they were not extinguished either by the automatic sprinkler system or by FDNY because water was not available. By 3:00 p.m. to 4:00 p.m., these fires were generally concentrated on the east and north sides of the northeast region. The local fires on the upper floors (Floors 19, 22, 29, and 30) were not observed after approximately 1 p.m.

3. Initial Local Failure for Collapse Initiation. Fire-induced thermal expansion of the floor system surrounding Column 79 led to collapse of Floor 13 that triggered a cascade of floor failures. This, in turn, led to loss of lateral support to Column 79 over nine stories, resulting in the buckling failure of Column 79.

4. Vertical Progression of Failure. The buckling of Column 79 (the collapse initiation event) triggered a vertical progression of floor system failures to the east penthouse and subsequent cascading failure of the adjacent interior columns on the east side of the building (i.e., Columns 80 and 81). The vertical progression of floor system failures spread to include the entire east region all the way to the top of the building.

5. Horizontal Progression of Failure. The interior columns buckled in succession from east to west in the lower floors due to loss of lateral support from floor system failures, forces exerted by falling debris, and load redistributed from other buckled columns.

6. Global Collapse. The exterior columns buckled at the lower floors (between Floors 7 and 14) due to load redistribution to the exterior columns from the downward movement of the building core. The entire building above the buckled-column region then moved downward in a single unit, as observed, completing the global collapse sequence.

\section{Other Possible Hypotheses.}

- $\quad$ Fuel oil fires did not contribute to the collapse of WTC 7.

- Hypothetical blast events did not contribute to the collapse of WTC 7. NIST concluded that blast events could not have occurred and found no evidence of any blast events.

- $\quad$ The Con Edison substation played no role in the fires that caused the collapse of WTC 7. 


\subsection{DETAILED PROBABLE COLLAPSE SEQUENCE}

8. Collapse of WTC 2. The collapse of WTC 2 did not cause any structural damage to WTC 7, nor did it ignite a fire in WTC 7. Damage caused by WTC 2 was limited to window breakage in the four-story lobby area on the south face of WTC 7.

9. Collapse of WTC 1. The collapse of WTC 1 caused (1) structural damage that severed seven (out of 58) exterior columns on the lower floors of WTC 7; (2) initiation of fires at 10 floors between Floors 7 and 30; (3) extensive window breakage on the south face of WTC 7; and (4) loss of city water that supplied the automatic sprinkler system on the lower zone of WTC 7.

- The severed columns were located between Floors 7 and 17 on the south face (5 columns) and the west face (2 columns) near the corner. The analysis considered two scenarios: (1) a region of structural damage consistent with the seven severed columns extending over all 12 damaged floors and inward to the core where columns, girders, beams, and floors were removed; and (2) no structural damage. In the first scenario, the damage extended from the south face all the way to the core over the lower seven floors (only at areas where the columns were observed to be damaged), extended half way from the south face to the core over the middle three floors, and was limited to just the exterior structural framing members over the upper three floors.

- Observations indicate that the fires were located in five distinct groups of floors $(7 / 8 / 9$, 11/12/13, 19, 22, and 29/30). These fires were first observed between 11 a.m. and 12:30 p.m. (WTC 1 collapsed at 10:28:22 a.m.). They were typically observed as single floor fires. Fires observed later on floors adjacent to the single floor fires were observed to lag by one half to one hour.

- In most instances, the fire on any given floor likely initiated near the damaged southwest region, though collapse initiation did not occur until nearly seven hours later in the northeast region. Unlike the WTC towers, there was no dispersion of jet fuel in WTC 7 causing simultaneous fire initiation over extensive areas of a single floor or over multiple adjacent floors.

- There was no evidence to suggest that the sprayed fire resistive material (SFRM) was damaged, except in the immediate vicinity of the debris impact on WTC 7 from the collapse of WTC 1. This is consistent with observations NIST made in the Deutsche Bank building that suffered similar debris damage from the collapse of WTC 2.

10. Growth and Spread of Fires. The fires that caused the collapse of WTC 7 were located on the lower floors where there was no gravity-fed tank to supply the automatic sprinkler system. Fires on Floors 11, 12, and 13 were more severe due to higher combustible loads (6.4 psf) than those on Floors 7, 8, and 9 (4 psf). By 3:00 p.m. to 4:00 p.m. (about two hours before the collapse of WTC 7), the fires were generally concentrated on the east and north sides around the northeast region.

- The automatic sprinkler system on the lower floors of WTC 7 (below Floor 21) required direct water supply from the street level mains. The city water mains were unavailable to 
supply the lower zone following the collapse of WTC 1. Also, FDNY decided not to fight the fires due to the lack of water and safety considerations.

- The fires on Floors 7, 8, and 9 spread in a clockwise direction (southwest to north to east) while the fires on Floors 11, 12, and 13 spread in a counterclockwise direction (southwest to east to north).

- Fires on the upper floors (Floor 19 and higher) were not observed after approximately 1 p.m. It is possible that some fires could have been extinguished by the gravity-fed sprinkler system that supplied Floors 21 and higher.

11. Initial Local Failure for Collapse Initiation. The simple shear connection between Column 79 and the girder that spanned the distance to the north face (to Column 44) failed on Floor 13. The connection failed due to shearing of erection bolts, caused by lateral thermal expansion of floor beams supporting the northeast floor system and, to a lesser extent, by the thermal expansion of the girder connecting Columns 79 and 44. Further thermal expansion of the floor beams pushed the girder off its seat, which led to the failure of the floor system surrounding Column 79 on Floor 13. The collapse of Floor 13 onto the floors below-some of which were already weakened by fires - triggered a cascade of floor failures in the northeast region. This, in turn, led to loss of lateral support to Column 79 in the east-west direction over nine stories (between Floors 5 and 14). The increase in unsupported length led to the buckling failure of Column 79, which was the collapse initiation event.

- The failure of the girder-to-column connections was caused primarily by the thermal expansion of the large span-length northeast floor beams. Additional factors that contributed to the failure were the absence of girder shear studs that would have provided lateral restraint and the one-sided lateral support to the girder provided by the northeast corner floor beams.

- In addition to the failure of the connection to Column 79 for the girder spanning to Column 44 on Floor 13, which had the most severe fire condition, the same connection on Floors 8 to 12 were partially damaged due to the failure of some or all of the four bolts. Complete failure of the connection required girder walk-off in addition to the failure of all four bolts.

- The temperatures in the columns in WTC 7 did not exceed $300^{\circ} \mathrm{C}$ and, therefore, the columns did not buckle due to direct fire-induced thermal expansion or weakening. The interior columns were not thermally restrained and, therefore, did not develop increased loads due to thermal expansion which could have led to buckling.

12. Vertical Progression of Failure. The buckling of Column 79 (the collapse initiation event) triggered a vertical progression of floor system failures to the east penthouse and subsequent cascading failure of the adjacent interior columns on the east side of the building (i.e., Columns 80 and 81). The vertical progression of floor system failures spread to include the entire east region all the way to the top of the building since all three columns in this region had buckled.

- The buckling of Column 79 at the lower floors led to downward movement of the upper section of Column 79. The adjacent floor framing was pulled downward, leading to the observed kink in the east penthouse roof framing. 
- A line of window breakage was observed over multiple floors (Floors 37 to 44) between exterior Columns 43 and 45, centered around Column 44, which was connected directly to Column 79 with a girder at each floor.

- Under increasing tensile in-plane floor forces, the floor framing connections to Column 79, adjacent columns (i.e., 80, 76), and the exterior columns all failed. The cascading failures of the lower floors (Floors 6 to 14, both inclusive) surrounding Column 79 led to increased unsupported length in, falling debris impact on, and loads being re-distributed to adjacent columns. This led to buckling of Column 80 and, through a similar process, buckling of Column 81, resulting in a vertical progression of failure of the floor systems across the entire east side of WTC 7.

13. Horizontal Progression of Failure. The interior columns buckled in succession from east to west in the lower floors due to loss of lateral support from floor system failures, forces exerted by falling debris impact, and load redistributed to them from other buckled columns.

- The first north-south line of core columns (i.e., Columns 76 to 78) buckled since they had lost lateral support, were impacted by falling debris, and had loads redistributed to them from adjacent buckled columns.

- Truss 2, which collapsed due to accumulated weight and impact loads from falling debris, precipitated the buckling of Columns 77 and 78 a few moments earlier than Column 76. The failure of Truss 2 caused the failure of the transfer girder linking Columns 77 and 78A which supported Column 78.

- The horizontal progression of failure was sensitive to the extent of the estimated initial structural damage in WTC 7 due to the collapse of WTC 1.

o For the debris impact damage scenario, some of the interior columns on the west began buckling as the horizontal progression of interior column failures approached the middle of the core. For example, the middle line of interior columns directly behind the initially severed exterior columns buckled before the two north-south lines of columns immediately to their east. The middle line of interior columns lost lateral support in the north-south direction over 11 floors in response to the structural damage that was imposed. The results of this scenario were consistent with observations except that the screening wall on the roof fell downward before the west penthouse.

o For the no debris impact damage scenario, the horizontal progression of column failures occurred in order from east to west after collapse initiation (i.e., buckling of Column 79) and the vertical progression of failures on the east side. This scenario matched the observations where the screening wall on the roof fell downward before the west penthouse.

14. Global Collapse. The exterior columns buckled at the lower floors (between Floors 7 and 14) due to load redistribution to the exterior columns from the downward movement of the building core. The entire building above the buckled-column region then moved downward in a single unit, as observed, completing the global collapse sequence. 
- A line of window breakage was observed over multiple floors (Floors 33 to 39) initially in line with exterior Column 55, then spreading east toward Column 54. Column 55 was tied back to the west edge of the building core by a girder (similar in size to the girder connecting Column 44 and 79 on the east side) and a floor beam.

- The buckling of the exterior columns initiated on the west face of the building. The floor connections to the columns had not yet failed in this region because there were no fires observed on the west side on Floors 10 through 14 at any time during the day (unlike on the east side) and the floors pulled the exterior columns inward.

o The exterior columns adjacent to the (seven) columns severed in the southwest region due to the collapse of WTC 1 buckled first because additional load was distributed to them as a result of the damage.

- The overall simulation of the collapsing building with debris impact damage better matched the video observations of the global collapse.

- The building collapsed under the no structural damage scenario with a fire having the same characteristics as was experienced in WTC 7 on September 11, 2001.

- It was recognized that uncertainties existed in the fire simulations, thermal analyses, analyses of the structural response to fires, and the analyses of global collapse, including assumptions made where data were not available. The propagation of uncertainties in the inter-dependent analyses was minimized by conducting sensitivity studies and multiple analyses with a range of values for critical parameters, and by determining the best fit between the analysis results and observed events from photographic and videographic evidence. The occurrence and timing of the analytical results closely matched the observed events (e.g., east penthouse descent, followed by global collapse), which demonstrates the effectiveness of this approach for the interdependent analyses.

- There are greater uncertainties in predicting the precise progression of the collapse sequence as the analysis proceeded due to the random nature of the interaction, break up, disintegration, and falling of the debris. The uncertainties deriving from these random processes increasingly influenced the deterministic physics-based collapse process. Thus, the details of the progression of horizontal failure and final global collapse were sensitive to the uncertainties in how the building materials (steel, concrete) and building systems and contents interact, break up, and disintegrate.

\subsection{OTHER POSSIBLE HYPOTHESES}

15. Role of Diesel Fuel Fires. The hypothetical fuel oil fires on the 5th and 6th floors did not contribute to the collapse of WTC 7. The worst-case scenarios associated with fires being fed by the ruptured fuel lines could not be sustained long enough, or could not have generated sufficient heat, to raise the temperature of a critical column (i.e., Column 79) to the point of significant loss of strength or stiffness. Column 79 was critical because observations and analysis indicated clearly that the failure of this column initiated collapse. Additionally, such fires would have 
produced large amounts of visible smoke that would have emanated from the exhaust louvers; however, no such smoke discharge was observed.

- The 5th Floor was the only floor with a pressurized fuel line supplying nine of the emergency power generators on that floor. Two 6,000 gallon underground tanks supplied these nine generators, were always kept full for emergencies, and were full on September 11, 2001.

- Both 6,000 gallon tanks were found to be damaged and empty in the rubble pile several months after the collapse. This raised the possibility that the fuel may have contributed to a fire on Floor 5, a possibility that could not be distinguished from the fuel being consumed or dissipated in the burning rubble fire subsequent to the collapse of WTC 7.

- The gas temperatures from a pool fire on the 5th floor would have exceeded the boiling point of the coolant for the diesel generators in not much more than an hour, leading to engine failure. With all nine generators out of commission, there would have been no power to operate the fuel pumps for more than an hour or two, and the fires would have burned out well before columns in the region of the fire, including Column 79, experienced significant loss of strength.

- The day tanks on Floors 5 (supplying the remaining two emergency generators), 7, 8, and 9 that supplied fuel to the emergency generators on those floors did not contain enough fuel to be a significant contributor to the combustible load on the floors where fires were observed; it is unlikely that the tanks would have been re-supplied because of multiple safeguards in the fuel delivery system. In addition, none of the day tanks was located near the location of critical Column 79.

- FDNY personnel reported that they did not see any indication of burning liquid fuels before the building collapsed.

16. Role of Hypothetical Blast Events. Hypothetical blast events did not cause the collapse of WTC 7. NIST concluded that blast events could not have occurred and found no evidence of any blast events.

- The minimum explosive charge (lower bound) required to fail a critical column (i.e., Column 79) would have produced a pressure wave that would have broken windows on the north and east faces of the building near Column 79. Such a blast event would have resulted in a sound level of 130 to 140 decibels (a sound level consistent with a gunshot blast or a jet plane that is 10 to 20 decibels louder than a rock concert in front of speakers), at a distance of at least half a mile (if unobstructed by surrounding buildings, for example, along Greenwich Street). There were no witness reports of such a loud noise, nor was such a noise heard on audio tracks of videotapes that recorded the WTC 7 collapse.

- Prior to preparing a column for controlled demolition, walls and/or column enclosures and SFRM would have to be removed and replaced without being detected. Preparing the column includes steps such as cutting sections with torches (which produces noxious and odorous fumes) and careful placement of charges and an initiation device. Controlled demolition usually prepares most, if not all, interior columns in a building with explosive charges, not 
just one column. It is unlikely that explosive charges would have been applied to just one column or that such activity could have taken place without being detected.

- Observations for WTC 7 do not match the typical sequence of events for a controlled demolition. Video evidence clearly shows a sequence of failures (initiation, vertical progression, horizontal progression, and global collapse) based on a single point of initiation. This collapse sequence is inconsistent with a typical controlled demolition where charges are placed in multiple locations across the building and detonated in rapid succession.

17. Role of Con Edison Substation. The Con Edison substation played no role in the fires that caused the collapse of WTC 7. Electronic communications into and out of the Con Ed substation show that the substation continued to operate until it was intentionally shut down at 4:33 p.m. Additionally, there was no evidence of a fire in the Con Edison substation.

- Even though utility power to the rest of WTC 7 was lost at 9:59 a.m., auxiliary utility power to the Con Edison substation from transmission switching station feeders allowed internal operations to be maintained. At 4:33 p.m., the utility control center isolated the WTC 7 Con Edison substation by opening the $138 \mathrm{kV}$ circuit breakers feeding the WTC 7 substation.

- Fire detector signals from the Con Edison substation were monitored off-site throughout the day. One fire detector within the Con Edison substation gave an alarm when WTC 1 collapsed, and stayed in alarm mode until the substation was isolated from incoming feeders at 4:33 p.m. However, there were no other indications (e.g., no high temperature alarms from the transformers, no visible smoke emanating from the Con Edison building) that a fire occurred within the substation during that period of time. Likely causes of the fire alarm were the smoke and dust dispersed in the area of the substation from the collapse of WTC 1. 
This page left blank intentionally. 


\section{Chapter 14 \\ PRINCIPAL FINDINGS}

\subsection{INTRODUCTION}

This chapter presents the findings of the NIST Technical Investigation, organized according to the first three of the four Investigation objectives for Building 7 of the New York World Trade Center (WTC). The fourth objective ("Identify areas in current building and fire codes, standards, and practices that warrant revision") is the subject of Section 14.5. The findings were derived from the extensive documentation in the preceding chapters and NIST NCSTAR 1-9A. While NIST was not able to compile complete documentation of the history of WTC 7, due to the loss of records over time and due to the collapses, the investigators were able to acquire information adequate to arrive at and firmly support the findings and recommendations compiled in this chapter and the next. The chapter begins with summary statements and continues with the listing of the full set of principal findings.

\subsection{SUMMARY}

\section{Objective 1: Determine why and how WTC 7 collapsed.}

- WTC 7 withstood debris impact damage that resulted in seven exterior columns being severed and subsequently withstood fires involving typical office combustibles on several floors for almost seven hours.

- The collapse of WTC 7 represents the first known instance of the total collapse of a tall building primarily due to fires. The collapse could not have been prevented without controlling the fires before most of the combustible building contents were consumed.

- WTC 7 collapsed due to uncontrolled fires with characteristics similar to previous fires in tall buildings. The fires in WTC 7 were similar to those that have occurred previously in several tall buildings (One New York Plaza, 1970, First Interstate Bank, 1988, and One Meridian Plaza, 1991) where the automatic sprinklers did not function or were not present. However, because of differences between their structural designs and that of WTC 7, these three buildings did not collapse. Fires for the range of combustible contents in WTC $7-20 \mathrm{~kg} / \mathrm{m}^{2}$ $\left(4.0 \mathrm{lb} / \mathrm{ft}^{2}\right)$ on Floors 7 to 9 and $32 \mathrm{~kg} / \mathrm{m}^{2}\left(6.4 \mathrm{lb} / \mathrm{ft}^{2}\right)$ on Floors 11 to 13 - persisted in any given location for approximately $20 \mathrm{~min}$ to $30 \mathrm{~min}$. Had a water supply for the automatic sprinkler system been available and had the sprinkler system operated as designed, it is likely that fires in WTC 7 would have been controlled and the collapse prevented.

- The probable collapse sequence that caused the global collapse of WTC 7 was initiated by the buckling of Column 79, which was unsupported over nine stories, after local fire-induced damage led to a cascade of floor failures. The buckling of Column 79 led to a vertical progression of floor failures up to the east penthouse and to the buckling of Columns 80 and 81. An east-to-west horizontal progression of interior column buckling followed, due to loss 
of lateral support to adjacent columns, forces exerted by falling debris, and load redistribution from other buckled columns. The exterior columns then buckled as the failed building core moved downward, redistributing its loads to the exterior columns. Global collapse occurred as the entire building above the buckled region moved downward as a single unit.

- The collapse of WTC 7 was a fire-induced progressive collapse. The American Society of Civil Engineers defines progressive collapse-also known as disproportionate collapse-as the spread of local damage, from an initiating event, from element to element, eventually resulting in the collapse of an entire structure or a disproportionately large part of it (ASCE 7-05). Despite extensive thermal weakening of connections and buckled floor beams of Floors 8 to 14, fire-induced damage in the floor framing surrounding Column 79 over nine stories was the determining factor causing the buckling of Column 79 and, thereby, initiating progressive collapse. This is the first known instance where fire-induced local damage (i.e., buckling failure of Column 79; one of 82 columns in WTC 7) led to the collapse of an entire tall building.

- WTC 7 was prone to classic progressive collapse in the absence of debris impact and fireinduced damage when a section of Column 79 between Floors 11 and 13 was removed. The collapse sequence demonstrated a vertical and horizontal progression of failure upon the removal of the Column 79 section, followed by buckling of exterior columns, which led to the collapse of the entire building.

- Neither the transfer elements (trusses, girders, and cantilever overhangs) nor the "strong" floors (Floors 5 and 7) played a significant role in the collapse of WTC 7. Neither did the Con Edison substation play a significant role in the collapse of WTC 7.

- There was no evidence to suggest that there was damage to the SFRM that was applied to the steel columns, girders, and beams, except in the vicinity of the structural damage from the collapse of WTC 1, which was near the west side of the south face of the building.

- Even without the initial structural damage caused by debris impact from the collapse of WTC 1, WTC 7 would have collapsed from fires having the same characteristics as those experienced on September 11, 2001.

- Early fires in the southwest region of the building did not play a role in the collapse of WTC 7. The fires in this region were not severe enough to heat the structure significantly; and, unlike the northeast region where collapse initiated, there were no columns supporting long span floors in the southwest region.

- The observed descent time of the upper 18 stories of the north face of WTC 7 (the floors clearly visible in the video evidence) was 40 percent greater than the computed free fall time. A more detailed analysis of the descent of the north face found three stages of its speed or velocity: (1) an initial increasing descent rate at less than free fall speeds that corresponded to the buckling of the exterior columns at the lower floors, (2) a downward descent at an essentially free fall speed for approximately $2.25 \mathrm{~s}$, and (3) a decreasing descent rate at less than free fall speeds as the north face encountered resistance from the structure below. 
- Diesel fuel fires did not play a role in the collapse of WTC 7. The worst-case scenarios associated with fires being fed by the ruptured fuel lines (a) could not have been sustained long enough, or could not have generated sufficient heat, to raise the temperature of a critical column (i.e., Column 79) to the point of significant loss of strength or stiffness, or (b) would have produced large amounts of visible smoke that would have emanated from the exhaust louvers. No such smoke discharge was observed.

- Blast events did not play a role in the collapse of WTC 7. Based on visual and audio evidence and the use of specialized computer modeling to simulate hypothetical blast events, NIST concluded that blast events did not occur, and found no evidence whose explanation required invocation of a blast event. Blast from the smallest charge capable of failing a critical column (i.e., Column 79) would have resulted in a sound level of $130 \mathrm{~dB}$ to $140 \mathrm{~dB}$ at a distance of at least half a mile if unobstructed by surrounding buildings (such as along Greenwich Street or West Broadway). This sound level is consistent with standing next to a jet plane engine and more than 10 times louder than being in front of the speakers at a rock concert. There were no witness reports of such a loud noise, nor was such a noise heard on the audio tracks of video recordings of the WTC 7 collapse.

\section{Objective 2: Determine why the injuries and fatalities were so high or low depending on location, including all technical aspects of fire protection, occupant behavior, evacuation, and emergency response.}

- There were no serious injuries or fatalities because the estimated 4,000 occupants of WTC 7 reacted to the airplane impacts on the two WTC towers and began evacuating before there was significant damage to WTC 7. Evacuation of the building took just over an hour.

- The occupants were able to use both the elevators and the stairs, which were as yet not damaged, obstructed, or smoke-filled.

- Building management personnel held the occupants in the building lobby until they identified an exit path that was safe from the debris falling from WTC 1 across the street.

- The decision not to continue evaluating and fighting the fires was made hours before the building collapsed, so no emergency responders were in or near the building when the collapse occurred.

\section{Objective 3: Determine what procedures and practices were used in the design, construction, operation, and maintenance of WTC 7.}

- $\quad$ The design of WTC 7 was generally consistent ${ }^{1}$ with the NYCBC.

- Consistent with the NYCBC, there was no redundancy in the source of water supply for the sprinkler system in the lower 20 floors of WTC 7. Since there was no gravity-fed overhead

\footnotetext{
${ }^{1}$ NIST did not conduct an exhaustive review of the plans and specifications for WTC 7 to determine compliance with the NYCBC, for the reasons stated in Disclaimer No. 4 (see page ii).
} 
tank supplying these floors, the sprinkler system could not function when the only source of water, which was from the street mains, was not available.

- The passive fire resistance design of the WTC 7 structural system was based on catalogued ASTM E 119 test data. Practice today (and in the 1980s) for the fire resistance design of structures, based on the use of ASTM E 119 standard test method, is deficient since the method was not designed to include key fire effects that are critical to structural safety. Specifically, such practice does not capture: (a) important thermally-induced interactions between structural subsystems, elements, and connections - especially restraint conditions; (b) system-level interactions-especially those due to thermal expansion-since columns, girders, and floor subassemblies are tested separately; (c) the performance of connections under both gravity and thermal effects; and (d) scale effects in buildings with long span floor systems.

- Determination of the actual fire performance of the WTC 7 structural system was not the responsibility of any of the design professionals associated with the design, construction, or maintenance of WTC 7. This was typical of practice in the 1980s, and continues to be the practice today. Current practice also does not require design professionals to possess the qualifications necessary to ensure adequate passive fire resistance of the structural system. In current practice, architects typically rely on catalogued ASTM E 119 test data to specify the required passive fire protection that is needed for the structure to comply with the building code. They are not required to explicitly evaluate the fire performance of the structure as a system (such as analyzing the effect of the thermal expansion or sagging of floor beams on girders, connections, and/or columns). Structural engineers are not required to consider fire as a load condition in structural design. Fire protection engineers may or may not be called upon to assist the architect in specifying the required passive fire protection. Thus, none of these professionals has been assigned the responsibility to ensure the adequate fire performance of the structural system.

- The design of WTC 7 did not include any specific analysis of how the structural system might perform in a real fire. There is a critical gap in knowledge about how structures perform in real fires, particularly considering: the effects of the fire on the entire structural system; the interactions between the subsystems, elements, and connections; and scaling of fire test results to full-scale structures (especially for structures with long span floor systems).

\subsection{THE MECHANISMS OF BUILDING COLLAPSE}

\subsubsection{Debris Impact Damage from the Collapse of WTC 1}

- WTC 7 was damaged by debris from the collapse of WTC 1, which occurred at 10:28:22 a.m. However, WTC 7 collapsed at 5:20:52 p.m., nearly seven hours later.

- The structural damage to WTC 7 was primarily located at the southwest corner and adjacent areas of the west and south faces, on Floors 5 through 17. Severed columns were located between Floors 7 and 17 on the south face (six columns) and the west face (one column) near 
the southwest corner. Cladding damage extended over much of the south face, and ranged from broken windows to removal of granite panels and windows.

\subsubsection{Reconstruction of the Fires}

- There were fewer photographs and videos of the WTC 7 fires than there were of the fires in the WTC towers. This resulted in intermittent coverage of the building exterior from about 11:00 a.m. until just after the collapse at 5:20:52 p.m. Nonetheless, the visual evidence was sufficient to guide the reconstruction of the growth patterns of the fires.

- Fires were observed on multiple floors of WTC 7 following the collapse of WTC 1 . The fires were likely to have started at locations facing WTC 1, caused by flaming debris, induced electrical failures, etc.

o Early fires were seen on the southwest corner of Floors 19, 22, 29, and 30 shortly after noon. These were short-lived. Firefighters reported seeing fires on the south and west faces of WTC 7 as soon as visibility allowed (estimated to be 11:00 a.m. to 12:00 p.m.).

o Sustained fires occurred on Floors 7, 8, 9, 11, 12, and 13. The fires on these six floors were fed by combustibles (e.g., desks, chairs, papers, carpet) that were ordinary for commercial occupancies.

o Unlike the situation in the WTC towers, there was no widespread spraying of jet fuel to ignite numerous workstations simultaneously. Rather, in the earlier hours of the fires, the flames spread from one workstation to another, which is a much slower process.

- On each floor, the local fire origin likely occurred at a single workstation component or office furnishing item.

o On Floors 7 through 9 (open landscaping), the initial fire was likely spread by flame contact with an adjacent workstation and then radiative ignition of a workstation cluster across an aisle. By the time this second cluster was fully involved, the prior cluster burned out. Eventually the upper gas layer over enough of the huge open space was likely hot enough for radiatively enhanced ignition of multiple workstations, i.e., non-linear growth.

o On Floors 11 through 13 (enclosed offices), the fire likely grew within an office, reaching flashover in several minutes. After about 5 to 15 minutes, the ceiling tile system likely failed and the hot gases created a local hot upper layer. Thermal radiation from this layer ignited adjacent offices. Offices across a corridor likely ignited more slowly.

- The collapse of WTC 7 was not caused by diesel fuel fires or by fire-induced failure of the transfer trusses on Floors 5 and 6.

o Simulation of hypothetical, worst-case fire scenarios on these floors showed that pool fires, associated with ruptured diesel fuel lines, (a) would have raised the temperatures near the generators to the point where they all would have failed, cutting off the electrical 
power to the fuel pumps, (b) could not be sustained long enough, or generated too little heat, to raise the temperatures of the steel and concrete structure to the point of significant loss of strength or stiffness, and/or (c) would have exhausted smoke from the exhaust louvers, which was not observed.

o A diesel fuel spray fire on Floor 5 would have been less damaging than a pool fire. To be a spray, the fuel escape rate would have been too small to heat Column 79, even if it hit it directly.

o The day tanks on Floors 7, 8, and 9 contained diesel fuel equivalent to only a few percent of the office combustibles on those floors. Safeguards in the fuel delivery system would have prevented the tanks being re-supplied. The supply tanks for the day tanks on Floors 8 and 9 were found to be nearly full several months after the collapse of WTC 7. The heat from a day tank fire on Floor 7 would not have reached the transfer trusses or Column 79.

o The absence of diesel fuel fires on Floor 5 was consistent with the information from interviews that sometime after 1:00 p.m., OEM and FDNY staff climbed the east stairway of WTC 7 and did not see much damage on Floors 4, 5, or 6 from their viewing location. They made no mention of fire, heat or smoke.

o The transfer trusses and a girder were isolated from the diesel fuel lines and the generators by masonry walls. No mechanism for indirect heating of Transfer Truss 1 or 2 was found.

- There was no evidence that the fires spread from floor to floor, except, perhaps, just prior to the collapse of the building.

- The fires on Floors 7 through 9 generally spread clockwise from the southwest corner of the floor. The fires on Floors 11 through 13 generally spread counterclockwise. All the fires were burning in the northeast region at around mid-afternoon.

- Simulations of the fires using the Fire Dynamics Simulator (FDS) generated air temperatures comparable to those in large-room fire tests of office workstations. Compared to the actual fires, the simulated fires followed the same general paths. The simulations of the Floor 12 fires (and thus the derivative Floor 11 and 13 fires) may have overestimated the duration of the fires and the fraction of the burning near the north face windows, relative to the fraction of burning in the interior of the tenant space.

- Doubling the estimated combustible fuel load on the open-landscaped Floor 8 from $20 \mathrm{~kg} / \mathrm{m}^{2}$ $\left(4 \mathrm{lb} / \mathrm{ft}^{2}\right)$ to $40 \mathrm{~kg} / \mathrm{m}^{2}\left(8 \mathrm{lb} / \mathrm{ft}^{2}\right)$ led to a predicted fire spread rate that was slower than actually observed. Decreasing the combustible fuel load on the highly partitioned Floor 12 from 32 $\mathrm{kg} / \mathrm{m}^{2}\left(6.4 \mathrm{lb} / \mathrm{ft}^{2}\right)$ to the estimated load on Floor 8 had no significant effect on the fire spread rate. This indicated that the overestimation of burning duration was less likely due to overestimation of the fuel load and more likely due to excess burning (of combustible vapors from fire-heated office furnishings) near the windows relative to the burning in the building interior. 


\subsubsection{Fire-induced Thermal Effects}

- Calculated fire-elevated temperatures in the interior columns, including Columns 79, 80, and 81, stayed below $200{ }^{\circ} \mathrm{C}$ on all of the floors. The exterior column temperatures were below $150{ }^{\circ} \mathrm{C}\left(300^{\circ} \mathrm{F}\right)$, except on Floors 12 and 13 , where the east and south exterior columns reached $300{ }^{\circ} \mathrm{C}\left(570^{\circ} \mathrm{F}\right)$. At these temperatures, structural steel experiences relatively little loss of strength or stiffness. Thus, WTC 7 did not collapse due to fire-induced weakening of critical columns.

- The simulated fires on Floors 7, 12, and 13 heated portions of the tops of the floor slabs to over $900{ }^{\circ} \mathrm{C}\left(1650^{\circ} \mathrm{F}\right)$. In all cases, significant temperature gradients were observed through the thickness of the slab. The temperatures of some sections of the beams supporting Floors $8,12,13$, and 14 exceeded $600{ }^{\circ} \mathrm{C}\left(1100^{\circ} \mathrm{F}\right)$. The temperatures of some sections of the floor beams at Floors 9 and 10 reached $400{ }^{\circ} \mathrm{C}\left(750^{\circ} \mathrm{F}\right)$.

- Raising the fire-generated air temperatures by 10 percent, which was within the range of reasonable and realistic fires, raised the peak temperatures in the floor beams and slabs by about $70^{\circ} \mathrm{C}\left(170^{\circ} \mathrm{F}\right)$. Additionally, the areas over which the temperatures of the floor beams exceeded $600{ }^{\circ} \mathrm{C}\left(1100^{\circ} \mathrm{F}\right)$ increased. A 10 percent increase in temperature resulted in a roughly 30 percent increase in the heat flux to structural members. Comparable changes in the opposite direction resulted from lowering the fire-generated air temperatures (Case A).

\subsubsection{Structural Response and Collapse}

\section{Initiating Event}

- The buckling failure of Column 79 between Floor 5 and Floor 14 was the initiating event that led to the global collapse of WTC 7. This resulted from thermal expansion and failures of connections, beams, and girders in the adjacent floor systems.

- The connection, beam, and girder failures in the floor systems, and the resulting structural responses, occurred primarily at temperatures below approximately $400{ }^{\circ} \mathrm{C}\left(750{ }^{\circ} \mathrm{F}\right)$, well below the temperatures at which structural steel loses significant strength and stiffness.

- Thermal expansion was particularly significant in causing the connection, beam, and girder failures, since the floor beams had long spans on the north and east sides (approximately $15 \mathrm{~m}, 50 \mathrm{ft})$.

o Heating of the long beams resulted in proportionately large thermal elongation relative to the other components of the floor system, in effect, compressing the beams along their length. This led to distortion of the beams and breaking of the connections of the beams to the floor slabs. Furthermore, the simple shear connections used in the typical floor framing were not able to resist these axial compressive forces that developed as the floor framing was heated.

o At Column 79, heating and expansion of the floor beams in the northeast corner caused the loss of connection between the column and the key girder. Additional factors that 
contributed to the failure of the critical north-south girder were (1) the absence of shear studs that would have provided lateral restraint and (2) the one-sided framing of the east floor beams that allowed the beams to push laterally on the girders, due to thermal expansion of the beams.

o The fires thermally weakened Floors 8 to 14 . As Floor 13 fell onto the floor below, a cascade of floor failures continued until the damage reached the massive Floor 5 slab, leaving Column 79 without lateral support for nine floors. The long unsupported length of Column 79 led to its buckling failure.

- Blast events did not play a role in the collapse of WTC 7. NIST concluded that blast events could not have occurred, and found no evidence whose explanation required invocation of a blast event. Blast from the smallest charge capable of failing a critical column (i.e., Column 79) would have resulted in a sound level of $130 \mathrm{~dB}$ to $140 \mathrm{~dB}$ at a distance of at least half a mile if unobstructed by surrounding buildings (such as along Greenwich Street and West Broadway). This sound level is comparable to a gunshot blast, standing next to a jet plane engine, and more than 10 times louder than being in front of the speakers at a rock concert. The sound from such a blast in an urban setting would have been reflected and channeled down streets with minimum attenuation. However, the soundtracks from videos being recorded at the time of the collapse did not contain any sound as intense as would have accompanied such a blast.

\section{Vertical Progression of Collapse}

- Once Column 79 buckled, there was a vertical progression of floor system failures up to the east penthouse, followed by the buckling of Columns 80 and 81 .

o The buckling of Column 79 at the lower floors led to downward movement of the upper section of Column 79. The adjacent floor framing was pulled downward, leading to the observed kink in the east penthouse roof framing.

o As the lower floors surrounding Column 79 fell downward, Column 80 and Column 81 had increased unsupported lengths as well as falling debris impacts and loads being redistributed from adjacent columns. This led to buckling of Columns 80 and 81, and resulted in a vertical progression of failure of the floor systems up to the roof level across the entire east side of WTC 7.

- Columns 79, 80, and 81 were the only interior support for the gravity loads in the eastern region of the building. Once these three columns buckled and their upper sections began to descend, there was insufficient support for the floors, up to the east penthouse.

- $\quad$ None of these columns was significantly weakened by elevated temperatures; temperatures did not exceed $300^{\circ} \mathrm{C}\left(570^{\circ} \mathrm{F}\right)$ in the core or perimeter columns in WTC 7. 


\section{Horizontal Progression of Collapse}

- Columns 76 through 78 were the next line of columns to buckle, due to loss of lateral support, impact by falling debris, and load redistribution from Columns 79 through 81 . The failure of Truss 2 was not essential to the failure of Columns 77 and 78, as they would have buckled like the other columns.

- The remaining interior columns buckled in succession from east to west in the lower floors due to loss of lateral support from floor system failures, forces exerted by falling debris impact, and load redistributed to them from other buckled columns.

- The initial westward progression and the overall speed of the collapse was not sensitive to the extent of the estimated structural damage to WTC 7 due to the debris from the collapse of WTC 1 . When the global collapse was nearly complete, there was some small sensitivity to the extent of the initial damage in the southwest portion of the building.

\section{Global Collapse}

- The exterior columns buckled at the lower floors (between Floors 7 and 14) due to load redistribution to the exterior columns from the building core as the interior columns buckled and the building core moved downward. The entire building above the buckled-column region then moved downward in a single unit, as observed, completing the global collapse sequence.

- Computer simulations of the fires, the thermal heating of the structure, the thermally induced damage to the structure, and the structural collapse can be used to predict a complex degradation and collapse of a building. The overall features and timing of the prediction were consistent with the videographic evidence.

- It was recognized that uncertainties existed in the fire simulations, thermal analyses, analyses of the structural response to fires, and the analyses of global collapse, including assumptions made where data were not available. The propagation of uncertainties in the inter-dependent analyses was minimized by conducting sensitivity studies and multiple analyses with a range of values for critical parameters, and by determining the best fit between the analysis results and observed events from photographic and videographic evidence. The occurrence and timing of the analytical results closely matched the observed events (e.g., east penthouse descent, followed by global collapse), which demonstrates the effectiveness of this approach for the interdependent analyses.

- The uncertainties in predicting the precise progression of the collapse sequence increased as the analysis proceeded due to the random nature of the interaction, break up, disintegration, and falling of the debris. The uncertainties deriving from these random processes increasingly influenced the deterministic physics-based collapse process. Thus, the details of the progression of horizontal failure and final global collapse were sensitive to the uncertainties in how the building materials (steel, concrete) and building systems and contents interacted, broke up, and disintegrated. 
- These computational models comprise a set of research tools that can take months (eight months in this case) for a complete simulation. Their adaptation for engineering practice would forestall future disasters, while reducing the potential for structural overdesign.

\subsection{LIFE SAFETY FACTORS}

\subsubsection{Evacuation of WTC 7}

- By the conventional measure of life safety, the evacuation of WTC 7 was successful, as NIST identified no life-threatening injuries or fatalities among the estimated 4,000 building occupants on September 11, 2001.

- Most of the occupants initiated their own evacuation shortly after WTC 1 was attacked.

- Evacuation of the building took just over an hour to complete, which was about $30 \mathrm{~min}$ longer than the estimated minimum time if the elevators and stairs had been used to maximum advantage. Nonetheless, the building was safely evacuated prior to the collapse of WTC 2. Some of the additional evacuation time was due to the considerable crowding in the lobby. Occupants arrived in the lobby from both stairwells, from the elevators, and from other WTC buildings, and were held in the lobby until a safe exterior exit was identified by emergency management officials.

- The calculated stairwell capacity was insufficient to meet the requirements of the NYCBC in effect during the design and construction period, if the building were occupied at the calculated maximum level $\left(\approx 14,000\right.$ people). ${ }^{2}$ The capacity was sufficient for the normal occupancy of the building ( $\approx 8,000$ workers plus visitors), estimated by NIST, and was more than sufficient for the occupancy on September 11, 2001 ( $\approx 4,000$ people), also estimated by NIST. The stairwell capacity met the requirement of the (subsequent) 2000 edition of the IBC, but not the 2003 edition of NFPA 5000.

- The separation of the stairwell doors met the requirement of the 1968 NYCBC. On some floors, the separation of the stairwell doors was below the remoteness requirements in the (current) 2000 IBC and the 2003 NFPA 5000.

- Evacuation management at every level did not provide prompt evacuation instructions to building occupants during the event. NIST was not able to determine whether specific guidance was delivered to the occupants via the public address system.

- In addition to the length of time that WTC 7 withstood the internal fires, some specific human actions likely contributed to the speed and overall success of the evacuation.

\footnotetext{
${ }^{2}$ When WTC 7 was being designed, many details of tenant spaces were unknown. Therefore, NIST used a conservative calculation of net floor area which does not account for tenant spaces which are normally unoccupied. While the NYCBC in effect at the time of design allowed for these reductions to net floor area calculations (spaces such as columns, fixed cabinets, furred-in spaces, equipment and accessory spaces would be subtracted from gross area), this calculation would require specific knowledge of tenant layout details and would preclude future changes to the floor layouts after stairwell construction.
} 
o Evacuation drills had been conducted every six months.

o The decision to prevent occupants from exiting the stairwells out into the streets where they could be impacted by debris from WTC 1 and WTC 2 likely prevented injuries and deaths.

o Using the loading dock exit to provide overhead protection, combined with the scaffolding protection along the other side of Washington Street, was an example of spontaneous decision-making on the part of the building management personnel which likely contributed to the positive outcome.

\subsubsection{Emergency Response}

- Faced with a disaster of an unprecedented nature, the involvement of the emergency management personnel with regard to WTC 7 was limited. Nonetheless, no lives were lost as a result of the collapse of WTC 7 .

- The loss of numerous firefighters, company officers, and chief officers in the collapses of WTC 1 and WTC 2 led to a changing command structure for the rest of the morning, as new command posts were established and several different chief officers took command and relinquished command of operations at the WTC site.

- Due to the focus on rescuing people trapped in the debris field, providing aid to the injured, and the loss of water in the hydrant system, FDNY was not able to consider the possibility of fighting the fires in WTC 7 until approximately 1:00 p.m. At approximately 2:30 p.m., FDNY gave the order to forego firefighting activity and for personnel to withdraw to a safe distance from the building.

- Con Edison shut off all power to the substation under WTC 7 at 4:33 p.m.

\subsection{CODES, STANDARDS, AND PRACTICES}

\subsubsection{General}

- WTC 7 was designed and constructed as a "tenant alteration project" of The Port Authority. Its design and construction were based on the 1984 edition of the Tenant Construction Review Manual.

- Although the PANYNJ was not subject to the NYCBC, the 1968 NYCBC, including amendments to January 1, 1985, appears to have been used for the design and construction provisions of WTC 7, based on citations in the construction documents.

- The type of building classification used to design and construct the building was not clear from the available documents. Based on the height, area, primary occupancy classification, and installation of a fire sprinkler and standpipe system, the minimum construction type (permitted by NYCBC) was type 1-C (2 h protected) classification. However, some documentation, including some building drawings and specifications for bidders on the 
contract for applying SFRM to the structural steel, indicate a type 1-B (3 h protected) classification.

\subsubsection{Building Design and Structural Safety}

- $\quad$ NIST found no evidence to suggest that WTC 7 was not designed in a manner generally consistent ${ }^{1}$ with applicable building codes and standards in effect at the time of construction.

- WTC 7 was adequately designed for vertical loads due to gravity and lateral loads due to wind.

o The vertical (gravity) load resisting system comprised the core and exterior columns, which received gravity loads from the floor framing. Of particular note were the three core columns on the east side of the building (Columns 79, 80, and 81), which supported large span floor areas with approximately $15 \mathrm{~m}(50 \mathrm{ft})$ spans on at least one side.

o Above Floor 7, the lateral load resisting system comprised the exterior moment frame with a perimeter belt truss at Floors 22 through 24. There were also a perimeter belt truss between Floors 5 and 7, diaphragms at Floors 5 and 7 that transferred lateral wind loads to the core columns, and bracing in the core below Floor 7 that transferred lateral loads to the foundation. However, this system was not able to provide a secondary load path for gravity loads.

o Above Floor 7, there was no bracing, or other load redistribution mechanism, to transfer gravity loads between interior columns. The floor framing, which was the only load path between columns, could not redistribute loads between columns because the shear connections from the interior floor beams to columns were only designed for transferring vertical shear loads.

o Transfer girders, trusses, and cantilever overlays were used to transfer column loads above Floor 7 to a different column layout below Floor 5.

- The structural design did not explicitly evaluate fire effects, which was typical for engineering practice at that time and continues to remain so today. Many of the shear connections in WTC 7 were not capable of resisting lateral loads resulting from thermal expansion effects in the steel floor framing when the floor beams were heated.

\subsubsection{SFRM Requirements and Application}

- It is likely that the Monokote MK-5 SFRM, applied to the steel framing and metal decks, was undamaged by the impact of the debris from the collapse of WTC 1, except in the area where direct structural damage to WTC 7 occurred.

- NIST simulations showed that, for the heaviest columns in WTC 7, when properly insulated, it would have taken an exposure of about $7 \mathrm{~h}$ at post-flashover upper layer gas temperatures to raise the steel temperature to $600{ }^{\circ} \mathrm{C}\left(1100{ }^{\circ} \mathrm{F}\right)$, the point at which the steel strength would have been reduced by half. A similar calculation indicated it would have taken about $4 \mathrm{~h}$ to 
reach this temperature for an insulated lighter column. These times are both far longer than the time over which post-flashover gas temperatures were sustained in the computed WTC 7 fires. For comparison, this steel temperature would have been reached in under one-half hour if the insulation were not applied.

- It is unlikely that the collapse of WTC 7 would have been prevented had the insulation thickness on the floor beams been increased by 50 percent, from $13 \mathrm{~mm}(1 / 2 \mathrm{in}$.) to $19 \mathrm{~mm}$ (3/4 in.). NIST calculations indicated that the time to reach the steel temperature of $649{ }^{\circ} \mathrm{C}$ $\left(1200{ }^{\circ} \mathrm{F}\right.$ ) would have increased by about $10 \mathrm{~min}$ to $20 \mathrm{~min}$.

- The ASTM E119 test does not capture critical behavior of structural systems, e.g., the effect of thermal expansion or sagging of floor beams on girders, connections, and/or columns. The thermal expansion of the WTC 7 floor beams that initiated the probable collapse sequence occurred primarily at temperatures below approximately $400{ }^{\circ} \mathrm{C}\left(750^{\circ} \mathrm{F}\right)$. Thus, to the extent that thermal expansion, rather than loss of structural strength, precipitates an unsafe condition, thermal expansion effects need to be evaluated. The current fire resistance rating system, which does not include thermal expansion effects, is not conservative.

\subsubsection{Fire Safety and Fire Protection Systems}

- $\quad$ WTC 7 had the following active fire protection systems: fire alarms, smoke and heat detectors, manual pull stations, smoke control systems, and automatic sprinklers. Each was designed, constructed, and apparently maintained consistent with applicable building codes and standards.

- The standpipe and automatic sprinkler systems were divided into three zones. As prescribed by the NYCBC, each zone had a primary and secondary water supply.

o The primary water supply for fire protection for the high zone (Floors 40 through 47) and mid-level zone (Floors 21 through 39) was from two water storage tanks on the $46^{\text {th }}$ floor. The secondary supply was pumped from the city water main.

o The primary water supply for fire protection for the low zone, floors 1 through 20, was a direct connection to the city water mains. The secondary supply was from an automatic fire pump, which was connected to the city water main as well.

- $\quad$ Since the city water main had been compromised as a result of the collapses of the two towers, there was no water supply to control the fires on the $7^{\text {th }}$ through $13^{\text {th }}$ floors. By contrast, the early fires on the $22^{\text {nd }}, 29^{\text {th }}$, and $30^{\text {th }}$ floors may have been assisted by the sprinkler system on the upper floors, whose primary water supply was from the storage tanks on the $46^{\text {th }}$ floor.

- The architectural drawings indicated that there were fire-rated walls between tenant spaces on the same floor and between tenant spaces and the building core. Spaces housing mechanical equipment, power transformers, emergency power generators, and other such equipment were enclosed in fire-rated partitions. While the partitions between offices, conferences rooms, 
etc. were not required to be fire-rated, there was evidence from both the visual evidence and the fire simulations that some of these partitions did retard the spread of the fires.

- $\quad$ There was no evidence of floor-to-floor fire spread until perhaps just before the WTC 7 collapse. Thus, the fire-rated floors were successful as fire penetration barriers.

\subsection{FUTURE FACTORS THAT COULD HAVE MITIGATED STRUCTURAL COLLAPSE}

In the course of the Investigation, NIST and its contractors were aware that there were existing, emerging, or even anticipated capabilities that could have prevented the collapse of WTC 7, had they been in place on September 11, 2001. NIST did not conduct studies to evaluate the degree to which building performance could have been improved on September 11, 2001, had the capabilities been available. These include:

- More robust connections and framing systems to better resist the effects of thermal expansion on the structural system, which is not currently considered in design practice.

- Structural systems expressly designed to prevent progressive collapse. The current model building $\operatorname{codes}^{3}$ do not require that buildings be designed to resist progressive collapse.

- Better thermal insulation (i.e., reduced conductivity and/or increased thickness) to limit heating of structural steel and to minimize both thermal expansion and weakening effects. Currently, insulation is used to protect steel strength, but it could also be used to maintain a lower temperature in the steel framing to limit thermal expansion.

- Automatic fire sprinkler systems with independent and reliable sources for the primary and secondary water supply.

- Improved compartmentation in tenant areas to limit the spread of fires.

- Thermally resistant window assemblies which limit breakage, reduce air supply, and retard fire growth.

\subsection{HUMAN PERFORMANCE FACTORS}

Human performance factors contributed to the outcome of no loss of life at WTC 7:

- $\quad$ Reduced number of people in WTC 7 at the times of airplane impact on the towers.

- Shortness of delay in starting to evacuate.

- Evacuation assistance provided by emergency responders to evacuees.

- Participation of the building occupants in recent fire drills.

\footnotetext{
${ }^{3}$ For an explanation of model building codes, see Section 5.1 of NIST NCSTAR 1.
} 
- Decision not to continue reconnaissance of the building and not to fight the fires within.

Other human performance factors did not play a life safety role in WTC 7 on September 11, 2001, but could have been important had the fires been more widespread, the building damage more severe, or the building occupancy at full capacity:

- Accuracy and reliability of communications among emergency responders and building occupants.

- Efficiency of management of large-scale emergency incidents. 
This page intentionally left blank. 


\section{Appendix A \\ The Con Edison Substation In WoRLd Trade Center 7}

\section{A.1 INTRODUCTION}

A unique feature of WTC 7 was that the 47 story high-rise building was constructed above a Consolidated Edison Company of New York (Con Edison) substation (SS) ${ }^{1}$ that supplied power to the entire WTC complex, as well as lower Manhattan. As a result, details about the construction and operation of the Con Edison substation were required in order to have a more complete understanding of the behavior of WTC 7 on September 11, 2001.

Based on numerous records, many furnished by Con Edison, this appendix:

- documents the general operation of the Con Edison power grid that served the WTC site on September 11, 2001;

- chronicles the events that took place on the electric power system supplying the WTC complex following the aircraft impacts on WTC 1 and WTC 2 to determine whether the power system behaved normally and predictably, and to establish the availability of power for rescue and fire fighting purposes in the immediate aftermath of the attack; and

- documents the distribution of power to WTC 7 between the time that WTC 2 collapsed and the time that WTC 7 began to collapse.

This appendix does not address the subsequent restoration activities to re-establish power to the area.

This effort provided insight into the availability of electrical power to pump water for the automatic sprinkler systems, the possible links between the fires that were observed in WTC 7 and the power distribution system, and whether any dramatic events may have initiated at the substation that could have contributed to the building's structural collapse.

\footnotetext{
${ }^{1}$ Technically, a substation consists of a set of transformers used to supply power to a specific area. As such, the Con Edison substation in WTC 7 was actually comprised of two substations. When referred to individually in this report, these substations are identified as "Substation \#1" (SS \#1), which consisted of transformers 1 through 5, and "Substation \#2" (SS \#2), which consisted of transformers 6 through 9. When the entire Con Edison complex within WTC 7 is referenced, it is identified as the "substation" or the "Con Edison substation."
} 
Table A-1. Times for major events on

September 11, 2001 (Chapter 5).

\begin{tabular}{|c|c|}
\hline Event & Time ( $\pm 3 \mathrm{~s})$ \\
\hline First Plane Strike - WTC 1 & 8:46:30 a.m. \\
\hline Second Plane Strike - WTC 2 & 9:02:59 a.m. \\
\hline Collapse of WTC 2 & 9:58:59 a.m. \\
\hline Collapse of WTC 1 & 10:28:22 a.m. \\
\hline Collapse of WTC 7 & 5:20:52 p.m. \\
\hline
\end{tabular}

\section{A.2 PHYSICAL LAYOUT OF THE CON EDISON WTC 7 SUBSTATION}

Figure A-1 provides an overall plan view of the WTC building complex that relates the buildings cited in the text to the geographical layout. The Con Edison substation (indicated in red in Figure A-1) was located on Barclay Street, and comprised the first two levels along the north side of WTC 7 . The 47 story building was considered a "tenant alteration" (Syska \& Hennessy 1984) by The Port Authority of New York and New Jersey (PANYNJ) to the original building housing the substation. Figure A-2 is a photograph of WTC 7 that shows the roof over the north portion of the substation and the Barclay Street facade, taken some time before September 11, 2001.

Construction of the two story building housing the substation, originally known as the Keystone Building, was begun in 1967. The nine transformer vaults that housed the $138 / 13.8 \mathrm{kV}$ units were situated along the northern and western edges of the building, covering an area of about $85 \mathrm{~m}$ by $43 \mathrm{~m}$ ( $278 \mathrm{ft}$ by $140 \mathrm{ft}$ ) on the $1^{\text {st }}$ floor level. There was manhole access to the splicing chambers for both the incoming $138 \mathrm{kV}$ and outgoing $13.8 \mathrm{kV}$ cables (Syska \& Hennessy 1984a). The extensive line-up of $13.8 \mathrm{kV}$ switchgear was situated in two rows to the south of the transformer vaults (Syska \& Hennessy 1984a). Access within the substation was provided by stairwells on the west side, in the center, and on the east side of the building. None of these stairs extended into the 47 story building above. Roll-up doors secured the two driveways on Barclay Street and Washington Street (PANYNJ 1987). 


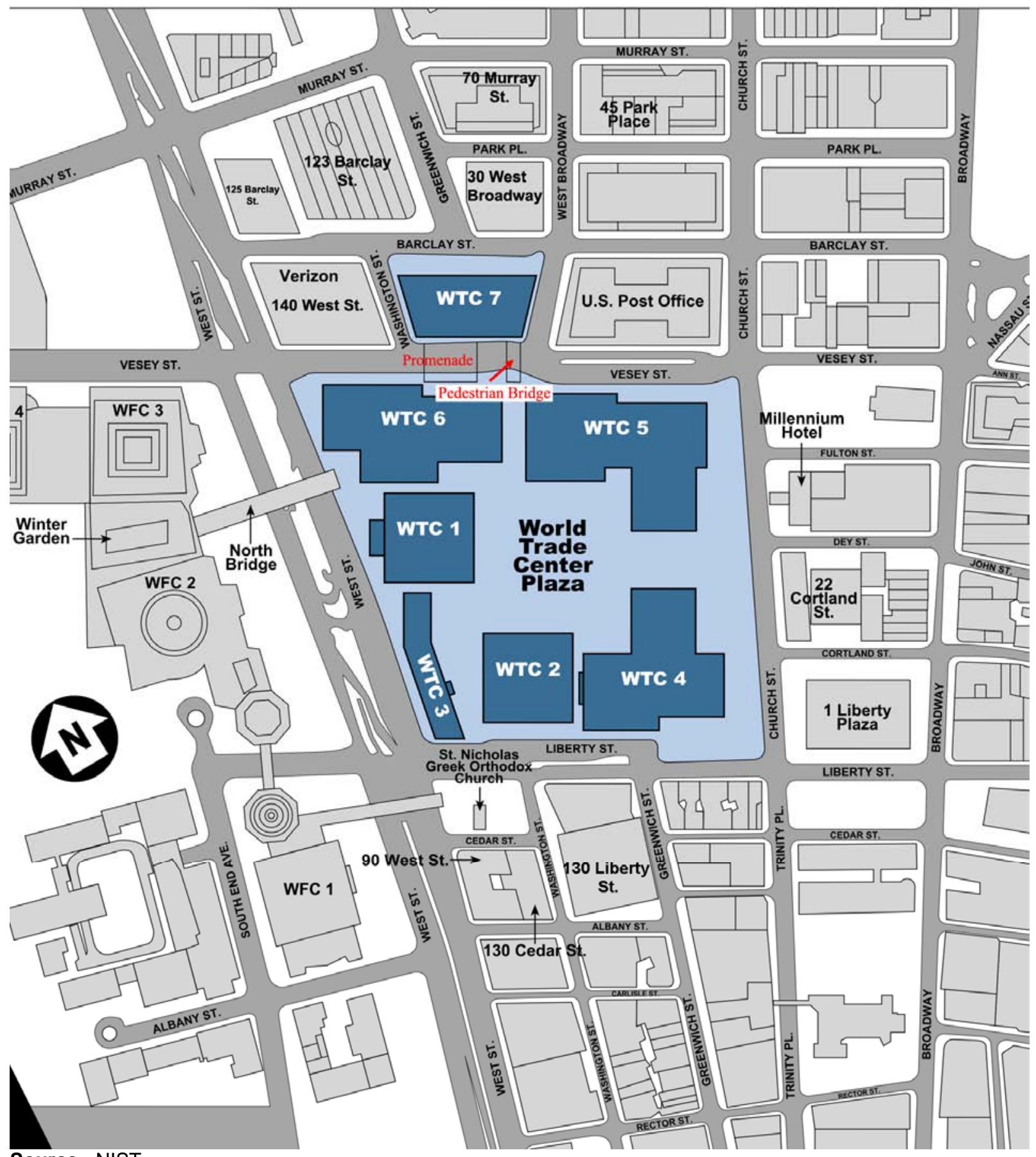

Source: NIST

Figure A-1. WTC site indicating the Con Edison substation location within WTC 7. 


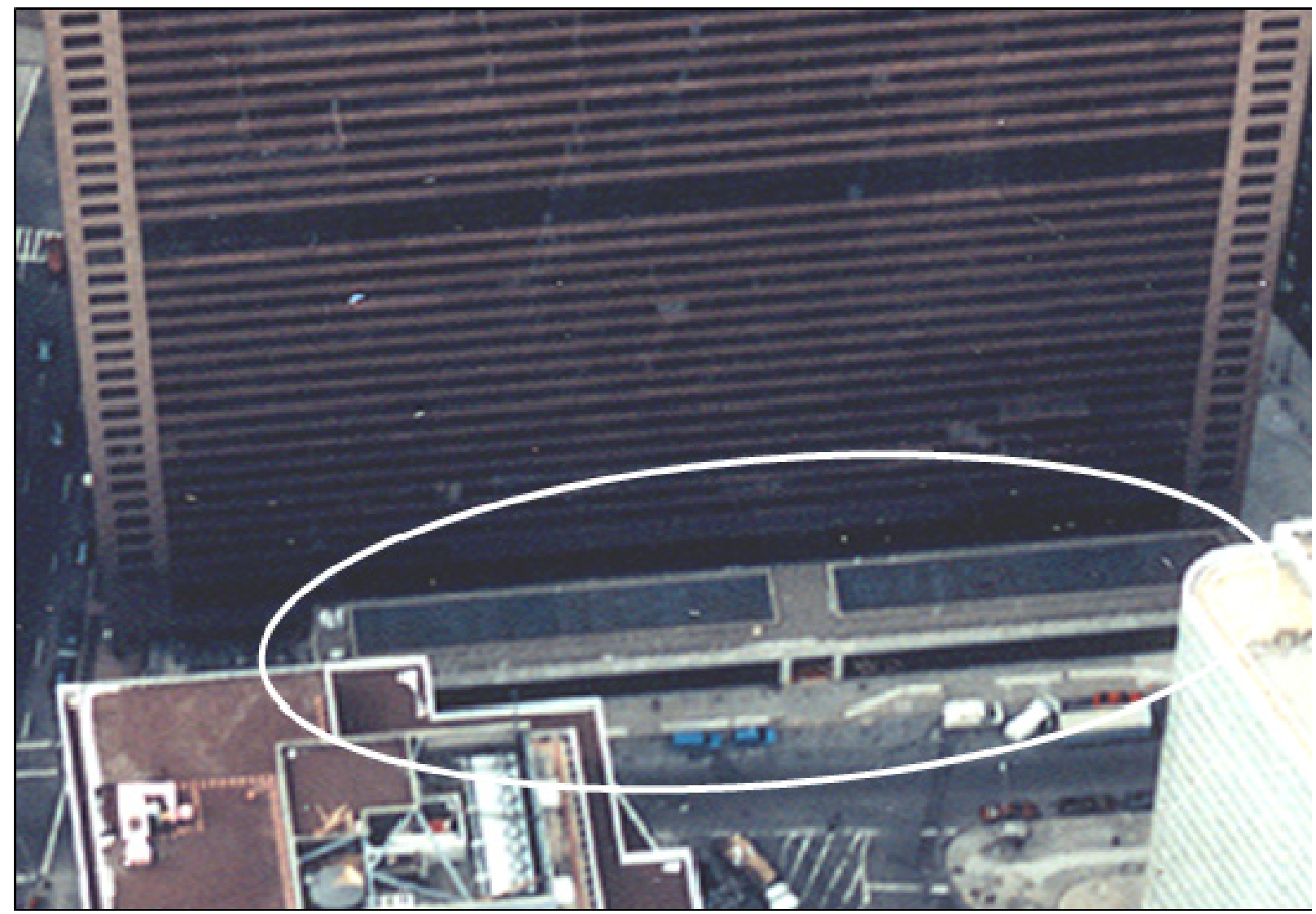

Source: Con Edison; reproduced with permission

\section{Figure A-2. Aerial view from the north side of WTC 7 showing the Con Edison substation along Barclay Street. (Photo taken prior to September 11, 2001.)}

\section{A.3 OVERVIEW OF THE ELECTRIC POWER NETWORKS SUPPLYING LOWER MANHATTAN}

\section{A.3.1 Background on Power Distribution Systems}

To understand what happened at the Con Edison substation on September 11, 2001, this section provides a brief description of power distribution systems in general, and, in Table A-2, defines some commonly used technical terms. The remainder of Section A.3 describes the networks supplying the WTC site. The sources material to Section A.3 are the Con Edison references in Section A.8.

Electric power is often generated in locations remote from the major centers of demand. There are a variety of good reasons for this (e.g., the provision of cheap hydro generation in eastern Canada). The transmission of bulk electric power from the locations where it is produced to load centers where it is consumed is accomplished using high voltages ( $115 \mathrm{kV}$ to $765 \mathrm{kV}$ in North America) in order to reduce the electrical losses that would be a consequence of low voltage transmission. However, safety and space requirements demand that it is ultimately utilized at much lower voltage levels (e.g., $110 \mathrm{~V}$ in the residential situation). As a consequence, a transition is needed from the high-voltage (HV) bulk transmission network to the consumer's premises (industrial and residential). This is usually accomplished in a number of stepped voltage reductions through a network which is usually radial. This 
means that any break in the network will result in the loss of power at all points "downstream" of the break.

Table A-2. Glossary of Technical Terms Associated with Electrical Power Networks.

\begin{tabular}{|c|c|}
\hline Term & Definition \\
\hline 3-phase & $\begin{array}{l}\text { a system of electrical power generation and distribution which uses three conductors } \\
\text { carrying alternating current which is phase separated by } 120^{\circ}\end{array}$ \\
\hline busbar & $\begin{array}{l}\text { high current-carrying conductors (usually in substations) used to connect power system } \\
\text { equipment in parallel }\end{array}$ \\
\hline capacitor bank & $\begin{array}{l}\text { an assembly of capacitors located at strategic points in the network to provide reactive } \\
\text { compensation in order to regulate the voltage levels }\end{array}$ \\
\hline circuit & see "feeder" \\
\hline circuit breaker & $\begin{array}{l}\text { a switch designed to interrupt on command the high currents encountered during power } \\
\text { system fault conditions }\end{array}$ \\
\hline disconnect switch & $\begin{array}{l}\text { a circuit switch used for isolating sections of a network, but without the ability to } \\
\text { interrupt fault current in the same way as a circuit breaker }\end{array}$ \\
\hline feeder & $\begin{array}{l}\text { a set of conductors used to distribute power from a substation, with either underground } \\
\text { cables or overhead lines (circuit is sometimes used synonymously with feeder) }\end{array}$ \\
\hline generator & $\begin{array}{l}\text { a rotating electromechanical device capable of transforming the mechanical power from } \\
\text { a prime mover into synchronous 3-phase electrical power }\end{array}$ \\
\hline network & $\begin{array}{l}\text { an assembly of feeders and substations for the transmission and distribution of electric } \\
\text { power }\end{array}$ \\
\hline protective relaying & $\begin{array}{l}\text { a generic term given to the equipment used to determine, from measurements of voltage } \\
\text { and current, whether abnormal conditions exist, and issue trip commands to circuit } \\
\text { breakers according to a predetermined protocol }\end{array}$ \\
\hline radial structure & $\begin{array}{l}\text { a network topography in which electrical power is distributed outwards through } \\
\text { radiating feeders from a single source }\end{array}$ \\
\hline ring structure & $\begin{array}{l}\text { a network topography in which electrical power may be derived from more than one } \\
\text { routing }\end{array}$ \\
\hline SCADA & acronym for Supervisory Control and Data Acquisition \\
\hline SOCCSX & Consolidated Edison Company acronym for their Control Center \\
\hline substation & $\begin{array}{l}\text { the location of an assembly of transformers, circuit breakers and control equipment at } \\
\text { nodal points in a power system }\end{array}$ \\
\hline switchboard & $\begin{array}{l}\text { an assembly of switches, fuses and metering equipment used to distribute power at low } \\
\text { voltages }(<600 \mathrm{~V})\end{array}$ \\
\hline switchgear & $\begin{array}{l}\text { a generic term for a piece of power system switching equipment, including various } \\
\text { forms of circuit breaker, fuses, isolators, etc. }\end{array}$ \\
\hline T-connection & the solid junction of two feeders without the facility to isolate either feeder \\
\hline tap changer & $\begin{array}{l}\text { a device associated with a transformer which allows its turns-ratio to be adjusted } \\
\text { (sometimes automatically on load) for the purpose of regulating voltage }\end{array}$ \\
\hline transformer & $\begin{array}{l}\text { an electromagnetic device designed to change the voltage level of a power system } \\
\text { network }\end{array}$ \\
\hline Y-connection & a system of interconnection of the 3-phase windings in a generator or transformer \\
\hline$\Delta$-connection & a system of interconnection of the 3-phase windings in a generator or transformer \\
\hline
\end{tabular}


The radial network from a bulk supply point usually has a "tree" structure so that power is delivered through the tree "trunk" to a plurality of "branches." The places from which the branches radiate are usually termed substations and are the locations in which most of the power system equipment is concentrated. Substations, which vary enormously in size and complexity, are where the voltage stepdown is accomplished by means of transformers which supply power to the branches at progressively lower voltages. The connections joining the substations are usually termed feeders, which, in general, could be either overhead lines or underground cables. (In highly urban areas, these are more likely to be underground cables.) For reasons of optimization, power is both generated and transmitted on a 3-phase basis, which implies that each feeder (or circuit) actually requires three phase conductors. In the case of cables, these may be three separate cables or, sometimes at the lower voltages, the three conductors are combined into a single multi-core cable.

The network is usually segregated, and each end of the feeders is provided with switches (usually located with the transformers at the substations) to permit the isolation of the major elements of such a system. This isolation, which can be accomplished by switch operation, facilitates two important functions: (1) it permits parts of the system to be isolated for maintenance, and (2) it permits the system to be segregated to isolate feeders, or other equipment, which develop faults.

In systems handling large amounts of power it is necessary that faulted sections be isolated quickly to limit the dissipation of large amounts of energy and concomitant damage. To facilitate this, the switches referred to above (called circuit breakers) are capable of automatic operation at power levels for worst case conditions. (Since each feeder is normally 3-phase, the circuit breakers actually have three switches - one for each phase.) The detection of an abnormal condition is accomplished by equipment called protective relays.

Protective relaying is a fundamental underpinning of power system design. Automatic protection systems must be applied to power networks at all levels both to provide safety from electrocution and fire hazards and to safeguard apparatus. Automatic protection systems can vary from fuses applied to low voltage distribution systems to sophisticated and fast-acting systems applied to extra high voltage bulk power networks. The selection and design of protective relaying systems usually involve compromise to achieve both sensitivity and discrimination. The latter is needed to insure that the minimum extent of the network is disconnected to clear a fault, so that disruption of supply to consumers is minimized.

These relays sample both currents and voltages on the network and diagnose conditions (such as an unacceptably high current) which require operation of the circuit breakers to isolate a section of the network. In order to overcome the inherent lack of reliability in a radial arrangement, it is common practice to provide dual- or multiple-circuit lines connecting the same points in the system. In that way, the loss and automatic isolation of one feeder does not necessarily interrupt the radial supply since the feeders in parallel may be able to carry the prevailing load.

In the same way that reliability is improved by providing parallel feeders, substations are often provided a bank of transformers. The transformers in a bank are connected in parallel by a series of conductors usually termed busbars. By this means, a transformer may be taken out of service through the operation of circuit breakers on either side (automatically because of a fault in the unit, or manually for maintenance), and the load carried by the remaining units. Equipment in large substations is often provided with other diagnostic sensors to provide an indication of abnormal conditions. The measurement of oil temperature in a transformer would be a simple example. 
Conditions in the substation and the status of circuit breakers are often transmitted by a telemetry system to a remote control center responsible for system operation. Manual operation of circuit breakers may also be possible by remote control. Such systems of monitoring and control are often referred to as SCADA (Supervisory Control and Data Acquisition) systems.

\section{A.3.2 Supply of the WTC Complex from the Con Edison System}

In common with typical U.S. practice, the power system at the WTC complex was distributed radially from a bulk supply point, and was progressively stepped down in voltage through the system. There was no ring structure which would have permitted power to be fed from more than one direction. The Con Edison substation housed transformers to change the voltage level, circuit breakers to permit system segregation, and numerous other items of support, control, communications, and metering equipment. The substations were connected with underground cables that permitted the flow of power to the consumer. (Con Edison 1969; Con Edison 2005c; Con Edison 2005f; Con Edison 2005h; Con Edison 2005i)

Circuit breakers were located at both ends of the high voltage feeders so as to permit the isolation of parts of the network. These had three important functions:

- Faulted sections of the system could be isolated thus preventing a fault from shutting down the complete network.

- $\quad$ Some limited network reconfiguration could be made under abnormal circumstances.

- $\quad$ Sections of the HV system could be isolated for maintenance.

In the context of the WTC Investigation, the first function was of paramount importance. In the event of a fault on the system, the abnormal condition was detected through the monitoring of voltages and currents at the substation. Various forms of protective relaying were employed to detect the location of the fault and trip the appropriate circuit breaker(s) so as to quickly isolate (automatically and without intervention from the system operator) the minimum extent of the network needed to remove the faulted section (Con Edison 2005c). Because this was a radial system, all supply was lost downstream of the operated breaker.

Figure A-3 is a highly simplified diagram of the power supply arrangements which were in place on September 11, 2001, in the vicinity of the WTC complex. Bulk power was fed into the area at a nominal voltage of $138 \mathrm{kV}$ through five 3-phase feeders that were supplied from a transmission switching station that was operated by Con Edison. These circuits fed the two WTC substations physically located at the base of WTC 7, as well as a third substation at the Seaport location. A "T" connection fed the Seaport substation, as shown in Figure A-3. These substations served to reduce the voltage to a nominal $13.8 \mathrm{kV}$ by means of a series of transformers rated at 65.3 MVA (Megavolt Ampere). The five transformers (one of which was normally not in use) located in SS\#1 supplied both the WTC complex and also the Cortland network in Lower Manhattan. The four transformers in SS\#2 were supplied at $138 \mathrm{kV}$ from feeds through SS\#1 and similarly supplied the Battery Park and Park Place networks through $13.8 \mathrm{kV}$ cables. (Con Edison 2005c; Con Edison 2005e; Con Edison 2005f; Con Edison 2005h; Con Edison 2005i) 


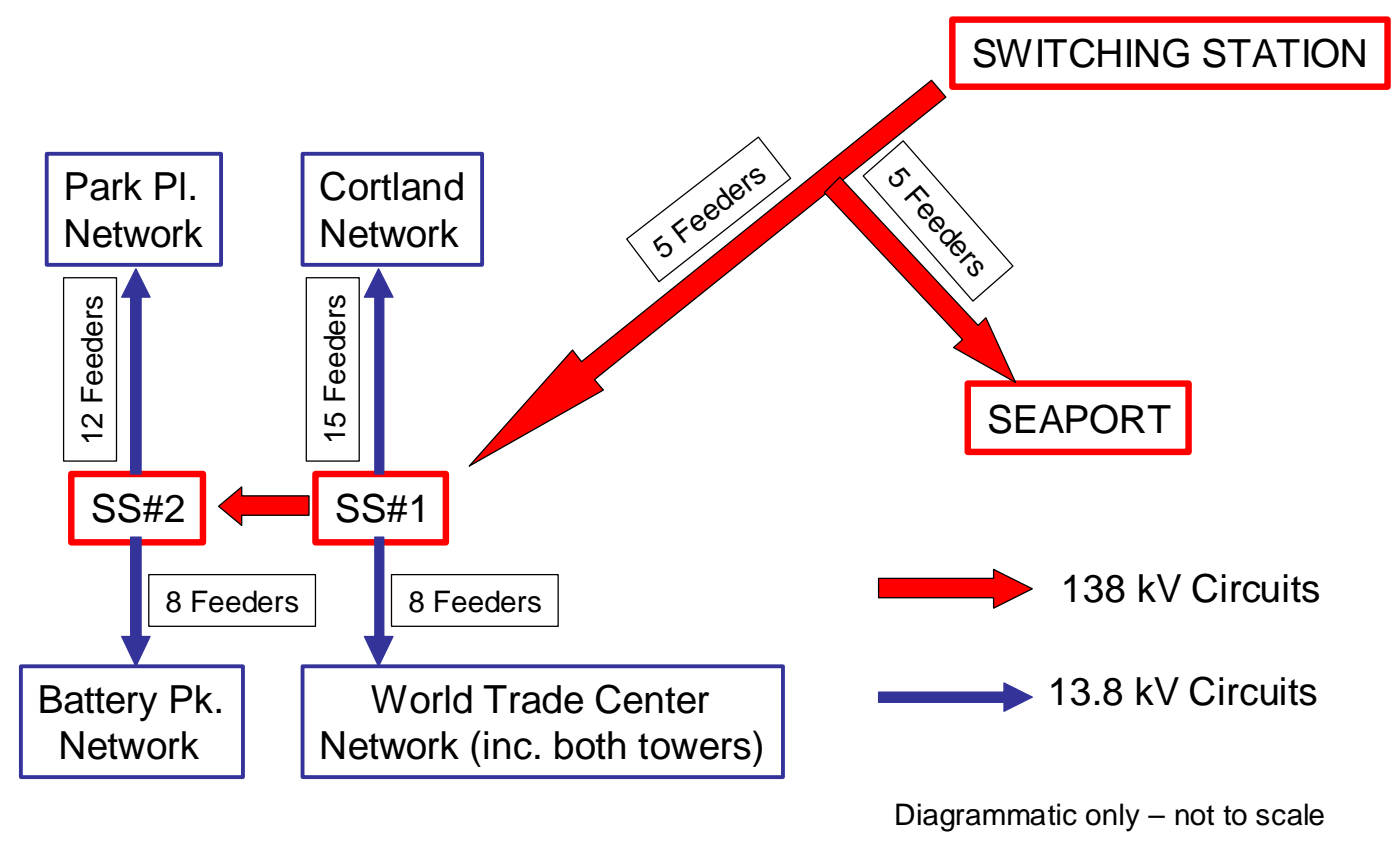

Figure A-3. Simplified diagram of the World Trade Center power supply.

The primary electrical supply to the WTC towers was entirely dependent on the feeds from SS\#1 in the WTC 7 building. Substation \#1, in turn, was supplied at higher voltage from the $138 \mathrm{kV}$ substation at the transmission switching station. The use of multiple feeders for both the $13.8 \mathrm{kV}$ and $138 \mathrm{kV}$ circuits provided considerable redundancy to safeguard against equipment failures. Similarly, the substation arrangement provided a parallel configuration which permitted the sharing of these circuits under abnormal conditions to allow for contingencies (Con Edison 2005f). Prior to the attacks on September 11, 2001, all these circuits were operational, and the load was light. As a result, normal conditions prevailed (Con Edison 2005a; Con Edison 2005g).

\section{A.3.3 Substation Operations and Building Supply}

\section{Substation Staffing}

The Con Edison substation in WTC 7 was staffed on the daytime shift, Monday through Friday, by a single senior substation operator, who was on duty during the events on September 11, 2001. In addition, two mechanics from the Con Edison Substation Operations Transformer Group were assigned to perform scheduled work at the substation and were on site or arrived shortly after the first aircraft struck WTC 1. After the event began, two senior substation operators and an assistant substation operator were dispatched to and arrived at the substation to assist the senior substation operator (Con Edison 2005a; Con Edison 2005b). Subsequently, four additional substation operations personnel (the area manager, a senior planning analyst, and two field planners) arrived at the substation. The substation was evacuated sometime between 10:20 a.m. and 10:25 a.m. (Con Edison 2005b), just before the collapse of WTC 1, the tower closer to WTC 7. Remote operation of the switchgear was possible for these substations, and telemetry was available to permit monitoring of many of the important parameters and functions from Con Edison's remote Energy Control Center (ECC). From logs of this supervisory system, switching and other operations, including the WTC emergency systems, were chronicled. 


\section{Electrical Equipment Utilized in the Con Edison Substation}

All nine transformers were rated at 65 MVA (with full cooling) on a 3-phase basis (Con Edison 2005d). They were insulated with conventional oil/cellulose materials, unlike the step-down transformers in WTC 1 and WTC 2, which were filled with silicone fluid to reduce the flammability hazard. The oil impregnant was a naphthalenic-based mineral oil with an autoignition temperature of about $250{ }^{\circ} \mathrm{C}$, in conformance with IEC 60296 (IEC 2003). The units were not identical to each other and were manufactured by more than one supplier. There were small differences in the cooling protocols and in the means for dealing with oil expansion. However, these differences were not considered important in the context of the Investigation. These transformers were rated on a multiple basis (with and without forced air/oil circulation), cooled with radiators and fans, and equipped with load tap changers for making voltage adjustments. All the transformers were $\Delta$-Y connected, with the low voltage Y-connected secondary grounded through a reactor. Facilities were provided for on-site and remote monitoring of the usual critical parameters/functions, including oil temperature, tap change operation, oil level, and nitrogen blanket pressure.

The circuit breakers controlling the incoming $(138 \mathrm{kV})$ and outgoing $(13.8 \mathrm{kV})$ feeders were also not identical to each other (Con Edison 2005d). In SS\#1, air-magnetic circuit breakers were the predominant technology. The $13.8 \mathrm{kV}$ breakers were continuously rated at $1200 \mathrm{~A}$, with an interrupting capacity of 1000 MVA. On the other hand, in SS\#2, vacuum interrupters were employed, having a current rating of $1000 \mathrm{~A}$ or $3000 \mathrm{~A}$ and an interrupting capacity of $1000 \mathrm{MVA}$. In both substations, circuit breaker operation was facilitated through a 125 V DC supply. The power was needed for manual and automatic circuit tripping and closing. The supply was provided by means of batteries which permitted relaying and circuit breaker operation in the event that local power was not available. Two independent battery systems were provided with charging facilities from an auxiliary power supply fed from the $38 \mathrm{kV}$ busbars (Con Edison 2005d).

The circuit breakers controlling the cable feeders supplying the WTC were all provided with timed overcurrent protective relaying with an instantaneous element set for a rapid disconnection for close-in faults (Con Edison 2005c). This protective scheme was designed to detect over-current and ground faults, and would provide automatic operation of the circuit breakers. Both substations were also provided with reactive support. This took the form of three $20 \mathrm{MVAr}$ (Megavolt Ampere reactive) capacitor banks connected at the $13.8 \mathrm{kV}$ busbars in each substation. The capacitor banks were designed to support the voltage in the presence of line drop in the circuits.

\section{Supply of power to WTC 7}

The main power from the Con Edison substation for the 47 story WTC 7 building above was routed through four 3-phase feeders (designated 37M02, 37M03, 37M06 and 37M08) rated at $15 \mathrm{kV}$ each, with circuit breakers at both ends. These cables were routed in two concrete-encased conduits within the south side of the building core, adjacent to the elevator banks, from the $1^{\text {st }}$ floor level to the $5^{\text {th }}$ floor (Syska \& Hennessy 1984a). The main distribution center for WTC 7, including switchgear and transformers, was located along the central south perimeter of the $5^{\text {th }}$ floor (Syska \& Hennessy 1984a). The incoming circuits were protected with conventional ground fault and over-current protection, as well as directional and zero-sequence relaying. (This equipment provided automatic circuit breaker operation in the event of faults.) Each feed was then routed separately, via a further set of circuit breakers, to three collection 
busbars through $13.8 \mathrm{kV} / 480 \mathrm{~V} 2.8 \mathrm{MVA} \Delta$-Y transformers (12 transformers in all). Interlocks were provided to insure that manual switching operations were done in the correct sequence (Syska \& Hennessy 1984b). Since each of these collector busbars derived power independently from each of the four incoming Con Edison feeders, a considerable degree of redundancy existed. Unlike those in the Con Edison substation, these transformers were filled with silicone oil and housed in segregated transformer vaults on the south side of the $5^{\text {th }}$ floor (Syska \& Hennessy 1984c) with the associated switchgear cabinets nearby. From the three collection busbars, power was distributed through the building via numerous switchboards and risers rated at $460 \mathrm{~V}$ and up to $5000 \mathrm{~A}$.

The $5^{\text {th }}$ floor of WTC 7 also housed a generator room with five generators in the southwest corner, six generators along the north wall, and dual battery banks and associated chargers. Two of the $5^{\text {th }}$ floor generators fed an emergency switchboard through automatic transfer switches, which were designed to be "break-before-make" to avoid the possibility of back-feeding power into the Con Edison system. In this way, essential loads could have been supplied even in the event of a complete failure of the utility network.

\section{A.3.4 Description of the Power Supply for the Remaining WTC Complex}

Figure A-3 indicates that eight circuits were employed to feed the WTC complex at $13.8 \mathrm{kV}$. This was done via cables from the Con Edison SS\#1. All the cables were routed through splicing chambers on the A-1 level to a primary distribution center (PANYNJ 1998), where the circuits were split and cables routed to feed numerous other substations in the WTC complex, all nominally at $13.8 \mathrm{kV}$ and 3-phase. The distribution to the various satellite step-down substations was as follows:

- four circuits supplied the NE Plaza substation, WTC 5

- $\quad$ six circuits supplied the Customs House building, WTC 6

- four circuits supplied the SE Plaza substation, WTC 4

- $\quad$ eight circuits supplied WTC 1 through numerous substations

- $\quad$ eight circuits supplied WTC 2 through numerous substations

- $\quad$ seven circuits were used to provide refrigeration power

- $\quad$ two circuits supplied the hotel, WTC 3.

In the case of WTC 1 and WTC 2, distribution of electrical power within the buildings was not done entirely at low voltage, due to the size of the load and the height of the structures. This necessitated $13.8 \mathrm{kV}$ cable risers within the building to feed substations located on Floors 7, 41, 75 and 108, in addition to three lower level substations (PANYNJ 1988). Two separate substations were located on each of these floors. Each had a $1500 \mathrm{kVA}$ transformer for each incoming feeder, with a disconnect switch on the primary side (PANYNJ 1990). In each tower, the eight high-voltage circuits were divided into two groups of four, and the four circuits routed (together) to the substations on each side of the tower. For example, in WTC 1, four circuits fed the substations on the north side and four on the south side. However, each group of four circuits was routed all the way to the top (i.e., to the substations on the $108^{\text {th }}$ 
floor) with 3-way splices made to provide "T-off" connections to the substations at the $7^{\text {th }}, 41^{\text {st }}$ and $75^{\text {th }}$ floors. The transformers fed a common 4000A busbar on the secondary side. Power was then distributed to the relevant locations through a low-voltage switchboard.

The supply of large parts of the structure at a higher voltage does imply that a cable failure, due, for example, to the aircraft impacts, would have necessitated the tripping of the $13.8 \mathrm{kV}$ circuit breaker controlling that entire circuit. Even though each substation obtained a supply from multiple feeders, cables routed in close proximity were all vulnerable simultaneously. However, the practice of splitting the eight circuits into two groups of four does mean that, although damage to the cables would cause connected substations on all levels to lose power, the substations at all levels on the other side of the building could continue to operate. This is discussed further in the context of the aircraft impacts.

\section{A.4 TIME LINE OF CON ED SUBSTATION EVENTS}

\section{A.4.1 Tripping Events, Substation \#1}

Table A-3 provides a record of activity on September 11, 2001, for all the feeders into and out of SS \#1, together with the associated circuit breaker designations transcribed from the system diagrams (Con Edison 2005f) . The first number of the circuit ID corresponds to the network being served:

37: $\quad$ World Trade Center (all seven buildings, as described above)

\section{5: $\quad$ Cortland Network}

38: In-feed from the transmission switching station (at $138 \mathrm{kV}$ )

Prior to the impact of the first aircraft, all the feeder circuit breakers were closed, and all indications were that the power system was operating normally. The columns on the right of Table A-3 depict the times at which circuit breaker operations took place (either automatically [A] as a result of the operation of the protective relaying, or manually $[\mathrm{M}]$ by operations commanded by the control center). This information was transcribed from the Control Center station logs (Con Edison 2005g) and a Con Edison incident report (Con Edison 2005g). Events are given in eastern daylight time.

Of primary interest from Table A-3 is that two of the circuits tripped automatically at 8:46 a.m., as a result of collateral damage caused by the aircraft impact into WTC 1, and a further two were lost at 9:03 a.m. in the same way, when WTC 2 was impacted by an aircraft. Note that for each aircraft impact, all the circuits were not damaged initially, presumably as a result of dividing the power and providing two separate routings to the substations on either side of the towers. At 9:59 a.m., the remaining four circuits feeding the entire WTC complex tripped automatically. As a result, power to all seven of the WTC buildings from the utility was lost. This occurred, as designed, by the operation of the installed protective relays without any utility intervention. No evidence indicated that the faults on the cable system or in the WTC distribution substations were caused by anything other than the collapse of WTC 2. 
Table A-3. WTC Substation \#1 tripping sequence.

\begin{tabular}{|c|c|c|c|c|c|c|c|c|}
\hline $\begin{array}{l}\text { Circuit } \\
\text { ID }\end{array}$ & $\begin{array}{c}\text { Breaker } \\
\text { ID }\end{array}$ & $\begin{array}{l}\text { Transformer } \\
\text { Circuit }\end{array}$ & Network & $\begin{array}{c}\text { Trip } \approx \\
8: 46\end{array}$ & $\begin{array}{l}\text { Trip } \approx \\
9: 03\end{array}$ & $\begin{array}{c}\text { Trip } \approx \\
9: 59\end{array}$ & $\begin{array}{l}\text { Trip } \approx \\
10: 28\end{array}$ & $\begin{array}{l}\text { Trip } \approx \\
16: 33\end{array}$ \\
\hline 37M01 & $13 N$ & 1 & WTC & & & A & & \\
\hline 37M02 & $23 \mathrm{~N}$ & 2 & WTC & A & & & & \\
\hline 37M03 & $13 S$ & 1 & WTC & & & A & & \\
\hline 37M04 & $43 \mathrm{~N}$ & 4 & WTC & & A & & & \\
\hline 37M05 & $33 N$ & 3 & WTC & & & A & & \\
\hline 37M06 & $43 S$ & 4 & WTC & & A & & & \\
\hline 37M07 & $23 S$ & 2 & WTC & A & & & & \\
\hline 37M08 & $33 S$ & 3 & WTC & & & A & & \\
\hline $15 \mathrm{M} 81$ & $21 \mathrm{~S}$ & 2 & Cortland & & & A & & \\
\hline 15M82 & $41 \mathrm{~S}$ & 4 & Cortland & & & A & & \\
\hline $15 \mathrm{M} 83$ & $32 \mathrm{~N}$ & 3 & Cortland & & & A & & \\
\hline 15M84 & $21 \mathrm{~N}$ & 2 & Cortland & & & A & & \\
\hline 15M85 & $22 \mathrm{~S}$ & 2 & Cortland & & & & & M \\
\hline 15M86 & $42 \mathrm{~S}$ & 4 & Cortland & & & & & $\mathrm{M}$ \\
\hline $15 \mathrm{M} 87$ & $31 \mathrm{~N}$ & 3 & Cortland & & & & & $M$ \\
\hline 15M88 & $22 \mathrm{~N}$ & 2 & Cortland & & & & & $\mathrm{M}$ \\
\hline 15M89 & $11 \mathrm{~N}$ & 1 & Cortland & & & A & & \\
\hline 15M90 & $11 \mathrm{~S}$ & 1 & Cortland & & & A & & \\
\hline 15M91 & $32 \mathrm{~S}$ & 3 & Cortland & & & A & & \\
\hline 15M92 & $42 \mathrm{~N}$ & 4 & Cortland & & & A & & \\
\hline 15M93 & $41 \mathrm{~N}$ & 4 & Cortland & & & & & M \\
\hline 15M94 & $31 \mathrm{~S}$ & 3 & Cortland & & & & & M \\
\hline 15M96 & $12 \mathrm{~S}$ & 1 & Cortland & & & & & M \\
\hline 38M11 & CI-1 & 1 & $\begin{array}{l}\text { TR } 5138 \\
\text { TSS }\end{array}$ & & & & & $\mathrm{M}$ \\
\hline 38M12 & CI-2 & 2 & $\begin{array}{l}\text { Tr } 7138 \\
\text { TSS }\end{array}$ & & & & & $\mathrm{M}$ \\
\hline 38M13 & CI-3 & 3 & $\begin{array}{l}\text { Tr } 10138 \\
\text { TSS }\end{array}$ & & & & & $\mathrm{M}$ \\
\hline 38M14 & CI-4 & 4 & $\begin{array}{l}\text { Tr } 8138 \\
\text { TSS }\end{array}$ & & & & & $\mathrm{M}$ \\
\hline 38M15 & CI-5 & 5 & $\begin{array}{c}\text { Tr } 9138 \\
\text { TSS }\end{array}$ & & & & & M (16:34) \\
\hline L\&P1 & $12 \mathrm{~N}$ & 1 & Aux.Power & & & & & M $(17: 46)$ \\
\hline
\end{tabular}

A: Automatic circuit breaker trip by protective relaying $\quad$ M: Manual trip at control center

TSS: Transmission Switching Station operated by Con Edison 
Unlike the rest of the complex, power supply to WTC 7 was not routed through the primary distribution center, since the Con Edison substation was in the same building. Table A-3 suggests that some utility power was available to all of the buildings, including WTC 7, until almost 10 a.m. After that time, although utility power was available at the Con Edison substation, it was not available to consumers in WTC 7. However, since WTC 7 was still intact at that time, the loss of all utility power would have activated the emergency generator automatic transfer switches to provide emergency power. The two WTC $7900 \mathrm{~kW}$ emergency generators were equipped with auto engine starting controls, and some emergency generation was running in WTC 7 before the building's eventual collapse in the afternoon. ${ }^{2}$

Power was still coming into the WTC Con Edison substation after 10 a.m. since the $138 \mathrm{kV}$ circuits from the transmission switching station were still energized (and some of the feeders supplying the Cortland network were still functional) since circuit breakers designated CI-1 through CI-5 were still closed. (See Table A-3.) Auxiliary power at the Con Edison substation was also still available through two $500 \mathrm{kVA}$ transformers (breaker L\&P1 was still closed) fed from the $13.8 \mathrm{kV}$ busbars in both SS \#1 and SS \#2 even though power to the rest of the building was lost at 10 a.m.

At 4:33 p.m., the utility control center made a decision to open all the remaining Cortland circuits and isolate the WTC 7 substations by opening the $138 \mathrm{kV}$ circuit breakers. This decision was made about two hours after FDNY officers decided to completely abandon WTC 7 and the final order was given to evacuate the site around the building (Chapter 6). Opening the Cortland circuits resulted in the loss of auxiliary power at the Con Edison substation, but because the primary power supply had already been lost to the rest of WTC 7 at 10 a.m., this additional action would have had no effect on the rest of WTC 7 (including emergency generation if it had still been available). The Con Edison substation was also equipped with emergency battery back-up which was designed to operate emergency lighting and fire protection systems for a limited period of time in the event that all other power was lost to the substation.

\section{A.4.2 Tripping Events, Substation \#2}

Analogous information for SS \#2 is provided in Table A-4, from which it may be seen that some circuits to the Battery Park network and one to Park Place were lost during the morning due to the automatic operation of the protective relaying. At 4:33 p.m., in concert with the actions taken in SS \#1, Con Edison decided to isolate the remaining Battery Park and Park Place feeders and to shut down SS \#2 by opening the $138 \mathrm{kV}$ breakers CI-6 through CI-9 supplying the transformers in SS \#2.

\section{A.4.3 Isolation of the $138 \mathrm{kV}$ Network}

As illustrated in Fig. A-3, the five circuits supplying SS \#1 and SS \#2 from the transmission switching station were also supplying the Seaport substation. At 4:33 p.m., when Con Edison decided to shut down the WTC substations, all of the $138 \mathrm{kV}$ substation breakers were opened at SS \#1 and SS \#2. However, two of the feeders (38M13 and 38M15) were left energized from the transmission switching station (Con Edison 2005i). This meant that although both substations were effectively shut down, live terminations were present at the supply side of circuit breakers CI-3 and CI-5 (in SS \#1) and CI-7 and CI-8 (in SS \#2). This was done with the hope of preventing the Seaport substation also from losing all power, which would have led to the loss of power to consumers fed from that substation in the Fulton Network (Con

\footnotetext{
${ }^{2}$ WTC 7 Interviews 1, 2, 3, January, 2004.
} 
Edison 2005i). This condition existed until the collapse of WTC 7 at 5:21 p.m. when damage to the cable terminations caused faults on both of the remaining live feeders, and protective relaying at the transmission switching station opened the circuits automatically with the consequent loss of power to the Fulton network that was fed through the Seaport substation. The collapse of WTC 7 destroyed the Con Edison substations within the building.

\section{A.4.4 Monitoring of Safety Systems}

The Con Edison substations in WTC 7 were provided with a Supervisory Control and Data Acquisition (SCADA) system (Con Edison 2005g) which continuously monitored and logged the vital parameters of the substations. In particular, it documented switching operations and provided flags when key parameters changed or appeared anomalous. These logs were made available to the NIST team by Con Edison. The Investigation staff studied the entries between 8:00 a.m. and 8:40 p.m. on September 11, 2001. A considerable volume of these log entries involved housekeeping matters such as removing and returning apparatus in the scan sequence, but the entries also were the source of the timing of both automatic and manual tripping of the circuit breakers documented in Tables A-3 and A-4. As soon as a circuit breaker was tripped, the system topology changed, and the load currents in the substation changed accordingly. In turn this often caused key voltages to fall momentarily (as a result of the fault) and then rise (as a result of the fault clearance). Such fluctuations caused voltage deviation alarms and the relaying equipment in the substation to signal operation of transformer on-load tap-changing equipment (a device designed to change the ratio of a transformer to restore its terminal voltage to the prescribed level). The SCADA logs are full of such entries, which chronicle the large number of circuit breaker operations resulting from the sequence of events at the WTC that day.

Careful study of the large number of entries indicated that, with a few notable exceptions, the actions were explicable in terms of the events taking place on that date. The exceptions were fire alarms which occurred in WTC 7 Con Edison SS \#1. The following fire alarm signals were recorded for SS \#1 on September 11:
- 10:00:10 a.m. "Alarm"
- 10:00:18 a.m. "Normal"
- 10:00:23 a.m. "Alarm"
- 10:01:00 a.m. "Normal"
• 10:28:58 a.m. "Alarm"
- $\quad$ 4:34:07 p.m. "Normal"

These communications were obtained from the SCADA data transmitted from the World Trade Center substation to Con Edison's Energy Control Center (ECC). The substation operator's log on which the substation operator recorded incidents, such as fire alarms, was destroyed when WTC 7 collapsed on the substation (Con Edison 2005a). 
Table A-4. Con Edison WTC Substation \#2 tripping sequence.

\begin{tabular}{|c|c|c|c|c|c|c|c|c|}
\hline $\begin{array}{l}\text { Circuit } \\
\text { ID }\end{array}$ & $\begin{array}{c}\text { Breaker } \\
\text { ID }\end{array}$ & $\begin{array}{c}\text { Transformer } \\
\text { Circuit }\end{array}$ & Network & $\begin{array}{c}\text { Trip } \approx \\
8: 46\end{array}$ & $\begin{array}{c}\text { Trip } \approx \\
9: 03\end{array}$ & $\begin{array}{c}\text { Trip } \approx \\
9: 59\end{array}$ & $\begin{array}{l}\text { Trip } \approx \\
\text { 10.:28 }\end{array}$ & $\begin{array}{c}\text { Trip } \approx \\
16: 33\end{array}$ \\
\hline 14M21 & $61 N$ & 6 & Batt. Park & & & & & M \\
\hline 14M22 & $61 S$ & 6 & Batt. Park & & & & & M \\
\hline 14M23 & $81 N$ & 8 & Batt. Park & & & & A & \\
\hline 14M24 & $71 \mathrm{~N}$ & 7 & Batt. Park & & & & A & \\
\hline 14M25 & $71 S$ & 7 & Batt. Park & & & A & & \\
\hline 14M26 & $91 S$ & 9 & Batt. Park & & & A & & \\
\hline 14M27 & $81 S$ & 8 & Batt. Park & & & A & & \\
\hline 14M28 & $91 N$ & 9 & Batt. Park & & & A & & \\
\hline 34M31 & $62 S$ & 6 & Park Pl. & & & & & M \\
\hline 34M32 & $72 \mathrm{~N}$ & 7 & Park Pl. & & & & & M \\
\hline 34M33 & $82 \mathrm{~N}$ & 8 & Park Pl. & & & & & M \\
\hline 34M34 & $92 S$ & 9 & Park Pl. & & & & & M \\
\hline 34M35 & $62 \mathrm{~N}$ & 6 & Park Pl. & & & & & $\mathrm{M}$ \\
\hline 34M36 & $72 S$ & 7 & Park Pl. & & & & & $\mathrm{M}$ \\
\hline 34M37 & $82 S$ & 8 & Park Pl. & & & & & $\mathrm{M}$ \\
\hline 34M38 & $92 \mathrm{~N}$ & 9 & Park Pl. & & & & A & \\
\hline 34M39 & $63 S$ & 6 & Park Pl. & & & & & M \\
\hline 34M40 & $73 N$ & 7 & Park Pl. & & & & & M \\
\hline 34M41 & $83 S$ & 8 & Park Pl. & & & & & $\mathrm{M}$ \\
\hline 34M42 & $93 \mathrm{~N}$ & 9 & Park Pl. & & & & & $\mathrm{M}$ \\
\hline 38M11 & CI-6 & 6 & $\begin{array}{l}\text { TR } 5138 \\
\text { TSS }\end{array}$ & & & & & $\begin{array}{c}M \\
(16: 47)\end{array}$ \\
\hline 38M13 & CI-8 & 8 & $\begin{array}{c}\text { Tr } 10138 \\
\text { TSS }\end{array}$ & & & & & M \\
\hline 38M14 & CI-9 & 9 & $\begin{array}{c}\text { Tr } 8138 \\
\text { TSS }\end{array}$ & & & & & $\mathrm{M}$ \\
\hline 38M15 & CI-7 & 7 & $\begin{array}{c}\text { Tr } 9138 \\
\text { TSS }\end{array}$ & & & & & M \\
\hline
\end{tabular}

A: Automatic circuit breaker trip by protective relaying $\quad$ M: Manual trip at control center

TSS: Transmission Switching Station operated by Con Edison 
The substation building fire alarm system was designed to activate when it detected the presence of smoke, at which time a zone indicator light on the substation fire alarm panel would be illuminated and an audible alarm inside the control room would sound. Activation of the substation fire alarm also would transmit an "alarm" indication to the ECC.

The "normal" notation was transmitted to the ECC when the substation operator acknowledged the alarm by manually pressing the alarm-reset button. This would allow a subsequent fire alarm to be recorded at the ECC and not be masked by the prior alarm. If the smoke condition persisted, pressing the reset button silenced the audible alarm at the substation, but the visual indicator on the substation alarm panel remained lit. The alarm could also clear itself at the substation and transmit a "normal" notation to the ECC without operator intervention, if the condition that triggered the alarm subsided.

Personnel present in the substation on September 11, 2001, before the evacuation observed dust in the substation atmosphere in the proximity of ventilation louvers on the west side of the substation facing Washington Street (Con Edison 2005a). Dust, in addition to smoke and other particulate matter, can trigger a smoke alarm. Since both dust and smoke filled the air at street level along Washington Street after the collapse of WTC 2, it was possible for such smoke and dust to have activated a smoke detector within the substation. The rapid sequence of "Alarm" and "Normal" signals between 10:00:10 a.m. and 10:01:00 a.m. is consistent with an automatic clearing of the alarm. Prior to the evacuation of the substation between 10:20 a.m. and 10:25 a.m., the Con Edison building was searched for the presence of personnel. The person who conducted the search did not observe any evidence of fire or burning material at that time (Con Edison 2005a).

The 10:28:58 a.m. alarm condition persisted until the remaining transmission switching station circuit breakers were opened at around 4:33 p.m. A huge amount of additional dust and smoke was generated when WTC 1 collapsed, and would have remained in the air or contaminated the smoke detector during the period the alarm condition persisted.

\section{A.5 PHYSICAL CONDITION OF THE CON EDISON BUILDING FOLLOWING THE COLLAPSE OF WTC 1}

Following the evacuation of the substation shortly before the collapse of WTC 1, the Con Edison portion of WTC 7 was secured by Con Edison, and there was no evidence of anyone reentering the substation building up to the time when WTC 7 collapsed. From the photographs and videos examined, the exterior of the substation suffered no significant direct damage due to the collapse of WTC 1. Figure A-4, a photograph taken sometime in the afternoon, shows the northwest corner of WTC 7, along with a considerable amount of debris on Washington Street. Aside from what appear to be superficial scrapes on the two large street level louvers south of the driveway door, this portion of the building looks intact. (Note that the broken panes above the louvers spanned the $3^{\text {rd }}$ and $4^{\text {th }}$ floors of WTC 7 and were not connected to the Con Edison substation.) 


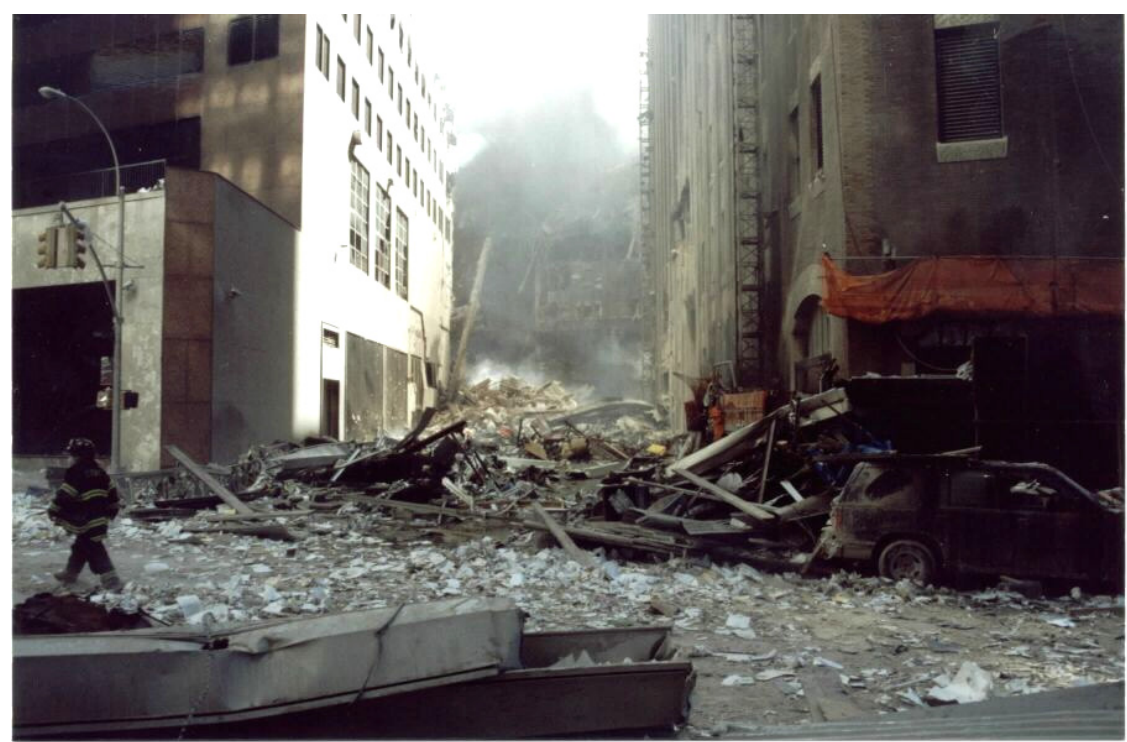

Figure A-4. Northwest corner of the Con Edison substation (building on left), showing light damage from WTC 1 debris. (Photo taken sometime in the afternoon on Sept. 11, 2001.)

George Miller/NYCTA

Figure A-5 shows another view of the Con Edison portion of WTC 7, shot from a police helicopter at about 3:00 p.m. Fires can be seen on the $7^{\text {th }}$ and $12^{\text {th }}$ floors of WTC 7. Light debris is visible on the grill work which formed the roof of the north portion of the Con Edison substation; this portion of the Con Edison substation appears to be intact, with no visible evidence of smoke. No photograph, video record, or witness account gathered during the investigation identified smoke or flames originating from the Con Edison portion of WTC 7.

The collapse of WTC 7 buried the Con Edison structure and all the equipment in it. Figure A-6 shows the collapsed building at the beginning of the salvage and clean up operations, viewed looking south from Greenwich Street.

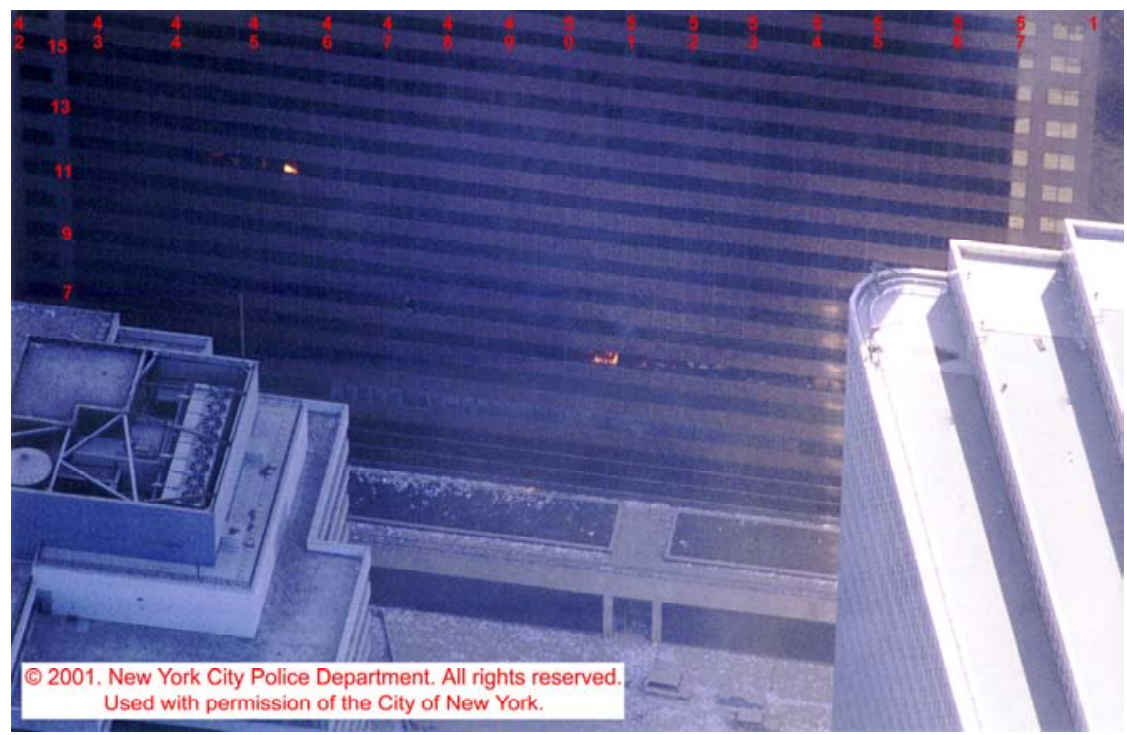

Figure A-5. Aerial view of the middle of the north side of the Con Edison substation, taken at 2:57 p.m. $\pm 5 \mathrm{~min}$ on September 11, 2001.

Source: NYPD Aviation unit photo, 2-50 \#21 


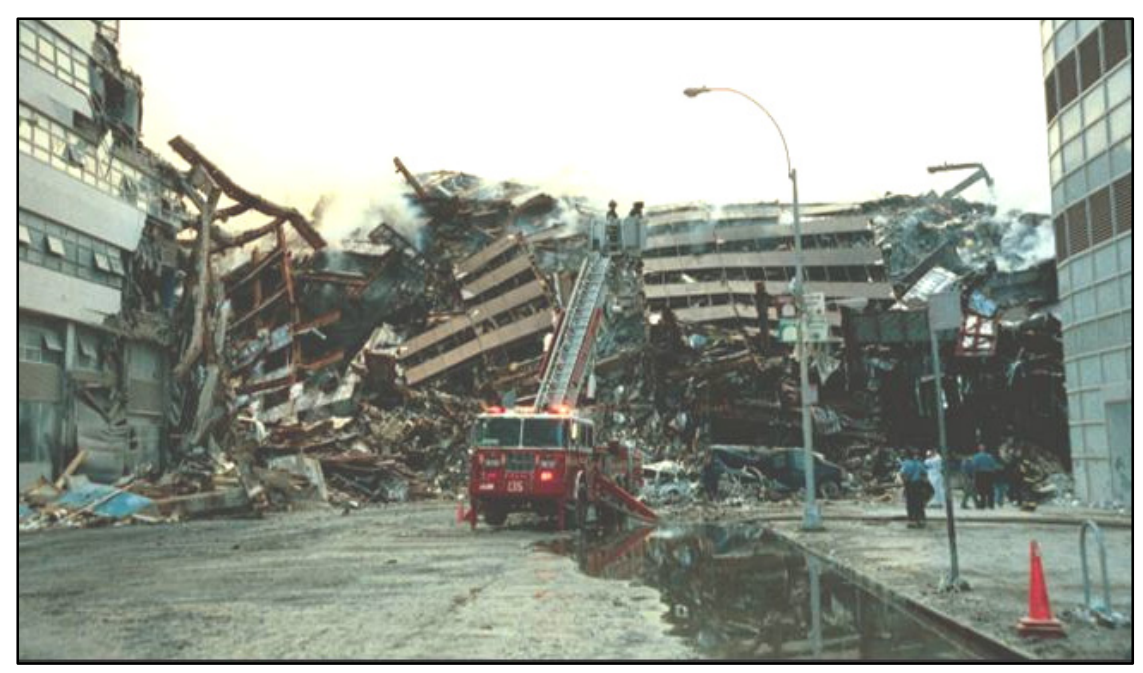

Figure A-6. Debris pile from collapse of WTC 7 onto the Con Edison substation, viewed looking south from Greenwich Street, date undetermined.

Source: Con Edison, reproduced with permission

The photographs in Figures A-7 through A-9 were taken during the salvage operations. Four of the nine transformers that were part of SS \#1 and SS \#2 are depicted in these photographs.

The left photograph in Figure A-7 was taken about five weeks after September 11, 2001. It shows the remnants of the Con Edison substation after the removal of much of the debris. The area outlined in a dotted white line is enlarged in the right photograph in Figure A-7A. From its location in the pile, this appears to be transformer \#4, but also may be \#8 or \#9. The interior of this transformer was described as being severely thermally damaged, possibly by fire ${ }^{3}$.
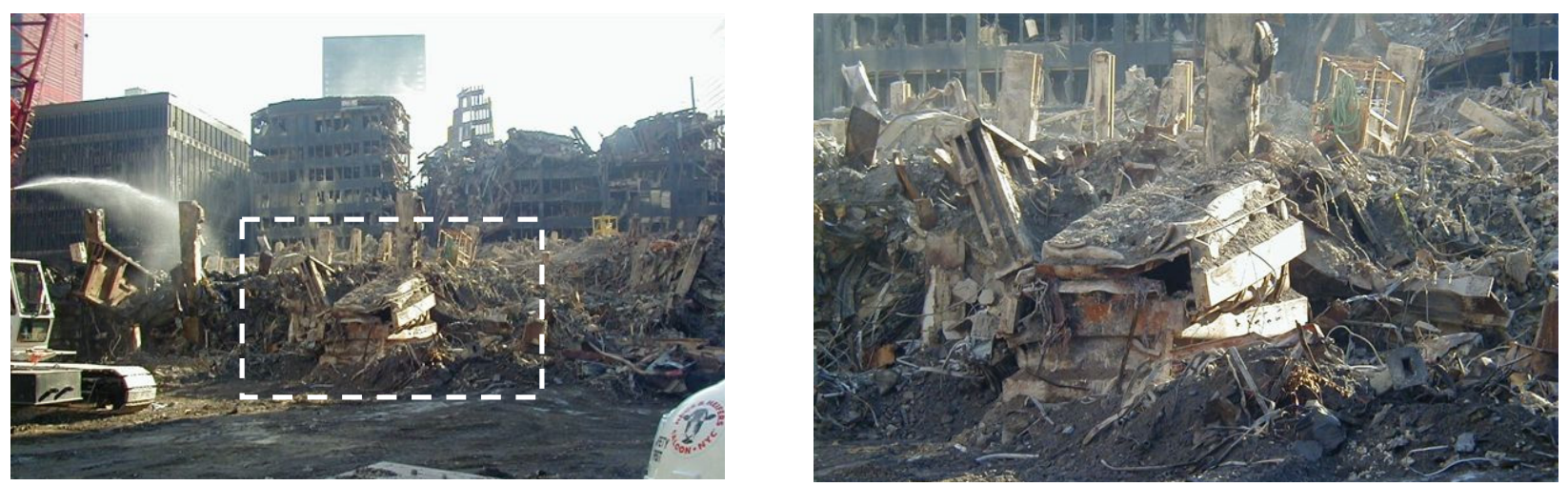

Source: G\&S Technologies, reproduced with permission

\section{Figure A-7. Photographs taken on mid-October, 2001, showing Con Edison transformer} \#4 (or \#8 or \#9) uncovered from the debris pile of WTC 7.

A similar assessment of thermal damage was made for transformer \#1, shown on the right in Figure A-8. This is in contrast to transformer \#6, which is the unit on the left in Figure A-8. The gray paint on transformer \#6 is clearly evident, with little indication of rust or excessive heat.

\footnotetext{
${ }^{3}$ NIST Interview with G\&S Technologies, August, 2005.
} 


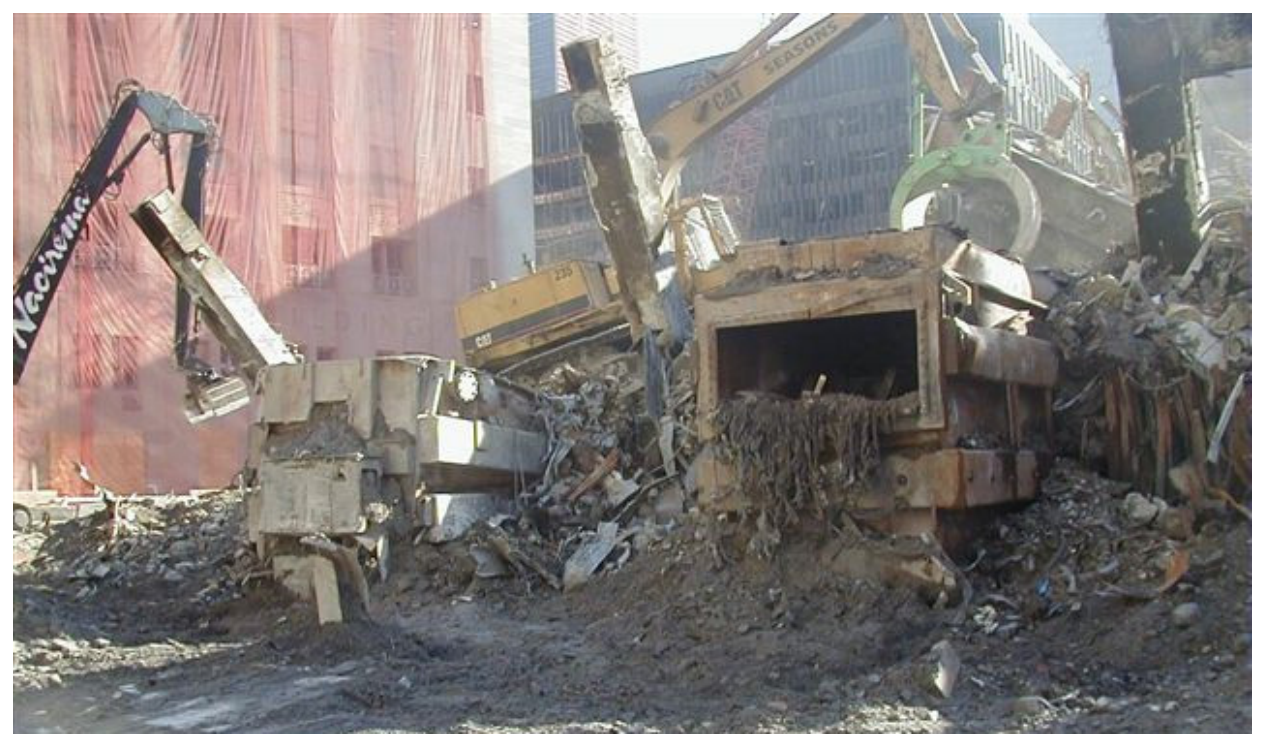

Figure A-8. Photograph taken in mid-October, 2001, showing Con Edison transformers \#6 and \#1 uncovered from debris pile of

Source: G\&S Technologies, reproduced with permission WTC 7.

Transformer \#7 (or possibly \#5) is barely visible within the white box in Figure A-9. This transformer and the other three depicted in Figures A-7 and A-8 were not salvageable and were discarded.

NIST was unable to determine whether the thermal damage to the transformers occurred due to electrical overheating, due to a fire in the substation after the SCADA logs were terminated around 4:33 p.m., or due to burning within the rubble pile subsequent to the collapse of WTC 7.

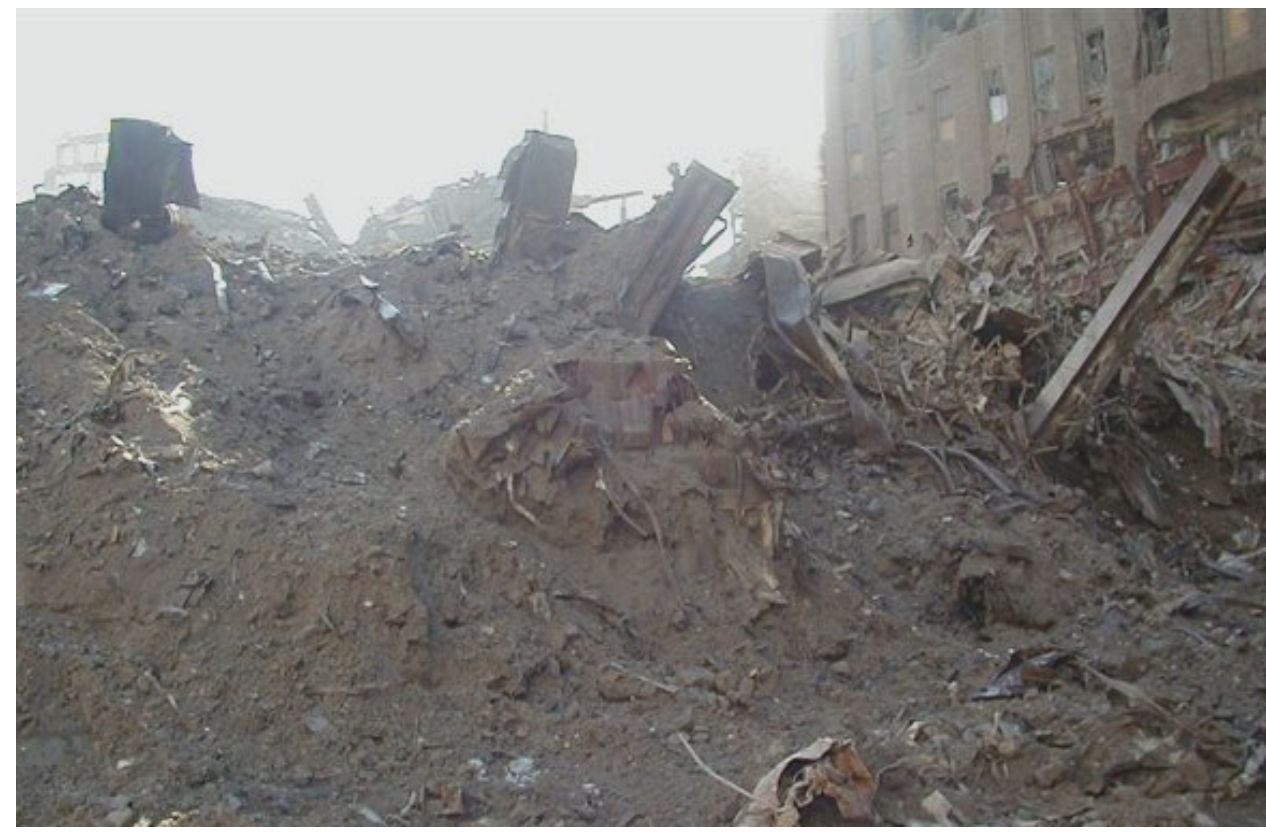

Source: G\&S Technologies, reproduced with permission
Figure A-9.

Con Edison transformer \#7 (or \#5) uncovered from debris pile of WTC 7; photo taken midOctober, 2001. 


\section{A.6 POWER SOURCES FROM OTHER THAN CON-EDISON}

\section{A.6.1 Inventory}

Backup electrical generation capacity is common for large commercial and government operations, such as some of those that were housed in the WTC complex and elsewhere in lower Manhattan. Under normal conditions, these distributed organizations receive their electricity from Con Edison, but in the event of a utility power outage they use their own generators to carry them through the power interruption. When the local generation capacity exceeds needs, the excess may be used to back up the utility by connecting to the network. Guidelines exist (IEEE 2003) for the protection of distributed generators and the network to which they are connected. Table A-5 provides an inventory of the distributed generation capacity in Lower Manhattan. The table is organized according to the networks depicted in Figure A-3.

Table A-5. Inventory of Distributed Generation in Lower Manhattan. (Con Edison 2005j)

\begin{tabular}{|l|c|c|c|}
\hline \multicolumn{1}{|c|}{ Network } & $\begin{array}{c}\text { No. of } \\
\text { Installations }\end{array}$ & $\begin{array}{c}\text { Total } \\
\text { Capacity (MVA) }\end{array}$ & $\begin{array}{c}\text { Connected } \\
\text { Load (MVA) }\end{array}$ \\
\hline Park Place & 4 & 18.1 & 10.8 \\
\hline WTC & 2 & 34.4 & 20.7 \\
\hline Cortland & 9 & 28.6 & 16.0 \\
\hline Bowling Green & 14 & 38.1 & 22.4 \\
\hline
\end{tabular}

Although it would appear that many megawatts of excess power were available, none of these machines were network connected, and no contracts were in place for Con Edison to buy back excess capacity. If any of these sources had been available on September 11, 2001, destruction of the feeders caused by the collapses of WTC 1 and WTC 2 would have prevented any dispatch of these sources of power to the grid.

Since all power from the primary Con Edison system to the towers was lost by 10 a.m., it was important to examine the availability of other sources for fire fighting and emergency operations. The emergency systems at the WTC had the following backup power sources if the primary and secondary sources through the eight feeders from Con Edison were disrupted:

- Tertiary power from a feeder from the PATH substation

- Emergency generator plants

- Local battery backup 


\section{A.6.2 PATH Tertiary Connection}

Documentation (PANYNJ 1968) indicates that a single 3-phase 2 MW feed was available to the WTC complex from the PATH subway system, which was installed after the 1993 bombing incident as a precautionary measure. This is important since this source of power was independent from Con Edison. The power was derived from Public Service Electric and Gas of New Jersey (PSEG), and originated at the PATH substation \#3 through an isolator under PATH operational control (PANYNJ 2005a). This $27 \mathrm{kV}$, 3-core shielded cable ran about $50 \mathrm{~m}$ in concrete-encased conduit to a tertiary emergency switchgear room also located at platform level. The feeder supplied emergency power through a 2 MVA, $\Delta-\mathrm{Y}$, $27 \mathrm{kV} / 480 \mathrm{~V}$ 3-phase cast coil dry-type transformer (and a further 480V/120V step down to the emergency control panel through an automatic transfer switch). These arrangements had the capability of maintaining some emergency power from PSEG even in the event of the loss of all connection to Con Edison. In this way, fire fighter service freight elevators, stairwell lighting, and some other emergency loads within the WTC towers could have been maintained.

SCADA logs for September 11, 2001, indicate that at 9:02 a.m., the WTC emergency feed breaker closed automatically, activating this tertiary source of power. This occurred at the instant when WTC 2 was impacted and also corresponded to the time that the Con Edison logs indicated that two of the eight WTC $13.8 \mathrm{kV}$ feeds from Con Edison were destroyed. (See Table A-3.) Emergency power would have been available from the PATH substation until about 9:59 a.m. when automatic protection opened the emergency feed breaker and de-energized the tertiary $27 \mathrm{kV}$ feeder (PANYNJ 2005a). The collateral damage resulting from the collapse of WTC 2 at 9:59 a.m. was such that supplies from both Con Edison and from PSEG were compromised simultaneously.

\section{A.6.3 Emergency Generation for Local Use}

Perhaps of equal significance were the emergency generators situated in the WTC complex itself. By design, numerous generators would have been available after the utility supply was interrupted until the generators themselves were destroyed by the building collapses. The main emergency power transfer switching provided limited power not only for WTC 1 and WTC 2 but also for WTC 3, WTC 4, WTC 5, and WTC 6. The emergency power would have provided electricity to operate emergency lighting, fire pumps, and some elevators in WTC 1 and WTC 2.

An emergency power control and distribution system with six additional 1 MW Waukesha continuously rated generating units was installed in WTC 1 and WTC 2, with the power being routed to critical equipment (exchange fans, sewage ejectors, fire pumps, etc.). It is not known if these units were running or started, but they were provided with automatic synchronizing equipment. If undamaged by the initial impact, they could have provided some emergency power until the collapse. There would have been, for example, enough power to run one elevator in each bank plus the fire fighter's service car. All elevator emergency power controls were relocated to a main lobby console when the new fire command station was built after the 1993 bombing of WTC 1. The presence of an automatic transfer switch also indicates that emergency power may not have been available until normal utility power was lost at about 10 a.m.

There was also a limited amount of local battery backup to provide stairwell lighting. This was known to have operated at the police desk in WTC 5 after the collapse of WTC 2 (PANYNJ 2005b). 
Emergency power for WTC 7 was not provided from the main emergency center in the WTC complex, but documentation (Chapter 3) indicates that there were numerous generators on several floors of WTC 7, as shown in Table A-6. The base emergency power for the entire building (other than for the Con Edison substations) was supplied by the two $900 \mathrm{~kW}$ generators on the $5^{\text {th }}$ floor. These units were equipped with automatic engine start controls and were known to have been operating after 10 a.m. when utility power to the 47 story building was lost. ${ }^{2}$ The base emergency power was sufficient to supply electricity to the fire pumps, the fire alarm system, other emergency equipment, and the fuel pumps and peripheral equipment necessary to keep the emergency diesel generators operating. The other nine generators on the fifth floor were dedicated to providing emergency power to the Salomon Brothers spaces. These were also designed for automatic operation in case utility power was lost to the areas leased by Salomon Brothers.

Emergency power for the Mayor's Office of Emergency Management (OEM) was supplied by the three generators on the seventh floor. Single diesel generators on the eighth and ninth floors provided emergency power for the American Express and Secret Service tenants, respectively (Chapter 3). No information was found regarding the possible operation of these units on September 11, 2001.

Table A-6. Emergency generation available in WTC 7. (NIST NCSTAR 1-1J 2005)

\begin{tabular}{|c|l|c|c|}
\hline Floor Location & \multicolumn{1}{|c|}{ Tenant } & Number of Generators & Power/Generator \\
\hline 5 & Base building & 2 & $900 \mathrm{~kW}$ \\
\hline 5 & Salomon Brothers & 9 & $1750 \mathrm{~kW}$ \\
\hline 7 & OEM & 3 & $500 \mathrm{~kW}$ \\
\hline 8 & American Express & 1 & $350 \mathrm{~kW}$ \\
\hline 9 & Secret Service & 1 & $125 \mathrm{~kW}$ \\
\hline & & Total Capacity: & $19.5 \mathrm{MW}$ \\
\hline
\end{tabular}

\section{A.7 SUMMARY}

- The Con Edison substation was comprised of two electrically separated substations (SS \#1 and SS \#2) in the first two stories of the north side of WTC 7. Bulk power was delivered at $138 \mathrm{kV}$ to the substation supplied from a transmission switching station operated by Con Edison, and distributed at $13.8 \mathrm{kV}$ to the entire WTC complex, as well as to the Cortland, Battery Park, and Park Place networks in Lower Manhattan. At the start of the day on September 11, 2001, normal conditions prevailed at the Con Edison substation.

- Eight feeders supplying the WTC complex from SS \#1 in WTC 7 were provided with overcurrent and ground fault protection, which appears to have operated as designed in response to the damage sustained by the aircraft impacts and subsequent building collapses. These automatic operations occurred at 8:46 a.m., 9:03 a.m., and 9:59 a.m., resulting in the loss of all primary power to the WTC towers by $10 \mathrm{a} . \mathrm{m}$. These were correct automatic operations over which the power company had no control. The damage sustained was so massive that the redundancy that would normally have been provided by having eight separate circuits was not effective in increasing reliability. Indeed, given the overriding need to provide safety in 
high-voltage apparatus, it would have been difficult for any system at this power level to survive the damage sustained.

- Between the time of initial aircraft impact and the collapse of WTC 2, some utility power remained within all of the WTC buildings.

- All power to the WTC complex was cut at 9:59 a.m., either from automatic circuit breakers tripping or from physical damage to the feeder lines caused by the collapse of WTC 2 .

- Alternatives to Con Edison power were potentially available at the WTC complex. A significant amount of electricity for use in the event of an emergency was fed through the subway tunnel from New Jersey. There were emergency supply generators in the towers; however, no evidence was found that these units provided power to aid firefighting and rescue after 10 a.m.

- Even though utility power to the rest of WTC 7 was lost at 9:59 a.m., auxiliary utility power to the Con Edison substation itself was still available from the transmission switching station feeders, allowing internal operations to be maintained. There is also evidence that the emergency diesel generators that supplied base power to the rest of WTC 7 did operate after the collapse of WTC 2, but no information was found regarding the operation of these emergency generators following the collapse of WTC 1.

- At 4:33 p.m., the utility control center made a decision to isolate the WTC 7 Con Edison substation by opening the $138 \mathrm{kV}$ circuit breakers feeding the WTC 7 substation. This decision was made by Con Edison management about two hours after the Fire Department of New York (FDNY) officers had the building and immediate surroundings evacuated.

- Con Edison employees observed no fires or significant physical damage to the substation prior to the time when the substation building was evacuated (between 10:20 a.m. and 10:25 a.m.). NIST found no evidence that significant physical damage to the Con Edison portion of WTC 7 occurred due to the collapse of WTC 1 at 10:28 a.m.

- Signals from the Con Edison substation continued to be monitored offsite throughout the day on the supervisory control and data acquisition (SCADA) logs. One fire detector within the Con Edison substation did go into alarm when WTC 1 collapsed, and stayed in the alarm mode until the substation was totally isolated from incoming feeders at 4:33 p.m. However, there were no other indications (e.g., no high temperature alarms from the transformers, no visible smoke emanating from the Con Edison building) that a significant fire occurred within the substations during that period of time. Possible sources of the fire detector alarm were the smoke and dust dispersed in the area of the substations from the collapse of WTC 1.

- Photographs of several Con Edison transformers uncovered during site clean-up showed clear evidence of thermal damage. NIST acquired no material from these transformers and did not determine whether this thermal damage occurred due to electrical overheating, due to a fire in the Con Edison substation, or due to burning within the rubble pile subsequent to the collapse of WTC 7. 
- NIST identified no events initiated at the substation that may have contributed to the structural collapse of WTC 7.

\section{A.8 REFERENCES}

Con Edison. 1969. Consolidated Edison Company of New York, Drawing A175040-17, General Arrangement of $138 \mathrm{kV}$ Equipment and $13.8 \mathrm{kV}$ Switchgear Equipment in 1st Flr.

Con Edison. 2005a. Telephone call between J.K. Nelson and Con Edison, July 21.

Con Edison. 2005b. Email from Con Edison to NIST, August 19.

Con Edison. 2005c. Letter from Con Edison to NIST, April 1, 1984, Appendix D: Con Edison Trade Center \#1 Substation (prior to 9/11/01) relay types and settings.

Con Edison. 2005d. Letter from Con Edison to NIST, April 1, 1984, Appendix A: Rubenstein Engineering PC., Specification \# EI-5451 and EI-5413.

Con Edison. 2005e. Power Network Map of Lower Manhattan.

Con Edison. 2005f. Letter from Con Edison to NIST, April 1, 1984, Appendix B: 13.8 kV Substation oneline diagrams \# 1-301 and \# 2-302.

Con Edison. 2005g. Letter from Con Edison to NIST, April 1, 1984, Appendix F: Alarm List relating to TC1 and TC2 from SOCCSX.

Con Edison. 2005h. Letter from Con Edison to NIST, April 1, 1984, Appendix E: Con Edison District Operations Incident Report.

Con Edison. 2005i. Letter from Con Edison to NIST, April 1, 1984, Appendix G: 138 kV one-line diagram.

Con Edison. 2005j. Letter from Con Edison to NIST, April 1, 1984, Appendix C: Local connected Distributed Generation.

IEC. 2003. International Electrotechnical Commission, Standard 60296, Ed. 3.0, b:2003 Fluids for electrotechnical applications - Unused mineral insulating oils for transformers and switchgear.

IEEE. 2003. Institute of Electrical and Electronics Engineers, Standard 1547, Standard for interconnecting distributed resources with electric power systems.

PANYNJ. 1968. Port Authority of New York and New Jersey, Drawing E-P-38, Relocation of $13.8 \mathrm{kV}$ Distribution Feeders from B-1 Level, PATH substation one-line diagram, Joseph R. Loring \& Associates.

PANYNJ. 1987. Port Authority of New York and New Jersey, Port of New York Authority Engineering Department Architectural Drawing 104-1, Electrical Substation Superstructure. 
PANYNJ. 1988. Port Authority of New York and New Jersey, Drawing ES-1, Relocation of $13.8 \mathrm{kV}$ Distribution Feeders from B-1 Level, 13.8 kV Service and Distribution System Riser Diagram, Joseph R. Loring \& Associates.

PANYNJ. 1990. Port Authority of New York and New Jersey, Drawing E-PR-7, Relocation of $13.8 \mathrm{kV}$ Distribution Feeders from B-1 Level, Typical substation, Joseph R. Loring \& Associates.

PANYNJ. 1998. Port Authority of New York and New Jersey, Drawing E-2, Relocation of $13.8 \mathrm{kV}$ Distribution Feeders from B-1 Level, 13.8 kV Feeder Riser Diagram.

PANYNJ. 2005a. Port Authority of New York and New Jersey, Email from Con Edison to NIST, May 4.

PANYNJ. 2005b. Port Authority of New York and New Jersey, Telephone call between J.K. Nelson and PANYNJ, May 7.

Syska \& Hennessy. 1984. Syska \& Hennessy Engineering, WTC 7 Specifications, Mechanical and Electrical Systems.

Syska \& Hennessy. 1984a. Syska \& Hennessy Engineering, Electrical Drawing E-23, WTC 7, Single-line diagram.

Syska \& Hennessy. 1984b. Syska \& Hennessy Engineering, Electrical Drawing E-3, WTC $71^{\text {st }}$ Floor Plan - Power.

Syska \& Hennessy. 1984c. Syska \& Hennessy Engineering, Electrical Drawing E-11, WTC $75^{\text {th }}$ Floor Plan - Power. 
This page intentionally left blank. 


\section{Appendix B \\ ANALYSIS OF SEPTEMBER 11, 2001 SEISMOGRAM DATA}

\section{B.1 INTRODUCTION}

During the September 11, 2001, World Trade Center (WTC) disaster, seismic signals generated by aircraft impacts and building collapses at the WTC site were recorded by seismographic stations around the metropolitan New York City area operated by the Lamont-Doherty Earth Observatory of Columbia University (LDEO). This appendix reports the analysis of the seismic records to assist the WTC Investigation in reconstructing the timing and magnitude of ground motion that may have been linked to specific events surrounding the collapse of WTC 7. The focus was on all recorded seismic signals generated between the times of collapse of WTC 1 and WTC 7. The specific objectives were to:

- analyze seismic records of Sept. 11, 2001 recorded at stations around the metropolitan New York City area for identifying seismic signals that may have been due to partial collapses at the WTC site in general, and WTC 7 in particular;

- characterize all observable seismic signals generated by the WTC disaster for the time window between the collapse of WTC 1 and WTC 7; and

- review data and information provided by NIST to identify seismic signals with possible sources at the WTC site.

The seismic records reviewed in this study were acquired as part of the routine earthquake monitoring network in the northeastern United States, and the seismometers were not optimized to capture the seismic signals from the collapse of the WTC towers or of WTC 7. The Investigation Team attempted to extract as much information as possible from these signals, which in some cases were not much greater than the background noise. This report documents the activities performed by LDEO, including the analysis of the seismic records, the characterization of the observable seismic signals, and the association of identifiable seismic signals with possible collapse events using information available at NIST.

\section{B.2 SEISMIC DATA AVAILABLE FOR ANALYSIS}

Seismic events generate three dimensional waves that emanate from the source in a way that is dependent upon the strength and depth of the event and the surrounding geological features. A seismogram is a record of the very small motions created by these waves as they pass a sensor, displayed in graphical form as an oscillating curve $(\mathrm{nm} / \mathrm{s})$ over a period of time. The energy radiated from the seismic event is related to the square of this ground speed and the duration in time over which the motion occurs. An accurate estimate of the radiated seismic energy requires complex correction terms; and, as a result, it is customary to characterize the size of an earthquake only in terms of the peak amplitude of the ground motion, $\mathrm{M}_{\mathrm{L}}$, or the familiar Richter scale.

The LDEO seismic station located in Palisades, NY, (referred to as PAL) records three components of seismic waves: north-south, east-west, and vertical. This allows determination of the direction of the 
incoming waves. Three-component data are also useful for characterizing source properties. For example, an earthquake generates strong shear waves in the transverse component (perpendicular to the direction of wave propagation). In contrast, an explosion source excites strong longitudinal waves (similar to a sound wave) along the direction of propagation. Seismic signals excited by a building collapse are basically due to a vertical force acting on the ground surface; hence, seismic shear waves $(S)$ are excited near the surface, and subsequently travel as surface waves. The primary wave $(P)$ excitation is maximum on the axis of force (vertically downward) and is relatively weak compared to $S$ wave excitation near the source region (up to a few tens of kilometers). Note that seismic $P$ waves are longitudinal and propagate similarly to sound waves. $P$ waves travel with a speed of about $6 \mathrm{~km} / \mathrm{s}$ near the Earth's surface and can propagate through a fluid at a slower speed $(\approx 1.5 \mathrm{~km} / \mathrm{s}$ in water at standard conditions), whereas $S$ waves propagate only through planar elastic solids (e.g., competent bedrock), with a speed of about $3.5 \mathrm{~km} / \mathrm{s}$ near the Earth's surface. Fundamental-mode Rayleigh waves $(R g)$ are short-period, seismic shear waves with strongest amplitudes near the free surface of planar elastic solids. A Rayleigh wave is efficiently excited by a shallow seismic source (at depths less than a few $\mathrm{km}$ ); and, hence, it can be used as an indicator for a shallow seismic source, such as a building collapse.

There were six stations within $100 \mathrm{~km}$ of the WTC site, including the station PAL which was the closest (34 km) to Manhattan. Figure B-1 shows their locations. PAL is the quietest site among the stations, and it serves as the reference station for the analysis. PAL is equipped with a three-component, broadband seismometer as well as three-component short-period sensors. Modern broadband seismometers, widely used since the early 1990s, have a natural period between a few tens to a few hundreds of seconds and are designed to record long-period seismic signals from large distant earthquakes, as well as high frequency signals from small local earthquakes (up to about $20 \mathrm{~Hz}$ ). The different components of three-component broadband seismometers are designated using the following nomenclature: BHZ (vertical-component), BHN (north-south component) and BHE (east-west component). When two horizontal components are rotated to align with the great circle path between the source and receiver, the pure longitudinalcomponent (denoted as BHR) and the transverse-component (BHT) are obtained. Short-period seismometers usually have a natural period of about $1 \mathrm{~s}$ and are designed to record high frequency signals from local and regional earthquakes (usually up to about $100 \mathrm{~Hz}$ ). Short-period stations are usually equipped with only a vertical-component seismometer, and its component is designated as EHZ. The sensors used in the stations examined in this study are listed in Table B-1. The components of these sensors are indicated on the figures of recorded seismic signals.

Figure B-2 shows the complete digital seismogram recorded at PAL for the time window from 10:00 EDT to 17:30 EDT on Sept. 11, 2001. Each trace is thirty minutes long. Broadband data sampled at $40 \mathrm{~Hz}$ and band-pass filtered from $0.8 \mathrm{~Hz}$ to $10 \mathrm{~Hz}$ are plotted. Seismic signals in this frequency band correspond to ground velocity, and the amplitude of the background noise level ( $\approx$ thickness of the traces) is approximately $100 \mathrm{~nm} / \mathrm{s}$. The frequency band between $0.8 \mathrm{~Hz}$ and $10 \mathrm{~Hz}$ captures most of the signals generated at the WTC site as well as main signals from regional earthquakes and quarry blasts. The aircraft impacts generated signals with dominant frequencies in the $1 \mathrm{~Hz}$ to $1.5 \mathrm{~Hz}$ range, whereas the collapses of the buildings at the WTC site generated frequencies in the band from $0.6 \mathrm{~Hz}$ to $10 \mathrm{~Hz}$ (see Figure 1 in Kim et al., 2001). In this study, the seismic signals in the time window between the collapse of WTC 1 and WTC 7 were analyzed. There are a number of seismic arrivals (signals) identifiable in Figure B-2 among the background noise. Identifying the sources and characterizing these signals were the primary objectives of this study. 


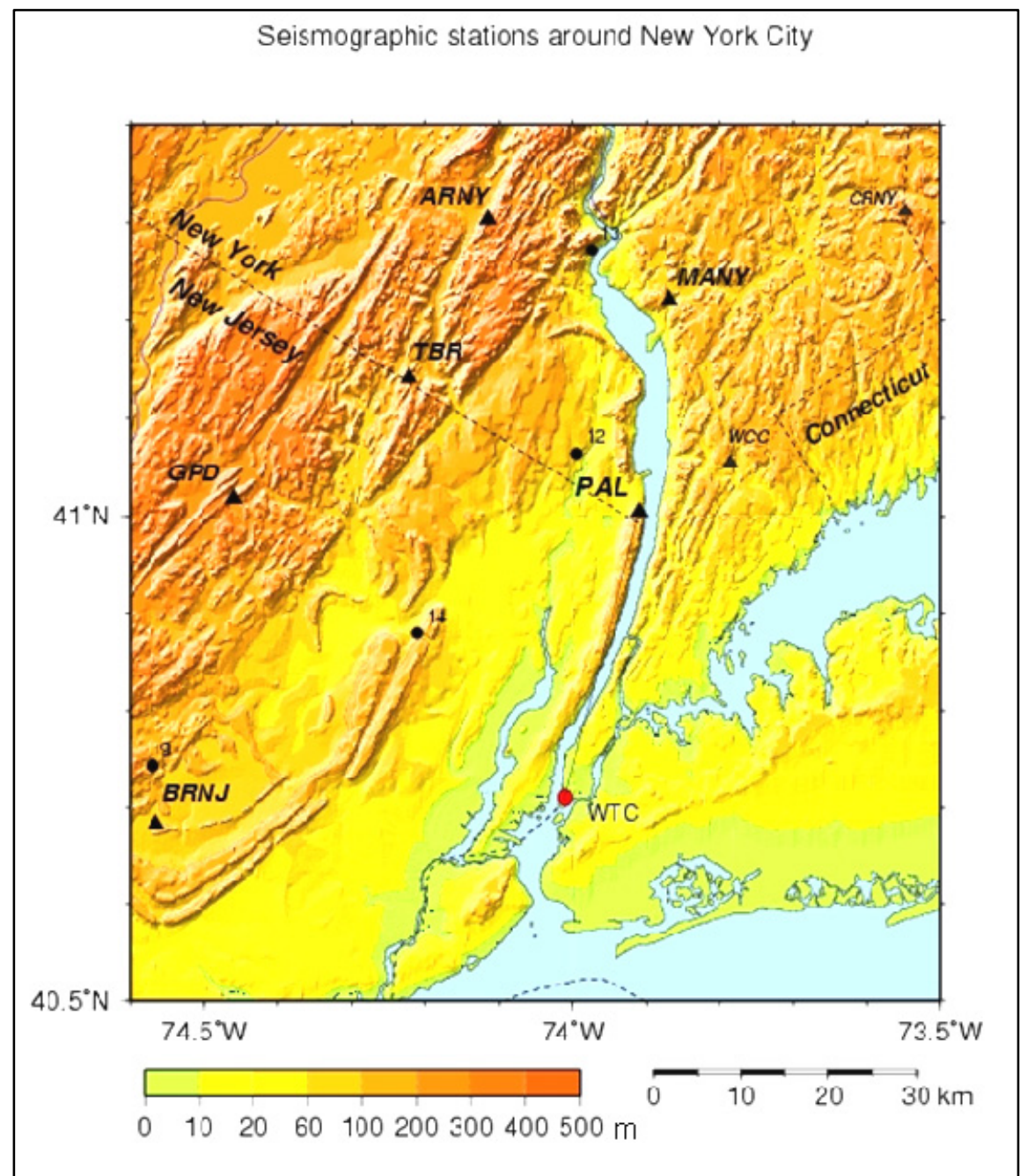

Figure B-1. Seismographic stations (solid triangles) that recorded events at WTC.

Table B-1. List of seismic stations around New York City used in this study.

\begin{tabular}{|l|c|c|l|l|l|}
\hline Station Code & $\begin{array}{c}\text { Distance } \\
\mathbf{( k m )}\end{array}$ & $\begin{array}{c}\text { Azimuth } \\
(\mathbf{(})\end{array}$ & $\begin{array}{c}\text { Sensor } \\
\text { type/make }\end{array}$ & $\begin{array}{c}\text { Digitizer/sample } \\
\text { rate }\end{array}$ & \multicolumn{1}{|c|}{ Location } \\
\hline PAL & 33.8 & 15.2 & BB/STS & 24 bit A/D & Palisades \\
\hline BRNJ & 46.7 & 66.2 & BB/CMG & 16 bit A/D & Basking Ridge \\
\hline GPD & 50.7 & 312.2 & SP/HS & 12 bit A/D & Green Pond \\
\hline TBR & 50.9 & 339.9 & SP/HS & 12 bit A/D & Table Rock \\
\hline MANY & 57.9 & 12.0 & SP/HS & 12 bit A/D & Mount Airy \\
\hline ARNY & 66.2 & 352.6 & SP/HS & 12 bit A/D & Arden House \\
\hline
\end{tabular}

Notes: $\quad$ Distance $=$ epicentral distance in kilometers from WTC 1 to the station

Azimuth = azimuth of the station from WTC 1 measured clockwise from North.

Sensor type: $\mathrm{BB}=$ broad-band seismometer; $\mathrm{SP}=$ short-period seismometer

sps = samples/second; $\mathrm{A} / \mathrm{D}=$ analog-to-digital converter. 


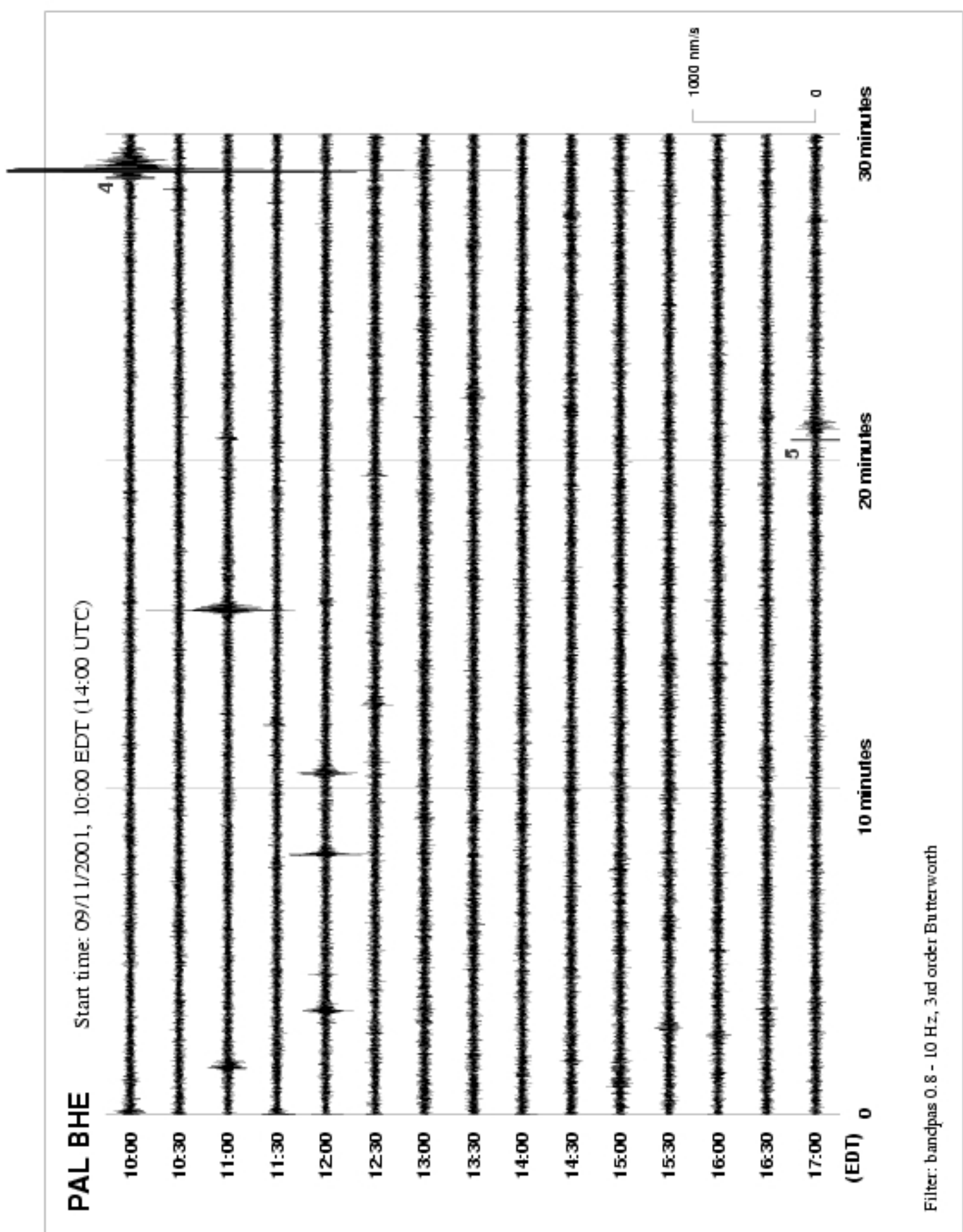

Figure B-2. PAL seismic recordings $(\mathrm{nm} / \mathrm{s})$ on EW component, beginning at 10:00 EDT. Sampling rate: $40 \mathrm{~Hz}$; filtered from 0.8 to $10 \mathrm{~Hz}$. 


\section{B.3 PREVIOUSLY IDENTIFIED SEISMIC EVENTS AT WTC}

In September 2001, researchers at LDEO analyzed seismic records from the WTC disaster and reported their findings for five major events at the WTC site (Kim et al., 2001); the event time, equivalent magnitude on the Richter scale, the dominant period of ground vibration, and the duration of the signal are shown in Table B-2 for the major events. The origin times listed in column 3 of Table B-2 are taken from Kim, et al. (2001), and were also used in the FEMA report (McAllister 2002). These times were estimated from PAL records assuming that large amplitude arrivals corresponded to signals that had traveled with a speed of $2 \mathrm{~km} / \mathrm{s}$. Hence, $34 \mathrm{~km} / 2 \mathrm{~km} / \mathrm{s}=17 \mathrm{~s}$ and the origin time was estimated as $17 \mathrm{~s}$ earlier than the signal arrival time. In the fall of 2003, origin times of the first four events were slightly revised based upon re-examination of the seismic data. There was a seismic arrival about $4 \mathrm{~s}$ prior to the surface wave arrival on three-component records from the collapse of WTC 2. The seismic arrival was found on the north-south component record, which is the radial component and is roughly aligned with the longitudinal direction of wave propagation. This seismic arrival was identified as an $S$ wave with a speed of about $3.4 \mathrm{~km} / \mathrm{s}$ propagating through competent bedrock (the Manhattan schist of the Paleozoic age). The travel time of the $S$ wave was $10 \mathrm{~s}(34 \mathrm{~km} / 3.4 \mathrm{~km} / \mathrm{s})$, which moved the origin time to $3 \mathrm{~s}$ later than the initial determination using $2 \mathrm{~km} / \mathrm{s}$ Rayleigh waves. The revised estimates for the events associated with WTC 1 and WTC 2 are listed in column 4 of Table B-2.

The origin time for the collapse of WTC 7 (event 5) was also re-examined. In addition to the more accurate wave speed that led to a $3 \mathrm{~s}$ adjustment for the events in the towers that also applied to the timing of events originating from WTC 7, a misidentified phase in the earlier paper (Kim et al., 2001) led to the need for an additional $6 \mathrm{~s}$ correction to the event time; hence, $9 \mathrm{~s}$ was added to the earlier estimate, producing the current value of 17:20:42 EDT for the collapse of WTC 7.

When the current estimates for the time of impact of WTC 1 and WTC 2 by the first and second aircraft, respectively, are compared to the videographic evidence presented in NCSTAR 1-5A and Table 5-3 of Chapter 5 of this report, the agreement is within $2 \mathrm{~s}$, as can be seen by comparing the first two entries of column 4 to the first two entries of column 5 in Table B-2. The times attributed to the collapses of WTC 1 and WTC 2, however, differ between the seismic study and NCSTAR 1-5A by about $10 \mathrm{~s}$ (compare entries 3 and 4 of column 4 to entries 3 and 4 of column 5 in Table B-2). The reason for the discrepancy is that NCSTAR 1-5A used the sudden tilting of the upper portion of the towers to signal collapse initiation; a seismic signal, though, is not generated until a substantial portion of the building debris hits the ground. If this time interval is accounted for, the NCSTAR 1-5A times compare well with the seismic origin times.

The current estimate for the collapse of WTC 7 based upon the seismic data is $10 \mathrm{~s}$ earlier than the time reported in Table 5-1 (Chapter 5), that is based upon the video record. (Compare the bottom entries of columns 4 and 5 in Table B-2). Table 5-1 used the global collapse of the building as the marker for the event (i.e., the downward movement of the north face), not the first evidence of downward motion of the east penthouse, which occurred about 7 s earlier (see Table 5-3). The implication of the relative timing of the seismic signal and the visual observation is discussed later in this Appendix after the details of the seismic signature have been presented. 
Table B-2. Major seismic events previously reported.

\begin{tabular}{|c|c|c|c|c|c|c|c|}
\hline \multirow[b]{2}{*}{$\begin{array}{l}\text { Event } \\
\text { Source }\end{array}$} & \multicolumn{3}{|c|}{ Event Time (EDT) } & \multirow[b]{2}{*}{$\begin{array}{l}\text { Table } 5-1 \text { of } \\
\text { Chapter } 5 \text { of } \\
\text { This Report } \\
\quad( \pm 1 s)^{b}\end{array}$} & \multirow{2}{*}{$\begin{array}{c}\text { Equivalent } \\
\text { earthquake } \\
\text { Magnitude } \\
\text { (Richter } \\
\text { Scale, } \pm \text { 0.1) }\end{array}$} & \multirow[b]{2}{*}{$\begin{array}{l}\text { Dominant } \\
\text { Period } \\
\text { (s) }\end{array}$} & \multirow[b]{2}{*}{$\begin{array}{c}\text { Sustained } \\
\text { Signal } \\
\text { Duration } \\
\text { (s) }\end{array}$} \\
\hline & ID & $\begin{array}{c}\text { Kim et } \\
\text { al., } 2001\end{array}$ & $\begin{array}{c}\text { LEDO } \\
\text { current } \\
\text { Estimate }^{\mathrm{a}}\end{array}$ & & & & \\
\hline $\begin{array}{l}\text { WTC } 1 \\
\text { impact }\end{array}$ & 1 & $8: 46: 26$ & $08: 46: 29 \pm 2$ & 8:46:30 & 0.9 & 0.8 & $14 \pm 2$ \\
\hline $\begin{array}{l}\text { WTC2 } \\
\text { impact }\end{array}$ & 2 & 9:02:54 & 09:02:57士4 & 9:02:59 & 0.7 & 0.6 & $6 \pm 2$ \\
\hline $\begin{array}{l}\text { WTC } 2 \\
\text { collapse }\end{array}$ & 3 & 9:59:04 & 09:59:07士2 & 9:58:59 & 2.1 & 0.8 & $10 \pm 1$ \\
\hline $\begin{array}{l}\text { WTC } 1 \\
\text { collapse }\end{array}$ & 4 & $10: 28: 31$ & $10: 28: 34 \pm 2$ & $10: 28: 22$ & 2.3 & 0.9 & $9 \pm 1$ \\
\hline $\begin{array}{l}\text { WTC 7 } \\
\text { collapse }\end{array}$ & 5 & $17: 20: 33$ & $17: 20: 42 \pm 4$ & $17: 20: 52^{\mathrm{c}}$ & 0.6 & 0.8 & $17 \pm 2^{\mathrm{d}}$ \\
\hline
\end{tabular}

a Derived from signal arrival and estimated travel times from WTC site to PAL

b Based upon events observed in videos and photographs; collapse times were based on collapse initiation, not time of ground impact

c NCSTAR 1-5A timing was based on downward movement of the WTC 7 roofline and not the downward movement of the east penthouse that occurred earlier.

d Total duration of BHE PAL signal in Fig. A-6, including a possible second arrival

\section{B.4 CHARACTERISTICS OF SEISMIC SIGNALS FROM WTC EVENTS}

Seismic records from the five major WTC events show no clear $P$ or $S$ wave arrivals. Short-period seismic surface waves, mainly of the Rayleigh type, are the predominant seismic waves on records at regional distances (few tens to few hundreds of kilometers). Figure B-3 shows the three-component seismic records at stations PAL and BRNJ from the collapse of WTC 1. NS- and EW-component records were rotated to longitudinal-component (BHR) and transverse-component (BHT) orientations to show the effect of wave propagation. The time of 10:28:34 EDT is the estimated origin time (i.e., the estimated travel time has been subtracted from the arrival time) for the PAL BHT signal at the "Rg" indicator (note that $R g$ indicates the arrival of a seismic surface wave of the Rayleigh type which propagated at $2.4 \mathrm{~km} / \mathrm{s}$ ). The time scale at the top and bottom of the figure illustrate the relative signal arrival times and durations. Vertical-component seismic records at local stations PAL, BRNJ, TBR, MANY and ARNY from the collapse of WTC 1 are shown in Figure B-4. The epicentral distance and azimuth at each station are given at the end of each trace.

Surface waves on the transverse-component are strongest at PAL, whereas at BRNJ, the transversecomponent has the least amplitude. The seismic signals excited by the building collapses are basically due to vertical forces acting on the ground surface, and hence, seismic waves are strongly excited near the surface and subsequently travel as surface waves. In addition, the surface waves recorded at station PAL, located due north from the WTC, are strongest on the EW component record. This is a unique 
09/11/2001,10:28:34 (EDT), 40.712, -74.013, h= 0 km, North Tower Collapse, 0.6-5 Hz

$\begin{array}{llllllllll}0 & 10 & 20 & 30 & 40 & 50 & 60 & 70 & 80 & 90\end{array}$

PAL BHZ

$0.13 \mathrm{E}+04$

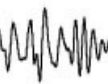

$33.8 \mathrm{~km}$

$\mathrm{az}=15.2$

baz $=195.3$

PAL BHR

$0.15 \mathrm{E}+04$

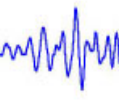

$33.8 \mathrm{~km}$

$\mathrm{az}=15.2$

baz $=195.3$
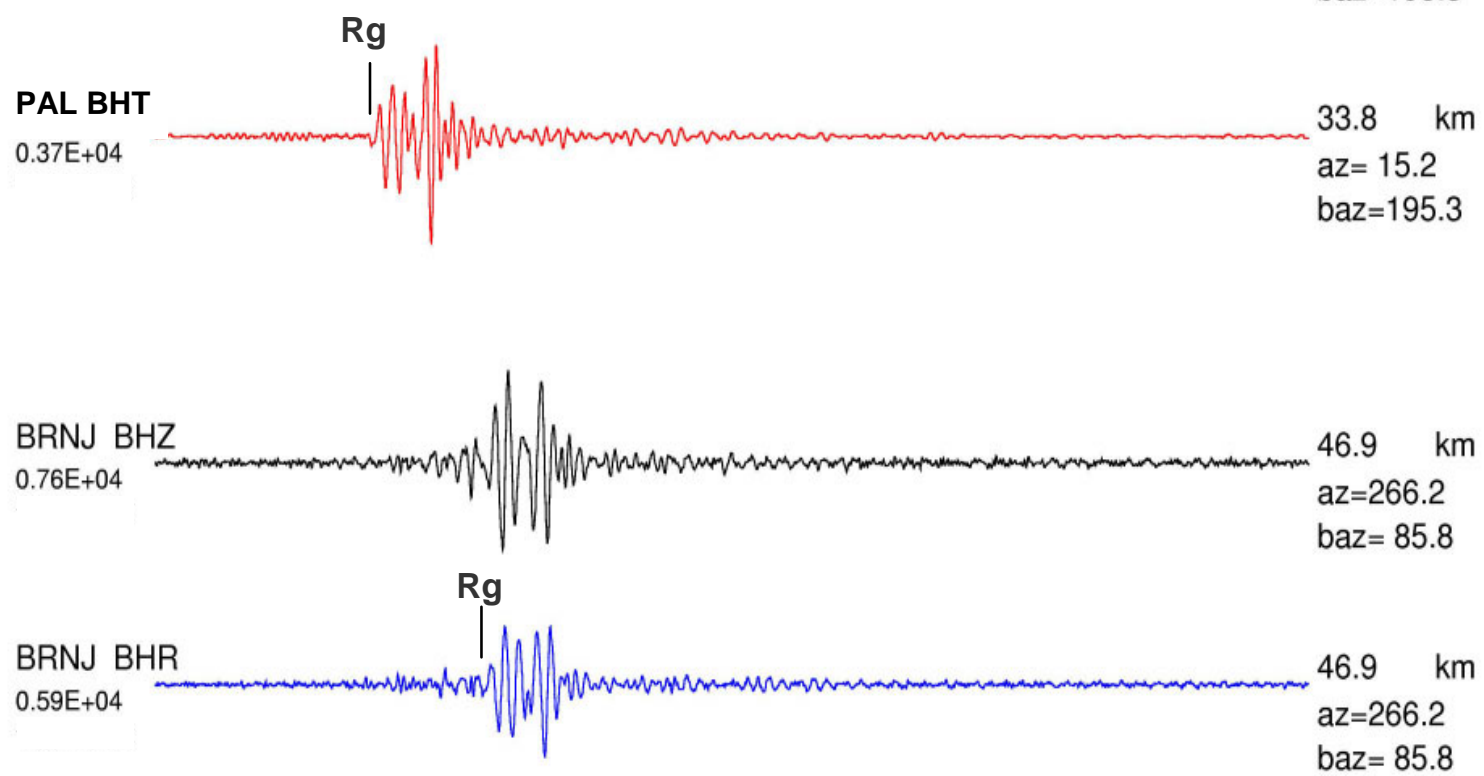

BRNJ BHT

$0.16 \mathrm{E}+04$

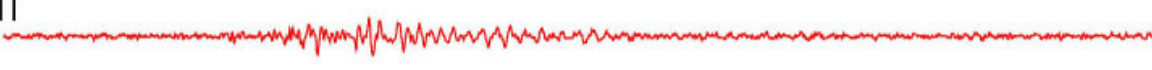

$46.9 \mathrm{~km}$

$\mathrm{az}=266.2$

$\mathrm{baz}=85.8$

$\begin{array}{cccccccccc}0 & 10 & 20 & 30 & 40 & 50 & 60 & 70 & 80 & 90 \\ & \text { time (sec) }\end{array}$

Figure B-3. Three-component seismic records at stations PAL and BRNJ from the collapse of WTC 1. 
Seismic signals from the WTC 1 collapse (North Tower)

09/11/2001, 10:28:34 (EDT), $40.712^{\circ} \mathrm{N}, 74.013^{\circ} \mathrm{W}$, Bandpass filter: 1 - $10 \mathrm{~Hz}$
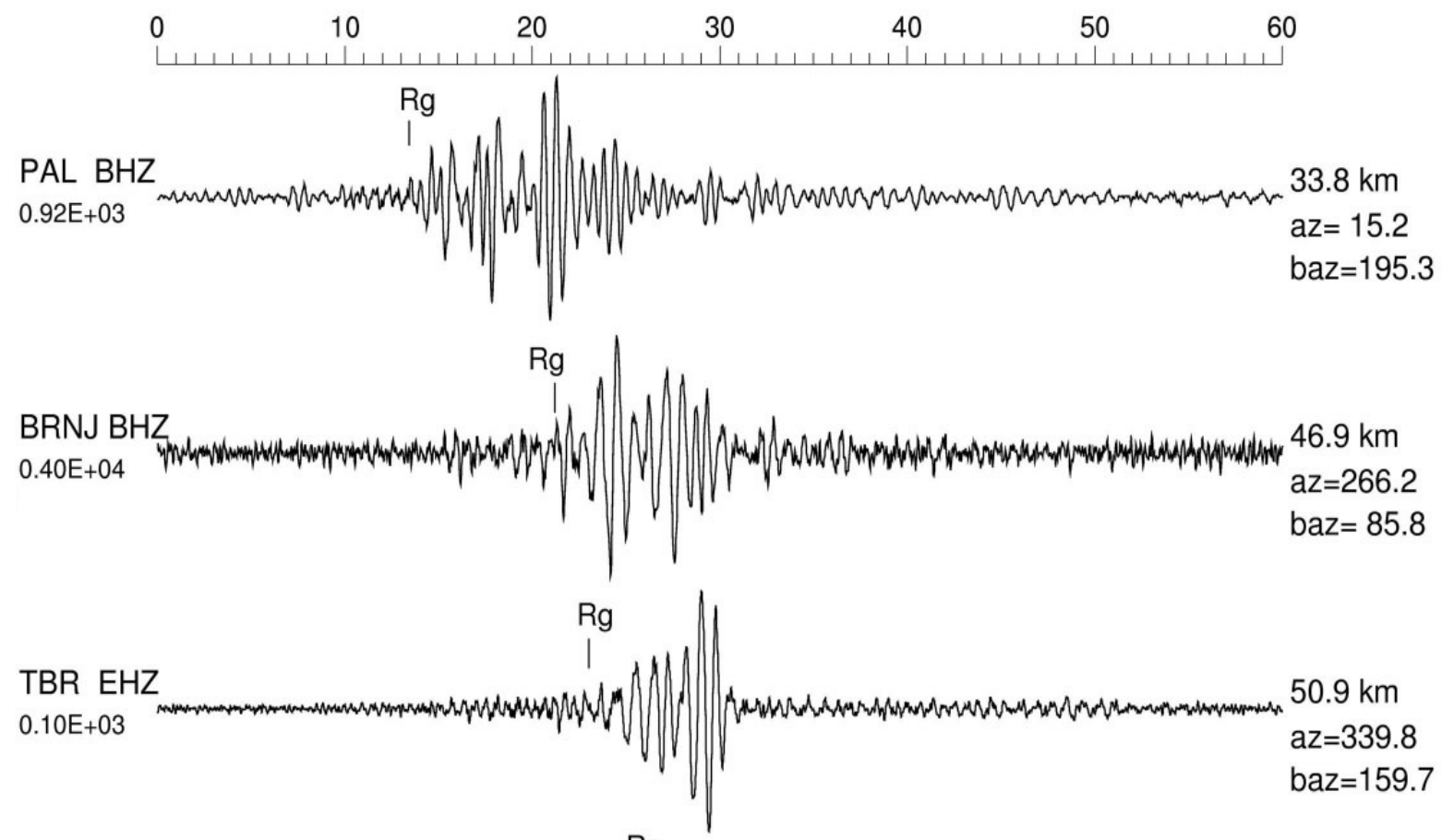

$\mathrm{Rg}$
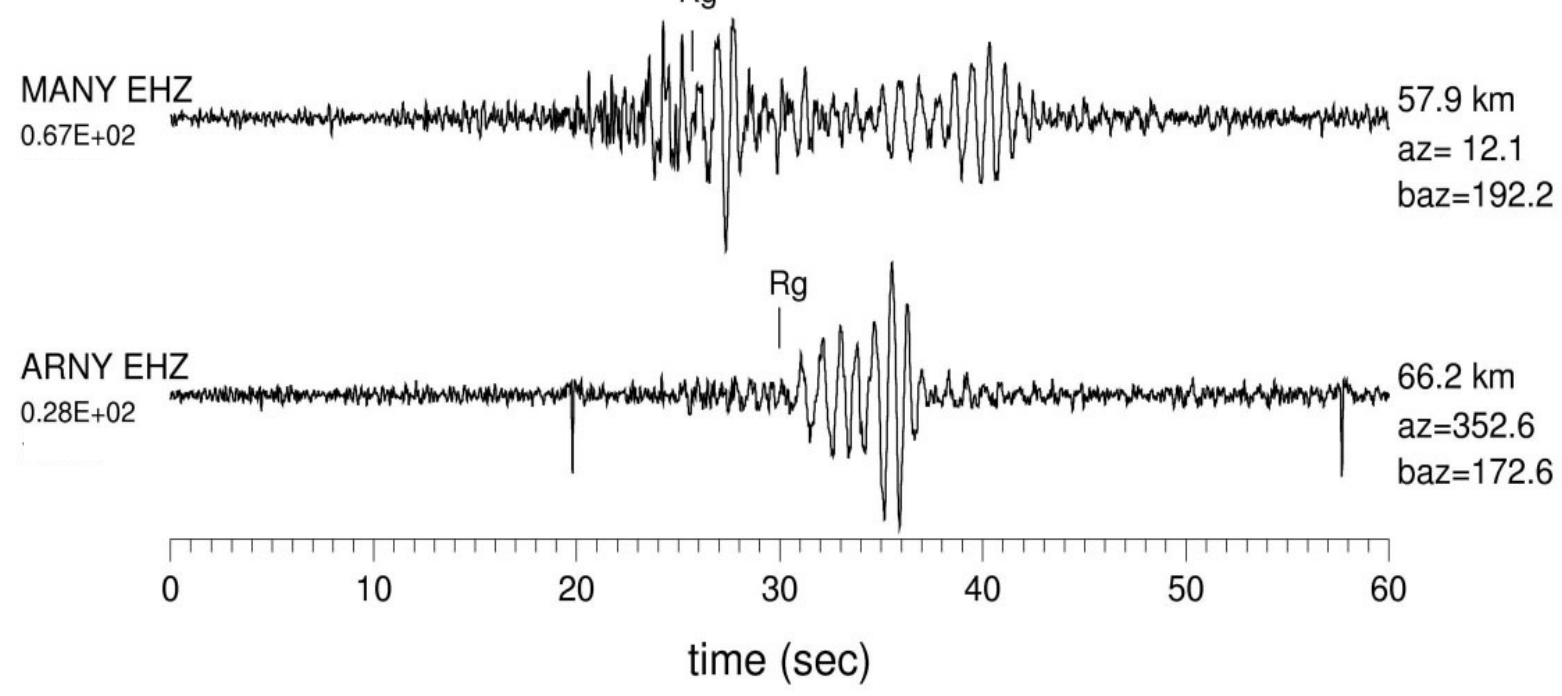

Figure B-4. Vertical-component seismic records at local stations PAL, BRNJ, TBR, MANY and ARNY from collapse of WTC 1.

(Spikes at $20 \mathrm{~s}$ and at $58 \mathrm{~s}$ on ARNY record are due to electrical noise). 
observation because Rayleigh-type seismic surface waves should be strong in the vertical and radial directions, and weak in the transverse direction, as is the case for station BRNJ shown in Figure B-3. This is an interesting propagation effect due to strongly contrasting properties of shallow rock layers along the wave propagation path between the WTC and PAL which is nearly parallel to the Hudson River. Lateral refraction is caused by contrasting shallow rock layers at the boundary between highvelocity crystalline metamorphic rocks of the Manhattan prong and low-velocity Triassic rocks of the Newark basin (Anderson and Dorman 1973). When the wave leaving the source at the WTC site enters the rock underlying the Hudson River, much of its energy can be trapped in a wave guide along the river in the form of a lens or tube and undergo multiple lateral refractions along its passage. Hence, there are several distinct criteria for characterizing seismic waves generated at the WTC site and observed at stations around New York City. These criteria are:

- seismic surface waves generated at the WTC site and observed at PAL have stronger EWcomponents than vertical- or NS-components (Figure B-3);

- seismic surface waves, mainly of the Rayleigh type, travel at about $2.4 \mathrm{~km} / \mathrm{s}$ between the WTC site and stations in the region, and the surface waves arrive first at station PAL, followed by BRNJ, GPD, TBR and so on, as listed in Table B-1 (Figure B-4); and

- $\quad$ no clear $P$ or $S$ wave arrivals are observed due to the vertical force nature of the sources at WTC (Figures B-3 and B-4).

\section{B.5 SEISMIC SIGNALS FROM THE WTC 7 COLLAPSE}

East-west and vertical component seismic records from five stations around New York City, filtered to pass signals below $5 \mathrm{~Hz}$, are plotted in Figure B-5 for the time during the collapse of WTC 7. As before, $R g$ indicates the arrival of the seismic surface wave of the Rayleigh type which propagated with a speed of $2.4 \mathrm{~km} / \mathrm{s}$. $P g$ and $S g$ indicate $P$ - and $S$-wave estimated arrival times from the WTC site using a velocity model for the region (these wave arrivals were not detectable). The Rayleigh waves were quite weak and difficult to discern clearly at most of the stations. Nevertheless, $R g$ waves at PAL, BRNJ, TBR and ARNY were stronger than the background noise in Figure B-5.

Three-component records at PAL associated with the WTC 7 building collapse are shown in Figure B-6 (including frequencies up to $10 \mathrm{~Hz}$ ). The event origin time, based on the arrival of the Rayleigh type of shear wave $\mathrm{Rg}$ on the BHE component, was estimated to occur at 17:20:42 EDT with an uncertainty of $\pm 4 \mathrm{~s}$. Notice that the seismic signal strengthens at about $21.5 \mathrm{~s}$, following the initial $R g$ wave arrival at $14.5 \mathrm{~s}$. A $P$-wave from the Fox Islands earthquake (event \#17) would have arrived about $11 \mathrm{~s}$ after $R g$, and would have had nearly equal amplitude and duration on both the N-S (middle trace of Figure B-6) and E-W (lower trace) components of the seismic signal. Since the N-S component is small in Figure B-6 (compared to the amplitude of $\mathrm{Rg}$ ), that the signal beginning at $21.5 \mathrm{~s}$ is likely due to the sustained period of collapse of WTC 7.

The WTC 7 building collapse was observed to have two distinct phases. First, an internal structural failure occurred which led to the observed east penthouse movement, when it sank below the roofline. Second, the entire building began to collapse about $7 \mathrm{~s}$ later, when the roofline and building exterior were observed to start moving downward. The first phase resulted in interior debris falling to the lower floors of WTC 7 on the east side, which transmitted impact loads to the foundation. The debris fell over several 
Vertical-component seismic signals generated by WTC building 7 collapse 09/11/2001, 17:20:42 (EDT), 40.714 $\mathrm{N}, 74.012^{\circ} \mathrm{W}$, Bandpass filter: 0.6-5 Hz
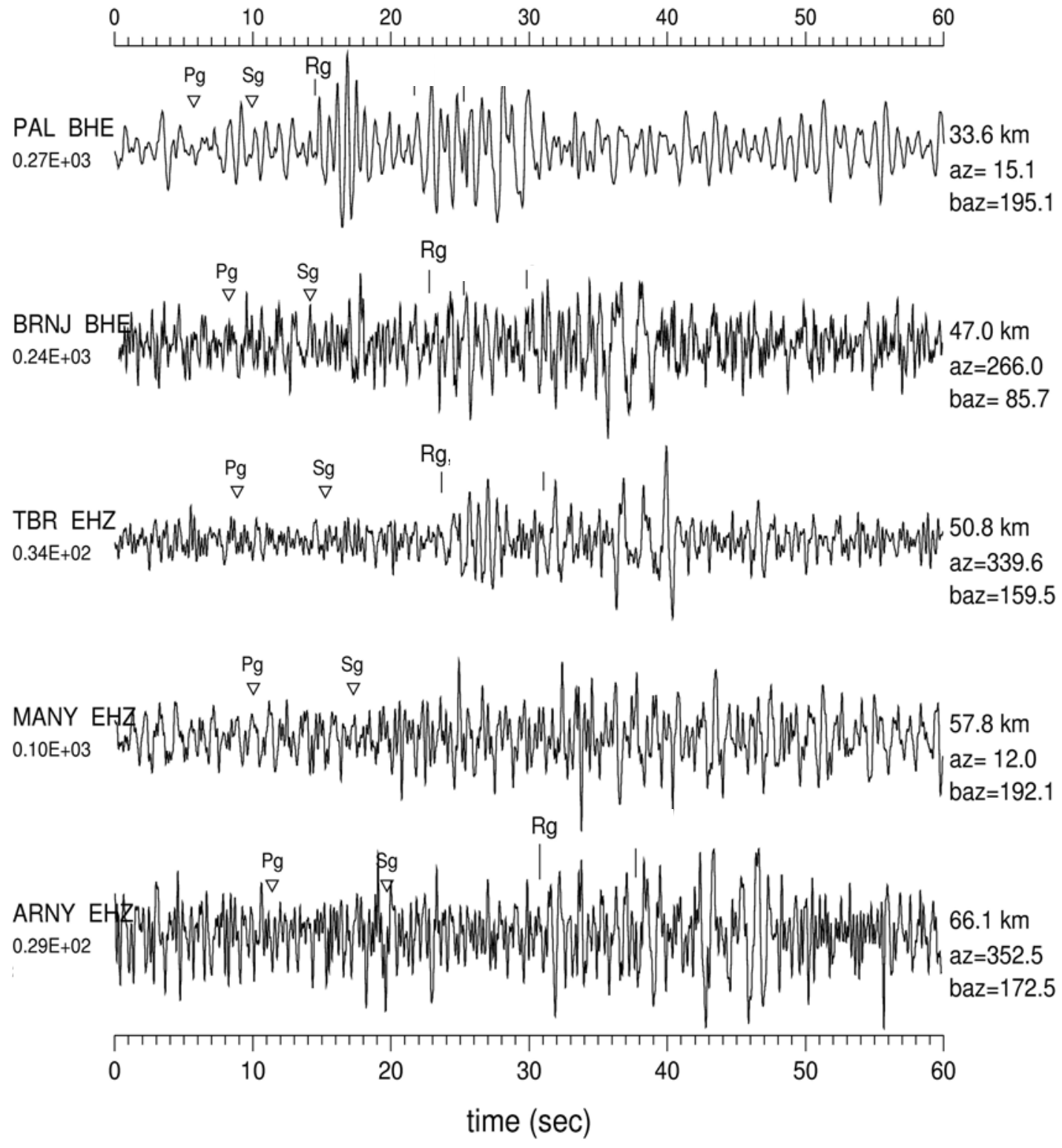

Figure B-5. East-west (BHE) and vertical (EHZ) component seismic records, $0.6 \mathrm{~Hz}$ to 5 $\mathrm{Hz}$ filtered, at PAL, BRNJ, TBR, MANY and ARNY from collapse of WTC 7. 
Three-component records at Palisades, NY (PAL) from WTC building \#7 collapse 09/11/2001, 17:20:42, 40.714 $\mathrm{N}, 74.012^{\circ} \mathrm{W}$, Bandpass filter: 1-10 Hz
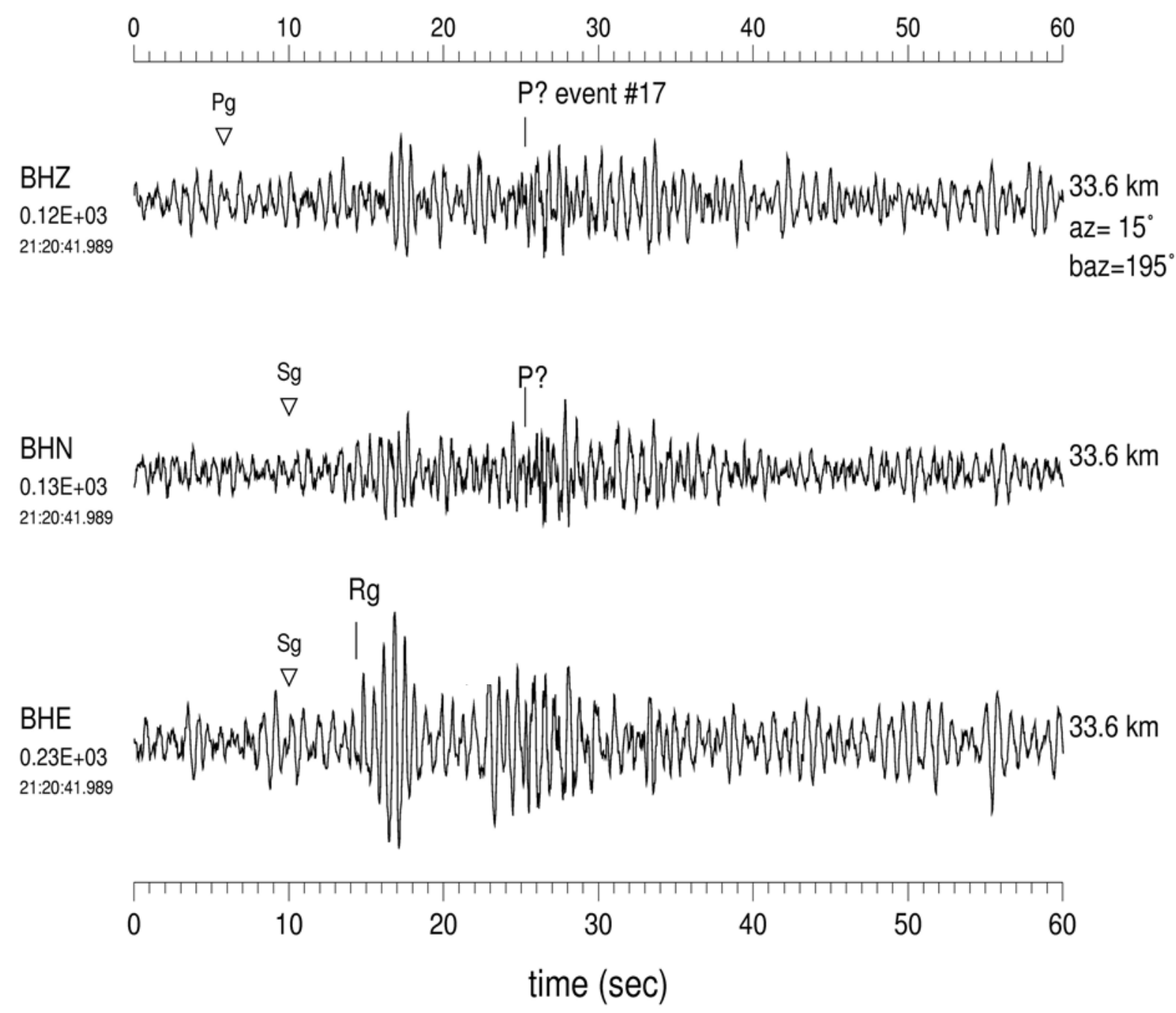

Figure B-6. Three-component seismic records, $1 \mathrm{~Hz}$ to $10 \mathrm{~Hz}$ filtered, at PAL from collapse of WTC 7. 
seconds, but the exact time duration is unknown, as is the timing relative to the observed east penthouse movement. The first phase triggered other interior structural failures which led to the observed global collapse initiation about $7 \mathrm{~s}$ after the east penthouse moved downward. Debris may have fallen prior to the observed movement of the building exterior, but the duration and timing of the falling debris is unknown. The falling debris from the global collapse would also have transmitted impact loads to the foundation.

While this qualitative sequence of events is consistent with what might be construed as two arrivals in the PAL BHE traces shown in Figures B-5 and B-6, caution is required when interpreting signals that are small. For example, the signals in Figures B-3 and B-4 all recorded the same event, the collapse of WTC 1. Even so, signal amplitude and duration vary depending upon the location of signal arrival. The signal variations may be due to differences in the geological features along the signal path as well as local differences in construction. For instance, WTC 1 and WTC 2 were both located inside the foundation bathtub structure and had multi-story basements while WTC 7 was located north of the bathtub structure and had no basement. It is not known how these construction features may have affected signal transmission.

\section{B.6 SCREENING OTHER SEISMIC EVENTS}

Using all available seismic data from the six stations around New York City, 17 seismic signals were identified in the time window between the collapses of WTC 1 and WTC 7. These could have been generated by relatively large distant earthquakes (magnitude usually greater than 6 ), regional earthquakes (distance ranges between few tens to few hundreds of kilometers), and other signals generated by anthropogenic sources such as quarry blasts, chemical explosions, or impacts from heavy falling debris hitting the ground. To determine which seismic signals may have been generated by the WTC buildings, all of these signals were examined to identify their source and location. Table B-3 lists the 17 signals, beginning with ID \#6 to distinguish these from the first five strong signals attributed to the events listed in Table B-2. The event origin time, location, and magnitude are provided.

\section{B.6.1 Earthquakes}

Two of the events listed in Table B-3 (\#6 and \#17) were associated with distant earthquakes, as confirmed in the Preliminary Determination of Epicenters bulletin from the National Earthquake Information Center, U.S. Geological Survey. The seismic records show teleseismic $P$ wave arrivals from a strong earthquake (ID \#6) that occurred in West Irian Jaya (New Guinea), Indonesia. There appears to be a weak teleseismic $P$ wave arrival from a second, less intense distant earthquake (event \#17 in Table B-3) at around $10 \mathrm{~s}$ after the arrival of the Rayleigh wave generated by the collapse of WTC 7. Since the teleseismic $P$ waves (epicentral azimuth $\Delta=61^{\circ}$ ) are usually strong only in vertical component records, this signal did not interfere with shear signals from WTC 7.

\section{B.6.2 Local Quarry Blasts}

The largest of the remaining signals listed in Table B-3 show relatively clear $P$ and $S$ arrivals, and were strong enough to be recorded at several stations in the region so that the source location could be identified. Based on the location and characteristics of seismic signals, local quarry blasts in the region were identified. Usually, seismic signals from a local quarry blast show strong short period surface 
Table B-3. Minor seismic signals recorded around New York City on Sept. 11, 2001, and examined in this study.

\begin{tabular}{|l|c|l|c|c|c|l|}
\hline $\begin{array}{c}\text { Event } \\
\text { ID }\end{array}$ & $\begin{array}{c}\text { Origin Time, EDT } \\
(\mathbf{h h : m m : s e c )}\end{array}$ & $\begin{array}{c}\text { Latitude } \\
\mathbf{(} \mathbf{N})\end{array}$ & $\begin{array}{c}\text { Longitude } \\
\mathbf{(} \mathbf{E})\end{array}$ & $\begin{array}{c}\text { Depth } \\
\mathbf{( k m})\end{array}$ & $\begin{array}{c}\text { Magnitude } \\
\mathbf{( M}_{\mathbf{L}} \mathbf{)}\end{array}$ & \multicolumn{1}{|c|}{ Comments } \\
\hline 6 & $10: 56: 51$ & -0.578 & 133.13 & 33 & 6.5 & $\begin{array}{l}\text { distant earthquake from } \\
\text { Indonesia* }\end{array}$ \\
\hline 7 & $11: 00: 45$ & 40.420 & -75.05 & 0.01 & 1.1 & quarry blast \\
\hline 8 & $11: 14: 58$ & 40.620 & -74.71 & 0.01 & 1.3 & quarry blast \\
\hline 9 & $11: 29: 41$ & 40.744 & -74.57 & 0.01 & 0.9 & quarry blast \\
\hline 10 & $11: 40: 50$ & 43.039 & -73.29 & 0.01 & 1.4 & quarry blast \\
\hline 11 & $12: 02: 20$ & 42.472 & -73.69 & 0.01 & 1.2 & quarry blast \\
\hline 12 & $12: 07: 52$ & 41.064 & -73.99 & 0.01 & 0.6 & quarry blast \\
\hline 13 & $12: 10: 15$ & 41.273 & -73.97 & 0.01 & 0.6 & quarry blast \\
\hline 14 & $12: 42: 21$ & 40.879 & -74.21 & 0.01 & 0.6 & quarry blast \\
\hline 15 & $12: 49: 14$ & 41.427 & -74.14 & 0.01 & 0.6 & quarry blast \\
\hline 16 & $16: 18: 48$ & 41.475 & -74.08 & 0.01 & 0.2 & quarry blast \\
\hline 17 & $17: 10: 55$ & 52.461 & -169.28 & 33 & 5.1 & distant earthquake from Fox \\
\hline $18 \#$ & $11: 20: 17$ & 40.71 & -74.01 & 0 & $<0.5$ & only at PAL \\
\hline $19 \#$ & $12: 03: 56$ & 40.71 & -74.01 & 0 & $<0.5$ & very weak at PAL \\
\hline $20 \#$ & $12: 40: 25$ & 40.71 & -74.01 & 0 & $<0.5$ & very weak at PAL \\
\hline $21 \#$ & $13: 51: 32$ & 40.71 & -74.01 & 0 & $<0.5$ & very weak at PAL and GPD \\
\hline $22 \#$ & $15: 32: 30$ & 40.71 & -74.01 & 0 & $<0.5$ & very weak at PAL \\
\hline
\end{tabular}

* Origin time, location, depth and magnitude are from Preliminary Determination of Epicenters determined by NEIC/USGS (National Earthquake Information Center, U.S. Geological Survey).

\# These events could not be located because the signals were detected only on one or two stations, where they were too weak to pick arrival times of $P$ or $S$ waves. It was necessary to assume that events occurred at the WTC in order to infer a possible origin time. 
waves; these blasts involve approximately 100 holes in the bedrock and about $36000 \mathrm{~kg}$ of ammonium nitrate and fuel oil. However, the strength of seismic signals or ground vibration due to these large quarry blasts are much reduced due to the practice of sequential firing of blasting caps with 25 ms delays. The peak amplitudes of the seismic signals from quarry blasts are approximately proportional to the maximum charge size per delay, not the total charges detonated within a quarry blast. Note that each delay consists of shot holes fired within $\pm 8 \mathrm{~ms}$, hence a quarry may have several delays. (Kim et al. 1994). An example of waveform data from a quarry blast (ID \#8 in Table B-3) is shown in Figure B-7. (Note that the teleseismic $P$ wave also shown in Figure B-7 as event ID \#6 is associated with the distant earthquake that occurred earlier.) Ten of the events in Table B-3 (ID \#7 through ID \#16) were associated with quarry blasts, with magnitudes varying between 0.2 to 1.4. The locations of these events are plotted on the map in Figure B-8.

\section{B.6.3 Unidentified Weak Signals}

In addition to the seismic signals already discussed, about a dozen other weak signals were recorded by one or more of the seismic stations in the area. These were screened to identify those that had characteristics of the previously identified signals emanating from the WTC site; namely, signals with the strongest amplitudes in the east-west component at PAL. All but five of the weak signals at PAL were eliminated based on this criterion. Because the signals were very weak and (except for ID \# 21) not detectable at stations other than PAL, it could not be positively confirmed that they originated, in fact, from the WTC site. An examination of the video and photographic records by NIST at times corresponding to these weak signals did not reveal any particular events that could have acted as sources for this seismic activity.

\section{B.7 SUMMARY OF SEISMIC DATA}

Table B-4 lists, according to the time of occurrence, all 22 seismic signals identified between 8:46 EDT and 17:21 EDT on Sept. 11, 2001, recorded at six stations around the metropolitan New York City area. Figure B-9 is a seismogram of the period starting at 10:00 EDT taken at the PAL station, with event ID numbers included. Events \#4 and \#5 (in blue) are the collapses of WTC 1 and WTC 7, respectively; events \#6 through \#17 (in black) have been attributed to distant earthquakes and local quarry blasts; and events \#18 through \#22 (in red) are undetermined.

The five largest seismic events were due to collisions of the two aircraft into the WTC towers, their subsequent collapses, and the collapse of WTC 7. Consistent event times for the impact of the towers by the aircraft were obtained between the current seismic analysis and the analysis of the photographic evidence in NCSTAR 1-5A.

The times attributed to the collapses of WTC 1 and WTC 2 in Table 5-1 (NIST NCSTAR 1-9), column 3, and Table 3-1, column 3 (NIST NCSTAR 1-5A) differ from the seismic signal times because the column 3 times refer to the time when the upper portion of each tower above the airplane impact damage was observed to suddenly tilt, while a seismic signal was not generated until a substantial portion of the building debris hit the ground. If this time interval is accounted for, the NCSTAR 1-5A times compare well with the seismic origin times. 
Quarry blast, $10 \mathrm{~km} \mathrm{NW}$ of Somerville, NJ; Teleseismic PKP phases from event \#6 09/11/2001, $11: 14: 57.62$ (EDT), $40.62^{\circ} \mathrm{N}, 74.71^{\circ} \mathrm{W}$, Event \#8, Filter: BW 1 - $10 \mathrm{~Hz}$
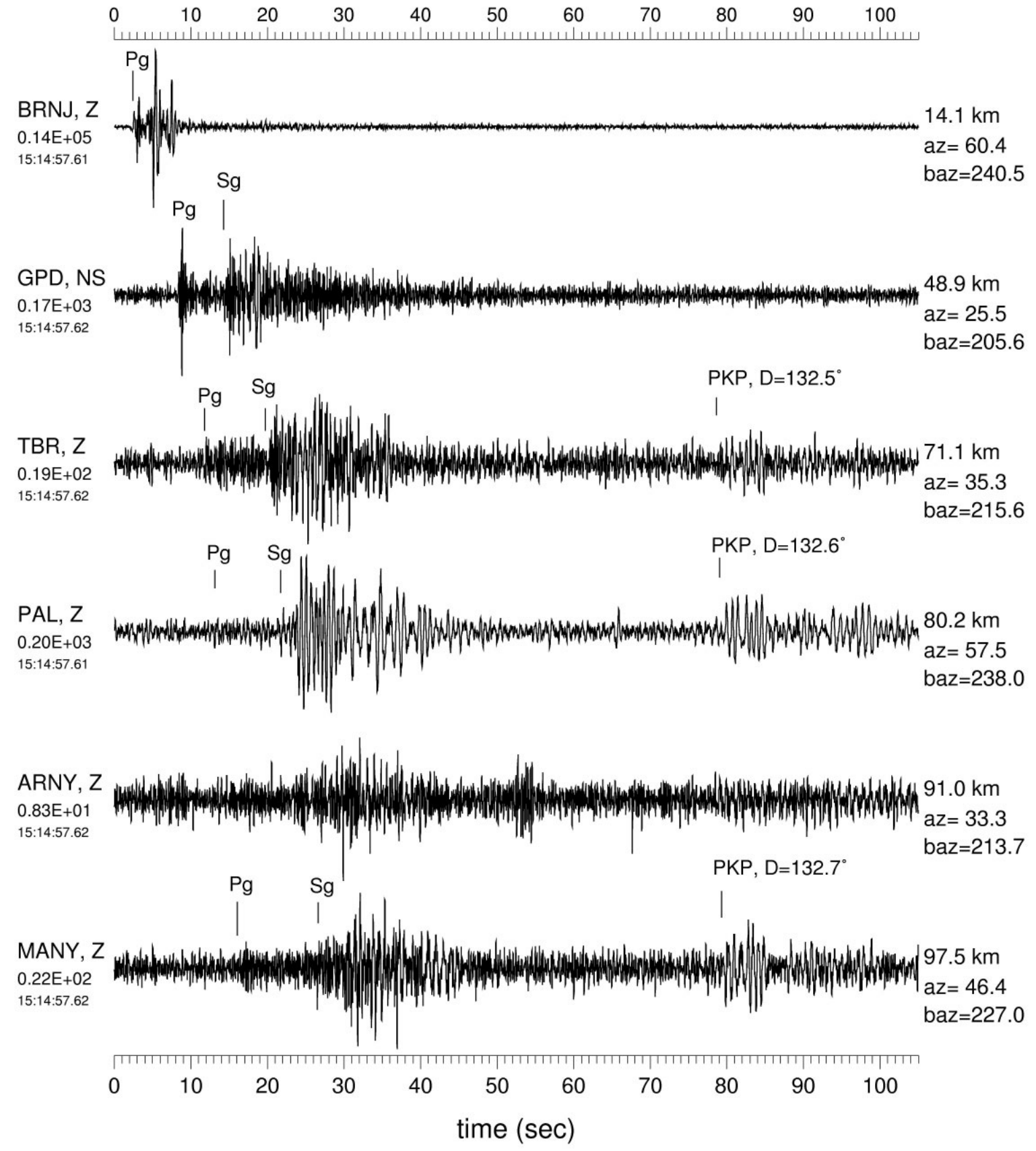

Figure B-7. Vertical component seismic records from quarry blast (ID \#8) recorded at seismographic stations around New York City (PKP is ID \#6). 
Local seismic events around New York City on 09/11/2001

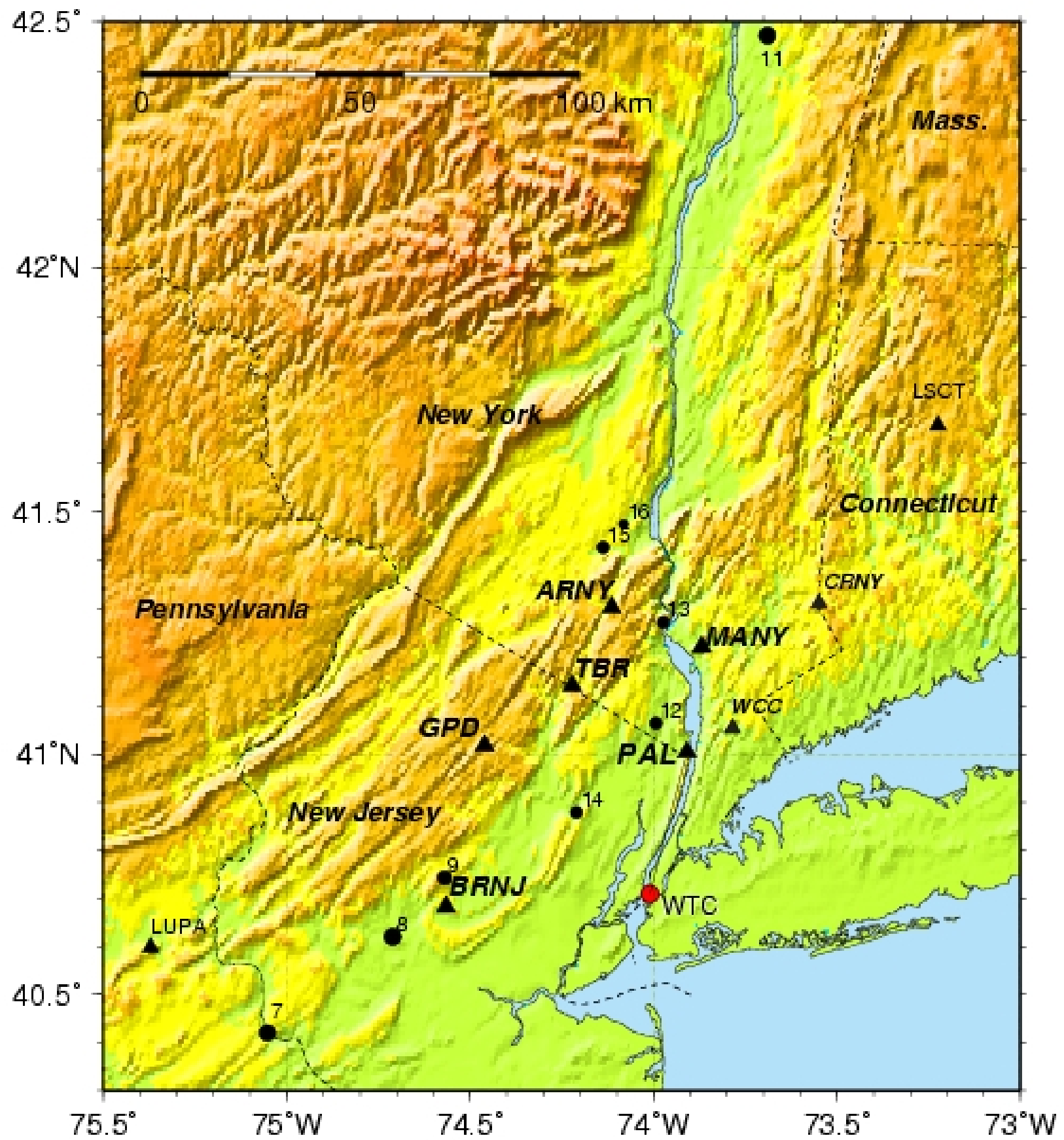

Figure B-8. Epicenters of local quarry blasts on Sept. 11, 2001.

The event ID numbers are given in Table B-3. 
As discussed further in Chapter 12, there were two phases in the probable WTC 7 collapse sequence that could have resulted in seismic signals.

- The first comprised the initial local failure and the vertical progression of failure. These began prior to the descent of the east penthouse (as suggested by the increasingly larger magnitudes of vibration of the building as described in Appendix C) and involved a cascade of floor failures within the east side of the building. The interior debris falling onto the lower floors of WTC 7 on the east side transmitted impact loads to the foundation. This impact would have coincided roughly with or slightly preceded the initial descent of the east penthouse, about $7 \mathrm{~s}$ prior to the visible initiation of global collapse. This time estimate is within the uncertainty in collapse time determined by NIST from the video record as listed in Table 5-1.

- The second seismic phase comprised the global collapse of the building, as seen in the videos (Section 5.7). Here, the entire building above the fire-damaged and buckled floors moved downward as a single unit, transmitting impact loads to the foundation. One would have expected seismic signals from this second phase of collapse to be generated over this entire episode (which lasted approximately $14 \mathrm{~s}$ ) since debris was continuously impacting the ground either unobserved within the core or externally as seen from the videos of the perimeter walls. However, because the total energy dissipated by the impact was distributed over a long period of time, the strength of the signal at any given time was small and difficult to interpret.

Twelve other signals analyzed in the current study could be associated with specific seismic events, including two natural earthquakes and ten quarry blasts and explosions at construction sites. Five weak signals may have originated from sources at the WTC site based upon the criterion that E-W component signals at PAL are stronger than signals for the N-S or vertical components, but their location and strength could not be confirmed by the other stations. These signals were very small in amplitude (Richter magnitudes below 0.5), and all but one were not recorded at the other stations of the seismic network, putting them close to the level of the "noise" that accompanies daily earthquake monitoring activity at the reference station PAL.

Thus, the collapse of WTC 7 observed in the videographic evidence can be associated with the signals on the seismic record. There were no other seismic signals that could be associated with other specific events at the World Trade Center that were identifiable in the videographic or photographic records gathered by NIST, or with any events reported by witnesses that were interviewed by NIST. 
Table B-4. Summary of seismic events recorded 8:46 to 17:21 on Sept. 11, 2001.

\begin{tabular}{|c|c|c|c|c|c|c|}
\hline $\begin{array}{c}\text { Origin Time, } \\
\text { EDT } \\
\text { (hh:mm:sec) }\end{array}$ & $\begin{array}{l}\text { Event } \\
\text { ID }\end{array}$ & $\begin{array}{l}\text { Latitude } \\
\quad\left({ }^{\circ} \mathrm{N}\right)\end{array}$ & $\begin{array}{c}\text { Longitude } \\
\left({ }^{\circ} \mathrm{E}\right)\end{array}$ & Depth (km) & $\begin{array}{l}\text { Magnitude } \\
\qquad\left(\mathbf{M}_{\mathrm{L}}\right)\end{array}$ & Event Type \\
\hline $8: 46: 29$ & 1 & 40.71 & -74.01 & 0 & 0.9 & WTC 1 impact \\
\hline 9:02:57 & 2 & 40.71 & -74.01 & 0 & 0.7 & WTC 2 impact \\
\hline 9:59:07 & 3 & 40.71 & -74.01 & 0 & 2.1 & WTC 2 collapse \\
\hline $10: 28: 34$ & 4 & 40.71 & -74.01 & 0 & 2.3 & WTC 1 collapse \\
\hline $10: 56: 51$ & 6 & -0.578 & 133.13 & 33 & 6.5 & $\begin{array}{l}\text { distant earthquake } \\
\text { from Indonesia }\end{array}$ \\
\hline 11:00:45 & 7 & 40.42 & -75.05 & 0.01 & 1.1 & quarry blast \\
\hline $11: 14: 58$ & 8 & 40.62 & -74.71 & 0.01 & 1.3 & quarry blast \\
\hline $11: 20: 17$ & 18 & $40.71 *$ & $-74.01 *$ & $0 *$ & $<0.5$ & unknown* \\
\hline $11: 29: 41$ & 9 & 40.74 & -74.57 & 0.01 & 0.9 & quarry blast \\
\hline $11: 40: 50$ & 10 & 43.04 & -73.29 & 0.01 & 1.4 & quarry blast \\
\hline $12: 02: 20$ & 11 & 42.47 & -73.69 & 0.01 & 1.2 & quarry blast \\
\hline 12:03:56 & 19 & $40.71^{*}$ & $-74.01 *$ & $0 *$ & $<0.5$ & unknown* \\
\hline $12: 07: 52$ & 12 & 41.06 & -73.99 & 0.01 & 0.6 & quarry blast \\
\hline $12: 10: 15$ & 13 & 41.27 & -73.97 & 0.01 & 0.6 & quarry blast \\
\hline $12: 40: 25$ & 20 & $40.71 *$ & $-74.01 *$ & $0 *$ & $<0.5$ & unknown* \\
\hline $12: 42: 21$ & 14 & 40.88 & -74.21 & 0.01 & 0.6 & quarry blast \\
\hline $12: 49: 14$ & 15 & 41.48 & -74.14 & 0.01 & 0.6 & quarry blast \\
\hline 13:51:32 & 21 & $40.71 *$ & $-74.01 *$ & $0 *$ & $<0.5$ & unknown* \\
\hline $15: 32: 30$ & 22 & $40.71 *$ & $-74.01 *$ & $0 *$ & $<0.5$ & unknown* \\
\hline $16: 18: 48$ & 16 & 41.48 & -74.08 & 0.01 & 0.2 & quarry blast \\
\hline $17: 10: 55$ & 17 & 52.46 & -169.28 & 33 & 5.1 & $\begin{array}{l}\text { distant earthquake } \\
\text { from Fox Islands }\end{array}$ \\
\hline $17: 20: 42$ & 5 & 40.71 & -74.01 & 0 & 0.6 & $\begin{array}{l}\text { WTC } 7 \text { collapse } \\
\text { initiation }\end{array}$ \\
\hline $17: 20: 50$ & $5^{\prime}$ & 40.71 & -74.01 & 0 & 0.6 & $\begin{array}{l}\text { WTC } 7 \text { perimeter } \\
\text { wall collapse }\end{array}$ \\
\hline
\end{tabular}

*Although the latitude and longitude are those of the WTC site, the signals were small and, except for ID \#21, unconfirmed by a second station; hence the source, location and magnitude of these events could not be accurately determined. 


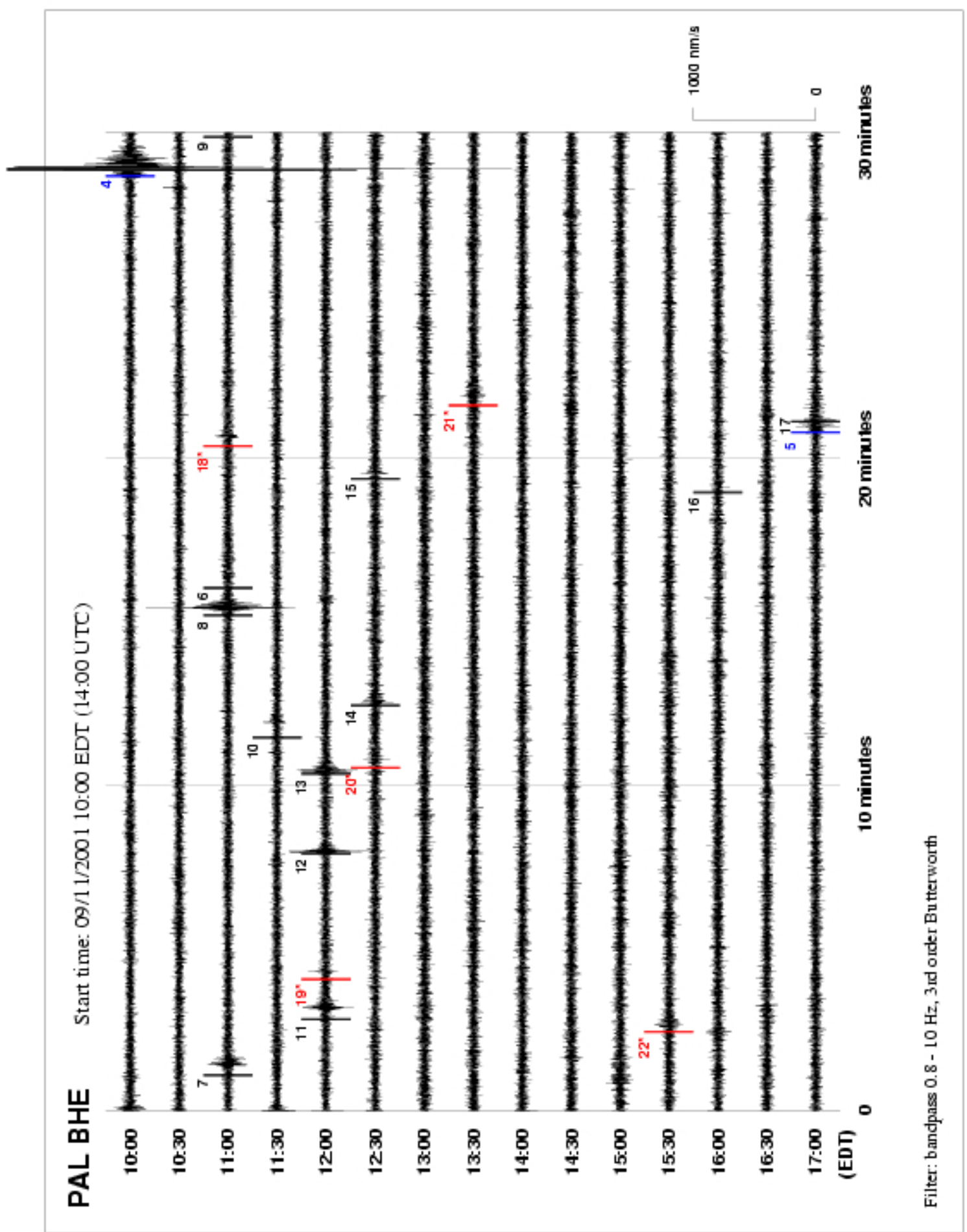

Figure B-9. Events identified on PAL seismogram.

Refer to Table B-4 for location, strength and description of event type. 


\section{B.8 REFERENCES}

Anderson, J. and J. Dorman, 1973. Local geological effects on short-period Rayleigh waves around New York City, Bull. Seism. Soc. Am., 63, 1487-1497.

Kim, W. Y., D. W. Simpson and P. G. Richards, 1994. Characteristics of high-frequency spectra of regional phases from earthquakes and chemical explosions, Bulletin of the Seismological Society of America, 84, 1365-1386.

Kim, Won-Young, L.R. Sykes, J.H. Armitage, J.K. Xie, K.H. Jacob, P.G. Richards, M. West, F. Waldhauser, J. Armbruster, L. Seeber, W.X. Du and A. Lerner-Lam, 2001. Seismic waves generated by aircraft impacts and building collapses at World Trade Center, New York City, EOS, Transactions of the American Geophysical Union, 82, 565-571, Nov. 20.

McAllister, T., ed. 2002. World Trade Center Building Performance Study: Data Collection, Preliminary Observations, and Recommendations. FEMA 403, Federal Emergency Management Agency. Washington, DC, May. 


\section{Appendix C \\ Video ANALYsis of WTC 7 BUILDING VibRations Before \\ COLLAPSE}

\section{C.1 DETERMINATION OF BUILDING VIBRATION DATA}

\section{C.1.1 Introduction}

A tripod-mounted news camera positioned on the west side of West Street near Harrison Street captured the entire collapse sequence of WTC 7, starting seven minutes before the east penthouse began to fall into the building. The result was the Camera 3 video clip discussed in Chapter 5 (see Figure 5-186 which has been reproduced as Figure C-1). This fixed view from northwest of WTC 7 provided an extended record as events leading to the collapse caused the building to shake. Image analysis of this video clip revealed that WTC 7 started to move prior to its collapse.

Analysis of the vibration pattern of WTC 2 from a video clip in the database of photographs and videos collected by the Investigation Team provided valuable information regarding damage to WTC 2 upon aircraft impact (NIST NCSTAR 1-5A, Appendix K). The Investigation Team felt that a similar analysis of the Camera 3 video clip could reveal the presence of structural disturbances contributing to the collapse sequence of WTC 7, adding information to the visual evidence of the disappearance of the east penthouse and the vertical "kink" or fault line during collapse.

\section{C.1.2 Video Used in Analysis}

Figure C-1 shows a single frame taken from the Camera 3 video. The north face of WTC 7 is centered within the frame, with portions concealed by buildings located between WTC 7 and the camera. The top 10 floors of the 47 story building are fully visible, with the top 14 floors visible along the right-hand (northwest) edge.

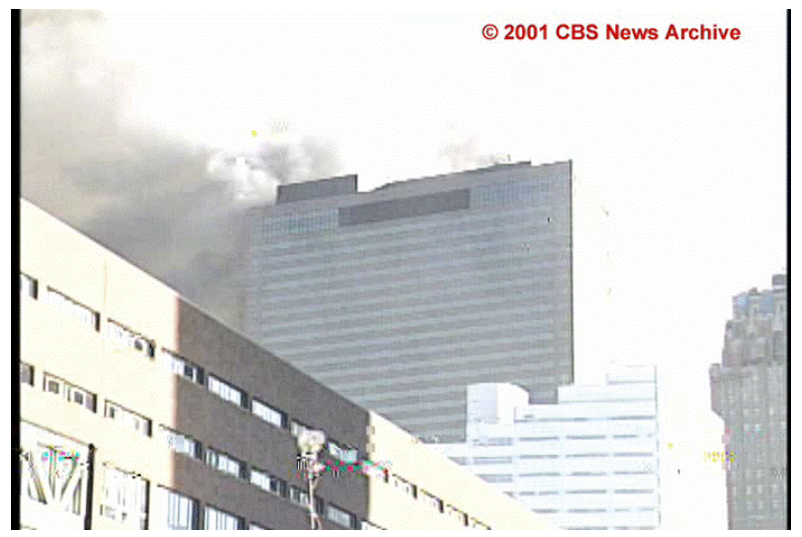

Figure C-1. A single frame from the Camera 3 news video shot on September 11.

The west edge of WTC 7 (to the right in the frame) was of the most interest in this analysis. This was the northwest corner of the building, which was clear of smoke throughout the recorded period. From the 
camera's perspective, the angle of this edge appears close to vertical. This provided excellent amplification of the building motion. The tripod mount kept fluctuations in viewpoint to a minimum, although they were not be negligible. In the previous WTC 2 moiré analysis, frame-to-frame and slow motions of a tripod-mounted camera were found to be a source of error.

The news video was imported into the visual database from a VHS cassette recording of the original broadcast. The importation process saved all video clips in the standard digital video format of DV NTSC. In this process, each analog image from the videotape was converted into a digital image with the standard frame size of 720 pixels wide by 480 pixels high. The pixel width was 0.9 times pixel height, generating the standard video width-to-height ratio of 4:3. The frame rate was 29.97 frames per second.

\section{C.1.3 Moiré Technique for a Single Marker Point}

The moiré effect occurs when two closely spaced gratings with a small angle between them are superimposed, generating fringe patterns that attract the eye. An example is shown in Figure C-2. A close look at the moiré pattern in frame (c) shows that the fringes consist of light areas that the human eye links together. These light areas are the points where lines from the two gratings intersect. The smaller the angle between the gratings, the larger will be the distance between the fringes, which is the wavelength of the moiré pattern. Figure $\mathrm{C}-3$ shows the effect of moving one grating sideways relative to the other. If grating \#1 were shifted to the right by one-half of the spacing between lines, the intersection points, and thus the moiré fringes, move vertically by half the distance between fringes. The moiré pattern is highly sensitive to the positions and angles of the gratings relative to each other and strongly

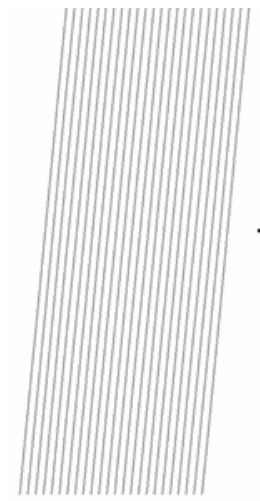

a) Grating \#1

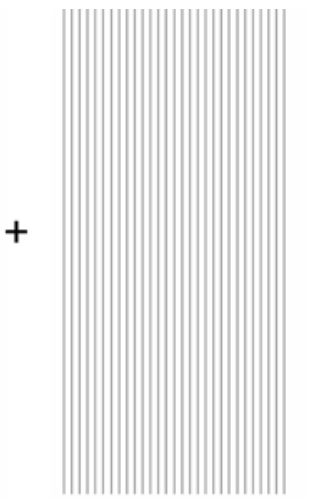

b) Grating \#2

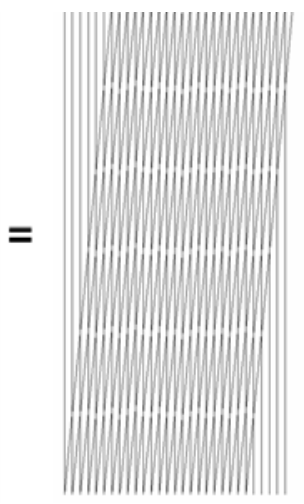

c) Moiré Pattern amplifies any sideways motion of the lines.

\author{
Figure C-2. Demonstration of moiré \\ fringe pattern resulting from two \\ gratings superimposed at a slight angle.
}

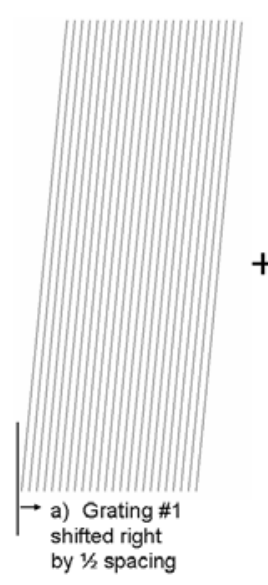

680

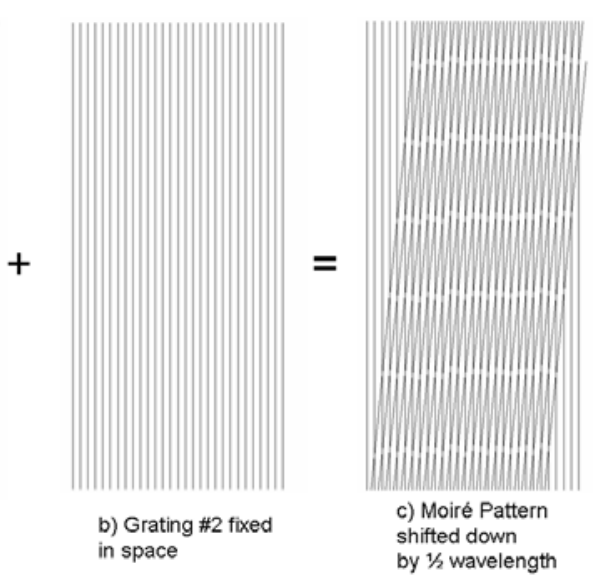

Figure C-3. Effect of a small shift of one grating on the location of the moiré fringe pattern. 
A true moiré pattern requires two sets of multiple lines. However, the principle of high sensitivity to motion of the points of intersection works for any lines at small angles to each other, even two single lines. In the video frame shown in Figure $\mathrm{C}$-1, there was a strong, nearly vertical line along the right edge of WTC 7 that defined the northwest corner. The natural set of vertical lines that provided a fixed reference in any digital video was the set of pixel columns. (For a nearly horizontal line, the natural fixed reference would be the pixel rows.)

A close look at the news video was needed to determine how best to use this approach to study the vibrations of WTC 7. Figure C-4 zooms in on the northwest edge of the building in one of the frames. The overlaid grid, marking every tenth pixel, demonstrated that this edge was very close to vertical. In this figure, the pixel rows were numbered from 140 at the top to 380 at the bottom, and the columns were numbered from 300 at the left to 660 at the right. Figure C-5 further enlarges the northwest edge, which was defined by a dark column of pixels (pixel column 518 in this region), surrounded on each side by a lighter column of pixels. However, the location of the darkest pixel shifted with vertical position along the northwest edge. Looking toward the bottom of Figure C-5, pixel column 517 to the left became lighter and pixel column 519 to the right became darker, while looking toward the top, pixel column 517 became darker and pixel column 519 became lighter. As was shown in Figure C-4, this was a result of the slight angle that the northwest edge makes with the vertical in the camera frame.

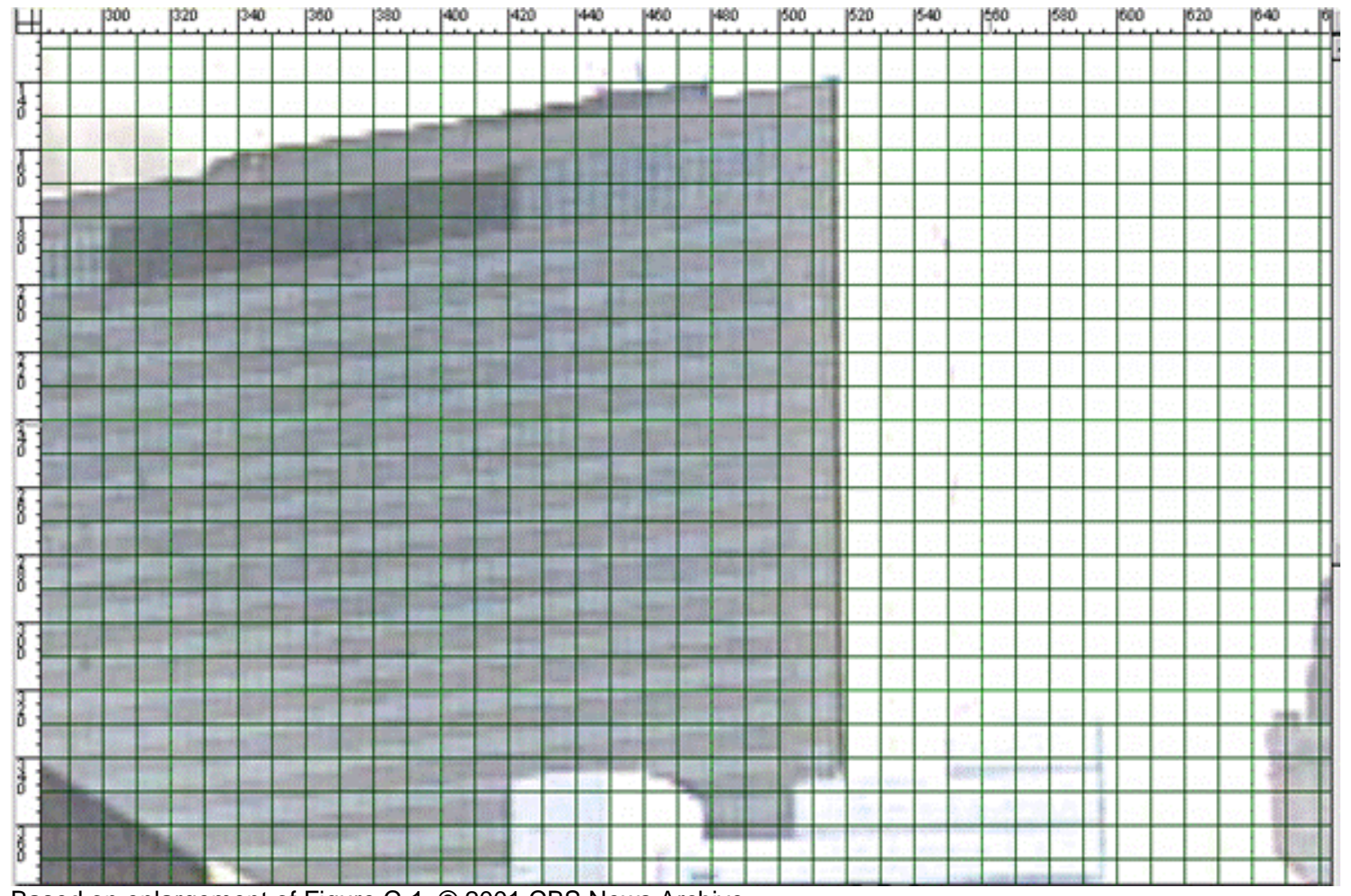

Based on enlargement of Figure C-1. (C) 2001 CBS News Archive

Figure C-4. Pixel grid of the north face of WTC 7, showing that the northwest edge was nearly vertical. 


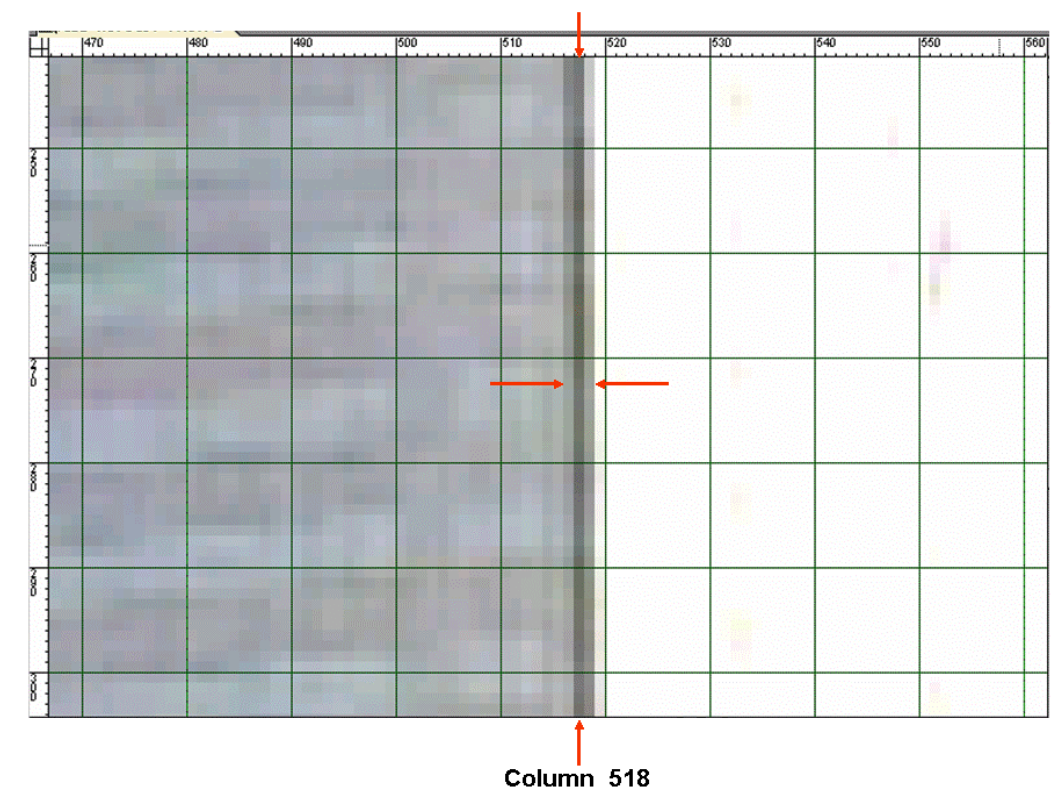

Figure C-5. Enlargement of northwest edge of WTC 7 from Figure C-4. Center arrows indicate the row at which pixel intensities were judged to be equal to left and right of column 518 .

Based on enlargement of Figure C-1. (c) 2001 CBS News Archive

Consider the pixels in the center of Figure C-5 between the two horizontal arrows. At this height, the pixels to either side of the dark pixel in pixel column 518 were of roughly equal intensities. If WTC 7 were to move slightly to the right (westward), pixel column 519 would get darker at this location, and the point at which pixel columns 517 and 519 were of equal intensity would move to a higher location along the northwest edge. For building movement to the left (eastward), the reverse is true, and the marker point of equal intensity would move downward. If the vertical location of the marker point of equal intensity were tracked in time, it should provide information about the motion of WTC 7.

The first estimation of the vertical location of the point at which pixel columns 517 and 519 were of equal intensity as a function of time was completed by eye. The results are shown in Figure C-6 for the final $18 \mathrm{~s}$ before initiation of the WTC 7 collapse and the final minute before the collapse initiation.
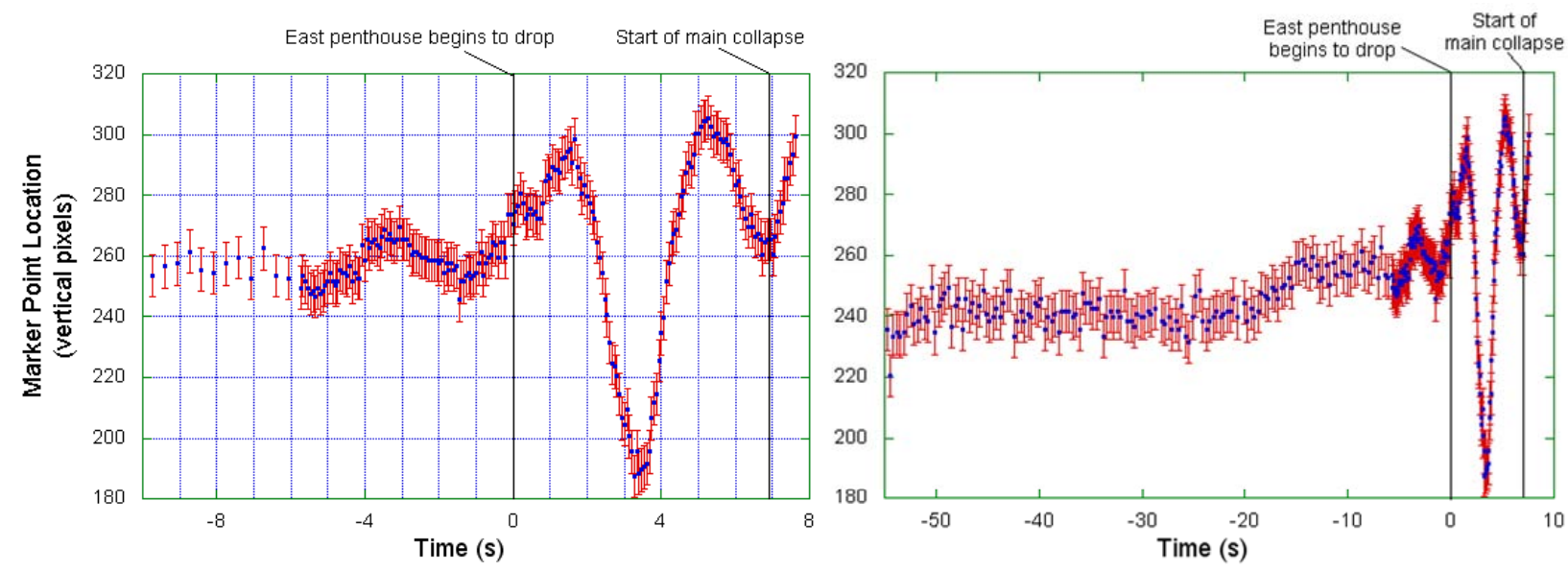

Figure C-6. Marker point data for final $18 \mathrm{~s}$ (left) and the final minute (right) prior to the collapse of WTC 7. 
Data were collected for every other frame for approximately the final $13.5 \mathrm{~s}$, and for every tenth frame preceding that point. The vertical pixel position of the marker point on the vertical axis was higher for movement downward (indicating northwest corner motion toward the east). The red lines at each data point showed estimated uncertainties of \pm 7 pixels. This was a rough estimation, reflecting an inherent risk of error due to the brighter pixels to the right of pixel column 519 and darker pixels to the left of pixel column 517, as well as to the fluctuation of intensity levels along pixel columns 517 and 519 . Despite this, the capability of this method to amplify sideways building vibrations was clear. With this near vertical orientation of the northwest edge of WTC 7 relative to the pixel columns, the marker point of equal intensity moved up and down by a total of more than a hundred pixels.

The point at which pixels to either side of the central dark pixel were equal in intensity was not the only point that could have been selected for tracking. A second, easily identifiable marker point was one at which two adjacent pixels had the same intensity, e.g., for pixel columns 518 and 519. However, in order for the selected marker point to be tracked over the course of the video, it had to remain along the northwest edge of WTC 7. Because of the large extent of building motion, the marker point that was chosen was the only one that did not fall off either the top or bottom of the northwest edge during the duration of the video.

As presented in the timeline in Table 5-3 of Chapter 5, the video frame in which the east edge of the east penthouse started to move downward was assigned time $t=0 \mathrm{~s}$. The time at which the initial motion of the main collapse of WTC 7 was detected was found to be $t=6.9 \mathrm{~s}$.

Of particular interest in the initial results from this analysis was the observation that the onset of vibrations preceding the final collapse of WTC 7 occurred several seconds before the east penthouse began to fall, as shown in Figure C-6.

\section{C.1.4 Conversion of Magnitude from Vertical Pixels to Distance}

The magnitude of the motion was estimated using the number of vertical pixels that equated to a single horizontal pixel and a conversion factor between horizontal pixels and actual distance.

The vertical motion of the marker point that equated to a single horizontal pixel width was determined by counting the number of vertical pixels between the studied marker point and the next point along the northeast edge of WTC 7 at which pixel values were equal on each side of the central dark column. The marker point used in the analysis was the intersection of intensities along pixel columns 517 and 519; the marker point one horizontal pixel to the left was the intersection of intensities along pixel columns 516 and 518. Where this marker was available and had not dropped off the top of the northeast edge, the difference between these two points one horizontal pixel apart was found to be $100 \pm 10$ vertical pixels.

The conversion factor between horizontal pixels and distance along the north face of WTC 7 was obtained by determining the width of this face in both horizontal pixels and in feet. Due to the camera location, points on the north face near the northwest edge were closer to the camera than points near the northeast edge. However, this distortion was small, since the width of the north face was much smaller than the distance of WTC 7 from the camera. The perspective view of the camera looking up at WTC 7 also introduced some error into the measurement of the number of pixels for the width, as did the uncertainty of a couple of pixels in the exact location of the edges defining the north face. Given these sources of error, an estimate for this video of the width of the north face of WTC was $301 \pm 4$ horizontal pixels. 
Since the true dimension of the north face was $329 \mathrm{ft}$, the conversion factor was $1.09 \mathrm{ft} \pm 0.02 \mathrm{ft}$ per horizontal pixel. Combining this with the equivalence of $100 \pm 10$ vertical pixels for each horizontal pixel gave the final conversion factor of $1.1 \mathrm{ft} \pm 0.1 \mathrm{ft}$ (13 in. $\pm 1 \mathrm{in}$.) for each 100 pixels of vertical marker motion.

\section{C.1.5 Automation of Moiré Analysis}

Because of the inherent risks of error in collecting data from this video by eye, as mentioned in Section C.1.2, an objective determination of the intersection point using the actual intensity values was needed. An automated determination of this point enabled data to be collected over the entire 7.5 min duration of this video from start to WTC 7 collapse, a total of 13,558 frames.

To prepare for analysis, the video clip was exported into a sequence of images, with each image carrying the data for a single frame of the video. Each frame was then converted from the original RGB color into grayscale values. This combined the values from the red, green, and blue channels and simplified the analysis. Possible intensity values for each pixel ranged from 0 for black to 255 for white. This image manipulation was accomplished using Adobe Photoshop software.

Figure C-7 demonstrates the automation procedure for the analysis. The close-up of the northwest edge of WTC 7 in (a) shows the area around the point at which pixel columns 517 and 519 had the same intensity value in this frame of the video. The intensity values for these two columns along the length of the northwest edge, from pixel row 340 near the bottom to 140 at the top, were extracted and plotted in Figure C-7(b). Fluctuations in the values are apparent in this plot. To find the intersection point of the pixel intensity plots for these two pixel columns, the data for each column were first fitted to a smooth curve. A third-order polynomial least-squares fit gave a good compromise between the variance (a measure of the distance of each data point from the curve) and an estimate of the error in determining the intersection point. Figure C-7(c) shows the two curves resulting from this fit and the intersection point for this particular video frame. The analysis procedure was implemented using Mathematica software.

One source of uncertainty in this analysis was the curve-fitting process; another arose from defects in the video images. Many of the frames from this video contained defects, such as the color and black-andwhite patterns in the lower center and lower left of Figure C-1. Similar defects occurring along the northwest edge being used for the analysis were responsible for some outlier points in the results.

Figures C-8 and C-9 show the results of performing this analysis on each video frame, over the final $22 \mathrm{~s}$ before collapse and over the entire duration of the video, respectively. 

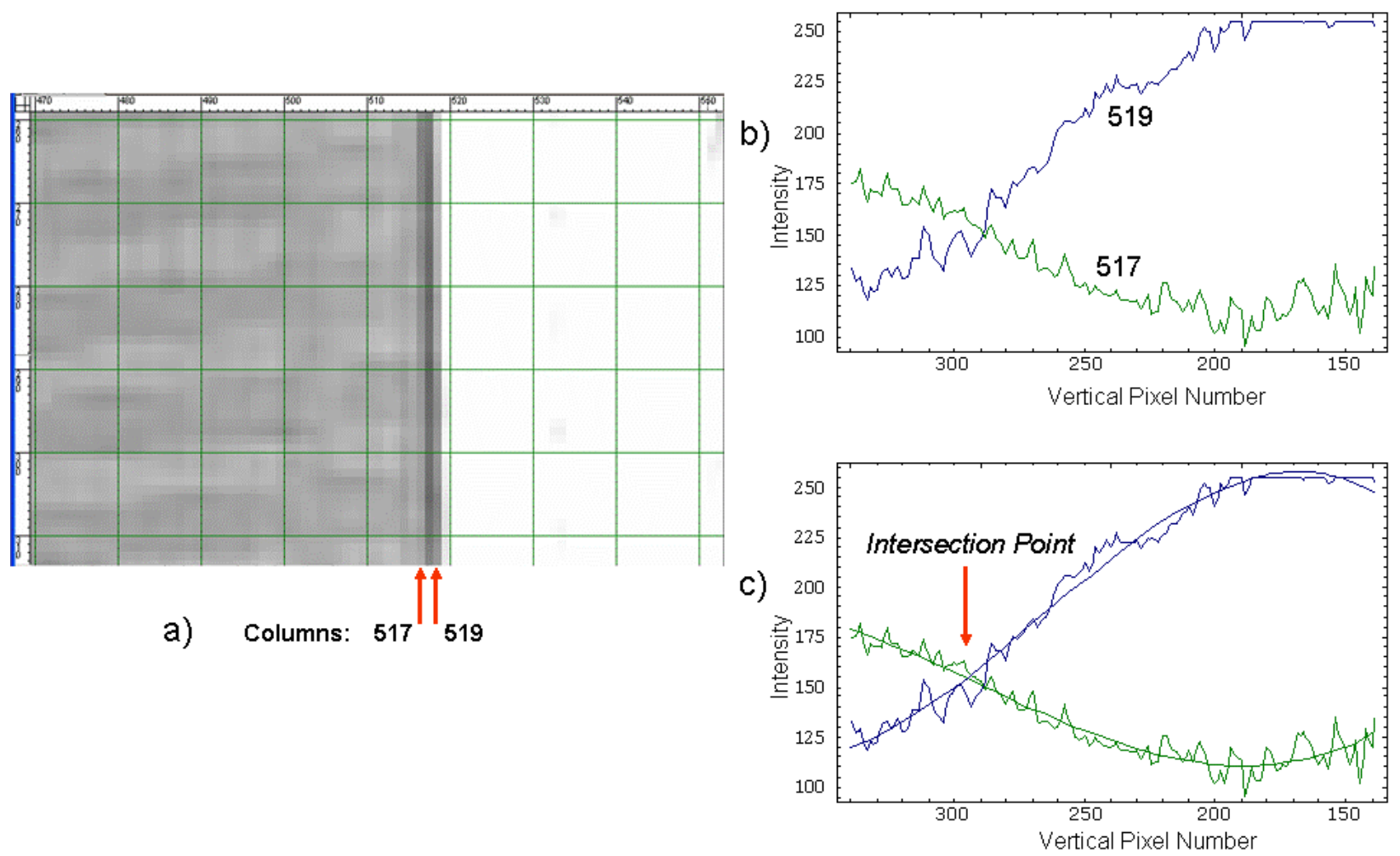

Figure C-7. Automated determination of intersection point. a) close-up of northeast edge of WTC 7 in grayscale, b) plot of pixel intensity vs. vertical pixel number for pixel columns 517 and 519, and c) polynomial fit showing the intersection point.

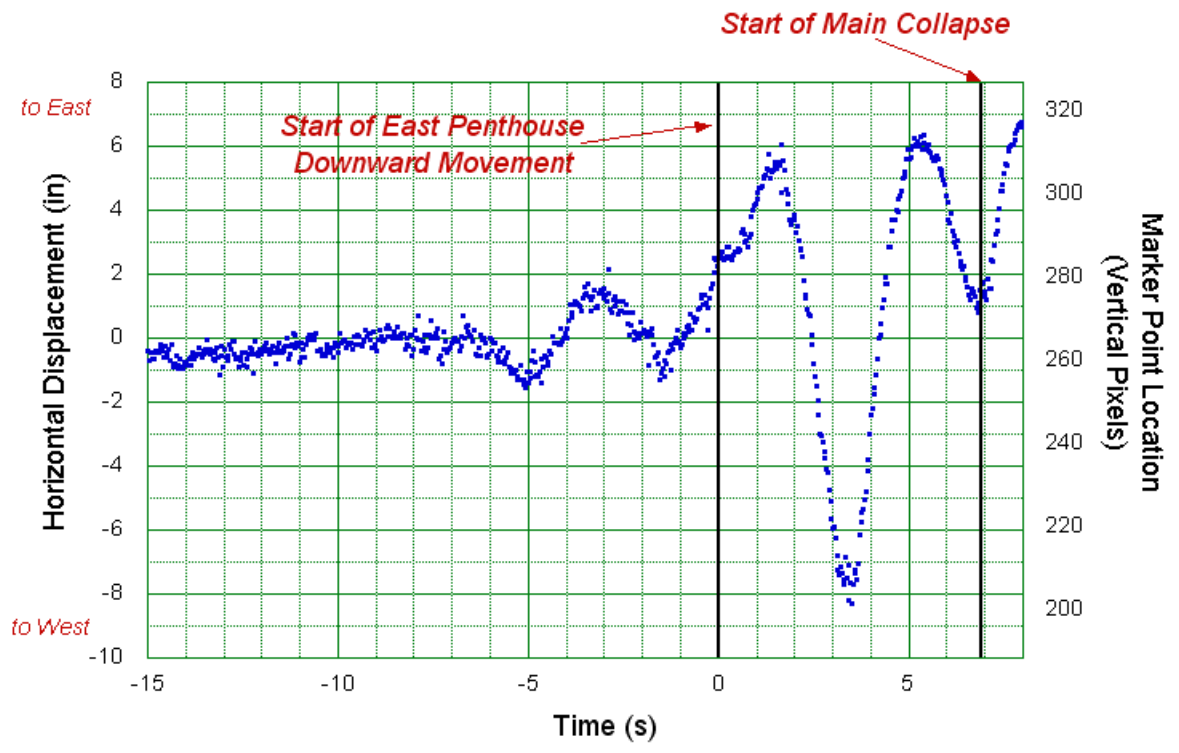

Figure C-8. Horizontal displacement of northwest corner of WTC 7 and marker point location for final $22 \mathrm{~s}$ before the start of penthouse downward movement. 


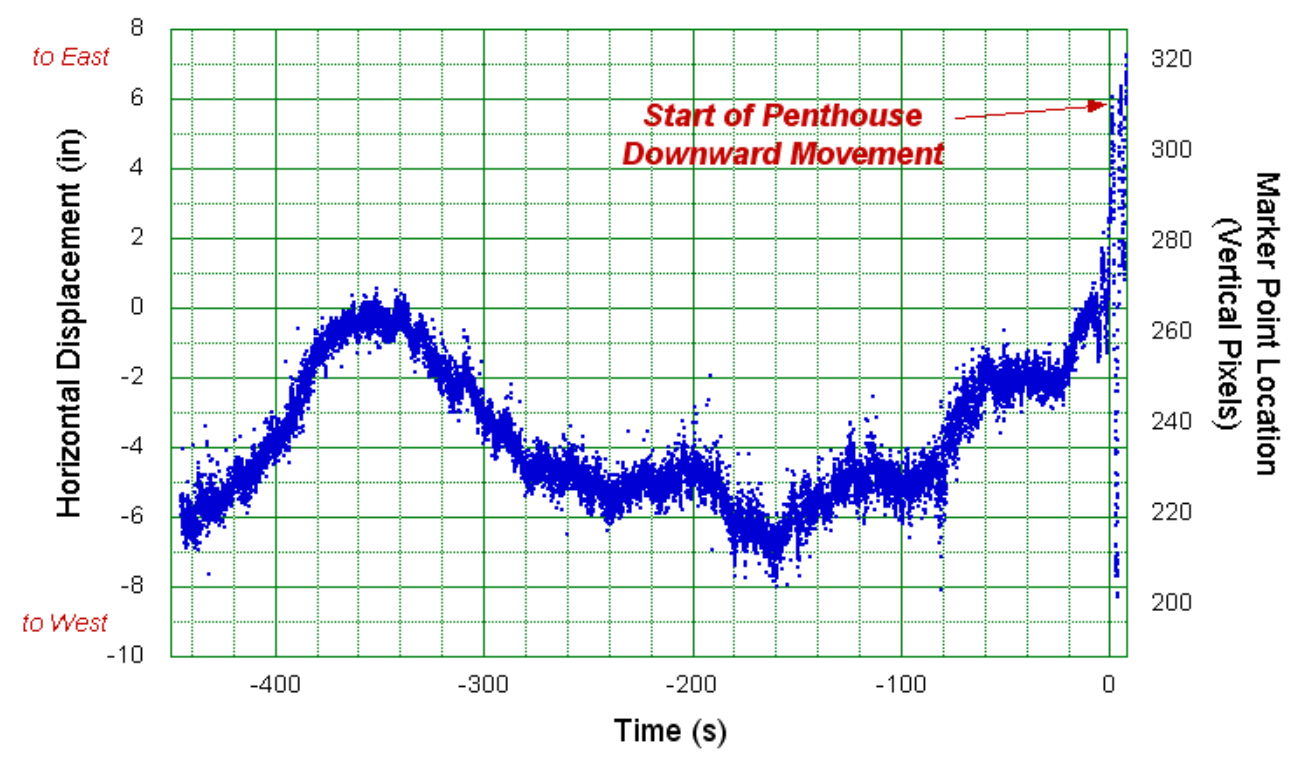

\section{Figure C-9. Horizontal displacement of northwest corner of WTC 7 and marker point location for full $7 \frac{1}{2} \mathrm{~m}$ min duration of video before collapse initiation.}

Using the conversion factor determined in section C.1.3 allowed labeling of the vertical axis in both marker locations by vertical pixel number and in inches of horizontal displacement. The zero point for displacement was chosen to be vertical pixel number 265, the location of the marker point at the time when final oscillations began. In Figure C-8, some important behavior is apparent. Starting at about $6 \mathrm{~s}$ before the penthouse began its downward movement into the building, there was an abrupt change in the slope of the data that marked the beginning of oscillations that continue until collapse. There was also a second abrupt change in the data at about $1.5 \mathrm{~s}$ before the penthouse started moving downward.

In Figure C-9, there are major changes in the location of the marker point that occurred over long time intervals of $20 \mathrm{~s}$ or greater. These changes were likely due to movement of the camera.

The harmonic motion that began $6 \mathrm{~s}$ before the penthouse began to fall had an amplitude of nine vertical pixels, equivalent to sideways motion of $0.1 \mathrm{ft}$, or slightly over one inch in each direction. The maximum range of motion, which occurred after the penthouse had disappeared, totaled about 107 vertical pixels, or about 14 in. \pm 1 in. Section C. 2 takes a closer look at these vibrations.

\section{C.2 VIBRATION RESULTS}

Of primary interest in this analysis was any information that could shed light on the collapse sequence of WTC 7. The starting point of the final set of building vibrations at $6 \mathrm{~s}$ before the east penthouse began to fall indicated that an event had occurred within the building at that time. In addition, a comparison of the oscillatory period with a model of the building's motion indicated the mode that had been excited by the event. Whether the building swayed in a single plane with a translational mode or twisted with a torsional mode, this information provided more insight for the structural engineer trying to piece together the sequence of events. 
The frequency content of the data in Figure C-8 was determined using the same method described in NIST NCSTAR 1-5A, Appendix K. The time-dependent displacement of the marker point was assumed to take the form of a damped harmonic oscillator, which is described by the following equation:

$$
d=\left[A+B\left(t-t_{0}\right)\right]+C e^{-D\left(t-t_{0}\right)} \sin \left[2 \pi\left(t-t_{0}\right) / E+F\right]
$$

where

$$
\begin{aligned}
& d=\text { displacement, in. } \\
& t=\text { time, } \mathrm{s} \\
& t_{0}=\text { time at which the penthouse begins to move downward, } \mathrm{s} \\
& A=\text { baseline offset, in. } \\
& B=\text { linear slope of the baseline, in./s } \\
& C=\text { initial amplitude at time } t_{0}, \text { in. } \\
& D=\text { decay rate, }(\mathrm{s})^{-1} \\
& E=\text { oscillatory period, } \mathrm{s} \\
& F=\text { phase angle, radian }
\end{aligned}
$$

The values to be determined were A, B, C, D, E, and F. The frequency was equal to the reciprocal of the period, $E^{-1}$. This mathematical model included the period, amplitude, and decay rate of the oscillations, and also included the possibility of a linear change in the zero point of the displacement with time. To accurately fit this model to the data, a good approximation was needed for each of the six variables to be determined. These approximations were then used as starting points for a nonlinear least squares fit of Eq. (1). The calculations were carried out in vertical pixel units and converted to inches. The uncertainty values given in this section do not include the conversion uncertainty.

The video showed that the east penthouse was descending between time $\mathrm{t}=0 \mathrm{~s}$ and $\mathrm{t}=2.0 \mathrm{~s}$. During the time that the east penthouse was falling, the harmonic motion of the building was clearly disturbed, as can be seen in Figure C-8. The displacement of the marker point was on a plateau for the first half second after the penthouse began to fall, and the time from the minimum in the data at about $-1.5 \mathrm{~s}$ to the maximum at about $1.7 \mathrm{~s}$ was about double that for oscillations before $\mathrm{t}=0 \mathrm{~s}$ or after $\mathrm{t}=2.0 \mathrm{~s}$. The mathematical model assumed free harmonic motion and was not appropriate for looking at building motion when a forcing function was being applied. The time periods studied using this model were therefore from $t=-6.0 \mathrm{~s}$ to $\mathrm{t}=0 \mathrm{~s}$ and from $\mathrm{t}=2.0 \mathrm{~s}$ to the start of collapse at $\mathrm{t}=6.9 \mathrm{~s}$. The motion from just after the plateau in the data at $\mathrm{t}=1.0 \mathrm{~s}$ to collapse was also analyzed. All the results are shown in Table C-1. 
Table C-1. Modes from nonlinear least squares analysis for WTC 7 data.

Total uncertainties are twice the standard deviation, $\sigma$.

\begin{tabular}{|c|c|c|c|c|c|c|c|}
\hline $\begin{array}{l}\text { Time Range } \\
\text { (s) }\end{array}$ & Period (s) & $\begin{array}{l}\text { Amplitude } \\
\text { (in.) }\end{array}$ & $\begin{array}{c}\text { Decay Rate } \\
\left(\mathrm{s}^{-1}\right)\end{array}$ & $\begin{array}{c}\text { Phase } \\
\text { (radian) }\end{array}$ & $\begin{array}{c}\text { Offset } \\
\text { (in.) }\end{array}$ & Slope (in./s) & $2 \sigma$ (in.) \\
\hline$-6.0-0$ & $3.61 \pm 0.06$ & $1.3 \pm 0.1$ & $-0.05 \pm 0.04$ & $0.9 \pm 0.1$ & $1.0 \pm 0.1$ & $0.22 \pm 0.04$ & 0.6 \\
\hline $2.0-6.9$ & $3.46 \pm 0.06$ & $12.0 \pm 1.0$ & $0.19 \pm 0.02$ & $4.7 \pm 0.1$ & $-6.6 \pm 0.5$ & $1.70 \pm 0.10$ & 0.9 \\
\hline $\begin{array}{c}2.0-6.9 \\
\left(2^{\text {nd }} \text { mode }\right)\end{array}$ & $1.65 \pm 0.02$ & $0.7 \pm 0.3$ & $0.10 \pm 0.10$ & $3.9 \pm 0.4$ & $-0.1 \pm 0.1$ & $0.03 \pm 0.03$ & 0.5 \\
\hline $1.0-6.9$ & $3.75 \pm 0.04$ & $11.0 \pm 1.0$ & $0.17 \pm 0.02$ & $5.3 \pm 0.1$ & $-4.4 \pm 0.4$ & $1.20 \pm 0.10$ & 1.3 \\
\hline $\begin{array}{c}1.0-6.9 \\
\left(2^{\text {nd }} \text { mode }\right)\end{array}$ & $1.85 \pm 0.04$ & $2.0 \pm 0.4$ & $0.30 \pm 0.10$ & $5.3 \pm 0.2$ & $0.3 \pm 0.1$ & $-0.05 \pm 0.04$ & 0.7 \\
\hline $0.5-6.9$ & $4.04 \pm 0.05$ & $9.0 \pm 1.0$ & $0.10 \pm 0.03$ & $5.7 \pm 0.1$ & $-2.3 \pm 0.4$ & $0.70 \pm 0.10$ & 1.8 \\
\hline
\end{tabular}

For the $6 \mathrm{~s}$ period from the beginning of oscillatory motion in the data to when the penthouse began to fall, the harmonic motion was found to have a period of $3.61 \mathrm{~s}$, an amplitude of $1.3 \mathrm{in}$., and an approximately zero decay rate. The total standard deviation from the nonlinear fit to this data (the square root of the estimated variance) was $\sigma=0.3 \mathrm{in}$. The total uncertainty, with a confidence level of 95 percent, equaled twice the standard deviation in both positive and negative directions, or \pm 0.6 in. Figure C-10(a) shows this mode superimposed on the original data. Subtracting the mode from the data resulted in the residual data shown in Figure C-10(b). The residual appeared random. If an oscillatory pattern had appeared in the residual, it would have suggested that a secondary vibration mode is present. In this case, the first mode found did a good job of matching the data.

The next modal analysis was performed for the time period from $t=2.0 \mathrm{~s}$, at the time when the penthouse was observed to completely disappear from the roof WTC 7, to $t=6.9 \mathrm{~s}$, when the main collapse began. The primary mode has a period of $3.46 \mathrm{~s}$, an amplitude of 12 in., and a decay rate of $0.19 \mathrm{~s}-1$. The total uncertainty was \pm 0.9 in. Figure C-11(a) shows a good comparison between the mode and the data. The residual, Figure C-11(b), indicates a secondary mode with a period of 1.65 s, amplitude of 0.7 in., and zero decay rate. This is plotted in Figure C-12(a). The residual, after the combination of these two modes had been subtracted from the original data, is shown in Figure C-12(b). By adding these two modes together, the total uncertainty was reduced to \pm 0.5 in., slightly better than the results for the time period before the fall of the penthouse.

To test how long the internal events within WTC 7 during the downward motion of the east penthouse drove the visible motion of the building, modal analyses were performed on wider time ranges of data, from $\mathrm{t}=1.0 \mathrm{~s}$ to the main collapse at $\mathrm{t}=6.9 \mathrm{~s}$ and from $\mathrm{t}=0.5 \mathrm{~s}$ to $\mathrm{t}=6.9 \mathrm{~s}$. The total uncertainty for these analyses increased significantly with time range, to $\pm 1.3 \mathrm{in}$. for the time range of $t=1.0 \mathrm{~s}$ to $\mathrm{t}=6.9 \mathrm{~s}$ and $\pm 1.8 \mathrm{in}$. for the time range of $\mathrm{t}=0.5 \mathrm{~s}$ to $\mathrm{t}=6.9 \mathrm{~s}$. Figure $\mathrm{C}-13$ gives visual evidence of the poorer fit for the former analysis. The discrepancies between the mode and the data were larger than in Figure C-11, and a strongly damped secondary mode was needed to fit the residual in Figure C-13(b). The modal analysis from $\mathrm{t}=2.0 \mathrm{~s}$ to $6.9 \mathrm{~s}$ gave the best quantitative representation of the oscillatory motion of WTC 7 immediately before the final building collapse. 
a)

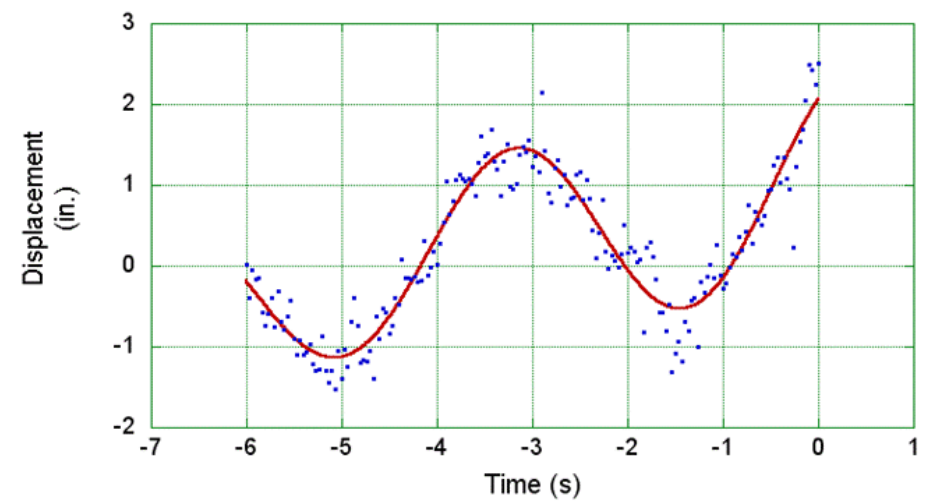

b)

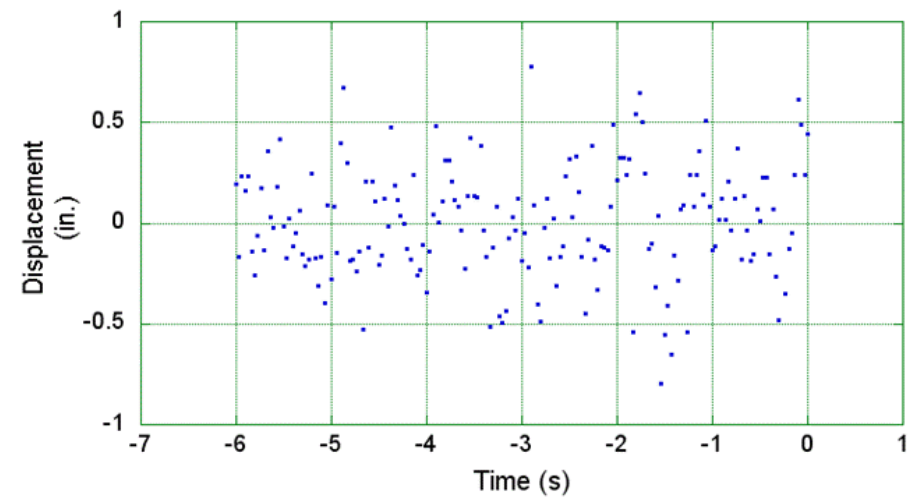

a)

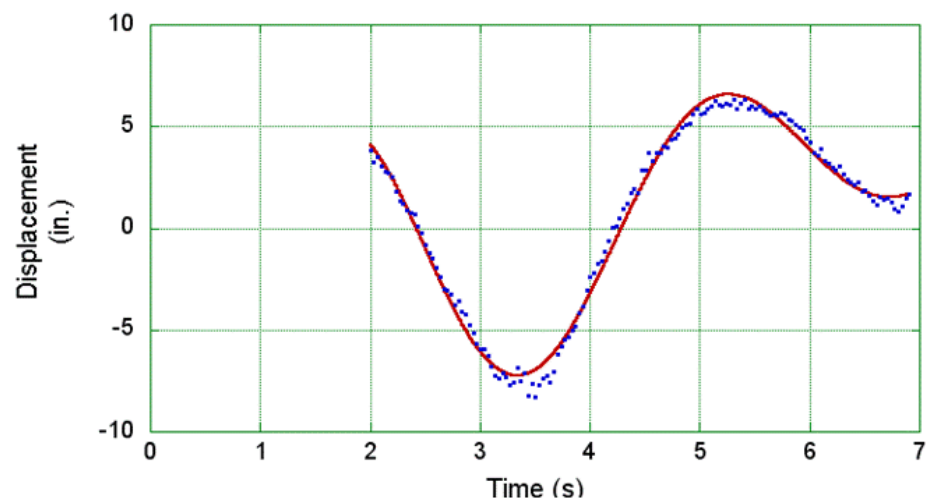

b)

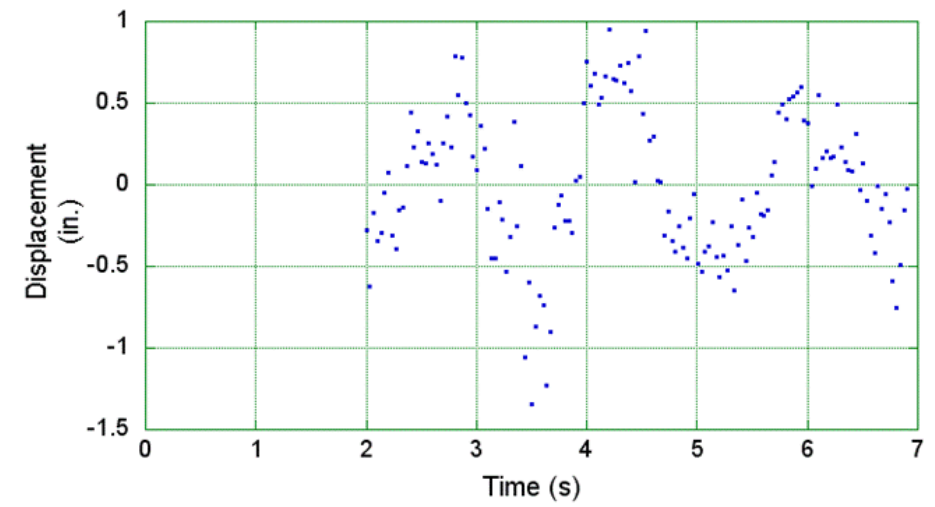

Figure C-10. a) Comparison of oscillation mode with data for $6 \mathrm{~s}$ period before the east penthouse began to move downward, b) residual after mode was subtracted from data.
Figure C-11. a) Comparison of mode with data for period from $t=2.0 \mathrm{~s}$ to $\mathrm{t}=6.9 \mathrm{~s}$, and $\mathrm{b}$ ) residual. 
a)

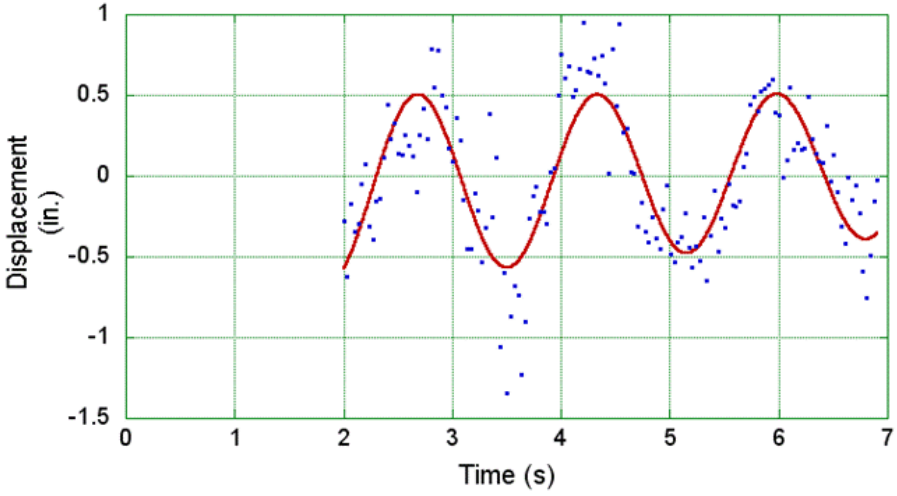

b)

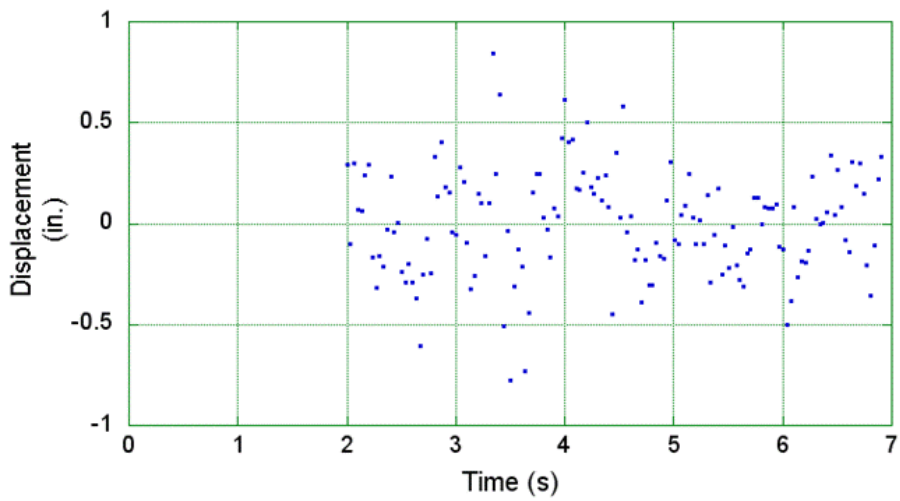

a)

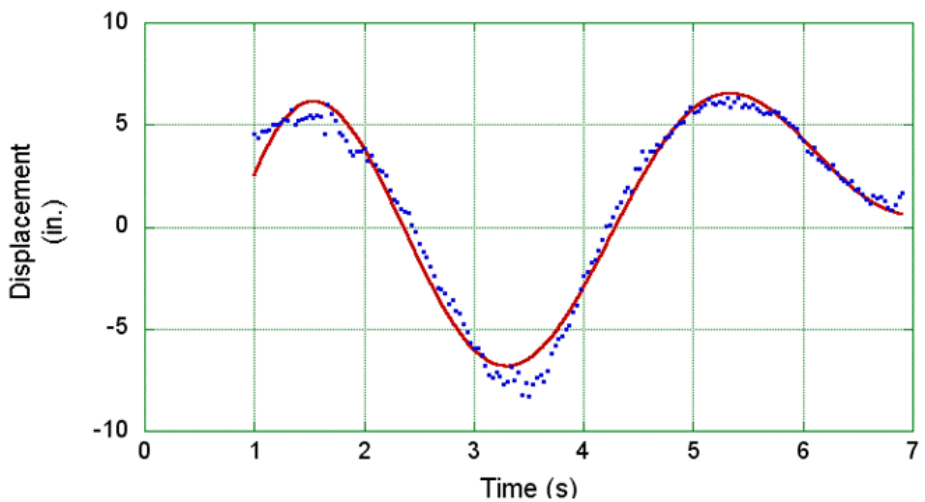

b)

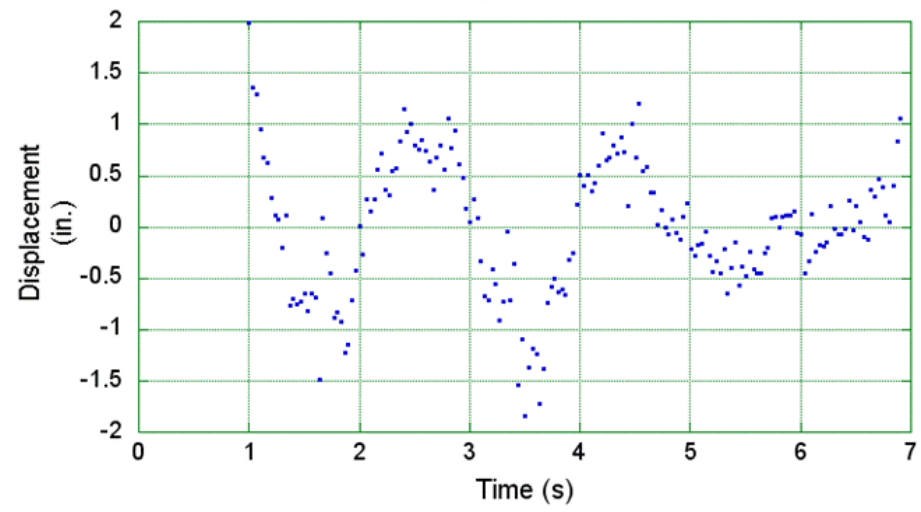

Figure C-12. a) Comparison of secondary mode with residual for period from $t=2.0 \mathrm{~s}$ to $t=6.9 \mathrm{~s}$, and $\mathrm{b}$ ) residual after both modes were subtracted from original data.
Figure C-13. a) Comparison of mode with data for period from $\mathrm{t}=1.0 \mathrm{~s}$ to $\mathrm{t}=6.9 \mathrm{~s}$, and b) residual. 
A final comparison of oscillation modes to data is shown in Figure C-14. Before the penthouse began to descend, an undamped mode of period $3.61 \mathrm{~s}$ described the building vibrations well. Between the time that the penthouse disappeared and the time that WTC 7 collapsed, a combination of a damped mode of period $3.46 \mathrm{~s}$ and an undamped mode of $1.65 \mathrm{~s}$ provided a good fit to the data.

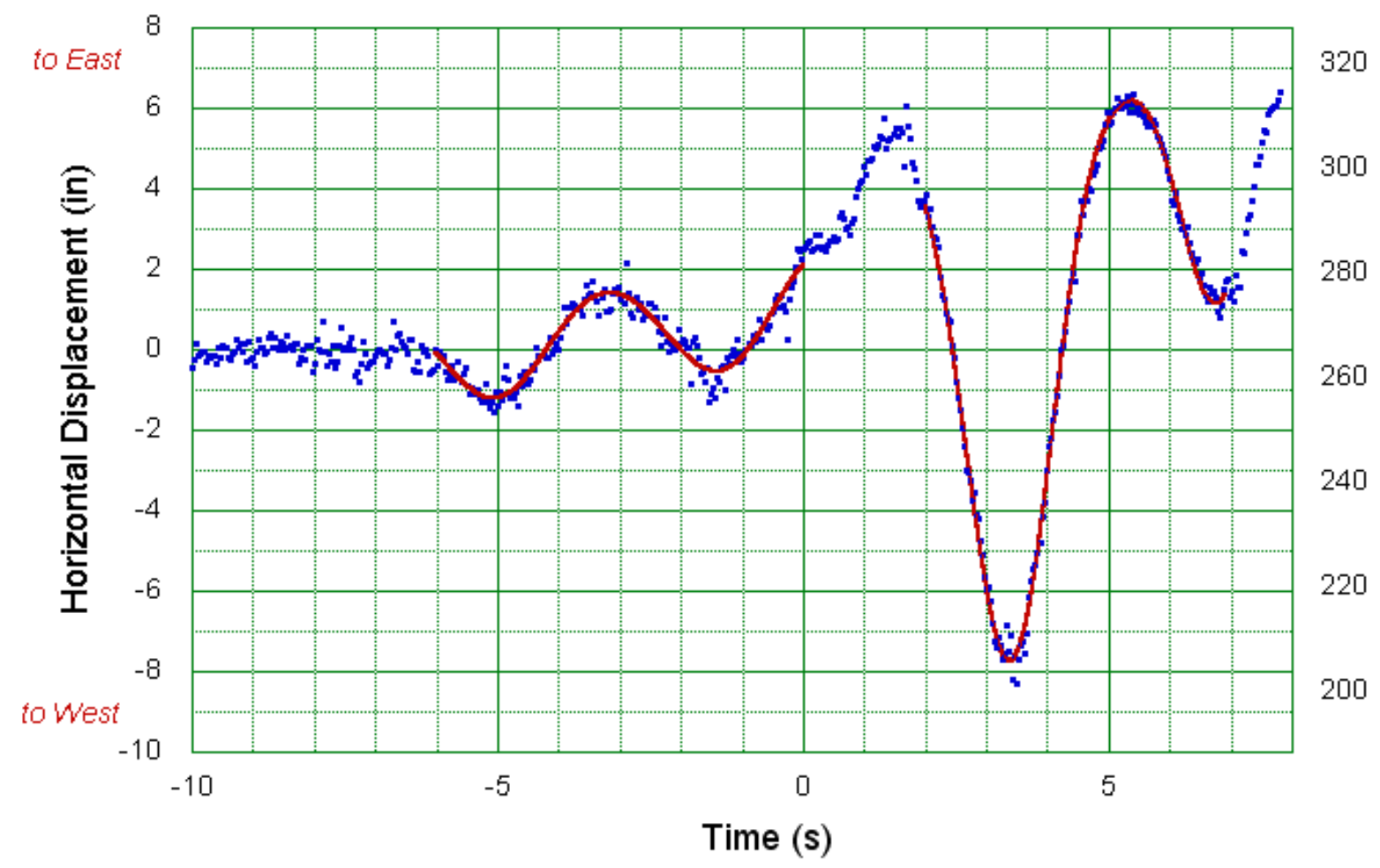

Figure C-14. Comparison of data with modes before and after penthouse fall.

\section{C.3 SUMMARY}

The tracking of a point marking the intersection between a near vertical building edge and the pixel columns of a digital video image provided details about the vibrations of WTC 7 just prior to collapse. An undamped vibration mode of period $3.61 \mathrm{~s}$ and amplitude slightly over $1 \mathrm{in}$. was observed during the $6 \mathrm{~s}$ before the east penthouse started to fall. A combination of a damped mode of period $3.46 \mathrm{~s}$ and an undamped mode of $1.65 \mathrm{~s}$, with a total range of motion of about 14 in., was observed from the time the penthouse had submerged below the roofline to the time of collapse initiation. 
This page intentionally left blank. 


\section{Appendix D \\ HYPOTHETICAL BLAST SCENARIOS}

\section{D.1 BACKGROUND}

As part of assessing alternative hypotheses for initiation of the collapse of WTC 7, a hypothetical blast event was considered. Scenarios of a hypothetical blast event that could have occurred in WTC 7 on September 11, 2001, were assessed, including blast location, size, and timing. Identification and analysis of hypothetical blast scenarios was conducted in three phases, with the results from each phase being used as input to the next phase. The three phases were:

- $\quad$ Phase I: Identify hypothetical blast scenarios to initiate structural collapse.

- $\quad$ Phase II: Assess the blast wave propagation inside the building and the corresponding response of the WTC 7 windows.

- Phase III: Assess the approximate distance from the building that the blast would have been audible in an urban setting.

For Phase I, a controlled demolition expert identified appropriate charge sizes and configurations. In Phase II, based on the specified charge from Phase I, the hydrocode SHAMRC was used to calculate the blast propagation through the building. The pressures at the outer walls of WTC 7 developed by SHAMRC were then used to assess window damage. In Phase III, acoustic analysis of sound propagation outside the building was carried out with a U.S. Air Force low overpressure acoustic wave propagation code called NLAWS.

The following sections describe the work performed in each of the three phases along with results.

\section{D.2 PHASE I: EXPERT RECOMMENDED PREPARATIONS FOR EXPLOSIVELY CONTROLLED DEMOLITION}

Phase I identified a single minimum plausible scenario for the explosive demolition of a selected column or truss. This included columns that supported large tributary areas and a critical truss cross-member. The analysis assumed that severance of one of these members could initiate building collapse. For successful demolition of a column, failure was defined as complete severance of the column section, or complete severance of sufficient sections of the flange, web, and cover plates, such that the remaining column section was insufficient to carry the column service loads, or that a lateral deflection of the column section would exceed its section width.

The hypothetical blast scenarios that were addressed fell into two categories:

- Those in which there was sufficient time to prepare the structures for an optimum set-up prior to demolition. The objective would have been to use the minimum possible amount of 
explosives in the demolition process. Preliminary cutting of structural members could have been performed.

- Those in which the demolition was to be performed in the shortest possible time. The objective would have been to set up for demolition during approximately a $6 \mathrm{~h}$ time frame, i.e., between the time WTC 7 had been evacuated and the time at which collapse occurred.

For each of the scenarios, the type and quantity of explosive material (e.g., shaped charges, C4 or other non-directional explosive materials) required to fail each of the selected column sections was identified. In addition, any special equipment or supplies, and the time required to prepare the column, were identified. For each scenario, expected secondary effects - fireballs, noise level, extent of window breakage, and dust expulsion - were estimated. Two approaches were considered, in which the column was or was not prepared with preliminary cutting.

Column sections selected for developing hypothetical blast scenarios were:

Column 79 at Floor 14 - W14x730 with two 26-in. x 2-in. side cover plates

Column 79 at Floor 5 - W14x730 with two 26-in. x 3-in. side cover plates

Column 80 or Column 76 at Floor 14 - W14x730 with two 12.5-in. x 4-in. web plates

Truss 2 diagonal - W14x730 with two 8-in. x 3-in. web plates

Column 81 at Floor 14 - W14x730 with two 12.5-in. x 1-in. web plates

Column 77 at Floor 14 or Column 78a at Floor 5 or Truss 1 diagonal - W14x665

For reference, Table D-1 defines section properties for the two considered column types.

Table D-1. Basic wide flange column parameters. (Dimensions in in.)

\begin{tabular}{|c|c|c|c|c|}
\hline Section & Web Height & Flange Width & Flange Thickness & Web Thickness \\
\hline W14X730 & 22.4 & 17.9 & 4.91 & 3.07 \\
\hline W14X665 & 21.6 & 17.7 & 4.52 & 2.83 \\
\hline
\end{tabular}

Side cover plate details are shown in Figure D-1, which illustrates the side plate attachment for the considered columns (Structural drawing S-17, Cantor 1985).

From all these combinations, a single hypothetical blast scenario was identified for all of the selected column or truss sections. This hypothetical blast scenario included preliminary cutting of the column or truss section, which required a smaller mass of explosive than an uncut section. The scenarios considered for the second category (place larger explosive charges in the minimum time possible and with minimal preparation) were estimated to have required an order of magnitude more explosive material and would have been less covert.

The lowest mass of explosive needed to sever any of the six column or truss sections was found to be $4 \mathrm{~kg}$ (9 lb) of RDX explosives in linear shaped charges. Charges would be placed on either side of the two cover plates and the web and sections would be cut out of the flanges. These would have to be initiated 


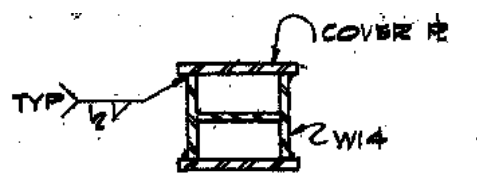

\section{TYP DET. OF COL. SIDE COVER L'S}

SEE COL. SCHAD. FOE COL. 4 \& SIZISS

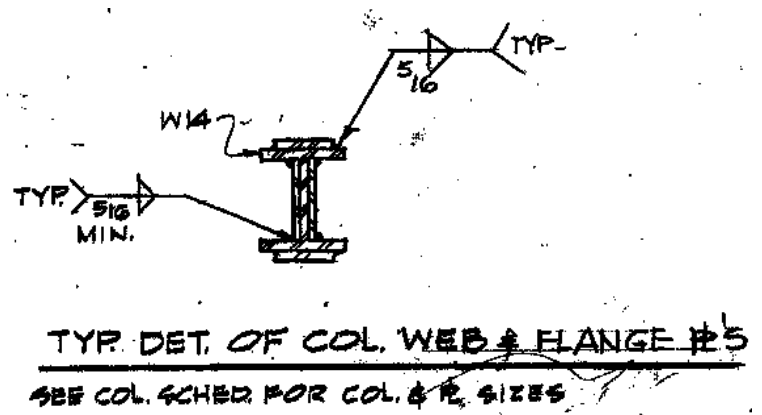

Source: Cantor 1985

Figure D-1. Column side plate attachment details.

using a detonating cord harness $(21,000 \mathrm{ft} / \mathrm{s}(6,400 \mathrm{~m} / \mathrm{s})$ velocity of detonation (VOD)), for simultaneity of initiation.

The other scenarios considered would have required much more explosive material, depending on the type and degree of column preparations conducted. Scenarios with a larger explosive charge would have generated much more window breakage and a louder sound, and were generally considered infeasible to carry out without detection.

The time constraint in the second scenario was not a determining factor. It would have taken a skilled burner with an oxy-propane torch about 15 minutes to make the cuts necessary to install the required linear charges of RDX. It would have taken another 5 minutes to place the explosive charges, plus the time to set up an initiation device. In addition, other preparations were required to clear the column for cutting, such as removing walls, column enclosures, SFRM, or other coverings that might have restricted access to bare steel at a column section. It was presumed that these activities could have been performed within the available time, though it is doubtful that such activities would not have been detected after the collapse of the WTC towers.

Preparations for a blast scenario prior to September 11, 2001would have been almost impossible to carry out on any floor in the building without detection. While the selected blast scenario considered one column, demolition with explosive charges usually prepares many columns in a building. Preparations would have included removal of column enclosures or walls, use of weld torches to cut column sections, installation of charges, and placement of wires for detonation. Occupants, support staff, and visitors would have noticed evidence of such activities, particularly since they likely would have occurred around more than one column. It is highly doubtful that such activities would have not been detected.

This single hypothetical blast scenario was applied to Column 79 in the Phase II blast modeling. While the selected blast scenario only considered one column, demolition with blast charges usually prepares 
many columns with explosive charges. It was even more unlikely that many columns could have been prepared for demolition without being detected.

\section{D.3 PHASE II: 2-D BLAST MODELING}

\section{D.3.1 SHAMRC Blast Modeling Code}

SHAMRC (Crepeau 1998, Crepeau 2001) is a U.S. government-owned hydrocode solver that is used for analysis of explosive detonations, shock propagation, and structure loads due to blast and fragments. SHAMRC has a proven record of accurate calculations of airblast structural loading for explosive weights of less than one pound to more than 4,000 tons. SHAMRC has also been used to calculate the formation and propagation of shaped charge jets and their interaction with structures. The code was well suited for the blast propagation analysis performed on WTC 7.

For the blast modeling effort, detailed two-dimensional SHAMRC hydrodynamic calculations were performed. The interior building layout was modeled to determine the transient pressure load inside the building after detonation. A two-dimensional analysis was sufficient to estimate pressures at window locations for a small charge constrained between floors. The pressure histories were then used to determine whether windows would have broken, which would have provided visible evidence of a small charge detonation outside of the building. The window fragility analysis was conducted with a separate computational tool, SFOM, using window geometry, material properties, and construction information as inputs to the model. The output from SFOM was Pressure-Impulse (P-I) failure curve predictions for WTC 7 windows. The SHAMRC-generated pressure histories were compared to the failure curves to predict window failure for each scenario considered.

\section{D.3.2 SHAMRC Blast Model Development}

\section{Floor Layout}

Three building layout configurations were considered during the blast analysis phase of the project:

- Layout 1: No partitions in the tenant floor area

- Layout 2: Moderate partitions in the tenant floor area

- Layout 3: Significant partitions in the tenant floor area

In preliminary analyses, Layout 1 , with an open floor plan in the tenant space, was shown to be less conservative because of a higher level of damage at the building perimeter than Layouts 2 and 3, which both included partitions in the tenant area. Therefore, Layout 1 was not revisited in the final analysis iteration. Analyses were carried out for Layouts 2 and 3 to explore the sensitivity of damage to partition density on the tenant floor space.

Layout 2 was a moderately partitioned floor similar to a Floor 7 layout in WTC 7. Layout 3 was a heavily partitioned floor, similar to a Floor 12 layout. The floor layouts and corresponding 2-D SHAMRC models are shown in Figure D-2 and Figure D-3 for Scenario 2 and Scenario 3, respectively. 


\section{Moderate Buildout in Tenant Area (Similar to Floor 7 Plan)}

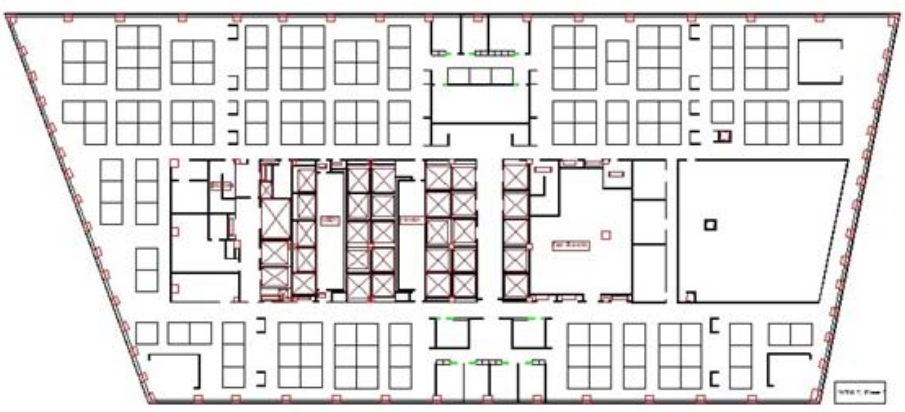

Divided rectangles are cubicles and are not considered since they don't extend full floor to ceiling height.

SHAMRC model of above layout

(including representation of initial blast circle centered at column 79)

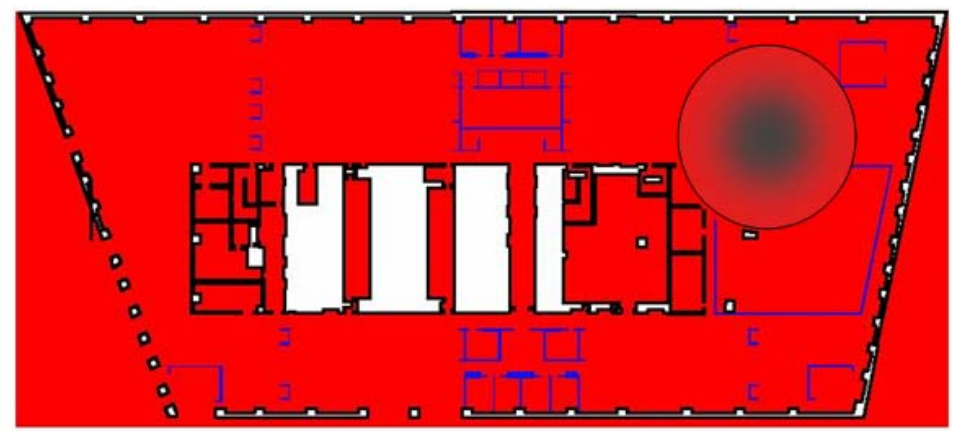

Based on material provided by American Express (see Chapter 3)

Figure D-2. Layout 2 floor plan layout and SHAMRC model.

Significant Buildout in Tenant Area (Similar to Floor 12 Plan), Most Conservative

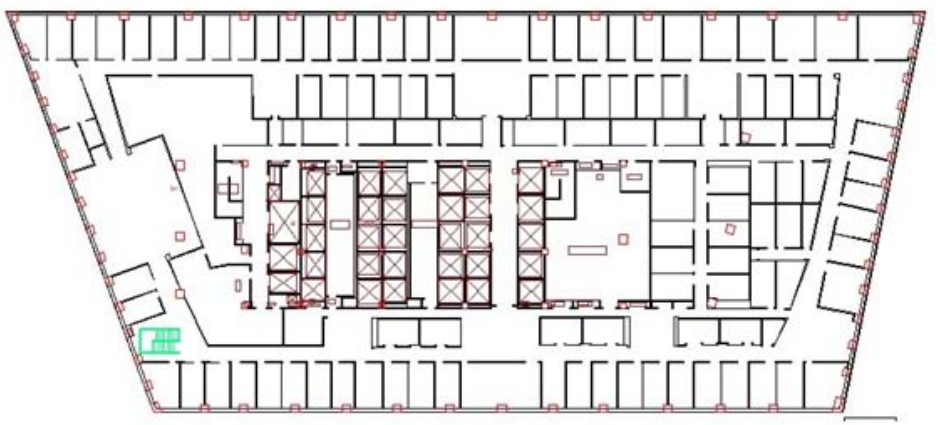

SHAMRC model of above layout

(including representation of initial blast circle centered at column 79)

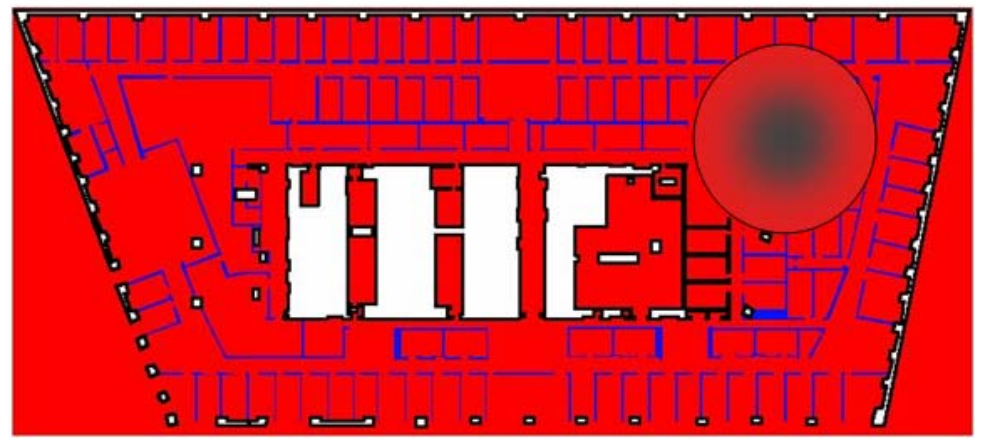

Based on material provided by American Express (see Chapter 3)

Figure D-3. Layout 3 floor plan layout and SHAMRC model. 


\section{Assumptions}

Some assumptions and simplifications were made in setting up and conducting the 2-D SHAMRC models of the WTC 7 floor layouts. Some key considerations for this effort were:

- The core walls and columns were treated as rigid, since the construction was heavy and less damage was expected from blast propagation. The key objective was to estimate blast pressures at window locations for subsequent window fragility and acoustic propagation analysis.

- The SHAMRC models for layout 2 and 3 included openings between columns at locations of window breakage from observations, as indicated in Chapter 5 . The window openings were along the south and west perimeters.

- Partition walls in the tenant area that extended from the floor to the drop ceiling were modeled as a dense fluid relative to the surrounding air. This commonly used "heavy air" CFD approach allowed for realistic blast wave reflections and propagation through the walls in the timeframe of the simulation (less than $1 \mathrm{~s}$ ), before the walls would appreciably deform. Partition wall properties were approximated based on composite wall construction.

- Cubicles were not modeled in this 2-D analysis since they did not extend the full floor height. Cubicles are shown in the Layout 2 Figure D-2 as divided boxes. The Scenario 3 layout did not include any cubicles.

- In the model, a fully developed, axisymmetric initial blast field centered on Column 79 was superposed on a uniform pressure field elsewhere in the model. The partition walls were not considered in this circle, as it was assumed that the blast would breach those walls.

\section{Run Configurations and Procedure}

The 2-D SHAMRC calculations were performed for the minimum explosive case identified in Phase I, which was a $9 \mathrm{lb}$ RDX blast centered on Column 79. Calculations were also performed for a lesser charge size of $2 \mathrm{lb}$ to evaluate threshold explosive requirements for window fragility. There were four blast analyses performed in total, consisting of two different charge sizes ( $2 \mathrm{lb}$ and $9 \mathrm{lb}$ of RDX) and two floor layouts (Scenarios 2 and 3).

For each SHAMRC blast modeling analysis, a 1-D/axisymmetric blast profile was generated for a given charge size and was allowed to fully develop before running the 2-D solution. Next, the circular blast profile developed in the 1-D/axisymmetric analysis was superposed on the 2-D floor layout that had been initialized under atmospheric conditions. Finally, the superposed blast solution was allowed to propagate transiently and interact with the 2-D structure.

Pressure-time data were saved at each station between exterior columns for comparison to predicted window P-I failure criteria. The pressure history was also used as input to the Phase III acoustic propagation analysis. Development of window failure criteria is discussed in the following subsection. 


\section{D.3.3 Estimation of WTC 7 Perimeter Window Fragility}

A Shard Fly-out Model (SFOM) (Meyer 2002*) was used to predict window breakage, based on the pressure profiles from the SHAMRC analysis. The SFOM was originally developed for the Defense Threat Reduction Agency (DTRA) to predict window breakage as well as size and shape of shards created by blast loading.

Within SFOM, window breakage can be predicted with a single-degree-of-freedom (SDOF) model, which outputs a pressure-impulse (P-I) failure threshold curve. This can be done for annealed glass and for thermally tempered glass (TTG). For insulated glass units (IGU), composed of two annealed panes, a relationship to monolithic annealed windows with a thickness equal to the sum of the two IGU thicknesses was assumed. The SDOF model assumed a triangular loading function. A stiffness function was defined as the slope of the resistance/displacement curve. Using these loading and stiffness functions and a Newmark integration procedure, displacement and velocity time histories were obtained for input pressure-impulse combinations. A break was defined to occur when a pressure-impulse combination resulted in a window displacement that exceeded the maximum displacement allowable.

In addition to the type of window and blast loading conditions, the SFOM required specification of window dimensions, density, strength and width of the interstitial air gap (assuming an insulated glass unit window configuration). Limited window construction information was available from WTC 7 architectural drawings. Where detailed information was unavailable, industry standards for the unknown specifications were applied. The following section views from the drawings, shown in Figure D-4 to Figure D-7, were used as guidelines of general window construction for the SFOM analysis. In particular, overall window dimensions, general window framing practice, and a 1-inch insulated glass dimension were noted in the drawings.

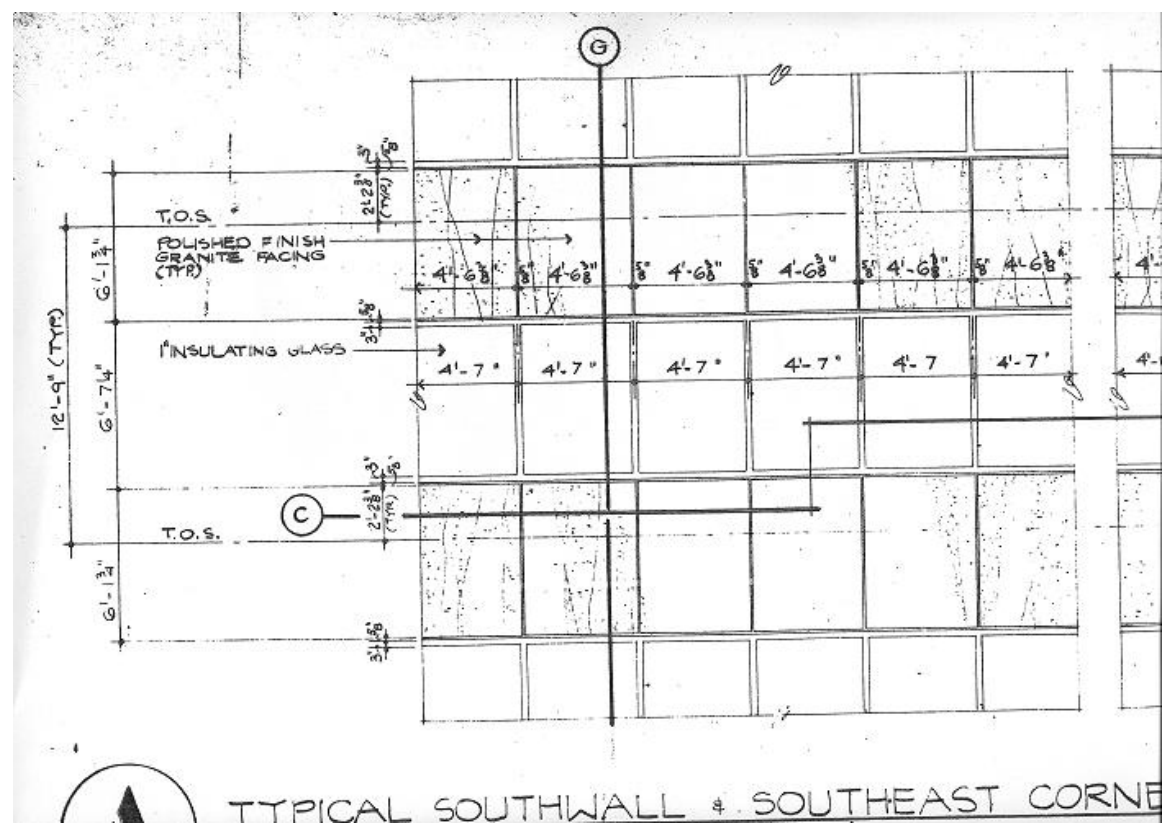

Source: Roth 1985

Figure D-4. WTC 7 Architectural Drawing 38, Detail A: Typical Southwall and Southeast Corner Elevation.

* Deleted reference January 2009. All pertinent material is contained in Meyers 2002. 


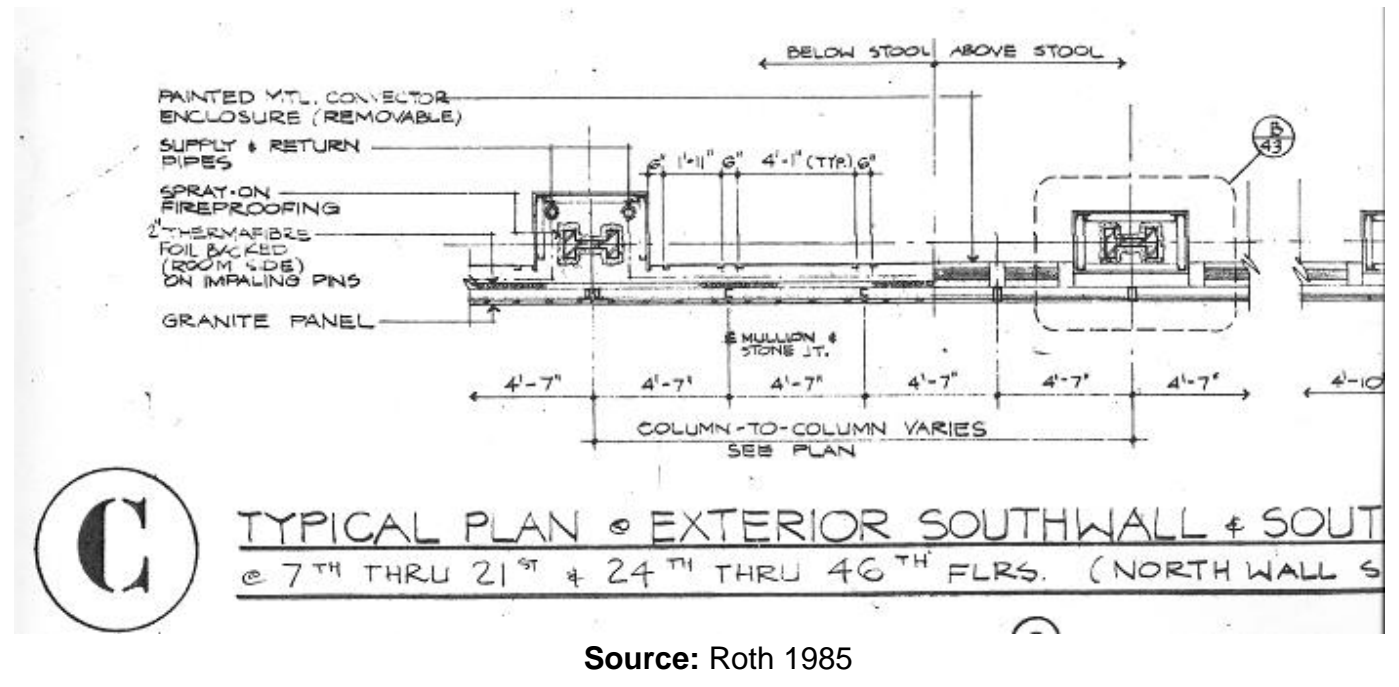

Figure D-5. WTC 7 Architectural Drawing 38, Section C: Typical Plan at Exterior Southwall and Southeast Corner.

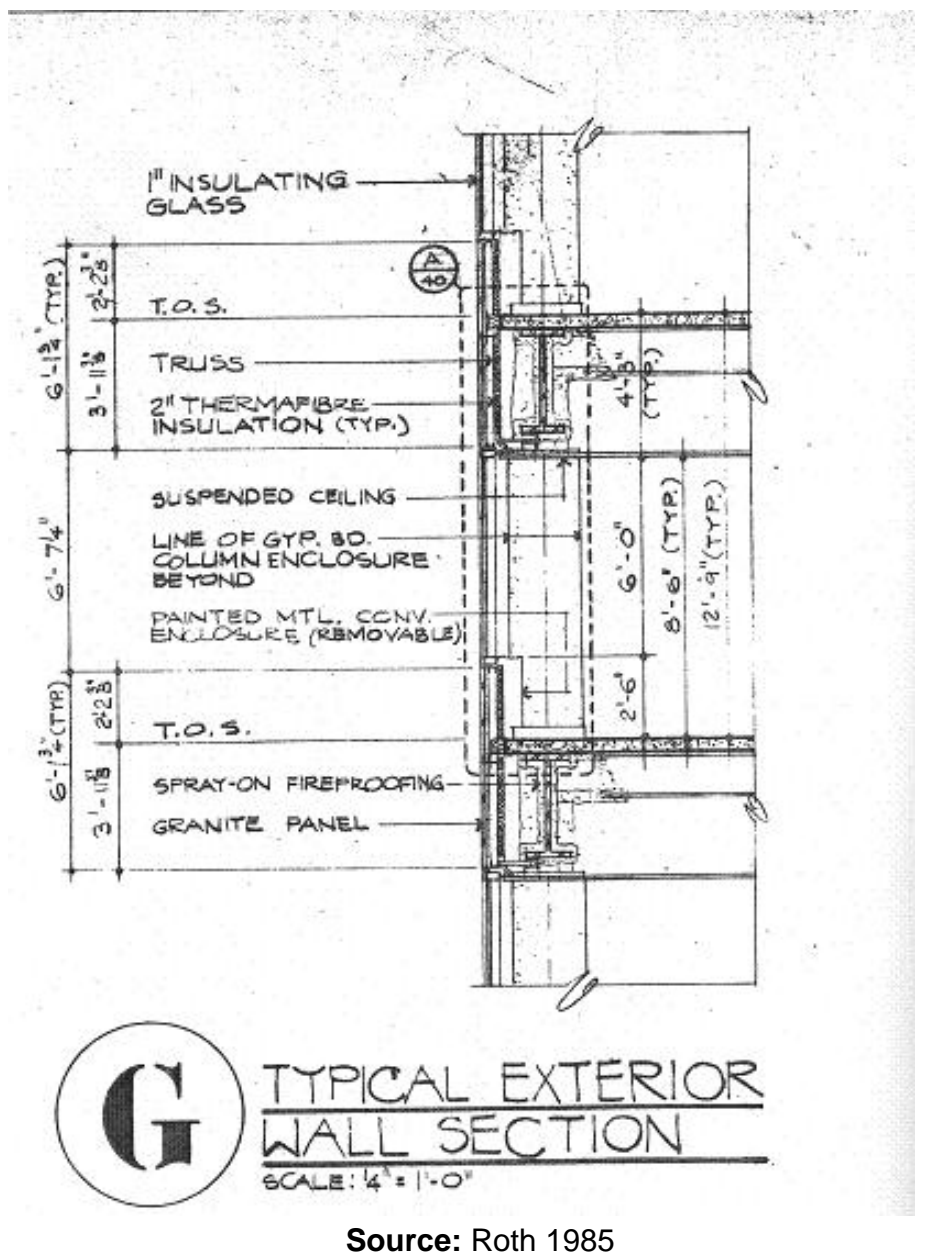

Figure D-6. WTC 7 Architectural Drawing 38, Section G: Typical Exterior Wall Section. 


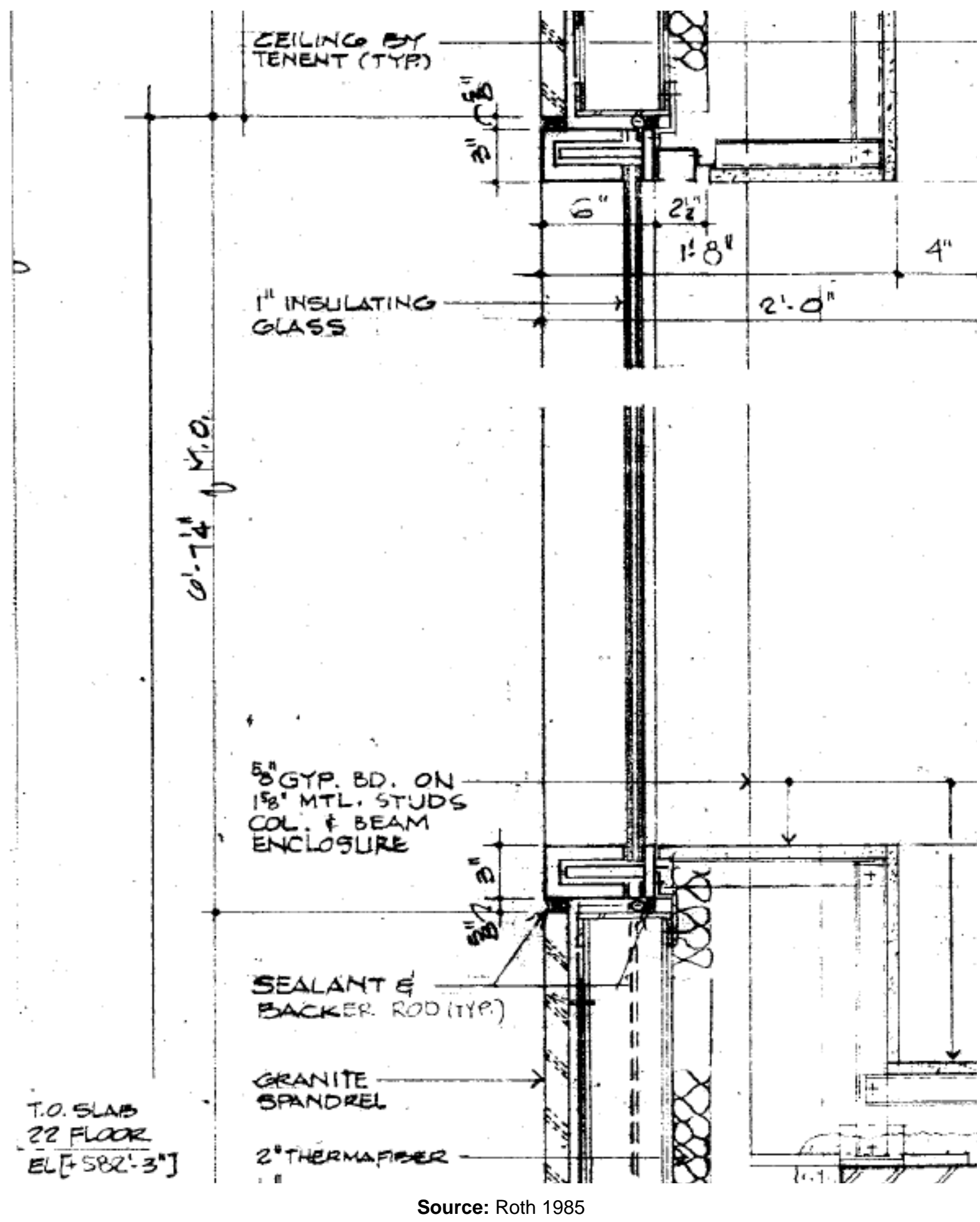

Figure D-7. WTC 7 Architectural Drawing 40, Section A: Typical Exterior Wall at Window.

The SFOM window fragility analysis was conducted using available and assumed window details. The resulting P-I curves for two window sizes are shown in Figure D-8. The P-I curves indicate that a minimum overpressure of 2.5 psi was required for window failure in WTC 7. Slightly different minimum impulses were required for failure for the two window sizes considered in the analysis. 


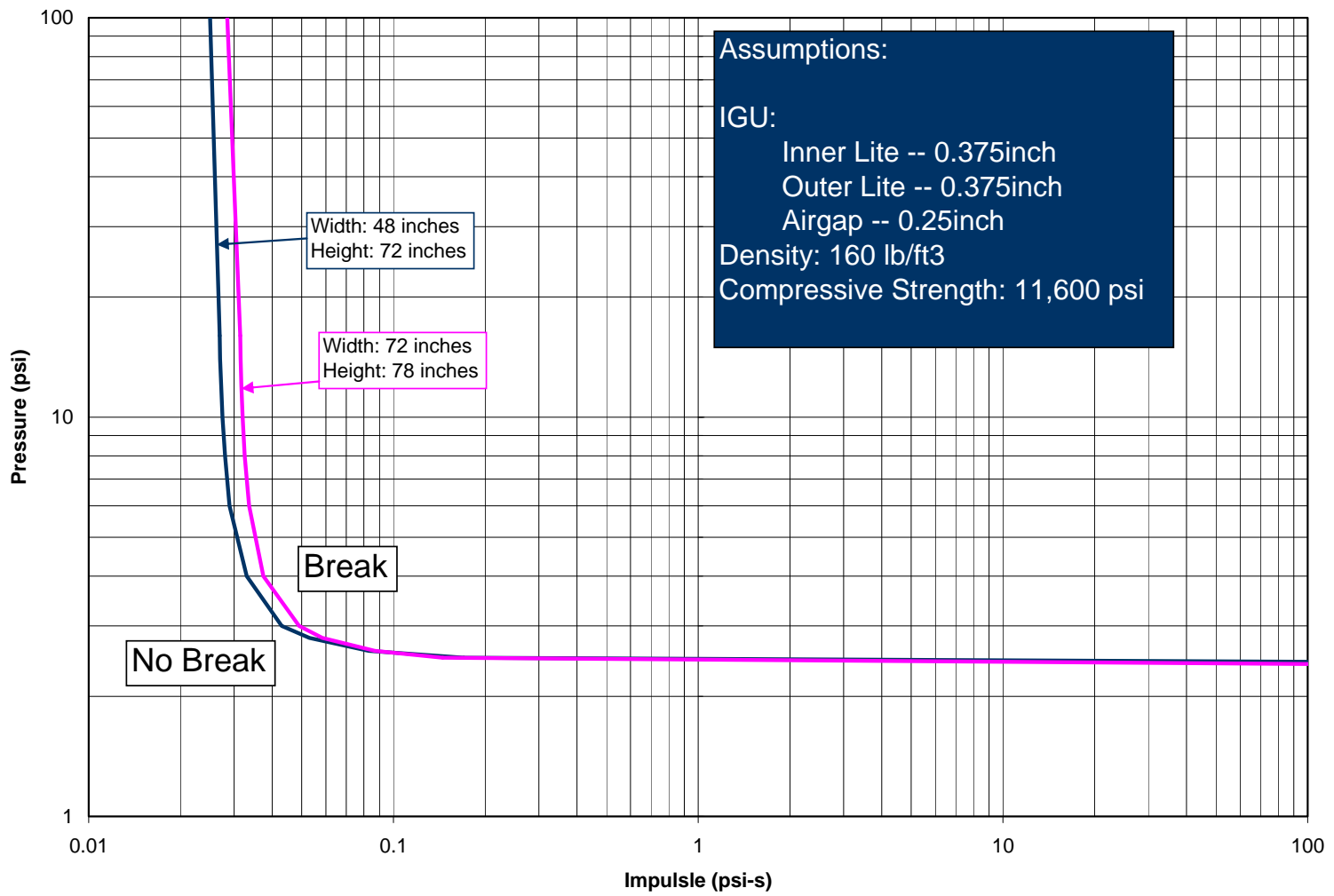

Figure D-8. Pressure-impulse requirements for WTC 7 window breakage.

In the next section, the window P-I failure curves were compared to the SHAMRC P-I data as a basis for predicting window failure locations for each blast analysis.

\section{D.3.4 Blast Modeling Results}

Key results from the Phase II blast analyses are shown in Figure D-9 through Figure D-14. Figure D-9 and Figure D-10 illustrate the predicted pressure-impulse levels at each window location around the building perimeter for Layouts 2 and 3, respectively. Two blast initiating charge sizes are shown: the minimum recommended $9 \mathrm{lb}$ of RDX explosive from Phase I, and a smaller $2 \mathrm{lb}$ charge to examine the sensitivity of the window breakage to charge size. The P-I values at each window location are overlaid on the predicted break/no-break criteria from the window fragility analysis conducted earlier in Phase II. Failure pressure-impulse curves are commonly used in blast analyses to illustrate system failure sensitivity to transient pressure loads.

Figure D-11 through Figure D-14 show plan views of the 2-D SHAMRC results for predicted window failure locations. Contours of peak overpressure are shown, as well, to illustrate pressure propagation throughout the floor. The maximum contour value, shown as purple, was set at 2.5 psi, which corresponds to the minimum overpressure required to break a window. Any area displayed as purple experienced overpressures at or above the 2.5 psi threshold, but did not necessarily experience the minimum required impulse. Only station numbers shown in blue experienced the necessary combination of pressure and impulse to exceed the failure threshold. 


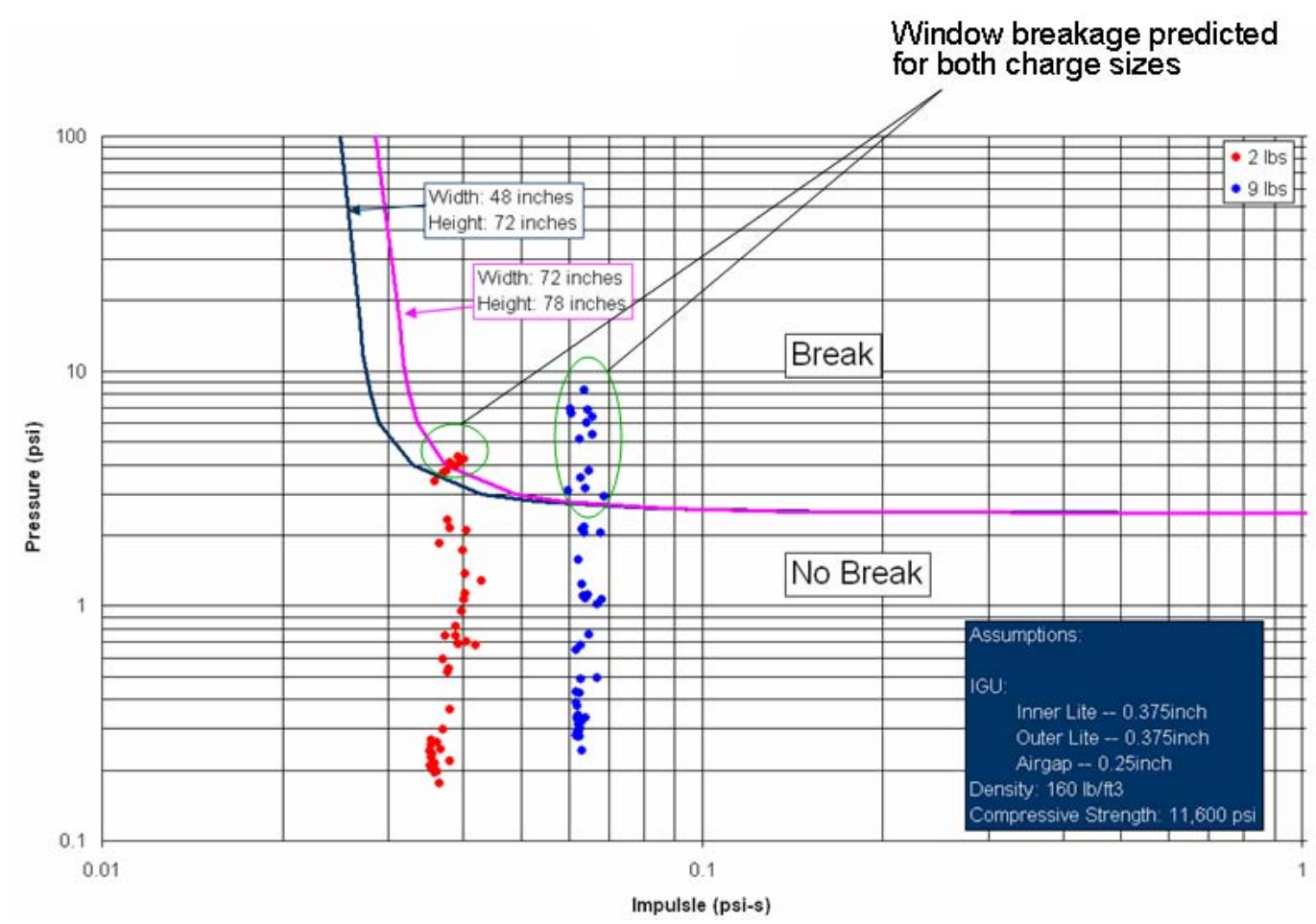

Figure D-9. Layout 2 pressure-impulse values at window locations compared to predicted failure profiles.

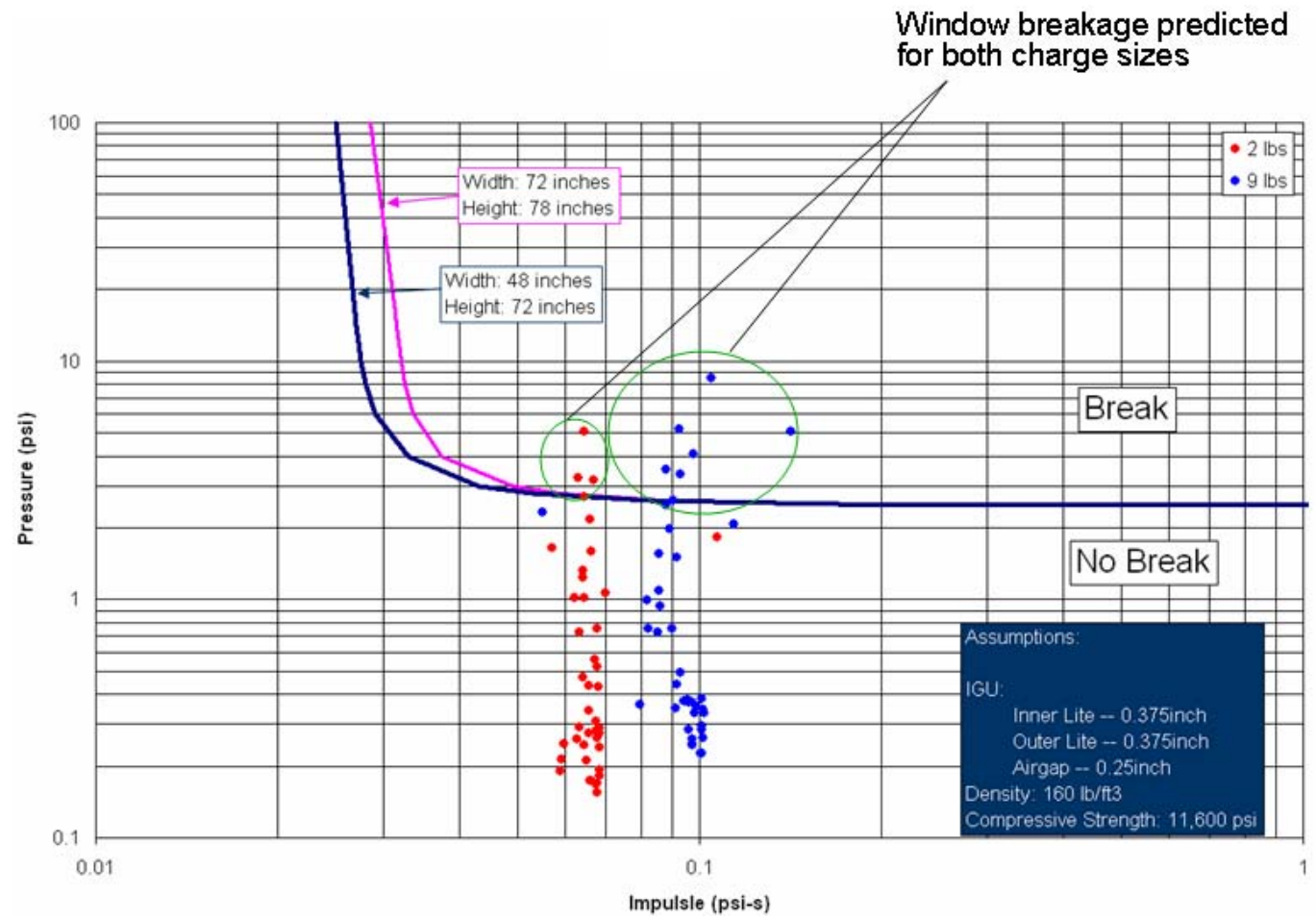

Figure D-10. Layout 3 pressure-impulse values at window locations compared to predicted failure profiles. 


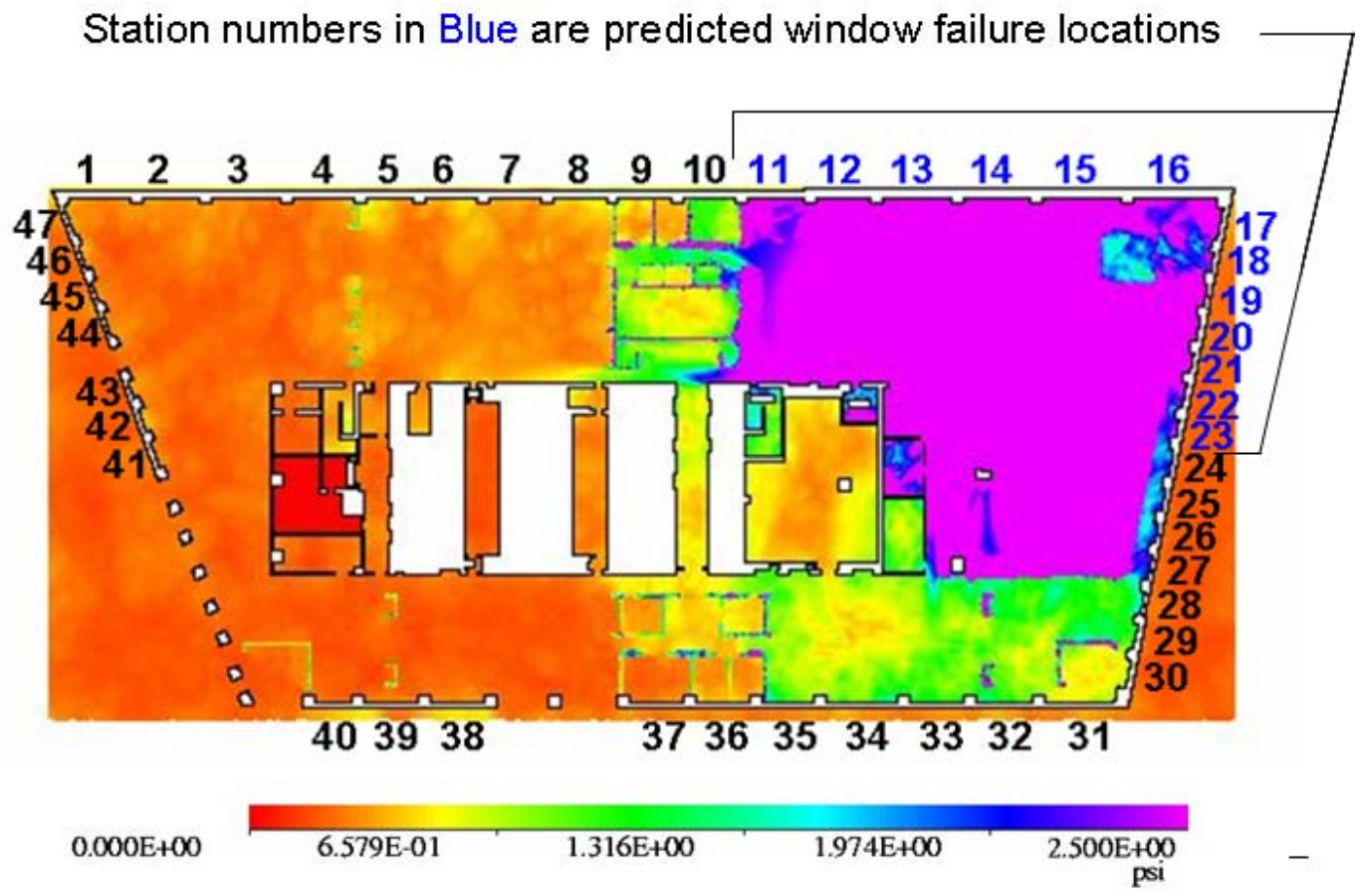

Figure D-11. Layout 2 peak overpressure and broken window locations, 9 lb charge.

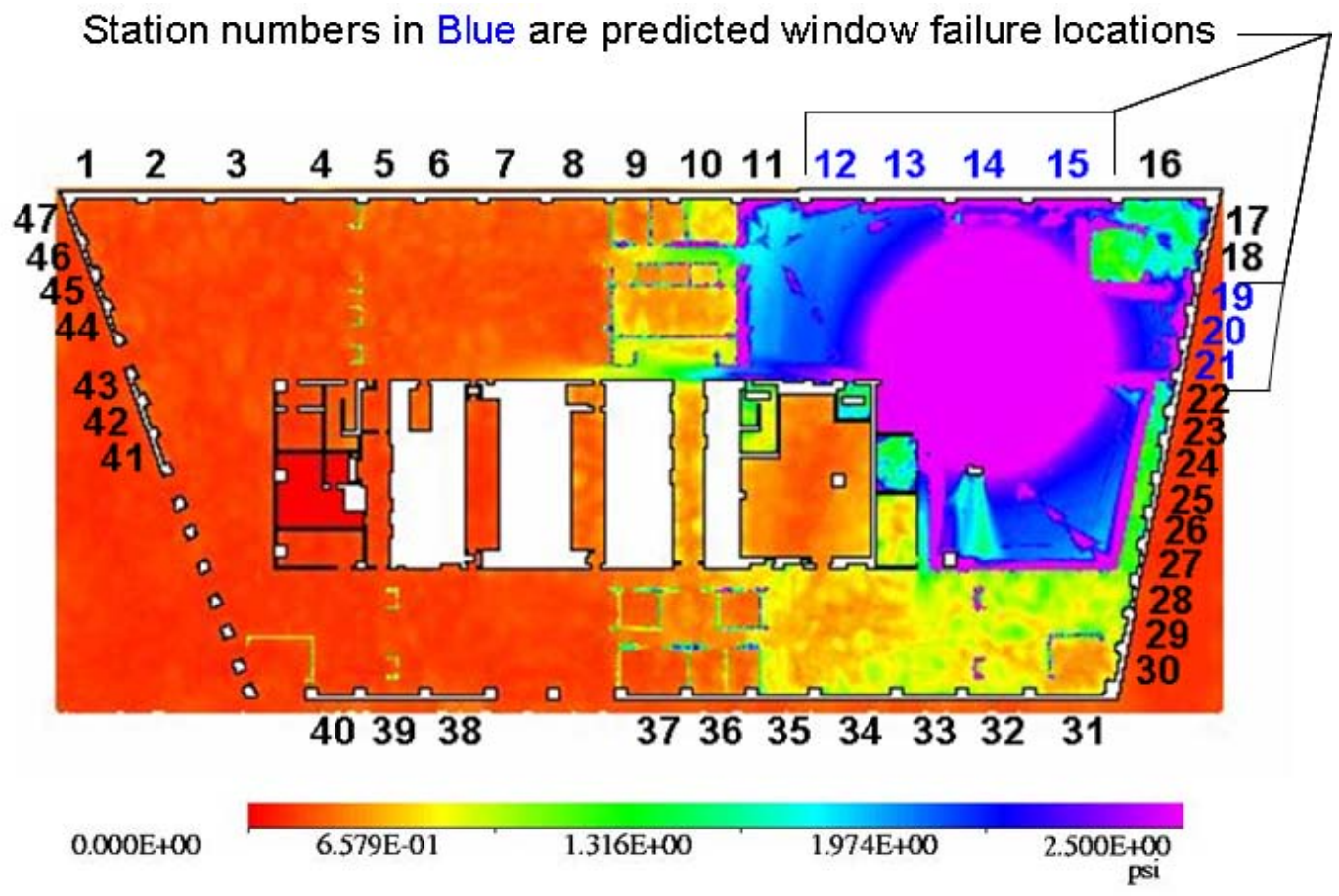

Figure D-12. Layout 2 peak overpressure and broken window locations, 2 lb charge. 


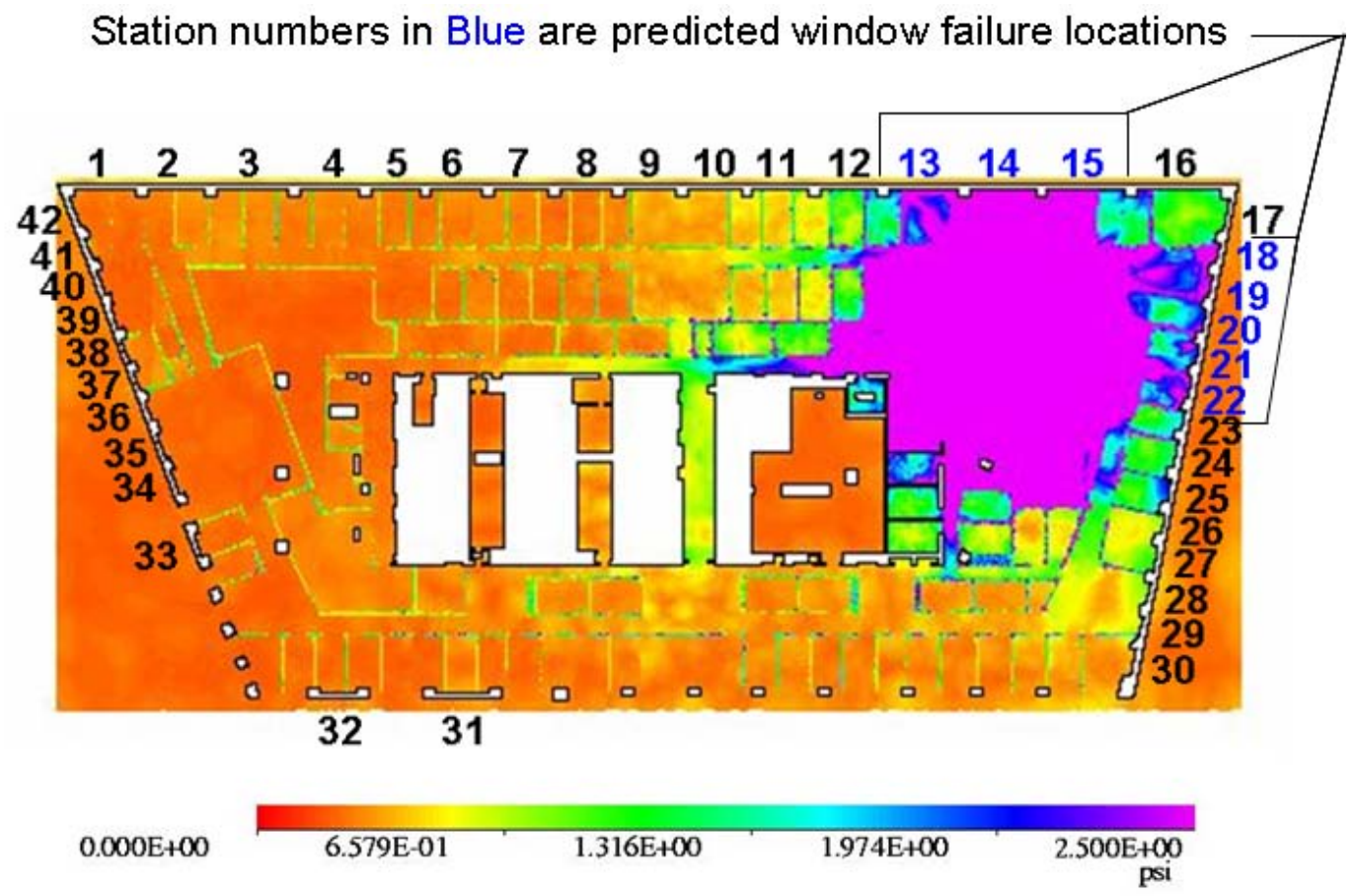

Figure D-13. Layout 3 peak overpressure and broken window locations, 9 lb charge.

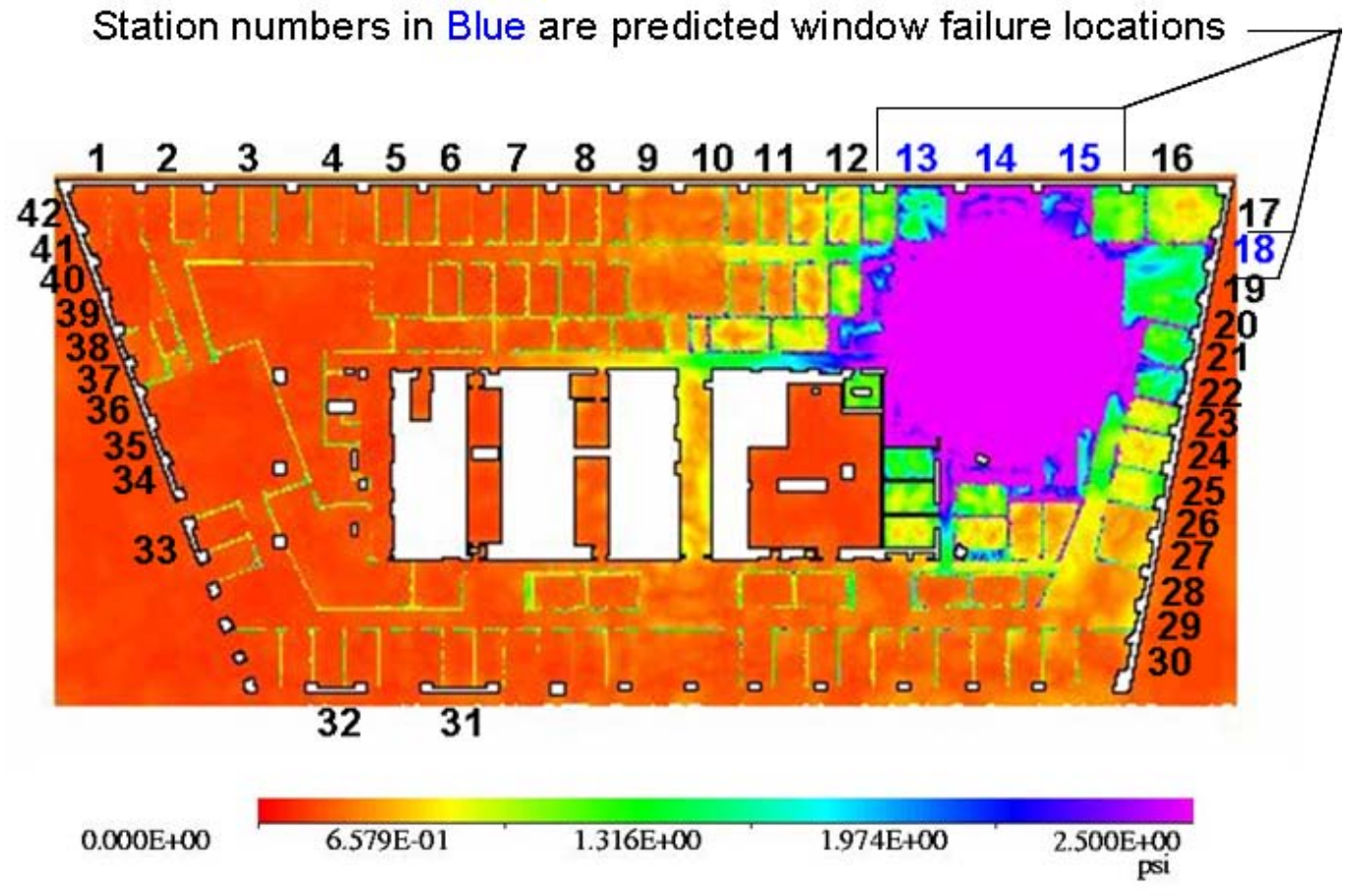

Figure D-14. Layout 3 peak overpressure and broken window locations, 2 lb charge. 
As expected, the more open Layout 2 resulted in more predicted window failure locations for a given charge size, compared to the more extensively built-out Layout 3. Furthermore, the larger 9 lb explosive charge resulted in more window failures than the corresponding $2 \mathrm{lb}$ charge analyses, predominantly on the east face of the building.

\section{D.4 PHASE III: 1-D ACOUSTIC ANALYSIS}

Based on the results from Phase II, representative overpressure waveforms from the predicted broken windows on the north and east faces, as well as from open areas at the southwest corner from WTC 1 debris damage, were used to make sound-distance propagation predictions.

The tool used to make the prediction, NLAWS, is a non-linear acoustic wave propagation solver that was developed about 30 years ago by the U.S. Air Force. The code takes the blast wave parameters of peak overpressure, material velocity and positive duration and constructs a triangular wave. It then uses the radius from the burst at the window to the point where conditions are specified for divergence of the wave. The code then uses spherical divergence to continue propagation of the wave in a constant atmosphere to a distance up to $1 \mathrm{~km}$ from the burst.

Figure D-15 shows a typical waveform at a broken window location and its Fourier transformation. Most of the sound lies below $200 \mathrm{~Hz}$. Approximately $40 \mathrm{~Hz}$ is the lower limit for human audible perception. In this frequency range, the blast would sound like a low rumble. Figure D-16 illustrates a typical waveform in the vicinity of the open window locations in the southwest corner.

Figure D-17 and Figure D-18 show the results of the acoustic analysis for both floor layouts, in which overpressure and sound pressure level vs. distance from the opening are plotted. Intense audible sound was predicted from all building faces for all four combinations of layout and charge size. If propagation were unobstructed, as would be the case for a person standing on a street with a direct view of any WTC 7 face with open windows, the sound level from all building perimeter openings at $1 \mathrm{~km}$ would be approximately 130 to $140 \mathrm{~dB}$. Adjacent buildings and their effect on the sound propagation was not considered in this analysis. The analysis was intended to be a simple estimate of the sound potential emanating from the building due to blast pressures.

To check the validity of the results, the close range values predicted by NLAWS are similar to the limited published data available for sound pressures from small explosives. Specifically, Hamby (2004) lists $190.6 \mathrm{~dB}$ for $2 \mathrm{lb}$ of TNT at a close standoff. Further, $1 \mathrm{lb}$ of TNT is listed as generating $194.1 \mathrm{~dB}$ at $6 \mathrm{ft}$, $186.1 \mathrm{~dB}$ at $10 \mathrm{ft}$ and $180.0 \mathrm{~dB}$ at $15 \mathrm{ft}$ standoff (Kinney 1985). These values correlate well with the range of values predicted by the NLAWS model. 

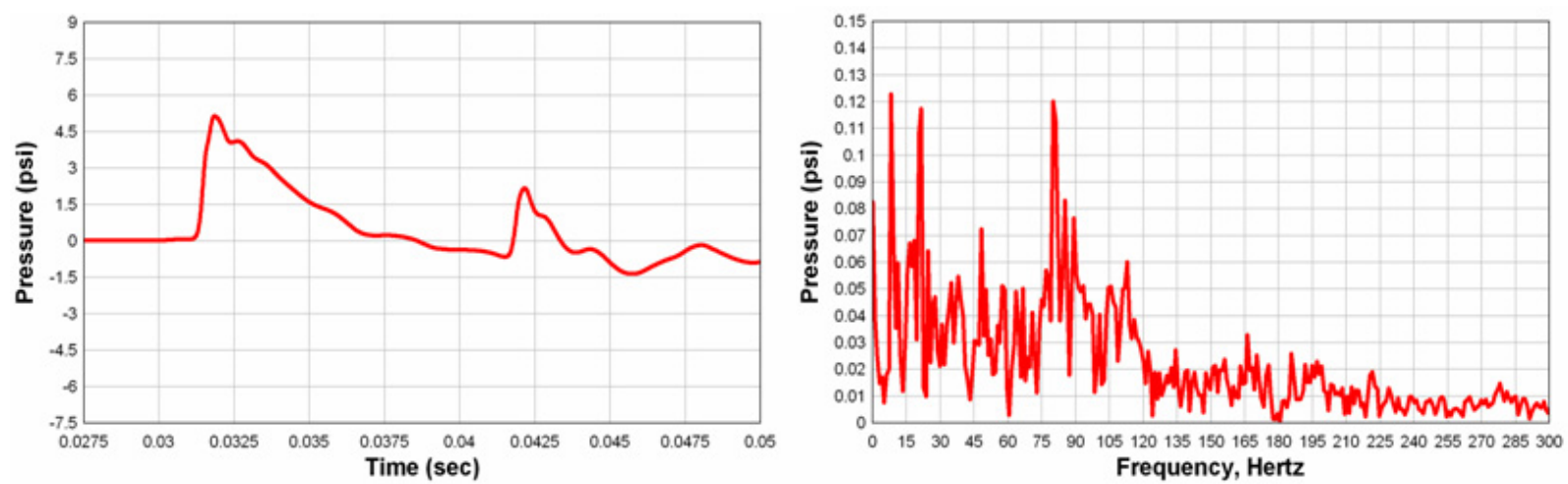

Figure D-15. Typical waveform and corresponding Fourier transformation at a broken window location.

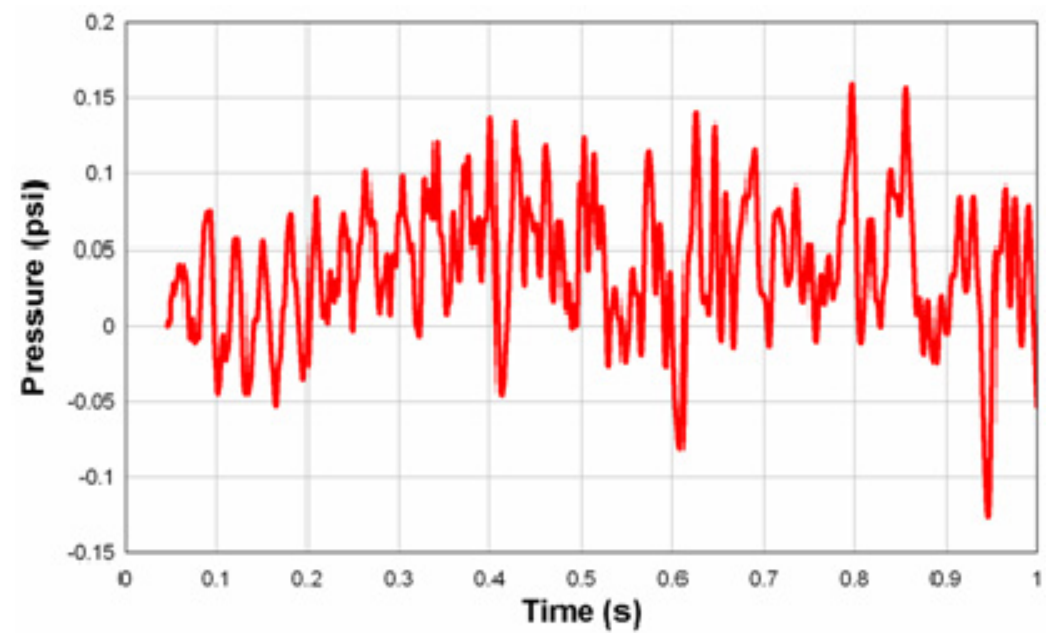

Figure D-16. Typical waveform in the southwest corner near the debris damaged windows. 


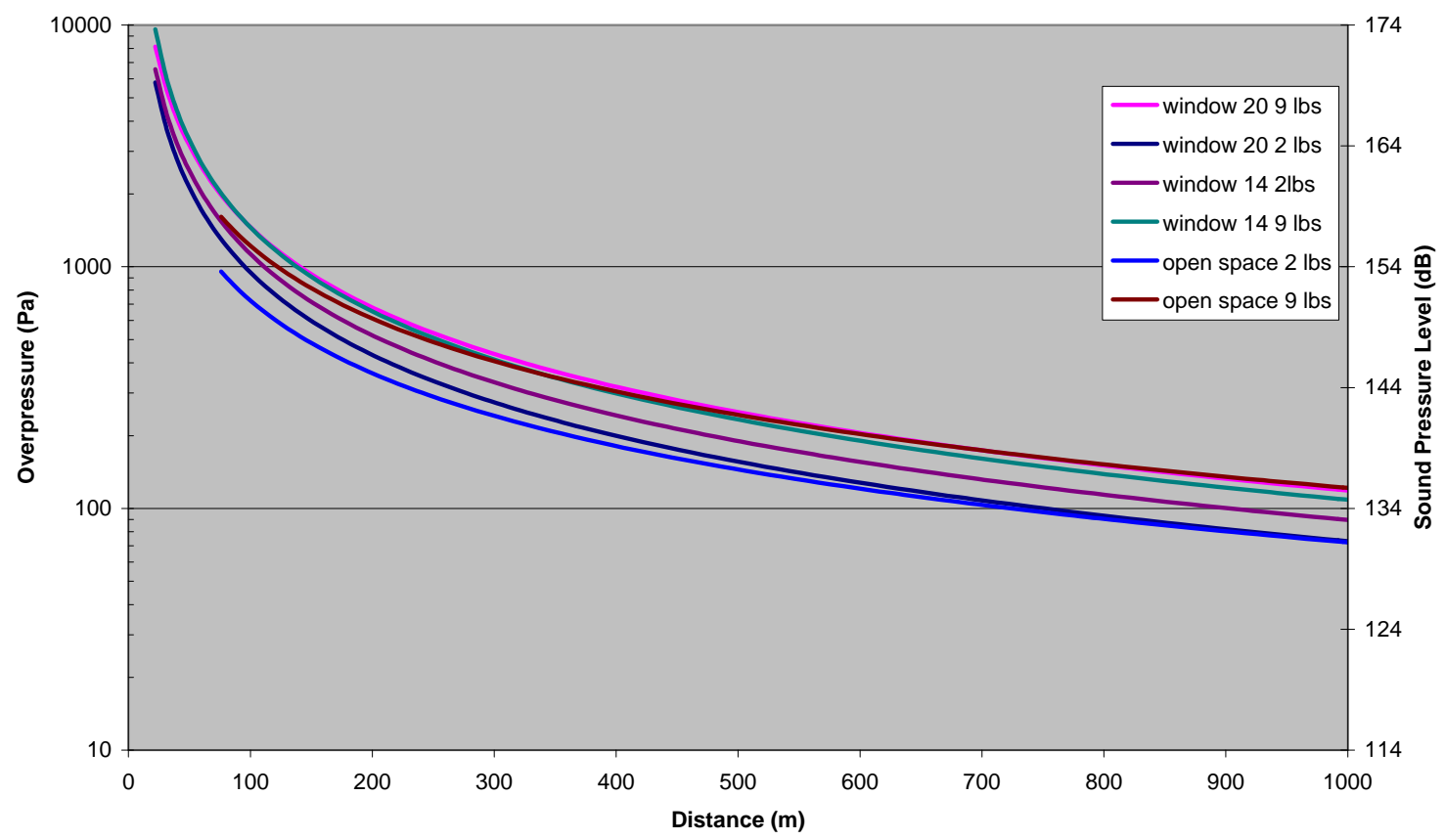

Figure D-17. Layout 2 acoustic overpressure-distance predictions.

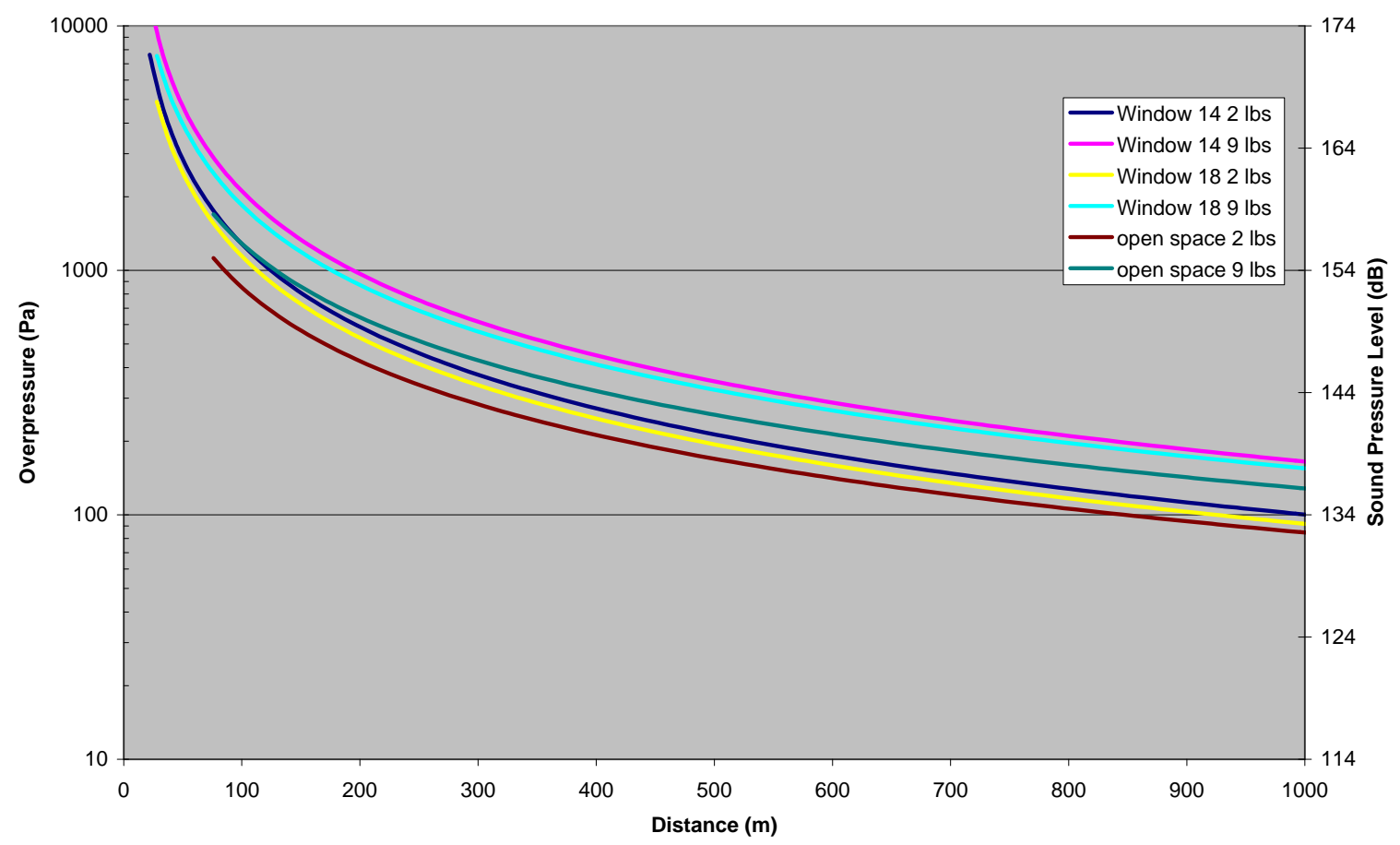

Figure D-18. Layout 3 acoustic overpressure-distance predictions. 


\section{D.5 SUMMARY}

In Phase I, hypothetical blast scenarios to initiate structural collapse were identified. In particular, a plausible scenario with the minimum amount of required explosive was identified and carried forward to the Phase II blast analyses. This scenario proposes a linear shape charge blast consisting of $9 \mathrm{lb}$ of RDX, centered on Column 79. The recommended column preparation for use of this shape charge required a minimum of 15 min to make initial cuts to the column with an oxy-propane torch, plus additional time for charge placement.

In Phase II, 2-D SHAMRC blast propagation calculations were performed for the minimum explosive case identified in Phase I. Calculations were also performed for a lesser charge size (2 lb) in the interest of evaluating threshold explosive requirements. There were 4 blast analyses performed in total, consisting of two different charge sizes ( $2 \mathrm{lb}$ or $9 \mathrm{lb}$ of RDX) and two floor layouts with differing partition densities in the tenant areas (Layouts 2 and 3). The primary conclusion from Phase II analyses was that windows were expected to fail on the north and east faces for even the most conservative blast loading case considered (the densely-partitioned Layout 3 with a $2 \mathrm{lb}$ charge). Other scenario and charge size combinations resulted in greater predicted damage.

In Phase III, an acoustic analysis was performed to assess the distance from the building that the blast would have been audible. Analyses were performed for both layout scenarios, using the pressure history and window failure location predictions generated during Phase II. For all scenarios and charge sizes, significant audible sound was predicted from all building faces. For locations where sound propagation was unobstructed, the sound level from all building perimeter openings at $1 \mathrm{~km}$ would have been approximately $130 \mathrm{~dB}$ to $140 \mathrm{~dB}$.

\section{D.6 REFERENCES}

Cantor. 1985. Irwin G. Cantor P.C., Structural Engineers, Structural Drawings, 7 World Trade Center.

Crepeau, J., Needham, C. and Hikida, S., SHAMRC second-order hydrodynamic automatic mesh refinement code. 2001. Methodology, 2001. Applied Research Associates, Albuquerque, NM.

Crepeau, J., SHAMRC second-order hydrodynamic automatic mesh refinement code. 1998. User's manual, 1998. Applied Research Associates, Inc., Albuquerque, NM.

Hamby, William, “Ultimate Sound Pressure Level Decibel Table,” 2004, http://www.makeitlouder.com/Decibel 20Level 20Chart.txt, 6 Jun 2008.

Kinney, Gilbert and Graham, Kenneth, Explosive Shocks in Air, $2^{\text {nd }}$ Edition, Springer, 1985.

**Deleted reference January 2009. All pertinent material is contained in Meyers 2002.**

Meyer, S.B., Becvar, K.E., Stevens, D.J. and Marchand, K.A., Shard Fly-Out Model, Final Technical Report prepared by Applied Research Associates, Inc. for the Technical Support Working Group, December 2002. 
Meyer, Sarah B., Becvar, Keith, E., Stevens, David J. and Marchand, Kirk A., 2002a. "Shard Fly-Out Model, User’s Guide,” TSWG Contract N39998-99-C-0671, ARA Project Number 0515, Applied Research Associates, San Antonio, Texas, November 27.

Meyer, Sarah B., Becvar, Keith, E., Stevens, David J. and Marchand, Kirk A., 2002b. "Shard Fly-Out Model, Technical Documentation,” TSWG Contract N39998-99-C-0671, ARA Project Number 0515, Applied Research Associates, San Antonio, Texas, November

Roth. 1985. Emery Roth \& Sons P.C., Architects, Architectural Drawings, 7 World Trade Center. 


\section{Appendix $E$ \\ Plasticity AND CREep MOdels For WTC 7 STEels}

\section{E.1 INTRODUCTION}

The finite-element structural analysis of the building required material models for tensile stress-strain and creep behavior of the steels and the strengths of the bolts used. This Appendix documents the methods used to generate those material models.

\section{E.2 METHOD FOR CREATING HIGH-TEMPERATURE STRESS-STRAIN CURVES}

At elevated temperature, the deformation characteristics of the steel can be represented in several ways. One is to include a temperature dependence in the ordinary stress-strain behavior. Up to temperatures of about $500{ }^{\circ} \mathrm{C}$, the stress-strain behavior of structural steel depends only weakly on the deformation rate. At higher temperatures, the strain rate dependence, and hence the time dependence, of the stress-strain behavior becomes more significant. At these elevated temperatures, the behavior is often termed "creep," although the strain rates relevant to fire conditions are often several orders of magnitude larger than those in traditional, long-term creep situations.

The stress-strain behavior represents an upper limit for the strength of the steel at all temperatures. As such, it was developed with data appropriate to a higher strain rate. The creep models captured the timedependent deformation and produced all the strain at temperatures above about $500{ }^{\circ} \mathrm{C}$.

Stress-strain curves and creep models were developed for three steels: ASTM A 36, ASTM A 572, and CSA G40.21-44W. The plastic portions of the stress-strain curves for all three steels were based on the behavior of WTC A 572 specimen HH-F1-1, a YS = 42 ksi 12WF92 shape taken from column line 605 between Floors 98 and 101 of WTC 1. Data tables in Appendix A of NIST NCSTAR 1-3D described the tensile tests. Other information can be found on page 54 of NIST NCSTAR 1-3D. The first step was to model the room- and elevated-temperature true stress-true strain behavior using a power-law work hardening formalism,

$$
\sigma=K \varepsilon^{n}
$$

In principle, both $K$ and $n$ depend on temperature, $T$, and strain rate, $\dot{\varepsilon}$. For the A 572 base steel, the work-hardening exponent, $n$, does not change monotonically with strain rate (Figure E-1). The dependence on strain rate is small and difficult to model, so it was expedient to ignore the rate dependence and choose an exponential form for the work-hardening exponent,

$$
n(T)=n_{0} \exp \left(-\left(\frac{T}{n_{2}}\right)^{n_{1}}\right)
$$

The parameter $n_{0}$ sets the room temperature value. The parameter $n_{2}$ sets the transition temperature where $n(T)$ begins to drop quickly, and the shape factor parameter $n_{1}$ sets the steepness of the transition. 


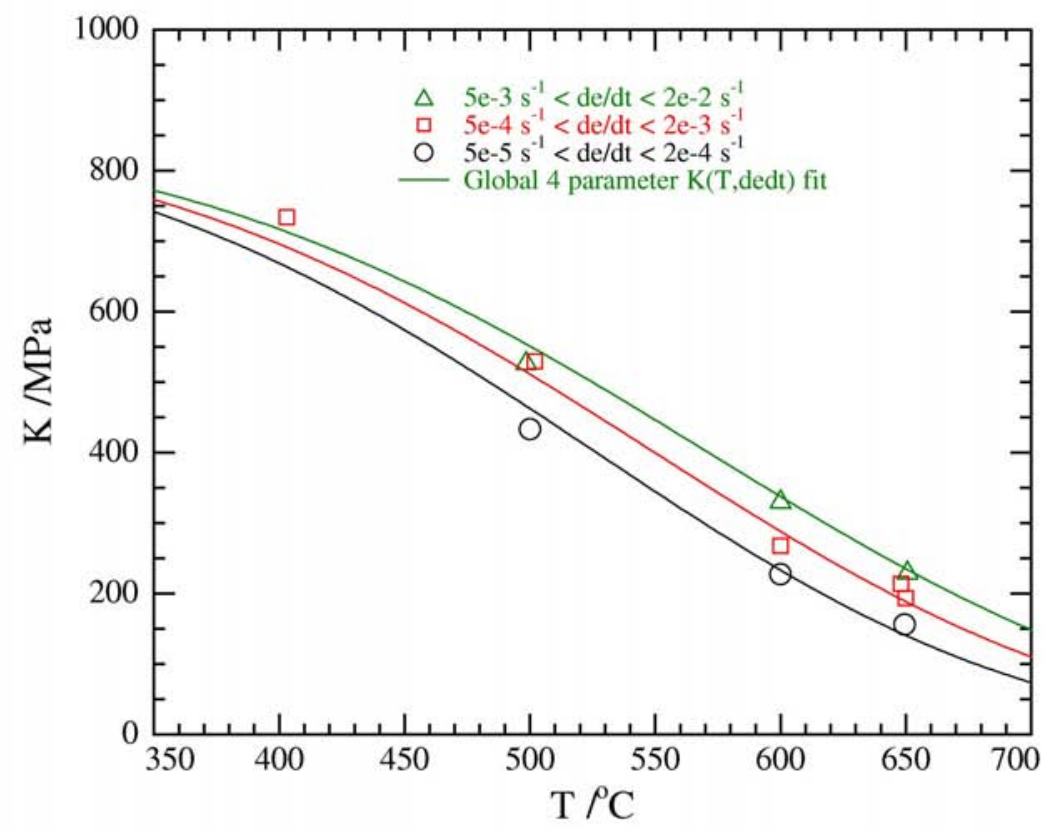

Figure E-1. Behavior of $K(T)$ and $n(T)$.

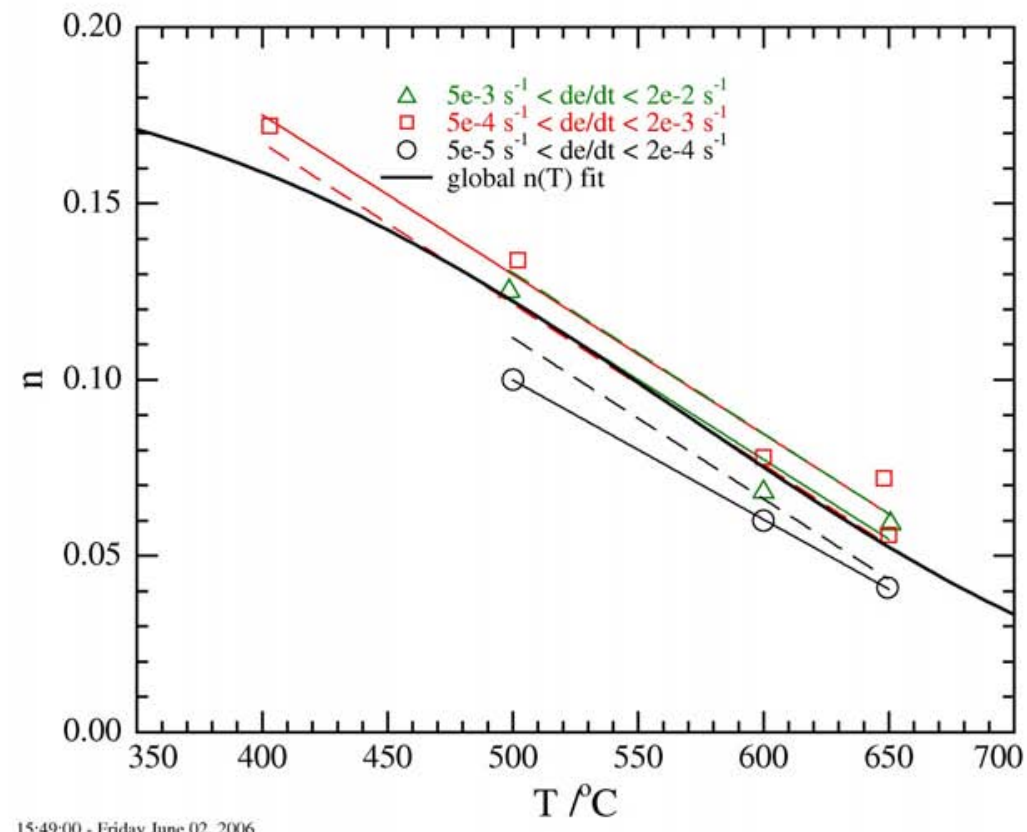

15:49:00 - Friday June 02, 2006

The factor $K$ depends on strain rate in a stronger and more predictable way at elevated temperature,

$$
K(T, \dot{\varepsilon})=k_{0} \exp \left(-\left(\frac{T}{k_{2}+k_{3} \dot{\varepsilon}}\right)^{k_{1}}\right)
$$

In this formalism, the parameter $k_{3}$ caused the behavior of $K(T)$ to depend weakly on strain rate at intermediate temperatures, but not at room temperature. 
These equations were purely empirical; the individual parameters were not physically based. Figure E-1 displays the behavior of $K(T)$ and $n(T)$ for the A 572 steel. Table E-1 summarizes the values of the parameters.

Table E-1. Values of the parameters for $K(T)$ and $n(T)$.

\begin{tabular}{|c|l|}
\hline Parameter & Value \\
\hline $\mathrm{k}_{0}$ & $+854.0 \mathrm{MPa}$ \\
\hline $\mathrm{k}_{1}$ & +4.1100 \\
\hline $\mathrm{k}_{2}$ & $+660.0^{\circ} \mathrm{C}$ \\
\hline $\mathrm{k}_{3}$ & $+10.27^{\circ} \mathrm{C} \mathrm{s}$ \\
\hline $\mathrm{n}_{0}$ & +0.1890 \\
\hline $\mathrm{n}_{1}$ & +4.0990 \\
\hline $\mathrm{n}_{2}$ & $+611.8^{\circ} \mathrm{C}$ \\
\hline
\end{tabular}

For tensile stress-strain behavior, ANSYS requires the first strain point to be at the yield strength, $F_{y}$, and that the slope of the stress-strain curve equal the Young's modulus, $E$, between $(0,0)$ and the first strain point. To use the plastic stress-strain behavior developed for A 572 to describe the behavior of A 36, it was necessary to scale the stress-strain curve in an appropriate manner. The method was to multiply the expression for $K(T)$ by a constant that made the true stress at true strain $=0.1$ roughly equal to the value of the stress for several WTC A 36 steels at room temperature. That coefficient was $k_{A 36}=0.862$. The parameter was estimated visually.

No literature data existed for the stress-strain behavior of CSA G40.21-44W plate. Its yield strength, $F_{y}=44 \mathrm{ksi}(300 \mathrm{MPa})$, is roughly midway between that of A 36, $F_{y}=36 \mathrm{ksi}$, and A 572, $F_{y}=50 \mathrm{ksi}$. It was, therefore, reasonable to estimate the coefficient, $k_{G 40.21}$, by linearly interpolating between the values for A $572 k_{A 572}=1.0$ and $k_{A 36}=0.862$. The value of the coefficient for CSA G40.21 was $k_{G 40.21}=0.941$.

The room temperature yield strength behavior of A 36 and A 572 was established using the formalism of the WTC mechanical properties report (NIST NCSTAR 1-3D, Equation 3-5, Section 3.5.1, page 65),

$$
\sigma_{y s}=k_{s} F_{y}+k_{\text {dynamic }}+k_{\text {flange }}
$$

where the factor $k_{s}=1.2$ is the historical average excess yield strength for rolled shapes.

Because the CSA G40.21-44W is in plate form, the estimate for static yield strength is slightly different (NIST NCSTAR 1-3D, Equation 3-6, Section 3.5.1, page 65),

$$
\sigma_{y s}=k_{p} F_{y}+k_{\text {dynamic }}
$$

where the factor $k_{p}=1.092$ was the historical average excess yield strength for plates.

The additive dynamic to static correction factor is

$$
\sigma_{y s}-\sigma_{y d}=-6.895(3.2+1000 \dot{\varepsilon})=k_{\text {dynamic }}
$$

where the strain rate is expressed in $\mathrm{s}^{-1}$ and the stresses are expressed in MPa. 
The strain rate used for the mill test report is assumed to be to be $d \varepsilon / d t=6 \times 10^{-4} \mathrm{~s}^{-1}$, which leads to $\mathrm{k}_{\text {dynamic }}=-26.2 \mathrm{MPa}$. The flange correction factor, $k_{\text {flange }}=-17.9 \mathrm{MPa}$ represents the correction for the fact that the specimen for qualification came from the web of the shape, but the flange, which is generally slightly lower strength, represents the bulk of the load carrying area.

Applying those corrections to the specified yield strengths for A 572 ( $\left.F_{y}=50 \mathrm{ksi}=345 \mathrm{MPa}\right)$, A 36 $\left(F_{y}=248 \mathrm{MPa}\right)$, and CSA G40.21-44W $\left(F_{y}=303 \mathrm{MPa}\right)$ produced the respective static (zero deformation rate) yield strengths,

$$
\begin{gathered}
\sigma_{y s}^{A 572}=369.6 \mathrm{MPa} \\
\sigma_{y s}^{G 40.21}=305.1 \mathrm{MPa} \\
\sigma_{y s}^{A 36}=253.7 \mathrm{MPa}
\end{gathered}
$$

The plastic portion of each stress-strain curve was combined with the elastic portion by first solving for the strain at yield via $\sigma=E \varepsilon_{y}$ and then solving the plastic stress strain equation for the strain at the yield static yield strength and shifting the strains left until the two strains were equal.

The temperature dependence of the elastic modulus, $E$, was taken from Equation 2-2 of NIST NCSTAR 1-3D,

$$
\begin{aligned}
& \quad E(T)=e_{0}+e_{1} T+e_{2} T^{2}+e_{3} T^{3} \\
& \text { where } \\
& e_{0}=\quad 206.0 \mathrm{GPa} \\
& e_{1}=-0.04326 \mathrm{GPa} /{ }^{\circ} \mathrm{C} \\
& e_{2}=-3.502 \times 10^{-5} \mathrm{GPa} /{ }^{\circ} \mathrm{C}^{2} \\
& e_{3}=-6.592 \times 10^{-8} \mathrm{GPa} /{ }^{\circ} \mathrm{C}^{3}
\end{aligned}
$$

Equation 7 was based on modulus measurements made at NIST for the World Trade Center investigation.

The results of this procedure for modeling the stress-strain behavior were reasonable. Figure E-2 compares the model to some actual data. The data for the A 572 are from specimen $\mathrm{HH}$, the base steel for all the steel models. The data for A 36 come from a variety of WTC and literature A 36 steels.

The elevated-temperature stress-strain curves do not follow any pre-ordained "master curve" behavior for yield strength. Instead, the yield strength is simply the intersection of the temperature-dependent Young's modulus with the suitably adjusted stress-strain curve evaluated for $\dot{\varepsilon}=0.011 / \mathrm{s}$. The intersection point is the first point in the model stress strain curves, and, by design, the slope between $(0,0)$ and the first stressstrain point is equal to Young's modulus at the temperature of interest. Figure E-3 compares the behavior of this "yield strength" for these curves to the master curve behavior generated in the WTC investigation. The small humps in the "yield strength" at temperatures in the range $400{ }^{\circ} \mathrm{C}<\mathrm{T}<550{ }^{\circ} \mathrm{C}$ arise from the complex interaction of $K(T)$ and $n(T)$, which were evaluated independently of each other. The actual stress-strain behavior, shown in Figures E-4, E-5, and E-6, decreases monotonically with temperature, and the individual stress-strain curves do not cross. All three "yield strength" curves in Figure E-3 lie above the original master curve, as they should because they represent data for larger strain rates. Their trend of generally decreasing strength with increasing temperature is correct. 


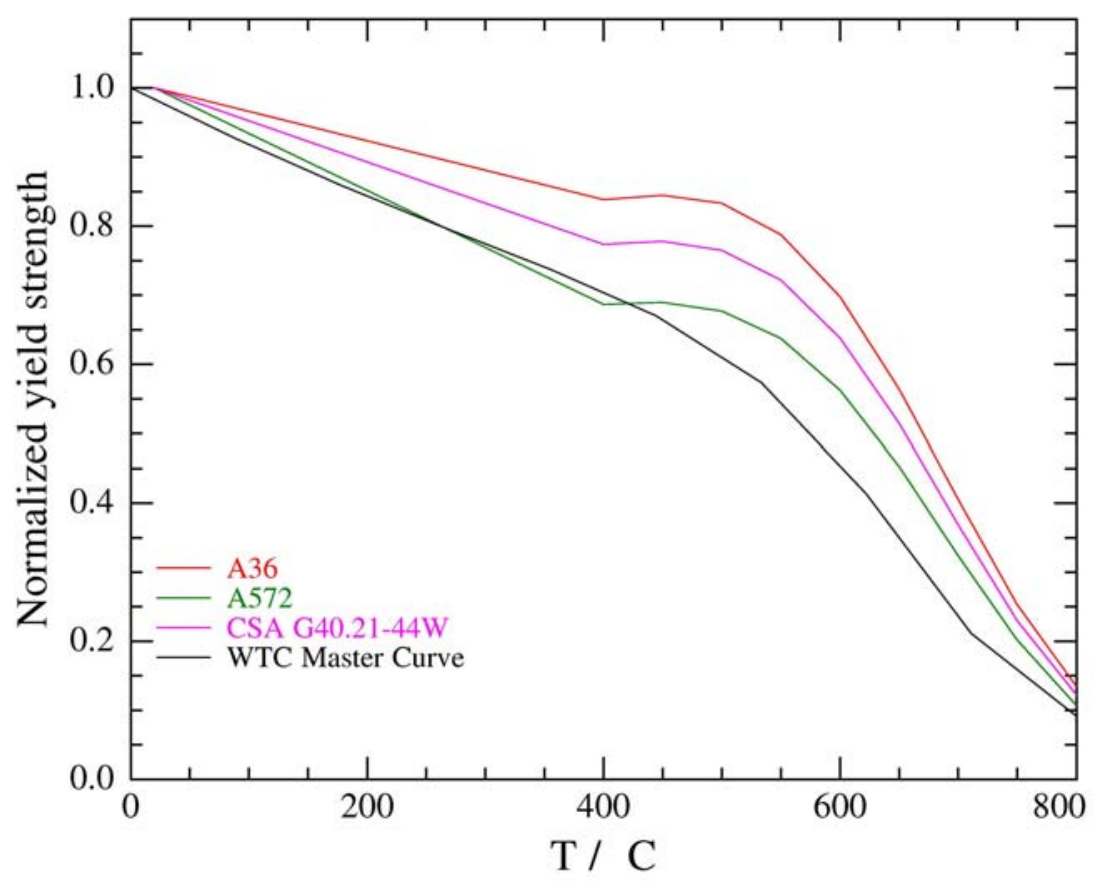

Figure E-2. Base and modeled stress-strain behavior at $20^{\circ} \mathrm{C}$ for A 36 and A 572 steels.

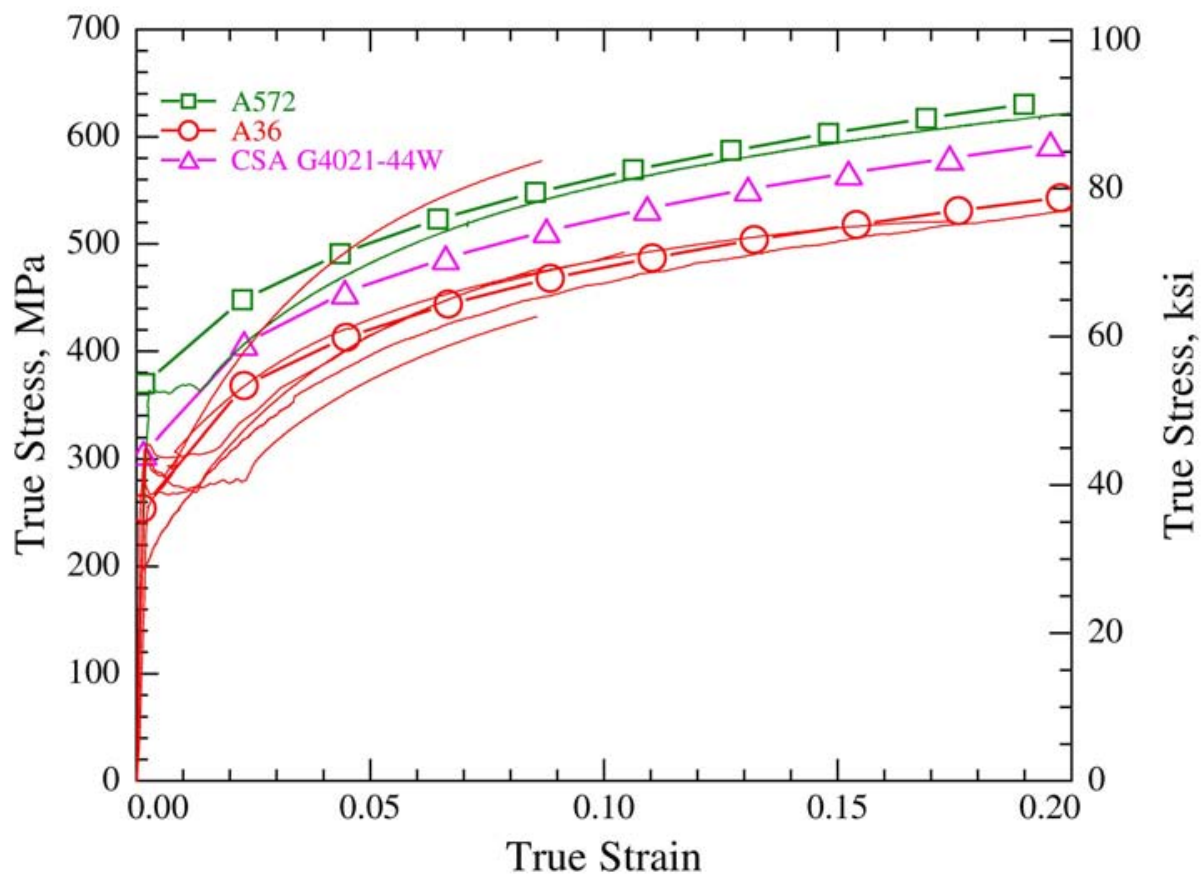

Figure E-3. "Yield strength" evaluated from the high-temperature stress strain curves and the master curve developed for the WTC investigation. 


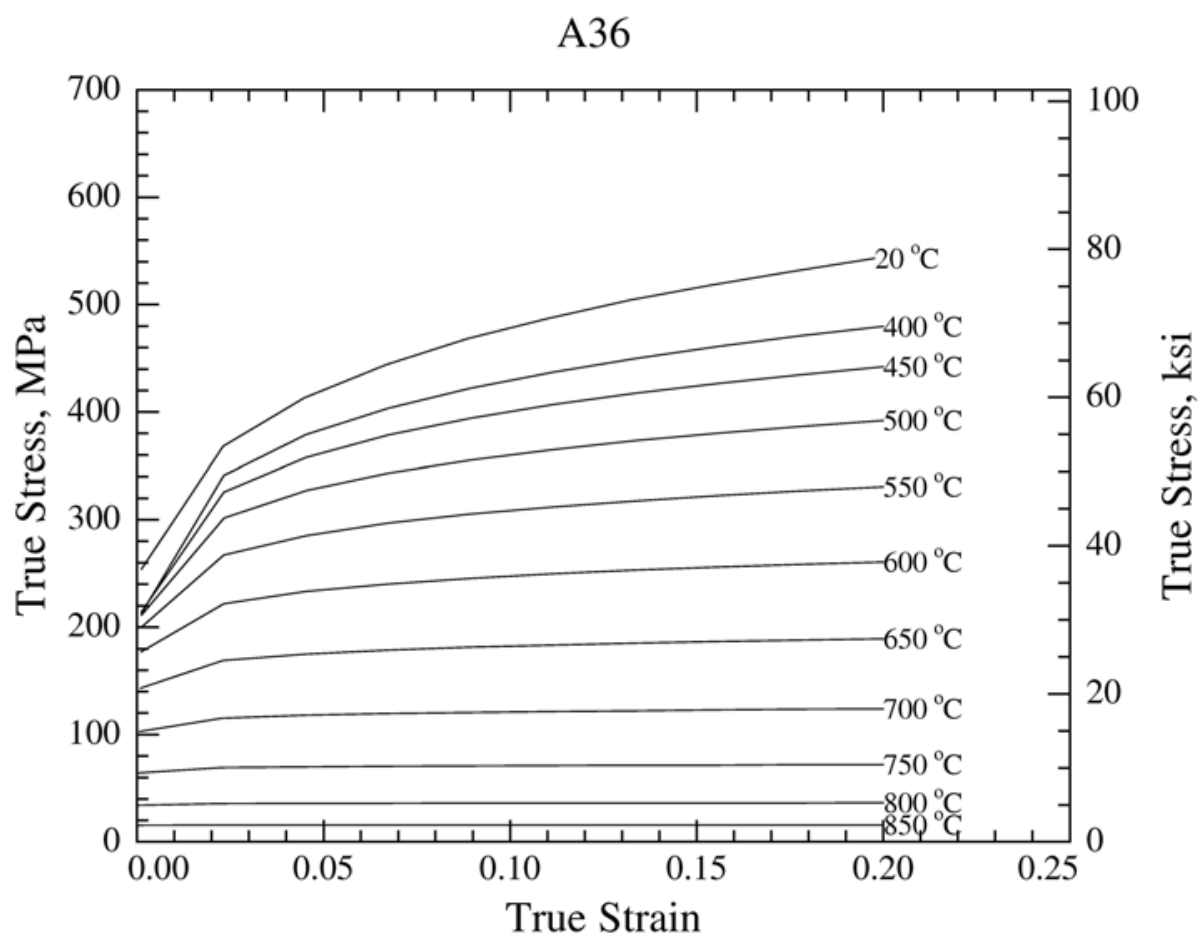

Figure E-4. Elevated-temperature stress-strain curves for $d \varepsilon / d t=10^{-2} \mathbf{s}^{-1}$ for A 36 steel.

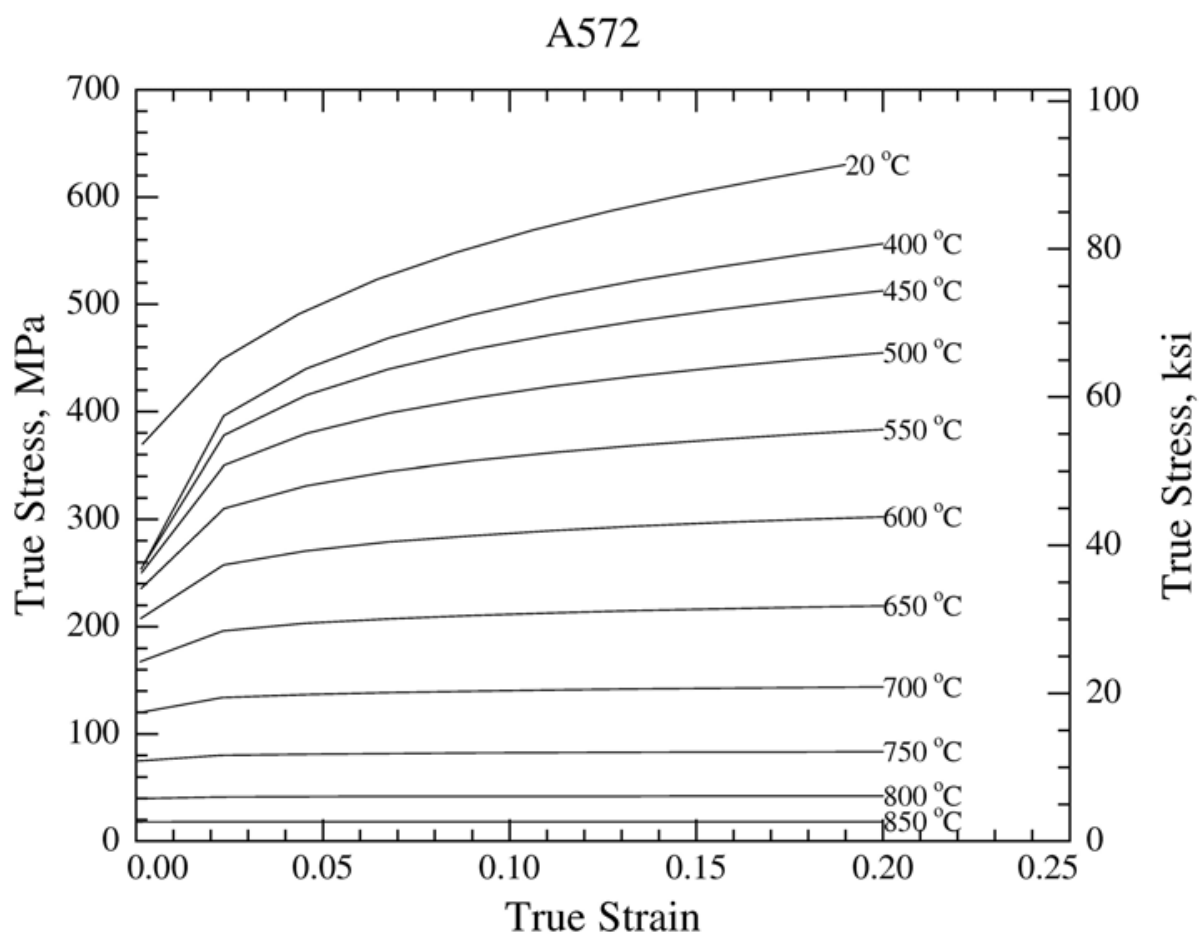

Figure E-5. Elevated temperature stress-strain curves for $d \varepsilon / d t=10^{-2} \mathbf{s}^{-1}$ for A 572 steel. 


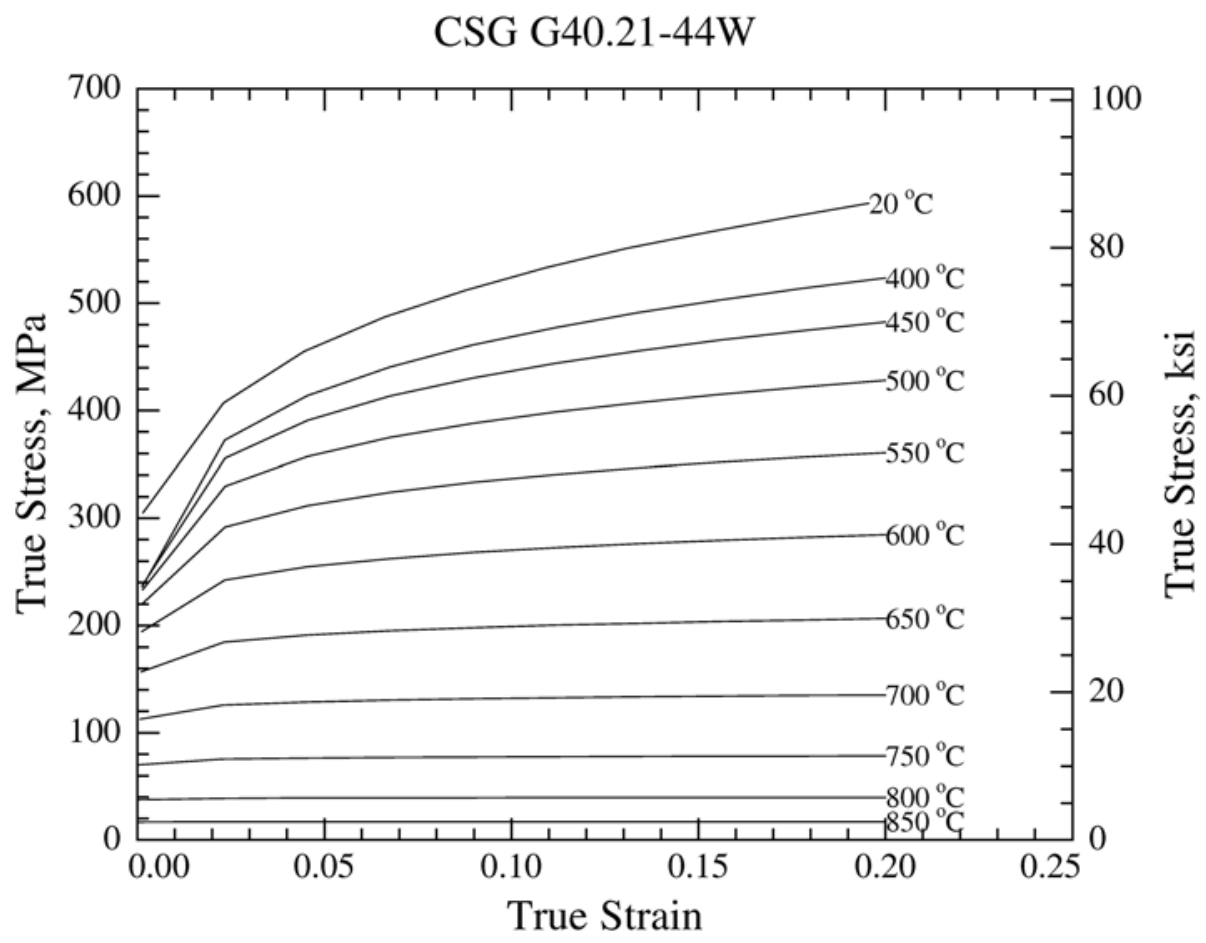

Figure E-6. Elevated-temperature stress-strain curves for $d \varepsilon / d t=10^{-2} \mathrm{~s}^{-1}$ for CSA G40.2144W steel.

\section{E.2.1 Tensile Strength}

The stress-strain models were expressed in terms of true stress and true strain. For design and analysis at room temperature, the tensile strength, TS, is an essential parameter. Although the true stress-strain behavior does not include a tensile strength, it was important that the tensile strength chosen be consistent with the true stress-strain behavior. The tensile strength of the A 36 steel model used in the WTC investigation for WF shapes was $T S=444 \mathrm{MPa}$, which the test specimen reached at an engineering strain, $e_{T S}=0.226$. The true stress-strain behavior for A 36 steel in this report was consistent with that value. The tensile strength, TS, of A 572 steel used as the model for the plastic behavior of all three steels reached $T S=512 \mathrm{MPa}$ at an engineering strain, $e_{T S}=0.173$. The engineering stress evaluated at this strain from the true-stress-strain curve was slightly larger than the measured value: TS $=520 \mathrm{MPa}$ vs. TS $=512 \mathrm{MPa}$ (measured). The recommended value was the engineering stress calculated from the true stress-strain curve at $e_{T S}=0.173: T S=520 \mathrm{MPa}$

No experimental data existed for the CSA G40.21-44W steel. The true stress-strain behavior modeled was essentially an average of the A 572 and A 36 behaviors, but chemically the steel is more like A 572 than A 36. Therefore, the estimated tensile strength was evaluated from the CSA G40.21-44W true stressstrain curve, at the true strain of the tensile strength of A 572: $e_{T S}=0.173$.

Table E-2 summarizes the recommended values for all three steels. 
Table E-2. Values of the tensile strength, TS, of A 36, CSA G40.21-44W, and A 572.

\begin{tabular}{|c|c|c|c|c|}
\hline Steel & $\begin{array}{c}\text { TS } \\
\mathbf{( k s i )}\end{array}$ & $\begin{array}{c}\text { TS } \\
\mathbf{( M P a )}\end{array}$ & $\varepsilon_{\text {TS }}$ & $\boldsymbol{e}_{\text {TS }}$ \\
\hline A 36 & 64.5 & 444 & 0.204 & 0.226 \\
\hline CSA G40.21-44W & 70.6 & 487 & 0.160 & 0.173 \\
\hline A 572 & 74.3 & 520 & 0.160 & 0.173 \\
\hline
\end{tabular}

$\varepsilon_{T S}$ true strain at the value of the tensile strength, $T S$.

$e_{T S}$ engineering strain at the value of the tensile strength, $T S$.

\section{E.2.2 ANSYS Stress-strain Models}

The analysis used the ANSYS multilinear isotropic hardening model (MISO). This model defines piecewise-linear stress-strain curves at fixed temperatures. The origin is not included, and the slope of the first segment between the implied $(0,0)$ and the first point, which is the yield strength, must equal the elastic modulus at the appropriate temperature. Each steel model, shown in Tables E-3, E-4, and E-5, consisted of ten stress-strain pairs, plus the implied $(0,0)$ at specific temperatures: $(20,400,450,500,550,600,650$, $700,750,800,850)^{\circ} \mathrm{C}$. The creep models consist of lines that define the temperature and stress-strain pairs, for example

TBTEMP, 20

TBPT, , $1.2370 \mathrm{e}-03,36.8$

The TBTEMP line defines the temperature as $20^{\circ} \mathrm{C}$. The TBPT line defines the strain-stress pair in which the strain is $1.2370 \times 10^{-3}$ and the stress is $36.8 \mathrm{ksi}$. Figures E-4, E-5, and E-6show the shapes of the stress-strain curves generated by the ANSYS models of Tables E-3, E-4, and E-5.

\section{E.3 METHOD FOR CREATING HIGH-TEMPERATURE CREEP CURVES}

\section{E.3.1 Background}

The WTC investigation developed a methodology for estimating the creep properties of untested steels based on creep models of existing steels. We evaluated several different scaling methods. Scaling the applied stress by the ratio of the tensile strength of the reference steel to that of the unknown steel produced the best agreement. We drew this conclusion by predicting, using the fitted creep models of Williams-Leir (1983), the behavior of each of five literature steels from a sixth literature steel, for all possible permutations of those six steels. Although tensile strength scaling produced the best agreement, in many cases the agreement was not very good. Frequently the predicted strain differed from the actual by more than a factor of ten. Differences of this magnitude correspond to temperature offsets of around $35{ }^{\circ} \mathrm{C}$ or stress offsets of $17 \mathrm{MPa}$. Not surprisingly, the agreement was best when the correction was small, and within a class, e.g., steels specified with $Y S=36 \mathrm{ksi}$ or $Y S=50 \mathrm{ksi}$. Because no steel relevant to the creep modeling was recovered from WTC7, it is impossible to create more accurate models. 
Table E-3. ANSYS stress-strain model for A $\mathbf{3 6}$ steel. ! Generated on Thu Jun 7 14:32:56 2007 ! ANSYS multilinear isotropic hardening (MISO) model for A36 steel

! Units:

! strain : true, natural units, dimensionless

! temperature: $\mathrm{C}$

! stress : ksi

TB, MISO $1,11,10,0$

TBTEMP, 20

TBPT, $, 1.2370 e-03,36.8$

TBPT, , 2.3063e- $-2,53.3$

TBPT, , 4. 4889e- $02,60.0$

TBPT, $, 6.6715 e-02,64.4$

TBPT, , 8.8541e-02,67.9

TBPT , 1.1037e-01, 70.7

TBPT, , 1.3219e-01, 73.1

TBPT , 1.5402e-01, 75.2

TBPT, $, 1.7584 \mathrm{e}-01,77.1$

TBPT $, 1.9767 e-01,78.8$

TBTEMP, 400

TBPT , 1.1891e-03, 30.9

TBPT, , 2.3279e-02, 49.5

TBPT, , 4.5369e-02, 55.0

TBPT, , 6.7459e-02, 58.5

TBPT, , 8.9550e-02, 61.2

TBPT , 1.1164e-01, 63.4

TBPT, , 1.3373e- $01,65.3$

TBPT, $1.5582 \mathrm{e}-01,66.9$

TBPT, , 1.7791e-01,68.3

TBPT , 2. 2.0000e-01, 69.6

TBTEMP, 450

TBPT , , 1. 2358e-03, 31.1

TBPT , 2. 3321e-02, 47.2

TBPT, , 4.5406e- $02,51.9$

TBPT , , 6.7491e-02, 54.9

TBPT, , 8.9575e-02, 57.2

TBPT, , 1.1166e-01, 59.0

TBPT, , 1.3375e-01, 60.5

TBPT $, 1.5583 e-01,61.9$

TBPT, , 1. 7792e- $01,63.0$

TBPT , 2. $0000 \mathrm{e}-01,64.1$

TBTEMP, 500

TBPT, , 1.2623e-03, 30.6

TBPT, , 2. 3344e- $-02,43.7$

TBPT, , 4.5426e- $02,47.5$

TBPT , , 6.7508e- $02,49.8$

TBPT, , 8.9590e- $02,51.6$

TBPT , 1.1167e-01, 53.0

TBPT, , 1.3375e-01, 54.1

TBPT $, 1.5584 \mathrm{e}-01,55.2$

TBPT, $, 1.7792 e-01,56.1$

TBPT, $, 2.0000 \mathrm{e}-01,56.9$

TBTEMP, 550

TBPT, $, 1.2438 e-03,29.0$

TBPT, , 2.3328e- $02,38.7$

TBPT, , 4.5412e-02, 41.4

TBPT, , 6.7496e- $02,43.0$

TBPT, , 8.9580e- $02,44.3$

TBPT $, 1.1166 e-01,45.2$

TBPT, $, 1.3375 e-01,46.1$

TBPT, $1.5583 e-01,46.8$

TBPT, $, 1.7792 e-01,47.4$

TBPT, $, 2.00 \odot \odot e-\odot 1,47.9$

TBTEMP, 600

TBPT, , 1.1555e-03, 25.7

TBPT, , 2. 3249e-02, 32.2

TBPT, , 4.5343e-02, 33.8

TBPT, , 6.7437e-02, 34.8

TBPT, , 8.9531e-02, 35. 6

TBPT, , 1.1162e-01, 36. 2

TBPT, $1.3372 e-01,36.7$

TBPT, , 1.5581e-01, 37.1

TBPT, , 1.7791e-01, 37.5

TBPT, , 2. $0 \odot \odot \odot$ - $01,37.8$

TBTEMP, 650

TBPT, 9.8708 - $04,20.8$

TBPT, , 2.3100e-02, 24.5

TBPT, , 4.5212e-02, 25. 4

TBPT, , 6. 7325e-02, 25.9

TBPT, 8.9437e-02, 26.3

TBPT, , 1.1155e-01, 26.6

TBPT, , 1.3366e-01, 26.9

TBPT, , 1.5577e-01, 27.1

TBPT, , 1.7789e-01, 27. 3

TBPT, , 2. $0 \odot \odot \odot$ - $01,27.4$

TBTEMP, 700

TBPT, , 7.5673e-04, 14.9

TBPT, , 2. 2895e-02, 16.7

TBPT, 4.5033e-02, 17.1

TBPT, , 6.7171e-02, 17.3

TBPT, 8.9309e-02, 17.5

TBPT, , 1.1145e-01, 17.6

TBPT, , 1.3359e-01, 17. 7

TBPT, , 1.5572e-01, 17.8

TBPT, , 1.7786e-01, 17.9

TBPT, , 2.000०е-01, 18.0

TBTEMP, 750

TBPT, , 5.0978e-04, 9. 3

TBPT, , 2. 2675e-02, 10.0

TBPT , 4. 4841e-02, 10.1

TBPT, , 6.7007e-02, 10.2

TBPT, , 8.9172e-02, 10.3

TBPT, , 1.1134e-01, 10. 3

TBPT, , 1.3350e-01, 10.4

TBPT, $, 1.5567 e-01,10.4$

TBPT, , $1.7783 e-01,10.4$

TBPT, , 2.000०e-01, 10. 4

TBTEMP, $80 \odot$

TBPT, , 2. 9683e-04, 5.0

TBPT, , 2. 2486e-02, 5.2

TBPT, 4.4675e-02, 5. 2

TBPT, , 6.6865e-02, 5.2

TBPT, 8. 9054e-02, 5. 2

TBPT, , 1.1124e-01, 5. 2

TBPT, , 1.3343e-01, 5.3

TBPT, , 1.5562e-01, 5.3

TBPT, , 1.7781e-01, 5.3

TBPT, , 2.000०e-01, 5.3

TBTEMP, 850

TBPT, , 1.4766e-04, 2.2

TBPT, , 2. 2353e-02, 2.3

TBPT, 4. 4559e-02, 2. 3

TBPT, , 6.6765e-02, 2.3

TBPT, , 8. 8971e-02, 2.3

TBPT, , 1.1118e-01, 2.3

TBPT, , 1.3338e-01, 2.3

TBPT, 1. 1.5559e-01, 2.3

TBPT, , 1.7779e-01, 2.3

TBPT, , 2. $000 \odot e-01,2.3$ 
Table E-4. ANSYS stress-strain model for A $\mathbf{5 7 2}$ steel.

!Generated on Thu Jun 7 14:32:56 2007 ! ANSYS multilinear isotropic hardening (MISO) model for A36 steel

! Units:

! strain : true, natural units,

dimensionless

! temperature : $\mathrm{C}$

! stress : ksi

$T B, M I S 0,1,11,10,0$

TBTEMP, 20

TBPT, 1.2370 e $-03,36.8$

$T B P T, 2.3063 e-02,53.3$

TBPT, , 4. 4889e-02, 60. 0

TBPT, $, 6.6715 e-02,64.4$

TBPT, 8.8541e-02,67.9

TBPT, $, 1.1037 e-01,70.7$

TBPT, 1.3219e-01,73.1

TBPT, $, 1.5402 e-01,75.2$

TBPT, 1.7584e-01, 77.1

TBPT, , 1.9767e-01, 78.8

TBTEMP 400

TBPT, , 1. 1891e-03, 30.9

TBPT, , 2.3279e-02, 49.5

TBPT, , 4.5369e-02, 55. $\odot$

TBPT, $6.7459 e-02,58.5$

TBPT, , 8.9550e-02,61.2

TBPT, $, 1.1164 e-01,63.4$

TBPT $, 1.3373 e-01,65.3$

TBPT , $1.5582 e-01,66.9$

TBPT, , 1. 7791e-01, 68. 3

TBPT, , 2.000०е-01, 69. 6

TBTEMP, 450

TBPT, 1.2358e-03, 31.1

TBPT, $, 2.3321 e-02,47.2$

TBPT, , 4.5406e-02, 51.9

TBPT, , 6.7491e-02, 54.9

TBPT, 8.9575e-02, 57.2

TBPT, , $1.1166 e-01,59.0$

TBPT, 1. 1.3375e-01, 60.5

TBPT, , 1.5583e-01, 61.9

TBPT, , 1.7792e-01, 63.0

TBPT, , 2. .000०e-01, 64.1

TBTEMP, 500

TBPT, , 1.2623e-03, 30.6

TBPT, , 2. 3344e-02, 43.7

TBPT , 4.5426e-02, 47.5

TBPT, , 6.7508e-02, 49.8

TBPT, 8.9590e-02,51.6

TBPT, , 1.1167e-01, 53.0

TBPT, , 1.3375e-01, 54.1

TBPT, , 1.5584e-01, 55.2

TBPT, , 1.7792e-01, 56.1

TBPT, , 2. $0000 \mathrm{e}-01,56.9$

TBTEMP, 550

TBPT, , 1.2438e-03, 29. $\odot$

TBPT, , 2. 3328e-02, 38.7

TBPT , 4.5412e-02, 41. 4

TBPT, , 6.7496e-02, 43.0

TBPT, 8.9580e-02, 44.3

TBPT, , 1.1166e-01, 45.2

TBPT, , 1.3375e-01, 46.1

TBPT, , 1.5583e-01, 46.8

TBPT, $, 1.7792 e-01,47.4$

TBPT, , 2.00००e-01, 47.9

\section{TBTEMP, 600}

TBPT, $1.1555 e-03,25.7$

TBPT, , 2. 3249e- $02,32.2$

TBPT , 4.5343e-02, 33.8

TBPT, , 6.7437e-02, 34.8

TBPT , 8.9531e-02, 35.6

TBPT, , 1.1162e-01, 36.2

TBPT $, 1.3372 e-01,36.7$

TBPT, , 1.5581e-01, 37.1

TBPT, , 1.7791e-01, 37.5

TBPT, , 2. $0000 \mathrm{e}-01,37.8$

TBTEMP, 650

TBPT , 9.8708e-04, 20.8

TBPT, , 2.3100e- $02,24.5$

TBPT , 4.5212e-02, 25.4

TBPT, , 6.7325e-02, 25.9

TBPT , 8.9437e-02, 26. 3

TBPT, , 1.1155e-01, 26.6

TBPT , 1.3366e-01, 26. 9

TBPT, , 1.5577e-01, 27.1

TBPT, , 1.7789e-01, 27. 3

TBPT, , 2. $0000 \mathrm{e}-01,27.4$

TBTEMP, 700

TBPT , 7.5673e-04, 14.9

TBPT, , 2.2895e-02, 16.7

TBPT , 4.5033e-02, 17.1

TBPT, , 6.7171e-02, 17.3

TBPT , 8.9309e-02, 17.5

TBPT, , 1.1145e-01, 17.6

TBPT, , 1.3359e-01, 17.7

TBPT , 1.5572e-01, 17.8

TBPT, , $1.7786 e-01,17.9$

TBPT, , 2. 0000 e-01, 18.0

TBTEMP, 750

TBPT, $5.0978 e-04,9.3$

TBPT, , 2.2675e- $02,10 . \odot$

TBPT , 4.4841e-02, 10.1

TBPT, , 6.7007e-02, 10.2

TBPT , 8.9172e-02, 10. 3

TBPT, , 1.1134e-01, 10. 3

TBPT , 1.3350e-01, 10. 4

TBPT, , 1.5567e-01, 10.4

TBPT, $1.7783 e-01,10.4$

TBPT , 2. 0000 e-01, 10. 4

TBTEMP, 800

TBPT, , 2.9683e-04, 5.0

TBPT , , 2.2486e-02,5.2

TBPT, 4. 4675e-02, 5.2

TBPT, , 6.6865e-02, 5.2

TBPT, , 8.9054e-02, 5.2

TBPT, , 1.1124e-01, 5.2

TBPT, $, 1.3343 e-01,5.3$

TBPT, $1.5562 e-01,5.3$

TBPT, , $1.7781 e-01,5.3$

TBPT, , 2.0000e-01, 5.3

TBTEMP, 850

TBPT, $1.4766 e-04,2.2$

TBPT $, 2.2353 e-02,2.3$

TBPT, 4. 4559e-02, 2.3

TBPT, , 6.6765e-02, 2.3

TBPT, , 8.8971e-02, 2.3

TBPT, $1.1118 e-01,2.3$

TBPT, , 1.3338e-01, 2.3

TBPT, $1.5559 e-01,2.3$

TBPT, $, 1.7779 e-01,2.3$

TBPT, , 2. $000 \odot e-01,2.3$ 
Table E-5. ANSYS stress-strain model for CSA G40.21-44W steel.

! Generated on Thu Jun 7 14:32:56 2007

! ANSYS multilinear isotropic hardening (MISO)

model for CSA G40.21-44W steel

! Units:

! strain : true, natural units,

dimensionless

! temperature : $\mathrm{C}$

! stress : ksi

TB, MISO $1,11,10,0$

TBTEMP, 20

TBPT, , 1. 4873e-03, 44.2

TBPT, $, 2.3048 e-02,59.1$

TBPT, , 4. 4609e-02,65.9

TBPT, $, 6.6170 e-02,70.6$

TBPT, 8.7731e-02, 74.3

TBPT, $1.0929 e-01,77.3$

TBPT, $1.3085 e-01,79.9$

TBPT, $1.5241 e-01,82.1$

TBPT, 1. 1397e-01, 84.1

TBPT, , 1.9554e-01, 86. $\odot$

TBTEMP, $40 \odot$

TBPT,, $1.3195 e-0334.2$

TBPT,, $2.3395 e-0254.0$

TBPT, , 4.5471e-02 60.0

TBPT, , 6.7546e-02 63.9

TBPT, 8.9622e-02 66.8

TBPT,, 1.1170 e-01 69.2

TBPT, $1.3377 e-0171.2$

$T B P T, 1.5585 e-0173.0$

TBPT , 1.7792e-01 74.5

TBPT, , 2.0000e-01 75.9

TBTEMP, 450

TBPT, 1.3685e-03 34.4

TBPT, , 2.3439e-02 51.6

TBPT, $4.5509 e-0256.7$

TBPT, , 6.7579e-02 60. $\odot$

TBPT, 8.9649e-02 62.4

TBPT,, $1.1172 e-0164.4$

TBPT, 1.3379e-01 66.1

TBPT, , $1.5586 e-0167.5$

TBPT, , 1.7793e-01 68.8

TBPT, , 2. 0000 e-01 70.०

TBTEMP, 500

TBPT, 1.3945e-03 33.9

TBPT, , 2.3462e-02 47.8

TBPT, 4.5529e-02 51.8

TBPT, , 6.7596e-02 54.4

TBPT, 8.9664e-02 56.3

TBPT, , 1.1173e-01 57.8

TBPT, , 1.3380e-01 59.1

TBPT,, $1.5587 e-0160.2$

TBPT,, $1.7793 e-0161.2$

TBPT, , 2.000०e-01 62.1

TBTEMP, 550

TBPT, $1.3707 e-0331.9$

TBPT, , 2.3441e-02 42.3

TBPT, 4.5511e-02 45.2

TBPT, , 6.7580e-02 47.0

TBPT, 8.9650e-02 48.3

TBPT, , 1.1172e-01 49.4

TBPT, , 1.3379e-01 50.3

TBPT, , 1.5586e-01 51.0

TBPT, $1.7793 e-0151.7$

TBPT, , 2.000७e-01 52.3

\section{TBTEMP, $60 \odot$}

TBPT, $1.2702 e-0328.2$

TBPT, , 2.3351e-02 35.1

TBPT , 4.5432e-02 36.9

TBPT, , 6.7513e-02 38.0

TBPT , 8.9595e-02 38.8

TBPT, , 1.1168 e-01 39.5

TBPT , 1.3376e-01 40.0

TBPT, , $1.5584 e-0140.5$

TBPT, , 1.7792e-01 40.9

TBPT, , 2. $000 \odot \mathrm{e}-0141.3$

TBTEMP, 650

TBPT, $1.0826 e-0322.8$

TBPT, , 2.3184e-02 26.7

TBPT , 4.5286e-02 27.7

TBPT, , 6.7388e-02 28.3

TBPT , 8.9490e-02 28.7

TBPT, , 1.1159e-01 29. $\odot$

TBPT , 1.3369e-01 29. 3

TBPT, , $1.5580 e-0129.5$

TBPT, , 1.7790e-01 29.7

TBPT, , 2.000७e-01 29.9

TBTEMP, 700

TBPT , 8.2841e-04 16.3

TBPT, , 2.2959e-02 18.2

TBPT , 4.5089e-02 18.7

TBPT, , 6.7219e-02 18.9

TBPT , 8.9349e-02 19.1

TBPT, , 1.1148 - 0119.2

TBPT , 1.3361e-01 19.3

TBPT , 1.5574e-01 19.4

TBPT, , $1.7787 e-0119.5$

TBPT, , 2.00००e-01 19.6

TBTEMP, 750

TBPT , 5.5732e-04 10.2

TBPT, , 2.2718e-02 10.9

TBPT , 4.4878e-02 11.1

TBPT, , 6.7038e-02 11.2

TBPT , 8.9199e-02 11.2

TBPT, , 1.1136e-01 11.3

TBPT, $1.3352 e-0111.3$

TBPT , 1.5568e-01 11.3

TBPT,, $1.7784 e-0111.4$

TBPT, , 2.0000e-01 11.4

TBTEMP, 800

TBPT, $3.2424 e-045.4$

TBPT, , 2.2510e-02 5.6

TBPT, 4. 4697e-02 5.7

TBPT, , 6.6883e-02 5.7

TBPT, , 8.9069e-02 5.7

TBPT, $1.1126 e-015.7$

TBPT, , 1.3344e-01 5.7

TBPT , 1.5563e-01 5.7

TBPT, , 1.7781e-01 5.7

TBPT , 2.0000e-01 5.8

TBTEMP, 850

TBPT, $1.6122 e-042.4$

TBPT, , 2.2366e-02 2.5

TBPT, 4.4570e-02 2.5

TBPT, , 6.6774e-02 2.5

TBPT, , 8.8978e-02 2.5

TBPT, $1.1118 e-012.5$

TBPT, $1.3339 e-012.5$

TBPT, $1.5559 e-012.5$

TBPT,, $1.7780 e-012.5$

TBPT, , 2.000९e-01 2.5 
Figure E-7 shows that the creep properties of the 36 ksi steels, taken from the models of Williams-Leir (1983) were remarkably similar. Figure E-8 shows that the creep behavior of the higher strength steels, also taken from the models of Williams-Leir (1983) was less consistent.
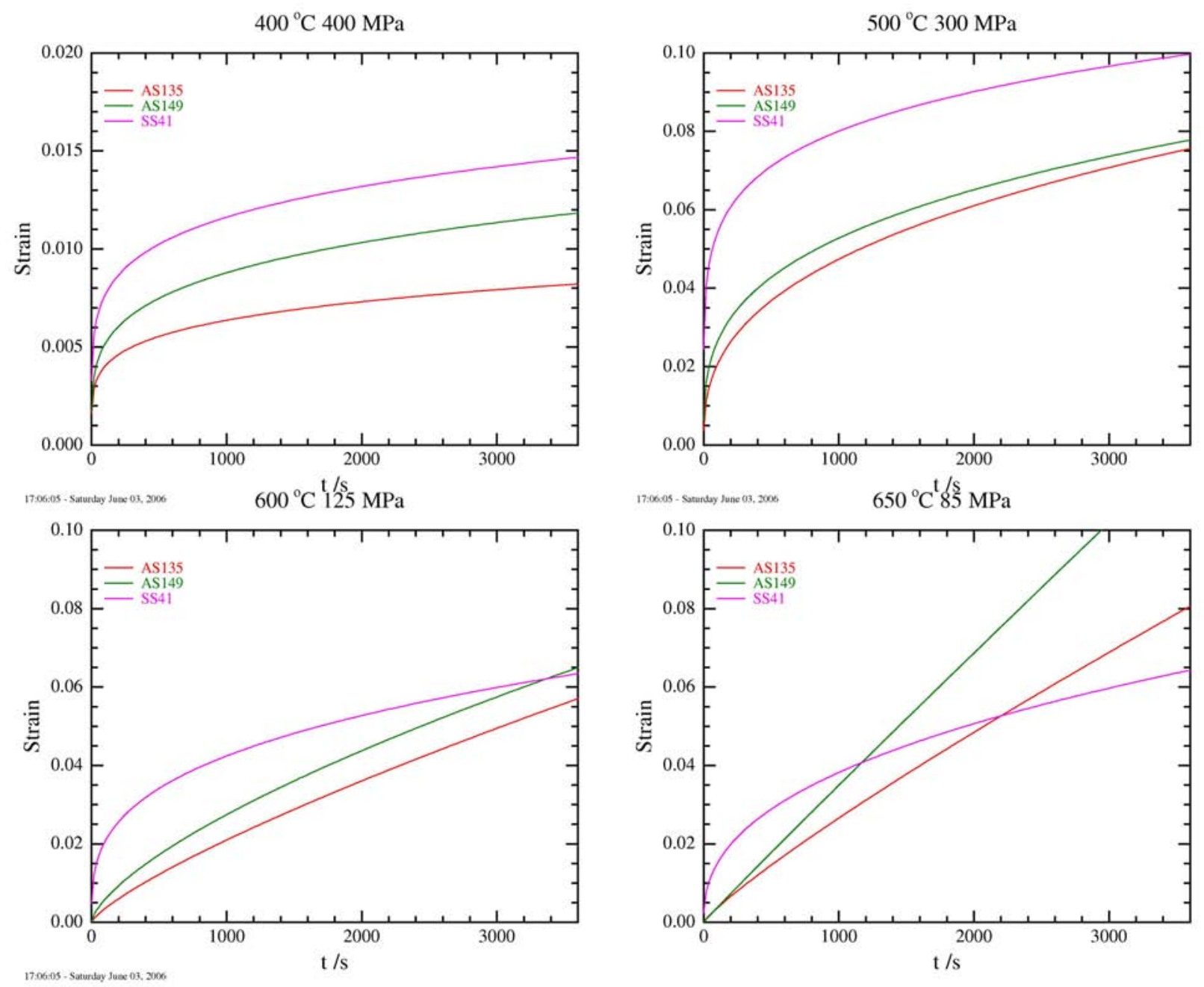

Figure E-7. Creep curves for various $36 \mathrm{ksi}$ steels, from the fits of Williams-Leir, evaluated at convenient temperatures and stresses. 
$400{ }^{\circ} \mathrm{C} 400 \mathrm{MPa}$

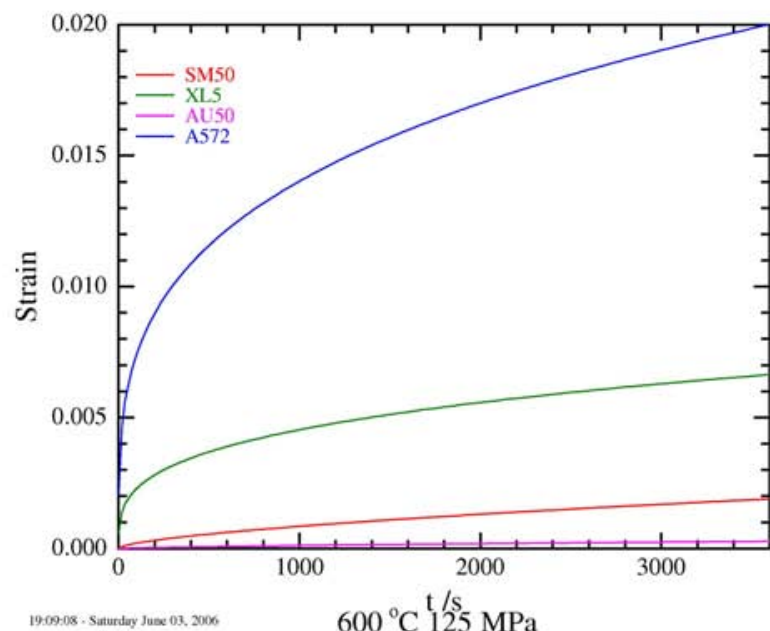

$600{ }^{\circ} \mathrm{C} 125 \mathrm{MPa}$

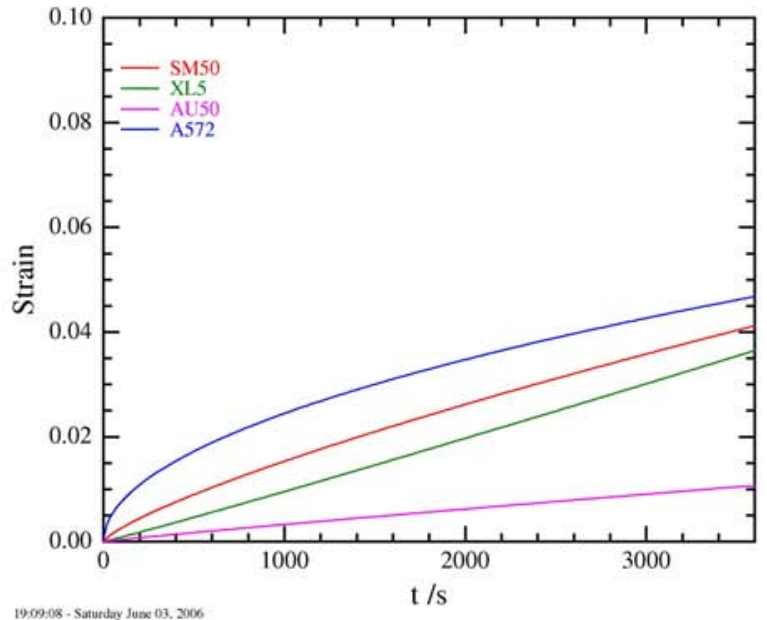

$500{ }^{\circ} \mathrm{C} 300 \mathrm{MPa}$
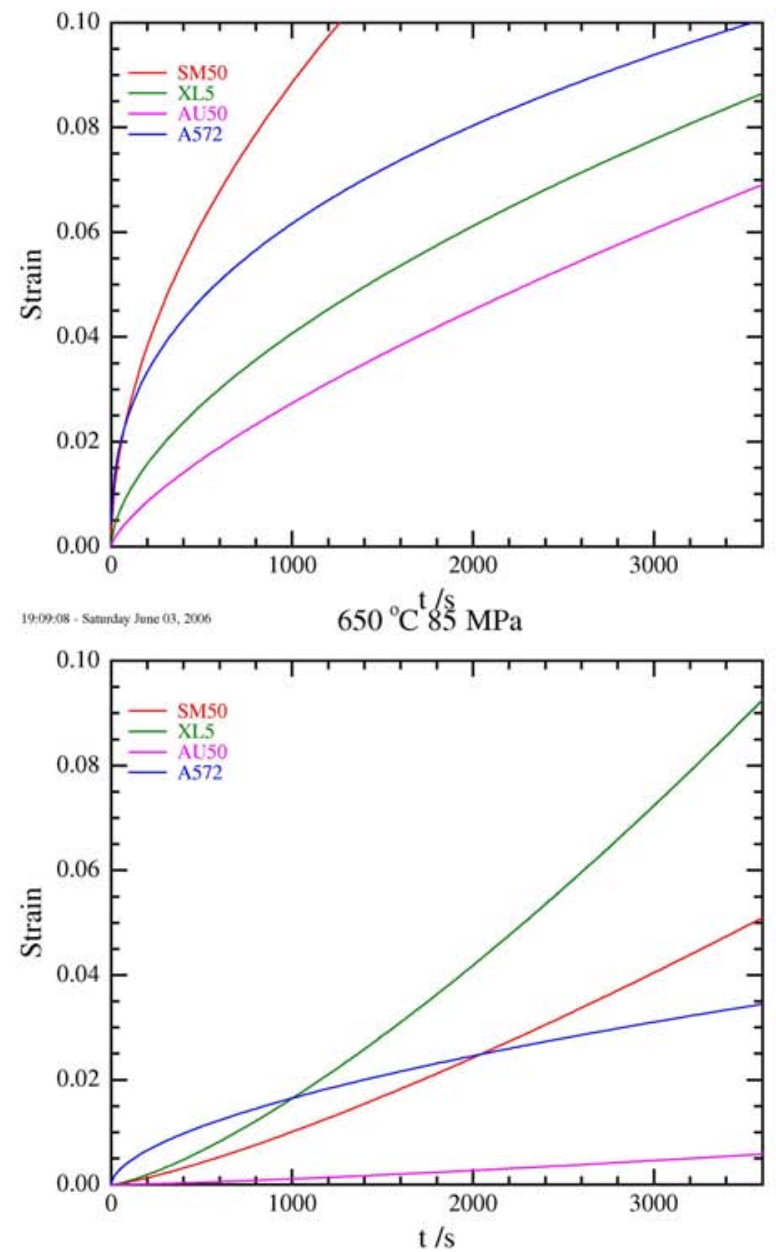

\section{Figure E-8. Creep curves for various high-strength structural steels, evaluated at other convenient temperatures and stresses.}

The A 36 steel creep behavior using the data from the WTC A 572 steel (specimen HH) was scaled using the tensile strength ratio method developed for the WTC investigation, but produced unacceptable results. Figure E-9 compares the A 572 creep data, the global model for creep strain of A 572, and the predicted creep strain for AS149 under those conditions, using the Fields (1989) model. Figure E-10 compares the predicted data for AS149, under the same conditions, using the Fields (1989) model, to the predicted creep behavior using the tensile strength scaling model based on the A 572 steel. The agreement for temperatures above $500{ }^{\circ} \mathrm{C}$ was unsatisfactory.

Predicting the behavior of the CSA G40.21 steel plate was even more difficult, because no experimental data existed for comparison. Given the lack of data, it was expedient to assume that the creep properties of CSA G40.21-44W were identical to the A 572. Both steels were specified with $T S \geq 65 \mathrm{ksi}$, even though the yield strength of CSA G40.21 is only YS = 44 ksi (300 MPa). Furthermore, the chemistry specification for CSA G40.21-44W admits both $\mathrm{V}$ and $\mathrm{Nb}$, which indicates that its chemistry is more like A 572 than A 36. 

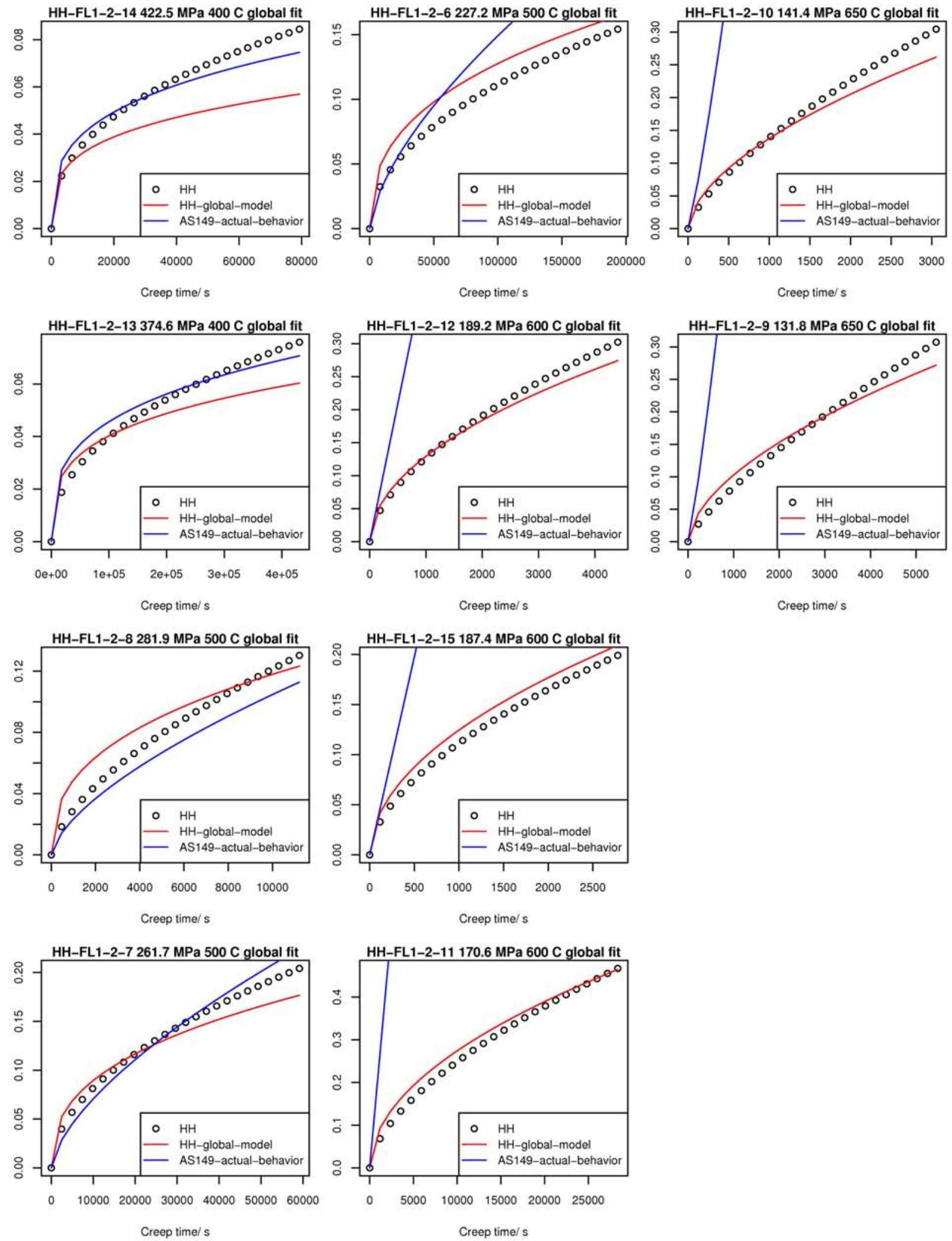

Figure E-9. Comparison of A 572 creep with predictions for AS149 steel. 

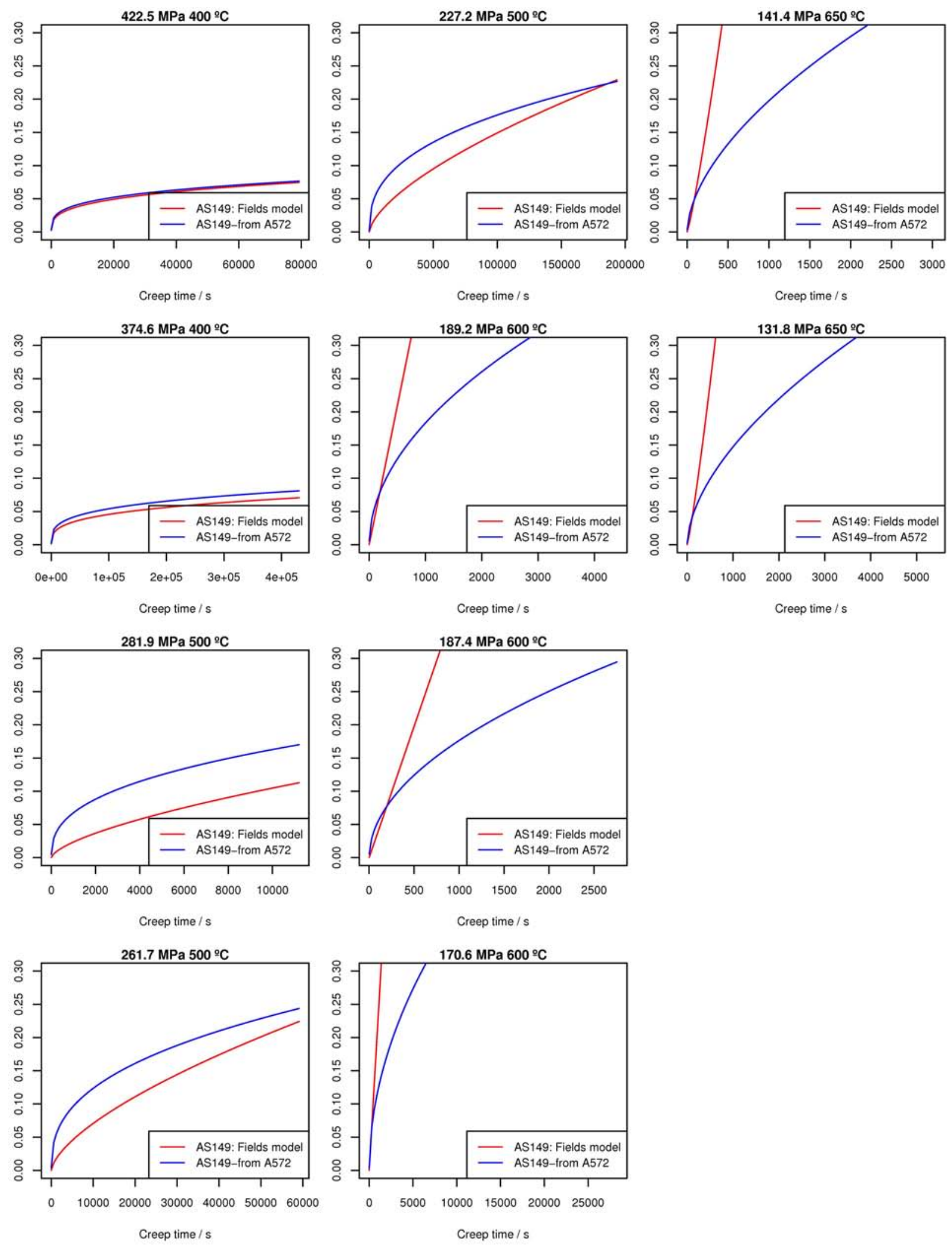

Figure E-10. Comparison of AS149 creep data with predicted data based on A 572 data and tensile strength scaling. 


\section{E.3.2 Method}

The creep behavior of the $Y S=50 \mathrm{ksi}$ steel was modeled on the behavior of WTC A 572 specimen HH. The creep behavior of A 36 steel was modeled based on the parameters in Fields (1989). That model is based on tests of Australian AS149 steel, which is similar to ASTM A 36. The creep behavior of CSA G40.21-44W was modeled under the assumption that it was identical to $Y S=50 \mathrm{ksi}$ A 572. The uncertainties in these models were estimated to be up to $40^{\circ} \mathrm{C}$ in temperature and $20 \mathrm{MPa}$ in stress, based on the observation that the predicted behavior could be as much as a factor of ten different from the observed behavior.

\section{E.3.3 ANSYS Creep Models}

The ANSYS implicit creep model 2 (time hardening) used in the analysis modeled the creep rate, $\dot{\varepsilon}_{\text {cr }}$, using independent functions of stress, $\sigma$, and time, $t$ :

$$
\dot{\varepsilon}_{\text {cr }}=C_{1} \sigma^{C_{2}} t^{C_{3}} \exp \left(-\frac{C_{4}}{T}\right)
$$

Instead of attempting to model the Arrhenius temperature dependence with a single constant, it was easier to specify the individual $C_{i}$ at each temperature of interest and set $C_{4}=0$. In that way it was possible to set the creep strain to identically zero below a lower limit temperature.

The Fields (1989) model for creep strain of AS149 as a function of time and stress has the form:

$$
\begin{gathered}
\varepsilon_{\mathrm{cr}}=A \sigma^{C} t^{B} \\
A(T)=10^{-\left(A_{0}+A T\right)} \\
B(T)=B_{0}+B_{1} T \\
C(T)=C_{0}+C_{1} T
\end{gathered}
$$

Expressed in the ANSYS format for creep rate as a function of time, stress, and temperature, the Fields (1989) model is:

$$
\begin{gathered}
\dot{\varepsilon}_{\mathrm{cr}}=A B \sigma^{C} t^{B-1} \\
A(T)=10^{-\left(A_{0}+A_{1} T\right)} \\
B(T)=B_{0}+B_{1} T \\
C(T)=C_{0}+C_{1} T
\end{gathered}
$$

The ANSYS parameters for creep rate have the form:

$$
\begin{gathered}
C_{1}=A B=10^{-\left(A_{0}+A T\right)}\left(B_{0}+B_{1} T\right) \\
C_{2}=C=C_{0}+C_{1} T \\
C_{3}=B-1=B_{0}+B_{1} T-1 \\
C_{4}=0
\end{gathered}
$$


The global model for strain as a function of time, temperature and stress for the WTC A 572 steel takes the same form as the Fields (1989) model, but the individual functions have different forms.

$$
\begin{gathered}
\varepsilon_{c r}=A \sigma^{n} t^{B} \\
A(T)=10^{-}\left(a_{0}+a_{1} T+a_{2} T^{2}\right) \\
B(T)=b_{0}+b_{1} T^{b_{2}} \\
n(T)=n_{0}+n_{1} T
\end{gathered}
$$

Tables E-6 and E-7 contain the ANSYS creep models used in the analysis.

\section{Table E-6. ANSYS creep model for A 36 steel}

! ANSYS creep model \#2 for A36

! edot $=c 1{ }^{*} \operatorname{sigma\wedge } c 2^{*} t \wedge c 3$

!Fields model: $e=A * \operatorname{sigma\wedge } c t \wedge b$

!strain $=0.01 * A p r i m e * 10 \wedge(-(A \odot+A 1 * T)) * \operatorname{sigma\wedge }(c \Theta+c 1 * T) * t^{\wedge}(b \odot+b 1 * T)$

$! C 1=A b=0.01 * A p r i m e * 10 \wedge\left(-\left(A \odot+A 1^{*} T\right) *(b \odot+b 1 * T)\right.$

$! C 2=C=C \Theta+C 1 * T$

$! c 3=b-1=b 0+b 1 * T-1$

! Aprime contains all the conversions from the original fields model to the units of this model

! time : seconds

! Stress : ksi

! Temperature: degrees $C$

! Strain : natural units

TB, CREEP $1,1,2$ ! creep model \#2

$T B, C R E E P, 1,10$, , 4, 2 ! creep model \#2,

TBTEMP, 23

TBDATA, 2, $\odot, \odot, \odot, \odot$

TBTEMP, 40०,

TBDATA, 2, 3.561852e-12, 4.66, - ๑. 7, ๑,

TBTEMP, 450,

TBDATA , 2, 1. 424203e-12, 4.98, - $0.525,0$,

TBTEMP, 500,

TBDATA, 2, 4.921699e-13, 5.3, - $0.35, \odot$,

TBTEMP, 550,

TBDATA , 2, 7.585412e-13, 5.62,-0.175, $\odot$,

TBTEMP, 600,

TBDATA , 2, 1. 196324e-12, 5.94, ๑, $\odot$,

TBTEMP, 650,

TBDATA, 2, 1.828985e-12, 6. 26, ๑.175, ๑,

TBTEMP, 700,

TBDATA , 2, 2. 734196e-12, 6.58, 0.35, 0 ,

TBTEMP, 750,

TBDATA , 2, 4. 018733e-12, 6.9, 0.525, ๑,

TBTEMP, 800,

TBDATA, 2, 5.82897e-12, 7.22, 0.7, ०, 
Table E-7. ANSYS creep model for A 572 and CSA G4012 steels

! ANSYS creep model \#2 for A572

!edot $=c 1{ }^{*}$ sigma^c $2^{*} t \wedge c 3$

!NIST model: $e=A$ * sigma^n $t \wedge b$

!strain $=\exp \left(e c \Theta+e c 1^{*} T+e c 2{ }^{*} T^{\wedge} 2\right) * \operatorname{sigma\wedge }\left(n \Theta+n 1^{*} T\right) * t \wedge\left(b \odot+b 1 * T^{\wedge} b 3\right)$

$! c 1=A b=\exp \left(e c \Theta+e c 1^{\star} T+e c 2^{*} T \wedge 2\right){ }^{*}\left(b \odot+b 1{ }^{*} T \wedge b 3\right)$

$! C 2=n=n \Theta+n 1 * T$

$! C 3=b=b \odot+b 1 * T^{\wedge} b 2$

!Units

! time : seconds

! Stress : ksi

! Temperature : degrees $C$

! Strain : natural units

TB, CREEP , 1, 10, 4, 2 ! creep model \#2,

TBTEMP, 23

TBDATA, $2, \odot, \odot, \odot, \odot$

TBTEMP, 40०,

TBDATA, 2, 5. 327526e-10, 3.419601, - $0.7223067,0$,

TBTEMP, 450,

TBDATA , 2, 8.514694e-10, 3.569716, - $0.6722258, \odot$,

TBTEMP, 500,

TBDATA, 2, 1.346261e-09, 3. 719831, - $0.617346, \odot$,

TBTEMP, 550,

TBDATA, 2, 2.107694e-09, 3.869946, - - .5577561, ๑, TBTEMP, 600,

TBDATA, 2, 3.270484e- $\odot 9,4.020061,-\odot .4935354, \odot$,

TBTEMP, 650,

TBDATA, 2, 5. $034164 e-09,4.170176,-0.424755, \odot$,

TBTEMP, 700,

TBDATA, 2, 7.693152e- $09,4.320291,-\odot .3514791,0$,

TBTEMP, 750,

TBDATA, 2, 1.168038e-08, 4.470406, - ๑.2737666, $\odot$, TBTEMP, 800,

TBDATA, 2, 1.763044e- $\odot 8,4.620521,-\odot .1916715, \odot$,

The model file contains lines such as:

TBTEMP, 40๑,

TBDATA, 2, 3.561852e-12, 4.66, - $\odot .7, \odot$

The line that begins with TBTEMP defines the temperature, and TBDATA statement that follows it defines the creep parameters at that temperature. In the example above, the TBDATA statement defines material model 2 (time hardening) and $C_{1}=3.561852 \times 10^{-12}, C_{2}=4.66$, and $C_{3}=-0.7$. The parameter $C_{4}$ is set identically to zero because the $C_{i}$ are specified at individual temperatures. Note that the creep rate is also explicitly set to zero at room temperature. ANSYS interpolates the behavior between the designated model temperatures.

\section{E.4 ELEVATED TEMPERATURE STRENGTH OF BOLTS}

For the elevated temperature strength behavior of bolts, the analysis used the same models that the original WTC investigation used. Section 6.4.5 of NIST NCSTAR 1-3D documents these models. The models developed were for the steels from which the bolts were made, rather than for the bolts. Bolt failure is complex at both room- and elevated-temperature, and no methodology exists for modeling the failure of bolts, as distinct from the steels from which they are made, at elevated temperature.

The retained yield strength, Fy, and retained tensile strength, TS, were expressed as functions of temperature via, 


$$
f=\frac{F_{y}(T)}{F_{y}\left(23^{\circ} \mathrm{C}\right)}=\left(1-A_{2}\right) \exp \left(-\frac{1}{2}\left[\left(\frac{T}{s_{1}}\right)^{m_{1}}+\left(\frac{T}{s_{2}}\right)^{m_{2}}\right]\right)+A_{2}
$$

and

$$
f=\frac{T S(T)}{T S\left(23^{\circ} \mathrm{C}\right)}=\left(1-A_{2}\right) \exp \left(-\frac{1}{2}\left[\left(\frac{T}{t_{1}}\right)^{n_{1}}+\left(\frac{T}{t_{2}}\right)^{n_{2}}\right]\right)+A_{2}
$$

These two equations are equations 6-1 and 6-2 of NIST NCSTAR 1-3D.

Table E-8 summarizes the values of the parameters in Equations 13 and 14, and originally appeared as Table 6-12 in NIST NCSTAR 1-3D.

Table E-8. Recommended values for the parameters in the strength reduction equations (Equations 13 and 14) for use with bolts.

\begin{tabular}{|c|c|}
\hline $\begin{array}{c}\text { Yield Strength Reduction parameters } \\
\text { (Equation 13) }\end{array}$ & $\begin{array}{c}\text { Tensile Strength Reduction parameters } \\
\text { (Equation 14) }\end{array}$ \\
\hline$A_{2}=0.07$ & $A_{2}=0.09$ \\
$m_{1}=6.8221$ & $n_{1}=5.0237$ \\
$m_{2}=1.0000$ & $n_{2}=5.0245$ \\
$s_{1}=491.0$ & $t_{1}=478.0$ \\
$s_{2}=810.0$ & $t_{2}=585.0$ \\
\hline
\end{tabular}

\section{E.5 REFERENCES}

Fields. B.A. and R.J. Fields. 1989. Elevated Temperature Deformation of Structural Steel. NISTIR 88-3899.

Williams-Leir, G. 1983. Creep of Structural Steel in Fire: Analytical Expressions. Fire and Materials. 7[2] 73-78. 
This page intentionally left blank. 
January 2009 Text Changes to the NIST Reports of the

Federal Building and Fire Investigation of the World Trade Center Disaster, NCSTAR 1A, NIST NCSTAR 1-9, and NIST NCSTAR 1-9A

Based on comments received, NIST has made the following changes to the reports on the collapse of World Trade Center Building 7:

1. In reports NIST NCSTAR 1A, NIST NCSTAR 1-9, and NIST NCSTAR 1-9A, appended the following two rows to the end of Table P-2. Public meetings and briefings of the WTC Investigation, with accompanying footnote:

\begin{tabular}{|l|l|l|}
\hline August 21, 2008* & $\begin{array}{l}\text { Gaithersburg, MD; } \\
\text { Teleconference }\end{array}$ & $\begin{array}{l}\text { Media and public briefing on release of all draft reports } \\
\text { for WTC 7 and draft recommendations for public } \\
\text { comment. }\end{array}$ \\
\hline August 26, 2008* & Teleconference & $\begin{array}{l}\text { Technical briefing on the probable collapse sequence } \\
\text { for WTC 7, draft reports for WTC 7, and draft } \\
\text { recommendations for public comment. }\end{array}$ \\
\hline
\end{tabular}

2. In report NIST NCSTAR 1-9, Volume 2, Chapter 11, page 533, corrected the text, with accompanying footnote, as follows:

Comparing Figure $11-51^{\star}$ to Figure 4-7, it can be seen that the temperature rise in the lower flange and web is similar. Figure 4-7 shows the temperature of a W24x55 floor beam with 0.5 in. of SFRM in a composite floor assembly for a constant $1100^{\circ} \mathrm{C}$ gas temperature below the concrete slab. Figure 11-51* shows the temperature of a W24x55 beam (no concrete slab) with 0.53 in. of SFRM for a constant $1100{ }^{\circ} \mathrm{C}$ gas temperature. The beam without a slab analysis was conducted to evaluate the effect of SFRM thickness on steel temperature for a floor beam. The lower flange and web in Figure 4-7 and the beam in Figure $11-51^{*}$ both reached $600{ }^{\circ} \mathrm{C}$ in 25 to $30 \mathrm{~min}$.

Thus, an increase in the SFRM thickness on the floor beams would have delayed heating of the floor beams by $10 \mathrm{~min}$ to $20 \mathrm{~min}$, but would not* have altered the outcome.

* Corrected text January 2009. Changes were made to this page only. Similar statements are correct in the original text for Chapter 11 Summary and in the findings and recommendations in NIST NCSTAR 1A.

3. In report NIST NCSTAR 1-9, Volume 2, Appendix D, pages 699 and 709, deleted text and added footnotes as follows:

Section D.3.3, Page 699, first sentence

A Shard Fly-out Model (SFOM) [Meyer 2002*, Marchand 2002] was used to predict window breakage, based on the pressure profiles from the SHAMRC analysis.

* All pertinent material is contained in Meyers 2002.

Section D.6, Page 709

Marchand, Kirk A., 2002. "Analysis of Insulated Glass Units Subjected to Blast Loadings: Model and

DataComparisons," AMSAA Contract DAADM01-97-D-0013, ARA Project Number 0093, Applied

Research Associates, San Antonio, Texas, July 19.

** Deleted reference January 2009. All pertinent material is contained in Meyers 2002.** 